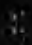
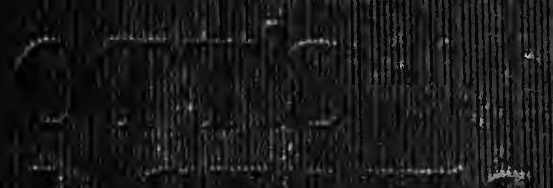

15
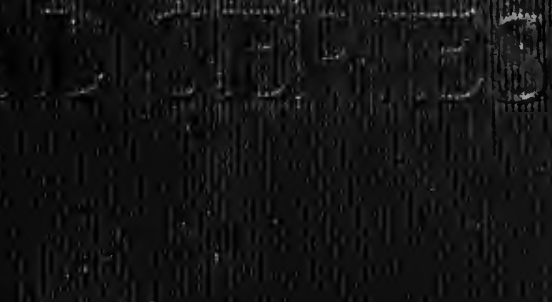

3)

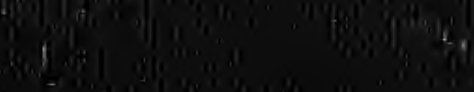




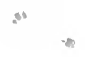

, 2

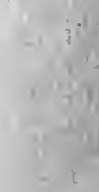


$?$

$1=$

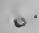


Digitized by the Internet Archive in 2007 with funding from Microsoft Corporation 
Edited by FRANCIS R. PACKARD, M.D.

\section{THE $\angle$ MEDICAL DISEASES}

OF

\section{INFANCY AND CHILDHOOD}

WITH POINTS ON THE ANATOMY, PHYSIOLOGY, AND HYGIENE PECU. LIAR TO THE DEVELOPING PERIOD

\section{$\mathrm{BY}$ \\ ALFRED CLEVELAND COTTON, A.M., M.D.}

Professor of Prediatries Rush Medieal College, University of Chicago; Attending Physician for

Diseases of Children Presbyterian Ilospital; Consultant to the Central Free Dispensary,

etc., etc. Formerly Physician-in-eharge of the Chicago Isolation IIospital and of the Infectious Disease Wards of the County Hospital. Member of

the XIII. International Medical Congress, Moseow. Honorary Member of the Société d'Hygiène, Paris, ete.

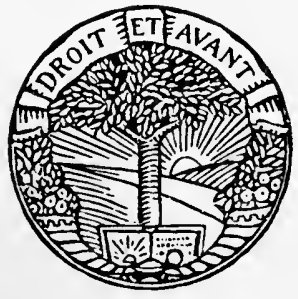

PHILADELPHIA \& LONDON

J. B. LIPPINCOTT COMPANY

1906 


$$
\begin{aligned}
& \text { W5200 } \\
& \text { C851m } \\
& 1906
\end{aligned}
$$

Copyrigbt, 1906, by J. B. Lippincott Company 


\section{TO THE PHYSICIAN'S WIFE}

IN TOKEN OF APPRECIATION OF THE UNTIRING DEVOTION OF A LOVED HELPMATE THIS WORK IS AFFECTIONATELY INSCRIBED BY THE AUTHOR 


\section{Preface}

IT was not without misgivings that the author acceled to the request of the J. B. Lippineott Company to prepare a work limited to six hundred pages comprising all the medical discases of infancy and childhood. For want of space case records and temperature charts are omitted, while discussions and opinions upon mooted subjects are necessarily restricted. The reader's indulgence is asked for the flavor of dogmatism, from which deductions drawn largely from personal expcriences are rarely free.

The need of a more thorough preparation for the study of elinical pædiatries than is afforded by a general knowledge of the Anatomy and Physiology of adult life is so evident that considerable space is devoted to these subjects with reference to the dereloping period.

Part I is practically a revision of the author's previously published Lessons on Anatomy, Physiology, and Hygiene of Infancy and Childhood.

The subject of Infant Feeding, always of paramount importance, is treated broadly in the hope of stimulating a genuine interest in principles rather than a blind following of dogmatic formulæ.

The author desires to acknowledge the unfailing courtesy and patience of the Publishers and to return thanks to the following gentlemen for reading manuscript and for valuable suggestions: Dr. John Edwin Rhodes, diseases of the Respiratory System; Dr. Theodore Tieken, disorders of the Blood and Glands; Dr. G. W. Hall, diseases of the Nervous System; Dr. W. J. Butler, Heart Disease and Eruptive Fevers; Dr. J. W. Vanderslice, Infant Feeding; Dr. J. A. Patton, diseases of the Genito Urinary Tract; Dr. Cassius D. Wescott, for practically rewriting diseases of the Eye. To Drs. John Ridlon and Wallace Blanchard for illustrative cuts; Dr. F. W. Allin for reading page proof and arranging index; Hon. Wm. H. Collins for corrections in phraseology. He also acknowledges with thanks the privilege of reproducing from Johnson Symington's "Anatomy of the Child" a few illustrations embodied in this work.

Especial acknowledgment is due to Dr. Julia D. Merrill for valuable assistance and advice in every stage of the work.

Cinicago, January, 1906. 


\title{
Contents
}

\author{
PART I
}

\section{Anatomy, Physiology, and Hygiene of the Developing Period}

\section{CHAPTER I}

ANATOMY OF THE NEW-BORN

The Skin-Skull-Ear-Face-Neck-Vertebral Column-Long Bones-Thorax - Larynx - Trachea - Lungs - Heart - Thymus Gland - Thyroid GlandLiver-Spleen-Pancreas-Kidneys-Suprarenals-Bladder-Urethra-Testicles-Ovaries-Uterus-Mammary Glands-Brain-Spinal Cord.........

\section{CHAPTER II}

\section{NORMAL GROWTII AND DEVELOPMENT}

Length-Weight-Bones of Head and Face-Nasopharynx-Dentition-Vertebral Column-Thorax-Lungs-Heart - Blood-Vessels-Thyroid-Thymus-Alimentary Tract-Stomach-Intestines-Liver-Spleen-Kidneys-Bladder-Uterus-Inguinal Canal-Nerrous System $\ldots \ldots \ldots \ldots \ldots \ldots \ldots \ldots$

\section{CHAPTER III}

\section{PHYSIOLOGY AND HYGIENE OF THE NEW-BORN}

Circulation of the Blood-Respiration-Temperature-Alimentary Canal-Urine -Skin - Sebaceous Glands - Sweat Glands - Lachrymal Glands - Nervous System-Sight-Hearing-Smell-Taste-Touch-Care of the New-Born....

\section{CHAPTER IV}

PIIYSIOLOGY OF THE FIRST YEAR

Development of Special Senses-Co-ordination-Cry-Spcech-Standing-Walking-Respiration-Pulse-Digestion-Feces-Urine.

CHAPTER V

HYGIENE OF THE FIRST YEAR

Protection and Food-Nursery-Sleep-Clothing-Baths-Exercise ........

\section{CHAPTER VI}

HYGIENE OF THE FIRST YEAR-CONTINUED

Food-Natural Feeding-Rules for Breast Feeding-Breast Milk-Variations In Quantity and Quality-Composition of Breast Milk-Milk ProductionColostrum Milk 


\section{CHAPTER VII}

HYGIENE OF LAC'TATION

Quantity of Milk-Conditions Influencing Breast Milk-Methods of Changing

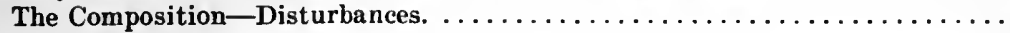

\section{CHAPTER VIII}

\section{MILK ANALYSIS}

Determination of Fat-Relation of Fat to Specific Gravity $\ldots \ldots \ldots \ldots \ldots \ldots$

CHAPTER IX

WEANING AND SUBSTITUTE FEEDING

Supplemental Feeding-Indications for Weaning-Wet-Nurses

CHAPTER $\mathrm{X}$

ARTIFICIAL FEEDING

Food Essentials-Development of Digestive Tract by Food-Comparison of Bovine and Human Milk

\section{CHAPTER XI \\ ARTIFICIAL FEEDING-CONTINUED ,}

Percentage Feeding-Failure in Percentage Feeding-Milik Laboratory-Milk Supply-Care of Milk-Sterilization-Pastcurization

CHAPTER XII.

ARTIFICIAL FEEDING-CONCLUDED

Home Modification of Milk-Methods of-Tables and Rules for-Difficulties of Artificial Feeding-Constituents of Cow's Milk-Objections to Cow's Milk-Efrorts at Correction-Other Infant Foods-Principles to be Observed in Artificial Feeding......................... 118-132

\section{CHAPTER XIII}

HYGIENE OF LATER INFANCY

Care of the Mouth and Nasopharynx-Care of the Feet and Legs-Development of Secretions-Change in Diet

\section{CHAPTER XIV}

PHYSIOLOGY AND HYGIENE OF CHILDHOOD

Normal Proportions-Education-Capacity for Attention.

\section{CHAPTER XV}

\section{CARE OF THE PREMATURE INFANT}

The Premature Infant-Incubators - Feeding - Temperature-Rate of

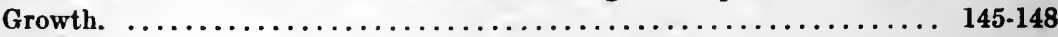

\section{CHAPTER XVI}

\section{CONGENITAL MALFORMATIONS}

Caput Succedaneum-Cephalhæmatoma-Meningocele, Encephalocele-Hydrencephalocele-Hernia Cerebri-Congenital Hydrocephalus-MicrocephalusSpina Bifida-Malformations of the Spinal Cord-Congenital Deformities of Extremities-Malformations of the Eye-Malformations of the EarHæmatoma of Sternomastoid (Caput Obstipum) - Cleft Palate (Harelip)-Branchial Fistulæ-Facial Defects-Malformation of the Digestive Tract-Congenital Dilatation of the Colon and Stomach-Umbilical Defects -Diastasis of the Recti Muscles-Diaphragmatic Hernia-Exstrophy of the Bladder (Ectopia Vesicæ)-Congenital Atresia of Urethra, Vulva, and Vagina - Epispadias (Hypospadias) - Navi (Birth-Marks; Port-Wine Stains)-Congenital Bony Defects (Osteogenesis Imperfecta)-Achondroplasia (Chondrodystrophia Fetalis)-Cleidocranial Dysastosis ......... 149 


\title{
PART II \\ Diseases of Children
}

\author{
CHAPTER I \\ DISEASES OF THF NEW-BORN
}

Examination of Children-Asplyxia-Inspiration l'neumonia of the Newly Born -Cyanosis Infantum-Atelectasis - Inanition Fever-Anuria-Sclerema Neonatorum-Paralysis ...........................

\section{CHAPTER II}

INFECTIOUS AND IIEMIORRIIAGIC DISEASES OF TIIE NEW-BORN

Susceptibility - Mastitis Neonatorum - Icterus Neonatorum-Grave IcterusPemphigus Neonatorum - Omphalitis - Tetanus - Erysipelas-Acute Fatty Degeneration (Buhl's Disease)-Epidemic Fremoglobinuria (IVinckel's Diseasc) -Hemorrhages-Melena-Vaginal Hemorrhages ..............

\section{CHAPTER III}

\section{DISORDERS OF YUTRITION}

Marasmus-Infantile Atrophy; Pedatrophy; Athrepsia; Simple Wasting-Rhachitis - Scorbutus (Infantile Scurvy) -Adipositas-Osteomalacia-Osteo-

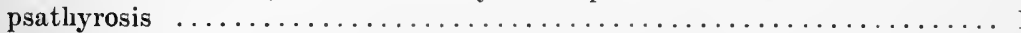

\section{CHAPTER IV}

\section{DISORDERS OF TIIE DIGESTIYE SYSTEM}

The Lips, Tongue, and Mouth-Perleche (Licking Disease of the Lips)-Macroglossia (Hypertrophy of the Tongue)-Acute Glossitis-Lingua Geographica (Desquamative Glossitis; Pityriasis Lingux)-Ulcer of the Tongue-Riga's Disease - Ranula - Tongue-Tie (Elongatio Frenuli) - Difficult Dentition Catarrhal Stomatitis (Stomatitis Catarrhalis) -Stomatitis Aphthosa (Stomatitis Herpetica; Vesicular Stomatitis; Follicular Stomatitis; Canker Sore Mouth)-Bednar's Aphthre (Aphthæ of the Palate)-Stomatitis Mycosa (Mycetogenic Stomatitis; Parasitic Stomatitis; Thrush; Muguet; Sprue; Soor)-Stomatitis Ulcerosa (Ulcerative Stomatitis; Putrid Sore Mouth)-Stomatitis Gangrenosa (Noma of the Face; Cancrum Oris) Stomatitis Membranosa-Gonorrhœal Stomatitis.................

\section{- CHAPTER V}

DISORDERS OF TIIE DIGESTIVE SYSTEM-CONTINUED

Diseases of the Throat, Pharynx, and Esoplagus-Acute Tonsillitis-Suppurative Tonsillitis (Phlegmonous Tonsillitis; Quinsy)-Follicular Tonsillitis (Lacunar Tonsillitis) - Chronic Tonsillitis (Hypertrophy of the Tonsils) Vincent's Angina (Ulcero-Membranous Tonsillitis) - Acute Uvulitis Pharyngitis - Acute Pharyngitis - Chronic Pharyngitis-Adenoid Vegetations-Retropharyngeal Abscess-Diseases of the Esophagus - Retro-

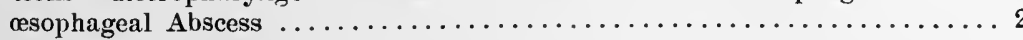




\section{CHAPTER VI}

DISEASES OF TIE GASTRO-ENTERIC TRACT

Vomiting-Congenital Hypertrophic Stenosis of the Pylorus; Pyloric SpasmAcute Gastritis (Acute Gastric Catarrh; Acute Gastrie Adenitis) -Gastric Ulcer and Hemorrhage-Intestinal Colic (Enteralgia; Neuralgia Enterica) -Acute Dyspepsia (Acute Indigestion)-Acute Enteritis (Summer Diarrhœa)-Cholera Infantum-Chronic Gastritis (Chronic Gastric Catarrh; Chronic Dyspepsia)-Amœic Dysentery-Incontinence of Fæces-Constipation-IIucous Disease (Chronic Intestinal Catarrb; Gastro-Duodenal Catarrh; Chronic Mucocolitis; Intestinal Indigestion; Tubular Diarrhœa; Myxoneurosis Coli; Colica Mucosa)-Intestinal Parasites (Worms)-Intussusception-Volvulus-Appendieitis-Proetitis and Reetal UlcerationProlapse of the Rectum and Anus-Fissure of the Anus-Rectal Polypi-

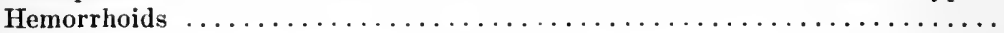

\section{CHAPTER VII}

\section{DISEASES OF TIIF LIVER AND PANCREAS}

Congestion of the Liver-Acute' Infectious Liver-Suppurative Hepatitis (Abscess of the Liver)-Cirrhosis of the Liver-Acute Yellow Atrophy of the Liver-Fatty Liver-Amyloid Degeneration of Liver, Kidney, Spleen, etc.Hydatids of the Liver-Tumors of the Liver-Syphilitic Pancreatitis......

\section{CHAPTER VIII}

DISEASES OF TIIE IIEART AND PERICARDIUM

Congenital Diseases of the Heart-Functional Heart Disease-Acute Endocarditis-Chronie Endocarditis (Chronie Valvular Disease)-Myocarditis -Adherent Pericardium (Chronic Pericarditis) ..................

\section{CHAPTER IX}

\section{DISEASES OF THE RESPIRATORY TRACT}

Rhinitis, Acute and Chronic (Coryza; Acute Nasal Catarrh; Cold in the Head) - Membranous Rhinitis-Syphilitie Rhinitis-Nasal Polypi-Epistaxis (Nose-bleed) - Congenital Laryngeal Stridor-Acute Laryngitis-Chronic Laryngitis - Syphilitic Laryngitis - Tuberculous Laryngitis - Pseudomembranous Laryngitis (Membranous Croup; True Croup)-Edema of the Glottis-Tumors of the Larynx-Foreign Bodies in the Larynx and Trachea -Tracheitis-Acute Bronchitis-Chronic Bronchitis-Fibrinous Bronchitis - Bronchiectasis - Asthma - Fibrinous Pneumonia (Lobar Pneumonia; Croupous Pneumonia; Pneumonitis)-Bronchopneumonia (Catarrhal Pneumonia; Lobular Pneumonia; Capillary Bronchitis)-Chronic Interstitial Pneumonia (Peribronchitis; Pulmonary Fibrosis; Fibroid Phthisis; Cirrhosis or Induration of the Lung)-Hypostatic Pneumonia-Abscess of the Ling and Pulmonary Gangrene-Ateleetasis (Collapse of the Lung)-Pul-

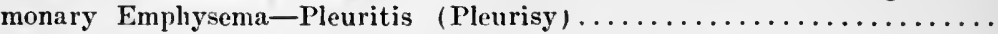

CHAPTER X

DISEASES OF TIE KIDNEYS, BLADDER, AND GENITAL ORGANS

Anuria and Oliguria-Hxmaturia-Hæmoglobinuria-Intermittent Albuminuria (Orthostatic, Postural, Cyclic, Funetional, Physiologieal Albuminuria) Kidneys (Malformations and Congenital Anomalies)-Acute NephritisChronic Nephritis-Uric Aeid-Calculi-Pyelitis (Pyelonephritis; Pyo- 
nephrosis)-Cystitis-Perinephritis (Paranephritis; Epinephritis)-Hydronephrosis-Balanitis, Posthitis, and Urethritis in Male Children-Simple Vulvovaginitis-Specitic Vulvovaginitis-Phimosis and Adherent PrepuceEneuresis (Incontinence of Urine)-Cryptorchidism (Undescended Testicle)

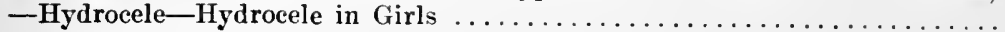

\section{CHAPTER XI}

\section{DISEASES OF THE NERYOUS SYSTEM}

Convulsions (Eclampsia; Spasms)-Epilepsp-Tetany (Tetanilla)-Laryngis. mus Stridulus (Laryngospasm; Cerebral Croup)-Thomsen's DiseaseMyotonia Congenita - Hysteria - Catalepsy - Chorea-Habit Spasm (Tic Convulsif; Habit Chorea; Facial Tic)-Imperative Novements-Spasmus Nutans (Head-nodding; Nystagmus)-Athetosis-Pavor Nocturnus (Night Terrors)-Speech Defects-Echolalia and Coprolalia-Aphasia-Masturbation - Reflexes - Reflex Disorders of Dentition - Headache-Meningitis Tuberculous Meningitis-Cerebro Spinal Meningitis-Simple Basic Meningitis (Infantile Basilar Meningitis of Non-Tuberculous Origin) Posterior Basic Meningitis-Encephalitis (Cerebritis)-Insolution (Sunstroke; Heat Prostration; Thermic Fever) - Thrombosis of the Cranial Sinuses-Tumors of the Brain-Abscess of the Brain-Hydrocephalus (Hydrops Cerebri; Water on the Brain)-Infantile Cerebral Palsies (Spastic Hemiplegia; Diplegia; Paraplegia)-Progressive Bulbar Paralysis (Labioglossolaryngeal Paralysis) - Idiocy (Imbecility and Feeble-mindedness) -Mongolian Imbecility-Amaurotic Family Idioey- aretic Dementia-Insanity-Transverse Myelitis-Acute Anterior Polionyelitis (Infantile Spinal Paralysis) - Tumors of the Spinal Cord-Syringomyelia (Myelosyringosis)-Hereditary Spinal Ataxia (Friedreich's Disease)-Landry's Paralysis (Acute Ascending Paralysis)-Hereditary Spastic Paralysis (Cerebrospinal Paralysis-Locomotor Ataxia (Tabes Dorsalis)-Multiple Sclerosis (Disseminated Sclerosis; Insular Sclerosis) - Progressive Muscular Atrophy (Hand Type of Aran and Duchenne); Leg Type of Charcot-Marie-Tooth (Peroneal Form); Muscular Atrophy with Pseudohypertrophy; Juvenile Form (Erb's Type); Facioscapulohumeral (Landouzy-Dejerine Type)-Multiple Neuritis.......

\section{CHAPTER XII}

DISEASES OF THE GLANDS, BLOOD, BOXES, AND JOINTS

Lymphatism-Simple Acute Adenitis-Chronic Adenitis-Hodgkin's Disease (Pseudoleukæmia; Lymphatic Anæmia; Adenia; Lymphadenoma)-Disorders of the Spleen-Disorders of the Adrenals-Disorders of the Thymus -Disorders of the Thyroid-Cretinism-Exophthalmic Goitre (Graves's Disease; Basedow's Disease)-Anæmia-Chlorosis-Pernicious AnæmiaLeukæmia-Hæmophilia-Purpura-Spinal Caries (Pott's Disease; Spondylitis)-Hip Disease (Morbus Coxarius); Coxitis-Knee-Joint Disease (White Swelling)-Dactylitis (Chronic Osteomyelitis; Spina Ventosa; Spina Pedarthrocace)-Chronic Polyarthritis, with Splenic and Glandular Enlargement-Acute Epiphysitis-Chronic Osteoperiostitis-Acute Osteomyelitis-Osteochondritis-Arthritis Deformans $\ldots \ldots \ldots \ldots \ldots \ldots$

\section{CHAPTER XIII}

\section{DISEASES OF THE EYE AND EAR}

Affections of the Lids: Blepharitis-Hordeolum, or Stye-Chalazion-Trichiasis - Distichiasis - Entropion - Ectropion - Ptosis. Injuries of the Eyelids: Ecchymosis - Insect-bites-Burns-Blepharospasm-Conjunctivitis- 
Trachoma-Interstitial Keratitis-l ritis-Cataract-Refraction of the Eye -Paralysis - Strabismus - Nystagmus - Exophthalmos. Diseases of the

Ear: Importance of Otitis Media-Ear Tumors-Internal Ear ..........

\section{CHAPTER XIV}

THE SPECIFIC INFECTIOUS DISEASES

Exanthemata - Scarlet Fever (Scarlatina) - Measles (Rubeola Morbilli)Atypical Measles (Complications and Sequelæ)-Rubella (Rötheln, German Measles)-Variola (Smallpox) -Vaccinia (Cow-pox)-Varioloid (Modified Smallpox)-Varicella (Chicken-pox)-Tubulated Differentiation of Exan-

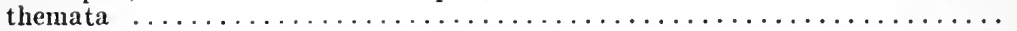

\section{CHAPTER XV}

TIE SPECIFIC IXFECTIOUS DISEASES-COXTINUED

Pertussis (Whooping-Cough; Tussis Convulsiva)-Influenza (La Grippe; Catarrhal Fever)-Epidemic Parotitis (Mumps)-Diphtheria-Diphtheroid (Pseudodiphtheria) - Intubation of the Larynx-Typhoid Fever (Enteric Fever)-Peculiarities of the Infantile Form of Typhoid Fever-Malaria (Intermittent Fever; Paludism)-Hereditary Syphilis-TuberculosisGlandular Tuberculosis-Abdominal Tuberculosis-Peritoneal Tuberculosis -General Treatment for Tubereulosis . . . . . . . . . . . . . . .

\section{CHAPTER XVI}

DISEASES OF THE SKIN

Prevalence in Childhood-Erythema Simplex (Redness of Skin)-SeborrhoaEczema-Miliaria-Urticaria (Nettle-Rash; Hives)-Impetigo Contagiosa - Herpes - Tinea Trichophytina (Ringworm) - Favus (Tinea Favosa; Crusted Ringworm; Honeycombed Ringworm)-Scabies (Itch)-Pediculosis-Furunculosis-Psoriasis-Iehthyosis-Scleroderma (Dermatosclerosis; Cutis Tensa Chronica) -Verruca (Warts) - Edemata ..............

\section{CHAPTER XVII}

GENERAL DISEASES

Diabetes Mellitus_Diabetes Insipidus-Rheumatism...............

\section{APPENDIX}

\section{SICK-BOOMI IIYGIENE}

Contagious Diseases-Therapeutic Suggestions-Massage-Lumbar PunctureHydrotherapy-Hot Pack-Cold Pack-Sponge Bath-Tub Bath-Hot Mustard Bath-Vapor Bath-Bran Bath-Shower Bath-Internal Use of Water -Nasal Irrigation-Lavage-Gavage-Irrigation of the Vagina-EnemaColonic Flushing. Dietary: Barley-Water or Gruel-Rice-Water-EggWater-Clam-Broth-Chicken-Broth-Beef-Broth-Mutton-Broth-OysterBroth-Scraped or Pulped Raw Meat-Raw-Meat Juice-Whey-Junket (Sweet Curd for Older Children)-Egg-Junket-Lime-Water-Cream-of-

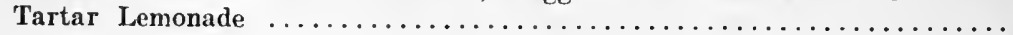

\section{FORMULARY}

Disinfecting Solutions-Mouth-Wash and Spray-Astringents-A Gargle to prepare the Throat for Tonsillotomy-Anodyne Sprays used in Tubercular Laryngitis-Infant Correctives-For Relief of Asthma-Rubefacients...... 


\section{Illustrations}

FIGs.

1. New-born-side, reclining (plate)

2. New-born-front, reclining (plate)

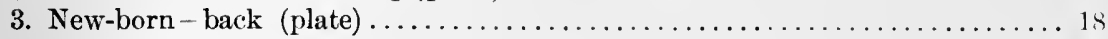

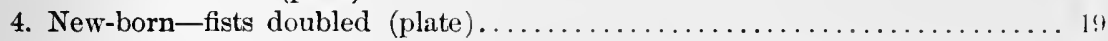

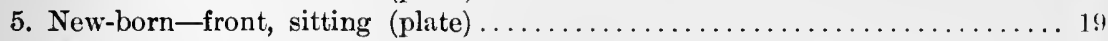

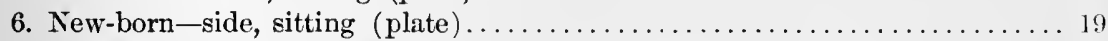

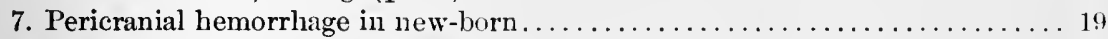

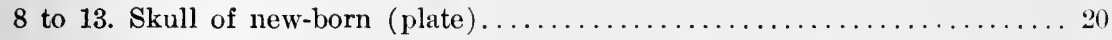

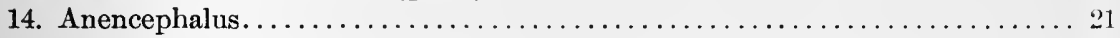

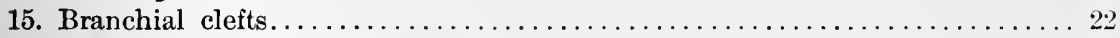

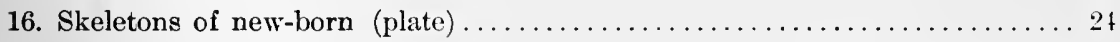

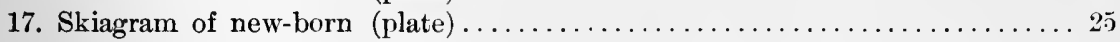

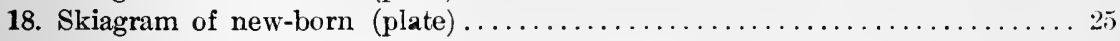

19. Lower end of femur, showing centres of ossification $\ldots \ldots \ldots \ldots \ldots \ldots \ldots 26$

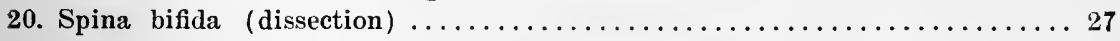

21. Lungs, beart, thymus and thyroid of still-born infant $\ldots \ldots \ldots \ldots \ldots \ldots \ldots 30$

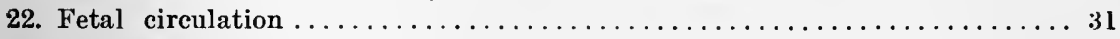

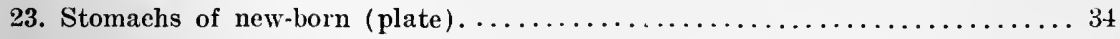

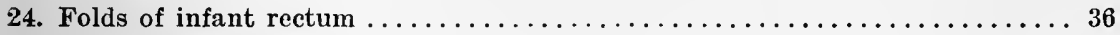

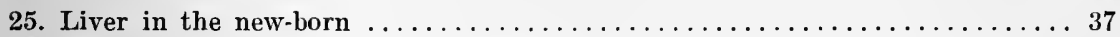

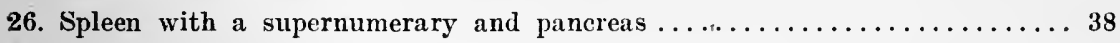

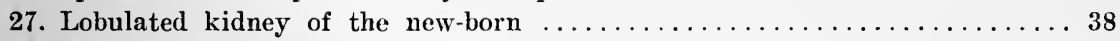

28. Mesial section of four months infant, showing distended bladder ....... 39

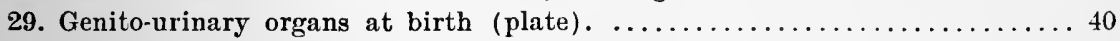

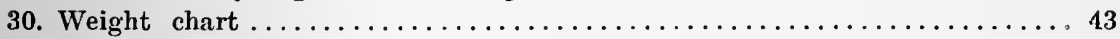

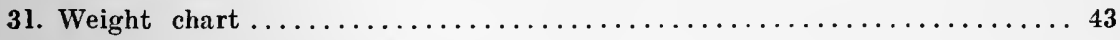

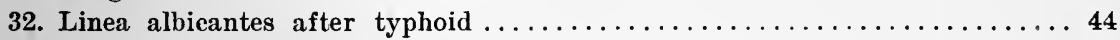

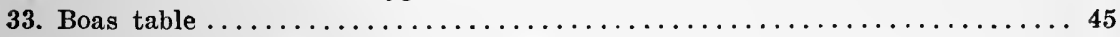

34. Coronal section of head through the auditory meati $\ldots \ldots \ldots \ldots \ldots \ldots \ldots 47$

35. Coronal section of head through the orbits $\ldots \ldots \ldots \ldots \ldots \ldots \ldots \ldots \ldots \ldots 43$

36. Vertical mesial section of head and trunk (plate) ................. 48

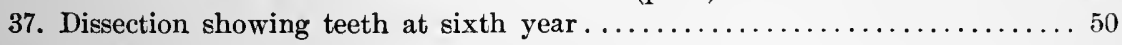

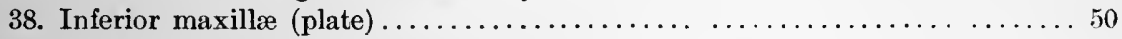

39. Horizontal section at third dorsal vertebra (plate) $\ldots \ldots \ldots \ldots \ldots \ldots \ldots \ldots . \ldots \ldots$

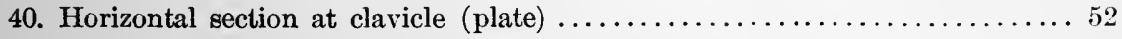

41. Von Starck's types of cardiac dulness $\ldots \ldots \ldots \ldots \ldots \ldots \ldots \ldots \ldots \ldots \ldots \ldots$

42. Horizontal section at the eleventh vertebra $\ldots \ldots \ldots \ldots \ldots \ldots \ldots \ldots \ldots \ldots$

43. Mesial section of pelvis at fifteen months $\ldots \ldots \ldots \ldots \ldots \ldots \ldots \ldots \ldots \ldots$

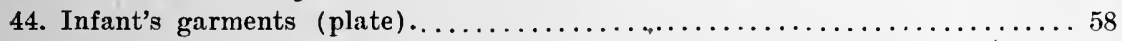

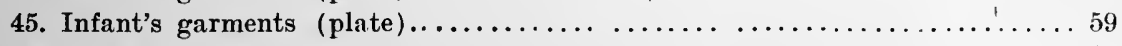

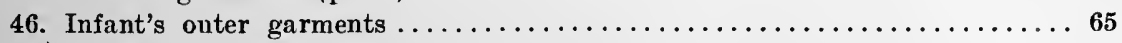

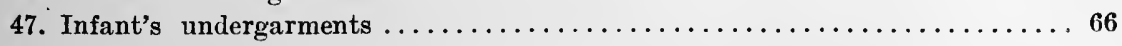

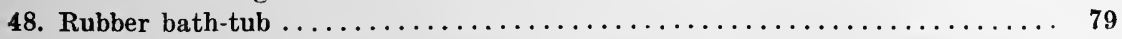




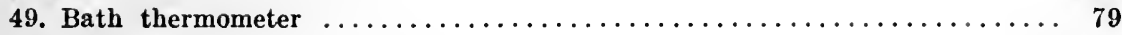

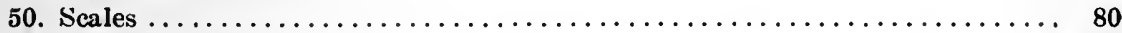

51. Correct position for nursing $\ldots \ldots \ldots \ldots \ldots \ldots \ldots \ldots \ldots \ldots \ldots \ldots \ldots \ldots \ldots \ldots$

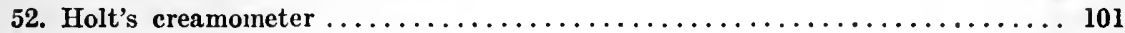

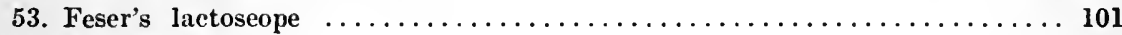

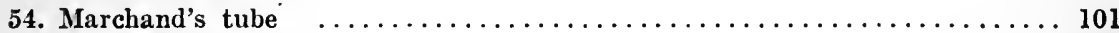

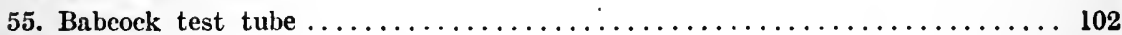

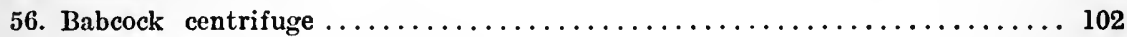

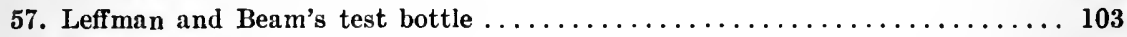

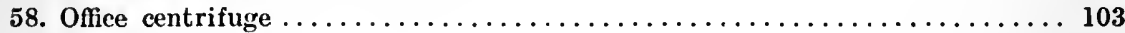

59. Lactometer ................................... 104

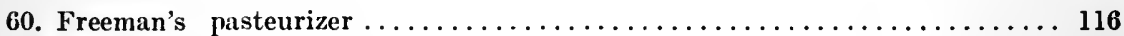

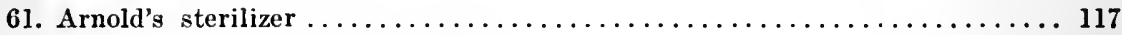

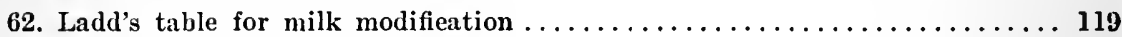

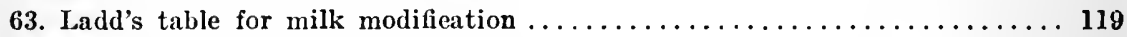

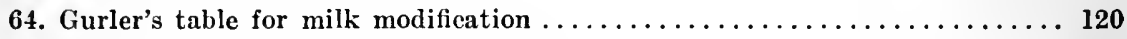

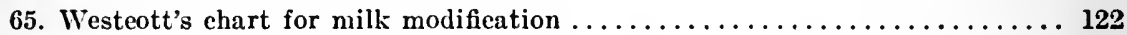

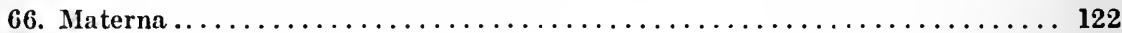

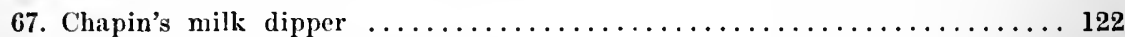

68. Connor's table for milk modification $\ldots \ldots \ldots \ldots \ldots \ldots \ldots \ldots \ldots \ldots \ldots \ldots \ldots \ldots$

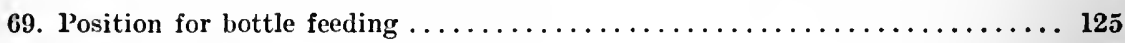

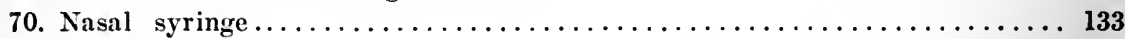

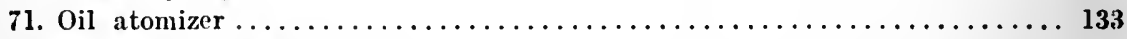

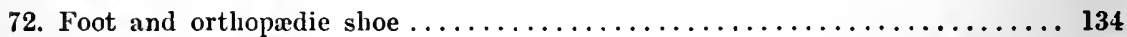

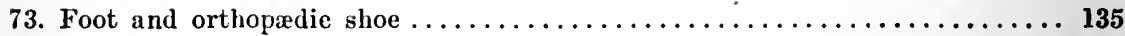

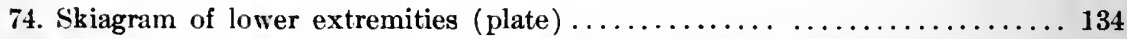

75. Skiagram showing effects of large, wadded diaper (plate) $\ldots \ldots \ldots \ldots \ldots \ldots$

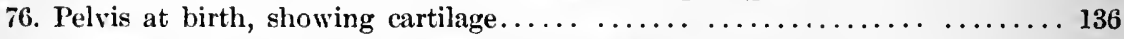

77. Skiagram showing pelvis constricted by tight diaper (plate) $\ldots \ldots \ldots \ldots \ldots 136$

78. Skiagram showing effect of tight bands on thorax (plate) $\ldots \ldots \ldots \ldots \ldots 136$

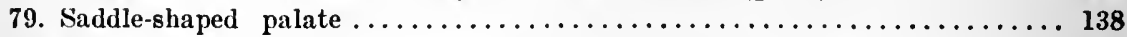

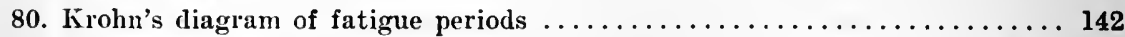

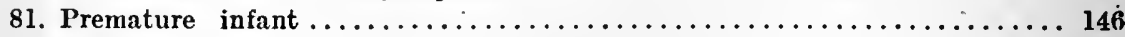

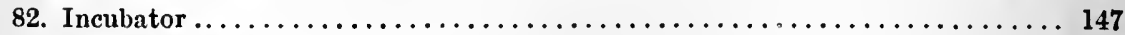

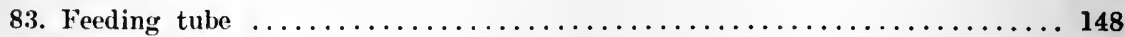

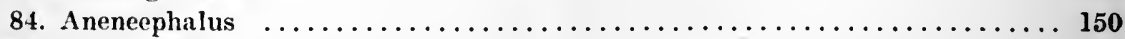

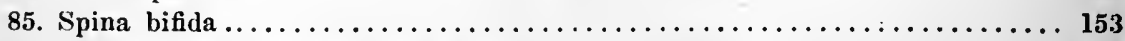

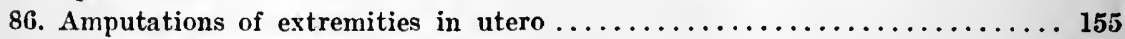

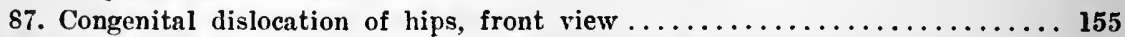

88. Skiagram of intra uterine malformations of fingers $\ldots \ldots \ldots \ldots \ldots \ldots \ldots 156$

89. Congenital dislocation of hips and back (plate) $\ldots \ldots \ldots \ldots \ldots \ldots \ldots \ldots \ldots$

90. Congenital dislocation of hip (dissection) (plate) $\ldots \ldots \ldots \ldots \ldots \ldots \ldots \ldots 158$

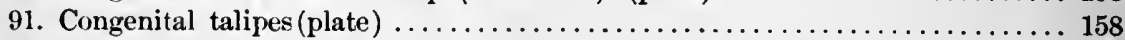

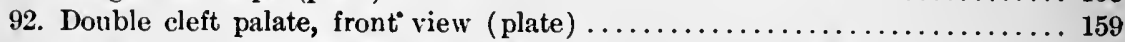

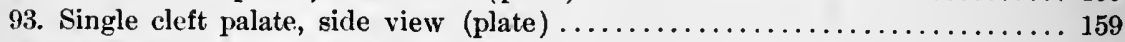

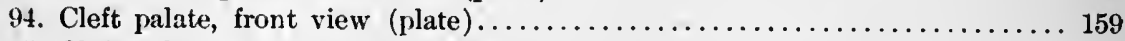

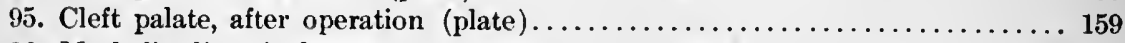

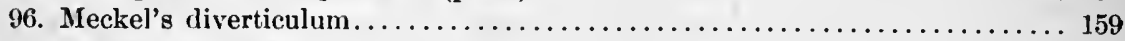

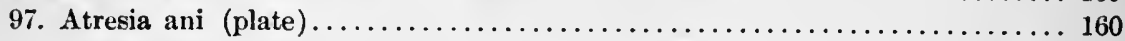

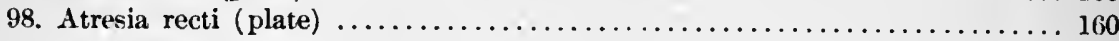




\section{ILLUSTRATIONS}

FIG.

99. Atresia of both anus and rectum (plate) . . . . . . . . .

100. Comm (plate) ...

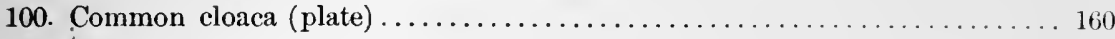

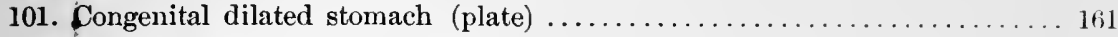

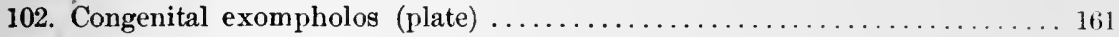

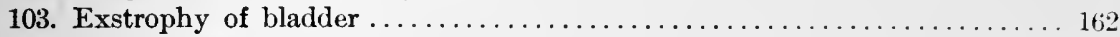

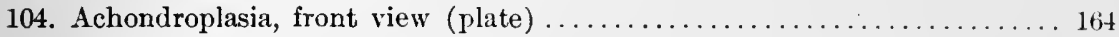

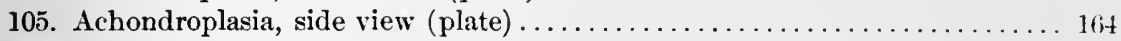

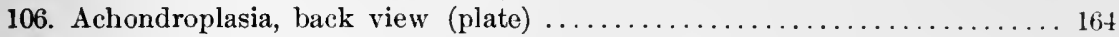

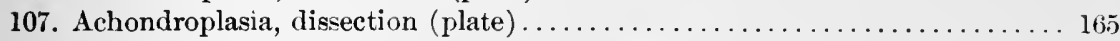

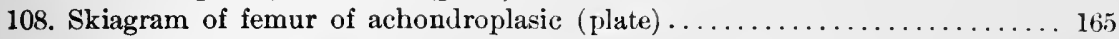

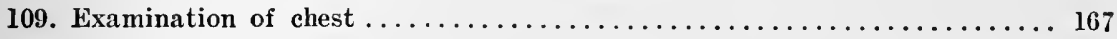

110. Infantile atrophy ............................. 184

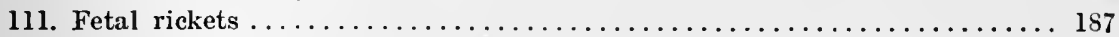

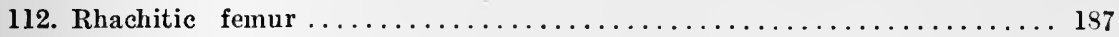

113. Rhachitic curvature of spine $\ldots \ldots \ldots \ldots \ldots \ldots \ldots \ldots \ldots \ldots \ldots \ldots \ldots$

114. Rhachitic curvature of spine $\ldots \ldots \ldots \ldots \ldots \ldots \ldots \ldots \ldots \ldots \ldots \ldots \ldots \ldots$

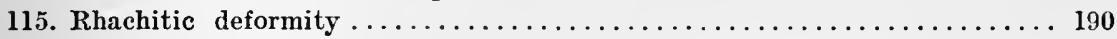

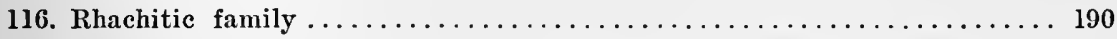

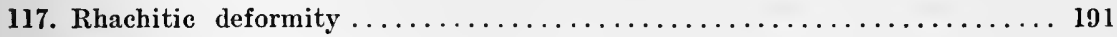

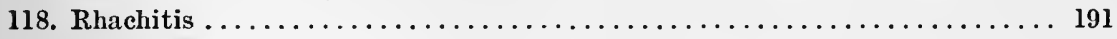

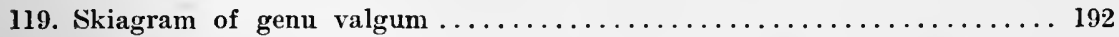

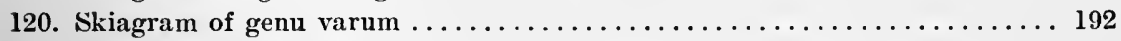

121. Rhachitic deformities $\ldots \ldots \ldots \ldots \ldots \ldots \ldots \ldots \ldots \ldots \ldots \ldots \ldots \ldots \ldots \ldots$

122. Same after correction $\ldots \ldots \ldots \ldots \ldots \ldots \ldots \ldots \ldots \ldots \ldots \ldots \ldots \ldots \ldots \ldots$

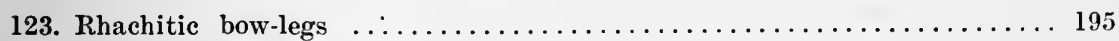

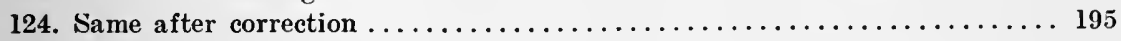

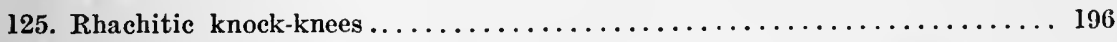

126. Same after correction $\ldots \ldots \ldots \ldots \ldots \ldots \ldots \ldots \ldots \ldots \ldots \ldots \ldots \ldots$

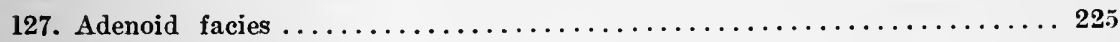

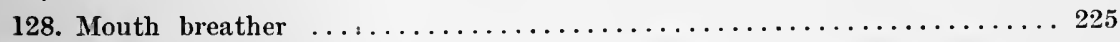

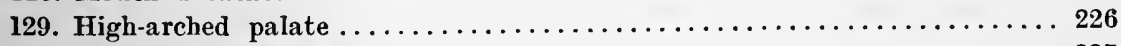

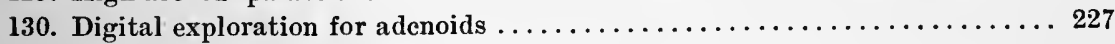

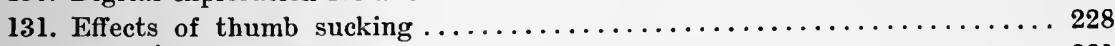

132. Characteristic attitude in retropharyngeal abscess $\ldots \ldots \ldots \ldots \ldots \ldots \ldots \ldots$

133. Skiagram of foreign body in œesophagus (plate) . . . . . . . . . . . . 232

134. Emaciation due to stricture of œsophagus $\ldots \ldots \ldots \ldots \ldots \ldots \ldots \ldots \ldots \ldots \ldots \ldots$

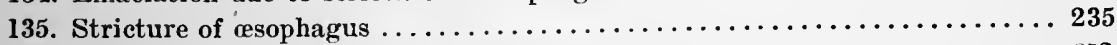

136. Ulceration of Peyer's patch (plate) . . . . . . . . . . . . . . . . 252

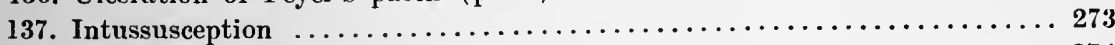

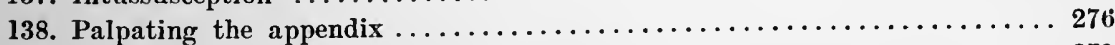

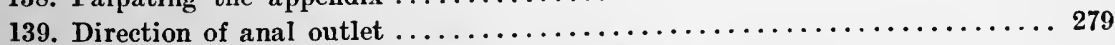

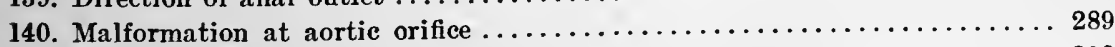

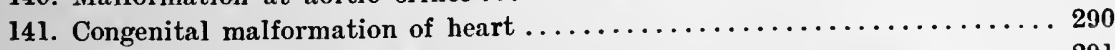

142. Congenital malformation of heart $\ldots \ldots \ldots \ldots \ldots \ldots \ldots \ldots \ldots \ldots \ldots \ldots \ldots$

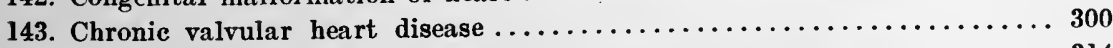

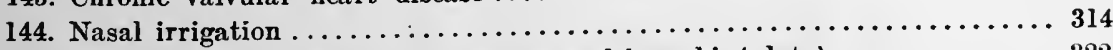

145. Diphtheritic membrane from trachea and bronchi (plate) ........... 322

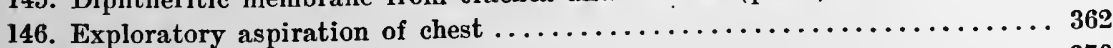

147. Rudimentary kidney .............................

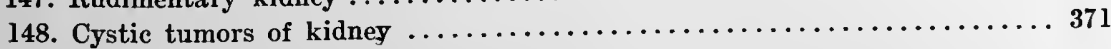


149. Tetany

150. Chorea

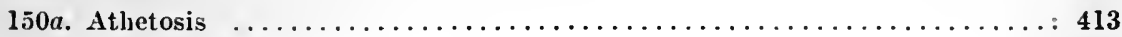

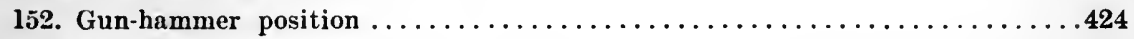

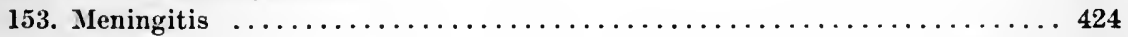

154. General purpuric eruption. Death on the 12tl. day of continuous

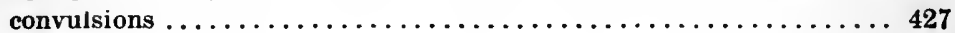

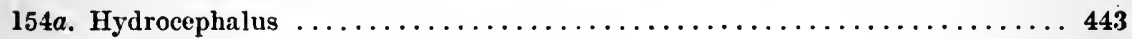

155. Congenital enlargement of thyroid gland $\ldots \ldots \ldots \ldots \ldots \ldots \ldots \ldots \ldots \ldots 44$

156. Brain hemorrhage after forceps $\ldots \ldots \ldots \ldots \ldots \ldots \ldots \ldots \ldots \ldots \ldots \ldots \ldots \ldots$

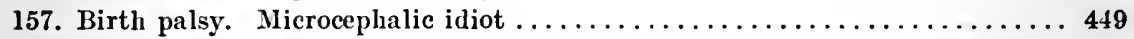

158. Cerebral palsy ................................. 449

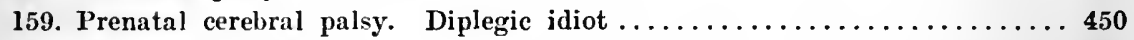

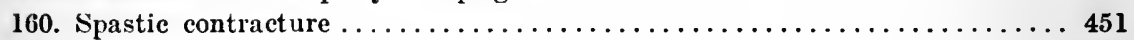

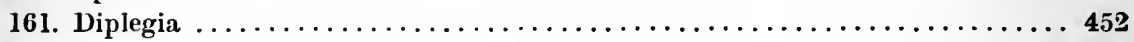

162. Seetion of medulla in bulbar paralysis $\ldots \ldots \ldots \ldots \ldots \ldots \ldots \ldots \ldots \ldots \ldots \ldots 4$

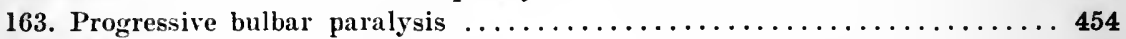

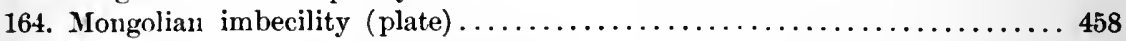

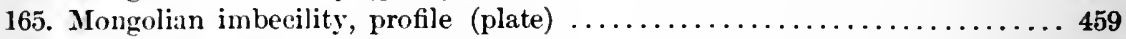

166. Tongue in Mongolian imbecility (plate) ..................... 459

167. Mongolian imbecility (plate) ............................. 459

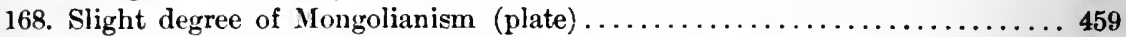

169. Amaurotic family idiocy, before development of symptoms......... 459

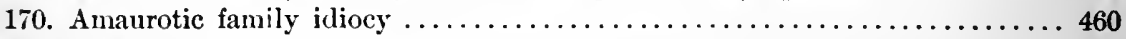

171. Eyeground in amaurotic family idiocy (colored plate) $\ldots \ldots \ldots \ldots \ldots \ldots \ldots 460$

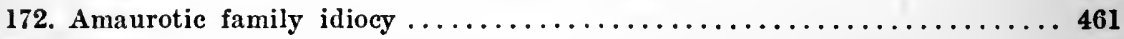

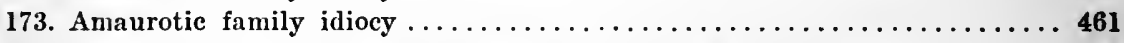

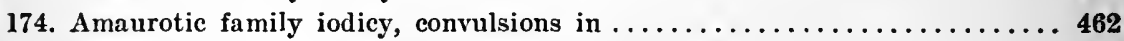

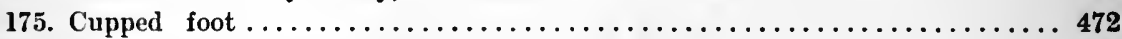

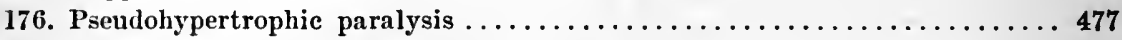

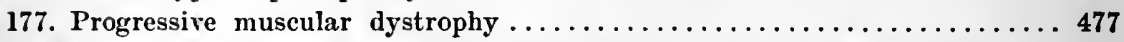

178 to 185. Pseudohypertrophic muscular paralysis, eight characteristic pos-

tures assumed in rising from the floor (plates) . . . . . . . . 478

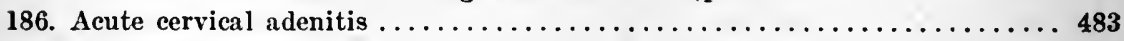

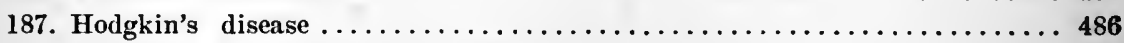

188. Hodgkin's disease with enlarged liver and spleen $\ldots \ldots \ldots \ldots \ldots \ldots \ldots . \ldots 47$

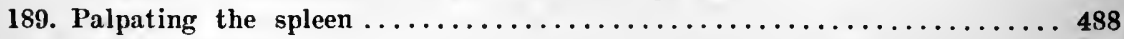

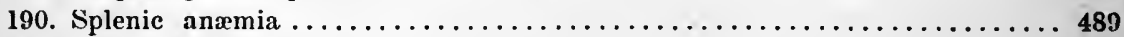

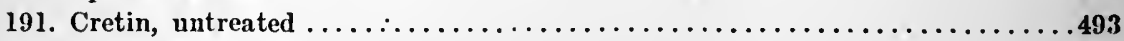

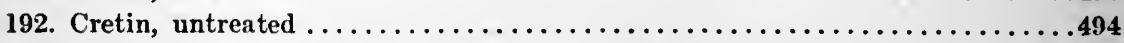

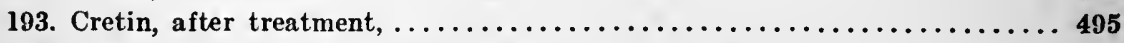

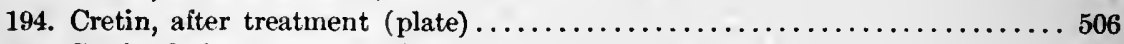

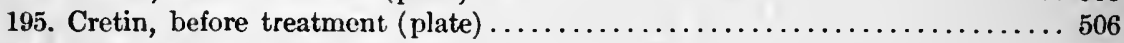

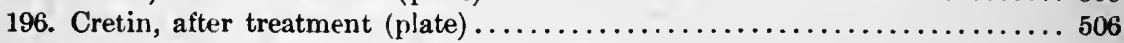

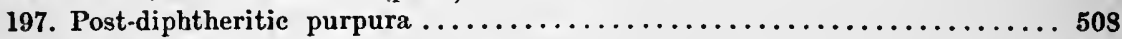

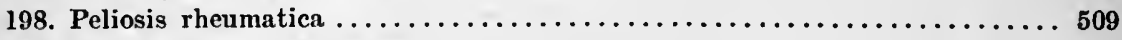

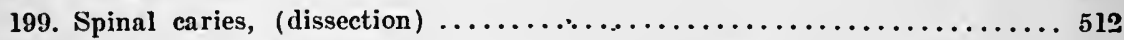

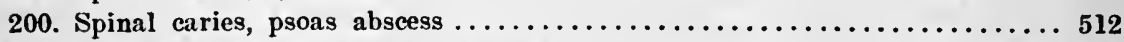

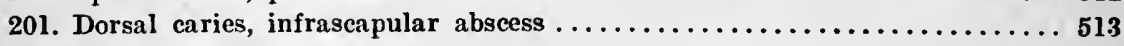

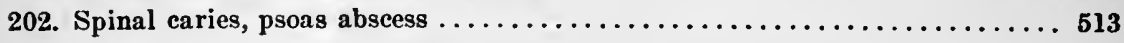




\section{ILLUSTRATIONS}

203. Characteristic posture of spinal caries

204. Hip disease

205. Tuberculous knee and elbow

206. Tuberculous sinuses of ankle

207. Tuberculous dactylitis.

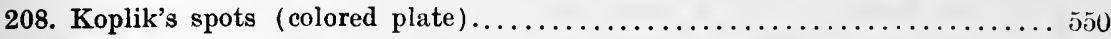

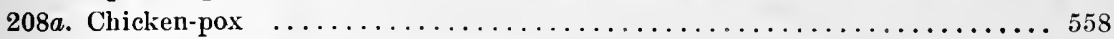

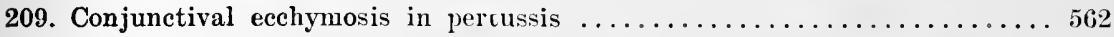

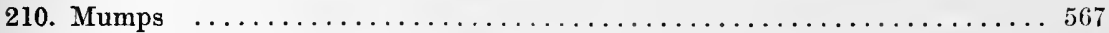

212. Rupture of tuberculous gland in trachea .................... 593

213. Rupture of tuberculous gland in œsophagus . . . . . . . . . . . . . . 594

214. Pulmonary tuberculosis with large liver $\ldots \ldots \ldots \ldots \ldots \ldots \ldots \ldots \ldots \ldots$

215. Mesenteric and pulmonary tuberculosis . . . . . . . . . . . . . . . 600

216. Tuberculous peritonitis with ascites $\ldots \ldots \ldots \ldots \ldots \ldots \ldots \ldots \ldots \ldots$

217. Tuberculous peitonitis with ascites, side view . . . . . . . . . . . 601

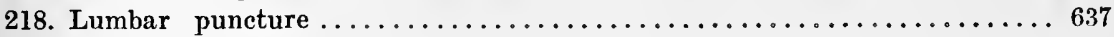

219. Nasal feeding . . . . . . . . . . . . . . . . . . . . . . . . . 640

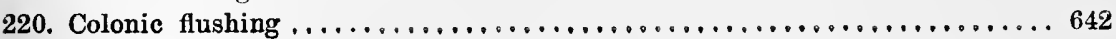




$$
\text { I }
$$




\title{
PART I
}

\section{Anatomy, Physiology, and Hygiene of the Developing Period}

\author{
CHAPTER I
}

\section{ANATOMY OF THE NEW-BORN}

\section{TIIE SKIN}

THE infant's integument at birth is usually more or less covered with a thick whitish substance, the vernix caseosa, which is most abundant in the flexures and depressions, and upon the scalp. It consists of a mixture of cast-off epithelium, lanugo, and the product of the sebaceous glands.

Usually upon delivery the color is dusky blue, owing to venous stasis from the long pressure. After a few full inspirations this color changes to the "boiled lobster" hue. About the third day exfoliation begins and continues for a week or ten days. During this time the hyperæmia is marked; this gradually subsiding, the skin assumes an ieteroid tint.

The texture of the skin is very delicate, and the downy growth, lanugo, which was more abundant in the sixth and seventh months of intrauterine life, still covers the body.

The margin of the nails projects far over the ball of the fingers. It was formed at an early period and is mueh thinner than the part resting on the bed of the nail. This margin breaks readily and becomes detached soon after birth.

At first view the large head, small chest, enormous abdomen, and insignificant extremities of a new-born infant seem out of all proportion (Figs. 1 to 6). Not until the student has gained a knowledge of development and growth up to this period can he adjust his ideas to accept these as normal.

Upon comparing the records of many hospitals in this and other countries, the average weight at birth for boys is found to be 3280 grammes and for girls 3130 grammes (about seven and one-fifth and seven pounds). The average length is forty-six to fifty centimetres (eighteen to twenty inches).

Many observations have shown a constant proportional relationship between the different members of the normal infant at birth. Any marked variation in these proportions is considered an abnormality of 
development. The following simple rule will aid the student in remembering this relationship. The circumference of the thorax in centimctres should equal one-half of the length plus ten. If estimated in inches, add four to half the length. The circumference of the head should equal that of the thorax plus two. The abdomen is usually one to two centimetres larger in circumference than the head, for example:

\begin{tabular}{|c|c|c|}
\hline Length & $\begin{array}{l}\text { Centimetres. } \\
\ldots .46\end{array}$ & $\begin{array}{c}\text { Inches. } \\
18\end{array}$ \\
\hline Circumference of thorax & $\ldots 33$ & 13 \\
\hline Circumference of head. & $\ldots 35$ & $13 \frac{3}{4}$ \\
\hline Circumference of abdomer & $\ldots 36$ & $14 \frac{1}{2}$ \\
\hline
\end{tabular}

From the abundant deposition of subeutaneous fat, the contour of the body and limbs is well rounded, the location of the articulations being marked by dimples. A marking never absent from a normal, plump infant after the first month is a deep sulcus extending around the inner aspect of the thigh.

Recent investigators have questioned the correctness of the statement that the bones of infants contain more animal matter than do those of adults,-viz., one-third. Their analyses go to prove that equal weights of bone contain, at all ages, and in all bones, nearly the same relative proportions of animal and earthy matter. A particle of bone is a definite, not a variable compound. Hardness and compactness depend upon the quantity of bone condensed in a given space. The softness and elasticity of the bones of infancy are due to their vascularity, the sponginess of their texture, and to the layers of cartilage and membrane not yet ossified. Equal weights of corresponding sections of adult and infant bones would certainly yield different percentages of earthy and animal matter. The error lies in regarding the sections as containing equal amounts of bone. A peculiarity of infant bones is seen in the composition of the red marrow which is found in all the long bones. It consists of seventy-five per cent. water, the twenty-five per cent. solids containing only one per cent. fat, while the yellow marrow of adult bones contains ninety-six per cent. fat.

The centres of ossification do not all appear at once, some not until after birth, but all in regular succession and at stated periods. The early ossification corresponds directly with the functional importance of the particular bone,-e.g., that of the lower jaw and ribs, which renders possible respiration and suetion from birth.

\section{THE SKULL.}

The head, being plastic, shows the pressure effects of recent parturition, sometimes presenting a great elongation. Not infrequently the contour is still further modified by the capnt sucedaneum. By the end of the first week the head has resumed its normal shape.

The integument covering the head is thicker than that of any other part of the body and is closely adherent to the aponeurosis of the occipito- 

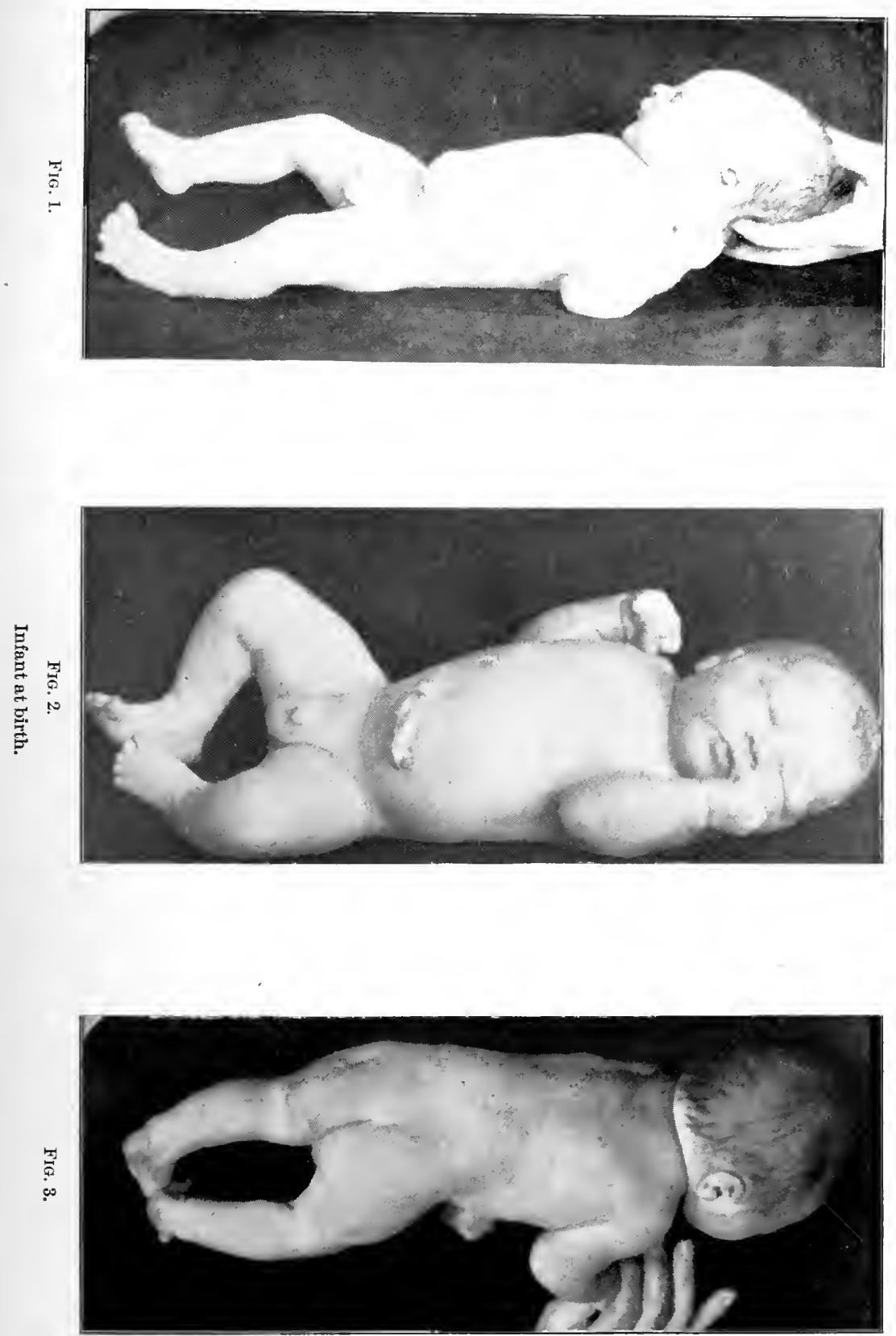


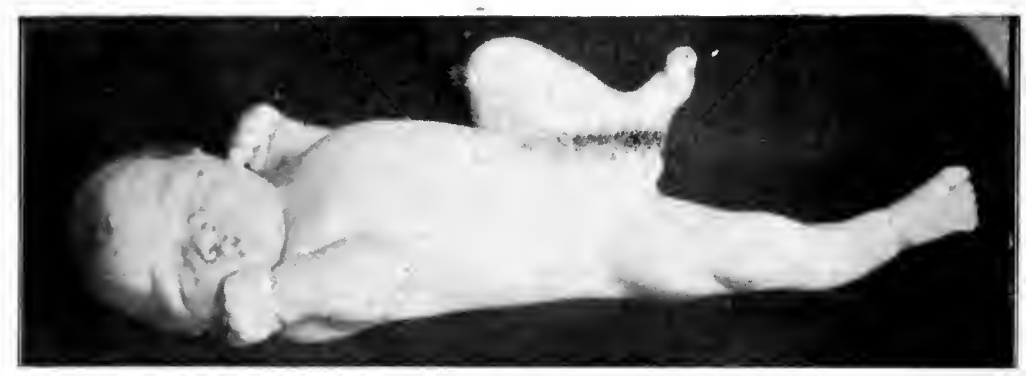

FIG. 4,

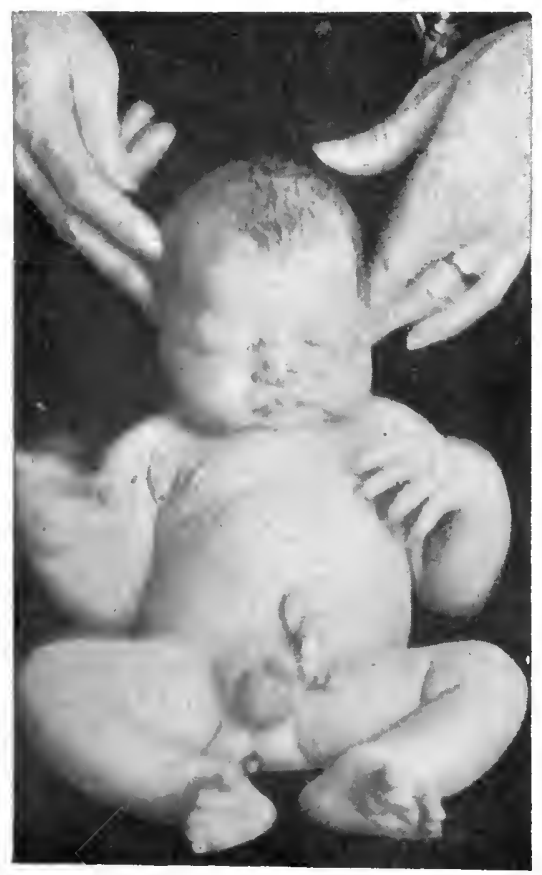

Fig. 5.

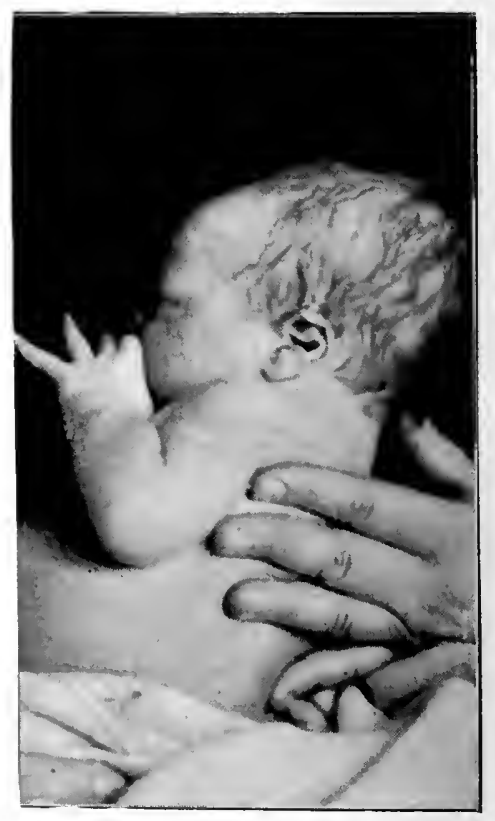

FIG. 6.

Infant at birth. 
frontalis muscle. The extreme mobility of the scalp in infaney is due to the loose attachment of the above-mentioned tissues to the pericranimm,points to be remembered in considering extravasations in this region (Fig. 7). The pericranium may be regarded as the remains of the outer layer of the developing membrane which surrounded the bones in fetal life. It is very slightly attached, except at the sutures where it blends with the dura mater.

The skull at birth presents marked peculiarities not only in its entirety, but also as to its individual bones, and further in the persistence of some of its chondral portions.

Considered as a whole the large size of the head compared with that of the body, and the predominance of cranial over facial proportions, are marked features; the proportion of face to cranium has been put as

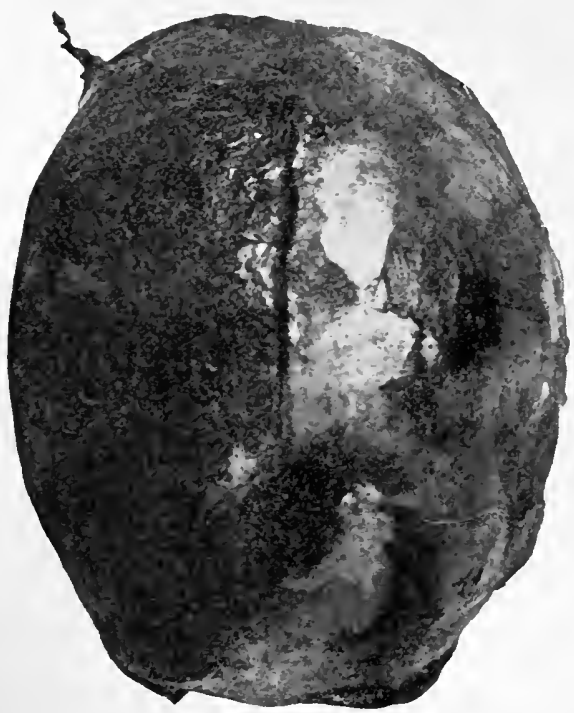

FIg. 7.-Pericranial hemorrhage in new-born. (Dr. P. Bassoe.)

1: 8 (Figs. $5,6,8$ ), while in later life it is as $1: 2$. The parietal eminences are large and conspicuous. Adjacent margins of the bones of the vault are separated by fibrous tissue continuous with the dura mater internally and the pericranium externally. The bones of the vault consist of a single layer without diploe. At the angles of the parietal bones are membranous spaces, ealled fontanelles. The largest and most important of these is the anterior median, which is situated at the junction of the frontal, sagittal, and coronal sutures (Fig. 9). It is quadrilateral, from two to four centimetres long and one to two centimetres wide, and immediately after birth it is slightly depressed. In this space there is a regular pulsation corresponding in frequency with the action of the heart. The posterior median fontanelle is smaller and triangular in shape. The remaining four lateral spaces are found at the inferior 
angles of the parietal bones and are irregular in ontline (Figs. 10 to 12). Supernumerary (Wormian) bones are frequently found in the line of sutures or at the fontanelles.

At the base of the skull the most striking points are, first, the absence of the mastoid processes, and, second, the large angle which the pterygoid plates form with the skull base. (In the adult the angle is almost a right one.) The base is relatively short, and the lower border of the mental symphysis is on a level with the occipital condyles. The facial skeleton is relatively small in eonsequence of the small size of the nasal fosse and the undeveloped condition of both jaws (Fig. 13). The external auditory meatus is found anterior to the middle of a straight line connecting the symphysis mentis and the occipital condyle. In the adult it is decidedly posterior to the centre of this line. Embryology shows that the vault of the skull is formed in membrane and the base in cartilage. Although in fetal life ossification begins first in the vault, at birth it is always more advanced at the base. Pathology often makes this distinction more manifest. Among the more common of the gross malformations is that which shows an entire absence of all parts of the cranium formed in membrane, while the base is more or less perfectly developed, as in the anencephalus (Fig. 14).

The occipital bone consists of four distinct plates: the squamo-, the basi-, and two ex-occipitals united by strips of cartilage. The first named portion, which is formed in membrane and belongs to the vault, is often separated from the ex-occipitals by a wide fissure (Fig. 11). These fissures are of interest for they have been mistaken for fractures. The fact is, it is difficult to fracture the skull of a young infant, as the bones are soft and yielding and a blow indents without fracturing. Another membranous space extends from the squamo-occipital portion to the foramen magnum. It is here that a hernia of the membranes or brain occurs. There is no jugular process and the grooves of the lateral sinuses are absent or but rudimentary.

The sphenoid consists of three pieces, the median, containing the basisphenoid, and the two lateral, which are made up of the greater wings and internal pterygoid plates. The dorsum ephippii is cartilaginous; there are no air-sinuses and the optic foramina are large and triangular (Fig. 13).

The temporal is also made up of parts which are easily separable,viz., squamous, petrosal, and mastoid. The mastoid process is not developed, and the jugular fossa is only a shallow depression.

The antrum is relatively large and resembles the tympanic eavity in having a very thin roof separating it from the cranial eavity, but it approaches much nearer the outer surface of the skull than does the tympanum. The mastoid cells are not present at birth, and it is of interest in this connection to know that they are not present in twenty per cent. of adult mastoids. The petrosal is of loose and open texture, resembling unglazed porcelain, thus offering a striking contrast to the dense and ivory-like petrosal of adult life. 


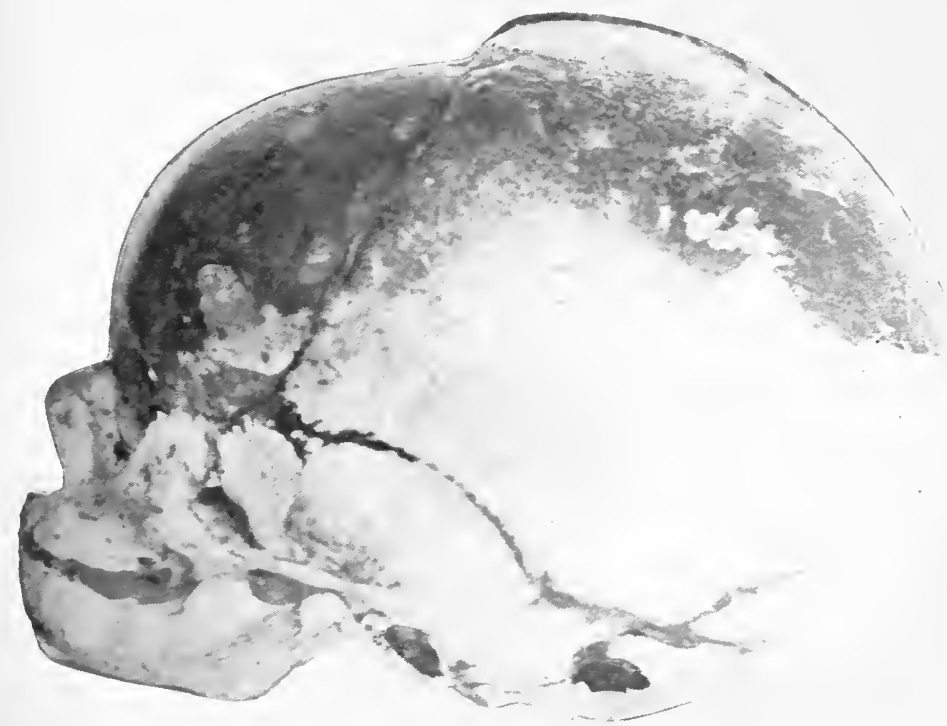

Fig. 8.-Skull of new-born. Frontal bone depressed by desiccation. (Dr. J. D. Merrill.)

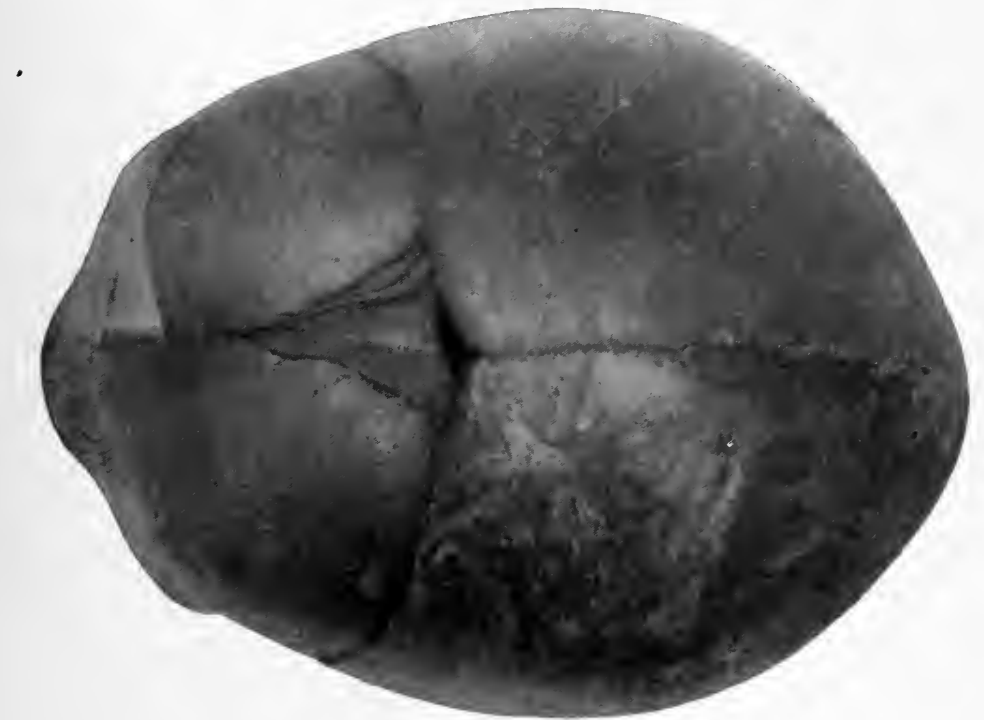

FIG 9.-Skull at birth. Vertex. (Dr. J. D. Merrill.) 


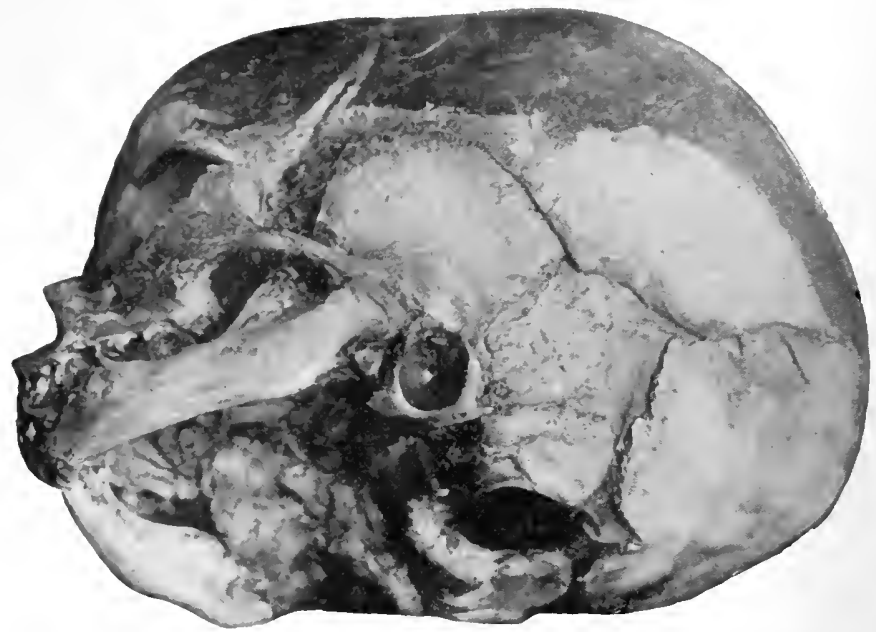

Fig. 10,-skull at birtl, showing tympanic membrane and notch of Revinus.

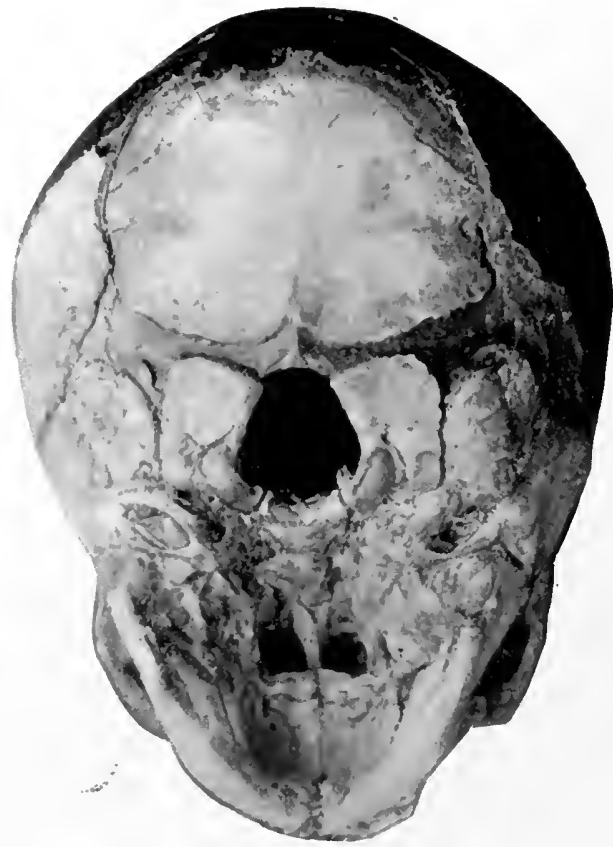

FIG. 11.-Skull at birth. Base. (Dr, J, D. Merrill.) 


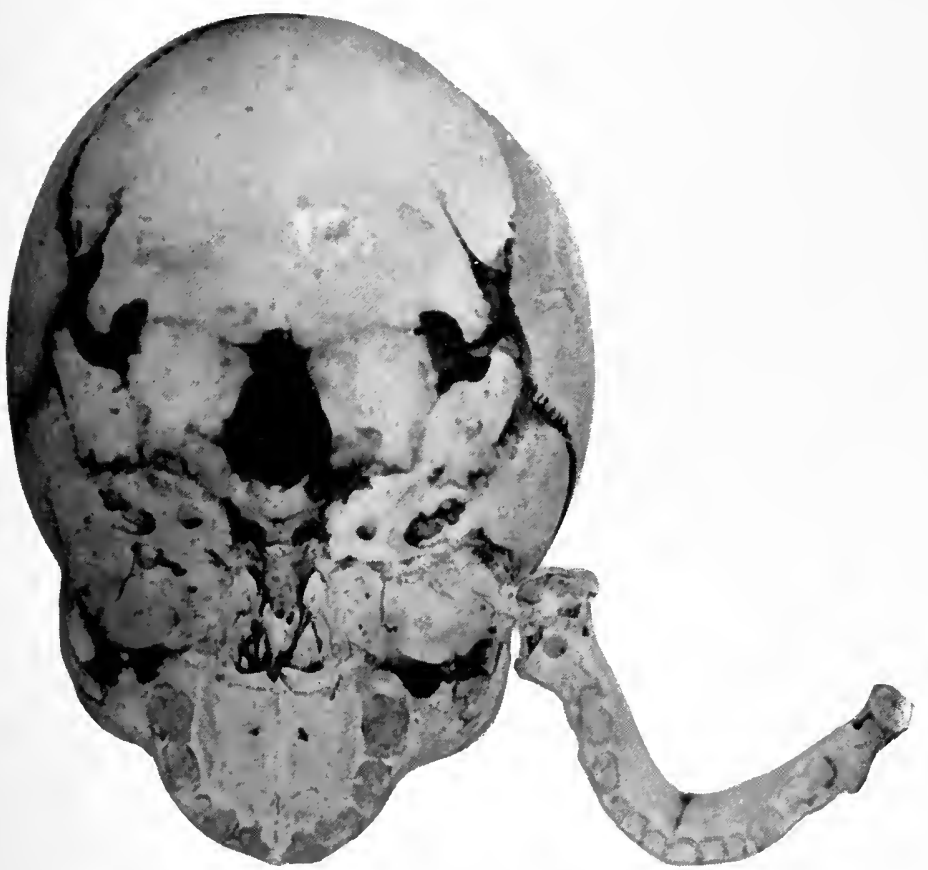

FIG. 12.-Skull at birth. Base. Teeth exposed by disseetion. (Dr. J. D. Merrill.)

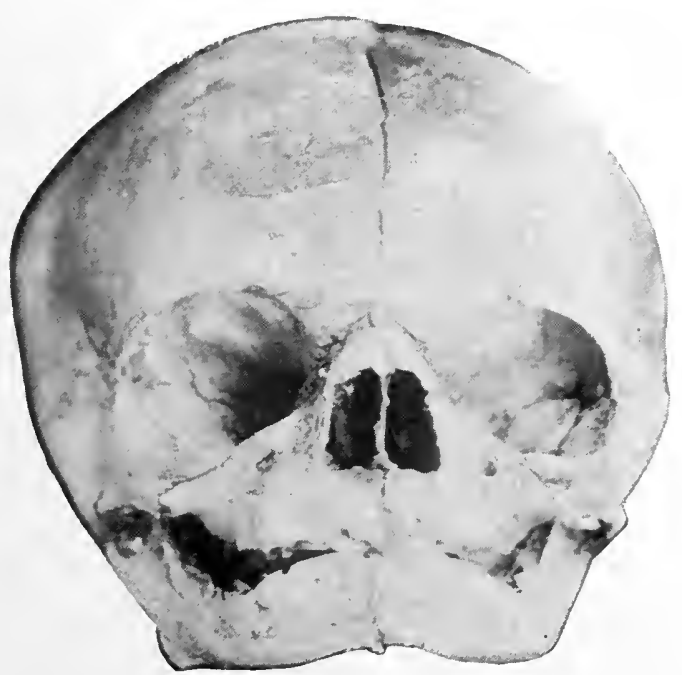

Frg. 13.-Skull at birth. Front. (Dr. J. D. Merrill.) 

The ear at birth presents some interesting conditions, for growth has been by no means uniform, and some parts are of full adult size and form, while others do not attain full development until after puberty. To the first class belong the internal ear and tympanic cavity with its ossicles and the mastoid antrum; in the second class are found the external auditory meatus, Eustachian tube, and the mastoid process. The external meatus is extremely short on account of the non-development of its bony portion, which is now represented by a mere ring (Fig. 10). It consists of an external part which is eartilaginous and an internal part which is osseo-fibrous. The canal passes inward with a decided downward inclination, so that the floor of the meatus lies nearly parallel with the outer surface of the membrane. The latter was formerly described as being more nearly horizontal than in the adult, but more recent investi-

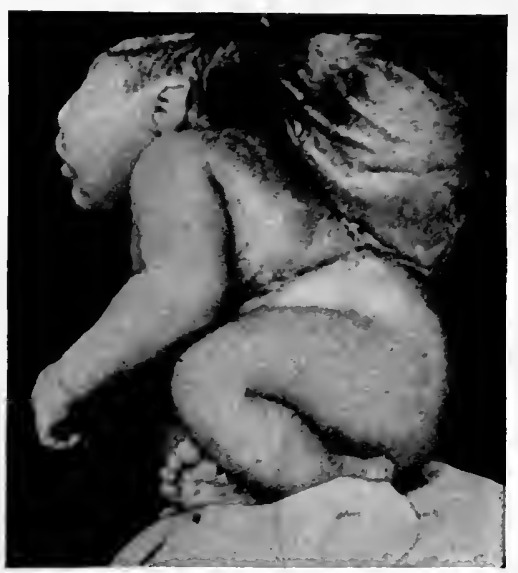

Frg. 14.-Anencephalus. (Rush Medical Museum.)

gation has proved that there is no perceptible difference between the inclination of the membrane of the new-born and that of maturity. The cavity of the middle ear is of about adult size, but there is one peculiarity in connection with the roof in the infant which is worthy of notice,viz., the existence of a petro-squamous suture. While it exists, it facilitates the extension of infections from the mucous membrane of the tympanum to the dura mater. The mucous membrane is deseribed as being in a swollen condition. To this and to the absence of air is ascribed the deafness of the first hours of extra-uterine life. Generally there is a deficiency in the upper part of the groove to which the tympanic membrane is attached, the notch of Rivinus, which is merely covered by the skin lining the meatus. At this unprotected area may occur the escape of fluid from the middle ear without perforation of the membrane. The membrana tympani is less securely attached at this notch than at the rest of its circumference; therefore, when subjected to violent concussion it is liable to give way at this point. 
The Eustachian tube differs from that of the adult in its length, the size of its lumen, its direction, and in the condition of its walls. The length is from seventeen to eighteen millimetres-about half that of the adult. The tympanic orifice is as large in the infant, but the pharyngeal opening is much smaller. The growth of the tube occurs mainly in the anterior portion and is associated with a projection of the posterior lip of the pharyngeal orifice on the lateral wall of the pharynx. The tube is nearly horizontal, forming an angle with the horizon of not more than ten degrees, while in the adult the inelination is about fortyfive degrees. There is searcely any osseous Eustaehian tube, six-tenths of it being cartilaginous.

In the parietal bones, the eminences, whieh indicate the spots in which ossification commenees, are large and conspicuous. The grooves for the

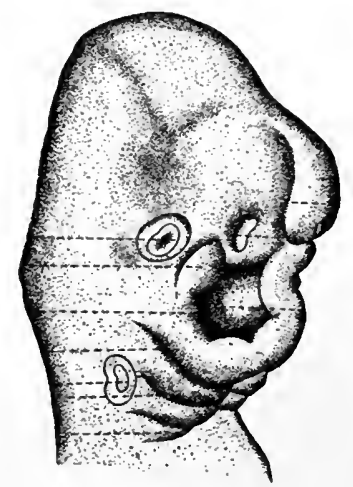

Fig. 15.-Branchial clefts. (Gray.)

blood-sinuses are absent or but slightly marked, as is the case in the other eranial bones.

The frontal consists of two bones separated by a median (metopic) suture (Fig. 13). The superciliary ridges and frontal sinuses are wanting. The nasal spine is absent and the orbital plates are often incomplete. There is no temporal ridge.

The ethmoid is made up of two scroll-like bones, very delicate and covered with depressions which give it a worm-eaten appearance. The ethmoid cells do not appear before the third year. It may be noted here that a constant communieation exists between the nasal veins and the superior longitudinal sinus through the foramen cæcum. This connection may, in part, serve to explain the occurrence of intracranial mischief as a consequence of inflammatory affections of the nasal cavity.

When the mouth is formed in the fœtus (Fig. 15), there is at first no separation between it and the nose; but the general cavity is gradually closed in by the horizontal plates of the superior maxillary and palate bones advancing towards each other, and the septum 
of the nose descending from above to join them in the middle line. Normally the only trace of the original fissure is the nasopalatine canal (Fig. 12).

At birth a peeuliarity of the palate bones is the equal length of the vertical and horizontal plates.

The inferior maxillary is represented by two nearly horizontal troughs of bone lodging the unerupted teeth. Eaeh half is joined at the symphysis by fibrous tissue (Fig. 12). 'The gums, composed of dense, fibrous tissue, form a tongh proteeting covering to the developing teeth. The margins of the superior and inferior maxillæ do not approximate at birth. The alveolar areh in the new-born deseribes almost the segment of a eirele; in the adult it is semi-elliptieal.

At birth, remnants of the primitive elondral skull are abundant. Cartilaginous tracts exist between the valious portions of the oceipital and also at the lines of junetion of adjacent bones. The dorsum eplippii is entirely cartilaginous, as are the styloid processes and a large portion of the hyoid.

THE FACE.

The rotundity of the face is due to the generous deposit of subcutaneous fat, especially over the cheeks. Over the buceinator museles, in addition to the ordinary subeutaneons layer of fat, there is an arrangement of fatty lobules surrounded by a capsule on either side. They have been called "sucking cushions," beeause they are thought to prevent the buecinator muscles being pressed inward between the alveolar arehes when a vacuum is produced in the mouth. The skin of the face is very thin and exceedingly vaseular, henee it is often the seat of nævi. It is attached to the adjacent struetures by loose, eellular tissue, exeepting over the alæ of the nose and over the ehin where it is elosely adherent to the parts beneath.

By some writers it is stated that the eye at birth is anatomically eomplete. However, others have elaimed that the macula lutea is not fully developed, that the cornea has not attained a full degree of transpareney, and that the recessus opticus is more marked, all of which would preelude the possibility of perfeet optic function, even if the brain were ready to receive and interpret impressions. .Examinations of the eyes of many new-born infants have shown them all to be hypermetropic. The eolor of the iris is a bluish gray. The pupils are large and sensitive to light. The lachrymal glands are not fully developed.

The tongue contains much lymphoid tissue, a considerable part of which is massed under the mueous membrane of the posterior third.

The arch of the hard palate varies in different individuals; a high, narrow arch being considered a stigma of degeneration.

The nose is of relatively small size and the respiratory portion is very small. The septal eartilage is usually straight. The height of the posterior nares is six to seven millimetres, and the breadth between the pterygoid processes at the hard palate is nine millimetres. 
With these dimensions it is easy to see how congestion would nearly obliterate the small passage and the resulting obstruction be a source of danger.

The pharynx is always widest near the hyoid bone and narrowest opposite the cricoid cartilage; hence foreign bodies which become lodged in the pharynx may be reached with the finger. The connective tissue between the pharynx and the spine is very lax, allowing large accumulations of pus, as in post-pharyngeal abscess and cervical necrosis. The internal carotid artery and the pneumogastric, glossopharyngeal, and hypoglossal nerves are in relation to the walls on either side, a point of interest from the symptoms caused by compression of these important structures from tumors in this region. The importance of the nasopharynx is due to the vascularity and the abundant supply of lymphatic glands and vessels in this region, particularly in the posterior wall. The opening of the Eustachian tube is at the level of the hard palate at birth. The horizontal direction of the tube and its unguarded orifice facilitates the infection of the middle ear from the nasopharynx.

\section{THE NECK.}

The neck is usually described as relatively very short. An examination of the skeleton shows the cervical portion of the spine is actually relatively long (Fig. 16) and, on account of the slight development of the facial part of the skull, the lower jaw occupies a high position, so that the length is still more increased. It is true the manubrium sterni is higher than in the adult, but this does not compensate for the slight vertical extent of the face. The thick layer of subcutaneous fat tends to make the neck appear short and thick (Fig. 3).

In the fœtus elefts occur between the branchial arches, which are five in number (Fig. 15). The first lays the foundation for the lower jaw; the second, the incus, styloid, stylohyoid ligament and the lesser cornu of the hyoid bone. From the third are formed the body and greater cornu of the hyoid, while the fourth and fifth take part in the formation of the soft parts of the neck below the hyoid.

\section{VERTEBRAL COLUMN.}

In the new-born infant the cervical and lumbar regions are nearly equal in length, while in the adult the ratio is $2: 3$. Much investigation has been made concerning the curvature of the spine at this period. In the living body it is impossible, from the great flexibility and the influence of muscular contraction and gravity, to estimate correctly the normal curve. The effects of gravity in frozen sections render the results by this method unreliable. Most authorities state that the spine presents two curves with their concavities forward, one in the dorsal region, and the other formed by the sacrococeygeal vertebræ.

A peculiarity of the infant spine is its extreme flexibility. It is, in fact, almost wholly cartilaginous at birth, the centres of ossification being present but the process only slightly advanced (Fig. 17). There are 

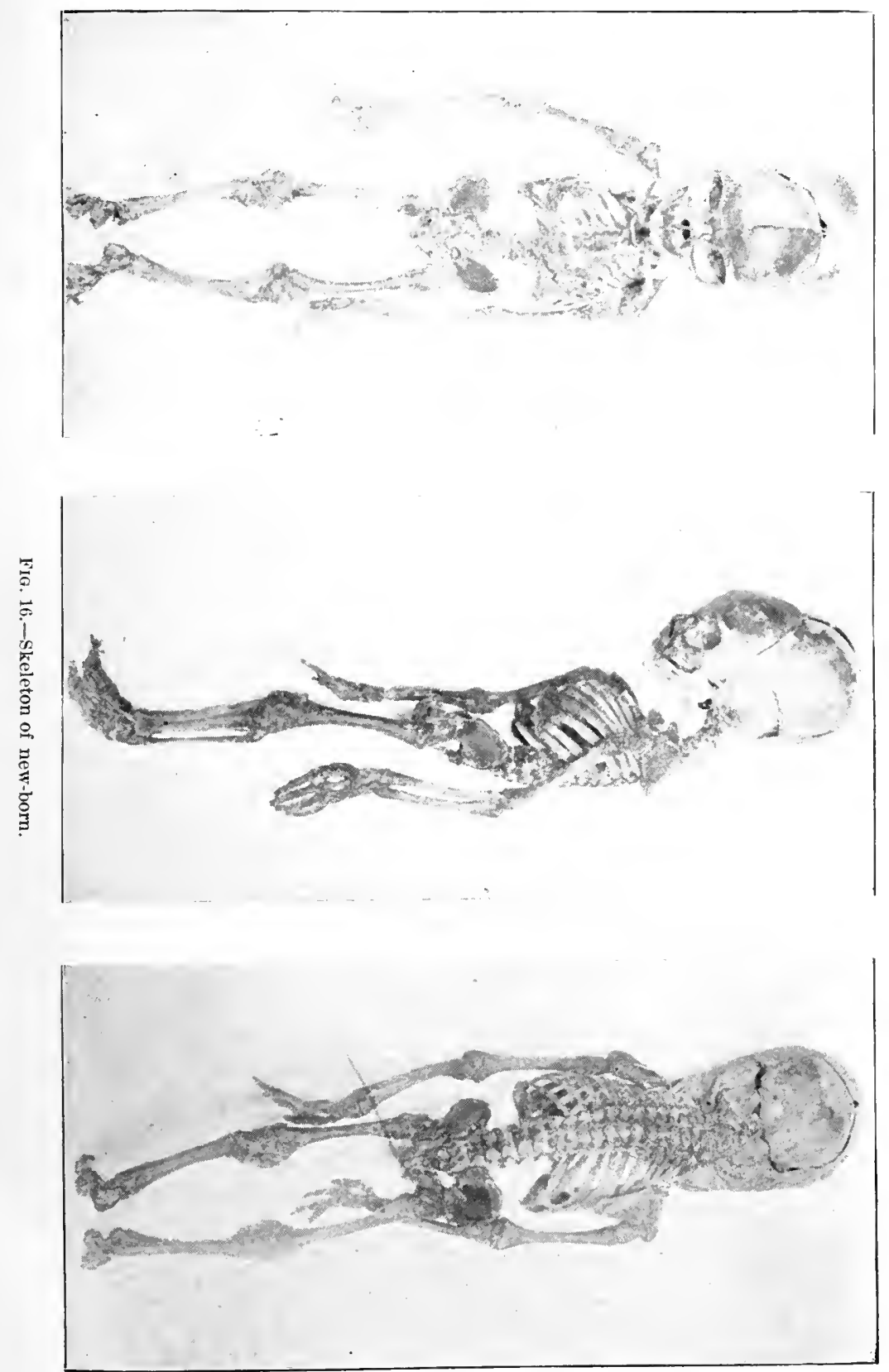

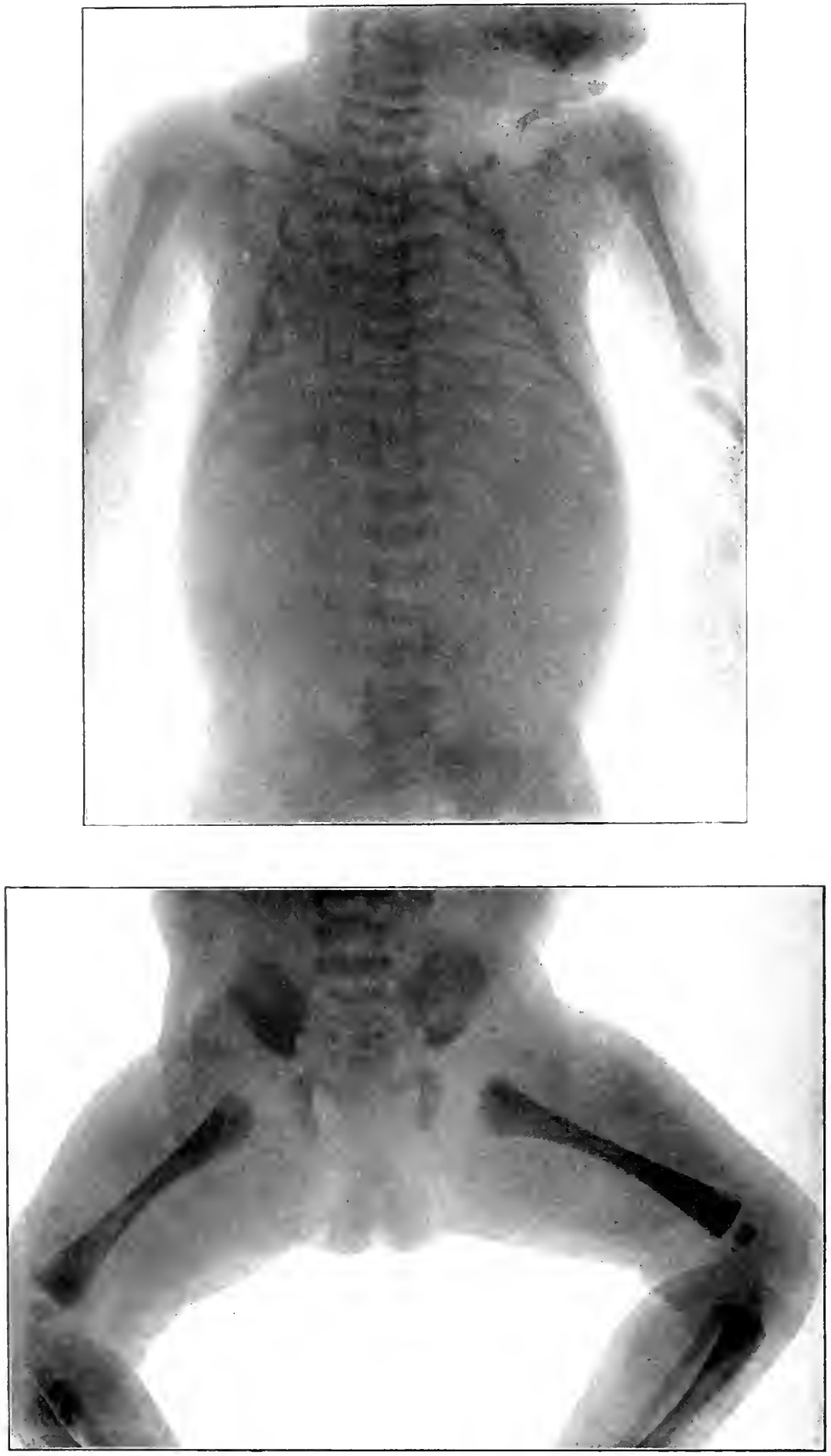

Figs. 17 and 1k. - skiagram of new-born infant. 
three nuclei for each vertebra, one for the body and one for cach lateral mass. Ossification of the bodies begins about the centre of the column (ninth dorsal) and extends upwards and downwards; while ossification of the lamina commences above and proceeds gradually downwards. (Arrest of development of the lamina gives rise to a cleft, spina bifida (Fig. 20), allowing a hernia of the membranes and sometimes of filaments of the cord. This usually occurs in the lumbar arches and upper part of the sacrum. ( Because of surgical interest, it will be well to remember that the fourth lumbar vertebra, at all ages, is on a level with the highest point of the crest of the ilium.

\section{LONG BONES.}

(The clavicle is peculiar not only in that it is the first bone of the skeleton to ossify, but that ossification in it begins in its primary substance before the deposition of cartilage.) At birth the entire shaft is bony, the ends only being cartilaginous. This bone is more frequently fractured during delivery than is any other (Fig. 17). It is stated that one-half the cases of broken collar-bone occur before the age of five years. This is explained by the fact that the elavicle is in a breakable condition at a time when most of the long bones still present much unossified cartilage in their parts. That the periosteum is comparatively thick and not closly attached to the bone are circumstanees that favor subperiosteal or green-stick fracture, which is characteristic of early years.

The scapula is chiefly osseous, only the coracoid and acromion processes, a narrow rim of the posterior border, and the tip of the inferior angle being cartilaginous. Sometimes a failure of union betwcen the acromion process and the spine occurs, the junction being effected by fibrous tissue. In some cases of supposed fracture of the acromion, with ligamentous union, it is probable that the detached segment was never united to the rest of the bone.

It may be said of the shafts of all the long bones at birth, that they are mainly cylindrical and free from ridges. The long bones afford the best example of the process of ossification, for it depends upon both membranous and eartilaginous formation. The process begins in the centre of the shaft (diaphysis), and proceeds towards the extremities (epiphyses), which remain cartilaginous until some time later, when centres of ossification occur in them also (Figs. 18 and 19). The extremities are separated from the shaft by a layer of epiphyseal cartilage until the growth of the bone is completed. Simultaneously with the ossific changes in the centre of the cartilage, a very vascular membrane is developed around the shaft. This is the periosteum, and consists of two layers which serve as a nidus for the ramifications of vessels which pass from it into the bone. In infants it is thick and vascular and is connected only at the epiphyseal cartilages, being separated from the shaft by a layer of soft blastema containing osteoblasts, from which ossification proceeds on the surface of the growing bone. Bones grow in length 
chiefly by the deposition taking place upon the extremities of the diaphysis and in the extension of the ossific centres of the epiphyses. They increase in circumference by deposition from the periosteum on the external surface, while the medullary canal is produced by absorption from within.

Owing to the long bones having separate centres of ossification, and the interposition of the layers of cartilage between them and the shaft until its full length is attained, the bone is indurated in the parts where the greatest strength is required, while the longitudinal growth is facilitated. About the centre of the shaft there is a large foramen leading obliquely into the medullary canal; through this passes the medullary artery, usually a branch of the main artery of the part of the limb to which the bone belongs.

The humerus and femur are nearly ossified in their whole length, the extremities only being entirely cartilaginous. The danger of separation of the epiphyses from external violence or undue traction in infancy and

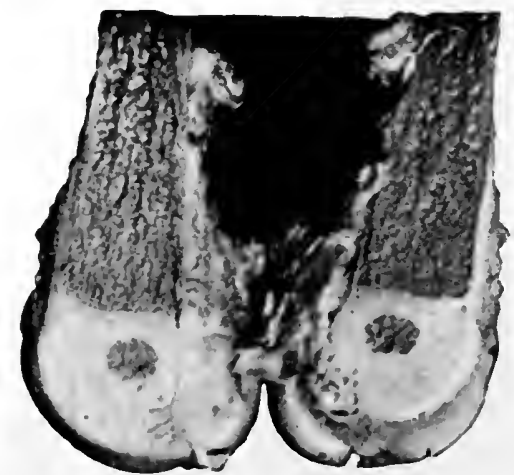

FIG. 19.-Lower end of femur showing sharp line of demarcation between diaphysis and epiphyseal cartilage, and beginning ossification in the latter. (Rush Medical Museum.)

early childhood is apparent. The ligamentous attachments at the articulations have been shown to offer greater resistance than the epiphyseal union, so that separation at that point would precede joint luxation or bone fracture as a result of rough handling. Just below the external condyle of the humerus there is a pit or dimple in the skin which is an important landmark, as here the head of the radius can be felt rolling in pronation and supination of the forearm.

The epiphyses which meet at the elbow unite with their shafts earlier than those at the opposite ends of the bones, and the foramina of the nutrient arteries are directed towards the elbow.

The bones of the wrists and hands are nearly all cartilaginous at birth. Owing to the peculiarities of fetal circulation the lower extremities have received less nourishment and are not as far developed as the upper extremities. 
THORAX.

A characteristic feature of the infant thorax is the relation between the anteroposterior and transverse diameters. In the adult the ratio is 1:3, while in the infant it is $1: 2$ or even less. Another peculiarity is the extreme compressibility. Owing to incomplete ossification, cartilaginous tissue predominates in the structure. It suggests in form a truncated cone, and in structure, an inverted basket (Fig. 17).

The sternum is practically a strip of cartilage in which there are

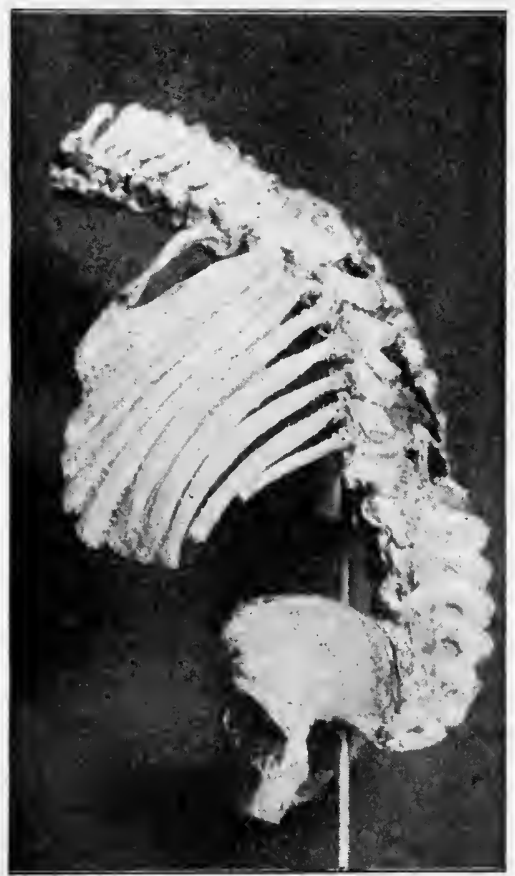

FIG. 20.-Spina bifida. (Rush Medical Museum.)

varying numbers of bone-centres. The upper border of the manubrium is usually about the level of the middle of the first dorsal vertebra, a higher position than in adult life, when it is at the level of the lower border of the second dorsal vertebra. It forms a considerable portion of the anterior surface of the thorax.

The ribs are more horizontal, particularly the upper six or seven. They are also flatter and more elastic than in later life (Figs. 16, 20).

\section{LARYNX.}

The larynx extends from the level of the body of the axis to the lower border of the fourth cervical vertebra. This is fully two vertebræ higher than in adult life. The chief characteristies of the larynx, besides the 
location, are the small size, the comparative slightness of the organ, and the smooth rounded form of the thyroid cartilage.

The high position of the infant larynx, with the low sloping pharyngeal vault, must be remembered in manipulations such as laryngoscopy and intubation, which in many instances are accomplished with extreme difficulty in very young children. On the other hand, the shortness and width of the oral carity, the compressibility of the base of the tongue and flexibility of the neck render comparatively easy, in most cases, a direct visual examination of the epiglottis, the upper portion of the larynx, arytenoids, and vocal cords. The lax attachment of the larynx to surrounding structures allows of its being brought more clearly into view by upward pressure on the cricoid cartilage, combined with downward and forward pressure on the median glosso-epiglottidean ligament, by a properly constructed tongue depressor.

\section{TRACHEA.}

As a rough rule it may be said that the calibre of the trachea corresponds to the size of the patient's forefinger. In the fœtus the trachea is flattened before and behind, its anterior surface being even somewhat depressed; the ends of the cartilages touch; and the sides of the tube, which now contains only mucus, are applied to one another. The effect of respiration is at first to open the trachea, but it still remains flattened in front, and only later becomes convex. In consequence of the high position of the larynx, the cervical part of the trachea is relatively longer at this period of life, but the increase in length is somewhat diminished by the higher position of the manubrium. The point of bifurcation of the trachea is opposite the third dorsal vertebra, about one vertebra higher at birth than in the adult.

\section{LUNGS.}

$\sqrt{\text { Rapid and remarkable changes occur in the lungs with the commence- }}$ ment of respiration. In the fotus at full term the lungs, comparatively small, lie towards the back of the chest, and do not bulge forward at the sides of the heart (Fig. 21). After respiration has been established they expand and completely cover the pleural portion of the pericardium and are also in contact with almost the whole extent of the thoracic wall, while their previously thin, sharp margins become more obtuse. In utero the alveoli and small air-passages are collapsed. At the first inspiration, comparatively little air is taken into the lungs, because of the force necessary to overcome the adhesions of the sides of the bronchioles and alveoli; but as one full inspiration follows another, inflation increases more and more until full distention is accomplished. If once the lungs have been filled with air, they are never completely emptied.

The introduction of air and of a greatly increased quantity of blood into the fetal lungs, converts their tissues from a compact, heavy substance into a loose, light, rose-pink, spongy structure which floats. These 
changes occur first at the anterior borders and proceed backward through the lungs; they, moreover, appear in the right lung a little sooner than in the left.

The absolute weight of the lungs, having gradually increased from the earliest period of development to birth, undergoes at that time, from the quantity of blood then poured into them, a very marked addition, amounting to two-thirds of their previous weight. Before birth the weight is $48 \mathrm{Gm}$., but after complete expansion it has risen to $80 \mathrm{Gm}$. Relative to body weight at the end of intra-uterine life the weight of the lungs is $1: 70$; after expansion it is $1: 35$ or $1: 40$, a ratio not materially altered through life. The specific gravity changes from 1.056 to 0.342 .

During fetal life the alveoli are entirely lined with small granular cells, but with the distention following the first respiratory efforts, many of the cells become transformed into large, thin, epithelial elements.

The lower border of the lungs will be found to reach posteriorly as low as the tenth rib on the right side, and the eleventh rib on the left; in the midaxillary line to the ninth rib, and in the mammillary line to the sixth rib on the left side, and to the fourth or fifth on the right. The degree of approximation of the lungs anteriorly is not as close as in later life.

\section{HEART.}

The average weight at birth is twenty and one-half grammes, or twothirds of an ounce. In the early stages of fetal formation the heart occupies nearly the whole of the thoracic eavity, and, comparatively speaking, is much larger than it is subsequent to birth. The auricular portion exceeds the ventricular, and the right auricle is more capacious than the left, the right ventricle being also larger than the left. The organ is placed vertically within the thorax at this early period. Just before birth, however, these peculiarities disappear, and the ventricular portion becomes the larger, the left having the thicker walls, and the whole organ rapidly approaches its permanent condition for life. It is yet somewhat larger in relation to body weight, the ratio being at birth $1: 120$, while in the adult it is $1: 160$. In contrast with this, it will be remembered that one of the characteristic features of the infantile thorax is the shortness of its transverse diameter. Since the vertical extent of the heart in relation to the anterior chest wall differs but little in infants and adults, it will naturally follow that the transverse diameter of the heart, as compared with that of the chest, is relatively greater in the former than in the latter. This naturally causes an extension outwards of the position of the apex beat in relation to the nipple. Hence it is normal for the apex beat to be either in the mammillary line or external to it. Clinicians are divided in opinion as to the intercostal space in which the apex beat is to be felt at birth. Most observers put it at the fourth.

The internal structure of the fetal heart differs from that of the adult chiefly in having an opening (foramen ovale) between the auricles, and 
in the presence of the Eustachian valve which directs the blood from the inferior vena cava through the foramen ovale. The latter generally becomes closed within the first week or ten days after birth, but may remain open longer, and in some instances has been found to be patent in the adult. The Eustachian valve soon atrophies after the establish-

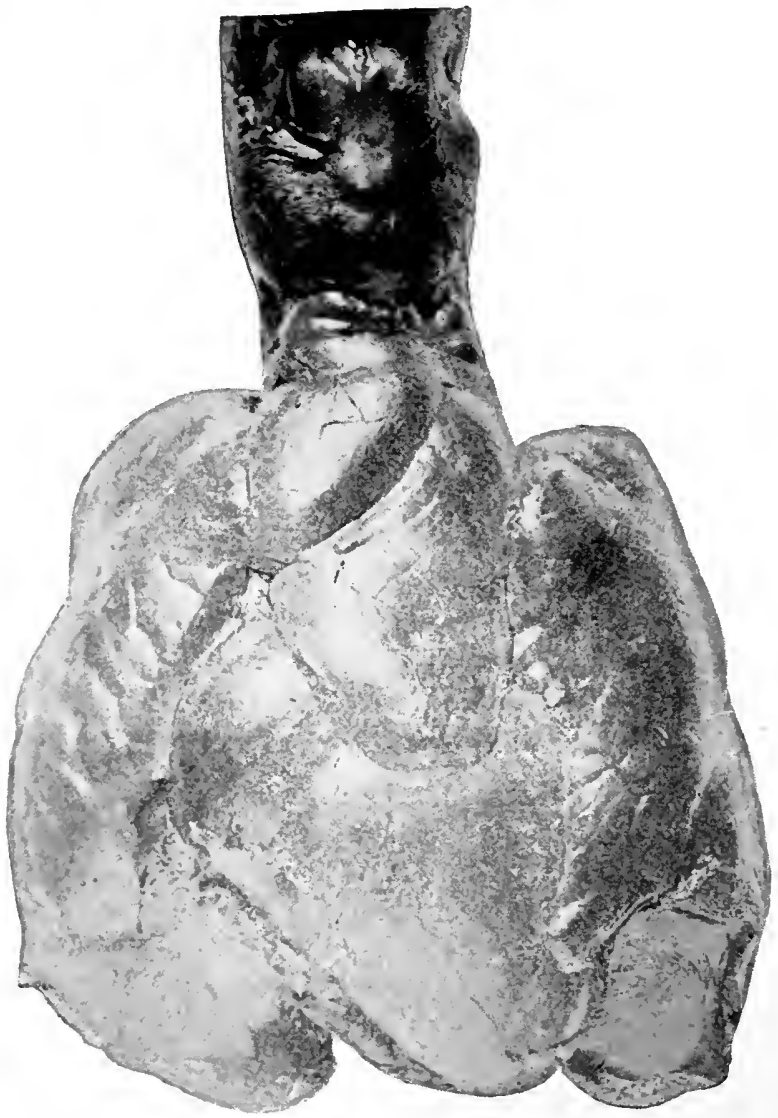

FIG. 21.-Lungs, heart, thymus and thyroid of still-born infant at full term. (Dr. J. D. Merrill.)

ment of the function of the lungs and the changed circulation of the blood. Contemporary with these structural alterations, there occur changes in the great vessels, which are requisite for the independent circulation of the blood. The pulmonary artery of the fœtus, after leaving the right ventricle, gives off the right pulmonary branch, and then divides into two other branches, the first of which is as large as the pulmonary artery itself and which directly joins the aorta at the termination of its arch, while the other goes to the left lung. The connecting branch between the pulmonary artery and the aorta is named the ductus arteriosus. It is really the continuation of the pulmonary artery. 
The fetal circulation consists of the entrance of arterial blood from the placenta into the body of the ehild at the umbilicus, by means of the umbilical vein, which ascends to the under surface of the liver (Fig. 2.2). Within this organ the greater part of the blood first circulates through the branches of the portal and hepatic veins, and thence passes to the inferior vena eava, but a portion of the blood conveyed by the umbilical

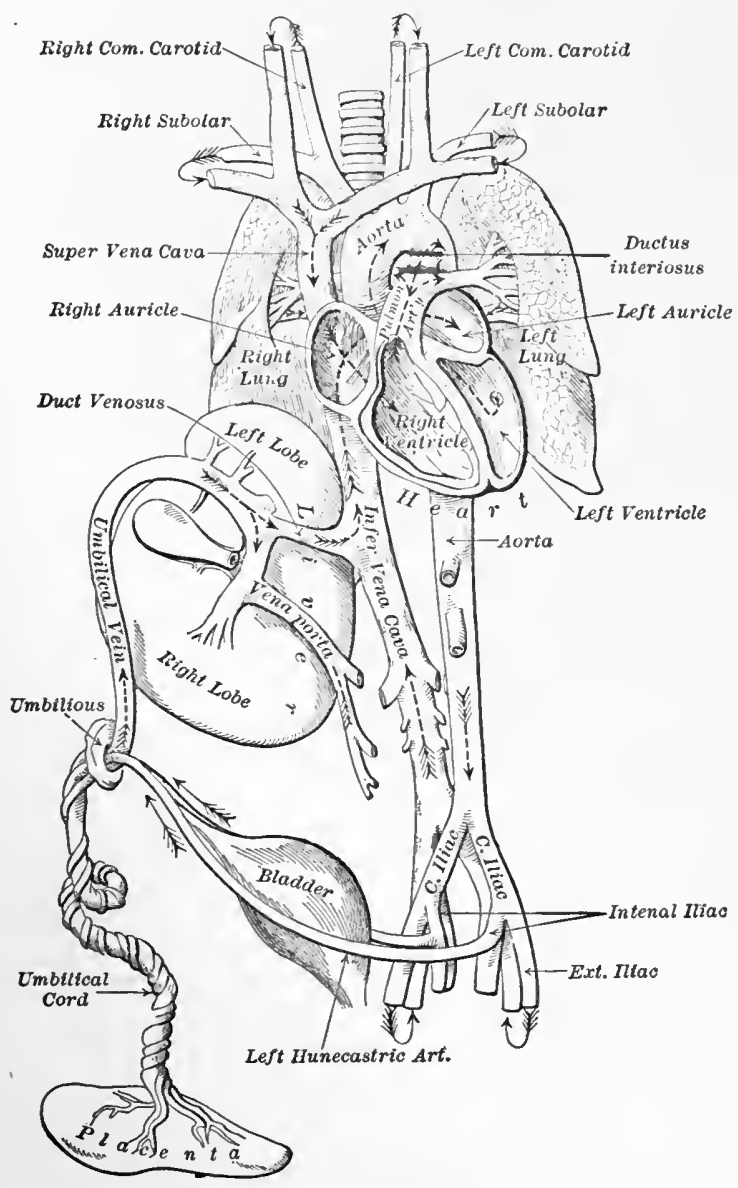

Frg. 22.-Fetal circulation. (Gray.)

vein is conducted by a small vein directly to the inferior vena cava, without passing through the substance of the liver; this vessel is called the ductus venosus.

The inferior vena cava empties all its blood into the right auricle, whence it is directed by the Eustachian valve through the foramen ovale into the left auricle. From the left auricle it passes into the left ventricle, and thence by means of the aorta it is distributed ehiefly to the 
head, neck, and upper extremities. The more immediate supply of pure blood to these parts accounts for their greater proportionate development at birth. The venous blood from the upper part of the body is returned into the superior vena cava and by it to the right auricle, which it passes to the right ventricle. From the latter it issues by the pulmonary artery, and is chiefly conveyed by its continuation, the ductus arteriosus, into the upper portion of the descending aorta, where it mixes with a portion of the blood from the left ventricle. From the descending aorta the blood passes through the abdominal aorta into the iliac arteries. The external iliae arteries carry part of this blood to the lower extremities, but the most of it is returned to the placenta by means of the hypogastric arteries, which are the eontinuation of the superior vesical branches of the internal iliac. They pass out at the umbilicus, where, under the name of the umbilical arteries, they twine around the umbilical vein in the substance of the cord, and return their impure blood to the placenta to be reoxygenated.

The umbilical vein and ductus venosus, after ligation at birth, atrophy and bccome converted into a fibrous cord which constitutes the round ligament of the liver. The coagula usually disappear from these vessels within five days. The ductus arteriosus and hypogastric arteries also contract after birth and become closed,--the former usually within the first ten days, and the latter within the first three or four days. The remains of the ductus arteriosus constitute the ligamentum arteriosum, which is attached to the concavity of the aorta. The bands resulting from the obliteration of the hypogastric arteries form the lateral false ligaments of the bladder.

A review of the development of the embryonic. heart sheds some light on the character of many congenital defects. It is claimed that pulsation has been noted in the human embryo as early as the fifth day, the entire circulatory apparatus being then represented by a few cells. From this in a few days is evolved a tube, the foundation of the heart and great vessels. By the end of the second week is seen an S-shaped organ which is still monolocular with two sets of vessels, the primitive veins and arteries. At the fourth week the cavity is partly divided by the growing septum into two compartments, one for the admission, the other for the discharge of blood. By the end of the eighth week a membranous process, which appeared early at the lower part of the apex and at the margins of the orifices of exit, has developed into a septum dividing the great efferent vessel into the aorta and pulmonary artery and forming the interventricular partition. The last part of this septum to be completed is the upper portion, lying immediately below the auricoloventricular walls. During this time the auricular portion of the heart is divided in a similar manner into right and left chambers by the interauricular process, which pushes inward and is not completed until after birth, the foramen ovale being the last part to close. The septum ventriculorum also not infrequently shows at birth a foramen. When present it is invariably in its upper portion. By far 
the commonest defect in development is seen at the pulmonary orifice either as (1) malformation of its valves, not infrequently two only being found, or the three coalescing in the form of a perforated circular diaphragm, or (2) there may be a narrowing below the valves, a stenosis of the conus. It is easy to understand how a primary stenosis of the pulmonary orifice or conus might influenee the development, not only in the septa but in the muscular walls of the right ventricle, through the obstruction to outflow from this cavity. In fact, a patulous septum ventriculorum is usually assoeiated with pulmonary stenosis with aeeompanying hypertrophy of the right ventricle (Fig. 142).

Occasionally arrest of development in the intervascular septum leaves a common trunk or chamber attached to the ventrieular portion of the heart, from which arises the aorta and pulmonary vessels (Fig. 141).

An entire absence of the septum ventrieulorum has been observed, as also has that of the auricles; so that bilocular and trilocular hearts are among the anomalies of arrested development, with a great variety of abnormalities in the position and formation of the vessels.

\section{THYMUS GLAND.}

This is a temporary organ which reaches its greatest size about the end of the second year. It appears as a narrow, elongated, glandular body, situated partly in the thorax and partly in the lower region of the neck (Fig. 21). Below, it lies in the upper anterior mediastinal space, behind the sternum as far down as the fourth rib eartilage and in front of the great vessels and perieardium; above, it extends upwards upon the trachea in the neek as high as the lower border of the thyroid eartilage. Considerable variation in size and shape has been found. The color is a grayish-pink, the consistence soft and pulpy, and the surface is distinctly lobulated. It consists of two lateral lobes which touch each other along the middle line. Occasionally the whole body forms a single mass and often there is an intermediate lobe. It measures about sixty millimetres ( $23 / 8$ inches) in length, thirty-seven millimetres (11/2 inches) in width, about eight millimetres in thickness, and weighs from five to fourteen grammes.

\section{THYROID GLAND.}

The thyroid at birth is of relatively large size, being in proportion to body weight as 1:240; while in the adult it is $1: 1800$. There are two lateral lobes united towards their lower ends by a transverse portion called the isthmus (Fig. 21). Each lateral lobe lies on the side of the trachea, extending from the fifth or sixth ring to the thyroid eartilage. The isthmus commonly lies across the second, third, and fourth rings of the trachea.

It is extremely vascular, its blood supply not being exceeded by that of any other equal area. Its freely anastomosing veins (the superior, middle, and inferior thyroid) open directly into the internal jugular and innominate. 
Like the thymus the thyroid has no duct after birth. It has recently been elaimed that the remains of an embryonic duct have been found leading to the foramen cæcum at the angle formed by the circumvallate papillæ. To the occasional persistency of this duct, a causative relationship has been claimed for the rare development of accessory thyroid tissue found as tumors at the base of the tongue.

Variations in the size, shape, and number of the lobes of the thyroid gland are common. At times the gland consists of two separate parts, one on each side of the trachea, or there may be only one lateral lobe, or the three portions may not be united.

The occurrence of accessory glands is of clinical interest, inasmuch as it helps to explain in certain cases the lessened severity of the symptoms following extirpation of the gland. These accessory glands are found in the region of the aorta, in the supraclavicular fossæe, and to the side of and behind the pharynx and large vessels of the neck.

Other glandular bodies, known as parathyroids, are found in close relation to the thyroid gland just behind the lateral lobes. There may be one or two of these bodies on either side, varying in size but averaging in length seven millimetres, in breadth two to three millimetres, and in thickness one and one-half millimetres. They differ from the thyroid not only in structure but also in function, the latter fact having been demonstrated by the differing effects following their removal.

BRONCHIAL GLANDS.

The bronchial lymphatic glands are found in three groups, the location of which is of interest on account of their relationship to adjacent vessels and nerves. The first group is in intimate relation with the trachea, the superior vena cava, recurrent laryngeal and pneumogastric nerves; the second set is found at the bifurcation of the trachea and roots of the lungs (hilus glands), where their enlargement would encroach on the esophagus, pneumogastric nerves, and the aorta; the third follows the larger bronchioles into the substance of the lungs, along with the bronchial and pulmonary vessels and nerves.

\section{DIAPHRAGM.}

The diaphragm forms a muscular partition between the chest and abdomen. It is described as occupying a higher position than in adults. The lungs in their pleuræ rest upon the muscular portions, while the heart in the pericardium lies above the central tendon. On each side of the ensiform cartilage is a triangular space which gives passage to the vessels to the anterior mediastinum. Occasionally this becomes the seat of a diaphragmatic hernia.

\section{ABDOMEN.}

In the child at full term and for the first two years the umbilicus marks the middle of the long axis of the body. The cord usually drops off at the end of five to seven days (occasionally this period is much longer, fourteen to twenty-three days), leaving a red and moist surface. 

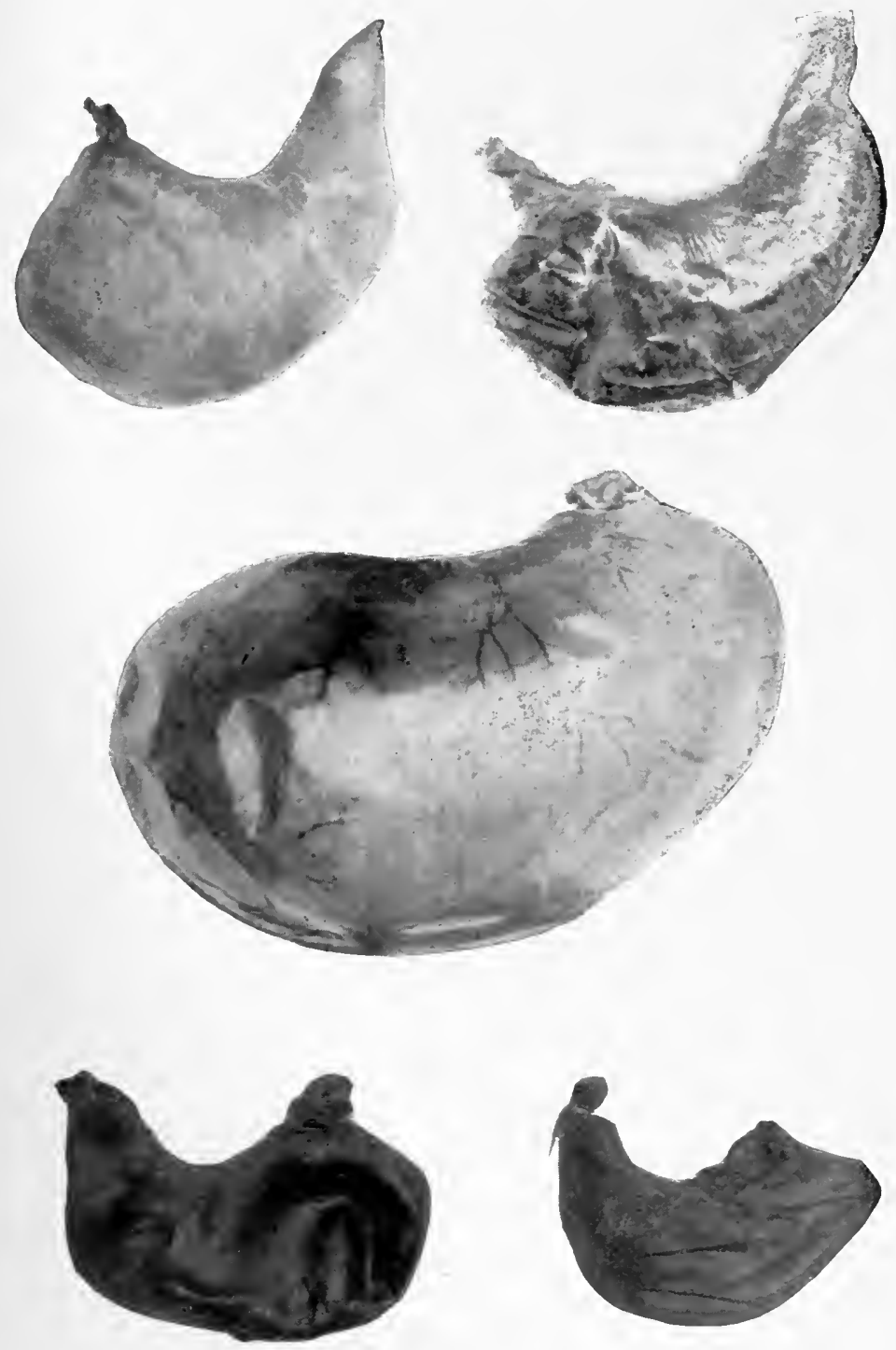

FIG. 23.-Stomachs of the new-born. 

THE ALIMENTARY TRACT.

When the alimentary canal first assumes a tubular form it is a simple, straight cylinder, placed in front of the vertebral canal, attached to it and to the rest of the embryo by a membranous fold or rudimentary mesentery. By degrees the canal, growing in length, becomes loopel at the centre, and straight at the upper and lower ends, while the part destined to be the stomach is dilated. This gradually turns on its side, and the border which is connected to the spine by a membranous fold falls to the left.

\section{ESOPIIAGUS.}

The œsophagus, commeneing at the termination of the pharynx opposite the body of the fourth cervical vertebra and the upper border of the thyroid eartilage, passes down through the posterior mediastinum and enters the stomach a little to the left of the median line. It presents three slight constrictions, the most marked being at the cardiac orifice where it passes through the diaphragm.

The first constriction is opposite the body of the first dorsal vertebra, a favorite seat for the lodgement of foreign bodies (Fig. 133).

\section{STOMACH.}

Contrary to generally accepted statements, the general form and position of the stomach are very similar to those of the empty and collapsed stomach of the adult, but in consequence of the large size of the left lobe of the liver, the whole of the anterior surface is usually covered by that organ. When the stomach is filled, the movement of its pylorus towards the right side is probably impeded by the large liver, thus tending to make the axis more nearly vertical. The fundus is usually less pronounced and the valvular constriction of the cardiac orifice is wanting, allowing easy regurgitation of the contents. The average capacity at birth is less than an ounce (Fig. 23). The thinness of its walls is noticeable and its mucous membrane presents numerous slight elevations due to the accumulation of lymphoid tissue which resemble in appearance the solitary follicles of the intestines.

\section{INTESTINES.}

In the early fotus the small intestine occupies the right side of the abdomen, while the large is represented by a straight tube that passes on the left side vertically from the region of the umbilicus to the pelvis.

At full term the duodenum forms a loop very suggestive of the mature arrangement,- - namely, with its openings at the highest level. As seen in casts, it presents more of a V-shape than the modified horseshoe of later life. The ends do not show the marked constrictions of the more advanced organ and the lining membrane does not present so distinctly the numerous folds, valvula conniventes.

The division into jejunum and ileum is arbitrary, but the upper 
part of the small bowel usually oceupies the left iliae fossa, and the lower the right.

The cacum, situated in early fetal life near the umbilieus, ascends in the abdomen towards the left lypochondrium. It next passes transversely to the right hypochondrium, deseending thenee into the iliac fossa. It may find permanent lodgement at any time during its development, thus explaining the many anomalous situations of this viscus.

The length of the small intestine is given at $2.87 \mathrm{M}$.; the excum and colon measure $30.5 \mathrm{Cm}$., exclusive of the sigmoid flexure, which is abont $25.3 \mathrm{Cm}$, in length. The latter is eurved in form and lies chiefly in the

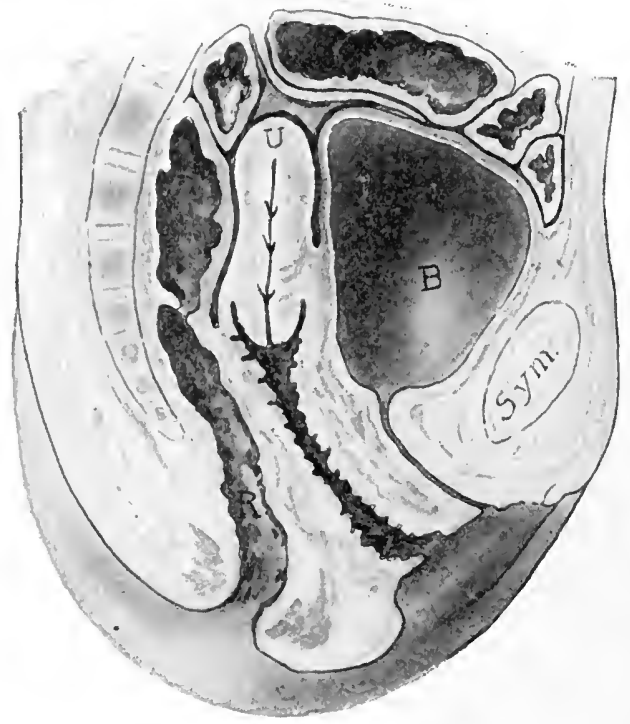

Frg. 24.-Mesial section, showing several folds of the infant rectum. (Symington.)

abdominal cavity, though it often presents great variations both in form and extent, at times extending in an irregular loop as ligh as the umbilicus.

The shallowness of the pelvis (Fig. 16), the slight coneavity of the sacrum, and the amplitude of the rectal tissues, give to the upper part of the rectum several lateral flexures, so that a mesial section of the infant pelvis includes not infrequently three or four folds of the rectum (Fig. 24). Its attachments to surrounding structures do not extend as high up in the pelvis as in later development. These conditions, with the more vertical position of the lower third, offer some explanation of the proneness to prolapsus in infancy.

LIVER.

The formation of this important glandular organ begins at a very early period of fetal life by a process from the intestinal tube. It was 
probably at first a symmetrical organ, but became pushed to the right by the rapid growth of the other abdominal viscera. Its growth is very rapid, so that at the third or fourth week of intrauterine existence it constitutes nearly one-half of the entire body weight, almost filiing the abdominal cavity. At birth its relative weight to that of the body is one to eighteen.

The superior border of the right lobe extends in the midscapular line to the seventh rib, in the midaxillary to the sixtl, and in the midclavicular line to the fifth rib. Its inferior border extends in the median line almost, and occasionally quite to the umbilicus. Generally speaking its lower border may be defined by a line from the lowest point of the ninth rib to the eighth left costochondral junction. Recent observations show that enlargement of the liver is a very eommon condition in the new-born. The lateral margin of the left lobe may be found an inch to the left of the median line, or it may fill nearly the entire left hypo-

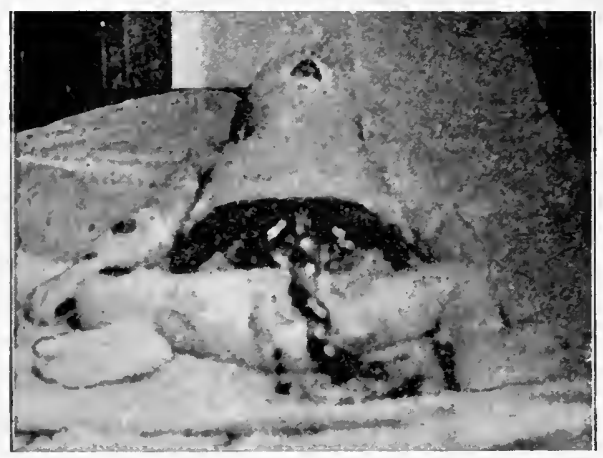

Fig. 25.-Large liver in the new-born.

chondrium (Fig. 25), completely covering the stomaeh. The upper border of the left lobe is difficult to outline because its substernal dulness is continuous with that of the heart.

\section{SPLEEN.}

At birth the average weight of the spleen is one-fourth of an ounce $(8 \mathrm{Gm}$.). Being situated in close apposition to the posterior and descending wall of the diaphragm, opposite the ninth, tenth, and eleventh ribs, and covered anteriorly by the large end of the stomach, it is seldom revealed by palpation or percussion. Not infrequently a supernumerary spleen is found varying in diameter from five to fifteen millimetres, sometimes attached to, at other times having no connection with, the primary organ (Fig. 26). Palpability of the spleen is evidence of its enlargement.

\section{PANCREAS.}

The pancreas is well formed by the second month of fetal life, at about the same time as the salivary glands, which it resembles in arrangement and function. 


\section{KIDNEYS.}

The kidneys at birth are comparatively large, while the lumbar part of the spine is relatively smail. It is not surprising that they extend lower down in relation to the vertebræ and the iliac crests than in the adult. At all ages the kidneys are found with their upper portions partly concealed behind the twelfth rib. Frozen sections show that, contrary to accepted opinion, the right is frequently as high as the left and not erowded down by the large liver, its position being posterior to that organ.

A gross peculiarity is the distinct lobulation of the surface, the lobules corresponding in number with the inter-

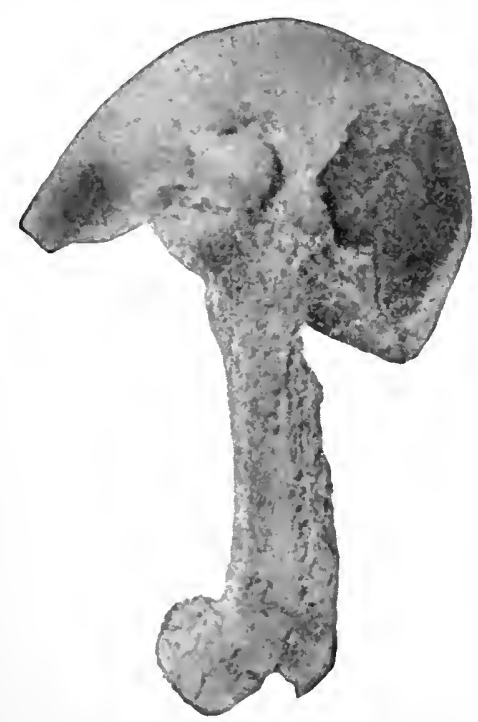

Fig. 26.-Spleen, with a supernumerary, and pancreas.

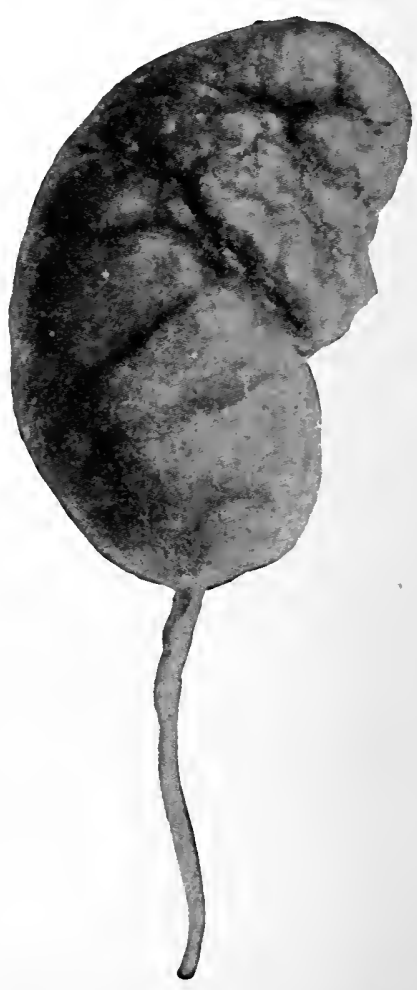

Fig. 27.-Lobulated kidney of the new-born.

nal pyramidal divisions (Fig. 27). Occasionally the kidneys are joined at one extremity, producing the horseshoe form.

\section{SUPRARENALS.}

In the fœus the suprarenal capsules are larger than the kidneys and at birth are relatively much larger than in adult life. They are very vascular, receiving their blood supply from the aorta, phrenic and renal arteries, whose branches converge to form a capillary plexus in the medullary substance of the gland. The suprarenal veins on the right side empty into the inferior vena cava, and on the left, into the left renal 
vein. They are well supplied with lymphatic vessels and nerves, the latter being derived chiefly from the renal and solar plexuses.

Masses of gland tissue resembling the adrenals are frequently found in adjacent parts of the body,-as the cortex of the kidners, liver, spleen, and testicles. They were formerly mistaken for masses of fat, but are now generally considered accessory suprarenal glands or " rests."

BLADDER.

The bladder is derived from the urachus, which is part of a membranous sac (the allantois) appended to the umbilicus in the early fetal state. At first the shape of the bladder is an elongated tube situated

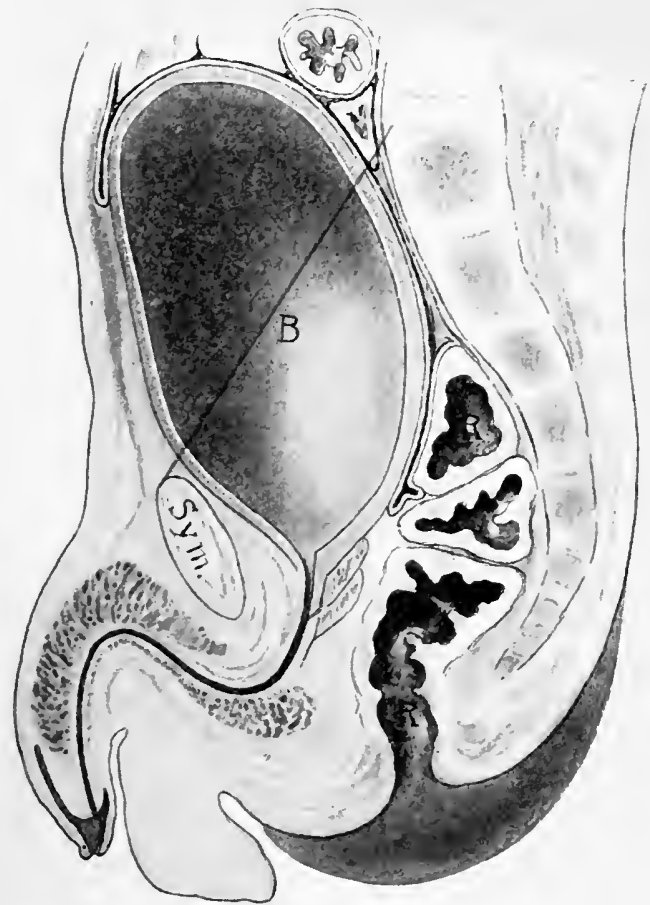

FIG. 28.-Mesial section of infant, 4 months. Distended bladder, showing extent of peritoneal investments. (Symington.)

in the lower part of the abdomen. In the new-born the eapacity is from two to four drachms (7.5-15 C.c.). It is usually described as an abdominal organ, but this is not strictly accurate. The small pelvic cavity is occupied mainly by the rectum and there is little room for the bladder, but if a line be drawn from the sacral promontory to the top of the symphysis, one half of the bladder will lie below it. The pelvis is more oblique, so that the whole organ lies above the pubic crest, and it is so loosely attached to the pelvic walls that but little force is required to push it into the abdomen. 
It is ovoid in shape when distended, with the larger end directed downwards and backwards. There is no marked fundus. The urethral orifice is at the level of the upper border of the symphysis. The bladder extends forwards and upwards in close contact with the pubes, until it reaches the anterior abdominal wall, against which it lies until near the umbilicus. The anterior surface is entirely uncovered by the peritoneum; posteriorly, the peritoneum reaches as low as the level of the orifice of the bladder (Figs. 24 and 28).

\section{URETHRA.}

The infant urethra in the male averages six centimetres ( $21 / 2$ inches). It is delicate in structure, quite distensible, and shows a marked constriction at the meatus,-points to be remembered in the use of instruments.

The prostate gland is small, its weight being about thirteen grains (0.85 Gm.).

At birth the glans penis is closely invested by the prepuce, which is frequently elongated, presenting a very small opening. The cohesion of the nucous membrane lining the prepuce, with that covering the glans, may be so firm as to border upon the pathological.

\section{TESTICLES.}

The testicles are formed below the kidneys in the lumbar region, and at about the eighth month of intrauterine life present at the internal openings of the inguinal canals, which are short and straight, gradually finding their way into the serotum.

The descent is accompanied by formation of the cord in an aggregation of its vas deferens, veins, arteries, lymphatics, nerves, and gelatinous tissue. The process of peritoneum which passes through the inguinal canal precedes the descent of the testicle, although it is not pushed before it, as formerly described, for in cases where the testicles have remained within the abdomen, the vaginal process may occupy its normal position in the scrotum. Ordinarily this process after birth becomes adherent to adjacent structures and is separated from the rest of the peritoneum, becoming gradually blended with the cord above the testicle.

\section{OVARIES.}

In early fetal life the location of the ovaries corresponds to that of the testicles. At birth they have only descended to the brim of the pelvis, with the uterine ends projecting into its cavity. They are whitish, smooth, and elongated bodies attached to the free ends of the ample convoluted tubes, the latter showing but one or a very few fimbriæ (Fig. 29). Ova are developed at an early period in the life of the embryo from germinal epithelium, and it is doubtful if their formation proceeds after birth. It is stated that there are 70,000 egg cells in the human ovary at birth. 


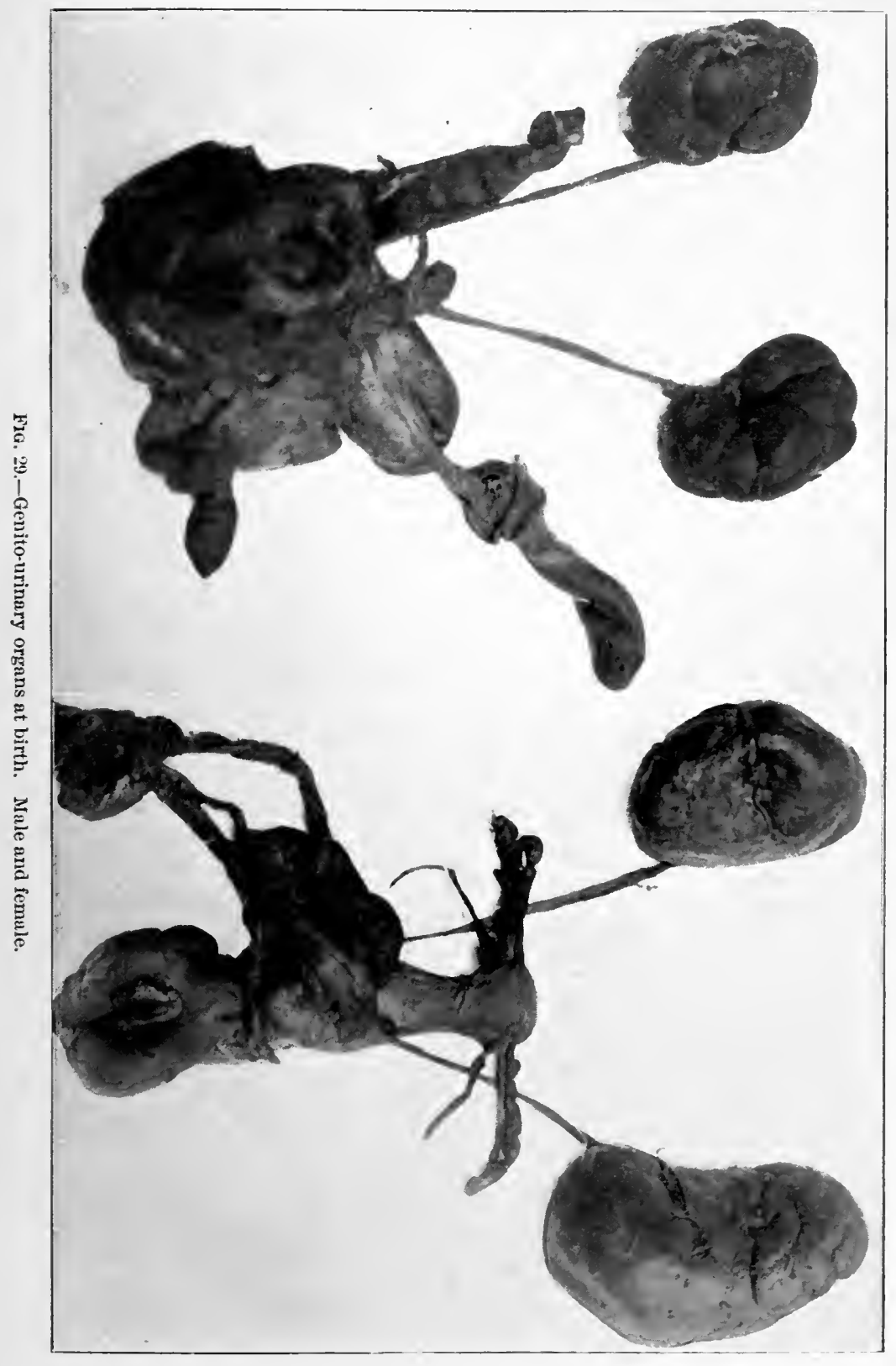





\section{UTERUS.}

The uterus at birth is from two and one-half to three eentimetres (1-11/4 inehes long (Fig. 29). There is no fundus, but the body approaches the two-horned form prevalent in lower animals. The cervix is longer, thicker, and firmer than the body. On opening the uterus the arbor vitæ will be found extending along its whole length, and there is no constriction corresponding to the internal os. 'The urethra and ragina of the infant are eomparatively large and distensible.

\section{MAMMARY GLANDS.}

At birth these are from five to eight millimetres (one-fifth to one-third inch) in diameter. The nipple with dartos is well formed and the secreting strueture is represented by slightly ramified ducts which contain a milky fluid.

\section{BRAIN.}

The delevopment and growth of the brain is very active during intrauterine life, so that at birth this organ is of relatively large size, and in general form and relation of its parts it presents a elose approximation to that of the adult. The anterior lobes and cerebellum, however, are relatively small. The ratio of brain weight to that of the body at birth is $1: 8$.

The dura is quite closely adherent to the skull, so that extravasations can with difficulty take place between them. The blood-vessels of the pia mater are exceedingly delicate, which partly aceounts for the frequency of cerebral hemorrhage at birth.

The fissure of Sylvius is higher and that of Rolando less vertieal than in the adult. The eonvolutions and sulei are somewhat shallow and simple. In fact, at an early stage of embryonie life the surface is quite smooth.

The brain substance is of a nearly uniform whitish eolor. On aceount of its large pereentage of water, it is of a soft, pulpy consisteney, requiring great care in handling.

\section{SPINAL CORD.}

In the earlier months of fetal life, the medulla spinalis oecupies the whole length of the vertebral canal, but as development proceeds, the spinal column grows more rapidly than the eontained eord, so that the latter appears as if drawn up, until at birth it terminates at the third lumbar vertebra. 


\title{
NORMAL GROWTH AND DEVELOPMENT
}

\author{
EARLY INFANCY
}

For the purpose of discussion, growth and development may be divided arbitrarily into many periods, but certain fairly well defined physiologic processes suggest five epochs,-viz., early and late infancy, early and late childhood, and youth.

Early infancy would correspond with the Süuglingsalter, or sucking period, of the Germans. The first dentition is usually complete at the end of thirty months, which, in this classification, would mark the beginning of childhood. Late childhood, commencing at the appearance of the permanent teeth, or about the sixth year, extends to puberty.

The importance of a familiarity with the rate of growth during the different periods of infancy and childhood, cannot be overestimated, as it is well known that irregularities in the growth are frequently the first intimations of disturbed nutrition or developing disease.

Increase in weight and length, and the measurements of the different members, bear normally a certain constant relation at different periods of life. No period of extrauterine life compares in rapidity of growth with that of the first six months.

Taking the birth weight as $3280 \mathrm{Gm}$. (about $71 / 4$ pounds) statistics show that the loss of weight in the first three days is about ten per cent. This is usually regained by the end of the first week. The reason for this early loss is quite apparent. It is due partly to the loss of fluids from the viscera as well as from the surface of the body, and partly to consumption of stored material prior to the establishment of lactation. This consumption is rapid, as there is increased metabolism incident to a greater muscular and circulatory activity in the presence of an increased supply of oxygen. From the examination of many tables it appears that the normal infant doubles his birth weight by the sixth month and trebles it soon after the twelfth month, growth being most rapid during the first four months of life.

The following charts from Holt give a fair idea of the weight curves for the first three weeks and twelve months, respectively (Figs 30 and 31 ).

\section{LENGTII}

Accepting the average length at birth as 48.2 centimetres (19 inches), we find a somewhat regular ratio of increase which doubles the birth length at the end of the fourth year, increase in length as in weight being most rapid in the early months of life. The increase during the first year (about half of the initial length) is nearly double that of any succeeding year.

A notable difference in ratio of growth appears during acute febrile 
FIG. 30.

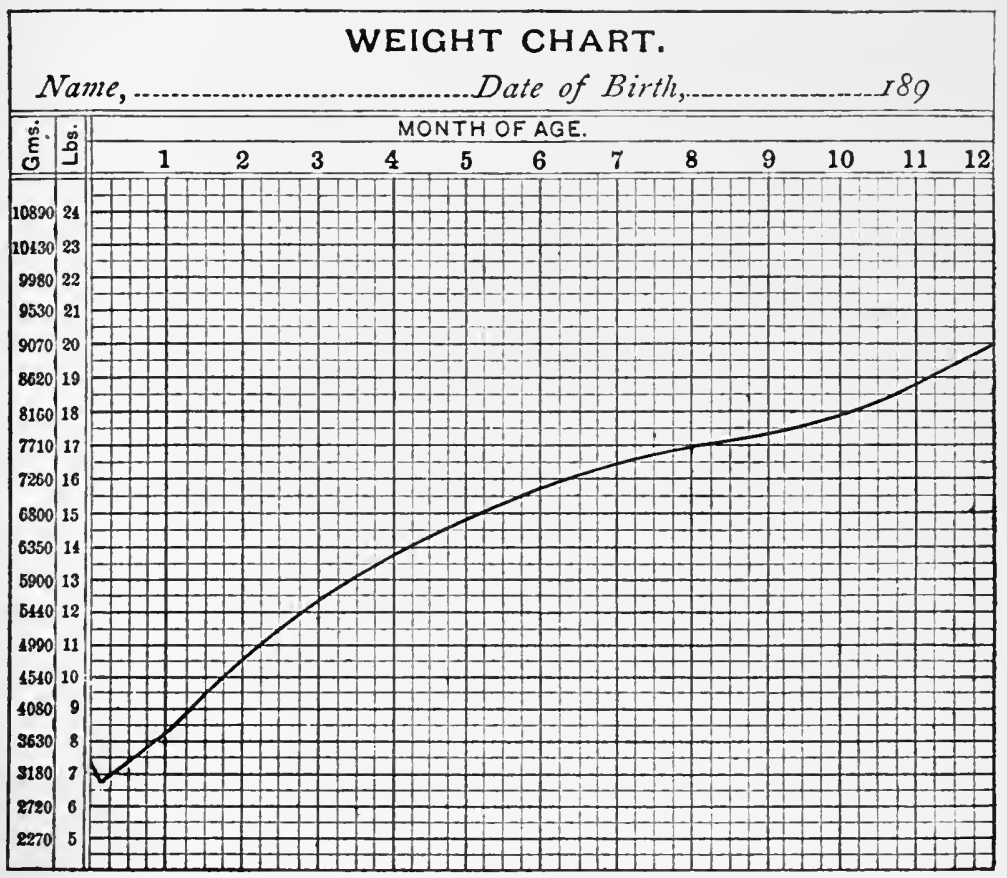

FIG. 31.

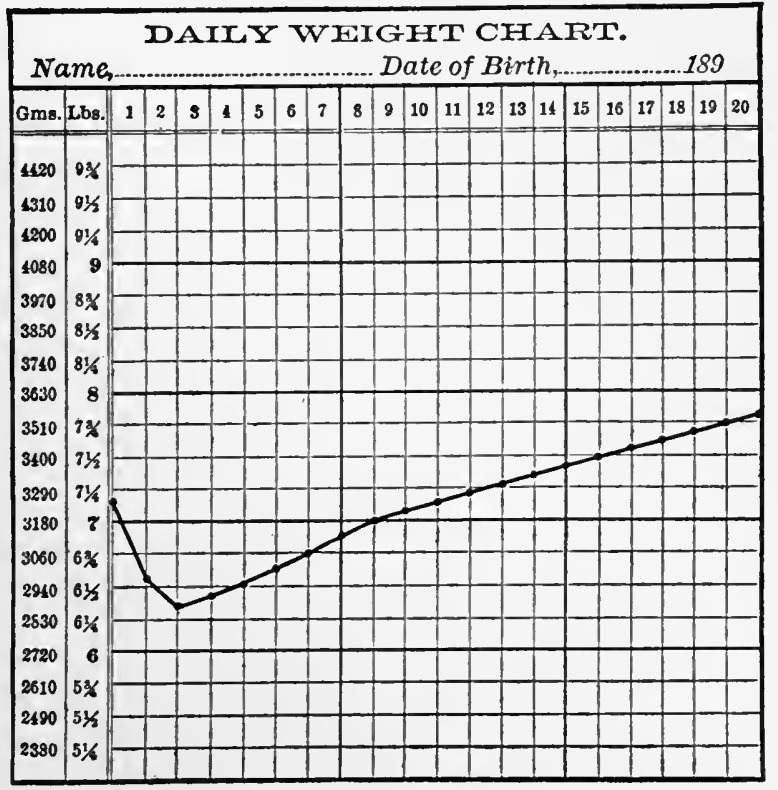


disorders, as the exanthemata, when the weight invariably diminishes, while the increase in length continues or may even be accelerated. Fig. 32 illustrates phenomenal growth in length during typhoid fever in a child of nine years.

The average increase of the second year is about ten centimetres (4 inches), and from that on to the age of eleven or twelve years from five to eight centimetres (2-3 inches) annually. After this period, for a year or two, for the only time, the height of girls exceeds that of boys.

Development in length is most rapid in the lower extremities, which

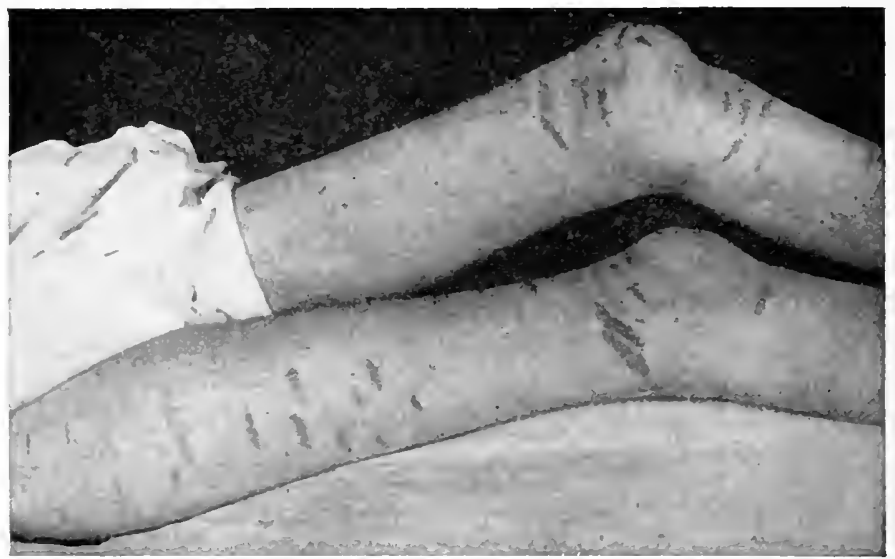

FIG. 32.-Linea alticantes after severe typhoid in previously fat child. (Dr. S. W. Kelley.)

fact constantly moves the centre of the body downward from the umbilicus, until maturity, when the centre is about the upper border of the symphysis.

Exceptions to this rule are seen in achondroplasia, rhachitis, and cretinism, where the long bones show retardation in longitudinal growth.

Porter's observations of a large number of school children of St. Louis, from six to sixteen years, show an average of nearly two pounds lower weight than the following table.

Of extreme interest is the relative growth of head and chest in infancy and childhood. Taking the average circumference of heads at birth (boys) measured at the level of the occipital protuberance, as 35.5 centimetres (13.9 inches), and that of the thorax just below the nipples and the angles of the scapulæ as 34.2 centimetres (13.4 inches), we find the ratio steadily decreasing until the two circumferences are equal before the end of the second year. From this on the ratio is reversed, the chest increasing more rapidly up to maturity.

The increase in the circumference of the head in early life is remarkable, and, like that of the body weight, is more rapid during the first year. Reference to the foregoing table shows the average growth of the head during the first six months to be 8 centimetres ( 3.3 inches); during the 
Table from Boas, showing Weight, Height, and Circumference of Chest axd

Head From Birth to tire 16til Year.

\begin{tabular}{|c|c|c|c|c|c|c|c|c|c|}
\hline \multirow{2}{*}{ AGE } & \multirow{2}{*}{ SEX } & \multicolumn{2}{|c|}{ WeIght } & \multicolumn{2}{|c|}{ HEIGHT } & \multicolumn{2}{|c|}{ CHEST } & \multicolumn{2}{|c|}{ IIEAD } \\
\hline & & Pounds & Kilos & Inches & $\mathrm{Cm}$. & Inches & $\mathrm{Cm}$. & Inches & $\mathrm{Cm}$. \\
\hline Birth & $\begin{array}{l}\text { Boys } \\
\text { Girls }\end{array}$ & $\begin{array}{l}7.55 \\
7.16\end{array}$ & $\begin{array}{l}3.43 \\
3.26\end{array}$ & $\begin{array}{l}20.6 \\
20.5\end{array}$ & $\begin{array}{l}52.5 \\
52.2\end{array}$ & $\begin{array}{l}13.4 \\
13.0\end{array}$ & $\begin{array}{l}34.2 \\
33.2\end{array}$ & $\begin{array}{l}13.9 \\
13.5\end{array}$ & $\begin{array}{l}35.5 \\
34.5\end{array}$ \\
\hline 6 months & $\begin{array}{l}\text { Boys } \\
\text { Girls }\end{array}$ & $\begin{array}{l}16.0 \\
15.5\end{array}$ & $\begin{array}{l}7.26 \\
7.03\end{array}$ & $\begin{array}{l}25.4 \\
25.0\end{array}$ & $\begin{array}{l}64.8 \\
63.6\end{array}$ & $\begin{array}{l}16.5 \\
16.1\end{array}$ & $\begin{array}{l}42.0 \\
41.0\end{array}$ & $\begin{array}{l}17.0 \\
16.6\end{array}$ & $\begin{array}{l}43.5 \\
42.2\end{array}$ \\
\hline 12 months & $\begin{array}{l}\text { Boys } \\
\text { Girls }\end{array}$ & $\begin{array}{l}20.5 \\
19.8\end{array}$ & $\begin{array}{l}9.29 \\
8.84\end{array}$ & $\begin{array}{l}29.0 \\
28.7\end{array}$ & $\begin{array}{l}73.8 \\
73.2\end{array}$ & $\begin{array}{l}18.0 \\
17.4\end{array}$ & $\begin{array}{l}45.9 \\
44.4\end{array}$ & $\begin{array}{l}18.0 \\
17.6\end{array}$ & $\begin{array}{l}45.9 \\
44.6\end{array}$ \\
\hline 18 months & $\begin{array}{l}\text { Boys } \\
\text { Girls }\end{array}$ & $\begin{array}{l}22.8 \\
22.0\end{array}$ & $\begin{array}{r}10.35 \\
9.98\end{array}$ & $\begin{array}{l}30.0 \\
29.7\end{array}$ & $\begin{array}{l}76.3 \\
75.6\end{array}$ & $\begin{array}{l}18.5 \\
18.0\end{array}$ & $\begin{array}{l}47.1 \\
45.9\end{array}$ & $\begin{array}{l}18.5 \\
18.0\end{array}$ & $\begin{array}{l}47.1 \\
45.9\end{array}$ \\
\hline 2 years & $\begin{array}{l}\text { Boys } \\
\text { Girls }\end{array}$ & $\begin{array}{l}26.5 \\
25.5\end{array}$ & $\begin{array}{l}12.02 \\
11.56\end{array}$ & $\begin{array}{l}32.5 \\
32.5\end{array}$ & $\begin{array}{l}82.8 \\
82.8\end{array}$ & $\begin{array}{l}19.0 \\
18.5\end{array}$ & $\begin{array}{l}48.4 \\
47.0\end{array}$ & $\begin{array}{l}18.9 \\
18.6\end{array}$ & $\begin{array}{l}48.2 \\
47.2\end{array}$ \\
\hline 3 years & $\begin{array}{l}\text { Boys } \\
\text { Girls }\end{array}$ & $\begin{array}{l}31.2 \\
30.0\end{array}$ & $\begin{array}{l}14.14 \\
13.60\end{array}$ & $\begin{array}{l}35.0 \\
35.0\end{array}$ & $\begin{array}{l}89.1 \\
89.1\end{array}$ & $\begin{array}{l}20.1 \\
19.8\end{array}$ & $\begin{array}{l}51.1 \\
50.5\end{array}$ & $\begin{array}{l}19.3 \\
19.0\end{array}$ & $\begin{array}{l}49.0 \\
48.4\end{array}$ \\
\hline 4 years & $\begin{array}{l}\text { Boys } \\
\text { Girls }\end{array}$ & $\begin{array}{l}35.0 \\
34.0\end{array}$ & $\begin{array}{l}15.87 \\
15.41\end{array}$ & $\begin{array}{l}38.0 \\
38.0\end{array}$ & $\begin{array}{l}96.7 \\
96.7\end{array}$ & $\begin{array}{l}20.7 \\
20.5\end{array}$ & $\begin{array}{l}52.8 \\
52.2\end{array}$ & $\begin{array}{l}19.7 \\
19.5\end{array}$ & $\begin{array}{l}50.3 \\
49.6\end{array}$ \\
\hline 5 years & $\begin{array}{l}\text { Boys } \\
\text { Girls }\end{array}$ & $\begin{array}{l}41.2 \\
39.8\end{array}$ & $\begin{array}{l}18.71 \\
18.06\end{array}$ & & $\begin{array}{l}106.0 \\
105.3\end{array}$ & $\begin{array}{l}21.5 \\
21.0\end{array}$ & $\begin{array}{l}54.8 \\
53.5\end{array}$ & $\begin{array}{l}20.5 \\
20.2\end{array}$ & $\begin{array}{l}52.2 \\
51.3\end{array}$ \\
\hline 6 years & $\begin{array}{l}\text { Boys } \\
\text { Girls }\end{array}$ & $\begin{array}{l}45.1 \\
43.8\end{array}$ & $\begin{array}{l}20.48 \\
19.87\end{array}$ & $\begin{array}{l}44.1 \\
43.6\end{array}$ & $\begin{array}{l}112.0 \\
110.9\end{array}$ & $\begin{array}{l}23.2 \\
22.8\end{array}$ & $\begin{array}{l}59.1 \\
58.3\end{array}$ & & \\
\hline 7 years & $\begin{array}{l}\text { Boys } \\
\text { Girls }\end{array}$ & $\begin{array}{l}49.5 \\
48.0\end{array}$ & $\begin{array}{l}22.44 \\
21.78\end{array}$ & $\begin{array}{l}46.2 \\
45.9\end{array}$ & $\begin{array}{l}117.4 \\
116.7\end{array}$ & $\begin{array}{l}23.7 \\
23.3\end{array}$ & $\begin{array}{l}60.6 \\
59.5\end{array}$ & & \\
\hline 8 years & $\begin{array}{l}\text { Boys } \\
\text { Girls }\end{array}$ & $\begin{array}{l}54.5 \\
52.9\end{array}$ & $\begin{array}{l}24.70 \\
24.01\end{array}$ & $\begin{array}{l}48.2 \\
48.0\end{array}$ & $\begin{array}{l}122.3 \\
122.1\end{array}$ & $\begin{array}{l}24.4 \\
23.8\end{array}$ & $\begin{array}{l}62.2 \\
60.8\end{array}$ & & \\
\hline 9 years & $\begin{array}{l}\text { Boys } \\
\text { Girls }\end{array}$ & $\begin{array}{l}60.0 \\
57.5\end{array}$ & $\begin{array}{l}26.58 \\
26.10\end{array}$ & $\begin{array}{l}50.1 \\
49.6\end{array}$ & $\begin{array}{l}127.2 \\
126.0\end{array}$ & $\begin{array}{l}25.1 \\
24.5\end{array}$ & $\begin{array}{l}63.9 \\
62 . \overline{5}\end{array}$ & & \\
\hline 10 years & $\begin{array}{l}\text { Boys } \\
\text { Girls }\end{array}$ & $\begin{array}{l}66.6 \\
64.1\end{array}$ & $\begin{array}{l}30.22 \\
29.07\end{array}$ & & $\begin{array}{l}132.6 \\
131.5\end{array}$ & $\begin{array}{l}25.8 \\
24.7\end{array}$ & $\begin{array}{l}65.6 \\
63.0\end{array}$ & $\begin{array}{l}21.0 \\
20.7\end{array}$ & $\begin{array}{l}53.5 \\
52.8\end{array}$ \\
\hline 11 years & $\begin{array}{l}\text { Boys } \\
\text { Girls }\end{array}$ & $\begin{array}{l}72.4 \\
70.3\end{array}$ & $\begin{array}{l}32.83 \\
31.87\end{array}$ & $\begin{array}{l}54.0 \\
53.8\end{array}$ & $\begin{array}{l}137.2 \\
136.6\end{array}$ & $\begin{array}{l}26.4 \\
25.8\end{array}$ & $\begin{array}{l}67.2 \\
65.8\end{array}$ & & \\
\hline 12 years & $\begin{array}{l}\text { Boys } \\
\text { Girls }\end{array}$ & $\begin{array}{l}79.8 \\
81.4\end{array}$ & $\begin{array}{l}36.21 \\
36.90\end{array}$ & $\begin{array}{l}55.8 \\
57.1\end{array}$ & $\begin{array}{l}141.7 \\
145.2\end{array}$ & $\begin{array}{l}27.0 \\
26.8\end{array}$ & $\begin{array}{l}68.8 \\
68.3\end{array}$ & & \\
\hline 13 years & $\begin{array}{l}\text { Boys } \\
\text { Girls }\end{array}$ & $\begin{array}{l}88.3 \\
91.2\end{array}$ & $\begin{array}{l}40.04 \\
41.36\end{array}$ & $\begin{array}{l}58.2 \\
58.7\end{array}$ & $\begin{array}{l}147.7 \\
149.2\end{array}$ & $\begin{array}{l}27.7 \\
28.0\end{array}$ & $\begin{array}{l}70.6 \\
71.3\end{array}$ & & \\
\hline 14 years & $\begin{array}{l}\text { Boys } \\
\text { Girls }\end{array}$ & $\begin{array}{r}99.3 \\
100.3\end{array}$ & $\begin{array}{l}45.03 \\
45.50\end{array}$ & $\begin{array}{l}61.0 \\
60.3\end{array}$ & $\begin{array}{l}155.1 \\
153.2\end{array}$ & $\begin{array}{l}28.8 \\
29.2\end{array}$ & $\begin{array}{l}73.3 \\
74.1\end{array}$ & & \\
\hline 15 years & $\begin{array}{l}\text { Boys } \\
\text { Girls }\end{array}$ & $\begin{array}{l}110.8 \\
108.4\end{array}$ & $\begin{array}{l}50.26 \\
49.17\end{array}$ & $\begin{array}{l}63.0 \\
61.4\end{array}$ & $\begin{array}{l}159.9 \\
155.9\end{array}$ & $\begin{array}{l}30.0 \\
30.3\end{array}$ & $\begin{array}{l}76.6 \\
76.8\end{array}$ & $\begin{array}{l}21.8 \\
21.5\end{array}$ & $\begin{array}{l}55.5 \\
54.8\end{array}$ \\
\hline 16 years & $\begin{array}{l}\text { Boys } \\
\text { Girls }\end{array}$ & $\begin{array}{l}123.7 \\
113.0\end{array}$ & $\begin{array}{l}56.09 \\
51.24\end{array}$ & $\begin{array}{l}65.6 \\
61.7\end{array}$ & $\begin{array}{l}166.5 \\
156.7\end{array}$ & $\begin{array}{l}31.2 \\
30.8\end{array}$ & $\begin{array}{l}79.2 \\
78.8\end{array}$ & & \\
\hline
\end{tabular}


second six months 2.4 eentimetres ( 1 ineh); during the second year, 2.3 centimetres (nearly 1 inch), and less than 1 eentimetre ( $1 / 3$ inch) the third year. By the seventh year the head has attained nearly its full development. The growth is most noticeable in the anteroposterior diameter.

This rapid growth of the head during the first six months apparently increases the anterior fontanelle which, however, diminishes in size towards the end of the first year and is ordinarily completely ossified by the middle of the second year. The sutures show the beginning of firm union about the ninth month. Differentiation between the outer and inner tables of the skull with the formation of the diploe proceeds gradually. Bony deposition in the vitreous table deepens the outlines of the great venous sinuses. The mastoid process beeomes distinet after the first year. From infaney to puberty there is a continuous formation of new bone from the periosteum on the surface of the mastoid portion of the temple bone. This process consists of cancellous tissue, and can be readily penetrated by the knife in operations for mastoiditis. Towards puberty, rarely earlier, the process beeomes hollowed into air-cells. The cells are lined with a delieate mucous membrane and eommunicate with the antrum and with one ancther. They vary in size in different bodies and on the two sides of the same head. The proximity of the lateral sinus renders it liable to beeome involved by extension of inflammation in suppurative disease of the mastoid cells, owing to the thinness of the bony septa between the cells and the sinus.

As the mastoid inereases in thickness, the antrum comes to lie at a greater depth from the surface and beeomes relatively smaller.

The bony ring, which represents nearly all of the osseous portion of the external auditory meatus at birth, has grown outwards to form the walls and the floor. The Rivinian noteh generally persists until puberty, and is not infrequently found in the adult.

It is calculated that in the adult the osseous portion forms two-thirds of the total length of the meatus. At the end of the first year, only the inner third has bony walls, and even in a ehild of six years, scarcely half is osseous. A knowledge of the length of the external auditory meatus at different ages is obviously important (Fig. 34). The following from Symington shows this, also the difference in length of the floor and roof of the meatus.

\begin{tabular}{l|c|c}
\hline AGR of Child & LENGTH of FLoor & LENGTH of Roof \\
\hline Two months & $17 \mathrm{Mm}$. & $13 \mathrm{Mm}$. \\
Six months & $19 \mathrm{Mm}$. & $16 \mathrm{Mm}$. \\
Two years & $22 \mathrm{Mm}$. & $16 \mathrm{Mm}$. \\
\hline
\end{tabular}

The only important change in the tympanum is the obliteration of the petrosquamous suture which often occurs by the end of the first year. 
The Eustachian tube doubles its length between infancy and maturity, the growth being especially rapid during the first few years, so that by the fifth or sixth year, its length is not far from that of the adnlt. The growth seems to oecur mainly in its anterior or pharyngeal portion. The tube changes its almost horizontal direetion to form an angle of at least forty-five degrees with the horizon. This descent of the tube does not keep pace with that of the nasal floor. At birth it is found at the level of the hard palate, while at the age of four years it is three or four millimetres above, and in the adult ten millimetres above.

Unlike that of the head, the growth of the face is a gradual process,

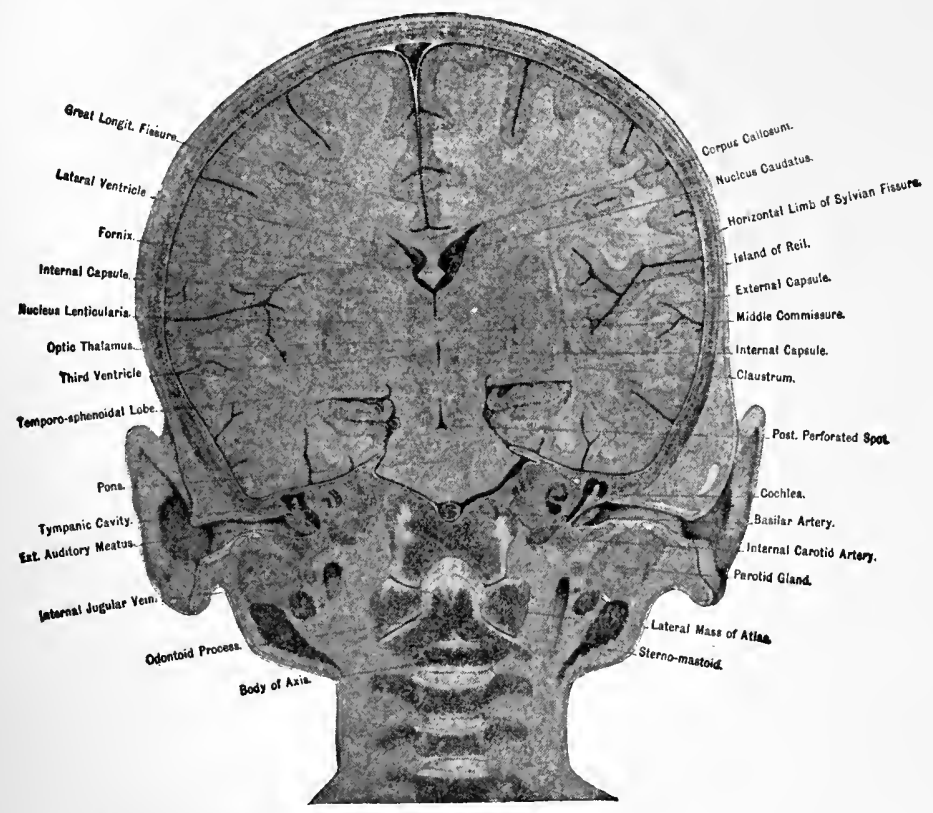

Fig. 34.-Coronal section of head at plane of external auditory meati. Girl of 5 years. (Symington.)

going on steadily from birth to adult life. The small size may be attributed to the rudimentary condition of the teeth and the smallness of the maxillary sinuses.

Ankylosis of the frontal bones begins early, and there may be no trace of the suture in the adult skull. The frontal sinuses appear about the seventh year. The ethmoidal cells appear at the third year. The communication through the foramen cxcum is closed about puberty.

The septum of the nose is usually straight up to the seventh year; after which it very commonly inclines to one side. The nasal sinuses increase in height simultaneously with the lengthening of the vertical plates of the palate bones (Fig. 35).

During the first year the two halves of the inferior maxilla ankylose, union taking place from below upwards, but is not complete until the second year. 
N.ASOPHARYNX.

As mentioned previously, the nasopharynx is richly supplied with lymphoid tissue. There is an aggregation of follicles in the posterior wall known as the third, pharyngeal, or Luschka's tonsil.

The different findings of surgical anatomists in respect to this area may well raise the question whether Luschka's tonsil is a normal anatomical entity. The rapid growth which this mass of lymphoid tissue frequently takes on in early years makes it of pathological interest.

From the lengthening of the face, the increasing distance between

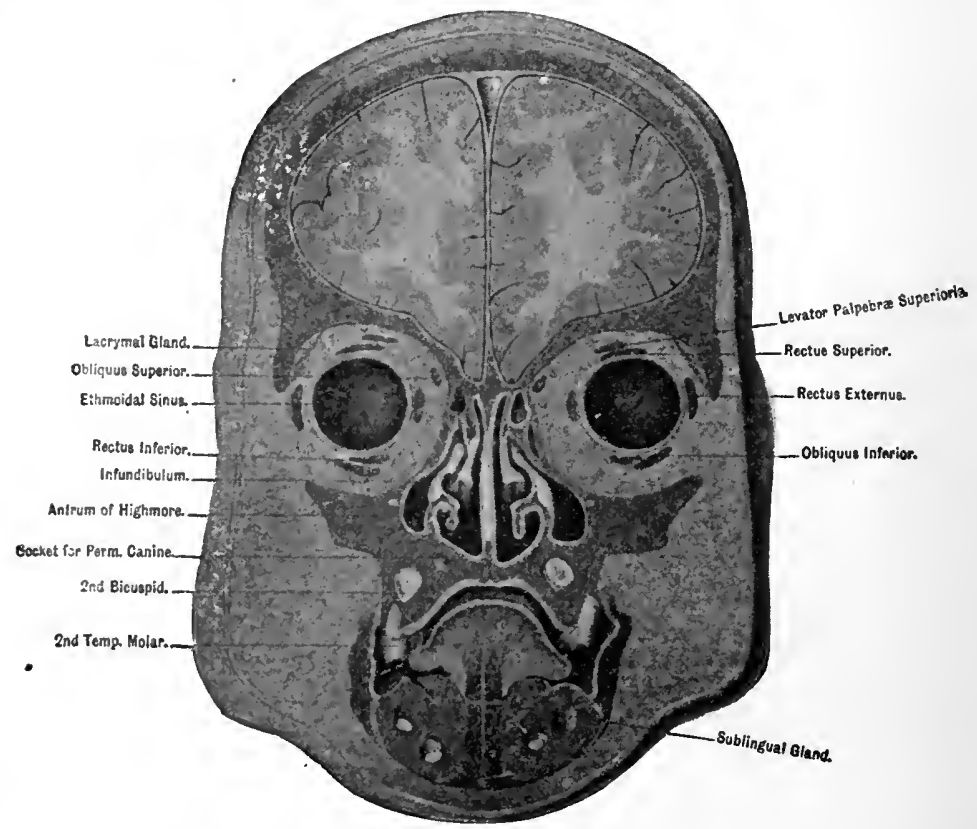

FIG. 35.-Coronal section of head. Girl of 5 sears. (Symington.)

the pterygoid plates, the diminishing obliquity of the vomer, and the subsidence of the soft palate which becomes more vertical, the vault of the pharynx becomes more eapacious (Fig. 35).

The posterior nasal openings, extremely small in infancy, develop irregularly. It is stated that their size is doubled in the first six months, then remaining stationary to the end of the second year, they again pass through a period of increased growth. The subsidence of the hard palate increases the capacity of the nasal respiratory tract, principally in the height of its inferior meati, the middle portions being wider than the openings, - - a point to be remembered in the lodgement of foreign bodies.

The antrum of Highmore, although small, is from birth lined with a mucous membrane which may become the seat of infection.

As before stated the frontal sinuses assume their relationship to the respiratory tract about the seventh year. 


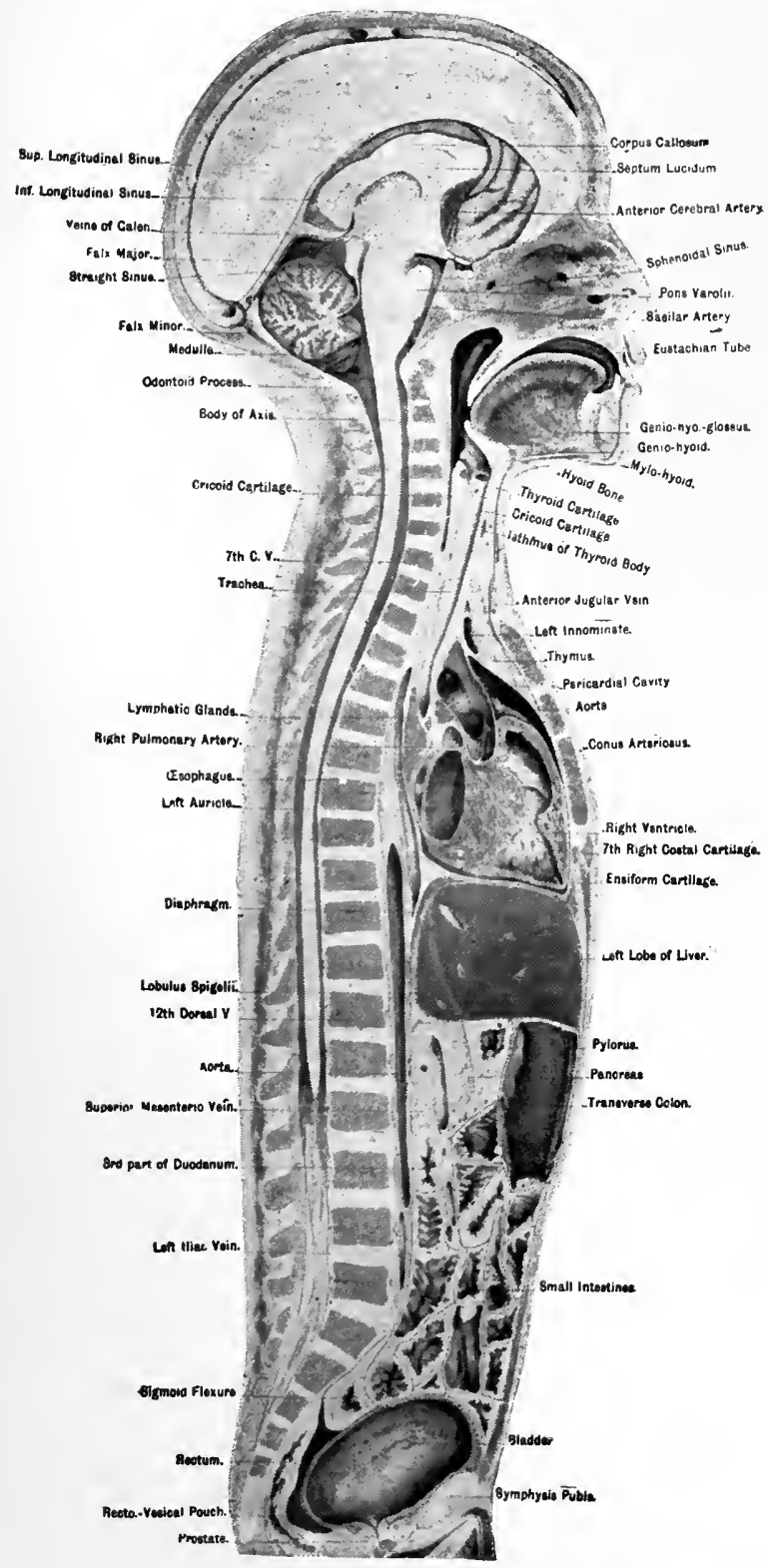

FIG. 36.-Vertical mesial section. Boy of 6 years. (Symington.) 

DENTITION.

The development of the temporary teeth begins with the first formation of the jaws, about the sixth week of intrauterine life. Briefly stated, they are simply calcified mucous membrane. At the time of birth the erowns of all the temporary incisors and canines are fairly advanced in calcification (Fig. 12), but it is not until about the age of four and one-half years that the milk-teeth are fully formed. Separated cusps of the temporary molars have also blended at birth, and caleification of the first permanent molars is just beginning in the form of a separate cap for eaeh cusp. These do not fuse until six months after birth. Dissection shows the germs of the permanent ineisors and eanines posterior and external to the corresponding milk-teeth; but there are no traces of the bicuspids or second permanent molars. These appear between the fourth and sixth months of life.

The temporary teeth are distinguished from the permanent by the marked bulging of the crown close to the neek, so that the latter shows a well-marked eonstriction. They are of smaller dimensions, espeeially the canines. The temporary molars are larger than the bieuspids whieh succeed them. The roots are smaller and more divergent.

With the completion of the erown and beginning of calcification of the root, the process of eruption commenees. The growth of the root propels the crown towards the surface of the gum, the superimposed tissue disappearing by absorption. Synchronously with the development of the root, the jaw increases in depth by the addition of new osseous material. The bony crypt is rebuilt around the neek of the tooth and forms the alveolus of the milk-tooth.

The eruption of the teeth is not a gradual and continuous proeess, but it occurs in groups, with intervals of repose between the successive groups. The lower central incisors appear from the sixth to the ninth month, their eruption being completed in about ten days. Then follows a resting period of two or three months, after which the upper incisors appear, both central and lateral. After a rest of a few months, come the lower lateral incisors and first molars; four or five months later the canines, and, finally, about the second year, the second molars arrive.

Order of Eruption of the Temporary Teeth.

Lower central incisors.................6th to 9 th month.

Upper incisors ..........................

Lower lateral incisors and first molars..........15th to 21 st month.

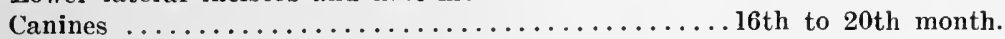

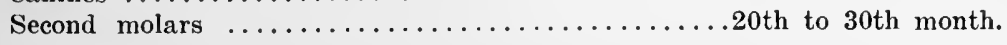

Scarcely a year elapses after calcification of the milk teeth is complete before absorption begins. There is still much to learn of the cause of this absorption, as it seems to be quite independent of the presence and pressure of the permanent set. Normally, absorption begins at the apex of the root and advances towards the crown. Shortly after the root 
has disappeared the crown is removed either by the advancing permanent tooth or by an accidental rupture of the attachment between the neck of the tooth and the mucous membrane of the gum.

As mentioned, the calcification of the permanent teeth begins before birth. The process extends to about the twelfth year. Just before the shedding of the temporary tecth-i.e., about the sixth year-there are more teeth in the jaw than at any other time of life (Fig. 37). There are present all the temporary teeth and the crowns of all the permanent set, excepting the wisdom teeth,-in all forty-eight.

The permanent teeth may be divided into two sets,- - the ten anterior, which succeed the milk-teeth, and six others that are superadded farther

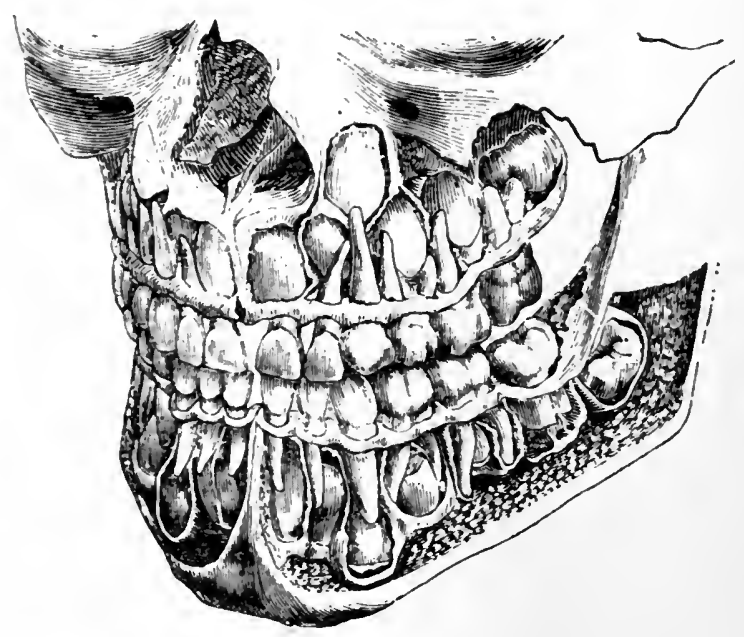

FIG. 37.-Dissection showing number of teeth at sixth year. (Talbot.)

back in the jaw. They arise from successive extensions of the common dental laminæe carried backwards. During the growth of the teeth the jaw increases in depth and length and undergoes changes in form (Fig. 38).

The space taken up by the ten anterior permanent teeth very nearly corresponds with that which has been occupied by the ten milk-teeth; the difference in width between the incisors of the two sets being compensated for by the smallness of the bicuspids in comparison with the milk molars which they succeed.

The room necessary for the accommodation of the three permanent molars in the alveolar arch is obtained by absorption of the anterior part of the coronoid process. This absorption is accompanied by a new formation of bone at the posterior part of the ascending ramus. This gradual remodelling of the bone is naturally a slow process. At certain periods in the growth there is not sufficient room in the alveolar arch for the growing sacs of the permanent molars; hence the latter are found enclosed in the bases of the coronoid processes of the lower jaw, and in 


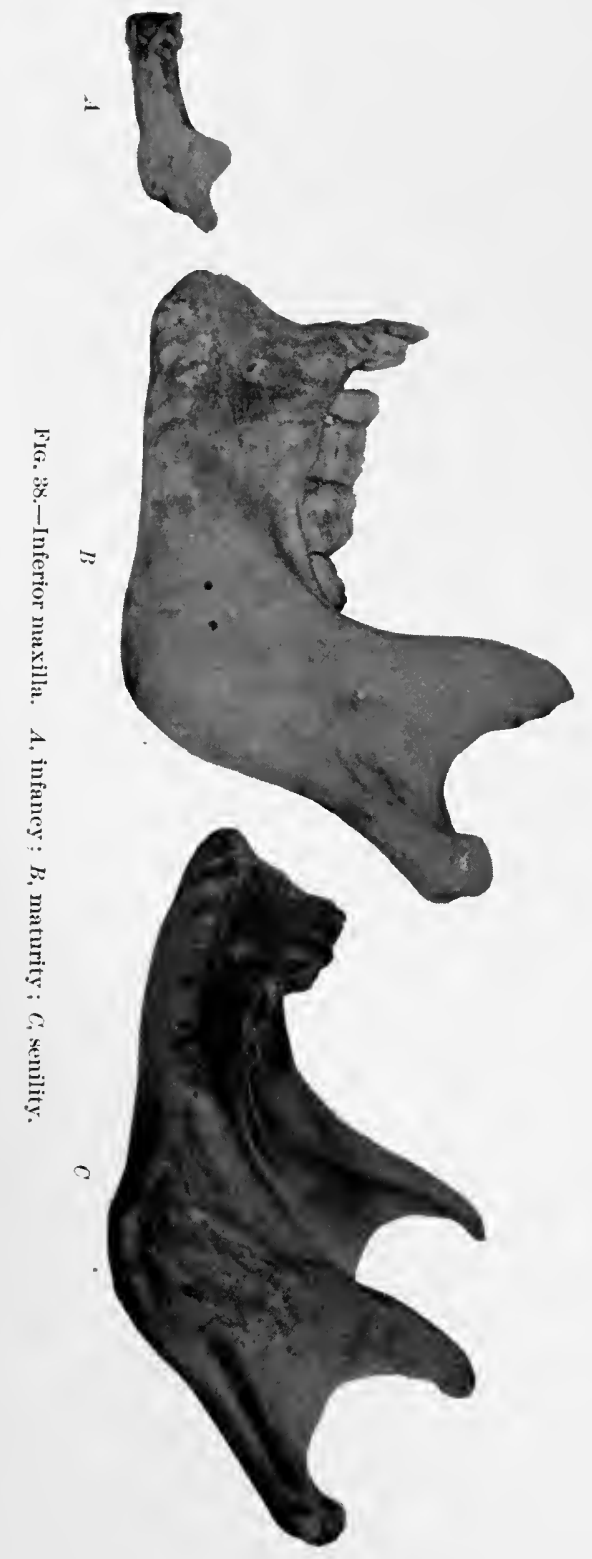




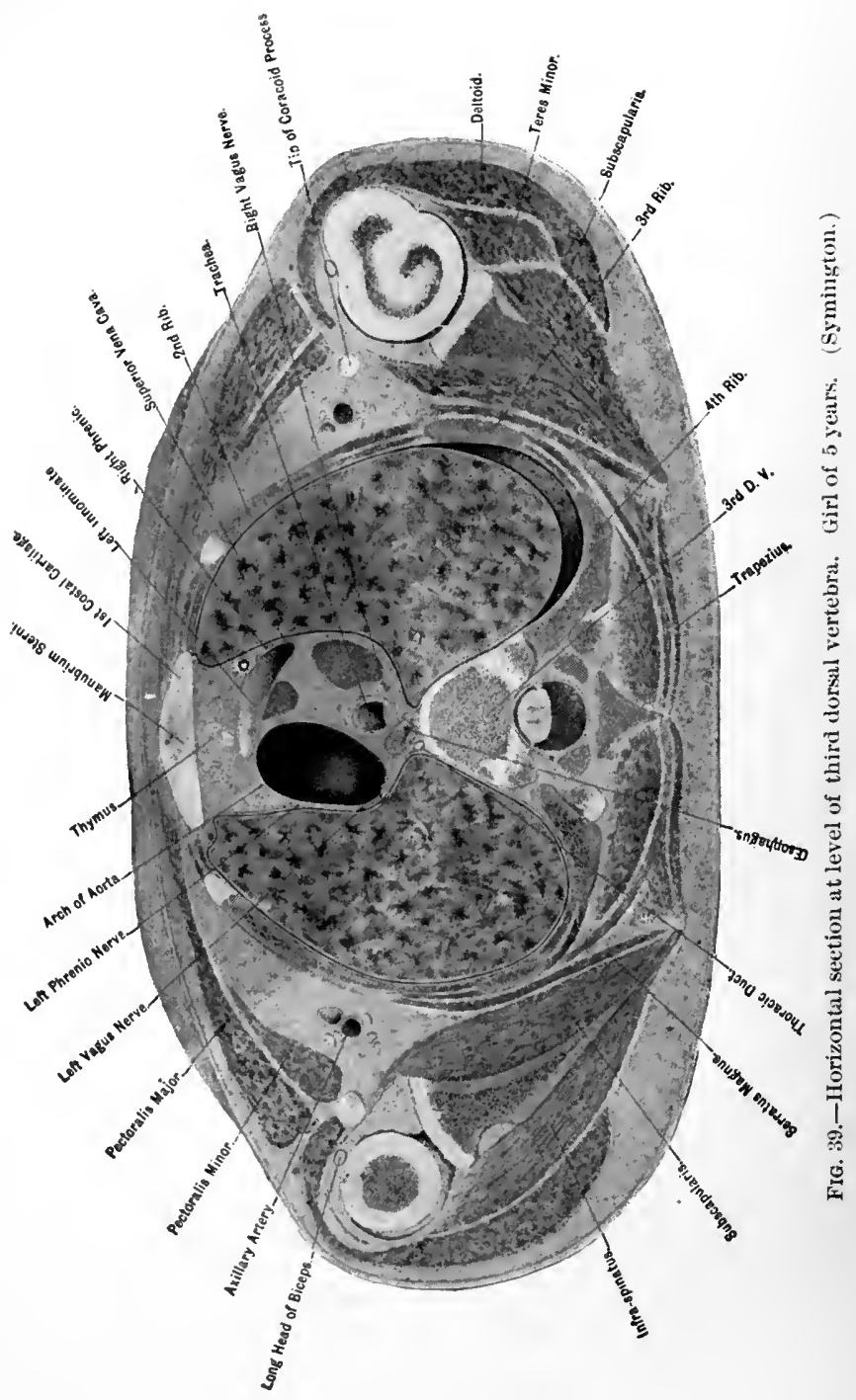


the maxillary tuberosities of the upper, but they afterwards assume their ultimate position as the bones increase in length.

As the permanent teeth erupt, the sockets of the temporary teeth disappear by absorption and new alveoli are built for the second set.

\section{Order of Eruption of Permanent Teeth.}

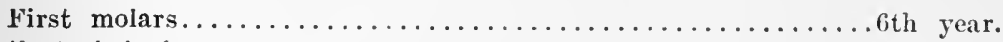

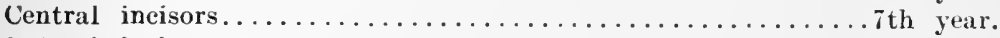

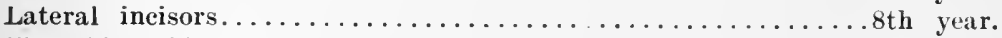

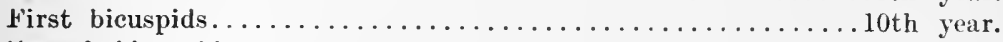

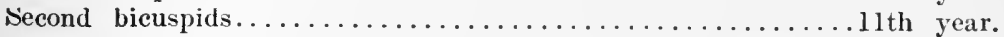

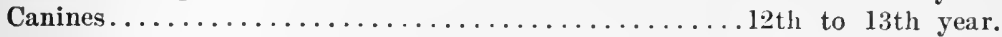

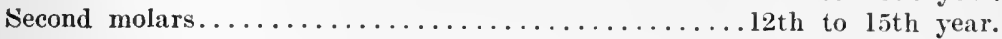

'Third molars......................

'The lower teeth usually precede the upper.

\section{VERTEBRAL COLUMN.}

As the spine develops and ossification proceeds, the ligamentous attachments become firmer and the vertebral column loses some of the great flexibility of early infancy.

The development of the curvatures, due in part to the superincumbent weight and in part to the action of the great muscles attached to the vertebræ, may be rendered abnormal by persistent vicious attitudes or unusual muscular contractions, resulting in unnatural curves, as in kyphosis, lordosis, and scoliosis. The maintenance of the permanent curvatures is due to changes in the thickness of the intervertebral substance. There may be great variation in the time of ossification of the vertebræ. The process begins before birth and is not fully completed before the thirtieth year.

THORAX.

As age advances the transverse diameter increases more rapidly than the anteroposterior, so that a cross seetion of the thorax from being, at birth, nearly circular becomes more elliptical (Fig. 39).

The backward and downward curvature of the ribs becomes more and more pronounced. It is accompanied by the subsidence of the sternum and attached costochondral areas, changing the chest from the more or less cylindrical form of infancy to the cone shape of the adult. On account of the compressibility due to the predominance of cartilaginous tissue, the shape of the thorax depends largely upon the continuous action of the muscles; hence the deformities so frequently observed as the result of retarded bone development.

\section{LUNGS.}

From infancy to puberty there is a gradual change in the structure of the lung. The air-cells increase in number and size, encroaching upon the connective tissue and diminishing the vascularity of the organ. The air-spaces developed from the terminal bronchi are covered with a continuous layer of nucleated epithelial cells, which, during the more ex- 
tended growth of the alveoli become flattened, lose their nuclei, and form thin plates. The blood-vessels become less tortuous and distensible. The changes in the lung result in a condensation of interstitial tissue, with increased firmness of the bronchioles and a more intimate relation to the parenchyma. The air capacity, which is small in early infancy, increases rapidly as the age advances.

As the thorax shows an excess of growth over other parts of the body, so the lungs have an even greater growth, since they not only keep pace with the increased capacity of the thorax, but finally fill a portion of the space formerly occupied by the thymus, and also cover to a greater extent in front the heart and great vessels. The backward curvature of the ribs, a feature of thoracic development, gives additional space for the lungs posteriorly on either side of the spinal column (Fig. 39). As in the adult, the apices of the lungs extend two finger-breadths above the clavicle (Fig. 40), and there is no constant difference in the location of the inferior borders.

A marked change occurs in the anterior boundaries; the wide angle between the anterior lower borders of the lobes, which is due in part to the encroachment of the abdominal viscera and in part to the flaring of the chondral arch, becomes less as childhood succeeds infancy.

There is no difference in the gross arrangement of the bronchi, save that in the development of the thorax the bifurcation of the trachea gradually assumes a lower relation to the spinal column until maturity, when it is found opposite the fourth dorsal vertebra.

The right bronchus occupies a more vertical position than the left, a point of interest, as it is more liable to the lodgement of foreign bodies and to infection from the larynx.

The descent of the inferior maxilla, the larynx, and the upper end of the sternum, keep nearly equal pace during the developing period until the age of puberty, when the larynx in the male takes on a remarkable growth, especially in its antero-posterior dimensions, bringing into prominence the well-known landmark, the pomum Adami.

In the adult the space between the top of the sternum and the chin with the head retracted is double that which it measures when the head is in the natural position, this increase occurring mainly between the chin and the cricoid cartilage. In the child, however, with the head similarly placed, the increase in space occurs between the cricoid cartilage and the top of the sternum, because in the child the cricoid cartilage occupies a higher position in the neck.

\section{HEART.}

It has been stated that the heart at birth is relatively large. The capacity of its two sides and the thickness of their walls are nearly equal, the auricular portion being still comparatively large. During infancy the weight of the heart increases rapidly, its rate being estimated at eighty per cent., the left ventricle showing the greatest increase, its wall doubling in thickness that of the right.by the end of the second 


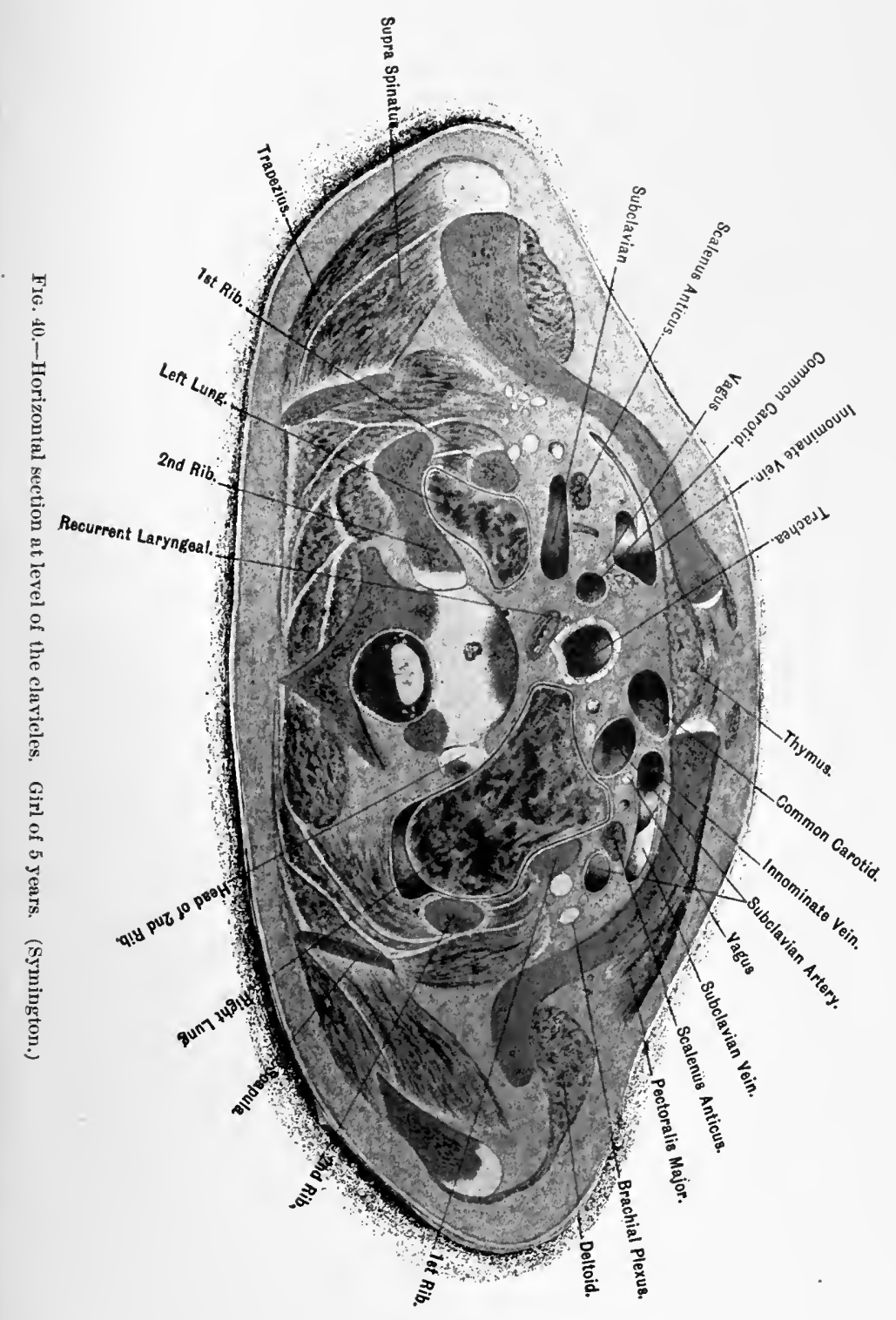



year. From the third to the tenth year the weight of the heart seems to fall behind in the general growth of the body, showing an increase of only ten per cent. At the approach of puberty it takes on a remarkable growth, stated to be as high as one hundred per cent.

The limit of the growth of this organ is said to be about fifty years.

The position of the heart in its relation to the anterior thoracic wall has been a subject of much controversy ; different observers locating the apex beat in early childhood all the way from the fourth to the sixth interspace, and from one to two finger-breadths on either side of the nipple line.

That clinicians should differ so widely in their conclusions would suggest either that hearts vary in their positions in different children, or are subject to variations in the same individual. It is more than
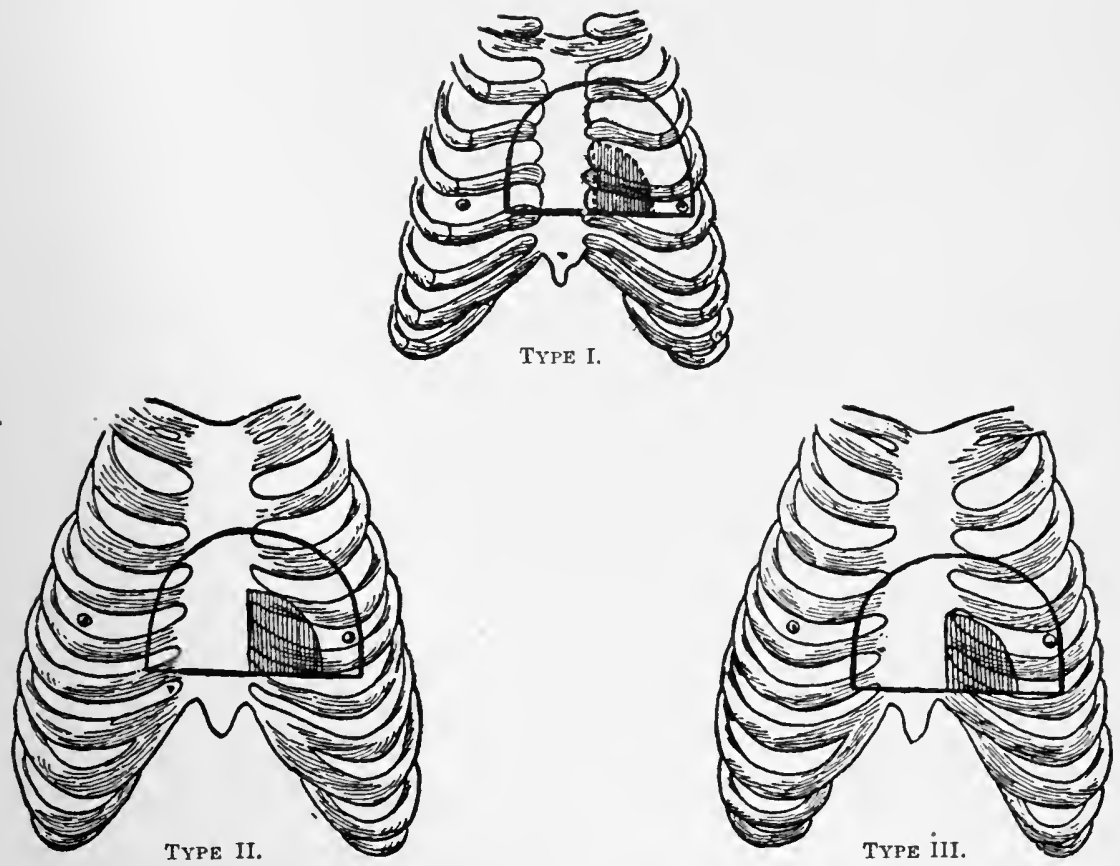

FIG. 41.-Von Starek's types of relatire and absolute cardiac dulness. Type I, first year ; Type II, from the first to the sixth year: Type 111, from the sixth to the twelfth year.

probable that both are true. It can be demonstrated that peculiar conformations of the thorax affect the position of the apex, as the crowded viscera must conform to their more rigid surroundings.

Again, the position of the individual, whether upright or horizontal, is known to change the position of the apex through the influence of gravity. So, too, any erowding from distended abdominal organs may lift the movable apex. In all probability there is no marked change in the relative height of this organ, though the more rapid growth 
of chest wall as compared with heart growth may bring the apex impact nearer the median line.

In very young infants the exact location of the apex is not always easy to determine, owing partly to the interposition of adipose and the want of systolic vigor. In early infancy the relatively large right ventricle, moreover, comprises the entire anterior aspect of the heart. The left ventricular apex, lying posteriorly, does not impinge against the chest wall with the definiteness of advanced childhood. The more transverse position of the heart itself and the sharper curvature of the costochondral region, obscures somewhat the apex behind the shelving border of the left lung, increasing the indefiniteness of the infantile apex beat. But later in childhood the heart beat is easily felt and may be more plainly noted than in the adult.

As a rule, the apex beat is located beyond the nipple line in early childhood, but in, or within that line in later childhood, and usually in the fourth or fifth interspace. The accompanying diagrams of von Starck's "Types" represent, with a fair degree of accuracy, the comparative areas of cardiac dulness, both relative and absolute, at different ages of childhood (Fig. 41). The larger majority of observers have located the right border of the heart to the right of the sternum at all periods of childhood.

\section{BLOOD-VESSELS.}

There are some changes in the blood-vessels that should be mentioned. The relative capacity of the arteries to the heart is greater in infancy and childhood, thus rendering the arterial tension low. The enormous growth of the heart at puberty produces a marked change in their relation.

The growth of the arteries is not uniform. This is best seen in the femoral and renal, as compared with the carotid and pulmonary, the two latter showing but little postnatal growth, while the former develop in a marked degree. This is a point of interest, as it helps to explain the tendency to renal congestion so noticeable in young children.

THYROID.

As ehildhood advances, with the disappearance of subcutaneous fat and the sinking of the manubrium sterni, the thyroid gland becomes more evident and can more easily be ontlined. The fluid contained in its cells, which in the fœtus and new-born is serous in character, changes gradually to a colloid material. Not infrequently the thyroid increases in size at the approach of puberty.

\section{THYMUS.}

The thymus increases in size up to the end of the second year; it is usually stationary until the sixth year, after which it gradually atrophies, disappearing from the neck and from behind the middle third of the sternum, its only vestige being a mass of fatty tissue in the superior 
mediastinal space. The atrophy is associated with a eloser approximation of the pleuræ and lungs, behind the sternum.

ALIMENTARY TRACT.

Within the first few weeks of life the mucosa of the mouth loses its dusky hyperæmic appearance, and at the same time the so-called epithelial pearls-small yellowish-white nodules frequently found in the median line of the hard palate-disappear.

The tongue and buceal surfaces become more moist with the increasing sceretions from the buccal, labial, and salivary glands.

The characteristic coating of the baby tongue persists during the greater part of the nursing period. The roof of the mouth gradually becomes more arched with the development of the alveolar ridges. The velum palati becomes ampler as it deseends to its more vertical position, the uvula elongates and the tonsils increase in size. The masses of fat (sucking pads) found in the buccal parietes diminish, although traces of them remain in later life.

Between the pharynx and the vertebral column is a considerable amount of loose connective tissue, containing the postpharyngeal glands; of interest as they may be the seat of retropharyngeal abscesses. With the body growth the pharyn $x$ and œesophagus lengthen, the latter curving somewhat as it follows the spine, with which it is in close relation (Fig. 36).

\section{STOMACH.}

The stomach develops rapidly, especially in the region of the fundus, increasing greatly in its longer curve, the walls thickening and becoming more museular.

The patulous cardiac orifice assumes gradually its valve-like arrangement, characteristic of later life.

The lymphoid tissue, which is abundant in the mucosa of the young stomach, gradually diminishes as the peptic glands increase in size and activity.

The position of the stomach, at first completely covered in front by the left lobe of the liver (Fig. 25), ehanges with its own rapid growth so that by the sixth month a portion of the lower border presents below that organ. After one year of age pereussion should outline at least a third of the normally distended stomach.

A great deal has been written in regard to the growth of the stomach in infancy. The difficulties in the way of measuring the capacity of this viscus during life, and its distensibility when filled post-mortem, render unsatisfactory all attempts to determine aceurately its size at different periods. Were the pylorus elosed the stomach could easily be filled with a known quantity of fluid, or, by weighing before and after nursing, the amount ingested could be determined. But even this method would lack accuracy, as allowance must be made for absorption. As the result of many recent post-mortem examinations and many weighings before and 
after nursing, some fairly approximate conclusions have been generally accepted.

The following table represents fairly the average capacity of the stomach at different ages: *

\begin{tabular}{|c|c|c|}
\hline & Centimetres. & Ounces. \\
\hline At birth $\ldots \ldots \ldots \ldots$ & .. 30 & \\
\hline At end of first month .. & .. $\pi 5$ & $2 \frac{1}{2}$ \\
\hline At end of second month & $\ldots 105$ & $3 \frac{1}{2}$ \\
\hline At end of third month. & . . 135 & $4 \frac{1}{2}$ \\
\hline At end of fourth month & .. 150 & 5 \\
\hline At end of fifth month .. & $\ldots 165$ & $5 \frac{1}{2}$ \\
\hline At end of twelfth month & 255 & $8 \frac{1}{2}$ \\
\hline
\end{tabular}

The growth of the stomach is most rapid in the first half of the first year, of which the first three months exhibit by far the greater rate of increase. By comparing the above with the tables of growth, it will be observed that the gastric capacity maintains a very constant ratio of increase with that of body weight in the first year of life.

\section{INTESTINES.}

Much has been said concerning the changes in the lower digestive tube during development. A few measurements may be given here.

Small intestine at birth-286 centimetres (9 ft. 5 in.).

Small intestine at end of second month-296 centimetres (9 ft. 9 in.).

After this its growth is very irregular.

Large intestine at birth-56 centimetres ( 1 foot 10 inches), of which the sigmoid represents 25.5 centimetres (10 inches) and the imperfect cacum abont 5 centimetres ( 2 inches). The growth is slight, or even none, for the first four months, but the following measurements have been verified:

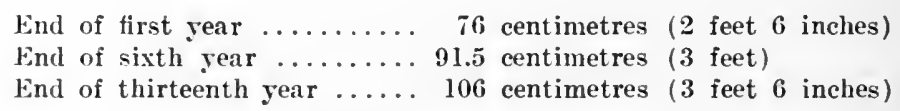

In the progress of growth differentiation occurs between the various portions, as duodenum, small intestine, cæcum, colon, and rectum.

That the growths of the different portions of this tube are not uniform and bear no constant relation to the growth of the body, would seem to explain the apparent anomalies of position and dimensions noted by different observers. Descriptions of aberrant bowels need occasion no surprise. The colon may extend directly from the hepatic flexure diagonally to the left iliac region, or from the splenic flexure to the right iliac, with the rectum on the right side of the sacrum. An

* Gastric capacity as mentioned above must not be confounded with the amount of food an infant may take, concerning which reference will be made in the chapter on foods. 
immense loop may be thrown out from the left iliac fossa which, reaching to the umbilicus, returns to the rectum, as a rudimentary sigmoid.

It has not been demonstrated that the small intestine follows a very definite course, or bears during its growth any constant relationship to other viscera, varying little in form or structure throughout its length until it joins the excum, which in the earliest infancy shows marked departure from the preceding tube. Many descriptions agree that this important organ is found in the very young relatively high without, however, any fixed habitat for itself or its appendix, the angle at the ileocæeal junction maintaining no constant value.

From this point on, the tube assumes the sacenlated form which is characteristic of the colon. The ileum gradually descends to its permanent position and the flexures assume their definite relations to the liver and spleen, though the lower termination exhibits vagaries in the length and position of that part known as the sigmoid. The rectum loses its relative redundancy as it adjusts itself to the increasing depth and posterior eurvature of the pelvis. One peculiarity of the lower digestive tube in infancy is the ample mesentery, an arrangement which allows adaptation of this convoluted tube to the rapidly increasing dimensions of the abdominal eavity.

\section{LIVER.}

The increase in the weight of the liver does not keep pace with that of the body, showing a tendency to fall behind throughout life. The

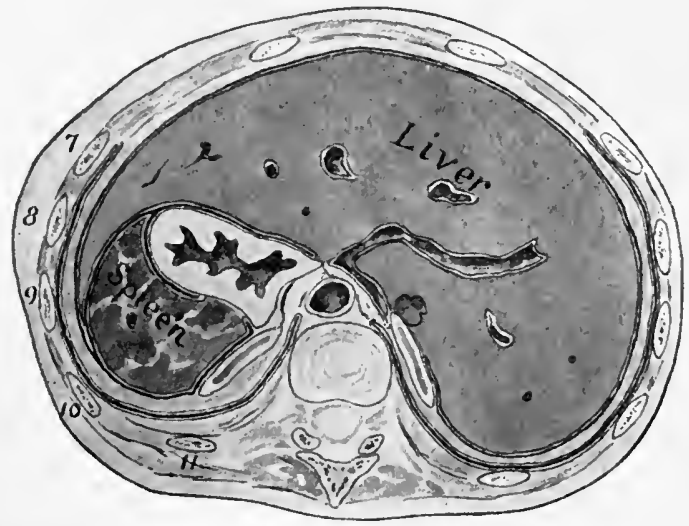

Fig. 42.-Horizontal section made at the lerel of disk between eleventh and twelfth vertebræ. Boy of 5 years. (Symington.)

relative reduction of liver weight at birth is not surprising when the changes in blood circulation at that time are considered.

The decrease in area of liver dulness is due to the increasing prominence of the rapidly growing stomach and the elongation of the abdominal spine (Fig. 42).

The retardation of growth is most marked in the left lobe, retiring as it does from a point midway between xiphoid and umbilicus to the 
restricted area found later in front of the pylorus. Advancing childhood with its lowered diaphragm shows the superior border of the liver one rib lower than in infancy.

The lower margin frequently found at birth midway between costal margin and crest of ilium, apparently ascends until at puberty it may correspond with the lower border of the ribs.

SPLEEN.

The peculiarity of the spleen in infancy and childhood is its ready tendeney to enlargement.

KIDNEYS.

The kidneys maintain their lobulated appearance for several years, assuming gradually the smooth surface that is a characteristic of adult life.

The relative slowness of their growth as compared with that of the spinal column sufficiently accounts for the apparent change of position of the superior and inferior borders.

BLADDER.

From the semi-abdominal position at birth, the bladder sinks downward as the pelvis develops in depth and breadth. This subsidence is,

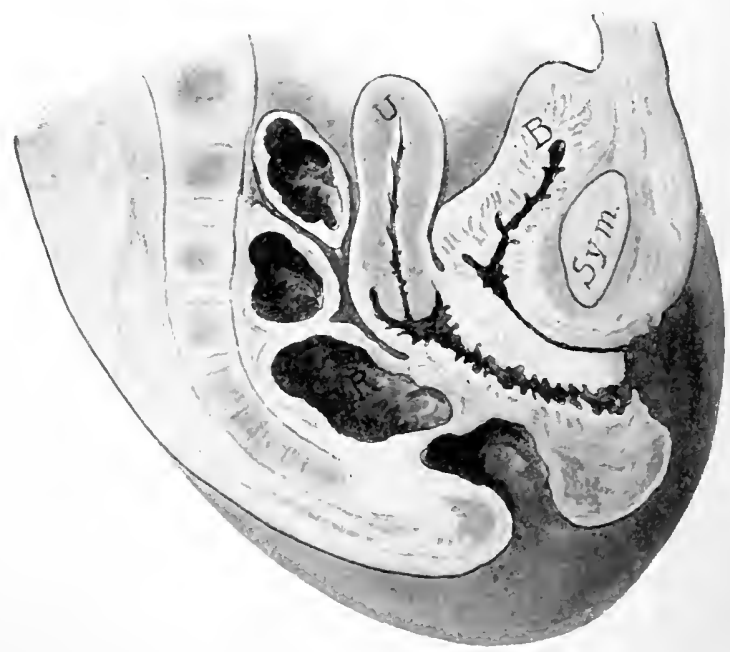

Fig. 43.-Distended bladder of an infant of 15 months. (Symington.)

no doubt, favored by the weight of the urine and the assumption of the upright position (Fig. 36).

Of surgical interest is the relation of the peritoneum to the bladder. at different periods of growth. As previously stated, the extensive anterior surface of the bladder at birth is devoid of peritoneal covering and lies in intimate relationship with the anterior abdominal wall, occu- 


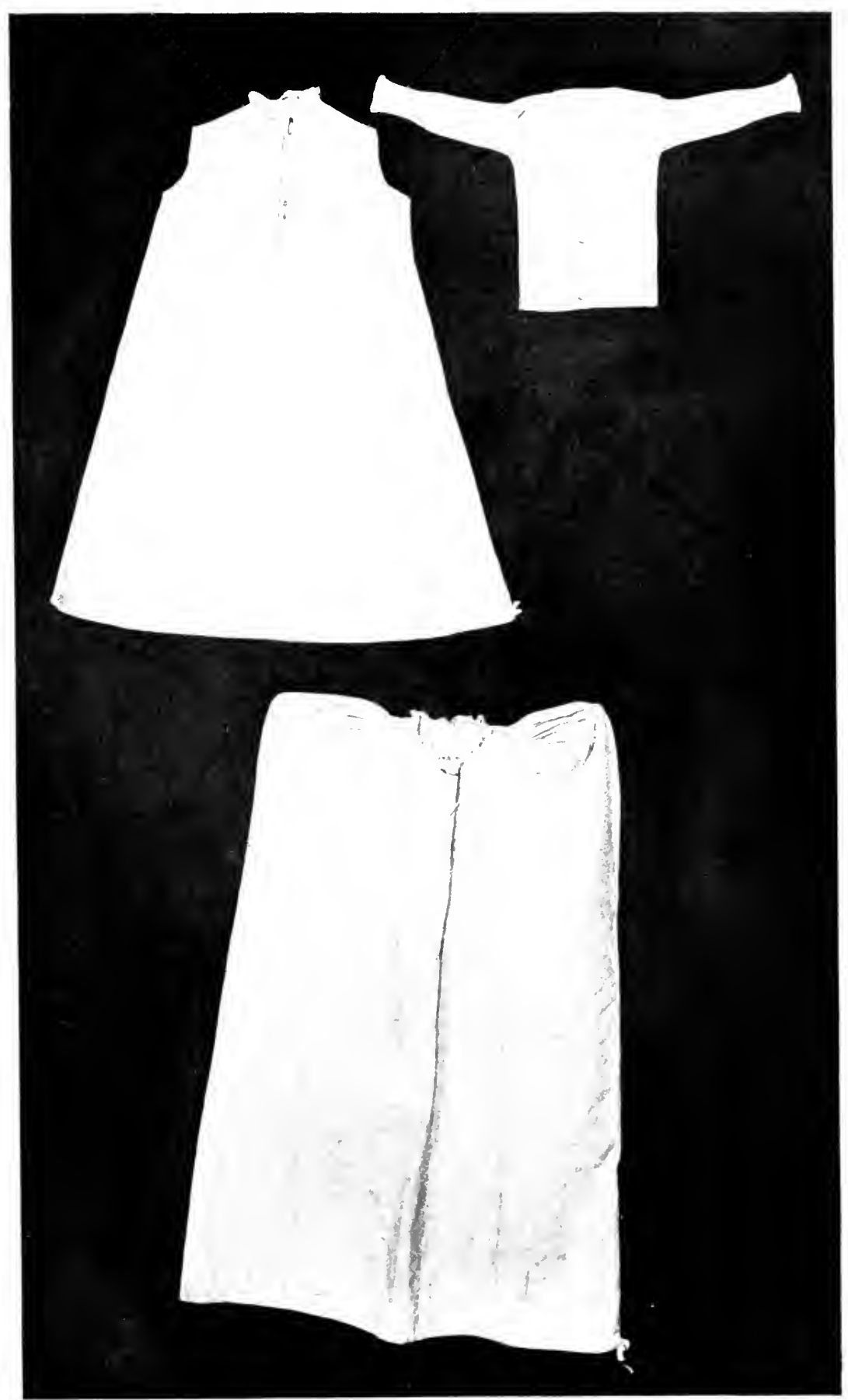

FIG. 44.-Clothing for young infant. Outer garment, sleereless slip, aud shirt. 


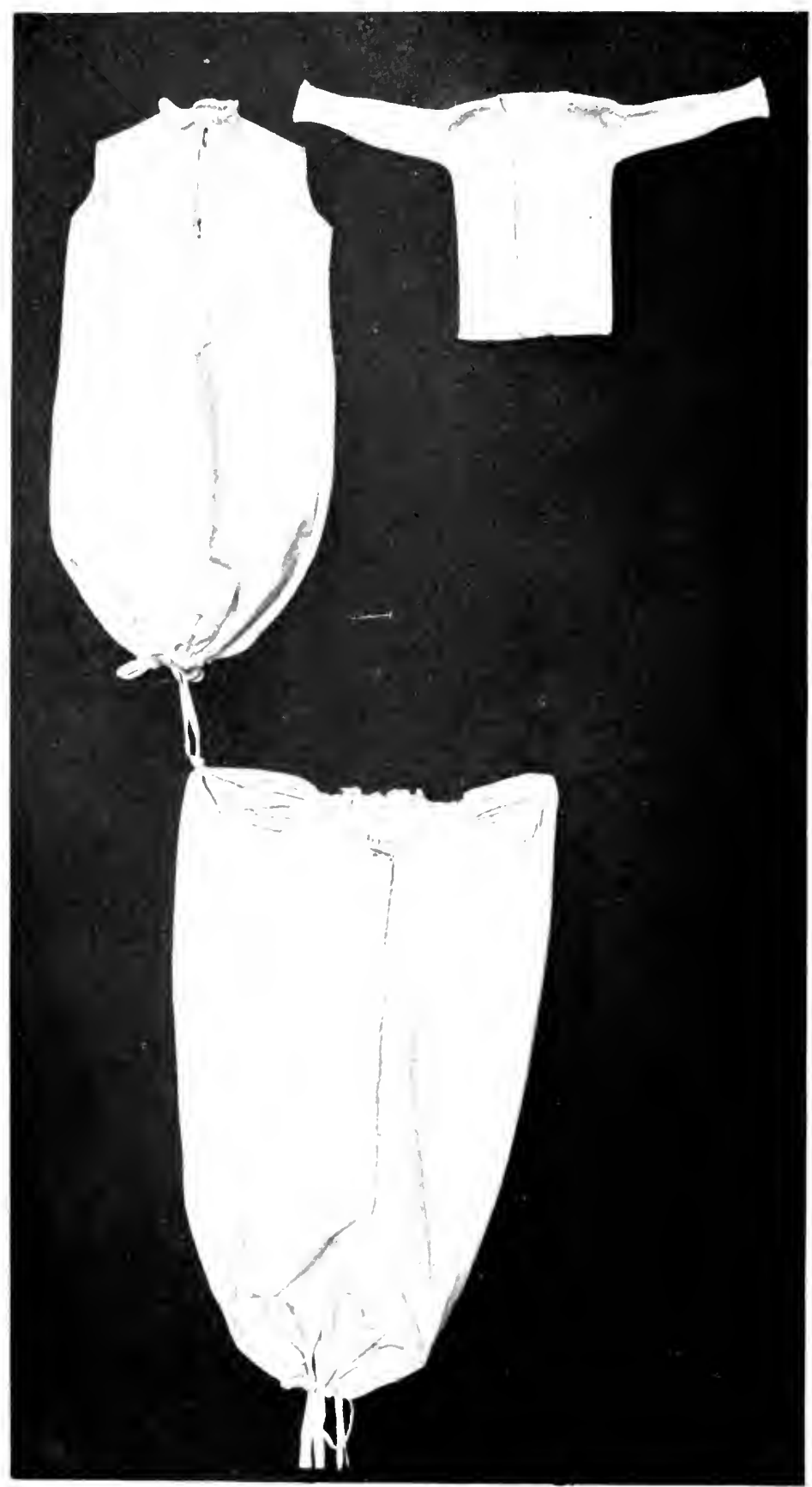

Fig. 4h.-Same as Fig. 44. Closed 
pying the lower two-thirds of the space between the symphysis and the umbilicus (Figs. 28 and 43).

In contrast, the posterior surface is invested with peritoneum as low down as the commencement of the urethra. In the growth of this viscus the broadening base is partially uncovered, the peritoneum being reflected upon the rectum, forming the rectovesical fold.

From about two drachms at birth to an ounce at six months the eapacity of the bladder shows great variations and is susceptible of great distention.

\section{UTERUS.}

The high position of the infantile nterus and ovaries changes with the pelvic development, the fundus maintaining its rudimentary form and structure until the approach of puberty, at which time differentiation from the cervical portion is rapidly established. About the same time the vagina assumes a more horizontal position, which, with the increasing anteversion of the uterus, diminishes the intervened angle.

No marked changes occur in the generative organs until the approach of puberty.

\section{INGUINAL CANAL.}

The internal and external inguinal rings, which were originally in apposition, become separated with the growth of the lower abdominal walls, the intervening tissue being elongated into a canal lying obliquely between the muscular layers.

\section{NERVOUS SYSTEM.}

By comparing the weight of the brain with that of the body at different ages, we find that their growth follows a quite similar course during the first year. From this time on, the ratio decreases, as is seen by the following table:

Ratio of Brain to Body Weight.

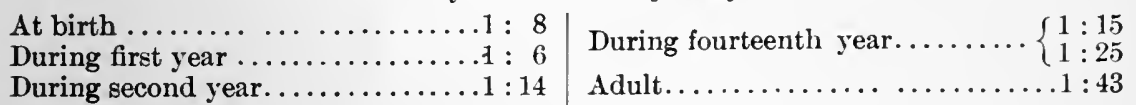

During third year $\ldots \ldots \ldots \ldots \ldots \ldots 1: 18$

The entire brain substance attains nearly its adult size by the seventh year. Owing to the large size at birth, the growth of the brain en masse is not remarkable, but the alteration in its consistency, the increasing differentiation of its gray and white substances, the deepening of the fissures and sulci, and the increasing complexity of the convolutions, all show the occurrence of a marked progressive change (Figs. 34 to 36 ).

The most rapid growth of the cerebrum is seen in the frontal lobes, altering the position and direction of the fissures of Sylvius and Rolando.

Cellular multiplication in the cortex is said to cease in the human being at the third month of fetal life. Although all the cells may be present at birth, they are in a very rudimentary state and may require 
years for growth before they attain the condition necessary for perfection of function. The term elaboration has been used to describe the change from the simple cell of the new-born, with its large nucleus and small amount of protoplasm, to the highly complex type of the adult. Out of the great number of cells present at birth, a considerable part are, probably, never highly developed even in the brains of those well educated and skilfully trained.

In the adult the medullary substance has been estimated at about thirty per cent. of the entire weight of nerve tissue. The highest rate of development thronghout infancy and early childhood occurs in the medullary portion. In very early infancy the peripheral nerves have sheaths of myeline, which later may be traced in the spinal cord, medulla oblongata, and finally to the cerebrum. The extent of medullation of any tract is an index of the degree of development of that tract.

In the same way may be traced the earlier development of those nerve areas which control merely bodily functions and reflexes. The higher intellectual functions show evidence of their activity later, although ultimately they monopolize the greater portion of the cortex.

The weight of the spinal cord to body weight at birth is $1: 500$; in adult life, $1: 1500$. In its longitudinal growth the spinal cord does not keep pace with that of its canal (Fig. 36). It is due to this relative shortening of the cord that the roots of the lower spinal nerves assume an increasingly higher relationship to the respective segments from whose foramina they emerge (a point of diagnostic and surgical interest). It will be remembered also in this connection that the tips of the spinous processes vary considerably at different ages in their relations to their respective vertebræ. 


\section{PHYSIOLOGY AND HYGIENE OF THE NEW-BORN}

\section{CIRCULATION OF THE BLOOD}

THE most noticeable physiological processes in the very young infant are respiration and circulation. The latter, having begun during prenatal existence, seems to be better established.

It is asserted that, at the instant of birth, the heart's action is suspended, to be resumed a fraction of a moment later. Be that as it may, it is quite evident that the radical change in the plan of circulation produces a disturbance of equilibrium, resulting in a marked increase of blood pressure in some vessels with corresponding diminution in others.

The diminished pressure in the right auricle, upon the ligation of the umbilical vein, tends to reduce the blood flow through the foramen ovale. Diminished pressure in the right ventricle encourages blood flow through the tricuspid opening. The increased afflux of blood to the lungs diminishes the current through the ductus arteriosus. The inflation and sudden congestion of the lungs, increasing the interthoracic pressure, is claimed to exert a special influence on the vessels at the base of the heart, favoring the occlusion of the ductus arteriosus. The early return of the pulmonic circulation, increasing the pressure in the left auricle, still further checks the tendency of the current through the foramen ovale and favors its early closure. It also increases the pressure in the left ventricle, which now sustains, for the first time, the burden of circulation, with resulting rapid growth in the thickness of its walls.

The heart, undoubtedly, has imposed upon it increased labor in the new arrangement, which probably accounts for the slowing of its action noted by some observers.

Shortly after birth the pulse-rate may vary from 120 to 140 per minute, although the disturbance of rate from slight eauses allows considerable latitude.

The arterial tension is low in early infancy, owing partly to the large size of the vessels relative to the heart, and partly to their great distensibility. Before the age of six months the pulse is not always easily counted at the wrist. The child's position has little or no effect on the rapidity of the heart's action. It is usually less frequent during sleep, although at the same time less regular.

The rhythm, like the rate of the heart's action, is subject to great variation even in health.

Physiologists have held that the infant at birth has relatively less 
blood than has the adult, the ratio to body weight being $1: 15$, against $1: 13$. The importance of a few grammes of blood, more or less, to the very young infant has only recently been fully appreciated. It has long been recognized clinically that babies bear a loss of blood poorly, but the importance of saving, at the time of birth, some of the maternal blood that is lost with the placenta has recently attracted attention.

The practice of waiting before severing the cord until all pulsation has ceased, has been improved upon, it is claimed, and some accoucheurs strip the cord towards the umbilicus, thus forcing its contained blood into the ressels of the infant before ligation. It is asserted that this procedure produces results in the early nutrition which are susceptible of clinical demonstration.

BLOOD.

During the first few days after birth the infant's blood shows great variations in the size and shape of the cells as if the type were not yet quite fixed. The majority of observers also find a few normoblasts at this time. These are not invariably present, doubtless because in some children the blood at the time of birth is more developed than in others. The hæmoglobin at birth and during the early weeks is relatively high (116 to 119 per cent.). The high percentage is due not only to a polyeythæmia but to a genuine increase of hæmoglobin in the individual cells.

The following table (Cabot) of the blood of the new-born shows a marked leucocytosis :

\begin{tabular}{|c|c|c|}
\hline$A G E$ & Red Cells & LevCocytes \\
\hline 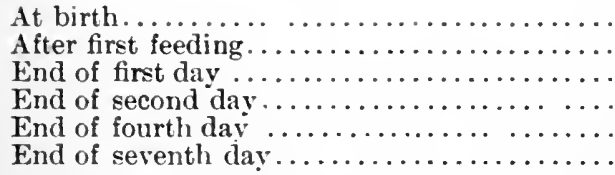 & $\begin{array}{c}5,900,000 \\
7,000,0000-8,800,000 \\
6,500,000 \\
6,000,000 \\
5,000,000\end{array}$ & $\begin{array}{l}17,000-21,000 \\
26,000-36,000 \\
24,000 \\
30,000 \\
20,000 \\
15,000\end{array}$ \\
\hline
\end{tabular}

This high increase is explained by some as a combination of blood concentration with a large digestion-leucocytosis. Of the white cells there is a relative increase in the lymphocytes in healthy infants. It is stated that the amount of fibrinogen is small, and that the blood of this period coagulates slowly. This is of interest in relation to hemorrhages in the new-born.

During the first few weeks the characteristics of the blood of the new-born-viz, the increase in number and varying size and shape of the red corpuseles, the great increase in the white, especially of the lymphocytes, the high percentage of hæmoglobin and the high specific gravity-all gradually disappear. In examining the blood of an infant we should remember that the question of a normal condition of the blood must depend upon the backwardness or forwardness of the infant's development. After the first few weeks the hæmoglobin and specific 
gravity sink to a lower level than in the adult, the percentage of hæmoglobin reaching as low, even, as sixty per cent. It is suggested that the eosinophilia usually present may be connected with the great activity in bone growth. The marked diminution of corpuscular elements, hiemoglobin, and specific gravity, after the first week, is presumably due to the increased metabolism ineident to rapid tissue formation.

That the growth of different organs and increase of function is in direct ratio to the blood supply, is demonstrated in the brain, which receives its blood directly from the aortic arch throngh the great ressels of the neck, its relation to the left heart being the most intimate. The same principle is true of the lungs. The liver, being supplied through the great portal vein, securing, it is claimed, one-seventh of the entire blood, would also illustrate this point. The rapid development of the lower extremities keeps pace with the marked increase in size of the femoral vessels. So, too, as was mentioned in a preceding chapter, the long bones show complete ossification earlier at the extremities towards which the nutrient arteries are directed.

Since the blood supply not infrequently depends upon the muscular activity of the part, the deduction is plain that restrained activity or interference by any means retards both function and growth. In the care of the young infant too much stress cannot be laid upon the importance of unrestrained freedom of motion for all the members, and avoidance of anything that tends to compress the vessels, such as long continued recumbency in one position, with possibly the addition of hypostasis in the dependent parts. In this respect, also, the clothing demands attention, that no bands or seams press upon the vessels and cause local deficiency or congestion.

\section{RESPIRATION.}

If any vital process is pre-eminent in its importance, it is that of respiration. . It has been demonstrated that young infants inhale more oxygen and exhale more carbon dioxide, relatively, than do adults. This is a result, no doubt, of the more rapid tissue change in the growing organism. It is claimed, however, that when completely deprived of air, life is sustained for a longer period by the very young infant. This should be remembered in efforts at resuscitation of the asphyxiated infant.

Respiration, beginning with postnatal life, is probably the least developed of the vital functions. Its want of vigor is partly due to the compressibility of the chest walls, to the lack of full development of the respiratory muscles, the yielding character of their points of origin and insertion, and partly to the narrowness of the upper airpassages. Added to these there are the enormous thymus, obtruding liver, and frequent abdominal flatus restrieting respiratory movement. Fortunately for the young infant its respiratory process has no fixed type. It may be partly thoracic or unilateral, but generally it is abdominal, adjusting itself to the ever-varying conditions of environment. Hence 
it is not strange that the rate and rhythm of respiratory movements are, in infancy, extremely variable. The average of many observations gives the rate from thirty to sixty per minute. A healthy infant may sigh, hiccough, or exhibit Cheyne-Stokes type of respiration, without evidence of any serious abnormality.

Inspiration is accomplished partly by the contraction of the muscles attached to the ribs, but principally by the contraction of the powerful muscular portion of the diaphragm, which, lengthening the vertical diameter of the thorax, canses the air to enter the glottis by atmospheric pressure. Expiration is due to the resilieney of the diaphragm, thoracic walls, and lung tissue, as they resume their former position.

The ratio of respiration to pulse in the very young infant is so inconstant that it is of little value. The yielding character of the thorax, as well as the undeveloped state of its muscles, renders him very susceptible to disturbances by compression, so that great eare should be exercised, not only in the handling of the infant, but also in the clothing, that no constriction of the chest occur. So, also, care of the nasal and pharyngeal tracts is necessary that no accumulations or growths interfere with the free access of air.

\section{TEMPERATURE.}

The temperature in early infancy does not exhibit that stability which is seen in later life, apparently trifling causes producing great variations. The rectal temperature of the new-born is from $99^{\circ}$ to $100^{\circ}$ F. $\left(37.2^{\circ}-37.8^{\circ}\right.$ C. $)$. Within the first hour it falls two or three degrees and fluctuates without apparent reason for a few days, with a general average of $98^{\circ} \mathrm{F}$. (36.6 C.). At the end of the first week it is about $99^{\circ}$ F. $\left(37.2^{\circ}\right.$ C. $)$, which may be taken as the average normal during early infancy.

The variability of temperature in infants is not surprising when we consider the conditions,-viz., the relatively great radiating surface of the body, the dilatability of the superficial capillaries, and the thinness of their investments; also the undeveloped state of the heat regulating centres.

In infaney, as in later life, the temperature shows a cycle of diurnal oscillations which corresponds with observations in regard to the daily variation in the heart's action and the older idea of fluctuation of the vital force. Most observers have found the temperature to be the highest in the afternoon and the lowest from twelve to four in the early morning. Rectal temperature only is reliable, as in the young infant the mouth cannot be utilized for that purpose, and the surface of the body, for reasons before stated, shows a temperature two or three degrees lower than that of the blood.

In view of the above-mentioned facts it would seem hardly necessary to warn the acconcheur against undue exposure of the new-born to influences which lower the temperature. Still, the practice of chilling the infant by unnecessary exposure, even to the extent of subjecting him 
to the tub bath, is so common that it cannot be too emphatically clenounced. A thorough application of warm oil to the surface, and the envelopment of the entire body in warmed material, as soft wool, is more rational.

Keeping in mind the intrauterine temperature from which the new-comer has emerged, the intelligent acconcheur will not neglect that of the lying-in room. The transition from $99^{\circ}$ to $75^{\circ} \mathrm{F} .\left(37.2^{\circ}-23.9^{\circ} \mathrm{C}\right.$. $)$ is certainly radical enough for stimulation of the respiratory and circulatory functions.

In his subsequent care it must never be forgotten that miformity of the surrounding temperature should be maintained and the child protected by clothing from excessive radiation. Nothing is more appropriate for this purpose than wool, and as lightness is a desideratum, two thicknesses, or even three when necessary, are better than one containing the same amount of material. As before stated, clothing must not be allowed to interfere with freedom of muscular movement or of blood circulation. The evils of the pinning blanket, the restraining diaper, the tight abdominal and thoracic bands, of the padded, closely enveloping wrap, the constricting sleeves, tapes, and strings, are too apparent to require prolonged criticism. The loading of the garments with embroideries, laces, and useless decorations should be discouraged.

To secure the benefits of clothing, and at the same time freedom from its injurions effects, is a problem, the solution of which has been long sought. The ideal protection would seem

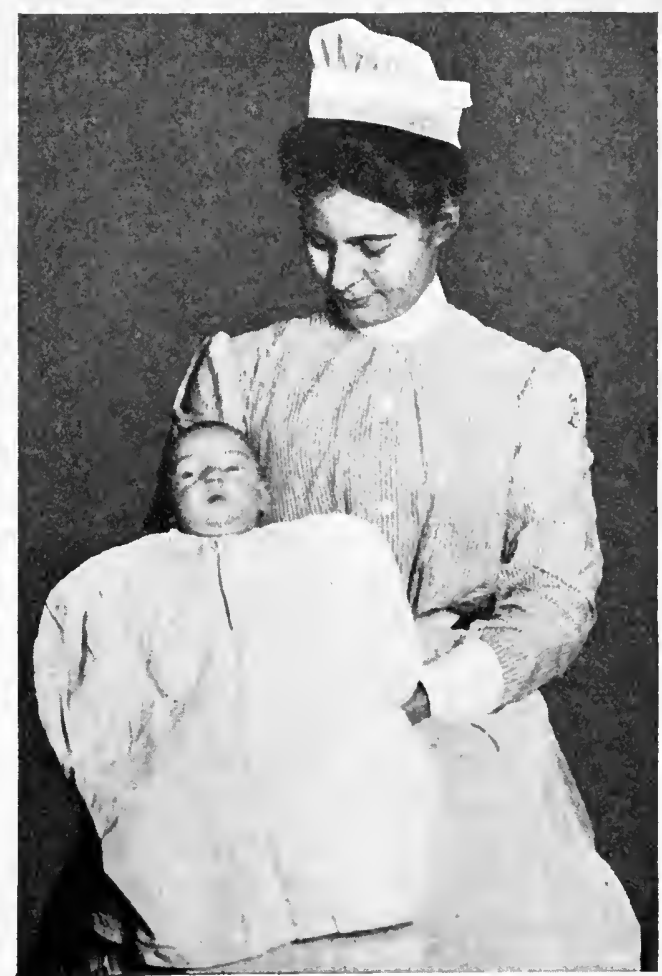

FIG. 46.-Infant clothed. to be afforded by a large blanket of light, flexible, nonconducting material, but this normal restlessness makes it difficult to keep the infant within its folds. A more definite garment, that cannot be thrown off while still allowing unrestrained freedom of movement, is in use in the infants' wards of some city hospitals. The garment is a bag so constructed that it envelops 
loosely the entire infant below the chin, closure being secured above by safety pins, and below by a drawstring (Figs. 44 to 47 ).

Additional protection against cold is afforded by separate undergarments, as a light knitted shirt, of silk or wool, free from seam or band, and one or more sleeveless slips, as occasion may require. The

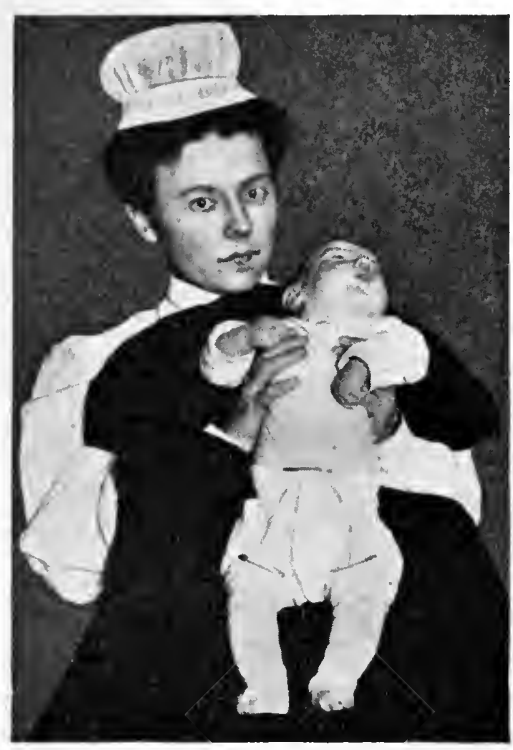

FIG. 47,-Outer garments removed. diaper should be light, with no more material than is absolutely necessary for the absorption of the discharges. Absorbent cotton, either loose or in pads, preferably the latter, retained by a T-bandage of some firm material, secured by a safety-pin, has been found to meet all the requirements. In exceptional cases some departure from the simplicity of the above may be desirable.

\section{ALIMENTARY CANAL.}

The labial and buccal glands of the new-born secrete mucus, which serves for protection. The salivary secretion, especially in the parotid, is established but feebly. The physiological properties of this secretion at birth have been a subject of extended investigation and animated discussion. It seems to be established that the saliva possesses a very slight amylolytic power, on account of the small amount of ptyalin at this early age.

At birth the gastric glands secrete pepsin in very small quantity. Free hydrochloric acid is not found. Lactic, which is mentioned as the principal acid of the infant stomach, is found only after the ingestion of milk. The mucous follicles secrete freely. The stomach at this early age is more of a receptacle for food than a digestive organ, coagulation of albumin by the rennet ferment representing nearly the whole extent of digestion accomplished in this viscus. It is claimed, however, that a considerable amount of fat is absorbed from its surface, through the agency of the lymphoid corpuscles, in which the stomach is particularly rich at this period.

The duodenum contains, besides the intestinal juices, the secretions from the liver and pancreas. The importance of the liver as a digestive organ has long been recognized, but much difference of opinion in regard to the exact rôle played by its secretion still exists.

"The bile of the new-born is distinguished by its poverty in the inorganic salts (with the exception, however, of iron salts), its poverty in cholesterin, lecithin, and fat, and particularly by the small percentage of special bile acids." (Jacubowisch.) If the above be true it would 
seem fortunate that the young infant is well supplied with lymphoid tissue, whose eorpuscles are supposed to aid in the absorption of fat.

The paucity of bile acids, it is said, allows a more eomplete action of the pepsin and panereatic secretion, which is usually retarded in the presence of these aeids. Although it is believed to-day that the bile has little if any baeterieidal power, other seeretions of the intestines, as well as those of the stomach and salivary glands, are known to possess this property.

Of the pancreatic secretion it has been shown that three of its ferments are present at birth,-viz., trypsin, steapsin, and a milk-eurdling ferment. But little amylolytie aetion has been demonstrated, although its proteolytic and lipolytic ferments are unquestionably active. It is thus seen that digestion is earried on to the greater extent in the duodenum and small intestine.

No bacteria are found in the intestines or their eontents at birth. Within twenty-four hours, however, two varieties are found in great abundance,-viz., bacterium laetis rerogenes in the small intestines and bacterium coli eommune in the large intestines and fxees. Shortly after birth, and sometimes before, meeonium is diseharged. This eontinues until the fæces are changed by the ingestion of milk, which produces light yellow, slightly sour and batter-stools of uniform eonsisteney. Decomposition produets - as indol, skatol, and phenol, with eolor changing to green-are normally found in stools that are kept long after diseharge. The number of stools may vary within physiological limits from one to six daily.

Meconium is a viscid, tarry-colored, odorless substance, feebly aeid, containing no bacteria. It is eomposed of intestinal mueus, bile, vernix caseosa, epithelial cells from the epidermis, hair, fat-globules, eholesterin crystals; also fatty acids and soaps.

\section{URINE.}

The size and complete development of the kidneys at birth would suggest a somewhat prolonged previous function. The finding of the constituents of the urine in liquor amnii is evidence of their eliminative activity. Urine is normally present in the bladder at birth and is usually voided within a short time, any delay beyond twelve hours occasioning some anxiety. The first urine voided is clear and of a pale amber color, unless long retained, in which ease it is dark and eloudy. Its specific gravity varies from 1.012 to 1.005 , and the reaction is acid.

A frequent marked peculiarity in the new-born is the presence of uric acid erystals, so abundant sometimes as to form infarets in the straight tubules of the kidney, even to the extent of their complete occlusion.

Traces of albumin and hyaline casts occasionally appear. Urea and inorganie salts are not found in large amounts during the first week, hence the low specific gravity. The quantity of urine in the first day varies from nothing to two ounces $(60$ C.e.). With the ingestion of 
fluids there is a corresponding increase in the amount voided; so that by the end of the first week it may range from five to thirteen ounces (150-390 C.c.). Because of the small size of the bladder and the lack of inhibitory control of the sphincter, micturition is frequent at this age, often thirteen to fifteen times in twenty-four hours. A tenacious vaginal discharge, which may be bloody, is oceasionally seen in the first few days.

SKIN.

The part played by the integument in the animal economy is such as to necessitate great activity in its growth and repair. Hence it is not surprising to find that it has the most abundant blood supply, with the greatest glandular activity. The skin of the infant is thin, delicate, velvety to the touch, and elastic to accommodate the varied movements. Its thinness and numerous capillaries give to it the characteristic pinkness of infancy. It is evidently well prepared histologically for frequent renewal and rapid growth necessitated by the constant attrition and expansion. The skin demands constant eare to prevent irritation and excoriation, especially about the buttocks, from the urine and frees. It seems hardly necessary to remark that the napkin should be removed as soon as it is soiled.

Disappearance of the lanugo, and exfoliation of the primitive epidermis, begin with the exposure to the air, and continue throughout the first two or three weeks. During this time the stump of the umbilical cord separates from the surface of the abdomen, by a line of demarcation, leaving a cicatrix, occasionally denuded of epithelium.

\section{SEBACEOUS GLANDS.}

The function of the sebaceous glands, active from the middle of intraaterine life, continues after birth, hence unremitting care is required to prevent accumulations, especially on the scalp. If crusts are once formed, frequent oiling may be necessary to soften them. Too frequent use of strong soap and water, as well as friction, should be avoided.

SWEAT GLANDS.

The sudoriferous glands are inactive at birth, and perspiration is not usually seen during the first weeks.

\section{LACHRYMAL GLANDS.}

The function of the lachrymal glands is not, as a rule, established at birth, tears usually making their appearance about the third month.

\section{NERVOUS SYSTEM.}

In regard to the functions of the nervous system, it may be said that at birth the infant is merely a bundle of reflexes, although its reflex excitability lacks the intensity shown later. Inhibition is poorly developed and the motor centres are quickly exhausted. A certain degree of myotonia and athetosis is normal in the young infant (Figs. 4 and 5). 
SIGHT.

It appears that, although the eye is complete in formation at birth, the infant has but feeble vision. It is evident from the play of features that a difference in the intensity of light is appreciated before the end of the first day. On the second day the eye is quickly closed on bringing a candle flame near.

IIEARING.

The sense of hearing is probably not present at birth, but is established within the first day or two, as the tympanum fills with air and the congestion of its mucous membrane subsides.

SMELL.

In all probability smell is the last of the special senses to develop.

TASTE.

The sense of taste is evidently well developed from birth, the young infant readily distinguishing milk from water.

TOUCH.

Tactile sensation is very acute in the lips, tongue, and eyes, although feeble in other areas. Many reflexes-as respiration, peristalsis, swallowing, winking, coughing, and sneezing-exhibit a romarkable prenatal development of mechanism.

\section{CARE OF THE NEW-BORN.}

From the foregoing it is evident that the new-born is entirely at the mercy of his surroundings. In fact, of all the mammalia, the human infant is the most helpless. The first duty after delivery is to see that his respiratory passages are free from secretions. This is aided by inverting the child and gently slapping the back of the chest with the hand. Careful introduction of the finger wrapped with dry gauze may be necessary to clear the larynx. The eyes should be cleansed from secretions by washing. with pure water or boric acid solution. The child should be received in a warm, dry blanket and his entire surface anointed with warm olive oil or lard. The eord may be freely dusted with boric acid and surrounded with gauze or absorbent cotton, or it may be cleansed with alcohol and dressed without powder.

Placing the baby on the right side presumably favors the closure of the foramen ovale, and prevents undue pressure from the heavy liver, in which position it may be left undisturbed for half an hour or more, after which the thoroughly emulsified vernix caseosa is easily removed by further inunction and gentle wiping with soft gauze. The navel dressing should be retained by a light flannel abdominal band, the simple garments adjusted, and the child laid in a warm, dark place for necessary 
repose. It is well to administer at this time a teaspoonful or two of warm sterilized water.

Too much stress cannot be laid upon the avoidance of all that tends to shock or fatigue, and the observance of absolutely aseptic details.

It is advisable to place the infant at the breast within a few hours after birth (the nipples having previously been eleansed with boric acid solution) as it is believed that the colostrum at this time is adapted to the needs of the infant's digestive tract.

It must always be remembered that an infant's needs are few but imperative-warmth, food, and repose. He should be disturbed only for his daily inunctions, ehange of clothing, care of eyes and nose, also for fresh napkins, or for food or drink. He should be put to the breast every two or three hours during the day and once at night. The practice of allowing the child to sleep by the side of the mother should not be encouraged. 


\section{CHAPTER IV}

\section{PHYSIOLOGY OF THE FIRST YEAR}

\section{DEVELOPMENT OF THE SPECIAL SENSES}

A definite knowledge of what constitutes normal function is no simple matter, since during the period of development not only are organs growing, but their separate and correlative functions are developing. Some mechanisms reach their complete perfection as to histologic structure while others are still in the formative stage. Observations on the motor oculi nerve show the perfection not only of its mechanism, but also of its function at an early period of infaney. This illustrates the method of growth, since this mechanism furnishes one of the channels of information before the higher centres are capable of utilizing it, the process being an educational one. 'Thus it is seen that all the special senses contribute to the development of the higher centres from which comes the evolution of ideas, these (special senses) in turn having been preceded by the lowest form of nervous phenomena,-viz., reflex action.

The nervous system of the infant shows well developed sensory and motor tracts, but the inhibitory power of the higher centres is tardier in its growth.

It is seen that taste and tactile sensibility, especially of the lips and tongue, are the first of the special senses to show activity; fortunately, as these are necessary in the instinctive efforts of the young to obtain sustenance.

Hearing, although demonstrated as present in the first twenty-four hours, is not developed sufficiently to differentiate between the mother's tones or the sounds accompanying the preparation of food, and other noises irrelevant to the infant's daily requirements, before the third month.

Although sensitiveness to light and blinking on the near approach of objects has been observed from the first weeks, still it is not until the end of the second month that the infant recognizes his mother by sight.

From birth the grasp of the hand upon any object touching the palm is remarkably tenacious and the normal position of the fingers is that of extreme flexion. The voluntary muscles show movements which are purposeless, irregular and asymmetrical, and suggestive of the mere continuance of intrauterine existence. Co-ordinate voluntary movements are first seen in the face and upper extremities, the hands showing prehensile propensities by the end of the third month. Objects are carried to the mouth at about this time. The many ineffectual attempts to locate the mouth indicate the vast amount of energy necessary to develop co-ordination. Although the apparatus including museles and nerves, 
both afferent and efferent, is fairly complete, it is seen that multiple repetitions of sensations, impressions, volitions, and efforts must occur ere the establishment of perfect co-ordination for the performance of the simplest voluntary motion.

It is not until about the end of the third month that the cry is recognized as expressing emotions, such as anger, hunger, pain, and the sounds indicative of pleasure. The transition from cry to voice depends upon the operation of larynx, mouth, and tongue. About this time tears are observed to accompany the crying. It is interesting to note that perspiration is not common before the end of the third month. Exceptionally, the appearance of these two secretions has been observed at a much earlier period. The salivary glands, also, seem to develop activity, drooling being a marked feature after the third month. It is claimed that the saliva at this time possesses the power of starch conversion to a limited degree.

Following the development of the senses of sight and hearing to the extent of differentiating as to the color and size of objects and the quality and direction of sound, we find co-operation of the muscles of the neck to a degree that the infant's head is held erect, balanced, and turned at will.

Although at birth well supplied with sensory apparatus and well developed tactile corpuscles, sensitiveness, with the exception of mouth and lips, is dull in the young infant, or rather, slow to respond to irritation; the association paths of nerve force not yet having become established by frequent repetition of impressions. After the third month sensation is generally well developed over the entire body; the forehead and external auditory meatus, it is said, being particularly sensitive.

From the sixth to the tenth month the infant should sit without support and soon develop automobility, as seen in creeping, rolling, or hitching toward desired objects. About this time he usually utters a few indefinite syllables, singly or repeated, as pa, ma, go, goo, etc.

By the twelfth month he is usually able to stand by a chair and, exceptionally, may walk at the end of the first year.

Infants exhibit a marked variation as to the time of the development of these different acquirements, dependent largely upon muscular vigor, education, and family tendency. A child left much alone will learn to develop earlier his resources.

During the first six months of life the respiration continues superficial and irregular, auscultation giving a soft, indistinct murmur, because, for want of inspiratory vigor, the air does not fully expand the alveoli. The rate has been variously stated from twenty-five to thirtyfive, or even higher, in the earlier months.

The pulse rate averages from 120 to 140 , is somewhat slower during sleep, and shows no dicrotic wave.

During the earlier months the temperature exhibits a tendency to fall below the adult normal. Pyrexia is frequently the result of trivial causes. 
The urine increases from about six ounces (180 C.c.) at the end of the first week to eight or sixteen ounces ( 240 or $\$ 80$ C.e.) at six months. Great variation in this is noticeable, dependent upon the secretions from the skin and bowels and the amount of fluids imbibed. The marked tendency to micturition is variable from causes not well understood, occurring sometimes every hour during the day and twice or thrice at night, while at other times several hours may elapse without urination. The urine is usually light in eolor, of low specific gravity, $1.00 \pm$ to 1.010 , rarely staining the diaper in health. The inorganie salts (phosphates, chlorides, and sulphates) inerease in (quantity as age advances and urea is more abundant.

Sugar sometimes appears in the urine of infants in the early months, the result, it is believed, of an excessive amount of saecharine material in the food.

The fecal discharges after the first few days are an orange yellow, frequently turning to green on exposure to air, are of the consisteney of batter, homogeneous throughout, inoffensive, but of somewhat sour odor and slightly acid reaction. The fæces eontain about eighty-five per cent. of water and average from three to five movements daily. These characteristics vary somewhat with the quality of food taken and the completeness of the digestive process.

The stomach of the infant at birth has been found to be little more than a receptacle for food in which the action of rennet, coagulating the milk, prepares it for the first step in the digestive process.

As the infant grows the eapacity of the stomach increases rapidly, its walls thicken, the gastrie glands develop at the expense of the mucous follicles and lymphoid tissue, so that fat absorption is relatively less free, while pepsin and hydrochloric acid secretions gradually beeome more abundant. These changes, it is evident, increase the importance of the stomach as a digestive organ.

During the latter half of the first year the stomach empties itself of a meal in from one to three hours; the time depending upon the quality of the food taken, cow's milk requiring the longer time.

The various complicated changes in the food during digestion have been described by physiologists under different names, both as to proeesses and products, resulting in much confusion of ideas. According to Kirke, the food is first changed into parapeptone or acid albumin; the next step results in propeptones or albuminoses; the third or final step is represented by the diffusible peptones, the finished product of gastric digestion. The last process, however, applies only to a limited portion of the stomach contents, for in the infant a part of the food soon escapes because of unguarded pylorus; early relaxation oecurring from the easily exhausted muscular structure. A portion of the water, milk-sugar, fats, and salts are absorbed from the surface of the stomach direetly into the blood.

The bile, by neutralizing the acidity of the chyme as it emerges from the pylorus, favors the process of pancreatic digestion, which is active 
only in alkaline media. As previously observed, the pancreatic secretion in the new-born shows proteolytic action (the power of digesting albuminoids), lipolytic action (the power of reducing fats), and the presence of a milk-curdling ferment; but the amylopsin (the stareh-digesting ferment) is slight. It is claimed that although a trace of this ferment has been found at birth, it is not present in sufficient quantity to exert much influence on starch until toward the niddle of the first year.

Radical differences of opinion obtain in regard to the relative amount of starch conversion by the enzymes of the saliva, pancreatic secretion, bile, and suceus enterieus; also as to the age at which they first become practically active. Recent observations assign greater importance to the amylolitic processes in young infants than was formerly accorded.

The importance of the different times of development of these active agents in the pancreatic secretion is evident in its relation to the different constituents of food acted upon, because it suggests the varying quality of aliment demanded by the child at the different stages of his growth.

A striking analogy is seen between the gastric and duodenal digestive processes; the pancreatic juices exercising in alkaline media functions quite similar to those of the gastric juices in acid media. It is a common error to assume that the stomach is responsible for a certain completed change in the aliment, converting it into a substance called chyme, wholly unlike that ingested, and that secondarily the duodenum further changes this chyme into a totally different substance, known as chyle, in which form only, absorption is possible. The facts seem to be that digestion in its entirety does not begin with the stomach and end with the ileum, but that this process, accompanied by absorption of some portion of the food, may occur in the mouth, in the stomach, in the duodenum, and throughout the alimentary tract. The saliva, which is known to act not only in the mouth, but in the stomach as well, proceeds with its conversion of starch until rendered inert by the excess of hydrochloric acid-a period of from fifteen minutes to two hours. The amylopsin from the pancreas acts similarly on the starches later on in the duodenum. The milkcurdling ferment of the stomach coagulates albumin in the acid medium, while that of the pancreas is acting similarly in an alkaline media. The pepsin of the stomach, after the action of the $\mathrm{HCl}$, converts acid-albumin into peptones. The trypsin of the pancreas, after the action of the bile, converts alkali-albumin into peptones, absorption taking place wherever and whenever the histological structures of the digestive tube and the character of the adjacent aliment favor that process.

A better understanding of the digestive processes of infancy has already resulted from facts recently established by van Slyke and Hart in their studies on the production of cheddar and cottage cheeses, in regard to the chemical behavior of caseins in the presence of acids, rennet, and pepsin. Dr. Thomas S. Southworth, in an article on this subject (Medical Record, Mareh 4, 1905), says :

"These discoveries make it clear that acids have a definite chemical 
action upon ealcium easein and ealcium paracasein, and have furnished proof that no gastric digestion by pepsin takes place until ealcium cassein or ealcium paracasein has been acted upon by acid and converted either into free casein or free paracasein (base-free proteids), or into their compounds with acid.

"Casein as it exists in milk is called ealcium casein. The rennet clot of milk is ealled ealcium paracasein. The products resulting from the action of small amounts of acid upon these two bodies, formerly called mono-acid salts, are now known as free casein and free paracasein. Those resulting from the action of larger amounts of acids, formerly called di-acid salts, are now known as lactate, hydrochloride, ete., of casein and paracasein.

"The first secretion of the stomach of the young is the ferment, rennin. The rennet ferment aets upon the calcium casein of the milk, forming a soft clot, which is called calcium paracasein (jumket). If no acid is present, this paracasein clot may pass on into the intestine, where it is readily digested by the pancreatie and intestinal secretions. The pepsin secreted by the stomach will not attack calcium paracasein in the absence of acid. But when hydrochloric acid begins to be seereted by the stomach this reacts with the calcium paracasein formed by the action of the rennet ferment, making first free paraeasein and then a definite chemical compound known as hydrochloride of paracasein, which is fitted for gastric digestion and is now readily attacked by pepsin, and true stomach digestion begins.

"The physical character of these curds, both in size and density, varies according to the species of the mammal, and the free paracasein and hydrochloride of paracasein eurds have a tendency to shrink and become more or less tough, depending upon the kind of milk. This tendeney to shrink into tough curds is especially marked in cow's milk.

"The digestion of the infant is in process of evolution and is not to be thought of as the same as the digestion of the adult. In the adult, gastric digestion is accomplished by the hydrochloric acid and pepsin of the gastric juice, which also disintegrates the food which leaves the mouth in particles of varying size. Digestion progresses most rapidly when free acid is present. In the young animal whose gastric function is in process of development, and who secretes at first no acid and later but gradually increasing amounts, coarse food causes disturbances for some time after birth, until both the stomach and its secretions are developed. It is one of the most remarkable things in nature that milk, which itself retains practically the same composition throughout lactation, is changed by the action upon it of the developing gastric secretions into forms and compounds which require at first moderate, and later more extended, gastric digestion, by which means the stomach is progressively called upon to perform more and more work, until it is sufficiently developed to begin its subsistence upon the types of food consumed by the adult of its species.

"If the stomach secretes a small amount of acid only, but little of 
the soft calcium paracasein clot is changed into the somewhat tougher free paracasein through the union of the acid with the calcium. The free paracasein is readily dissolved in dilute salt solution, which suggests an explanation of the good results claimed from the addition of salt to the infant's bottle. With such moderate secretion of acid by the stomach, a part only of the calcium paracasein is therefore prepared for gastric digestion by pepsin, while the remainder of the soft unaltered calcium paracasein, which cannot be attacked by pepsin, passes on into - the intestine, where it undergoes digestion by the intestinal ferment, trypsin, and other digestive secretions. A still more abundant secretion of gastric juice-i.e., of hydrochloric acid plus pepsin-will change more of the milk into a form suited for gastric digestion than a less abundant secretion. Thus the work performed by the stomach is normally regulated automatically.

"But this is not all, for when hydrochloric acid comes to be present in amounts greater than is necessary to form free paracasein with those parts of the ealcium paracasein clot which it can readily attack, depending upon the size and density of the curds, the excess of acid unites with some exposed portions of the free paracasein in such a way as to form a definite compound, hydrochloride of paracasein. Such a salt of paracasein is more difficult to digest in the absence of uncombined acid in the stomach than free paracasein, but when there is acid enough secreted by the stomach to also give uncombined free acid, the acid compounds of paracasein are more readily digested by pepsin. These changes in the curds increase the scope and task of gastric digestion by which the developing stomach is trained to cope with more and more difficult problems in its preparation for its future task of digesting the solid food of adult life. But since the calcium paracasein clot is attacked upon its surface by acid, and since the curds, especially of the milks of different species, may vary much in size and density, the chemical action of the acid may penetrate them to different degrees, and it is consequently entirely possible to have at the same time within the curd or in the gastric contents, in varying proportion, paracasein hydrochloride, free paracasein, and calcium paracasein, depending either upon the admixture or contact of the acid with the stomach contents or upon the strength and quantity of the gastric secretions."

That a very large percentage of the aliment is absorbed in the normal infant normally fed is shown by analysis of the fæces. Their physical characteristies have been already described. As a result of his observations upon infants fed wholly upon milk, Escherich states that the fæces consist of eighty-four to eighty-six per cent. water; that digestion and absorption of proteids in the alimentary canal are so efficient that but little is lost; that the whitish flakes and clots, nearly always seen, are composed largely of fat, and fatty and lactic acids in combination with lime; while cholesterin, traces of bilirubin, intestinal epithelium, and mucus may also be detected. In addition, large quantities of bacteria are always present; a fine, slender bacillus, named by this author 
the bacterium lactis ærogenes, and the polymorphie bacterium coli commune being the two chief kinds. Milk acids are always found, and to their presenee should be attributed the aeid reaction. Fermentation of milk-sugar leads to the development of earbon-dioxide and hydrogen, whieh are the prineipal gases in the intestinal tract of a healthy infant fed purely on milk, foul-smelling gases being conspicuous by their absence. Though the amount of faces varies much in sucklings, yet three per cent. of the milk ingested is the average proportion.

It is by the study of the digestive proeesses at different periods that the problem of physiological feeding must be solved. To him who would not only secure the highest results in infant nutrition, but also determine some of the questions as to the etiology of digestive disturbanees with their intricate pathologieal sequelie, the study of the physio-chemies of digestion will be fraught with interest. It is true that much remains to be learned eoneerning digestion, assimilation, and nutrition, but eonfessed ignoranee in regard to eertain ultimate processes affords no excuse for gross disregard of the knowledge already obtained. The ehild must be fed with due referenee to the physiological demands of the period or stage of development of the growing organism.

Considerable space has been given to the study of infantile anatomy and to the eonsideration of physiology, suffieient, it is hoped, to at least lay the foundation for the study of the phenomena to be observed in early infaney. That the purpose of this method of study may be more apparent, the subjeet of hygiene of the infant at this period will now be taken up. In fact, the ultimate purpose of this study should find its consummation in the establishment of some general prineiples or rules of management, by the application of which may be seeured to the infant the best conditions required by the peculiarities of his organization.

Man, as a finished entity, furnishes a study of great complexity as to his physiologic and hygienic requirements. How mueh more intrieate, then, must be the problem as to the requirements of the independent and correlated processes, during the ever-changing phases of the transitional periods of infaney.

Among all the obstacles to be overcome, two things particularly stand in the way of the application of the principles of hygiene of infaney: First, there is a want of information on the part of the physician, or a disinclination to apply his knowledge; seeond, the unwillingness of the mother to be guided in this respeet. (Two erroneous conclusions have taken firm hold of the lay mind, and to some extent of the professional mind also. One is, that the maternal instinet endows the mother with a knowledge that is suffieient for all the requirements of the infant; the other is, that the representative of seience, however highly endowed, knows but little of the requirements of the babe because of the inability to furnish verbal information.) 


\section{CHAPTER V}

\section{HYGIENE OF THE FIRST YEAR}

\section{PROTECTION AND FOOD}

\section{PROTECTION}

The absolute wants of the infant are few and simple and may be expressed in the two words, protection and food. The relative wants which are the outgrowth of efforts to supply these are numerous and complicated.

The infant must be protected from shock, to which he is peculiarly susceptible. Normal function, as, for example, digestion, may be arrested or perverted through shock alone. It may occur from sudden changes of temperature, from noise, from blows or jars, from unaccustomed motion, from fear or anger, from intense light, and from excessive or prolonged pain.

He should be protected from fatigue of the muscles, due either to excessive use or prolonged restraint, from protracted crying, and from efforts to overcome obstructed respiration.

Protection should be secured from infectious or irritating substances which may be introduced into the cavities of the body; from such irritations of the surface or mucous membranes as are caused by accumulations from bladder, bowels, and sebaceous follicles, or from extraneous matter-as strong soaps, corrosive substances, and rough clothing; also from rough handling in bathing, and finally from traumatisms with or without infection, - as falls and blows, especially on the head, bites of insects, scratches or abrasions from pins or neglected nails.

He also needs protection from air contaminated by exhalations from other people or by gases from defective heating apparatus, sewers, cesspools, garbage, or accumulations of filth, from decomposing vegetable matter from swamps or from filthy streets and alleys; from flies, not only because annoying, but as carriers of infection ; from household pets, - cats, dogs, rabbits, and poultry ; from contact with colored picturebooks and garments; from promiscuously laundered clothing and bedding, and from general refrigeration, or from lowered temperature of a single part, as cold hands or feet.

The above enumeration suggests a few of the many agencies through which normal metabolism and growth may be disturbed. That all these items should be carried in the mind of the nurse, and the infant properly protected in unspecialized environment, is practically impossible. The multiplicity of needs, viewed from the above stand-point, not to mention the item of regularity in feeding, bathing, sleeping, etc., makes an imperative demand for a systematic régime. This can only be secured by 
means of a separate nursery in which the means to the end are under full control.

\section{NURSERY.}

The room selected for this purpose should be remote from those in daily use by the family. It should receive direct sunlight during some portion of the day; should be of sufficient size to secure ventilation without noticeable draughts; must be finished and furnished with special reference, in the minutest detail, to asepsis,-- hence carpetless, except for rugs that may be aired daily; curtainless, so far as heary and unchangeable materials are concerned; devoid of mouldings, pictures, and fixtures which invite lodgement of dust. The walls should be painted to permit of thorough cleansing with water or antiseptic applications. There should be double windows to protect against draughts and to diminish direct radiation, with a system of heating and ventilation which is under absolute control. Window-sereens and mosquitonetting are indispensable for summer. A thermometer is a necessary fixture. It is desirable to maintain an even temperature of from $75^{\circ}$ to $80^{\circ} \mathrm{F}$. $\left(24^{\circ}-26.6^{\circ}\right.$ C.) during the first weeks, after which time, until the

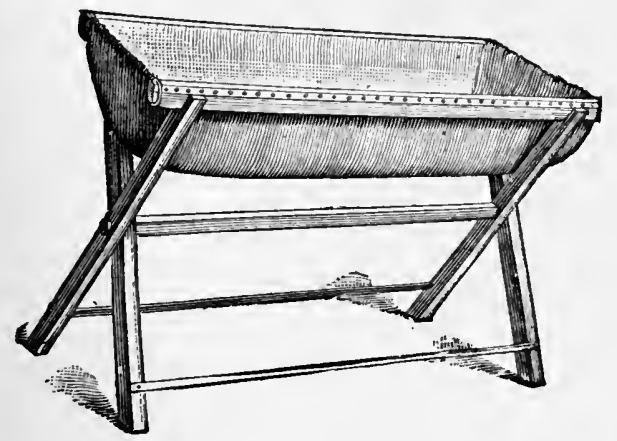

Fig. 48-Rubber bath-tub.

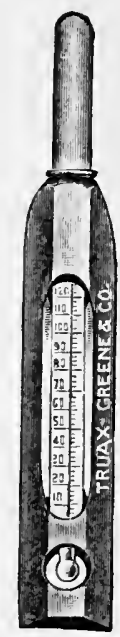

FIG. 49.-Bath thermometer.

ehild is three months old, about $75^{\circ} \mathrm{F}$. $\left(24^{\circ} \mathrm{C}\right.$.) is recommended. After that it may be gradually lowered to $70^{\circ} \mathrm{F}$. $\left(21^{\circ}\right.$ C.). In emergencies, such as the failure of the heating apparatus, or in extremely cold weather, hot-water bottles or flasks should be used in the crib.

Closets, cupboards, or wardrobes should have no connection with the nursery, nor should the family bath-room. In fact, the room should contain nothing save the furniture and articles indispensable for the care of the infant. The erib should be of metal, of simple construction, and fitted with noiseless rollers. The mattress should be filled with selected hair, and if a pillow be used it should be a very thin one of the same material. The bed should be protected by a rubber sheet and pad, and the covering should be of light wool.

The different articles necessary in a nursery are a noiseless clock; a shaded light; a bath-tub, flexible rubber (Fig. 48) preferred; a bath- 
thermometer (Fig. 49); scales (Fig. 50) and measuring-rod; a double ewer; soap-dish; soft towels and wash-cloths of gauze, as sponges are liable to be neglected; powder-box, puff-ball omitted; soft hair-brush

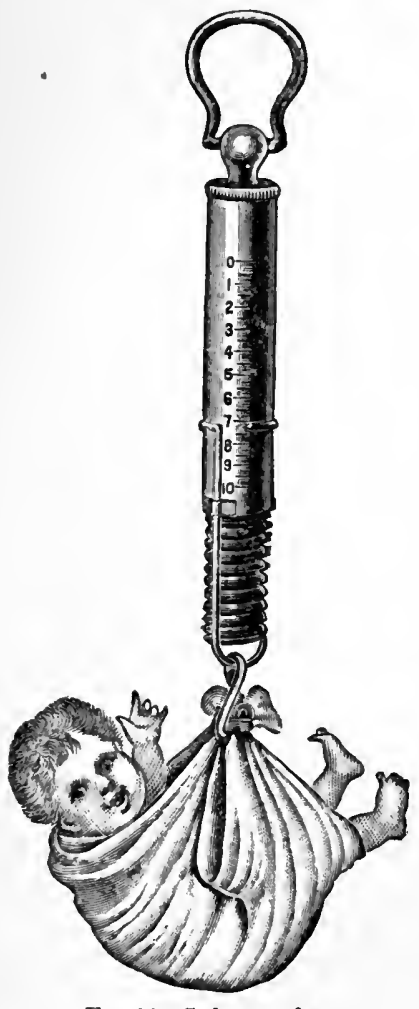

FIG. 50.-Infant scales. and diapers. A light, high, folding screen is a necessary adjunct. Door hinges should be oiled and floors deadened.

The nurse's bed should occupy an adjoining room with direct communication.

SLEEP.

A very young infant should sleep twenty hours out of the twenty-four; in fact, all the time when not being nursed, bathed, or changed. No definite statement ean be made as to the exact number of hours that a babe should sleep at a given age. No error will be made if the child be encouraged to sleep all that he will during the first year, being guarded against all noises and disturbances. Sleep is largely a matter of education. It is constantly being demonstrated that infants can be taught to sleep, waking at regular intervals for nourishment. Rocking or carrying are advised against as unnecessary and possibly harmful. Putting foreign bodies in the mouth, as the thumb or an artificial nipple for the purpose of inducing sleep or quiet, is unlygienic and irrational.

The normal position of the young infant during sleep is characteristic and suggestive of intrauterine life, the limbs flexed, the hands under the chin, the body turned to one side or the other, and the spine assuming a continuous convex curve. Any continued departure from this attitude should call for medical examination.

The sleep during the first few days is profound, but during the remainder of the year it is easily disturbed. Care should be observed that the position of the child is changed during the longest sleep of the night.

A healthy child upon awaking or after a bath usually indulges in a vigorous stretehing of his body and limbs.

\section{CLOTHING.}

The object of clothing for the infant is to secure uniformity of temperature. In the ideal nursery no reason is apparent why one portion of the body requires heavier clothing than another, hence material of uniform thickness is suggested for the protection of the trunk and limbs. Physiology, as well as elinical experience, furnishes good reasons for leaving the head uncovered in ordinary temperatures. 
An almost universal error in clothing infants is the neglect to allow unrestrained freedom of movement of all the muscular structures, whether toes, fingers, feet, hands, legs, arms, abdomen, dorsum, or thorax.

As to the form and texture of the clothing, that described on pages 65 and 66 is suggested, and the advantages emphasized of inclucling the hands in the covering as a prevention to the habit of putting the finger's in the mouth. This is a most unhygienic practice: first, because it favors the introduction of infections; second, because the subsequent chilling of the parts from rapid evaporation of moisture induces local congestions, causing symptoms of indigestion, colic, etc.; third, it leads to thumb-sucking.

The period during which the hands should be included in the outer garment need not exceed the first six or eight weeks of life. It will be remembered that buttons were not provided, as much discomfort and sometimes positive injury results from their pressure upon the delicate tissue. This is especially true, when, as is frequently seen, garments are buttoned down the back.

The need of protection against lowered temperature cannot be too greatly emphasized. First, the infant is peculiarly susceptible to the temperature of the surrounding air, on account of his extensive superficial area, as compared with weight. This, in connection with the great vascularity and thinness of the integument, gives a relatively enormous proportion of the blood in close relation to the surrounding atmosphere. Remembering, further, the fact that the total quantity of blood is comparatively small, it is easy to see that the circulating fluids may be quickly chilled in a medium of lower temperature. Second, normal metabolism requires a certain uniform temperature, and interference is especially disastrous during this period of rapid growth. Cold diverts the process of constructive metamorphosis into that of heat production, so that undue lowering of temperature interferes with growth. It also results in local disturbances and pathological conditions, as congestions, catarrh of mucous tracts, etc.

The adult is admirably adapted to the varying requirements of his surroundings. In no respect is this better shown than in his adaptability to the extremes of temperature, rendered possible through the automatic operation of the nervous and circulatory mechanisms.

In the infant, however, we observe a want of that harmonious cooperation. "An unstable equilibrium" expresses the condition of the partially developed nervous system as well as of the secretory and excretory apparatuses. Many disturbances from which the adult organism will recover easily its equilibrium may result in serious or permanent injury to the infant. The exaggerated reflexes, the imperfected vasomotor apparatus, the undeveloped muscular structures, and the transitional conditions of the glandular organs, may furnish some explanation for the indelible impressions resulting from marked vascular disturbance or interrupted function, so often seen in the young. 
That the morbid tendencies and processes which determine the pathology of later life are thus established, there is little reason to doubt. Figuratively, the seeds of disease are sown in infancy, followed by the well-known crops of morbid conditions familiar to the diagnostician of later years. . Too frequently heredity suffers unjust blame for conditions which originated in the neglect of hygiene in early infancy.

\section{B.ATHS.}

After the first week, the strong, healthy baby should be bathed daily, and it is not necessary to repeat reasons why this should be done in a warm room, by the heater in cold weather, with all currents of air shut off by the screen. The temperature of the first baths should be about blood heat $-98.6^{\circ} \mathrm{F}$. $\left(37^{\circ} \mathrm{C}.\right)$. Gradual reduction should be practised so that at the end of the month the temperature should be $95^{\circ} \mathrm{F} .\left(35^{\circ} \mathrm{C}\right.$.) ; at six months $90^{\circ} \mathrm{F}$. $\left(32^{\circ} \mathrm{C}\right.$.), and by the end of the year $90^{\circ}$ to $85^{\circ} \mathrm{F}$. $\left(32^{\circ}-29^{\circ}\right.$ C. $)$. It is well to finish bathing and drying the head before undressing the baby. The convenience of the double ewer is seen in having a supply of water free from soap for rinsing. Little soap is required, and if the skin be delicate, that known as " superfatty" is advised. Unless some irritation be present, no powder should be used. The addition of bran to the bath for children with a tendency to eczema, and of salt, for its stimulating properties, to the infants needing it, is recommended.

The daily bath should be given midway between feedings; and there should be the same regularity in this as in all other details. It should not last longer than five minutes, and the towelling, though thorough, must be lightly and quickly done.

Special care of the eyes, nostrils, and mouth must never be omitted. As soon as the temporary teeth have erupted, they should receive as faithful attention as the permanent, since they are subject to caries; moreover, the effects in gastro-enteric disturbances are greater in the infant.

In hot weather a rapid sponging with warm water at night may. secure restful sleep.

The duration of the bath, as well as the frequency, should depend entirely upon the reaction as seen by its effects on the capillary circulation. A cyanotic hue, chilliness of the surface, or signs of exhaustion; are always contraindications for frequent or prolonged bathing.

$x x$ Preparation in every detail before taking the child from the crib, with dexterity in execution, will lessen many of the evils of the bath.

The general bath may occasionally have to be omitted, but nothing short of a moribund condition should prevent local bathing and attention to the orifices; nor should the systematic changing of the clothing, properly aired and warmed, be omitted for any less reason.

It is well to bear in mind the difference between tub and local bathing, as the effeets upon the infant organism differ widely.

It is hardly necessary to state that, after bathing, the bath water, 
towels and wet cloths should be removed immediately from the room. Nor should the nursery ever be used as a drying-room for any fabrics. The filthy custom of hanging soiled diapers to dry should be condemned. In fact, they should be immediately washed. Diapers soiled with fecal discharges, kept for the inspection of the physician, should be removed at once from the nursery, as should all others.

\section{EXERCISE.}

Exercise is absolutely essential to the normal growth and development of all the muscular structures. Lusty erying, if not prolonged to the point of exhaustion, has a beneficial effect, in the deeper respiration thereby induced, with consequent improvement in oxygenation and circulation. Stretching, kicking, squirming, and waving of arms secure, in a measure, the needed exercise. Once or twice in the twenty-four hours the elothing may be removed and the infant allowed the utmost freedom of movement. Occasional gentle massage is advised, the infant's expression of pleasure being one of the immediate evidences of its beneficial effects. After the creeping age the infant usually secures enough museular exercise, and must be guarded against fatigue. The creeping pen, raised a few inches above the floor, is recommended for cleanliness and protection against the floor draughts and contact with the articles of furniture.

No matter how well ventilated the nursery may be, it is essential that the baby have frequent ehange of air. Direct sunlight is a great desideratum. Differences of opinion exist as to the age at which infants should be taken into the open air. The difference is probably due to local peculiarities of climate, and no rule of procedure may be laid down without taking into consideration the climatic conditions of temperature, humidity, and wind. It is advisable before taking the baby out of doors that he be gradually accustomed to the outside air by opening the windows of the nursery for a short period each day, keeping in mind the need of additional clothing in cold weather.

With the ideal nursery the needs for early outing are not so imperative as where the home surroundings are not conducive to the best hygiene. On general principles the child should have the benefit of open air and sunshine daily after the first month. The more weakly the ehild the greater the need. One caution should never be disregarded: in its outing, the infant must be protected from disturbance in securing his requisite amount of sleep. Properly protected from sun and wind, he should spend the greater part of the day in the open air. Rocking, walking with, and much coddling of infants should be discouraged. This subject should not be dismissed without reference to a practice that is as pernicious as it is common,-viz., the custom of regarding the baby as a plaything, an animated toy for the entertainment of the family, as well as of a large circle of admiring friends. Children are fond of babies and never tire of stimulating their funny performances. The same is unfortunately true of parents and friends. From a purely 
economic point of view such amusement is exceedingly expensive, and the mortality is constantly increased for the amusement of the elders. Nervous and mental wrecks too frequently owe the origin of their disorders to want of repose in early infancy, due to injudicious stimulation. In this connection let it be understood that all evidences of mental precocity, called " smartness," should be regarded as danger signals, and eall for repression rather than encouragement. An infant during the first year should neither be amusing nor amused. 


\section{HYGIENE OF THE FIRST YEAR-Continued}

\section{FOOD}

\section{NATURAL FEEDING}

For the second essential requirement of the infant-namely, nourishment-ample provision has been made by nature in an apparatus admirably adapted to his requirements.

Whatever may have been its origin, whether evolved through cycles of physiological development, from the lacerations produced by the mandibles of the young marsupials as they clung to the pectoral integument of the mother for protection, or whether created in its full perfection of function, the mammary gland in its adjustment to the needs of the nursing infant furnishes the highest example of organized mechanism.

The interest which centres about the method of milk production is ever increasing. The study as to its composition and the classification of the glands involved-whether secretory, excretory, or both-is engaging the attention of the best physiologists. So, too, the influences and conditions which may affect its production either by changing its quantity or its quality promise a fruitful field for the hygienist. It is not without good reason that attention is directed to the subject of lactation, for in the disturbance or perversion of this function is found, perhaps, the most prolific eause of the disorders of infancy. The increase of interest in this line of study is largely due to a rapidly growing tendency to ignore the normal method of nourishing the young. As a result of this tendency is seen increased pathologic conditions and a higher rate of mortality in infancy, with subnormal development and diminished vigor of those who survive the suckling period.

During gestation the evidences of provision for the establishment of this function are seen in increased physiological activity of the mammary glands. The increase in size and firmness of the breasts, the changes in color and texture of the integument, areolas, and nipples, and the enlargement of superficial veins, are all phenomena which so commonly accompany the pregnant state as to be accepted signs of that condition.

Even during gestation a milky substance is not infrequently seen to exude from the orifices of the nipples. At full term the mammary glands are evidently prepared for their function,-viz., furnishing aliment for the child. It is exceptional, however, that lactation is fully established at the time of parturition, and usually forty-eight hours elapse before milk is secreted in an appreciable quantity.

It is evident from the anatomy of the infant that he is especially adapted for the act of nursing. The pliable, prehensile lips and tongue, the absence of teeth, the well-developed musculature of the cheeks and 
jaws, the fatty pads increasing the buccal resistance to atmospheric pressure, all go to form an incomparable mechanism for grasping the nipple and promoting the outflow of milk by establishing a vacuum. This the infant does instinctively.

Of interest also in the peculiar adaptation of the mother, in the relative arrangement of the breasts to the upper extremities with the shortened clavicles, in the conformation of the breasts with their soft and yielding walls which collapse readily as the milk is drawn, in the position, size, and shape of the nipple with the many minute orifices and richness in erectile tissue; also in the manner in which the breasts are filled-the process going on most rapidly during nursing-and, finally, in the sympathetic arrangement which facilitates extrusion of milk under stimulation of the infant's lips and hands.

( That no fully developed milk is found in the breasts at the time of birth has been generally accepted as conclusive evidence that the newborn is in no immediate need of food.) In fact, as stated in a previous chapter, its deportment, if undisturbed, suggests the need of rest during the first forty-eight hours of extrauterine existence. This belief is so universal that attempts at feeding before nature has furnished the supply of milk have not met with general approval. To be sure, it is recommended that the child be put to the breast early, in the belief that the scanty secretion of colostrum plays some rôle in stimulation of peristalsis of the alimentary tract, and the expulsion of meconium. Probably, by so doing, the infant secures a modicum of the water so much needed at this time. The infant's habitual loss in body weight during the first days, as shown by tables in a previous chapter on growth, has been regarded by some as unnecessary. In fact, it is claimed to be unfortunate as interfering with the rate of subsequent growth. On this account it has been recommended that some nourishment be substituted during these first two days. It remains for more extended clinical observation to determine the value of this procedure, but with necessary hygienic precaution it seems permissible to administer some attenuated solution, as of milk-sugar, the water of which, at least, should meet a physiological demand.

The subject of suckling, proclaimed by many to be purely instinctive in both its maternal and infantile relations, is well worthy of careful study and the application of the best known principles of hygiene. Given normal mothers with normal infants, the disturbances of digestion, nutrition, and growth, though rare, are yet sufficiently frequent to raise the question of their etiology. Further than this, the great mortality of infants at the breast, from disorders occasioned by improper methods of suckling, makes it evident that instinct is not a sufficient guide. Reasoning from analogies furnished from lower mammalia is not profitable in reference to this point, since it would appear that in the higher intellectual development, woman's instinct becomes perverted or deranged to a certain extent.

Be that as it may, it is readily susceptible of demonstration that in-. 
telligent control or supervision of the act of suckling, averts or corrects many evil effects of its abuse when left entirely to instinct. A few rules may be formulated, the observance of which is manifestly important in the hygiene of nursing.

RULE 1.-Asepsis must be observed, since one of the commonest causes of infantile disorders is infections introduced into the alimentary tract.) To this end the nipple must be cleansed before and after nursing, as it is well known that milk remaining exposed to the air shortly swarms with micro-organisms, many of which are pathogenic when introduced into the digestive tract. Even the milk in the orifices of the ducts often becomes infected; hence the expression of a few drops is recommended before the application of the child.

RuLE2.- (The infant should be put to the breast every two hours during the day and once at night for the first six weeks. From six weeks to three months the intervals between nursings should be increased to two and one-half hours. During the latter part of this period the night nursing may be discontinued. Between three and six months the interval should be increased to three hours, representing seven nursings from five in the morning to eleven at night inclusive. Six nursings a day should be sufficient for a child at six months. By the end of the year he may be accustomed to five. If sleeping, he should be awakened at the proper time for nursing until the habit becomes established.)

This rule, though not so arbitrary in its requirements as Rule 1, should be somewhat rigidly applied, for, with few exceptions, nothing is more evident than that disturbed digestion, with all its train of evil consequences, is the common result of too frequent or irregular feeding. Without mentioning the effect upon lactation of irregularity in nursing, it must be borne in mind that the operation of the digestive function is a periodical one, and, within certain physiological limits, a matter of education and habit, so that regularity as to ingestion of food meets with corresponding regularity of the secreting organs. Passing the feeding hour induces overingestion from an overdistended mammary gland. This undue amount taken at an unusual time finds the digestive fluids unprepared; hence their incapacity for proper disposition of the unusual burden.

(The frequency of nursing, as laid down in the rule, is the result of many comparative observations upon healthy infants and of the known physiology of the digestive processes.) A certain definite time, as has been stated in a previous chapter, is necessary to the physiological disposition of an ingested meal. After this an interval of rest is requisite for the re-establishment of the function in its highest perfection. Nothing is more abhorrent to nature than " meals at all hours." The practice of the mother sleeping with the babe on her arm and quieting his restlessness throughout the night by offering the breast is, unfortunately, too prevalent, the result being that, instead of receiving one definite nursing, the helpless infant is made the victim of a perverted instinct, and sooner or later is permanently injured. 
It is seen that the digestive proeess is one of varied stages, each dealing with a ehanged condition in the mass of aliment. It is apparent from this last that the digestive seeretions, acting in sequence, are not at all times suitable for freshly ingested aliment. This is no mere theory, as every observer well knows the pernieious results of too frequent feeding, and probably no vicious practice presents such vexatious problems.

RULE 3.- The time occupied in nursing and the quantity ingested should be controlled by the mother.) At first thought this rule may seem impractieable, but a little reflection will show that it is not, and evidence is abundant as to the neeessity for its observance. Certain it is that the

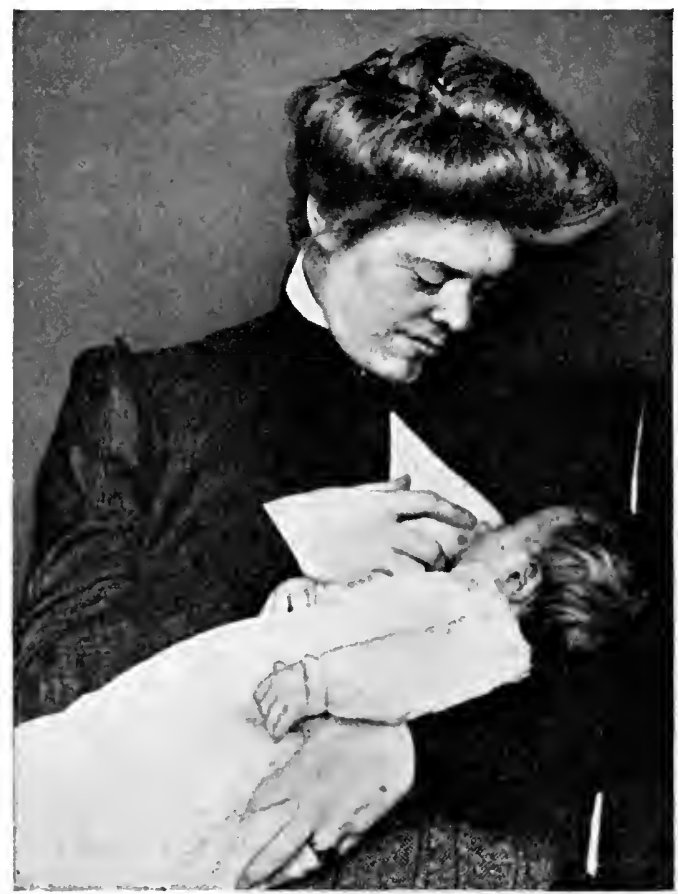

FIG. 51.-Correct position for nursing.

differences in the formation of the nipple and in the function of the gland in different mothers, affeet nursing more or less. There is a difference, too, in the nursing energy of different infants, so that one will oceupy half an hour in seeuring a meal, while another may gorge himself in ten minutes. The act of nursing in its perfeetion is the result of the mutual co-operation of mother and child and is a performance worthy of their undivider attention; in fact, it should demand it. A child eannot properly nurse the passive breast of a sleeping, or even an inattentive, mother. In eases where the nipple formation is imperfect, rendering the abstraction of milk laborious to the infant or painful to the mother, or where milk secretion is tardy or insuffieient, the mother 
should aid and encourage the babe by placing herself in full harmony with the pleasurable duty of the moment, and endeavor to secure a full response to the stimulating appeal of the tiny solicitor for a better supply. No verbal description can compass the art in which fingers, arms, bosom, eyes, voice, and the whole sentient being of the mother cooperate with the infant in the collection of his dues (Fig. 51).

On the other hand, where the milk gushes through patulous nipples, or in the case of infants who nurse with such avidity that the process, from beginning to completion, resembles a struggle against suffocation, the mother should control the outflow. This may be done by dextrous manipulation of the nipple between the fingers, by withdrawing from the infant's mouth, by diverting his attention, and in various ways prolonging the process. (It is safe to say that twenty minutes should be given to each nursing.) Prolonged too much, the infant as well as the mother suffers fatigue. Interference with digestion oceurs also under the principles above enumerated. Too rapid feeding throws into the stomach a large quantity of food, with the result of overdistention and the early escape from the pylorus of milk insufficiently converted. This is further augmented by the hydrostatic pressure of a superimposed column filling the csophagus. (Hasty feeding usually means overfeeding.) Not infrequently the stomach resents this abuse by immediate regurgitation of a portion of its contents, which has led to an erroneous belief quite prevalent, that the stomach is endowed with some sentient quality which enables it to reject superfluous aliment. That this is a pernicions error, the frequent occurrence of gastric dilatation and intestinal indigestion is ample evidence. It may be suggested to mothers who experience difficulty in restricting the overingestion of milk, that the nursing be preceded by the administration of a little sterilized water, possibly sugarof-milk solution, to partly satisfy the voracity which may be due largely to habit or thirst. (Instinet is no sure guide as to the amount a child $X$ should nurse.)

RULE 4. (Give water systematically and freely.) The baby's food, as will be shown later, is made up of several widely different constituents. Although all of them are essential for perfect nutrition, one or more may be temporarily deficient without immediate perceptible interference with vital processes. (In fact, one only must be present under all eircumstances, and this is water. Without water no digestion, absorption, or elimination is possible. Water enters largely into the composition of the infant's food, milk containing about eighty-eight per cent.) It has been shown that water is essential to peptone absorption, and many abnormal and even pathological conditions result from an insufficient supply. The restlessness of an infant is frequently only an expression of his thirst, and many of the symptoms of hunger are merely evidences of a demand for water. How often the pathetic spectacle is witnessed of forcing unrequired, consequently injurious, food upon an unwilling stomach in response to the infant's appeal for water. There is no difference of opinion in regard to the occasional need of water between 
nursings, althongh among the laity it is seldom recognized. This is as true in early as in later infancy,-in fact, the tendency at birth to excessive uric acid formation becomes pathologic unless water be freely supplied to dissolve the solid erystals, clear ont the renal tubulles, and render the urine less irritating. Evidences of pain, usually aseribed to intestinal colic, are too frequently indicative of urie acid irritation, and point to a need for more water. Fortunately, the doping of the baby with earminative teas, for the supposed intestinal spasm, occasionally fulfils the indication through the water of the deeoction.

\section{BREAST MILK.}

Coneerning the eomposition of human milk much has been written and quoted that camnot be accepted in the light of present knowledge. Either beeause of improved teehnique or from a greater number of observations, reeent analyses do not eorroborate the findings of many early chemists.

( Milk is an emulsion of innumerable minute globules of fat floating in plasma.) Its white color is produced, as in other emulsions, by reflection from the surface of the numerous eells.

(As it is a perfect emulsion, the fat globules remain distinct.) The older opinion, that a thin membrane of albuminous material surrounded each cell, is no longer generally held. From experiments, Quineke has proved that each fat globule, by moleeular attraction, is surrounded by a more elosely adherent layer of milk plasma, and not by a membrane. Among the globules are smaller particles of proteid matter. The examination of milk from a large number of women gives the speeifie gravity as 1.028 to 1.034 .

(All the five prineipal classes of foods are found in milk,-viz., water, fats, proteids (caseinogen, laetalbumin, lactoglobulin), carbohydrates, and salts, besides extractives and gases; also lecithin, cholesterin, eitric acid, and other substanees in varying proportions.)

( That these classes of foods are essential to normal nutrition and growth is susceptible of demonstration, both by well-known principles of physiology, and by daily elinieal observation. It is probable that perfeet metabolism is dependent upon the presence of all these food principles, although life may be maintained for a longer or shorter time if one or more be omitted from the diet (always excepting water). Thus an infant may exist for a time on water and carbohydrates, as solution of sugar of milk, or on water and proteids, or on water and salts; the result, however, invariably showing in impaired nutrition. This is so well recognized elinically that the absence of one or more of these essential constituents is not infrequently determined by the condition of the infant.)

A symmetrieal development requires not only the presence of all the constituents, but that they should maintain a certain definite quantitative ratio.

(The proteids furnish the only source from which the tissues obtain 
nitrogen, without which no protoplasm can exist, nor cell life be possible.) (A deficiency invariably results in retardation of development. Insufficient nitrogen means diminished metabolism, interrupted gain in body weight, lessened muscular force, anæmia with the weakened heart's action and dyspnœa, arrested seeretions, and all the familiar evidences of lowered nutrition.)

It was formerly taught that the purpose of fats was to(produce heat,) a very important function, as a certain degree of heat is necessary for tissue metamorphosis. It can be demonstrated that fat plays a double rôle and that, in addition to the maintenance of body heat, (it aids the proteids in cell development,) especially in the formation of bone and nerve tissue. Besides its synergistic agency in increasing the activity of the proteids, it serves another purpose by promoting absorption of the salts from the intestines. (It also maintains the healthy function of the lower bowel by promoting the passage of the frees, of which it normally forms about ten per cent.) (A defieieney of fat produces results such as always follow diminished metabolism, and frequently a group of signs of impaired nutrition so uniform as to have been elassified under the term rhachitis.)

The carbohydrates, in the form of milk-sugar, have occasioned no little discussion as to their value as compared with the preceding class. Some authorities place them third in importance; von Noorden and Kayser, however, have found that carbohydrates are of greater value as proteid sparers than are fats, as the latter eannot be substituted for their caloric equivalent of carbohydrates without loss of proteids oceurring. It has long been known that sugar increases the formation and deposition of fat, babies frequently showing a remarkable plumpness, even though fat and proteids be lacking in the food.'

The fourth group-the salts - consisting chiefly of calcium phosphate; potassium carbonate, sulphate, and chloride; sodium chloride, and a trace of iron, forms a small but fairly uniform and very important percentage of the total constituents. As a result of his analyses, Bunge claims that, with two exceptions, the percentage of salts in milk corresponds quite closely with the salts in the tissues of the nursling.

(A very essential and comparatively abundant salt is calcium phosphate, which is required for bone formation. Lime is taken in and assimilated by the organism in the form of organic compounds with the proteids.)

(The potassium salts, also abundant, are needed in the formation of muscular tissue and in the red blood-cell. A significant fact is the greater amount of potassium and lesser amount of sodium salts in milk than in the tissue of the infant.) During postnatal growth there is a relative increase in the muscles which are rich in potassium, and a diminution in the cartilages which are rich in sodium.

(Sodium chloride, as is well known, performs an important office in digestion, for, during the passage through the body, it facilitates the absorption of proteid food and increases tissue metabolism.) 
Wittmaack and Siegfried, from their analyses, found that nucleon or phospho-carnic acid accounts for 41.5 per cent. of the phosphorus in human milk. Practically all the phosphorus is in organic combination (nucleon and caseinogen).

The iron, so essential to the formation of blood, and, to a less degree, of the other liquids of the body, is present in mother's milk in extremely small quantity. The percentage is only one-sixth of that found in fetal tissues. (Infants enter the world with a store of iron in the liver, and to some extent in the spleen, which lasts them until they are able to take food other than milk.)

(As stated, the salts vary but little in percentage, but should a deficiency be present, the osseous, nervous, digestive, muscular, or circulatory system, would suffer the sooner, according to the individual constituents most at fault.)

Were the other ingredients present in normal mother's milk in proper proportions, the absence of water would render them valueless for food. It is only in a state of solution that most of these substances can undergo digestion in the intestines of the infant, or absorption through the villi. The normal secretions are relatively scant in proportion to the enormous work accomplished during the growing period. (Hence the necessity for water at all stages.)

The first group-the proteids, of which there are four or more-is chiefly represented by three albuminous substances, differing in their physical properties. An important member of this group is casein, which was formerly thought to be derived from caseinogen by a double process, first, through the action of the rennin enzyme, being changed to soluble easein; and, second, by the action of ealcium salt, precipitated in curd as a caseate of lime. Van Slyke and Hart have shown that this proteid exists in the milk as calcium casein, which is changed by rennet into ealcium paracasein. The action of small amounts of acid upon these two bodies produces free casein and free paracasein. With larger amounts of acid definite salts are formed, as lactate or hydrochloride of casein and paracasein respectively.

The other proteids, lactalbumin, lactoglobulin, etc., are not precipitated by rennin or acids, but coagulate with heat at from $158^{\circ} \mathrm{F}$. $\left(70^{\circ}\right.$ C. $)$ to $167^{\circ} \mathrm{F}$. $\left(75^{\circ} \mathrm{C}\right.$. $)$, and are known as the soluble or whey proteids. Lactalbumin differs from casein also in that it contains sulphur but not phosphorus. It is not identical with serum albumin, though it resembles it in many respects. Lactoglobulin is ordinarily present in very small amounts.

( The carbohydrates are found in the form of lactose, a sugar peculiar to milk, differing from other sugars in its inferior solubility in water, and lack of sweetness to taste.) It also resists the tendency to alcoholic fermentation, but readily yiclds lactic acid when attacked by the bacterium lactis ærogones of Escherich. Hüppe's bacillus, also the bacillus coli communis and many others, have this property of causing lactic acid fermentation and precipitation of casein in the form of casein or para- 
casein lactate. These lactates are susceptible to the action of pepsin and are refractory to putrefactive forms of bacteria.

Another carbohydrate has been described as existing in milk, named variously by different observers as "animal gum," "dextrin," "animal amyloid." Milk also contains its own specific enzymes which, as shown by Babcock and Russell, are capable of digesting the proteids, although at a very slow rate as demonstrated outside of the body.

The following table, from the analyses of Harrington and Kennicutt, is quoted by Rotch.

MINERAL CONSTITUENTS IN HUMAN MILK.

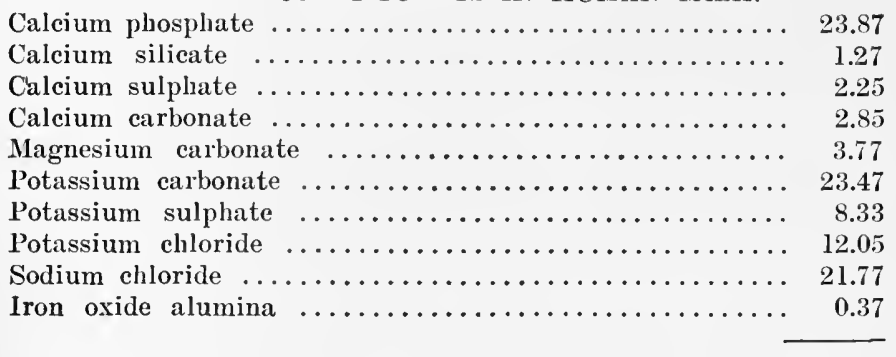

100.00

As before stated, normal milk contains these five constituents, which maintain a fairly constant percentage relationship. Frequent variations are, however, observed in normal milk as in different mothers, or in the same mother at different times, or in the same mother in different breasts, or, as is well known, in the same breast at the same milking, drawn at different times, as fore, middle, and last milk.

Of these constituents the percentage of fat is subject to the widest variation; next the proteids,- - the carbohydrates and salts rarely showing much change. These variations need not be considered as indications of abnormality, the only eriterion being their effect upon the child. An infant at the breast, digesting well and gaining in weight and strength, is ingesting normal milk, regardless of what the analysis may show.

The personal equation-the capacity of any particular infant to digest the varying constituents-must always be recognized as an unknown quantity. It is a fact of common clinical observation that the breast, at which one infant thrives, may not meet the requirements of another child of the same age.

As seen from the foregoing, it is evident that repeated analyses are necessary to determine the average constituents of one woman's milk.

The careful work of the Adriances has illustrated the varying quantities of these constituents at different stages of lactation as follows :

AVERAGE PERCENTAGES OF HUMAN MILK.

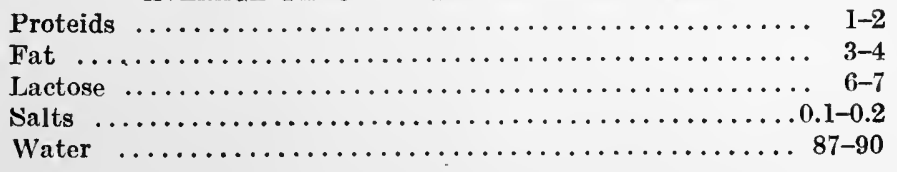


Average specific gravity, 1.028 to 1.034 ; reaction, alkaline. Additional significance attaches to their conclusions from the advantages they enjoyed of observing a large number of healthy women during long periods. A review of their observations leads to the following conclusions :

(1) The fat shows no constant changes during lactation. Its most marked characteristic is its variability.

(2) The carbohydrates, on the second day of lactation, are low, but rise rapidly during the first few days. This increase continues, but less rapidly up to the end of lactation.

(3) The proteids pursue a course the reverse of the carbohydrates.

(4) The salts diminish similarly to the proteids.

(5) The colostrum period has low earbohydrates, with a tendency to increase rapidly, and high proteids and salts, with a tendency to decrease rapidly.

(6) The milk of the later months of lactation shows a deficiency in proteids, ash, and total solids.

More recently human milk, by the phenolphthalein test, has been shown to be feebly acid.

The milk of the first ten or fourteen days possesses peculiarities that are not normally found at any subsequent period of lactation, and is known as colostrum. The characteristics of the milk of this period are:

(1) The presence of colostrum corpuscles. Normally these persist in the milk from seven to ten days. These are believed by Schäfer to be leucocytes which have migrated through the connective tissue. In the warm stage they show amœboid motion.

(2) The laxative effect upon the infant.

(3) The yellow color of the milk.

(4) Chemical characteristies; the fat may be very high or very low; the sugar (in the form of dextrose) is lower on the second day than at any other time, but increases rapidly up to the end of the second week; the proteids pursue the opposite course, being the highest on the second day but falling rapidly the first few days; the salts, like the proteids, are higher than subsequently. The most interesting feature of the above is seen in the forms of the sugar and proteids during the colostrum period. These proteids are the soluble albumins and globulins which are readily absorbed by the infant without gastric digestion. Colostrum coagulates with heat. Later, the soluble proteids and dextrose are largely replaced by casein and lactose (milk sugar) and normal lactation is established.

Having considered normal milk it will be well to discuss the changes which constitute departures from the normal, as seen by their effects upon the infant's nutrition. Before entering upon this subject the physiological process by which the milk is produced should be considered briefly, in order to better appreciate some of the influences that affect these changes. A peculiarity of the function of the mammary gland is that it persists during a more or less definite time and then subsides. 
Exceptions are seen in some cases of prolonged lactation, and in curious instances in which the function was established in women who had never conceived, under stimulation of the nipple by sucking, a point of clinical value.

Without taking time to review the strueture of the gland, attention is called to the fact that the alveoli are lined with columnar epithelium, and it is by means of these cells that this composite emulsion is produced.

The exact mode of its production from the eireulating fluids has been a subject of much discussion and extended research. The older belief that the cells of the glands operated as a sort of filter, the milk being derived directly from the blood, has been rejected as unscientific. Today three theories claim attention.

Stated briefly, the first explains the production of fat by an actual breaking down of the lining cells-a fatty degeneration-a process which it is estimated would require the renewal of the epithelium of the alveoli at least five times in the twenty-four hours.) This is held by some to be preposterous. (The second theory is a modification of the first, as only the free ends of the cells, after a stage of increased activity, appear to break down, liberating their products of metabolism, the fixed ends with the nuclei remaining to renew the process.) (The third attributes to the cells of the mammary gland, through the agency of the protoplasm, an energy analogous to other secreting structures,-viz., that they have the power of elaborating from the fluids a secretion peculiar to themselves, cell destruction being no more necessary than in other secreting glands.) A more exact knowledge on this subject would be valuable in its bearing upon the subject of changing the constituents of the milk by physiological methods, as feeding, etc., a matter which has hitherto been determined exclusively by clinical observation and experiment. Were the glands mere filters, as was formerly taught, it is reasonable to suppose that the quality of their products would partake of the nature of the blood constituents, and that changes in the latter would produce corresponding changes in the milk, a result which repeated observations have disproved.

No secretory nerves have yet been demonstrated in the mammary gland, but were clinical data wanting analogy would compel the acceptance of the hypothesis of nerve influence and control in the secretion of milk, probably through the cranial and sympathetic nerves. It is a fact of such common observation that mental conditions influence the milk supply, that no teacher denies it. 


\title{
CHAPTER VII
}

\section{HYGIENE OF LACTATION}

\author{
QUANTITY OF MILK
}

MuK secretion is subject to variations in quantity as well as in quality.) In the majority of cases it is regulated to meet the requirements of the infant, although instances are not uncommon in which the quantity is insufficient. On the other hand, it frequently occurs that the mother may successfully nurse two infants, as in the case of twins, or in wet-nursing in foundlings' homes, etc. From this it may be inferred that in some mysterious way, to a limited extent, the supply is regulated by the demand.

Some interesting observations have been made to determine the quantity of milk secreted during normal lactation. (By careful weighing of the child immediately before and after nursing the amount taken can be easily ascertained.) This work has been thoroughly done by Hähner, Laure, Ahlfeld, and others, with the following results as quoted by Holt:

AVERAGE QUANTITY OF MILK SECRETED DAILY UNDER NORMAL CONDITIONS

\begin{tabular}{|c|c|c|}
\hline At the end of first week & $\begin{array}{l}\text { Ounces. } \\
10-15\end{array}$ & $\begin{array}{c}\text { Grammes. } \\
(300-500)\end{array}$ \\
\hline During second week ... & $13-18$ & $(400-550)$ \\
\hline During third week. & $14-24$ & $(430-720)$ \\
\hline During fourth week ........ & $16-26$ & $(500-800)$ \\
\hline From fifth to thirteenth week & $20-34$ & $(600-1030)$ \\
\hline From fourth to sixth month. & 24-38 & $(720-1150)$ \\
\hline From sixth to ninth month. & $30-40$ & $(900-1220)$ \\
\hline
\end{tabular}

It will be observed by comparing the above table with those in Chapter II that the increase in quantity of milk ingested corresponds quite closely with the increase in stomach capacity and body weight, and that this increase in quantity is most rapid during the first three months, to meet the increasing demand for nutrition during this period. Further analysis of the reports of these cases shows that the larger infants took, not only absolutely but relatively, more than the smaller. As before noted, the growth of large babies is relatively more rapid than that of smaller ones. Attention is again called to the wonderful automatic adjustment of the quantity of milk to the needs of the child. It is believed that the surplus, if not drawn, is reabsorbed.

( It is a question whether the daily quantity of milk can be increased by any medicinal agent. It is well known, however, that the mammary secretion, both as to quantity and composition, is quite sensitive to many influences. A so-called "dry diet," in which there is a deficiency of water, usually diminishes the secretion, while, on the other hand, it may 
be increased by a liberal allowance of water, milk, cocoa, beer, and other fluids. )

(Attention is again directed to the mental attitude of the mother during nursing as influencing the quantity of milk. It must not be forgotten, however, that overanxiety to produce may defeat its object.)

(Loss of fluids from any cause-as copious perspiration, menstruation, or diarrhœa-may lessen the amount.)

The secretion of milk, when scanty, may be increased by any agency that increases normal metabolism-as diet, exercise, massage, electricity, fresh air, sunlight, congenial surroundings, freedom from discomfort, and an equable temperament. Sudden emotion-as grief, anxiety, anger, fear, or anything that produces shock or profoundly impresses the nervous system-may not only diminish the secretion, but oeeasionally may cause total suppression. It is suggested that regularity be observed in putting the ehild to the breast, even though there be little evidence of milk, as the secretion is undoubtedly promoted by the act of nursing. A reasonable analogy suggests the use of cow's or ewe's udder as a food for its galactagogue effect where milk secretion is seanty.

The frequent disturbances of digestion and mutrition in the nursling have led to much study, not only concerning the qualitative changes in his food, but also as to their canses.

It is accepted that the constituents of milk may be influenced by variations in the hygiene, especially in the diet of the mother. The former belief that the fat of the milk was increased by the fat ingested, has been repeatedly disproved by actual experiment, although Winternitz claims to have temonstrated the contrary in lower animals. It is believed to-day that the proportion of fat in the milk depends largely upon the amount of proteid in the mother's food, increase or diminution in the latter causing a like change in the former. This relation of proteids in the food to fats in the milk is a matter of daily observation. A mere ingestion of albuminoids, however, is not sufficient to produce a "rich milk," since thorough digestion and assimilation are essential to fat elaboration. Fat may be scanty in the milk, not only from an insufficiently nitrogenous diet, but also as a result of excess of fats in the food. Examples are not wanting of mothers who, in their efforts to enrich their milk, defeat this object by inordinate ingestion of cream.

The familiar spectacle of a rhachitic infant at the breast of the mother, whose diet consists largely of amylaceous and saceharine constituents, with a milk of a high specific gravity and low fats, emphasizes the importance of a knowledge of fat production. The substitution in this case of a diet of eggs for breakfast, meat for dinner and supper, with a cup of beef broth between times, and a limited supply of vegetables and sweets, will frequently show an increased percentage of fat in the milk, with subsequent improvement in the nutrition of the child.

It occasionally occurs that the infant shows the effects of excessive fat in the so-called fatty diarrhoeas, in which fat is seen in the diapers 
in glistening masses or floating as a pellicle on the surface of the water. Again, in the spitting babies who regurgitate their food shortly after nursing, analysis of the mother's milk shows sometimes as high as nine per cent. of fat. In such cases meats should be restricted and vegetables and breadstuffs encouraged in the mother's diet. Excess of fat in the diaper of a baby who shows no other signs of indigestion need not be regarded as pathological.

The proteids are rarely low, except in cases of exhaustion or debility, as from sickness or insufficient food. In this condition the milk is poor and watery, there being a deficiency in all the solids. In such cases the hygiene of the mother requires a liberal diet with all the accessories for the improvement of her general nutrition. Here nitrogenous foods are necessary to increase proteids in the milk. It may occur that the mother's milk, in cases of debility, shows an excess of proteids with a deficiency of other constituents, the debilitated infant exhibiting evidences of indigestion by constipation or diarrhœa and vomiting.

Excessive proteids may appear also in the overfed mother of sedentary habits, for whom exercise in the open air must be prescribed, with reduction of diet. Idleness and discontent may be replaced by congenial occupation, to the improvement of the milk in this respect. The relief of constipation or the alleviation of any bodily, discomfort may alone be sufficient.

Sudden disturbances in the digestion of a healthy nursling leads the physician at times to startling conclusions in his search for their etiology. Violent agitation of the nervous system of the mother may change the quality of the lacteal secretion almost instantly: the milk quite frequently, under these circumstances, resembling colostrum in its changed proteids, low fat, and colostrum corpuscles. Instances are known where convulsions and even death to the nursing infant have followed.

The analysis of the mother's milk frequently leads to the cause of the indigestion of the infant. The secretion of colostrum milk has been known to follow undue fatigue, excitement, anger, grief, coitus, also menstruation and conception. In fact, disturbances of digestion in the infant are frequently the first intimation of pregnancy in the mother. In the event of these disturbances, and should analysis of the milk show colostrum, the child should be removed from the breast until (excepting in pregnancy) the secretion approaches the normal. Meanwhile the breasts should be emptied regularly by the pump.

Both the quantity and quality of the milk is influenced by the frequency of nursing. Poor milk usually results from prolonged or irregular intervals in nursing. The more frequently the breasts are emptied the higher will be the percentage of solids, especially the proteids. The infant, restless from indigestion induced by excess of proteids, is unfortunately given the nipple at short intervals to quiet him. The result is increased indigestibility of the milk from greater excess of proteids. What is needed is water for his thirst, rest for his stomach, and rest for the mammary glands. 
The following from Rotch may best express a summary of the means at command for regulating the composition of mother's milk:

The percentage of proteid is increased by

Increased frequency of nursing.

Increased liberality of proteid food.

Insufficient exercise.

The percentage of proteid may be diminished by

Diminished frequency in suckling.

Diminished proteid food.

Increased exercise.

The percentage of fat is increased by

Increased proteid diet.

The percentage of fat is diminished by

Deficiency of proteid food.

Excess of fatty foods.

Fasting.

The percentage of water is increased by

Increased fluid diet.

The percentage of water is diminished by

Saline cathartics.

Diminished fluid diet.

As previously stated, the percentages of sugar and ash vary but little. 


\section{CHAPTER VIII}

\section{MILK ANALYSIS}

\section{DETERMINATION OF FAT}

THE relationship of the quality of the milk to the nutrition and wellbeing of the infant is a subject of ever-growing interest. The more lactation is studied, the greater significance attaches to its disturbances. It has been generally recognized that the relation was a causative one, and such expressions as "milk not agreeing with the baby" have in a vague way expressed the idea. Failures in the nutrition of infants were explained upon the hypothesis that some constituent was wanting or in excess in the mother's milk. Since no verification of this supposition was formerly practicable, even possible, no satisfactory corrective measures could be undertaken. In other words, the determination of the causes of digestive or nutritional disturbances amounted to little more than guess-work. It is true that careful chemical analyses were occasionally made, but these were so infrequent as to be of little value from the paucity of data thus obtained.

The relative quantity of fat was early recognized as important, and frequent attempts at its determination for clinical purposes were made. It was not until the importance of the relation of fat to specific gravity, in estimating total solids, was appreciated that efforts at milk examination began to assume practical value. The method, in general practice, of determining the percentage of fat, consists in allowing a sample of the milk to stand for a certain time at a given temperature until the line of demarcation between cream and milk is sharply defined. The percentage of fat is to eream as three to five.

A number of devices for the determination of fat percentage have been employed, among which may be mentioned Holt's and Chevalier's creamometers, Soxhlet's areometer, Feser's lactoscope, Marchand's tube, the lactocrit of De Laval, and Babcock's, also Leffman and Beam's methods. Several more elaborate chemical methods have been omitted as impracticable for the busy practitioner. Of the many devices four only will be described, the others being various modifications of the four principles therein employed.

(1) The gravity process employed by Holt.

(2) The optical test of Feser.

(3) The action of reagents as shown by Marchand.

(4) The combined action of reagents and centrifugation as employed by Babcock and by Leffman and Beam.

Holt's apparatus for this purpose consists of a slender glass cylinder, graduated to a hundred divisions (Fig. 52). This cylinder is filled to the 100 
zero mark and allowed to stand at a temperature of $70^{\circ} \mathrm{F} .\left(21^{\circ}\right.$ C. $)$ for twenty-four hours, or until the eream line is sharply drawn, when the percentage may be read from the graduations on the glass.

Feser's lactoscope consists of a slender glass cylinder, resting on a foot piece containing a short porcelain column projecting upwards from the bottom (Fig. 53). This column is marked with black transver'se lines. The test is applied by introducing, by means of the pipette shown in the figure, a given quantity of milk, which renders the central column invisible. This milk is gradually diluted with pure water, with frequent shaking to secure thorongh admixture. The process is continued until a degree of attennation is reacherl sufficient to bring into view the stria on the central column. The surface of the cylinder is so graduated that the quantity of the mixture is made to express the percentage of fat in the sample.

In Marchand's method a graduated glass tube is employed (Fig. 54). Pour in 5 C.c. of milk and a drop of caustic soda solution; add 5 C.c.

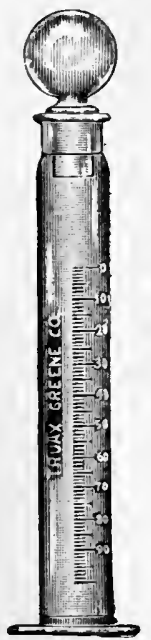

FiG. 52.-Holt's creamometer.

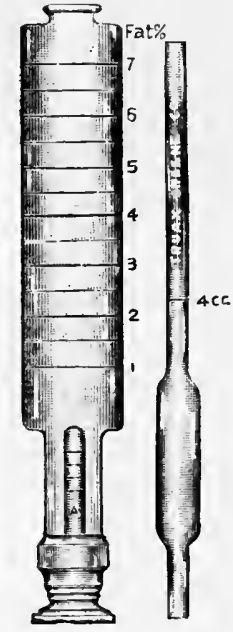

Fig. 53.-Feser's lactoscope.

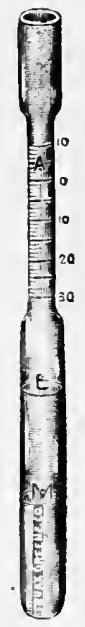

FIG. 54.-Marchand's tube.

of ether and shake the tube until the fat is extracted. On adding absolute alcohol and warming, the fat rises and can be calculated from the depth of the layer in the tube.

In the Babcock method, as well as in that of Leffman and Beam, the milk is acidified in order that the proteids may be changed to soluble acid albumin, which offers less resistance to the rising and aggregation of the fat globules. This is done in a peculiarly constructed bottle, having a long, slender, graduated neck (Fig. 55).

The bottle is then placed in a centrifugal machine (Fig. 56) and rotated from two to five minutes, the time depending upon the speed of rotation, when the separated fat appears as a distinct layer in the graduated neck where the percentage is easily read. 
In the Babcock method only sulphuric acid is employed, as follows: 17.5 C.c. of milk is poured into the bottle through a slender pipette, care being taken not to smear the neck, then 17.6 C.c. of strong commercial sulphuric acid (specific gravity 1.82) is slowly added; at the same time the test-bottle is given a gyratory motion to facilitate admixture without too sudden coagulation. The bottle thus filled nearly to the shoulder is placed in a centrifuge and revolved for five minutes with the speed of, at least, 1000. Sufficient boiling water is then introduced to fill the bottle well up into the graduated neck, when it is again centrifugated for one minute, after which the percentage of the supernatant fat may be read off.

The principle of the Leffman and Beam method is similar. Their test-bottles (Fig. 57) have a capacity of about 30 C.c. and are provided with a graduated neck, each division of which represents one-tenth per cent., by weight, of butter fat; 15 C.c. of milk are measured into the bottle, 3 C.c. of a mixture of equal parts of amyl alcohol and strong hydrochloric acid added; the bottle is then filled nearly to the neck with

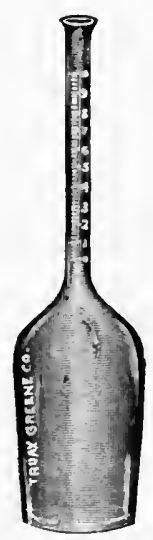

FIG. 55.-Babcoek's bottle.

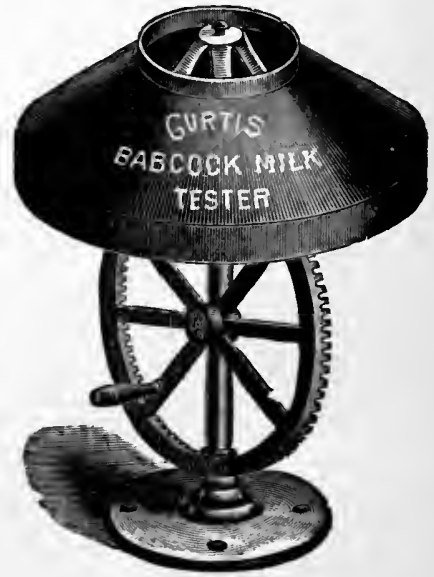

FIG. 56.-Babcoek's centrifuge.

concentrated sulphuric acid and the liquids are mixed by holding the bottle by the neck and giving it a gyratory motion. The neck is now filled to about the zero point with a mixture of sulphuric acid and water. It is then placed in the centrifugal machine (Fig. 58). After rotation for from one to two minutes the fat will collect in the neck of the bottle and the percentage may be read off, allowance being made for the meniscus. It is convenient to use a pair of dividers in making the reading. A smaller bottle is manufactured for this test and should it be used the following rule for the proportions of reagents may be employed. First, determine the capacity of the bottle to the shoulder: fifty per cent. of this for the milk, ten per cent. for the mixture of amyl alcohol and hydrochloric acid, and forty per cent. for the sulphuric acid. 
Of these methods for obtaining the percentage of fat, that of Ilolt has the advantage of simplieity. Its drawbacks are, first, the length of time-twenty-four hours being necessary for making the test; seeond, the employment of the arbitrary algebraic proportion; the ratio of fat to cream (three to five) being questioned.

The Feser lactoscope, being purely an optical test, is open to the objection of all color tests, that different eyes give different estimates. Furthermore, the fact that the same weight of fat retards more light when in the form of small globules than when in the form of large globules, renders this method of testing unreliable.

Marehand's test has not given the satisfactory results obtained by other methods.

For simplicity of detail and accuraey in results the Babeock method is rapidly displacing all others. A cheap machine, from which most excellent results are obtained, earrying as low as two bottles, may be sufficient. Nor is the water jacket of the larger Babcock machine essential to good work, since by the admixture of sulphuric acid with the milk sufficient heat is evolved to maintain fluidity of the fat long enough for the reading of one or two specimens. Where one sample only is rotated, the opposite arm of the centrifuge should be balanced with an equal weight to prevent accident.

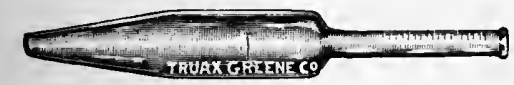

FiG. 57.-Lefiman and Beam's bottle.

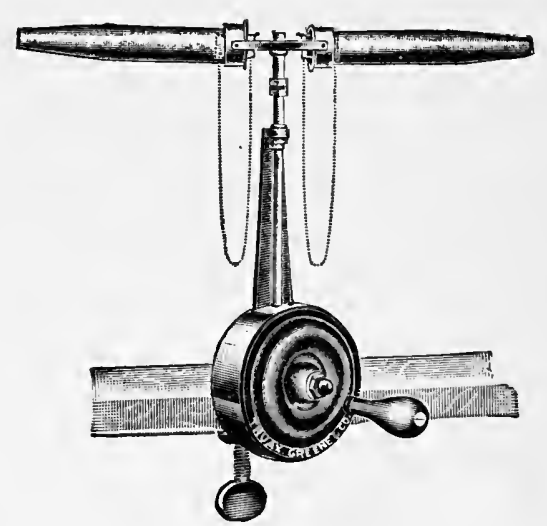

Fig. 58.-Centrifuge for Leffman and Beam's bottle.

The Leffmann and Beam process is here detailed, because of the two advantages it possesses: First, the bottles are adapted by their form and size to the ordinary office centrifuge; second, their capacity allows of the determination of fat from a smaller sample, a feature of practical importance because of the frequent difficulty in securing a larger quantity of breast milk.

The amount of fat in a given quantity of milk may be determined to within one-tenth of one per cent. by the above methods.

The differing effects upon the specific gravity of milk, produced by variations in its different constituents, enables us to form some estimate of the quantity of the other solids when the specific gravity and amount of fat are known. Thus inereasing the fat diminishes the specific gravity, while it is augmented by inereasing other solids. Conversely, diminishing the fat increases the specific gravity, while diminishing the other solids diminishes it. In other words, the higher the fat, the higher, 
of necessity, must be the total solids to maintain an average specific gravity, since fats have a tendency to lessen it.

Since the sugar and salts maintain a fairly constant proportion in milk, the determination of the proteids is next in importance. A number of mathematical formule have been employed for estimating more definitely than the above the percentage of total solids from the known fat and specific gravity. A method recommended by Richmond, which furnishes uniform results within the limits of ordinary variations, is here given. The total solids equal the sum of one-fourth the last two figures of the specific gravity, plus six-fifths of the percentage of fat, and the arbitrary decimal fourteen one-hundredths, the algebraic expression of the equation being as follows:

$$
\text { Total solids }=\frac{\mathbf{G r}}{4}+\frac{\mathbf{F}_{6}}{5}+.14
$$

In this method it is assumed that the sugar maintains a constant percentage of 6.5 per cent., and the salts 0.2 per cent. To illustrate the application of this equation, take, for example, milk with a specific gravity of 1.028 and fat of 4 per cent.:

$$
\begin{aligned}
& \text { T. } S=\frac{28}{4}+\frac{6}{5} \text { of } 4+.14 \\
& \text { T. S. }=7+4.8+.14 \\
& \text { T. S }=11.94 \text { per cent. }
\end{aligned}
$$

11.94 minus 10.70 (the sum of the fat, 4 ; the sugar, 6.5 ; and the salts 0.2 ) equals 1.24 (the remaining proteids) per cent.

Simpler in its application than Richmond's equation is the following

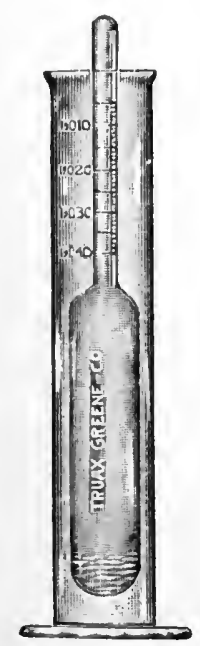

Fig. 59.-Hydrometer. rule given by Farrington and Woll, which furnishes approximately accurate results :

Divide the lactometer reading (Quevenne's scale), or the last two figures of the specific gravity, by 4 and add to this one-fifth of the percentage of the fat; result, solids not fat. By adding to this the weight of fat, total solids are obtained.

Example: Fat 4 per cent., specific gravity 1.028.

$$
(28 \div 4)+(4 \div 5)=7.8 \text { solids not fat. }
$$

Solids not fat 7.8 per cent. + fat 4 per cent. $=$ Total solids 11.8 per cent., a result differing but slightly from that obtained by Richmond's rule.

The objection that the above methods yield approximate, rather than positive, quantitative results, may be met by the statement that uniformity of procedure secures a standard of comparison of great clinical value, even though the determination in a given case may be lacking in chemic accuracy. The microscope is of value in ascertaining 
the size and uniformity of the fat globules, the presence of colostrum corpuscles, or other bodies foreign to milk, as bacteria, pus, or blood.

The specific gravity may be obtained by any standard hydrometer at $60^{\circ} \mathrm{F}$. ( $15.5^{\circ}$ C.) (Fig. 59). The specific gravity should be increased or diminished by 1 for every $10^{\circ} \mathrm{F}$. $\left(5.6^{\circ}\right.$ C.) above or below $60^{\circ} \mathrm{F}$. ( $15.5^{\circ}$ C.).

Milk, on account of its viscidity, retains minute air-bubbles after agitation, a fact to be borne in mind when obtaining specific gravity.

The Babeock milli-testing outfit, including centrifuge, bottles, milk pipette, acid measure, bottle brushes, lactometer, and thermometer (or, better, a combination lactothermoneter) may be obtained from any dairy supply-house. For dairy or municipal laboratory work, centrifuges are made for holding from four to thirty-two bottles, but for office-testing a two- or four-bottle machine is better. 


\section{CHAPTER IX}

\section{WEANING AND SUBSTITUTE FEEDING}

\section{SUPPLEMENTAL FEEDING}

IN the hygiene of infancy the question of substitute feeding is of secondary importance only to that of lactation. We are relieved of the responsibility of its consideration in the care of every nursling by one circumstance alone,-namely, the death of the infant, since from the first establishment of lactation, conditions may develop at any time which render breast feeding impracticable. The character of the lacteal secretion is subject to variations as a result of some well-known influences and of many that are still unknown. One series of changes, so constant as to be accepted as physiologic, consists in a steady decrease in the proteids and salts. The total solids maintain a somewhat uniform percentage until the seventh month, on account of the constant increase of the sugar. After this time, however, the decline in salts and proteids is so rapid that the percentage of total solids is steadily reduced. That the nutrition of the child should be affected visibly by the decline of these important constituents, especially at a time when material is demanded for rapid growth, is not a matter of surprise. This would appear to furnish good reasons, both physiological and clinical, for the commencement of supplementary feeding. Moreover, the eruption of the teeth, the changes in the salivary secretion as well as those of the stomach and pancreas, suggest preparation for digestion of a different class of foods.

The word supplemental is used here not to indicate a total change in the infant's food, but merely a reinforcement, particularly in those constituents which the waning function of the mammary gland evidently fails to supply. In addition, the changes in the digestive secretions, especially in the development of amylolytic power, afford more than a hint of a preparation for starch digestion.

The changes in breast milk, above referred to as constantly progressive, show considerable variation as to the time of their occurrence in different women. Thus, one mother may apparently have expended her best physiologic energy of milk elaboration by the end of the seventh month; while on the other hand, another may not show the same degree of deterioration at the fifteenth month. To the queries, When shall supplemental feeding begin? When shall substitute feeding be inaugurated? or, Shall weaning be effected gradually or abruptly?-it must be evident that no decisive answer can be given that will apply to all cases.

One indication for weaning is deficiency in normal development, 
which is frequently best shown by a failure to gain in weight. Ilowever, weight gain is not always evidence of normal nutrition, as many rhachitic babies make fat rapidly.

Due reference should be had also to the season, as it is well known that radical food changes should not be inaugurated at the commencement of, or during the heated term, when infants are especially susceptible to digestive disorders. Moreover, the eruption of an unusually troublesome tooth might well delay the change in food. Nany other circumstances, which need not be enumerated, should be taken into consideration, nor must it be understood from the foregoing that a radical change in the infant's diet is contemplated by the term "weaning." In fact, the process should be gradual, the infant having been accustomed to supplemental feeding as often as once a day, through a period of several weeks, and the food selected should conform somewhat closely to the milk of the mother, differing at first in the lower percentage of proteids and fat, as determined by repeated analyses of the breast milk.

The relation of an infant to his food is sometimes arbitrary, the explanation of which is ofttimes diffieult. Thus one infant fails steadily at the breast upon which another thrives. This has been observed even in the case of twins. Transient disagreement should not be considered sufficient cause for rejecting the breast, since many temporary disturbances may be correeted by attention to hygiene. Without taking time for an extended presentation of the advantages of breast feeding over all other methods, it should be stated that the consensus of opinion depreeates early weaning unless the fact be established that the mother's milk cannot be made to agree. In this connection it is well to eall attention again to the immense advantages to be derived from frequent examinations of the mother's milk, also to the prineiples of hygiene discussed in Chapter VII.

A child should be immediately removed from the breast upon the appearance of acute infectious disease in the nurse. So, also, in a wellgrounded suspicion of syphilis or tubereulosis a suitable wet-nurse should be secured in case the infant is free from speeifie infection.

The development of mastitis renders the affected breast unfit for nursing while suppuration continues.

The growing tendency on the part of both laity and physicians to recommend weaning upon the slightest pretext, suggests the need of more emphasis upon the injunction not to adopt substitution for breast feeding until it is clearly demonstrated that the latter cannot be made to agree. It should not be forgotten, in considering the advisability of substitution, that no a priori reasoning will deeide what food will agree in every ease.

In the majority of instances ehange in food is largely a matter of experiment. On the other hand, it must be remembered that many infants are deprived of their right to a fair start in life by being confined to the breast which fails to furnish all the requisites for normal nutrition. 
Reference is made in Chapter VII to the many influences that disturb lactation, transiently or permanently. The question as to the inflience of menstruation and coitus upon lactation is of paramount importance, and one concerning which the physician is often consulted. Concerning the latter, evidence is accumulating to show that excessive indulgence very frequently deteriorates the quality of the milk of the nursing mother, causing an increase in proteids, with the appearance of colostrum corpuscles. Under these circumstances the infant commonly gives evidence of acute gastro-intestinal disturbance.

Menstruation frequently disturbs lactation. Its early appearance may not require weaning, but a later return should suggest its advisability.

The occurrence of conception is an indication for the immediate removal of the child from the breast, as this condition renders the milk insufficient, if not positively injurious.

When it becomes erident, from any of the conditions enumerated, that substitute feeding is necessary, the question what shall be substituted is of the greatest importance. Errors in the management of substitute feeding are probably responsible to a greater extent than any other cause for the high infant mortality.

Without entering upon an extended discussion it may be claimed that the best substitute is the wet-nurse. The drawbacks to wet-nursing are many and extremely trying. It is probably on account of these that this substitution is not more frequently resorted to in this country. The difficulties attending the securing and selection of a suitable wet-nurse undoubtedly lead many physicians and parents to shut their eyes to its importance, and to accept the dictum of some eminent teachers that artificial feeding can be conducted successfully in ninety per cent. of the cases. They forget that the tacit admission that the remaining ten per cent. may survive only upon the breast, is the strongest argument in favor of giving to all infants the implied advantage of this best method of feeding. Who is willing to admit that he deliberately rejects the best simply because something inferior may, with eare, be made to do? It is to be hoped that with the growing appreciation of the importance of breast milk for young infants, systematized organizations for the supply of properly certified wet-nurses will soon supersede the haphazard method of selection now in vogue.

The wet-nurse should be chosen with definite reference to her temperament, the quantity and quality of her milk, and her freedom from syphilis or tuberculosis. Her milk should be examined both analytically and microscopically. The breasts and nipples should give evidence of abundant and free lactation. A firm small gland is preferable to the large fat variety. A point to be observed is that after nursing there should be a marked decrease in the size of the gland, which should refill within three hours. The nipple must be of good proportions and free from fissures and excoriations. On the whole, the best test for a nurse is the condition of her own child, who should always be carefully ex- 
amined as to his nutrition and freedom from syphilitic stigmata. On this account a nurse whose ehild is at least three months old is usually to be preferred. Nor is it essential that the ages of the infants should exactly correspond, providing lactation has become well established. Other things being equal, there are some reasons why a multipara should be selected.

It should be remembered that the funetion of lactation is at its best between the ages of twenty-one and thirty-five years. A nurse who has lost her child is more likely to give her undivided attention than one whose ehild has been displaced. Should the first wet-nurse's milk fail to agree it need be no cause for discouragement, as sometimes success is attained only after repeated trials.

In case a wet-nurse is not available, it will become necessary to adopt artificial feeding. More has been written and said eoncerning this subject during the past fifteen years than all other pediatrie subjects combined. 


\section{CHAPTER $\mathrm{X}$}

\section{ARTIFICIAL FEEDING}

\section{FOOD ESSENTINLS}

Artificial feeding of infants is a subject concerning which considerable partisanship has developed, and teachers have been designated as belonging to this or that class of "feeders."

A few essentials from Cheadle, although written sixteen years ago, may be of value in assisting the student to a practical application of some of the principles already outlined in the preceding chapters.

(1) The food must contain the different elements in about the same proportions as found in human mill,-viz., proteids, one to two per cent.; fats, three to four per cent.; carbohydrates, six to seven per cent.; salts, two-tenths per cent.; water, eighty-eight per cent. This represents theoretically the ideal for a balanced nutrition. The chemist can readily produce a mixture which duplicates breast milk in the nutritive value of its constituents and even resembles somewhat closely that emulsion in its physical appearance, but the dismal array of failures to reproduce mothers' milk by a synthetic arrangement of apparently similar constituents obtained from other sources, is an emphatic reminder of the limitations of both chemical and physiological knowledge.

(2) It should not be purely vegetable, but must contain a large proportion of animal matter. Most vegetable substances are deficient in available proteids and yield but a small quantity of fat. Moreover, it is known that the infant does not assimilate them as easily and fully as those derived from animal sources, even though these ingredients be supplied in the proper percentages.

(3) It must be in a form suited to infantile digestion. The digestive organs have only recently assumed their function, and are designed to deal solely with the bland, dilute, and easily dissolved nutriment of mother's milk. In the natural method of feeding the infant gets his nourishment in the same form at every meal; so in artificial feeding variety is not desirable. It is presumed that infants under six months are unable to digest much starch from the paucity of ptyalin and amylopsin; hence, for this age any great amount of starch in a food is enough to condemn it. As the walls of the stomach are lacking in muscular power and the secretions are feeble, it is evident that this organ is unable to deal with large masses of solid matter. Solids can be digested only in a state of minute subdivision.

(4) The total quantity in twenty-four hours must represent the equivalent, in nutritive value, of from one to three pints of human milk, 
according to the infant's age. No fixed rule can be given for all children. Careful observation of the infant as to whether he rejects some of his food soon after ingestion, or seems hungry half an hour after feeding, may prove a guide. The best indication that he is receiving his full equivalent is a steady weekly gain of from two to five ounces, - $\mathrm{or}$ more in the early months.

(5) It must possess the antiscorbutic property. It is not yet known in what this consists. It is known that infants at the breast very rarely suffer from scurvy, and that the disease is found among those fed upon condensed or sterilized milk, or upon desiccated preparations. Prompt recovery, with food unchanged (except the discontinuance of sterilization), has been reported by several observers. Fresh milk, therefore, possesses, in addition to the important principles, this antiscorbutic element, but not in large proportion, for milk in extreme dilution will not prevent the development of this disease.

(6) It must be fresh, clean, and free from excessive bacterial content. Hydrochloric acid has antiseptic properties, it is true, but the stomach secretes only a limited quantity of it during the first half year. Hence, infants are extremely susceptible to gastro-enteric disorders, having little resistance to bacterial invasion. The deadly toxins which develop in old milk may resist all efforts at sterilization.

(7) Another essential, voiced by Chapin, may well be added,-viz., in feeding young animals it is not only necessary to supply the proper quantities of nutritional elements, but they must be in such form as normally to develop the digestive tract.

This writer calls attention to the physical and chemical differences in the milk of various mammals, and shows that each is especially adapted not only to the nutrition but to the digestive development of its particular young,-as, for instance, the bovine calf, which, doubling birth weight in forty-seven days, attains pubescence in one year with a ruminant digestive tract twenty times the body length that must be fitted quickly to obtain food elements from coarse herbage. He needs a dense, quickly curding, rich proteid milk for early development of both muscular and secretory functions in his stomach, which constitutes seventy per cent. of the digestive tract. While the human infant, who doubles weight in one hundred and sixty days and attains puberty in fourteen years, finds only in his mother's milk the ingredients suitable for the development of his digestive tract, which is only six times his body length, and of which only twenty per cent. is stomach. Hence the early feeble gastric digestion must be slowly cultivated by gradually increasing density of the flocenlent curds characteristic of human milk alone.

It has been stated that the substitute feeding of infants is a broad subject. If the breadth of this subject be indicated by the number and apparent variety of infant foods on the market, a student may well quail before it. To the query why such a large number of foods and preparations, the reply has been made that commercial enterprise is 
responsible for this, as it is also for the innumerable foods and preparations for adult use; also that manufacturing ingenuity is stimulated to furnish presumed nutriment in a great variety of forms by the whims, caprices, and tastes of individual appetites.

Man is an animal with educated or perverted tastes which result in a demand for variety in his viands. He is capable, also, of determining, to some extent, the nutriment derived therefrom. At any rate, he may recognize some of the more immediate effects from the ingestion of different foods. The infant, on the other hand, is but slightly conscious of food effects, either immediate or remote. Rarely in early life has he tastes, either acquired or perverted. Instinctively he eraves nourishment, and is almost invariably satisfied with that furnished normally by the breast. Variety in form or flavor is neither desired nor desirable. Reference to the essentials above enumerated will show that uniformity of food, containing the five constituents, is what the infant requires and with which he is satisfied. The great variety of baby foods in the market is partly the result of prejudice and ignorance.

The average mother's withdrawing her breast from the infant is likened to a vessel at anchor in a safe roadstead, slipping the cable in the absence of pilot, chart, or compass. The baby knows not what he needs, the mother knows little more; but she can read, and the claims of the enterprising food agents attract her attention. Too often physicians, also, derive their supposed knowledge of infant dietetics from the same source.

The spectacle is by no means uncommon of anxious parents running the entire gamut of the advertised preparations in the market in the hope of stumbling upon something which will agree with the baby. Nor is this practice confined exclusively to the laity. On account of its cheapness and abundant supply, it is not strange that, in his quest for a substitute food, man should turn to the milk of the lower animals, possessing as it does the grosser physical characteristics of mother's milk, with the confirmation of its apparent identity by the earlier chemic analyses. So in different portions of the globe mammals, including the cow, goat, sheep, ass, mare, and camel, have contributed their lacteal product for the orphaned human infant. For obvious reasons the cow furnishes the most available product in civilized countries, where, unfortunately, substitute feeding is in greatest demand. But little question was raised in former years as to its value and availability as a substitute. Now and then, to be sure, in the discussion of infantile disorders, some astute observer might refer parenthetically to the fact that in critical conditions infants at the breast afforded more favorable prognoses than the bottle-fed. It was not until the attention of the world was arrested by the startling mortality in the latter class that the differences between the milks of different mammals in their relation to the requirements of the infant, began to be studied systematically.

The result is seen in the immense impetus given to the study of the food question, to the extent that the deductions of yesterday are refuted 
by those of to-day, and the accepted conclusions of last year's text-book may be obsolete ere a second edition leaves the press. In this critical research and rapid advance of knowledge, the whole world has furnished contributions from the best minds, but from no section has there been drawn more valuable practical application than during the past fiftecn years by a brilliant coterie of Americans. Leeds, Chittenden, Babeock, Harrington, Leffman and Beam, Jacobi, Rotch, Holt, Starr, Meigs, Chapin, Van Slyke, Russell, Hart, Richmond, and the Adrianees, have placed infant feeding in America on a plane in advance of other countries.

As a result of this work, some of the reasons why cow's milk does not meet all the requirements of the infant have been demonstrated. The results of recent analyses give the gross constituents of cow's milk and mother's milk as follows:

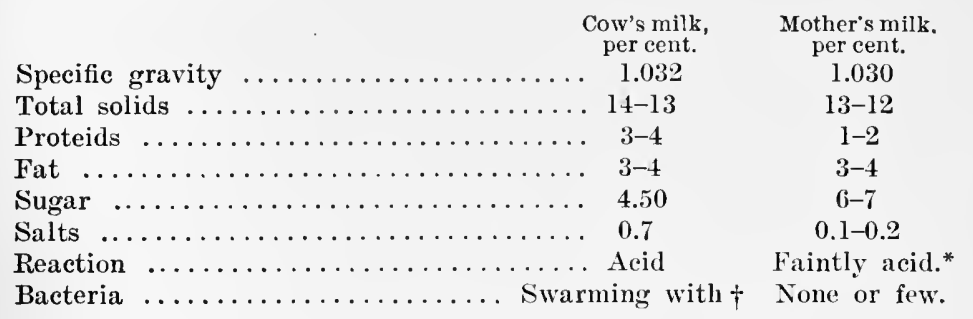

It will be seen that they differ but little in specific gravity, in the quantity of their total solids and water, and in their percentage of fat; more widely in their salts, sugar, and chemic reaction, and most widely in regard to their proteids and bacterial content.

So far as positively known, the fats and lactose in cow's milk have the same food value as similar constituents in breast milk. This statement, which is now questioned, may be disproven by a better knowledge of the chemistry of milk and the physiology of infant digestion. Many disturbances of digestion and nutrition are traceable directly to the proteids and fats.

* To phenolphthalein test.

$\dagger$ This refers to cow's milk as it reaches the consumer. 


\section{CHAPTER XI}

\section{ARTIFICIAL FEEDING-Continued}

\section{PERCENTAGE FEEDING}

THE excess of proteids in cow's milk has been considered the principal cause of its indigestibility. As a result of this belief, reduction of this constituent has been practised by the addition of water; so that rules for dilution of cow's milk in proportion to age of infant are found in older text-books. Results, however, showed that in these dilutions the nutrition suffered from a coincident diminution of fats and sugars. Consequently, it was recommended that the percentage of lactose and fats be maintained by the addition of sugar of milk, and cream, while the reduction of proteids was effected by the proper addition of water. This process of modification came to be known as the "Rotch method" from the energy displayed by that eminent teacher in perfecting its details. Laboratories for this modification have been established in the leading American cities, to which orders are sent for definite percentages of modified milk, as drugs are ordered by prescription from a pharmacy. Too much praise cannot be accorded the distinguished originator of the milk laboratory, since, more than any other agent, it has been the means of leading the profession to the habit of definite percentage feeding. It will be seen from the accompanying order blank that the physician may, at will, control the amount of different ingredients, varying their percentages to meet the apparent requirements of the little patient. For

$\mathrm{B}$

\begin{tabular}{|c|c|c|}
\hline \multicolumn{2}{|l|}{ Per Cent. } & REMARKS \\
\hline Fat $\ldots \ldots \ldots \ldots \ldots \ldots \ldots$ & & Number of Feedings .............. \\
\hline Milk-Sugar.............. & & Amount of each Feeding . ........... \\
\hline Albumoids . . . . . . . . . . & & Alkalinity...$\ldots \ldots \ldots \ldots$ per cent. \\
\hline Mineral Matter............ & & Heat at..$\cdots \cdots \cdots \cdots$ \\
\hline Total Solids.............. & & Infant's Age $\ldots \ldots \ldots \ldots \ldots \ldots \ldots \ldots$ \\
\hline Water................... & 10000 & Infant's Weight........... \\
\hline
\end{tabular}

Order

Date. 
some of the indications for these variations, the reader is referred to Chapter XII.

Percentage feeding, or the American method as it is designated abroad, while founded upon a misconception of the identity of the constituents of cow's milk and mother's milk, is still, now that these differences are better understood, by far the best method of feeding with the best of all substitutes.

Its adaptability to delicate changes in the proportions of constituents and, best of all, the habit of thinking in percentages and the consequent appreciation of the importance of slight variation in the food, not to mention the great advantage of a daily record of the diet, are but a few of the advantages over the haphazard rule-o'-thumb practice formerly in vogue.

Many of the failures in percentage feeding result from a mistaken notion that the modified milk must correspond in constituent percentages with human milk, forgetting the irreconcilable differences in their chemieal characters and the coagulability of the proteids, and the differences in digestive function of calf and child. At the beginning the percentage of ingredients, with the possible exception of lactose, should be low. After toleration is established they may be cautiously increased. Thus, a child normally nourished on breast milk yielding proteids 1.50 per cent.; fat 3.50 per cent.; lactose 6.50 per cent., if transferred to modified cow's milk might begin with proteids 0.50 per cent.; fat 2 per cent., and milk sugar 6 per cent. The amount for each feeding may well be too little rather than too much. A fair rule to follow in the majority of cases is that the proteids should rarely exceed one-third of the fats. Alkalinity is desirable not because mother's milk is alkaline, for it is not, but because it retards the precipitation of cow casein in its characteristic dense curds with which the infant digestive tract is unable to cope. For this reason the amount of lime-water or sodium bicarbonate ordered should be proportionate to the amount of proteids prescribed. The routine practice of ordering alkalinity five per cent., which means one ounce of lime-water in a twenty-ounce mixture regardless of the milk content, which may vary from one to sixteen or more ounces, is neither rational nor scientific if its purpose be as above stated. As a rule, alkalinity should be increased with increase of proteids.

No one can prescribe intelligently for an unknown patient. The infant's personal equation is always to be considered. Hence, arbitrary formulæ in text-books are apt to be misleading and pernicious. A modicum of brains is an essential ingredient in every bottle of food.

If the paucity of soluble albumin and the excess of the refractory casein in cow's milk (page 113) cause digestive intolerance soluble or whey proteid may be designated in the prescription up to 0.9 per cent., above which any increase must include some casein. The milk laboratory is in reality a food pharmacy from which any rational food mixture may be ordered. The physician may specify egg albumin, meat proteids, cereal gruels, jellies, cane-sugar, whey, or buttermilk in the mix- 
ture as his judgment dictates. So, too, sterilization, pasteurization, gravity cream or centrifugalized cream are subject to the physician's order.

The expense incident to the laboratory manipulation, and the impracticability of its establishment except in large cities, will necessarily limit the field of operation for this very valuable adjunct. Consequently home modification is of greater interest to the majority of practitioners. In this connection, the protection of the supply will ever continue to be the most important consideration in substitute feeding with cow's milk.

That many disorders of infancy are due to the presence of bacteria in eow's milk has long been known. Passing over the infections from the presence of such micro-organisms as those of tuberculosis, typhoid fever, scarlet fever, diphtheria, etc., for the time being, it may be stated that the proneness of cow's milk to decomposition, with its effect upon the nursling, was early recognized as constituting one of the commonest dangers of milk feeding. Hence the hygienic dairy management became
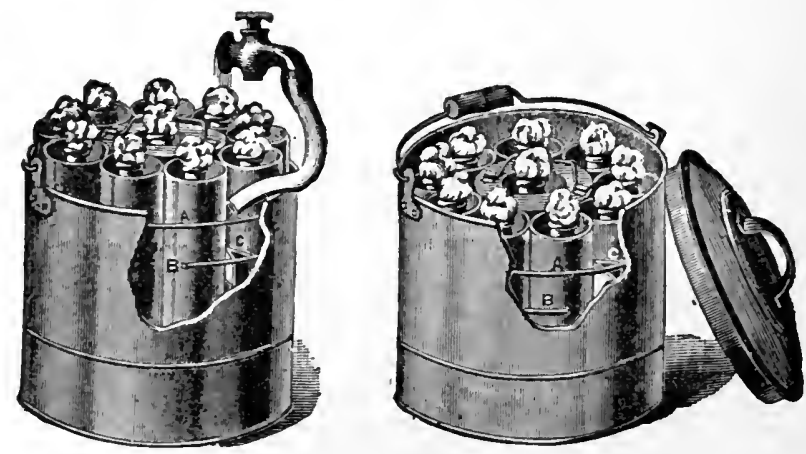

FIG. 60.-Freeman's pasteurizer.

a question of the highest importance. It has been demonstrated that milk production may be so guarded as to furnish a product comparatively free from pathogenic micro-organisms. The same care in the selection of the cow that was recommended in the selection of the wetnurse, the same aseptic details in her care and in the handling of the milk that were required in the chapters on infant hygiene, will insure food that is practically sterile.

All large cities now have milk commissions either in connection with or independent of the health departments. As a result of recent activity in this direction, eity milk supply has improved to a marked degree. A long step forward is the delivery on ice of milk cooled and bottled in the country. The Chicago Milk Commission, acting independently yet in unison with the municipal health anthorities, has during the past three years furnished thousands of children with milk, both whole and modified, at a price slightly below cost.

The question of grocery milk seems practically hopeless so far as reformation goes. Only by years of patient education may the public 
be brought to appreciate the dangers that lurk in the open ean of cheap milk. It rests with the doctor, who should inform himself thoroughly upon every phase of the subject. Cireulars giving full information may be obtained from health departments or milk commissions in any city, or from the United States Burean of Animal Industry.

In case the milk supply or its handling is not above suspicion, sterility may be secured by the applieation of heat. Different sterilizing devices are in use, from the mere scalding of the milk in a farina kettle to the more elaborate apparatus of Soxhlet, Arnold, Freeman, or Boeckman (Figs. 60, 61). A temperature of $212^{\circ} \mathrm{F}$. $\left(100^{\circ}\right.$ C.), maintained for over an hour, is required for complete sterilization. Milk thus treated and protected from subsequent infection will resist decomposition changes for two or three days, at ordinary temperature. For prolonged keeping, three sterilizations, after intervals of twenty-four hours, are

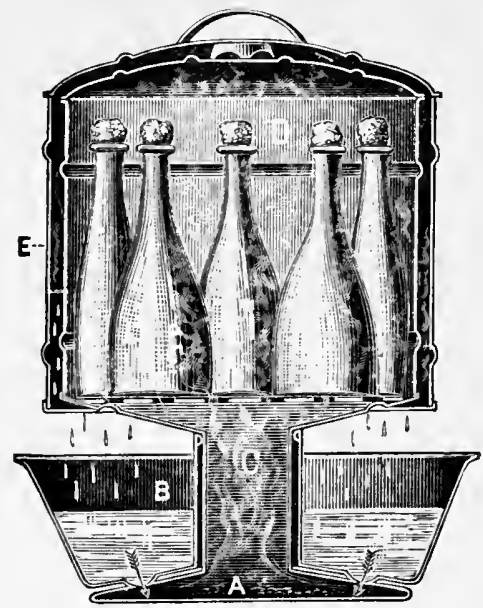

Fig. 61.-Arnold's sterilizer.

necessary. For immediate use, however, pasteurization-exposure to a temperature of $155^{\circ} \mathrm{F}$. $\left(68^{\circ} \mathrm{C}\right.$.) for forty minutes-is sufficient to meet all the requirements. Objections to prolonged boiling are due to changes in the nutritive quality of milk thus treated; the coagulation of the lactalbumin causing a loss in food value, at the same time the casein is rendered less soluble, as well as some of the calcium salts. Besides these changes the natural ferments are destroyed as well as the antiscorbutic element. If the milk, originally elean, is cooled to $40^{\circ} \mathrm{F}$. $\left(4.5^{\circ} \mathrm{C}\right.$. $) \mathrm{im}$ mediately after milking and kept on ice during shipment, it is better used raw in the majority of cases.

The dense coagulability of the casein of cow's milk renders the addition of an alkali necessary. For this purpose bicarbonate of sodium or liquor calcis may be used (preferably the latter, of which five to forty per cent. may be necessary). Of the sodium bicarbonate, one to two grains to the ounce of milk in the mixture may be sufficient. 


\section{CHAPTER XII}

\section{ARTIFICIAL FEEDING-Continued}

\section{HOME MODIFICATION OF MILK}

OF rules and methods for home modification a great number and variety have appeared, with the promise of more to come. Some are so crude as to amount to little more than dilutions, while others are so intricate in their formula and equation reductions as to be of little value except as mathematical curiosities. A rule from Baner, which commends itself on account of its simplicity and efficiency, is here given. Its application presupposes the percentages of fat, proteids, and sugar in cow's milk to be four each.*

First determine the quantity needed for the day's feeding and the percentages of ingredients. To find the amount of cream that will have to be used in the mixture, subtract proteid per cent. from fat per cent. and multiply the remainder by the total number of ounces of mixture divided by twelve. This gives the cream (16 per cent.) in ounces,-e.g., (Fat-Proteid) $\times \frac{\text { Quantity }}{\mathbf{1 2}}=$ Cream.

For estimation of milk, multiply quantity of mixture by proteids per cent. and divide by four. This gives total mixture of milk and cream. Subtract from this the amount of cream, the remainder will represent the milk,-e.g., Quantity $\times$ protelds $=$ mixture of cream and milk. Mixture-cream $=$ milk.

To obtain the amount of milk sugar, multiply the difference between sugar per cent. and proteid per cent., by quantity of mixture and divide

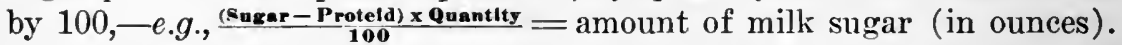

For twenty per cent. cream the denominator of the cream formula should be 16 instead of 12, and for twelve per cent. cream 8 would be required for the denominator. After the quantities of cream and milk have been determined, the rest of the total quantity of mixture is made up by the addition of water or other diluent. (Note.-The use of the centrifugal separator in our best dairies brings definite percentage cream within the reach of the majority of city consumers. Gravity cream from four per cent. milk may be obtained in approximately definite percentages as follows: Set the milk in a deep vessel on ice for twelve hours; the upper fifth will represent sixteen per cent. cream, best secured by siphoning from the bottom the lower four-fifths. Ordinary gravity cream represents sixteen per cent. fat; from this twelve per cent. cream may be obtained by taking two parts sixteen per cent. cream and one part milk of four per cent. fat.)

* The variability of different milks in their constituent percentages renders occasional testing necessary (page 100) for accuracy in feeding modifications. 


\begin{tabular}{|c|c|c|c|c|c|c|c|c|c|c|c|c|c|c|c|c|}
\hline & \multicolumn{4}{|c|}{$\begin{array}{c}\text { Twenty-ounce Mixtures, } \\
\text { percentage of }\end{array}$} & \multicolumn{4}{|c|}{ Ounces of Cream. } & \multicolumn{4}{|c|}{$\begin{array}{l}\text { Ounces of fat-free Milk } \\
\text { used with Creams of }\end{array}$} & \multicolumn{2}{|c|}{ Ounces of } & \multirow[b]{2}{*}{ 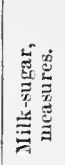 } & \multirow{2}{*}{ 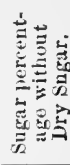 } \\
\hline$\frac{0}{2}$ & 馬 & 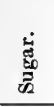 & 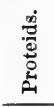 & 象总 & 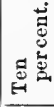 & 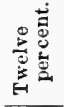 & 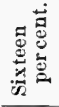 & 总 & 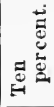 & | & 至 & 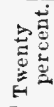 & 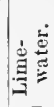 & 焉 & & \\
\hline & 1.50 & 4.50 & 0.25 & 5 & * & $*$ & * & $11 / 2$ & $*$ & $*$ & * & 0 & 1 & $171 / 2$ & 2 & \\
\hline $\begin{array}{l}\overline{2} \\
3\end{array}$ & 1.50 & 4.50 & 0.50 & 5 & $\begin{array}{l}3 \\
* \\
*\end{array}$ & $21 / 2$ & 2 & $11 / 2$ & 0 & $1 / 2$ & 1 & $1 \frac{1}{2}$ & 1 & $16^{22}$ & 2 & 0.61 \\
\hline 4 & 2.00 & 5.00 & 0.50 & 5 & * & $31 / 4$ & $21 / 2$ & ${ }_{2}^{2}$ & $*$ & 0 & $+1 / 2$ & 1 & 1 & $15^{3} / 4$ & $2^{2}$ & 0.73 \\
\hline 5 & 2.00 & 5.00 & 0.75 & 5 & 4 & $31 / 4$ & 219 & 2 & $3 / 4$ & $1 \frac{1}{3}$ & 213 & $2^{3} / 4$ & 1 & $141 / 2$ & $2^{-4}$ & 1.01 \\
\hline 6 & 2.00 & 5.50 & 1.00 & $\begin{array}{r}5 \\
5\end{array}$ & ${ }_{*}^{4}$ & $\begin{array}{l}31 / 4 \\
*\end{array}$ & $21 \frac{2}{2}$ & $\stackrel{2}{2}$ & $1_{*}^{13 / 4}$ & $\frac{21 / 2}{*}$ & $31 / 4$ & $3_{3}^{3}$ & 1 & 131 & 214 & 1.30 \\
\hline 8 & 2.50 & 5.50 & 0.75 & 5 & * & $41 / 4$ & $\begin{array}{l}31 / 4 \\
314 \\
3\end{array}$ & 213 & $*$ & $1 / 4$ & $11 / 4$ & $2^{\frac{14}{4}-1}$ & 1 & $11^{2} / 4$ & $\begin{array}{l}21 / 4 \\
21 / 4\end{array}$ & $\begin{array}{l}0.13 \\
1.01\end{array}$ \\
\hline 10 & $\begin{array}{l}2.50 \\
3.00\end{array}$ & $\begin{array}{l}6.00 \\
6.00\end{array}$ & $\begin{array}{l}1.00 \\
0.50\end{array}$ & $\begin{array}{l}5 \\
5\end{array}$ & $\begin{array}{l}5 \\
*\end{array}$ & $*^{41}$ & $\begin{array}{l}31 \\
33^{3}\end{array}$ & $21 / 2$ & $\begin{array}{l}1 \\
*\end{array}$ & $1^{13 / 4}$ & $2^{33}$ & $31 / 3$ & 1 & 13 & $2_{21}^{11}$ & 1.23 \\
\hline 31 & 3.00 & 6.00 & 0.75 & 5 & * & 5 & $3^{3 / 4} / 4$ & $\begin{array}{l}0 \\
3\end{array}$ & * & 0 & $11 / 4$ & $2^{-4}$ & 1 & 14 & $21 \%$ & \\
\hline 1 & & & 1. & 5 & 6 & 5 & $33 \frac{4}{4}$ & 3 & & & $21 / 4$ & 3 & . & & $2^{1 / 2} / 4$ & \\
\hline & & & & 5 & 6 & & 3 & & & & $31 \%$ & $41 / 4$ & & $11^{3} / 4$ & & \\
\hline 1 & & & 1. & 5 & 6 & & & & & & $4^{33}$ & $51 \frac{1}{3}$ & & $101 / 2$ & $21 / 4$ & 1.91 \\
\hline & & & & 5 & 6 & & $33^{3}$ & 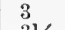 & & 61 & $7^{3}=4$ & $81 / 2$ & 1 & 713 & $2^{2}$ & \\
\hline 1 & & & 0. & 5 & * & * & $*$ & $31 / 3$ & * & & * & 0 & 1 & $151 / 2$ & $21 / 2$ & \\
\hline 1 & & & & 5 & * & 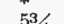 & $41 / 3$ & 313 & $*$ & * & 0 & $\frac{1}{01}$ & 1 & $171 / 3$ & $21 / 3$ & \\
\hline & $\begin{array}{l}3.50 \\
3.50\end{array}$ & $\begin{array}{l}6.50 \\
6.50\end{array}$ & $\begin{array}{l}1.00 \\
1.25\end{array}$ & 5 & 7 & $\begin{array}{l}00 / 4 \\
5^{3}\end{array}$ & $\begin{array}{l}41 / 2 \\
413\end{array}$ & $31 / 2$ & ${ }^{*} 1 /$ & 3. & $1 / 4$ & 4 & 1 & 1114 & 213 & 1.26 \\
\hline 2 & 3.50 & 6.50 & 1.50 & 5 & 7 & $5^{3 / 4}$ & $4 \frac{1}{2}$ & 31 & $2^{72}$ & $31 \frac{1}{4}$ & $\begin{array}{l}51 / 2 \\
41 / 2\end{array}$ & $\begin{array}{l}4 \\
51 /\end{array}$ & 1 & $10^{2}$ & 212 & $\begin{array}{l}1.68 \\
2.02\end{array}$ \\
\hline & 4.0 & 6.0 & 0.60 & 5 & * & $*$ & $*$ & 4 & $*$ & $*$ & $*$ & 0 & 1 & 15 & $21 / 2$ & 0.78 \\
\hline & 4.0 & & 0.7 & 5 & * & * & 5 & 4 & $*$ & * & 0 & 1 & 1 & 14 & $21 / 2$ & 1.12 \\
\hline & 4.0 & & 1.0 & 5 & * & * & 5 & 4 & $*$ & * & 1 & 2 & 1 & & 233 & 1.35 \\
\hline & 4.0 & & 1.2 & 5 & * & $6^{3} / 4$ & 5 & 4 & $*$ & $3 / 4$ & $21 / 2$ & $31 / 2$ & 1 & $111 / 2$ & $21 / 2$ & 1.68 \\
\hline & 4.0 & 7.8 & 1.50 & 5 & 8 & $63 / 4$ & 5 & 4 & 1 & 21 & 4 & 5 & 1 & 10 & $21 / 3$ & 2.02 \\
\hline & 4.0 & 7.0 & 2.00 & 5 & 8 & $6^{3} / 4$ & 5 & 4 & $31 / 3$ & $4^{33 / 4}$ & $61 / 3$ & $71 / 3$ & 1 & $71 / 3$ & $21 / 4$ & 2.56 \\
\hline 2 & $\begin{array}{r}4.00 \\
4.00\end{array}$ & 7.00 & $\begin{array}{l}2.50 \\
3.00\end{array}$ & $\begin{array}{l}5 \\
5\end{array}$ & $\begin{array}{l}8 \\
8\end{array}$ & $\begin{array}{l}6^{3} \\
6^{3}\end{array}$ & $\begin{array}{l}5 \\
5\end{array}$ & $\begin{array}{l}4 \\
4\end{array}$ & $\begin{array}{l}61 \\
91 \\
91\end{array}$ & $7^{71}$ & $91 / 4$ & $\begin{array}{l}10^{1} \\
13^{4}\end{array}$ & 1 & $\begin{array}{l}4^{3} \\
3^{3}\end{array}$ & ${ }_{11}^{2}$ & $\begin{array}{l}3.20 \\
388\end{array}$ \\
\hline & 4.0 & & 3.00 & 5 & 8 & 4 & 5 & 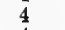 & $91 / 4$ & 1012 & $\begin{array}{l}121 \\
121\end{array}$ & 1314 & 1 & $13 / 4$ & 1 & $\begin{array}{l}.0 .00 \\
3.88\end{array}$ \\
\hline & 4.00 & 5.50 & 3.00 & 5 & 8 & 634 & 5 & 4 & $91 / 4$ & $101 / 2$ & $121 / 4$ & $131 / 4$ & 1 & $13 / 4$ & $3 / 4$ & 3.88 \\
\hline
\end{tabular}

* Combination impossible with percentage of cream indicated.

For 25 -ounce mixtures multiply the amount of each ingredient by $11 / 4$.

For 30-ounce mixtures multiply the amount of each ingredient by $11 \%$

For 35-ounce mixtures multiply the amount of each ingredient by $13 / 4$.

For 40-ounce mixtures multiply the amount of each ingredient by 2 .

For 15-ounce mixtures multiply the amount of each ingredient by 2144 .

FIG. 62.-Ladd's table.

\section{RULES FOR FEEDING}

Day feedings begin 6 A.M., end 10 P.M.

\begin{tabular}{|c|c|c|c|c|c|}
\hline 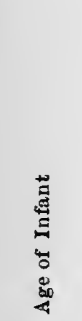 & 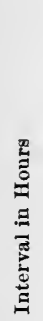 & 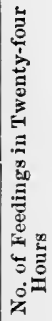 & 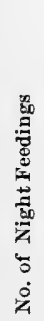 & 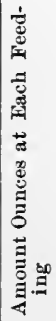 & 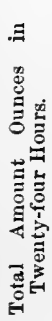 \\
\hline 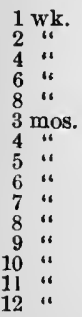 & $\begin{array}{l}2 \\
2 \\
2 \\
21 / 3 \\
2^{1} / 3 \\
2^{1} / 2 \\
21 / 2 \\
3 \\
3 \\
3 \\
3 \\
3 \\
3 \\
3 \\
3\end{array}$ & $\begin{array}{r}10 \\
10 \\
9 \\
8 \\
8 \\
7 \\
7 \\
6 \\
6 \\
6 \\
6 \\
6 \\
5 \\
5 \\
5\end{array}$ & $\begin{array}{l}1 \\
1 \\
1 \\
1 \\
1 \\
0 \\
0 \\
0 \\
0 \\
0 \\
0 \\
0 \\
0 \\
0 \\
0\end{array}$ & $\begin{array}{l}1 \\
11 / 2 \\
21 / 2 \\
3 \\
31 / 4 \\
4 \\
41 / 2 \\
5^{1 / 2} \\
5^{3 / 4} \\
66^{1 / 4} \\
7 \\
7 \\
81 / 3 \\
83 / 4 \\
9\end{array}$ & $\begin{array}{l}10 \\
15 \\
221 / 2 \\
24 \\
26 \\
28 \\
311 / 2 \\
33 \\
341 / 2 \\
371 / 2 \\
42 \\
42 \\
421 / 3 \\
431 / 4 \\
45\end{array}$ \\
\hline
\end{tabular}

\section{WHEY CREAM MIXTURES}

Whey cream mixtures may be obtaned by using whey as a diluent in place of the boiled water, preferably in the combinations containing low proteid percentages. Each 2 ounces of whey replacing an equal quantity of water in a twenty-ounce mixture will raise the whey proteid percentage 0.10 , and will increase the sugar percentage 0.50 . The total sugar percentage is, therefore, the amount contributed by the cream and fat free milk, which is indicated in the last column of the table-on the reverse of the card,-plus that of the whey. The amount of dry sugar which must be added to make the desired final sugar percentage can be easily calculated by reference to the following table:

1 measure of dry lactose in a $20-\mathrm{oz}$. mixture gives 2.00 per cent. of sugar.

$$
1 / 20 \text { “ “ “ “ }
$$

(One measure is approximately one level tablespoonful.)

Example. If in formula 21 fourteen ounces of whey are added in place of the saine quantity of water, the whey proteids are increased 0.70 per cent., making total proteids of 1.30 per cent. The sugar contributed by the cream is 0.78 ; by the whey 350 ,-making a total of 4.28 . The desired percentage of sugar is 6 , therefore the balance of 1.72 per cent. may be obtained by adding a little short of one measure of sugar.

Whey should be made of fat free milk, and should be heated to $150^{\circ} \mathrm{F}$. $\left(65^{\circ} \mathrm{C}\right.$.) before it is added to the cream mixture, to destroy the rennin enzyme. One quart of fat free milk will yield about twenty-four ounces of whey.

Formula on which the average Healthy BabY MaY be Started Premature .............. 1 or $2 \quad 4-6$ months.......... 24 or 25 $2-4$ weeks...........No. $5,8,9$ or $11 \quad 6-8$ months.......... No. 26 or 27 1-2 menths............ 12 or $13 \quad 8-9$ months......... No. 28 2-4 months.............. 19 or 20

TabLe for Estination of Fat Percentages in Creams.

One quart of whole milk, of 4 per cent. fat, will yield on an average, approximately :

Cream..........10 per cent. in the upper $8 \mathrm{oz}$, after 6 hours

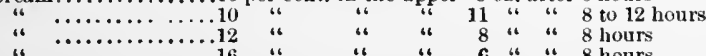

"

"

FIG. (33.-Ladd's table, reverse side. 
Ir. क.

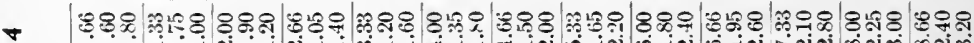
- -

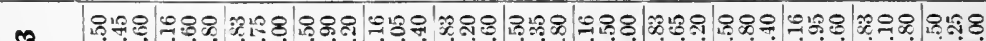
m - $-\mathrm{i}$ -

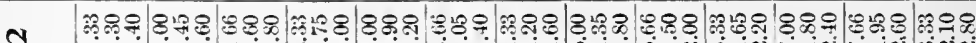

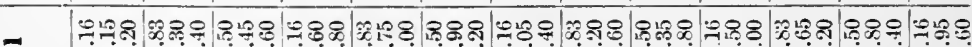
-

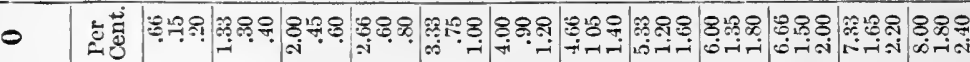

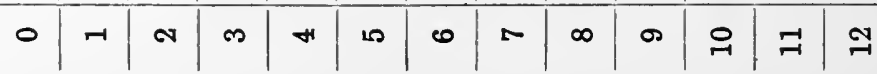


Dr. Maynard Ladd, of Boston, has published a table from which almost any desired formula may be quickly determined with reasonable accuracy. The table (Fig. 62) is printed upon a eard and carriet in the pocket for ready references. The reverse side (Fig. 63) gives rules for whey-cream mixtures (split proteids), suggestions about feeding, and estimations of fat percentages in different top milks. The tables are computed on the basis of milk which contains 4 per cent. fat, 4.50 per cent. sugar, and 3.50 per cent. proteids, and are used as tollows:

From the thirty formulæ seleet one whose fat, sugar, and proteid most nearly approximate the desired pereentages of these ingredients in a twenty-ounce mixture. Follow the line of this formula to the right to find the quantity in ounces of eream of a strength indicated at the top of the cream eolumn; also the neeessary quantity of skim-milk in the corresponding milk column; next the lime-water for a five per cent. alkalinity; then the boiled water diluent, and lastly the measures (tablespoonfuls) of milk sugar. Obviously to prepare a mixture of more than twenty ounces each ingredient must be proportionately increased. See last column.

H. B. Gurler, of DeKalb, Illinois, furnishes to physicians a table for home modification of his certified milk, which contains fat 4 to 4.2 per cent.; proteids 3.4 to 3.8 per cent.; sugar 4.6 to 5 per eent., and cream containing fat 16 to 16.2 per cent. (Fig. 64).

An ingenious chart for milk modification, designed by Dr. T. S. Westcott, of Philadelphia, consists of two revolving cardboard disks, with numbers so arranged that by simple manipulation the relative quantities of ingredients are automatically eomputed (Fig. 65).

Many practitioners who have not had previous drill cannot spare or will not take the time to work out these formulie for themselves. For their assistance many rules, approximately correct, in tablespoonfuls and ounces, have been suggested. A seven-panelled glass graduate, called the "Materna" (Fig. 66), has been presented by a New York firm, on each panel of which markings indicate the necessary amount of milk, sugar, water, lime-water, and eream, respectively, to secure certain percentages, which are also marked on the panel. Two objections should be noted: its routine employment may tend to divert the physician from thinking; the other is suggested by the directions for feeding by age of patient, which is about as uncertain a standard as color of hair. Some physicians employ slips, carrying printed directions to nurse or mother, so arranged that they may be changed easily to meet the requirements of particular cases.

Dr. H. D. Chapin has devised a method of removing the top milk from the milk bottle for home modification, which he claims is especially applicable to the needs of the nursery. He employs a small tin dipper with a vertical wire handle (Fig. 67). This dipper holds one ounce of cream or one ounce of granulated sugar, and a dipper and one-half represents an ounce of milk sugar. As a result of experiment and numerous assays, Dr. Chapin has found that if nine ounces are removed from the 
top of the bottle and mixed together the product represents, with great uniformity, twelve per cent. cream. To get eight per cent. cream it is

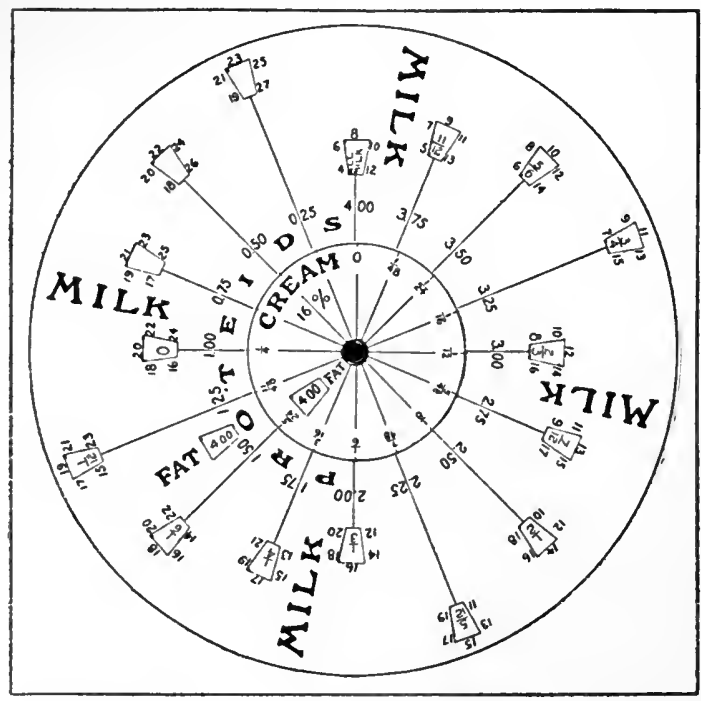

FIG. 65.-Westcott's chart.

only necessary to remove and mix sixteen ounces from the top of the bottle. The above is applicable only to milk which has been bottled long enough to allow segregation by gravity.

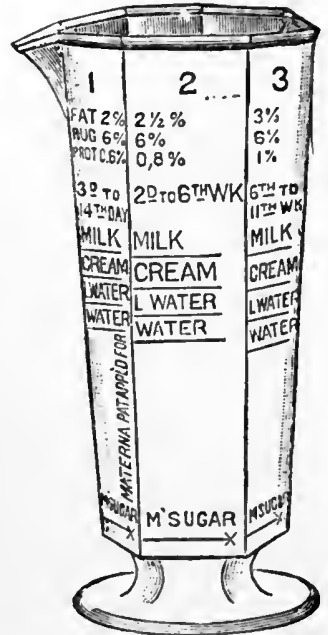

FIG. 66.-Mlaterna.

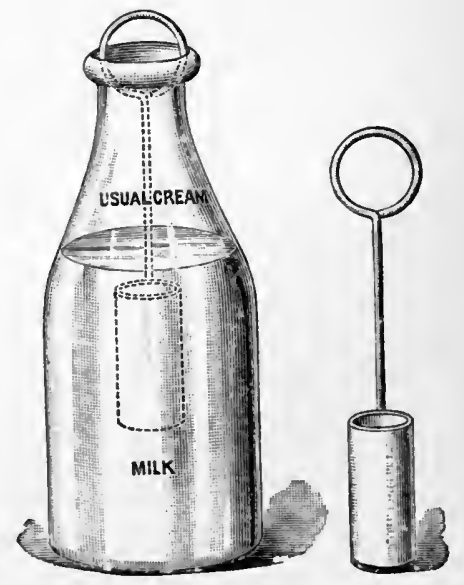

FIG. 67.-Chapin's dipper.

To prepare twenty-four fluidounces of food containing three per cent. fat, one per cent. proteids, and six per cent. sugar, use six fluid- 
ounces of twelve per cent. cream, eighteen fluidounces of diluent, and one and one-fifth ounces of sugar. Similarly, to prepare forty fluidounces of food containing four per cent. fat, two per cent. proteids, and seven per cent. sugar, use twenty fluidounces of eight per cent. cream, twenty fluidounces of diluent, and two ounces of sugar.

Dr. J. F. Connors has arranged a key, applicable to the home modification of bottled milk by the Chapin " dipper" method, eoncerning which the author says: "To make up any desired percentage mixture: (1) Look in the proteid column for desired percentage, using the one nearest to it. (2) Move in a horizontal line to the left until the desired percentage of fat is reached or near it. (3) The heading of the fat column tells what kind of milk is to be used; and (4) the first column

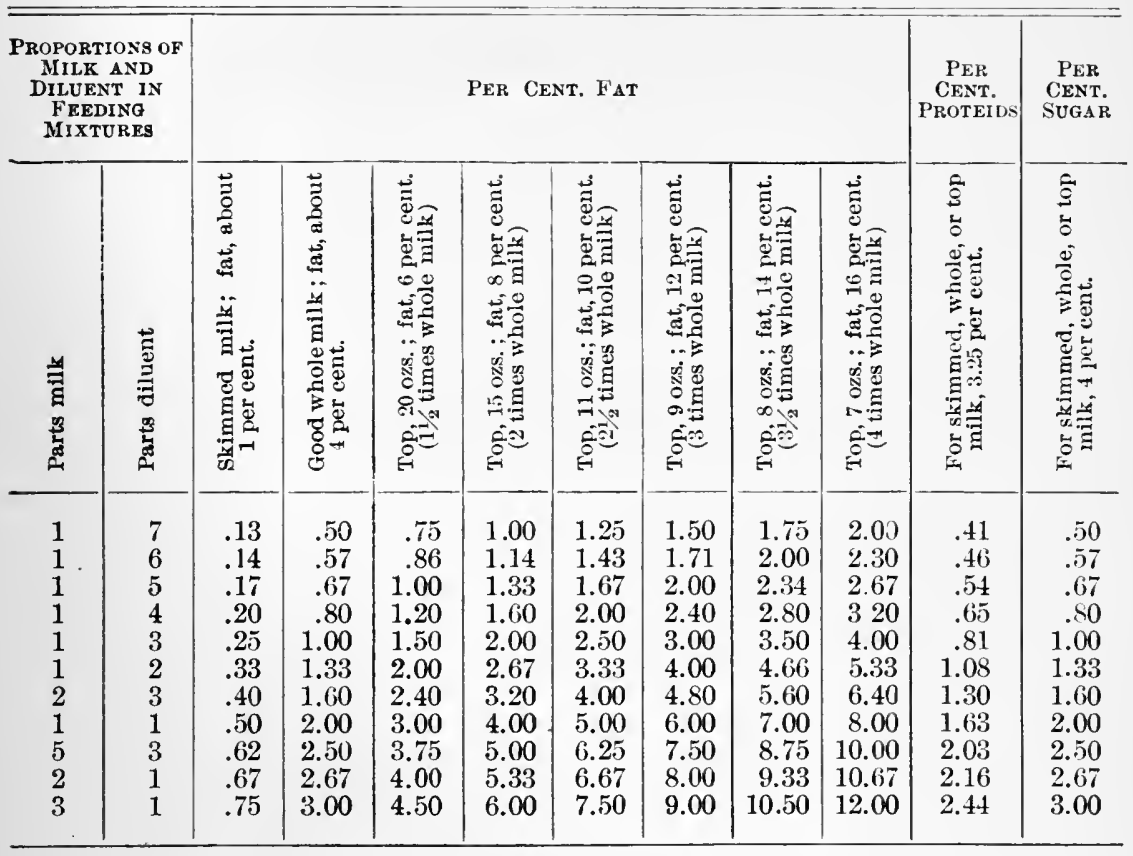

F1G. 68.-Dr. Connor's table.

of the table, what proportion of the feeding mixture the milk must be. (5) In preparing the food use good bottled milk and dilute all or part of it, depending on the quantity of food to be made up. Mixtures made from poor milk will be one-fourth weaker, from Jersey milk one-fourth stronger. (6) The sugar column shows the percentage of sugar in the diluted milk; one part sugar to fifty parts food add two per cent.; to thirty-three parts three per cent.; to twenty-five parts four per cent.; and to twenty parts five per cent. Two even tablespoonfuls of granulated sugar or three of milk sugar equal one ounce (Fig. 68).

In regard to all devices it is suggested that the young physician first 
form the habit of thinking and formulating for himself, after which he may best judge of their value. Whatever method be employed, one essential must never be lost sight of in order to secure even approximate accuracy of ingredient percentages,-viz., a predetermination of the gross constituents of the milk used. Certified milk gnarantees certain percentages. Centrifugalized cream may be ordered of definite fat per cent. and fat-free milk may be obtained by siphoning the lower half of the bottle after it has creamed. Milk of unknown quality may be tested by the methods described on page 100 .

In substitute feeding the aseptic care of the bottle, nipples, and all utensils eannot be unduly emphasized. The familiar death-trap known as the long tube nursing bottle has at last attracted the attention of legislators, so that in some localities not only the use but also the sale is prohibited by law.

For home modification the mother or nurse must be instructed in regard to all details and supplied with the necessary utensils. These include a good ice-box, two siphons (made by bending glass tubing), sterilizer or pasteurizer, thermometer registering to $212^{\circ} \mathrm{F}$. $\left(100^{\circ} \mathrm{C}\right.$. $)$, a dozen grachuated feeding tubes (large mouth without shoulder with small lip), bottle brushes, absorbent cotton, straining gauze, nonabsorbent cotton for stoppers, mixing pitcher, eight-ounce graduate glass funnel, tall cup for warming bottle, six black rubber nipples (to fit mouth of tubes, reversible for cleaning), bicarbonate of soda and boric acid.

Lime-water should be kept in corked bottles. Milk-sugar solution should be prepared fresh for each day's supply. The supply of food may be prepared once or twice in the twenty-four hours, dependent upon the time of milk delivery and number of tubes to be handled. The milk should always be kept on ice before and after preparation.

All bottles and utensils should be washed with hot soap-suds, then dozen graduated feeding tubes (large mouth without shoulder with ont with soap and water, rinsed and kept in a solution of soda or boric acid until again needed. Milk tubes when filled should be stoppered with nonabsorbent cotton so that in cooling the air may pass through. After warming to about $100^{\circ} \mathrm{F}$. $\left(38^{\circ} \mathrm{C}\right.$.) by standing the bottle in a cup of warm water, the cotton is replaced by the nipple.

After nursing, any food remaining in the bottle must be thrown away. Flies should never be allowed to touch food, utensils, or baby. Of course, the nurse will never touch the nipple with her lips. The temperature of the milk may be tested by allowing a few drops to fall upon the back of the hand. The bottle should be held inverted in the hand during the feeding so that the babe will not suck air (Fig. 69). If the milk flow be too free the nipple may be withdrawn from time to time so that about twenty minutes is consumed in the feeding, during which the babe would better be on the arm or lap of the nurse. If the milk does not drop freely enough more holes should be made in the nipple by means of a hot needle. 
The rules for feeding, as to regularity, number, and length of intervals, should be about the same as those given for infants at the breast (page 87). Water between feedings is generally required and to it ravenous infant should be freely given. The water should be boiled and cooled, and may be given from either bottle or spoon.

As a rule, artifieial feeding in the normal vigorous babies shoukl be begun with formulie representing low percentages. Especially is this true of the proteids. Taking average mother's milk as a standard the pereentage of sugar may be about the same, the fats about half, and the proteids about one-third, remembering that temporary error on the side of underfeeding is easier of eorrection than the more eommon mistake of overfeeding.

Since the milk of other mammals somewhat elosely resembles the human product, and its abundant supply is eo-extensive with man, the

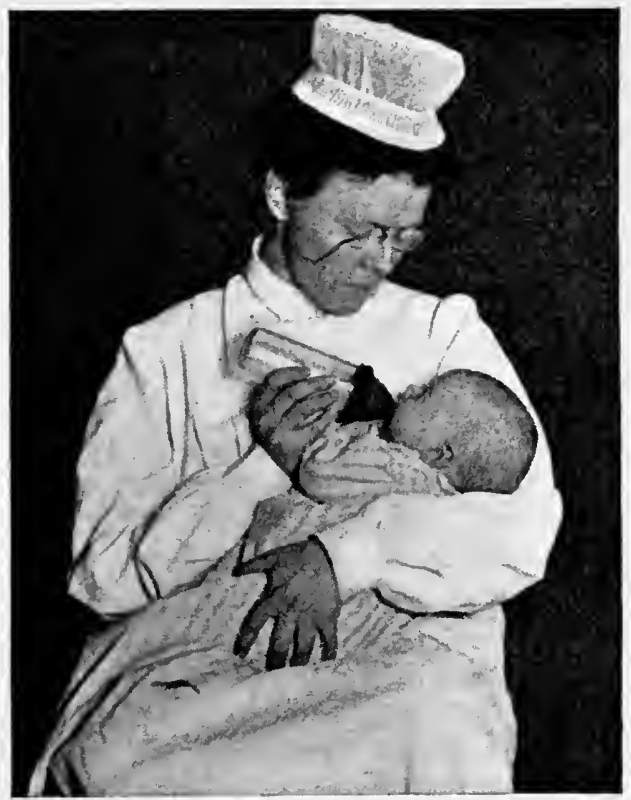

FIG. 69.-Correct position in artificial feeding.

question may again be raised why the multiplieity of baby foods, especially when it is known that milk is the eheapest. In this instance "eommercial enterprise" will not serve as an answer, for the demand must have existed to which the latter has responded. Without further argument it is quite evident that cow's milk has failed to fulfil all the requirements of substitute feeding, and in their need both laity and profession have turned to other sourees. Some of the objeetions to eow's milk as ordinarily obtained by the eonsumer have been mentioned (the high percentage of proteids, low percentage of sugar, reaction and in- 
fection). These objectionable features having been overcome, partly by the improved hygiene in production and handling, and partly by the elaborate percentage modification previously referred to, the question of substitute feeding would appear to have reached a solution. In this case the only obstacles to its universal adoption would seem to be the cupidity of the manufacturer of baby foods and the credulity of the purchaser. In fact, this is the view taken by many conscientious baby feeders. Were the solution of this problem attained, however, the most eminent observers and thinkers would not be found still struggling with it. As it is, medical literature and reports of society proceedings teem with discussions upon this ever-interesting subject. It is known that cow's milk, modified never so wisely, cannot be made to suit all requirements of infant digestion. Many infants, no doubt the majority, thrive on it, and the careful modification of its constituents has largely increased this number. There still remains, however, an appreciable percentage of eases in which the proteids of cow's milk are not tolerated, and occasionally the fats are nonassimilable.

The lowest reduction possible in the laboratory manipulations of cow's milk still leaves the proteids as 0.22 per cent. It is hardly necessary to state that no infant will long survive this reduction. A higher percentage of digestible proteids is absolutely essential to nutrition and growth. As shown in a previous chapter, their place cannot be filled by any known substitute. Moreover, the albuminoids of mother's milk differ essentially from those of cow's milk. By taking two watch-crystals, filled with a weak solution of acetic acid, and letting fall into them from a height of two or three inches a drop of mother's milk and a drop of cow's milk respectively, one of these differences becomes apparent,- the easein of mother's milk coagulating in light, loose floceuli, which disseminate throughout the fluid; that of the cow's showing dense and heavy eurds which fall to the bottom. In other words, the proportion of proteid coagulable by acid (casein) is much greater in cow's milk than in human milk. Whereas the proportion of calcium casein to lactalbumin in breast milk is only 1 to 2 , in cow's milk it is nearly 7 to 2 . In other words, while the casein of cow's milk is nearly four times that of breast milk, the noncoagulable proteids (lactalbumin, lactoglobulin, etc.) amount to less than half those found in breast milk.

It seems hardly necessary to repeat the statement that the finely subdivided precipitate of breast milk favors the action of the digestive secretions, while the dense curds of cow's milk resist this action so long that fermentation often ensues, with all its train of intestinal disturbances. Wroblewski demonstrated that human casein retains, during digestion, its nuclein in solution; it is fully digested; while in cow's casein the nuclein is not fully digested; a "paranuclein" is deposited undissolved and undigested.

From his studies of nucleon Siegfried found that cow's milk contains 0.057 and woman's milk 0.124 per cent. nucleon. In cow's milk the 
phosphorus of the nucleon is only six per cent. of the total amount of phosphorus contained in the milk; in woman's milk it is more than forty-one per cent.

Practically all the phosphorus in human milk is in organic combination (nucleon and caseinogen). Concerning this point Salkowski says : "These conditions are evidently of the greatest moment in the nutrition of the nursling. As the development of the bones is more rapidly accomplished in the nurslings fed on woman's milk than in those fed on cow's milk, the probable conclusion is this : that nucleon has an important part in the absorption and assimilation of phosphorus. The same should be said of calcium, which also combines with nucleon. Although woman's milk contains less calcium than cow's milk, more calcium is utilized and the nucleon is evidently an important factor in its absorption." Woman's milk contains more lecithin than that of other mammals, a fact of great importance, as lecithin is necessary to the development of the brain and nervous system, and is an important constituent of all cells.

From the above, some explanation may be drawn: First, as to why some infants cannot be induced to tolerate cow's milk in any of its possible modifications; second, why normal nutrition cannot be maintained even though digestive toleration be established. The assertion that strong children may tolerate cow proteids, even though not greatly reduced, does not apply, for the reason that it is for the weakly infant with the feeble digestion that the skill of the physician is sought. It was formerly believed that some of the other mammals furnish a more digestible proteid than the cow; hence the goat, ass, and mare, respectively, have been extolled for this quality of their product. Clinical observation, however, shows little advantage over cow's milk. The following analyses by König give the relative percentages of constituents :

\begin{tabular}{|c|c|c|c|c|c|}
\hline & Casein & Albumin & Fat & Sugar & Ash \\
\hline Goat & 3.20 & 1.09 & 4.78 & 4.46 & 0.76 \\
\hline Ass & 0.67 & 1.55 & 1.64 & 5.99 & 0.51 \\
\hline Ewe & 4.97 & 1.55 & 6.86 & 4.91 & 0.39 \\
\hline Mare & 1.24 & 0.07 & 1.21 & 5.67 & 0.35 \\
\hline
\end{tabular}

For feeble or impaired digestion, on account of the intractability of casein, partial predigestion of the milk has been practised; thus, the addition of pancreatic extract, commonly used in Fairchild's process, wrongly called "peptonization," has occasionally proved efficacious.

Fairchild's tubes contain extractum pancreatis and sodium bicarbonate in sufficient quantity for the treatment of one pint of cow's milk. The milk is first gently warmed, then the contents of the tube stirred in, and the mixture brought to a boil in ten minutes. The boiling arrests the "peptonizing" process and destroys the ferment. This partial conversion renders the casein more flocculent and less coagulable in the stomach, and allows its early escape into the intestine where the digestive process in early infancy rightly belongs. That such efforts at predigestion may, if prolonged, prove pernicious is evident in view of the 
seventh essential (page 111), since it defeats nature's methods of gastric development, from the lack of muscular and secretory stimulus afforded by the presence of curds of calcium paracasein and free paracasein in the stomach.

Koumiss, matzoon, and kephir-milk are merely expressions of an effort to rid cow's, mare's, and goat's milk of this offending substance by changing ealcium casein into the lactate or some other acid salt of casein before ingestion, so that dense coagulation in the stomach by the action of rennin is prevented.

Decaseinized Milk.-Into a pint of warm milk stir a teaspoonful of Fairchild's essence of pepsin. After coagulation (about twenty minutes) break up the clot with a fork, and strain through thin muslin without pressure. The whey containing soluble proteids, lactose, and salts, may be enriched by the addition of cream and sugar of milk, while the deficient albuminoids may be supplied from egg albumin. Egg white is also suceessfully used in laboratory modification for infants intolerant of cow casein. A liberal estimate gives one per cent. albuminoid from the white of one egg in a pint mixture, so that a prescription might be written and made up as follows:

$\mathrm{B}$

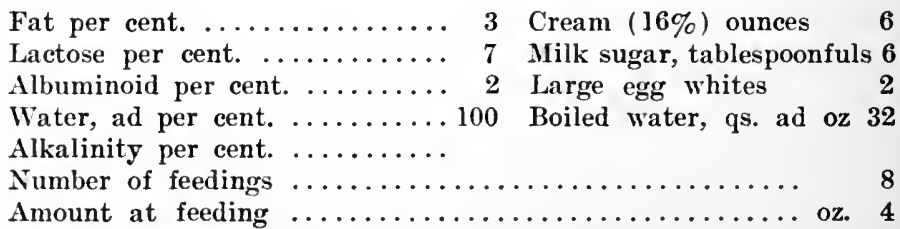

In the above prescription some of the proteids and lactose are still retained from the cream, necessary to secure the three per cent. fat. The egg, as a source of albumin, so long recognized as valuable in tiding over critical periods of indigestion in infants, has not received the consideration it deserves. Its ready solubility, its sterility when fairly handled, its richness in albumin, steady supply, and cheapness, all commend it; while its ready digestibility and assimilation by the most intolerant digestive tract have long been recognized facts. The objection that it is "troublesome and messy" would apply equally well to most of the food preparations. An objection that sometimes it induces ill-smelling dejections, might be met by the suggestion that a small quantity of sulphuretted hydrogen is innocuous, or the quantity of egg in the mixture may be reduced. As egg albumin does not fill the entire rôle of proteids in metabolism, and since it lacks the coagulability with rennin so essential to gastric development, it should never be employed to the entire exclusion of casein for long periods, but merely to tide over, or to help out, in conditions of intolerance to cow proteids.

For similar reasons the use of whey alone as a source of proteids should never be protracted beyond the period of emergency.

The yolk of egg may profitably be employed in feeding mixtures for 
infants who are intolerant of milk fat, the volatile acids of which often prove irritating. The ealorie fat value of the average yolk is claimed to equal that of one ounce of 20 per cent. eream. It also contains more lecithin and considerably less butyrie and other volatile acids. As the average yolk weighs three drachms, half a drachm in a two and a half ounce feeding would represent 1 per cent. of fat. This, with an appropriate amount of milk sugar added to whey, may be borne by a young infant whose digestive tract is intolerant of butter fat. Its nutrient value has been demonstrated beyond question.

\section{DECALCIFIED MILK.}

Since the heavy coagulability of eow proteids is held largely responsible for the dyspepsia, their reduetion will frequently relieve it, but not always. A little reflection may explain one of the anomalies most perplexing to those feeders who pin faith to the efficaey of eurd reduetion through extreme dilution with water. If in a given quantity of cow's milk a more or less dense eurd of ealeium paracasein be preeipitated by the rennin and acid of the stomach, it is probable (from its behavior in vitreo) that a diminution in the mere quantity of calcium easein, the rennin and acid remaining the same, will result in a denser eurd formation, although in lessened amount. This is seen by the persistence in the stools of undigested curds, even though the food be reduced to merely weak eream, sugar and water. This fact may help to explain the frequent improvement in digestion, and the disappearanee of eurds from the stools when the milk content of the food is notably increased; also the results claimed by M. Budin, of Paris, who for years has fed whole milk, on the ground that the dilution of cow's milk is one cause for the appearance of curds in the stools. To seeure not only toleration, but digestion and assimilation of the cow easein, in amounts suffieient for a balanced nutrition, would appear to be the kernel of this much discussed subject.

Attenuation of the caleium paraeasein curds through the mechanical action of cereal gruels, so long advoeated by Jacobi and recently demonstrated by Chapin, has been widely endorsed both in this country and Europe.

Since the large quantity of lime-salts is held responsible for the dense calcium paracasein eurds of eow's milk, it has been suggested by Dr. A. E. Wright, of England, that a portion of the ealcium salts be precipitated by sodium citrate (a salt not foreign to milk), and thus seeure softer paracasein curd in the infant stomach. Its action is demonstrated by Dr. F. J. Poynton, of London, as follows: Into each of two test-tubes, Nos. 1 and 2, is placed one ounce of cow's milk, five drops of rennet, and five drops of a 0.5 per cent. solution of hydrochlorie acid. Into No. 2 is also placed three grains of sodium eitrate. After standing an equal length of time, No. 1 exhibits a dense clot; No. 2 a very fine clot, the fluid showing greater transluceney than in No. 1. Dr. Poynton, at Great Ormond Street, and Dr. J. W. Vanderslice, at Chicago, are using the 
sodium citrate in their out-patient feeding with apparent suceess. Modification of the curd may be secured by varying the quantity of sodium citrate used, so that, within certain limits, the density of the curdling is under control.

For a moderate degree of disturbance one grain of sodium citrate to the ounce of milk is used; for more severe grades, two, three, or even five grains may be added. In practice the mother is instructed as to the proper dilution of the milk, and the proportions of cream and sugar for each bottle. In addition, she is given a bottle of "medicine" from which one teaspoonful is to be added to the baby's bottle before feeding. This "medicine" is an aqueous solution of sodium citrate; one, two, or three grains to the teaspoonful, according to the prescriber's judgment, based upon the evidences of casein indigestion.

The flexibility of this method of feeding commends it, since by increasing the strength of the "medicine" the quantity of milk may be augmented to meet the requirements of nutrition with lessened danger of casein indigestion.

As toleration and gastric vigor are developed, the sodium citrate may be gradually reduced and finally withdrawn.

It has been fashionable of late to decry the cereals as a source of the constituents for substitute feeding, and not without some reason, as the weazened infant, starved on starch, and the over-fatted, rhachitic, sugar-fed baby are familiar pictures. From the fact, early established by the physiologists, that the salivary and pancreatic secretions of young infants show limited amylolytic power, it was believed by many that starch should have no place in the diet of the infant. Indisputable clinical evidence, however, has demonstrated that a limited amount of well-cooked starch, in the form of cereal gruels and jellies, when mixed with milk, is not only tolerated, but favors nutrition; probably on account of its own partial conversion by the secretions, and partly through its influence in preventing the too dense coagulation of the cow proteids. Dextrinization of gruels (Appendix) undoubtedly adds to their food value. Analysis of barley water, given below, affords no explanation for the nutritive value it displays in many pathologic conditions in which, for a time, it is the only food ingested.

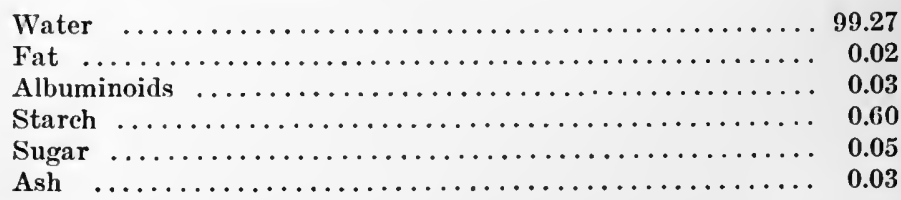

Many of the so-called baby foods contain little more than starch, and on that account cannot be too severely criticised; but the practice somewhat in vogue of denouncing the entire array of proprietary foods on that account is thoughtless and unjust.

There is enough reason for the condemnation of the majority of 
these foods because of the excess or deficiency of some constituents, but each should be judged upon its merits. On the other hand, there is much to recommend in some of these preparations, since intelligent manipulation, by supplying a deficieney, may convert a patent preparation into a most valuable adjunct in substitute feeding.

The multitude of preparations may be divided into four general classes, as to their composition, more of preparation, etc. :

(1) Milk foods, which consist wholly or partly of milk, with or without the addition of other ingredients, all or a portion of the water having been evaporated.

(2) So-called dextrinized foods, derived from cereal flour, in which the starch is partly converted by eooking and its own diastase, the great bulk, however, remaining as starch.

(3) So-called Liebig's foods, in which the diastasic action of malt is secured by its admixture with the ground cereal. It is then submitted to heat, with the result of partial or entire conversion into dextrin and maltose.

(4) A combination of Class 2 or 3 with milk, meat juice, or egg albumin.

A list of a few of the preparations in our market, with their analyses, is hereby tabulated.

Composition of some infant foods as prepared for the nursing bottle in comparison with mother's milk. Prepared according to directions for infants of six months:

\begin{tabular}{|c|c|c|c|c|c|c|c|c|}
\hline & \multirow{2}{*}{ 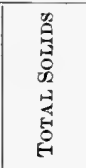 } & \multirow[b]{2}{*}{ 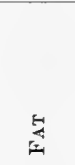 } & \multirow{2}{*}{ 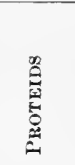 } & \multirow{2}{*}{ 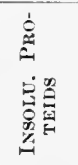 } & \multirow{2}{*}{ 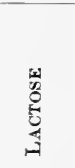 } & \multicolumn{2}{|c|}{$\begin{array}{c}\text { CARBOHY- } \\
\text { DRATES }\end{array}$} & \multirow[b]{2}{*}{$\frac{\mathbf{s}_{2}}{4}$} \\
\hline & & & & & & Solu. & Insolu. & \\
\hline Mother's milk ${ }^{1}$ & 13.26 & 4.13 & 2.00 & 0 & 6.93 & 0 & 0 & 0.20 \\
\hline Cow & 12.61 & 3. & 3.7 & 0 & 4.42 & 0 & 0 & 0.68 \\
\hline Condensed milik & 5.18 & 0.53 & 0.6 & 0 & .78 & 3.12 & 0 & 0.10 \\
\hline Peptogenic milk powder & 13.97 & 4.38 & 2.09 & 0 & 7.26 & 0 & 0 & 0.26 \\
\hline Milk & 8.09 & 0.59 & 1.1 & 0 & -5 & $9-$ & 1.13 & 0.11 \\
\hline Malted milk ${ }^{4}$. & 7.43 & 0.68 & 1.15 & trace & 1.18 & 4.20 & 0 & 0.29 \\
\hline Mellin's food 4 . & 12.00 & 2.85 & 2.62 & & 3.25 & 2.73 & 0 & 0.47 \\
\hline Nestlé's food ${ }^{4} . .$. . & 7.24 & 0.36 & 0.36 & 0.45 & 0.84 & 3.01 & 1.99 & 0.13 \\
\hline Imperial granum ${ }^{4} . \ldots \ldots$ & 8.47 & 1.54 & 1. 67 & 0.48 & 2.71 & 0.58 & 1.22 & 0.34 \\
\hline Eskay's albuminized fooc & 11.33 & 4.16 & 1.72 & & & & & \\
\hline
\end{tabular}

${ }^{1}$ Leeds. ${ }^{2}$ E. E. Smith. ${ }^{3}$ Minn. Dairy Rep., 1896. ${ }^{4}$ Chittenden. ${ }^{5}$ Leffman.

As stated, these analyses represent the constituent percentages as they appear in the nursing bottle ready for feeding. The condensed milk is attenuated with twelve parts of water, and its 3.12 per cent. of soluble carbohydrates is eane-sugar added as preservative.

Peptogenic milk-powder is prepared for feeding by heating the powder in a given quantity of milk, cream, and water. Mellin's food, Imperial Granum, and Eskay's food, all require the addition of milk or 
milk and cream for use. Milkine, Nestlés food, and malted milk are prepared with water only.

The most notable feature in these foods is the paucity of fat, which important ingredient, when present, is due almost entirely to the added milk or eream. Much the same may be said of the proteids in these foods, with perhaps the exception of milkine and malted milk. All are low in lactose, and four show from one to two per cent. insoluble carbohydrates, probably starch. Of the entire gromp nothing appears which is necessarily injurious to vigorous digestive organs. The excess of cane-sugar in condensed milk is frequently criticised as favoring fermentation if its use be long continued.

Applying the "essentials" (Chapter $\mathrm{X}$ ), it will be seen that no food, as presented here, fulfils all the requirements of nutrition, even if well borne. It is easy to see how some of these foods might prove very valuable by the addition of cream or milk-sugar, or both. Thus milkine and malted milk would be improved by an inerease of fat. Nestlé's food shows difficulties in adaptation to the requirements of the infant in the presence of insoluble proteids and earbohydrates, and in the low percentage of essential constituents.

Six things are to be kept constantly in mind in substitute feeding:

(1) That the long-continued use of food deficient in fat and lecithin tends to the production of malnutrition and rickets.

(2) Deficiency in soluble proteids retards all development. It is slow starvation.

(3) The use of cooked foods may result in scorbutus, hence even sterilized milk should not be administered continuously.

(4) Food which would not meet the requirements of nutrition for a long-continued period, because defieient in some essential constituent, may be used temporarily, as in travelling, weaning, or temporary removal from the breast.

(5) Gastric digestion must be developed by some substance which furnishes soft coagula, for which purpose nothing is known to equal milk.

(6) It is not sufficient merely to correct dyspepsia; the infant must be nourished and show a gain in weight and strength. 


\section{CHAPTER XIII}

\section{HYGIENE OF LATER INFANCY}

\section{CARE OF THE MOUTH AND NASOPIIARYNX}

AT the beginning of the second year the average child shows six teeth. The canines should have been cut before the end of the second year. The eruption of the second molars terminates first dentition, which should be completed by the thirtieth month. Too much emphasis cannot be placed upon the eare of the temporary teeth. Nechanical injuries to the enamel, also necrosis, should be guarded against. All defects should be repaired in order to preserve them in situ until complete absorption of the roots by their permanent successors. By this means, the normal conformation of the maxillary structures is secured during the rapid facial development. Many irregularities of the permanent teeth may be prevented by early eare of the temporary. Further, hygiene of the mouth is demanded becanse the decomposition of particles of food favors development of toxins and accumulation of many varieties of bacteria.

The use of a tooth-brush and antiseptic washes should be earnestly insisted upon. Of equal importance is the care of. the fauces, nasal passages, and pharynx. The above-mentioned areas, from the bacterio-

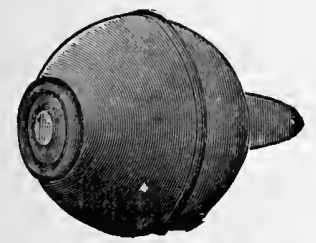

Fig, 70.-Nasal or ear syringe.

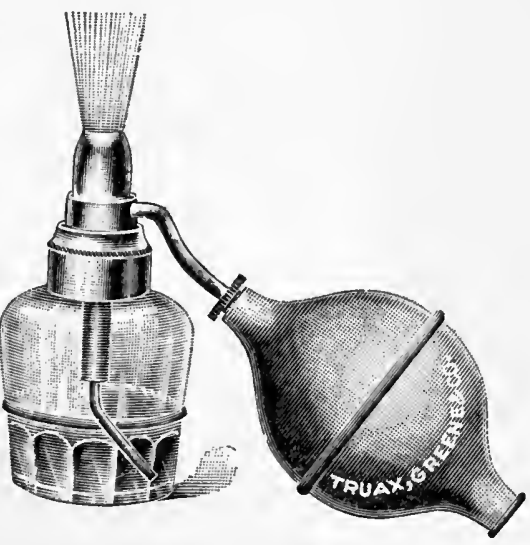

FIG. 71.-Oil atomizer.

pathological stand-point, are ordinarily the most filthy cavities of the body. Their intimate relation to the three vulnerable tracts-viz., the respiratory, digestive, and auditory systems---lends special significance to the demand that they be kept the freest possible from infective material or germs. During infancy and childhood the toilet of the mouth, nose, and nasopharynx is as important as that of the integument.

It is easy to accustom the infant to inspection and cleansing of the 
mouth and nose, if begun early - a point of practical value aside from prophylaxis, when later such inspection and treatment become necessary in acute pathologic conditions. The latter, however, it is believed, would rarely be necessary if the former were strictly observed. The child's toilet outfit is incomplete without a tooth-brush, nasal irrigator (Fig. 70), and an atomizer (Fig. 71).

From standing by the chair, the infant soon acquires independent locomotion, so that the second year is fraught with danger seldom encountered while in the nurse's arms,--such as liability to traumatism, undue changes of temperature, besides infection from substances introduced into the mouth, the common receptacle for all newly-found articles. There is also a tendency to introduce foreign bodies into the nasal and aural cavities, and trachea.

"Learning to walk involves a whole series of preliminary accomplishments, first among which is the ability to hold the head in equilibrium. This is usually accomplished about the fourth month. The next stage is reached a month or two later, in the ability to sit alone upright.

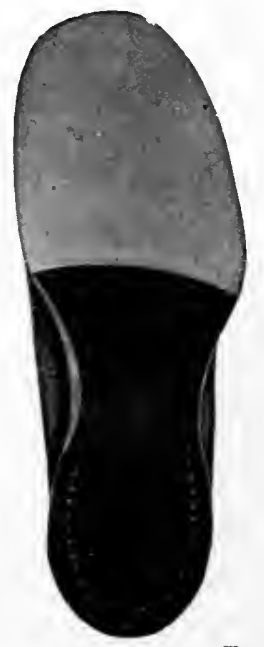

Fig. 72.-" "Orthopædic" shoe.

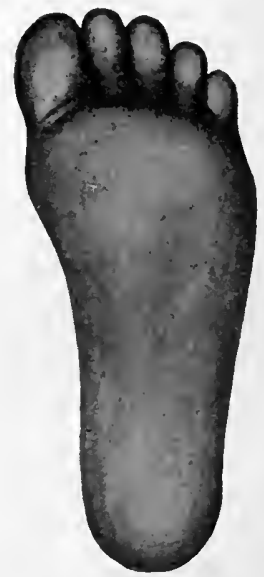

The soles of the feet are frequently turned towards each other-a partial reassumption of the intrauterine posture. To stand alone is the next stage, and anyone who has watched the attempts of a little child to stand upright and walk, will be convinced that he is moved to this by a natural instinct. Sometimes a child who has learned to walk, partially or wholly, reverts for a season to creeping, for no apparent reason." (Tracy.)

Care should be observed that children be not encouraged too much in this new accomplishment, as permanent injury to ligaments and articulations with deformity may result. According to Dane, the arch of the foot is well formed at birth, and generally protected by a pad of fat, which has led to an erroneous impression of flat foot. During 


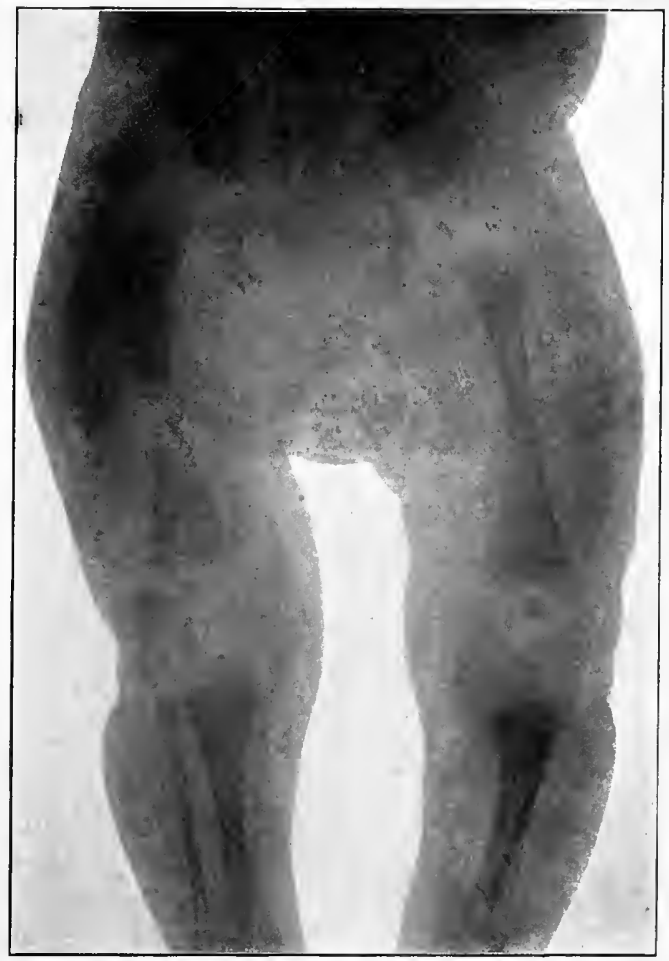

FIG. 74.-Normal development of infant femur and tibia. 


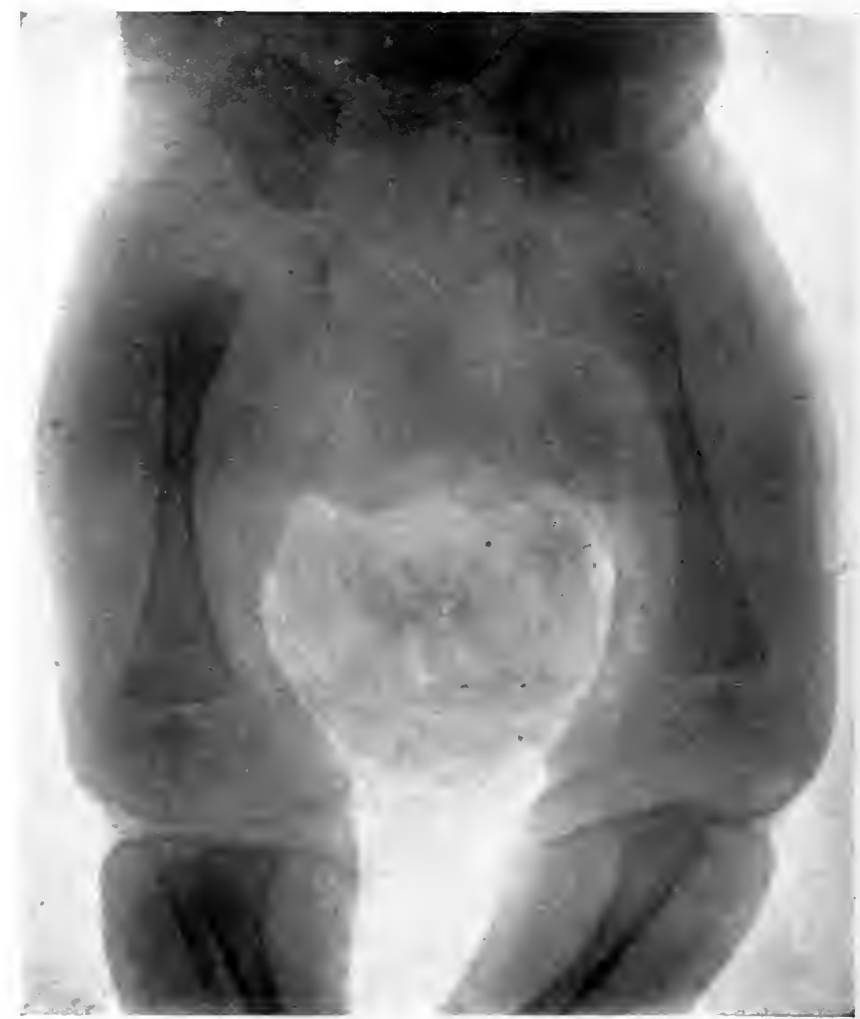

FIG. 75.-Disturbed alignment from wad of diaper; production of bow-legs. 
the first two years the arch suffers from the superineumbent weight, more particularly in heavy babies. With increased muscular development, however, the recuperative power of nature tends to the correction of this flattening, so that by the fifth year the arch has resumed its normal integrity. Infants instinctively protect themselves against this breaking down of the areh by turning the toes in, so as to bring the pressure to bear more upon the outer side. Efforts on the part of misguided parents to compel the turning out of the toes should be discouraged. The shoes usually made for infants are a good illustration of civilized barbarity. A wide-toed moecasin of flexible material, allowing free expansion to the foot, made rights and lefts, is recommended. The same may be said of socks. When old enough to walk out
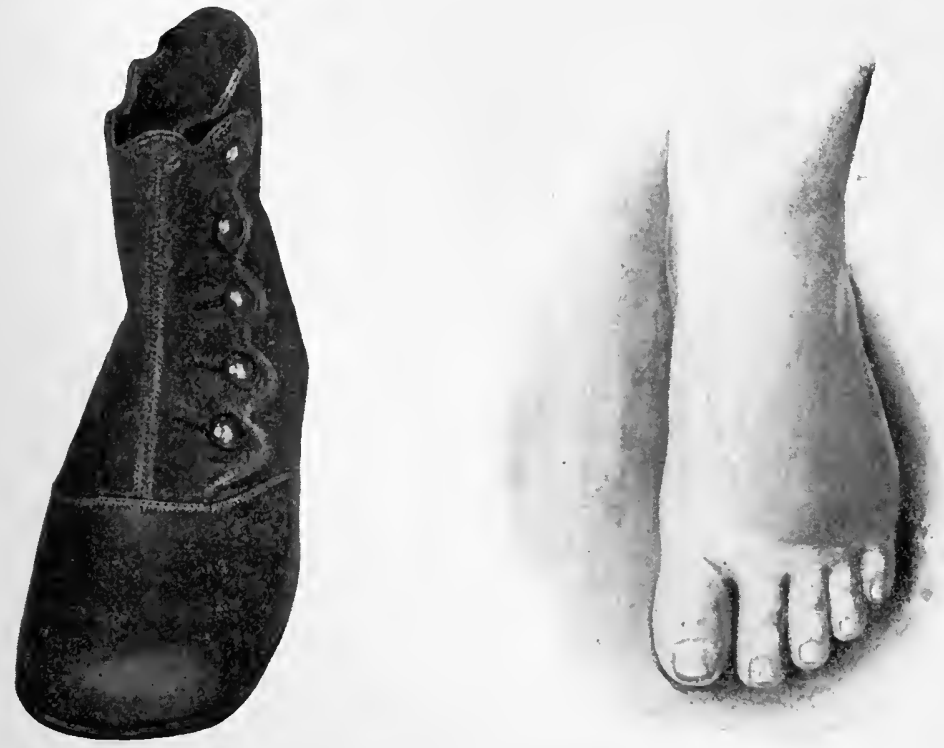

FiG. 73.-"Orthopædic" shoe.

of doors, the soles may be further protected by doubling the material, rather than by the use of stiff soles so much in vogue. Heeled shoes were never intended for human beings.

The relation of the "orthopædic" shoe to the child's foot is very well shown in Figs. 72 and 73.

The natural bow-legs of early infancy (Figs. 1,3 and 4) disappear in the third year, provided proper precaution has been observed against keeping the baby on his feet too long.

One cause, undoubtedly, of bow-legs is the large wadded diaper which acts as a fulcrum between the baby's thighs, when the legs are bound together by the heavy clothing. This tendency to curvature of the femora and the disturbance of their alignment with the tibix are seen in the skiagrams (Figs. 74 and 75). Figs. 76 and 77 also show 
the effects of tight diapers in their constriction of the pelvic bones during the plastic stage of infancy, at which time they consist of many centres of ossification, with a large amount of cartilage.

The effects of tight abdominal bands or pinning blankets in the compression of the lower thorax is also shown in the skiagram (Fig. 78). These errors in hygiene are too obvious to need further comment.

With development of the muscles, the rotundity of the form is gradually lost by the disappearance of subcutaneous fat, so that the child appears comparatively slender.

By the end of the second year the thoracic circumference exceeds that of the head, and the belly is less prominent.

The fontanelle has closed by the eighteenth month, and the frontal and malar eminences begin to assert themselves. The pulse-respiration ratio gradually establishes itself as $3: 1$, the respiration giving a hint of the future thoracic type. The pulse is normally about 100 to 115

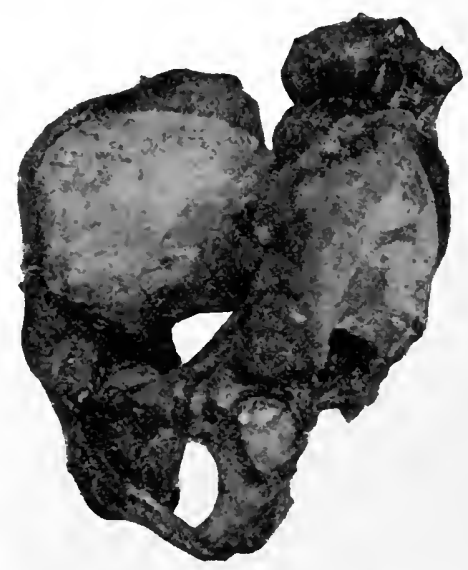

FIG. 76.-Pelvis at birth, showing cartilage.

during the second year, with the respiration 25 to 35 . Both are subject to disturbances from trivial causes.

The kidneys at the beginning of the second year attain their greatest relative weight.

The stomach from this time on falls behind the growth ratio of the body. In fact, the same may be said of all the viscera, with the exception of the left lung.

The eruption of the teeth has long been recognized as a suggestive indication for more solid forms of food. The changes in the salivary, gastric, and pancreatic secretions bespeak the increasing power of starch conversion and proteid digestion. The process of mastication, after the advent of the molars, stimulates, not only the salivary flow, but also that of the lower digestive secretions, which suggest the permissibility of foods in more concentrated form; so that it is not unusual to find farinaceous foods well borne early in the second year. In modifications of milk, 


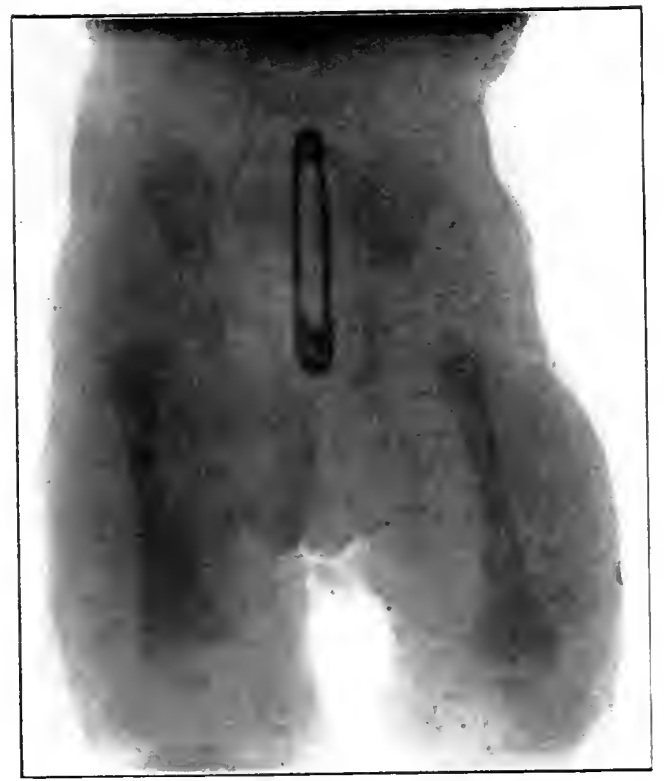

FIG. 77.-Constrietion of pelvis by tight dialer. Compare with Fig. 1s, skiagram of the same infant.

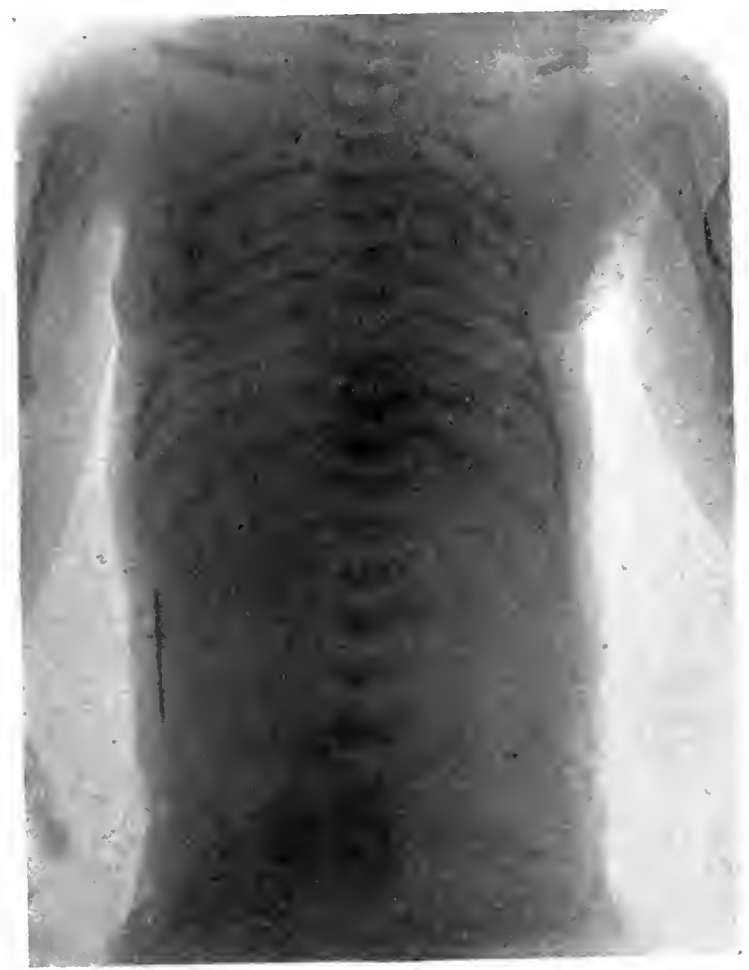

FIG. 78.-Compression of abdomen and lower thorax by tight bands. Compare with skiagram of same subject without band in Fig. 17. 

higher percentages of proteids are required, and a lower percentage of sugar is allowable, since this ingredient is formed from the starches. A liberal dietary for a normal infant, twelve to fourtcen months of age, might be represented by the following: Breakfast, 6 A.x., carefully cooked and strained oatmeal three and one-half ounces, milk four ounces, and cream one-half ounce; luncheon, $10 \mathrm{A.M}$., eight to ten ounces of warm .whole milk; dinner, 2 P.M., mutton, beef, or chicken broth, salted, with zwieback or water-biscuit-as much as he will take, up to twelve ounces; supper, 6 P.M., a cup of warm milk or oatmeal gruel; if the child wakens at night, a cup of milk may be given. Water should be supplied between times ad lib., but not immediately preeeding a meal. As the second year advances the quantities of proteids and starches may be cautiously increased. Not infrequently a good Liebig food may be used to advantage, enriched with cream. The need for fat should be borne in mind; also that the food should contain an antiscorbutic-as raw meat juice expressed from lean beef, raw egg albumin stirred up with cool water and milk, and occasionally orange juice or a well-baked apple. Toward the close of the year, hard water-cracker or zwieback may be munched as an accompaniment to milk. Stale bread or toast may be used with butter or soft poached egg, or meat gravies from the table roast. The following affords ample latitude for the selection of an appropriate diet: oatmeal with its high percentage of fats and salts, stewed apples, well-cooked rice, thoroughly baked white potato with butter and salt, eustards, junket, gelatin preparations, sago, cornstarch, tapioca well cooked and served with cream.

Children prone to constipation should have ripe bananas rubbed through a sieve, served with cream; also the juice from selected stewed prunes. Further than this, fruits are not advised during the second year, with perhaps the exception of the pulp of well-ripened, seeded grapes. Meat fibre is not advisable during this period, excepting a little scraped beef and thoroughly cooked fish. Sweetmeats are not recommended, because of the tendency to develop a distaste for the more staple articles of diet. The common practice of taking infants to the family table should be discouraged.

It would seem hardly necessary to refer again to the necessity for absolute asepsis, not only in foods, drinking water, and dishes, but in every detail of the daily care.

The infant cannot sleep too much. He should sleep from fourteen to sixteen hours out of the twenty-four during the second year-protection from noise, strong lights, and insects being necessary to secure rest. He will rarely go to sleep unless his stomach be filled.

An infant's nervous system is in so unstable a condition that no strain should be put upon its faculties. It is easy to see that by seemingly slight causes it may be injuriously affected. 


\section{CHAPTER XIV}

\section{PHYSIOLOGY AND HYGIENE OF CHILDHOOD}

\section{NORMAL PROPOR'TIONS}

$\mathrm{BY}$ the end of the third year the child's head and face may serve as an index of normal growth and development. The circumference of the head should measure not less than nineteen, and not more than twentyone inches. The head should be symmetrical in outline and free from bossæ. The forehead should not be prominent and bulging and should be free from ridges, horizontal or vertical.

The eye should exhibit no incoördination nor errors of refraction or accommodation.

The hearing should be unimpaired and the voice clear and resonant. The nostrils should be ample and well developed.

The teeth should be symmetrical in their arrangement and free from erosions and defects. The roof of the mouth with the teeth and soft

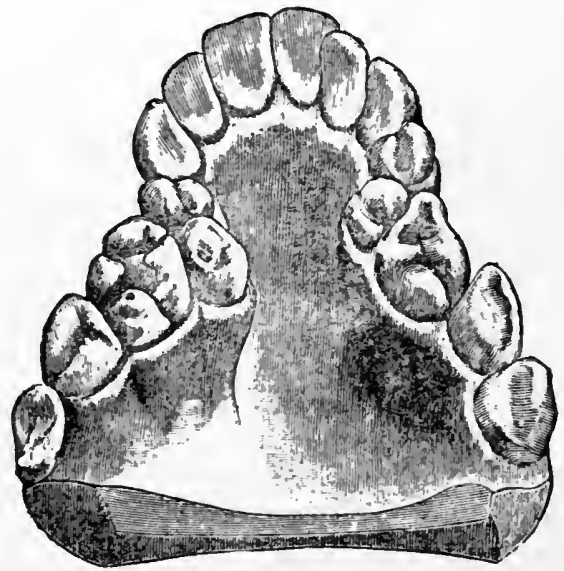

FIG. 79.-Saddle-shaped palate. (Talbot.)

palate should form a symmetrical low vault, free from the angles seen in Fig. 79.

The angles of the maxilla should have begun to assert themselves, with a perceptible broadening of the lower face.

The mastoid processes should be distinctly outlined and the ears normal in size and symmetrical in form.

The cervical, dorsal, and lumbar curvatures in the spinal column should be fully established and there should be no lateral deviations. 
The circumference of the chest should exceed that of the head by about one inch.

The thorax should be free from sulci or ridges, the sternum flattened, and the ribs free from beadings. Auseultation should give respiratory sounds audible in all parts of the lungs and puerile in eharacter. Absolute preeordial dulness should not extend to the right of the midsternal line, although the majority of observers find relative dulness to the right of the sternum at all periods of ehildhood. The heart rhythm should be trochaic rather than iambic in metre, as expressive of the relatively low arterial tension. The pulmonic seeond sound, eompared with the aortie, is aceentuated from the normally higher tension on that side. Liver dulness may extend two finger-breadths below the right anterior margin of the ribs. The epigastric depression should be noticeable. The umbilieus should be slightly above the centre of longitudinal measurement.

The hips should be perceptibly broadened and the limbs symmetrieal, showing neither bow-legs nor knoek-knees.

There should be no marked disturbances of general eo-ordinated movements. By this time the child's vocabulary may embrace about three hundred words, including some indieating color, and he has acquired the use of the first personal pronoun.

The above enumeration includes a few of the phenomena of normal development, from which the degree of deviation may indieate the extent of malnutrition, used in the broadest sense.

The idea of protection as given in the nursery should extend throughout childhood, with such modifieations as the ehanging anatomy and physiology demand. Although he may have aequired a considerable degree of digestive strength, as compared with the early infancy, still he needs watchful care over food and environment. In regard to the former, complete nutrition requires the five prineipal elements (page 90) in easily digestible form. The same regularity in feeding is important, although its frequeney and the quantity, as well as the material, should vary with the changing requirements. With advaneing age a greater variety in articles of diet is advisable. A caution is necessary on aceount of the tendeney to furnish the child the varied dietary of the adult, too frequently allowing him to seleet the artiele which tickles his palate or pleases his faney. No error would be greater, as the palate is no guide to the requirements of nutrition and malnutrition is invariably the result. A child regularly fed on properly seleeted foods will rarely injure himself by overeating. The use of eondiments (other than salt) and flavors to tempt the appetite, as well as tea, coffee, and stimulants, is deprecated.

Milk should hold first rank among the leading staples throughout childhood. Cultivation of the appetite for milk, too often neglected, proves extremely valuable, when in siekness it is necessary to restrict the food to liquid. It may be mentioned, as a hint in domestic economy, that milk is one of the cheapest as well as the best of foods. The 
tendency to decry the use of milk as an alleged source of tubercular infection has been carried further than later pathological findings would warrant. From the third year the child should gradually be accustomed to meat as a source of proteid, although it shonld not form a part of more than one meal a day, until after the sixth year. At any time it should represent only a small portion of the entire meal.

Thorough mastication should be made a feature of the child's training, and he should not be allowed to "wash down" imperfectly masticated food. From the end of the third year fruits should be given at least once a day. Pastry, even though not positively injurious, tends to pervert the appetite and leads to a distaste for the plain essential part of the dietary.

Excretions should be watched, for indications for changes in the diet. Concentrated highly acid urine would suggest diminution in proteids, especially meats, with increase in fluids, vegetables, and fruits. More particularly do lithæmic children with tendency to eczema, etc., need to be guarded in this respect.

Constipation may be corrected by the establishment of regularity in evacuating the bowels, preferably in the morning after breakfast, when the ingestion of food stimulates intestinal peristalsis. Constipation suggests the addition of more liquids and fruits. Sometimes it may be corrected by increasing the bulk of residue by coarser breads and vegetables.

No hard and fast rules can be made in regard to bathing. The tem. perature and duration of the bath should depend upon the reactionary effects upon the child. The wisdom of dragging the screaming child to the cold shower bath is not apparent when the previous admonitions concerning shock are remembered. Parents may err in the too frequent repetitions of the bath. General bathing should never follow immediately the ingestion of food.

During childhood retiring should follow soon after the light supper. Allowing children to study, read, or play by gas-light is not conducive to the rest and recuperation demanded after the day's fatigue.

The child under six is especially fortunate if he live in the country, where nature furnishes a great kindergarten for the symmetrical development of all his faculties. The inherent tendency of the normal child to develop himself is but the expression of the organized energy of perfect nutrition. His pertinacious instinct for investigation, the inherent curinsity of the child, furnishes a most complete training of brain and muscles.

The kindergarten of the city is but a makeshift, called into existence by the artificial environment of the home. The very fact that the education of the child in kindergarten and school is under control, renders it all the more dangerous, and necessitates the exercise of the finest judgment and broadest knowledge on the part of the teacher. If this be required for the normally developed child, how much greater the necessity in the various abnormal developments. 
"During those fits of rapid growth which sometimes oceur in childhood, the great abstraction of energy is shown in an attendant prostration, bodily and mental. The brain, which during early year's is relatively large in mass but imperfect in strueture, will, if recpuired to perform its functions with undue activity, undergo a structural advance greater than is appropriate to its age; but the ultimate effect will be a falling short of the size and power that would else have been attained. Various degrees and forms of bodily derangement, often taking years of enforced idleness to set partially right, result from this prolonged overexertion of the mind. Sometimes the heart is chiefly affected. Sometimes the conspicuous disorder is of the stomach. In many cases both heart and stomach are implicated. The sleep is often short and broken. (Excessive study is a terrible mistake, from whatever point of view regarded.') (Spencer.)

This quotation suggests that there is a natural course of development of nerve and muscle cells evolved from exereise. It is an error to force the exercise of. function too early, or to prolong the exercise to its impairment. It should be remembered that young nerve cells tire quickly, not yet having the stored energy of maturity.

The earlier education is naturally restricted to the grosser movements of the free limb type. During this stage of development, encouragement to occupations requiring the finer co-ordinations is elearly an error, which results not only in fatigue of the cells involved, but also in their permanent impairment. As a general axiom it may be stated that permanent injury surely follows prolonged exercise of any function, physical or mental, out of its order in the sequence of natural development. With this in mind young children will not be urged to occupations requiring refined differentiations, whether in the use of the needle, pencil, musical instrument, or in the study of numbers.

The artistic products of the kindergarten, displayed by proud parents and teachers as evidences of progress in the little pupil's training, too often suggest the fearful cost to future development of the overstrained faculties exercised in their production. That the children enjoy it should have no more weight than that the athlete enjoys the victory in the contest which ruined his heart.

As shown by the observations of Bowditch, Gilbert, Christopher, Porter, Roberts, and Stephenson, growth is not represented by a uniform rate; but periods are observed during which marked increase or retardation in the rate occurs. In fact, in one organ positive loss of weight is recorded, as in the brain, which at thirteen years weighs 1465 grammes, but at fourteen years only 1300 grammes. The loss, however, is more than recovered in the fifteenth year, when the average weight is 1500 grammes. (Vierodt.)

The heart shows a decidedly increased area of dulness after the sixth year. The great increase in its systolic vigor, however, awaits the remarkable hypertrophy of pubescence. Attention is called to a pronounced deficiency in the physical vigor of children from seven to nine 
years of age, which is termed the "period of fatigue." This is manifested not only in physieal but also in mental fatigne, and explains the exhibition of many nervous symptoms otherwise nuaceountable. It would appear that the proverbial laziness of this age has its foundation in normal physiologie conditions.

Krohn's diagram (Fig. 80) shows that the child of seven fatigues less readily than the child of six, but that the child of eight fatigues more readily than the ehild of either six or seven. The child of nine has a fatigue limit about equal to that of the child of seven. As the years advanee, the readiness of fatigne diminishes materially until the period of puberty, when again fatigue more readily oceurs than in the years immediately preceding.

Dr. Gilbert, in his examination of the ehildren of New Haven, found that "girls tire more easily at thirteen than at twelve, while with boys the variance comes a year later, from thirteen to fourteen. In close

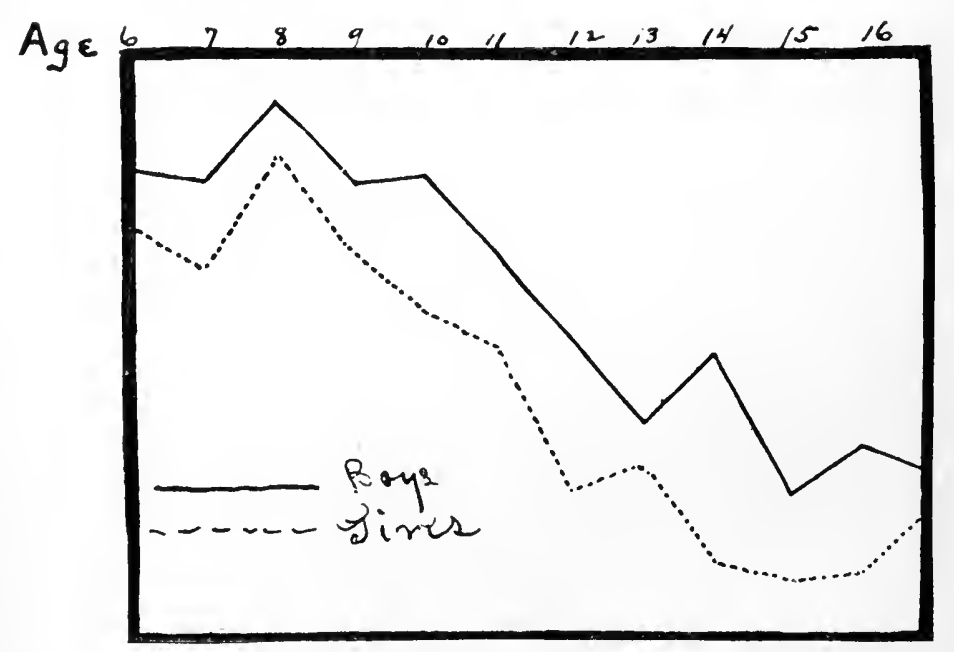

FIG. 80.-Krohn's diagram, showing fatigue periods.

connection with this is the growth in weight. Boys inerease 18.3 pounds between fourteen and fifteen years, and 17 pounds between fifteen and sixteen, but between sixteen and seventeen years the inerease is only 3 pounds."

The most rapid growth of girls eeases at thirteen, while at fourteen rapid growth of boys is just beginning. At about this age the girl reaches her maximum brain weight, just at the time that the boy's brain loses considerable weight, due to the large amount of blood being withdrawn from the brain to nourish viseera during their rapid revolutional changes at this period. Krohn states that at the onset of pubeseenee individual charaeteristies and idiosynerasies are intensified. Furthermore, the greatest of the hereditary qualities come out and the most dangerous of hereditary defects manifest themselves. It is at this time 
that nervous diseases, especially in higher centres, and also mental peculiarities, make their first real appearance.

From the foregoing, the conclusion is obvious that in the allotment of tasks in the arbitrary routine of exereises styled educational, the burdens must be distributed with due reference to these physiologic periods of development. To expect the same degree of progress during the fatigue period as may be secured in the preceding or subsequent years, would result not only in disappointment to parents, but also in permanent mental and physical injury to the child. At about eight years dilated ventricle with its mitral insufficiency is a familiar picture in pediatric clinics. The unstable equilibrium characteristic of pubescence, also, should be a warning of diminished eapacity for prolonged effort.

The researches of Edwin Chadwick furnish statisties which are of interest as indicating the limit of mental concentration at different periods of growth. Thus he finds that fifteen minutes is the limit of time that children of from five to seven years can concentrate attention upon one subject. That twenty minutes' attention is all that may be expected of children from seven to ten years, twenty-five minutes for those between ten and twelve, and that pupils from twelve to eighteen rarely exceed thirty minutes. It is seen from the foregoing that the capacity for sustained attention, in point of duration, is below the usually accepted belief as illustrated by the recitation schedules of our schools. The exhaustion of the power of attention renders every subsequent moment spent in the school-room worse than futile, from an educational standepoint. This is particularly true because the habit of inattention thus engendered is so fatal to educational progress.

The capacity for attention may be reduced below the normal by attending circumstances, so that, in certain cases, exhaustion speedily follows apparently reasonable school-room demands. Instances of this kind are not infrequently due to inferior nutrition from inadequate home hygiene, or a child may be worked beyond the eapacity of his strength from mistaken notions of economy on the part of the parents.

It has been repeatedly demonstrated that eye-strain is a prolific cause of early exhaustion of nerve force in school children, and that want of the application of the principles of opties is constantly laying the foundation for a great variety of pathological processes which handicap the future and shorten lives. Much good has been accomplished where attention has been given to better lighting, seating according to powers of visual distances, substitution of the clear tablet for the indistinct slate, improved size and forms of type in text-books, shorter hours of study, systematic testing of visual power and the application of corrective lenses or cylinders when needed.

Somewhat analogous to the preceding are the effects upon the child of ear-strain, whether due to defects in the organ of hearing, to imperfect acoustic arrangement of the room, or to indistinct enunciation of the teacher. A little observation will show that apparent dulness in the pupil is frequently the result of imperfect hearing, or of exhaustion 
from the undue effort to grasp the meaning of sentences but partially comprehended. Hence tests of hearing should be applied with a view to correction.

The tests of physical endurance inaugurated by Gilbert, in New Haven, and Christopher, in Chicago, bid fair to establish a standard for the amount of work to which pupils of different ages may be rationally assigned.

Muscular fatigue from constrained positions, as evidenced by restlessness of pupils so familiar to every teacher, has received much attention, so that the instructor may well be considered negligent.who does not vary the monotony of study and recitations with frequent brief exercises in physical culture.

It would hardly appear necessary to mention the absolute need of fresh air and deep inspiration, so long has physiology demonstrated the true function of respiration. Still, the school-room visitor often finds the need of much improvement in this direction. In proof of this may be cited the contrast in the attitude and facial expression of pupils immediately preceding and following the recess.

Vicious attitudes, resulting in permanent physical deformities, are too often caused by improper school furniture or its arrangement with reference to the light. The desk too high or too low, the relation of feet to floor, and the want of support to the spinal column, particularly to the dorsolumbar region, too frequently show their baleful effects in spinal curvature, with hip or shoulder deformities.

In regard to the length of sessions, and study out of school hours, there can be no difference of opinion. In the lower grades especially nothing is gained, though much may be lost, by requiring pupils to study their tasks at home. Overwork, if insisted upon, will give inferior results and that, too, at the expense of the impairment of the newly developing functions, far-reaching in consequences.

The subject of child labor, both from the humane and economic standpoint, has received so much attention in recent years that mere mention of the conclusions must suffice. By those who have thoughtfully studied this question the unwisdom of employing children during prolonged periods has been demonstrated in various ways. Reference to preceding pages will show some reasons why children, during the process of development, are incapable of continued effort requiring manual dexterity, even of the simplest type.

The limited store of energy at this stage allows early exhaustion of the nerve cells, with impairment of co-ordination. Thus it has been shown that accidents due to clumsy or awkward motions occur with significant frequency in the latter part of the day. The laws restricting child labor are not only humane and protective to a class who rightly should be protected, but also to the State, which in many instances must become responsible for the crippled. 


\section{CHAPTER XV}

\section{HYGIENE OF THE PREMATURE INFANT}

\section{CONDITIONS OF PREMATURITY}

IT is only in recent years that the subject of the eare of the prematurely born has engaged the attention of the profession. Formerly it was the accepted belief that the majority of infants born four to eight weeks before term were insufficiently developed to survive. In fact, this opinion was the logical outgrowth of the high rate of mortality at this age. The exception to the rule was seen in an occasional survival, evidently the result of unusual care in management or exceptional vigor of the infant.

The picture presented by the infant after seven months of intrauterine gestation is certainly not encouraging, and it is not strange that it was often laid away as unworthy of any effort at preservation. The respiration is shallow, irregular, frequently suspended for long intervals, and coming at times in gasps. The breath is sometimes cold, as of one dying from exsanguination. 'The heart's action is reduced at times to an almost imperceptible flutter, no wave being apparent in the arteries. The absence of subcutaneous fat (a deposition of the later weeks of gestation) gives the appearance of extreme emaciation, the feeble muscles showing like strings under the thin integument.

The skin is soft and of a raw red color. The nails are short, not extending to the ends of the fingers, and the integument of the dorsal surfaces is covered with lanugo. The eyes are sealed with a gummy secretion, the hair extends low on the forehead and the bones of the head are widely separated and very compressible in their membranes. In girls the labia minora project beyond the majora.

The temperature is usually subnormal, as heat production is defective. This defect is due in part to the imperfect manner in which respiration is carried on. The anterior portions of the lungs only are expanded, the posterior remaining atelectatic for many days. It is easy to understand why premature infants are prone to suffer from hernia.

These conditions, with the feeble wail or even absence of ery, and the almost motionless limbs, present a contrast to the normal infant which may afford some excuse for the lack of attention previously afforded this class (Fig. 81).

The temperature of the obstetrical chamber in premature delivery should not be under $91^{\circ} \mathrm{F}$. $\left(33^{\circ}\right.$ C. $)$, and at birth the child should be immediately wrapped in warmed blankets. The rule of not ligating the cord until pulsation has ceased is especially important. If artificial 
respiration be necessary, it is not wise to use the vigorous methods of Sylvester or Sehultze, or to expose the infant to the shock of inmersion in eold water. (See Asphyxin).

The idea of the incubator, or couveuse, wherever originated, was brought to the attention of the publie by Credé and Tarnier, who reported great saving of life by this means, the former having a mortality of but eighteen per cent. and the latter of thirty-three per cent. However, Credé wonld not aceept infants who weighed less than five and

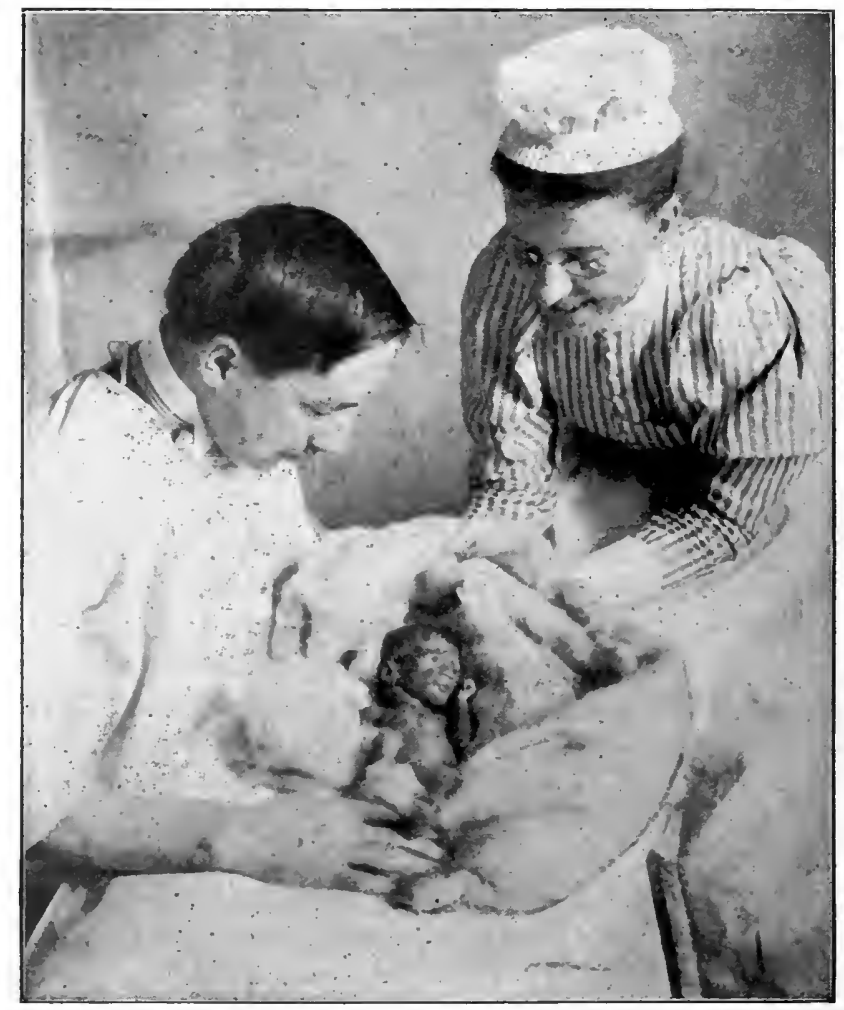

FIG. 81.-Infant ten weeks premature; weight at birth, $3 \frac{1}{2}$ pounds; weight at two weeks, $2 \frac{1}{2}$ pounds; weight at eight weeks, 8 pounds.

one-half pounds, while the limit placed by Tarnier was four pounds. The reports of these observers established the fact that lack of full development at birth was not necessarily an obstacle to survival and growth. The incubator, whether of the simple primitive type employed in the Leipzig Maternity by Credé, or the intricate, complicated device of the present day, has for its purpose the fulfilment of such hygienic principles as avoidance of shock, maintenance of warmth, and the supply of pure air (Fig. 82).

In the couveuse a temperature of from $88^{\circ}$ to $98^{\circ} \mathrm{F} .\left(31^{\circ}-37^{\circ} \mathrm{C}\right.$.) 
is maintained by hot water, which may be introduced between the double walls of the apparatus through coils of pipe, or by flasks of hot water placed in the false bottom. The nude infant rests in the upper portion upon soft wool, is covered with the same, and light is exchuded by an opaque lid. Air is supplied through an opening in the bottom, escaping through another at the top. The more elaborate apparatus includes a thermometer, a gas-jet for maintaining leat, a thermostat for its regulation, mechanism for regulating air-supply, and seales for weighing. In the absence of the couveuse, most excellent results may be secured by the exereise of a little ingenuity with a padcled clothesbasket, hot-water bottles, a pound of wool and a blanket. This is suggested because of the extreme importance of the immediate application of these principles, as even a temporary delay may allow a reduction of temperature that will endanger life.

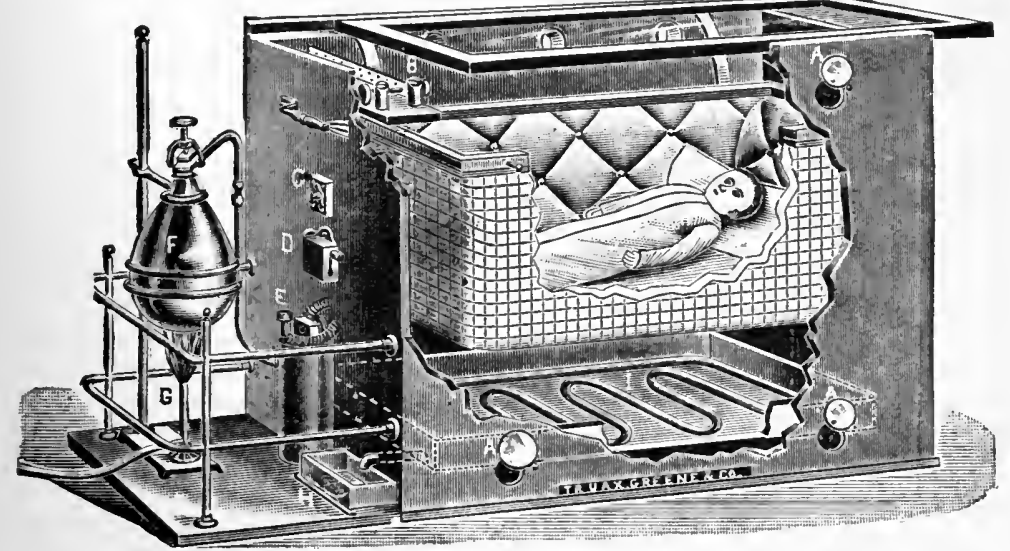

FIG. 82.-Incubator.

As close an approximation as possible to the conditions existing before delivery is the object sought. To this condition air and food must be added. The former should be pure, warm, and moist. The food must be of the character and administered in quantities best adapted to the immature digestive tract. These infants should not be required to wait until lactation is established, but should be fed within a few hours after birth.

Milk-sugar solution is well borne and furnishes heat. Fats are absorbed in smaller quantity and proteids are tolerated in extremely reduced percentages. A generous supply of water should be given. It has been suggested that the urine be watched for uric acid as an indication for the reduction of proteids in the food. For the purpose of nutrition and to prevent desiccation, daily oiling should be practised when not found irritating to the skin.

The disturbance incident to suckling, and the usual inability to nurse from muscular weakness, render breast feeding impracticable. The 
breasts should be pumped regularly and the milk, diluted with an equal part of 4 per cent. milk-sugar solution, may be given by a spoon or feeding-tube, preferably the latter, until the infant has gained sufficient strength to use the nipple. This tube is so constructed that compression of the bulb forces the fluid through the small nipple into the infant's mouth (Fig. 83). Small quantities, sometimes not exceeding a gramme, should be given hourly, keeping in mind that errors are usually on the

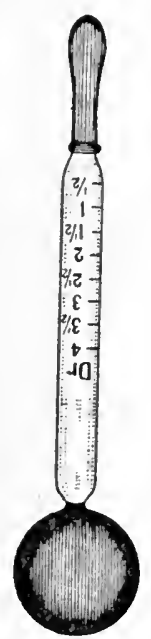

FIG. 83.-Feeding-tube. side of overfeeding. Failure to observe this point may induce regurgitation of food, or even death from embarrassed heart action. In some cases gavage may be required, or nasal feeding may be preferred.

It is generally accepted that the size and vigor of a full-term infant bear a direct ratio to the chances for rate of growth and survival. This is not less true when applied to premature infants. Some babies at full term are born to die, notwithstanding the best of attention, the full forty weeks of gestation failing to provide sufficient vigor for the maintenance of their vital functions. It is hardly reasonable to suppose that their chances would have been improved by premature delivery.

Reference has been made in a preceding chapter to the burden imposed upon the heart at birth, as seen in its uncertain, irregular action. It is not surprising that, at this earlier stage of development, the heart should be less well prepared to assume the burden of systemic circulation. In fact, there is imminent danger of syncope from the slightest disturbance. To guard against this the horizontal position must be maintained and all rough and unnecessary manipulations avoided, reducing the work of the heart to the minimum of physiological requirements. It may be even necessary to administer alcoholic stimulation in appropriate doses. The continued use of brandy with the food at this time has the sanction of the highest authorities.

As to the respiration and pulse, no definite ratio has been recorded. It is seen that the management of the premature infant requires constant watchfulness and extreme care as to details. By regular weighing and by watching the discharges, evidence is obtained as to his condition, which may serve as a guide for the amount and character of the food.

It is not unusual, when nutrition is well established, to find the temperature of the premature ranging higher than that of the full-term infant, which would seem analogous to his incompleted intrauterine existence when growth and development are seen at their highest.

If evidences of satisfactory progress appear in continuous gain, improved respiration, steadier heart action, undisturbed digestion, accompanied by rotundity of figure and livelier movements, a cautious reduction of temperature may be attempted and the infant may be gradually accustomed to the light and environment of the new-born at full term. 


\section{CHAPTER XVI \\ CONGENITAL MALFORMATIONS}

CAPUT SUCCEDANEUM

So common as to rank as a physiological phenomenon is the formation during delivery of a diffuse, boggy tumor, known as caput succedaneum. It varies in size with the duration of labor, and in position with the presentation. In the common left occipito-anterior presentation the tumor is found on the right parietal, extending over the posterior fontanelle and occipital bone. It consists of a serous infiltration of the scalp in that portion freed from pressure by the dilating os uteri. Compression of the scalp between the skull and bony inlet temporarily checks return circulation and canses the cdema. Often the overlying skin is bruised, and if the labor be severe the tumor may be purplish in color, although a considerable hemorrhage is rare. If there should be delay at the outlet a secondary tumor may form which is usually in the median line.

The fluid is absorbed in from two to four days and no treatment is required.

\section{CEPHALHЖMATOMA.}

Cephalhæmatoma, as its name suggests, is caused by an extravasation of blood between the cranial bones and their investments. Different varieties are recognized, due to different locations of the effused blood, as subaponeurotic, subperiosteal, subdural, or subarachnoid. Thus, it is seen that the tumor may be due to an extravasation purely external to the skull, or the blood may be connected with an accumulation within the cranium.

As stated in the chapter on Anatomy, from the close attachment of the pericranium to the dura at the sutures, a cephalhæmatoma must be limited in its area by the borders of the bone over which it occurs. Hence, it need never be mistaken for a hernia cerebri, which protrudes at an aperture or unprotected area. The apparent crater-like opening beneath the cephalhæmatoma, with the feeling of crepitation at its periphery, is due to the rapid deposition of bony material at the margin of periosteal separation, where the osteoblasts are still actively at work.

From a caput succedaneum it may be easily distinguished by the frequent extension beyond sutures and fontanelles, discoloration of skin, pitting on pressure and early disappearance of the latter.

The restricted hemorrhage is presumabiy due to pressure upon unusually fragile blood-vessels under peculiar hæmic conditions. It is almost invariably found in the children of poorly nourished mothers. 
It is not necessarily due to pressure during passage through the birthcanal, since cases are recorded of cephalhæmatoma in infants delivered by Cresarian section. Breech presentations also occasionally show this lesion, and instances are not wanting in which the tumor has been found on the head of the prematurely born.

The prognosis is usually favorable, in the absence of symptoms indicative of extensive intracranial extravasations.

A mild astringent placebo may be used as a prevention to surgical interference, absorption usually occurring in from two to ten weeks.

MENINGOCELE, ENCEPHALOCELE, HYDRENCEPHALOCELE.

The protrusion of a portion of the membranes of the brain through an opening in the skull, due to deficient ossification, is known as a meningocele. If there is also brain substance situated in the protrusion it forms encephalocele, or hernia cerebri. This is the most frequent

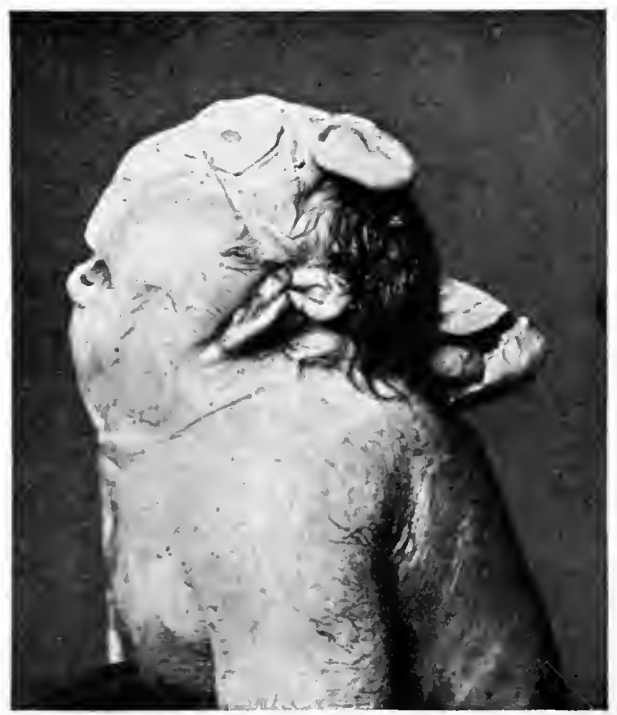

Frg. 84.-Anencephalus, acrania. (Rush Medical Museum.)

type. A marked degree of encephalocele, in which the greater part of the brain is outside the cranium, resting in a membranous sac and dragging the head backward, is termed exencephalus (Fig. 14). A still greater degree of arrest of development is the entire absence of braintissue, anencephalus. This is usually associated with absence of all the bones of the skull, excepting those at the base,-acrania (Fig. 84). If, in addition to the brain and its coverings, the tumor contain cerebrospinal fluid continuous with the ventricles, it is called hydrencephalocele.

The protrusion may vary in size from a small nut to that of the infant's head. It is usually translucent and pulsating, increasing with 
screaming. The tumor is in most instances reducible, but the reduction may cause symptoms of compression,- - opisthotonos, convulsions, or coma. The covering is thin, but not as defective as is frequently the case in spina bifida. Other deformities are often present. Although present at birth, these tumors are apt to inerease rapidly, followed by evidences of meningeal irritation, convulsions, and paralysis.

The most frequent site is in the occipital region, in the spaces between the centres of ossification of the occipital bone (Figs. 11 and 12), the posterior fontanelle, or the foramen magnum. Next in frequency the tumor is seen at the root of the nose, a little to one side of the median line, arising from the junction of the frontal and nasal bones. They have also been found in the mouth and pharynx.

The only explanation offered for the occurrence of these herniæ is an intrauterine hydrocephalus and defective ossification.

From cephalhæmatomata they may be differentiated by their location, pulsation, reducibility, and sharp, bony boundaries.

Infants, the subject of anencephalus, acrania, and exencephalus survive birth only a few days. The majority of cases showing lesser degrees succumb in the early months of life from rupture, meningitis, or convulsions. In a few rare cases a spontaneous decrease in size with recovery has occurred.

Tapping is of temporary benefit only. The injection of iodine and glycerin has been followed in some eases by shrinkage of the tumor. Clamping of the pedicle, excision, and other surgical procedures, have been successful in removing the protrusion, but the infants almost invariably have developed convulsions, hydrocephalus, and idiocy.

\section{CONGENITAL HYDROCEPHALUS.}

Hydrocephalus is of eongenital origin in the large proportion of cases. The accumulation of fluid within the cranium may be so great as to make delivery of the head impossible without aspiration. Much more frequently the head at birth is only slightly in excess of the normal size (34 to $36 \mathrm{Cm}$.) $\left(13^{3} / 5-14^{2} / 5\right.$ inches), but increases more or less rapidly. The fluid usually distends the lateral ventrieles, less often the fourth ventricle, and may be found between the meninges (external hydrocephalus).

The etiology is still unknown. Trauma to the mother during gestation, alcoholism, tuberculosis, and syphilis, in one or both parents, have been advanced as eauses by various observers. A family predisposition is recognized, two or more cases (in one instance seven) in the same family being reported. The cause of the accumulation of fluid in the ventricles may not be the same in all patients. There may be a local meningitis elosing the foramen of Magendie, some lesion of the chorioid plexuses causing an excess of secretion, a syphilitic leptomeningitis and endarteritis, or some obstruction to circulation, such as a brain tumor.

As stated, the large size of the head may not attract attention until 
the infant is two or three weeks, or as many months old. Sometimes the increase is rapid, averaging a centimetre a week. When advanced the fontanelles are large and bulging; the bones forming the vault become thin and widely separated; the skin covering them seems stretched and shiny, with distended veins; and the hair is seanty and dry. The face and body are relatively small, yet they may be of average size for an infant of that age. The prominent eyes are directed downwards, and are not fully covered by the lids. Occasionally nystagmus and strabismus are present. The ehild is unable to support the head, which rolls around helplessly. Other malformations are frequently associated. Convulsions and spastic paralyses are common. The brain always suffers to some extent, although if the pressure develop slowly the amount of impairment may be surprisingly little. The optic nerves, from stretching and pressure, may atrophy, but the other cranial nerves are rarely affected. The brain substance may be thinned to a few millimetres in thickness, with little distinction between the gray and white matter.

In slight degrees of hydrocephalus it may be difficult to differentiate from the large head of rhachitis. In the latter disease, however, the general shape of the vault is square rather than globular, the fontanelles are not always bulging, and there may be other signs,-as rosary or enlarged epiphyses. Repcated eareful measurements of the cranium will show if the enlargement be progressive.

Death quickly follows birth in marked cases. In a few instances recently reported, spontaneous evacuation has occurred through fissures at the base of the skull into the nostrils, followed by improvement and apparent recovery. The usual course is increasing weakness, irnbecility, and death from some intereurrent disease in the first five years of life.

Aspiration alone or with drainage may temporarily relieve symptoms of pressure, but this is usually the extent of benefit from surgery. Lumbar puncture may be as effective if the channel of communication be open. Compression by plaster or elastic bandage is advocated by some, but is open to the objections of interfering with eirculation and increasing the pressure on the brain. The possibility of the presence of hereditary syphilis makes the use of potassinm iodide and mercury worthy of trial in all cases. The other treatment must be symptomatic.

\section{MICROCEPHALUS.}

The term microcephalus is restricted by some to heads that measure less than 40.5 or $43 \mathrm{Cm}$. (16 or 17 inches) in children over one year. The more liberal definition of the word includes all those in whom the circumference of the head is much below the average for age, or greatly disproportionate to the body.

The theory that the condition arises from a premature ossification of the bones of the cranium is not now generally accepted as true in all cases. Microcephaly is probably due, in most instances, to inflammation or other diseases of the fetal brain.

Usually the anterior portion of the skull and brain are most affected. 
The forehead is narrow and low. Varying degrees of iodicy, as well as imperfect control of the limbs, are present.

Although the lack of development may be much more evident in some parts, the mass of the brain is lighter than the average, and the fissures and convolutions are shallow. There is frequently an increase of filid in the ventricles.

Craniectomy, consisting in the removal of a longitudinal strip of bone on one or both sides, parallel with the sagittal suture, was adrocated a few years ago. The results of the operation were not favorable enough to justify its practice.

MALFORMATIONS OF TIIE SPINAL CORD.

Very rare deformities of the spinal cord are, its entire absence, amyelia, a reduction in size, atclomyclia, or a division in halves, diplomyelia. In amyelia, nerve tissue may be replaced by a solid cord of connective tissue or one containing fluid in a central canal. This malformation is often associated with anencephalus and is incompatible

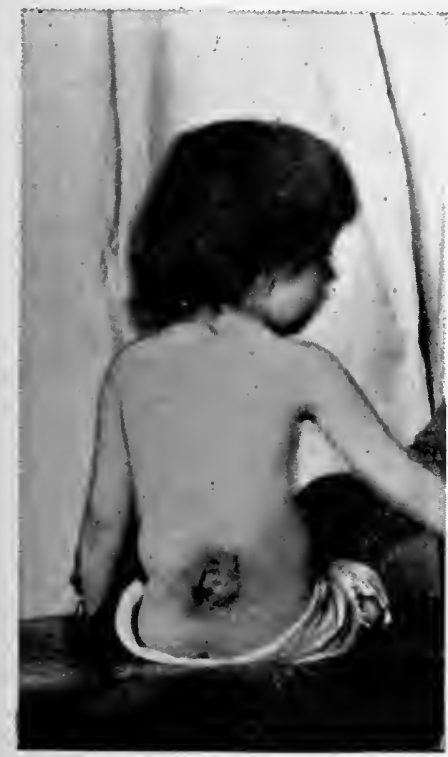

FIG. 85.-Spjina bifida.

with life. Syringomyclia is due to congenital imperfection of the spinal cord, which only needs some trauma in postnatal life, to act as an exciting cause. It is of interest to note that the gray substance of the cord shows a lack of symmetrical development in cases of intrauterine amputation of a member.

The most common and clinically important congenital malformation of the cord is spina bifida. This consists of a bony defect in the vertebral column, with protrusion of the cord or its membranes. It is seen as an elastic, more or less translucent tumor, varying in size from a hazelnut to a cocoanut, or even larger (Fig. 85).

It is stated that in a few instances the laminæ are not the defective parts, but the hernia protrudes through the bodies of the vertebra, presenting in the thorax or abdomen. It may also insinuate its way through an intervertebral notch.

Pressure on the tumor will reduce its size, but in nearly all cases there follow evidences of cerebral pressure, seen in greater tension of the fontanelle, changes in pulse and respiration, restlessness or convulsions. With the reduction, it may be possible to palpate the edges of the bony clefts. Imperfect development in other parts of the body is commonly seen in these patients.

Probably the nonunion of the vertebral arches is secondary to an 
increased pressure from an inflammation of the cord or its meninges in embryonic life.

The three varieties of spina bifida correspond to those of hydrocephalus. In the first the tumor consists simply of membranes and fluid, - meningocele spinalis. It is sometimes found in the cervical region, may be pedunculated, and is usually covered with integument which may be normal or the seat of a nævus. This form may be attended by no symptoms and offers the most favorable prognosis.

The second variety, meningomyelocele, is the most common, forming over sixty per cent. of all cases. It is usually located in the lumbosacral region, is sessile and contains nerve tissue as well as meninges. The cord and nerves spread over the inner surface of the sac, or a median dimple may mark the attachment of the cord to one point. Often there is an overgrowth of coarse hair surrounding the sac. Not only is there defect of bone but also of muscle and skin, so that the hernia has for a covering only the very thin, bluish-red meninges.

In the third variety there is a dilatation of the spinal canal, a cystic tumor, which also protrudes through the vertebral cleft. This is the form most often associated with hydrocephalus.

In the second and third varieties there is always some degeneration of the cord, cauda equina, or the nerves, due to pressure. This results in paraplegia, talipes, incontinence of urine and fæces, and frequently in bed-sores or other trophic lesions.

From imperfect covering, rupture of the hernia may occur at birth, but if not then it is very apt to result later. The usual course is gradual increase in size, and death from marasmus, convulsions, or septic meningitis after rupture. Either with or without operation these children do not often survive the second year of life. Very rarely instances of spontaneous cure are recorded.

The treatment is surgical. Unless rupture be imminent, many surgeons postpone operation until the fourth or fifth month of age, protecting the sac from pressure by a rubber ring and from infection by cleanliness. Aspiration and the injection of iodine and glycerin is thought by some to offer as favorable results as any method, but this is not devoid of danger. Convulsions and death have followed in a few hours in several cases. The more radical operation of dissection, return of nerve tissues to spinal canal, and careful suturing of opening, is quite as likely to be followed by hydrocephalus as are other methods.

\section{CONGENITAL DEFORMITIES OF EXTREMITIES.}

The congenital deformities of the extremities are almost as numerous as the articulations. In any one of these, growth may be inhibited or perverted by prolonged pressure in utero. Deformities may result, also, from constrictions from amniotic bands or loops of the umbilical cord. Not infrequently intrauterine amputations result from this cause (Figs. 86 and 87 ).

Of not uncommon occurrence is congenital dislocation of the hip, 
which may be either uni- or bilateral (Figs. 88, 89, and 90). Although occasionally hip dislocation may be regarded as an accident of labor, a large majority of cases result from causes that operate during gestation. Among those assigned are external trauma during gestation, uterine contractions acting upon the femur as a lever, effinsion into the joint cavity, malformation of the acetabulum or femoral head, and affections of the central nervous system of the child.

The most common form of dislocation is upwards and backwards. The thigh may form any angle with the axis of the body, up to $90^{\circ}$.

A not rare location of congenital deformity is the ankle and foot, which may exhibit all degrees from a slight subluxation, with relaxed ligaments, to extreme talipes or club-foot (Fig. 91.)

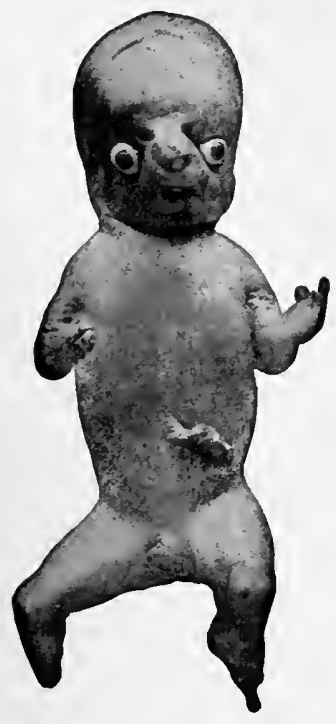

FrG. 86.-Amputation by strangulation of fœtal cord. (From cast in Warren Museum.)

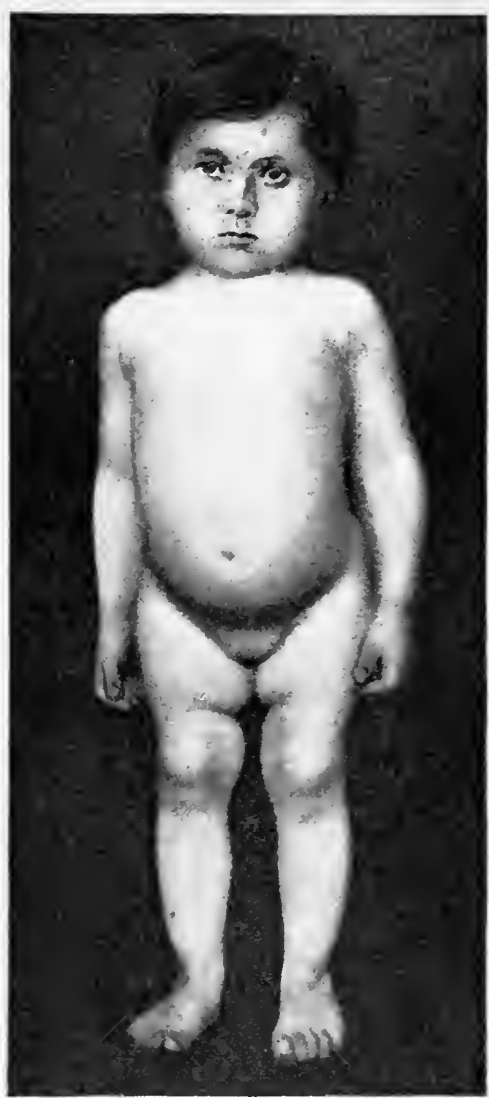

Frg. 87.-Double congenital dislocation of hip. Girl, aged $3 \frac{1}{2}$ years.

Deformities of this class should be promptly referred to the orthopædic surgeon, as much depends upon their early treatment.

\section{MALFORMATIONS OF THE EYE.}

So complex is its mechanism, it is not strange that the eye should be the seat of various congenital defects. The following are some of the most common : 
Anophthalmos is the eondition in which there is absence or mere rudiments of the eyeball. In microphthalmos (a partial arrest of development) there is more or less blindness according to degree of defect. There may be ankyloblcpharon, in which adherence of the eyelids, normal to fetal life, persists or is due to an intrauterine conjunctivitis. A family predisposition to congenital cataract is sometimes seen, extending through several generations. It is usually associated with other defeets of the eve, hence some degree of amblyopia is common.

A cleft in the eyelids, iris, or chorioid is termed colomba. Colomba iridis is usually found in the lower half, and may vary from a mere line to a quadrant.

Congenital ptosis, not attributable to pressure of forceps or other

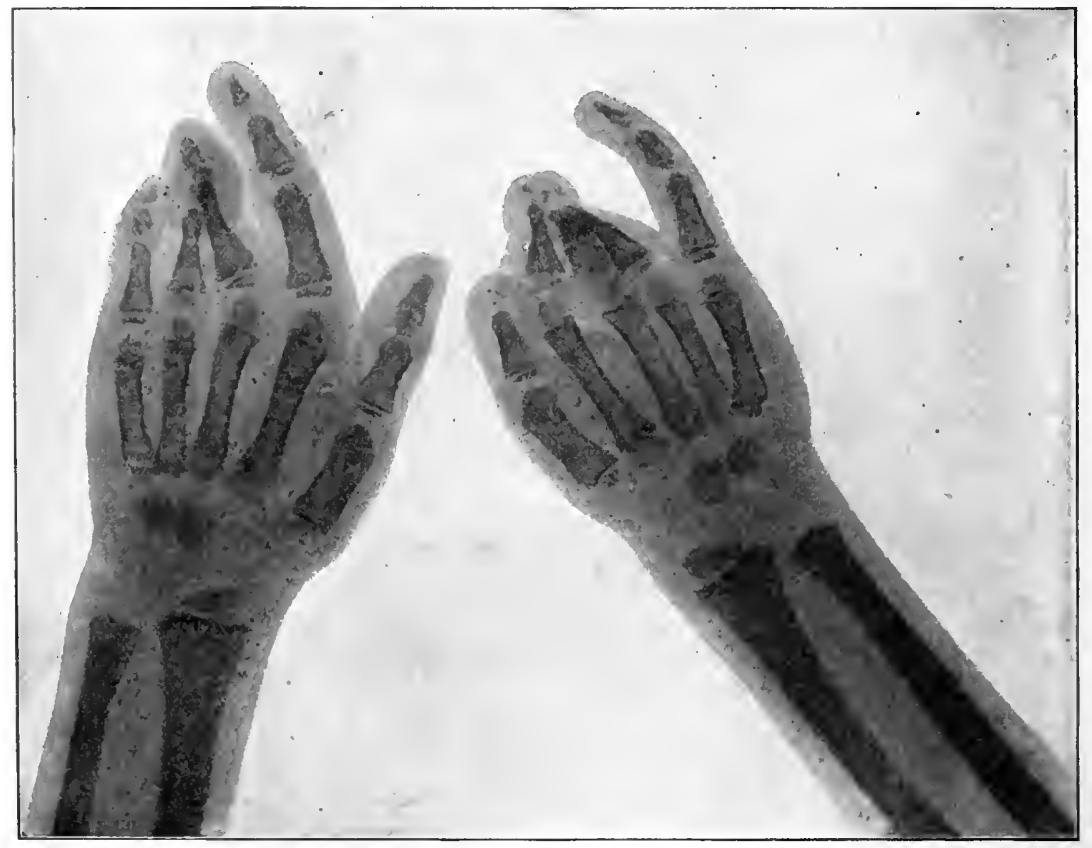

FIG. 88.-Congenital malformations of fingers due to constricting amniotic bands.

known cause, is occasionally seen. As the child gains control of muscular action, the drooping lessens, but probably never entirely disappears.

In Epicanthus there is a crescentric fold of skin at the inner eanthus, sometimes extending as far outward as the cornea. This peculiarity is sometimes transmitted for three or more generations.

The outer angle of the eye is a not uneommon site for DERMOID CYSTS, having the usual varied contents. If growth is rapid in one of these eysts, immediate extirpation is advisable.

In Albinism there is a congenital defieieney of pigmentation of iris and chorioid, as well as of the skin and hair. The pupil often looks pink 
because the fundi are lighted through the sclerotics, and nystagmus is common. With growth there is usually a slight increase in pigmentation.

\section{MALFORMATIONS OF THE EAR.}

In the development of the ear, in the second and third months of fetal life, bits of cartilage are in some way detached from the original mass, or fail to unite, and form supormumerary auricles or auricular appendages. These are sometimes seen as smooth, wart-like projections, sessile or pedunculated, located more frequently in front of the ear. They may vary in size from a pinhead to a walnut, and may be the only anomaly present. The pedunculated forms are easily removed.

Various deformities of the external ear are frequently seen and, because sometimes associated with imperfect development of the brain as well as other parts of the body, are classed by some writers as stigmata of degeneration.

The auricles at birth are often folded forward and in many cases may remain outstanding, unless persistent efforts are made to press them back in place. Strips of adhesive plaster are sufficient for retention in new-born infants. In older children it may be necessary to excise a portion of the skin and cartilage from the posterior surface of the ear and suture to the skin over the mastoid process.

A more serious defect is congenital atresia of the external auditory canal. This is often associated with malformation of the auricle or with its entire absence. The labyrinth may be normal and bone conduction good. The operation for the formation of an artificial canal has not been permanently successful. Whatever the explanation may be, it is of interest that suppurative otitis media or mastoiditis has never been reported in these cases.

\section{HEMATOMA OF STERNOMASTOID-CAPUT OBSTIPUM.}

Occasionally there is noted, a week or two after birth, a swelling in the sternomastoid muscle, usually of the right side. This tumor is in the sheath of the muscle, in its middle or upper portion, and by many observers is believed to be due to trauma during labor, eausing rupture of blood-vessels and muscle-fibres, and later a myositis. The large majority of these cases occur during breech presentation, and traction on the neck is thought to be a cause. In a smaller percentage forceps have been used. The lack of tone present in deep asphyxia probably favors the escape of blood. Hæmatomata have also been recorded in normal labors and an intrauterine origin is claimed by some writers.

The tumor seems tender to pressure and the infant cries on sudden motion involving the sternomastoid.

Its usual course is towards recovery without deformity, although wry-neck sometimes results. Nothing in the way of treatment is needed beyond careful support of the head at all times. 


\section{CLEFT PALATE-HARELIP.}

Cleft palate is simply an imperfect closure of the fetal gap in this region. It is in the median line and often involves the soft palate and uvula. If the cleft in the hard palate include the alveolar border it leaves the median line and follows the suture between the maxillary proper and the os incivisum. This defect is usually associated with a corresponding fissure in the upper lip (harelip), which rarely, if ever, occurs in the median line (Figs. 92 to 95 ).

The defect may interfere with nursing and occasionally with deglutition, while the catarrh, frequently associated with this malformation, favors infection. Modern surgery affords great relief for cleft palate, hence all cases should be referred early to the specialist. If neglected, speech defects result which are difficult of correction. Like many other congenital defects, the condition is usually accompanied by lowered nutrition and feeble resistance, a fact to be remembered in prognosis.

\section{BRANCHIAL FISTULE.}

Certain congenital fistulæ are sometimes found within the neck, which are due to the partial persistence of one of the branchial clefts. In the fœtus these clefts occur between the branchial arches, which are five in number (Fig. 15). When present at birth these fistulæ appear as very fine canals opening into minute orifices in one or both sides of the anterior surface of the neck, leading backwards and upwards towards the pharynx or esophagus. The length may be from five to ten millimetres and the diameter from that of a bristle to an ordinary probe. They usually exist about the line of the third or fourth cleft, and are often found just above the sternoclavicular joint. Certain polycystic, congenital tumors, occurring as hydrocele of the neck, may be developed from imperfectly closed clefts.

The treatment is surgical.

\section{FACIAL DEFECTS.}

A failure in union of the branchial clefts may result in a large median opening, extending from the inferior maxillæ to orbits. A minor degree of malformation, more frequently seen, is macrostoma, in which the cleft extends from the angles of the lips towards or to the ears on one or both sides. Fissures or fistulæ are occasionally found at the outer angles of the eyes, alæ nasi, or in the lower lip.

\section{MALFORMATION OF THE DIGESTIVE TRACT.}

Very rarely there is atresia, more or less complete, of the mouth at birth, requiring immediate operation.

(Tongue-Tie and Macroglossia are discussed in Part II.)

Of interest, only as a peculiarity, is the bifurcation of the uvula. More serious is the persistence of a septum at the upper end of the œsophagus occluding the mouth at the pillars of the fauces. Other 


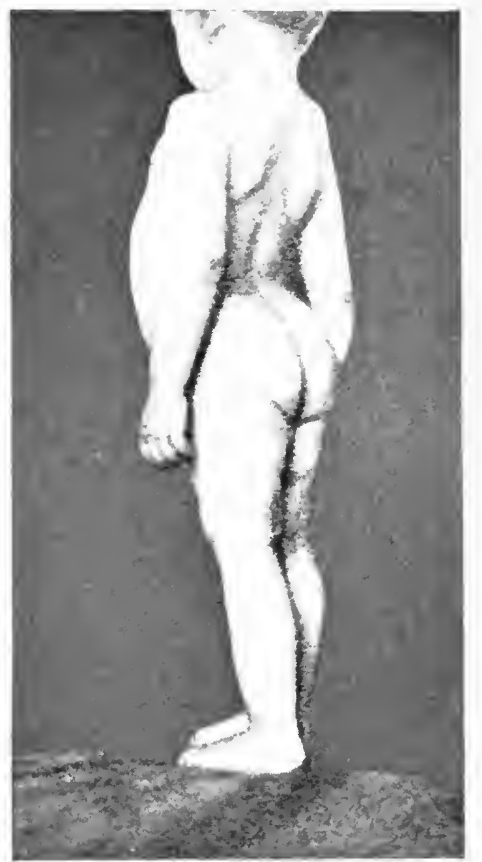

Fig. 89.-_ame as Fig. 88, side view.

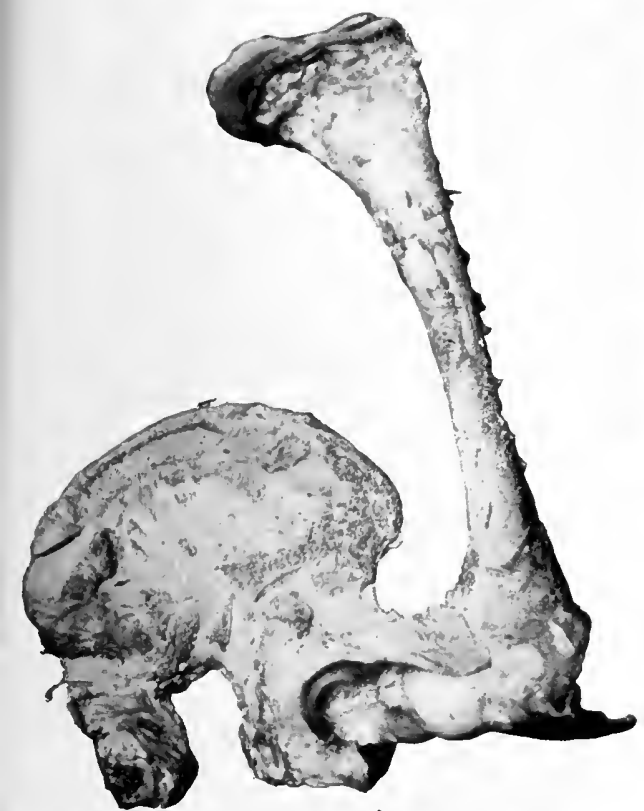

FIG. 90.-Dislocation of hip. (Rush Medical Museum.)

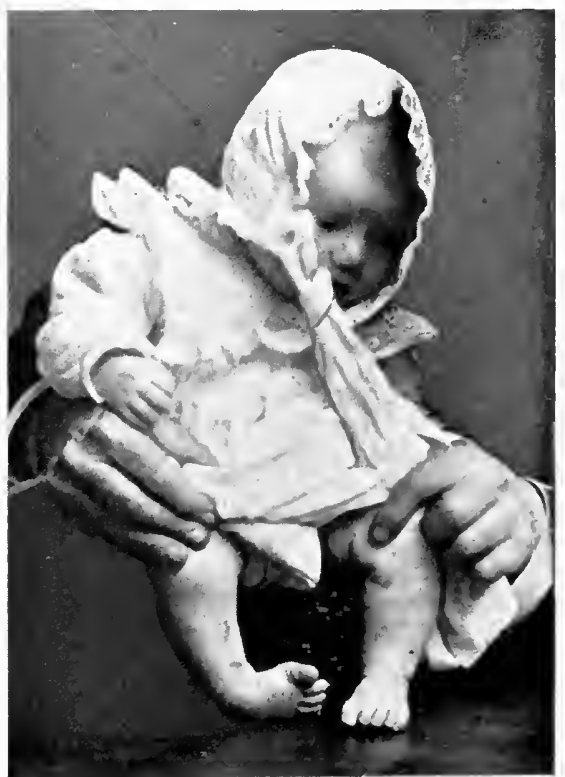

FIG, 91,-Congenital club foot. (Dr. W. Blanchard.) 


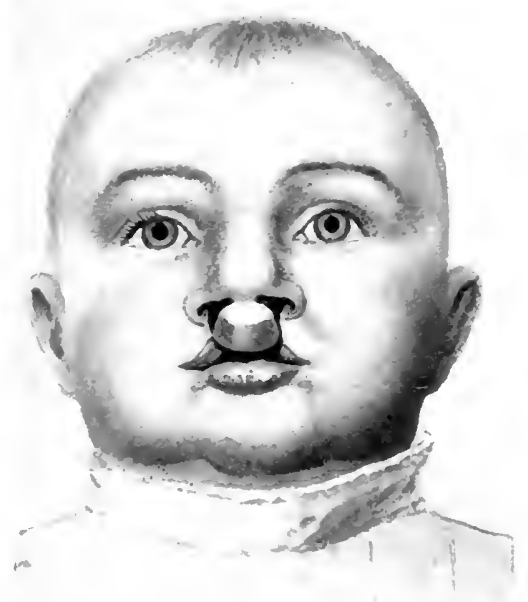

Flg. 92--Doublo eleft palate with harelip. (Brophy.)

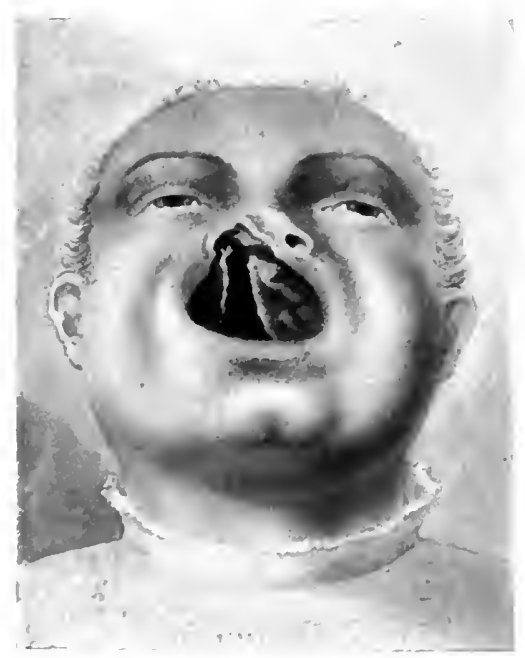

F19. 94.-Single "left palate with harelip.

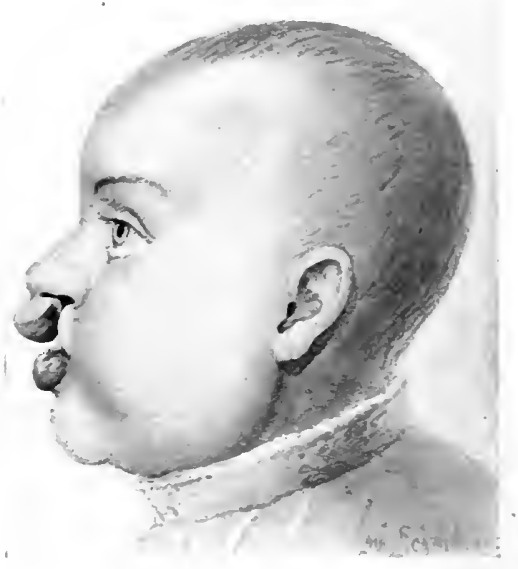

Fri. 93,-Side view of Fig. 92.

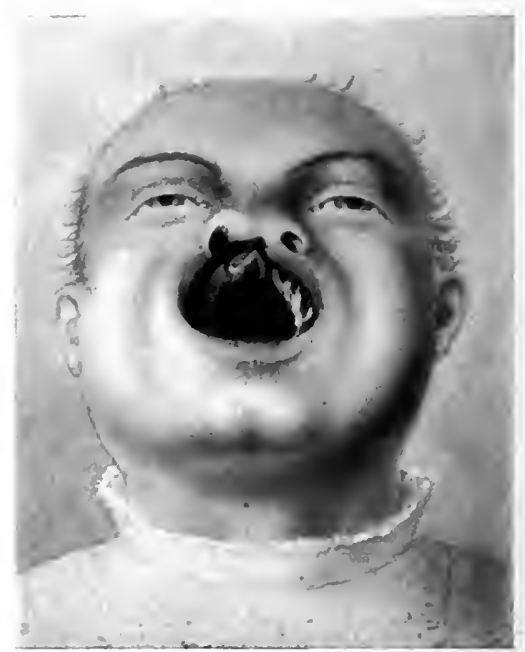

Frr. 95. - Same after operation for closure of pulate. (Bropty.) 
malformations of the resophagus are ocelusion at any portion, bifureation of its upper end, absence of partition between it and the trachea, and fistulous communication with the external surface.

The most common defect of the stomach is a congenital stricture of the pylorus, which is deseribed in Part II. From either imperfect development or a fetal peritonitis, any part of the intestines may be occluded, the most frequent sites, besides the pylorus, being at the orifice of the common bile duct, Meckel's diverticulum, and the ileum. The lesion may be a stricture, or the intestine may be represented merely by a cord of fibrous tissue of several centimetres' length. The symptoms are persistent vomiting, absence of stools, rapid emaciation, and early death. The omphalo-mesenteric duct may persist (Meckel's diverticulum, Fig. 96) and remain patent throughout its extent, forming a fecal fistula. It may protrude as a tumor at the umbilicus, or, by shutting in a loop of intestine, may cause strangulation.

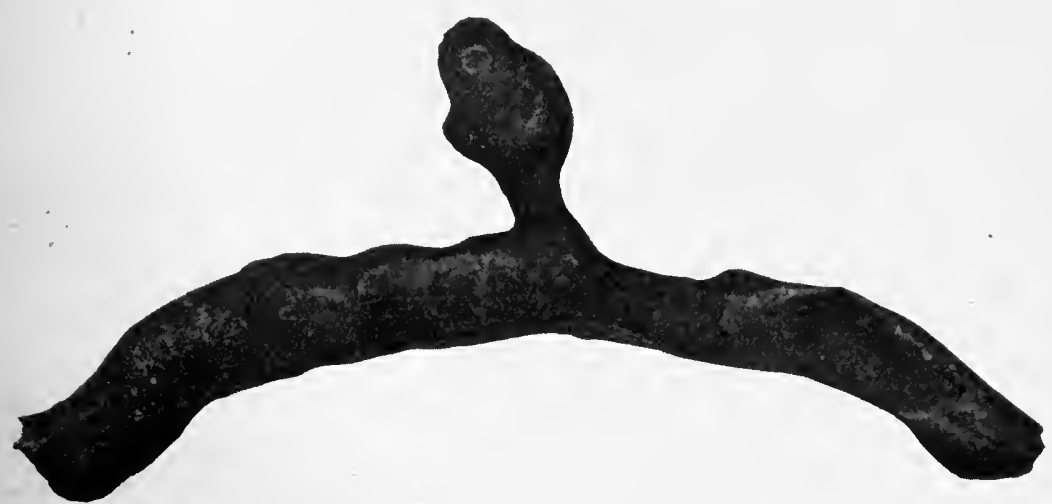

FIG. 96-Meckel's diverticulum.

Atresia ANI of mild degree consists simply in a failure of invagination of the skin while the rectum is normal in location (Fig. 97). In the second form the rectum has been arrested in development or diverted from its course, the anal portion having been fully formed, but ending in a blind pouch (Fig. 98). In the least favorable class both anus and rectum are defective in development and may be several centimetres apart (Fig. 99). If the imperforation is located high up in the rectum the diagnosis is recognized by the absence of stools, distended abdomen, and unhealthy tint of the skin. Operative measures in the first class are simple and successful. In the second and third they are much more difficult and it may be necessary in either instance to form an artificial anus.

Other malformations of the rectum are its abnormal termination in the bladder, urethra, vagina, or perineum (Fig. 100). In these eases the treatment is surgical, but immediate operation is not so urgent as in the forms of atresia. 


\section{CONGENITAL DILATATION OF THE COLON AND STOMACH.}

Several cases of enormous dilatation of the colon, existing since birth, have been recorded. The walls of the large intestines are usually hypertrophied and present many ulcerated areas. These ulcers are probably due to irritation and infection from retained fxces. In some cases the dilatation has been eaused by stricture or occlusion of some portion of the sigmoid or rectum from maldevelopment or fetal peritonitis. In others, which have been termed idiopathic, it has been impossible to ascribe a cause.

The symptoms are obstinate constipation, followed by varying intervals of diarrhœea, abdominal distention which entirely disappears after evacuation of the bowels, and progressive emaciation.

Medical treatment has been of little benefit. The only hope of relief is in surgery, either by excision of a portion of the redundancy or entire ablation of the colon, forming an artificial anus or joining the small intestine to the rectum.

The stomach is occasionally found enormously distended at birth, without evidence of pyloric stenosis (Fig. 101).

UMBILICAL DEFECTS.

An abnormality that rarely occurs is a congenital hernia in the cord, which must be distinguished from the umbilical hernia developed after birth. In the congenital form, a portion of the intestine or liver may work its way in among the structures of the cord and receive its coverings from them. There are a few cases reported of the intestine being included in the accoucheur's ligature.

In the fotus the intestinal canal is cut off from the yolk-sac by the gradual growth of the ventral plates and their ultimate union in the middle line. This union occurs latest at the umbilicus. In some cases of imperfect development the anterior wall is more or less entirely absent, and the viscera are either entirely uncovered or protected only by amnion and parietal peritoneum. This condition, congenital exomphalos, is usually associated with other deformities which are inconsistent with any but very brief existence (Fig. 102). Reposition of the viscera and closure of the cleft have been successful in a few instances.

From the mode of development it is easy to see how a congenital fistula at the umbilicus may result from persistent patency of the urachus. If there be no obstruction to the discharge of urine through the urethra, touching the opening of the sinus with the solid nitrate of silver is usually sufficient. If the urine continues to discharge at the umbilicus, it will be necessary to freshen the surface of the fistula and close with sutures.

DIASTASIS OF THE RECTI MUSCLES.

Diastasis is due to a defective union of the abdominal walls in the median line. The marked cases have occurred in rhachitic children. In 


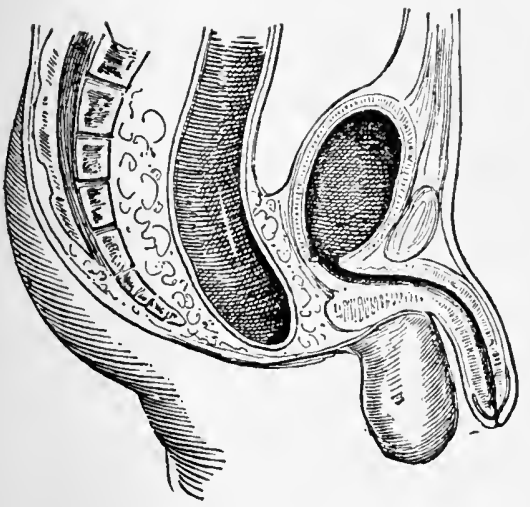

FIG. 97,-Atresia ani. (Keating.)

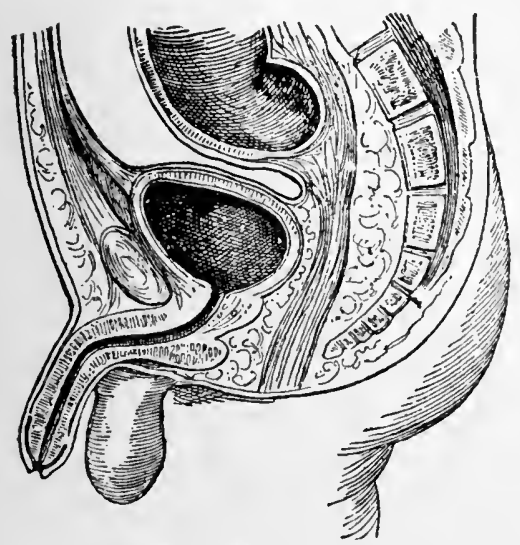

Fig. 99.-Absence of rectum.

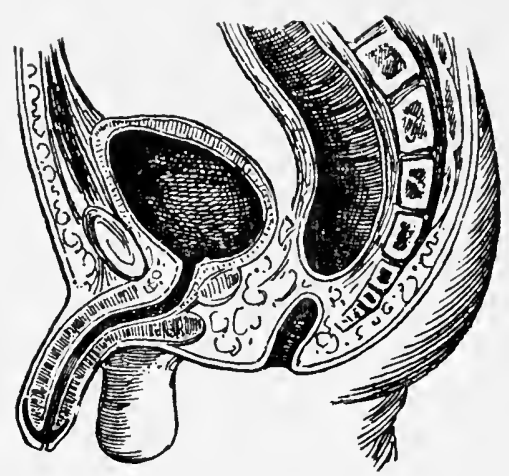

FIG. 98.-Rectal occlusion. (Kenting.)

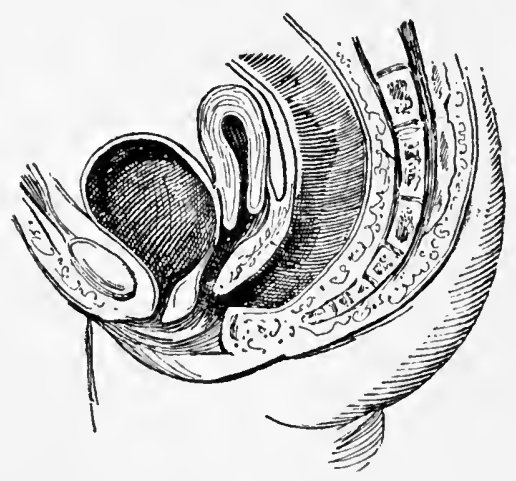

Fia, 100.-Common cloaca. 


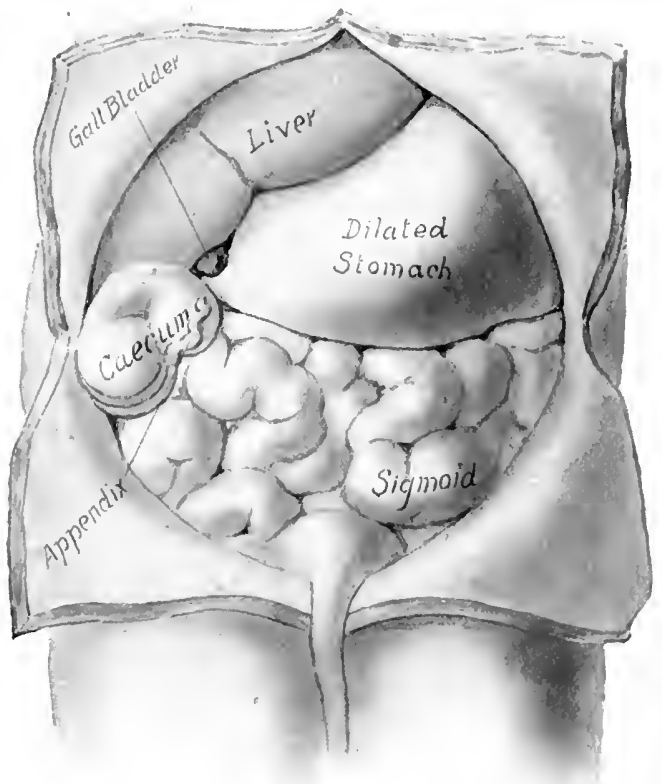

FIG. 1C1.-Dissection of new-born, dilated stomach displacing liver. (Dr. J. D. Merrill.)

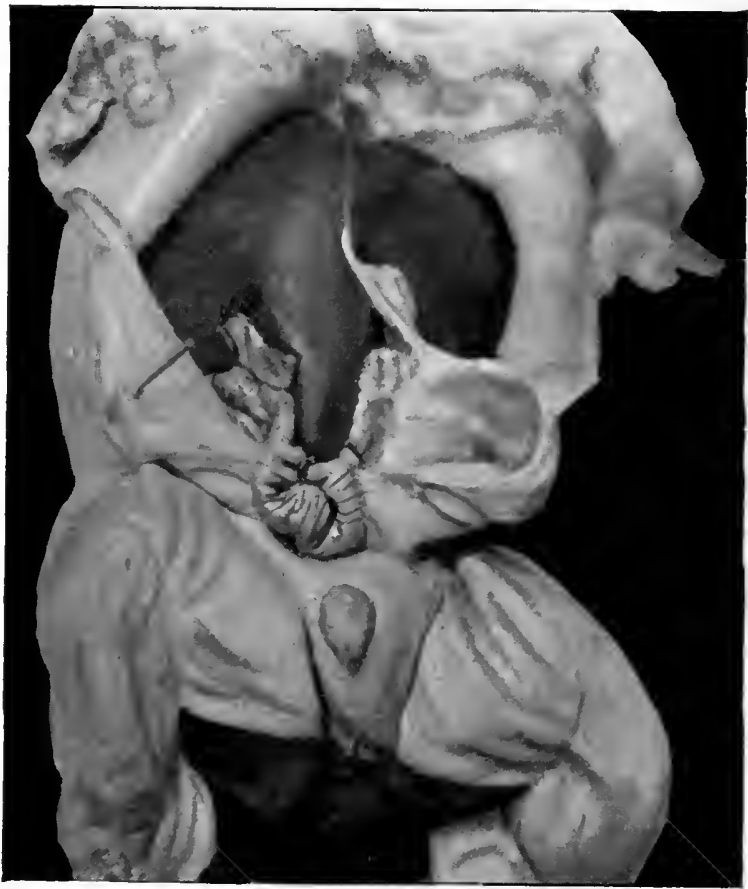

Fig. 102.-Exomphalos including a portion of the liver and loop of intestine. 
them the lowered muscular tone of the stomach and intestines has resulted in fermentation and tympanites, with increased pressure against walls that are congenitally weak and also poorly nourished. The separation may be slight or equal the width of three fingers. It is seen in the upper portion of the abdomen, extending from the point of the sternum to the umbilicus. If of slight degree it may be brought out by causing the patient to raise the head and shoulders from the bed. Bringing the edges together by adhesive plaster or bandage, with attention to digestive disturbances, is usually sufficient treatment.

Congenital inguinal hernia ineludes not only those cases in which the rupture is actually present at birth, but also those which develop in the early weeks and months of extrauterine life. It has been stated that the funicular process is patent in fifty-nine per cent. of all infants at birth. Distention of the abdomen from flatulent indigestion, or straining due to a phimosis or coughing, are probably the chicf factors that determine the presence of a rupture.

Boys are much more frequently subject to inguinal hernia than girls, and in a large proportion of eases the right side is the one involved, owing to the earlier closure of the process on the left side.

The symptoms are the same as in adults and the diagnosis is made by the same methods. Enlarged lymphatic glands, hydrocele, and fatty tumors are to be excluded by the consistency, translucence, and reducibility of the swelling.

The prognosis is far more favorable in early life than later. Many small hernias in young infants doubtless recover spontaneously, owing to the natural tendency to closure of the peritoneal pouch. This tendency should be favored by care in feeding so that abdominal pressure be not increased by flatulence, or it may be that circumcision should be the first step in the treatment. In nearly all cases under four years, the trial of a truss should be made before resorting to surgery. The exceptions to this are hernias that are increasing in size, complicated by hydrocele strangulated, or those that cannot conveniently receive proper care.

In young babies the wool truss usually gives satisfactory results and has the advantage of small cost. A skein of wool is passed under the body at the waist line. One end is passed through the other at a point corresponding with the external abdominal ring, then carried between the thighs and fastened behind to the portion encircling the waist. As to the length of time the truss should be worn, the rule has been given that if begun before the age of one year, it should not be discarded before the third year; if not worn before the age of three, it should be kept on until the age of seven.

In cases requiring operation the prognosis is good, even in very young infants. Recovery has followed the operation for double inguinal hernia in an infant twenty-four hours old.

Femoral hernias are extremely rare, even in girls. The prospect of cure by a truss is much smaller in this form. 


\section{DIAPHRAGMATIC HERNLA.}

Occasionally there are reported cases of diaphragmatic hernia. In these there is a congenital deficiency of a portion of the diaphragm (the left anterior border has been the part affected in nearly all the cases), allowing the escape of a less or greater portion of the abdominal viscera into the thorax. 'The heart is crowded to the right and the development of the left lung is interfered with. The grouping of symptoms produced are often puzzling, and in most instances the condition has been discovered for the first time at the autopsy. Naturally the prognosis is unfavorable.

Congenital Heart Disease is diseussed in Part II.

EXSTROPHY OF THE BLADDER-ECTOPIA VESICE.

One of the most remarkable deformities is exstrophy of the bladder (Fig. 103). Here, not only is there deficiency of the abdominal wall but

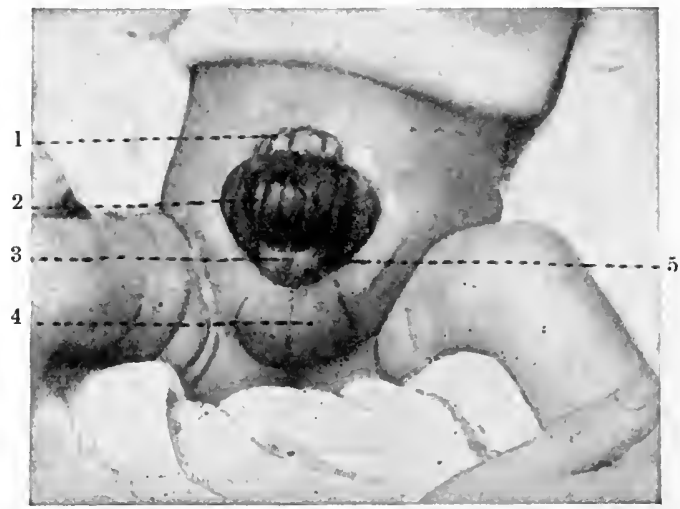

FIG. 103.-Exstrophy of the bladder. 1, Umbilical cicatrix; 2, bladder wall; 3, rudimentary peuis; 4 , scrotum; 5 , inguinal hernia.

also of part of the genito-urinary apparatus. In complete cases of extroversion there is absence of the umbilicus and of the anterior wall below it. There is no symphysis, - a gap existing between the pubes; there is absence of the anterior wall of the bladder, of the greater part of the penis, and of the roof of the urethra. The scrotum is also bifid and the testicles are usually undescended.

The urine escapes constantly from the openings of the ureters, eausing irritation of the skin and an ammoniacal odor. The unprotected bladder wall becomes irritated from the friction of the clothing.

Deflecting the ureters into the rectum has been successful in a few cases, but in others it has been followed by an ascending pyelonephritis. Plastic operations are usually deferred until the third or fourth year.

For cryptorchidism, sec Undescended Testicles, Part II. 
CONGENITAL ATRESIA OF URETHRA, VULVA AND VAGINA.

Anuria in the new-born may be due to an imperforate urethra. The obstruction is usually merely a thin layer of membrane which is easily punctured by the probe. Congenital contraction of the meatus or stricture of any portion of the urethra is sometimes present causing slow micturition, retention, and resultant cystitis. Cohesion of the inner surfaces of the labia minora occasionally require separation, which is usually accomplished without difficulty.

There is occasionally seen an abnormality resulting from the nonabsorption of the septum formed by the infolding at the cloaea. This results in an imperforate hymen.

Atresia of the vagina is frequently not discorered until puberty. If the condition be recognized, incision of the imperforate hymen or septum of the vagina should be made during later infancy, as the membrane is then thinner and less vascular than later in life.

Phimosis (see Part II).

\section{EPISPADIAS-HYPOSPADIAS.}

Sometimes the inferior wall of the urethra and corresponding part of the corpus spongiosum are wanting, as in hypospadias; or there may be a deficiency in the superior wall of the canal and adjacent parts of the corpora cavernosa, as in epispadias. The last-named condition is much rarer than hypospadias. In both forms of malformation there is deficient power of retention of urine and consequent intertrigo, cystitis, and erosion. Plastic operations are indicated, but are not always snccessful, as fistulous openings are apt to persist.

\section{NAVI-BIRTH MARKS; PORT-WINE STAINS.}

The skin of the face is very thin and exceedingly vascular, hence it is often the seat of nævi. These are of two forms, pigmented and vascular. A pigmented nævus having a smooth surface is known as novus spilus; if warty and uneven, novus verrucosus, and if covered with coarse hair, ncevus pilosus.

The first form consists simply of a circumseribed hyperpigmentation of the skin. In the second and third forms, there is often hypertrophy of connective and fatty tissue.

Nævi may be found on any part of the body, but their favorite sites are the face, neck, and back. The outer surfaces of cerebral and spinal hernias are commonly covered by these moles.

The cause of these localized hypertrophies is unknown. The part played by maternal impressions continues to be debatable, with the balance of opinion against any logical connection.

Pigmentary nævi may increase in extent as the patients grow, and show no tendency to disappear spontaneously. In early life they constitute merely blemishes, but as they are liable to malignant degeneration, their removal in childhood is advisable,- - at least in the case of the 
larger growths. This may be done by "stippling"' with eautery, by electrolysis, or excision.

The vascular nævi are made up of anomalous blood-vessels, capillary, venous, or arterial. Often they are not perceptible at birth, but become evident in the first weeks of life. They vary greatly in size and color, and all are obliterated by pressure. This variety also selects the face and neck as favorite locations, but also oceur on the mucous membranes, as well as the surfaces of kidney, liver, and spleen. The etiology is as obscure as is that of pigmented moles.

Those most frequently seen are small, not elevated above the skin, and having vessels of eapillary size. A large proportion of these disappear without treatment in a few months. The term "port-wine mark" is applied to nævi of the size of the hand or larger. In these, distinet bloodvessels are sometimes seen and the surfaces are often uneven. When these nævi form large, elevated, lobulated, erectile, or pulsating tumors they are termed angiomata cavernosa. They often attain a large size and are a source of danger to the child from hemorrhage following a slight injury. Later in life they are subject to degenerative changes. The smaller nævi should not be interfered with in infancy or early childhood, as they may disappear spontaneously. If treatment be required by the parents, painting with collodion may cause obliteration of the small marks. For the larger nævi, corrosive sublimate and collodion $(1: 10)$ or ethylate of soda may be repeatedly applied, but removal by electricity is the most satisfactory method of treatment.

\section{CONGENITAL BONY DEFECTS-OSTEOGENESIS IMPERFECTA.}

Several varieties of defective bony formation have been described under various names, but there is no uniformity of classification.

Oceasionally at birth there is absence or rudimentary formation of some one of the long bones, as the clavicle or bones of the forearm and leg. Usually this defect is symmetrical.

The occurrence of actual rhachitic deformities at birth must be recognized, although rare, and many eases that have been reported in the past as fetal rickets are now known to be examples of achondroplasia.

Unusual fragility of the bones, fractures occurring in spite of the greatest care or even in utero, may be present in the absence of all evidence of rickets or syphilis, constituting the osteogenesis imperfecta of some writers. There may be great brittleness, the bones consisting of a very thin shell of osseous tissue, or they may be so lacking in mineral matter as to be easily bent or cut.

The only known treatment is to protect the bone from traumatisms and to improve the general nutrition by all available measures.

\section{ACHONDROPLASIA-CHONDRODYSTROPHIA FETALIS.}

Recognition of achondroplasia and differentiation from cretinism and rickets are becoming general, owing to the renewed interest in the disease during the past ten years. The essential points are a dwarfed stature 

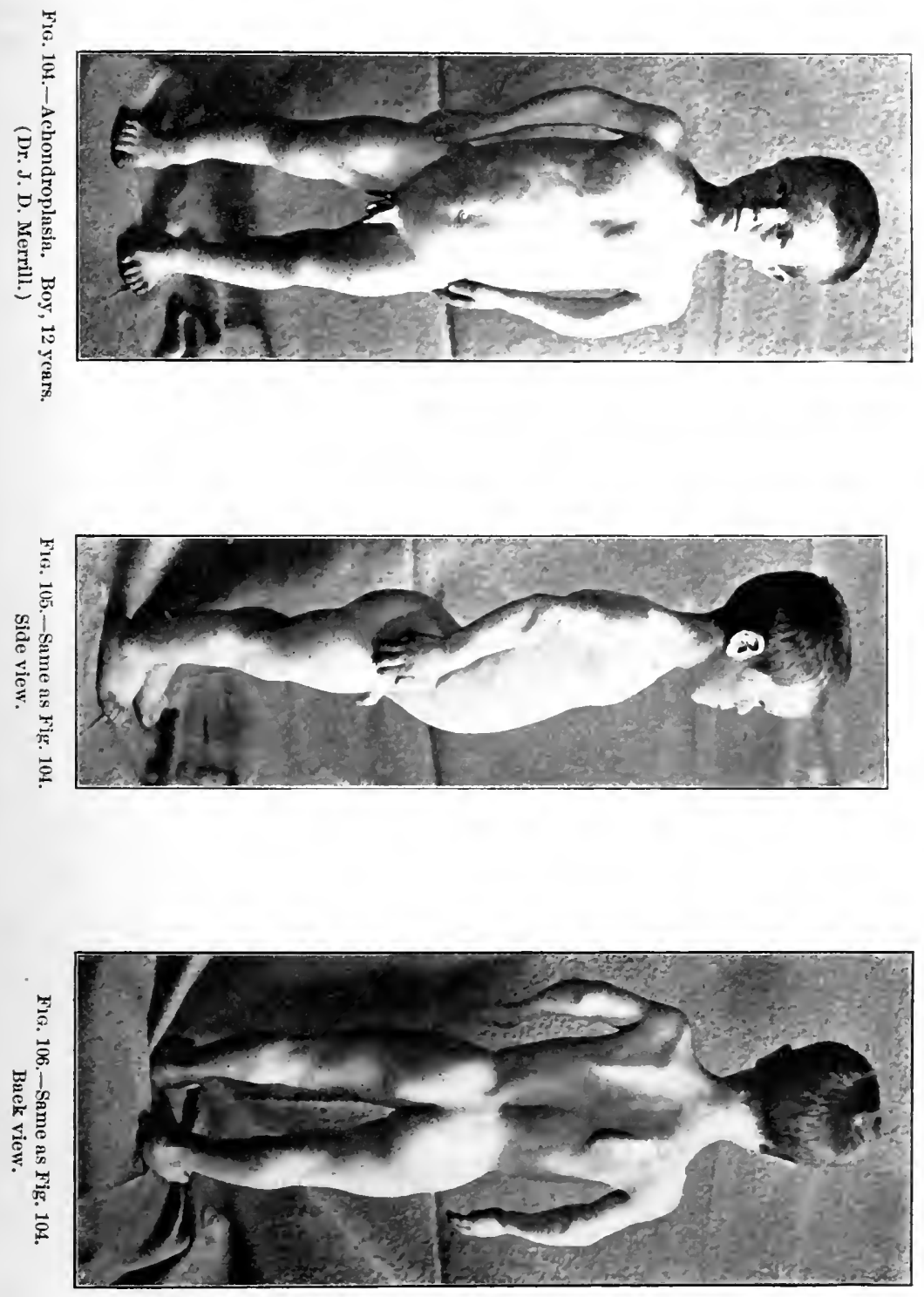


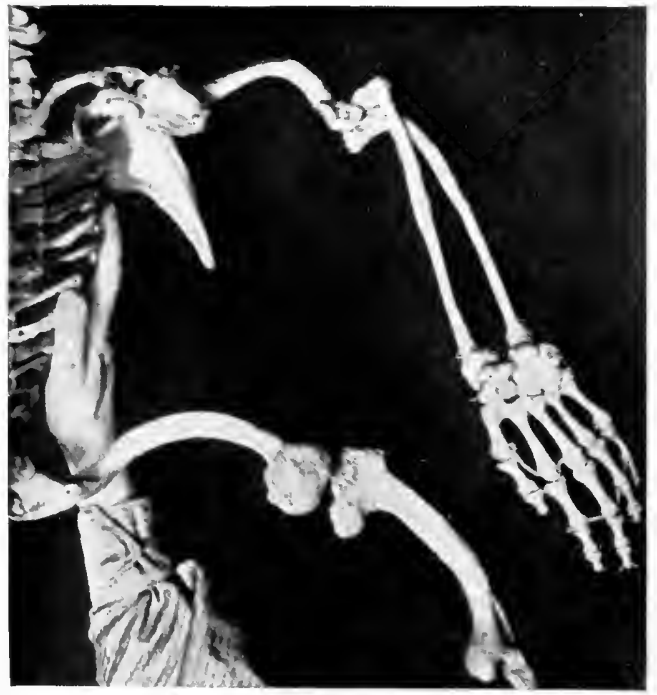

Fig. 107.- Shortened, curved bones of achondroplasia. (Rush Medical Museum.)

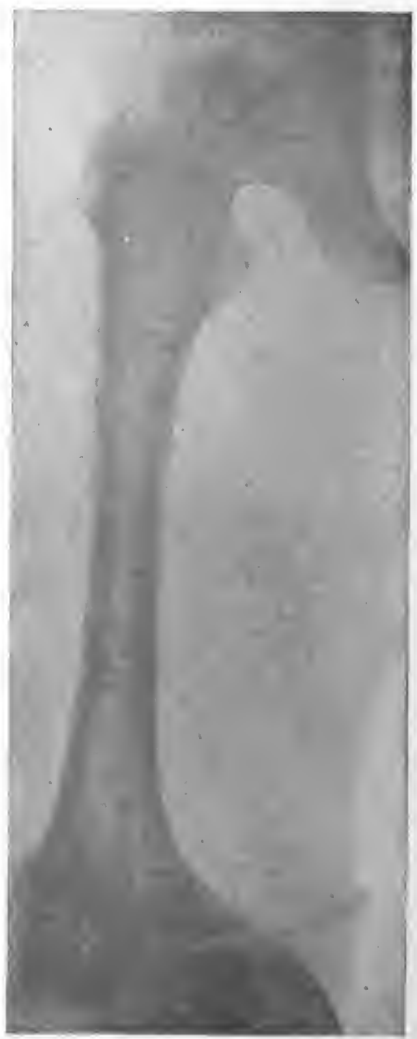

FlG. 108.-Skiagram of achondroplastic thigh, showing enormous condyles and short femur. 
due to shortened limbs, the trunk aequiring normal development; a. large dome-like head with retraction at the root of the nose from premature ossification of the bones at the base of the skull; and unimpaired mentality (Figs. 104 to 108).

In the extremities the shortening is partieularly marked in the humer: and femora. All the epiphyses are large and the limbs are eurved or distorted. The hands are short and the fingers separate, forming the trident hand. The distal phalanges seem to eseape deformity.

Most achondroplasiaes die soon after birth, but those who surrive early childhood possess ordinary health.

As the name implies, the defect is in the cartilages, and the eause must be operative in the early months of fetal life. Bones formed in membrane and those developing from cartilage at a later period are not involved. The thyroid gland has been reported normal; none of the symptoms of eretinism, excepting dwarfism, are present, and thyroid extract offers no hope of relief.

\section{CLEIDOCRANIAL DYSOSTOSIS.}

An odd combination of congenital bony malformations has recently been studied and reported. In these infants there is aplasia of the clavicles, a flattening of the oceiput, and an inereased transverse diameter of the skull. The fontanelles remain open even to adult life, and there is defective development of teeth, palate, and other bones of the face. The mind is not affected. The peeuliarity may be present in several members of the same family, also in the second generation. Not even a satisfactory theory of the etiology has been advanced. 


\section{PART II \\ Diseases of Children \\ CHAPTER I}

\section{DISEASES OF THE NEW-BORN}

\section{EXAMINATION OF CHILDREN}

The first essential for the successful study of the manifestations of disease in infancy and childhood is a thorough familiarity with the normal child at various stages of growth. A second essential is a complete knowledge of the morbid tendencies peculiar to the different periods of development. A third essential is a recognition of the fact that the unstable equilibrium of infancy and childhood responds to functional disturbances in a varied and irregular manner with a frequent extravagance of symptoms from apparently trivial causes.

The absence of all subjective symptoms in infants and young children throws the diagnosis in this class of patients entirely upon rational signs and objective symptoms. Although the science of symptomatology is the same in all classes of patients, the art of its application to diseases of early life is peculiar.

In examining infants and children inspection must furnish the larger part of information, and the study of symptoms must frequently take the place of the more exact diagnostic measures of adult life. No routine method may be prescribed in dealing with children. Tact and patience are all-important and delay in a direct examination is often wise. If the child be sleeping he should not be aroused until the opportunity is utilized for thorough inspection. If possible, before entering the nursery or sick-room, the physician should secure a complete history, including all possible items of heredity, birth, feeding, growth, previous attacks of sickness, and manner of onset of the present illness. In securing the history, suggestive questions should be avoided. Usually, although it may prove tedious, the uninterrupted narration of parent or nurse will furnish valuable information to the discriminating doctor.

An inspection during sleep may afford a more truthful picture of the child's condition than can be secured in waking moments. First, the decubitus should be observed, the relative position of the head and trunk, whether normally relaxed or rigidly retracted. The sleep, whether quiet or disturbed, the color, texture, moisture, and temperature of the skin, the respiration, whether quiet and regular or irregular, sighing or noisy 
from obstruetion in the upper air-passages, the play of the alae nasi, the supraclavienlar and intereostal depressions with inspiration, and the presence of eyanosis, are all important indieations. The open mouth, the half-elosed eyes, moaning, and twitching of facial museles, are also significant. Does the ehild lie "high" or with his head burrowed in the pillow? The size and tension of the fontanelle should be noted and the character and frequeney of pulse eompared with respiration.

If the ehild be awake, the physician may do well to seem to ignore his presenee. The egotism and timidity of children make them suspicious of any direet advanee, while, if ignored, their curiosity, if tactfully utilized, may soon lead to easy terms of aequaintance. Most siek ehildren resent being stared at too elosely. By indirect inspection there may be noted contour, posture, muscular movements, locomotion, and faeial expression,

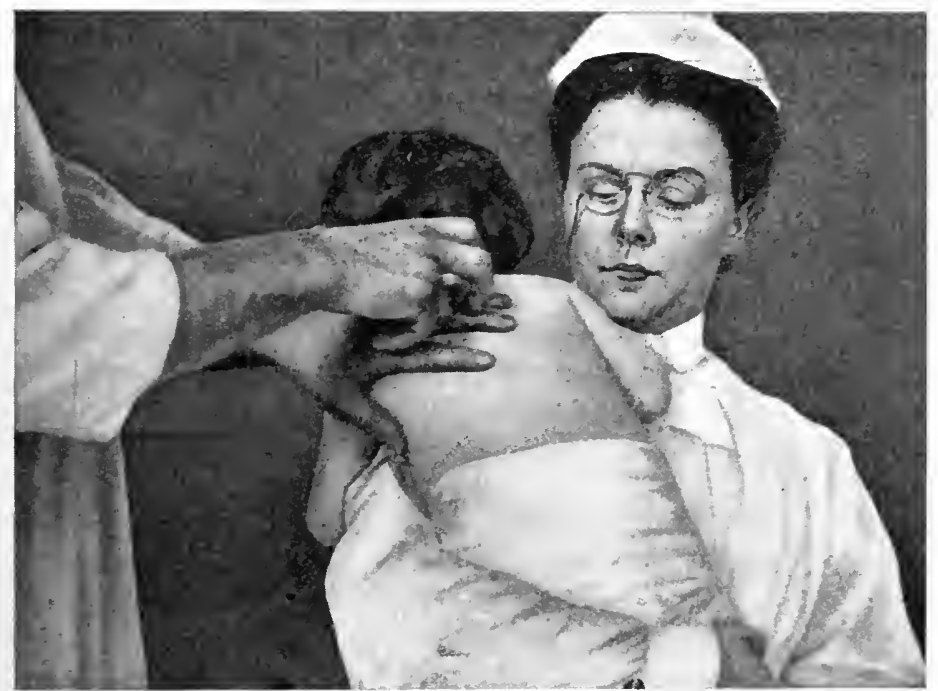

FIG. 109.-Position for examination of the chest.

while the ear takes eognizance of every sound,-as erying, talking, breathing, or coughing. If the infant be over three months of age, note if he holds up his head; if six months, does he sit unsupported; if a year or more, does he stand or walk without limp or dragging of a foot? Is there a discharge from nose, eyes, or ears? If the child ean be coaxed to the doetor's knee mueh information may be gained by taking advantage of the opportunity for palpation, percussion, and auseultation.

The ehild shonld be stripped, if practicable, and plaeed upon a pillow on the mother's lap or table, where thorough examination may be made by inspection, palpation, percussion, and auscultation. It is obviously impracticable to attempt this routine examination of a child screaming and struggling in an agony of fear. A little subterfuge may secure a part where the whole is denied. The infant held against the nurse's 
breast, with its head over her shoulder, presents quite sufficient dorsal surface for brief, immediate auscultation and even percussion, if tactfully employed (Fig. 109). The latter, to be valuable, must always be gentle. Fremitus or its absence may be noted, and palpation of the abdomen, limbs, and superficial lymph nodes adroitly secured. Mcanwhile, skin eruptions and lesions, aural and nasal discharges, texture of skin, hair, and nails should all be observed.

Rectal temperature should be taken and may be usually managed without a struggle. Rectal examination may be made, if necessary, even in young infants, with the lubricated finger, and may give information as to tumors, intussusception, appendicitis, adhesive peritoneal bands, and enlarged lymph nodes.

The physician should always examine the infant's diapers, not trusting to the description of the mother or nurse, and, when possible, the urine. For this purpose the dejections should be saved until his visit. Urine may be secured even from young infants by placing a pledget of absorbent cotton enclosed in a fold of rubber tissne against the genitals. For boys, a small bottle or rubber cot may be employed, and for girls a boat-shaped vulcanized receptacle, retained in position by a four-tailed bandage or by adhesive straps and diaper. If necessary, catheterization should be resorted to, with proper aseptic precautions.

The child's eyes may furnish valuable information in strabismus, nystagmus, pupillary reaction or inequalities, corneal haziness, phlyctenular ulcers, or amaurosis. There may be ptosis, exophthalmos, or the deflected visual axis of hydrocephalus, facial or other voluntary motor paresis, muscular dystrophies, pseudohypertrophy, exaltation or abolition of reflexes, spasticities, contractures, flaccid paralysis, bow-legs, or knock-knees, rhachitic pseudoparalysis, bony enlargements, tuberculous and syphilitic epiphysitis, or arthritic tenderness.

The mouth should always be examined last, by which means alone may be determined the condition of the tongue, teeth, gums, buccal surfaces, palate, tonsils, and pharynx. Without this knowledge no diagnosis should ever be attempted.

The X-ray is ofttimes a valuable aid, not only for the location of foreign bodies, fractures, dislocations, bony deformities, and tumors, but for enlarged and displaced viscera, areas of consolidation and exudations.

\section{ASPHYXIA.}

IN the parturient chamber a most welcome sound is the cry of the child, not only as a signal of the termination of the most difficult stage of labor, but as an indication of the establishment of the most important function of the newly born. The experienced ear of the accoucheur interprets that cry as to its prognostic value, a loud and sustained quality indicating unquestioned respiratory vigor.

If, however, the cry be feeble or absent, his attention is immediately engaged as to the presence or absence of respiration, the depth and frequency of the movements involved, the color of the skin, and the action 
of the heart. Pulmonary respiration may not be established immediately after delivery, and as placental respiration ceases with the ligation of the cord, vital proeesses are reduced rapidly, and the ehild may die of asphyxiation,-literally for want of breath. The exact instant at which death occurs in these cases of pulmonary asphyxiation no one ean determine, and probably no condition so frequently presents itself to the physician in which his skill and timely services may unquestionably maintain the vital processes.

It is well known that perseverance in his efforts is often rewarded by the establishment of respiration in eases where, for many minutes, the results seemed hopeless. Occasionally asphyxiation oceurs after pulmonary respiration has been established, at times eoming on sucldenly with almost eomplete arrest; at other times, gradually, the feeble respiration becoming more and more shallow until finally suspended.

As before stated, there is marked eyanosis of the superfieies, the mucosa particularly showing a deep purple hue. The general indieations of intense congestion, swollen appearance of the face, slow, labored heart action, all give evidence of pulmonary obstruetion. As the coma deepens from accumulation of carbon dioxide, the heart's action becomes more rapid and feeble, the extremities eold, and the surface pallid, with final cessation of heart beat. On the other hand, there may be from the beginning shallow, irregular inspiration, feeble, rapid heart, colorless surface, and flaceid limbs, - all evidences of feeble vital proeesses. These two pictures represent different types of suspended animation, from deficiency of oxygen, and may be due to quite different causes-the first, to mechanical obstruetion to the entrance of air from any eause; the second, to an enfeebled condition of the musculature of the cireulatory and respiratory systems. Between these two distinct types-namely, asphyxia livida and asphyxia pallida-many variations may oecur.

In his efforts for the relief of asphyxia neonatorum, the term applicable to all of these conditions, the physician must be governed by the type to which the individual case most inclines. Efforts at cardiae or respiratory stimulation are entirely out of order when the trouble is due to mechanical obstruction from inspired mucus in the glottis or fluids in the pulmonary tubes. On the other hand, worse than useless are such violent measures as artificial respiration by swinging through the air the chilled body of the pallid infant, whose fluttering heart shows the need of warmth and cardiac support. Fortunately, asphyxia may be relieved by prompt aid in a great majority of cases, particularly of the sthenic variety, and occasionally of the asthenic type.

The indications are plain,- - viz., the removal of obstruction from the respiratory passages, whether nasal, pharyngeal, laryngeal, or tracheal. As mentioned in a previous chapter, the first may be accomplished by a pledget of absorbent cotton; the second, by a finger wrapped with dry gauze. The glottis may be freed from tenacious secretion sometimes by skilful manipulation of a curved canula, with bulb attachment for exhaustion of the air, or by direct suction through a catheter by the 
mouth of the operator. These efforts should be aided by inversion of the child, thus securing the influence of gravity in the escape of fluids, and also determination of blood to the medulla. Artificial respiration should be practised when there is suspended action from feebleness of the respiratory muscles. Alternating hot and cold applications and faradization for cardiac as well as respiratory stimulation may be useful.

Rhythmic traction of the tongue is sometimes successful in establishing respiration. Too often a vital requirement is overlooked in allowing the infant to become chilled,- warmth being of the greatest importance.

\section{INSPIRATION PNEUMONIA OF THE NEWLY BORN.}

There is a popular belief that the infant is sometimes "born with a cold," in corroboration of which, symptoms of catarrhal involvement of the bronchial tree, including cough, dyspnœa and fever, are cited. In brief, the classical symptoms and sometimes signs of infantile bronchopneumonia are seen in the new-born. Inspiration pneumonia is a term applied to the condition. The infection is evidently due, as the term implies, to material drawn into the lungs of the infant during his passage through the parturient canal, and presupposes the presence of microorganisms, or the pre-existence of endometritis, vaginitis, ete.

The treatment is chiefly prophylactic and should be directed toward early disinfection of the birth canal. As to the infant, the existence of a lobular pneumonia requires supporting measures, stimulation, rest, etc.

\section{CYANOSIS INFANTUM.}

The term "blue baby"' is frequently used by the laity, and the title, morbus coruleus, is occasionally seen in the older literature. Broadly speaking, it is applicable to any form of cyanosis, and includes in its etiology all the causes of deficient oxygenation of the blood. The term is usually applied to infants with eongenital malformations or structural defects of the heart and great vessels (see CoNGenital HearT Disease). With few exceptions it is the right heart that is affected, the most frequent lesion being stenosis of the pulmonary orifice, with or without anomaly of its valves. The patulous foramen ovale and ductus arteriosus, formerly considered the causative lesions, are now regarded as secondary to the pulmonary obstruction. So, too, as a result of increased pressure in the right ventricle must be regarded the occasional incomplete ventricular septum. A long continuance of pulmonary stenosis usually results in enormous hypertrophy of the right heart. The skin does not always exhibit the distinctive hue, but occurrences of cyanosis are induced upon active exertion, and if the patient survive to the age of childhood, the finger-tips show the characteristic clubbing due to retarded circulation. This disorder may arise from a variety of vasculo-cardiac malformations regarded as pathologic curiosities, the differentiation of which is extremely difficult prior to the autopsy.

The prognosis and treatment depend largely upon the symptoms, drugs proving of but little avail. Freedom from exertion and excite- 
ment is absolutely necessary for eomfort and safety. Though the mortality is high, the patient not infrequently survives to maturity.

ATELECTASIS.

In many infants at birth the inflation of the lungs is not complete, a portion retaining its fetal condition. This state, known as atelectasis, probably obtains to a limited extent in all new-born during the first few days; the atelectatic portions gradually expanding with the nomally increasing vigor of respiration. It is usually the lower posterior borders that remain unexpanded, although their consolidation is often masked by the emphysematous condition of overlying superficial vesicles. In fact, the extent or even the existence of congenital atelectasis is rarely diagnosed by physical signs, this condition being most frequently indicated by the symptoms. Slight degrees of atelectasis may produce no symptoms, the condition escaping notice entirely. Shallow, rapid respirations, recurring cyanosis, feeble cry, and subnormal temperature with tendency to collapse, are symptoms strongly indicative of unexpanded lung. Atelectasis may be due to any of the causes of asphyxia neonatorum. Paresis of the respiratory centres, brain pressure, and premature birth are also frequent factors.

Long continued maintenance of one position favors atelectasis, through interference in circulation from pressure and hypostasis. By reference to the chapter on Hygiene of THE NEW-Born, it is seen that frequent changing of position and occasional massage are advised. Hence one objection to institutional management of infants is that they are confined too closely to cribs, leading a purely vegetative existence. As previously stated, lung capacity is the exponent of infant vitality. Hence it necessarily follows that impairment of vitality is in direct ratio to the extent of unexpanded lung. The atelectatic condition is susceptible of spontaneous correction, failing in which it continues a menace to life. Fatal ending of a mild bronchitis is often due to pre-existing atelectasis.

The treatment is purely rational,-viz., efforts to secure expansion through deep inspiration. For this purpose prolonged crying, short of exhaustion, must be encouraged. Massage, flagellation, and sprinkling the chest with cold water will assist. The longer the condition persists the more difficult will be its correction. Hence early efforts should be continued. Fresh air supply and maintenance of bodily warmth are especially insisted upon, nor must it be forgotten that the defective lung will poorly endure pressure, as from distended abdominal viscera, sudden death from this added cause being not infrequent. For threatened collapse due to respiratory enfeeblement, inhalation of oxygen and hypodermics of strychnia are indicated.

The prognosis depends upon the extent of involvement and the persistence of the condition.

\section{INANITION FEVER.}

Within the last few years attention has been called to the development of pyrexia in infants during the first four days of life. A want 
of nutrition seems to be the sole etiologic factor, as in these cases there is a rapid disappearance of the fever upon the administration of proper nourishment. 'This inanition fever has been frequently observed, and, for the present at least, must take its place in the nosology of the newborn. From the first to the fourth day of extrauterine life the temperature may range from $99.5^{\circ}-106^{\circ} \mathrm{F}$. $\left(37.5^{\circ}-41^{\circ} \mathrm{C}\right.$.), approaching the normal usually abruptly upon the establishment of lactation or upon the administration of artificial food. In these febrile cases it has been noticed that the loss of weight is more marked than in the nonfebrile. The importance of recognizing this condition from the pyrexias due to known infections is apparent. The treatment would call for properly attenuated artificial food. By this means it is believed that the, so-called, normal loss of weight may be reduced to the minimum, if not altogether prevented.

It is known that inanition fever may cause death at this early age, even when the child is apparently taking the breast normally. It is the duty of the physician to assure himself that the child is actually getting a sufficient amount of suitable food, and the first sign of pyrexia or failure to gain in weight should lead to examination of the breast and its secretion. Water, of course, is always indicated.

\section{ANURIA.}

Anuria in the new-born is a condition that has received too little attention. It may range from a trivial functional disturbance to the gravest organic lesion, and such a variety of canses may obtain in this condition that the question of early micturition must ever be regarded as one of importance. A new-born child, who has not urinated during the first twenty-four hours of life, demands special care at the hands of the physician. The causes of anuria may be stated briefly, as occlusion of the urethra, ureters, or renal tubules, or the obliteration of the secreting structures by cystic degeneration, inflammation, or neoplastic growths. The urethra may be occluded by a mucous plug or the meatus closed by a gummy secretion sufficient to prevent the outflow of urine. The ureters may be blocked by calculi or the uriniferous tubules may be plugged by uric acid crystals. The extrusion of urine may be prevented by pressure from tumors, abnormal anatomical relationship, or by torsion, flexion, or constriction of the ureters. The urethra may be imperforate from arrested development.

Without entering into the differentiation of the various causes of anuria, it should be stated here that the physician must satisfy himself of the patency of the lower urinary apparatus, the absence of neoplastic growths and cystic degeneration before venturing upon a favorable prognosis. Even then, fatal terminations have occurred where the post-mortem showed no abnormality other than a persistent general blocking of the tubuli uriniferi with uric acid.

In a large majority of these cases urination is established by merely freeing the urethra and by a liberal use of water, which presumably 
dissolves the uric acid concretions and prevents their reaccumulation by flushing out the tubules. Water should be administered not only by mouth, but also by free eolonic flushing, while elimination by the intestinal tract should be promoted by repeated doses of calomel. To these may be added hot baths and fomentations over the lumbar and hypogastric regions. Diuretics other than water are of doubtful utility, with the exception, perhaps, of a modified simola mixture (Formula 38), of whieh a teaspoonful may be given four to six times a day.

Strange as it may appear, convulsions due to anuria alone are of rare occurrence, and, when present, eonstitute one of the late symptoms.

\section{SCLEREMA NEONATORUM.}

Sclerema neonatorum, representing a eondition rather than a disease, is rarely seen in this country, although it is reported as of not infrequent oceurrence in European institutions. As its name signifies, the characteristie feature is a hardening and condensation of the skin, which process extends to the subeutaneous fat and areolar tissue. It is not a true œedema, as there is no pitting on pressure. This disease is sometimes congenital, oceurring oftenest in premature infants, and is frequently associated with pulmonary atelectasis.

Beginning upon the dorsum of the foot or in the eheeks, the induration extends rapidly to other portions, usually to the fatty eushions of the body, as the nates, and may within a few days involve the entire cutaneous surface. 'The skin has a hard feel, and eannot be pieked up or moved upon the subjacent tissues, giving a rigidity to the whole body as though encased in leather. At times the stiffness renders nursing impossible from inability to move the jaw. The temperature is invariably subnormal, having been observed as low as $80^{\circ} \mathrm{F} .\left(27^{\circ} \mathrm{C}\right.$.). The heart's action is slow and feeble, and the respiration is retarded and shallow. Discoloration is eommonly observed, a dusky or somewhat ieteroid hue prevailing. Death is the usual termination within the first week. Occasionally recoveries are noted after a somewhat prolonged convalescence.

The most rational etiology of this strange disorder is that of solidification of the subeutaneous fat from eontinuously lowered temperature incident to malnutrition and atrophic conditions. It is claimed that the fat of the infant solidifies at $86.6^{\circ} \mathrm{F} .\left(30^{\circ} \mathrm{C}\right.$. $)$, while that of the adult withstands a temperature below $32^{\circ} \mathrm{F} .\left(0^{\circ} \mathrm{C}.\right)$. The fat of infants being rich in palmitine and stearine may explain its ready solidifieation.

In the treatment, attention should be specially paid to artificial heat, the eouveuse being admirably adapted to the purpose. Carliae and respiratory stimulation, with the exhibition of alcohol, should be employed, and nutrition be kept up by forced feeding and nutrient enemata, care being observed not to embarrass the feeble heart and respiration by overdistention of the stomach.

Ichthyosis (see DisEases of THE SkIN). 
OBSTETRICAL PARALYSIS-PERIPHERAL BIRTH PALSY; ERB'S PALSY.

Paralysis resulting from injury to the peripheral nerve-trunks is not an uncommon accident of birth. Of most frequent occurrence is facial paralysis, usually unilateral, due to pressure upon the trunk, or some of the branches of the seventh nerve, by the forceps blade. It may also be due to prolonged pressure contact with some bony prominence of the birth canal, as the promontory of the sacrum or the tuberosity of the ischium. The muscles involved may be all of those included in the distribution of the facial nerve, if the traumatism occur proximal to its main bifurcation, or only those muscles supplied by the temporofacial, if the pressure has been exerted higher up on the cheek.

Although the paralysis no doubt immediately follows the injury, it may escape early observation if confined to the muscles of the upper face, as the symptoms may be masked by the puffiness of the palpebral tissues so commonly seen after delivery. If the muscles of the cervico-facial distribution are affected, however, the first crying of the child will reveal the asymmetry, the mouth being drawn towards the unaffected side. The tongue, of course, is not involved. Later, upon subsidence of the birth cedema, the entire side of the face may show obliteration of characteristic curves, with inability to close the eye, and slight ptosis of the lid.

Nursing is never interfered with, as this is accomplished largely by the jaws and tongue, although the inaction of the buccal structures may allow the retention of particles of milk between the gums and cheek on the affected side.

The diagnosis from palsy of cerebral origin is not difficult, if it be remembered that facial palsy due to central lesion above the pons shows hemiplegia of the opposite side. Moreover, the muscles supplied by the temporal branches of the facial nerve escape.

Recovery usually takes place in from a few days to a few weeks dependent upon the extent of injury to the nerves.

Less common than the facial is the upper arm type of birth paralysis from injury to some cord of the brachial plexus. The arm hangs helpless at the side, the forearm extended and in pronation, the palm facing ontward and backward. The muscles of the hand and fingers are not involved in this motor paralysis. The arm often appears slightly swollen, and its temperature is lower than that of its fellow. The plexus, or nerve trunk, most frequently the fifth cervical, may be injured during birth by pressure of the finger or blunt hook in the axilla in efforts to bring down the arm, or the misplaced forceps blade may impinge upon this nerve or upper part of the plexus in the neck. The nerve may also be stretched or lacerated by undue traction upon the arm, or in breach presentation the clavicle may be forced upward and backward so as to compress the nerve upon the transverse processes of the fifth and sixth cervical vertebræ. It has been claimed that constriction of the neck by coils of the umbilical cord may produce this result.

This form of paralysis is readily diagnosed at the time of its occurrence. When first seen, after long duration, the differentiation from 
anterior poliomyelitis may present some diffieulties. However, spinal paralysis rarely results in upper monoplegia. The group of muscles involved in Erb's paralysis is eharacteristie, and usually a history of difficult labor is seeured.

Differentiation from fracture of the humerus or epiphysis may be made from the absenee of surgical signs of these aceidents, by the eharaeteristic position of the hand above described, and by the electrieal reaetion of the museles, whieh is ehanged only in the neuritis. From cerebral palsy, with its flexed arm, spasticity, and hemiplegia, this flaeeid, monoplegie, peripheral paralysis is readily distinguished.

The prognosis is favorable as to ultimate reeovery in the majority of cases. Extensive injury, followed by parenchymatous neuritis, may result in permanent paralysis with extreme and rapidly developing atrophy. Contraetion of the subseapularis may cause disloeation of the humerus. The question of duration depends upon the eleetrieal reaction of the affected muscles. Early reeovery may be expeeted in the presenee of faradie response, and a decrease or diminution in the reaction of degeneration is a hopeful indication. Return of faradic exeitability gives promise of speedy recovery. The deltoid is the last of these muscles to recover its function, and its atrophy is the most prominent feature of the resultant deformity.

Peripheral paralysis of the lower extremities, from injury to the lumbar and sacral plexuses is almost unknown, because of the thorough protection afforded these struetures by the adjacent muscles and adipose tissue. Paraplegia from hemorrhage into the spinal eord or its meninges, from laeeration during delivery, has been reported, but is extremely rare.

The treatment of obstetrieal paralysis, like that of other traumatic neuritides, requires rest to the dependent limb. This is best seeured by wrapping the flexed arm in eotton wool, with support as in the treatment of a fraetured elavicle. No massage or electrieity shonld disturb the injured struetures during the first two or three weeks, nor is any treatment necessary if early signs of reeovery are evident. If the affeeted muscles show little or no response to faradization at the end of a month, the treatment should be massage and passive motion, with a mild galvanic current, for a few minutes each day.

Later contractures may be prevented by the applieation of padded splints. If after six months there is no improvement in the affeeted museles, as seen in the reaction of degeneration, the question of surgieal proeedure for the artifieial anastomosis of the affected nerve with some healthy trunk should be considered. Recent reports of grafting from the spinal accessory and hypoglossal, in nerve degeneration following this form of neuritis, are encouraging, and justify hope for the few cases of obstetrical palsy that are refractory to medical treatment. 


\section{CHAPTER II}

\section{INFECTIOUS AND HEMORRHAGIC DISEASES OF THE NEW-BORN}

\section{SUSCEPTIBILITY}

The thinness and delicacy of the skin and mucous membrane partly account for the ease with which infection occurs in new-born infants. A satisfactory explanation of the great susceptibility shown at this time is yet to be made, and the following can only be stated as facts: that there exists a marked lowered resistance to the invasion of many bacteria and that the symptoms are often obscure, as there is more or less absence of the reaction seen in the adult. Moreover, sepsis is particularly apt to be attended by hemorrhages, not only from, and in the skin, but also from. mucous membranes and in all viscera.

Among the diseases positively and probably due to infection are mastitis, inspiration pneumonia, ophthalmia neonatorum, icterus, pemphigus, omphalitis, umbilical arteritis and phlebitis, tetanus, erysipelas, hemorrhages, acute fatty degeneration, and epidemic hæmoglobinuria.

\section{MASTITIS NEONATORUM.}

During the first week of life it is not unusual for the infant's mammary glands to show undue prominence. Upon pressure there exudes a whitish fluid resembling breast milk, with which, in fact, it is identical. This curiosity is all the more interesting in that it may occur in both sexes. The old dames of the lying-in chamber not infrequently consider the expression of this secretion as a part of the infant's toilet, as a result of the old superstition that by the removal of this "witches' milk" future trouble might be averted. Whatever may be the prophylactic benefit, certain it is that as a result of this rough usage, the gland sometimes becomes infected and mastitis follows. That this mastitis of the new-born is always dependent upon traumatism is difficult of demonstration. That it is an infection from the entrance of septic bacteria from without, is unquestionable, and occasionally it results in extensive suppuration and breaking down of tissue.

Its treatment should be prophylactic, care being necessary to prevent irritation of the enlarged glands from pressure of clothing, especially of the tight abdominal band. In case of abscess, evacuation and dressing with the usual antiseptic precantions are necessary.

ICTERUS NEONATORUM.

More or less icterus during the first few days of life is so common that many authorities regard it as physiological. A number of lying-in 
institutions record as high as sixty and even eighty per cent. of jaundice in infants born therein. These figures must inchude cases in which the staining of the skin is not general, or so slight as to be revealed only after pressure with the finger. The yellow tinge appears usually the third day of life, gradually replacing the earlier boiled-lolster hue, and continues from seven to ten days with no untoward symptoms. Many observers have noted, however, that the majority of icteroid infants are not so vigorous and show greater loss of weight, which is more slowly regained, than in the normal infant.

The more marked cases show discoloration of the sclera, presence of bile in the urine and its absence from the stools. Many theories have been advanced in explanation of this mild form of icterus neonatorum, among which are rapid disintegration of red blood-corpuseles following birth, with release of hematin into the tissues; œdema of Glisson's capsule from prolonged hepatic stasis due to pressure or constriction of the cord during parturition; and the persistent patency of the ductus venosus, diverting an undue portion of portal blood containing bile pigment from its passage through the liver. It is also claimed that the sudden diminution of pressure in the hepatic vessels which follows the change of circulation from fetal to postnatal life allows the escape of bile from the hepatic ducts to adjoining blood-vessels by osmosis. Occasional postmortems upon infants, dying while jaundiced, have shown occlusion of the common bile-duct by a tenacions mucous plug.

Treatment.-It is evident that no specific treatment is indicated in these mild, transient forms of infantile jaundice, other than careful feeding and attention to hygiene, with the free administration of water.

Occasionally a pseudojaundice is observed from the inordinate use of saffron tea, with which the infant has been dosed for supposed intestinal disturbance.

\section{GRAVE ICTERUS.}

The preceding form of simple icterus neonatorum must be differentiated from jaundice, accompanied by grave conditions, such as congenital occlusion of the bile ducts; umbilical phlebitis; hepatitis, specific or non-specific; acute fatty degeneration (Buhl's disease), and infectious hæmoglobinuria (Winckel's disease). Congenital occlusion of the common, hepatic, or eystic duct is presumably due to a prenatal peritonitis extending to the ducts, or to pressure accompanying or incident thereto. Mere atresia of the common duct at its duodenal orifice may be the result of intrauterine duodenitis. Absence of the large bile ducts, also of the gall-bladder, has been noted and explained both on the ground of the result of intrauterine inflammation, and of arrested development. To the latter cause, also, is attributed imperviousness of the common duct which appears embryologically as a solid cord, its lumen developing later. If the occlusion have existed for any considerable time in utero; the meconium will be light in color. Tarry meconium does not preclude congenital stenosis of more recent occurrence. The icterus is 
marked, including the selerotics; the urine is dark brown, and post-mortems show bile-staining of all the tissues.

The liver and spleen may be both enlarged. The abdomen may be further distended by intestinal flatus. Diarrhœa may occur with frequent watery, light-colored stools; or constipation with putty-or claycolored stools may be the rule. Umbilical hemorrhage may result from congestion of the portal vessels. The temperature is rarely above the normal, usually below. The infant fails to gain in weight, inclines to somnolence, loses appetite, and dies from general asthenia, in coma or convulsions, in from six weeks to six months. Death may be hastened by umbilical or other hemorrhages or by acute intercurrent disorders.

Since no medical treatment avails and early death is assured, surgieal interference would seem to suggest the only relief from the persistent cholæmia.

\section{PEMPHIGUS NEONATORUM.}

Pemphigus in the new-born presents at least two forms, syphilitic and non-syphilitic. In the first, the bullous eruption is present at birth or develops soon after, in emaciated, eachectic children. The lesions are small, flabby, and dull-colored, having a livid base. Wherever else they may be located, the palms and soles are sure to contain some of the lesions. Other signs of congenital syphilis are usually present. The course of the disease is slow, with occasional intervals of improvement, but the child usually dies of cachexia or of some intercurrent disease.

The non-syphilitic form is doubtless contagions, as epidemics in hospitals and neighborhoods have occurred. The ordinary pus germs are present in the fluid filling the vesicles, but it is difficult to accept them as more than accompanying the, as yet, undiscovered infective microorganism.

The bullæ are considerably larger than those of the syphilitic variety, do not appear for several days after birth, and the favorite sites are the abdomen and buttocks, but very rarely are they seen on the palms and soles. The lesions may develop on any other portion of the body and even on the mucous membrane. During an epidemic, healthy children as well as the delicate yield to the infection. While only a few lesions are present, there may be no evidence of systemic disturbance, but with a generalized eruption there is likely to be considerable pyrexia, restlessness, and vomiting.

The points of entrance for the infective agent are abrasions in the easily lacerated skin of the new-born infant. Naturally, the umbilicus is frequently involved-periumbilical pemphigus. In this form the base presents a reddened areola. The bullæ are easily ruptured, allowing the escape of the serous, bloody, or purulent contents, and leaving a moist, reddened surface. This forms a superficial ulcer that, in the majority of cases, quickly heals.

Complications, such as empyema, gangrene, or general sepsis, are occasionally seen, but the prognosis is better than in adults. 
Prophylaxis by isolation of the patient and eareful disinfection of attendants, should be strictly enforced. It also excludes rough handling of the infant's skin. As curative measures, incision of each bullat and the application of fifty per cent. ichthyol ointment are advised. Some prefer disinfecting baths, gentle drying, and the use of dusting powders, -as boric acid, salicylic acid, and oxide of zinc.

\section{OMPHALITIS.}

The navel is the portal most liable to infection by bacteria from attendants' hands, the dressing of the cord, and from the clothing. Omphalitis may develop in from three days to as many weeks after birth, and is indieated by a ring of reddened, swollen, and painful tissue around the stump. The inflammation may be localized, in which ease the prognosis is good under simple warm boric acid dressings. A less favorable course is extension over a large surface of the abdomen, involving the deeper tissues or throngh the umbilical arteries or veins, resulting in general sepsis.

In addition to the surgical care of the superficial area of inflammation, stimulation is indicated.

\section{TETANUS.}

Tetanus is rarely seen in new-born infants. The umbilieus is doubtless the most frequent point of entrance for the bacillus. It has appeared as early as the second day of life, and seldom develops later than the fifteenth.

Trismus, rendering nursing difficult, is the first symptom noted. The spasms rapidly involve the muscles of the face, trunk, and extremities, followed by distinct convulsions, alternating with intervals of partial relaxation. Death in spasms or coma usually occurs by the second or third day.

The prevention of tetanus by cleanliness is obligatory with every medical attendant of an obstetrical case. The navel should be antiseptically dressed, and tetanus antitoxin should be administered. Nerve sedatives, such as warm baths, bromides, chloroform (by inhalation), chloral (per rectum), belladonna, or even opium, should be given in doses sufficient to control spasms. If swallowing be impossible, the food and medicine may be given by the nasal tube. Every unnecessary disturbance, by touch or sound, should be avoided.

\section{ERYSIPELAS.}

The streptococcus of erysipelas may find entrance throngh the navel, through abrasions of the skin, or through fissures about the anus. The prognosis is especially bad if the invasion occur at the umbilicus, as peritonitis and numerous metastases in lungs, heart, kidney, and spleen occur.

The invasion and symptoms are the same as in the adult. The infant 
should be isolated and the infection combated by warm antiseptic fomentations, or ten per cent. ichthyol ointment over the affected area, and systemic stimulation.

\section{ACUTE FATTY DEGENERATION-BUHL'S DISEASE.}

A rare and fatal disease of the new-born infant is Buhl's disease. It may develop in an apparently healthy infant in whom the umbilicus shows no outward sign of infection. The onset is gradual, with vomiting, cyanosis, jaundice, and hemorrhages, causing inanition and death within two weeks. Upon autopsy there is found fatty degeneration of liver, kidneys, myocardium, and intestinal villi. The only treatment is symptomatic.

\section{EPIDEMIC HEMOGLOBINURIA-WINCKEL'S DISEASE.}

The symptoms of Winckel's disease resemble closely those of acute fatty degeneration, with the greater evidence of bacterial origin in its contagiousness. It also differs in the acute onset, greater tendency to disintegration of the red blood-cells, and in being quickly fatal. Death follows in most cases in less than forty-eight hours.

HEMORRHAGES.

Hemorrhages in the new-born may be due to mechanical causes during parturition, as from pressure caused by vigorous contractions of the uterus or compression by the forceps. The asphyxia, usually present in tedious labors, favors the escape of blood from atony of the vessels.

The meninges of the brain and cord frequently show rupture of their minute vessels. Larger meningeal hemorrhages are of more serious import and are the cause of birth palsies. Other viscera are also the seat of hemorrhages, which may be wholly unsuspected until discovered postmortem.

Excluding the hemorrhages from pressure during birth, there are occasionally seen cases in which the probable cause is microbic infection, although the specific organisms have not been definitely determined. It is well known that infants suffering from congenital syphilis are especially liable to hemorrhages which, as a capillary oozing from navel, nose, bowels, and other organs, are extremely difficult to control. What part in this hemorrhage the syphilitic affection of the vessels and deterioration of the blood plays, and how much is due to other infection, cannot be stated.

The local use of adrenalin solution externally seems more efficacious than suturing or attempts to ligate the bleeding vessels. Mercurials, in the form of gray powder or calomel, should be given by month in eases due to syphilis. Gelatin may be given by mouth or rectum, but the possibility of tetanus requires careful sterilization if used hypodermically. Some benefit is claimed from the use of calcium chloride. 
MELENA.

Melena, or hemorrhage from the gastro-intestinal tract, may occur in the first two weeks of life, rarely later. It may be the only hemorrhage present or may be associated with those from other tracts. Occasionally numerous minute ulcers in the stomach and intestines are seen upon postmortem examination.

Care should be taken in the diagnosis to exclude blood swallowed during nursing from fissured nipples.

The prognosis of melena is grave, as in fully one-half the cases death ensues.

\section{VAGINAL HEMORRHAGES.}

Comparatively frequent and of slight importance, unless associated with other evidences of a hemorrhagic tendency, is a bloody mucous discharge from the vagina of new-born girls. It usually ceases by the third day and does not reappear, excepting in very rare instances of precocious menstruation. No treatment is required. 


\section{CHAPTER III}

\section{DISORDERS OF NUTRITION}

MARASMUS-INFANTILE ATROPHY； PEDATROPHY; ATHREPSIA; SIMPLE

\section{WASTING}

Wasting of the tissues, or general atrophy, is very common in the subacute and chronic diseases of infancy, especially those of fatal termination. In such it must be regarded as a symptom of malnutrition, in which some organic cause limits constructive metabolism while retrograde tissue metamorphosis continues. While the exact cause may be undeterminable during life, post-mortem examination usually furnishes some clew to the etiology of the morbid process. In such cases the wasting is secondary; but when no sufficient cause can be found by either ante- or post-mortem examination the disorder has been termed by common consent simple atrophy, or marasmus.

This disease has been placed among the disorders of nutrition because it presents all the symptoms of starvation. Indeed, it can be produced in the young infant by gradually withdrawing a portion of his daily food. Strictly speaking, the terms marasmus, infantile atrophy, etc., are employed as equivalent to "wasting from unknown eause," clearly a reflection upon the limitations of our knowledge of pathology in the early stages of development.

The clinical phenomena, as well as the morbid changes, are those of starvation. The most constant lesions of the digestive tube, such as atrophy of the intestinal villi and tubules, dilatation of the stomach, thinning of the gastro-intestinal mucosa, atrophy of the lymphoid tissue, and maldevelopment of the agminate glands, large, fatty liver, small spleen, and cortical pallor of the kidneys, with some parenchymatous degeneration, have all been the subjects of animated discussion as to their post-or propter-hoc relation to the athrepsia.

Of the theories advanced in explanation of the remarkable wastingsuch as exogenous infection, primary atrophy of the digestive tract, and autointoxication from morbid disassimilation products-the last named offers a promising field for research. The metabolic diatheses of infancy are but little understood, and much may be expected in the near future from painstaking study along this line.

Some infants are marantic from birth, at which time they are undersized and show feebleness and malnutrition. This is frequently accounted for by ill health of the mother during gestation or by hereditary dyscrasia in which syphilis, tuberculosis, alcoholism, gout, old age, and exhausted vitality figure prominently. Among the poorer classes unhygienic environment in the crowded districts of large cities furnishes the victims of 
marasmus which fill the dispensaries. Other disorders, such as gastroenteritis, bronchitis, etc., may complicate the ease, to any one of which the athrepsia might be due. The history is quite common that the infant was puny and feeble from birth, and in the majority of instances was bottle-fed. On the other hand, athrepsia may develop in a child born plump and vigorous, with a history of good health up to an ill-advised weaning or until after an acute attack of summer complaint, bronchopneumonia, or one of the exanthems, after which no food seemed to afford nourishment. Here again artificial feeding is a most common feature of the history. In crowded hospital wards the picture of marasmus is familiar, and the tendency of well-nourished infants, admitted for acute disorders, to become marantic during convalescence is so generally recognized as to raise the question of the wisdom of long residence and of large aggregations in one hospital. The frequency and intractability of athrepsia in crowded wards lends color to the claim that exogenous infection is an important etiologic factor.

Symptoms.-Although the cause may be unknown, the picture is typical of a vicious eircle in which all the physiologic functions show reactionary impairment until nutrition, oxidation, and vitality are reduced to the lowest point. Emaciation is extreme. All the fat disappears except the sucking pads. The voluntary muscles are reduced to mere strings over which the wrinkled skin hangs in folds. The fontanelle is depressed, the face is drawn and wrinkled, giving the appearance of senility, which is intensified by the hollow temples, sunken eyes, thin lips, and toothless gums. The skeletal structures show distinctly beneath the skin. The rectal temperature is rarely above normal, and may be one or two degrees below, while the extremities and superficies are usually quite cold. The respiration is shallow, the pulse weak and irregular, and the ery, at first fretful, becomes a feeble whine until silenced in exhaustion. The common symptom, hunger, is evinced by constant sucking of the elaw-like fingers, the anxious, watchful expression, and the avidity with which the child takes everything offered in the form of food. The hunger is never satisfied until the apathy of exhaustion supervenes, after which bare life may be prolonged in a semivegetative state when for days or weeks death seems imminent (Fig. 109).

The symptoms vary as intercurrent disorders develop,-such as intoxication fever, bronchopneumonia, vomiting, and diarrhœa from gastrointestinal indigestion, etc. Various skin lesions, such as furunculosis, intertrigo, ecchymoses, and bed-sores are common.

Anæmia is marked, though corpuscular loss may not be so apparent on account of blood concentration. Edema, especially of the feet and legs, may occur as a late sign, but effusion into the cavities is rarely reported.

The abdomen may be flat from atrophy of intestinal and mesenteric tissues, or distended with flatus. The stools may be normal or show any of the varieties of indigestion or constipation.

Cervical rigidity and pseudomeningeal symptoms with twitchings and 
convulsions are not uncommon in the later stage, or the long-expected death may oceur suddenly, without immediate premonitory symptoms.

Prognosis.-The prognosis in marasmus is so dependent upon the primary cause - the degree, the environment, and the treatment-that it must be guarded until after a thorough study of all the factors which enter into this condition. Pedatrophy is extremely intractable, and one of the most fatal disorders of infaney.

Diagnosis.-Simple infantile atrophy is too often the diagnosis in eases where a more eareful study would reveal the true eause of the

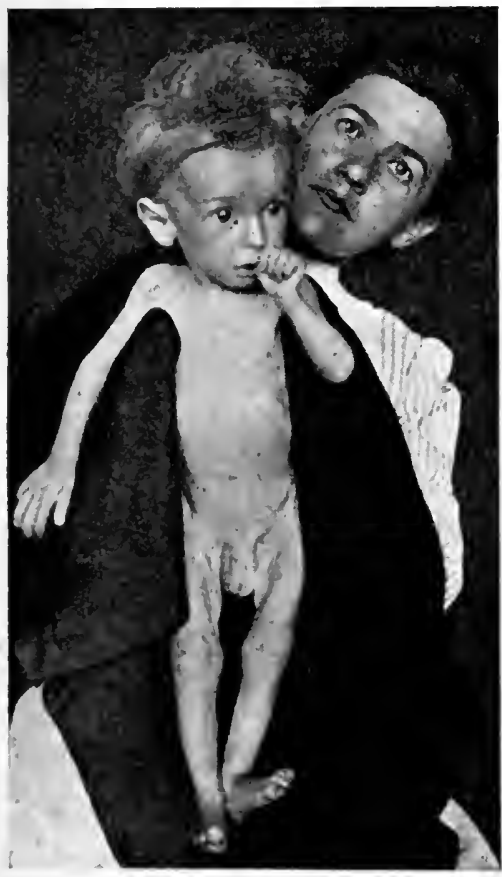

Fig. 110.-Infantile atrophy. Age, 1 year; weight, ten and one-half pounds. athrepsia. Repeated examination of the mother's milk may show a deficiency in quantity or quality. The child may not nurse well because of painful stomatitis, congenital defeets of palate, obstruction to respiration, or defective nipple. Ignorance or carelessness in the hygiene of early lactation may easily start the vicious circle in feeble infants. Masked forms of dyspepsia may inangurate the morbid process, espeeially in bottle-fed babies. Congenital syphilis rarely fails to furnish some specific symptoms other than the athrepsia. From tubereulosis the diagnosis of pedatrophy is sometimes impossible. The evening rise in temperature in the former and the usual subnormal temperature of the latter should be kept in mind, though complications may give rise to fever in pedatrophy. The pulmonary hypostasis of maransis must not be confounded with tubereular lesions, which may give rise to signs in the anterior and upper chest, while the former always occupies a strip of the posterior and inner borders of the lungs. Tabes mesenterica and abdominal tubereulosis, in addition to the fever, may show ascites or enlarged masses in the mesentery.

Meningitis should give exaggerated reflexes and other symptoms be. sides the frequent eharaeteristie eye findings of that disease.

Treatment.-No specific medication is known for simple atrophy. Good hygiene is all-essential. The food must be adjusted, if possible, to the digestive capacity of the individual. Most of these eases are aggravated by high proteids and fats whieh probably inerease autointoxieation from their disassimulation produets with reduetion of alkalinity of the body fluids. 
Fats should be reduced to the minimum, proteids cut down to the lowest point; carbohydrates should be increased, and alkalies supplied with the food and by enteroclysis.

This rule is only general, as each ease must furnish the basis of its own treatment. Breast milk for young infants must be secured, if possible, though it may be necessary to limit the amount and to supplement the feeding with milk-sugar solution, cereal gruels, and sodium bicarbonate, or lime-water. The vegetable acids in orange- and grape-juice may prove valuable, so, also, daily massage with olive oil or emulsions of mixed oils and fats.

Cleanliness, fresh air, and sunshine are essential, to secure which it may be necessary to remove the child from crowded hospital and home environment. A change of climate is often productire of the greatest benefit.

\section{RH.ICHITIS.}

Rickets is the most prevalent among the infantile disorders of nutrition,--for such it must be classed until a more exact knowledge of its true nature is obtained. Of the many theories which have been advanced concerning its causation a few are still advocated, such as insufficient amount of calcium salts in the blood; imperfect absorption of these salts from the intestine; deficiency of earthy salts in the food; diminished deposition of these salts from subalkalinity of the blood: rapid dissolution of salts by an acid in the body fluids; also, that the disease is an exogenous infection, that it is due to autoinfection, and that the bone changes are inflammatory in character. It is the consensus of opinion, however, that its true etiology is yet to be discovered, or that a combination of causes, including some of the above, is responsible. The predisposing causes are pretty well understood as residing in malhygiene, especially in bad air, improper food, and absence of sunlight. Every physician is satisfied that a combination of these influences can produce the disease, though he may not always predict with eertainty whether the malhygiene will result in rickets, scorbutus, or marasmus.

That rickets is on the increase is probable, but that its symptoms are better known and earlier recognized is equally true, and its wide prevalence generally acknowledged. No class is exempt; since some of the above-mentioned elements of malhygiene obtain in the homes of the wealthy as well as among the poor; but it is from the latter that the ranks of the rhachitic which swarm our dispensaries are recruited. As before stated, it is a disease of the temperate zone, to which Europeans and Americans show the greatest susceptibility, and is most commonly seen in its exaggerated form in this country among children of Southern people who have taken residence in the colder, changeable Northern climate. Thus, negroes and Italians furnish the most familiar examples. Rickets is rarely seen in a country infant fed at the breast. The few exceptions are among those who have been nursed long overtime, whose mothers are exhausted by overwork, prolonged lactation, and frequent childbearing, and among the products of later conceptions in 
families whose older children may give no evidence of the disease. In eities, though the proportion is small in the breast-fed, its oceurrence is not rare. Breast milk, poor in fats and proteids, may apparently produce the disease, since the rhachitic symptoms disappear when these constituents are increased by improved hygiene of the mother or improved supplemental feeding of the baby. That prerhachitic digestive disturbances are very common has led many to adopt the theory of autointoxication as the true etiologic explanation. By others indigestion is regarded as one of the usual manifestations of the dyscrasia.

The great majority of rhachitic infants are found among those deprived of breast milk, especially those whose diet is deficient in fat and proteids. Many infant foods on the market show a paucity of these two ingredients, - especially of fat with a corresponding excess of starchy and saceharine constituents. Among the effects of their ingestion is early rapid gain in weight and rotundity from large deposits of fat, but the tissues are soft and flabby, and indigestion usually precedes, but may accompany or follow the development of rickets.

It is generally accepted that the increase in the frequency of rhachitis is in direct ratio with the prevalence of artificial feeding, especially with foods consisting largely of carbohydrates with a scarcity of nitrogenous elements. (Sce chapter on Foods.)

There is little or no evidence of heredity in the causation of rickets further than that low vitality and vitiated metabolism predispose to rhachitic changes. In this way syphilis, tuberculosis, and alcoholism undoubtedly exert a predisposing influence.

Rhachitic changes are usually seen between the sixth and twentyfourth months, most noticeably in the second year. Though symptoms may appear earlier, rarely a congenital case is reported (Fig. 111). Many cases of so-called fetal rickets present changes not characteristic of this disease and belong rather to achondroplasia (Chondrodystrophy fetalis) and cretinism. Late rickets deseribed by European writers as occurring about the age of puberty are certainly not frequent in this country, where the inception is rarely seen after the third year. So, also, reported cases of acute rickets, if carefully analyzed, often prove to be either a rapid development, under conditions which caused sudden lowering of vitality, or rhachitic changes which had previously passed unobserved, or cases of scorbutus with which rhachitis is not infrequently complicated.

Pathology.-Probably no organ or tissue in the body is exempt from the morbidity of severe rickets, although the only changes pathognomonic of the disease as at present recognized are seen in the bones. For clinical purposes it is sufficient to state that the bones show a deficiency of inorganic material (principally of the lime salts) which in normal bone constitutes two-thirds, while one-third is organic matter. (See chapter on Anstomy.) In rhachitis this ratio may be reversed. Because of increased vascularity at the proliferative zones, retarded calcification at the epiphyses and along the shafts, and inereased bone absorption in the medullary cavities (Fig. 112) the entire bone becomes light, spongy, and 
plastic, bends readily under superimposed weight, strain of muscles or malposition, and fractures (green-stick) occur from slight violence. The increased vascularity in the growth zones causes active proliferation of cartilage cells which, with the retarded ossification, results in an accmmulation of osteoid material in these areas with rapid increase in size of the epiphyses. Or it may cause doughy accumulations over the ossific centres of the cranial bones which, while thickened in some spots, may be thinned in others,- -notably where subject to pressure, as in the occipital bone of the skull. These enlargements are most pronounced in the

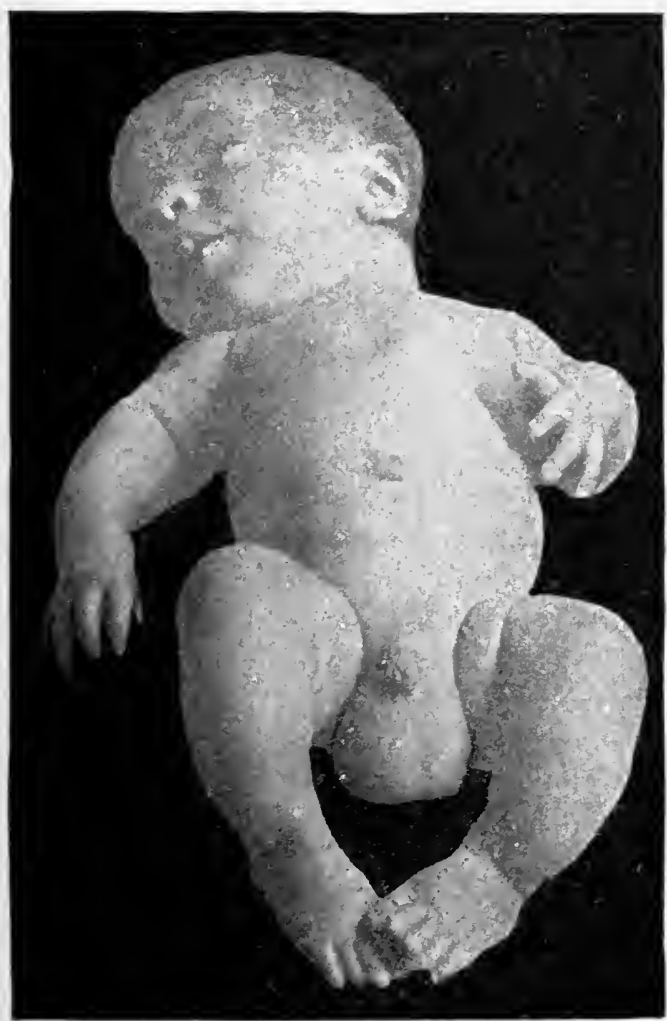

Fig. 111.-Fetal rickets.

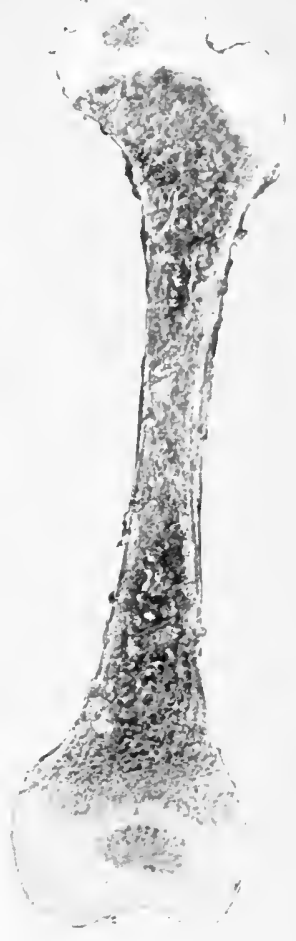

F1G. 112.-Rhachitic bonc.

epiphyses subject to the greatest motion from the stimulation due to increased blood-supply. From their constant movement in respiration these eniargements are first seen at the anterior ends of the ribs, of which the sixth is most notably affected from its greater range of movement. In young infants the epiphyses of the forearms show early swelling above the active wrist joints, while in children who have begun to walk, the lower ends of the tibix show early changes. After a period varying from three to twenty months the rhachitic process is arrested, true ossification is resumed, much of the osteoid material is absorbed, and 
eburnation occurs, the newly formed bone beeoming harder than normal. The enlargement of the epiphyses may disappear, but if the degree of riekets has been severe or prolonged, some permanent effects will remain in deformities and retardation of longitudinal growth.

These deformities are partieularly noticeable in the ehest, which assumes characteristic shapes influenced more or less by the condition of its contained viseera during the period of greatest plasticity. Prolonged dorsal deeubitus eauses Hattening of the back and of the posterior curvature of the ribs, with pushing forward of the anterior ends, and advancement of the sternum. If pulmonary atelectasis or obstruction to free entrance of air obtain from adenoids, rhinitis, or complicating pulmonopathy, external atmospheric pressure opposing the pull of the inspiratory muscles eauses a flattening of the chest at its most yielding points. These are the anterior lateral parietes just above the line of resistance offered to depression by the subjacent liver, spleen and stomach, where a permanent suleus is commonly seen (Harrison's groove). The lines of greatest mobility may show a groove along the eostocartilaginous junetion on either side of and parallel with the sternum, in which case the breast-bone is pushed forward like a prow (pigeon-breast). Under pressure the ends of the ribs may knuckle, eausing depressed or funnelshaped sternum. The lower margin of the ribs usually flares outward owing to the eontraeted ehest, the enlarged abdomen, and the pull of the accessory muscles of inspiration. The permanent ehanges in the cranial bones are seen in the parietal and frontal bosse which, with the flattened vertex and occiput, give the cuboid head. The maxills show the effeets of rhachitis in that the lower faee appears small in comparison with the broad expanse of forehead. The superior maxilla may be narrowed and elongated with high-arching palate, while the inferior is polygonal with flaring lower borders and an inward inclination of the alveoli which allows later overriding of the upper jaw. Dentition is delayed, the teeth erupting irregularly and showing early erosion from deficient enamel and lack of calcium salts. Later they may be crowded and irregular in their implantation owing to abnormal contour of the jaws.

Deformities of the extremities are seen in eurvatures from weight; muscle-tug, and infractions causing bow-legs, knoek-knees, twisted and anterior curved tibie, with curvatures of the femora humeri, clavieles, and scapulæ.

The pelvis may be distorted by the yielding of the isehii from sitting. The sacrum may be foreed downward and forward from its superincumbent weight while sitting or standing, causing shortening of its anteroposterior diameter. A general contraction may result from tightly constricting diapers during the plastic stage (Fig. 113), a condition which in girls is of the gravest import with reference to future parturition. Characteristic of the rhachitic state is laxity of ligaments which, yielding, allow deformities, such as flat-foot, talipes varus and valgus, genu varum and valgum, which are accentuated by the curving or infrac- 
tions of the leg and thigh bones. The vertebral ligaments, also stretehing, allow kyphotic and rotary distortions of the spinal column, while all the articulations show undue mobility (Figs. 113 to 115 ).

The muscular system is atonie, so that support to the trunk is defective and permits the spinal distortion above mentioned when the child assumes the vertical position. Atony allows distention of the stomach and bowels with constipation, meteorism, and enlarged abdomen, while hernia, especially umbilical, prolapsus ani, and intussusception of the bowel are consequent conditions. Weakness of the leg muscles causes backwardness in learning to walk, or, having been acquired, the function is lost. The child may not be able even to sit without support.
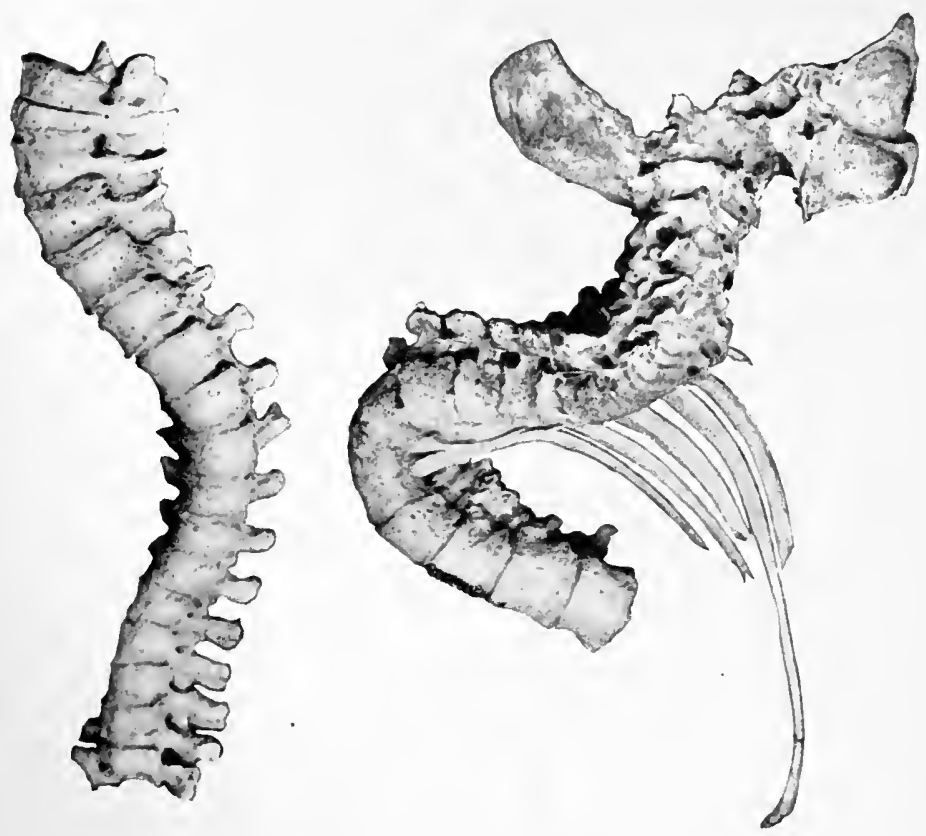

Figs. 113 and 114.-Rhachitic curvature of spine. (Rush Medical Museum.)

The mucous membranes show a predilection to catarrh, especially of the respiratory tract. Owing to yielding thoracic walls and feeble muscles this favors bronchitis, bronchopneumonia, atelectasis, emphysema, and hypostatic congestion,- -all of which intensifies the vicious circle by interference with oxygenation from respiratory inefficiency.

The nervous system shows instability by profuse head sweating, disturbed sleep, kicking off the bedelothes, night terrors, hyperæsthesia, and pain on handling (which may also be due to tenderness of the enlarged

epiphyses), easily induced spasm of the glottis (laryngismus stridulus), and convulsions (tetany). There is general irritability, fretfulness, and hyperexcitability, - a condition not uncommon in poorly nourished nerve-tissues from any cause. 
The profuse sweating leads to sudamina and eczema, and induces catarrh of the upper respiratory tract from "cold catching." Various skin eruptions result from the faulty metabolism and toxic products of indigestion. The lymph-nodes may show enlargement as the result of neighboring lesions of skin or mueosa, and the obsolete term, "serofula," has frequently been misapplied to cases now recognized as rhachitic. The cushiony pad on the dorsum of the foot is not rare in infant rickets and suggests angioneurotic cedema, although there is no pitting on pressure.

The spleen is palpable in a fair proportion of eases and oeeasionally

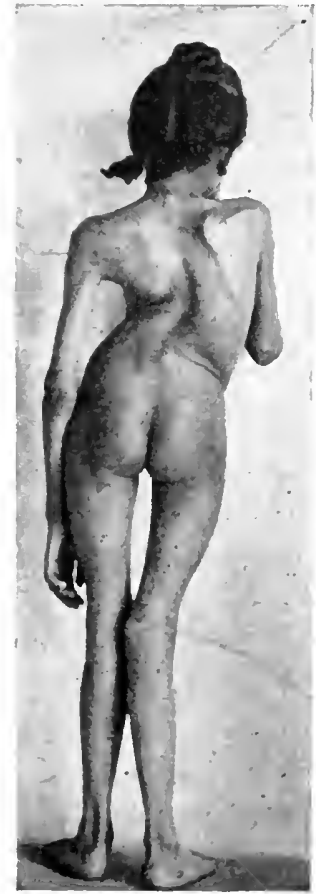

FIG. 115.-Khachitic deformities. (Dr. John C. Cook.)

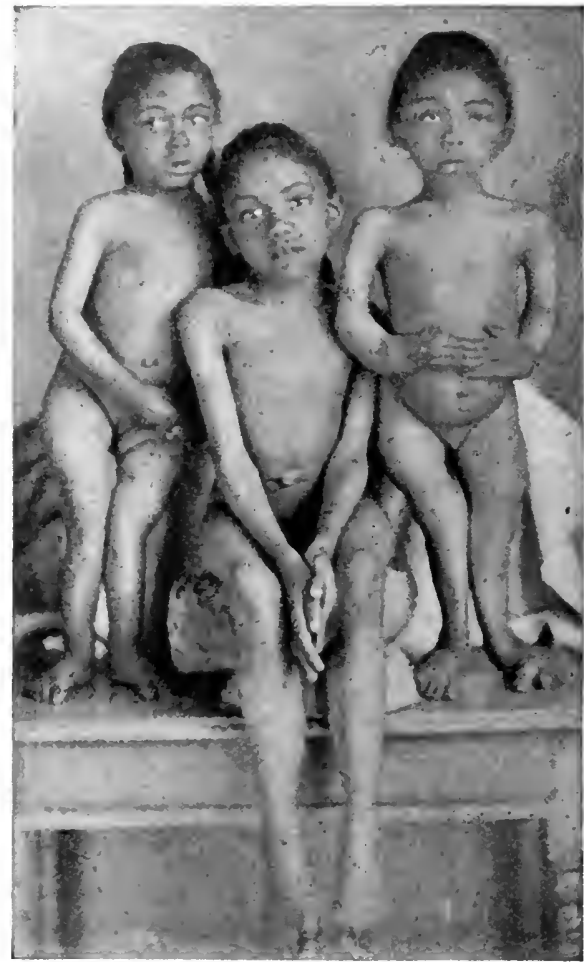

FIG. 116.-Rhachitic family, breast-fed; later diet chiefy bread and molasses ; Jived in basement. (Dr. John C. Cook.)

it is-enormously enlarged, so also the area of hepatic dulness may be considerably increased, although the prominence of both these organs is due in part to their being erowded down by the contraction of the ehest.

The blood shows no constant or characteristic changes in rickets save that of secondary anæmia which, in severe or prolonged cases, may become extreme. In this case the only peculiarity is its low eolor index and a lymphocytosis, whieh some observers have associated with the marked enlargement of the spleen.

Symptoms.-The visible lesions and their immediate effects constitute 
the chief symptoms of marked rhaehitis. Clinically they arrange themselves into three groups, - viz., nervous, muscular and osseous, - to which may be added dyspeptic and catarrhal. A plump baby becomes irritable and weak, has head-sweating, night-kicking, with or without apparent indigestion. Teething is delayed, walking is delayed or discontinued, the tissues become flabby, the child does not sit up well, nor stand, the spine curves backwards, the fontanelle is wide, the hair is worn off the occiput, the child cries when handled, and becomes fretful. He may show breath-holding, crowing inspiration, or a peculiar clucking in his throat. The physician may be consulted for convulsions (see Tetany), for paralysis (pseudorhachitic), for diarrhœa, or constipa-

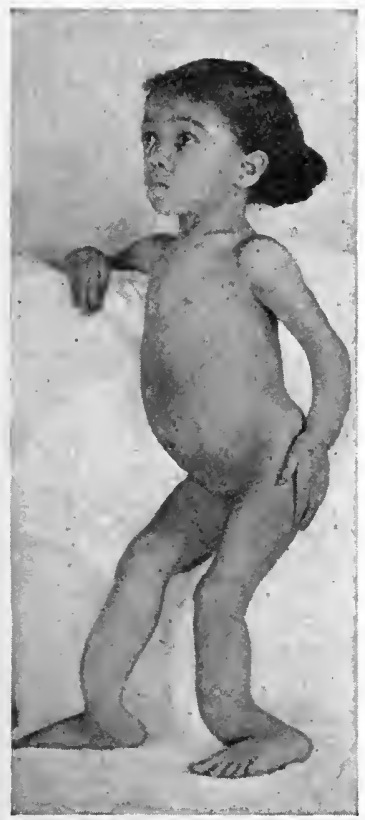

Fig. 117.-Rhachitic deformities. (Dr. John C. Cook.)

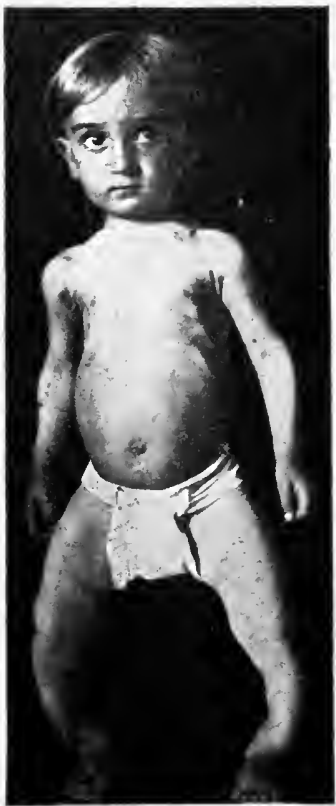

FIG. 118.-Rhachitis.

tion, when the foregoing history is obtained. Examination, even in the early stage, rarely fails to find the "rhachitic rosary" which, in fat babies, may be felt if not seen following the diverging lines of the costocartilaginous junctions. Possibly only one enlargement may be detected - the sixth-but one is sufficient. The head may begin to assume cuboidal shape from frontal and parietal bosse, and pressure with the finger over the occipital bone may find yielding spots (craniotabes). Later, the epiphyses show enlargements, especially those of the ulna and radius at the wrists, or of the malleoli above the ankles. In all cases the enlargements are bilateral and symmetrical. The later and more obvious bony signs of rickets appear as bow-legs, knock-knees, talipes, in- 
fractions, and bizarre deformities (Figs. 113 to 120 inclusive), which come properly under the subject of orthopadies.

Prognosis.-Children rarely die of rhachitis per se. It is usually some concomitant or intercurrent disorder that terminates life. Of these the pulmonopathies find in the rhachitic child most favorable conditions which, if survived, leave the patient with permanently damaged chest and respiratory organs,--a standing invitation to tubercular infection.

The active rhachitic processes cease or begin to diminish before the end of the second year, although occasionally porosity and fragility of the bones may continue for some time later. The minor defects are remedied

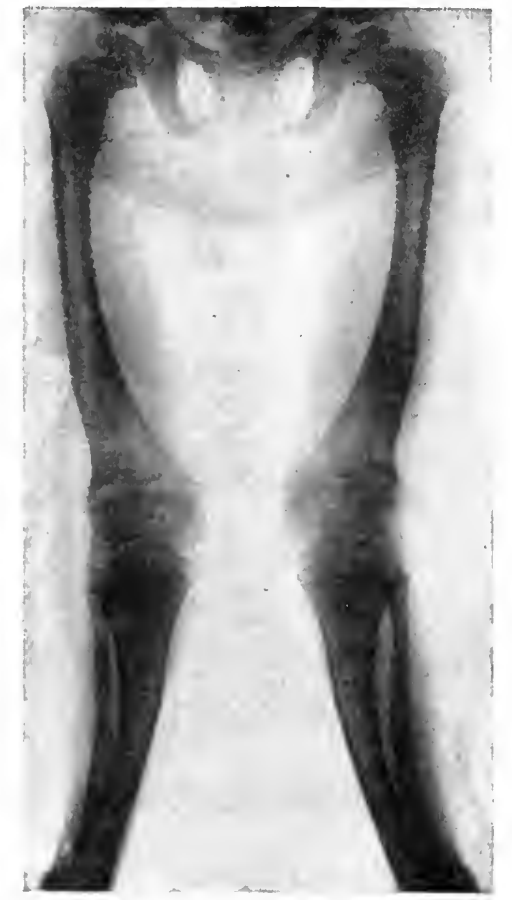

FIG. 119.-Skiagram of genu valgum. (Dr. Wallace Blanchard.)

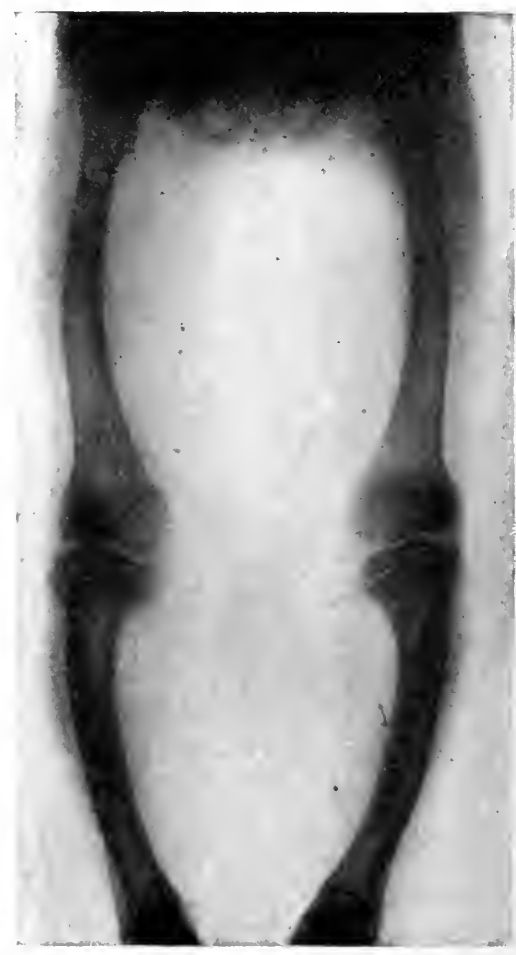

FIG. 120.-Skiagram of bow-legs. (Dr. Wallace Blanchard.)

to a remarkable degree, but a register of the disease remains in the major deformities of chest, head, and face, which are carried into adult life. The legs may remain short and the long bones more or less curved, so that in extreme cases osteoplastic surgery must be in voked for restoration of their normal function.

Diagnosis.-The picture of marked rhachitis is unmistakable. It is only in its incipiency and some of its rare late manifestations that its recognition is difficult. Moreover, its early diagnosis is of the highest importance since it is here that its correction is most easily effected and 
its far-reaching results averted. Head sweating, night restlessness, with kicking off the bedclothes (unless unduly burdened), delayed dentition, late closure of the fontanelles, delayed standing and walking, weak back, slight enlargement of the epiphyses, beading of the ribs-which must always be felt for-and prominent abdomen, should be taken as evidences of rhachitis, regardless of the avidity for food or appearance of fatness, too often considered as evidence of good health.

It should be remembered that marasmus may exist to an extreme degree without the faintest suggestion of rickets.

The large head may be mistaken for hydrocephalus, but the internal pressure in the latter causes a more symmetrical bulging than do the bossa of rickets. The large, globular head, with bulging fontanelle, tiny face, and deflected visual axes, are not often seen in rickets, but it is possible for the two conditions to exist in the same child.

The pseudorhachitic paralysis must be distinguished from essential paralysis which it resembles only in locomotor incapacity. The muscles, although weak, will move the limbs in response to reflex irritation, as may be seen by tickling the soles of the feet. If the muscular atony be extreme it involves the entire system and is not confined to particular groups of museles, as in paralysis. Moreover, other evidences of rhachitis are present. However, a rhachitic child is not immune to essential paralyses and museular dystrophies, which may at any time supervene.

Scorbutus may complicate rhachitis-in fact, a form has been recognized as "scurvy-rickets"- but the two disorders need never be confounded, as each has its peculiar semeiology and pathology (q. v.), while the former yields promptly to antiscorbutic treatment.

Syphilitic bony enlargements will not be mistaken for rhachitis if it be remembered that the latter always involves the epiphyses of the long bone, is symmetrical and never breaks down to form sinuses; while syphilis, in its earlier stage, shows enlargement at the epiphyseal juncture, is rarely bilateral, is boggy to the feel and tender, and tends to neerosis and abseess formation. In later stages it is the shaft over which thickening occurs. Rhachitic kyphosis and kyphoscoliosis is distinguished from tuberculosis spondylitis by the convexity of the deviation in place of the angular deformity of the latter, and by the absence of spinal rigidity in the early stages, which may be shown by suspending the child from the arm pits, whereupon the kyphosis disappears; or by raising the child by the feet while he lies face downwards, and noting the flexibility of the dorsal spine.

Treatment.- Since there is no known specific for rhachitis the treatment, from our knowledge of the etiology, must be hygienic. The diet must be suitable to age and the condition of the digestive function of the individual infant.

The paucity of fat and proteids and the excess of carbohydrates usually seen in prerhachitic diet, as well as the prevalence of dyspepsia, suggest the key to the method of feeding. Fat from cream, fried bacon, boiled beef-bone marrow, and cod-liver oil are accessible and should be 
given as the stomach will allow, preferably with or just after other food, which should eontain proteids up to the point of toleration. At this age milk should form the basis of the food. If at the breast, repeated analyses of the mother's milk should determine its quality (see MiLk ANALYsis), and efforts should be made to improve its defects by attention to the mother's hygiene. In obstinate eases supplemental feeding may be neessary, although rarely weaning unless the breast fails from prolonged lactation or other eauses. In artifieial feeding raw milk is to be preferred, and some raw fruit juice, espeeially that of orange or grape, should be given two or three times daily. Excess of sugar must be avoided. A limited amount of eereal gruels as diluents of the milk mixture is frequently useful; and digestive ferments, as pepsin and pan-

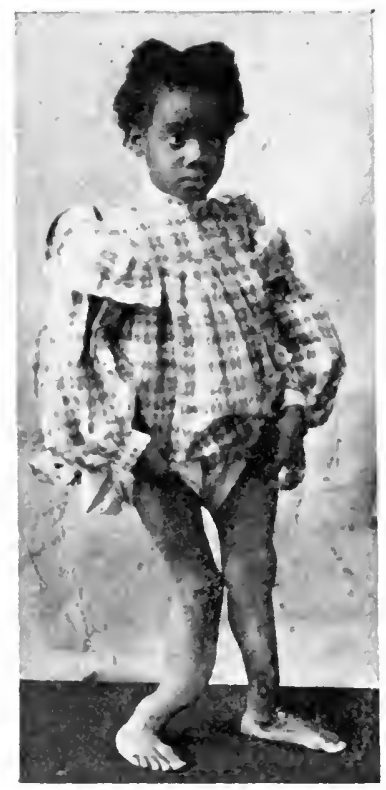

FIG. 121.-Rhachitic deformities. (Dr. Wallace Blanchard.)

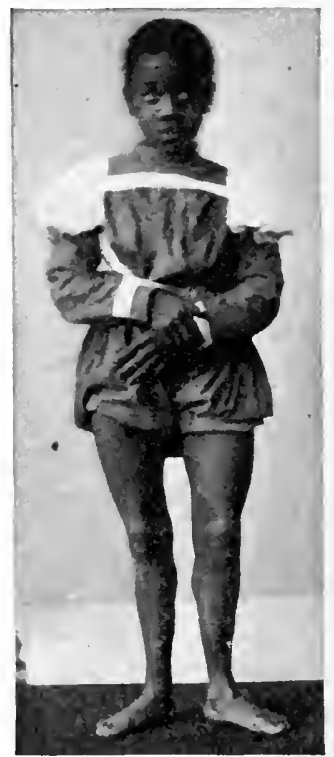

Frg. 122.-Same as Fig. 1:1, after correction. (Dr. Wallace Blanchard.)

creatin, may serve a temporary purpose, but should never be long continued. Lime-water, unless constipation be marked, sodium biearbonate or sodium eitrate, and always some common salt, should enter into every meal.

The general hygiene requires careful attention. Fresh air and sunlight are essential, and bathing, with salt friction, must be enforced. A rhaehitie ehild must never be subjeeted to cold bathing until after complete reeovery. Change of elimate may be necessary to secure the requisite hygiene.

Intercurrent and eomplicating disorders must be met by appropriate treatment. The routine practiee of giving phosphorus, phosphates, and 
hypophosphites medically is of questionable utility, especially if it in any degree divert attention from the proper fecding and care of the baby. The lime phosphate should be secured from the food of which breast milk furnishes the highest percentages available. The anæmia may need iron and arsenic.

While the bones are soft, deformities may be prevented by keeping the child off his feet, employing daily massage with oil to promote metabolism. The temporary use of retention splints and braces may be serviceable during the plastic stage to preserve alignment of the articula-

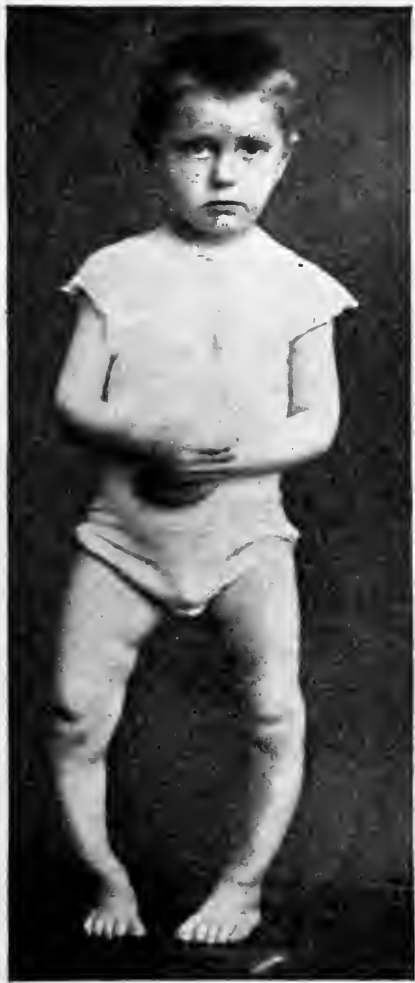

Fra. 123.-Rhachitic bow-legis. (Dr. Wallace Blanchard.)

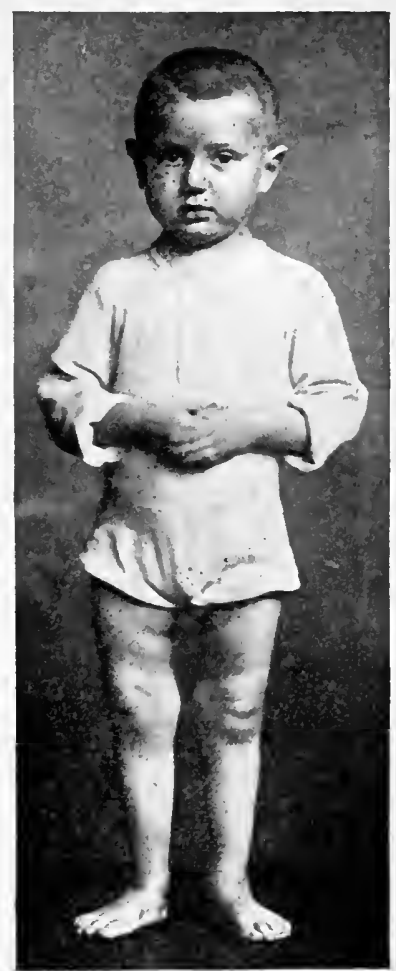

Fig. 124.-Same as Flg. 123, after correction. (Dr. Wallace Blanchard.)

tions for which the lax ligaments and weak muscles are insufficient, but efforts to correct established deformities by such means are frequently disappointing, Post-rhachitic deformities of the-trunk and extremities demand the skill of orthopæedic surgery, the brilliant results of which speak for themselves (Figs. 121 to 126 ).

\section{SCORBUTUS-INFANTILE SCURVY.}

In no disorder is mismanagement in the diet more apparent than in scurvy. Although infantile scurvy was unrecognized thirty years ago, 
to-day its clinical entity is so well established as to become a familiar picture to all who practise among children. There is little doubt, since the early descriptions of Cheadle and Barlow, that the occurrence of scorbutus has been steadily on the increase. Nor is this difficult of explanation, as our present knowledge of its etiology places the responsibility upon certain errors in infant diet which are known to prevail with steadily increasing frequency.

The fashion or frailty which deprives the infant of normal breast

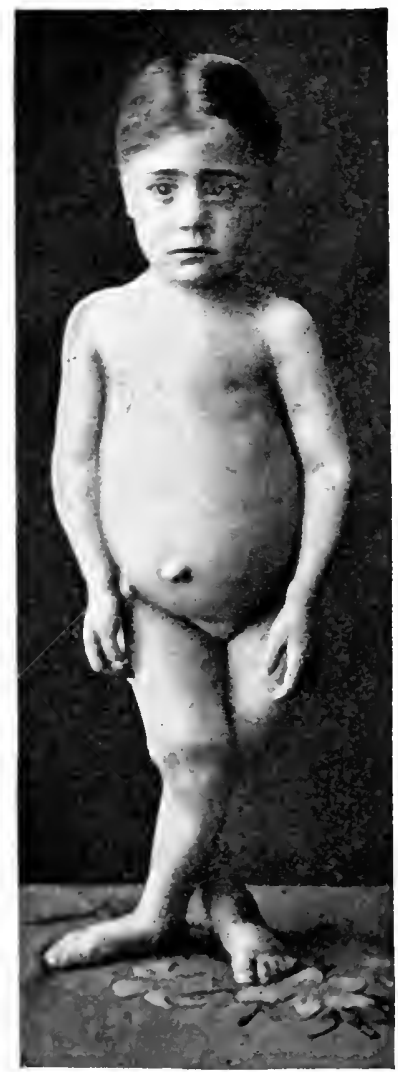

FIG. 125,-Rhachitic knock-knees. (Dr. Wallace Blanchard.)

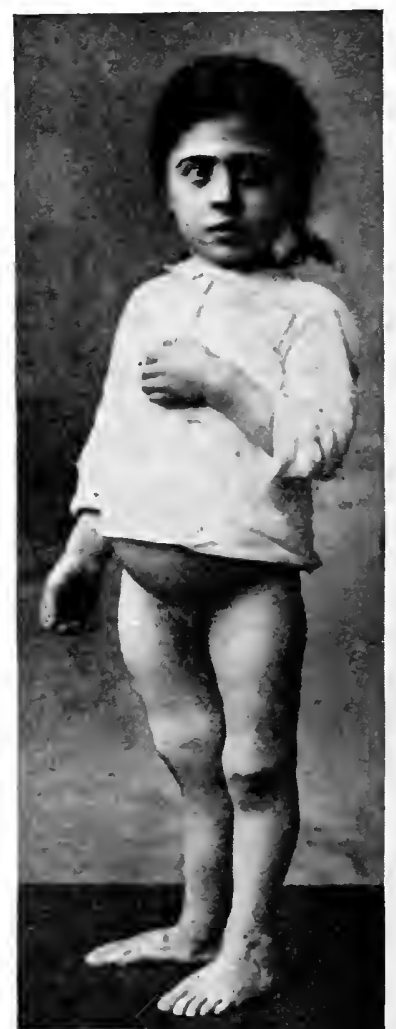

Fig. 126.-Same as Fig. 125, after correction. (Dr. Wallace Blanchard.)

milk is undoubtedly the most responsible factor in the etiology. The fad or actual necessity for sterilization of infant foods is another. The claim that malhygienic environment is a potent factor is not substantiated by analysis of three hundred and seventy-nine reported cases, of which eighty-seven per cent. were observed in private practice. Whether the disease is caused by a hyperacidity or a subalkalinity of the blood from a deficiency of organic salts, especially of potash, by ptomaine- 
poisoning from imperfect digestion, or is due to infection of microbic nature, the fact has been amply demonstrated that a proper "hange in the dietary effects a prompt relief of all the symptoms. The disease is most commonly seen between the fifth and eighteenth months, although it has been found in earlier infancy and older children.

The essential manifestations are due to hemorrhages into the various organs and tissues. The most common sites and those producing the most characteristic lesions are in the periosteal structures of the long bones and the mucosa of the month, particularly the gums and hard palate. The skin, also, frequently shows purpuric lesions as petechia and ecchymoses. Epistaxis is not infrequent, and blood occasionally appears in the stools and urine. Extravasations of blood may occur under the serous membranes, as the pleura, pericardinm, or meninges of the brain; also, in the deep muscular structures as well as in the medulla of the bones. The bones themselves show changes principally characteristic of rickets, with which this condition is frequently associated. It differs from rickets, however, in its predisposition to hemorrhages. The epiphysis may be separated from the shaft and dislocated by the amount of extravasation. This may extend through the cellular tissue to the neighborhood of the articulations, although rarely into the joint cavity. The blood itself shows no changes except those common to a simple, secondary anæmia.

The onset is insidious. The frequent association of rhachitis and the gastro-enteric disturbances, common to this age, mask the earlier symptoms of scorbutus. A routine examination of the urine may give the first intimation of its existence in the discovery of a slight hæmaturia; or the mother may discover that the fretfulness of the baby on handling is due to tenderness of the ehest or limbs. When seen at this stage, in the absence of complications, the baby may appear plump and well nourished but is usually pale. Examination shows one or more limbs, usually the lower, painful to touch, with possibly uniform swelling above the knee or near the lower end of the tibia. The child's efforts to immobilize the affected member is in sharp contrast to the restless activity normally present. The temperature may be only slightly elevated, normal or even subnormal. The skin may show petechiæ or ecchymoses. Examination of the mouth reveals tumefaction of the gums, or there may be only a faint pink line along the gingival border of the upper jaw. If teeth be present the gingivitis is more marked, purple or livid tumefactions almost covering the crowns of the teeth. Slight pressure may cause bleeding. There may be drooling of stained saliva of very offensive odor. In grave eases, the gums and palate may go on to ulceration. The eyelids may be swollen and dark with ecchymosis, or the eyeball protuberant from extravasation of blood within the orbit. Diarrhœa or dysentery may oceur with blood-streaked mucoid stools, or there may be history of recurrent epistaxis.

In neglected cases the picture is one of profound cachectic anæmia, with fetid, ulcerative gums and swollen, hard, painful limbs, œdema of 
the extremities and apathetic facies, disturbed only by motion or touch of the affected members.

Differential Diagnosis.-The diagnosis is to be made from rheumatism, for which it is most frequently mistaken, especially when the periosteal swellings are bilateral. Careful manipulation will show the freedom of the joint from involvement while the rise in temperature is not so marked. Although the purpuric spots may simulate rheumatic peliosis the latter does not show the extensive gingivitis of scurvy. It should be remembered that rheumatism is rare at the age when purpura is common. A history of a fall or blow upon the afflicted part may mislead the mother and even the physician. If hemorrhage is sufficient to separate the epiphysis the pain and crepitus on motion may simulate the effects of violence. The above mentioned corroborative symptoms of scorbutus should quickly affirm the true nature of the disorder.

The evidence of pain on handling, especially of the thorax at the costochondral junction, from extravasation of blood at these points, may lead to the diagnosis of rhachitis. This should be excluded by the hemorrhagic tendency in other parts of the body. Purpura hemorrhagica simulates scorbutus in so many points, that by some they are considered but different manifestations of a blood dyscrasia. The periosteal lesions of scorbutus, however, rarely complicate these disorders. Hæmophilia need not be mistaken for scorbutus, if due attention is given to the history of heredity, and previous bleeding and careful examination be made of the joint,- - a frequent seat of hemorrhage in hæmophilia. Nor is the extensive sponginess of the gums present in the latter disorder. Operations have been attempted upon scorbutic lesions of the periosteum under the mistaken diagnosis of osteosarcoma and osteomyelitis. A physician familiar with the symptoms just mentioned will rarely make this mistake. Hæmaturia, hemorrhages from other mucosæ, and blood examination showing absence of lymphocytosis and eosinophilia, would remove all suspicion as to the presence of these grave lesions.

Syphilitic periostitis, essentially chronic in its development, is preceded, usually, by other suggestive lesions.

Leukæmia, with its splenic and glandular enlargement, aside from its distinctive blood picture, should occasion but little trouble in differentiation.

All the typical lesions of a well developed scorbutus may not always be present. The pain on motion may be slight, the mouth symptoms may be wanting, or at best a faint, pink line may appear at the base of the gums or a deeper pink line may show at the finger nails. Urinalysis, which should always be made, may reveal albumin and only a rare red corpuscle. The restlessness may be attributed to an ordinary intestinal disturbance, and the anæmia without local hemorrhages, to malnutrition. In such and all doubtful cases, in fact, the therapeutic test is invaluable, as many suspected cases may be thus relieved by the timely change of diet indicated in scorbutus.

Treatment.-The treatment in general use, because almost universally 
successful, is the substitution of raw milk for the pasteurized or sterilized milk or carbohydrate foods in use. In addition, fruit acids-as the juice of grapes, orange, lemon, or pineapple-from one to four teaspoonfuls, an hour distant from each feeding, will rarely fail to relieve in a few days all hemorrhages and pain incident thereto. Older children may eat raw fruits,-apples, grapes, oranges, lemons, etc. Baked potatoes contain, especially near the skin, a high percentage of potassium salts, invaluable in scorbutic conditions. Boiled spinach is useful for the same reason.

No grave disease offers a more satisfactory field for successful treatment. The prompt recovery, from simple changes in the food, is the best evidence of its dietetic etiology. Neglected or undiagnosed cases almost invariably terminate fatally in from two to four months. The extravasations may be followed by suppuration and extensive necrosis of bone and other tissues. Death may be due to some intercurrent disease, such as pneumonia, cerebral hemorrhage, etc.

\section{ADIPOSITAS.}

Independent of Buhl's disease, excessive fat deposition may be congenital, or adipositas may develop during the nursing period. This may be accompanied by weak musculature and lax ligaments without other signs of rhachitis. Usually in infants the fat may be reduced by daily massage, reduction of the carbohydrates and hydrocarbon in the food, the use of vegetable acids in fruit juices-orange, lemon, grape and apple-and the administration of alkalies, such as sodium or potassium bicarbonate.

In later childhood adipositas may prove serious and intractable, especially when accompanied by anæmia and fatty heart. The muscles are weak and general debility may supervene with dyspnœa and tachycardia.

In addition to the above considerations in diet, water ingestion should be limited. (These children are great drinkers and overload the weak heart.) Exercise up to the safety limit, with thorongh daily massage, is important. In extreme cases thyroid extract or iodothyrin may be cautiously administered.

The type is occasionally familial, and these children fall easy victims to intercurrent disease.

\section{OSTEOMALACIA.}

A number of bony defects resemble rhachitis in the paucity of lime salts. Among these are osteomalacia and osteopsathyrosis. (For Achondroplasia, Cranial Dysostosis, and Osteogenesis Imperfecta, see page 163.)

Osteomalacia, although a disease of adult life, is occasionally met with in children, and a few congenital cases have been reported. It is claimed, however, that the latter are cases of achondroplasia or so-called fetal rickets.

In osteomalacia the lime salts are deficient, as though the bones had been soaked in dilute hydrochloric acid, so that they yield readily, bend- 
ing or fracturing under slight strain. Unlike rickets there is no increased deposition of bone under the periosteum to compensate for the rapid absorption from the medullary surface. Neither do they show rhachitic enlargements of the epiphyses. The fragilitas ossium leads to innumerable fractures with resulting deformities, all of which are painfully tender under pressure and slow of repair. To all the deformities of rhachitis, save those of epiphyseal enlargements and rib beading, are added reparative callosities from united, and psendarthroses from ununited fractures.

The congenital types are either still-born or succumb early to inanition, while those who survive early infancy readily become marantic or fall an easy prey to intercurrent disease.

Osteomalacia, occurring in later childhood, retards pubescence, a condition of infantilism persisting. Anæmia is present with amenorrhœa in girls. The tendency to bone fractures is associated with muscular atony and often extreme debility. Few of these children reach adult life.

The only known treatment is indicated by the pathology: Iron and arsenic for the anæmia; phosphorus, cod-liver oil, sea air and bathing, with glycerophosphates of lime and the compound hypophosphites, for the bones.

\section{OSTEOPSATHYROSIS.}

Osteopsathyrosis is a term applied to a form of fragilitas ossium, with tendency to fracture, which is occasionally seen in infancy and childhood. It differs from rhachitis in the absence of typical enlargements, and from osteomalacia in the greater rigidity, less frequent bending from bone-softening, and in the absence of pain, especially in the upper limbs, at the seat of fracture.

The bones are small and brittle and show paucity of lime; the muscles are atonic and the ligaments relaxed, allowing subluxation at the joints. The prognosis is discouraging.

Treatment is the same as for osteomalacia, with careful oil massage and avoidance of active exertion that will jeopardize the fragile bones. 


\title{
CHAPTER IV
}

\section{DISORDERS OF THE DIGESTIVE SYSTEM}

\author{
THE LIPS, TONGUE, AND MOUTH
}

\section{MACROCHEILI.A - IYYPERTROPHY OF THIE LIPS}

The lips-more frequently the upper-may be greatly thickened and elongated, to such an extent as to constitute a deformity. Iypertrophy of the lip is occasionally seen as a result of local lesions of the mucosa from long continued irritation, especially in children of the limphatic diathesis. In them it constitutes a form of lymphangitis.

Congenital macrocheilia, when unsightly, may be corrected by a surgical operation which consists in the removal of a wedge-shaped portion of the free border of the lip.

\section{PERLECHE-LICKING DISEASE OF THE LIPS}

Perleche is an infectious disorder of the lips seen most frequently in school children who are exposed by common use of drinking cups, pencils, whistles, etc. Strepto- and staphylococei have been found in the lesion.

The lips, beginning at the angles of the mouth, become hot and swollen, and fissures oceur in the mucous membrane, which becomes macerated, thickened, and opaque, and comes off in patches and strips.

There is itching and smarting, which leads to constant licking (hence the name), which increases the irritation. The disease lasts two or three weeks and must not be confounded with herpes of the mouth or facial eczema, either of which may complicate it. The treatment consists in cleanliness and the use of astringents, such as alum, sulphate of copper, or nitrate of silver, in weak solution. If very moist and sodden the mucosa of the lip may be dusted with bismuth subnitrate and zine oxide in equal parts. Prophylaxis requires separate drinking cups, eating utensils, towels, etc.

\section{MACROGLOSSIA-HYPERTROPHY OF THE TONGUE}

Aside from the congenital macroglossia which is usually associated with other defects, as in cretins and imbeciles, the tongue may become greatly enlarged by an increase of all or any of its constituent tissues. There may be muscular hypertrophy or overgrowth of fibrous tissue at the expense of muscular structure. Cystic degeneration of interstitial tissue may occur, or overdistention of lymph-spaces, with resultant de- 
velopment of eavernous lymphangioma. The lymphoid bodies may hypertrophy, causing lymphadenoma, or lipomatous masses may enter into the lingual enlargement. In any ease, the mouth may be too small to hold the tongue which, pressing against the teeth, gives them a forward inclination and results in erosions of the mucous membrane by friction. This irritation in turn increases the swelling and hypertrophy, while desiceation of drooling saliva and decomposing secretion upon the projecting portion of the tongue, with its foul odor, produces sometimes a disgusting and painful condition.

The relief of macroglossia is purely surgical,-by abbreviation or by excision of a portion of the organ. In some forms, the hypertrophy may be arrested by ligation of its arteries.

\section{ACUTE GLOSSITIS.}

Acute glossitis, or inflammation of the tongue, although rare in childhood, is occasionally seen from traumatisms due to burns, pricks, stings, bites, erosions from carious teeth, or any lesion which allows entrance to infections organisms. It may occur as a complication of tonsillitis or any acute angina. The inflammation extends to the deeper structures through abrasions of the mucous membrane.

The symptoms are fever, increased salivation, pain and swelling of the tongue, which may entirely fill the cavity of the mouth, protruding beyond the teeth, so that introduction of food and even fluids is attended with great difficulty. The swelling may extend backward so as to threaten respiration from pressure on the glottis. Exceptionally, an abscess may form in the deep structure of the tongue. In this case the distention may be so great as partially to bury the upper incisors in the dorsum of the organ.

In mild cases the treatment should consist in free purgation, antiseptic mouth washes, pieces of ice allowed to dissolve in the mouth, and liquid diet. In severe eases free incisions should be made along the dorsum, parallel with the median line. Where the distention is great, a thin curved depressor may be insinuated between the dorsum and upper incisors, along which a gum lancet may be introduced on the flat, and then turned with its eutting edge downward and quickly withdrawn, making a free incision an inch or more in length.

The exit of blood and pus will relieve the swelling, dyspnœa, and other urgent symptoms, after which the mouth and wound should be frequently cleansed with boric acid solution.

\section{LINGUA GEOGRAPHICA-DESQUAMATIVE GLOSSITIS; PITYRIASIS LINGUÆ.}

These are terms applied to a tongue which shows pale pink, circumseribed areas denuded of epithelium, bounded by whitish circular zones of elongated filiform papillæ. There may be from one to a dozen of these patches over the dorsum of the tongue, but they are most frequently secn near its edge. They vary in shape from time to time as the 
alternation of papillary hypertrophy and epithelial desquamation proceeds. The intermingling of the whitish boundaries of these pale, glazed areas gives to the circular borders a serpentine appearance, so that a great variety of patterns may be seen at different times. This has given rise to the term "geographical tongue." The process of desquamation is probably due to the action of micro-organisms, the nature of which is as yet unknown.

It is seen most frequently in childhood and bears no relation to any other disease. The child suffers no discomfort and exhibits no disturbance of function. It appears most frequently in bottle-fed infants and a relation to rhachitis is suggested, although the claim for syphilitic causation has been adequately disproven.

The condition has little clinical significance save as a curiosity, and its recognition is only valuable to prevent confusion with other conditions of diagnostic importance.

The duration of these epithelial changes is indefinite and may continue, with variations, for many years. No treatment is indicated.

\section{ULCER OF THE TONGUE.}

An ulcer on the under side of the tongue, just in front of the frænum, is occasionally seen in infants after the eruption of the lower median incisors. It is commonly associated with pertussis or with any cough that is violent or frequently repeated. (This ulcer is caused by rasping the protruding tongue against the sharp edges of the incisors during fits of coughing.) It is usually shallow, from two to six millimetres in diameter, is indolent in character, and shows little tendency to bleeding and suppuration. No treatment is necessary, other than astringent antiseptic applications, as prompt healing follows the cessation of the cough.

\section{RIGA'S DISEASE.}

Riga's disease is a name given to a sublingual growth one-quarter inch (0.6 Cm.) in diameter, which begins as an ulceration in the site above mentioned. It is described as occurring endemically in southern Italy independent of cough or other known cause. Only a few cases have been reported outside of Italy. A characteristic bacillus is claimed to have been found in the milk of the mother and organs of her infant dying from this disease. Reports agree in regard to the indurated character of the lesion, which assumes the proportions of a sessile, disklike tumor, made up, chiefly, of hypertrophied epithelium and connective tissue infiltrated with a large mass of round cells embedded in fibrin.

Among the anomalous characteristics ascribed to these growths are the non-involvement of adjacent lymph nodes, early recurrence of the growth after its removal (which is readily effected without hemorrhage), its disproportionate associated disturbances, such as gastro-intestinal 
disorder, cnlargement of liver and spleen, with marasmus, and frequent fatal terminations. Recently reported cases give a more benign character to this growth and good results after excision.

\section{RANULA.}

A tumor is occasionally seen in the floor of the infant's mouth, varying in size from a pea to a chestnut or even larger. If situated at one side of the frenum or involving that structure, and if translucent, pearl-colored, thin-walled, and fluctuating, it is probably a ranula. 'This is a cystic tumor due to the blocking of the mouth of a mucous follicle, or to a congenital occlusion of the glands of Nuhn. It is filled with a glairy, transparent fluid, and when evacuated the cyst walls are collapsible. The tumor is painless and, if small, affords no inconvenience. It may be so large as to interfere with nursing and, in older children, it may render speech and deglutition difficult.

Cysts in this locality may be caused by the occlusion of Wharton's duct, or the ducts of Bartolini and Rivinus, by salivary calculi. These do not, however, constitute true ranulæ. Dermoid eysts from congenital persistence of a branchial cleft may encroach upon the floor of the mouth, but may be differentiated by their deeper situation, lack of translucency, and denser feel, their contents being sebaceous matter and. epidermal detritus.

Ranule may be readily emptied by simple incision, but the prompt healing of the sac is followed by refilling. Its extermination requires. excision of a good portion of its anterior wall, with the application of the solid nitrate of silver to promote shrinkage and obliteration of the sac.

Occlusion by salivary calculi and distention of the ducts from retained secretion may be relieved by a probe introduced into the orifices, and gentle massage to dislodge the concretions. Failing in this a more extensive surgical operation will be necessary.

\section{TONGUE-TIE-ELONGATIO FRENULI.}

Tongue-tie is a condition in which protrusion and free mobility are restricted by the extent of the frenular attachment which, in some cases, reaches to the extreme tip of the organ. This occurrence is rare, however, and the condition has been unduly magnified as a possible obstacle to nursing. Occasionally, in older children, defects in speech are attributed to this cause. Greater freedom may be allowed the tip of the tongue by snipping with blunt scissors the anterior border of the frenum near its attachment to the floor of the mouth, pointing downward to avoid wounding the ranine arteries.

This operation is rarely needed and should never be undertaken without inquiring concerning a history of hæmophilia. Undue extension of the incision from laceration may result in retrolapsus of the tongue. 


\section{DIFFICULT DENTITION.}

The relation of dentition to the disturbances of infancy has bcen a much-mooted question, it having been held by many that a purely physiological process could not be held responsible for pathologic conditions in remote and unassociated organs and tissues. The consensus of opinion, however, derived from clinical observation, is found to-day occupying a middle ground between that of a previous generation which blindly attributed most of the ailments of infancy to dentition and that class of moderns who stoutly proclaim that tecthing produces nothing but teeth.

That either radical view is productive of much harm is apparent in the number of lost opportunities for the early relief of grave conditions, due to the mistaken diagnosis of "teething," on the one hand, and in the neglect to recognize the existence of pain and serious reflex disturbances, caused by abnormal dentition, on the other.

From the multitude of clinical facts and an analytical study of the relationship of the innervation of certain parts to the eirculation in other parts, it is not difficult to see why a process so commonly accompanied by elevation of temperature, local congestion, pain, anorexia, tenderness, irritability, restlessness, and a loss of weight, should at least act as a predisposing cause to many pathological processes, in which congestion is a preliminary stage. Otalgia, if not suppurative otitis ; cerebral hyperæmia, if not meningitis; disturbed digestion, if not enteritis, and many other manifestations of profound derangement of the nervous equilibrium may be attributable, directly or indirectly, to difficult dentition.

The normal process of development and eruption of the teeth has been described elsewhere (Part I), so that a few abnormalities only need be mentioned. That the general nutrition of the infant has an important influence over the character of the teeth is evident, as in rhachitic malnutrition the teeth may come throngh ont of the usual order, most frequently the incisors appearing singly instead of in pairs, the upper preceding the lower. Early dentition is often attributable to rhachitis, in which case the teeth are fragile and decay quickly. Usually, however, rhachitis causes late dentition, and a year or eighteen months may have elapsed before the first erown shows through the gums. The narrowing of the alveolar ridges, in the plastic state, from pressure of lips, teeth, and tongue, is claimed to be partly responsible for delayed and irregular eruption, while paucity of earthy salts, a known condition of rhachitis, is undoubtedly one cause of retarded and irregular growth of the teeth. Other forms of malnutrition and disease leave their impress upon tooth formation, in defective dentine and enamel, as seen in the horizontal ridges and grooves caused by acute infections and syphilis. The well known deformities of the last named is referred to under that subject (Part I). The unstable functions of the developing period coincident with dentition, the most important of which is digestion, 
should warn us to safeguard it by special attention to diet. When the eruption of groups of teeth is imminent the food should be reduced and plenty of water given to relieve the thirst so commonly mistaken for hunger. The hot and swollen gums should be protected against infection by antiseptic lotions. The restlessness and nervous condition of the infant may well merit mild sedatives, as bromide of sodium in full doses, frequently repeated, and avoidance of all that tends to disturb or fatigue. The suffering of the screaming, irritable infant, as the tooth-crown approaches the surface, is usually due either to the overlying tissue, in which case the gum is swollen, congested, hot, and tender, or to reflex or congestive pains in other localities, usually the middle ear. In the former case the symptoms may be relieved by the gum lancet which should be used with aseptic care, eutting down full upon the crown, with a linear incision, if it be an incisor, or with a crucial incision, if it be a molar; in the latter instance so directed as to relieve the pressure over each of the four advancing cusps. If the gum be not swollen, hot, and tender, the lance is useless and relief of pain must be sought in hot or anodyne applications to the painful area. In either case bromide of sodium, two to five grains $(0.13-0.32 \mathrm{Gm}$.) in syrup of lactucarium, one-half to one teaspoonful, may be given at intervals of two hours, until rest is secured.

The difficulties of second dentition may be obviated in a great measure by intelligent care of the deciduous teeth, in the prevention of early decay and loss before the development of the alveolar structures so essential to a symmetrical arrangement of their successors. The mouth disorders, alveolar abscesses, and toothache, so common to the period of second dentition, may be minimized by daily care with brush and soap, and frequent inspection for defects.

\section{CATARRHAL STOMATITIS-STOMATITIS CATARRHALIS.}

The commonest affection of the mouth in infancy is simple eatarrhal inflammation. In fact, this form precedes and accompanies all other forms of stomatitis. It may be due to traumatism, from hot or corrosive substances, or from abrasions of the delicate mucosa by misdirected efforts in cleansing the oral cavity. The artificial nipple of the nursing bottle may, if not properly adjusted to the size of the infant's mouth, cause irritation or erosion. Disease and malnutrition play an important part in the lowered resistance of the mucosa to the infectious organisms ever present in the infant's mouth. The perverted action of the secretory glands may lead to the excretion of irritating substances from infections and toxin absorption in other parts of the body. Hence the frequent occurrence of stomatitis in gastro-enteric infection. All general infectious diseases cause hyperæmia or inflammation of the mucous membrane of the mouth. It is here that the first lesions appear in nearly all the acute exanthemata.

There may be in acute catarrhal stomatitis only a general or local hyperæmia and hypersensitiveness, or the membranes may be greatly in- 
flamed, with pain, tenderness, and increased secretion of tenacious, glairy mucus. There may be fever, restlessness, thirst, and disinclination to take food, on account of the pain induced. The nursling refuses the breast. The tongue is coated and the bowels are commonly constipated although diarrhœa may precede and accompany the attack. 'The drooling of acrid saliva may irritate the lower lip with resultant swelling and excoriations. Other lesions of the mouth due to infectious organisms, following in the wake of simple catarrhal inflammation and lowered nutrition from inability to take food, is a common result of long-continued painful mouth disease. Uncomplicated catarrhal stomatitis, however, is usually of short duration with a tendency to recovery upon the removal of the exciting cause. The prognosis is therefore good.

The treatment consists in the avoidance of acrid substances or the irritating products of decomposing food, and the application of soothing antiseptic washes, such as sodium-bicarbonate, boric acid, potassium permanganate, or sterilized water. Obstinate cases may require painting the inflamed membrane with a weak solution of nitrate of silver $(0.5-1$ per cent.). Indigestion must be corrected and bowel disturbance relieved by efficient laxatives or high colonic flushings.

STOMATITIS APHTHOSA-STOMATITIS HERPETICA; VESICULAR STOMATITIS; FOLLICULAR STOMATITIS; CANKER SORE MOUTH.

The mucous membrane of the mouth is frequently the seat of an herpetic eruption-stomatitis herpetica. The age of greatest susceptibility corresponds somewhat elosely to the period of first dentition, to which many ascribe etiologic significance. Its occurrence in babies at the breast is not as frequent as in those fed from the bottle. Simple aphthous ulcers are occasionally seen in adults. Stomatitis aphthosa is usually attended in children by febrile disturbance and malaise. The temperature may reach $103^{\circ} \mathrm{F}$. $\left(39.5^{\circ} \mathrm{C}\right.$.). The tongue is coated and there is often digestive disturbance, with green, foul-smelling stools. The lesions, if seen early, appear as round or oval. slightly raised pearly spots from one to five millimetres in diameter. Of these there may be one or a dozen, occurring singly or in groups. The most common site is on the margin of the tongue or inner surface of the lower lip at its junction with the gum, although the first appearance may be as a solitary vesicular lesion on the tonsil. Within twenty-four hours, in exceptional cases, the mucous membrane, especially about the fauces, may be studded with the eruption, which tends to coalesce, forming a continuous patch or plaque. The patches of coalescence at times resemble a diptheritic exudate, for which it is occasionally mistaken. The epithelial covering disappears, leaving the discrete vesicle as a shallow ulcer, with a white or yellowish base, surrounded by a zone of hyperæmic tissue. The lesions are extremely sensitive. The salivary secretion is excessive, and in the drooling infant may cause irritation and excoriation of the lip and chin. A peculiarity of these shallow lesions is the absence of the fetid breath so characteristic of ulcerative stomatitis. The painful lesions interfere with feeding or 
any motion of the tongue. The child is irritable and restless. The duration, if uncomplicated, is from three to seven days, although a succession of crops may continue the affection for two or three weeks.' The exudative floor of the shallow ulcer is gradually raised above the level of the surrounding epithelium, and cast off with spontaneous healing and without cicatrization.

Pathologically, this form of stomatitis closely resembles herpes of the skin, from which it differs only in the peculiarities of its location. A point of resemblance is seen in the diseases which they commonly accompany, such as pneumonia, typhoid, malaria, and indigestion. No specific organism has as yet been found in aphthæ, and it is generally regarded as a result of toxins which affect the terminal filaments of the superficial nerves.

The discovery of its coincidence with epidemics of mouth-and-foot disease in cattle has excited great interest in the question of its transmissibility, Under certain conditions it appears to be contagious, although the mass of clinical evidence tends to the contrary, in the ordinary form of the disease.

Diagnosis.-It is to be diagnosed from ulcerative and diphtheritic stomatitis and from the lesions of variola and varicella, as they occasionally appear in the mouth. The absence of fetor and the location of the ulcers may exclude the first named, and the early disappearance of the rare coalesced patches proves its non-diphtheretic character. The nature of varicellar and variolous lesions of the oral mucosa is revealed by the concurrent or subsequent eruption on the skin.

Prognosis. - The prognosis is favorable in the great majority of cases. Occasionally, some of the lesions become infected and develop into an ulcerative stomatitis.

Treatment.-The treatment is essentially the same as for the catarrhal variety, in addition to which the ulcers may be gently touched with tincture of chloride of iron, or the peneil of mitigated lunar caustic. If the. infant refuses to nurse, it may be fed with the stomach-tube introduced through the nose. Older children may be given ice cream, if not contraindicated, as warm fluids cause pain.

\section{BEDNAR'S APHTHE-APHTHÆ OF THE PALATE.}

Among the ulcerative lesions of the mouth should be mentioned Bednar's aphthæ, which, according to the American classification, may be considered a misnomer. Bednar's aphthæ, or plaques pterygoidiennes, appear usually as a double lesion of the mucous membrane on opposite sides of the month at about the line of junction between the hard and soft palate. Occasionally these erosions occur in the median line from denudation of the epithelial pearls there situated. They are due to superficial erosions from traumatism of the mucous membrane covering the hamular processes of the pterygoids. The finger, the artificial nipple, or even the base of the baby's tongue in nursing, may cause erosions of the delicate epithelium over these unyielding portions of the palate. 
Subsequent infection, uleeration, neerosis, and even sloughing may ensue, with production of the symmetrical characteristic lesions described first by Bednar. Rarely the ulcerative process may extend until the entire mucosa of the soft palate is involved. It oceurs during the first month of life and with greater frequency in babies fed from the bottle, especially in those of low vitality, with unsanitary surroundings.

The treatment requires removal of the canse: The artificial nipple should be abbreviated and rough cleansing of the mouth must be stopped. If the ulcers prove obstinate the infant may be fed with a spoon or by a tube introduced through the nose.

Topical applications are necessary as for other ulcerative conditions of the mouth. The healing is usually prompt after removal of the cause of irritation.

STOMATITIS MYCOSA-MYCETOGENIC STOMATITIS; PARASITIC STONATITIS;

THRUSH ; MUGUET; SPRUE; SOOR.

Stomatitis myeosa is a disease produced by a vegetable parasite in the form of a fungus growth, probably a mould, though its precise elassification is still a matter of dispute.

The spores of this fungus are everywhere present in the air, and may be found in the mouths of healthy infants. In fact, there is no cavity or tissue of the body in which they may not be found. They cause stomatitis when the oral mueosa furnishes a favorable soil for the growth of the mycelium and reproduction of spores,-i.e., when fissures or erosions exist, or the membrane is softened by a eatarrhal stomatitis. Finding lodgement they multiply between the epithelial cells, which are crowded aside and destroyed until the fungus appears upon the surface of the mucosa in the form of small white flakes, which closely resemble milk curds, for which they are frequently mistaken. Attempts to remove these flakes, however, will show the mistake, as they adhere quite firmly and, when dislodged by foreible wiping, leave abraded surfaces which may bleed slightly. The adjacent mucosa is less moist than usual and the oral secretions are slightly acid. The white flakes are usually first seen upon the tongue and buceal membrane where they multiply rapidly and spread over the adjacent surfaces covering the palate, fauces and uvula with a thick, whitish mass which occasionally resembles a pseudomembrane. The growth, if uncheeked, may spread over the lips and invade the œesophagus, and has been found in the stomach, though such oceurrences are rare in this country. The disease, in itself, is not painful but the attending eatarrhal stomatitis may oceasion much discomfort. Rarely other infeetions supervene, and ulcers form with painful lesions and bad breath.

Thrush is essentially a disorder of the early suckling period, although it may oceur at any period of infancy under favorable conditions,namely, feeble mobility, lowered resistance, and implantation of the specifie fungus upon a surface denuded of epithelium. It is seen in 
the mouths of patients in extreme debility, and is an oceasional precursor of death in exhausting disease.

Thrush is due to lack of aseptic care of the nipple or of any substance that is introduced into the mouth. The disease is not self-limiting, and results in athrepsia from extension, or from associated infections which interfere with feeding and digestion.

The prognosis is good under proper treatment, which consists in thorough cleansing of the mouth with a solntion containing borax twenty grains $(1.3 \mathrm{Gm}$.$) , glycerin two drachms ( 7.5 \mathrm{C.c})$., and rose-water two ounces (60 C.e.) ; or, sodium bicarbonate ten grains $(0.65 \mathrm{Gm}$.) to the ounce ( 30 C.c.) of water, in milder cases. The mouth-wash should be applied with a gauze swab before and after feeding, with care to avoid further abrasion of the delicate mucosa.

Prophylaxis is all-important, as mycetogenic stomatitis in all its forms is readily transmissible; hence the prevalence of thrush in institutions for babies where strict aseptic precautions are neglected.

\section{STOMATITIS ULCEROSA-ULCERATIVE STOMATITIS; PUTRID SORE MOUTH.}

Ulcerative stomatitis is characterized by fetid breath, ulceration of the gums, and profuse salivation. It may develop at any age after the eruption of the teeth, but is more frequently seen between the third and tenth year. It is usually associated with lowered nutrition, malhygiene, and infection of the mouth from any cause. It occasionally follows the infectious diseases, the germs of which were formerly regarded as causative. It may result from certain mineral poisons, such as lead, phosphorus and mercury. It was formerly quite common as a result of the medicinal administration of large doses of the last-named drug. A not uncommon cause in young infants in scorbutus. Ulcerative stomatitis is undoubtedly infectious and probably contagious, as it occurs endemically among hospital and dispensary patients and among soldiers and miners in barracks or camps.

The question of its microbic origin is still in doubt, although two organisms have been isolated,-namely, a large fusiform bacillus, in form resembling the Klebs-Loeffler, and a slender spirillum which suggests a kinship between stomatitis ulcerosa and Vincent's angina.

Its occurrence in scorbutus is suggestive of a probable etiologic factor,-namely, a blood dyscrasia, in which the local manifestations are intensified by malhygienic conditions of the mouth, as want of cleanliness of the teeth and tartar accumulations. Although the lesions may occur on any part of the oral mucosa, they usually affect first the gums of the lower incisors, where the ulceration may appear as a dirty gray line on the gum margin. The gums are swollen and tender and bleed readily on pressure. The margins rise toward the crown of the teeth, both internally and externally, as the process extends backward toward the molar. The disease is usually unilateral, but it may be bilateral and may involve the entire structures of both jaws. Later, the spongy gums fall away from the teeth and pus wells up in the intervening fissure, or 
burrows through the alveolar process with subsequent invasion of the jaw and formation of sequestra. The teeth may loosen in their sockets and fall out. The ulcerative process may extend to the buceal mucosa, either at its junction with the gum or opposite the molar teeth, where it appears as a yellow streak or patch which later breaks down, learing an open ulcer with foul bottom and ragged, undermined edges. The submaxillary and cervical lymph nodes are swollen and tender, but rarely suppurate. There may be little or no elevation of temperature in mild cases, but with the extensive ulceration and necrosis, systemic infection may occur with fever and other evidences of sepsis. Loss of appetite and the painful condition of the mouth lessen the ingestion of food, and nutrition suffers. Other forms, such as herpetic stomatitis, may accompany the ulcerative; and neglected cases may result in gangrene.

Prognosis.-Untreated ulcerative stomatitis may run a more or less rapidly destructive course, with extensive loss of tissue and resultant deformity, or death from systemic infection. No serious disease yields more readily to treatment, and, if recognized early, may be arrested and cured in from five to ten days. Advanced cases in eachectic children may tax the patience of the physician, but recovery, excepting loss of teeth and slight deformity from loss of carious bone, may be assured if careful attention be given to the details of treatment and nutrition.

Treatment.-The cause should be ascertained, if possible, and receive appropriate treatment, as fruit juices and fresh vegetables in scorbutus, sulphuric acid and potassium iodide for plumbism, and improved hygiene and nutritious food for the marasmic. The removal or prompt treatment of carious teeth must be attended to, with cleansing of the oral cavity by antiseptic irrigations, such as saturated boric acid, potassium permanganate $(1: 2000)$, hydrogen peroxide diluted with four times its quantity of water, or, probably the best of all, a two per cent. solution of potassium chlorate. Obstinate ulcers may be touched with the solid nitrate of silver, powdered sulphur, or burnt alum. The cheeks should be separated from the affected gum by a pledget of gauze, frequently renewed, to prevent extension to the buccal surface. For internal administration, chlorate of potash is justly regarded as specific in stomatitis ulcerosa. It may be given to a child of three years in twograin $(0.13 \mathrm{Gm}$. $)$ doses every two hours, well diluted. Its beneficial effects are frequently seen during the second day in diminished fettor and salivation. The use of this remedy must be watched, as renal insufficiency and cardiac depression may follow its use in susceptible children. Scanty urine and cyanosis are indications for its discontinuance. Tincture of iron, five to ten minims $0.3-0.6$ C.c.) doses, or the aromatic sulphuric acid, properly diluted, four times a day, may be substituted.

Prophylaxis consists in the daily routine cleansing of the mouth and teeth of children. This is all the more necessary during sickness when the secretions are perverted, and decomposing débris accumulates rapidly. During the administration of mercurials, stomatitis may be pre- 
cipitated by neglect of these precautions or by the local irritation of a jagged, earious tooth.

STOMATITIS GANGRENOSA-NOMA OF THE FACE; CANCRUM ORIS.

Noma is the most severe and fatal form of stomatitis in children. It is fortunately rare, occurring usually in the interval between first and second dentition. Noma is undoubtedly of infectious origin and is clearly communicable, although its sporadic occurrence is frequently reported. A number of organisms accompany its progress, among them the streptococei, spirill:e and Klebs-Loeffler bacilli, to no one of which may its specific etiology be attributed. The gangrenous character of the process, which is a true necrobiosis, is apparently due to a combination of circumstances, prominent among which is lowered cellular resistance from malhygiene and previous disease. It may follow the acute exanthems-typhoid fever, pertussis, scurvy, enteritis, syphilis, etc.-and is frequently preceded by ulcerative stomatitis.

The lesion usually begins on the lateral aspect of the gums, or buccal mucosa opposite the molars, probably as a result of abrasion, trauma, dental caries, and want of cleanliness. It is usually unilateral, though it may spread to both sides.

Attention is first attracted by the gangrenous odor of the breath, followed by discovery of the ulcer, which spreads rapidly and deeply into the subjacent tissue. The submaxillary and cervical glands enlarge, the cheek is swollen, pale and tumid, the oedema involving the eyelids. There is remarkable absence of pain and the fever may be slight in the early stages, with subnormal temperature towards the close. The drooling of ichorous saliva is excessive and the eadaveric stench is indescribable, as the rapid destruction proceeds through mucosa, connective tissue, bone, and muscle. By the third day, sometimes earlier, a red spot appears on the integument of the cheek which deepens in color to blue, purple, and black, rapidly increasing in area as the necrosis spreads over the face, destroying every tissue in its path until arrested by death of the child from exhaustion. Rarely the disease is arrested by spontaneous formation of a line of demarcation, whereupon the dead tissues slough away, the teeth fall, bony sequestra are thrown off, and the child survives with frightful cicatricial deformity.

The diagnosis from ulcerative stomatitis is made by the darker color of the lesion, the rapid extension of the necrosis, and the tendency to perforation of the cheek.

Treatment.-The early fatality of cancrum oris makes prompt treatment imperative, as in surgical procedure lies the only known means of arresting the necrotic process. Upon the appearance of noma no delay is excusable, as every hour may represent extensive loss of tissue. Disinfectants and deodorants-as peroxide of hydrogen, permanganate of potassium, and formalin-as mouth washes, may limit the digestive disturbance from infectious material swallowed, and render the atmosphere of the sick-room tolerable for the attendants. Cases are reported 
in which injections of antistreptococcic and antidiphtheritic sera have seemed to arrest the disease. Favorable results have recently been claimed for the red-light treatment. From our present knowledge, however, the conscientious physician will not temporize with gangrenous stomatitis, as prompt and thorough surgery affords the best known means of relief.

From the exhausting nature of the disease, alcoholic stimulation is indicated to its fullest extent, and the heart should be supported by strychnia and digitalis. Concentrated, easily digested foods are essential for the maintenance of nutrition. Rectal feeding may be necessary on account of the usually disordered state of the stomach. The highly infectious nature of noma mist not be forgotten, as its extension to other inmates of the house or ward, has been known to follow a lapse in the strictest antiseptic regimen. Analogons processes with fatal termination have been known to develop in the external ear, nose, and genitals of children from direct infection through carelessness of the attendant.

\section{STOMATITIS MEMBRANOSA.}

A pseudomembrane may form in the mouth and on the lips as a result of irritants, such as hot drinks, and also during the conrse of acute infectious fevers. The most pronounced type is seen in diphtheria.

These membranes are usually the result of bacterial growth and are frequently an extension forward of a croupous angina. In rare instances, membranous stomatitis is primary. It may be attended by considerable systemic disturbance, although the lymph-nodes sometimes show surprisingly little involvement. The membranes may become desiccated and darkened from exposure to the air and from slight hemorrhages from fissures in the mucosa. Under proper treatment they disappear by attrition or in masses, leaving the mucosa reddened and sometimes denuded of epithelium.

The diagnosis from diphtheria depends upon the absence of KlebsLoeffler bacilli; from mycotic stomatitis, by the absence of the characteristic thrush fungus.

Treatment.-The treatment consists in soothing alkaline antiseptic mouth-washes or sprays, such as Seiler's solution (Formula 11) or permanganate of potassium, 1:1000.

\section{GONORRHEEAL STOMATITIS.}

Gonorrhœal infection of the mouth occasionally occurs during the infant's passage through the birth canal, or from subsequent exposure through carelessness of the nurse or mother.

Reported cases describe the lesion as yellowish patches occurring on portions of the tongue and hard palate most liable to erosion which, in all probability, must precede the infection by the gonococcus. There is little evidence of inflammation or tenderness, and the pus formation is limited, when compared with the action of the gonococeus on other 
mucous membranes. The diagnosis is made by the presence of the organism of Neisser and by the accompanying conjunctivitis, vulvitis, or vaginitis.

In the infant, gonorrhœa of the mouth is more tractable than is that process in other locations, yielding readily to alkaline washes and weak solutions of protargol, which should be used two or three times daily. In obstinate cases the patches should be brushed lightly with one or two per cent. solution of this drug.

Syphilitic stomatitis will be considered in the chapter on that subject. 


\title{
DISORDERS OF THE DIGESTIVE SYSTEM-Continued
}

\author{
THE THROAT, PHARYNX, AND CESOPHAGUS
}

\section{ACUTE TONSILLITIS}

Acute tonsillitis in childhood presents all the varieties seen in the adult. The most common forms are simple or eatarrhal; follicular or lacunar; croupous or non liphtheritic; diphtheritic; suppurative or phlegmonous tonsillitis, and peritonsillar abscess.

Simple catarrhal tonsillitis is probably most frequently seen and is the usual accompaniment of acute pharyngitis. It is at times epidemic, presumably infectious, and may accompany most of the acute infectious diseases of childhood. Like all acute catarrhal inflammations it is precipitated by exposure to dampness and cold. The vitiated air of badly ventilated homes and school-rooms appears to excite it. It may vary in intensity from the transient sore throat of a day, with little or no indisposition, to a severe constitutional seizure with rise of temperature, headache, anorexia, general malaise, and difficult deglutition.

Constipation and lowered vitality are frequent precursory conditions. Some children and families show a predisposition to eatarrhal inflammation of the tonsils. It is frequently associated with acute or chronic inflammation of the rhinopharyngeal tract. The susceptibility to tonsillitis in rheumatism is referred to in the description of that disease.

In simple tonsillitis the mucous membrane is congested, although the tonsils usually show but moderate enlargement, unless chronically hypertrophied. The adjacent mucosa shares the vaseular engorgement. 'The tongue is coated and the upper deep cervical glands may be enlarged. In the first twenty-four hours the temperature may reach $104^{\circ} \mathrm{F}$. $\left(40^{\circ} \mathrm{C}\right.$. $)$, and may as suddenly fall. An uncomplicated case of moderate severity will subside in three or four days with no other treatment than rest in bed.

Treatment.-The treatment consists in free catharsis, keeping the child quiet, and the use of a mild antiseptic gargle or spray (Formula 11) every two or three hours. If deglutition be painful, cracked ice may be put in the mouth to relieve the thirst. The diet should be light, consisting of milk.and other liquids.

The chief interest in the condition attaches to the possibility of the later development of other infections, as diphtheria, which is favored by the lowered vitality and abnormal condition of the mucosa. 
SUPPURATIVE TONSILLITIS-PLEGMONOUS TONSILLITIS; QUINSY.

This form of tonsillitis, although infrequent in infancy, is often seen in later childhood and pubescenee. Oecasionally, instead of complete subsidence of the more acute symptoms of simple catarrhal tonsillitis, the fever, malaise and intense loeal hypermia may inprove but the tonsils remain somewhat swollen. After an interval of a day or two, following a second exposure to eold, one or the other tonsil again becomes painful. The ehild has chilly sensations followed by a rise in temperature, deglutition beeomes extremely diffieult and the jaws may be separated but slightly and with great pain. The tongue is foul, the breath fetid, sordes eollect on the teeth, and the throat is harassed by tenacious secretion which can neither be swallowed nor expectorated, on account of the pain on the least movement of the museles of the jaw. Pain radiating to the ear is complained of, and otitis media is not an uncommon complication by direet infeetion through the Eustachian tube. There may be torticollis. The voice is non-resonant, as if the throat were full of food.

If the rigid jaw will permit, the palpating finger may outline the considerably enlarged tonsil as a more or less firm, boggy, or elastic mass, extremely sensitive to touch. The effeets of pain, loss of sleep, and want of nourishment, soon show in the weakened condition and haggard appearanee of the child. The swelling and evidences of toxæmia may continue from three to six days, when there is sudden disappearance of the distressing symptoms from spontaneous rupture and discharge of the tonsillar abseess. This collection of pus may be in the substance of the tonsil, in the peritonsillar tissue, or, having started in either place, may invade the other. Evacuation of the pus is immediately followed by subsidence of the swelling and usually by rapid eonvaleseence. Occasionally, however, the opposite tonsil takes on active inflammation and the history of phlegmonous tonsillitis is repeated.

The prognosis, as to life, is favorable with the rare exeeption of aecidental death from hemorrhage or suffocation. The former may follow erosion of the carotids by burrowing of the tonsillar abscess. Suffocation may be caused by aspiration of pus discharged during sleep, by celema of the glottis from extension of the inflammation, or by an enormously distended tonsil. In the narrow pharynx of the young child, obstruction to respiration may arise to such an extent as to render tracheotomy imperative. In all eases of tonsillitis in children rheumatic endoearditis should never be forgotten, and the heart should receive daily examination. Very commonly, with or without continuation of fever, an apical murmur may develop, and the area of dulness may be found extending beyond the nipple.

Not only the possibility of these accidents but the distressing pain emphasizes the importance of early evacuation of the abscess. This in the struggling child is by no means a trivial or easy operation. The patient must be wrapped in a blanket and held by the assistant as for 
intubation; a strong tongue depressor is forced into the mouth and the jaw depressed so that the bistoury, guarded to the last quarter inch by adhesive plaster, may be introduced. A cut of one-half inch may be made toward the median line. Even if the abseess be not reached relief is afforded by the local bleeding, and the pus discharge may follow later, having a less distance to burrow.

Preceding this, however, relief may be afforded by spraying the month and fauces with an antiseptic alkaline solution (Formula 12) for the removal of tenacious and deeomposing secretions. In older children cautious spraying of the nasopharynx may cleanse that cavity of much infectious material. Care must be observed, by limiting the quantity, not to force fluids into the Eustachian tube. The nasal passage may also be used for liquid feeding through the small stomach tube. Pieces of iee may be swallowed to diminish thirst and local hyperimia when there is great dysphagia. In the same way ice cream may be tolerated because of the analgesic effect of cold. Expressed raw meat juice may be mixed with the cream before freezing. For extreme pain Dover's powder, one-half to one grain $(0.03-0.065 \mathrm{Gm}$.), may be neeessary. In the developing stage the astringent effect of iron, preferably the tincture of the chloride diluted with three to six parts of glycerine, applied directly to the tonsil, tends to limit the extent of the inflammation. Some cases may be aborted if treated promptly by the application to the inflamed tonsil of a drop or two of guaiacol on a pledget of cotton held in the grip of long forceps.

The free use of ealomel, one to four grains $(0.065-0.26 \mathrm{Gm}$.$) accord-$ ing to age, is recommended in the early stage. This may be followed by smaller doses at intervals of four hours throughout the attack. Occasionally it may be administered dry upon the tongue, combined with sodium bicarbonate. The intense congestion may be somewhat diminished by hot pediluvia and the application of hot poultiees to the neck. Small ice bags applied to the angle of the jaw are also useful if well borne. The child should be kept in bed, and when rupture of a large abscess is threatened he should be propped in the sitting position, so that a sudden discharge may find free exit through the mouth.

\section{FOLLICULAR TONSILLITIS-LACUNAR TONSILLITIS.}

Follicular tonsillitis is common in childhood, and is probably not so rare in early infancy as formerly was supposed. A routine practice of throat examination in all febrile disturbances in early life will, undoubtedly, reveal tonsillar inflammation in cases where pain in the throat is not a marked symptom. In this variety, not only may the superficial surface of the tonsils and adjacent mucosa be involved in a catarrhal inflammation, but the tonsillar crypts or follicles-and frequently those of the posterior pharyngeal wall-seem specially selected in the inflammatory process.

The evidences of infectiousness and communicability are beyond question. It often attacks different members of a family in quick succes- 
sion. Any or several of the various resident bacteria may be found in increased numbers and activity. Exposure to the cold, damp weather of the winter and early spring is recognized as an exciting cause, and local epidemics at this time are of frequent occurrence. Rheumatic children show a decided predisposition to this affection. Its favorite seat is in tonsils chronically hypertrophied, so that liability to follicular tonsillitis increases with repetition of attacks.

The attack in older children occasionally begins with a chill, though vomiting is more often seen in infants. The temperature may range from $101^{\circ}$ to $105^{\circ} \mathrm{F}$. ( $38.5^{\circ}-40.5^{\circ} \mathrm{C}$.), with the usual constitutional symptoms. Constipation is common at the beginning, though in babies, diarrhœa with green stools may quickly follow, possibly from the swallowing of the infected mucus. In fact, tonsillitis in infants may be overlooked in the treatment of a gastro-enteritis. There may be a slight enlargement and tenderness of the lymphatic glands at the angles of the lower jaw. A view of the throat shows a reddened mucosa, especially over the tonsils, which are somewhat enlarged and contain one or more yellowish-white pinhead spots, on one or both tonsils, marking the mouths of the crypts. These exudative spots project slightly from the surface of the tonsil and represent the visible portion of the inflammatory débris with which the crypt is distended. This mass consists of exfoliated epithelium, bacteria (principally cocei), exudative lymph, and, in some cases, fibrin in agglutination varying from semisolid in acute tonsillitis to "cheesy" consistency in chronic cases. As the inflammation advances other follicles extrude their contents until the exudation assumes a punctate appearance, with a tendency to rapid coalescence.

The temperature may be remittent in character, showing evening exacerbations for two to five days. There is usually sensitiveness of the throat with painful deglutition. The tonsillar patches may disappear with the subsidence of the fever, but often persist for several days. Slight permanent tonsillar hypertrophy is the rule, and this is augmented with each succeeding attack.

In the beginning, the diagnosis from eatarrhal tonsillitis is impossible, and can only be made later with the appearance of the plugs in the crypts. After coalescence, the diagnosis from the membranous form may be difficult and depends largely upon the non-extension of the membrane to the urula, velum, or faucial pillars. From diphtheria, which should always be suspected until disproved, the culture test is the only positive means of differentiation.

The prognosis, if uncomplicated, is favorable.

Diphtheria, peritonsillar abscess, endocarditis, otitis, hypertrophied tonsils and adenoids are among the complications and sequelæ.

Treatment.-The treatment consists in free catharsis by calomel, ipeeac and soda, and in local applications of alkaline and antiseptic sprays, as Seiler's or Dobell's solution. In view of possible diphtheritic infection or invasion of the deeper tonsillar structures, a drop or two of pure liquid guaiacol may be applied on a small compressed pledget of cotton 
to the affected areas. The smarting eaused by the application is immediately followed by local analgesia. The deep penetrability of this antiseptic agent is well proven. Tiucture of iron, ten per cent., in glycerin, may be used as a gargle or spray, or swallowed, in half teaspoonful doses, three or four times a day, both for its local astringent and general restorative effect. In rheumatic cases sodium salicylate, two to ten grains $(0.13-0.65 \mathrm{Gm}$.) with an equal quantity of sodium bicarbonate, should be administered every two or three hours to avoid heart complication. Bromide of sodium and ammonium may be given by mouth or rectum for extreme restlessness. High temperature calls for tepid bathing. Applications to the neck of cold or heat, as found most agreeable, may conduce to the child's comfort.

The management of convalescence by proper nutrition and tonics should never be neglected.

Pseudomembranous tonsillitis, as it occurs in diphtheria and the exanthemata, is discussed under the specific diseases with which it is associated.

CHRONIC TONSILLITIS-HYPERTROPHY OF THE TONSILS.

Hypertrophy of the tonsils may develop at any period of childhood and it is occasionally congenital. Many children show an hereditary predisposition to enlargement of the tonsils, iu common with hypertrophy of lymphoid tissue in other regions. This constitutes a prominent feature of lymphatism. Adenoid vegetations in the nasopharynx often accompany and frequently act as an exciting cause for hypertrophy of the faucial tonsils. Among the pernicious effects of obstruction of the upper respiratory tract, mouth-breathing has been mentioned. This compensatory habit induces faucial irritation from the constant current of unwarmed, unmoistened, and unfiltered air, which in the child predisposed to lymphoid hypertrophy, quickly results in enlargement of the tonsils. The rheumatic diathesis, also, predisposes to tonsillar enlargement, usually as a result of repeated attacks of pharyngeal inflammation. Many cases, however, are seen with no history of acute tonsillitis. In addition to diathetic predisposition, climate exerts a positive influence in the production of these overgrowths. In this country they are more common along the Atlantic coast and the Great Lakes region, where sudden changes in temperature and humidity are prevalent.

In infancy the enlargement is principally an increase in the lymphoid tissue, the tonsils remaining soft. In older children there is increase, also, in the connective tissue, the enlarged tonsils showing sclerotic changes, with compression of the follicles, deeper fissuring, and occasional deposition of calcareous material. The degree of enlargement and the effects upon the child differ widely. Deglutition is rarely interfered with, except during acute exacerbations.

Marked tonsillar hypertrophy gives a peculiar quality to the voice. It sounds as though the throat were full of soft food, and articulation is indistinet. Snoring in sleep may result through relaxation of the velum 
palati. In rare cases extreme hypertrophy may interfere with the free ingress of air through the diminished lumen of the pharynx, or from downward pressure upon the epiglottis. 'This condition, if it persist, will produce the same defects that are seen in chronic obstruction from hypertrophic rhinitis or adenoid regetations in the nasopharynx. The deafness attributed to enlarged tonsils is more often due to the accompanying adenoids.

The interference with phonation, when occurring in early infancy, probably retards the development of speech. The retained secretions, by reason of tonsillar enlargement, favor decomposition and cause fetor of the breath. The swallowing of the -secretion, which is increased in quantity, is productive of digestive disturbance and resultant impairment of nutrition. In addition to this the broken sleep intensifies the malnutrition and induces a great variety of nervous symptoms.

Although hypertrophied tonsils rarely threaten life, their presence furnishes favorable cultural conditions for a variety of infections. This is especially true of diphtheria.

Slight tonsillar hypertrophy may gradually disappear after puberty without treatment. No case should be neglected, especially in infancy and early childhood, on account of the handicap to development, and the tendency of the morbid condition to increase. Some of the ill effects may be minimized by keeping the mouth and throat clean by the use of gargles and sprays. The last may best reach the posterior portion of the tonsil through the nasal passages. The tonsils may be painted daily with tincture of chloride of iron, pure or diluted with three parts of glycerin, or occasionally with tincture of iodine or five per cent. solution of nitrate of silver.

Constitutional treatment for malnutrition and lymphatism, such as outdoor cxercise, cool bathing, cod-liver oil, and syrup of the iodide of iron, should be adopted.

Undoubtedly the best treatment, when the tonsil is sufficiently large to interfere with normal functions, is amputation. The mucosa should be cleansed and rendered less sensitive by a course of gargling or atomization of a solution of boric acid and potassium bromide for a few days prior to the operation (Formula 16). The glands should be entirely removed, as any portion left favors redevelopment.

No objection to the removal of enlarged tonsils is recognized, save the possibility of infection or tronblesome hemorrhage. The presence of acute inflammation or a history of hemonhilia contraindicates the operation. An astringent gargle, as a two per cent. solution of alum, should be used after amputation. The result of tonsillotomy is sometimes disappointing from failure to recognize that faulty habits of respiration and speech must be overcome by patient and persistent training.

VINCENT'S ANGINA-ULCERO-MEMBRANOUS TONSILLITIS.

This disease appears as a tonsillitis, pharyngitis, or stomatitis. It is caused by a needle-shaped bacillus which is usually associated with a 
spirillum. This spirillum, identical with that found in carious teeth, was first described by Vincent, in 1896, as the cause of uleero-menbranous angina. This organism is commonly present in the deeper layers, although its share in the etiology of this disease is still questioned. Among the predisposing canses are lymphatisn, syphilis, eruption of teeth, carious teeth, and malhygiene of the month. The disease is communicable, small epidemies having been reported. The affection of the tonsils is often preceded by similar lesions in the mouth and pharynx.

The chief characteristic is a greasy, friable, diphtheroid pseudomembrane, which may be unilateral or involve both sides by extension. Within thirty-six hours ulceration occurs in the tonsil. The ulcers may be quite extensive and present the punched-out margin and foul base of the chancroid. The breath is offensive with a characteristic fetor. Salivation is marked and deglutition is painful. The lymph nodes at the angle of the jaw are hard and tender, although periglandular odema is absent. There is little evidence of constitutional involvement. Fever is often slight, compared with the extent of the local lesion.

Diagnosis.-Vincent's angina is to be diagnosed from diphtheritic, follicular and syphilitic sore throat, each of which it may accompany and intensify by symbiosis. It should be stated, however, that the presence of Vincent's spirillum in the secretions of the throat is said to preclude diphtheria. The chief points in differentiation are the extreme fetor of the breath and the slight constitutional disturbance, as compared with the fever and malaise of follicular tonsillitis. The hard, nodular adenitis is found instead of the periglandular swelling of diphtheria. 'The greasy friability of the membrane-which may be partially wiped off-is in contrast with the firm adherence of the diphtheritic exudate, and the absence of paralyses with post-diphtheritic neuritis. The short duration of the disease and its amenability to treatment, differ from the obstinacy of syphilitic lesions. The main diagnostic point, however, is the presence of the bacillus and spirillum of Vincent.

The prognosis is favorable, as the lesions yield readily to treatment.

The treatment is principally local, in which two drugs are advocated as specifics,-viz., menthylene-blue applied in powdered form to the lesions, and potassium chlorate, locally and internally, its local effects being secured secondarily through its elimination by the salivary glands. The quantity of the latter drug in twenty-four hours may vary, according to age, from ten to thirty grains $(0.65-1.95 \mathrm{Gm}$.) in broken doses. Most of the antiseptic sprays and gargles, from boric acid solution to hydrogen peroxide, have been recommended. The ulcers, if extensive or foul, may be touched with nitrate of silver, tincture of the chloride of iron, or iodine. In young children the objection to topical application is so obvious that the internal use of potassium chlorate and milder gargles or sprays are preferable in a disease presenting little evidence of general intoxication.

The contagious character and the possibiiity of diphtheria require prompt isolation in every case. 


\section{ACUTE UVULITIS.}

The urula may share in the inflammation of acute pharyngitis, or it alone may be the seat of the attack. The mucous membrane is reddened and cedematous and the urula swollen to double its normal size. Troublesome eough is the most obvious symptom and there may be slight fever.

Treatment consists in the application of mild astringents, as alum or tannin solutions; also ice internally and externally.

Elongation of the uvula may be congenital but is more frequently the result of uvulitis. The urula drags upon the base of the tongue and causes an irritating cough and constant attempts at swallowing. It may cause romiting. Astringent applications may reduce the elongation, or the tip of the uvula may be amputated. If bleeding be troublesome the cut surface should be touched with solid silver nitrate, or Monsel's solution of iron.

\section{PHARYNGITIS.}

The history of a child without an attack of pharyngitis would be a rarity. With the exception of rhinitis no disorder is so common in infancy and childhood. Although it may present many varieties as to extent, and degree of severity, it will be discussed under two forms,namely, acute and chronic pharyngitis.

\section{ACUTE PH.ARYNGITIS.}

Etiology.-Catarrhal inflammation of the pharyngeal mucosa rarely occurs independently of lesions of contiguous mucous tracts. Like them, it is probably due to infection. Among the predisposing causes, such as heredity, lowered nutrition, and exposure to cold and dampness, infancy itself is undoubtedly the most important. The period of rapid development is characterized by an abundance and hyperactivity of lymphoid tissue. This activity, in the highly vascular and loosely attached mucosæ, invites the easily induced congestion. The tendency to these catarrhal inflammations is in direct ratio to the degree of lymphatism of the individual ehild. Impoverished nutrition, syphilis, and rheumatism furnish opportunity which exposure to cold, damp, overheated, foul, or otherwise irritating atmosphere, further renders favorable for infection of the mucous membrane by the resident bacteria.

Symptoms.-The common symptoms are a feeling of dryness and smarting in the throat and pharynx, intensified by breathing cold or contaminated air, with a frequent irrepressible desire to clear the throat or cough. There is usually a rise of temperature, $100^{\circ}$ to $103^{\circ} \mathrm{F}$. $\left(37.8^{\circ}-\right.$ $39.5^{\circ} \mathrm{C}$.), which may have been preceded by vomiting or chill. The usual febrile accompaniments-malaise, anorexia, headache, foul tongue, and feverish breath-are present, and there is painful deglutition, not always proportionate, however, to the extent of the inflammation. Tenderness and pain at the angle of the jaw and glandular enlargement are common. 
The throat, when examined at the inception, appears red and dry. A few hours later the mucous membrane is covered with a glistening, tenacious secretion. The inflammation may involve all the visible portions, the fauces, pillars, uvula, and pharyngeal wall, or it may be confined to the latter surface. The erythema may be in streaks or patches with normal membrane between. Again, it may present a punctate appearance with bright red papilla showing through the secretion which covers the duller red of the surrounding parts.

Rhinitis, tonsillitis, laryngitis, one or all, may accompany the pharyngeal inflammation. Cough, frequently attributed to a bronchitis, may be due solely to the pharyngeal disturbance. Various forms of stomatitis may precede or accompany a pharyngitis and modify the pharyngeal lesion. Herpetic lesions are seen implanted on the pharyngeal wall, or the follicles which stud the mucosa may appear turgid and even œedematous,- - a form of inflammation to which the term follicular pharyngitis is applied.

In uncomplicated simple pharyngitis the temperature subsides in a few days and the soreness and redness disappear. A week's time may show the tissue in an apparently normal condition.

Diagnosis.-The diagnosis of pharyngitis refers to its proper interpretation rather than to the existence of the lesion, and is especially important, since much may depend upon an early recognition of associated disorders. Oceasionally, pharyngitis may be an indication of digestive disorders and yields to their correction. It may be an expression of rheumatism, and, recognized as such, should put the physician on the alert for cardiac complications. Associated arthritic and muscular symptoms should be looked for.

Rheumatic pharyngitis is characterized by sudden onset, pain out of proportion to the apparent congestion, and often abrupt disappearance of all symptoms.

Quite frequently pharyngeal inflammation heralds the onset of the acute infections, such as scarlet fever, measles, variola and diphtheria, in which differentiation may be made by the character of the throat lesions and accompanying symptoms,-e.g., mottled throat and Koplik's spots of measles, the intense diffuse redness of scarlet fever, and the discrete papillary eruption of variola, or the appearance of psendomembrane upon the mucosa, which should give warning of its true nature, and lead to prompt isolation of the patient. Syphilis and tuberculosis are rare factors in the pharyngitis of early childhood.

The prognosis depends upon the cause.

Treatment.-The treatment of simple acute pharyngitis requires rest in bed for two or three days, free evacuation of the bowels, cold compress to the neck, gargles or sprays of alkaline, antiseptic solutions (Formula 11). Spraying through the nares, when the posterior wall is the only part involved, is a most efficient method. Cold demulcent drinks, as flaxseed tea or iced slippery-elm water, or swallowing bits of ice, afford 
comfort and relieve the congestion. Pain in the ear is eommon, but otitis media may develop without pain. Heat applied to the ear gives relief. The ear-drum should be examined frequently for evidences of suppuration.

\section{CHRONIC PHARYNGITIS.}

Repeated attacks of pharyngitis tend to hypertrophy of the structures of the lymphoid ring. The posterior pharyngeal wall, in the chronic state, presents a persistent hyperæmia with irregular masses of elevated tissue, varying in size from a pinhead to a pea.

The surface may be dry or may be covered with a tenacious secretion which extends downward from the vault. This chronic form of pharyngitis is not common in early childhood.

There is a feeling of dryness in the throat and a frequent cough, hawking, or screatus, to remove the viscid mucus extruded from the hypertrophied follicles. 'This condition, accompanied by enlarged Luschka's tonsil and hypertrophie rhinitis, is not infrequent in later childhood, especially in the eatarrhal regions of the Great Lakes and Atlantic seaboard, where sudden changes of temperature are frequent.

'The fetid breath, constant hawking to dislodge the tenacious secretion, the impaired resonance of the voice, and the snuffling or snoring respiration during sleep, all mark the victim of chronic pharyngeal catarrh.

The treatment of chronie follicular pharyngitis is the same as that of allied conditions in the nasal and tonsillar mucosa. Benefit may be derived from the application of astringents, as tincture of iodine, two per cent. solution of nitrate of silver, and bland, oily atomization. The indications for improvement of the general health by diet, outdoor exercise, and judicious use of tonies and attention to hygiene, should never be overlooked. The removal of tonsillar and nasopharyngeal growths should not be neglected. In obstinate cases, removal to a salubrious climate may be necessary for eomplete cure.

In rheumatic children, alkaline waters and the salicylates are valuable to intercept acute attacks and to lessen the tendency to chronicity of pharyngeal inflammation.

The syphilitic dyscrasia should be kept in mind. Occasional courses of potassium iodide, alternating with the iodide of iron, have proved beneficial in some chronic cases of doubtful etiology.

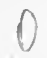

\section{ADENOID VEGETATIONS.}

Hyperplasia of the pharyngeal lymphoid tissues, first recognized by Czerniak in 1860, were ealled adenoid vegetations by Meyer, of Copenhagen, who first described them in 1868 .

With the possible exception of rhachitis and lymphatism, with which they are frequently associated, there is probably no common condition of childhood of more serious import than adenoids. The immediate and remote influences, not only upon the nutrition and growth of the child, but upon his susceptibility to infections and his resistance to disease, 
bear an important relation to the morbidity and mortality of the developing period.

From the mass of accumulating evidence it is apparent that the profession is finally awakening to the importance of this relatively eommon affection.

Adenoids consist of nodules of hyperplastic pharyngeal lymphoid tissue grouped into masses and eovered with eiliated epithelium. They are the result of an overgrowth of lymphoid tissue normally found in the pharyngeal vault. They appear closely related to the tonsils in structure and function, and the mass is known as the third, or Luschka's tonsil. They differ from the tonsils, however, in the variety of forms of arrangement of their nodular masses, which may be broad, sessile, pedunculated; cauliflower, stalactite, or coxcomb; firm in texture or friable. From the vault they may

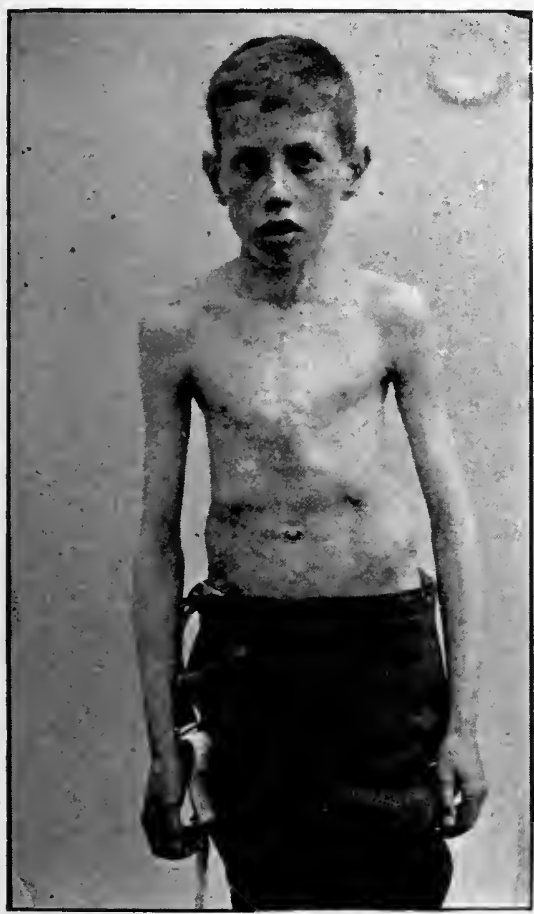

Fig. 127.-Adenoid facies and chest. extend forward to the ehoanæ of the nose, or backward to the lower border of the velum, and may fill the entire nasopharynx.

Though frequently hereditaryi.e., of familial type, and oceasionally congenital-it is believed that

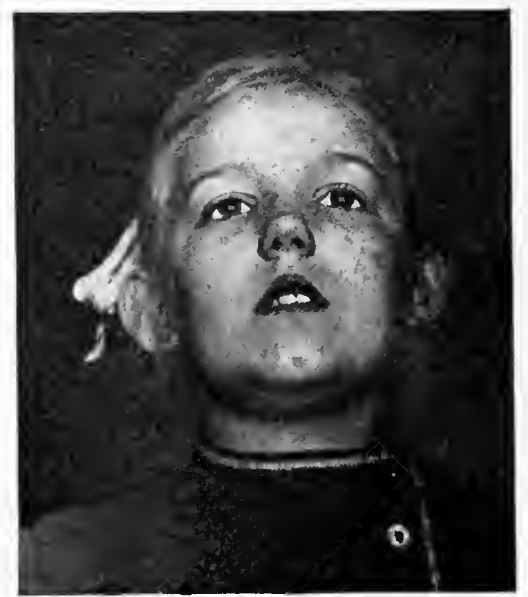

FIG. 128.-Mouth-breather.

this tendency to overgrowth of lymphoid tissue may result through transmission of other debilitating parental dyscrasiæ. Adenoids frequently accompany cleft palate and are common in deaf-mutism, which in some instances is regarded as a result of these vegetations.

Symptoms.-Among the early symptoms of adenoids are snoring in sleep; restlessness; recurrent attacks of nasopharyngeal catarrh; bad breath; bloody discharge from the nose or throat, or tendency to 
epistaxis; sensitive throat with tonsillar hypertrophy; susceptibility to taking cold upon slight exposure; pyrexia from insignificant causes; laryngeal spasm with or without laryngitis; bronchial asthma, and cough without bronchial lesion.

Advanced cases present appearances so typical that "adenoid facies" stands for a symptom complex of this condition (Figs. 127 and 128). The sallow complexion; thick, expressionless lips; open mouth; crowded, irregular teeth, with arched or saddle-shaped palate; narrow nostrils with weak alæ showing indentation at juncture of superior and anterior lateral cartilages; the flattened nasal bridge with its congested transverse vein; and the dull eyes having the appearance of being too wide apart, with their frequently congested tarsal structures; also dulness of hearing and the want of alertness, all give to the confirmed mouth-breather the appearance of sluggish or deficient mentality. The voice is nasal and non-resonant, especially in singing, and the consonants $M$ and $N$ are sounded as $B$ and $D$, respectively.

The effects of obstructed respiration in neglected cases appear in general malnutrition, muscular atony, anæmia, headaches, disturbed

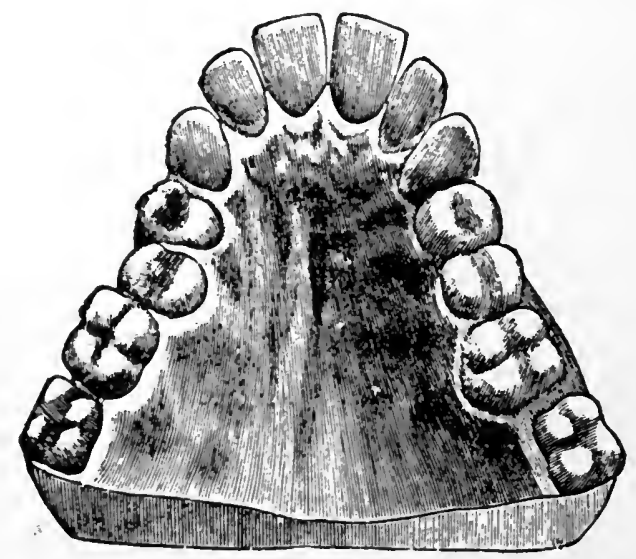

FIG. 129.-High-arched palate.

sleep, bad dreams, night terrors, nervous instability, with disturbed reflexes, and possibly epilepsy. The appetite is impaired; digestion disturbed; deafness with or without aural discharge is common; ocular disturbances are not infrequent, with phlyctenulæ of the conjunctivæ. Growth is retarded, and the chest may show marked rhachitic deformity with shallow respiration. The child is the victim of every intercurrent disorder, both dietetic and infectious; while bronchopneumonia and tuberculosis are ever threatening finalities in the sequence of morbid processes.

The abundance of lymph follicles in the retronasal and pharyngeal mucosa in infancy is undoubtedly the predisposing cause of adenoids at this period, while the low, receding pharyngeal vault, with the meagre 
postnasal openings, are largely accountable for their obstruction to respiration.

Exposure to cold and dampness, with resulting rhinopharyngeal catarrh, is a recognized cause. The first appearance of symptoms frequently follows an attack of diphtheria, measles, scarlatina, or influenza. The most commonly observed age for troublesome adenoids is from three to ten years, though the first symptoms usually appear

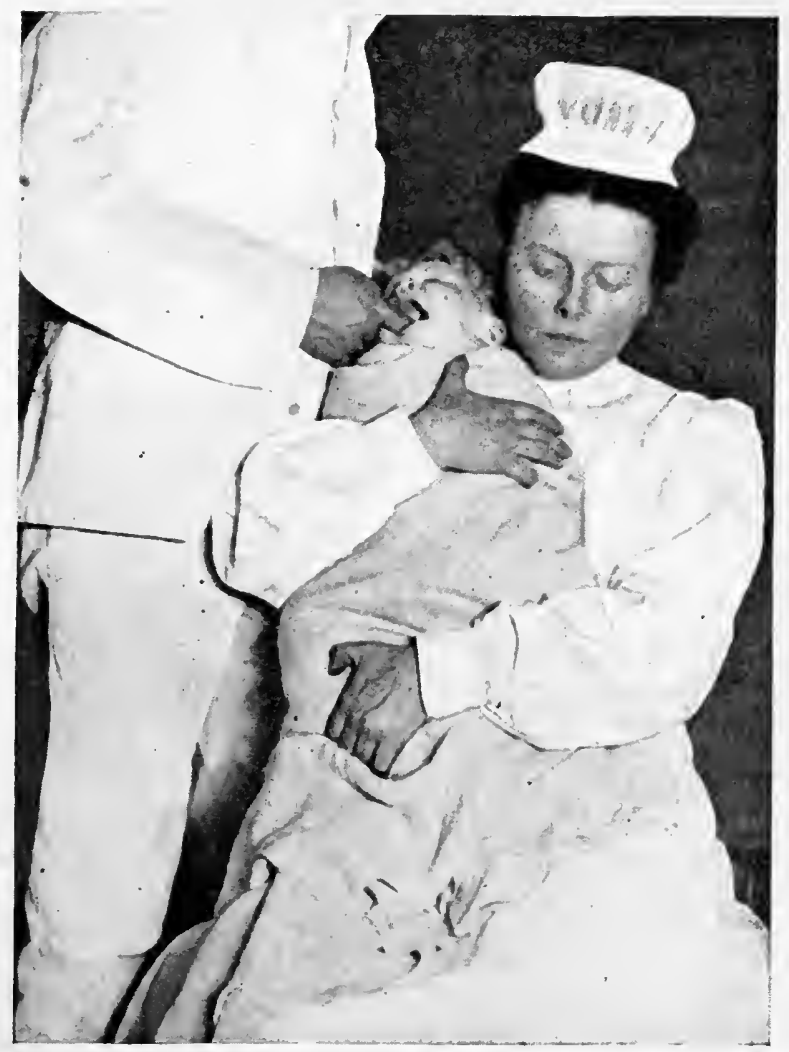

Fig. 130.-Digital exploration for adenoids.

between one and three years, and occasionally are seen from earliest infancy.

Much confusion still exists as to the etiologic relationship between some of the prominent accompaniments of adenoids and the postnasal vegetations themselves. Recurrent rhinitis is undoubtedly both a cause and an effect of the post-nasal hypertrophy. The occlusion of the Eustachian tubes, which interferes with the ventilation of the tympanum with the consequent congestive, exudative, or suppurative otitis, may be due to hyperplastic constriction of their orifices independent of any obstruction by the masses of hypertrophied Luschka's tonsil. 
The term "adenoid habit" has been applied to a tendency to hypertrophic changes in the lymphoid ring which includes the postnasal space, vault, and posterior pharyngeal wall, pharyngeal tonsil, and postdorsal surface of the tongue.

Mental dulness may be induced by plugging the inferior nasal passages with wax, and eye disturbances have followed suturing the nostrils in rabbits.

The changes in the upper respiratory and lymph-tracts of the mouth. breather-viz., the narrow face and high palate, which diminishes the capacity of the nares, causing congestion of blood- and lymph-vesselsmay be due either to hereditary or mechanical influences, as pressure, prenatal or parturient, which would eause narrowing of the facial bones. In such eases hypertrophy of the pharyngeal lymphoid tissue would only be a part of the morbid sequence. Stagnation of lymph-channels-Schneiderian, antral, and ethmoidal-follows. Cerebral effects, such as mental dulness, headaches, accompanied by trophic disturbances,

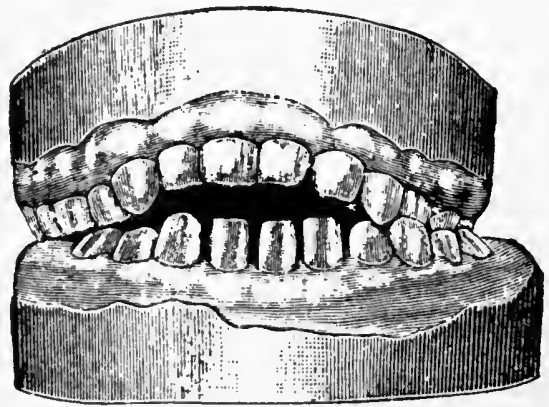

FIG. 131.-Effect on jaws of thumb-sucking and continued use of the "soother" during infancy.

may be occasionally aseribed to impaired function of the pineal and pituitary bodies.

That the deformity of face, palate, alveolar arches, nasal septum, and meati are caused solely by the postnasal obstruction, there is reason to doubt. A more natural explanation is that accorded to pressure, both direct and atmospheric, caused by thumb-sucking, late nursing from breast or bottle, and the continued use of the "soother."

Diagnosis.-Adenoids may be suspected in infants or children who exhibit symptoms of obstructed respiration, recurrent nasopharyngeal catarrh, deafness or otitis, general malnutrition, anæmia or reflex nervous disturbances. The presence of these growths may be verified by palpation. The child must be held with arms secured, sitting on the lap of an assistant, while the physician stands above so that his index finger may enter the angle of the mouth, pass readily behind the velum, and gently explore the vault with palmar surface and tip (Fig. 130). A gag between the jaws will insure greater freedom and safety to the examiner. The vegetations may be felt as soft, velvety masses, like angleworms, or in ridges, eushions, or lobules, at the posterior nares 
or on the pharyngeal vault. Hypertrophy may be felt with the trained finger when but little can be seen with the rhinoscope. P'osterior rhinoscopy, with tractable older children, gives good results and is a valuable adjunct in diagnosis when tonsillar enlargement is not too great.

Adenoids may be differentiated from fibroids as much softer. more friable, and not so well defined. Malignant growths are extremely rare in this situation. Polypi of the nasopharynx or of the nasal fossie are very rare in infancy and early chilclhood. Retropharyongeal abscess runs too acute a course to be mistaken for adenoids. Nasal obstruetion may be excluded by nebulizing into one nostril albolene, or other oily substance, which should be returned through the other nostril if the meati are patulous.

Aside from their effects in lowering resistance to infection through trophic influence, the rôle of adenoids, not only in their furnishing in the nearly closed cavity of the pharynx an ideal incubator, but also in affording through their masses ready entrance to the circulation of pathogenic organisms, is of vast pathologic importance. Rheumatic infection is so commonly associated with activity in the structures composing the lymphoid ring that tonsillar hypertrophy is accepted as one of the signs of the rheumatic diathesis.

Tubercle bacilli in Luschka's tonsil, with characteristic lesions, are reported by many observers, ranging in frequency from three to ten per cent. of the cases examined. Primary tuberculosis of adenoids is probably more common than earlier studies have shown.

Prognosis.-During pubescence the amplification of the pharyngeal vault and the heightening of the nasal fossæ relieve somewhat the obstructive symptoms of adenoids. At this time, or earlier, the growths themselves usually tend to atrophy; the overgrowth of fibrous tissue, which is perivascular in its arrangement, probably hastens this result.

The removal of the adenoids may relieve obstruction to respiration and interrupt the resultant morbid processes, but the damage to aural structures and the trophic effects of their prolonged influence may be beyond repair. The physician should be conservative in his estimate of the benefit to be derived from treatment or even removal.

Treatment.-The treatment, is prophylactic, palliative, and curative. Anything that tends to interrupt the vicious circle of which adenoids form a part, retards by so much their growth; hence, protection from catarrhal infections by attention to clothing, climate, and ventilation must be observed, with prompt treatment for the relief of acute angina and rhinitis. Nutrition must be maintained to the highest degree by the best known hygiene, special attention being directed towards any tendency to rhachitis and other nutritional disorders. In this connection the services of the physician are rarely more valuable than during convalescence from the contagious diseases of infancy and childhood.

The question of early orodental surgery to correct facial, palatal, and nasal deformities due to prenatal or hereditary influences seems worthy of consideration. 
Much may be accomplished by a thorough daily toilet of the nose, pharynx, and mouth. From infancy children may be habituated to the use of bland medicated albolene nebulizations, also to sprays of common salt or boric acid in aqueous solution.

When the adenoid is small, or appears as a somewhat acute growth, medicinal and hygienic treatment may arrest its development or even occasionally cause marked shrinkage. Guaiacol carbonate, one to three grains $(0.065-0.2 \mathrm{Gm}$.), four times a day; syrup of the iodide of iron, five to fifteen minims $(0.3-1.0$ C.c.), three times daily; or syrup of hydriodic acid, fifteen to sixty mininis (1.0-3.75 C.c.), three times daily, may be given on alternate weeks for a period of several months.

When the growth causes trouble in the auditory, respiratory or nervous systems prompt removal of the obstruction by surgical procedure must be the rule.

Unless the conditions are urgent the operation should be deferred until after the second year. Early summer, for obvious reasons, is a more suitable time than late fall or winter. An acute angina or rhinitis would warrant postponement until recovery. Since adenoids furnish a route for infections, care must be observed, in operating, to avoid states where reinfection is likely to occur, as after acute infectious disorders, or during epidemies where exposure is possible. Recent endo- or pericarditis, rheumatism, or chorea, should warn the surgeon to wait for complete recovery.

The list of disorders in which relief has followed the removal of adenoids includes voice defects, mouth-breathing, mental dulness, epistaxis, hæmatemesis, headache, deafness, otitis and rhinitis, bronchitis, laryngitis, asthma, laryngospasm, stammering, chorea, rheumatic attacks, enuresis, broken sleep, night terrors, tetany, convulsive seizures from apparently innocent causes, masturbation, many nervous habits and ties of reflex origin, adenitis, torticollis, sclerosis and other orthopædic conditions due to lowered nutrition and repeated infections; also indigestion, diarrhœal attacks, and malnutrition.

\section{RETROPHARYNGEAL ABSCESS.}

Retropharyngeal abscess is peculiar to infancy. It is rarely seen after the third year and occurs oftenest from the sixth to the fourteenth month. The collection of pus between the posterior pharyngeal wall and the vertebral column is most frequently due to a suppurative inflammation of the lymph nodes with which this region is well supplied in infancy. After the third year this chain of glands usually undergoes atrophy. This form of retropharyngeal abscess has been termed primary or idiopathic, although it is undoubtedly due to infection through the lymph channels from the faucial or pharyngeal mucosa. It occasionally results from the burrowing of pus in cervical tuberculous spondylitis.

A predisposition to this affection is seen in children of syphilitic, tubercular, or lymphatic diathesis. It has been known to follow trauma, 
as wounds to the mouth or pharynx, and at times it develops as a seriuel to the acute infectious diseases of childhood.

Symptoms.-Although the condition is usually accompanied by fever and other evidences of abscess formation, the first symptom to attract attention to the lesion is interference with swallowing and breathing. The baby refuses to nurse, or repeatedly lets go of the nipple. The mother may have noticed a peculiar sound with inspiration, like a soft snore or clucking noise, which may have been attributed to nasal obstruction or to laryngeal stenosis from eroup. There may be labored efforts at inspiration with depressions of the yielding portions of the chest wall,

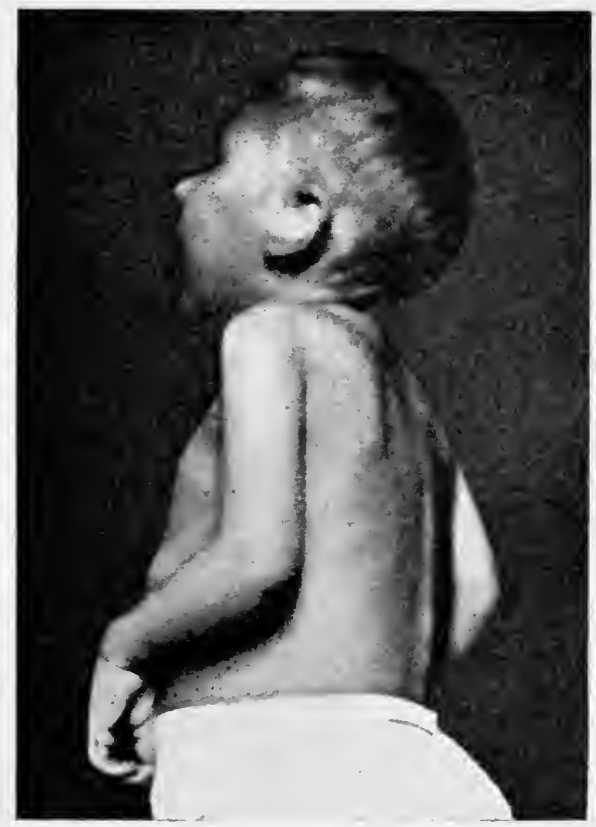

FIG. 132.-Cervical spondylitis, retropharyngeal abscess, otitis media.

with cyanosis and evidences of impending asphyxia. The cry has a peculiar throaty quality as though the infant were being strangled. The attitude is characteristic (Fig. 132), the head being inclined backwards and towards the affected side. Lymph-nodes may be felt under the angle of the jaw and occasionally a tumefaction appears behind the sternomastoid muscle. The mouth may be open, as with noisy breathing the child endeavors to overcome the respiratory obstruction. The facial expression in older infants denotes anxiety and is sometimes indicative of pain. Inspection of the mouth may reveal nothing abnormal, or the soft palate may bulge forward and a fulness of the posterior pharyngeal wall is apparent. In either case the pharynx should be carefully explored with the finger (Fig. 130), when the presence, the dimensions, and the consistency of the tumor may be readily made out. The abscess 
may be high up behind the soft palate, or low, opposite the laryngeal orifice, and is usually at one side of the median line. A word of caution: the abscess may be ruptured by the exploring finger, in which case the baby should be immediately turned head downward to prevent the escaping pus from entering the glottis.

In the suppurative form the onset is rapid, so that acute dyspnœa may develop within twenty-four hours after the first symptom. Oceasionally, however, lymphadenitis of the retropharyngeal area may not proceed to suppuration, in which case the symptoms of pain and dyspnœa become less marked and disappear spontaneously.

The tubereulous variety, with burrowing pus, is gradual in development and may produce symptoms of pharyngeal encroachment increasing throughout a period of several weeks.

Diagnosis.-T' one familiar with the picture of retropharyngeal abscess the diagnosis is not difficult and may always be made by exploratory palpation, when inspection is unsatisfactory. Laryngeal stridor and spasmodic laryngitis cause paroxysms of dyspnœe, whereas the respiratory difficulty in retropharyngeal abscess is continuous. The cough, too, of catarrhal laryngitis, is loud and clanging, while that of abscess has no croupy quality. Diphtheria of the larynx gives a husky ery or complete aphonia, and may show diphtheritic membrane on other portions of the faucial or nasal mucosa. The position of the head in retropharyngeal abscess is characteristic and is seen in no other obstructive lesion. If the abscess be seated low down, or if it be accompanied by œdema of the glottis, the obstructive symptoms from pressure may closely resemble those of laryngitis, from which it may be diagnosed only by palpation.

As young infants rarely breathe through the mouth, obstructive respiration due to occlusion of the nares may be relieved by pressing the month open.

Prognosis.-The prognosis is grave because of the possibility of accident. Death may oceur from asphyxia, especially in feeble infants. Spontaneous rupture of the abscess during sleep is always attended by danger of suffocation. Early diagnosis and proper treatment is almost always followed by speedy recovery.

Treatment.- The abscess should be opened and its contents evacuated. A straight bistoury, guarded to one-quarter inch of its point, may be guided by the index finger of the left hand to the most prominent part of the tumor and a vertical incision made from one-half to one inch in length. The child, with jaws separated by a mouth gag, arms pinioned in a sheet, and held by an assistant, should be inverted instantly upon the withdrawal of the knife, to prevent aspiration of the pus into the larynx. After this the finger should be again introduced and pressure made to empty completely the abscess cavity. The child should be kept under observation for several days, as the incision may heal too quickly and the cavity refill. In this case a second operation will be .necessary. In many instances, especially in those where the abscess is 


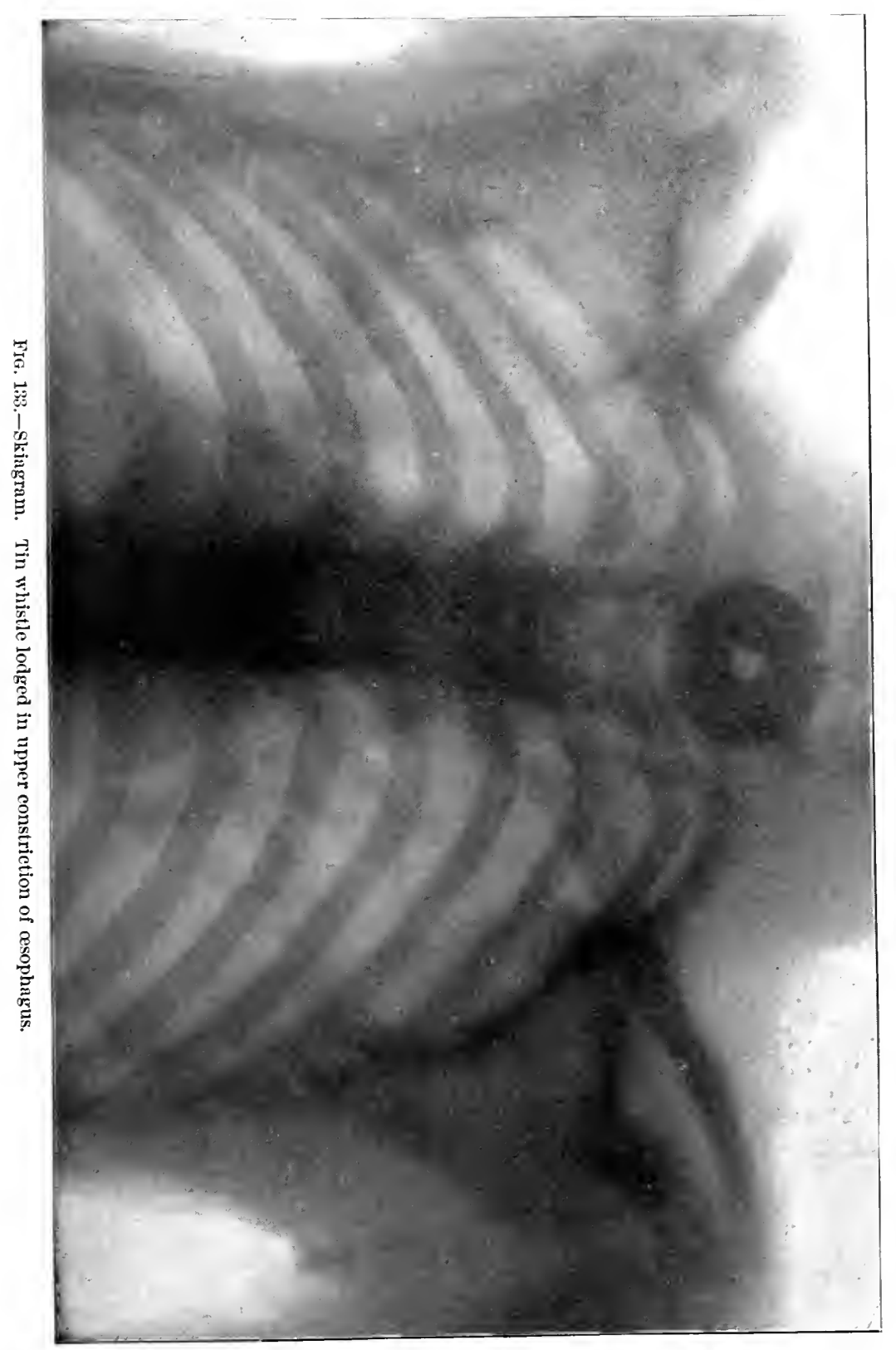



due to tuberculosis of the cervical vertebra, operation from the outside of the neck is preferable. By this means the danger of infection of the tuberculous tract with pus germs is lessened and better drainage is secured.

The condition of the infant usually calls for restorative and tonic treatment to improve nutrition and combat the depression cansed by the suppurative process.

Probably the prophylaxis resides in attention to the daily toilet of the mouth and upper respiratory tract, especially in infants who are predisposed to catarrhal and suppurative lesions, also in those suffering from the acute exanthems.

DISEISES OF THE GEOPHAGUS.

The cesophagus is rarely the seat of pathological processes in children.. When they do occur, however, they are of so grave importance as to merit mention. As stated on page 159, congenital defects of the œsophagus are oceasionally seen,- $\mathrm{such}$ as stenosis complete or partial, diverticula, tracheo-œsophageal fistula, imperfect closure of a branchial cleft, or entire absence of the cesophagus.

Congenital narrowing of the cesophagus near its lower end may allow some of the food to pass into the stomach, although a portion is regurgitated. The œsophagus gradnally becomes dilated or sucenlated above the constriction. The digestion may be good, but the stools are scanty and the child succumbs to inanition. Passage of a bougie may locate the constriction and determine its extent. The relief is by surgical operation after reasonable efforts at dilatation have failed. Rectal feeding should supplement that by the mouth until an operation may be made, and should constitute a part of the after treatment.

A tracheo-osophageal fistula usually terminates in an aspiration pneumonia.

Acute csophagitis may be caused by the ingestion of corrosive liquids, such as acids, ammonia, concentrated lye, or even hot drinks; also from the swallowing of foreign bodies which lacerate the mucous membrane, or become impacted and set up inflammation by their presence. Diseases of the mouth and pharynx, such as diphtheria and thrush, by extension, may involve the entire length of the gullet, diminishing or eompletely occluding its lumen with a solid mass of parasitic growth.

The symptoms of œsophagitis are dysphagia or aphagia, salivation, and vomiting. The child eries and refuses to take food, or the fluids may be regurgitated with evidence of pain. There are usually some febrile symptoms.

The presence of membranous or mycotic lesions of the mouth or throat may confirm the diagnosis of osophageal complication. In other cases there may have been a history of traumatism. If a foreign body has been swallowed the physician should satisfy himself that this has not been retained in the cesophagus. He should remember the three normal constrictions-namely, pharyngeal, diaphragmatic, and that portion 
- crossed by the aorta,- - the narrowest of which is the upper, where flat bodies are wont to lodge in close relation to the posterior walls of the larynx (Fig. 134). In this position they may be easily removed with the eurved forceps. The fluoroseope is invaluable in locating foreign bodies that have been swallowed, so that mueh harmful probing, formerly thought necessary, may now be avoided. It is important that lodged bodies be properly remored from the csophagus before swelling inereases the impaction and results in inflammation and ulceration. If low down, soft foods, such as mush or mashed potatoes, should be given, or the probang may be gently used to push it through the cardiac orifiee. Essophagotomy may be necessary; or gastrotomy, as a less difficult operation, may be performed.

Esophagitis from extension of oral thrush should be treated by the administration of alkalies, as bicarbonate of soda, Vichy water, ete. It may be neeessary to pass a bongie or rubber tube through to the stomach to dislodge the fungoid growth from the lining membrane. When corrosive acids or alkalies are swallowed, they should be immediately followed by a neutralizing solution and later by sweet oil or albolene. In

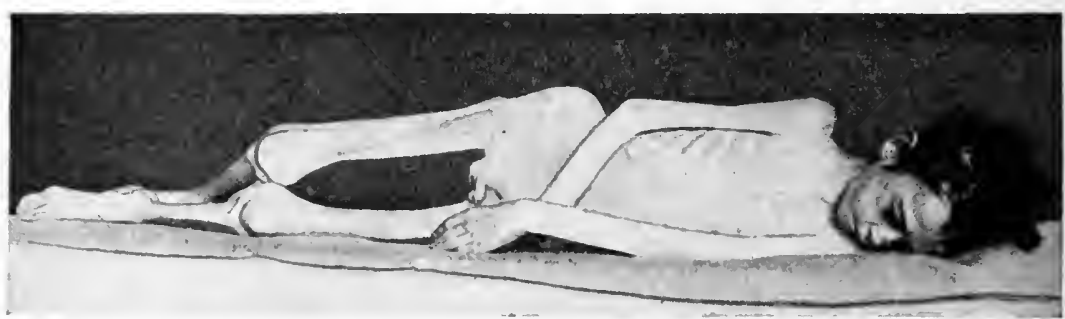

FIG. 131.-Extreme emaciation from stricture of the cesophagus. (Dr. J. A. Robinson.)

inflammation of the esophageal mueosa from any eause, feeding by the mouth is eontraindicated and rectal alimentation must be temporarily substituted until the parts have had time to heal, although ice cream and small lumps of ice may be taken and frequently will alleviate the pain and satisfy the thirst. Anodynes are rarely required, although a small dose of codeine may be given when necessary to secure sleep.

Suprarenal extract is worthy of trial to diminish the hyperæmia.

Strictures of the cesophagus invariably follow deep erosions of its lining membrane by the aetion of acid, alkalies, scalding fluid, or steam. Some months may elapse after recovery from the traumatism before the stricture is severe enough to cause symptoms (Figs. 134,135). The relief of these acquired strictures should be sought in surgical measures.

Functional disturbances of the mosophagus are not rare, such as reflex hyperexeitability with spasmodic atresia. This is particularly noticeable in children of neurotie heredity.

It has been termed a local hysteria which oceasionally gives rise to dysphagia or aphagia, regurgitation of liquids or solids, and belching of gas. Undoubtedly cesophageal spasm is an important element in all 
organic and inflammatory lesions, as frequently a stricture that prevents the passage of a bougie disappears under chloroform.

The treatment for this purely nervous phase of œsophageal disorders

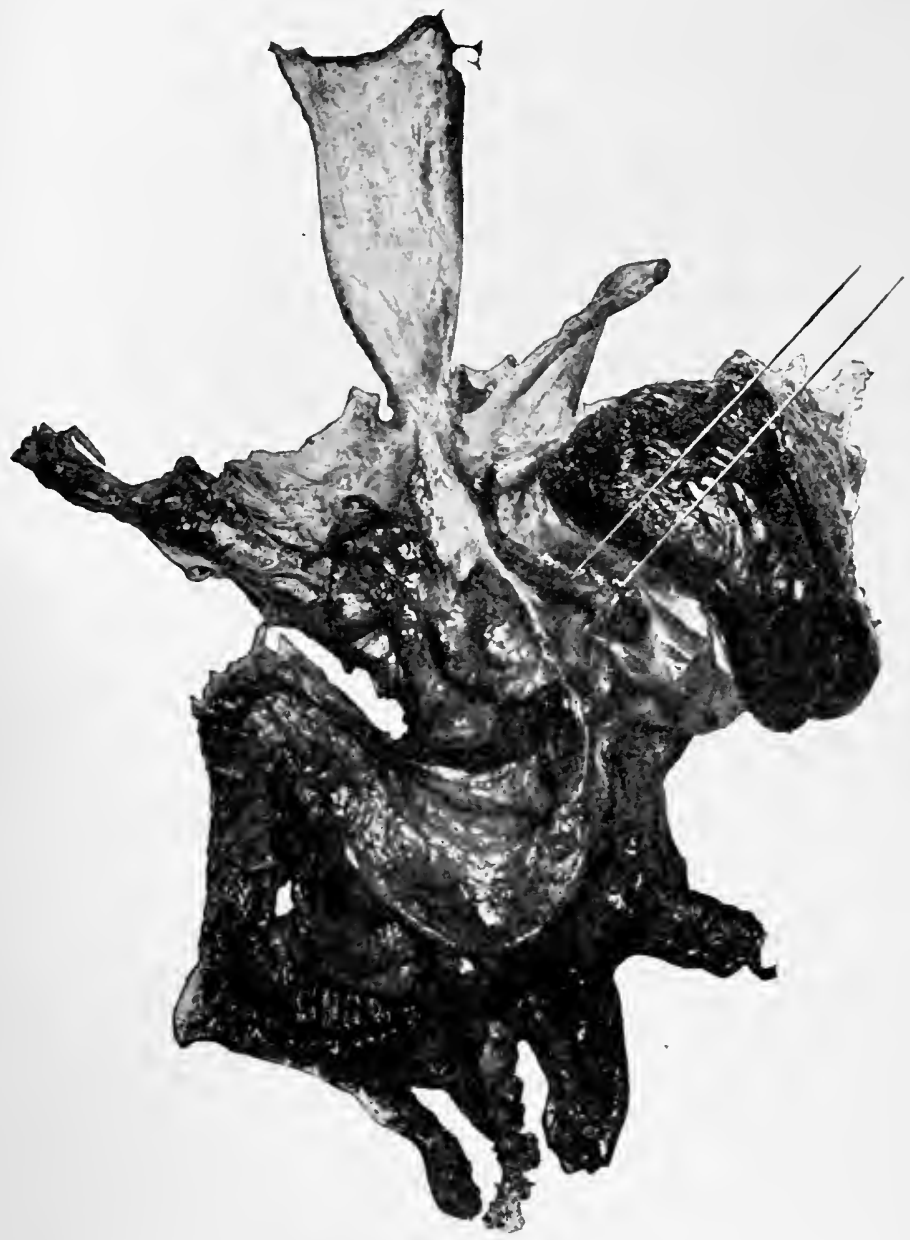

Fig. 135.-Stricture of œesophagus.

is in the use of antispasmodics: bromide, valerian, or asafetida; and by general nerve tonies: iron, quinine, and strychnia, by cold bathing and properly directed suggestion.

\section{RETRO-CESOPHAGEAL ABSCESS.}

Retro-œsophageal abscess is occasionally found post-mortem in children in whom it was the immediate cause of death from pressure on the pneumogastric nerve. Abscess in this locality may be due to burrowing of pus from a retropharyngeal abscess, or may be the result of Pott's 
disease of the cervical or upper dorsal vertebræ (Fig. 132), or of suppurative adenitis of the postœsophageal lymph-nodes, following scarlet fever, measles, and influenza.

The most prominent symptom of post- or periœesophageal abscess is dyspnœa, most marked on inspiration, but withont disturbance of deglutition. Diagnosis is rarely made during life. This condition may be suspected in tuberculosis of the lower cervical or upper dorsal vertebræ when dyspñœa and spasmodic irritative cough are present.

The dyspnœa may call for tracheotomy. Spontaneous relief may follow rupture into the cesophagus, or rupture into the trachea may cause death from suffocation. Surgery should be invoked for the possible relief by drainage through external incision. 


\section{CHAP'TER VI}

\section{DISEASES OF THE GASTRO-ENTERIC TRACT}

\section{VOMITING}

Vomiting, although properly regarded as a symptom, occurs in so many widely diverse disorders that brief mention of a few of the more common is appropriate.

Perfectly healthy infants frequently vomit immediately after nursing, the returned milk showing little or no change in odor or consistency. In this case the act is merely one of regurgitation due to repletion and is probably conservative. It is unaccompanied by nausea, pain, or any change in the attitude or temper of the infant. It is significant only of hasty or overfeeding and is invariably corrected (excepting in occasional cases where it has become a habit) by attention to the hygiene of feeding (q.v.). A word of caution may be necessary in regard to passing over, as unimportant, all eases of regurgitation, sinee obstinate dyspepsia may frequently have its beginning in overfeeding.

Vomiting of Indigestion.-Vomiting is the most common symptom of acute dyspepsia and is usually accompanied by epigastric pain or discomfort and nausea, symptoms of the latter frequently appearing in pallor of the prolabia and facial grimacing. Elevation of temperature commonly accompanies this form, also prostration of varying degree, dependent upon the nature and continuation of the cause. That irritation of the stomach from the products of indigestion is the cause of the emesis is confirmed by the character of the vomitus, which is abnormally acid and may show putrefactive changes. In milk-fed babies the contents of the stomach may be ejected in dense, cylindrical, sour-smelling curds, so large that strangulation seems imminent and, indeed, is an occasional occurrence. To this elass belongs emesis from any agent that causes direct irritation of the gastric mucosa, whether chemical or mechanical.

Vomiting is a prominent symptom of obstructive lesions of the prima via, whether œsophageal, pyloric, or intestinal, as in intussusception, volvulus, or fecal impaction. An attack of appendicitis also is usually accompanied by vomiting. As these subjects are all discussed elsewhere, it may suffice here to refer merely to the stercoraceous character of the vomitus in persistent lower bowel obstruction, and to the intermittent profuse emesis from the greatly dilated stomach of pyloric stenosis.

In infants and young children, pyrexia, independent of its cause, is rarely unattended by vomiting. This is not so true of older children where a sudden rise of temperature, preceded or accompanied by vomit- 
ing, is very suggestive of the onset of an acute exanthem. This is particularly true of scarlet fever, erysipelas, and variola. A characteristic of the initial vomiting in eruptive fevers is that it is very rarely repeated.

Under the head of reflex vomiting is included the occurrence of emesis from causes independent of the stomach and its contents. Good illustrations of this type are seen in the cerebral vomiting in meningitis, cerebral tumor, or in cerebellar disease. In this class the vomiting is projectile in character and occurs without nausea, coated tongue, or other evidences of indigestion. Reflex vomiting may be caused by pain or irritation in parts remote from the stomach, as in otalgia, dentition, eyestrain and intestinal worms.

Irritation of the fauces undonbtedly belongs to the reflex class of causes, and may explain the vomiting due to pertussis, paroxysms of coughing, or to expectoration of tenacious mucus. The presence of adenoid growths in the nasopharynx may cause vomiting by reflex excitation. The effects of shock from blows, falls, or burns in the production of emesis are explained in this way. Neurotic vomiting, aside from that which occurs in nervous dyspepsia, may be occasioned by fright, outbursts of anger, excitement, fatigue, or grief, in susceptible children, and especially in nervous girls of the chlorotic type.

Toxæmia from any cause may be accompanied by vomiting which, if persistent, should lead to an examination of the urine for possible nephritic disorder.

Allied to the toxæmic is the disorder known as recurrent or cyclic vomiting. This may develop at any age, but is most frequently seen between the second and seventh years. A peculiarity of this disorder is its cyclic character, the attacks recurring at intervals of from a few weeks to several months. During the intervals, the child enjoys his normal health. The vomiting may be ushered in by prodromes, such as anorexia, malaise, coated tongue, sweetish odor of breath, constipation, elevation of temperature, and hebetude. In a child subject to this disorder, any of the above symptoms give warning of an approaching paroxysm. The first emesis may eject only the partially digested contents of the stomach and resemble an attack of acute dyspepsia. The nausea and vomiting continue until glairy mucus, tinged with bile or slightly blood-stained, appears. Everything introduced into the stomach, even the blandest fluid, is promptly ejected and the usual gastric sedatives prove futile. In severe attacks great exhaustion ensues and even life may be threatened. A few fatal cases have been reported. During the attack the urine is diminished in quantity, is highly acid, and shows increased percentage of solids. The urea is disproportionally in excess of uric acid. Albumin is occasionally found. The presence of acetone and an excess of the xanthin bodies, both during and after the attack, have been reported. After a period varying in duration from three to seven days, the vomiting suddenly stops, the stomach resumes its function, and the child rapidly regains its normal status." 
These attacks continue at intervals of a few months until the approach of puberty, at which time, or before, they gradually assume the character of migraine, which may terminate in epilepsy.

The etiology of recurrent vomiting, although still obscure, has been the subject of considerable study in this country, from which the majority of cases have been reported. That they are not due to gastritis is evident from the sudden, spontaneous recovery and absence of all gastric disturbance during the interval. The theory of a recurrent neurosis of the pneumogastric as a cause of cyclic romiting seems to lack proof. At present the general trend of opinion points to a lithremic diathesis as the underlying cause. A distinct heredity is seen in its occurrence in children of gouty parentage. A review of reported cases shows that the attacks occur with the greatest frequency in the winter months, when elimination by the skin is at its lowest.

Treatment.-In a child subject to cyclic vomiting, prophylaxis is available if the prodromal symptoms of the attack be recognized early. Prompt administration of full doses of calomel and soda, with a small quantity of ipecac, at this stage may abort the paroxysm or greatly mitigate its severity. During the height of the seizure free administration of alkalies is indicated to counteract the acid intoxication. The intolerance of the stomach compels resort to enteroclysis, by which means from one to two drachms of sodium bicarbonate should be given daily in proper solution. Rectal alimentation of predigested food will be necessary to maintain the strength of the child. The stomach, meanwhile, should be allowed absolute rest from food, medicine or even water. In prolonged attacks, with great prostration, a hypodermic injection of morphine will control the vomiting, and the hypodermoclysis of normal salt solution is valuable as a cardiac supporter.

Keeping in mind the lithæmic diathesis, the habitual constipation, the capricious and frequently voracious appetites of these children, with their proverbial precocity and preference for mental rather than physical exercise, the physician should insist upon strict adherence to hygienic and dietetic rules. The child should be compelled to live out of doors, even though withdrawal from school and study or an entire change of climate may be necessary. Regular, moderate feeding must be enforced.

The diet should be of substantial but easily digested food, of which meat proteids should form but a small proportion. Questionable fruits and vegetables, such as strawberries, tomatoes, asparagus, rhubarb, and salads, should be interdicted. Other fruits may be supplied raw, in small quantities, or freely when cooked, as well as cereals, milk, eggs, fish, butter, and occasionally chicken, beef, and mutton in moderate allowances. Pastry, highly seasoned foods, tea, coffee, and alcoholics should never be allowed. Free drinking of water must be insisted upon, preferably alkaline and saline, such as Vichy, Carlsbad, Friedrichshall, and Hunyadi, both for their alkaline and laxative properties. The administration at intervals of an alkali, as sodium bicarbonate or 
benzoate, in moderate doses, threc or four times daily for a period of two or three weeks, is advised, with occasional mercurial or rhubarb purgation.

CONGENITAL HY'PERTROPHIC STENOSIS OF THE PYLORUS; PYLORIC SPASM.

This condition is reported with such increasing frequency in recent years that it must be accepted as of no great rarity. Both from the symptoms and the post-mortem findings, it is evident that the degree of stenosis varies in different cases and at different periods in the same patient, with a tendency to progressive increase in the narrowing of the pylorus. It is also evident that at least two classes of pyloric obstruction are found,-congenital hypertrophic stenosis, and spasmodic pyloric constriction.

Whatever be the early condition, the general symptoms of pyloric obstruction are the same, with the exception of variations as to the time of their first appearance. These are vomiting immediately after nursing (at first of unchanged milk with no evidence of bile), constipation, or very small bowel movements, scanty urine, dilatation of the stomach, small, hard, movable tumor in the pyloric region, visible gastric peristalsis, flattened lowered abdomen, and progressive emaciation and atrophy.

Vomiting is the earliest symptom noted and may begin within the first three or four days, or the infant, apparently well nourished, may pass several weeks with no evidence of gastric disturbance. Usually the child is first treated for ordinary gastric dyspepsia. The stools may have been normal in color and consistency, so that constipation and emptiness of the bowel with the persistent vomiting may lead to the diagnosis of acute intestinal obstruction. The copious vomiting, the absence of bile and fecal odor and the dilatation of the stomach with its exaggerated peristalsis, the waves of which may be seen through the attenuated abdominal walls, point to a lesion of the pylorus. Usually, this may be felt in adranced cases as a hard tumor, although in the early stage it may be concealed by the overlying liver.

The prognosis is always grave, and in the absence of intelligent treatment positively bad. Lavage and rectal alimentation, withholding all food from the stomach for a time, administration of sedatives, such as bromides, chloral, and belladonna, to overcome spasm of the pylorus, and massage with nutrient inunctions, comprise the general plan of medical treatment.

After a time, varying according to the case, small quantities of bland liquids, such as albumin water, may be tentatively administered by mouth to test the stomach as to the patency of the pylorus. The appearance of yellow stools after the ingestion of a little modified milk or whey would encourage perseverance in this line of management. Return of the vomiting with increase in gastric dilatation should lead to surgical interference in the form of gastroenterostoms or divulsion of the pyloric orifice. 
ACUTE GASTRITIS- $A$ CUTE GASTRIC CATARRH; ACUTE G.ASTRIC ADENITIS.

Acute inflammation of the stomach is probably not nearly so common as was formerly supposed. Many cases diagnosed as acute gastritis show no lesion of the stomach at the post-mortem.

The etiology of disorders of the complex structures of the gastric mucosa with their widely varying functions must necessarily be complicated and obscure. Among the apparent causes may be mentioned, first, perverted action of the various secreting glands with immediate and remote results leading to inflammation; second, active congestion from irritation of the glands, resulting in gastric adenitis; third, passive congestion of the gastric mucosa from interference with return of blood supply through the liver, resulting in excessive activity of the mucous cells. To these may be added traumatism from introduction into the stomach of corrosive substances, laceration from rupture of distended vessels and embolism with ulceration. The action of pathogenic mieroorganisms under these favorable conditions undoubtedly plays an important rôle in gastric inflammation, although to what extent it is difficult to say. Acute indigestion, improper food, rapid or overfeeding, the effects of cold or shock, also various infections, are all recognized as exciting causes of acute gastritis.

The most common form of gastritis in early childhood and infancy is called catarrhal, although the more serious phase of the disorder lies in the adenitis of the secreting glands, which may be primary or secondary to the catarrhal lesions. Macroscopically, the gastric mucosa is reddened and swollen in somewhat circumscribed areas, and bathed with mucus which may be stained brown from slight hemorrhage, and collects, by gravitation, towards the pyloric end. If an irritant has been swallowed, erosions of the mucosa are found upon the rugx. Pearly or grayish-green membrane is seen covering the rugæ along the greater curvature, beneath which the wall of the stomach is greatly thickened. This rare form of pseudomembranous gastritis is seldom diagnosed except at the autopsy.

Numerous shallow ulcerations are sometimes seen, with pus and bacteria, although in infancy they are probably of rare occurrence and never lead to perforation. Microscopically, patches of the mucosa are seen to be infiltrated with round cells, and erosions of the epithelium are numerous. In the tubes differentiation between the principal and parietal cells is difficult. Numerous minute extravasations of blood are found, and the submucous structures may show round-cell infiltration.

Symptoms.-The onset of acute gastritis is usually sudden, attended by a sharp rise in temperature, headache, coated tongue, and foul breath. The pulse is rapid, irregular, and respirations are accelerated. Constipation usually precedes the attack, but may give way to diarrhœa. The most pronounced symptom is vomiting, at first of sour-smelling, partlydigested food; later, of mucus which may be brown or black from slight hemorrhage, or bilious if the vomiting be prolonged. There is usually 
distention of the abdomen, with pain and tenderness over the epigastrium. In severe eases, the temperature may at first range high, $104^{\circ}$ to $105^{\circ} \mathrm{F}$. $\left(40^{\circ}-40.5^{\circ} \mathrm{C}\right.$. $)$, occasionaliy with delirium or, in young ehildren, convulsions. Usually after the first day the pyrexia is less marked. With persistent romiting the eoating of the tongue disappears from the tip and edges, leaving them bright red in eolor. Diarrhœa may develop early, espeeially in infants, and the persistence of frequent foulsmelling stools, of varying eolor and eonsisteney, would indicate extension of the inflammation to the duodenum and small intestine. Oceasionally jaundice appears later as a result of the duodenitis. Thirst is pronouneed and insatiable throughout the attack, although vomiting may follow every ingestion of liquids. In infants the thirst simulates hunger, but in older children there is always anorexia. The prostration is marked, amounting, in severe eases, to extreme debility with rapid emaciation. The urine is seanty, high-eolored and heavy.

The attack may last from five to ten days, although, if mismanaged, it may continue for three or four weeks.

The prognosis is good, as children rarely die of uncomplicated gastritis.

Diagnosis.-From acute indigestion, gastritis may be diagnosed only by the persistenee of its symptoms, which, if lasting more than three days, may be regarded as indieative of actual inflammatory lesions of the stomach. The diagnosis from the acute exanthems will be made by the appearanee of the eharacteristic rash and early cessation of vomiting in the latter. Pneumonia may be differentiated by the persistence of epigastric pain, tenderness, distention, vomiting, and the absenee of other symptoms and physieal signs of that disease. From typhoid fever, which in infancy and young children may closely resemble a mild gastritis in its onset, the differentiation is at times quite difficult. Epistaxis, splenic and hepatic enlargement, and the appearance of rose spots render probable the diagnosis of typhoid, which is eonfirmed by the Widal test.

Treatment.-In the treatment of aeute gastritis, the withholding of food and drink from the stomach is of the first importance. In infants and tractable older ehildren the stomach should be washed out with sterilized water containing thirty grains to the quart $(2 \mathrm{Gm}$. to the litre) of bicarbonate of soda. No treatment for the pyrexia is required save sponging at a temperature agreeable to the patient. In older children an ice-bag over the epigastrium may lessen pain and diminish the frequency of the vomiting. If constipated, the bowels should be immediately relieved by an enema of soapy water. If an early full dose of castor oil can be given and retained it will be of incalculable benefit in clearing out the digestive tract, thus limiting the extension of the morbid process. If the oil cannot be retained frequent small doses of calomel, ipecac and soda (Formula 24) may be given every half hour. This may be eontinued for ten or twelve doses, when the interval may be inereased to two hours. If the vomiting be severe and persistent, bismuth subnitrate, two to ten grains $(0.13-0.65 \mathrm{Gm}$.$) , may be added to the dose, with repeti-$ 
tion of the lavage daily. The thirst must be satisfied by small high enteroelysis of normal salt solntion, three or four times in the twentyfour hours. Small bits of ice may be swallowed. In severe cases no attention to food is necessary in the first forty-eight hours, after which, until subsidence of the vomiting, nourishment must be secured by rectal alimentation, using predigested food in small ruantities. If prostration be severe and symptoms grave, stimulation may be secured by small doses of brandy or aromatic spirits of ammonia, diluted with ice water. Iced champagne or the hypodermic use of strychnia may be required in extreme cases. As the gastric symptoms subside, tincture of nux romica in small doses, according to age, properly diluted, may be given for its stomachic effect, three or four times a day. Bland liquid foods, such as barley-water, albumin-water, whey, strained grtuels, etc., should be cautiously administered in small quantities every two to four hours. This must be withdrawn, however, on the reappearance of vomiting. The return to the usual diet should be gradual, as errors in this respect are largely responsible for the continuation of this disorder.

In gastritis from corrosive poisons the stomach should be immediately irrigated with large quantities of water containing the chemical antidote. The child should be fed on egg-water until bland food may be tolerated. Stimulants should be administered by rectum or hypodermically.

\section{GASTRIC ULCER AND HEMORRHAGE.}

Ulceration of the stomach, although rare before puberty, may occur at any age and has been found post-mortem in the earliest infancy.

The lesion may be a round perforating nlcer presumably of embolic origin; multiple follicular ulcerations which are shallow and usually seen in connection with suppurative gastritis; tuberculous ulcers and ulceration in hemorrhagic diseases of the new-born, or congenital ulcer of the stomach. In all cases the lesion is probably dependent upon local devitalized conditions or dyscrasia, such as purpura, hemophilia, leukxmia, scorbutus, septicæmia, and anæmia following the acute infectious fevers. The gastric ulcer of the chlorotic girl is not rare.

The symptoms are frequently obscure, the ulceration being diagnosed at the autopsy. There may be pain and tenderness and the usual symptoms of acute gastritis, but the most important diagnostic signs are blood in the vomitus and dark, tarry stools. If the hemorrhage be considerable, evidences of rapidly developing anæmia may lead to the suspicion of gastric ulcer. In fact, this may be the first intimation of the lesion.

The prognosis is always grave, especially in depraved conditions of the blood, although shallow follicular ulcerations, when diagnosed, are amenable to treatment. There is always immediate danger of fatal hemorrhage. Ulcer in the lower end of the stomach may upon healing lead to cicatrization and pyloric thickening with subsequent stenosis.

As the most important symptom is hemorrhage, gastric ulcer must be diagnosed from hæmatemesis due to other causes. Hemorrhages of the 
new-born are discussed on page 178. Severe and often fatal hemorrhages may occur from capillary oozing from the gastric mucosa in scorbutus, purpura, hemophilia, malaria, and in anumia, or from passive congestion duc to obstructive lesions of the liver, heart, or lungs. Spurious hæmatemesis is very common, due to blood previously swallowed from lesions of the lips, gums, mouth, throat, adenoids in nasopharynx, and from fissures of the nipple. The absence of gastric symptoms and the good condition of the child will help in locating the source of the bleeding.

The treatment for ulcer of the stomach requires absolute rest for that organ, hence rectal alimentation. The child must be kept absolutely quiet by opium if necessary. Small pieces of ice may be swallowed. Bismuth subnitrate or bismuth subgallate may be given in full doses and later nitrate of silver. Stimulants may be necessary if there is much depression and should be given by rectum or hypodermically. The bowels shonld be relieved by high enemata and the ice-bag over the epigastrium may diminish congestion. Reliable preparations of the suprarenal glands in appropriate doses should be administered in all cases of severe gastric hemorrhage from whatever cause.

\section{INTESTINAL COLIC-ENTERALGIA; NEURALGIA ENTERICA.}

Colic in infants usually means abdominal pain, paroxysmal in character, without inflammatory or other changes in the intestines. The colic most frequently seen in young infants is due to irregular contractions of some portions of the bowel, resulting in undue pressure from retained gaseous or liquid contents. Pain may also be due to uric acid crystals and concretions in the renal tubules, pelves, or ureters, and also to vesical spasm. Inflammatory lesions of the peritoneum, appendix, or any portion of the digestive tract, may be the cause of pain. Enteralgia may occur also as a neurosis with no apparent local lesion. So, too, the pain due to thoracic inflammations, as pneumonia or pleurisy, may be referred to the abdomen in young children through involvement of the intercostal nerves. All visceral or abdominal inflammatory lesions may give rise to pain, more or less spasmodic in character. The most common cause of suffering in early infancy is attributable to flatulent distention of the bowel from the fermentation of food and intestinal secretions. Colic occurs in both breast- and bottle-fed babies, and is seen most frequently during the early months, in both well-nourished and marasmic infants, although with greater frequency in the latter.

Intestinal colic is presumably due to some error in diet, either as to quantity or quality of food or as to the methods or frequency of feeding, although an inherent tendency must occasionally share the responsibility, since twins, nourished from the same breast, often show a remarkable difference in this respect. That disturbance in the normal relationship of the constituents of breast milk may affect the nursling is a fact commonly recognized, so that anything which markedly disturbs the mother is likely to produce colic in the child (Chapter IV, Part I). 
Exeess of proteids appears frequently as the offending constituent. This is more often seen in babies fed on cow's milk. Excess of carbohydrates or amylaceous food may induee colic from fermentation of these substances; also exposure to cold and too hasty mursing after an unusually prolonged interval. In some instanees, however, no canse can be traced and the periodieity of eolie under apparently normal conditions, and the faet of its regular recurrence in the early evening, still continues to furnish an unsolved nursery problem.

The evidenees of eolie are unmistakable, although the determination of the cause may tax the diagnostician. Paroxysmal sereaming, rigid, distended abdomen, thighs flexed or alternately flexed and extended, vigorous writhing motions of the body, and cold hands and feet, indieate abdominal pain. If borboryomi are heard, or flatus eseapes from the bowel with evident relief, the disturbance is surely due to intestinal eolic. In a sereaming child, with no evidence of flatus or spasmodic eontraction of the bowel, the physician should seareh long and well before making a diagnosis of intestinal eolie. A peculiarity of eolie as a transient funetional disturbance appears in the entire absence of ill effeets after the paroxysm has subsided.

Treatment.-In the treatment of intestinal colie no effort should be spared to determine, if possible, the eanse. Examination of the mother's milk, observation as to the methods of feeding, careful analysis of all the conditions preceding and attending the attack, and a study of the diapers, may lead to a solution and suggest the means of correction. For the relief of the paroxysm, heat applied to the extremities and over the abdomen, by means of hot-water bottles or Japanese hand-stoves, massage of the abdomen with the warm hand dipped in oil, or the administration of hot earminative drinks to relieve the local spasm and promote the expulsion of flatus, are among the measures most frequently successful. A hot colonic flushing with a few ounces of soapy water, to which a teaspoonful of milk of asafetida has been added, may start the flatus. Frequent administrations, in teaspoonful doses, of water as hot as can be borne by the mouth, to which a little kïmmel, gin, peppermint, or anise has been added, may eause the expulsion of gas and secure relief. Bicarbonate of soda, in one or two grain $(0.065-0.13 \mathrm{Gm}$.) doses, may be given with the carminative. In obstinate eases, a teaspoonful of castor oil or milk of magnesia as a laxative, followed by the earminative, may be neeessary. Two or three drops of aromatie spirits of ammonia or one of Hoffman's anodyne may be given in hot water, with the magnesia. Only in extreme eases should an opiate be resorted to. The best form for this purpose is paregorie, one to five minims $(0.06-0.3 \mathrm{Gm}$.) in hot water.

Intestinal eolic is rarely of grave import, although convulsions have been known to follow a prolonged attaek, and in many instanees the eolie is an early expression of dyspepsia, whieh may result in severe gastroenteritis. Usually, however, the attaeks are amenable to treatment and generally cease after the third or fourth month. 


\section{ACUTE DYSPEPSIA-ACUTE INDIGESTION.}

Dyspepsia is not only the most common disorder of infancy but is more largely responsible for the mortality of the developing period than all other disorders combined. This is particularly true of the early period when the double burden of function and growth taxes the digestive processes to their utmost limit. The most frequent causes of indigestion are improper food or faulty methods of feeding.

The infant at the breast may suffer from changes that affect the mammary secretion, such as improper diet, impaired health, overwork, emotional disturbances, menstruation, and pregnancy. Irregular or overfeeding is a frequent cause of indigestion, as is too rapid nursing from a breast that yields milk freely.

The child's digestive function may be impaired by exposure to extremes of temperature, by shock, excitement, fatigue, or anything which lowers vitality or profoundly affects the nerrous system,- - as the intoxication of the acute infectious diseases. Dyspepsia appears in occasional instances to be hereditary, as some infants show a tendency to digestive disturbance from the most trifling causes. It is a well understood fact that infants at the breast are rarely subject to indigestion of a serious character. The great majority of dyspeptic babies are found among the bottle-fed. That artificial feeding may be regarded as a predisposing cause of indigestion is perfectly rational when we consider the difficulties in the production of a synthetic aliment suitable to the requirements of the infant stomach (Chapters X-XI, Part I) and the greater liability of the bottle-fed to accidental infection.

Among the conditions which affect digestion teething is often emphasized. Certain it is that during dentition disturbed digestion is of more frequent occurrence than prior or subsequent to this period. Undoubtedly numerous other causes operate at this time from which the younger infant is exempt, and to which the more developed digestion of the older child is partly immune. Among these causes are trifling with food not properly in the baby's dietary, increased exposure to draughts and temperature changes which comes with the creeping and toddling age, and the greater opportunity for infection through the mouth,- - that common receptacle for all objects within reach.

In older children as in infants, malhygiene plays the principal etiologic rôle in digestive disturbances. Inappropriate food-as condiments, entrées, rich puddings, pastries, and sweetmeats-is a frequent cause, while overfeeding, too rapid eating, imperfect mastication, and nerve exhaustion are of common occurrence.

The symptoms of acute indigestion include abdominal pain and distention, elevation of temperature $\left(102^{\circ}-104^{\circ} \mathrm{F}\right.$., $39^{\circ}-40^{\circ} \mathrm{C}$. $)$, headache, vomiting, anorexia, diarrhea, thirst, coated tongue, and foul breath. The vomitus is usually acid, ill smelling, and in the infant may consist of masses of solidified casein. The dejections are usually accompanied by foul flatus, and consist of undigested or decomposing food. In some 
children there is marked disturbance of the nervous system, with restlessness, grinding of the teeth, and even delirium. In infants there may be convulsions.

The diagnosis from other acute disorders may frequently be made from the history of dietetic errors and from symptoms pointing to the digestive tract, although it must be borne in mind that the onset of most of the acute infectious diseases is accompanicd by gastro-enteric disturbances. These occasionally act as a determining cause of the graver affections.

The prognosis of acute indigestion is rarely scrious if the condition be met by appropriate treatment. Neglected and maltreated cases may result in visceral inflammations, severe intoxications, and athrepsia.

In treating acute dyspepsia we should assist nature in getting rid of the offending material by prompt emesis and eatharsis, and allow the stomach complete rest by withholding food until the irritation has sub. sided. The fever, pain, and nervous disturbance will usually disappear with thorough evacuation of the bowels. Small doses of ealomel, onefifth to one-tenth grain $(0.013-0.0065 \mathrm{Gm}$.), with sodium bicarbonate onehalf to one-quarter grain $(0.032-0.016 \mathrm{Gm}$.), should be given every hour until six to ten doses have been taken. This should be followed by a saline or a dose of castor oil. If the vomiting is not excessive from the beginning, a full dose of castor oil may be administered at once. Its action, if delayed, should be assisted by enemata of saline solution. If vomiting be severe the stomach should be washed out with a hot, weak solution of bicarbonate of soda and boiled water, ten grains to the ounce (0.65 Gm.-30 C.c). The hot-water bottle or weak mustard paste, applied over the stomach, may be necessary for the relief of pain. The child should be kept in bed and food should be withheld until the subsidence of all acute symptoms, after which the feeding may be cautiously resumed in attenuated form and reduced quantity.

ACUTE ENTERITIS-SUMMER DIARRHCEA.

It is too early to claim that all acute gastro-intestinal disturbances in children are due to toxins introduced through the mouth. It is possible that such a claim may never be substantiated. If, however, the theory of food infection as the prime etiologic factor in enteric disorders be proven valuable as a working hypothesis in their prevention and cure, then it should be accepted until displaced by more positive knowledge. A classification of diarrhœal disorders on the basis of pathologic lesions, however interesting, may well be relegated to the dead-house where alone their character is demonstrable. It is well known that autopsies on children dying of diarrhœal diseases have often been full of surprises to the pathologist, not only in regard to the presence or absence of enteric lesions, but as to their nature, location, and extent. The terms duodenitis, ileitis, colitis and proctitis, singly or hyphenated, with their modifying adjectives-functional, catarrhal, irritative, toxic, infectious, follicular, ulcerative, or membranous-are interesting and useful in describing the 
findings upon the post-mortem table. But since the findings eannot be predicted with any degree of certainty from the history of the disease, a elassification based thereon can hardly be serviceable as a guide to either treatment or prognosis.

By a sort of common consent, acute disorders, with diarrhœa as the principal symptom, which involve the small intestine have been called enteritis, while those of the large intestine are called colitis. In many cases, no doubt, strictly speaking, this would be an unwarrantable use of the suffix, as he is a bold pathologist who claims that all acute enteric disturbances resulting in diarrhoa are inflammatory. That acute intestinal indigestion may result in inflammatory lesions of the bowels there is not the slightest doubt, but no one can determine the exact time at which the inflammatory process begins. It is fairly safe to assert that almost all acute inflammations of the intestines begin with indigestion, and many diagnosticians are eontent to employ the suffix only after the third day of continued fever and diarrhœa.

As before stated, gastric and intestinal indigestion cannot clinically be disassociated, although the preponderance of the symptoms may point more decidedly to one or the other condition. Most frequently, however, gastric indigestion precedes that of the bowel, and the clinical picture is familiar in which a gastro-entero-colitis begins with vomiting and ends with dysentery.

Etiology.-The etiology of acute indigestion has been made to include eongenital predisposition, infancy; and summer heat among its predisposing causes. Improper feeding, infections, and sudden refrigeration are some of the exciting causes. Undoubtedly, feeble action of the digestive seeretion is peculiar to some children, whether as an inherited or acquired dyscrasia. Such children are brought through the nursing period with the greatest difficulty. The clinical histories show a continuous struggle in the adaptation of their food to a feeble digestive function.

The claim that normal infancy predisposes to indigestion is unfair to the infant. That his helplessness renders him peculiarly susceptible to neglect, is self-evident; so also is his feeble resistance to infections to which he may be carelessly exposed. Prolonged summer heat, which was formerly regarded as the principal exeiting cause of digestive disturbance, is now allowed to rank among the principal predisposing causes. Endless statistics are available to show the prevalence of diarrheal disorders in the summer months. Prolonged excessive heat (over $80^{\circ}$ F., $26.6^{\circ}$ C.), with humidity, inhibit digestion so that the amount of fats and proteids easily disposed of during temperate weather, may overwhelm the digestive function during the hottest days of summer. Again, the heated term is precarious to the neglected infant because of the luxuriant growth of pathogenic micro-organisms, and the increased contamination and rapid decomposition of food with the production of dangerous toxins.

That errors in feeding are the prime cause of indigestion is widely 
in evidence. These errors may be divided into two principal classes, first, in the method of feeding, and second, in the quality of food. 'To the first class belong those disorders in which a normal food may cause disturbance by overingestion, or by irregularity in feeding. 'T'o this class belongs the majority of disturbances in infants who nurse at the breast. A good illustration is seen in the overingestion of normal breast milk during the hot days of summer, when the caloric requirements of infant metabolism would suggest a reduction in both fats and proteids. The increased demand for water, to make good the deficiency caused by perspiration, draws the infant to the breast as its only known means of supply. The thirst, already increased by beginning indigestion, is met with an increased ingestion of unrequired food to the further detriment of the overworked digestive function. Thus a vicious circle is established which soon results in fermentative changes in the infant's prima via from digestive incompetency. Irregular feeding means overfeeding, and develops the factors of impaired lactation, as well as impairment of the infant's gastric and duodenal secretions (Chapter VI, Part I). The frequency of indigestion among the breast-fed, however, is insignificant compared with its prevalence among the bottle-fed. The dangers that lurk in artificial feeding have not only to do with the amount and method of ingestion, but are in close relation to the unsuitability of the food, and to an added and most prolific source of danger,namely, the increased liability to infections, not only from accidental contamination, but from fermentative changes due to resident milk bacteria and also from their toxins.

The disturbances due to candies, sweetmeats, unripe and inappropriate fruits, and to other dietetic errors of childhood, are too familiar to need mention. The possibility of introducing infectious material and irritant poisons in this way adds greatly to the dangers of indiscriminate feeding in older children.

Exposure to cold may precipitate an attack of acute indigestion, in the absence of any apparent error in diet, probably through changes in the quality or quantity of the digestive fluids from disturbed circulation. Fatigue, excitement and shock may interfere with the digestive process, with resultant vomiting or diarrhœa.

The chemico-physies of perverted digestion is too obseure to warrant dogmatic deseription of its functional pathology. Broadly stated, where the normal changes in the food are incomplete or long delayed, fermentative processes may supervene with the production of substances and gases which irritate the intestinal mucosa and cause an outpouring of mucus with increased peristalsis. Putrefactive changes in the residuum of undigested food may evolve toxic products which are not only local irritants but which, by absorption into the circulation, may produce general symptoms of profound disturbance. It is usually held that the diarrhœa and vomiting which commonly accompany acute indigestion are conservative processes through which nature seeks relief from the offending material. 
Symptoms.-Besides the vomiting and diarrhœe there may be fever, $102^{\circ}$ to $105^{\circ} \mathrm{F}$. $\left(39^{\circ}-40.5^{\circ}\right.$ C. $)$, rapid pulse, headache, anorexia, thirst, coated tongue, and colicky pains. Tenesmus frequently accompanies the exaggerated peristalsis which, with increased secretions, contributes to the diarrhœa. In infants the prostration is marked, as shown by the drawn, pallid features, and general museular weakness. The urine is scanty in proportion to the loss of fluids from the bowel, and may contain albumin and occasionally hyaline and fine granular casts. Bile may stain the urine, if the catarrhal condition involve the duodenum from occlusion of the common duct, in which case icterus is present. In mild attacks there is restlessness, disturbed sleep, and night terrors. In more severe intoxication there may be delirium and convulsions or coma with death, a not rare termination in delicate infants.

The diarrhœa may not be marked at first-in fact, there may be constipation with the initial vomiting-but the movements soon increase in frequency and follow closely the ingestion of food, numbering from four to twelve a day. As the disease progresses the vomiting may diminish or subside unless excited by injudicious feeding. At first the stools may differ from the normal only in being more liquid and abundant and in their offensive odor. They change as the indigestion continues, varying in consistency and color which, in infants, usually becomes green with whitish or yellowish curds and particles of tongh casein resembling broken kernels of sweet corn. Tufts of mucus and soapy fats may be mixed with the "chopped-spinach" stools, or the movements may be slimy, watery, or yeasty from the gases of fermentation. Their acid character causes tenesmus and pain, which is relieved by the evacuation, while intertrigo and excoriation of the buttocks may result. Fatty acids may be present. The microscope may show numbers of intestinal bacteria and, if cereals enter into the food, the iodine-test will give the blue reaction of starch. The green stools of infancy, due to the chromogenic bacillus (Lesage), are decolorized by the addition of a drop of nitric acid. When this color, however, is due to biliary salts, the green changes to pink, purpie, or violet on the addition of the acid. Green stools are rarely seen in children after the third year.

The prognosis in mild attacks of acute indigestion under favorable conditions, if treated early, is good, but so much depends upon the environment, the stage of the disorder, thermic and atmospheric conditions, age of the child and the possibility of virulent bacteria having invaded the mucosa through erosions of the epithelium, that the prognosis should be guarded. Infants at the breast respond so much more readily to corrective measures than do those brought up on the bottle, that the difference in tractability is equivalent to two different types of disease.

Treatment.-Two indications are paramount. First, stop the feeding; sccond, clean out the prima via. A full dose of castor oil may be given, or if not tolerated, ealomel, one-fifth to one-half a grain (0.013$0.032 \mathrm{Gm}$.), with soda bicarbonate, one-half to two grains (0.032-0.13 $\mathrm{Gm}$.), may be given every hour for four or five hours, after which one- 
half to one-quarter of that amount may be given every hour or two and continued at lengthening intervals for a day or two. Ordinary eases of indigestion will yield to this simple treatment. For the food, water must be substituted for twenty-four hours, after which nu'sing may be resumed with strict attention to hygiene. If bottle-fed, the strength of the food must be reduced by the addition of water or cereal gruel. The errors in diet or method of feeding responsible for the attack must be sought for and corrected, and the mother or nurse thoroughly instructed in the essential details of aseptic hywiene. (Chapter XII, Part I.)

Instead of recovery in response to withdrawal of food and eleaning out of the bowels, vomiting, fever and diarrhua may persist, the stools becoming watery and frequent, with particles of undigested food or flakes of casein. They may be fetid and musty, or stimy and odorless, with pinkish flecks or gouts of brighter blood. The abdomen is retracted or distended, the tissues flabby from loss of adipose and from muscular weakness. There may be cervical rigidity, head-rocking, exaggerated reflexes, strabismus or semicoma, suggestive of meningitis. The infant may be fretful or apathetic. The dry month, pallid skin, pinched features, hollow orbits, and depressed fontanelle with the foregoing symptoms point to acute gastro-intestinal infection, in the perpetnation of whieh bacteria play an important rôle regardless of the primary eause of the disturbance. That the bacteria, pre-existent in the bowel, rapidly multiply and assume virulent pathogenic activity under conditions rendered favorable by indigestion, there is every reason to believe. Solutions of continuity of the epithelium allow entrance to the mucosa for these organisms and their toxins, which thence find their way into the lymph channels and blood-vessels. They even invade remote organs and tissues with resulting lesions peculiar to the location, such as pneumonia, pleurisy, endocarditis, meningitis, or extensive adenitis of the mesentery and lymph-nodes of the gut itself. A variety of resident organisms may become virulent and assume pathogenic activity under these circumstances, such as the streptococcus and members of the coli group, while the cascin ferments-such as the bacillus subtilis, bacillus mesentericus, and tyrotrix tenuis-are found only in the stools of infants fed on cow's milk. Such infections have been called endogenous, and probably to this class belong those disturbances ascribed to autoinfection, lithæmia, etc., which occur sporadically without apparent dietetic error or other explainable cause.

In contrast to the above are ectogenous infections, of which cow's milk is the most prolific source. In addition to the bacterial content, old milk may convey a poison (tyrotoxicon) which is capable of causing the most violent forms of intoxication, and against which, when once formed in milk, no amount of sterilization will avail. Many kinds of bacteria or their toxins gain ingress from without and induce or contribute to gastro-enteric morbidity,-as the proteus vulgaris, streptococcus, peptonizing bacteria, bacillus pyocyaneus, colon bacillus, staphylococeus, and many varieties of saprophytic organisms. A variety of recently 
isolated organisms, closely identified with the bacillus dysenteriæ of Shiga, have claimants for the elief etiologic rôle in the enteritides of children, but thus far their eonstant presence has not been demonstrated nor is the type of symptoms or lesions constant with which they are assoeiated. Whatever the future may reveal, for the present, at least, the etiology of summer diarrhoea in its protean forms and lesions, must be regarded as multiplex and more or less obseure as to the true relationship of its numerous factors.

Indigestion, feeble resistance, contaminated food, and hot weather, are recognized eauses in sporadie enteritis, while its prevalence in epidemic form in families and tenement-houses, and in institutions where large numbers of ehildren are in close relation, savors strongly of contact transmission of the morbific agents, quite suggestive of the manner of typhoid fever transmission.

From the lesions found post-mortem it is evident that no portion of the gastro-enteric mucosa is exempt, although the most vulnerable areas below the stomach are the lower ileum and the colon,- -hence the term entero-colitis, as generally applied.

Even in severe cases of short duration there may be only a general hypersmia of the mucosa not at all proportionate to the severity of the symptoms. In prolonged enteritis erosions of the mueous membrane and many minute hemorrhages are usually seen, and the solitary follieles and Peyer's patches may show extensive hyperplasia or even ulceration. Exceptionally nleerative lesions occur early (Fig. 136), but as before stated, there is no constant relation between the severity of the symptoms, their duration, and the anatomical lesions of the bowels.

Pseudomembranous lesions are oecasionally found, consisting of inflammatory exudate, epithelium, blood-cells and bacteria. These membranes oceur in circumseribed patches, or may cover a considerable portion of the ileocolie mueosa to which it is firmly adherent. Beneath the pseudomembrane the inflammation may involve the entire structure of the bowel, and even appear as a circumseribed exudate on the peritoneal surface.

Diagnosis.-The diagnosis of gastro-enteritis must be made from the mode of onset and history of symptoms, but mainly from the character of the stools. From the aeute exanthems, pneumonia, or influenza whieh are frequently ushered in by vomiting and diarrhœa, a positive diagnosis must often wait upon the development of characteristic signs or the eruptions of the specific disease. It should be borne in mind that pneumonia is a frequent eomplication of a later stage of entero-colitis. Usually, however, the gastro-enteric disturbance subsides as the infection develops, to which it is secondary. Typhoid fever, in the atypical forms occasionally eneountered in infancy, may present many diffieulties. Usually the vomiting is less persistent in proportion to the high temperature which in children may attend the onset of that disease, and the common aceompaniment of enlarged spleen and liver may aid in differentiation before the time for rose spots and Widal reaction. The 


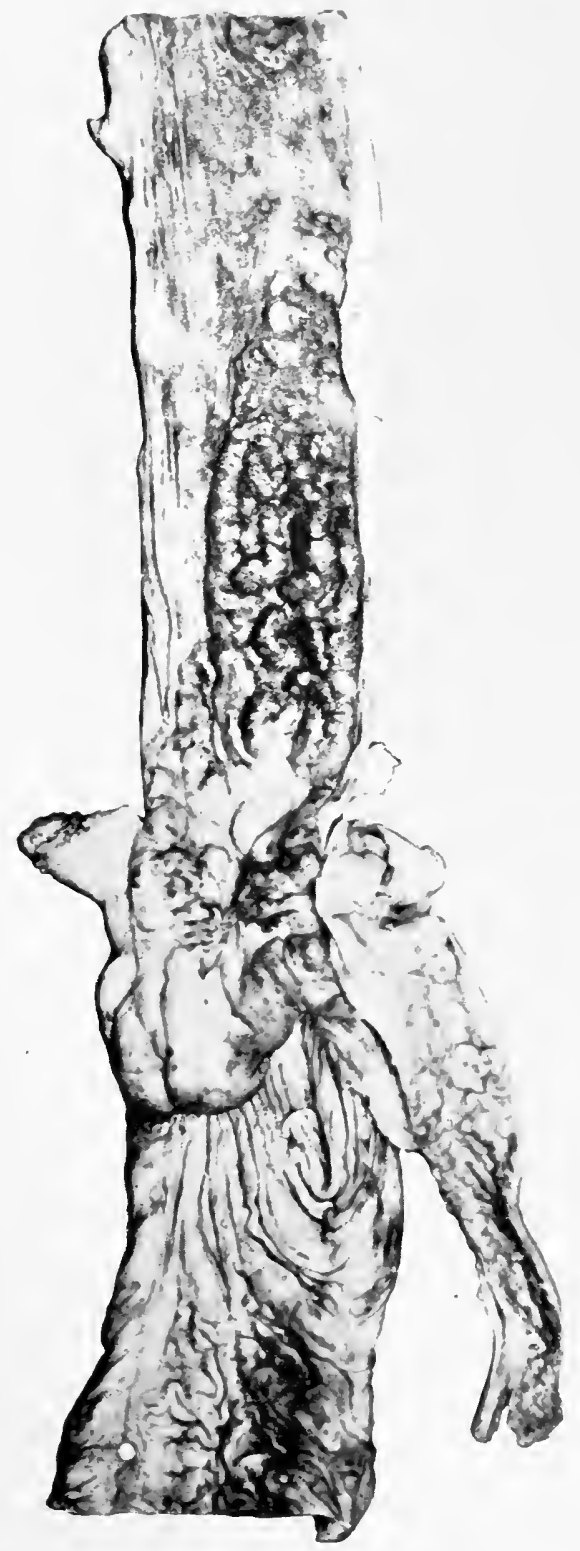

Fig. 136-Ulceration of Pever's patch. Infant of 14 months. Death on the fourth day, with symptoms of meningitis. Brain negative. 

cerebral and nervous symptoms of acute gastro-enteric disease may so closely simulate meningitis as to delay positive diagnosis for several days. Indeed, the post-mortem demonstration of intestinal lesions in children dying from a supposed meningitis is not of rare occurrence (Fig. 136). A complete history of the case rarely shows bulging of the fontanelle in entero-colitis, and constipation, rather than diarrhera, is the rule in meningitis. The encephaloid symptoms, frequently seen towards the termination of fatal colitis, are usually due to cerebral ancmia which the condition of the fontanelle and an examination of the ocular fundus should confirm.

Entero-colitis is occasionally mistaken for intussusception of the bowel. The absence of pyrexia in the early stage, marked prostration, severe paroxysmal pain, early mucoid bloody stools free from fecal matter and, above all, the presence of a tumor, nsually in the left iliac region, should render the diagnosis of intussusception plain.

Prognosis.-The prognosis in acute gastro-enteric disorders should always be guarded. The age of the patient, the method of feeding, whether natural or artificial, previous physical condition, the stage of the disease when first seen, the season of the year, the lyygiene of the environment, the intelligence of the nurse, and the apparent exciting cause,-all must be taken into consideration as important factors in the tractability of the disease. Some children exhibit from the beginning unmistakable evidences of a virulent type of infection, as in the socalled cholera infantum. Exacerbations of temperature, after the subsidence of acute early symptoms, should always be regarded with apprehension as reinfection is frequent, even during convalescence. The progressive character of enteric disorders must always be kept in mind and the possibility of the supervention of follicular, ulcerative and membranous lesions upon an apparently mild case of indigestion should keep prognostication in abeyance. The symptoms of acute entero-colitis may subside with proper treatment in from five to ten days, but more frequently the diarrhoea will be prolonged into the third week.

Treatment.-The treatment must fully meet three indications : first, to remove the cause; second, to counteract the effects; and, third, to maintain strength. Although the immediate cause may be obscure, indigestion is so intimately connected with the perpetuation of the morbid process that food must be immediately withdrawn, even though it may not contain the primary morbific agent. The possibility of increased infection through substances introduced into the mouth is so great that, in the words of Cromby, one must "stand guard before the digestive tube." All the predisposing and contributing influences must receive attention. Torrid summer heat should call for immediate removal of the child, when possible, to the sea-shore, lake-side, or mountains. For the children of unsanitary homes and congested districts, many of our great cities have public parks, floating hospitals, and sanatoria on piers, where the heat is tempered by large bodies of water and the air is pure. The depressing effects of atmospheric heat may be somewhat 
ameliorated by lowering the temperature of the sick-room by a generous use of tubs of broken ice and the play of electric fans, when better means are not available.

The danger of reinfection should lead to a conscientious care of all discharges. Soiled napkins and clothes should be immediately placed in a can with a tight cover, until inspected by the physician. After this they should be placed in some disinfecting solution, as bichloride of mercury, $1: 2000$, before washing and boiling. Flies must be excluded by screens at windows and doors, and netting over the baby-carriage. As a rule, the open air is preferable throughout the day. All water used about the patient should be sterilized and the source of ice should be above suspicion. Much infected and infectious material in the prima via may be removed by free catharsis, lavage and colonic flushing. These should be immediately resorted to, first, by the administration of a full dose of eastor oil which, if not well borne by the stomach, may be replaced by calomel, one-tenth to one-fourth grain $(0.0065-0.016 \mathrm{Gm}$.) with sodium bicarbonate, one to two grains $(0.065-0.13 \mathrm{Gm}$.), given every hour or oftener for from six to ten doses, after which the quantity may be reduced and the interval lengthened according to the amelioration of the symptoms and the character of the stools. The stomach, especially if vomiting persists, may be washed out with sterilized water or weak boric acid or bicarbonate of soda solution, one drachm to the pint ( $4 \mathrm{Gm}$.$1 / 2$ litre), once or twice in the twenty-four hours. Frequently one or two washings will suffice. In older children, where the introduction of the tube is impracticable, copious draughts of warm sterilized water containing sodium bicarbonate may be given, thus cleansing the stomach by emesis. IIigh colonic flushing not only rids the lower bowel of irritating and infectious material, lessening the danger of early lesions of the mucosa, but induces a free discharge of the contents of the small intestines, thus diminishing the intoxication from absorption. When we consider the acrid character of the alvine discharges, as seen in their effects upon the unbroken integument about the anus and buttocks, the rôle played by this agency in causing erosions of the intestinal mucosa (the most serious lesions of enterocolitis), is so apparent that the value of colonic flushing needs no further emphasis. The water used for this purpose may be simply sterilized or contain boric acid or bicarbonate of sodium and should be used copiously. From two to six pints (1-3 litres), once to thrice daily, may not be too much in the early stage of a severe case. Besides its detergent effect, enteroclysis satisfies the demand of the tissues for water, so necessary in the depletion of the body fluid by diarrhoea. Again, the increased metabolism of intoxication, with diminished normal alimentation, quickly develops a paucity of alkali in the circulating fluids and a condition of subalkalinity unfavorable to constructive metamorphosis supervenes. Hence the need of sodium chloride and sodium bicarbonate by enteroclysis.

The results of efforts to neutralize the infection of the alimentary tract by drugs do not warrant their extensive use, although empiricism 
and theoretical reasoning have furnished a host of agents for this purpose and many eminent practitioners still eling to their salol, resolein, naphthol, salieylates, sulphoearbolates, and similar preparations. Next to ealomel, which, undoubtedly, has some antiseptic value, bismuth subnitrate, subearbonate, or subgallate has been found valuable in diminishing irritability of the gastro-intestinal tract. After positive assurance of its freedom from arsenie, bismuth in doses of from three to ten grains $(0.2-0.65 \mathrm{Gm}$.), aeeording to age, should be given every half hour until the mueosa is thoroughly coated with the drug. This may be inclicated by the appearanee of black powder in the stools.

For fever and restlessness tepid sponging should be employed. A little alcohol may be added to the water for its refrigerant effect. If there be mueh cerebral excitement an ice-eap may be employed, and if convulsions threaten, bromide of sodium, five to ten grains $(0.3-0.65$ Gm.), with possibly the addition of two to five grains $(0.13-0.3 \mathrm{Gm}$.) of ehloral in an ounee ( 30 C.e.) of water may be administered per reetum, after the return of a colonic flushing, where it should be retained by pressure on the anus until absorbed. With high temperature and cold extremities, sinapisms should be applied to the hands and feet. For severe colic and exaggerated peristalsis, opinm is invaluable but must be used with great eaution and never until the eontents of the intestinal traet have been thoroughly evaeuated. Mneh harm will follow the too early or injudieious use of this drug, and great benefit may acerne from its justifiable exhibition. It should rarely be given by month and never in combination with other agents. Administration by reetum in half an ounee (15 C.e.) of boiled stareh, after a thorough eleansing of the bowel, is the most eligible method. The dose of the tinetura opii deodorata may be from one to two minims $(0.065-0.13 \mathrm{Gm}$.) to a ehild of one year and may be repeated every two hours until the tormenting tenesmus is quieted. No greater error obtains than misgnided efforts to "cork up" the bowels. The safety of the patient depends upon free evaeuation, henee in early eessation of diarrhøal movements, with eontinued symptoms of intoxieation, small doses of eastor oil or oft-repeated doses of calomel should be resumed to secure bowel movements.

A mistake too frequently made is that of treating the diarrhœa and forgetting the patient. The prostration and inanition eonsequent upon general infeetion and arrested assimilation eall for early supporting measures and nutrition must be maintained. In severe eases feeding by the mouth is worse than useless, as digestion is inhibited and the aliment but furnishes material for fermentation and bacterial growth. Water only should be given by the mouth for the first twenty-four hours or for a longer period, if necessary. Nutrient enemata may be administered once in three or four hours, preferably after a movement and always after a colonic flushing, and should be retained by pressure on the anus. With the subsidence of vomiting and improvement in the dejeetions, feeding by the mouth may be attempted, first with albumin-water to which a little salt is added, or barley-water followed by oatmeal-gruel thor- 
oughly cooked and strained, and partly dextrinized by the addition of a teaspoonful of malt extract to every four ounces. The quantity at first must be very small-from one to three teaspoonfuls every hour-and may be gradually increased with lengthening intervals according to toleration. Later, sterilized whey may be added, but milk should be withheld until convalescence is well established and then given only in attenuated modifications. These children require watching during the rest of the summer and may not be able to resume milk diet during that time. The common error lies in the too early return to milk feeding. Good cereal preparations afford their greatest service as substitutes for milk in these cases. In breast-fed infants the mammary secretion should be maintained by a regular use of the breast pump during the enforced fast, and a return to normal feeding in these cases may with safety be made much earlier than in the bottle-fed class. Care is necessary that the nursling be not returned to full diet at first. Water should be substituted before nursing for at least half the meal for a few days. The act of suckling should be prolonged by interruption and compression of the nipple, so that the food be slowly ingested. The remainder in the breast should be withdrawn by a pump.

The diet of older children in convalescence should consist principally of cereal gruels, partly dextrinized by thorough cooking and the addition of malt extract, the better class of proprietary foods, small amounts of expressed raw meat juice, and soft-boiled or poached eggs. Toast or zwieback may be added. Fruits and vegetables must be avoided during hot weather, although baked potatoes and well boiled rice may be given. Meats should be interdicted, and milk, even thoroughly sterilized, must be used with great caution during the hot weather, or until full recovery.

If the atttack be prolonged, great prostration may ensue with weak and irregular heart action and threatened collapse. In this case stimulants are indicated. Brandy, both as a stimulant and a food, is the most eligible and may be given in doses of five to twenty drops, according to age, diluted with eight to ten times the amount of water. If contraindicated, or vomiting is induced, the brandy or its equivalent in cologne spirits may be given per rectum or hypodermically, although by the latter means only in extreme cases.

Hypodermoclysis of normal salt solution may sustain the heart when absorption from the bowel is deficient. From four to six drachms (1523 C.c.), to which from one-fourth to one-half of a grain (0.016-0.032 Gm.) of caffeine citrate is added, may be given to a young infant at one injection.

In mucoid or bloody stools, indicative of extensive lesion of the lower bowel, weak solutions of tannic acid may be introduced through the long tube, or an emulsion of subgallate of bismuth, two or three drachms (7.5-11.5 C.c.) to as many ounces (60-90 C.c.) of mucilage of acacia may be administered in the same way every three or four hours, if necessary. 
CHOLERA INFANTUM.

A form of acute intestinal intoxication, although nosologically belonging with the acute infectious diseases, is taken up here because of its intimate clinical association with gastro-enteritis. The diflerentiation between cholera infantum and severe cases of gastro-enteritis is not always clear. The diagnosis quite frequently depends upon the early fatality. Much difference of opinion prevails as to the frequency of cholera infantum and the percentage of its mortality. A most eminent American pediatrician recently declared in a public lecture that he had met with but three undoubted eases, all of which were fatal, while another equally eminent authority in an adjoining city speals of cholera infantum as not of such rare occurrence and places the mortality at 66 per cent. The etiology of the disease is still unknown, although it occasionally develops during the course of enterocolitis. It may be preceded by a mild attack of indigestion, or may occur in an infant apparently in the best of health. Cholera infantum is undoubtedly an acute infectious disease producing early and pronounced systemic intoxication, with vomiting and diarrhœa as the chief and constant symptoms. Its etiology is intimately associated with milk feeding and hot weather. Babies nourished exclusively at the breast seem to be exempt.

Symptoms and Course.-The onset is usually abrupt, beginning with vomiting which is persistent, and fever which may reach $10: 3^{\circ}$ to $107^{\circ} \mathrm{F}$. $\left(39.5^{\circ}-41.5^{\circ}\right.$ C. $)$ in the rectum, accompanied or followed in a few hours by choleraic diarrhœa, which rapidly drains the body of fluids. After the first few movements the copious stools are little more than colored serum which the napkin absorbs like urine and gives off first a putrefactive and later a musty odor. From the first the prostration is profound, with rapid emaciation, so that in a few hours a plump infant may show the pinched, pallid features, lustreless, sunken eyes with rapidly gathering film, drawn mouth, depressed fontanelle and overriding bones of profound collapse. The extremities and superficies are cold and corpse-like, while the thermometer in the rectum registers a temperature of $107^{\circ} \mathrm{F}$. $\left(41.5^{\circ}\right.$ C.). The abdomen becomes flattened: the respiration shallow and sighing, or it may assume the Cheyne-Stokes type; the feeble cry is reduced to a whine or moan, while apathy deepens into fatal coma, and death may occur with or without convulsions, frequently within twenty-four hours from the beginning of the attack. Occasionally death is postponed for two or three days, and rarely a case recovers.

Pathology.-Post-mortem examinations show no anatomic lesions sufficient to explain the severity of the symptoms. The gastro-enteric mucosa is hyperæmic, with minute hemorrhages and areas denuded of epithelium. The liver may show slight fatty degeneration. The kidneys and heart present beginning degenerative changes, and the lungs show areas of collapse and hypostatic pneumonia in the dependent portions. The blood in the vessels is inspissated and shows tardy coagulability. 
During life the erythrocytes may reach seven millions or even eight millions per C.c., and there is usually a disproportionate leucocytosis, occasionally amounting to eighty thousand per C.c., with a high percentage of polymorphonuclear neutrophiles. The picture is not only one of extreme oligxmia sicca, but also of a virulent systemic intoxication with cardiac depression and paralysis of the vasomotor nerve-centres resulting in local congestions and transudation of serum into the intestines.

Treatment.-The sudden onset and rapid progress of cholera infantum leaves but little time for the employment of remedial measures, frequently successful in gastro-intestinal intoxication of milder type. In cases which develop more gradually as in those preceded by acute gastroenteric indigestion, early treatment as outlined in the preceding pages, it is believed, might avert the more severe effects by early elimination of the morbific agent. The indications for treatment in addition to those given under ACUTE GASTRO-ENTERITIS, are, first, to counteract the profound depression; second, to overcome the tendency to blood concentration by increasing the volume of the fluids in the body. The question of food in the first forty-eight hours is immaterial, as no digestion or assimilation is possible in the disturbed state of the circulation. Brandy should be administered from the beginning, or small doses of iced champagne. Absorption from the stomach and intestines is questionable, and the more efficient method is by hypodermic injection. Digitalin and citrate of cafteine may be given in the same way to sustain the heart. In the algid state the empty superficial vessels and failing pulse would suggest the use of nitroglycerin, which should be frequently repeated in doses of from one two-hundredth to one one-hundredth of a grain $(0.0003-0.00065 \mathrm{Gm}$.$) . One-fiftieth to one one-hundredth of a grain$ $(0.0013-0.00065 \mathrm{Gm}$.) morphine with atropine, one five-hundredth to one one-thousandth $(0.00013-0.00006 \mathrm{Gm}$.) for a child of one year, hypodermically, is considered the most valuable therapeutic agent. This may be repeated every hour or two for the relief of vomiting and purging and to sustain the action of the heart. Stupor or coma contraindicates the use of opium. The similarity of the symptoms between choleriform intoxication and those which follow ablation or sudden functional arrest of the suprarenal glands has led to the suggestion of the employment of the suprarenal extract in cholera infantum. In view of the desperate character and high mortality of this disease, the tentative employment of this agent seems justifiable.

Of equal importance to the need of stimulation is the demand for water in the drained tissues. Ice-water in small quantities should be given frequently by mouth. Enteroclysis of sterilized water containing sodium bicarbonate and chloride, each a drachm to the quart $(4 \mathrm{Gm}$. to the litre), should be freely employed. Hypodermoelysis of normal salt solution from four to six drachms (15-22.5 C.c.) should be given every one or two hours, depending upon the frequency of the alvine discharges. Hot baths or packs are indicated in the algid state to promote 
superficial circulation. This may be aided by sinapisms applied to the extremities.

\section{CHRONIC GASTRITIS-CHRONIC GASTRIC CATARRH; CHRONIC DYSPEPSL.}

Following an attack of acute gastritis that has been indifferently treated or allowed to relapse from neglect of dietary precautions, a subacute or chronic dyspepsia may develop. This condition may also develop insidiously in babies whose food is faulty, as in the continued excess of some constituent, such as fat. In older children repeated slight violations of dietary hygiene may gradually lead up to an inadequacy of gastric function so that by degrees the incomplete digestion results in products which are irritative.

A catarrhal condition of the mucosa follows with not only interference in the secretion of normal digestive fluids but with fermentative changes in the excess of mucus thus produced. Congestion, both active and passive, in the vessels of the mucosa favors the morbid process until structural alterations are seen, such as cellular infiltration, obliteration of glandular structures, and occlusion of tubules. Occasionally, though rarely in infancy, there may be increase in the interstitial tissue so that the gastric mucosa presents some fibrosis, a chronic adenitis and an advanced catarrhal condition, marked by excess of mucus. There is atrophy of the muscular structures and frequently dilatation of the stomach, due to continued pressure from aceumulations of food, mucus and the gases of fermentation. It is impossible to conceive of chronic gastric dyspepsia without intestinal disturbances and, in fact, elinically the two conditions are always associated, the latter as a natural sequence of the former. The symptoms of chronic gastritis do not always point directly to the stomach. Rhachitis or atrophy in the infant, also arrested development, physical weakness and anæmia in the older child, may first attract attention. Usually, however, symptoms of indigestion are present, such as coated tongue, foul breath, eructations of gas, pyrosis, nausea, and vomiting after meals, or acid mucus vomiting in the morning. Colic in the infant and gastric distress in older children are sometimes relieved by eating. Occasionally cough may cause a suspicion of lung trouble. Restlessness, loss of sleep, and eapricious or inordinate appetite, may lead to the diagnosis of intestinal worms. Constipation with abdominal distention, borborygmi and flatulence from foulsmelling gas, is common in older children. Dilatation of the stomach may occur, especially in rhachitic children and in infants who are habitually overfed.

The upper border of the stomach remaining fixed, constant dragging may cause gastroptosis, so that the greater curvature may be found far to the left, and extending below the level of the umbilicus. In this sacculated form the viscus cannot readily empty itself through the pylorus. The food is long retained, undergoing fermentative changes until relieved by emesis. The symptoms of dilatation, aside from those of chronic indigestion, are an increased area of tympany on percussion-which 
must be distinguished from distention of the transverse colon-and occasional vomiting of a large quantity of fluid and partly-digested food. The capacity of the stomach may be determined by measuring the water siphoned out through the tube after filling the organ.

Prognosis.-The prognosis in early infancy is bad on account of the tendency to marasmus and, in the summer months, to acute fatal enteritis. In older children the disorder may continue indefinitely or may be cut short by fatal intercurrent disease, against which these children show little resistance. Judicious management, begun early, will do much to relieve this condition and a cure may be expected in the majority of cases.

Treatment.-An important part of the treatment consists in securing the intelligent co-operation of parents and nurse, since the regulation of the diet as to quality, also as to the frequency and method of feeding, is absolutely essential. The stomach should be washed out daily with warm sterile water, to which, if much fermentation be present, sodium bicarbonate or Seiler's solution may be added. The food for infants should at first be moderate in quantity and contain low percentages of fat, proteids and carbohydrates. Regular intervals of from two to three hours must be observed. As the stomach recovers its tone the quantity and percentages may be gradually increased. Occasionally gruels of dextrinized cereals are better tolerated than the most carefully modified milk, and may be temporarily substituted. Older children who resist lavage may be compelled to drink daily copiously of warm soda solution, if possible, to the production of emesis, not only to relieve the stomach of food remnants but to dissolve and remove the tenacious mucus which clings to its walls, interfering with the action of the digestive secretions. The use of the alkalies in these cases is not so much to neutralize the hyperacidity as to dissolve the viscid mucus which accompanies the catarrhal inflammation.

The diet must be restricted to plain and easily digested articles of food. Condiments, much meat, eandies, and pastry, should be rigidly excluded. Fruits should be stewed and cereals thoroughly cooked. No hard and fast rules for diet can be laid down, but careful observation is necessary that each case be fed according to its special requirements.

In infants, as well as in children, the tincture of nux vomica is valuable as a stomachic tonic. It stimulates the normal gastric secretion and improves peristalsis by toning up the muscular structures. Full doses act best in the majority of eases; two minims (0.12 C.c.) for each year of age, properly diluted, may be given four times daily, preferably before feeding. If the tongue remain coated and breath foul, dilute hydrochloric acid, in similar doses, should be given after food. Anæmic children may require iron, of which the organic preparations are preferable, althongh the tincture of the chloride may be substituted for the hydrochloric acid with good advantage. In marasmic babies and extremely delicate children with weak hearts, daily massage with inunctions of absorbable fats may help out the exercise and feeding. 
The value of sunlight, fresh air, and moderate exercise can not be overestimated, and a change of climate is frequently of great service.

\section{AMEBIC DYSENTERY.}

A form of colitis due to the amoba coli, and known as one of the varieties of tropical dysentery, is only occasionally met with in the northern portions of the United States. Although many returned soldier's from the Philippines, since the Spanish-American war, were found to be suffering from amœbic colitis, but few cases of this disease have been reported in children. With the widesprearl impetus to the bacterial examination of the diarrhoal dejecta, given by the Shiga-Flexner investigations, the paucity of reported findings of the amoeba coli would seem to disprove the claim, recently made, for a wider prevalence of this form of colitis in children.

From the reported cases there is apparently but little difference between the amœbic colitis and that due to other causes, with perhaps the exception of a lower range of temperature and a more marked tendency to chronicity of the former disease. Like the amobic dysentery of adults, the onset may be acnte and terminate fatally in two or three weeks. Usually, however, the acute onset subsides to a subacute course, with periods of remission and with alternating constipation and diarrhœa. The stools contain mueus and oecasionally blood. If the child survive the acute attack he becomes emaciated and weak and finally dies from exhaustion or succumbs to some intercurrent disease. Occasionally cases seemingly recover, but the usual course is prolonged and obstinate, with a recurrence of the symptoms after the slightest dietetic error.

A common lesion of chronic amœbic colitis is the formation of ulcers in the colon and rectum. A characteristic of these ulcers is that they undermine the mucosa and may burrow in the submucous tissues; whereas, the lesions of the ordinary ulcerative colitis are shallow and superficially situated upon the ridges of the mucous membrane. In children, abscesses of the liver and other viscera, common to the amœbic colitis of adults, are seldom found.

The diagnosis from other forms of colitis is made from the presence of amœbas in the bowel movements.

Aside from tonies and a diet of predigested foods, the special treatment of a case of amcbic dysentery consists in enemata of quinine, in solutions varying in strength from $1: 5000$ to $1: 250$, for the purpose of destroying the amœba.

\section{INCONTINENCE OF FACES.}

Incontinence of fæces is a common symptom in transverse myelitis or in paraplegic conditions from injury to the lumbar spine. Loss of the control of the sphincter is occasionally seen in adynamic nervous condition and is common in the resultant prostration of acute or chronic disease, such as typhoid fever, pneumonia, or tuberculosis. Obstinate 
constipation with fecal impaction of the rectum, may result in sphincter incompetency from overstretching. In such cases the tone is usually recovered in a few days after the removal of the cause.

The treatment of this condition, aside from that of the disease upon which it depends, includes the use of nux vomica or strychnia, with or without belladonna. Iron is indicated in the anxmia, preferably the tincture of the chloride, which may be given well diluted in doses of from two to ten minims ( $0.12-0.6$ C.c.) three times a day. When constipation exists such purgatives as aloes may be added. In certain neurotic children with atony of the sphincter ani, fluid extract of ergot in doses of five to fifteen minims (0.3-0.9 C.c.) three times a day may be found useful.

\section{CONSTIPATION.}

Many causes have been assigned for the obstinate constipation so frequently encountered in infancy and childhood. Certain anatomical and physiological conditions are contributory. Among the former are (1) the transitional developmental state of the intestine, seen in the movable cxeum; (2) the relatively long descending colon, the enormous erratic loop of the sigmoid, and the redundant rectum, most of which lies above the pelvic brim; (3) the loose mesenteric attachments necessary for the changing relation of future growth; (4) the immature state of muscular structures and secreting glands. In addition to the local instability of the gut, the inefficient musculature of the abdominal walls renders forced expulsory efforts at defecation futile in the infant. Among the recognized causes may be mentioned: first, diet; second, conditions which induce muscular atony; third, pain or spasm.

Since the onward movement of aliment and fæees through the intestine is dependent upon its vermicular action, it is evident that anything which diminishes peristalsis favors constipation. The contents of the bowel may be such as not to excite peristalsis from blandness of consistency or deficiency in bulk. Occasionally constipation in the nursling occurs from paucity of fat or from excess of proteids in the mother's milk. Poor breast milk may lead to constipation from deficiency in all the solids, and hence paucity of residual matter. On the other hand, excess of fat with paucity of sugar may lead to constipation from indigestion and the resultant congestion of the mucosa and interference with secretions. Tenacious mucus, adherent to the villi, may obtund the sensibility of the intestinal wall to the detriment of peristaltic response. Babies fed on cow's milk are particularly prone to constipation for the above reasons; also children who are fed boiled or even pasteurized milk. Diminished intestinal secretion due to loss of fluid from diabetes, from excessive perspiration, profuse diarrhœa, or insufficient ingestion of water, undoubtedly favors constipation. Paucity of bile either from insufficient secretion or from obstruction to its discharge into the duodenum, may lead to torpor of the bowel. Excess of starchy and saccharine foods which from fermentation causes distention of the bowels with gas, inhibits peristalsis from paresis of the muscular structure. Pro- 
longed use, also, of the coarse foods with bulky residuum may diminish the activity of the bowels.

Whatever be the condition of the bowel contents, atony of the muscular structure will diminish peristalsis and result in fecal accumulation. This condition is more apt to obtain in the large intestine, which is practically only a receptacle. General malnutrition or myasthenia after acute diseases are frequent causes of muscular atony of the bowel. Overdistention of the gut from fecal accumulation robs the tissues of their resiliency and obtunds the reflex excitability through which peristalsis is established, so that constipation may be the result of habitual neglect to evacuate the bowels. This may come about through preoccupation, the child's unwillingness to leave play, through painful defecation from spasm of the sphincter due to anal fissure or hemorrhoids.

- Constrictions due to congenital malformations, visceral displacements, inflammatory adhesions, or to neoplasms, may cause obstruction of the bowels.

Symptoms.-Though never fatal, per se, the results of habitual constipation are interference with various physiological functions, which produce symptoms. The coated tongue, foul breath, muddy complexion, and concentrated urine, are all expressions of defective elimination by the bowel. Restlessness, irritability, anæmia, and malnutrition are common accompaniments. Gastric indigestion, hepatic torpor, embarrassed heart action and dull intellect, with odema and coldness of the extremities, may all be due to stasis from venous congestion of the splanchnic area. Colic and tympanitic distention of the gut in constipation is common, while respiratory embarrassment and disturbed heart action may be increased to a dangerous degree by upward pressure of the diaphragm.

Anal fissure, rectal prolapse, and hemorrhoids result from straining and the passage of large masses of hardened frees. Prolonged pressure and irritation of the mucosa may cause ulcerations. Appendicitis, perityphilitis and intussusception are among the resultant disorders of constipation.

The stools are usually dry, crumbling, and light-colored from lack of bile; or putty-like, dark, tenacious, and malodorous. The dejection may be in round marble-like masses and coated with mucus. The retention may be only in the rectum, the frees showing no evidence of indigestion. The lowered vitality from diminished metabolism, and the copræmia due to resorption of retained excreta, make constipation a predisposing factor in all diseases which prey upon impaired resistance. Occasionally ribbon-like dejections may occur daily, or there may be intermittent diarrhoeal discharges even though large masses are retained at the flexures of the colon.

The diagnosis of constipation is usually self-evident, although digital exploration of the rectum and palpation along the colon will reveal unsuspected fecal retention in many cases. Careful examination should never be neglected in children showing any of the above mentioned symp- 
toms. Irritation about the anus or blood-streaked stools should always arouse suspicion of constipation in spite of the reported daily evacuation of the bowels.

Treatment.-The endless variety of treatment suggested but proves the obstinacy of the disorder. Probably no condition of infancy or ehildhood is fraught with greater annoyance and in which therapy is so frequently disappointing. The problem for its relief is in the determination of the principal cause. The history of the symptoms and a careful exploration of the rectum will do much to eliminate structural lesions. The character of the freces and analysis of the mother's milk may furnish clues. Paucity of fat may be corrected by the administration of a teaspoonful or two of eream before putting the child to the breast, until improvement of the mammary secretion is secured (see Chapter on LaCTation). Dry stools call for water, which should be freely given between feedings. Occasionally the milk diet may be improved by the addition of farinaceous gruels, as strained oatmeal. In older children who drink milk freely, well cooked starchy foods served with sugar and cream may be partially substituted. Animal broths and meats may be added if the dict has been too exclusively eereal. The overingestion of eream as a remedy for constipation, though a great benefit in many cases, sometimes defeats this purpose. Some infants improve by being allowed to suck molasses taffy, and other children may be given cornmeal mush or brown-bread, with free supply of molasses. Corn and whole-wheat bread, with plenty of treacle and ripe fruits, are frequently useful. Stewed prunes may be added to the dietary, and washed figs, which most children love, may be allowed. Chopped figs, soaked over night, in a decoction of senna, a half ounce (15 C.c.) of the dry leaves to a quart (1 litre) of water, will be eaten readily by the child and may be given at bedtime to promote a morning evacuation.

Improvement of the general muscular tone by all available agents is a great desideratum. Fresh air and freedom to play are important. Although usually regarded as contraindicated, iron in some organic preparation may be necessary for the anæmia and muscular atony. Nux vomica is valuable to promote peristaltic vigor, while massage of the abdomen must not be overlooked.

For the immediate relief of lower bowel or rectal aceumulations, soapy water enemata or gluten suppositories should be used. The introduetion of a soap tent, previously dipped in warm water, may be all that is required to empty the rectum. In obstinate reetal torpor, peristalsis may be exeited by a small clyster of pure glycerin, or a glycerin suppository first dipped in warm water may be introduced.

The administration of laxatives by month should be avoided until all other means for correction have failed. Oceasionally the aecompanying indigestion demands attention; and the heavily coated tongue and foul breath, indieative of repressed elimination, may call for small doses of calomel, ipecac, and soda, repeated at frequent intervals for a day or two. Aloes combined with nux vomiea and eascara, in eligible form, 
may act as a tonic, corrective, and peristaltic persuader to the entire intestinal tract, but should not be long continued or relied upon to the exclusion of the hygiene and dietary measures above mentioned. Castor oil and rhubarb, of such common use, are contraindicated as constipating in their secondary effects. In insufficient biliary secretion, as indicated by light-colored stools, sodium phosphate, two to four grains (0.13$0.25 \mathrm{Gm}$.), should be given to a nursling with every feeding. In older children, five to ten grains $(0.3-0.65 \mathrm{Gm}$.) may be used on the food in place of common salt.

In large fecal aceumulations evaeuant enemata should be preceded by an injection of olive oil, from a drachm to two ounces (4-60 C.c.), which is allowed to remain for half an hour or more to soften and lubricate the fecal mass. Sweet oil may also be administered by the mouth to good advantage. An eligible preparation is glyeerin one ounce 30 Ce..), sweet oil two ounces (60 C.e.), one egg, and simple elixir one ounce (30 C.c.). This should be thoronghly shaken in a bottle and given in teaspoonful doses four times a day to a child of one year. (To be kept on ice or frequently renewed.)

Anal fissure, spasm of the sphineter, and hemorrhoids call for surgieal treatment. Of chief importance in the prevention and correction of constipation is the establishment of the habit of regular defecation. Too much emphasis cannot be laid upon this hygienic measure whieh, if observed, would render constipation in ehildren as rare as it is now common. At a certain time each day, preferably after breakfast, the child should be placed upon a stool in such a position that the abdominal muscles may best act to reinforce the expulsive efforts of the bowel. For children the ordinary seat in the eloset is too high, so that a footstool should be supplied of sufficient height to give a firm support. The mother or nurse may well afford the time to supervise the child's morning defecation until regularity of habit is insured.

MUCOUS DISEASE-CHRONIC INTESTINAL CATARRH; GAS'IRO-DUODENAL CA-

TARRH; CHRONIC MUCOCOLITIS; INTESTINAL INDIGESTION : TUBULAR DIARRHGA; MYXONEUROSIS COLI; COLICA MUCOSA.

Under the above and other names has been described a condition that is not uncommon in children between the sixth and twelfth years, and is oceasionally seen in younger children and infants. Althongh not generally classed among the inflammations, the condition may be preceded or accompanied by lesions of the gastro-intestinal mucosa, varying from mere areas of hyperæmia to extensive structural changes, such as ulcerations, dilatations, and ptosis. Typical mucous disease, however, shows no lesion of the intestinal mucosa, the mucus found clinging tenaciously to the lining membrane of the colon, differing from normal mucus only in quantity and density, the latter from its loss of water by absorption.

Three sets of manifestations contend for priority in this disorder, to each of which prime etiologic importance has been ascribed by different 
observers. First, the functional digestive disturbance; second, the structural alterations in the digestive viscera; third, the nervous and constitutional condition of the child. A predisposition is seen in feeble and high-strung children of neurotic parentage and in those debilitated from previous disease, especially from pertussis and attacks of acute indigestion.

Symptoms.-The child is usually listless, easily fatigued, or irritable, and shows emaciation, with muddy or icteroid color of the skin. This is dry, harsh, and may be scaly. The hair is dry, the eyes dull, with dark eircles, the tongue is swollen and coated or shows irregular glazed patches, and the tonsils are hypertrophied with more or less follicular pharyngitis. The breath has a peculiarly offensive odor; the prolabia are frequently pallid as in nausea. Circumscribed areas of flushing may appear on the cheek. A short, dry cough, without pulmonary lesions, is common. There is disturbed sleep, grinding of teeth, and night terrors. The appetite is capricious, frequently insatiable, with periods of anorexia. The wasting of the tissues is marked in spite of the large amount of food ingested. This, with the congh and the loss of strength, may lead to the apprehension of tubereulosis.

The second set of symptoms is associated with functional digestive disturbances. The abdomen is distended and is in marked contrast to the general emaciation. It may, at times, show tenderness on pressure. Borborygmi, and the escape of flatus by mouth or rectum, are common. Constipation is the rule, alternating with attacks of diarrhoea, during which the discharges are sometimes very offensive, showing undigested and putrefying food and large quantities of mucus. The mucus, as it comes away, may assume odd forms, resembling a ribbon or tapeworm. Occasionally membrane-like casts of the gut are discharged entire, but rarely is a true membrane, blood, or pus seen in these stools.

The third set of conditions is seen in the dilatation of the stomach and colon, particularly the transverse portion. The lower border of the transverse colon may sag far below the level of the umbilicus. There may be enormous dilatation of the sigmoid flexure. Fissures of the anus may occur, with rectal prolapse and stasis in the lower hemorrhoidal veins.

Etiology.-Many observers have claimed that the affection is a neurosis, and cite the nervous disturbances and constitutional condition in confirmation. Others attribute to the enteroptosis a mechanical cause for the constipation and excessive secretion with its periodic discharge. A more rational etiology appears to be along the line of chronic gastrointestinal indigestion, originally from predisposition, but accentuated by dietetic errors due to caprice and malhygiene. The practice, among the poorer classes, of sharing with the children the varied diet of their elders; and among the pampered children of the well-to-do the injudicious eating of sweetmeats, rich food, and pastries, is so commonly associated with mucous disease as to suggest causal relations.

Theoretically, if not practically, chronic gastric indigestion and duo- 
denal catarrh, with resulting copræmia, serve as a partial explanation for many of the symptoms. Whether the enteroptosis be due to dilatation from accumulations of gases and aliment, or from anomalous detachment of the tenth rib, is immaterial, the atony of the muscular structures of the prima via but shares the general atonic condition of the muscular system.

The disease is essentially ehronic, the above symptoms being varied by acute exacerbations of anorexia, occasional vomiting, colicky pains, with some rise in temperature, and general malaise, followed within a few hours by diarrhea which may continue for several days, causing considerable depression. After the attack, which usually terminates in a profuse discharge of mueus, the habitual constipation returns with an obstinacy which leads to the frequent use of laxatives.

Diagnosis.-The diagnosis from general tubereulosis, or from pulmonary tuberculosis with intestinal complieations, is rendered probable by the usually normal or subnormal temperature and the absence of pulmonary and other physical signs of that disease. It must be remembered, however, that the debility incident to mucous disease favors the development of tuberculosis or any infection to which the ehild may be exposed.

Occasionally the ribbons and shreds in the stools are mistaken for tapeworm or ascarides, which error the nervous and digestive symptoms would appear to confirm. Examination of the stools with a lens will determine the presence of worms or their ova. Parasites frequently accompany this mucoid disease of the intestines.

The prognosis is hopeful, under strict dietetic and hygienic management, although the disease is essentially chronic and runs an extremely tedious course. It may continue for years with exacerbations under varying influences which affect the neurotic child.

Treatment.-The treatment consists in careful regulation of the daily life and supervision of the child's diet. All that makes for development, conservation of physical vigor and repression of sentimental, neurotic and morbid tendencies, must be encouraged. The ehild must be relieved of arduous school duties for which the stimulation of healthful outdoor occupation and pastimes must be substituted. The daily cold bath and oil massage will help to improve the general atony. The bowels must be taught to move regularly by a diet containing a large amount of residual matter. In this way the intestines are filled with a softened mass which takes up the mucus and promotes peristalsis. Young child́ren may take unstrained oatmeal porridges made from unbolted cereals, with plenty of rich, fresh cream, or even well cooked wheatbran mush, ground popcorn, graham, whole wheat, or corn bread, with a liberal supply of butter, and baked potato with gravy. A free supply of salt, eream, sugar of milk, and butter may be given, but cane-sugar, milk, finely-ground cereals and meats should be interdicted. Older children may take, in addition to the above, almost all kinds of fresh vegetables and fruits, such as currants, cranberries, gooseberries, grapes, figs, prunes, etc. Additional fat may be given in the form of olive oil 
with salads. Pastry, confections, and fine starch or flour puddings should be carefully excluded, and cocoa should be substituted for milk. A moderate amount of meat, especially fat bacon, is allowable. Saline waters, such as Kissingen, should be used freely.

It is impossible to more than suggest an outline of diet. The prineiples to be kept in mind are the use of food having a bulky residuum, the liberal supply of fats, the generous use of salt and saline waters, the avoidance of cane-sugar and concentrated carbohydrates, and the discontinuance of routine purgative medication. The details of treatment must be adapted to the peculiarities of the individual case.

An occasional enema of normal salt solution may be given when it does not induce painful spasm of the bowel. High enemata of sweet oil, four to ten ounces, are preferable, and in the beginning may be repeated daily. With a well filled colon, judicious abdominal massage may accomplish much in promoting peristalsis. Obstipation from painful spasm of the gut calls for hot abdominal applications. Anodynes, as small doses of opium and belladonna will relieve the spasm and frequently promote evacuation of the bowel contents.

Changes either to or from the above mentioned diet should be made gradually. Bearing in mind the underlying neurotic diathesis and the recurrent character of the intestinal disturbance, the child should never be pronounced cured of mucous disease until many months after the disappearance of an excess of mucus from the stools, and substantial gain is evident in weight and general vigor.

\section{INTESTINAL PARASITES-WORMS.}

Parasites are sometimes found in the intestinal tract in great numbers and considerable variety, and were formerly considered responsible for most of the ills of childhood. As the true nature of various diseases became better understood, intestinal worms were gradually relegated to the background, until recently medical writers of distinction have gone so far as to claim that worms in the digestive tract were productive of no disorder, nor, indeed, of any symptoms that might indicate their presence. To substantiate this assertion, numerous post-mortem discoveries of worms are cited in patients dead from aceidental causes who have exhibited in life no evidence of these parasites. Frequently the first intimation of intestinal parasites is their presence in the stools or vomitus of individuals enjoying good health.

On the other hand, however, it is a matter of too common observation that the expulsion of intestinal worms has resulted in the relief of symptoms of grave disorders which could be attributed to no other cause. The too common custom among physicians of making light of the etiologic importance of intestinal worms simply because of their undue prominence in the lay mind, is neither judicious nor scientific. Tapeworms do rob the host of an appreciable amount of aliment which, in some instances of achylia or enfeebled digestion from any cause, may be a determining factor in malnutrition and lowered resistance to incidental infection. The 
Uncinaria Americana, and probably other forms of the anchylostomata, cause by their presenee in the small intestine symptoms analogous to those of pernicious anæmia, with as surely fatal results, if not relieved by expulsion of the parasite. Lesions and morbid processes in the intestinal tract and adjacent struetures are too frequently associated with the common nematode guests to hold these parasites altogether blameless; while the known aecidents due to the invasion, by the round-worm, of sinuses, tubes, and duets, are suffieiently eommon to make their presence in the prima via a menace to the health, if not the life of the host.

Reflex disturbances, espeeially in the highly sensitive organisms of children, from energetie intestinal parasites, may present such a variety of phenomena that their mere enumeration would be tedious. The seeptic who questions the relationship of cause and effeet in these eases must be satisfied with the same explanation which serves in the solution of other pathologieal problems,-i.e. the cessation of the symptoms upon the removal of the eause, namely, the worm. No one disputes the evil effects of the oxyuris vermicularis both through direct irritation and reflex disturbances.

The evidence of hæmatologists coneerning the findings in the presence of intestinal parasites eannot be ignored. Bothriocephalie anæmia is an entity which calls for anthelmintie therapy with an assurance of suceess, regardless of the mooted point as to whether the parasitie disturbance be due entirely to the abstraction of blood or in part to a toxæmia in the host from a normal or pathologieal seeretion of the worm. It has been shown that eosinophilia in varying degree aceompanies intestinal parasites of whatever form or variety. This faet alone, although its full significance may not at present be fully explained, is suffieient to refute the elaim that helminthiasis is produetive of nothing but worms.

The most eommon intestinal parasites found in ehildren are the oxyuris vermicularis (thread-, pin-, or seatworm), asearis lumbricoides (round-worm), tænia mediocanellata (beef tapeworm), the tænia solium (pork tapeworm), and rarely the tænia elliptica.

The oxyuris vermicularis (pin-worm) is seen in the dejeetions or about the anus and genitals of children, and looks like a white thread from one-half to one centimetre in length, the female being about twice as long as the male.

The ova enter the ehild's body with the food or drink, usually by means of polluted water, unclean hands, or through the ageney of flies and dust. The enveloping membrane is dissolved in the stomach, releasing the embryo, which develops rapidly in the small intestine, arriving at full maturity in the exeum and appendix. Here feeundation oeeurs and the parasite, eharged with ripening ovules, finds its way to the sigmoid and reetum, its favorite habitat. The eggs are deposited in this locality in enormous numbers and are extruded with the dejections to enter the body of another host. Through lack of eleanliness the child may reinfect himself with the ova of his own parasites.

The symptoms are prineipally due to the pruritus ani and the irrita- 
tion of the genitals from the active motility and migratory habits of these thread-worms. This is particularly noticeable at night, eausing restlessness and disturbed sleep, and often leads to masturbation.

The diagnosis is made from the symptoms. Oxyuris vermieularis should always be suspected from the symptoms above mentioned. By parting the nates, the worms are often seen in the anal region. Mieroscopic examination of the frees will reveal the eggs, which are unsymmetrically ovoid in shape and about one five-hundredth of an ineh $(0.05$ $\mathrm{Mm}$. ) in length.

Treatment.-These parasites may be destroyed by eopious enemata of salt solution, three to four drachms to the quart (15 C.e.-1 litre) of sterilized water, every second night until the worms disappear. A most effieient remedy used in the same way is infusion of quassia, one ounce to the pint (30 C.c. $-1 / 2$ litre). The pruritus may be treated with equal parts of unguentum hydrargyri and vaseline, applied nightly. Sinee these parasites infest the bowel as far up as the duodenum, eaeh enema will destroy only a limited number and may have to be repeated many times to rid the gut of their presence. It is often advisable to administer an anthelmintic by mouth in conjunction with the loeal treatment. The best agent for this purpose is santonin, to which ealomel is added to seeure prompt elimination and prevent toxie effeets of the former drug, to which young children are especially susceptible. To a child of two years, one-fourth of a grain $(0.016 \mathrm{Gm}$.) of eaeh, with a little sugar of milk, may be given three times a day for six doses. To seeure prompt effect the medicine is best given on an empty stomaeh, preferably after a free purgation with eastor oil. Yellow urine and transient xanthopsia follow the administration of santonin. Giddiness and tremors are indicative of the toxie action of the drug and their oeeurrenee suggests its withdrawal or diminution.

The ascaris lumbricoides (round-worm) resembles somewhat the common earth-worm. It is from five to fifteen inches $(12-37 \mathrm{Cm}$.) long, oneeight to one-fourth $(0.31-0.63 \mathrm{Cm}$.) of an inch thick, tapering gradually to pointed ends. It is yellowish-pink when first passed, ehanging to a light brown upon exposure, and is marked by fine transverse rings. The male is readily reeognized by his smaller size and ineurved tail. The female shows a genital orifiee at the anterior third of the ventral surface from which the fecundated ova are extruded in enormous quantities. The eggs are oval, about one five-hundredth of an ineh $(0.05 \mathrm{Mm}$.) long and have a thick, tough shell with a brownish nodular surface. The vitality of the eggs is great, as they may remain in water or damp earth for years in a dormant or slowly developing state. Probably an intermediate host furnishes the developing medium for the embryo, although recent experiments show that a few weeks of exposure to light and air ripens the ovum so that when ingested by the child the gastric juiees dissolve the envelope and liberate the embryo. A free embryo develops into a mature egg-produeing worm in about three months. Probably the eommon source of trematode ova is drinking water which 
has been polluted by surface drainage or sewage. Raw fruits, vegetables, and salad greens no doubt furnish means of transmission to the hummm mouth. Ascarides may exist singly or by thousands, although rarely are many found in one host. 'Their usual habitat is the upper portion of the small intestine, but their migrating propensities lead them into the stomach, lower bowel, vermiform appendix, common hepatic duct, vagina, bladder, asophagus, larynx, Eustachian tube, etc. In these situations they give rise to symptoms peculiar to the structure and function of the invaded area. Perforation of the bowel and stomach by lumbricoids has occurred, probably through ulcerations from a previous disease.

They are occasionally vomited during pyrexia from any cause, but most frequently they leave the body by way of the rectum, dislodged by the excessive peristalsis of catharsis.

A positive diagnosis ean be made only by the presence of the parasite or its ova. Most of the symptoms attributed to the round-worm are common to dyspepsia and chronic enteric catarrh, hence the professional scepticism.

The question of cause and effect in the relationship between intestinal worms and excessive intestinal mucus has been much discussed. Certain it is that the two conditions are frequently associated. Malnutrition, indigestion, and marasmus, with all their dependent conditions and symptoms, not to mention the host of reflex disturbances from gastrointestinal irritation, have been occasionally relieved by the expulsion of intestinal parasites.

Treatment.-Of the anthelmintic drugs in common use one has proved so efficient and safe that it is justly regarded as a specific. Santonin, after a limited non-saccharine diet for two or three days and after the bowels have been cleared by a purgative, should be given as directed in the treatment for pin-worms. After an interval of a fortnight the series of six doses may be repeated with similar preparation.

Tanice (tapeworms) are much more frequently encountered in children than many authors are willing to admit. They are occasionally found in young infants, especially bottle-fed babies, and have been reported in the newly born. The growing practice of feeding raw beef juice to babies and chopped or pulped beef to children easily explains the advent of the mediocanellata, while ground meat and raw or imperfectly cooked sausage containing pork are so frequently eaten by children that invasion by the solium is understood.

Other forms of tapeworm are found in children. One, the trenia elliptica, has for its intermediate host the louse or flea frequently found on domestic pets.

Tæniæ continue to grow by adding new segments to their length as long as the head retains its hold by suckers or hooklets upon the mucosa -usually of the upper part of the small intestine-so that as intestinal peristalsis of the host sweeps the free end downward the parasite may attain the full length of the intestinal tract. Although usually solitary, two or more tæniæ may occupy the same gut, and as they grow to their 
full length in from six to twelve weeks the detached segments are constantly escaping from the anus and may be found in the clothing or stools. Their reeognition is easy, although in mucoid stools, odd ribbonlike forms suggestive of cestodes are often seen. Free purgation often brings away several links or large masses of the worm, but as long as the head remains unexpelled the parasite may live to share his host's pabulum for ten or twenty years.

The symptoms of truia are those of malnutrition and anæmia, accompanied by voracious or eapricious appetite, abdominal pain, muscular cramps, and digestive disturbances. The diagnosis requires segments or ova from the rectum of the host. The blood findings are interesting, and all cases of progressive anixmia should suggest the possibility of worms. The mieroscope will show the ovum in the dejections.

Treatment.-The most efficient tæniacides are male fern and pomegranate root. Oleoresina aspidii, dose ten minims ( 0.6 C.c.) for a child of five years, may be given in milk or in eapsules every hour for four doses. Pelletierine tannate, dose one-half grain $(0.032 \mathrm{Gm}$.) for a child of five years, may be given in simple elixir or milk. The administration of the anthelmintic should be preceded by low liquid diet or an absolute fast for twenty-four hours and a morning saline purge. After the bowels have moved freely one dose of the pelletierine should be given, or four doses of male fern, at intervals of forty to sixty minutes, the child being kept in the recumbent position. Four hours later a full dose of castor oil should be given to carry off the worm. This seemingly simple treatment, to insure success, must be supervised by the physician in person or by a thoroughly instructed nurse, for unless the head of the parasite is secured the worm will renew its growth in from six to twelve weeks. The movement must be washed on a fine sieve and the head sought for. In ease of its non-appearance copious colonic flushing with normal salt solution may secure it.

The prophylaxis against worms in general is cleanliness and avoidance of raw meats, raw vegetables, and unsterilized water.

\section{INTUSSUSCEPTION.}

Intussusception, or invagination of the bowel, is frequent in early life. About fifty per cent. of all cases are reported as occurring in children under ten years of age, of which number the first year claims more than half. Its frequency in infancy is explained by the susceptibility of the gut to peristaltic disturbances, the prevalence of diarrhœal conditions, greater amplitude of its mesentery, and the mobility of the cxcum. With rare exceptions the invagination proceeds from above downwards, the lower portion of the gut turning in as it is dragged onwards by the advancing apex (Fig. 137). Intussusception may occur at any portion of the intestinal tract, although probably less than one-third begin in the small intestine. The commonest starting-point is at the ileocæeal junction, whence" the small bowel may be swallowed by the large one or, as more frequently happens, the colon swallows itself, advancing the ileocæ- 
cal valve as the apex of the invagination until, in rare cases, it may reach the rectum or even protrude from the anus. Occasionally the vaginating reduplicates, so that instead of three, five or even seven thicknesses of the intestine have been found between the periphery of the mass and the lumen.

The result of extensive invagination is constriction of the vessels of the gut and mesentery, which is dragged in, causing congestion, swelling, inflammation, adhesion, necrosis, and sloughing of the incarcerated portion. The degree of obstruction depends upon the extent of the lesion and the amount of swelling and constriction, though the passage is usually blocked.

The exciting cause of intussusception is often obscure, although enterocolitis, ulceration of the bowel, appendicitis, Meckel's diverticulum, chronic indigestion, constipation, colic, typhoid fever, pertussis, intestinal worms, injuries to the abdomen, and exposure to cold have all been noted as precedent or associated conditions.

The most prominent symptoms are pain in the umbilical region, and vomiting, spasmodic in character, which, if long continued, may in older children become fecal. The onset is usually sudden, the infant arousing from sleep with a sharp ery: The stools become scanty and frequently cease altogether, although by the second day usually bloody mucus is passed. Some cases begin with a mild diarrhœa and suddenly develop the

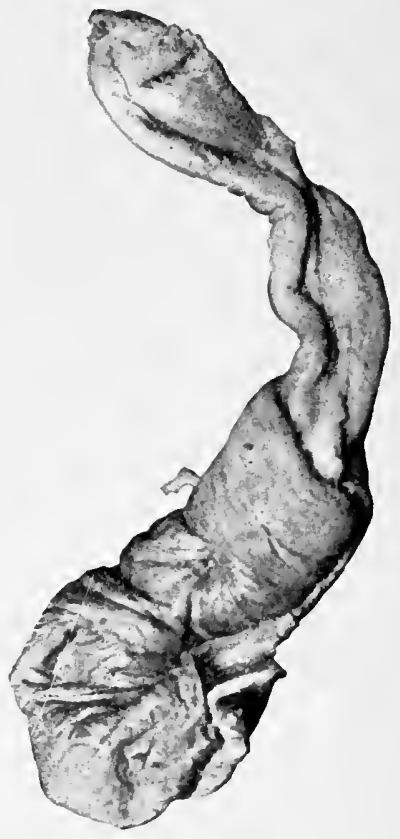

Fig. 137.-Intussusception. pain, vomiting, and bloody stools. The temperature may be normal or subnormal and symptoms of prostration and collapse rapidly develop. A chronic form is encountered in which symptoms of obstruction are wanting, the real condition being unsuspected until an abdominal tumor is discovered. Tumor is present early in a large majority of cases and may be located anywhere in the abdomen, but as the disease progresses it is rarely absent from the left side and is frequently located in the rectum or sigmoid.

The picture of acute intussusception in the infant is characterized by the absence of fever and cerebral symptoms, the paroxysms of pain and vomiting, the anxious facies, pinched and pallid features, perspiration, symptoms of collapse and, later, apathy, coma, or convulsions. After the second day there may be fever from local peritonitis or infection. Cessation of pain after the third day in severe cases usually means gangrene. The duration varies from two to seven days. In seventy-five per cent. of the fatal cases death occurs on the fourth day. 
The diagnosis is made from the severe paroxysmal pain, vomiting, discharge of bloody mucus in the absence of fæces, and principally by the presence of tumor. In examination for tumor the rectum should be explored under anæsthesia.

Prognosis.-Neglected intussusception is usually fatal, although a few cases of spontaneous reduction have been reported. Occasionally, after a portion of the bowel has sloughed away, adhesions preserve the continuity of the tube, although in children such recoveries are usually followed by death in a few months from sequelæ. If diagnosed early, the probabilities of relief by intelligent treatment are fair; yet recurrences after reduction are not uncommon at any time from twelve hours to six weeks.

Treatment.-Early laparotomy is the rational treatment. As each hour's delay increases the gravity of prognosis in a geometric ratio, no time should be lost in measures which only occasionally have proved successful. While waiting for the surgeon and during the anæsthesia for examination, distention of the bowel by warm salt solution may be tried, care being observed not to use too much force. The child should be inverted and the warm solution introduced through a catheter from the fountain, which must not be elevated more than three feet. Meanwhile gentle massage of the abdomen should be performed to promote the filling and reduction of the gut. All food must be withheld and morphine should be given hypodermically to arrest the pain and peristalsis.

\section{VOLVULUS.}

Sudden obstruction may occur from a twist or kink in the gut. If the lesion be high in the bowel, vomiting will be an early symptom upon which, with the pain and obstipation, the diagnosis depends. From intussusception it is differentiated by absence of bloody mucus discharge and of tumor. The only treatment is abdominal section to straighten the kink, which should be done promptly.

\section{APPENDICITIS.}

Appendicitis is occasionally found in infants a few months old, but the diagnosis is rare before the third year. Records from a large number of cases show something more than ten per cent. in the first decade of life. It is probable, however, that many mild attacks of appendicitis are overlooked in infancy or are diagnosed as acute intestinal colic.

The etiology of inflammation of the appendix is obscure. The theory that as age advances there are progressive changes resulting in overgrowth of the connective tissue, and predisposing to congestion, may help to explain the greater frequency of appendicitis in older patients.

In children, as in adults, reports of this disease show a large preponderance in males. An explanation of the relative infrequency of appendicitis in girls has been offered in the fact of the frequent existence of the appendico-ovarian ligament which carries an additional blood 
supply to this organ, furnishing a collateral circulation clenied to the other sex. Functional disturbance of the bowels, particularly constipation, precedes the attack with sufficient regularity to appear as an exciting eause. Worms, both the oxyuris and lumbricoid, have been found in the appendix and may act as morbific agents. The bacteria involved in this inflammation are usually the pneumo- and streptococeus and the bacterium coli communis, the last named organism being rarely absent.

Pathology.-The lesion may be catarrh of the mucous lining, ulceration, perforation, or gangrene, which may be followed by the secondary lesions of peritonitis or pyæmia.

Despite the extended discussion given to the subject of appendicitis during the past two decades, anatomical knowledge is still wanting in regard to the appendix of infancy and childhood. It is claimed that at this period the appendix is more funnel-shaped and less liable to constrictions in its proximal portions. Its irregularity in infancy has been remarked, both in regard to its varying length and the aberrancy or mobility of the cxeal pouch to which it is attached. Thus it is found sometimes in the region of the umbilicus, occasionally on the left side and rarely in the sae of an inguinal hernia, but almost always it is in a higher location than is usual in the adult. It is claimed that in infancy the mesentery is frequently attached to the entire length, thus giving to the tissues of the appendix a relatively freer blood supply.

Lesions.-Probably in a large majority of instances the disease begins as a catarrhal inflammation and frequently terminates as such, with merely the production of lymph. How many of these mild attacks of simple catarrhal appendicitis are entirely overlooked is a matter of conjecture. If constriction at the neck or at any other point occur, the incarcerated contents act as a foreign body upon the swollen mucosa. This, with the omnipresent bacterium coli communis, may light up a suppurative or ulcerative process which may involve all the lavers of the appendix. Perforation by ulceration or by gangrene, with escape of contents into the peritoneal cavity, must result in peritonitis. Whether the peritonitis be general or circumscribed depends upon the location and extent of the peritoneal adhesions. A localized abscess may be due to the presence of plastic lymph which walls off the escaping pus, in which the appendix seemingly dissolves. A retroperitoneal abscess may develop from invasion of that area by pus germs.

Symptoms.-The three cardinal symptoms of appendicitis are local abdominal pain, tenderness, and rigidity of the recti muscles. The pain is intermittent and may be severe, acute, lancinating, or colicky. Usually in infants and young children the pain is not definitely located, and when referred by the child to a particular region, this is most often the umbilicus. Occasionally the pain is slight or wanting. Tenderness is seldom absent, and careful palpation may frequently locate it in the right inguinal region, although it is sometimes most marked on the left side. At times the entire abdomen is hyperæsthetic either to deep or superficial pressure. Rigidity of the abdominal muscles is most always present, 
especially in the right lower quadrant. Fever is a common symptom and may range from $100.5^{\circ}$ to $105^{\circ} \mathrm{F}$. $\left(38^{\circ}-40.5^{\circ}\right.$ C. $)$. The extent of the pyrexia is not uniformly in keeping with the gravity of the lesion. In contrast to the rather low range of temperature the pulse of appendicitis is always rapid-one hundred and twenty to one hundred and sixty or higher-and is thin and thready in character. Vomiting is a common accompaniment of severe attacks, and the tongue is usually furred. A persistent heavy coating, as in adults, is considered evidence of suppuration. Thirst or intense constipation is the rule, although diarrhoea may precede or accompany the attack. In severe cases the face is pale or of leaden color and the features are drawn and anxious, when not distorted by paroxysms of pain. The characteristic position of the child is in the dorsal decubitus with the right leg slightly drawn up, or the knee may be flexed against the abdomen.

The onset may be sudden, resembling an attack of indigestion, with colic and vomiting. In the acute catarrhal variety, all symptoms may subside in forty-eight hours without a diagnosis of appendicitis. Later,

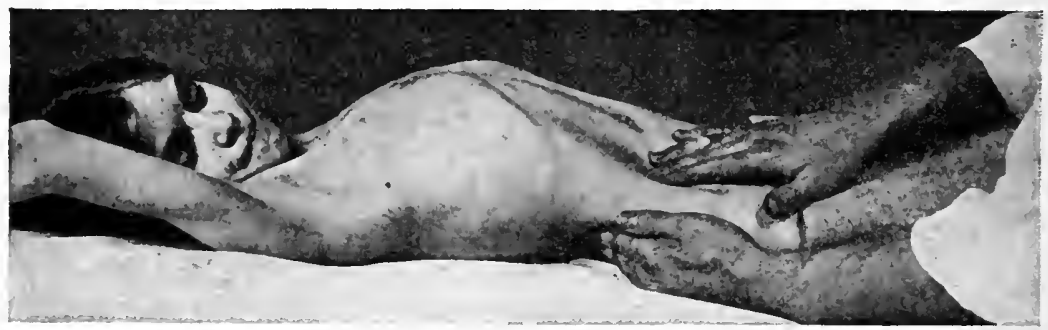

FIG. 138.-Palpating the appendix.

if careful palpation be made (Fig. 138), there may be felt in the right iliac region a slight thickening and induration of the appendix. Sometimes no evidence remains. A number of such attacks may occur in the course of two or three years, which in the history of the case are given as recurrences of indigestion. This diagnosis is discredited in many instances by post-mortem evidences of old inflammatory lesions.

A severe suppurative appendicitis may develop during the course of or after the subsidence of one of these mild acute attacks. In this event there will be exacerbation of all the symptoms, and palpation after the second or third day may reveal the tumor. McBurney's point is rarely of any value in the location of lesions of the appendix in infants.

Perityphilitic abscess, as it was formerly called, may occasionally be diagnosed by the boggy feel of this tumor, the history of chill in older children, the fluctuating temperature, the persistently furred tongue suggestive of sepsis, the marked leucocytosis, also by careful digital exploration through the rectum and by the aspiration of pus through the hypodermic needle. If the pus is completely encysted, marked septic symptoms and leucocytosis subside, so that too much stress should not 
be placed upon the leucoeyte eount as diagnostie. The anrmia of appendieitis, especially in long-continued eases, is a well recognized fact, both as to the falling off of the erythrocytes to two or three millions per C.e., and as to the diminution of hæmoglobin, which may reach sixty or even forty per eent.

The duration of appendieular abseess is somewhat indefinite and may persist for weeks with general symptoms of mild or severe septicemia. Oeeasionally, after the third or fourth day of a mild attack of appendieitis, fulminant symptoms develop, with extensive peritonitis, collapse and death in forty-eight hours; the post-mortem showing gangrene and sloughing of the appendix. Exacerbations of temperature, with sudden rise in leueoeyte eount to more than twenty thousand per C.c. are suggestive of extension of the suppurative proeess. Rupture may oecur with discharge of eontents into the bowel, followed by subsidence of symptoms and rather prompt reeovery. If the abscess opens into the peritoneal eavity, aeute symptoms of general peritonitis develop, such as pain, abdominal distention, and tympanitis, weak and thready pulse and collapse. Peritonitis, whether cireumseribed or general, is always accompanied by rapid inerease in leneocytes, unless the prostration is so extreme as to lower the resistanee beyond response to the infection. In this case death is an early termination.

Diagnosis.-The diagnosis of appendicitis from other acute eonditions with similar symptoms is often extremely diffieult. Aeute indigestion or constipation with colie and impaeted exeum may simulate appendicitis, although in the former the higher temperature and early subsidenee of aeute symptoms, while in the latter absenee of tenderness and abdominal rigidity, should reveal the eharaeter of this disorder. Obstruetion of the bowel from volvulus or aeute intussuseeption may lead to a suspieion of appendicitis. The absenee of fever, the presenee of bloody mucoid discharges from the rectum, and the demonstration of the eharacteristic tumor of the left side, should dispel doubt.

Hepatie and renal colie are rarely accompanied by fever and loealized tenderness in the right iliae fossa.

Psoas or perinephritic abseess should be distinguished from one of appendicular origin by the preceding history and symptoms pointing to dorsal spondylitis in the former and oecasionally by the urinary findings in the latter.

In typhoid conditions the Widal test should be applied, and the possibility of peritonitis from perforating typhoidal uleer should not be forgotten.

A number of cases of coexisting enteroeolitis and appendicitis have been reported. In young infants the common oecurrenee of the former and the rarity of the latter should be kept in mind, although in all eases careful palpation of the abdomen should be practised.

Pneumonia in young ehildren, especially of the lower right lobe, very frequently occasions abdominal pain and tenderness from pleuritic involvement of the lower dorsal nerves. A careful examination of the 
chest, and search for the characteristic disturbance of the pulserespiration ratio should establish a diagnosis as to lung lesion.

In children acute peritonitis should always lead to a suspicion of appendicitis as a cause, although it should be remembered that infection from gonorrhœal vulvovaginitis may extend to the peritoneal cavity, and that tuberculosis of the peritoneum is common enough in infancy and childhood. In fact, tubercular ulceration may be the primary lesions in appendicitis.

Prognosis.-The prognosis of appendicitis in children should always be regarded as grave, since the extreme variability and uncertainty of its course render the statisties of recovery of little prognostic value in any given case.

'Too often a record of suceessfully treated cases is interrupted by sudden fatality, which should serve as a constant reminder of the uncertainty of any medicinal method of treatment. To be on the safe side the disease should be regarded as surgical from first to last. The objections to an operation rarely weigh against its advantages. The argument that many cases recover under medical treatment is offset by the well known tendency to recurrent attacks of the disease. The diametrically opposite practice among our best physicians in regard to the use of laxatives and opium is in itself an argument in favor of surgery.

When the diagnosis of appendicitis is established the surgeon should be called in consultation. Meanwhile reason teaches and experience has proven the value of opium for the relief of the pain, and of the local application of the ice-bag over the lesion. The child must be kept absolutely quiet in bed during even the mildest attack. A preliminary cleaning out of the bowels with a full dose of ealomel, one to five grains (0.065$0.3 \mathrm{Gm}$.), with sodium bicarbonate, two to five grains $(0.13-0.3 \mathrm{Gm}$.), may be advisable, after which the colon may be occasionally unloaded by moderate enemata of saline solutions. Food should be absolutely withheld and water sparingly given, if at all. Morphine hypodermically in doses barely sufficient to relieve severe pain is indicated. If the icebag is not well borne, hot applications may afford relief. The constant danger of peritonitis and its extreme fatality in young children should never be lost sight of, against which must be remembered the low mortality of early surgery.

\section{PROCTITIS AND RECTAL ULCERATION.}

Proctitis is an inflammation of the rectum and often accompanies enterocolitis. It may, however, oceur independently of catarrhal conditions of the upper bowel. In this case it may be due to bacterial infection through the anus. Tubercular and syphilitic lesions are also found in the rectum, and traumatisms with resultant infections may lead to ulceration. Such injuries are frequently the result of ignorance or carelessness in the use of thermometer or rectal tube, and of the abuse of suppositories in rectal medication. Parasites, as the oxyuris vermicularis, may cause inflammation. In diphtheria of the genitals we may 
have a membranous proctitis; whereas tubercular and gonorrhœal infection of the rectum always produces ulcers which are usually located just above the inner sphincter.

Symptoms.-The symptoms are pain, tenesmus, and discharges of mucus, very often accompanied by blood and pus. The sphincters are frequently relaxed. There may be pouting of the anal mucosa or extensive prolapse of the rectum. The ulcerations are usually shallow, though they may perforate the intestinal wall and form ischiorectal abscesses. These tend to extensive burrowing and destruction of tissue. If situated near the margin of the sphincter they lead to fistulous open-

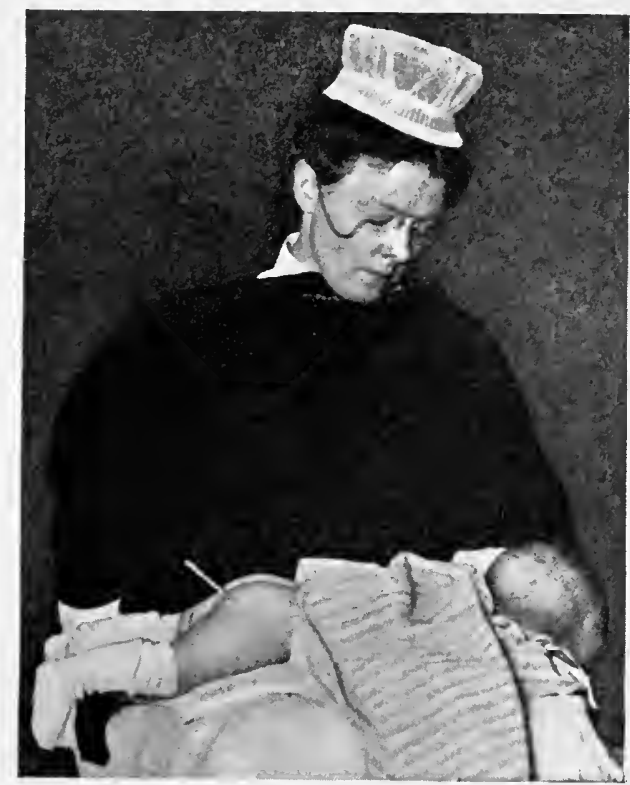

FIG. 139.-Position of infant for introduction of thermometer.

ings into the gut, as well as to the surface. No diagnosis is necessary, save as to the variety and cause of the lesion, upon which depends the mode of treatment.

Treatment.-For the treatment of proctitis complicating iliocolitis, sufficient has been said under that subject. Simple catarrhal inflammation of the rectum usually yields promptly to the removal of the cause, as worms, constipation, polypus, etc. Careful irrigation with saturated boric acid solution, and suppositories of opium and belladonna to relieve the pain and tenesmus, may be used. Gonorrhœal infection requires prompt bactericidal injections, such as protargol solution, two to five per cent., or nitrate of silver in similar solution, which should be neutralized by salt solution. Rectal ulcers often prove extremely obstinate and may be very painful if in close proximity to the sphincter. They give rise, at times, to sufficient hemorrhage to cause anæmia. The general 
health may be impaired, which condition increases the intractability of the local lesion from the lowered vitality of the tissues. The ulcers should be freely irrigated with permanganate of potassium $(1: 1000)$ twice daily. Cocaine, morphine, belladonna, or suprarenal extract, may each prove useful in relieving pain and diminishing hyperæmia. It may be necessary to introduce a speculum and touch the ulcers with solid nitrate of silver every second or third day. Frequent applications of iodoform or aristol are found beneficial. If an abscess form outside the bowel it should be freely opened, drained, cleaned and treated according to the usual surgical method. Syphilitic and tubercular lesions, aside from their local treatment, call for constitutional treatment, which is discussed under their separate heads.

Prophylaxis is important in the prevention of proctitis by the early removal of the causative conditions and by care in the clinical and therapeutic invasion of the bowel. A study of the rectum shows that the axis of the outlet, instead of running parallel with the long axis of the body, points backward at an angle of forty-five degrees, so that entrance to the gut must be from behind to avoid impinging against the wall of the viscus. The practice of introducing a hard tube, or the sharper thermometer from between the thighs, frequently causes abrasions of the softened mucosa of the posterior wall which it meets at a right angle. Fig. 139 shows the direction of the anal outlet and the proper position of the infant for the introduction of the thermometer.

\section{PROLAPSE OF THE RECTUM AND ANUS.}

Prolapsus ani is not uncommon in infancy and early childhood. The mucous membrane of the anus may alone protrude with eversion of the external sphincter, or the lower portion of the rectum may pass through the sphincter and appear as an invaginated dark-red or purplish tumor protruding from the anus to the distance of two or three inches (5-8 Cm.).

Etiology.-Its frequent occurrence in childhood is explained by the immature condition of the sphincter muscles, by the redundancy of the infant rectum, its straight lower third, the loose attachment to the shallow pelvis and the want of development of the levatores ani. The descent of the rectum is induced in debilitated infants by much straining due to constipation, proctitis, difficult micturition, or paroxysms of whoopingcough. It occurs most frequently during the relaxed conditions attending diarrhœa. Any condition which favors muscular atony and absorption of fat predisposes to rectal prolapse, hence rickets and marasmus have been ascribed as causes. Rectal polypi, by their teasing presence, may induce eversion of the anus and bring on prolapse.

The symptoms are easily recognized and are to be distinguished from those of hemorrhoids, polypi, and intussusception. If the case be not severe the prolapsed portion returns shortly after the bowel movement.

Treatment.-Its return is facilitated by oiling the protruding mass and inverting the child while gentle pressure is made with the fingers 
covered with gauze. If much congestion and tumefaction have oceurred, ice may be applied or the mucosa may be painted with a two prr cent. solution of cocaine, or a solution of suprarenal extract may be used to deplete the vessels. Exceptionally it may be necessary to dilate the sphincter by introducing two fingers through the invaginated portion. In older children suspension by the arms will aid in dragging the abdominal viscera upwards. To prevent recurrence, constipation, if it exist, must be relieved by mild laxatives and clysters of cold water, while mild astringents, as alum, tannin, or adrenalin solutions, may be applied. Children should not be allowed to strain during defecation. To this end the infant should lie on his side, or the perineum may be supported or buttocks compressed by the hands of the nurse. Older children should have the commode elevated so that the feet may not rest upon the floor, or the seat may be given a forward slant. The custom of allowing children to sit for a long time at stool is harmful. After a movement the horizontal position should be maintained for a half hour or more.

A pad may be placed against the anus and retained by a T-bandage, or a broad strip of adhesive plaster may be applied so as to hold the buttocks together and thus support the anus.

Nux vomica and ergot may be given to tone up the muscular system, or hypodermic injections of strychnine or ergotine in the vicinity of the anus may be of more advantage in severe cases.

All measures to improve nutrition should be employed.

The prognosis is good, but in rare cases surgical methods must be resorted to.

\section{FISSURE OF THE ANUS.}

Fissure of the anus in infants and young children is of frequent occurrence and may be due to the passage of hard, dry scybala and traumatisms, as from scratching or the careless introduction of thermometers or syringes.

These fissures give rise to severe pain at defecation and for some time after. They are frequently the cause of fecal retention and constipation. The spasmodic action of the sphincter prevents healing of the lesion which may proceed to ulceration. The child is irritable and presents symptoms of reflex nervous disturbances which may seriously impair nutrition.

The treatment is simple. Cleanliness and a few applications of nitrate of silver, followed by a bland ointment, with measures for the relief of the constipation, will usually effect a cure. Obstinate cases may require stretching of the sphincter to overcome spasmodic action and allow healing. This, of course, should be done only under complete anæsthesia.

\section{RECTAL POLYPI.}

Polypoid growths in the rectum, although rarely seen in young infants, are common after the second year. They are usually single, pe- 
dunculated, and situated on the posterior wall of the rectum, from one to two inches above the internal sphincter. They may, however, be multiple, more or less sessile, and located in different parts of the rectum, sigmoid, descending colon, or even the cæcum. They may vary in size from a split pea to a cherry.

Two varieties are recognized, first, the myxomatous or myxofibromatous, and, second, the adenomatous. The former is always benign; the latter may develop malignant characteristics. Although it was formerly taught that the simple mucoid polyp was the one most frequently found in the rectum, later investigations have proved that the lymphoid variety is the one with which the pediatrist has most frequently to deal. There is good reason to believe that it occurs in association with adenoid hyperplasia in other parts of the body as a result of that diathesis, the status lymphaticus, or lymphatism.

Unquestionably the presence of these tumors frequently escapes recognition, as they may be expelled by rupture of their attenuated pedicles.

The first symptom is usually bright blood which coats the stool but is not mixed with the fæces. Occasionally uneasy sensations in the rectum, continual tenesmus and pruritus, attract attention. Anal fissures are frequently associated with rectal polypi. Considerable loss of blood has been known to occur from this cause, resulting in marked anæmia.

The diagnosis is made by digital exploration. Occasionally the polyp may be seen after a bowel movement, presenting at the anal orifice as a smooth dark red body.

The treatment is by removal, which the usually long pedicle renders easy. If the operator fears the rare occurence of hemorrhage from torsion, removal may be done by ligation or the snare, through a speculum. If the presence of polypoid tumors be diagnosed in the colon by palpation through the abdominal wall, their removal must be by incision and colotomy.

\section{HEMORRHOIDS.}

The possibility of hemorrhoids, although of rare occurrence in childhood, should be kept in mind in the diagnosis of anal prolapse and rectal polypus. Two or even all of these conditions may be coexistent.

The treatment of hemorrhoids in children does not differ from that in adult life. 


\section{DISEASES OF THE LIVER AND PANCREAS}

\section{CONGESTION OF THE LIVER}

Congestion of the liver, although strictly speaking not a disease, is a condition which precedes every structural disorder of that organ. Its early recognition and relief, therefore, are not only important for the restoration of normal metabolism, but for the arrest of those anatomic changes-such as hemorrhages, cloudy swelling, parenchymatous and fatty degeneration, and hyperplasia of connective tissue-which may ultimately lead to irreparable structural lesions of the liver.

Some writers claim for the developing period a comparative immunity from this condition which is of so common occurrence in mature life. Analysis of the facts, however, will hardly bear out this claim.

Hepatic congestion is usually considered as active or passive. Of the former the attributable causes are overfeeding, too rich food, acute infections, acute gastroduodenal catarrh, chilling and shock. To all of these the infant or child is as frequently subject as the adult, or even more so.

The passive form may be due to cardiac incompetency, pulmonary obstruction from pneumonia, emphysema, or atelectasis, pleuritis, chronic gastroenteritis, climatic conditions, syphilis and malarial poisoning, any one of these, singly or in combination.

With the exception of the less frequent syphilis, structural heart lesions, and emphysema, the child enjoys no exemption from these causes. Moreover, to the careful observer the eight-year-old heart may show incompetency as frequently as does that of the adult, and partial atelectasis or pulmonary collapse in the infant is of more common occurrence than adult emphysema.

The subjective symptoms of hepatic congestion are often overlooked in early childhood or incorrectly interpreted. The hepatic enlargement is considered normal to that age. The alcoholic stools of the infant are attributed to the milk diet, while the headache and malaise are disregarded. Scorbutus, now rarely seen in adult life, keeps pace with the increasing prevalence of artificial feeding.

The treatment of hepatic congestion consists in the correction of the diet, especially in regard to the overingestion of fats, carbohydrates, alcohol, and coffee. Depletion of the engorged hepatic vessels should be secured by the use of calomel three to ten times every twenty-four hours, or sodium phosphate, given in milk or used as a condiment in place of sodium chloride, until its purgative action is secured. For older chil- 
dren ammonium chloride is useful. Water is always indicated, especially the alkaline and saline. In prolonged, obstinate cases, this treatment may be followed by a course of dilute nitrohydrochloric acid, well diluted. Massage and exercise in the open air are important.

The treatment for the passive form of congestion consists principally in relief for the primary disorder.

\section{ACUTE INFECTIOUS LIVER.}

It has long been known that during the course of most of the acute infectious diseases constant and marked changes occur in the liver. Those most frequently found are active hyperæmia, dilatation of vessels, round-cell infiltration, formation of new tissue, parenchymatous and fatty degeneration and consequent interference with function.

Usually the hepatic disturbance subsides upon recovery from the primary disorder, but convalescence may be interrupted by symptoms of acute infection of the liver. There are chills, recurrent and irregular pyrexia, malaise, prostration, anorexia and vomiting. Palpation will diselose enlargement and tenderness of the liver and other symptoms of hepatic abscess. For weeks and even months the temperature may show fluctuations suggestive of sepsis. The urine may contain blood, albumin, and casts.

Recovery is slow, with gradual subsidence of all the symptoms, the liver finally regaining its normal size and consistency.

Post-mortems, in fatal cases, disprove the existence of abscess.

The treatment is symptomatic and supportive.

\section{SUPPURATIVE HEPATITIS-ABSCESS OF THE LIVER.}

Since hepatic abscess may be due to traumatism, empyema, perityphilitis, pelvic peritonitis, umbilical phlebitis, dysentery, lumbricoids in the bile ducts, tuberculosis, or other infectious diseases, children are prone to this disorder in proportion to their proneness to the causative conditions.

The signs and symptoms of suppurative hepatitis have no special characteristies in infancy. Usually hepatic pain is less prominent and may be wanting. The normally large liver, especially when increased by congestion, may lead the practitioner to a mistaken diagnosis of abscess in his efforts to locate a suspected collection of pus. The occasional interposition of the bowel between the low, rounded margin of the liver and palpating finger, may yield the variation in density and even the fluctuation, described by some as diagnostic of anterior or marginal abscess of the liver. So, also, pressure upon the right hypochondrium may by upward displacement elicit pain in the infant, due to an unsuspected pleurisy.

With rare exceptions, exploratory aspiration alone may demonstrate the presence of abscess, single or multiple.

The prognosis of a single abscess is favorable in proportion to the 
probability of its rupture externally or into the bowel. Multiple abscesses are necessarily fatal.

The treatment is essentially surgical.

\section{CIRRHOSIS OF THE LIVER.}

Cirrhosis of the liver is more common in infancy and childhood than was formerly supposed. Reported cases now number many hundreds. The condition may be congenital, although in all probability such cases are due to syphilitic affections of this organ. No good reason is apparent why syphilitic cirrhosis should be included in a general description of this disorder, since the effect upon the hepatic function differs little, if any, from other forms ; nor is it necessary to attempt, in this limited work, a refined differentiation between the two forms,- -namely, hypertrophic and atrophic cirrhosis. A study of reported cases shows that in children enlargement of the liver preceded atrophy in nearly every instance. The fact that the autopsies show a large preponderance of atrophic cases proves only the terminal condition of the liver, which might have shown hypertrophy in its initial stage. Infants show a higher percentage of the hypertrophic form than do adults. This, again, may be due to the fact that infants succumb more rapidly to the interference with metabolism and toxæmia.

Hepatic cirrhosis may be due to chronic passive congestion from cardiac or renal disease, an increasing stenosis of the bile ducts, or congenital occlusion of the same. Syphilis, tuberculosis, and malaria are common causative factors. The frequency with which it has been preceded by acute infections, especially scarlet fever and measles, gives color to the claim of their influence in its development. Rhachitis is not uncommonly mentioned in the histories of infantile hepatic cirrhosis. Undoubtedly ptomaine poisoning in the marasmic and in children with gastroduodenal catarrh, must not be overlooked as at least a predisposing cause. The ignorance of parents in regard to the effect of the use of coffee, tea, and alcoholic stimulants, is responsible for a large percentage of cirrhotic livers. The effects of these poisons are especially noticeable in the growing organism.

The symptomatology and diagnosis do not differ essentially from those of adult cases. Ascites, usually a late sign, emphasizes the gravity of the condition. Icterus is usually present in some degree. Convulsions are of more frequent occurrence than in later life. The course is more rapid.

The prognosis, always grave, is brightened in syphilitic cases where the heroic use of mercurials and iodides have proved efficacious. Nonsyphilitic cases, also, have improved under these agents. No case should be pronounced hopeless when we recall the recuperative energy of young tissue.

Treatment.-A recognition of the predisposition should lead us to the early treatment of gastroduodenal catarrhs and hepatic congestion in children, especially in those with incompetent hearts, or during con- 
valescence from acute infections. The same is true after shocks, burns, and exposures to cold. 'The actual hyperplasia of Glisson's capsule, in the early stages, may be diminished by the use of ealomel in one-tenth to one-fourth grain $(0.006-0.016 \mathrm{Gm}$.) doses, four times a day, or daily inunctions of mercurial ointment, ten to twenty grains $(0.65-1.38 \mathrm{Gm}$.), while the biliary stasis may be relieved by the continuous use of ammonium chloride in doses of two to ten grains $(0.13-0.65 \mathrm{Gm}$.) every four hours. Saline aperients-as sodium sulphate, phosphate, and magnesium eitrate-should be given to the extent of three or four liquid stools daily. The frequent accompanying renal cirrhosis should not be overlooked. Such diuretics as calomel, squills, copaiba, alternating with potassium acetate and citrate, should be administered to secure free elimination by the kidneys.

The best of hygiene is necessary with only moderate exercise. The diet should include proteids that are easily digested, avoiding excessive ingestion of fats with only a moderate amount of starchy and saccharine material. Fruits, soups and broths should be given, but milk should be made the main article of diet.

\section{ACUTE YELLOW ATROPHY OF THE LIVER.}

Acute yellow atrophy of the liver is very rare in infancy and childhood. Recently two such cases have been reported,-one in an infant of one month, and the other in a new-born child. The symptoms and post-mortem findings differ but little from those seen in adults.

The effects of some mineral poisons, as phosphorus, antimony and arsenic, are so similar to the symptoms of acute yellow atrophy as to suggest that some agent which produces general intoxication with selective action on the liver is probably the primary etiologic factor in this disease.

Recoveries of two children from acute yellow atrophy are on record.

Until the cause is better understood, all treatment remains unsatisfactory. Efforts should be made to correct the accompanying gastroduodenal eatarrh, and general supporting treatment given.

\section{FATTY LIVER.}

Fatty liver is found most frequently in children subject to wasting disease, especially tuberculosis. It may accompany chronic gastrointestinal indigestion and is usually developed in pale, anæmic, fat babies, with large abdomens and other evidences of rickets.

It has also been found in apparently robust children who eat excessive quantities of fatty and saccharine foods. Overfeeding, with the absence of exercise and fresh air, will develop fatty liver in the absence of any other positive disorder, excepting a mild indigestion.

The symptoms are enlargement of the liver, without tenderness, pain, icterus, or ascites.

The treatment is that of the affection upon which it depends,-correction of the diet and exercise of the muscles, or massage when the latter is impracticable. Depletion of the portal congestion, by mercurials 
and salines, will materially assist in the recovery when not dependent upon some primary incurable disease.

AMYLOID DEGENERATION OF LIVER, KIDNEY, SPLEEN, ETC.

Although the precise defect in metabolism which permits the deposit of amyloid substance in the middle coat of the arterioles, resulting in the peculiar anatomic change known as waxy liver, lardaceous kidney, sago spleen, or amyloid degeneration of gastro-intestinal villi, thyroid and other glandular structures, is not definitely known; a remote etiologic or predisposing factor is recognized in chronic tuberculous and syphilitic processes, especially those of long standing or of suppurative nature, as osteitic, subperiostitic and arthritic affections. For this reason amyloid degeneration is of special interest, as children are particularly prone to such suppurative diseases of the bones.

The symptoms in childhood offer no conspicuous difference from those seen in the adult. This condition of the liver may be suspected when marked enlargement of this organ is present, unaccompanied by pain, tenderness or evidences of arrested hepatic function, with splenic enlargement, in a long-standing case of suppurative cachexia.

The prognosis is hopeless unless the cause of the cachexia can be removed, and that early in the history of the amyloid deposition,--in fact, operations in advanced cases are contraindicated.

HYDATIDS OF THE LIVER.

Reports of foreign observers show that hydatid disease of the liver is occasionally seen in children. In America, however, few cases are on record. The reason for this infrequency is not apparent, unless it be due to the fact that hydatid eysts require a long period of time for their development, so that the echinococcus of infancy may pass unobserved until the occurrence of the pronounced symptoms in mature life. In childhood, moreover, on account of the yielding character of the walls and surrounding tissues, pressure symptoms are less marked. Otherwise the history presents no special peculiarities.

Treatment.-Surgery furnishes the only relief, outside of spontaneous rupture.

\section{TUMORS OF THE LIVER.}

Neoplasms of the liver are so rarely seen in infancy and childhood that some recent writers make no mention of them. Adenomata, however, are found at an early age, and undoubted cases have been reported of malignant carcinomatous and sarcomatous growths, even in infancy.

The fact that hepatic cancer is, in some instances, secondary to cholecystitis or obstructive calculi gives color to the claim that prenatal inflammation of the biliary structures may precede the malignant neoplasm in early life.

The gloomy prognosis of cancer stimulates the hope that the promise of successful hepatic resection may see an early fulfilment. 


\section{SYPHILITIC PANCREATITIS.}

Probably the most common pancreatic disease of infaney is syphilitic cirrhosis, which has been reported in an advanced stage as early as the third month of life. In syphilitic pancreatitis there is rarely glycosuria, as the islands of Langerhans maintain their functional activity in spite of the general connective tissue overgrowth. As in most of the pancreatic diseases, the purely alimentary secretion is interfered with, excess of fat in the stools being a common result.

Pancreatic tuberculosis appears in childhood, not only as part of a . general tuberculous invasion, but also as a primary lesion.

Cysts of the pancreas are of occasional occurrence and have been reported in infants of such tender age as to suggest prenatal origin. Cysts may be caused by occlusion of the pancreatic duct by calculi, or by a biliary calculus in the common duct. The obstruction has in several instances been due to lumbricoides. Parasitic eysts, also, have been found. Cystic formation is due most frequently to traumatism. Panereatitis by infection through the duct of Wirsing from adjacent duodenal eatarrh is possible. This organ may be involved in general amyloid degeneration without causing symptoms. Abscesses of the pancreas are reported, as in pyæmia and variola.

Diagnosis of pancreatic inflammation is extremely difficult. Among the symptoms noted are epigastric pain and tenderness, extending toward the right shoulder, more or less vomiting, and sometimes symptoms which resemble intestinal obstruction. However, there may be diarrhœa, with excess of fat in the stools, and glycosuria. The presence of a cyst or neoplasm, if large enough, may be diagnosed by its location, especially if aceompanied by some of the symptoms above mentioned. Hemorrhage into the pancreas may be quickly fatal.

In the treatment of non-malignant pancreatitis predigested foods are indicated, with the administration of pancreatic extract of the raw glands of the sheep. The syphilitic variety calls for mercury and iodides. Cysts and malignant neoplasms demand prompt surgical procedure. 


\section{CHAP'TER VÍI}

\section{DISEASES OF THE HEART AND PERICARDIUM}

\section{CONGENITAL DISEASES OF THE HE.IRT}

Diseases of the heart in early life may be structural or functional, congenital or acquired, acute or chronic. The vessels are rarely the seat of morbid changes, although injury to the vessel walls or infection may induce thrombosis with ocelusion or septicamia. In rare instances arteriosclerosis is observed even in childhood, and hypoplasia is occa-

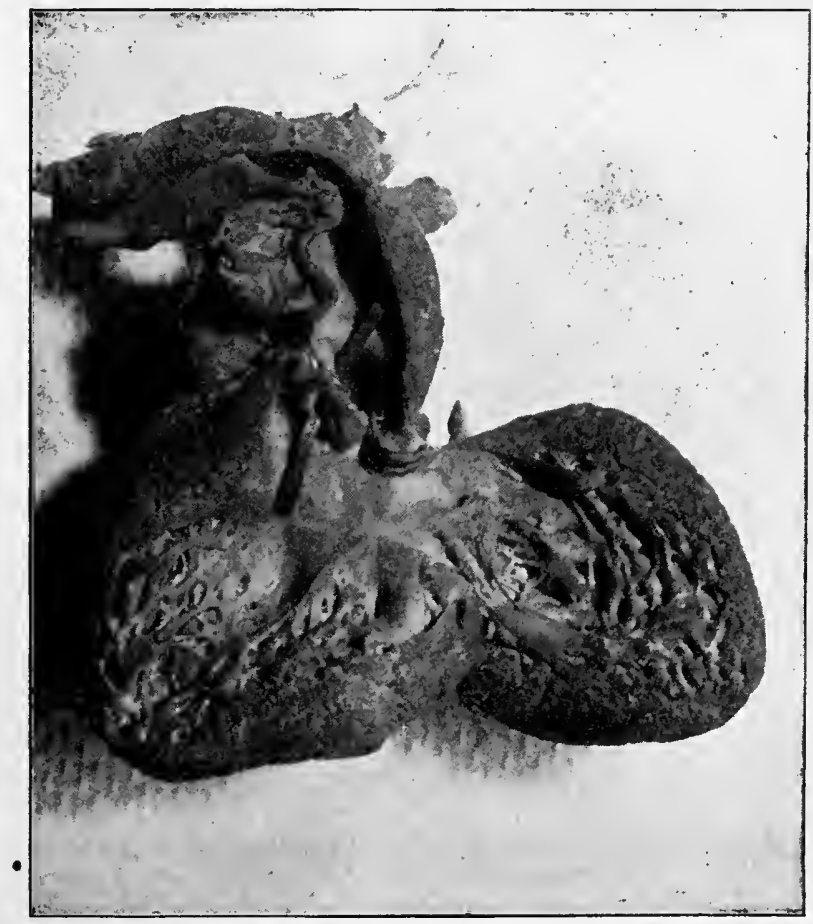

FIG. 140.-Congenital malformation at aortic orifice. Stick inserted through false passage behind semilunar valve.

sionally seen and may be hereditary. Narrowing of the isthmus of the aorta and even atresia have been reported.

Congenital cardiac disease is, in the large majority of cases, due to malformation of the heart or anomalous arrangement of its vessels 
either from arrest of development or from intrauterine inflammation. There may be a persistence of fetal conditions as a result of either process. The causes of developmental anomalies in the heart are generally obscure. In a few instances prenatal endocarditis has seemed to follow a rheumatic infection in the mother. Again, other associated anatomical defects, as spina bifida, anencephalia, polydactylia, etc., suggest a common etiology.

Among the commonest congenital anomalies are stenosis of the pulmonary conus or artery, defects in the ventricular or auricular septa, and persistent patency of the ductus arteriosus. The semilunar valves

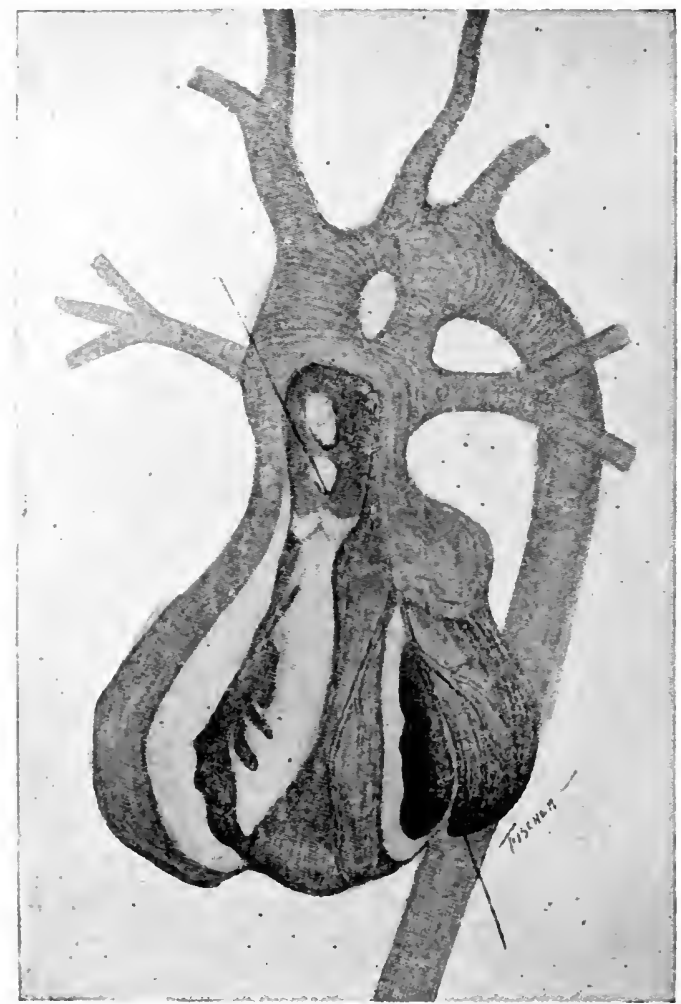

Fig. 141.-Cardiac malformation. Common trunk for aorta and pulmonary artery. Bristle passed through foramen ovale.

may be absent or rudimentary, increased or decreased in number or fenestrated. Two or more valves may be adherent, greatly narrowing the orifice, or the base of a valve may be attached to a fibrinous band stretched across a portion of the auriculoventricular ring, leaving a free passage behind. A false passage may be formed behind the base of a semilunar valve (Fig. 141).

Aberrant chordæ tendinæ may cross the ventricle, having no con- 
nection with valves and eolumnæ, giving rise to peculiar vibrations,the so-called musical heart.

The aorta and pulmonary artery may arise from a eommon trunk, from one or other of the ventricles, or from both (Fig. 142). Either ventricular or auricular septum may be entirely wanting, the heart being tri- or bi- or unilocular. The vessels emerging from the heart may be transposed. The heart itself may be displaced. It has been found in the right side of the chest, in the neck, in the abdomen, or in the chest wall, covered only by the integument.

Congenital heart diseases are usually confined to the right side, while those of postnatal origin select the left. Of the many eongenital defects

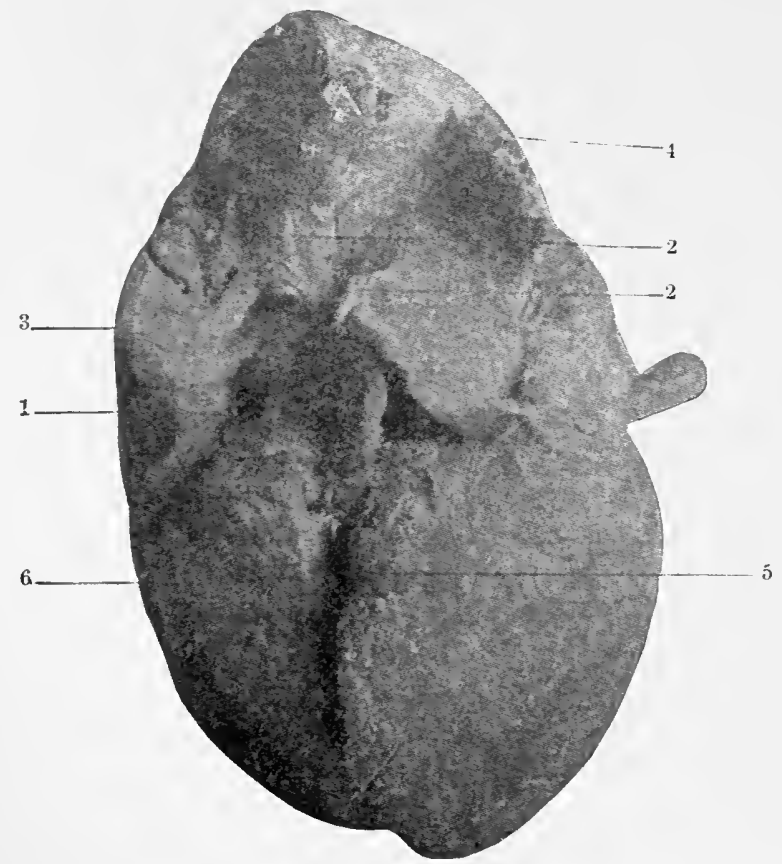

FIG. 142.-Congenital malformation of the heart. Boy, 11 years old. Stenosis of pulmonary conus. 1, malformation of pulmonary valve (2 cusps); 2,2 , aneurysm of right ventricular wall ; 3 , acute mural endocartis; perforate ventricular septum.

it rarely oceurs that one is found alone. Thus the most eommon, pulmonary stenosis, is generally accompanied by defeet in the ventrieular septum, by patent ductus arteriosus, foramen ovale, and by right-sided hypertrophy, all of which are compensatory to the obstruction in the pulmonary outlet (Fig. 142). The pateney of the fetal openings may also persist as conpensatory to obstruetion in the eirculation of the lungs, as in congenital atelectasis. Both pulmonary and tricuspid insuffieiency oeeasionally oeeur as a result of fetal endoearditis.

Symptoms.-CThe principal symptoms of congenital heart disease are 
cyanosis, dyspnœa, tumultuous action of the heart, right-sided hypertrophy, loud, widely diffused murmurs, clubbed fingers and toes, and retarded development. Of these the most constant is eyanosis, which may be noted at birth or appear for the first time weeks or even months later. It may vary in degree from a slight blueness of the lips and nails to a dusky hue of the entire integument. The cyanosis may be present only during spells of excitement, erying, or coughing, or during some unusual exertion, or it may be continuous for months or years. There may be clubbing of the terminal phalanges of the fingers and toes from venous stasis, which is rarely accompanied by œdema of the extremities.

Cardiac hypertrophy may cause bulging of sternum or ribs from pressure during the plastic period of infancy, with or without rhachitis. Growth is retarded, children who survive remaining puny and stunted in stature. Even slight exertion occasions dyspnœa with tachycardia. The chest wall vibrates over the tumultuous heart and occasionally a distinct thrill is discovered on palpation of the præcordia. Abnormal heart sounds, when present, are usually systolic, loud and harsh in character, frequently heard all over the chest, but with greatest intensity in the pulmonic area. In the combined lesions double murmurs are sometimes present and the varieties as to character and location may be extremely confusing. Occasionally no murmur is heard in congenital heart disease and cyanosis may be absent, the condition being unsuspected until discovered in the course of routine examination, as shown by the hypertrophy and dilatation of the right ventricle. Congenital heart lesion may be suspected from physical or mental backwardness unexplained by other causes.

Diagnosis.-The diagnosis of congenital from acquired disease of the heart is aided by a history of cyanosis (the earlier the development the more probable its congenital origin), the harsh character of the murmurs with their greater basic intensity, and the signs of right cardiac involvement. The diagnosis of the precise nature of the lesions is at times difficult, if not impossible, from the confusion of symptoms and signs due to a multiplicity of structural defects.

Prognosis.-The prognosis is always grave, a large majority dying in the first year and many in the first weeks of life. When compensation is efficient, life is occasionally prolonged to mature years. The possibility of intercurrent disease, however, in which the function of the crippled heart would prove inadequate, must always be kept in mind.

Treatment.-Management of congenital heart defects should be directed, first, towards the conservation of cardiac energy ; second, to protection from the dangers of dilatation. The first requires the best of care as to nutrition, bathing, fresh air, sunshine and cautiously-graded exercise. Systematic massage will often promote the circulation and lighten the functional burden of the heart. The second demands the avoidance of all conditions that impose extra work upon the already overtaxed 
heart, such as undue excitement, violent exercise, inflammations, or congestions. The child must be protected from sudden chilling of the surface and from all infectious disorders, especially those which cause pulmonary congestions, as bronchitis, measles, and pertussis. The tendency to endocarditis in defective hearts should be remembered and a rheumatic diathesis would require special prophylaxis against inflammations of that type. Routine treatment with drugs is useless and may be clangerous. Attacks of dyspnoea with tachycarclia call for measures to equalize the circulation. Pressure from distention of the abdominal viscera must be relieved by prompt evacuation of the bowels and the correction of gastro-enteric disturbance. Obstruction to the blood eurrent from pulmonary congestion may require the derivative action of rubefacients, heat to the extremities, etc. Extreme cases of right-heart distention may demand leeches to the right side of the chest. The free use of bromides will often allay cardiac excitement. Aromatic spirits of ammonia may avert threatened syncope. A judicious use of digitalis, carefully watched, sometimes strengthens the systole and quiets the delirium cordis.

FUNCTIONAL HEART DISEASE.

Functional heart disturbance is a term applied to abnormal cardiac signs and symptoms in the absence of structural lesions. Strietly speaking, it should be classed among the neuroses.

Evidences of functional disturbance may be either motor (arhythmia, tachycardia, bradycardia, syncope and palpitation), or sensory (precordial pain or uneasiness, nausea and vertigo).

The difference of opinion among authorities as to the infrequency of functionatcardiac disease in infancy and early childhood is evidently due to a misunderstanding as to the scope of the disturbances included under the term. No cardiac phenomena are more common in infancy than the variations of rhythm and frequency from apparently insignificant causes. In fact, all the motor manifestations before mentioned are seen in infancy and childhood, and have been attributed to the imperfect co-ordination and undeveloped inhibition characteristic of this period. It may be that the cardiac neuroses of later life offer no better explanation of their etiology as they appear in the unstable inhibition of highly neurotic individuals. The sensory phenomena are never seen in infancy and rarely in young children. Heart consciousness, as it is termed, is evidently a result of education, and attains its height of clinical perfection in the hysterical woman. Next to unstable inhibition, anæmia is probably the commonest contributing cause. The exciting causes may be limited only by the number of causes of reflex disturbance, whether mental, emotional, respiratory, digestive or sensory. Fatigue, excitement, and shock are undoubtedly the most prominent factors in the precipitation of an attack, although the use of certain drugs, such as tea, coffee, tobaceo and alcohol, diminish the stability of the heart's action.

Perversion of organic secretions, also pressure, produce well known 
symptoms of cardiac disturbance, as the tachycardia of exophthalmic goitre, seen occasionally in childhood. The syncope, sometimes fatal, from an enlarged thymus, and the bradycardia of postepileptic coma, present etiologic features still open to discussion.

Functional cardiopathies appear in the form of recurrent attacks, varying in duration from a few minutes to an hour. With recurrence of an exciting cause the symptoms may return at intervals for many days or indefinitely.

The child may show merely a disturbance of pulse-rate and rhythm or there may be sinking spells with pallor, unconscionsness, and muscular collapse. During these the heart-beat is feeble and indistinct and the respiration is shallow and irregular.

The diagnosis of functional from structural disease is not always easy, as the latter may exhibit all the symptoms of the former. The main points of difference in favor of functional disorder are the short duration of the attack, the rarity of persistent venous congestion, the brevity or absence of dyspnœa and cyanosis, the infrequency of pulmonary engorgement and accentuation of the second pulmonic sound, and the character of the cardiac murmurs when present. These murmurs are usually soft, basic, and transmitted only to the vessels of the neck, rather than harsh and apical, with more definite conduction. The heart rarely shows the enlargement so common in organic disease, although a dilated left ventricle with the systolic murmur of relative incompetency, somewhat frequently observed in anæmic children, seems to occupy an intermediate place between organic and functional affections. The error of pronouncing a heart diseased upon the discovery of adventitious sounds would be less common if the accidental murmurs of the child's heart were better understood.

The soft systolic bruit common to infectious fevers, the cardio-respiratory murmur of vesicular emphysema, and the before-mentioned sounds due to anæmia and transient incompetency, are all encountered in childhood.

Repeated observations should precede a positive diagnosis of organic disease in a child suffering from anæmia.

The treatment for the relief of an attack of syncope requires the recumbent posture and diffusible stimulants,-as camphor by mouth or inhalation; whiskey, or aromatic spirits of ammonia. Friction and warmth to the extremities, cautious inhalation of ammonia with cold affusions to the face and precordia may be employed. Tachycardia and delirium cordis require sedatives and antispasmodies, such as bromides, valerian, and asafetida. Mental suggestion may be used, and the relief or removal of any known exciting cause should be attempted. Evacuation of the bowels by a high colonic flushing may be necessary, and milk of asafetida may be administered per rectum. Heart spasm (pseudoangina) with vasomotor constriction may be relieved by nitroglycerin, one one-hundredth of a grain $(0.0006 \mathrm{Gm}$.) or the inhalation of nitrite of amyl. 
For the general condition cardiac and hæmic tonics, as iron, quinia and strychnia, are indicated, conjoined with nutritious diet and improved hygiene, which should protect the child from overwork, worry, or excitement.

\section{ACUTE ENDOCARDITIS.}

Acquired heart disease is of common occurrence in childhood, although not frequent before the third year. It is now generally believed that acute endocarditis is always secondary and due to some infectious organism. In childhood, rheumatism is the etiologic factor in about seventy-five per cent. of the cases. In fact, the endocardial inflammation is sometimes the first and, occasionally, the only manifestation of the rheumatic diathesis. Chorea and angina so frequently precede or accompany rheumatic endocarditis that they are justly regarded as manifestations of a common infection which occasionally simulates the adult type in the development of arthritic symptoms. Acute endocarditis is also a sequel of other infections, such as scarlet fever, pneumonia, empyema, influenza, typhoid fever, measles, diphtheria, and septic bone disease. Most of the pyogenic bacteria, from the frequent streptococcus and pneumococcus to the rarer gonococeus and colon bacillus, have been found present in the excrescences of acute endocarditis.

Acute endocarditis almost always involves the left side of the heart, in which point it differs from endocarditis of prenatal origin, which is rarely left-sided. Occasionally, however, an acute exacerbation may develop upon chronic right heart lesions or malformations. The inflammation is usually confined to that portion of the endothelium covering the valves, especially along their line of closure, although it sometimes extends to other portions of the ventricular lining. In an overwhelming majority of eases the mitral valve is the one involved, the aortic being far less frequently affected.

In an acute attack the endothelium covering the valves becomes congested, loses its lustre, and the valve becomes thickened and œdematous. Areas of hyperplasia develop in the subendothelial structures in circumscribed elevations or verruccæ. Endothelial hyperplasia and partly organized exudate may give rise to fungiform excrescences which, becoming detached by the blood stream, lodge in distant organs, as the spleen, brain, kidneys, and lungs. If infected, these emboli may cause multiple abscesses. Erosion of the soft epithelium results in ulceration (ulcerative endocarditis). In severe endocarditis, the myocardium is usually affected to a greater or less degree and acute dilatation is an ever-threatened danger, with its weakened systole and disturbance of valvular coaptation. Distortion of the valves, by the later shortening and thickening of their free borders, further interferes with their coaptation, while adherence at their points of junction may diminish the lumen of the opening, so that obstruction as well as valvular insufficiency may result. Inflammatory softening and ulceration of the endocardium may lead to perforation of the valve.

Symptoms.-The onset of an acute endocarditis, developing inde- 
pendently of other disorders, presents the general symptoms of an acute infection, such as malaise, fever, possibly nausea or vomiting, anorexia, irritability, restlessness, or stupor, with rapid and sometimes irregular pulse and dyspnoea, with or without eyanosis. Young children rarely complain of palpitation or the precordial pain frequently seen in adults. The true nature of the disturbance is often overlooked, especially if accompanied by pharyngitis, tonsillitis, indigestion or during the prevalence of influenza, the febrile symptorns being usually attributed to those disorders. A routine examination of the heart, however, will prevent such errors in diagnosis. In the first day of a mild attack tachycardia and arhythmia may be the only evidence of cardiac involvement. Usually by the second or third day a soft systolic bruit is heard most distinctly at the apex and transmitted to the left. The heart may be seen to pulsate violently through the thin chest wall and the delirium cordis is occasionally accompanied by a thrill. Sometimes as early as the second or third day the area of cardiac dulness is extended to the left, the apex beat lying without the nipple line. Daily examinations may show increasing intensity of the systolic murmur, diffuseness of the apex beat and greater dilatation. Dyspnoea, dry cough, cyanosis, and accentuated second pulmonic sound indicate increased labor of the right heart and pulmonary congestion from inefficiency of the weakened left heart. As the disease progresses occasionally a systolic murmur, developing at the base and transmitted towards the neck, shows involvement of the aortic valves. In rare instances this region is primarily affected.

In the majority of first attacks of acute endocarditis the symptoms may gradually subside in from two to four weeks, leaving a more or less dilated left ventricle, some thickening of the affected valves, and persistent murmurs indicative of incompetency or stenosis. Rarely the heart appears to recover entirely, leaving no indication of the inflammatory process.

The terms malignant, infectious, and ulcerative endocarditis have been applied to attacks in which the virulence of the infecting organism leads to extensive destruction of the endothelium or subjacent valvular tissues, and to the development of abscesses from infective emboli in other organs of the body. This form is rare in early childhood. It most frequently develops on the site of lesions which have resulted from repeated attacks of simple endocarditis. Malignant endocarditis may occur as a terminal affection in children with congenital heart defects. It rarely occurs in a previously sound heart and is most often met with as a complication of general septic and toxic disorders. The clinical picture is one of severe sepsis with its intermittent temperature, profuse sweats with or without rigors, hepatic and splenic enlargement, and profound prostration. There is usually a cardiac murmur corresponding to the valve affected, although this sign may be due to an old lesion. The pulse is extremely arhythmic. There is general ataxia, accompanied by delirium or stupor. There may be vomiting and diarrhoea and later hæmaturia, epistaxis and petechiæ. Hemiplegia from cerebral embolism 
may develop and simulate meningitis. The cough may produce sputum containing pus from abscesses in the lungs. Sudden pain in the left hypochondrium may follow septic infarets in the spleen.

Diagnosis.-The diagnosis of acute endocarditis slıould be based upon the increased area of cardiac dulness, rapid and arhythmic pulse, precordial distress, dyspnœa, and adventitious sounds. An endocardial murmur differs from the friction rub of pericarditis which is heard with both sounds of the heart, also from the accidental bruits which are heard usually at the base.

Malignant endocarditis may be diagnosed from meningitis by evidence of cardiac involvement, history of previous endocardial attacks, and the occurrence of multiple septic processes. From malaria, whose temperature, sweats, and splenic enlargement it may simulate, it may be differentiated by the presence of cardiac symptoms and absence of plasmodia in the blood and reaction to quinine. Typhoid fever shows a more gradual onset, and the presence of the Widal reaction. From uncomplicated pneumonia it is diagnosed by the temperature curve and physical signs. The leucocytosis of malignant endocarditis will aid in the diagnosis from typhoid and malarial fevers.

Prognosis. - The prognosis in simple acute endocarditis is good so far as life is concerned, since children very rarely die in the first attack. A predisposition to subsequent attacks is among the sequelæ, the most common of which is chronic endocarditis. The prognosis in malignant endocarditis is extremely grave. Rare recoveries have been reported, although with permanently disabled hearts.

Treatment.-The main points in the treatment of acute simple endocarditis are to reduce the work of the heart to the minimum, to allay cardiac excitement, and to maintain free elimination. Upon the first suspicion of endocarditis the child should be put to bed and given a purgative. A small bag of ice or the Leiter coil over the precordia will quiet the heart's action without impairment of its tone. Even young children may be accustomed to the cold if the application be made gradually, layers of flannel being at first interposed between the ice-bag and the chest. Sleep, however, induced, is the most favorable condition for cardiac tranquillity. Bromide of sodium, from one to ten grains (0.065$0.65 \mathrm{Gm}$.) in syrup of lactucarium, may be given every two hours if necessary. Pain and restlessness, if persistent, may best be met with opium, if the above-mentioned measures fail. Morphine, hypodermically, is the most satisfactory form of administration. The dose must be carefully gauged by the requirements of the case, the age of the child, and the possibility of idiosyncrasy. Dover's powder, one-half to two grains $(0.03-0.13 \mathrm{Gm}$.) may be given by mouth, if the use of the needle excites the child. A frequent repetition of the opiate is rarely necessary, as the effects of one dose may continue for hours.

The food should be liquid, easily digested, and reduced in quantity to avoid the possibility of heart embarrassment from pressure of distended stomach and bowels. 
The possibility of rheumatism should be kept in mind as the most frequent cause of heart disease in childhood. Rheumatism should be combated by the free administration of salicylates and alkalies. Digitalis, strychnia, and other cardiac stimulants, are generally held to be harmful in acute endocarditis. The routine administration of aconite, veratrum, and the coal-tar products which depress the heart, should be condemned. In advanced stages of the disease, where the heart's action is weak and anæmia develops, the ice should be removed and warm applications made over the precordia. In threatened syncope aromatic spirits of ammonia or alcoholic stimulants may be given and normal salt solution should be employed by enteroclysis or subcutaneously.

Daily examinations of the heart should be made to determine the extent of right-heart embarrassment, resultant from the enfeebled. left heart. The application of leeches to the right hypochondrium should not be postponed when the right auricle shows persistent dilatation of two finger-breadths in the fourth right interspace.

The child should be kept in bed for several weeks after the subsidence of all acute symptoms, as incalculable damage to the crippled valves and weakened myocardium may follow early heart-strain. Good ventilation and carefully regulated nutritious diet should be supplemented by iron, quinia, and strychnia, in view of the anæmia and muscular atony.

The tendency to recurrent attacks of endocarditis should never be forgotten. Against this a prophylactic regimen should be adopted. Woollen clothing should be worn summer and winter, the weight adapted to the season. The child should be accustomed to the daily cool bath. His diet should never lack a free supply of alkalies, vegetables, and fruit juices. Violent athletics or prolonged tests of endurance should be prohibited for the child who has suffered from endocarditis.

Malignant endocarditis, in addition to the above treatment, will require early a more pronounced support and stimulation. Alcohol, am-. monia, quinia, and strychnia should be freely administered. The primary focus of infection should be sought and treated secundum artem. The patient should be removed from contaminated air and unhygienic surroundings.

\section{CHRONIC ENDOCARDITIS-CHRONIC VALVULAR DISEASE.}

In childhood chronic valvular disease is the common sequel of acute endocarditis. Although the valves may appear to escape permanent injury from one attack of acute inflammation, it is exceptional that a second attack leaves the valve unchanged. Many causes which operate to produce chronic valvular lesions in the adult, such as arteriosclerosis, gout, syphilis, and alcoholism, are absent or extremely rare in childhood. The susceptibility of the valves to rheumatic poison-occasionally the only expression of rheumatism-is much greater in the child.

The changes most commonly observed in childhood are those of form and consistency due to the growth of adventitious tissue or to the 
consolidation and contraction of inflammatory exudate. The valves may be unequally shortened or thickened, or their free borders deformed by papillary excrescences so that perfect coaptation is no longer possible, rendering them incompetent. Fenestration of the valve leaflets from perforating ulcers may add to their insufficiency. Two leaflets may become agglutinated, or increasing fibrosis may diminish the lumen of the valvular ring so as to obstruct the free flow of blood. The chordie tendinxe may be thickened and shortened. Deposition of lime salts may occur, stiffening the valves and increasing the stenosis of the orifice. The auriculo-ventricular valve is the commonest seat of disease on account of its vascularity, the semilunar valves having no vessels within their substance.

Other causes of valvular incompetency may be seen in acute dilatations from heart-strain, where the valves themselves are not altered except in their relationship to the enlarged ring. Valvular sclerosis without previous acute inflammation may be favored by this accidental condition, so that permanent organic deformity may result. Chronic valvular disease is occasionally discovered in children giving no history of acute endocarditis, rheumatism, chorea, or exanthems, but who have a history of family heart disease, so that a hereditary type must be recognized.

- Any or all of the valves may be subject to sclerotic changes. Those occurring on the right side are a result of congenital lesions, or may be due secondarily to left heart disease. The mitral valve is the seat of chronic lesions in childhood in nienty per cent. of cases. Of these, incompetency is the most common lesion, exceeding stenosis more than eight to one. Next in order of frequency are aortic lesions, in which the relative frequency of incompetency and stenosis is still a mooted question. The combination of mitral insufficiency and aortic lesion is not uncommon. The right heart may duplicate the lesions of the corresponding valves of the left, although tricuspid stenosis and pulmonary insufficiency, as acquired lesions, are practically unknown in childhood. Sooner or later secondary changes inevitably follow crippling of the valves. Of these, dilatation from increased blood pressure is an early result. This is usually more pronounced in the auricle. Hypertrophy of the heart muscle, which is regarded as compensatory, gradually develops as a result of the increased work. In long-continued disease hypertrophy may yield to a secondary dilatation. This is apt to follow any acute illness, especially rheumatism.

Symptoms.-Mild valvular defects, with good compensation, may exist for years with few or no symptoms. The symptoms of more marked deformities are those due to pulmonary congestion, such as cough, dyspnoa and cyanosis, induced by violent or even moderate exertion. There may be epistaxis, vertigo, headache, and fainting. Rarely older children complain of palpitation or precordial distress. In extreme cases with right-heart incompetency there may be orthopnœa with superficial venous congestion and clubbing of fingers and toes, œdema beginning in 
the feet and becoming general, enlargement of the liver and spleen, albuminuria from renal congestion, anæmia, digestive disturbances, and retarded growth. The commonest sign is an increased area of cardiac dulness which may extend to the left even as far as the axillary line, and downward to the sixth interspace, at the same time the right border of the heart may be outlined two or three finger-breadths to the right of the sternum. Dulness may appear as high as the second interspace. Instances of such enormous cardiac enlargement, however, are not common and indicate the involvement of all the cardiac chambers. Hypertrophy of the left ventricle is indicated by increased dulness extending downwards and to the left, with well defined apex beat and firm, distinct systolic impact against the chest wall. Dilatation also shows cardiac en-

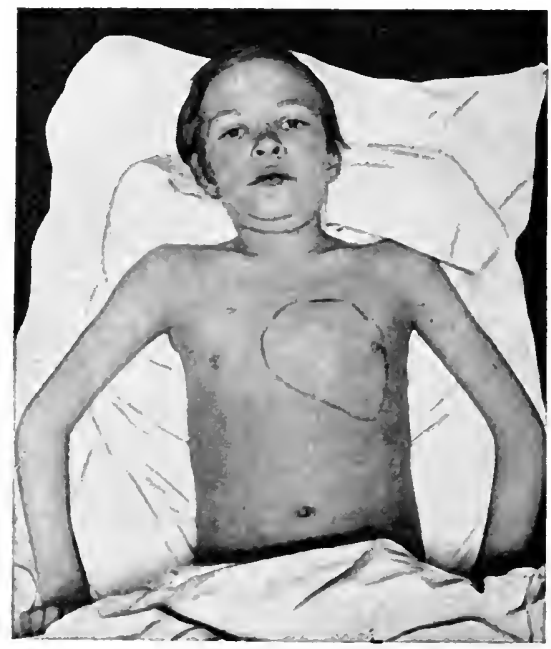

FIG. 143.-Chronic valvular heart disease, with dilatation and orthopncea.

largement, but the apex beat is diffuse, the impact less distinct, and if the chest wall be thin the systolic movements appear on its surface in wave-like undulations.

Diagnosis.-In the diagnosis of chronic valvular disease it should be remembered that so-called hæmic or accidental murmurs, although occasionally discovered, are less frequent in early childhood than in adult life; that in children between the ages of six and fourteen years the loud bruit of mitral incompetency is frequently due to acute dilatation of the ventricle without disease of the valve, and that the murmurs of organic lesions are usually more intense, heard over larger areas of the chest and are associated with cardiac enlargement.

The differentiation between the separate or combined valvular lesions is made from the same signs that obtain in valvular disease in adult life.

The failure of compensation may be attended by symptoms which 
suggest the gravity of the condition. The heart's action becomes rapid, tumultuous, and arhythmic, and the area of cardiac dulness may be noticeably increased. The murmurs may change in character or disappear entirely. 'The pulse is weak, compressible, irregular, or intermittent, while the face may show pallor or eyanosis. The jugulars, particularly the right, may be seen to pulsate. Breathing is hurried. There is usually cough and the child shows evidence of weakness or prostration. Effects upon the circulation may appear in odema of the extremities, hepatic enlargement, ascites, and passive renal congestion with scanty urine containing albumin and casts. When death occurs, the heart is arrested in diastole.

Prognosis.-The prognosis in chronic valvular disease depends upon the degree of compensation and the probability of its maintenance. The common mitral insufficiency and the rare aortic stenosis afford the most favorable prognosis, since they are usually well compensated in hypertrophy of the left ventricle. About puberty the normal increase in the heart musele and enlargement of the aorta still further lessen the embarrassment of the circulation, so that if this period be reached before secondary dilatation occurs, the outlook may be quite favorable. Mitral stenosis gives little promise of improvement, since the normal physiological congestion of the lungs in childhood is intensified by this lesion more than by any other, and secondary dilatation of the right heart quickly follows. In this lesion, especially, the probabilities of serious pulmonary disorders must be reckoned with and the possibility of emboli from the diseased valve must be remembered. Anæmia, with its pathologic consequences, is one of the common results of chronic valvular disease. A crippled heart renders grave any or all of the acute disorders of early life.

The rare aortic regurgitation is almost always accompanied by great compensatory hypertrophy of the left ventricle.* Compensation may continue for years, although a water-hammer pulse, throbbing carotids, attacks of vertigo, faintness, and even pulmonary congestion from secondary lesions of the mitral valve, may be present. In no other valvular lesion is danger of sudden death so imminent as in aortic insufficiency. When compensation fails, any unusual affux of blood may arrest the heart's action in diastole from overdistention of the exhansted left ventricle. Tricuspid incompetency, with throbbing jugulars, dilated right auricle and general venous stasis, as a heritage of left-heart lesions, heralds the approach of terminal symptoms.

The rarity of organic lesions in the liver and kidneys and of degenerative changes in the heart and vascular system, the recuperative energy of the developing period, the developmental changes in the relative capacity of the heart, aorta, and pulmonary vessels, all tend to

* In this lesion the area of cardiac dulness is increased downward, the apex reaching at times as low as the eighth rib, while in mitral incompetency the apex migrates to the left. 
render more favorable the prognosis of chronic valvular lesions in childhood, despite the gamut of acute infectious diseases which the crippled heart must run.

Treatment.-The management of chronic valvular disease can be dictated by no hard and fast rules, as it must depend upon the peculiarities of each case. During adequate compensation no treatment of the disease itself is indicated. A careful supervision of the child's hygiene is necessary, as errors in diet, excessive exercise, or exposure to cold or infection, may interfere with the equilibrium of the circulation and precipitate an attack of endo- or pericardiąl inflammation, or induce acute dilatation. Since the tendency of cardiac disease is to anæmia, the diet should receive strict attention, not only as to its nutritive value, but as to its digestibility, as indigestion with its intoxications and pressureeffects from flatulent distention is especially likely to increase the difficulties of the heart.

Excessive ingestion of fluids may suddenly increase the volume of blood to the detriment of the heart's action. The use of stimulants (tea, coffee, alcohol), or effervescing drinks (as soda, pop, and charged waters), should be interdicted for obvious reasons. Especial care is necessary against exposure to contagious diseases and pulmonary disorders on account of the inflammatory and congestive conditions they impose upon the heart's precarious compensation. For the same reason all occupations and amusements must be devoid of the possibility of heartstrain, from overexertion, fatigue, or excitement. When compensation is threatened from any cause, much may be done to preserve it, not only by attention to the above-mentioned rules, but by the employment of certain remedies. The child should be kept in bed to reduce the necessary work of the heart to the minimum. Sedatives may be necessary to allay excitement and secure sleep. Bromide of sodium or potassium, and even opiates, may be indicated. Free catharsis by calomel and soda, followed by salines, will diminish renal and portal congestion and remove toxic irritation.

Of the many drugs which act directly upon the heart, digitalis unquestionably heads the list in failing compensation. This is especially true in the chronic valvular disorders of childhood, since at this period there is rarely renal, hepatic, or arterial sclerosis, which frequently contraindicates the use of this drug in adult life.

The rarity of aortic lesions still further reduces the objections to the use of digitalis. When the pulse is rapid, irregular, and weak, the tincture of digitalis, unless contraindicated, may be given three to five times in twenty-four hours, in doses of from one to eight minims $(0.06-$ 0.5 C.c.) according to the age of the child and the effect upon the circulation. The object is to lengthen the diastole, give rest to the heart muscle and strengthen the systole. If the increased arterial tension from the action of digitalis embarrass the heart, this may be relieved by the addition of nitroglycerin, one two-hundredth to one one-hundredth grain $(0.0003-0.0006 \mathrm{Gm}$.). If the stomach is intolerant of even 
fat-free digitalis administered in ice-water, the tincture of strophanthus may be substituted in corresponding doses. When avoidable, the use of digitalis should not be continued for long periods. Intermittency of the pulse, developing under its use, is a signal for its withdrawal, or for the substitution of some other agent. In many instances, however, digitalis is not only well borne but required for periods of many weeks or months. Strychnia is invaluable as a heart supporter aud should be given from four to six times in the twenty-four hours, preferably by hypodermic injection in doses ranging from one five-hundredth to one-fortieth of a grain $(0.00012-0.0015 \mathrm{Gm}$.). The alleged idiosyncrasy against this drug in children is less frequently noted than formerly. In extreme cases it should be pushed to its physiologic limit, with intervals of three or four hours between doses. Caffeine citrate, alone, but preferably in combination with one or all of the before-mentioned drugs, is a valuable cardiac stimulant in doses of one-twentieth to one grain (0.003-0.065 Gm.).

To tide over crises, alcohol and aromatic spirits of ammonia may be needed. Dropsy, from failure of compensation, will require depletion by diuretics, such as potassium acetate and citrate, infusion of digitalis, diuretin, one to five grains $(0.065-0.32 \mathrm{Gm}$.) or by free hydragogue catharsis, compound jalap powder, one to ten grains (0.065-0.65 Gm.), or by calomel and salines. It may be necessary to relieve the local odema by punctures and scarifications and the ascites by aspiration.

Dyspnœa, cough, and restlessness that do not improve under heart stimulation, may require small doses of atropine and codeine, to which, for sleeplessness, bromides of sodium or ammonium may be added.

The necessity for absolute rest in bed and freedom from excitement during the occurrence of acute ailments, however trifling, cannot be too strongly emphasized. There must be constant supervision, not only during the acute exacerbations but during convalescence, and in fact throughout childhood.

\section{MYOCARDITIS.}

Under the term myocarditis may be included, for clinical purposes, any condition or process which affects the integrity of the heart muscle. The question as to whether such changes be inflammatory or degenerative, parenchymatous or interstitial, cireumscribed or diffuse, is usually determined at the autopsy. Primary myocarditis is probably rare in infancy and childhood, although sufficiently common as a fetal lesion.

Acute dilatation of the left ventricle in the course of infectious diseases, as diphtheria, scarlet and typhoid fevers, and also during attacks of endo- and pericarditis, has long been recognized as a grave complication or sequel. The frequent increase in the area of cardiac dulness with the signs of developing relative mitral insufficiency in acute febrile disorders, confirms the growing belief that the heart muscle rarely escapes the deteriorating effects of the systemic invasion of pathogenic bacteria or their toxins. That the left ventricle should be the most frequent seat 
of these inflammatory or degenerative lesions is due to its greater activity. Occasionally the right heart first yields, as in pertussis and pneumonia, emphasizing this same principle.

Post-mortems show the heart to be pale, flabby, and usually enlarged. It may present mottled areas of gray or yellow, interspersed with pale or normal tissue. Whitish streaks or fibrinous plaques appear beneath the endo- or pericardium, also islands of hypertrophied tissue are seen squeezed forward by surrounding zones of contracting fibrosis, producing a polypoid effect upon the cardiac intima. Yielding portions of the myocardium may result in aneurysms. There may be fatty, granular, or hyaline degeneration of the muscle fibre, minute multiple abscesses in the heart wall, thrombi in the smaller vessels, and sclerotic areas of varying size with cicatrization.

Symptoms.-The signs and symptoms of myocarditis bear no relation to the character or extent of the changes in the myocardium. Unfortunately, there are no pathognomonic symptoms of this grave condition. In all acute infections, during prolonged fevers and in endo- and pericardial inflammations, involvement of the myocardium should always be suspected when the pulse becomes weak, thready, slow, irregular, or intermittent. The disturbance of rhythm first approaches the fetal type; later, remissions occur in the force of the systole, with indistinctness of the apex beat. Careful percussion may show increased area of dulness extending downward and to the left, indicative of dilatation. In this case a systolic murmur from a relative insufficiency may first be heard. Dulness, also, may extend two or three finger-breadths to the right of the sternum in obstructive disorders of the respiratory tract, or as secondary to dilatation of the left ventricle. Right myocarditis invariably produces enlargement of the liver and spleen and venous engorgement of the abdominal viscera. Dyspnœa on slight exertion, with pallor of the face, is an early evidence of left myocardial insufficiency. Subsequent eyanosis indicates extension to the right heart.

Whether a condition frequently observed in acute infections, especially rheumatic, in which there is early increase in the area of cardiac dulness, occasionally accompanied by a soft systolic bruit, may be myocarditis is an interesting question, since the disappearance of these signs with the recession of the infection and the absence of cardiac sequele are suggestive of a spontaneous cure. The dilated or "weak heart" so frequently encountered in convalescence from severe acute disease, as typhoid and scarlet fevers, and especially diphtheria, is no doubt frequently due to changes in the myocardial structure, more extensive than those which constitute the general myasthenia. The functional activity of the heart, as compared with that of the voluntary muscles, may furnish a reason for its greater susceptibility to bacterial intoxication.

Prognosis.-The immediate prognosis is more favorable in children, on account of the absence of vascular and organic sclerosis, than in adult life. Acute nephritis following scarlet fever may prove a deter- 
mining factor in an unfavorable outeome of the myocarditis. The prognosis of a myocarditis which results in extensive parenchymatous and interstitial changes in the heart muscle must necessarily be grave, although with care the unimpaired muscular fibres may serve to maintain moderate functional requirements for an indefinite period. A case is recently reported of heart rupture in a young infant from multiple abscesses in the myocardium. However, with the difficulties attending the diagnosis of myocarditis, who shall deny that many cases result in complete recovery?

Treatment.-The treatment must apply in the majority of cases to a suspected condition. It is essentially prophylactic against acute dilatation with its resultant incompetency. Prevention of intoxication should be attempted by the early use of known specific agents, such as antitoxin in diphtheria, salicylates and alkalies in rheumatism, and the ice-bag in endo- and pericarditis.

The details for treatment are the same as for endocardial inflammation with which the myocarditis is so frequently associated. Special care should be directed to keeping the patient recumbent long after the subsidence of all acute symptoms. It is better to keep the child in bed for many weeks than to subject the weakened heart to undue strain with the possibility of sudden arrest or permanent disablement. The demands upon this organ should be minimized by every known means. Violent purgation should be avoided and emesis prevented. A free supply of oxygen must be insured and the cylinder at the bedside may be necessary.

\section{ACUTE PERICARDITIS.}

Acute pericarditis is not often seen before the third year, although it is occasionally found in early infancy and may develop in utero. It is frequently met with after the third year and is one of the most common fatal complications of rheumatism. It is rarely if ever primary, and is undoubtedly due to infection by one or more of a variety of pyogenic organisms. After rheumatism, it is encountered most frequently in pleurisy, pneumonia, the acute exanthems (especially scarlet fever), tuberculosis, and pyæmia. It is seldom found alone, but is usually accompanied by myocarditis and endocarditis. The pericardial sac is analogous to an articular synovial cavity, and its inflammations to those of an articular synovitis. The relation of pericarditis to rheumatism and other infectious processes further strengthens the morbid analogy and common etiology. Pericarditis may also follow trauma of the precordia (as from a blow), rupture of an abscess from degeneration of cheesy mediastinal glands, and perichondritis or necrosis of the ribs and sternum.

The products of a pericardial inflammation may be serum, fibrin, pus, and sometimes blood. These vary in their relative amounts in different cases or in different stages of the same attack. The effusion of serum may be sufficient to distend the pericardial sac to its extreme limit, or so slight as to fail to lubricate the opposing surfaces. In this 
latter event an exfoliation of endothelium allows considerable friction between the denuded layers, with stimulation of fibrinous exudation.

Pericarditis is at first usually cireumseribed but may become general. There is congestion of the vessels, quickly followed by an exudate which may at first be merely a thin pellicle easily detached, becoming later a fibrinous mass covering the affected area. The exudate may be likened in consistency and appearance to buttermilk, milk, cream, butter, and soft cheese. Pus cells or leucocytes are entangled in the fibrin and the exudate is not infrequently tinged with blood. The blood may be sufficient in quantity to constitute a true hemorrhage. In infancy and childhood the purulent form of pericarditis is most commonly seen, especially accompanying empyema of the left side. The pericardial sac may be distended with pus, which may find exit into the mediastinum or burrow into the supraclavicular region. In the presence of plastic fibrin adhesions may form between the opposing surfaces so that after repeated attacks the pericardial sac may be entirely obliterated. Miliary tubercles may stud the pericardium, especially in connection with a tubercular process in the lung or mediastinal glands. In the serous variety the exudate may be absorbed, as also may a small amount of pus, with occasionally little or no remaining evidence of the disease. The permanent thickening of the parietal pericardium and the presence and extent of adhesions depend upon the amount of plastic exudate and the frequent recurrence of the disease. The external layer of the pericardium is occasionally alone involved in a mediastinitis. This may occur with or independently of a pleuritis or pneumonia. In addition to a thickened and adherent pericardium, the heart is usually enlarged from dilatation due to the accompanying myocarditis, and chronic valvular lesions are common as a result of the endocardial involvement.

Contracting adhesions of the sac may hamper the heart's action and impede its growth, restricting its blood supply by pressure upon the coronary arteries, and thus favor degenerative changes in the myocardium with resultant myasthenia, dilatation, and their train of grave consequences.

Symptoms.-The symptoms of pericarditis in early childhood are not distinctive from other eardiopathies with which it is frequently associated. There may be febrile symptoms with moderate rise of temperature, restlessness, and, in some neurotic children, delirium. There is usually embarrassment of the heart action and oceasionally precordial uneasiness or distress in older children, with palpitation and irregular pulse. Dyspncea, orthopnœa, anxious facies, and cyanosis, may be present, dependent upon the amount of the pericardial effusion and the extent of myocardial and endocardial involvement. In severe pneumonia and extensive pleurisy the symptoms of the accompanying pericarditis are undistinguishable save as a prolongation of the primary disease. In the purulent form there are symptoms of septicæmia, irregular fever, chills, and sweating, with great and early prostration.

Early œdema of the thoracic wall is suggestive of purulent effusion. 
The physical signs include the basic double-friction rub carly in the attack, although usually missed because of its brief duration; also the flatness of the percussion note of the precordia dependent upon the amount of effusion. An early absorption of the effusion will eause the friction sounds to reappear. The heart sounds are muffled and indistinct; the apex beat may appear to be higher and is diffused. Even with a small effusion there may be prominence of the chest wall in the precordial region. In young infants most of the symptoms and physical signs may be wanting, the patient suecumbing to the purulent invasion which is first diagnosed at the autopsy.

The average duration of an attack of acute pericarditis with spontaneous resorption is from two to four weeks. The rheumatic form is apt to be persistent or to recur at short intervals, eovering, with its exacerbations and remissions, a period of several months.

The prognosis as to life in an acute attack is good, with the exception of the tubercular and purulent varieties. If the latter be not relieved by surgical means or the spontaneous escape of pus through perforation, it usually leads to early fatal termination.

Diagnosis.-The diagnosis of pericardial effusion from dilatation of the heart and empyema is at times extremely difficult. In dilatation, even with bulging precordia, the pulsations of the heart are often visible in a wave-like undulation beneath the thin chest wall. Cardiac murmurs, if present, are heard more distinctly. If the area of dulness extend far beyond the point of apex beat it is suggestive of pericardial distention. Fluid in the pleural cavity may be misleading. Usually palpation and auscultation give evidence of muffled indistinetness of systolic impact in large pericardial effusions. In extensive left empyema and serous pleural effusion the heart should show some displacement to the right, which, with uninterrupted dulness to the extreme left, will explain the cause. The concurrence of pericardial and pleuritic accumulations is so common as to render the diagnosis of the former condition extremely difficult. The character of the effusion can only be determined by aspiration, although toxic symptoms may occasionally point to its purulent character and a blood-count may show leucocytosis. Localized pericarditis with a walled-off effusion at the base of the heart may cause dyspnœa and dysphagia from pressure on the trachea and cesophagus, simulating mediastinal tumor. From this it is to be differentiated by the slow development and afebrile history of the latter, although the enlargement of tuberculous glands in the mediastinum may be accompanied by elevation of temperature.

Treatment.-If a pericarditis be diagnosed in the early or dry stage much good may be accomplished by the application of ice to the precordia. This should be retained in position by a bandage or vest with a layer of flannel interposed between the ice-bag and skin. The objection of fretful children usually subsides under the comforting effect of the cold. This treatment is believed to diminish the intensity of the inflammation and to restrict the amount of effusion. It also tends to quiet the 
cardiac excitement and conserve the tone of the heart muscle. Where the ice-bag is not well borne and when the heart's action shows signs of exhaustion, especially in infants, warm applications may be made to the precordia. These must be light, and care must be exercised to avoid wetting the clothing. An ideal for this is a small Japanese " hot-box," separated from the skin by a few layers of flannel.

The primary infection which the pericarditis complicates should receive appropriate treatment, whether it be rheumatism, pneumonia, pleurisy, or one of the eruptive fevers. Two important desiderata must be borne in mind in the treatment of pericarditis : first, to limit the overaction of the heart by all reasonable means; second, to relieve the general renous stasis which attends the cardiac insufficiency. For the former, absolute rest in a semirecumbent position must be enforced, since increasing dysprica and palpitation are aggravated by the dorsal decubitus. On no account should the patient be allowed to assume the upright position. Codeine is valuable for the relief of precordial pain, cardiac excitement and insomnia.

For the heart-fag, indicated by the rapid and weak pulse, stimulants are required, of which strychnia is, perhaps, the best. Great tact is necessary in the administration of strychnia to children, especially in cardiopathies where excitement is productive of much harm. The bitter taste of the alkaloid frequently arouses the child's opposition to all medication and even to food and drink, whereas the hypodermic needle, if awkwardly employed, induces a state of frantic terror. This may be avoided by adroitness and dexterity that prevent the child from witnessing the subcutaneous injection.

Digitalis is contraindicated in the early stage of pericardial inflammations. In experienced hands it may occasionally do good in the rapidly failing and intermittent pulse of a later stage when other remedies have proved ineffective. Caffeine citrate is useful and may be given by the mouth. The large and tender liver, scanty urine, and evidences of venous stasis below the diaphragm, may be greatly relieved by free diuresis and hydragogue catharsis. Small doses of calomel and soda, frequently repeated, should be followed by salines. If the signs of pericardial effusion be marked this should be repeated sufficiently often to secure several watery stools daily. Instead of weakening the child this treatment will frequently relieve dyspnœa. Free diuresis may be secured by potassium citrate or acetate, or by diuretin, two to five grains (0.13$0.32 \mathrm{Gm}$.), thrice daily. In older children a reliable infusion of digitalis leaves, one to four drachms $(3.75-15.0 \mathrm{Cc}$.$) , may prove efficient. That$ these measures promote resorption of pericardial effusion in many cases there is little reason to doubt. As in the other acute cardiopathies, the diet requires special attention that the patient's strength be maintained without distressing complications from distended stomach and bowels. To this end concentrated, easily digested liquids, such as liquid peptonoids, beef juice, somatose and milk, should be given in small quantities at intervals of from two to four hours. 
The fatality of purulent pericarditis renders imperative the evacuation of the pus. So, too, the overdistended pericardium should be relieved of serum when the degree of pressure threatens the action of the heart. Exploratory puncture may be made with an aspirating needle to determine the character of the fluid. If serous, it may be withdrawn by aspiration. Much discussion has arisen as to the most eligible site for puncture. Two things to be avoided are wounding the heart and puncturing the internal mammary arteries, which parallel the sternum about one-half inch distant from either border. A puncture in the fifth interspace on either side of the sternum will reach the pericardial fluid with but little danger of touching the heart. The internal mammary artery may be avoided either by introducing the needle close to or an inch away from either sternal border. If pus be demonstrated by aspiration, pericardotomy should be performed.

\section{ADHERENT PERICARDIUM-CHRONIC PERICARDITIS.}

Post-mortems frequently show adherent pericardium in the absence of ante-mortem diagnosis of pericardial inflammation. There is usually a history of pneumonia, pleurisy, tuberculosis, or liver disease, and frequently of rheumatism, although the symptoms of the latter may have been reported as insignificant. The pericardium is found to be thickened, and adhesions between its opposing layers occur in patches or throughout its entire extent, completely obliterating the sac. Occasionally a deposition of lime salts is found upon the visceral layer in plaquelike crusts, presumably due to the absorption of purulent exudate. The outer layer may also be adherent to the adjacent pleura, diaphragm, and mediastinal structures. The heart nearly always is enlarged, its ventricles, especially the left, being hypertrophied but more frequently dilated. Evidences of myocarditis and endocarditis, such as degeneration and sclerotic lesions of the heart wall and hyperplastic deformities of the valves and ostia are rarely absent.

Chronic pericarditis may result from the snccessive recurrence of acute attacks, or it may develop iusidiously and be chronic from the beginning. It has been found in the new-born infant, showing its development in utero, also at the post-mortems of young infants where its presence was unsuspected during life.

Among the signs of adherence of the pericardium to adjacent structures are permanent extension of precordial dulness, usually obscured heart sounds and systolic retraction of the chest wall over the apex beat, followed by a diastolic impact. The same retraction may be seen below the angle of the left scapula in the tenth interspace (Broadbent's sign). Diastolic collapse of the cervical veins is sometimes present (Friedreich's sign). Persistent enlargement of the liver in a child with venous stasis, anasarea, and ascites, in the absence of known causative lesion, should suggest chronic pericarditis.

Adherent pericardium is a permanent lesion. The prognosis is unfavorable because of secondary lesions of the heart and changes in other 
viscera from interference with the circulation. Death may occur suddenly from cardiac failure.

The condition demands free action of the bowels and kidneys, the withdrawal of effusions by paracentesis when necessary, reduction of the heart's work to the minimum by rest in bed, and the exhibition of cardiac tonics and stimulants, such as strychnia, digitalis, strophanthus, caffeine citrate, and iron for the progressive anæmia. Under favorable conditions, with great care, life may continue for many months. 


\section{CHAP'TER IX}

\section{DISEASES OF THE RESPIRATORY TRACT}

RHINITIS, ACUTE AND CHRONIC-CORYZA; ACUTE NASAL CATARRII; COLD IN THE HE.ID

Acute rhinitis is the most common disorder of childhood and may be seen in earliest infancy. Three factors are prominent in its etiology,viz., lowered vitality, exposure to cold and dampness, and the presence of pathogenic bacteria.

A predisposition to nasal eatarrh may be inherited. This appears either as a proneness of mucous tissues to develop pathologic conditions, or in the malformation of the facial and nasal bones which favors vascular congestion. Rhachitic and lymphatic children are favorable subjects for rhinitis, as are the underfed, half-clad and poorly-housed children of squalor. The victims of malhygiene, however, are not always the neglected children of poverty, since in homes of affluence the too frequently overheated rooms, imperfect ventilation, and indoor restraint lessen the stability of the vascular system, thus favoring local congestions upon the slightest exposure to lowered temperature. The first stage of rhinitis is eharacterized by vascular engorgement of the nasal mucosa, transudation of serum with lachrymation, sneezing, and a feeling of frontal fulness. The swelling of the mucosa diminishes the lumen of the nasal fossæ, causing partial obstruction to inspiration. A smarting sensation is produced by the impingement of air upon the inflamed Schneiderian membrane. In the infant this obstruction may so interfere with nasal respiration as to render continuous nursing difficult or impossible, so that insufficient nutrition may be a direct result.

Symptoms.-Rise of temperature, which may be slight, $100^{\circ}$ to $101^{\circ} \mathrm{F}$. $\left(37.5^{\circ}-38^{\circ}\right.$ C. $)$, headache, general malaise or irritability, usually usher in a common cold. Occasionally at this stage the attack aborts, all the symptoms disappearing in a few hours. As the congestion of the vessels is somewhat diminished the mouths of the muciparous follicles pour out their secretion, eausing increased viscidity of the nasal discharge. The sensitiveness of the Schneiderian membrane lessens, as does obstruction to the passage of air through the nasal fossæ. The mucoid eatarrh becomes mucopurulent and may cause excoriation of the integument of the alæ nasi and upper lip. A wide range of variation is observed in the intensity of the symptoms in different attacks. Acute rhinitis may occur sporadically but more often appears in epidemic form. It is frequently confined to a family or the inmates of a house and is probably communicable. The bacterial examination of the discharge in coryza shows all the microbic varieties usually present on the nasal mucous membrane 
but in vastly increased numbers. Of these no one has been selected to bear the exclusive etiologic responsibility.

From an uncomplicated coryza, under favorable conditions, the child recovers in one or two weeks. The tendency to recurrence upon exposure is marked, so that a succession of acute attacks may follow with brief or almost imperceptible intervals of remission. The Schneiderian mucosa may show local tumefaction and hyperplasia with submucoid hypertrophy. This hypertrophy may extend to the osseous structures, seen in the enlargement of the turbinated bones which, with the increase in bulk and vascularity of the soft tissues, cause varying degrees of obstruction.

Chronic rhinitis is not infrequently the result of oft-recurring attacks of the acute form. The line can not be sharply drawn between prolonged continuation of a series of acute or subacute attacks and the acute exacerbations of a mild chronic catarrh. Neither is the clinical distinction always evident in chronic rhinitis between the simple and hypertrophic varieties. So, too, the character of the nasal discharge of chronic catarrh in the same individual may appear as mucoid, mucopurulent or purulent. As a rule the discharge is not so profuse in chronic as in acute rhinitis. It may be gray, green, bloody, abundant or scanty, and may show a tendency to form crusts. These, decomposing, give rise to a most offensive odor (ozena). Ulcerative lesions of the mucosa may occur. In older children the accessory nasal sinuses (antrum, frontal or ethmoidal) may become involved in a local or general sinusitis. Syphilitic heredity may induce bony necrosis with a fetid, purulent or ichorous discharge and more or less destruction of the cribriform or nasal bones resulting in "saddle nose." Chronic rhinitis is frequently caused by imperfect ventilation and retained secretion, due to the presence of adenoid growths in the rhinopharynx. It may also be caused by the presence of a foreign body in the nares. In the latter case the unilateral and purulent character of the discharge is suggestive. Nasal polypi, though rare in childhood, may occasion a catarrhal discharge from the side involved.

The atrophic form of rhinitis, although rare in childhood, has been reported as early as the fourth year. When the change from turgescence and hypertrophy to atrophy of the nasal tissues occurs it is impossible to determine. Occasionally atrophic changes have developed insidiously with no history of acute rhinitis, attention being first attracted by the ozena. If advanced, an examination shows enlargement of the nasal chambers, with adherent crusts of dried secretion.

The effects of rhinitis, immediate and remote, are as serious to the well-being of the child as the disorder is common. Among the symptoms of chronic rhinitis, in addition to the discharge, are frontal fulness or headache, especially on arising in the morning; bad taste, impaired appetite, perversion of the special senses-hearing, taste and smell; indications of posterior nasal irritation-screatus, snuffling and spitting ; diminished vocal resonance, fetid breath, and coated tongue, inexplicable by other conditions. Among the secondary effects are otitis, through con- 
tiguity of tissue, with all its results; extension of catarrhal lesions to any part of the respiratory mucosa; impaired digestion from decomposing nasal secretions which have been swallowed, and conjunctivitis and keratitis from extension through the lachrymal duct. But most far-reaching in its baleful influence is the obstruction to respiration caused by the nasal stenosis.

Prognosis.-Rhinitis rarely, if ever, destroys life, except through some of its many secondary affections, hence the too-frequent indifference to nasal catarrhs on the part of both layman and practitioner. The diagnosis, "common cold," unfortunately relieves the parental mind of all anxiety, and a second professional eall is rarely encouraged "unless something serious develops."

Though atrophic rhinitis, strictly speaking, may never be cured, the fetor and crust formation may be minimized by persistent appropriate treatment, such as the use of oily sprays to soften the crusts, thorough cleansing twice daily with atomization, or, better, irrigation with a mild alkaline antiseptic solution (Formulas 11 and 12). Crusts that are refractory to irrigation must be gently removed by a cottonwrapped probe dampened in a weak lysol solution. Deodorants and stimulating solutions and powders should be used by atomization and insufflation.

Treatment of Acute Rhinitis.-The busy physician would better devote some of his valuable time to the enlightenment of parents concerning the far-reaching possibilities of the neglected "cold in the head" than later to expend all his energies in diagnosis and treatment of the pathological conditions.

The ehild should be put to bed, though the fever may be slight and the malaise not pronounced. A full dose of castor oil should be given, or tablets containing calomel, ipecac, and soda (Formulas 24 and 25), may be given every hour for four doses, then every two hours for six doses. If necessary this should be followed by citrate of magnesia or other saline to secure repeated bowel movements. Warm bathing is always in order and is especially valuable if the fever be high. Hot compresses may relieve the headache and sensation of tightness. The extremities should be kept warm, and hot pediluvia, with or without mustard, are valuable adjuncts. Careful nasal irrigation with tepid normal salt solution may be used three or four times daily to remove the tenacious mucus. Atomization of lavolene or albolene should follow the irrigation to soothe and protect the irritable mucosa (Fig. 71, Part I). In extreme stenosis, cautious applications twice daily of one or two per cent. solution of cocaine will deplete the engorged mucosa. The nasal obstruction to nursing in the very young infant may be relieved by instillation of a drop or two of adrenalin solution (1:5000) in each nostril.

The spiritus mindereri is valuable to promote diuresis and diaphoresis, which may be further aided by hot drinks of lemonade, aromatic teas, or diluted milk. In severe cases with high temperature the hotpack may be applied. There should be an abundant supply of fresh 
air warmed to $70^{\circ} \mathrm{F} .\left(21^{\circ} \mathrm{C}\right.$.), its dryness lessened by the slow evaporation of water containing turpentine, thymol, or eucalyptol.

The diet should be restricted to fluids in small quantities, and even the nursling should be freely supplied with water. The first outing after convalescence should depend upon the weather, dampness and strong winds being avoided.

Treatment of Chronic Rhinitis.-In the chronic rhinitis of children foreign bodies, extreme hypertrophies, exostoses, marked deflection of the septum and polypoid or adenoid growths, if present, should be removed. Most of these cases may profitably be referred to the specialist.

Chronic simple or hypertrophic rhinitis in a child is rarely incurable. Its proverbial intractability is the result of fresh accessions from the frequent recurrence of causative conditions. Of primary importance is attention to the ehild's general health, as catarrhal processes luxuriate in lowered vitality. Constipation and indigestion must be relieved. The quality of the blood should be improved by regular habits, fresh

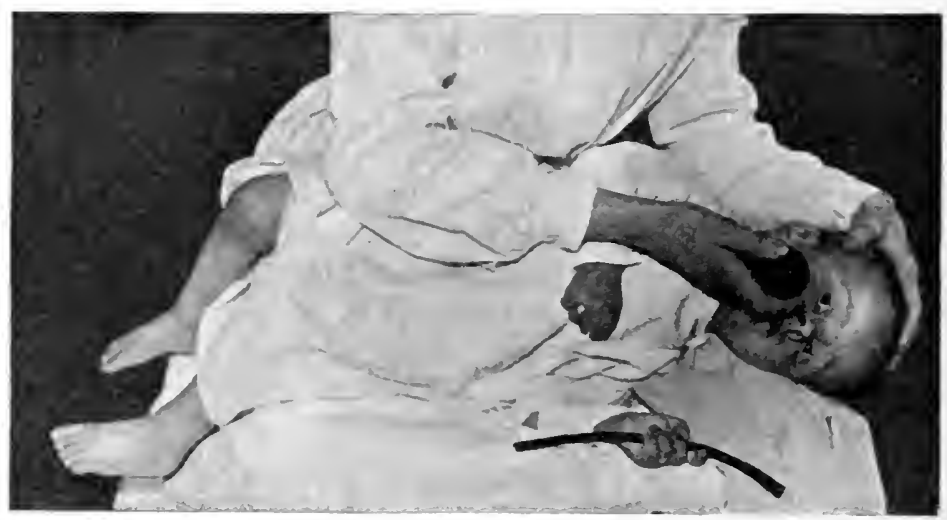

Fig. 144.-Niasal irrigation.

air, exercise, nutritious food, and the judicious administration of hæmic tonics and restoratives, as iron, manganese, arsenic, quinine and codliver oil. For frequently recurrent attacks it may be necessary to change residence to a more equable climate.

The main objects of treatment should be to relieve irritation, deplete congestion, and stimulate the morbid mucosa to normal activity. The excessive mucoid secretion furnishes a favorable culture medium for residential bacteria, which multiply therein with pus formation and decomposition. Irritating toxins and decomposing débris perpetuate the morbid process. The removal of the discharge is the first essential in the local treatment. Twice daily, or oftener if the case demands, the nasal mucosa must be cleaned by mild, tepid solutions of alkalies, because of their well known property of dissolving mucus. Combinations of an alkali with antiseptics, such as sodium bicarbonate, biborate, and clloride, with eucalyptol, menthol, or carbolic acid, are frequently useful. Solu- 
tions of mercurie ehloride or potassium permanganate may be necessary when the diseharge is very purulent. Redundancies and hypertrophies may eall for astringent applications, as solutions of alum, tannic acid, sulphate or sulphoearbolate of zinc. In older children cotton tamponage with hygroscopie or astringent agents, as glycerin or glycerite of tannin, may be employed (Formula 14). In the same way, iodine or iodide of potassium in glyeerin and water may be applied, the tampon being allowed to remain for several hours. Cleansing irrigation requires the nasal douche or atomizer. The infant's nasal tract may be irrigated by means of a half-ounee syringe with a soft rubber tip, which oecludes the nostril. As the ehild lies upon its side the tepid fluid is introdueed very gently into the upper nostril and allowed to flow freely from the lower (Fig. 144). Older ehildren may be taught to use the nasal douehe, allowing the fluid to cirenlate freely from one side of the nasopharynx to the other, the lower part of which is oeeluded by the apposition of the soft palate to the posterior wall. This aetion of the palate may be secured by breathing through the mouth during irrigation.

\section{Prophylaxis. (See Hygiene.)}

\section{MEMBRANOUS RHINITIS.}

A form of acute rhinitis is seen in children in whieh a membranous deposit appears over the nasal mucosa. This croupous or membranous rhinitis resembles nasal diphtheria, from which it is frequently indistinguishable save by baeteriologieal examination. The membranes may extend to the nostrils, where they appear as a grayish-white eroupous deposit, which when stripped from the underlying mueosa leaves that surface clean without bleeding. When removed the membranes re-form in a few days and by their presence narrow the lumen of the nasal passages.

The ehief interest lies in its differentiation from diphtheria, whieh must still depend mainly upon the isolation of the Klebs-Loeffler organism. However, the history of exposure, the presenee of a membranous exudate in other loealities, the profound systemie disturbance, glandular enlargements, foul-smelling discharge from the nose, albuminuria and the sequel, neuritis, point almost positively to diphtheria. Moreover, diphtheritic membranes are more closely adherent, and bleeding follows their removal.

In all eases the appearance of membrane in the nares should lead to a suspicion of diphtheria and to prompt isolation of the patient until cultural tests have been made.

The prognosis is favorable, though the duration may extend to three or four weeks.

The treatment consists in loeal cleansing with alkaline solutions and astringent applieations (Formulas 10 to 15). Calomel and tincture of the ehloride of iron in full doses are usually administered to combat the hyperinosis. 


\section{SYPHILITIC RHINITIS.}

The only indication of syphilis in the new-born may be "snuffles," with little or no discharge from the nostrils. Occasionally, however, there may be a mucosanious discharge or even epistaxis. The tendency to necrosis of the nasal bones with deformity rarely occurs in congenital rhinitis. The mistake is frequently made in regarding every case of snuffles in young infants as syphilitic. Regurgitated milk in the posterior nares is a frequent cause of snuffles and respiratory obstruction.

The coryza of syphilis usually develops from the second to the fourth week.

The treatment is constitutional by mercurial inunction and attention to nutrition. (See Syphilis.) Local treatment consists in cleansing the nose with oily applications (Formula 9) by atomizer, a cotton-wrapped probe, or nasal dropper. The difficulty in nursing, from the nasal accumulations, requires their frequent removal. If necessary a rubber tube may be passed through into the pharynx and allowed to remain in situ during each nursing.

\section{NASAL POLYPI.}

Nasal polypi, both mucons and fibrous, are occasionally seen in childhood, though rarely before the sixth year. Their most common location is the middle meatus, from the outer wall of which they depend by a more or less elongated pedicle. They may be single, multiple, or bilateral, and give rise to symptoms of occlusion and mild chronic rhinitis. They are aggravated by dust-laden atmosphere and damp weather.

The diagnosis is made by examination with speculum and mirror, and their removal, when pedunculated, is best accomplished by means of the wire snare, or they may be seized with the forceps and twisted off. The resulting hemorrhage, if severe, may be checked by packing with a strip of gauze saturated with a five per cent. solution of antipyrin.

Foreign Bodies in the Nose.-Children and infants very frequently introduce small objects, such as peas, beans, and beads, into the nose where they become impacted. If long retained the mucous membrane swells and partly or entirely conceals the object. The symptoms are those of partial occlusion with unilateral discharge. The probe may reveal their presence if the mirror and speculum fail. Specially devised scoops and forceps may be necessary to effect their removal, but they may often be easily removed by engaging them in the loop of a wire snare. If recently introduced, the body may be dislodged by air forced into the opposite nostril.

\section{EPISTAXIS-NOSE-BLEED.}

Epistaxis is common in children, especially in boys between the ages of four and twelve years. It is rarely seen earlier. Syphilitic rhinitis in infants is sometimes accompanied by nasal bleeding, though epistaxis is not a frequent feature in the hemorrhages of the new-born. 
Nose-bleed may be the result of capillary oozing or direct hemorrhage from rupture of the arterioles in any part of the nasal mucosa, although its most frequent site is the anterior and inferior portion of the septum. Usually it is trivial in character but occasionally causes extreme exsanguination.

Several explanations have been offered for the frequency of epistaxis in childhood, among which are the greater tendency to local congestions from trifling causes, the fragility of the vessel walls and the relative thinness of the supporting mucosa.

The causes may be local or general. Among the former are traumatisms, blows, falls, picking at the nose, foreign bodies, adenoids, varicosities, erosions, and chronic rhinitis. General causes include all conditions which favor congestion, either active or passive, such as typhoid fever, diphtheria, and measles; violent exercise; mental excitement and cardiac hypertrophy; constipation, cold extremities and whooping cough; also stasis from heart, lung, liver, and kidney lesions. Various blood conditions favor epistaxis, as hæmophilia, scurvy, purpura, anæmia, chlorosis, leukæmia, rheumatism, and syphilis.

Epistaxis frequently oceurs during sleep, and, if the blood be swallowed and vomited, may be misinterpreted. Epistaxis may occur only rarely from some aceident or it may be recurrent. If frequent it may be serious from the resultant anæmia. Habitual nose-bleed is suggestive of eardiac incompetency, and examination will often reveal valvular defects. Obstinate constipation and badly ventilated school-rooms are undoubtedly responsible for many cases of recurrent nose-bleed.

Treatment.-The child should be kept quiet in the sitting position. For obstinate epistaxis the bleeding point should be located and pressure applied, if possible. This may be accomplished when hemorrhage is in the anterior portion by compressing the ala against the septum. Insufflation of astringent solutions, as alum, tannin, sulphate of zinc, antipyrin, etc., are sometimes useful. Adrenalin solution $(1: 1000)$ may be applied on a swab. The bleeding may be arrested through reflex action by the momentary application of cold to the face, but more particularly to the cervical and dorsal spine. Revulsion may be secured through hot pediluvia and evacuation of the bowels by enema. If other means fail, tamponage or plugging, anterior or posterior, should be resorted to. A strip of gauze introduced into the naris will favor clotting. Pressure may be secured by means of an ice-bag or rhineurynter. If one is not at hand it may be improvised from a condom, fingerstall or even a kid-glove finger, which, tied over the end of a catheter, is introduced and inflated, the end being secured by a thread. One caution in the use of rubber bags: the distal end should not project through the posterior naris, as yielding in the line of least resistance the rubber will balloon in the pharynx. For permanent cure of varicose areas cauterization may be necessary.

In children subject to frequent epistaxis the predisposing cause 
should be sought in some of the before-mentioned conditions and measures instituted for its relief.

A thorough examination with careful review of the child's history may bring to light organic or systemic conditions little suspected. A frequent mistake lies in confining treatment to the seat of hemorrhage and overlooking the causative constitutional condition.

\section{CONGENITAL LARYNGEAL STRIDOR.}

Rarely a peculiar defect is noticed in the respiration of very young infants. The act is accompanied by a purring sound, sometimes ending in a gasp or crow, as though the entrance of air were momentarily prevented by some obstruction in the larynx. This noisy inspiration is not usually continuous; is increased by excitement, and disappears during sound sleep.

In the absence of malformations of, or growths in, the upper respiratory tract, this congenital stridor is explained by some as a neurosis. There is thought to be incoördination between the inspiratory muscles of the chest and those which control the opening of the glottis. The inrush of air, in response to chest expansion, finds the vocal cords insufficiently relaxed, a form of laryngeal chorea.

The fact that in some of these infants the epiglottis is seen to be unduly curved has suggested that its inopportune approximation may be the cause of the stridor. Prolapse of the mucosa of the laryngeal ventricles, or falling in of the relaxed glottic walls, has also been offered in explanation.

Whatever may be the cause, expiration is unimpeded, the voice is clear, cyanosis is absent, and there is no interference in normal development. The stridor gradually disappears in later infancy. As the child's health and growth do not seem to be affected, no treatment is necessary.

Congenital stridor is not to be confused with laryngismus stridulus, a disorder rarely seen before dentition and usually associated with rhachitis and tetany.

\section{ACUTE LARYNGITIS.}

Though acute laryngitis is common to all ages it assumes special importance among the diseases of childhood. The reason for this is the greater tendency at this age to respiratory stenosis, not only from the small lumen of the child's larynx, which can ill afford reduction from inflammatory thickening, also from greater plasticity of the exudate in acute catarrhs, but principally from the predisposition to laryngospasm. In fact, the gravity of simple catarrhal inflammation of the larynx is in direct ratio to the tendency to spasm which is due to the instability of the nervous system.

Laryngitis is seen most frequently between the second and fifth years. Like other inflammations of the respiratory mucosa, it is undoubtedly due to microbic infection and rarely if ever occurs, except from trauma- 
tism, in the absence of other lesions of the respiratory tract, such as rhinitis, adenoids, pharyngitis, tonsillitis, or bronchitis. It may oceur secondarily to most of the acute exanthems, especially measles, scarlet fever, and variola.

Among the exciting causes are exposure to cold and dampness, also traumatisms from direct violence or from inhalation of irritating vapors or fluids. A predisposition to laryngeal affections is seen in some children who show other evidences of lymphatism, and may possibly be explained by the richness in lymphoid bodies of the subglottic mucosa.

Symptoms.-The symptoms of acute catarrhal laryngitis are those of laryngeal irritation and occlusion of varying degree,-viz., cough and obstructed respiration. The cough is characteristically violent, explosive, and is variously described as harsh, barking, metallic, brassy, or clanging. Aside from these symptoms the child may show little evidence of general disturbance. Usually there is a slight rise in temperature, rarely a high fever, in uncomplicated cases. The temperature, cough and hoarseness, with malaise and anorexia, may continue for a week or more without alarming symptoms. On the other hand, the invasion may oceur unexpectedly at night, with the classical symptoms of croup. The child is suddenly aroused with loud, clanging cough, and crowing inspirations which can be heard throughout the house. With staring eyes, distended nostrils, and pallid face bedewed with perspiration, he clutches at his throat in the terror of impending suffocation. The inspiration is labored and stridulous. The suprasternal, clavicular, and intercostal depressions with each inspiration, and the tense and rigid neck, show the effort of the inspiratory muscles to overcome laryngeal obstruction. The picture of air-hunger is marked as the child sits up in bed or restlessly throws himself to and fro. The dyspnœa is increased by the child's mental excitement, which is aggravated by the panic of the household. The hastily summoned physician may arrive in time to witness these symptoms, but must frequently be content with a history, the child having fallen asleep after vomiting induced by domestic remedies. He may show little evidence of the recent disturbance. Occasionally, the attack is prolonged to extreme asphyxiation, the violent muscular effort to overcome the obstacle to inspiration causing pulmonary congestion from aspiration of blood. The superficies are pale from depletion of their vessels, and the nails and lips are cyanotic from venous stasis and accumulation of $\mathrm{CO}_{2}$. Under earbonic acid narcosis the spasmodic element subsides, with immediate relief of the dyspnœa, which is followed by the sleep of exhaustion. If the inflammation be subglottic, however, the tumefaction of the mucosa and adhesive quality of the exudate may so obstruet the larynx as to prolong the dyspnœa, so that in rare instances a feeble child may succumb. Usually the following day finds the patient apparently well, although the second and even the third night may see the symptoms repeated. Rarely for several consecutive nights the attacks may occur, with diminution in their severity. 
Prognosis.-The prognosis as to recovery is good, though recurrences are common until developmental changes, such as increased amplitude of the larynx and stability of the nervous system, diminish the susceptibility.

Treatment.-The treatment in a mild case requires little more than keeping the bowels free, application over the larynx of turpentine and lard, and spraying the nares and pharynx with Seiler's solution several times a day. It may not be necessary to keep the child in bed unless to prevent exposure, but the temperature of the room should be even. The air should be moistened by evaporation of water to which a drachm (3.75 C.c.) of eucalyptol, thymol, or tincture of benzoin has been added. Warm drinks should be frequently given and the child should even be roused for a drink of warm milk during the night.

Night attacks of stridor may sometimes be averted by syrup of ipecac in small doses, two to fifteen minims (0.12-0.90 C.c.) during the day and two doses of the mixed bromides of sodium and ammonium, two to ten grains (0.13-0.65 Gm.), according to age, an hour before and at bedtime.

In severe attacks the dyspnœa may be relieved by emesis induced by teaspoonful doses of syrup of ipecac, repeated every fifteen to thirty minutes. If necessary, this may be followed by two to five grain (0.13$0.32 \mathrm{Gm}$.) doses of powdered alum in a teaspoonful of sugar and by copious draughts of warm water. In rare instances of failure to secure emesis the stomach should be emptied by the stomach-tube. Hot fomentations should be applied over the larynx. In older children an ice-bag may be substituted. The bowels should be evacuated by an enema, and calomel, in small repeated doses, is useful.

If the glottic spasm persist, bromides, five to ten grains (0.32-0.65 $\mathrm{Gm}$.$) , according to age, with one to ten grains (0.065-0.65 \mathrm{Gm}$.) of chloral may be administered per rectum, and repeated if necessary in an hour. Opium in the form of camphorated tincture, five to twenty minims (0.3-1.25 C.e.) may be given to quiet the nervous excitement.

Protracted dyspnœa with increasing cyanosis may require intubation of the larynx. If ineffectual, on account of œdema of the glottis, a rare complication in acute laryngitis, tracheotomy may be necessary.

\section{CHRONIC LARYNGITIS.}

Chronic laryngitis is usually the outgrowth of repeated attacks of the acute catarrhal form, with resultant permanent congestion and hyperplasia of the mucous membrane. It is a frequent accompaniment of tonsillar and adenoid enlargements or of hypertrophic rhinitis. It is undoubtedly aggravated by and may be due to mouth breathing. Syphilis and more rarely tuberculosis are also causes of chronic laryngeal inflammation.

The whole mucosa in chronic catarrhal laryngitis is hyperæmic, the vocal cords may be thickened and their surfaces show erosions which occasionally result in shallow ulcers. The thickening often ex- 
tends to the neighboring tissues, interfering with the pliability of the epiglottis.

From habitual huskiness the voice may become whispering or there may be complete aphonia. There are recurrent exacerbations, easily induced by fatigue, dampness, inhalations of smoke or dust, or by visceral disturbances which cause congestion of the upper respiratory tract. There is frequent effort to clear the throat by "hemming" or coughing, although the amount of expectoration is small.

Hoarseness in early infancy is always suggestive of syphilitic laryngitis and may be present in the first week of life. The history or the presence of other syphilitic lesions would point to the character of the laryngitis. The type of lesion is most frequently that of condyloma which primarily attacks the epiglottis. It can sometimes be recognized without the use of the mirror.

Tuberculous ulcers may appear primarily in the larynx. This is very rare in early childhood, as tubercular lesions in this locality are usually secondary to those in the lungs. These ulcers give rise to pain which is constant and severe, in addition to the other symptoms of laryngitis. They are usually accompanied by some rise of temperature, general malnutrition, and indications of tuberculosis in other areas.

Prognosis.-Chronic laryngitis is not a self-limiting disease and may prove extremely refractory to treatment: The catarrhal cases usually recover after removal of adenoid growths or correction of other disorders of nose and pharynx.

Treatment.-Mild alkaline and antiseptic solutions may be sprayed into the pharynx so that nebulized liquid may reach the laryngeal mucosa. In the same way diluted astringent solutions, as nitrate of silver, protargol, or sulphate of zinc, may be used (Formula 13).

Aside from the removal of adventitious growths in the nose and pharynx, hygiene is the most potent factor in the treatment of chronic laryngitis. Correction of gastric, hepatic, or renal disorders may be required, also avoidance of all known eauses of laryngeal irritation. Since the symptoms are ameliorated during the warm season, removal from a damp, changeable climate to one that is dry and more equable offers the most promising results.

\section{SYPHILITIC LARYNGITIS.}

The prognosis in syphilitic laryngitis is better in children than in adults, as the lesions are usually more superficial and less destructive. Stenosis from cicatricial contractions may require intubation, in which case the tube may have to remain in situ for several months. Antisvphilitic treatment in the form of mercurial inunctions and potassium iodide must be continued until the disappearance of all symptoms.

TUBERCULOUS LARYNGITIS.

The general treatment of tuberculous laryngitis should be that of tuberculosis. In addition to the cleansing sprays, the pain may be 
alleviated by the use of anodyne solutions, such as cocaine, menthol, adrenalin, etc. (Formula 17).

PSEUDOMEMBRANOUS LARYNGITIS-MEMBRANOUS CROUP; TRUE CROUP.

Pseudomembranous laryngitis is an inflammation of the larynx characterized by the formation of a false membrane which may involve the epiglottis and supracordal tissues, or it may be wholly confined to the subglottic mucosa. Whatever be its location, the pseudomembrane formation in the larynx, as on other mucous surfaces, is due to bacteria. Among the micro-organisms most commonly found are the Klebs-Loeffler bacillus, psendodiphtheria bacillus, and the strepto-, pneumo-, and staphylococcus. Analysis of a large number of cases of membranous laryngitis showed Klebs-Locffler bacilli to be present in about eighty per cent. Pseudomembranous laryngitis may occur as a primary affection, but is more frequently secondary to diphtheria of the nose, tonsils, or pharynx. The pseudomembrane shows no structural peculiarities characteristic of the etiologic microbe. Its extent varies in different cases and it may involve the entire trachea and even the smaller bronchi (Fig. 145). It may be so thick as to diminish greatly the lumen of the larynx or it may appear as an extremely delicate deposit on the mucosa, so that symptoms of stenosis may be only exceptionally due to the blocking of the larynx by the actual membrane. The element of spasm undoubtedly operates in the majority of cases in the causation of asphyxia.

The symptoms of primary pseudomembranous laryngitis, aside from obstructed respiration, are rarely severe. The temperature seldom rises above $101^{\circ} \mathrm{F} .\left(38.3^{\circ} \mathrm{C}\right)$. There is but little glandular involvement, as the laryngeal mucosa is poorly supplied with absorbents. Hoarseness and cough, which mark the invasion, increase in severity as the disease progresses, with signs of dyspnca especially seen upon inspiration. Later the expiration shows obstruction, the cough, at first clanging, becomes aspirant, and the voice is reduced to a whisper or there is complete aphonia.

All the symptoms of respiratory obstruction described under catarrhal laryngitis may appear, but are usually more gradual in their development. Sleep gives but temporary relief from the progressive stenosis. The condition is indicative of grave danger from impending asphyxiation in which the disease soon terminates, in the absence of prompt relief. The course from inception to fatal termination may cover a period of from one to five days.

Diagnosis.-Membranous croup may be differentiated from foreign bodies in the larynx by the history, sudden onset, and absence of fever in the latter; from retropharyngeal abscess by the character of the cough and the presence of a tumor in the post-pharyngeal wall. From catarrhal laryngitis the differentiation is, at times, extremely difficult, but as a rule the onset is less acute, the fever less marked, the development of stenosis more gradual and progressive, and less relieved by sleep, the cough is less frequent and noisy, aphonia is more common, and stridor 


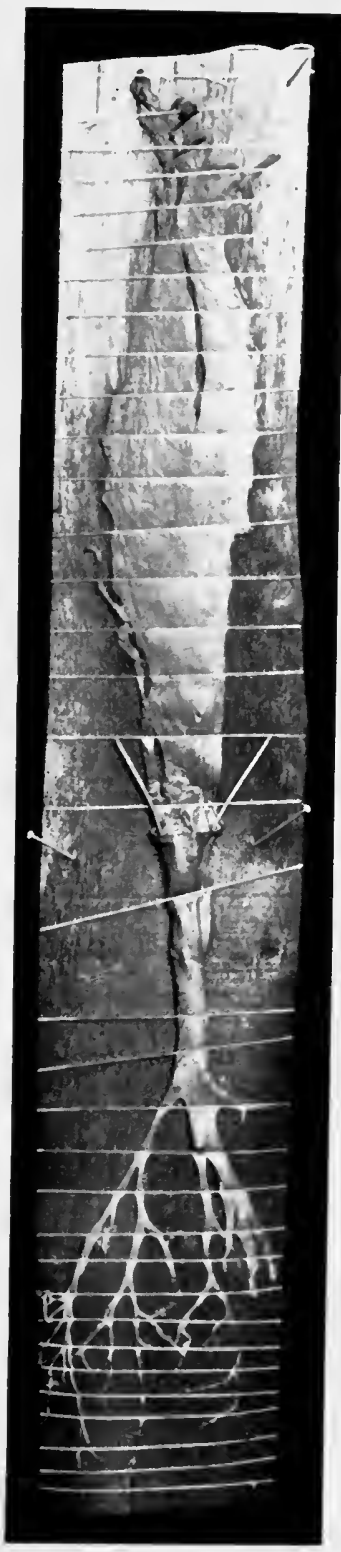

FIG. 145.-Diphtheritic membrane from trachea and bronchus, coughed during intubation. (Dr. S. W. Kelley.) 

appears both in inspiration and expiration in the later stage. The bacterial examination, which should never be omitted, will in this form of laryngitis show Klebs-Loeffler bacilli in the majority of cases. As the smear can rarely be secured from within the larynx, culture tests must be made from the secretions of the adjacent mucosa. Negative findings do not disprove the existence of true diphtheria.

Treatment.-Every case should be isolated and treated as a suspected case of diphtheria. The present trend of opinion favors the early use of antitoxin in full doses (4000 to 6000 units). The administration of calomel, ipecae, and soda should be commenced early and continued until the bowels act freely. Rest in bed, pure air warmed to from $70^{\circ}$ to $75^{\circ} \mathrm{F}$. $\left(21^{\circ}-24^{\circ}\right.$ C. $)$, and moistened by evaporation of water containing turpentine, eucalyptol, or compound tincture of benzoin, with entire frecdom from excitement, must be secured. 'The diet should consist of warm liquids. If the pulse be weak and rapid, alcoholic stimulants and strychnia should be given. For respiratory stenosis, an emetic, such as ipecac or alum, may be tried but should not be frequently repeated. Vaporladen air, from the croup-kettle or water-pail in which heated bricks are placed, under an improvised tent, usually relieves the dyspnœea and may be repeated as often as beneficial. During these inhalations, the child should be protected from the moisture by a blanket or rubber sheet.

Mercurial sublimations are sometimes useful and may be administered under the tent by placing fifteen to forty grains $(1-26 \mathrm{Gm}$.) of calomel on a heated surface, as a fire-shovel raised to a red heat. This is preferable to an alcohol lamp on account of safety. The room should be aired after each sublimation, which may be repeated every three or four hours if beneficial. The air-hunger renders the need of oxygen too obvious to require emphasis. A supply of fresh warmed air should never be neglected, and the can of oxygen at the bedside may prove of inestimable value. In extreme stenosis intubation of the larynx may be necessary to relieve the dyspnœa. (See Diphtheria.). Uncomplicated cases which escape asphyxiation tend to recovery in from five to seven days.

\section{CEDEMA OF THE GLOTTIS.}

Edema of the glottis is occasionally the cause of laryngeal stenosis in children. The infiltration of serum occurs chiefly in the epiglottis and aryepiglottic folds. The loosely attached mucosa becomes at times enormously distended and presents the appearance of tense pale pink tumors. Overhanging the glottis they approximate at each inspiration, so that complete occlusion and suffocation may result.

This much-dreaded condition may be caused by the swallowing of hot liquids, corrosive acids, or alkalies, or by the inhalation of steam and irritating vapors. It is an occasional complication of inflammations of the mucosa of the pharynx and larynx, or of perichondritis. It may accompany scarlet fever, variola, erysipelas, diabetes, etc., or may be 
caused by the irritation of a foreign body. Rarely it appears as an angioneurosis and is then classified as an idiopathic œdema. Most frequently cedema of the glottis is seen as a grave complication of diseases of the heart, kidneys, lungs, and liver, and it may be the terminal condition of extreme hydræmia.

The prominent symptoms are inspiratory dyspnca-expiration being unaffected-stridor and cough. The voice may be clear, since the vocal cords are rarely involved. The sensation of a foreign body in the larynx leads to frequent efforts to clear the throat with but little expectoration. If due to local inflammation there is dysphagia and tenderness on pressure over the cricoid cartilage. If the cedema develop as a result of remote organic lesion, pain is not a prominent feature.

The diagnosis from other forms of laryngeal stenosis is made by direct inspection, laryngoscopic examination, or by palpation. The œdematons masses may sometimes be felt with the finger.

The prognosis of œdema of the glottis is grave if unrelieved.

Treatment.- The indications are for derivation and local depletion. For the first, free catharsis, hot foot-baths, and general diaphoresis are means to be recommended. Cold applications to the neck and the swallowing of cracked ice may prove beneficial. Astringent sprays, as weak solutions of tannic acid, alum, cocaine, or adrenalin, should be used locally. All conditions tending to favor local infiltration should receive appropriate treatment. Scarification is the most efficacious procedure for local depletion. A curved bistoury, wrapped with adhesive plaster to one-eighth of an inch of the point, may be introduced over the epiglottis, guided by the index finger of the left hand which depresses the point, so that it engages the tumefied mucosa of the glottis. The incisions should be made at the outer borders to prevent the escaping blood and serum from entering the larynx. In extreme dyspnœa prompt tracheotomy should be performed.

\section{TUMORS OF THE LARYNX.}

Cough and steadily increasing dyspnœa, which persist for weeks or months, may be due to the presence of new growths in the larynx. The form most frequently seen in childhood is that of papilloma, which is occasionally met with in very young infants and may be congenital.

These growths are single or multiple, sessile or pedunculated, and are generally located on or near the vocal cords, hence interfering with phonation. The most frequent site is the anterior commissure. No definite cause for these tumors is known, although their occurrence in connection with warty growths in other parts of the body has given rise to the suggestion of a "papillomatous diathesis."

The symptoms are similar to those of chronic laryngitis with possibly more marked tendency to aphonia and recurrent attacks of asphyxia. The history shows a progressive eharacter. The diagnosis from chronic laryngitis must be made by the laryngoscope. 
The prognosis as regards life is grave in infancy as there is a tendency to recurrence after removal. In this respect laryngeal papillomata prove an exception to the rule regarding benign tunnors. 'There is danger, especially in young infants, of suffocation from mechanical obstruction and easily induced spasm of the larynx. The growth itself is provocative of catarrhal inflammation and renders the larynx especially susceptible to diphtheritic and other infectious proeesses. Failures in intubation are occasionally due to narrowing of the glottis from the presence of these growths.

The treatment is surgical in the removal of the tumors through the mouth by means of specially devised instruments, or by thyrotomy or laryngotomy. Occasionally tracheotomy must be performed to avert threatened asphyxiation from spasm or from engagement of a peduneulated growth in the ehink of the glottis.

FOREIGN BODIES IN THE LARYNX AND TRACHEA.

Foreign bodies of great variety not infrequently have found their way into the child's larynx through accidental aspiration. This is most likely to occur during fits of conghing, crying, or sneezing, while holding some small body in the mouth, or during the mastication of food. Children sleeping with some object in the mouth are liable to this accident, as during sleep the glottis is relaxed. Paralysis of the laryngeal muscles, especially after diphtheria, favors the entrance of substances through the chink of the glottis. They may lodge in the ventricles, bringing on a fit of coughing by which they are expelled, or by a spasm of the glottis they may be retained and cause alarming symptoms of suffocation. Such a body occasionally passes into the trachea or down into the right bronchus, where it may become impacted, shutting off the air from the right lung.

Lumbricoid worms sometimes find their way throngh the glottis. At times the larynx or trachea is invaded by the rupture of a caseating gland in the neighborhood.

The first symptoms--cough, dyspnœa, and aphonia-vary greatly with the size and form of the foreign body and its location. Congh, excited by the irritation, is usually severe and prolonged to extreme exhaustion. Occasionally the cough and dyspnœa may cease for hours, only to return with increased intensity when the body is dislodged from some part where it was temporarily impacted. Peas, beans, or dried cereals may, by swelling from absorption of moisture, increase the dyspnœa and irritation. Indestructible substances, as beads, coins, etc., have been known to remain in the larynx for many days and even years with but little disturbance. Lodging in the bronchus they may cause inflammation and ulceration, and, escaping into adjoining tisśue, give rise to pneumonia, pleurisy, abscess, or emphysema. Small bodies sometimes move up and down with each respiratory excursion and may be heard by auscultation over the trachea, rattling against its walls. If impacted in a bronchus, a foreign body may give rise to pain located at one side 
of the sternum, while the respiratory murmur may be feeble or wanting in that lung.

Diagnosis.-The diagnosis, although usually plain from the history and symptoms, is sometimes difficult. The sleeping child, with some small body in his mouth, may awaken suddenly with all the symptoms of acute laryngitis, and occasionally cases have been treated as such even to tracheotomy, when the cause was revealed as a foreign body in the larynx. Antitoxin has been administered for a supposed laryngeal diphtheria which proved to be due to a grain of popcorn or a nut. Pertussis which baffled all remedies for months has terminated with the expulsion of a small coin. The X-ray will aid in the location of a body if it be of sufficient density.

The prognosis is always grave.

The indications are for the immediate removal of the foreign body. Care should be exercised not to crowd a lodged body further down the larynx by rude palpation. If the substance is known to be smooth and symmetrical, slapping the child on the back, while suspended with head downward, may promote dislodgement. If not immediately relieved the child should be placed in the hands of a specialist.

\section{TRACHEITIS.}

Tracheitis, independent of inflammation of the larynx or bronchi, is rare and of short duration. Its involvement in a general respiratory catarrhal inflammation is common. Foreign bodies, if long retained, cause tracheitis of varying intensity, and occasionally acute catarrh may have its beginning in this tube.

Among the symptoms are tickling, burning, or pain upon the inspiration of cold air, as well as some tenderness on pressure over the trachea. The expectoration is not as profuse as is that of bronchitis.

The diagnosis from bronchitis is not easy, although a sense of heat in the throat or behind the sternum, in the absence of bronchial râles, is suggestive of tracheitis.

The treatment of acute catarrhal inflammation of the trachea is essentially the same as that of acute bronchitis. In addition, inhalations of compound tincture of benzoin, eucalyptol, or terebene, one teaspoonful to the pint of boiling water, will relieve the pain, or oily sprays may be used.

Diphtheritic tracheitis is not an uncommon sequel of laryngeal diphtheria. Instances are known in which the false membrane developed on the tracheal mucous membrane in the absence of laryngeal diphtheria. Examination of the sputum revealed the presence of the Klebs-Loeffler bacillus when diagnosis from clinical symptoms and laryngoseopic examination failed.

ACUTE BRONCHITIS.

Catarrhal inflammation of the mucous membrane of the large and medium-sized bronchi is more frequent in childhood than in later life. 
The explanation for this frequency is seen in the greater prevalence of causes, both predisposing and exciting. Of the former may be mentioned some of the anatomical peculiarities of infancy, also, lowered vitality resulting from malnutrition, constipation, dentition, and rhachitis. Among the latter are the infectious diseases and greater exposure to chilling of the surface.

From the first breath until late childhood the lungs are physiologically congested. As compared with mature development the ratio of alveolar to tubular capacity is less. The ratio of vascular capacity to that of the right heart is less, so that the lungs are relatively overworked. One evidence of this appears in the ratio of respiration to pulse-rate, which is less than in later life. Anatomical peculiarities are seen in the tortuosity and distensibility of the pulmonary blood-vessels, the loose attachment of the bronchial mucosa, the want of rigidity of the thoracic parietes, the underdevelopment of the respiratory museles, and the yielding character of their points of origin and insertion. Since active hyperæmia or passive congestion are commonly recognized as preliminary to acute catarrhal inflammations, there is in the engorgement of the bronchial mucosa of infancy a eonstant predisposition to bronchitis. The instability of the circulation through imperfect development of vasomotor control in infancy shows the pathological effects of disturbanees nowhere better than in the already surcharged bronchial and pulmonary vessels. As the development and persistence of all catarrhal processes are favored by lowered vitality, the well known tendency of the developing period-with its double burden of metabolism-to debility from trifling disturbances helps to explain the frequency of bronchitis in children.

Rhachitis, a disease of infancy, shows a special predisposition to catarrhs of the respiratory tract as well as to mechanical defects of the chest which handicap respiration.

Bronchitis is a common accompaniment of the acute infectious diseases, such as measles, influenza, pertussis, typhoid and scarlet fevers, and is occasionally associated with fermentative and putrefactive disorders of the digestive tract. It is usually preceded by rhinitis, pharyngitis or tracheitis and bears an intimate relation thereto, both in predisposition and etiology. "Catching cold" is the commonest explanation of its causation. Children are especially susceptible to lowered temperature because of their relatively large radiating surface, and the large percentage of blood in the superficial capillaries exposed to surrounding influences. The helplessness of infants during the creeping and toddling age, their exposure to drafts and the chilling effects of wet diapers and drool-soaked clothing, as well as the want of intelligence in older children and their reckless exposures to wet and cold, are among the common exciting causes of bronchitis in childhood.

The etiologic relationship of micro-organisms to bronchitis is the same as that seen in catarrhs of other mucous tracts. The bacteria found in the sputum of bronchitis include the entire flora of the bronchial tree. 
Their pathogenic importance increases with the development of conditions favorable to their multiplication and invasion of the mucosa through the broken or attenuated epithelium. The preponderance of this or that pathogenic organism in a given case of eatarrh of the respiratory tract may depend upon the form of organism prevalent in the community. In this way different epidemies of nasal, pharyngeal, or bronchial catarrhs are frequently attributed to different miero-organisms. It should not be forgotten, however, that most epidemies of acute eatarrh present other common etiologic conditions, such as atmospheric humidity, prevailing winds, changeable temperature, and malhygiene. Although distinguished bacteriologists claim to have isolated a specific organism in the micrococcus catarrhalis, mixed infection is the rule in all inflammatory processes of the respiratory mucosa.

Symptoms.-An attack of acute bronchitis usually develops somewhat suddenly, with the history of exposure and more or less rhinitis, pharyngitis, or laryngitis. Cough is a common and early symptom, at first dry, irritating, and ineffectual. There is always some elevation of temperature and usually more or less malaise. These symptoms may vary in degree from a barely pereeptible indisposition to a state of profound hyperpyrexia with headache, vague myalgias, and pain in the chest, especially induced by coughing. This may be frequent and racking. Infants manifest their discomfort by restlessness, irritability, and thirst. Constipation is a frequent precursor and accompaniment of acute bronchitis. Loose, green stools, however, often follow an outbreak of bronchitis in young infants and have been attributed to gastrointestinal infection from the swallowed sputum. In infants, vomiting is frequently caused by fits of coughing, so that the child may actually lose an appreciable amount of nourishment in this way. The stage of dry cough rarely lasts more than twenty-four hours and is succeeded by the stage of expectoration in which the cough is softened by the outpouring of mucus into the tubes. In older children this is extruded at the termination of each paroxysm. Children under four or five years of age almost invariably swallow the sputum.

The expectoration is, at first, a scanty, whitish, viscid mucus, but rapidly increases in quantity and becomes yellowish, mucopurulent, and may be colored by dust or soot. Acute bronchitis is self-limited and, if uncomplicated, runs its course in from five to ten days. The temperature has usually reached its height $-101^{\circ}$ to $103^{\circ} \mathrm{F} .\left(38.3^{\circ}-39.4^{\circ} \mathrm{C}\right.$. $)$ - the second day of the attack, gradually subsiding to normal in from three to five days. Acceleration of pulse usually keeps pace with the rise in temperature, but increase in respiration is ont of all proportion to either. This disturbance of pulse-respiration ratio is characteristic of acute pulmonopathies and may reach, even in simple bronchitis, a ratio of two to one instead of the normal three or three and one-half to one. This hurried respiration, the play of the alæ nasi and the presence of cyanosis are indicative of a severe attack, regardless of temperature. The severity of the attack depends largely upon the size of the tubes 
involved in the inflammation. If this be confined to the larger tubes and trachea, the bronchitis is mild and usually of short duration, although the cough may be severe and expectoration profuse. A more severe type, however, is that which affects the medium-sized tubes, involving the entire thickness of their walls. In this form there is intense congestion with rapid exfoliation of epithelium, in places denuding the nutcous lining to its basement membrane. The tubes often become blocked with accumulations of inflammatory exuclate made up of epithelial débris, leucocytes, bacteria and pus.

The gravest type, and one which occur's most frequently in infants because of anatomical peculiarities, is bronchitis of the capillary tubes, which, with their paucity of muscular fibres and alssence of ciliated epithelium, are anatomically and histologically related to the alveoli themselves. So that the old terms "capillary bronchitis," and "alveolar" or "suffocative" catarrh, not only represent this clinical picture, but are also suggestive of the pathological processes of this frequently fatal disorder of infancy.

In a mild case of bronchitis, inspection shows nothing but a slightly increased frequency of respiration. In severe types there are dyspnœa, cyanosis and recession of the less resistant parts of the chest wall during inspiration.

Percussion gives unaltered resonance, and ausenltation during the first stage reveals slight exaggeration of normal, puerile respiratory sounds, or there may be dry, sonorous or sibilant râles, indicative of an altered lumen of the tubes from zones of irregular congestion of the mucous lining. In the moist stage auscultation reveals many râles varying in character and distribution according to the consistency and location of the secretion. A few rhonchi only may be heard over the larger tubes, and these rarely may be limited to one side of the chest. Coarse bubbling or purring râles indicate fluidity in the large bronchi. Crepitation imparted to chest walls may be felt through the clothing, and is often a cause of anxiety to the mother. Fine, moist, or subcrepitant râles indicate secretion in the smaller bronchi and are heard in circumscribed areas. The conductivity of the infant chest and the thinness of its walls render the medium râles audible over most of its surface. The occlusion of even a considerable number of the smaller tubes may not appreciably diminish the respiratory murmur, on account of the transmissibility through infants' lungs of the exaggerated respiratory sounds from the unaffected areas.

Diagnosis.-Bronchitis may be distinguished from acute or chronic affections of the upper respiratory tract and from cough due to other causes by the physical signs,-i.e., by the presence of râles, fremitus, character of cough and, in older children, sputum. Intensification of symptoms and a prolonged high temperature should lead to a suspicion of bronchopneumonia.

Prognosis.-The prognosis of acute uncomplicated bronchitis in children is usually good, although that accompanying the acute infectious 
diseases not infrequently develops into a bronchopneumonia. Bronchitis in young infants must always be regarded as a serious disease, on account of the anatomic and physiologic peculiarities of the respiratory apparatus at this period, and the tendency to development of the capillary form. Weakly infants not infrequently succumb to attacks of uncomplicated bronchitis. In very young infants there may be persistence in some portions of the lung of congenital atelectasis; or occlusion of some of the tubes and absorption of the residual air may result in collapse of the area thus cut off (acquired atelectasis).

Treatment.-The indications for treatment in these conditions are the maintenance of oxygenation and support of the infant's strength, as death is due to exhaustion and asphyxiation. In the very beginning of an attack the intensity of the pulmonary congestion may sometimes be diminished by revulsant measures which cause determination of blood to other areas. Hence the use of purgatives, hot-baths and rubefacients to the surface and extremities. The air of the room should be warm $-70^{\circ}$ to $72^{\circ} \mathrm{F} .\left(21^{\circ}-22.2^{\circ}\right.$ C. $)$ - and moistened by the evaporation of water containing turpentine, eucalyptol, ereosote or compound tincture of benzoin. The bowels should be freely opened by calomel, ipecac, and bicarbonate of soda, or a full initial dose of castor oil. The chest and trunk in young infants should be masséed with warmed camphorated oil. In older children, an application of turpentine and lard, one to four, will prove more stimulating. The use of poultices and fomentations in acute pulmonary inflammations has been the subject of much discussion, probably not so much on account of their doubtful efficacy, but because of the frequency of their abuse and malapplication. Few practitioners have failed to observe the beneficial effect of a properly applied warm poultice. It should be light, warm, and made to cover the entire chest, and must be retained in place without undue constriction or embarrassment of respiratory movements. Poultices are contraindicated in conditions of exhaustion and profuse bronchorrhœa. Except in the hands of a trained nurse their application is so doubtful that the careful physician may well discard the routine ordering of poultices. A rational substitute is a jacket of cotton between layers of cheesecloth, covered by protective tissue. This should be cut to fit and pinned smoothly about the thorax. If the temperature be high in the early stage, spiritus ætheris nitrosi, two to five minims (0.12-0.3 C.c.), or liquor ammonii acetatis, five to twenty minims (0.3-1.25 C.c.), may be administered every two to four hours, for the first day or two. The food should be restricted to a minimum allowance and water freely supplied. Older childrep should receive only liquid food and that warmed. Copious draughts of hot carminative teas may be useful to promote elimination. Mild cases may require nothing further.

In the moist stage, vigorous infants may be assisted in ridding their tubes of profuse secretions by the timely administration of an emetic, as the syrup of ipecacuanha, in teaspoonful doses. The use of expectorant and cough mixtures is so frequently abused that much gain in the aggre- 
gate will result from their abandonment in young children. Cough of sufficient frequency to deprive the ehild of needed rest may recfuire bromide of sodium, one to four grains $(0.065-0.26 \mathrm{Gm}$.) in syrup of lactucarium, fifteen to sixty minims $(0.72-3.75$ Gm. $)$, according to age, every three hours. If obstinate, relief from cough may be secured by the use of heroine, one one-hundredth to one-fiftieth grain $(0.0006-0.0013$ $\mathrm{Gm}$.), or even camphorated tincture of opium, in moderate doses, not too frequently repeated. Profuse bronchorrhoea which threatens life by drowning may call for the administration of atropine or belladonna in doses of one one-thousandth to one five-hundredth grain $(0.00006-0.00013$ $\mathrm{Gm}$.) of the former, or one to two minims (0.06-0.12 C.c.) of the latter, to eheck secretion and sustain respiration. Emptying the trachea and bronchi may be aided by the force of gravity. Holding the child with face and head downward during a fit of conghing may be followed by the expulsion of a considerable quantity of mucus. The tendeney to hypostasis in tubular catarrhs of infants calls for a frequent change of position and, although sleeping quietly, the ehild should be turned every hour or two.

Cyanosis demands oxygen, secured by free ventilation or even cylinders of oxygen by the bedside. The heart should be sustained by the use of alcohol and strychnia.

Accumulations of gas in the stomach and bowels, which by their pressure embarrass respiration, must be relieved by enteroclysis, massage, and catharsis. The convalescence from a severe attack of acute bronchitis should receive careful attention, as there is a marked tendency to recurrence upon slight exposure, with the ever-threatening danger of bronchopneumonia, or the acute attack may become chronic.

There should be supervision of the hygiene, including nutritious food. The administration of cod-liver oil in the winter months, and of tonies, such as quinine, iron, and strychnia, are indicated. When a paroxysmal cough persists, inhalations of creosote are recommended, especially at bedtime. For recurring elevations of temperature during convalescence, carbonate of guaiacol, one to three grains $(0.065-0.20 \mathrm{Gm}$.), with sugar of milk or in capsule, may be given four times a day.

Delicate children, prone to pulmonary disorders and those in whom there is a tubercular heredity, may require change of climate to secure the free outdoor exercise essential to complete recovery.

\section{CHRONIC BRONCHITIS.}

Repeated attacks of acute bronchitis may result in the chronic form of the disease. It is frequently a sequel to the acute bronchitis of pertussis, measles, influenza, and other infectious diseases. All conditions which favor mechanical pulmonary stasis may cause chronic bronchitis, such as heart disease, especially mitral incompetency and ehronic disorders of the kidneys, liver, and stomach. Children of rheumatic, tuberculous, and lymphatic diatheses are prone to chronic bronchial catarrhs. Chronic bronchitis is particularly common in rhachitis and in children 
of persistent lowered nutrition. Catarrhs of the upper respiratory tract, and especially adenoid vegetations, often lead to chronic inflammation of the bronchi. This disease is the usual accompaniment of certain pathological conditions of the respiratory apparatus, such as pulmonary tuberculosis, chronic vesicular emphysema, asthma, bronchiectasis, and compression of the lungs from chest deformities or enlarged bronchial and mediastinal glands.

Symptoms.-The symptoms differ from those of the acute form in the frequent absence of fever and general malaise. The cough is less frequent, occurs often in paroxysms resembling pertussis, and is usually most troublesome at night and upon waking in the morning. The expectoration of older children varies in quantity and character with the accompanying condition. It may be scanty, white, and frothy, or copious, mucoid, or mucopurulent and fetid. Damp cold weather precipitates an exacerbation which may continue for weeks, until the approach of warm or dry weather. Intervals of quiescence of several weeks duration, especially during the summer months, may precede another attack.

In uncomplicated chronic eatarrh of the bronchi, inspection and percussion may give negative results. The auscultatory signs vary from those of the acute form, principally in the diminution or subsidence of râles after a paroxysm of coughing and free expectoration, and in the reaccumulation of mucus causing a reappearance of râles modified by the viscidity of the secretion and size of the affected tubes.

Diagnosis.-Chronic bronchitis is differentiated from coughs of reflex origin by the chest signs and expectoration; from uncomplicated pertussis by the absence of râles and the history and course of the latter disease; from tubereulosis by the absence of fever and other constitutional symptoms peculiar to that disease.

Prognosis.--The prognosis of uncomplicated primary bronchitis depends upon the diathesis and environment of the patient. When secondary to other pathologic conditions, the prognosis must share that of the causal disorder. In estimating the outcome of chronic bronchitis, the tendency to chronic enlargement of the bronchial glands, as a standing invitation to tubercular infection, should not be overlooked. So, also, the susceptibility of children with ehronic bronchial eatarrhs to repeated attacks of pneumonia must be considered.

Treatment.-The treatment should be addressed to the predisposing and underlying causes when they are determinable. Improved environmental and nutritional hygiene, with the exhibition of tonies, such as iron, cod-liver oil, and fresh air, are usually necessary. For the bronchial catarrh a few medicinal agents have proved serviceable, such as potassium iodide, syrup of hydriodic acid, compound solution of iodine, syrup of the iodide of iron, and alkalies or alkaline waters. Creosote, guaiacol, or terebene may be given internally or by inhalations.

The multiplicity of drugs recommended for chronic cough, regardless of its origin, has undoubtedly resulted in much harm to the digestive 
organs and consequent impairment of nutrition. The long-continned use of opiates and anodynes should be discouraged for obvious reasons.

\section{FIBRINOUS BRONCHITIS.}

A curious but rare form of bronchitis is that in which the expectoration shows casts of the bronchi, even of the smaller tubes. It is found at all ages, although very rarely in infancy. It is still a matter of doubt whether these macaroni-like casts, composed of fibrin or coagulated mucin, are the result of a true fibrinous exudate or are formed by the coagulation of mucin throngh the action of acid forming bacteria. The easts sometimes contain air-bubbles and float in water, where they may be disentangled and their true nature revealed. Masses have been expeetorated which showed, when unrolled, a perfect cast of an entire bronchus with all its principal branches. T'his form of bronchitis is distinct from the croupous bronchitis which results from an extension of laryngeal diphtheria to the bronchial tree. The symptoms do not differ from those of ordinary acute or recurrent bronchitis except in severity of dyspnoea and the great relief following expectoration. Other conditions, such as bronchiectasis and emphysema, usually accompany the chronic form of bronchitis, and its relation to asthma has been suggested not only by the presence of Charcot-Leyden crystals and Curschmann's spirals, but from reported attacks which alternated with certain skin eruptions.

The disease has a recurrent tendency and is usually accompanied by febrile symptoms of varying intensity. The diagnosis is made alone from the tube-casts in the expectoration. It is obstinate in character and favors the development of pulmonary adenitis and tubercular infection.

The prognosis is serious, rather because of the possibility of dependent pathological lesions, such as pneumonia, tuberculosis, emphysema, and bronchiectasis, than from the bronchitis itself.

The treatment by inhalations of vaporized lime-water has proved beneficial, as the exudate is'soluble in alkaline solutions. The administration of potassium iodide is claimed to have hastened recovery in some instances.

\section{BRONCHIECTASIS.}

Dilatations of one or many bronchial tubes, with atrophic or hypertrophic changes in their walls and sclerosis of the peribronchial tissues, are occasionally seen in childhood and even in young infants. The loss of resiliency in these sacculated or cylindrical dilatations allows the accumulation of mucus and inflammatory products which quickly undergo decomposition from the action of saprophytes and other bacteria. Fetid breath, paroxysmal cough and copious expectoration of putrid sputum, result from the emptying of these cavities. Whatever theory as to the origin of the morbid process which results in this cavity formation be accepted, the clinical histories show previous existence of bronchitis, either simple, chronic, or as an accompaniment of measles, 
or some other infectious fever. The bronchial walls, weakened by bronchitis or bronchopneumonia, may yield to unusual intratubular pressure. Undoubtedly lowered nutrition or systemic disease renders the bronchial tubes less resistant, so that a succeeding attack of severe pertussis may readily precipitate the dilatation of the bronchioles from the increased air-pressure during the paroxysms of coughing. When the collection of decomposing secretion has become established, the infection of adjacent or even remote tissues, with general systemic disturbance, is readily explained.

Symptoms.-The symptoms of bronchiectasis are rarely pathognomonic. There is cough, usually paroxysmal, occurring most frequently in the morning or upon marked change of position, with expectoration of a large quantity of fetid sputum. This is occasionally blood-stained, or hemoptysis may occur. In very young children who do not expectorate, the vomitus shows the presence of the mucopurulent secretion which has been swallowed. More or less dyspnœa is common, dependent upon the extent of tubular involvement and the accompanying vesicular emphysema, or collapse of adjacent areas. The cough may be strangling in character because of the large quantity of secretion. After free expectoration the dyspnœa is greatly relieved until the dilated tubes refill.

Advanced cases show a rise of temperature indicative of toxæmia from this permanent nidus of infection. The appetite is capricious or fails entirely, and the child's condition is one of increasing debility and developing cachexia, with hectic fever and night sweats suggestive of pulmonary phthisis. Chest deformity from recession of a portion of the thoracic wall, clubbing of the fingers and toes, and even bony enlargement of the terminal phalanges, are seen in severe long-continued cases. These symptoms are usually associated with some degree of cyanosis.

Among the physical signs, inspection shows diminished movements of the chest, which may be increased after the cavities have been emptied. Percussion may yield dulness over a large collection, changing to resonance after the accumulation has been discharged. Resonance, also, over adjacent emphysematous areas may be found. Auscultation gives amphoric breathing over an empty sacculation, and all the varieties of moist râles, from those of the accompanying bronchitis to large gurglings.

A milder degree of bronchiectasis than the above described is undoubtedly much more common.

Diagnosis.-Although positive diagnosis is rarely possible, this condition should be suspected in children who expectorate copiously in the morning or after unusual exertion. The sputum may be mucoid or mucopurulent, with little or no odor.

The diagnosis of severe cases from pulmonary tuberculosis is, in some instances, extremely difficult, and must be made chiefly by the presence of bacilli in the sputum. From abscess and gangrene of the lungs, the history of slower onset and the absence of histologic elements of lung tissue in the sputum may establish a diagnosis. An empyema 
secondary to bronchiectasis may add the local signs of the former to the history of the pre-existing disease. A sacculated empyema or a lung abscess, not communicating with a bronchus, should yield pus to the exploring needle, non-fetid in character, contra to that of a purulent bronchiectatic accumulation.

Prognosis.- The prognosis of marked and advanced bronchiectasis is grave, although the mild type of limited dilatation may show occasional tendency to spontaneous recovery.

Treatment.-The treatment includes the best of hygiene, tonies, and restoratives, with removal to a dry climate and life in the open air. Anodynes and cough sedatives are contraindicated, since free evacuation of the dilated bronchi should be encouraged. This may be promoted by a radical change of posture, even to inversion of the patient several times a day. Hore or less suceessful attempts to correct the fetor have been made by inhalations of vapor of turpentine or creosote in boiling water. For internal administration guaiacol carbonate is recommended in doses of one to five grains $(0.065-0.32 \mathrm{Gm}$.) four times a day, in capsules; or creosote in from one-fifth to one minim (0.01-0.06 C.e.) doses, alone in capsule or in combination with liquid peptonoids, may be given. Onions and garlic should be eaten freely with the food, or syrupus allii, in doses of from one to two teaspoonfuls, may be taken three or four times a day. These latter contain a volatile oil which is eliminated by the pulmonary membrane.

Modern surgery already includes bronchiectasis in its lists of operable conditions. The percentage of recoveries has not been very gratifying thus far, as many dangers and uncertainties attend the operation, except in selected cases.

\section{ASTHMA.}

Asthma is a disease of all ages and may occur in the youngest infant. The first decade of life is claimed to furnish one-third of the whole number of cases. The period of adolescence, however, shows a considerable diminution in the susceptibility to asthma. Regardless of all the facts brought forward to substantiate the different theories as to the true nature of asthma, the hypothesis of a neurosis suffices to carry all the clinical phenomena of this disorder.

Asthma, etiologically remarkable in its variety, appears in infancy perhaps most frequently as a reflex neurosis due to irritation of some portion of the respiratory tract; hence it is oftenest seen in relation to either preceding or accompanying bronchial catarrh. The element of heredity is undoubtedly a strong predisposing factor, as asthmatic, gouty, and neurotic family histories are secured in many cases.

Of the many conditions known to act as exciting causes of asthmatic attacks there may be mentioned rhinitis, nasal and pharyngeal growths, adenoids, hypertrophied tonsils, bronchial catarrh, digestive disturbances, intestinal parasites, eruption of the teeth, inflammation of the middle ear, malaria, exposure to dampness, and the inhalation of irri- 
tating substances. As a result of the last-named cause hay fever is probably the most familiar example.

The attack may come on suddenly, without premonitory symptoms, or it may develop during the course of a bronchitis. The characteristic feature is the dyspnoa, in which the obstruction occurs in expiration, which is prolonged and wheezing in character. The respirations are slow, with complete reversal of the respiratory rhythm,-expiration being four to six times as long as inspiration. The distress and air-hunger are marked in severe cases; the face has an anxious look, is pale, and may be cyanosed, as the child, with rigid neck- and trunk-muscles, braces himself in sitting posture and labors to expel the excess of residual air from the alveoli and tubes. The dyspnoea differs from that of croup in that the soft parts of the neck and chest do not recede on inspiration, nor is phonation much affected, although the ehild may refuse to talk and may even refrain from crying from dread of the increase in dyspnoea.

The attacks come on most frequently during the night and may last from a few hours to several weeks. In the latter case there are remissions and exacerbations of varying duration and intensity. As in the adult, the day during which the child is apparently in normal health is followed by a night of distressing dyspnoea, of which the succeeding day shows no signs. These attacks may recur night after night, until the child shows evidences of exhaustion from loss of sleep and deficiency of oxygen. Occasionally the asthma terminates as abruptly as it developed, and there may be no repetition for weeks or months.

In young infants there is usually more or less fever, although in older children the temperature is sometimes subnormal, and cough is not a constant symptom, yet it may be frequent and severe if the attack be accompanied by acute bronchitis. In infants, frequently, the clinical picture is that of severe bronchopneumonia, and the sudden and unexpected subsidence of all the symptoms may be the first intimation of the true nature of the attack. Percussion early may yield slight dulness, to be succeeded later, especially in older children, by hyperresonance. The character of the chest-sounds revealed by auscultation in a well-developed paroxysm of asthma is unmistakable. They consist mostly of sibilant or sonorous râles, more or less musical in character, in great variety of pitch and intensity, heard all over the chest both upon.inspiration and expiration. These are accompanied quite frequently, in young children and infants, by moist râles. The chest is usually distended from the excess of residual air, and the play both of the thoracic walls and diaphragm is restricted, while the respiration may be accelerated to sixty or seventy per minute. Expiration is always prolonged.

Examination of the sputum in older children shows the presence of small round bodies like sago grains (perles de Lannec), Curschmann's spirals, Charcot-Leyden crystals, and also eosinophiles. The latter are increased in the blood preceding, during, and following the asthmatic attack, with or without leucocytosis, and may reach as high as fifty per 
cent. with an average of from eight to twenty per cent. of the leucocyte count.

Asthma is rarely fatal, although infants occasionally succumb to a single attack. The post-mortems show no anatomic changes in the respiratory tract to indicate the eause of the tumultuous disturbance. Asthma developing in infancy or childhood may continue, in recurring paroxysins throughout life. An interesting phase of asthma, seen especially in children of gouty heritage, is the alternation of astlımatic seizures with skin eruptions. Urticaria is occasionally displaced by a paroxysm of asthma and reappears upon the subsidence of the dyspnœa, to be followed again by another asthmatic attack. These urticarial wheals disappear from the integument, but may reappear upon the mucosa of the mouth, pharynx, larynx, and trachea, to the limit of the laryngoscopic view. This fact seems to corroborate the angioneurotic theory of asthma which would attribute the respiratory obstruction to tumefaction of the bronchial mucosa, due to urticarial wheals, instead of the spasmodic contraction of the circular muscular fibres of the bronchi, as claimed by the former hypothesis.

Diagnosis. - The diagnosis of asthma from all other forms of dyspnoea is made from its abrupt onset and termination, the prolonged expiration, the peculiar characteristic râles, and the microscopical examination of the sputum and blood. Bronchial or true asthma is to be differentiated from false asthma or dyspnœa due to cardiac, renal, or thymic causation.

Treatment.-The treatment of an attack of asthma in childhood is important, not only on account of the distressing dyspnoa, but because of the importance of interrupting the paroxysms before the recurrent habit is firmly established.

The exciting cause should be sought and removed if possible. This may necessitate the recognition and treatment of dyspepsia, constipation, intestinal worms, and also adenoids or other disorders of the upper respiratory tract. Nutrition must not be overlooked, and frequently a course of tonics, generous diet, and cod-liver oil, with fresh air, exercise and cool or cold bathing, may be necessary to tone up the general nervous system. The gouty diathesis may call for antilithics and alkaline waters. Any existing bronchitis should receive appropriate treatment.

The paroxysm of asthma may yield to inhalations of the fumes of burning nitre paper and stramonium leaves, agents which enter into the composition of several celebrated asthma cures (Formula 27). Inhalations of steam and creosote, thirty drops of the latter in a pint of boiling water, will aid in relaxing spasm. In extreme cases, where life is threatened by asphyxiation, chloroform may be used, o: there may bc given ipecac, one-tenth to one-twentieth grain $(0.006-0.003 \mathrm{Gm}$.) with $\frac{1}{180}$ of a grain $(0.0003 \mathrm{Gm}$.) of nitroglycerin every half hour for three or four doses. This is especially effective if bronchitis be present. For paroxysms that begin with sneezing or evidences of rhinitis, one to 
three minims (0.06-0.18 C.c.) of adrenalin chlorine solution $(1: 1000)$ may be applied to the nasal mucous membrane, or a smaller dose may be given hypodermically and repeated, if necessary, every two hours for four or five doses. Tincture of belladonna or its alkaloid may be given in small doses every two hours, from one-half to two minims (0.03-0.12 C.c.) of the former or from $\frac{1}{2000}$ grain to $\frac{1}{150}$ grain $(0.00003-$ $0.00024 \mathrm{Gm}$.) of the latter, according to age, until it produces flushing of the face and dilatation of the pupils. This should occur after the second or third dose. Morphine is probably the most efficient agent for the relief of the asthmatic paroxysms, but for obvious reasons it should only be exhibited as a last resort. Potassium iodide has undoubted value in the affection and should be given in doses of from one to five grains $(0.065-0.32 \mathrm{Gm}$.) four times a day.

The principal sequelæ of prolonged and repeated asthmatic attacks are pulmonary emphysema and dilatation of the right heart.

\section{FIBRINOUS PNEUMONIA-LOBAR PNEUMONIA; CROUPOUS PNEUMONIA; PNEUMONITIS.}

Fibrinous pneumonia is an inflammation of the lungs due in a large majority of cases to the pneumococcus (the diplococcus of Fraenkel). This organism is often found in the upper air-passages of those in perfect health, but more frequently during an epidemic in house or community.

Pneumonia is found at all ages and may be congenital, the fotus having become infected through the placenta of a pneumonic mother, the pneumococcus being found in pulmonary secretion and blood of both patients.

Lobar pneumonia is not as frequently reported during the first two years of life as after that period. It is of most common occurrence from the second to the fifth year, after which its frequency diminishes until the tenth year. The disease predominates in boys over girls in the ratio of three to two.

Since the pneumococcus may induce primary as well as secondary inflammations in other organs-as endocarditis, meningitis, pleuritis, and arthritis-it is probable that the location of the morbid process is subject to determining causes outside of the infective organism. This supposition is strengthened by the fact that all individuals exposed to the infection do not develop similar lesions and many escape entirely. Exposure to sudden chilling of the surface is nniversally recognized as an important determining cause. In this country, at least, there is unanimity of observations concerning the greater prevalence of pneumonia during the winter and spring months. Vital statisties from a number of large cities, also the opinions of many observers, show pneumonia to be on the increase.

Pathological Anatomy.-The pathologic process does not differ from that in the pneumonia of adults, with the exception that in younger children the proliferation of epithelium and transudation of cellular 
elements are more marked. The speeifie lesion in pneumococeic pneumonia is a fibrinous exudate into the pulmonary alveoli, which becomes choked with serum, red and white eells, and epithelial débris entangled in fibrin filaments. Usually an entire lobe is involved in the morbid process, which has given rise to the designation, "lobar pmeumonia," a misleading term, sinee only a portion of a lobe may be invaded. The process may involve more than one lobe on the same or opposite sides of the ehest. Although the opinions of observers vary as to the relative frequeney of the involvement of the different lobes, the average from a large number of reports shows a slight preponderance of the left lower. Next in order of frequeney is the right upper, and then the right lower lobe. The right middle and left upper lobes are rarely the seat of primary infection. The younger the infant the more frequent is the oceurrence of upper lobe lesion. The involvement of an entire lung is not uneommon, or lobes on opposite sides may be affeeted simultaneously or sueeessively. In fact, the inflammation may travel the entire eirenit in sueeessive invasions, which follow elosely the resolution of other involved portions.

Pneumonia runs a definite course, during which it presents four fairly well marked phases. The first stage is that of invasion, in whieh there is engorgement of the alveolar blood-vessels with transudation of serum into the air-eells.

The second stage is that of red hepatization, and shows complete consolidation of the area involved, whose cut surface is uniformly dark, resembling liver, changing to brighter red when exposed to the air. The alveoli are engorged with the exudate which, protruding on the eut surface, presents a granular appearance. The affeeted portion of the lung is swollen to the extent of full expansion and shows indentations on its outer surface from pressure of the ribs. This stage lasts usually from two to five days, but may continue much longer,--in rare cases for several weeks.

During the third stage-gray hepatization-the lung beeomes mottled gray and yellow by irregular deeolorization from the disappearanee of the blood pigment and increase in the leucocytes. In the fourth stage, resolution follows by the general liquefaction of the inflammatory produets in the air-vesieles and eapillary tubes. Mueh of this is absorbed by the lymphaties and the remainder is foreed into the bronchioles, from which it is eoughed up. Pus corpuseles may be numerous and, if suppuration be extensive, abseesses may form. Usually, however, the liquefied products rapidly disappear, leaving the lung struetures in the normal condition.

Symptoms.-Although the onset of pneumonia is usually more or less abrupt, the symptoms and physieal signs may not be very marked for the first two or three days. In fact, the typical symptoms of the adult type may be masked or absent until late in the attaek. In infancy, especially, this disease is so frequently wrongly diagnosed as to affect its reported percentage of prevalence. The one common symptom 
is fever, from $102^{\circ}-107^{\circ} \mathrm{F}$. $\left(39^{\circ}-41.6^{\circ} \mathrm{C}\right.$. $)$. A preceding chill is occasionally noted in older children and rarely a convulsion in infants. Initial vomiting is not uncommon and is oceasionally accompanied by diarrhœa. Cough may or may not be present, and depends largely upon the extent of bronchitis. Younger children and infants show fretfulness, or hebetude with somnolence if the temperature be high. Anorexia, thirst, and coated tongue usually accompany the fever. There is proportional acceleration of the pulse, which is usually full and sustained, but may be weak. The most significant symptom and one rarely absent is increased respiration. There is a characteristic change in the pulse ratio which may be three, two and one-half, or only two to one, instead of the normal three and one-half or four to one. The play of the alæ nasi with inspiration is nearly always present, varying in degree with the extent of lung crippled. Expiration is frequently accompanied by a short terminal moan, or a sharper expiratory grunt if much pleurisy be present. The face is usually congested, may be deeply flushed, occasionally eyanotic, rarely pale, and its expression may indicate pain or preoccupation, according to the amount of dyspnœa or stupor. Herpes about the mouth and nose is commonly seen in pneumonia. The eyes are usually heavy and lustreless.

The cough, which is generally present, is short, dry, and restricted, the latter on account of the pain which it induces. More or less constant pain is present, and in young children this is often referred to some portion of the abdomen or, in fact, to any part which shares in the distribution of the lower intercostal nerves. Occasionally this pain is pleuritic and is located over the affected area. In infants palpation of the abdomen will elicit pain, probably from upward pressure of the displaced viscera.

The temperature $-102^{\circ}$ to $105^{\circ} \mathrm{F} .\left(39^{\circ}-40.5^{\circ} \mathrm{C}\right.$.) - develops early and continues throughout the attack. Slight daily remissions of one or two degrees are the rule. Cases in which the temperature rose to $107^{\circ} \mathrm{F}$. $\left(41.5^{\circ}\right.$ C. $)$ have been reported. Seven days is the average course of pneumonic fever, although the crisis may rarely occur on the third day, and occasionally is delayed to the fifteenth day or even later. The temperature fall is abrupt. In from six to twenty-four hours it reaches the normal or even two or three degrees below. In children especially the crisis of pneumonia may be preceded by a rapid defervescence, after which it again rises to its former height. This false or pseudocrisis is followed a day or two later by a permanent subsidence, - a true crisis. This pseudocrisis may occur twice or even three times before the real crisis is reached, and may cause confusion in the practitioner's mind and lack of confidence in his diagnosis, especially if the pulmonary sigńn be masked.

This defervescence by crisis is almost pathognomonic of fibrinous pneumonia, occurring in older children quite regularly and in about seventy-five per cent. of younger children, although in infants lysis by remissions of temperature is quite common. With the subsidence of 
fever the pain subsides, cough becomes moist, and the expectoration, which before was scanty or wanting, becomes more abundant in older children. The sputum changes from a glairy, mucoid, or rusty material, to a mucopurulent character, and may be darkened by blood ("prune juice").

The pulse is reduced in frequency, slowing down to fifty beats per minute in extreme eases, but it may become irregular, rapid, and weak. The respirations also follow the temperature, although rarely reaching normal until after complete resolution. Return of febrile symptoms always indicates a fresh invasion of the pneumonia or some complication, such as pleurisy or other inflammation.

From the very beginning of the attack the signs of prostration are quite marked. Even in cases of moderate severity the child is willing to go to bed. With high temperature the somnolence may approach coma or there may be headache, cervical rigidity, delirium, tremors, and other symptoms simulating meningitis.

The physical signs to one unfamiliar with pneumonia in infancy are often misleading. Inspection occasionally shows diminished respiratory movements on one side, especially in the infraclavicular region.

In infants and young children percussion may fail to outline the inflamed area by dulness, because of the limited extent, deep situation of the lesion, resonance of overlying healthy lung, or tympanitic extension from the gas-distended abdominal viscera.

In the infant, local hyperresonance on percussion, with high temperature, cough, and characteristic disturbance of pulse and respiration, should suggest a pneumonic consolidation in some other portion of the lung. Repeated examinations will usually show a circumseribed area of dulness, even in young infants, although this sign may be elusive during the first three or four days of the attack. Careful auscultation may locate the pneumonia by diminution of respiratory murmur over a limited area, while other parts of the chest may show exaggerated sounds. Mixed râles indicative of the accompanying bronchitis are frequently present. Later, the area of consolidation may reveal somewhat tubular breathing with subcrepitant râles, although the crepitant râles of invasion are rarely heard. Vocal resonance may be increased and fremitus from crying may be occasionally distinguished by careful palpation. It is significant of pneumonia that children rarely ery lustily, because of the pain and dyspnœa incident to deep inspiration. The area of cardiac dulness is increased in the third right interspace from engorgement of right heart due to pulmonary obstruction, and may extend two finger-breadths to the right of the sternum. The pulmonic second sound is greatly accentuated for the above reason, although it should not be forgotten that a moderate degree of accentuation is normal in infancy. The spleen may be enlarged and palpable, while in severe right heart distention the area of hepatic dulness is notably increased. 
The urine shows the high color, increased specific gravity, and acid concentration peculiar to febrile disorders. Following the crisis the amount of urine is greatly increased and for a day or two contains a considerable amount of uric acid and urates.

Blood.-The blood findings of most practical value in pneumonia relate to the variations in the number of white corpuscles. Leucocytosis is the rule in this disease and is usually most marked at the time of crisis, when it is generally regarded as a favorable symptom. The diminution of lencocytes after the crisis is abrupt and may aid in differentiating between the occurrence of real and pseudocrisis. A persistence or recurrence of leucocytosis is suggestive of a new invasion or complication of the pneumonic process. The interpretation of a leucopenia must depend upon the attending eonditions. If accompanied by high temperature and increase in general symptoms, it is of grave prognostic importance; whereas with mild symptoms, leucopenia may be merely indicative of a very mild type of infection. Although in pneumonia the increase in white cells is seen chiefly in the polymorphoneuclear neutrophiles, in children there may be marked increase in the lymphocytes. It is claimed that Fraenkel's pneumococeus is present in the blood of all cases of fibrinous pneumonia and may be demonstrated in the centrifugate if a large ruantity of blood be examined. In one drop, however, the majority of the examinations will fail to reveal its presence. It is considered that the abundance of these organisms in the blood bear a direct relation to the gravity of the disease.

The course of fibrinous pneumonia in childhood is atypical in a ratio inversely to age; hence the terms wandering, recurring, of short duration, central, massive, cerebral, abdominal, with delayed resolution, and mixed.

Clinical evidence points to abortive pneumonia as not of infrequent occurrence. It is possible that many cases of febricula in children are due to an aborted pneumonic invasion. It is probable that in many of these cases the infection is overwhelmed before exudation is complete, as the expectoration after defervescence is characteristic of alveolar involvement, although the entire period of febrile movement may not exceed forty-eight or even twenty-four hours. Of a different nature, however, is the pneumonia of exceptionally short duration (two to four days), in which all the phenomena of a typical course, from initial vomiting to erisis and resolution or fatal termination, have been observed. Recurring pneumonia is simply a repetition of the inflammatory process in the same area, while wandering or creeping pneumonias are merely successive invasions of different areas.

Central pneumonia is particularly interesting because of the frequent absence of physical signs and pain owing to the deep situation of the lesion. Although suspected, this form of pneumonia may be impossible of diagnosis in the absence of typical blood findings and sputum. Temperature crisis, after a period of cough and accelerated respiration, is very suggestive of a deep-seated pneumonia. 
The term massive has been applied to a pneumonia in which the alveolar exudates overflow into smaller bronchial tubes with resultant physical signs of enlarged area of dulness and alsenee of respiratory murmur. Cerebral pneumonia is a misnomer, the ontgrowth of cerebral symptoms which not infrequently accompany pnemmonia in children, from the well-known fact that the cerebral functions are readily affected in persistent high temperature, active hyperamia, mechanical stasis, or any acute toxamia. Pneumococcic infection is an occasional cause of meningitis which may occur either separately or in connection with pneumonitis.

The term abdominal pneumonia has arisen from the occurrence of abdominal symptoms, as pain in different localities, for reasons previously stated, and also from the not uncommon accompaniment in children of digestive disturbances.

Prolongation of the attack far beyond the usual period may oceur in weakly children and marasmic infants, in which the temperature decline is by lysis. In other cases, frerfuently in robust children in which erisis occurred at the end of the usual period, physical signs of consolidation persist sometimes for weeks or months, although the child may eat well, put on flesh, and suffer no discomfort, save that incident to curtailment of respiration. The recovery of the affected lung, although delayed, may be complete in every respect.

The typical symptoms of a fibrinous pneumonia may be masked by a coincident catarrhal pneumonia. Atypical pneumonias are reported in which the pneumococcic infection is reinforced by streptococcic, as from a middle-ear disease, or Friedländer's bacillus. During epidemics of influenza, pneumococcic pneumonias may be modified by infection with the Pfeiffer bacillus.

Complications and Sequela.-Next to bronchitis, which almost always accompanies pneumonia, pleurisy is the most frequent complication. It usually appears over the parietal surface of the affected lung, where the pneumonic process is most superficial, as a fibrinous exudate or dry pleurisy. In many cases it occasions but a small transudation of serum in the pleural cavity. The layer of exudate, however, may be thick and pultaceous, occluding the lumen of the aspirating needle so as to render exploratory puncture negative. Empyema not infrequently develops, in which the pneumococeus is found in pure culture in a large percentage of cases. It may be suspected in instances where dulness over the affected side persists, with an increase in leucocytosis, after the crisis of the pneumonia, although there may not be the barrel-shaped distention seen in large pleuritic effusion.

In ratio of frequency inversely to age of patient, as a complication in fibrinous pneumonia, is otitis media. In a majority of these the otitis is purulent and examination of the pus will show the diplococeus pneumoniæ.

Pericarditis, as a complication, occurs more frequently in left-sided pneumonia, and is usually of the fibrinous or exudative type. Charac- 
teristic friction sounds are usually obscured by those of the accompanying pleuritis, or by the adventitious respiratory sounds from the lung. If the pericardium be the seat of an extensive effusion, the heart by counterpressure against the consolidated lung may be displaced to the right. Unfortunately, increase in dulness to the right of the sternum is so frequently indicative of right-heart distention as to render differentiation difficult or impossible. However, a weak pulse, diffuse and indistinct apex pact, and evidences of sudden impairment of the heart's action, should give a clue to pericarditis with effusion.

Of more frequent oecurrence as a complication is endocarditis of the left heart, which may be malignant. The gravity of the prognosis is correspondingly increased. The possibility of infective emboli from this source greatly adds to the complication, and diminishes the chances of recovery.

Rare complications of pneumonia occur in the forms of peritonitis, arthritis, and nephritis. A suppurative cellulitis occasionally develops from metastasis of the infection.

Meningitis may precede or complicate fibrinous pneumonia, with or without suppurative otitis media. This complication, although rare, occurs most frequently in infants and young children, and must be distinguished from the cerebral symptoms of pneumonia due to hyperpyrexia and altered circulation of the meninges. Cerebrospinal or epidemic meningitis, due to pneumococcic infection, may complicate or follow fibrinous pneumonitis. This pneumococcus of Fraenkel has been found quite frequently as the causative agent in epidemic meningitis during the prevalence of the former disease.

A recurrence of vomiting, convulsions, delirium, coma, or opisthotonos, would indicate the development of this complication. Lumbar puncture and examination of the cerebrospinal fluid will aid in the diagnosis.

Among the sequelæ, abscess and gangrene of the lung are the most important. Owing to the difficulty of differentiation from empyæma these are usually first diagnosed at the post-mortem.

PuImonary fibrosis or interstitial pneumonia is an occasional sequel and will be discussed under that subject.

Diagnosis.-Fibrinous pneumonia may be diagnosed by the sudden onset with chill, vomiting, convulsions, disturbed pulse-respiration ratio, cough, expiratory moan, or grunt, the usual physical signs when present, and continuous high temperature ending in crisis. It is confirmed by the examination of the rusty sputum in older children and by marked leucocytosis which disappears with crises.

Prognosis.-The prognosis of uncomplicated fibrinous pneumonia in children, after the second year, is more favorable than in adults. Infants under that age bear pneumonia badly, the mortality rate being from twenty to forty per cent. in strong infants, and higher in the cachectic and poorly nourished. Among conditions which favor the prognosis in children may be mentioned their freedom from organic renal, arterial, and cardiac lesions, to which may be added the active recuperative 
metabolism of the developing period. The extent of the lung lesion bears less constant relation to the mortality than the persistence, beyond eight or ten days, of abnormally high temperature. The viruleney of the infective agent undoubtedly has great influence on the mortality, as it is well known that the death-rate varies with different epidemies, regardless of the method of treatment.

Treatment.-For a self-limited disease running a definite course of short duration, with a tendency to reeovery without damaging lesions, pneumonia has been the subjeet of much overtreatment. A specifie treatment is not known and probably never will be until a pnemococcic antitoxin is discovered. Those at present adrocated have proved of doubtful efficieney, and the subject of antipneumonococeic serum must still be considered in the experimental stage. If eertain conditions obtain during an attack of pneumonia which threaten the structural or functional integrity of vital organs, measures for relief are indieated. Among the urgent conditions are overdistention of the right heart from obstruction to the pulmonary eireulation; interferenee with respiratory movements in the crippled lung by pressure from overdistention of abdominal viscera, or from the weight of external applications, or constricting clothing; passive cerebral hyperæmia from venous stasis in the lesser circulation; interference with normal metabolism from diminution in the quantity of inspired oxygen and accumulation of toxins in the blood from diminished elimination.

As a rule, in the early part of an attack of pneumonia the bowels should be freely opened by ealomel combined with ipecac and soda (Formulas 24 and 25), small doses every hour until free eatharsis is secured. If this be delayed beyond the tenth or twelfth dose it may be aided by one or two teaspoonfuls of castor oil or a full close of magnesium citrate. This treatment may be profitably repeated at intervals of a few days throughout the course of the disease. The stomach and bowels should be kept free from gaseous distention by eareful attention to the frequency of feeding and the quantity and quality of the food. This in older children should be concentrated and liquid, given in small amounts. In the nursling, half or more of his food should be replaced by water. In fact, water should be freely supplied to the pneumonia patient, except where there is marked evidence of right heart engorgement. Gastric flatus contraindicates food until relieved. Sulphocarbolate of soda, a grain $(0.065 \mathrm{Gm}$.) for each year of age, in repeated doses, is sometimes valuable. Hot carminative infusions, as of peppermint, anise, or gaultheria, may prove useful. Intestinal gas is best relieved by high enemata of normal salt solution or soapy water containing mills of asafetida or a few drops of turpentine. Since it is known that the mucosa of the upper respiratory tract swarms with pathogenic bacteria, frequent applications of alkaline and antiseptic solutions should be used by swab and atomizer to cleanse these areas (Seiler's or Dobell's solution).

The call for oxygen must be met by a free supply of pure air admitted from outdoors for the sole use of the patient and nurse. In extreme 
cases pure oxygen from the can may be used to increase the supply. In hyperpyrexia the temperature of the room need not be kept at the ordinary sick-room standard so long as the patient's extremities are kept warm. It is a common error to burden the pueumonia patient with blankets and to close the windows and doors to the admission of air from fear of draughts. In prolonged high temperature- $104^{\circ}$ to $106^{\circ}$ F. $\left(40^{\circ}-41^{\circ}\right.$ C. $)$-with restlessness and delirium, improvement follows sponging with tepid water and alcohol ( 3 to 1 ) for five to fifteen minutes. This may be repeated as often as necessary. Antipyretic drugs are rarely indicated, and usually do more harm than good. Quinine and tincture of iron throughout the attack are advocated by many physicians of wide experience. The effect on the stomach and the bitter taste of quinine are obstacles to its use in young children. An aqueous solution of the bisulphate of quinine, five to ten grains $(0.3-0.65 \mathrm{Gm}$.) may be administered by rectum, if considered sufficiently important. Inunctions of quinine and lard, or lanolin ( 1 to 8 ) may be applied freely to the surface of the body with massage. Organic iron preparations, as the peptonates, are most eligible for young children. In older children the American tincture of the chloride may be preferred for the antiseptic action of its hydrochloric acid. The official mixture of iron, quinia, and strychnia presents a happy combination when the last-named drug is indicated.

Cough and pain frequently deprive the little patient of rest, so essential for the maintenance of strength, in which case analgesic and sedative measures may be required. The triple bromide mixture, sodium, potassium, and ammonium, one-half grain $(0.003 \mathrm{Gm}$.) of each for each year of age, in syrupus lactucarii (Aubergier's), fifteen to forty minims (0.9-25 C.c.) may be sufficient. Persistent pain may require larger doses or even the exhibition of codeine, one-tenth grain $(0.006 \mathrm{Gm}$.), to a child three to five years of age; Dover's powder, one grain $(0.06$ Gm.), or even morphine hypodermically. This latter agent should be used with great caution and only in the earlier days of the illness. Its fairly earned reputation for mischief is due to maladministration after the patient has become exhausted, and when the depressed respiratory function is easily overwhelmed. It is especially important that the strength of the patient be preserved during the early days of the attack, hence the demand for sedation at the only period in which it is compatible with safety. Diuresis should be encouraged, if necessary, by the administration of spiritus mindereri in from one-quarter to two drachms (1-8 C.c.) doses, repeated every two or four hours as necessary, or enteroclysis of normal salt solution once or twice every twenty-four hours. Applications to the chest, as a routine treatment, are of doubtful utility and in many instances are harmful. Many physicians employ ice-bags over the area of lung lesion as soon as that is determined. With this object in view, they auscultate and percuss industriously, several times daily, for the earliest evidences of localization. In skilful hands, it is believed much may be accomplished in the way of limiting the 
extent of the pneumonic process by this early application of ice-bags.s. Their indiscriminate or careless use may expose the patient not only to much discomfort but to considerable risk of injury from refrigeration. The prejudice against blood-letting is so strongly entrenched that its advocacy is likely to arouse an opposition, well fortified in physiologie theories, regarding the value of eaeh drop of the life-sustaining fluicl. Independent, however, of the question of the relation of hamic conclitions to the inflammatory process, it may be safely asserted that for purely mechanical reasons a little blood may be profitably withdrawn when the right heart is overdistended. For this purpose two to six leeches may be applied to the right hepatic region whenever the line of cardiac dulness advances two or more finger-breadths to the right of the sternum in the fourth interspace. Irregular heart action and very marked accentuation of the second pulmonic sound, accompanied by rapid and feeble pulse, may, during the pyrexia, call for digitalis, in which case the tincture in doses of three to six minims $(0.18-0.36$ C.c.) may be given to a child of eight years, and repeated every three or four hours.

Pulmonary engorgement, with or without cyanosis, is sometimes relieved by the hot bath or by stimulating rubefacients applied over the thorax. At the crisis, cardiac stimulation is most frequently indieated, and at this time strychnia and alcohol, with or without digitalis, are most serviceable. The dose of the former should be sufficient to produce decided tonic effect on the heart and may be rapidly advanced from one two-hundredth of a grain $(0.00033 \mathrm{Gm}$.) in infants to one-sixtieth or one-fortieth of a grain $(0.001-0.0015 \mathrm{Gm}$.) in a child of eight years, and repeated every three hours. Alcohol, in the form of good whiskey or brandy, may be given in teaspoonful doses in milk every two to four hours. Artificial warmth to the body should be supplied at the period of crisis.

In delayed resolution, the indications are to maintain the strength of the patient and to be on the alert for complications. In the ordinary uncomplicated fibrinous pneumonia a frequent use of the placebo may be necessary.

\section{BRONCHOPNEUMONIA-CATARRHAL PNEUMONIA; LOBULAR PNEUMONIA; CAPILLARY BRONCHITIS.}

Bronchopneumonia is essentially a disease of infancy and early childhood. It is infrequent after the sixth year and rare in adults. The age of most frequent occurrence is the first two years of life. This form of pneumonia is never a primary disease, but is always secondary to a bronchitis, hence its name.

In its multiplicity of pathologic forms the one common lesion is a bronchiolitis (capillary bronchitis), the inflammation involving the entire thickness of the tubular walls and extending more or less into the surrounding tissue (peribronchitis). In this way not only the adjacent alveoli are included in the inflammation but also the terminal air- 
vesicles by direct extension of the morbid process along the smaller tubes. The bronchioles are occluded by an accumulation of mucus, epithelial cells, and bacteria, while the blood-vessels of the alveolar septa are engorged and the air-spaces filled with mucopus, epithelium, leucocytes, and occasionally a small amount of fibrin. The paucity or absence of fibrin and the common occurrence of bronchiolitis and peribronchitis are the distinguishing features of bronchopneumonia as compared with fibrinous pneumonia. The lesions of bronchopneumonia may be limited to circumseribed areas including but one or a few bronchioles and adjacent lobules with intervening areas of normal or emphysematous lung tissue. By extension, these inflammatory areas may coalesce so as to involve an entire lobe. A cut section of the affected lobe may show coincident and in close proximity different inflammatory stages, such as congestion, red and gray hepatization, and resolution, interspersed with areas of atelectasis, vesicular emphysema, and dilated bronchial tubes. Where the pneumonic areas approach the surface of the lung the overlying pleura is congested, showing darker colored depressions from collapsed lobules, and is either lustreless or covered by a plastic exudate. This pleuritis may result in cohesion of layers or an accumulation of serum or pus in the pleural sac. Bronchopneumonia is usually bilateral and found in the lower lobes or occasionally in the posterior portions of the upper lobes. The apices generally show compensatory emphysema in proportion to the extent of the lower lobe involvement.

Etiology.-Infancy, marasmus, rhachitis, syphilis, lymphatism, poor hygiene, climate, season, infectious diseases, exposure to cold, and the aspiration of blood, food, or other foreign substances, are among the chief predisposing causes. The infectious diseases, in order of frequency, are bronchitis, measles, influenza, diphtheria, typhoid and scarlet fevers. The exciting causes may be one or more of a variety of the infectious organisms commonly present in the nose, mouth, or pharynx, which have become pathogenic in the lowered resistance of the disordered bronchial mucosa.

Of all the causes of death during the first two years bronchopneumonia is assigned in from seventeen per cent. in private practice to forty per cent. in institutions. The susceptibility of infants to bronchitis (the common precursor of bronchopneumonia) has been discussed on page 327 . The clinical fact that young infants and children, or those weakened by previous disease, are the subjects of bronchopneumonia, while the more favored, rugged, and older children develop fibrinous pneumonia, finds some explanation in a series of experiments conducted by Dr. A. Wadsworth.*

* Animals were inoculated with pneumonia exudates of varying degrees of virulence with the following results: In the normal animals a virulent exudate caused a bacteriæmic type of infection without much lesion of the lungs; when less virulent matter was used no lesion appeared in the lungs. In animals previously subjected to trauma, cold, and the injection of irritating substances, the inoculation 
The occurrence of bronchopneumonia with gastro-enteritis may add to the explanation of its frequency during a period when the latter disease is most prevalent. That bronchopneumonia is not as strictly eonfined to the months of inclement weather as is fibrinous pneumonia may be due to the fact that its predisposing conditions and precursory disorders prevail at all seasons of the year. In older children bronchopneumonia rarely occurs except as an accompaniment or seruel of the acute exanthems previously mentioned. In this case the exciting mieroorganism is most frequently that of the pre-existing disease, usually associated with the pneumococeus of Fraenkel.

Of a large number of bacterial studies of bronchopneumonia the pneumococcus was found alone in more than fifty per cent. and was associated with other bacteria in twenty-five per cent. Of other organisms, alone or associated, were found the streptococci and staphylococei and bacilli of Friedlander, Klebs-Loeffler, coli communis, and tuberculosis.

Symptoms. - The symptoms of bronchopneumonia vary so widely in different cases that this disease may be said to have no fixed type. 'The same wide variation is true also of the physical signs, which may be absent entirely, so that the pneumonia may be overlooked or its symptoms attributed to the disease to which it is secondary. The onset may be abrupt or gradual; there may be hyperpyrexia or the temperature may show little if any rise throughout the attack; cough may be absent, slight, or frequent and distressing. There may be fretfulness, restlessness, delirium, or apathy, somnolence, and stupor. Probably the most usual form of development is seen in the intensification of all the symptoms during an attack of bronchitis from which the infant may have suffered for several days. The temperature rises to $103^{\circ}$ or $104^{\circ} \mathrm{F}$. $\left(39.5^{\circ}-40^{\circ}\right.$ C.) with morning (rarely afternoon) remissions of one to three degrees. The pulse is quickened, 120-150, but does not maintain its ratio with the accelerated respiration, which reaches fifty or even ninety per minute, changing in character to the pneumonic type, the pause occurring after inspiration, expiration being accompanied by a grunt or moan. Dilatation of the nostrils and recession of the soft parts of the chest walls accompany inspiration. The expression of the face is that of preoccupation or even anxiety. The child may insist upon sitting or being supported in the upright position to facilitate breathing.

The cough may be dry and hacking, or whistling in character, and is followed by a short cry indicative of pain. More or less cyanosis is

produced pulmonary lesions which were usually of the bronchopneumonic type. Lobar lesions developed chiefly in animals showing greater power of resistance. Animals were then immunized by injecting high virulence and low virulence micrococci. In the animals protected by the high virulence micrococei a lobar type of lesion was obtained. If the resistance were not sufficient to prevent the production of the bacteriæmic type of infection, the lesions were generally of the bronchopneumonic form. Lobar pneumonia developing in a resistant and immunized animal was comparable to lobar pneumonia developing in a robust individual. 
present or is easily induced by coughing, excitement, or nursing. 'Thirst is evident but the child may refuse the breast or liquids on account of the dyspnœa. There are coated tongue, anorexia, frequently distended abdomen, green stools and, occasionally, early vomiting.

Percussion in the first two days of the attack may yield nothing except hyperresonance. Auscultation shows a variety of moist râles indicative of bronchitis, possibly subcrepitation and exaggerated respiratory sounds. Occasionally, by the second day, a circumseribed area may be found over which the breath-sounds are indistinct, and light percussion shows dulness.

All the symptoms may increase in intensity, the sthenic pulse may become weak and irregular, cyanosis become marked, the right heart show distention, and cerebral symptoms, with rigidity of the neck, may develop. Possibly a well-defined area of consolidation may be located in a posterior or lateral portion of the lung, with bronchial breathing and increased vocal resonance. The cough is restricted and the sputum which escapes from the trachea is swallowed, to which fact is attributed the oceasional accompanying gastric disturbance. The attack may continue from one to three weeks for the mild cases, with a gradual improvement of all the symptoms as the temperature declines by lysis. In a small number of cases a true crisis occurs like that of fibrinous pneumonia. Occasionally there are exacerbations as other portions of the lungs are involved in the inflammation, so that the pneumonia may cover a period of from four to twelve weeks.

Weakly children and marasmic infants at times develop bronchopneumonia which may run a fatal course in from two to six days, with normal or subnormal temperature. The cough may be slight or absent altogether, rapid respiration and cyanosis being the principal indications of pulmonary lesion.

In infants gastro-enteritis not infrequently terminates in a fatal bronchopneumonia of brief duration, in which the symptoms are masked or the lung invasion may be marked by a sudden rise of temperature, with cough and rapid respiration. In measles the pneumonia may accompany the exanthem or develop after the disappearance of the rash. This type is apt to be severe on account of the weakened resistance due to the primary disease. It frequently runs a prolonged course, followed by death or obstinate sequelæ.

Complications.-The commonest complication of bronchopneumonia is pleuritis, which is often followed by a serous or purulent effusion. Although the blood in bronchopneumonia usually shows an increase in lencocytes, a marked leucocytosis developing in the course of the disease should make us suspicious of pyothorax. Examination of pus from the pleural eavity reveals the infective agent of the disease, usually the pneumococcus, alone or accompanied by other forms.

Cardiac complications are not common, although pericarditis is occasionally seen. It is rarely diagnosed from the pleuritic effusion with which it is associated. Purulent meningitis develops in a small number 
of cases and should not be confused with the cerebral symptoms of the stage of hyperpyrexia. Stomatitis of varions forms and degrees of intensity is common in protracted bronchopneumonia.

Gastro-enteritis, although frequently the prinary disease of bronchopneumonia, especially of young infants, is not common as a secondary complication.

Sequela.-Among the sequelæ are chronic bronchopneumonia, enlargement of the bronchial glands, bronchicetasis, emphysema, tubereulosis, abscess and gangrene of the lung. The last named are rarely scen except in pneumonia due to the aspiration of foreign substances. As all of these conditions are separately considered elsewhere, it may suffice to state that although bronchopneumonia due to tubereulosis is common, pulmonary tuberculosis is not so frequently a sequel of bronchopneumonia as was formerly tanght. The appearance of miliary tubereulosis in eachectic children may possibly have been hastened by the debility incident to the pneumonia, or it may be that the cough and eongestion may have promoted the resolution of cheesy pulmonary nodules, liberating tubercle bacilli.

Diagnosis.-In the absence of positive signs of other diseases, bronchopneumonia may be diagnosed in an infant by persistent fever, cough and rapid respiration, which has a ratio to pulse-rate of 1 to $21 / 2$ or 1 to 2. From uncomplicated bronchitis, bronchopneumonia may be diagnosed in the first two or three days, and occasionally throughout the attack, only by the greater intensity of the symptoms. Sometimes, however, subcrepitant râles heard at the base of the lungs indicate bronchopneumonia. The increased resonance on percussion also suggests pneumonia. The continuance of the temperature beyond three or four days, with dyspnea and prostration, are not common to bronchitis. In cachectic children with enlarged superficial lymph-nodes, the diagnosis of acute catarrhal pneumonia from tuberculosis is often impossible. In some instances the diagnosis may be determined by the presence of tubercle bacilli in the sputum. From fibrinous pneumonia, it differs in the preceding bronchitis, age of the patient, occurrence in weakly children, or those recovering from the infectious disorders, more gradual onset, rarity of early signs of consolidation, atypical course, tedious resolution, tendency to relapses, and defervescence by lysis.

Prognosis.-The mortality of bronchopneumonia is high. The conditions unfavorable to recovery are early infancy, malnutrition, cachexia, bad environment, and the gravity of the infection to which the pneumonia is secondary. In infants of the first year the mortality may exceed fifty per cent. As a complication in whooping-eough, diphtheria, measles, and scarlet fever, the prognosis is grave in inverse ratio to age. In the gastro-enteritis of infants, bronchopneumonia is frequently a fatal complication. In all the acute infectious disorders of childhood, bronchopneumonia should be closely watched for, as its development adds doubt to a prognosis otherwise hopeful.

Children in institutions and crowded tenement districts show little 
resistance to this disease as compared with those in good sanitary surroundings.

Treatment.-The evidences of the contagious character of secondary bronchopneumonia demand prophylactic measures in epidemies of measles, pertussis, diphtheria, scarlet fever, or influenza. Efiorts at disinfection of the mouth, nose, and pharynx of the child suffering from an acute infectious disorder, by the use of antiseptic sprays and gargles, should never be neglected. Poorly nourished or rhachitic children, as well as those convalescing from acute disorders, should be protected from undue exposure to cold and dampness on the one hand, and from confinement in poorly ventilated rooms on the other. Children with whooping-cough should be kept in the open air when possible. The sputum and vomitus of pneumonic patients should be promptly destroyed and their clothing and bedlinen should be regularly disinfected, while the patient must be isolated from other children. In no other disease is good nursing, in all that the term implies, more valuable than in bronchopneumonia. Since no specific medicine is known, the treatment must conform to the indications of the individual case.

The fatality of the first four days, during the stage of intense congestion, may be lessened by early derivative and revulsant measures, such as prompt catharsis, enteroclysis, and the application of rubefacients to the chest and heat to the extremities. To maintain hyperæmia of the surface, mustard paste may be applied to the chest for a few minutes, at intervals of a half hour, or turpentine and lard ( 1 to 4 ), with thorough massage every four to six hours for the same purpose. The tendency of turpentine to induce strangury must be kept in mind and the urine watched. The hot bath, with or without mustard, causes determination of blood to the surface, relieves congestion of the lungs, and is efficient in the developing cyanosis. The feet should be kept hot by means of a hot-water bottle, and the head cool by frequent bathing with tepid water and alcohol or, in severe cases, by the ice-cap.

Leeches may be applied to rugged infants for the relief of congestion of the right heart, as in fibrinous pneumonia. Delicate infants and children weakened from the primary disease often require early stimulation by brandy, strychnia, digitalis, or nitroglycerin. Belladonna or its alkaloid not only aids in sustaining the heart but stimulates respiration and helps to allay the troublesome cough which is depriving the child of needed rest. Small doses of bromides are useful for restlessness. If cerebral symptoms develop, it should be given in full doses. Opium is rarely indicated in bronchopneumonia, and many popular expectorant mixtures may well be omitted. A vigorous child may be given an emetic of ipecac to expel tenacious mucus. Inverting the child will aid the extrusion of viscid sputum from the trachea and larynx, and frequent changing of the position will lessen the hypostasis in dependent portions of the lung. Persistent high temperature calls for frequent sponge bathing or packs, the temperature of which, if reaction 
be good, may be reduced from $95^{\circ}$ to $80^{\circ} \mathrm{F}$. $\left(35^{\circ}-26^{\circ}\right.$ (.) or even to $70^{\circ} \mathrm{F}$. $\left(21^{\circ} \mathrm{C}.\right)$, according to indications.

The dyspnea from bronchial secretion and congestion calls for noist atmosphere. The croup kettle and tent often afford relief. 'T'upentine, eucalyptol, and creosote may be added to the boiling water. Cases have been reported of phenic acid poisoning in infants from the iong-eontinued inhalations of vapo-cresoline in a closed room. The evident demand for oxygen should keep free ventilation uppermost in the minds of the physician and nurse.

From the nature of the disease and the character of its victims, the need of supporting measures in bronchopneumonia is obvious, hence the greatest care should be given to feeding. The diet must be liquid, concentrated, and administered frequently in small amounts, in order to secure the best nutrition and avoid the serious complications of indigestion and overdistention of the stomach and intestines.

Convalescence, so frequently tedious, requires the judicious oversight of exercise and food, and the use of tonies; as iron, quinia, and strychnia. Protracted convalescence is best met by removal to a climate where the patient can have an outdoor life, and yet be free from extremes of temperature and humidity.

CHRONIC INTERSTITIAL PNEUMONIA-PERIBRONCHITIS; PULMONARY FIBRO-

SIS; FIBROID PHTHISIS; CIRRHOSIS OR INDURATION OF THE LUNG.

Under the above terms a variety of conditions is indicated which may result from a prolongation or from frequent recurrence of pneumonic attacks. The law holds good here that prolonged irritation and congestion of organs or tissues result in hyperplasia of connective tissue. In the lungs this fibrosis occurs at the expense of the functionating structures, so that their identity is lost. The tubes may become strangulated or distended by the contraction of the surrounding fibrous tissue. Alveolar septa and bronchial walls are thickened, the air-cells are crushed together or filled with organized exudate, the pleuræ are thickened, agglutinated and bound to the lung by fibrous bands which penetrate its walls. As a result there is diminution in the size of the lung, with areas of increased density in one part and compensatory emphysema in another, and sacculated or cylindrical bronchiectasis in the denser portions. Extensive fibrosis is usually confined to one lung, more frequently to the base, although induration occasionally appears primarily in the apex.

The heart may become displaced by contraction of the lung, and its right side become dilated or hypertrophied from obstruction to the lesser circulation.

Symptoms.-The symptoms and signs of chronic pneumonia will obviously vary with the degree and duration of the fibroid changes. The continuance of cough, rapid respiration or dyspnœa, with physical signs of delayed resolution after the subsidence of temperature in acute pneumonia should, in the absence of emphysema, arouse the suspicion of a chronic process. This is especially true in children of feeble re- 
sistance who show progressive emaciation and prostration, and in those who have suffered from repeated attacks of pneumonia. The temperature may be recurrent at intervals of weeks or months upon the slightest exposure. The health may not appear much affected in the early stages, although the child usually shows deficiency in vigor, is short of breath upon slight exertion, and, if old enough, expectorates, sometimes copiously in the morning, foul-smelling sputum. Physical examination may reveal consolidated areas of dulness and absence of respiratory sounds in some parts of the lungs, with hyperresonance and amphoric breathing from dilated tubes and emphysematous lobules in others. As the process advances, the respiratory movements of the affected side diminish and there may be retraction and later recession of the chest wall, which amounts to a deformity, with later curvature of the spine, prominence of the clavicle, depression of the shoulder, and clubbing of fingers and toes. Hectic fever may develop with emaciation and general debility. Hæmoptysis is occasionally seen.

Diagnosis.-Excluding empyema, which should have been demonstrated early by exploratory puncture, the main interest centres in the diagnosis of chronic pneumonia from pulmonary tuberculosis. In many cases this is extremely difficult as the cirrhotic process may not have become sufficiently extensive to obscure the sounds of the accompanying bronchitis. When hectic temperature is an accompaniment, pulmonary fibrosis may closely simulate pulmonary tuberculosis. The majority of children, however, who have not succumbed to intercurrent disease before this stage, are old enough to expectorate. Repeated sputum examinations should reveal Koch's bacilli in most cases of tuberculosis.

The coexistence of a tubercular process in the apex with general fibroid phthisis is probably not a rare condition, although undiagnosed because walled off by the adjacent fibrosis.

Prognosis.-Chronic interstitial pneumonia is essentially a progressive disease and when well established a cure is not to be expected. Much may be done, however, for the relief of symptoms and prolongation of life. In the earlier stages cures are possible. The condition of the lungs is such as to favor tubercular invasion or the development of tuberculosis from caseous degeneration of preexisting tuberculous lymphnodes, so that chronic pneumonia frequently terminates as a miliary tuberculosis.

Treatment.-The treatment is mainly hygienic and supporting. The most nutritious food should be supplemented by cod-liver oil and general tonies, as iron, arsenic, quinia, and strychnia, while iodine, iodide of potassium, or syrup of the iodide of iron, are considered, to a certain. extent, specific in promoting absorption of exudates and the arrest of fibrosis. Life in the open air, with but moderate exertion, should be followed as far as possible. A change of climate may be necessary to secure the proper conditions of dry atmosphere and uniform temperature. Inhalations may be used as for bronchiectasis and bronchitis (pages 329-333). Breathing exercises and light gymnastics may do much 
to retain respiratory power and increase oxygenation. Stimulating expectorants, especially of the balsamic class, may be useful.

\section{HYPOSTATIC PNEUMONIA.}

Hypostatic pneumonia is a condition which develops in the course of debilitating disease as a result of enfeeblement of the circulation and prolonged decubitus. It oceurs in the most dependent portions of the lungs, notably on the posterior surface where, yielding to the persistent venous stasis, the alveoli become filled with loosened epithelium and blood elements by diapedesis from the engorged and weakened vessels in their walls. It is usually bilateral.

The condition is not, strictly speaking, inflammatory and is not accompanied by a rise in temperature. It is usually diagnosed at the autopsy and was formerly supposed to be due to agonal or post-mortem changes. Indications of pulmonary hypostasis, however, are present before death and may be seen in the respiratory embarrassment and sometimes in the dulness on percussion which oceupics a strip parallel with the spine on both sides of the chest posteriorly. This condition adds gravity to the disease which it complicates, as typhoid fever, marasmus, and, especially, bronchopneumonia.

The treatment of hypostatic pulmonary congestion is mainly prophylactic and consists in frequent changes in the position of the little patient, especially from the dorsal decubitus; while stimulation of the heart is maintained by the administration of digitalis, alcohol, strychnia, or citrate of caffeine. In infants, strong black coffee may be useful.

\section{ABSCESS OF THE LUNG AND PULMONARY GANGRENE.}

Although abscess of the lung rarely occurs except as a complication or sequel of other acute processes, it is worthy of separate consideration on account of the gravity of the condition and the difficulties attending the diagnosis.

Later reports show the occurrence of pulmonary gangrene in childhood to be of greater frequency than was formerly supposed. Abscesses of the lung may be single or multiple, and may vary in size from a small pea to the involvement of an entire lobe. They may be caused by infectious emboli from distant suppurating foci ; aspiration of foreign bodies which, becoming impacted in the smaller bronchi, excite inflammation; infected perforating wounds of the lung, and by extension of a pyothorax. It may follow any of the acute infectious diseases, but by far the greatest number of reported cases of pulmonary abscess have occurred as sequels to croupous or bronchopneumonia. Any or all of the pyogenic as well as saprophytic microbes may participate in the process. Abscesses are occasionally drained which show a preponderance of the pneumococcus. The pus of the abscess may burrow through into the pleural cavity or into a neighboring bronchus. In the latter case pus will appear in the sputum if the child be old enough to expectorate. The fetor of the breath will suggest the gangrenous process. Shreds 
of fibrous tissue may be found in the sputum, and hæmoptysis from eroded blood-vessels may occur. The fever and cough are frequently mistaken for that of an extension of the primary disease. Evidences of infection are seen in the great prostration, the erratic temperature and the leucocytosis, all out of proportion to the cough and extent of lung lesion. The physical signs may be those only of the primary bronchopneumonia, or may be those of a pleuropneumonia with sacculated effusion.

Diagnosis.-Pulmonary abscess is very frequently mistaken for empyema, and operations have been made which reveal only adherent pleural surfaces, even though previous aspiration had shown pus. Coarse pleuritic friction sounds should negative the supposition of pus in the pleural eavity even though there be dulness on pereussion and diminution or absence of respiratory sounds. The repeated failure to find pus by aspiration, after demonstrating its presence at the same level by a previous puncture, is quite suggestive of a lung abscess as against pyothorax. From putrid bronchitis with bronchiectasis the diagnosis is to be made by the absence of elastic fibrous tissue and lung elements in the sputum in these diseases, as well as by the more marked evidences of sepsis, - as prostration and high temperature in the case of abscess. Pulmonary tuberculosis may simulate gangrene of the lung in the formation of vomicæ, with or vithout hemorrhages. Differential diagnosis can only be made by the demonstration of Koch's bacillus.

Prognosis.-The prognosis is always grave, although in series of operations for the relief as high as sixty-one per cent. of recoveries have been reported. Too frequently, however, the diagnosis of pulmonary abscess is made at the post-mortem.

Treatment.-The treatment is essentially surgical, the result depending much upon the early diagnosis, the nearness of the abscess to the chest wall, and the character of the infecting organism.

\section{ATELECTASIS-COLLAPSE OF THE LUNG.}

Pulmonary atelectasis is frequently seen in infancy and childhood, and may be congenital or acquired. The former condition has already been described (page 171). In this connection it is sufficient to state that some degree of congenital atelectasis may persist for varying periods and may become an important factor in a bronchitis or bronchopneumonia of infancy.

Acquired atelectasis is due to collapse of air-vesicles of one or more lobules or even of an entire lobe, and most frequently occurs in infants or children of feeble muscular development, especially the poorly nourished and rhachitic. Alveolar collapse may be due to any one of three classes of causes, or to all operating conjointly: First, occlusion of a bronchus or bronchiole will produce collapse of the alveoli in the area of distribution, whether the obstruction be due to a foreign body, a viscid plug of mucus, or to swelling of the mucous lining of the tube. Whether the residual air is forced by the resiliency of the acini past the obstruc- 
tion which blocks the return of fresh air, or, being imprisoned in the vesicles distal to the plug, is absorbed by the blood-vessels, the result is the same,-viz., a collapse of the vesicles by pressure of surrounding alveoli which develop compensatory emphysema. Second, collanse of a portion of the lung may be caused by pressure from adjacent structures, as from a pleuritic or pericardial effusion, mediastinal tumors, abdominal distention, rhachitic or spondylitic deformity of the ehest wall or from the superincumbent weight of the infant's body in prolonged, unchanged decubitus. 'Third, disturbed innervation, as paresis of the pnenmogastric (after diphtheria) or intracranial compression of the respiratory centre may induce lung collapse. Atelectasis may oceur as a serious complication in any of the acute or chronic pulmonapathies and is especially frequent in whooping-congh with bronchitis. Bronchopneumonia rarely develops, it is claimed, withont more or less precedent atelectasis, and, in turn, no doubt causes extension or multiplication of areas of collapse.

The location and extent of the atelectasis depends upon that of the obstruction or compression which induces it. In bronchial catarrhs the posterior and more dependent portions of the lung, especially the lower lobes, are the favorite sites. These are usually bilateral. The consolidations may occur in many circumscribed areas, in size from a pinhead to a walnut, and when superficial appear post-mortem as depressions on the lung surface. This tissue is darker than that of the surrounding lung and does not crepitate on pressure. If recent, the alveoli may be inflated by moderate force. If of long standing, these areas are condensed, carnified, and sink in water.

Symptoms.-The symptoms are those of deficient oxygenation depending for their intensity upon the extent of lung area involved. This, in the absence of other demonstrable causes of dyspncea and cyanosis, should always suggest the probability of lung collapse.

The respiration is rapid with inspiratory dyspnœa and recession of the chest walls. The pulse is rapid and feeble with normal or subnormal temperature unless elevated by accompanying infection. The extremities are cold and an intermittent cyanosis is usually seen. Auscultation and percussion yield equivocal signs because of the bronchopneumonia and emphysema nearly always present. Dulness due exclusively to atelectasis can rarely be demonstrated.

Atelectasis may develop suddenly in the course of an acute bronchopneumonia in which the physical signs, especially if the atelectatic areas be diffuse, may be ambiguous or indistinguishable from the pre-existing disorder. Percussion dulness may be rendered resonant from adjoining or overlying emphysema. Resonance, fremitus and auscultatory signs of consolidation are masked from the same reason. In large areas of collapse dulness on percussion, absence of respiratory sounds, and retraction of the chest wall over the area in inspiration may be found.

Diagnosis.-Collapse may be suspected in any bronchopulmonary dis- 
order upon the sudden development of dyspnœa, eyanosis and of rapid respiration out of proportion to pulse and temperature.

From pleurisy it is diagnosed by the absence of friction sounds, bulging chest wall and ægophony heard over an effusion. From pneumonia it is distinguished by the absence of fever, by the character of the sputum and presence of ehest retraction.

Prognosis.-The prognosis of pulmonary atelectasis depends upon its duration and the removability of the eause. The longer the duration the more serious the import, as, after long compression, changes occur in the vesicle walls which prevent their re-aëration. Hypostatic congestion adds still further to the embarrassment of the function of the affected lung. In feeble children demonstrable atelectasis must always be regarded as grave.

Treatment.-As acquired atelectasis is always secondary, the treatment should be directed to the removal of the primary eause. After withdrawal of a pleuritic effusion and recovery from the bronchitis or bronchopneumonia, the child should receive careful attention. Cool bathing and outdoor exercise each day should be insisted upon. The diet and method of feeding should be under strict supervision, that the general nutrition and strength be improved. Distention of stomach or intestines must be avoided. Respiratory exercises, gradually increased and persisted in, will do much to develop the weakened lungs. In infants, this desideratum must be secured by frequent change of position, massage, causing crying by spanking, sprinkling with cold water, etc. Tonies are indicated.

For relief of the dyspnœa occurring suddenly in an attack of bronchopneumonia alternate hot and cold baths, stimulating liniments to the chest, and a free supply of oxygen are recommended. Liquefying the viscid mucus is favored by having the air of the room moistened by steam from water containing turpentine, eucalyptol, or benzoin.

\section{PULMONARY EMPHYSEMA.}

Emphysema not infrequently accompanies the pulmonopathies of infancy and.childhood. In fact, the relatively greater amount of connective tissue favors the development of interlobular emphysema in early life. Vesicular emphysema may develop under conditions which cause increased air-pressure in the pulmonary alveoli. The loss of resiliency in the walls of the vesicles which allows their overdistention is apparently due to inflammatory lesions of the lung tissue, hence emphysema is more developed during and after bronchitis, pneumonia, etc. The groups of alveoli which yield most readily to dilatation are those situated in the superficies of the lung, especially at the apices and along the free borders, also those adjacent to areas of collapsed lobules, as in compensatory emphysema. Among the causes of this stretching of the airvesicles and infundibula may be mentioned: first, prolonged violent paroxysms of coughing, followed by a sudden inrush of air, as in pertussis and chronic bronchitis; second, back-pressure in the bronchioles 
from obstruction to expiration, as in stenosis of the larynx and upper air-passages, obstruction in the tubes due to secretions, exudate, or congestion of their mucous linings, and most frecpuently to spasmodic asthma.

The interalveolar septa may give way under the pressure, so that two or more air-cells may appear as one enormously distended or the rupture of the alveoli may allow air to escape into the interstitial areas, causing interlobular pulmonary emphysema. In this form the air may find its way along the root of the lung into the mediastinal areolar tissue and thence into the cellular tissue of the body, becoming a general subcutaneous emphysema.

In either form of pulmonary emphysema the lungs are actually enlarged and contain an excess of residual air.

Symptoms.-There is shortness of breath on slight exertion or continued dyspnœa, with or without asthma. The anteroposterior diameter of the chest is increased, the general shape being that of full inspiration. The color of the skin is cyanotic from easily induced venous stasis. 'The fingers, in long-standing cases, are clubbed and the right heart shows dilatation with or without hypertrophy and oceasional tricuspid insufficiency with accentuation of the second pulmonic sound. Percussion of the chest gives increased resonance, with diminished areas of cardiac and hepatic dulness from extension of the emphysematous lung borders. Auscultation gives a prolonged expiratory murmur of low pitch, with the râles of the co-existing bronchitis or asthma. The heart sounds are somewhat obseured by overlying lung tissue and the apex beat is diffuse.

Prognosis.-The prognosis of acute pulmonary emphysema in childhood is usually good, unless due to a chronic intractable lesion.

Treatment.-The treatment should include the best of hygiene and the relief of all underlying causes of emphysema.

General subcutaneous emphysema may be due to traumatism in any portion of the respiratory tract, which allows the escape of air into the areolar tissue. It may follow a puncture of the aspirating ncedle. Its principal symptom is dyspnœa and its sign is a swelling and puffiness of the skin which does not pit, but yields a crackling crepitus on pressurc.

Cases occasionally recover under judicious treatment, which should include restriction of respiration and compression over the seat of puncture by bandaging, with the judicious employment of sedatives.

\section{PLEURITIS-PLEURISY.}

Pleurisy is a very common disease of childhood and is seen most frequently in the first five years of life. The youngest infants are not exempt, as autopsies on still-born children have shown pleural adhesions resulting from inflammation in utero. A predisposing cause is malnutrition and lowered vitality; hence it accompanies or follows most of the disorders and infections of early life. It is most frequently secondary to pneumonia. It rarely occurs as a primary disease in infants, although such cases have been reported in later childhood. There is much reason, 
however, to believe that even these are due to a mild type of bronchopneumonia during which the pleuritis develops so rapidly as to obscure the early symptoms of the primary disease. Probably the best and possibly the only illustrations of a primary pleuritis are seen following traumatism or as an expression of rheumatic poison.

Pleuropneumonia is the term applied to cases where the onset of the pleural inflammation is apparently coincident with that in the lung. Exposure to cold is recognized as a determining cause, although the exciting cause is believed to be a microbic infection from any of the pyogenic bacteria. During infancy and childhood the infective agent is the pneumococcus in two-thirds of the cases. This corresponds in frequency with that agent in the pneumonias of this period. In fact, it is probable that pneumonia rarely occurs without more or less involvement of the adjacent pleura. Pleurisy may be secondary to any of the acute exanthems and most of the infectious diseases of childhood, as well as rheumatism, nephritis, enteritis, and suppurative lesions in any part of the body, although extension from the lung is probably nearly always its origin in young infants.

Pleurisy occurs more frequently in boys. Like the pneumonias with which it is usually associated, it is seen most commonly during the season of greatest inclemency. Tuberculous pleurisy is infrequent in early childhood as compared with adult life.

In pleurisy the inflammation may vary widely as to the location and extent of the pleura involved, the quantity and character of the inflammatory products, as well as in the degree of constitutional intoxication. Upon these different effects is based the classification of the disease into dry, serofibrinous, and purulent pleurisies. It may be unilateral or bilateral, fissural, interlobular, or diaphragmatic.

From the onset the affected pleura loses its glistening appearance and may be coated with an exudate of fibrinoplastic lymph (entangling bacteria, leucocytes, or pus corpuscles), which forms a gray, green, or yellowish coating, varying in thickness from a sheet of paper to two or three millimetres. The pleura may become greatly thickened, sending processes of newly organized connective tissue from the visceral layer into the interlobular spaces of the lung to a considerable depth. The exudate favors the neighborhood of the interlobar fissures in its first appearance, but is usually more extensive on the parietal pleura. The rapid organization of the fibrinous coagulable lymph in the exudate results in adhesions between the opposing pleuræ. In extreme cases the entire sac may be obliterated by their agghutination. Usually, however, the exudate is restricted to limited patches. The tug of respiratory movements upon the plastic material stretches the adhesions into fibrinous bands or ribbons of varying length and density. Obviously the most intimate adhesions will occur at points least disturbed by the respiratory movements, as in the apices. Newly organized fibrinous tissues may convert the pleural sac into a multilocular structure. There is always more or less increase in the serous secretion in pleurisy, but the relative 
amount of serum, fibrin, and pus varies in different cases. The funntity of serum may vary from one to forty ounces. The form known as " dry pleurisy" rarely, if ever, exists in infants and young children extept as a form of pleuropneumonia. When the quantity of fluid is great the lung is compressed. This, if long continued, may result in loss of resiliency and in atelectatic consolidation. The diaphragn is forced downward, with displacement of spleen and liver, and the heart is crowded toward the unaffected side. This displacement is most marked in left-sided effusions when the cardiac impulse may be forced far to the right of the sternum.

Where extensive adhesions exist, in the absence of copious effusion, the lung may be bound down by its own thickened plenra and hyperplastic interlobular connective tissue, so that it never fully regains its former size and function. In this case the thoracic walls of the affected side show a corresponding retraction with resulting permanent deformity of the chest and spine.

Symptoms.-The onset of pleuritis is usually abrupt, but may be insidious and unsuspected until announced by the signs of accumulated fluid in the chest. Occurring in the course of a bronchopneumonia or an exanthem, the onset may be marked by a distinct exacerbation in temperature with pain and dyspnœa. In older children the pain may be over the affected side, but in infants it is usually referred to the epigastric or umbilical region. Distinct pain may be wanting or may be only elicited by firm pressure over the abdomen which displaces the viscera upward. The pulse follows the febrile movement and may be full and sthenic. It may show labored irregularity in proportion to the obstruction in the pulmonic circulation. If the effusion be large, especially on the left side, with extreme cardiac displacement, the heart becomes twisted upon its attachments and labors under great disadvantage.

Short restrained cough is a frequent symptom and the respiration is commonly restricted on account of the pain. In young infants, evidences of severe pain are usually wanting and the friction rubs are rarely heard. This is explained in part by the early occurrence of the effusion. With a large effusion, inspection of the chest may show unilateral bulging. This may be confirmed by comparative measurements from spine to midsternal line. Young children rarely show the intercostal bulging seen in older children. Percussion gives flatness with a peculiar sense of increased resistance to the finger. The heart-beat may be displaced to the right of the sternum in extensive accumulations on the left side, or to the axillary line when the pressure develops in the right pleural eavity. Displacement of the liver is sometimes demonstrable, continuous dulness extending as low as the umbilicus. Traube's space (the area of stomach resonance) may be obliterated in left-sided effusion. The line of dulness varies but little with changes of position. Gentle percussion may outline limited collections in the lower lateral portion of the chest. The effusion, though free, does not always tend to 
collect in the lowest part of the pleural cavity. At the same time hyperresonance may be elicited in the infraclavicular region of the affected side.

In the so-called dry forms of pleuritis and occasionally in the early stage of the serofibrinous type, auscultation over the affected side yields a characteristic friction sound. This may be differentiated from the finer crepitations of pneumonia, which it resembles, by its presence during both inspiration and expiration. Vocal fremitus and bronchophony may be diminished or obliterated and replaced by xgophony over a large collection. The vocal and respiratory sounds may be heard with a quality of remoteness if but little fluid intervene between the lung and chest wall. Walled off collections in sacculated pleurisy yield their physical signs in different areas independent of gravitation. In pleurisy, with extensive fibrinoplastic exudate, percussion may show dulness

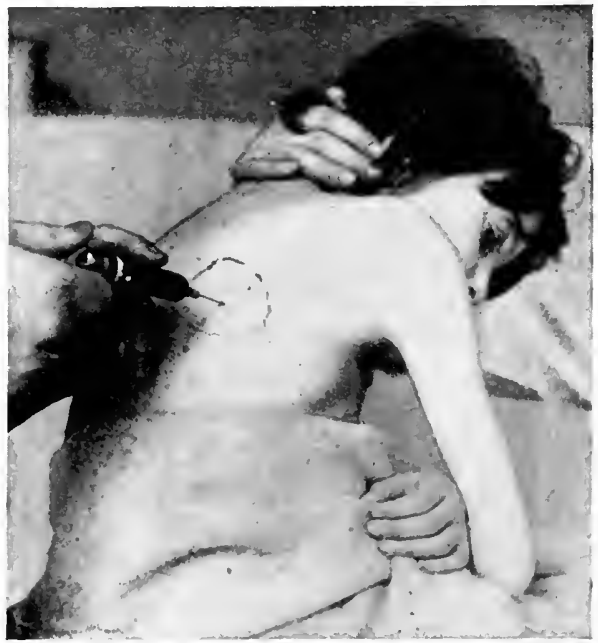

FIG. 146.-Exploratory aspiration of ehest.

over the affected area from the thickened pleuræ through which, however, the voice and respiratory sounds are transmitted with a quality of nearness.

The course and duration of pleurisy in infancy and childhood are modified by those of the disorder with which it is associated. The febrile movement may subside in from three to five days. The serous fluid gradually disappears by resorption so that in two or three weeks there is no evidence of the attack save, possibly, a thickening of the pleuræ and occasional circumseribed cohesion of the surfaces. The effusion, however, may not be absorbed and the continuation of temperature with emaciation, prostration, profuse sweating, and other evidences of sepsis, may suggest the presence of pus. This is further confirmed if the chest wall of the affected side become œedematous and an examination of the blood shows leucocytosis. 
Diagnosis.-The diagnosis of pus may be positively made by exploratory aspiration of the chest. This may be clone by a large hypodermic needle under proper aseptic precautions, after careful location of the area of greatest dulness (Fig. 146). If thick pus be present it may not flow readily through a small needle, and as the sharp needle may wound the surface of the lung or diaphragm during the movements of respiration or struggles of the child, a small trocar may best serve the purpose of puncture. This should be removed inmediately, learing the canula in situ. Deep puncture is rarely necessary,--two centimetres being sufficient in most eases.

Pleurisy should not be confused with hydrothorax, which is of noninflammatory origin and which is occasionally met with as a part of a general cedema, due to disease of the heart, liver, or kidneys, or to a hydræmia of general wasting. The diagnosis should be made by other evidences of organic lesions and the general symptoms of the primary disorder.

Pleurisy with serous effusion is diagnosed from other pulmonary disorders by flatness on percussion, with absence or diminution in vocal fremitus, lessened severity of general symptoms, and displacement of the heart-beat. The diagnosis is confirmed by the aspirating needle.

Prognosis.-The prognosis in simple acute pleurisy depends upon the character of the effusion. If this be serous or serofibrinous, resorption usually oceurs, unless tuberculous. In infancy the large majority of cases are of a purulent character, or a primary serous effusion becomes purulent if absorption is long delayed. In rare cases a moderate amount of pus may be absorbed from the pleural cavity without apparent detriment to the patient. As a rule empyema, unless relieved, produces general secondary infection with fatal termination. The pus may find exit by burrowing through the chest wall, diaphragm, or into a bronchus. The prognosis of empyema depends upon its early recognition and treatment, the character of the pus, and the age of the patient. If diagnosed before the development of general septicamia or while the strength of the patient is little reduced, early evacuation of the pus gives promise of speedy recovery. This is particularly true if the pneumococcus be the infecting organism. Hence the importance of microseopic examination of the pus obtained by exploratory aspiration. If the effusion shows streptococci, tubercle bacilli, or mixed pyogenic forms, the prognosis is grave, although, with the exception of tubercular infection, life may be saved by prompt, thorough, surgical treatment.

Sacculated collections in the pleural cavity and pulmonary abscesses are usually diagnosed post-mortem. Isolated exudation in a fissural inflammation and a diaphragmatic pleurisy present many difficulties in differentiation 'from each other or from pulmonary abscess in the substance of the lung. The aspiration may show different kinds of fluid from different punctures closely adjacent, or the needle may find pus at one aspiration and fail to find it with repeated later efforts, although introduced at the same point. In this latter event a deep-seated abscess 
may be suspected. In the former, separate walled off collections exist, representing different stages of pleuritic inflammation.

Treatment.-Acute pleurisy, if seen early, should be treated by revulsants, eliminants, and, if necessary, by sedatives. Free catharsis by an initial dose of ealomel, followed by a saline, with rubefacient applications or dry cups to the surface of the chest, and heat to the extremities, tend to relieve the congestion and lessen the effusion. Reapplications of weak mustard paste, sufficient to cause marked hyperæmia, or of tincture of iodine diluted with one or two parts of alcohol, may be made. Movements of the chest should be restricted by a flannel bandage. Strapping, so beneficial in adults, is objectionable in infancy on account of the extreme delicacy of the skin. Excellent results are obtained in allaying the pain and shortening the duration of the attack by the use of the ice-bag.

For severe pain, restlessness, and dyspnœa, codeine by the mouth or hypodermically may be used in appropriate doses. Frequently one administration suffices to secure relief for many hours.

Pleurisy, preceded or accompanied by arthritic or other manifestations of rheumatism, may call for the exhibition of salicylates, which are claimed, in addition to bactericidal properties, to limit the amount of exudation and also to promote absorption. Tepid sponging affords comfort and promotes elimination by the skin. Diaphoresis, diuresis, extreme catharsis, and dry diet are of doubtful utility in limiting the quantity of fluid in the pleural cavity and have little effect in causing absorption of the exudate. Care of the stomach and bowels is necessary to secure nutrition and prevent pressure upon the diaphragm from overdistention.

A rapid, weak, and irregular pulse may require a cardiac stimulant, as digitalis, strophanthus, caffeine citrate, or strychnia. In large effusions with marked cardiac displacement and dyspnoea relief may be obtained by puncture and drainage of a portion of the fluid. If nonpurulent, the remainder may disappear gradually by absorption. If the fluid persist beyond two or three weeks, potassium iodide, one to ten grains $(0.065-0.65 \mathrm{Gm}$.) according to age, four times a day, may hasten absorption. Syrup of the iodide of iron, arsenic, or the elixir of iron, quinia and strychnia, may be given as hæmic restoratives. After the acute stage the child should be allowed to sit up and soon to move about in the open air. Deep breathing should be practised daily to expand the lung. Young children may be encouraged to blow a horn or soapbubbles for the same purpose. If the effusion persist, after a period of several weeks, it should be evacuated to prevent permanent injury to the lung from long compression. This may best be done through a hollow needle or' canula, the flow of fluid being promoted and the entrance of air prevented by a vacuum aspirator, such as Dieulafoy's. In large collections, the puncture should be made in the midaxillary line in the fifth or sixth interspace, avoiding the lower border of the rib. The child should be in a half-reclining position, the affected side 
uppermost. A local anæsthetic, as the ethyl chloride spray, may be employed. In the case of a very nervous or undisciplined child general anæsthesia may be neeessary. The fluid should be withdrawn very gradually. Too rapid expansion of the lung induces conghing and should be restrained by eompression of the chest by the hands of a murse or by a firmly drawn bandage. During the operation, and immediately after, the pulse must be watehed, as stimulants may be necessary. Complete evaeuation of a serous effusion is rarely necessary or advisable. After withdrawal of the needle, sepsis and entranee of air may be guarded against by the application of a collodion dressing or a bit of plaster over the puneture. If the lung be tuberculous it is well not to disturb the fluid in the chest unless it eauses threatening symptoms, as by its presenee eompression and rest of the affected lung is seeured, with its favorable effeet in limiting the extent of the tuberenlar process.

The diagnosis of empyema ealls for prompt surgical interferenee. As a rule thorough evaenation of the pus and eomplete drainage are the great desiderata; hence rib resection is generally favored by the surgeon. In pneumoeoeeie pus, however, good results are usually obtained by incision and the quiek introduetion of a double drainage tube between the ribs. In addition to aseptie preeautions, four important points are to be observed in this simple operation: First, avoid too low a site for the incision, as the rising diaphragm may press upon the tube and occlude it; seeond, prevent the entranee of air by eonstant pressure upon the ehest wall during and after the introduetion of the tube; third, do not wait for the pus to stop flowing before applying the dressing; and fourth, retain an abundant absorbent dressing by a firmly applied bandage. Irrigation is rarely neeessary, as the gradual expansion of the lung encourages free drainage into the absorbent dressing. The tube should be shortened at eaeh dressing as the depth of the cavity diminishes. One-half of the tube should be fenestrated, the other half entire, and held together by a safety-pin passed through their walls to prevent them from dropping into the pleural cavity.

Resection of a rib should be referred to the surgeon. 


\section{DISEASES OF THE KIDNEYS, BLADDER, AND GENITAL ORGANS}

\section{ANURIA AND OLIGURIA}

Total suppression of the urine in the new-born may be due to malformation of some portion of the urinary tract, as imperforate urethra or ureters, occlusion of either by calculi, mucous plugs, blood-clots, or accumulations of uric-acid crystals. Occasionally, from having emptied the bladder during birth, the infant will pass no urine for from twelve to twenty-four hours. This fact, and the rapid loss of fluids from bowels and by evaporation from the surface, together with non-ingestion during the first two days, might well explain the scanty secretion. The frequent appearance of large quantities of uric acid (brick-dust) after temporary suspension, and the presence of uric-acid infarcts in infants dying of anuria, are sufficient explanation for a common obstruction in very young infants.

Scant urine, or total suppression in older babies and children, may be due to any cause which operates by diverting the fluids to other channels, as colliquative diarrhœa, vomiting, and sweating. Obviously, high temperature and hemorrhages diminish the amount of fluid to be excreted. In older children particularly, nervous influences, as hysteria, affect the secretion of urine to a remarkable degree. Irritation of the urinary tract by certain substances may cause a vesical strangury or complete or partial suppression from acute renal congestion. Turpentine, cantharides, salicylates, the carbolic acid group, ether and chloroform, act in this way, whether taken internally, by inhalation, or by application to the surface, and are not infrequent causes of oliguria or even anuria. Passive congestion from thrombosis of the inferior vena eava, or renal vein, has been reported.

Differential Diagnosis.-Anuria should be differentiated from retention. The distended bladder will appear as an abdominal tumor above the pubis, which disappears upon catheterization. .The retention may be due to obstruction by calculus, or partial vesical paresis from overdistention. It may be a symptom of grave neurosis, as from transverse myelitis or other affections of the spinal cord.

Prognosis.-The length of time a child may live with complete anuria varies from three to fourteen days. The lateness of the development of uræmic symptoms in infants is an interesting clinical fact.

Treatment.-Anuria should be treated with due reference to the cause. Congenital malformations and calculus call for prompt surgical 
interference. Water is the best diuretic, especially for the new-born. In older children spiritus ætheris nitrosi, potassium acetate or citrate, may be given every hour or two. Hot fomentations over the kidneys or hot baths are useful. Enteroclysis of hot normal salt solution is, perhaps, the most efficient procedure.

\section{HEMATURL.}

Blood may be present in the urine, giving it a dark red color, a smoky amber hue, or may only be discoverable by detection of corpuscles, by chemical test, or by the microscope. If the urine be streaked with blood its probable source is the urethra or bladder. If from the ureters, pelvis of kidney, or renal tubules, it is uniformly disseminated throughout the urine, and will form tube casts or the larger ureteral moulds. The passage of the urine into two glasses will occasionally give a hint as to the source of the blood in the difference between that seen at the beginning and at the close of micturition.

Irritation; trauma from falls, blows, eatheterization; calculi; acute nephritis; active or passive hyperæmia of the kidneys or of the entire urinary tract, are the principal causes. To these should be added such blood dyscrasiæ as hæmophilia, scorbutus, purpura, and syphilis; also neoplasms of the kidney or bladder, and besides malaria, the use of quinine, chlorate of potassium, etc.

Recurrent hæmaturia may require differentiation between calculus or uric acid crystals and carcinoma as to the cause. Stone should produce its vesical and tubular symptoms. (See Calculus.) The rather profuse hemorrhage from carcinoma rarely occurs until far enough advanced to be located by palpation. The presence of renal sand in the urine when first voided and still warm is very suggestive as a cause.

The prognosis and treatment are entirely dependent upon the eause. The general indications are rest and protection from cold. If severe or continued, such hæmostatics as ergot, gallic acid, and suprarenal extract may be tried.

\section{HEMOGLOBINURIA.}

The blood pigment may appear in the urine, as proved by Heller's test or spectrum analysis, accompanied by few or no red corpuscles. Albumin is always present, and the urine may be red or almost black from the blood pigment it contains. The nature of the hæmolysis which allows the escape of the hæmoglobin from the cells is still in doubt. Most of the exciting causes are those common to hæmaturia.

A paroxysmal hæmoglobinuria from unknown etiology occurs with chill followed by fever, the temperature rising from $101^{\circ}$ to $104^{\circ} \mathrm{F}$. $\left(38.5^{\circ}-40^{\circ}\right.$ C. $)$. The urine clears up after the subsidence of the fever, with the exception of a transient albuminuria. Obviously the treatment depends upon the cause.*

* For epidemic hæmoglobinuria in the new-born, see Winckel's Disease. 
Intermitent ALBUMinURIA-ORThostatic, POSTURAL, CYCLIC, FUNCTIONAL, PHYSIOLOGICAL ALBUMINURIA.

The causes of albuminuria constitute a subject the discussion of which has brought out such a variety of opinions that a detailed consideration here is obviously impracticable. Is the term physiologic albuminuria a misnomer? Those who hold that albumin may not be present in normal urine are referred to the albuminuria of the newly born, which appears in over fifty per cent. of infants. On the other hand, those who claim that cyclic albuminuria may be devoid of pathologic significance are referred to the many instances in which unquestionable nephritis followed. When the great variety of pathologic conditions that may cause or at least precede the appearance of albumin in the urine is consid: ered, the inclination is strong towards the conclusion that its presence is never without some pathologic significance, and that the diagnosis of physiologic albuminuria is but another expression for undetermined causation. Without appreciable kidney lesions or any other evidence of impaired health, albumin in slight amounts may appear in the urine, either continuously or periodically (cyclic), for months or even years. It may be absent from the urine secreted while in a horizontal position (first morning urine), only to reappear in that voided sometime after rising or during the day (postural or orthostatic albuminuria). Albuminuria is occasionally induced by the overingestion of proteid food (dietetic albuminuria), and is now known to be a common accompaniment of gastro-enteric disorders of infancy. An analysis of all the evidence in many cases of albuminuria without demonstrable kidney lesion yields many facts too significant of albumin production to be disregarded. Thus albuminuria of the new-born most frequently follows dystocia. Both eyclic and continuous albuminuria usually are observed in children who show some deviation from perfect health, - as anæmia, indigestion, headache, vertigo, tendency to nervous irritability, syncope, and malnutrition. Transient albuminuria may follow cold baths, shock, fright, unaccustomed muscular exercise, and undue fatigue, not to mention the long list of intoxications and infections of all grades of severity. In addition to this we may have intermittent albuminuria, even in demonstrable nephritis.

In all the varieties of hæmic, cardiovascular, angioneurotic, and trophic conditions, there resides and ultimately may be demonstrated a cause for every form of albuminuria.

The significance of albuminuria depends entirely upon associated conditions, such as the presence or absence in the urine of blood, pus, casts, excessive number of epithelial cells, or mucus, and the existence of cardiac hypertrophy, high-tension pulse, fever, etc.

Too commonly neglected is differentiation of serum-albumin and serum-globulin from the other proteids of slight, or as yet unknown, pathologic importance, such as nucleo-proteids, albuminoses, and fibrin. The presence of globulin, a usual accompaniment of albuminuria, is only 
significant when its quantity equals or exceeds that of serum albumin, as in amyloid degenerations. Nucleo-proteid alone is not indicative of renal lesion, but may be due to epithelial desquamation in any portion of the urinary tract. Of special interest in differentiation is extrarenal albuminuria or urine contamination with albumin from mucus, blood, or pus, after its exit from renal tubules.

The appearance of albumin in the urine is of more frequent occurrence in infancy and childhood than in adult life, for the reasons that the conditions conducive thereto are more common,-as the greater metabolism, the activity of the glandular system, the prevalence of acute infectious diseases, the frequent recurrence of febrile disturbances, and a greater tendency to uric acid formation. In this connection the remarkable increase of metabolic and circulatory activity of pubescence is significant. The amount of albumin is usually small,--from a mere trace to one-eighth of one per cent.

Although evidence of the albuminuria of functional disturbance is increasing, the careful physician will not jump at the conclusion from the co-existence of some possible functional cause, but will regard every case with a proper degree of suspicion of beginning organic changes in the kidney, and keep the case under close observation.

\section{KIDNEYS-MALFORMATIONS AND CONGENITAL ANOMALIES.}

Probably no other organ exhibits a greater freqnency or variety of congenital anomalies than does the kidney. There may be entire absence of one or both, rudimentary formation, fusion, multiple kidneys, atrophy, movable, eystic degeneration, double pelvis, hydronephrosis, and supernumerary ureters. Entire absence of both kidneys has been reported,a condition which renders continued extrauterine existence impossible. In these subjects other congenital defects are usually present.

In the absence of one kidney, the corresponding ureter is wanting. Where this tube is present, a mass appears at the upper end representing a rudimentary or extremely atrophied kidney, possibly with renal artery and vein (Fig. 147). Intrauterine inflammation is probably responsible for this arrest of growth or retrograde change. Under these circumstances the opposite organ is always enlarged from the necessity of increased function. The deficiency is rarely diagnosed during life. This condition is of special interest in view of subsequent risk from the development of renal insufficiency during the infectious diseases of childhood.

The kidneys may be fused at their upper, middle, or lower portions. commonly the latter, forming the "horseshoe" kidney, which usually is supplied with two pelves and ureters. This anomaly, with the preceding, is of surgical interest when conditions requiring nephrectomy arise.

Double ureters arising from separate pelves in the same kidney are occasionally seen and may enter the bladder in a common or separate opening. The latter is of interest in cystoscopic work. In this connec- 
tion the possibility of anomalous position of the ureteral orifice in the vesicle wall should be borne in mind.

Displacement of the kidney, congenital or acquired, is not rare, and occurs most frequently in girls. The kidney may be movable or fixed, displacement varying widely in degree from mere palpability even to the pelvis. It has even been found in the umbilical cord at birth. This possibility conveys a caution, as it has been injured from want of recognition. Occasionally this organ is fixed in malposition, in the

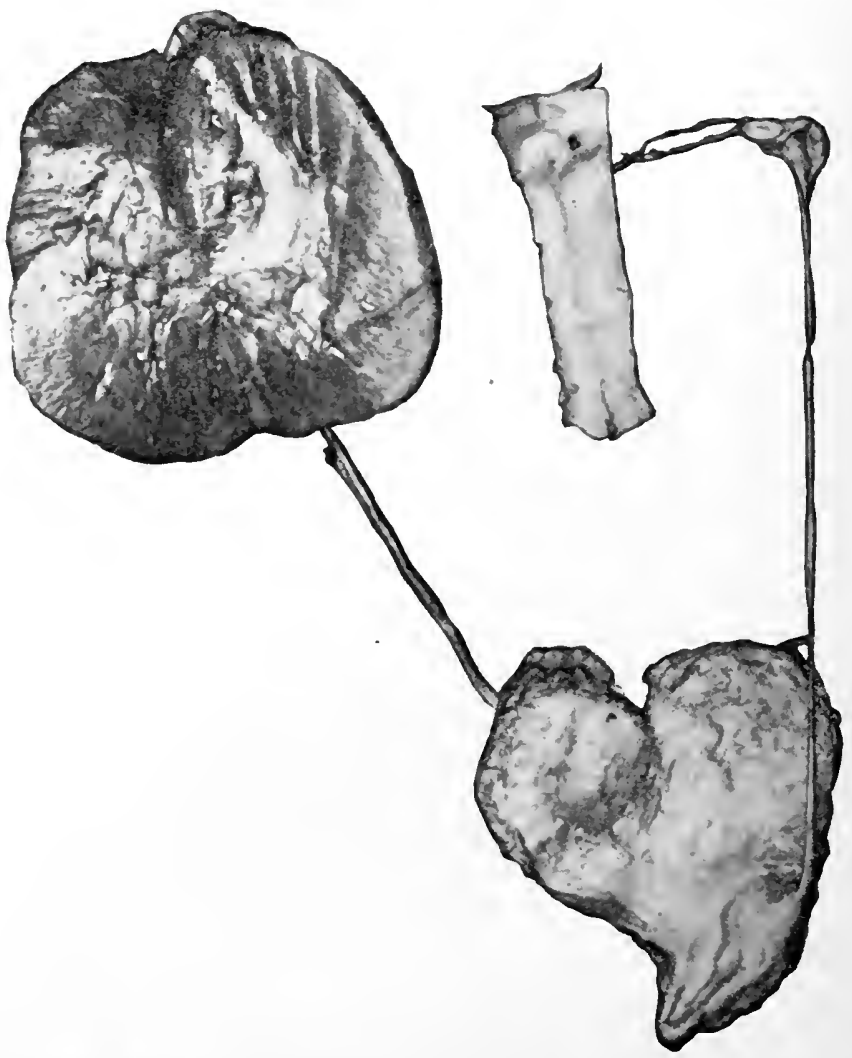

FIG. 147.-Rudimentary kidney, aorta, renal rein, and artery. Right kidney enlarged, showing acute inflammation engrafted upon a diffuse nephritis. Boy, 4 years old.

pelvis, below or at the sacral promontory. In this locality the " horseshoe" kidney is usually found. Exploration of the rectum will sometimes reveal the dislocation.

Symptoms attributable to nephroptosis are pain and discomfort in the epigastric region independent of digestive disturbance, and dragging in the loin, relieved by recumbency and abdominal support. The coated tongue and jaundice have been explained by the dragging on the duodenum through the mesonephron. Constipation is attributable to the same 
influence on the colon. Scant urine may be the result of tramsient hyctronephrosis from twisting of the ureter in movable displacements. Renal mobility, aside from traumatism, may result from two canses, the rapid absorption of the fat which assisted in retention of this organ in its normal position, and the relaxation of extreme debility, congenital or otherwise, of which the displacement of the kidney is but a feature of the general splanchnoptosis.

In the treatment, before the consideration of surgieal interference, efforts should be directed to the general condition and improvement of the muscular tone, particularly of the abdominal wall. 'Temporary or even permanent relief may be secured by an abdominal bandage.

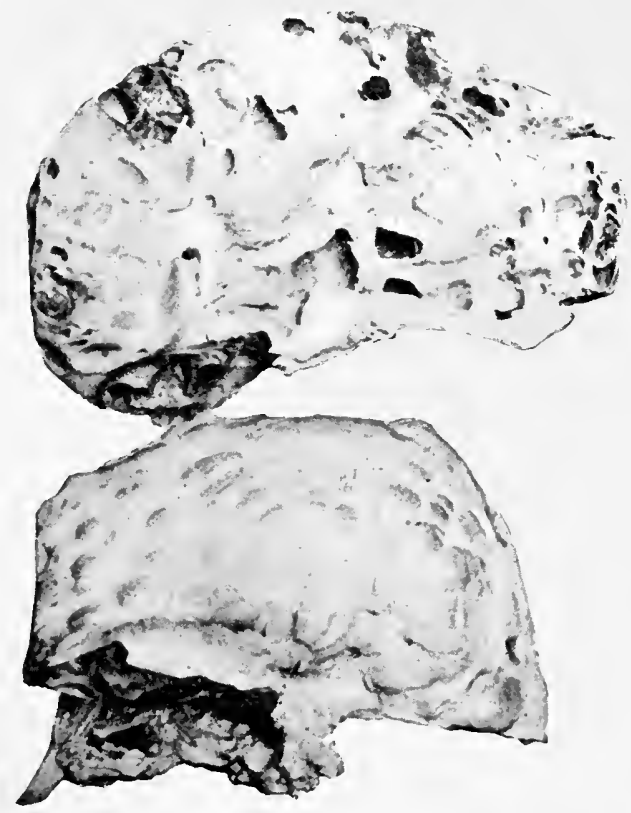

Fig. 148.-Double cystic tumor of kidney. (Rush Medical Museum.)

Congenital cystic degeneration of the kidney is presumably due to developmental arrest or perversion in the embryonic tubules, with the formation of terminal pouches. These subsequently fill with fluid and may attain enormous dimensions, rendering delivery difficult or impossible. One kidney alone is rarely affected. These cysts, although usually multiple at birth, develop rapidly with a tendency to coalescence, and obliteration of all normal histological structures (Fig. 148). When discovered, they appear as abdominal tumors, with evidences of renal insufficiency. If both kidneys are involved, differentiation from hydronephrosis and malignant tumors may be assumed from the bilateral character. Most frequently the infant does not long survive birth; although occasionally these tumors develop slowly until adult life. 
The true nature is usually revealed at the post-mortem. No curative measures are of any known value.

\section{ACUTE NEPHRITIS.}

Renal morbidity is rarely, if ever, confined to one variety of histologic elements, so that the terms glomerulo, tubular, and interstitial, as applied to acute nephritis, express only a partial differentiation between the coincident pathologic processes and conditions of the disease called nephritis. Not only do different renal elements suffer simultaneously, to a different extent, but consecutively the pathologic picture changes with the advancement of the morbid processes.

In view of these facts, the term acute nephritis is deemed sufficiently comprehensive to express a disturbance of renal function which is very common in infancy and childhood. No separate consideration is given to acute renal congestion for the reason that it may safely be regarded as the initial stage of acute nephritis without jeopardizing either the etiology or therapy. A primary form of acute nephritis, especially among very young infants, is reported by some observers. The diagnosis can be made only in the absence of any known cause.

Acute nephritis is usually due to the presence of toxins either of ectogenous or endogenous origin. Its relation to acute infection is accepted as proof of their etiologic importance. There is ample evidence that it may be due to syphilis. Increasing evidence shows its relation to gastrointestinal disorders, especially of young infants. Many chemical and medicinal agents are known to act as exciting causes, as are also extensive burns of the skin. The question as to the influence of cold and damp in the production of renal ineompetency in children has been much diseussed. The mass of elinical evidence, however, points to such exposure as a frequent cause, at least in the precipitation of an attack of acute nephritis.

The causative relation of uricacidosis has received confirmatory evidence by recent observations upon young infants in the frequent findings of these infarets in those dying from acute nephritis.

The symptoms of acute nephritis may be quite irregular in the order of their appearance. A mistaken notion that certain classical symptoms are always present is extremely unfortunate, because many cases are, no doubt, overlooked. The symptoms, too, may be masked by those of the preceding or accompanying disease, of which the nephritis is a complication or sequel. The most important and almost constant indication of acute nephritis is the condition of the urine, which should be systematically examined in all diseases and conditions which nephritis may follow.

The urine at first is usually lessened in quantity, although voided frequently, or there may be complete anuria. The specific gravity is usually high. The appearance is turbid, smoky, or even dark red from the contained blood-cells. On standing it deposits a heavy sediment. Microscopic examination shows crystals of uric acid and oxalate of calcium, 
renal epithelium, red blood-eells, also hyaline, epithelial, and blood-casts. Albumin is nearly always present, from one-fourth to one per cent., or the urine may even solidify on boiling. Oceasionally, however, the speeific gravity may be low on account of the diminished excretion of solids. The pereentage of urea may be higher than normal, although the total quantity exereted is always diminished.

In favorable eases the quantity of urine may gradually increase even from total anuria, with more or less rapid dininution in the albumin, blood, and easts, with increase in the amount of urea, the kidneys resuming their normal function within a week. Many regard this early reeovery as evidenee of acute hyperemia rather than acute nephritis, although the diagnosis as such is impossible prior to its early termination.

The return of the kidneys to their normal function may be more gradual, so that weeks elapse before the urine is entirely free from evidences of renal insuffieiency. Even then the tendeney to reappearanee of albumin and easts from slight or unapparent causes is the rule. Hence the importanee of systematie urinalyses long after apparent recovery. Chronic forms of renal disease almost always have their origin in acute attaeks. Unfortunately, the urinary findings proceed from bad to worse, diminished quantity and inereased pathological constituents rendering prognosis extremely grave.

There is usually moderate fever at the beginning of the attack, oceasionally following a ehill, although the temperature may be normal and in rare instances subnormal throughout. The rise in temperature is frequently mistaken for a eontinuation of the primary disease, and in the absence of other symptoms, without examination of the urine, the diagnosis will be overlooked. Vomiting is oeeasionally an early and frequently a late and unfavorable symptom, presaging uræmia. So, also, headache in older ehildren, dimness of vision from hemorrhagie retinitis, restlessness, or apathy, may be the precursor of uræmie eoma or convulsions. Edema, next to the urinary findings, is the most eommon aeeompaniment of acute nephritis; indeed, this symptom has long been regarded as pathognomonie and is occasionally the first and only (always excepting the urine) indieation of renal involvement. The evelids appear puffy. There is slight pitting on pressure over the sternum. The feet and ankles swell. The serotum or labia and the dorsal portions of the body become œdematous. Later, dropsical effusions may appear in the serous cavities, peritoneal, pleural, and pericardial. Edema of the glottis and lungs may develop, the patient dying of asphyxia unless promptly relieved.

Although the cdema in young infants may be only moderate, it is rarely absent, and careful examination of the extremities and sternum will probably reveal some pitting on pressure. It is claimed that an inerease in the body weight shows increased water in the tissues, not revealed by inspection.

The pulse in children does not oftcn show the high arterial tension 
indicative of renal disease in adults. Neither is the accentuation of the second aortic sound so noticeable. The pulse is often rapid and irritable in character, the cardiovascular signs depending largely upon the nature and duration of the antecedent disease.

Anæmia appears early in the disease and is most marked when the nephritis develops in a later stage of the severer acute infections. This is especially true in diphtheria.

The ever-impending danger in acute nephritis is uræmia. Uræmic coma or convulsions may occur late in the disease or may usher in the attack as a first indication of renal insufficiency. The degree of uræmia is at all times an index of the gravity of the disease. Hebetude, lethargy, and impaired vision are significant forerunners of coma, while headache, vertigo, restlessness, delirium, twitchings, and heightened patellar reAexes are indicative of impending eclampsia.

The diagnosis of dropsy due to cardiac insufficiency, with passive renal congestion, should not be difficult after careful examination of the heart and urine. If the patient is seen for the first time in the more advanced stage of acute nephritis with a normal amount of urine, little albumin, and low specific gravity, chronic interstitial nephritis may be suspected, but the history of the acute attack would clear up the diagnosis.

The prognosis, always grave, is darkened by the decrease in the amount of urine, the increase in its morbid constituents, and the development of indications of uræmia. The occurrence of pulmonary and glottic cedema, before referred to, are of serious import, while complications, such as pneumonia, or endocarditis and pericarditis, greatly lessen the chances of recovery. Especially in young infants are such complications fatal. Early recognition, prompt treatment, and intelligent care will limit the mortality to exceptional cases.

Treatment.-Prophylaxis requires the promotion of excretion in children suffering from any infectious disease, especially scarlet and typhoid fevers, diphtheria, or gastro-enteritis. Upon the appearance of the first evidence of æedema, as puffiness of the eyes, prompt catharsis should be induced by calomel, ipecac and soda, while thin stools should be maintained by the frequent administration of salines. The congestion of the first days of acute nephritis occasionally shows marked relief from the application of ice-bags to the lumbar region. This is applicable only to older children, as is also the use of dry cups over the kidneys. For babies a mild sinapism or warm eataplasm, sprinkled with mustard, to the lumbar surface, is preferable. Applications of turpentine in these cases should be avoided; so, also, the employment of all drugs that favor renal congestion,- as carbolic acid, cantharides, and the balsamic and salicylate group. The child should be protected from cold, overeating, and fatigue. The etiologic rôle of gastro-enteritis among infants should be remembered, so that the correction of digestive disturbances be not neglected.

It is safe in every condition of coma from unknown cause to induce 
prompt purgation. The urine should always be examined, though catheterization may be necessary to secure a specimen. For eollecting the urine of infants a teacup may be retained under the grenitals by a napkin, with a little dexterity. Or in the male child a rubber bag may be supported by tapes passing around the loins. Ordinarily the child may be induced to urinate by the application of the cold wet hand over the bladder, with a little pressure.

The treatment of renal insufficiency consists essentially in promoting vicarious elimination by the bowels and skin. The crippled kidneys should be further relieved by the reduction of proteid ingested and by limitation of muscular activity, reducing metabolism to the lowest possible degree. The child should be kept in bed between blankets.

The odema is a contraindication to the ingestion of a large quantity of fluids, as in high albuminuria the kidneys excrete with difficulty, the tissues of the body becoming waterlogged, and the heart overburdened. Thirst may be relieved by cracked ice and small drinks frequently repeated. Cream, bread and butter, rice and other cereals, and bland vegetable soups, form the safest dietary as long as æedema persists. With the disappearance of cedema and an increased flow of urine, the menu may be more generous and include eggs, milk, fruits, legumes, and small amounts of meat. It is now taught that there is no ground for the former general belief in the greater safety of "white" meat. The weight, temperature curve, and quality of pulse should be daily watched, as by them may be determined if the diet is adapted to the excretory power of the kidneys. In extensive cedema salt should be restricted, since it favors the retention of water in the tissues. The routine practice of restricting the diet to large quantities of milk, with the copious administration of water, for its presumed effect in flushing out the kidneys, is particularly pernicious in renal insufficieney with large dropsical accumulations. Later in the disease, when the renal congestion has somewhat subsided, as indicated by the increased urination, fluids may be given with good effect. In acute cases all stimulating diureties are not futile but injurious.

The development of uræmic symptoms demands more active purgation and diaphoresis. The latter may be secured by dry heat, hot baths, or hot packs. Jaborandi and its derivatives are contraindicated, especially in infants. Calomel and jalap, or compound jalap powder, are useful. Hydragogue cathartics and eream-of-tartar lemonade in moderation may replace the water. For eclamptic attacks, the hot pack is indicatcd, with chloral and bromides per rectum. The hypodermic use of morphine or codeine may be necessary in recurrent convulsions. The coal-tar products should not be used. For weak heart with low arterial tension digitalis may be administered, but its routine use in all cases should be discouraged.

The development of pulmonary œdema may call for the use of nitroglvcerin and strophanthus, with dry cupping over the thorax, and if accompanied by high arterial tension, venesection of the median basilic 
vein, in addition to the above treatment. (When blood is drawn for the relief of renal engorgement, it should be taken from the lower extremities.)

The anæmia of convalescence calls for the use of iron, Basham's mixture preferably, or the tincture of the chloride, in moderate doses. Rest in the recumbent position and protection from exposure to cold should be maintained for weeks after the subsidence of acute symptoms. When practicable, transfer to a warm and equable climate is recommended.

Return to the usual dietary should be very gradual, the urine being closely watched. Its diminution or the reappearance of morbid elements calls for the prompt resumption of hygiene according to the principles previously enumerated.

\section{CHRONIC NEPHRITIS.}

Prolonged venous blood stasis in the kidney, as in other organs, eventually produces cell proliferation and hyperplasia of connective tissue. This is followed by pressure effects on the epithelial elements of the parenchyma of the organ due to contracting interstitial tissue. Some recent post-mortem reports of infants showed only vestiges of the kidney as the result of cirrhotic and degenerative changes. As has been seen, active hyperæmia, from whatever cause, with its increased influx of infective or toxic material, causes changes in both the parenchyma and stroma, with a predilection for the former, so may passive hyperæmia cause changes, although less rapidly, especially in the stroma. These structural and functional changes in their relation to each other and in the sequence of their occurrence, their persistence and extent, depend largely upon the manner of onset, also the extent of and duration of the passive hyperæmia through which they are induced.

The cause of this passive hyperæmia may be general or local, as from affections of the heart and lungs or from mechanical pressure of new growths, congestions, or any condition which obstructs the renal circulation on the venous side.

The futility of the claim for continned independent existence of a single kidney lesion is apparent; any case of long duration would furnish the evidences of chronic diffuse nephritis. Simply for convenience in description, the division of chronic nephritis into parenchymatous and indurative or interstitial is made, according as the epithelium, or stroma, suffers the more in any particular case at the time of investigation.*

Chronic nephritis may develop so insidiously as to attract no attention. The child may show underdevelopment for age, recurrent headaches, restlessness, fatigue upon slight exertion, moderate œdema or

* Chronic nephritis has usually been regarded as of infrequent occurrence in early life. The probability, however, is that more urinalyses, and more exact methods of examination, and an increased number of post-mortems, would increase the frequency of its diagnosis. 
digestive disturbanees from no apparent cause. Some or all of these symptoms may subside only to reappear after a few weeks or months with increasing intensity. The slight dropsy may become general, with effusions into serous cavities and threatening symptoms of pulmonary œedema. Examination of the urine shows it to be scanty, of high specific gravity, and eontaining all varieties of easts and a large amount of albumin. Between the exacerbations the quantity of urine increases with lowering speeifie gravity and diminution of albumin.

These symptoms may have been preceded months or even years by an attack of acute nephritis or an obscure history of dropsy following an acute infeetious fever. The tendency of chronic nephritis is to increase in the persistency of its symptoms, with developing anamia, asthenia, and shorter intervals of relief, mutil invalidism is firmly established. Uræmic symptoms may develop at any time with threatening or actual fatality.

The duration of the disease may be from one to many years, if not shortened by intereurrent disorders, the patient succumbing at last to insufficieney of renal funetion.

The prognosis depends upon the early diagnosis and the treatment. Very few cases are cured, although much may be done to ameliorate the condition and defer the fatal termination.

In the interstitial variety of chronic nephritis, the rarest form in childhood, the symptoms usually are very obscure and their development gradual. Among those regularly eharaeteristie of this form are cardiac hypertrophy and inereased arterial tension, normal or increased quantity of urine of low speeifie gravity, 1.002 to 1.010 , with little or infrequent albumin or easts and disturbance of vision from retinitis, a rare oecurrence in the other varieties of nephritis. The oceurrence of retinitis may be the first intimation of renal disturbance, or this result may occur among the terminal symptoms. Heredity undoubtedly has a plaee in the etiology as have also rheumatism and syphilis. As its approach is most insidious its duration is the longest.

The diagnosis is difficult and depends upon the findings of a systematie, long-eontinued examination of the urine, with the elassieal symptoms before mentioned. In a ehild high arterial tension, with left ventricular hypertrophy not eompensatory of a valvular lesion, should always arouse suspicion as to its renal origin. Instanees of atheromatous arteries in young ehildren are not wanting, a significant fact in its relation to cerebral hemorrhage.

The prognosis is hopeless as to the renal lesion, although with due attention to hygiene and treatment, life may continue with apparent comfort for many years.

The value of a knowledge of renal disease depends, first, upon an early recognition of the morbid tendency of the individual; seeond, upon the alertness in diseovering the earliest indieations of impaired renal function; third, upon the intelligent application of physiology and hygiene to the function of elimination and to the relief of the affected 
part; fourth, upon successful recognition and removal or amelioration of the exciting cause. The same general principles of treatment mentioned in the acute variety apply to the chronic type during its exacerbations. The treatment of the ever-prevailing anxmia as well as the complications and crises which arise during its course, is not peculiar to this disease.

Recently surgery has offered some interesting procedures, such as decapsulation, scarification, and efforts to establish collateral circulation in the kidney. These are at present sub judice.

Amyloid degeneration of kidney may follow renal changes under eonditions which favor amyloid invasion of other organs, as after prolonged suppurative processes of bone, lung, and other tissues. The diagnosis is made from the presence of waxy casts in the urine, with splenic and hepatic enlargements.

\section{URIC ACID.}

Probably all new-born infants have more or less uric acid crystals in the urinary tract. Post-mortems of the new-born very commonly reveal infarcts in the straight tubules of the kidney. On section of the kidney they appear as brownish-red, fan-shaped areas. Under low magnifying power, these areas are seen to be engorged with erystalline bodies, uric acid infarcts. So great may be the accumulation that the tubules are blocked with them with resultant complete anuria. Under these conditions the infant may die within the first week without having voided urine.

Uric acid crystals are commonly seen upon the diapers of young infants as reddish-brown stains, most abundant in the first days of life, after which they gradually disappear as the free ingestion of liquor flushes the kidneys and aids in their excretion. The presence of these crystals, by their mechanical irritation in the renal tubules, pelves, ureters, and bladder, causes colicky pains, tenesmus, frequent micturition, and priapism.

\section{CALCULI.}

In the presence of colloid material, as mucus in the urinary tract, the uric-acid granules form concretions known as gravel or calculi. These stones in infancy and childhood are largely composed of uric acid and urates, both amorphous and crystalline, but may be mixed with triple phosphates and other salts.

Statistics show a large preponderance of renal calculi in children over adults. When we consider the number of infants who escape careful examination, it suggests the probability of the still greater preponderance of gravel disorders in early life. Calculi may be formed in the pelvis of the kidney and if not too large may be swept into the bladder by the stream of urine. In either situation their size may be augmented until symptoms reveal their presence.

A calculus as large as a cherry has been found in the bladder of a 
still-born male infant. The eoncretion may be single or multiple, smoothly rounded or irregularly shaped, with roughened surfaces.

Vesical calculi are found in male children twenty times as frecunently as in females, the short distensible urethra allowing freer passage while the concretion is yet small.

That the formation of calculi follows an heredity has long been known. Certain families of gouty and rhemmatic diatheses show marked recurrence of this trouble in suecessive generations.

Frequent micturition during the day, without nocturnal incontinence, sudden stoppage of the stream while urinating, difficult micturition with straining, tenesmus, and pain on the under sicle of the penis, also any symptoms of vesical irritation or pain in the region of the bladker while riding over rough roads, running, jumping, etc., are suggestive of vesical calculus. Severe paroxysmal pain beginning in the lumbar region, radiating towards the pubis, with retraction of the corresponding testicle, may indicate the passage of a calculus through the ureter. Sudden cessation of pain occurs when the stone reaches the bladder. Oecasionally the pain may be so severe as to cause collapse or even eonvulsions. Dull, aching, persistent pain in the region of the loins, radiating to other parts of the body - as the hips, thighs, bladder, or scrotum, especially after active or violent exercise, with alternating exeess and seantiness of urine, with nausea or rigors-are among the indieations of stone in the pelvis of the kidney, too large to engage in the ureter.

The urine in any of these conditions is acid, of high specific gravity, deeply pigmented and smoky. It may contain albumin, hyaline and granular casts, cylindroids, renal and vesieal epithelium, blood, and sometimes pus.

The diagnosis of calculus, in spite of the familiar symptoms, is not unattended with difficulty. Any or all of the symptoms may be produced by other conditions, - as eystitis, genital irritation from phimosis, retained smegma, lumbricoids, oxyurides, or any cause of rectal irritation, pyelitis, or appendicitis. As routine urinalyses becomes more general fewer calculi will escape detection. The X-ray has aided in diagnosis when the stone is of considerable size. The diagnosis of vesical calculus may be positively confirmed only by the use of the sound, which, if practicable, should be introduced with the patient under anæsthesia. Keeping in mind the sharper curve of the juvenile urethra, care should be taken not to penetrate the posterior wall and enter the ischiorectal fossa instead of the bladder.

The treatment is prophylactic and curative. Infants and children, whether from heredity or other cause, who show a tendeney to uricacidosis, should be required to drink freely between meals alkaline waters, as Vichy or Lithia. To a young infant a grain of potassium acetate or citrate may be administered in water, after nursing, until the urine is rendered less acid and the diapers are free from stain.

The diet of older children should be non-stimulating, consisting of fish, fresh vegetables, fruits, proteids and fats in moderation, avoiding 
the excessive use of carbohydrates on account of their tendency to disturb digestion.

The passage of a renal calculus through the ureter may be facilitated by heat applied over the lumbar-dorsal region or by hot sitz-baths. Morphine or codeine may be used hypodermatically, but cautiously, as after the extrusion of the stone extreme narcotism may follow its heroic exhibition. Chloroform anæsthesia is admissible, not only for its analgesic but for its relaxing effect upon the tubal spasm.

The presence of stone in the bladder or kidney calls for early surgical interference for its removal, as prolonged irritation will result in catarrhal and suppurative conditions.

\section{PYELITIS-PYELONEPHRITIS ; PYONEPHROSIS.}

The pelvis of the kidney may become infected from the blood, the urine, or from suppurative processes in adjacent organs and tissues. Various pyogenic organisms have been found, including the typhoid, tubercle, and colon bacilli. Pyelitis is frequently associated with pyelonephritis and ureteral obstruction from calculus or congenital malformations, and it may result eventually in the destruction of the kidney.

Uric acid crystals by mechanical irritation may induce catarrhal inflammation of the pelvis of the kidney, which may become purulent with mixed infection. In the same way, hydronephrotic accumulations may become purulent.

Pyelitis may follow any of the infectious fevers, or it may result from infection through the bladder or urethra. Its development in the course of enterocolitis in diapered infants is of special interest in connection with the colon bacillus as showing the peregrinations of that bacterium. Reports show that nearly all of these cases have occurred among girl babies. For similar reasons they are more subject to pyelitis from gonorrhœal vulvovaginitis. Cystitis is probably the most common source of infection. It may be caused by the ingestion or external application of such agents as turpentine, cantharides, copaiba, earbolic acid, etc.

The disease is more common in infancy than was formerly supposed, as pyuria, the diagnostic symptom, has in the past been frequently oyerlooked or attributed to mysterious origin.

Traumatism and exposure to cold may act as causes. During or following acute infectious diseases pyuria may be the only symptom of. this disease, and the fever, if present, attributed to the primary disease. The attack is usually ushered in by a sharp chill, followed by considerable pyrexia, even $105^{\circ}$ to $106^{\circ} \mathrm{F} .\left(40.5^{\circ}-41^{\circ} \mathrm{C}\right.$.), with headache, anorexia, and vomiting. The temperature is usually irregular, chills recurring at intervals of a few days with all the indications of severe infection. There may be rapid loss of weight. The urine is scanty, high colored, sometimes bloody, and contains pus in varying amounts, with epithelium of caudate variety, and, if nephritis coexist, tube casts. Unless relieved 
early, symptoms of the consequent eystitis are added to those of the original disease.

A sudden disappearanee of the pus may be indicative of obstruction in the ureter by a ealeulus, blood-elot, or inspissated mucus, which, being overeome by inereasing pressure, allows the reappearance of pus in a copious discharge, resembling the rupture of an abscess.

The disease may beeome ehronic and, with occasional aeute exacerbations, run a course of months or even years.

Dull pain in the dorsal lumbar region is suggestive of caleulus. Careful examination of ehildren's urine, in all eases of pyrexia, may not infrequently reveal an unsuspected pyelitis and help to lessen the number of unelassified fevers. Catheterization of the ureters is of special value in differentiation from eystitis and to determine the unilateral or bilateral charaeter. The question of a stone may be settled by skiaseopy.

From eystitis, diagnosis may be made by the aeid urine, eaudate pelvic epithelium, larger amount of pus, the presenee of casts from the kidneys, and absenee of vesieal pain and tenesmus.

The prognosis depends upon the etiology. Primary uneomplieated pyelitis should yield promptly to treatment in a few weeks. If tuberculous, the prognosis is grave, and, if assoeiated with malignant neoplasms, hopeless.

Treatment.-Acute uncomplieated pyelitis requires rest in bed, fluid diet (espeeially milk), free eatharsis by ealomel, ipeeae, and soda, and by diuretics, partieularly potassium eitrate, suffieient to neutralize the acidity of the urine. The patient must be supported, and tonies may be necessary, with iron for the anæmia. Urotropin is indieated for its antiseptic effect and methylene-blue is sometimes useful in obstinate cases. The diagnosis of the presence of a calculus should call for early surgical interference.

\section{CYSTITIS.}

Cystitis is by no means rare in ehildhood. It oceurs more frequently in girls than boys. It may range in severity from a mild transient catarrh to the most intractable chronic form, with destruetive lesions and hyperplastic changes in the mueous and submueous tissues.

Etiology.-The most frequent eause of hyperæmia of the bladder is exposure to cold. Infection may be due to a variety of miero-organisms, among which are the coli eommunis, typhoid and tuberele bacilli, the gono-, staphylo-, and streptocoeei. The most common are the eolon bacillus and gonocoeeus. The routes of infeetion may be by way of lymphaties, blood-vessels, ureters, urethra, or by eontiguity from neighboring organs.

Inflammation of the bladder is a common accompaniment of nephritis, pyelitis, and diabetes mellitus, and is frequently a eomplieation or sequel of the aeute infectious fevers. Uric acid ealeuli, overdistention, retention from any cause, and traumatism, are among the frequent exciting eauses. Both trauma and infection may follow eatheterization. 
Symptoms.-The most prominent symptoms are deep-seated pain, frequent micturition with ardor urinæ, tenesmus, and rise in temperaturc, occasionally preceded by a chill. Early in the attack the urine is high colored, turbid, acid, concentrated, and may contain blood, pus, mucus, large numbers of vesical epithelial cells, and bacteria. Later the urine may be neutral or alkaline, or become so shortly after passing. It may be very turbid and ropy. More advanced cases show the urine putrid and alkaline from ammoniacal decomposition. The child is fretful and irritable.

In prolonged cases there may be exacerbations and remissions with loss of weight and anæmia.

Diagnosis.-The diagnosis is plain. Examination of the urine is sufficient to establish the nature of the affection and usually the etiology.

Prognosis.-The prognosis depends upon the infecting agent and complications. A chronic pyelonephritis must never be lost sight of. Chronicity of this affection calls for careful cystoscopic exploration for vesical lesions, as ulcers, adventitious growths, etc. Tuberculosis renders the prognosis grave. Acute simple cystitis should recover inside of two weeks.

Treatment.-In acute cystitis the child should be put to bed. Saline laxatives should be administered with a neutralizing diuretic, such as acetate or citrate of potassium. The child should be made to drink large quantities of water. The diet should be reduced in quantity and confined to liquids. Hot sitz-baths and fomentations may relieve the pain and tenesmus. In gonorrhœal infection, or when there is much pus, the bladder should be washed out daily with weak solutions of boric acid, potassium permanganate, creolin, or lysol. Urotropin every four hours is valuable where there is decomposition or fermentation, and salol may be used in the absence of nephritis. Severe pain or tenesmus calls for the use of hyoscyamus or belladonna by mouth or rectal suppository. Restlessness and insomnia may require bromides. The presence of stone, new growths, and tumors should relegate the case to the surgeon.

\section{PERINEPHRITIS-PARANEPHRITIS ; EPINEPHRITIS.}

Perinephritis occurs, with or without suppuration, in the fibrous and adipose tissues which surround the kidneys. It is of interest in children because of the resemblance of its symptoms to those of other inflammations common at this age, and the frequently mistaken diagnosis.

Paranephritis may be secondary to suppurative processes in adjacent structures as pyelonephritis, appendicitis, peritonitis, abscess of the liver, spleen, or intestines, or it may be due to a septic embolus from a remote region. A number of eases have been called primary because of the absence of any known source of infection. Traumatism, exposure to cold, and constipation, appear to have been contributory causes in some instances. The symptoms are those of acute inflammation of moderate intensity,-chill, fever of irregular type, local pain and tenderness accompanied by swelling in the affected lumbar and ileocostal areas. Later 
there is dulness on percussion, with evidences of infiltration of the subcutaneous tissues. Occasionally, swelling and tenderness are found at the pubis or the upper inner aspect of the thigh from the burrowing of pus. The thigh of the affected side is slightly flexed and resists extreme extension but is freely movable in other directions. Pain is occasionally referred to the abdomen, grom, and knee. When suppuration occur's the presence of a fluctuating tumor may sometimes be made out and confirmed by the aspirating needle. The tumor is not movable nor does the urine present any abnormality unless there is some involvement of the kidney. Then the urine may contain pus, albumin, and casts. Resolution may oecur in from ten days to ten weeks. Even longer time may ensue before recovery.

The pus may burrow into the peritoneal cavity with fatal peritonitis, or it may perforate the diaphragm and enter the pleural eavity. It may burrow extensively between the museles and, eseaping through the sacrosciatic noteh, appear at the buttoeks. The adjacent kidney may suffer from pressure or become involved in the extensive suppuration. The prognosis, however, is surprisingly good considering the gravity of the lesion and the danger of involving important organs.

Differential Diagnosis.-Perinephritis may be mistaken for a gravitation abscess from a tuberculous spine, but the absence of angular deformity of the spine and the rapid course would serve to differentiate. A blood examination should show leucocytosis. Operations for supposed perityphilitis have been made in which the appendix was found normal with a retroperitoneal accumulation of pus from a perinephritic inflammation. It differs from hip disease in its more acute onset, absence of other evidences of tuberculosis, greater mobility of the limb, absence of hip-joint pain or tenderness on pressure, rapid development, and early termination.

From typhoid fever, for which it is sometimes mistaken in an early stage, the diagnosis must be made by the more acute onset with ehill, the absence of hebetude, the localization of pain and tenderness, the negative reaction to Widal test, the absence of Eberth's bacillus in the urine, and the presence of leucocytosis.

Treatment.-For early abortive treatment, the patient should be put to bed, the bowels opened freely, and hot poultices or ice-bags (according to age) applied to the affected side. As soon as pus is located, drainage should be secured by free incision.

\section{HYDRONEPHROSIS.}

Hydronephrosis is due to an obstruction to the flow of urine in the ureter, bladder, or urethra, with a resulting distention of ureter or renal pelvis, or both. It may be either unilateral or bilateral. It is occasionally congenital and a cause of dystochia.

Among the causes may be mentioned phimosis, imperforate urethra, vesical calculus, stenosis at ureteral orifice, abnormal insertion of ureters into the bladder, valvular folds or growths in the linings of ureters, 
tortuosity of these tubes, pressure from adjacent tumors, strangulation from nephroptosis, obstruction from calculus, parasite, or a blood-clot in tube or pelvis, and angular insertion of ureter in pelvis. Occasionally careful post-mortem fails to reveal any cause.

The retention of urine may be complete or intermittent, dependent on the nature of the obstruction. The pressure of accumulated urine induces distention of the entire tract above the obstruction. Occasionally this is most noticeable in the ureter, which may equal in size the large intestine. The accumulating pressure in the renal pelvis and calices may destroy the parenchyma, leaving but a thin shell of cortical tissue, the resulting tumor reaching enormous proportions.

The retained urine in these eysts may change to a clear fluid, acid or neutral, presenting but few urinary characteristics.

The symptoms are sometimes absent and when present are variable, depending upon the cause and the extent of involvement. Single hydronephrosis may be suspected from the presence of an abdominal tumor, which produces bulging and flatness on percussion, in the region of the kidney. The diagnosis is not always easy, and differentiation may be made from malignant growths by the absence of cachexia and by catheterization. From cysts of other abdominal organs, parasitic eysts of the kidney, also from pyelonephrosis, catheterization of the ureter should aid in diagnosis.

The treatment is the relief of the causative disorder, when possible. If the other kidney be unaffected, surgical operation occasionally affords good results. The majority of congenital hydronephrotics die during the first year.

BALANITIS, POSTHITIS, AND URETHRITIS IN MALE CHILDREN.

Balanitis, an acute inflammation of the mucous membrane of the glans, and posthitis, an inflammation of the preputial mucosa, are not uncommon either in infancy or childhood. They may be caused by any irritation, as from retained smegma, uric acid, traumatism, masturbation, and general lack of cleanliness. As preputial stenosis interferes with proper cleansing of the glans, prophylaxis should include dilatation and retraction or circumcision in early infancy. The mucous membrane is reddened, swollen, tender, and bathed in purulent secretion. Not infrequently œdema of the prepuce is extensive, phimosis marked, and urination difficult, with some smarting and "ballooning" of the foreskin. The treatment is simple irrigation with some antiseptic solution, as boric acid, permanganate potassium, or bichloride $(1: 1000)$ solution. This may be done by introducing the nozzle of the syringe into the preputial orifice and distending the foreskin so that all parts may be reached by the fluid. This should be repeated several times a day. If the inflammation be intractable and the phimosis marked, the foreskin should be slit up the dorsal surface. Circumcision is not advisable during the acute inflammation.

Simple urethritis occurs in childhood and rarely in early infancy. 
It may be due to the extension of a balanitis, introduetion of foreign substanees, traumatisms from falls and blows, irritating urine, or the passage of a sharp ealeulus. Usually the inflammation is confined to the fossa navieularis. There is a purulent discharge, more or less pain on micturition, and priapism. The adjacent glands may become indurated and extensive balanitis may aggravate the condition and modify the treatment. The treatment should eonsist of free eatharsis by salines, and neutralizing the urine by the use of bicarbonate of soda with a plentiful supply of water. Irrigation is rarely neeessary, except in unusually obstinate eases. Mieroseopic examination of the discharge shonld be made in all cases to assure differentiation from specifie urethritis, the symptoms of which in some instances are identieal with those of the simple form.

Specific urethritis is due to gonococeal infeetion, the source of which is always a human gonorrhœa, as this infeetion is eonfined to man.

Burning pain at the end of the penis on urination is often the first symptom of urethral gonorrhœa. The discharge from the meatus of yellow, greenish pus, sometimes slight, is the eharacteristie symptom. Upon examination, this is found to eontain the gonoeocei of Neisser. Untreated, the diseharge may continue for months, gradually diminishing in quantity after the first week. Ardor urinæ, priapism, and even chordee, are the most distressing symptoms. Lymphadenitis of the inguinal glands may rarely proeeed to suppuration. Cystitis is an oceasional sequel. Prostatitis rarely oeeurs in ehildhood, owing to the undeveloped condition of that gland. Orchitis and epididymitis are not infrequent. Arthritis in the ankles and knees should be watehed for and conjunctivitis guarded against.

Prognosis.-No age seems exempt from gonorrhœa, as cases have been reported in the new-born, infeeted from the birth-passage. Stricture, as in the adult, may follow urethritis in ehildren.

An early diagnosis is important, that the disease may be aborted while yet the infeetion is confined to the anterior urethra and before the baeteria have found lodgement in the crypts of the deeper structures. To this end a free flow of alkalinized urine must be eneouraged by the copious ingestion of water with potassium citrate or acetate in frequently repeated doses. The ehild should be kept in bed, regardless of symptoms, with extreme preeautions as to the spread of the infeetion. The diet should be non-stimulating and confined prineipally to milk.

Irrigations, such as potassium permanganate $(1: 3000)$ or saturated solution of boric acid, if used in the early stage, should be eonfined to the anterior urethra by compression of the penis at its middle portion, and used only after a urination. In advanced or subacute gonorrhœa irrigation without the introduction of a catheter may be made by repeatedly filling the bladder by means of a fountain syringe, with a blunt tip pressed against the meatus.

The swelled testieles always require the dorsal decubitus, with the scrotum supported by a bandage plaeed across the thighs. Hot fomenta- 
tions or poultices, with the administration of codeine by mouth or suppository, may be needed for the relief of pain. The bowels should be kept open. Guaiacol, five to fifteen per cent., in olive oil, applied once or twice a day to the swollen scrotum, is often very valuable.

\section{SIMPLE VULVOVAGINITIS.}

At birth a viscid secretion is frequently found between the lips of the vulva. With ordinary eare and cleanliness this disappears in a few days. It may persist, however, in the victims of malnutrition and occasionally a purulent discharge, with all the symptoms of inflammation, may follow. The discharge may become quite profuse and excoriation may be produced, with pain upon micturition from involvement of the urethra. Occasionally this affection is persistent, resisting ordinary methods of treatment.

Not infrequently, in older infants and children, vulvovaginitis develops from which there may be a profuse mucopurulent discharge. The parts are reddened, the vulva, hymen, and vaginal mucosa are swollen and inflamed. Microscopic examination of the discharge shows a variety of pus organisms, strepto-, staphylo-, and pneumococeus, with bacillus coli communis predominating. The disease is evidently communicable, as it extends through families and institutions. Neglect of cleanliness, scabies, traumatisms, irritation from clothing, masturbation, worms, and irritating urine are mentioned as exciting causes. It is most commonly seen in poorly nourished children and in those of lowered vitality following acute infections. These catarrhs show a marked predilection for the rhachitic, lymphatic, and tubercular diatheses.

The disease is never fatal, its complications rarely extending further than the adjacent glands, which occasionally suppurate.

Careful attention to hygiene, with daily irrigations of the affected mucosa with warm saturated solution of boric acid, will usually effect a cure in from one to four weeks. The inflamed labia should be dusted with a powder and separated by a pledget of cotton or gauze. The urine should be rendered less irritating by the free use of water or a weak dilution of potassium citrate. The bowels should be kept free by citrate of magnesia. Tonies of iron or cod-liver oil, with generous diet, are necessary to overcome the tendency to lowered vitality.

\section{SPECIFIC VULVOVAGINITIS.}

A more virulent form of vulvovaginitis is that due to infection by the gonococeus. This infection among infants and children is either alarmingly on the increase or else it was wofully overlooked by former clinicians. Numerous reports of epidemies in hospitals and institutions, as well as from private practice, all attest the virulence, intractability, and wide range of complications and sequelæ of infections from the Neisser organism. The ocular conjunctiva and the mucosa of the genitals, more particularly that of the vulva and vagina, show a remarkable susceptibility to this infection. Especially is this true of infants under 
three years of age. Other tissues occasionally afford ports of entry to the circulation,--as the umbilicus, the oral, nasal, or pharyngeal mueosa, and accidental lesions of the integument, since suppurative phlegmonous endocardial and arthritic inflammations are reported with no evident lesions of the genito-nurinary tract. It is probable that an unobserved stomatitis may have served as a prinary focus in some of these cases. The usual mode of infection is by direct contact, although among infants and children there is ample reason to believe that it is frequently carried by intermediate agents; hence all discharges of a suspicious character, from whatever source, should be immediately destroyed,-if on cloths, by fire; if on garments, by bichloride solution $(1: 1000)$. The parent, nurse, and physician must be constantly alert, and the conscientions use of soap and water, with nail brush and lysol, should be insisted upon.

The peculiar odor of gonorrhœal vulvovaginitis in diapered infants suffering from diarrhœal disorder, in which the colliquative stools mask the discharge, may be the first intimation of this infection.

The period of incubation may be from two to ten days. The appearance of the discharge may be preceded by a rise in temperature, which is frequently masked by some pre-existing disease. The child in previously good health will exhibit distinct symptoms of malaise, anorexia, and elevation of temperature, frequently preceded by rigor or chilliness. In hospitals, whence the largest number of reports are derived, the victims are patients admitted for other disorders; so that, occurring in post-operative, post-typhoid, and tuberculons children, or as a complication to some other acute disorder, the initial symptoms too frequently are misinterpreted, incurring the loss of a few days of grave significance to the non-infected infants in the same ward. No other organism is capable of producing so enormous an amount of pus from so limited an area in so short a time. The pus is yellow, often with a greenish tinge, and leaves a characteristic stain upon the linen, which it stiffens. Local heat and tenderness are common, although occasionally the child experiences no further discomfort than pruritus. Smarting and tenesmus on urination are present when the infection invades the urethra. This, strangely, occurs less frequently in the infant than in the adult. Occasionally, however, painful micturition is the first symptom to attract attention to the local disorder. The acute period of the disease is selflimiting, the period of most active pus formation extending from ten to twenty days. The extent of the immediate injury depends upon the nature of the tissue involved, the vulvovaginal mucosa showing but little damage as compared with the structures of the eye, cardiac intima, and peritoneum. Peritonitis, either local or general, is an occasional complication and is fatal in twenty per cent. of the reported cases. Endocarditis is one of the most serious of the gonococcus lesions, while arthritis and metastatic abscesses may result in fatal general pyæmia. The farreaching effects of gonorrhœal infection, however, are seen in its tendency to recrudescence upon slight provocation; so that successive attacks may involve the entire genito-urinary tract, sterilizing the repro- 
ductive organs, and leaving a heritage of pelvic, vesical, and renal morbidity which ruins the mature life.

Diagnosis.-The diagnosis is made by the microscope, in the discovery of the gonococcus of Neisser.

Treatment.-The first indication in treatment is to destroy the specific micro-organism by any means not injurious to the tissues. Hence early diagnosis is important so that applications may be made before the deeper structures are involved. Superficial irrigation, even with solutions of undoubted bactericidal power, fail to reach the harboring sulci and rugæ of the tumefied mucosa unless most earefully and thoroughly applied. For this a speculum must be used, and the parts swabbed from above downwards with a two per cent. solution of nitrate of silver, ten per cent. protargol, or fifteen per cent. argyrol, after which a pledget of cotton moistened with saturated boric acid solution should be left in situ. It may even be necessary to pack the vagina, or in advanced cases to treat the endocervical mucosa. The treatment should be repeated three or four times the first day, after which the application may be made once a day with a thorough irrigation with potassium permanganate (1:2000) every two or three hours. Under this treatment the discharge diminishes rapidly, with subsidence of the acute symptoms. These reappear with active pus formation, if there is interruption in the treatment. The complete sterilization of the invaded tract will often tax the practitioner's ingenuity to the utmost, for even after the cessation of all purulent discharge with negative smears for several successive days, the treatment is stopped at the risk of a recrudescence of all the symptoms.

There is no known means of determining that the disease has terminated. Some physicians discharge the case as cured if at the end of two weeks from the disappearance of all symptoms successive smears prove negative.

From the first symptom the vulva should be covered by a sterile pad of gauze or cotton retained by a diaper; the patient must be isolated and specialized in every detail of nursing, as care of dietary, bedclothing, utensils, and thermometer. Sterilization and isolation must be the watchword in the strictest sense. Nurses and parents must be made to realize the gravity of the infection with which they are dealing. Gonorrhœal infection will undoubtedly soon receive its proper recognition as one of the most virulent and dangerous of the infective diseases, and secure the necessary legislation for the protection of the innocent that is now accorded to some other common but less formidable disorders.

\section{PHIMOSIS AND ADHERENT PREPUCE.}

The normal coherence of the prepuce and the glans penis at birth may, from lack of proper attention, continue throughout infancy into childhood. Whenever seen, this condition should be relieved by dilatation and retraction, which operation may be aided by the introduction of a probe between the prepuce and glans, sweeping it around in such a manner as to release adhesions. If there be much phimosis the inelas- 
ticity of the foreskin, especially in older ehildren, may make this extremely difficult or unadvisable because of the resultant paraphimosis. Frequently, however, repeated efforts at dilatation and retraction will prove successful in apparently unpromising cases. The manipulation should be attended with aseptic detail, aided by a little oil or vaseline. Oceasionally circumcision will be found neeessary, not only for cheanliness, but to release the incareerated glans. Splitting the prepuce on its dorsal surface with a sharp-pointed bistoury, along a grooved director introduced under the foreskin, produces equally good results with the former operation. The mueons membrane should be secured to the integument at the raw edges with interrupted catgut sutures. Before suturing some operators trim off the redundant corners on either sille.

The phimosis may be atrophic in which there is a deficiency of tissue, the scanty prepuce pressing tightly on the glans, which, during erection, shows slightly through the small opening; or hypertrophic when the redundant tissue is elongated into a pendulous point, with extreme, unyielding stenosis.

Some of the immediate effects of extreme phimosis, especially if coherence between the two layers of mucosa be firm, is constant pressure upon the glans during the normal congestion of micturition, with retardation in growth and development of the organ. Frequent desire for micturition, with obstruction to the flow, causes straining, resulting in some instances in hernia, hydrocele, and prolapsus ani. 'The retained urine produces irritation, which invariably leads to much handling of the parts and masturbation. Decomposition of the urine, with the retained smegma, lights up a balano-posthitis which may possibly involve the urethra and lead to vesical catarrh. This may be the beginning of a pyelonephritis of later years. It is not strange that eonstant local irritation during the developing period should, through the delicate reflex mechanism of the reproductive system, affect to a remarkable degree the development and function of organs and tissues apparently remote. Nor that the equilibrium of the nervous system, unstable as it is before the full establishment of inhibition, should exhibit many anomalous and strange phenomena. The disorders attributed to preputial abnormalities are legion. A few may be mentioned: urinary incontinence and retention, restlessness, night terrors, epilepsy, headache, amaurosis, strabismus, chorea, convulsions, pseudoparalysis, hysteria, indigestion, diarrhœa, marasmus, with innumerable tics, habits, and many psychological disturbances.

The female prepuce, formed by the junction of the nymphæ, is usually at birth more or less adherent to the glans clitoris. If this intimate adhesion persist throughout childhood, the sensitive glans is constricted, interfering with the circulation so as to cause hyperæmia, irritation with resultant masturbation, and a train of psychic and neurotic disturbances similar to many of those enumerated above. It is claimed that this condition may result in hypererethism with erotic tendencies, or in extreme sexual apathy in later life. Eminent authorities recom- 
mend a release of the clitoris from a too closely enveloping prepuce as essential to its normal growth and freedom from irritation.

That the condition described as an abnormality is as frequent in occurrence or as far-reaching in its morbid effects in the girl as preputial defects are in the boy, is highly improbable. Undoubtedly, occasional instances occur of serious derangement in the girl, for which the physician should be on the alert.

\section{ENURESIS-INCONTINENCE OF URINE.}

Enuresis is a functional disorder in which the retention of the urine is only partially under control of the patient. Complete incontinence is extremely rare at any age, and is probably due to some malformation or to a total paralysis of the vesical sphincter. A case is reported in which one ureteral orifice opened into the urethra, resulting in a continuous oozing of urine. Urinary continence is only relative in degree, and it is seen in the youngest infant to a certain extent, the contents of the bladder being evacuated at intervals. The mechanism, including the bladder, its muscles, and nerve supply, constitute an apparatus which operates automatically to a certain extent independent of higher nervecentres, during infancy. With increase in vesical capacity the intervals between its evacuations lengthen. To the purely reflex mechanism of bladder, sphincter, lumbar centre, and nerves afferent and efferent, there is added, with increasing age, the influence of the inhibitory centre in the cerebral cortex. As inhibition develops more rapidly, and is perfected earlier in some individuals than in others, so the degree of urinary continence varies in different infants at the same age. Educational efforts in their developing effects upon higher centres of inhibition show early results in the control obtained over the reflex function of urination. Arrested cerebral development illustrates this in the frequency of enuresis in idiots.

The normal operation of this function may be interfered with by a great variety of disorders, either general or local, acting alone or in combination. So that incontinence may be due to abnormal conditions of the bladder, of the urine, of the nervous system, or of different organs and tissues which may influence the function through reflex disturbances.

Intolerance of the bladder from congestion may be due to the presence of a foreign body, such as a calculus, uric acid, sand, worms, etc., or to cold or the irritating character of the urine from concentration, hyperacidity, bacteria, sugar, or the products of inflammatory processes in the kidney; or chemical decomposition of the urine, constipation, rectal tenesmus, fissure and polypi, irritation due to worms, phimosis, preputial adhesions both in boys and girls, vulvovaginitis, masturbation, or any cause of genital hyperæmia may induce vesical intolerance. Small size of the bladder is sometimes found, although this condition is probably a result as well as a cause of frequent micturition.

The nervous mechanism involved in bladder control may be impaired by disease, traumatism, or pressure, so that the nice balance 
between the action of bladder contraction and sphincter control is disturbed. Spinal disease or injury may interrupt conduction of nerve influence from the inhibitory centre in the cortex. The local neurosis may be only a part of a general neurasthenia, so that malnutrition or exhaustion from general septic condition, or convalescence from acute disease, may have incontinence of urine as a result.

Treatment.-In the treatment, the cause of vesical irritation should be sought and relieved by appropriate measures. Examination of the urine, both chemically and microscopically, should never be omitted, as a most frequent cause of vesical intolerance is here found. Concentrated highly acid urine calls for dilution and neutralization by copious drinking of alkaline waters. If the incontinence be noeturnal, the ingestion of water should be restricted towards bedtime. Bromides, belladonna, and hyoscyamus are well-known obtunders of vesical hyperæsthesia and should be given preferably towards the latter part of the day. Coffee, tea, and alcoholic stimulants must be strictly interdicted. The clothing of the child should be such as to protect from the chilling of the surface, and the diet must be non-stimulating and regulated so as not to exceed the limit of perfect digestion. Excess of earbohydrates, especially sweets, may be more injurious than a moderate amount of proteids. Irritability of spinal nerve-centres, as seen in the exaggerated reflexes of the lower portion of the body, such as cremasteric, gluteal, patellar, and ankle, would suggest the use of bromides and ergot. The general neurasthenia with accompanying anæmia requires specially appropriate hygiene, of which cold bathing, general and local, forms an important part, with tonies and hæmic restoratives, such as arsenic and iron. The tincture of the chloride has a reputation as specific in vesical disorders. The use of the interrupted current is highly regarded by many practitioners, one moist electrode being applied to the perineum and the other to the sacral or suprapubic region. The practice of introducing electrodes, sounds, etc., into the urethras of young children should be discouraged when any other measure can be substituted.

Local irritative conditions of the rectum and genitals should reccive attention. Preputial stenosis should be corrected, and the glans and corona freed either by circumcision or dilatation and retraction. The clitoris should be released from an adherent prepuce. Balảnitis, urethritis, or vulvovaginitis should receive special attention. The anal sphincter should be stretched for fissure,-a procedure usually requiring a general anæsthetic. The rectum should be freed from polypoid growths and thread-worms.

Since the vesical trigone is its most sensitive portion, the position of the child may be changed with benefit, as by elevating the foot of the bed or compelling him to lie on his side or abdomen. In addition to the above, other procedures will suggest themselves according to the pathology of the special case.

An adjuvant to all therapeutic measures is the systematie training of the child. The prevention of the habit is of paramount importance, since 
correction, when once established, is most difficult even after the removal of all obvious causative factors. Evacuation of both bladder and rectum before going to bed should be observed. The child should be taken up to urinate at least once, preferably early, in the night. He must be constantly encouraged to overcome the habit, but never by fear of punishment. The early development of self-control by tactful teaching is of the highest importance, and constant watchfulness must be the rule on the part of parents and physician against the recurrence of morbid conditions productive of enuresis. The majority outgrow the habit by the seventh year, and it rarely extends beyond puberty.

\section{CRYPTORCHIDISM-UNDESCENDED TESTICLE.}

As previously stated, occasionally at birth one or koth testicles are absent from the scrotum, the descent having been arrested within the abdomen or at some point below the internal inguinal ring, often in the inguinal canal, where it may be felt as a small tumor. In the majority of cases its descent will be accomplished without interference. The question of surgical intervention depends upon the fact that, if long incarcerated, pressure in its malposition not only arrests its growth but degenerative changes may occur.

Operation may be postponed as long as there is evidence of progress of the organ through the canal, as indicated by its changed position.

The possibility of hernial contents, a common accompaniment of arrested descent, should be remembered, as the diagnosis of hernia and application of a truss is not infrequent. This may occasion not only much discomfort but positive injury to the gland. The prolonged distention, too, of the inguinal canal, favoring the development of subsequent hernia from its patulous condition, is an argument in favor of early surgical correction.

\section{HYDROCELE.}

Hydrocele occurs quite frequently in the infant. It is stated that in only ten per cent. of post-mortems of infants has the processus vaginalis been found closed at birth. Any undue collection of fluid in the infant's peritoneal cavity might result in hydrocele in the remaining ninety per cent.

Hydrocele consists of a collection of fluid in the tunica vaginalis, and may appear in the scrotum in free communication with the abdominal cavity, when it is termed congenital hydrocele. The testicle will be felt behind the accumulation of fluid. Change in position and slight taxis will cause a return of the fluid to the peritoneal cavity. Continuous pressure from a truss over the external inguinal ring will obliterate the communicating eanal. The canal, however, may have been already obliterated at Poupart's ligament, so that the fluid cannot return to the abdominal eavity. This is known as the infantile form, as it is the most common in infancy and childhood.

Another form, known as hydrocele of the cord, is found above the 
serotum; the lower portion of the canal having been obliterated, the upper end, still patulous, is freely communicable with the peritoneal cavity. It usually fills the inguinal canal and is frequently associated with hernia. It is easily reduced by pressure.

Encysted hydrocele of the cord differs from the last named only by the closure of its abdominal end, the eyst appearing as a small oblong tumor in or just below the inguinal canal. Vaginalitis may serve as an explanation for the encysted variety. It may be mistaken for an enlarged. lymphatie gland, from which it differs in consistency, or for an undescended testicle, from which it may be diagnosed by the presence of the testicle in the scrotum. From a hernia it is distinguished by the termination of the tumefaction before it reaehes the internal ring, and also by the non-increase in size upon the infant's crying or coughing. Water in the serotum shows translucener when viewed through an opaque tube pressed against the tense tissues. IIernia renders the sac opaque. This is a test whieh should never be omitted. There is occasionally a gurgling on pressure when the hernial sac contains a loop of the intestine.

The treatment of infantile and encysted forms of hydrocele is by aspiration by means of a hypodermic syringe, or puncture with a small trocar, allowing the fluid to flow into the cellular tissue whence it is quickly absorbed. Usually one withdrawal of fluid is sufficient, but if not, the operation should be repeated. This rarely fails to effect a cure. In older children an obstinate hydrocele will frequently yield to applications of collodion or tincture of iodine and the internal administration of potassium iodide.

HYDROCELE IN GIRLS.

A tumor of the labia majora or of the inguinal canal is suggestive of hydrocele in girls. It is to be differentiated from inguinal or pudendal hernia, a rare condition in girls, by the usual points of differentiation. From vulvovaginal cysts and from abseess of Bartholini's gland, by the absence of pain, redness, and inflammatory symptoms.

Hydrocele in girls is rarely seen, and when found should be treated as in the other sex. 


\section{CHAPTER XI}

\section{DISEASES OF THE NERVOUS SYSTEM}

\section{CONVULSIONS-ECLAMPSIA ; SPASMS}

Muscular spasms are disorderly reflex acts involving one or more muscles or groups of muscles. The term convulsion is applied to spasms which involve a large number of voluntary muscles and may include the entire motor system. Spasm may occur in unstriped as well as in voluntary muscle and is usually employed to designate a local disturbance, as vesical, sphincteric, and laryngospasm.

Whether a convulsion be the result of an overflow of motor impulse, a discharge of stored energy, or an explosion of nervous force, the clinical fact is evident that infancy is peculiarly susceptible to this form of motor disturbance. The percentage of frequency during the first quinquennium is shown by the following: About 45 per cent. of all cases oecur in the first six months of life; 22 in the second six months; 25 in the second year; 5 in the third; 2 in the fourth; 1 in the fifth.

It has been claimed that in infaney the motor ganglion cells show greater susceptibility to irritation. On the other hand, it has been shown that excitation of nerves and muscles in the earliest infancy (the first five weeks of life) is induced only by very strong electrical currents, and even with these the contractions are slow. All observers agree that in the evolution of nerve function the higher or inhibitory centres are the last to develop. After the removal of the cerebrum, convulsions have been induced in lower animals by irritation of the pontobulbar area.

With the development of the inhibitory centres in the cortex the tendency to convulsive phenomena rapidly diminishes, so that after the fifth year eclampsia, not resulting from a brain lesion, is somewhat rarely seen.

An undoubted predisposition to eclamptic seizures is attributable to hereditary influences, as in neurotic, alcoholic, gouty, rheumatic, and tubercular family histories. Rhachitic infants, also, show increased nervous irritability with retarded development of inhibition. Although producing similar phenomena, the exciting causes of convulsive attacks differ widely in importance as to the gravity of their significance. These causes may be reflex, toxic, or anatomic. The reflex causes result from peripheral irritations of the gastro-intestinal tract,-as undigested articles of food or intestinal parasites; from genital lesions; from the presence of adenoids, or foreign bodies in the ear; from the effects of burns or cold to the surface of the body; from fright, excitement, fatigue, or from anything causing protracted or severe pain. 
Among the toxic causes are the acute infections, some drugs and chemical agents, uræmia, and acute or chronic indigestion.

The anatomic causes include any condition involving structural change in the brain, intracranial pressure-as from hydroceplialus or tumors-abscesses, hemorrhages, embolism, thrombosis, or meningitis.

The precipitation of a convulsion may be due to two or more of these exciting causes, as in the familiar gastro-enteritis, accompanied by the absorption of toxins, also the infection of whooping-cough, with asphyxiation and possible intracranial hemorrhage.

In many instances the exact operation of the exciting cause is not known. Sudden reduction of the volume of blood within the cranium will frequently induce eclampsia. On the other hand, intense cerebral congestion is known to produce the same effect, so that a depressed or distended fontanelle may precede or accompany a convulsion.

Convulsions rarely occur without some prodromal symptoms, such as muscular twitchings of the extremities, facial grimaces, restlessness, pallor, or nausea, which the experienced eye readily interprets as evidences of disturbed equilibrium.

No further indications of eclampsia may be seen for hours, or at all; or they may be quickly followed by ocular symptoms, such as conjugate deviation, lateral or upward, with dilatation of the pupils and a fixed and staring expression of the eyes; the nostrils dilate, respiration becomes audible, rigidity of the entire body develops, with slight retraction of the head and spine; cyanosis supervenes, the jaw is set, frequently upon the tongue, and a frothy secretion issues from the lips. The rigidity may last from one to several seconds, or may be absent. It is replaced or followed by a series of rhythmic contractions which may involve the entire trunk and limbs, or may be confined to certain groups of muscles, unilateral or bilateral, and are most apparent in the flexors. The contractions are sharp and jerky, and, when general, may be so violent as to cause injury from contact with surrounding objects. The force and frequency of the clonic spasms decrease gradually until apparently from exhaustion they cease altogether. This cycle is usually completed in from one to five minutes, occasionally extending over a longer period. During the entire attack consciousness is more or less in abeyance, and a deep stupor or coma often supervenes. All general eclamptic seizures are clonic in character, the so-called tonic stage consisting of rhythmic spasms so rapid that the intervals are inappreciable.

Diagnosis.-As all convulsions are merely symptomatic of some morbid condition, the diagnosis consists in the differentiation of the underlying cause. The history of the case frequently affords a clue. In the absence of any aid from this source, as in the sudden seizure of a patient seen for the first time, a thorough examination will be needed. The temperature should be taken, as pyrexia would suggest the onset of an acute infection, while its absence would exclude the probability of a meningeal inflammation. Pupillary inequality or disturbed reaction 
would suggest intracranial lesion, with further corroboration by tension of the fontanelle and the condition of the retinal vessels. Spasticity or paralysis, unilateral or bilateral, may indicate grave cerebral lesion. Inspection may show lesions or traumatisms causing peripheral irritation. Puffiness of the eyes or cedema of the legs would lead to examination of the urine for renal disease. Palpation and eatheterization may show an overdistended bladder. Tympanitic distention of the abdomen, with examination of the stools or vomitus, might furnish evidence of the cause arising from the digestive tract. Throat lesions and skin eruptions would suggest the onset of an acute exanthem. Enlargement of the liver and spleen might indicate malarial infection, of which the convulsion represents the rigor. Auscultation and percussion of the chest might furnish signs of a developing pneumonia.

The prognosis obviously depends upon the underlying cause. If the convulsion be the initial symptom of an acute infectious disease it probably will not recur, having the same significance as the initial rigor. If it occur during the course of an established exanthem, its import is more serious as indicative of a complication, possibly cerebral, or it may be a terminal symptom of an acute or ehronic disease. If cerebral lesions or toxæmia be excluded, the probabilities are that the convulsions are but the expression of peripheral irritation, by far the commonest cause in infancy, and of which gastro-intestinal irritation constitutes a large percentage. The convulsion itself is of minor importance as regards danger to life, although rare cases have been recorded in which death oceurred in a primary convulsion from asphyxiation or apoplexy, so that the possibility should never be lost sight of. The danger, however insignificant the exciting cause may be, lies chiefly in the possibility of some damage to the cerebral structures far-reaching in its consequences. Another danger, which compels a guarded prognosis, is that this convulsion may prove to be the first of a series of attacks which ultimately lead to an established epilepsy in an infant with marked predisposition, hereditary or acquired. Statistics show that fifty per cent. of the cases of convulsions in infancy are followed in later life by serious neuroses, such as epilepsy, petit mal, somnambulism, chorea, melancholia, and migraine.

Treatment.-An attack of convulsions may be aborted, if anticipated in time by the premonitory symptoms, by the prompt removal of a peripheral irritation. A sharp and prompt purgative is rarely contraindieated. Calomel, ipecac, and soda may be given in doses of one or two grains $(0.065-0.13 \mathrm{Gm}$.) of the first and last-mentioned drugs, with oneeighth to one-fifth of a grain $(0.008-0.013 \mathrm{Gm}$.) of ipecac, to be repeated every hour for three or four doses. The last dose should be followed an hour later by two teaspoonfuls of castor oil. A full enema of normal salt solution should precede all medication. The child should be given a hot: bath, $110^{\circ} \mathrm{F}$. $\left(43^{\circ} \mathrm{C}\right.$.), or preferably a hot pack of the same temperature. A turkish towel wrung out in hot water should envelop the patient from neck to heels. Meanwhile the head should be kept cool by an ice-bag or 
compresses wrung out in cold water. A tablespoonful of ground mustard in the five-gallon bath, or a little dry mustard sprinkled over the towel pack, will promote the determination of blood to the surface. Bromides and chloral may be administered, by mouth or rectum, in full doses, every two hours, if necessary. In obstinate cases, where one convulsive seizure follows another in quick suecession, chloroform may be given by inhalation sufficient to control the eclampsia. In case of failure to interrupt the convulsions by the above means, hypodermic injection of morphine, one-fifticth to one-twentieth of a grain $(0.0013-0.003 \mathrm{Gm}$.), may be given and repeated in three hours if necessary. If the gums be swollen from erupting teeth, free lancing will secure local depletion with occasionally prevention of the threatened eclampsia. Whatever the treatment be, gentleness to secure the confidence of the child and the co-operation of the parents is a great desideratum. With a known or suspected predisposition to eelampsia, the best of hygienic conditions and food suitable to the digestive capabilities of the child are indicated. He should be relieved of all exciting or debilitating influences and requirements, whether of the school or the home.

\section{EPILEPSY.}

Epilepsy is characterized by a recurrence of seizures in which there is loss of consciousness with convulsions of greater or less severity, from no apparent cause. The series of attacks may begin at any period of life, and although the diagnosis of epilepsy is not easy in infancy, many cases are known to have their origin at this period. Post-mortems of epileptics show no common anatomic lesion, and many show none at all. Statistics from a large number of cases show that fourteen per cent. have their origin in the first five years of life, and more than twelve per cent. in the first three years. Intrauterine and birth injuries not infrequently result in confirmed epilepsy. Heredity unquestionably plays an important rôle in the etiology. Various competent observers have placed the responsibility of heredity upon a history of ancestral epilepsy, other neuroses, syphilis, or tuberculosis in from forty-five to sixty-five per cent. of all cases. In considering this phase, it should be remembered that a large proportion of the progency of neurotics, alcoholies, syphilities, and degenerates fortunately die in infancy.

Among the many other assigned causes may be mentioned traumatism, the exanthems, metallic poisons, hemorrhages, sunstroke, disorders of the pubescent period, masturbation, intestinal parasites, undigested food, severe fright,--in fact, anything that has a tendency to excite convulsions or establish the habit.

Epileptic attacks, although varying widely in the degree and intensity of clinical manifestations, are divided, according to the difference in onset and period of duration, into two general classes known as major, or grand mal, and minor epilepsy, or petit mal.

A major epileptic seizure is distinguishable from an attack of severe simple convulsions only by the preceding aura and the initial cry 
(present in less than fifty per cent. of all cases), and a greater tendency to somnolence which follows the seizures.

The ery is particularly shrill and startling, sometimes being due to fright and at others only to unconscious spasm of the respiratory muscles. The aura, a prodrome of the seizure, may precede it by a few seconds or even minutes and may consist of one or more of a great variety of sensations and impressions. Perhaps the most common in children is an epigastric distress passing up to the pharynx. There may be a sensation of coolness, as of a breeze blowing on some part of the body, a peculiar odor or taste, queer sounds as of ringing in the ears, or hissing like the escape of steam. There may be visual disturbances, as diplopia, musce volitantes, or distinct images as of a face or other object. Whatever one of these or of many other sensations be present, the same is usually repeated at the beginning of each attack, so that the patient soon learns its significance as a warning. Dilatation of the pupils is always present as the first eclamptic expression. The convulsive phenomena do not differ from those due to peripheral irritation and show similar variations.

The seizures known as petit mal resemble the major attacks in their conformity to the three essentials in the definition, namely, loss of consciousness, muscular spasm, and periodicity. The unconsciousness may be evident only as a temporary aberration, a transient interruption to the current of ideas attested by a momentary arrest of speech or occupation, which is resumed without the child's knowledge of the interruption. Usually there is no premonitory aura or initial cry. Clonic spasm may be barely perceptible or entirely absent. The child rarely falls or bites his tongue, and the attacks are frequently described by parents as fainting spells,- -an obvious misnomer, as by careful observation they may be differentiated from attacks of syncope by the rigidity, however transient. If doubt exist in regard to these "spells," in which there is only slight rigidity and brief suspension of mental activity, the fact of their recurrence at longer or shorter intervals would aid in establishing the diagnosis.

Focal or Jacksonian epilepsy is a term given to clonic convulsive seizures confined to a single muscle or group of muscles. Consciousness is maintained, henee it is not a true epilepsy according to the definition. The recurrent character, however, is present. Jacksonian epilepsy is always due to some gross lesion in the motor cortex. The member first involved in the convulsive attack indicates the area of the lesion. Partial epilepsy frequently extends to other members and finally develops into the major form of the disease.

"Masked" epilepsy inchdes a variety of atypical phenomena which are more or less associated with the typical epilepsy, although lacking in many of its salient features. Of this variety "psychic" epilepsy is interesting as an explanation of the recurrence of mental aberration, uncontrollable outbursts of temper, or unusual and inexplicable conduct on the part of children otherwise apparently normal. Observation 
extending many years will show some of these cases developing ultimately true epilepsy or even mania.

The duration of an epileptic seizure may be from a few seconds to five minutes, rarely exceeding this. The frequency of the attacks may vary from one in several years to fifty or more a day, when one attack follows another so closely that eonscionsness is hardly regained. This grave condition is known as status epilepticus, during which the temperature rises, cyanosis is extensive, and death may occur at any moment.

In the early part of its history the attacks may oceur only at night (nocturnal epilepsy) and pass unnoticed, unless very severe. They are sometimes discovered by nocturnal enuresis or tongue wounds which are explainable in no other way. Day attacks usually succeed later, with increased frequency and severity.

Diagnosis.-The diagnosis of epilepsy is not made from the convulsion itself, which presents no distinguishing feature from eclamptic seizures from a variety of causes,-as cerebral lesions, hemorrhages, meningitis, hydrocephalus, tumors, and abscesses. In these there would be in the intervals some form of paralysis, spasticity, exalted reflexes, rise of temperature, focal symptoms, or bulging fontanelles in infants.

From uræmia it may be distinguished by the absence of æedema and fatty and granular casts, although albumin and hyaline casts are often found the first hours following an attack.

The stigmata of hysteria are less marked in childhood, and hence are of less aid in diagnosis. The characteristies of the urine differ from those of epilepsy in that the solids are diminished after an hysterical attack. In epilepsy, on the eontrary, the solids, especially urea and phosphates, are increased. Deep unconsciousness is not present, and the spasmodic movements of hysteria differ in that they represent mere exaggerations of normal movements. The absence of tongne-biting and traumatisms from falls or violent contact with furniture, etc., would point to hysteria.

The ordinary eclampsia of infancy and childhood disappears with the removal of the eause. The history of the case, the absence of an aura, and principally the recurrence of attacks, are diagnostic points.

Prognosis.-Death from epilepsy in childhood is exceedingly rare, although fatal accidents, to which the attacks subject their victims, occasionally occur. Asphyxiation may result from a prolonged spasm of the respiratory muscles. Infancy and childhood often mark the beginning of a disease whose baleful or fatal effects wreck adult life.

A few spontaneous recoveries are on record which are eredited, in some instances, to the occurrence of some acute disease or the changes incident to some "period of stress," as pubescence or adolescence.

Hereditary eases prove the most intractable, with the greatest tendency to idiocy and insanity. Degenerative brain lesions also furnish a gloomy prognosis. Focal varieties, if taken before the paroxysms become general, afford a field for surgical treatment with some hope of relief. 
The same is true of convulsions from recent traumatisms, if early operation is undertaken.

Treatment.-The therapy of epilepsy has improved in recent years by the abandonment of the myriad medicinal agents for one or two of known value. No drug has ever proved a specific, but the greatest amount of amelioration, with an occasional cure, has followed the judicious use of bromides. Whether this agent acts solely by obtunding the irritability of nerve-centres, or transmissibility of nervous impulses, or restricts the action of toxins in the blood (a property claimed to be proven upon lower animals by the injection of bromides and toxins), it certainly las been demonstrated that under its administration the paroxysms of epilepsy have been lessened in frequency and their severity mitigated. 'The drug should be administered in moderately full doses for months and years, with intervals of remission of a few days each month. Nor should its use be discontinued until several months after the cessation of the attacks. The tendency of epilepsy to recur after months or even years should cause the drug to be resumed after any disturbance of health, as a preventive. The combination of bromide of potassium, sodium, and ammonium, it is claimed, is more efficient than the single salt. It should be given, well diluted with an alkaline water, three times daily, the night dose being larger for the nocturnal form. If a regular periodicity of attack be apparent, an increase in the quantity of bromides should precede the time of the expected seizure.

It is now believed that the bromides may be given in small doses, but with increased efficiency; if sodium chloride be withheld from the diet. The substitution of the bromide for the chloride salt is worthy of trial. The well-known tendency of bromides to cause acne, as well as anæmia, may be counteracted by the oceasional course, for a few days, of Fowler's solution. The possibility of syphilis in the etiology warrants the addition of potassium iodide to the daily therapy.

The treatment by drugs will be of little avail if the hygiene be neglected. Every possible influence that may cause intoxication or excite reflex irritation must be removed. The condition of the digestive organs requires particular attention, hence the correction of constipation is indicated to prevent decomposition of food and formation of ptomaines in the intestinal tract. With this in view, nutrition must be maintained by foods most easily digested. Excess of carbohydrates, as well as too much meat, must be avoided. Exercise without fatigue, occupation without worry or excitement, with a free outdoor life, should be the rule.

If an aura precede the attacks, abortive treatment may be tried by the cautious inhalation of amyl nitrite or the use of nitroglycerin.

No procedure ean shorten the duration of an attack or mitigate the severity after the spasm has developed. Efforts at friction, massage, or reduction of the contractions are useless. Care should be taken to prevent traumatism by bruises and falls. A cork or piece of wood should be inserted between the teeth to prevent biting the tongue. 
TETANY-TETANILLA.

Tetany is a condition of increased nervous irritability manifested by repeated tonie spasms. These eonvulsions are confined principally to the flexors of the hands and feet, but may involve the legs and arms, including their adduetors. In rare eases, the large abdominal muscles become affeeted, as well as those of the thorax, neck, and pharynx.

The older reeords show that it oeenrred with about equal frequency in children and adults, but more recent reports indieate a large number of eases in early life.

No specific cause for tetany is known, although it is generally recognized that conditions of lowered nutrition, espeeially rhachitis, favor the

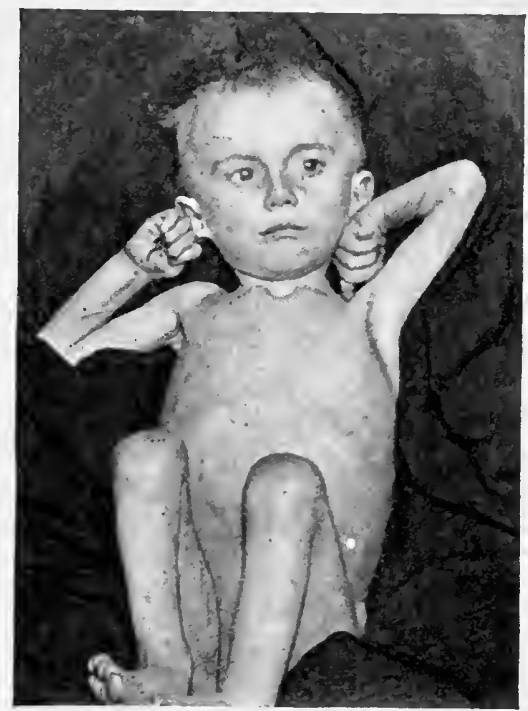

Fig. 149.-Unusual form of tetany. Rhachitic infant of 15 months. Tonic spasm lasting five weeks, with laryngismus. Complete recorery in one week under treatment with chloral and bromides. (Dr. C. A. Wade.)

attacks. Gastro-enteritis, with dilatation of the stomach, has been the most frequent precursor. Some form of intoxication is generally eonsidered an active agent in the causation.

Tetany is most eommonly seen in the winter and spring months. Agents or influences that cause reflex irritation may induce the attacks in those predisposed to tetany. Thus, pressure or a blow over a nervetrunk will eause a characteristic spasm in the musele it supplies,- -as pressure on the femoral nerve causing spasm of the leg ('Trousseau's sign), or light pereussion over the trigeminus below the zygoma producing contraction of the facial musele (Chvostek's sign). The galvanic or faradic eurrent reveals hyperexcitability of many groups of muscles (Erb's sign). 
The picture of tetany is unique and is easily recognized. The condition is described as carpopedal spasm involving one or all four of the extremities in a tonic rigidity. The feet are in a position of pes equinus or equinovarus, with plantar flexed toes. The knees may be slightly flexed upon the thighs, or the latter may be so strongly adducted that the legs cross. The hands are flexed upon the forearm, rotated inward, with occasional flexion at the elbow and firm adduction to the chest. The fingers and thumbs are flexed at the metacarpo-phalangeal joints in the characteristic position known as the accoucheur's hand. All the joints implicated are rigid. These positions are maintained with a degree of unyielding spasticity for days and in extreme eases for weeks. Sometimes there are tremors in the affected limbs and occasional fibrillary twitchings of the muscles least involved. Pain is shown by the whining ery of the patient and is increased by any effort at active or passive extension.

The duration of the disorder, as well as the periods between the spasms, vary in length. There may be an extreme degree of exhaustion dependent upon the duration and intensity of the spasms.

As a rule there is no disturbance of temperature. When pyrexia does occur it is attributed to some accompanying condition, most frequently gastro-enteric infection. Intense desire with inability to urinate shows spasm of the bladder, while occasionally respiration is embarrassed by involvement of the diaphragm and muscles of the abdomen and trunk.

Remissions and exacerbations of varying length may succeed each other for weeks and even months, with a probability of recovery in a large majority of cases, although death may oceur from pneumonia resulting from embarrassed respiration.

Tetany may be diagnosed from spasms due to cerebral lesions by its tonic character and absence of focal symptoms; from tetanus by its local character, being usually restricted to the extremities, and the absence of trismus.

The treatment for the contractures and pain may include dry heat to the affected parts, warm baths long continued, large doses of bromides, hyoscine hydrobromate, bromidia, chloral preferably by rectum, bromoform cautiously administered, morphine or codeine hypodermatically, or even inhalations of chloroform in extreme cases. Massage, passive motion, and electricity should be avoided. The gastro-enteritis, if present, demands special treatment (lavage, ete.), and the bowels, if constipated, should be freely opened. As malnutrition is the chief underlying cause, the most important treatment is that for rhachitis.

\section{LARYNGISMUS STRIDULUS-LARYNGOSPASM ; CEREBRAL CROUP.}

Laryngismus stridulus is also known by the terms asthma rhachiticum, internal convulsions, and breath-holding spells. It is a neurosis, the manifestations of which appear in irregular spasmodic action of some of the muscles of respiration. One of its most familiar forms is a narrowing of the glottis by spasmodic contraction of its adductors, obstruct- 
ing the free entrance of air. Abortive and irregular efforts at inspiration, as well as expiration, show that some or many of these opposed muscles, and also the diaphragm, may be involved in the irregular spasmodic attack. These phenomena are so frequently associated with those of carpopedal spasm as to more than suggest a common etiology.

The well-known instability of nervous equilibrium in rhachitis is apparent as a predisposing factor in the spasmodic action of the muscles involved in this disorder. This is emphasized by statistics which show that an exceedingly large proportion of infants subject to laryngismus exhibit other evidences of rhachitic malnutrition. When we consider the age of its most frequent occurrence (from five to eighteen months) it is evident that in many of the younger patients these attacks antedate the more pronounced bony changes of rhachitis. Any occurrence which disturbs this unstable equilibrium may act as an exciting cause of an attack. Among the causes usually mentioned are fright, anger, indigestion, cold, or any trivial disturbance, as suddenly lifting the child, bathing it, etc.

Exceptional cases are reported in young infants and even in the newly born, also as late as the eighth year. Post-mortems after fatal attacks of laryngismus stridulus fail to show any anatomic lesions explanatory of the phenomena.

Undoubtedly this disorder is more common in Great Britain and Europe than in America, which emphasizes its close association with rhachitis, more widely prevalent in those countries.

The attacks show no preference between night and day and may occur during sleep, from which the child is aroused by their violence. They appear more frequently in the winter and spring months, probably from poorer hygiene, closed rooms, and greater liability to bronchial catarrhs. As in other neuroses, the existence of a family type has been claimed by some, but this has been explained by others on the ground of routine family malhygiene.

As its name implies, laryngismus is a spasmodic inspiratory stridor, with a crowing sound produced by the intake of air as it rushes through the narrowed ehink of the glottis. It may appear as a prolonged whoop after a series of almost inaudible expiratory sobs, resembling somewhat pertussis. With less disturbance or conscious recognition, an occasional short vocalization is heard upon inspiration. Sometimes a child gives one or two short inspiratory crows when startled, as when suddenly aroused from sleep. During fits of anger or after fright or crying, the familiar phenomenon of breath-holding illustrates one form of the disorder. In contrast to this the apnœa may be prolonged to extreme asphyxiation. The respiratory muscles are temporarily quiescent in extreme inspiration. Sometimes the abdomen heaves spasmodically as the diaphragm contracts, until sudden relaxation of the laryngeal spasm allows the inrush of air. During the severe spasms consciousness is sometimes suspended, carpopedal or general clonic convulsions follow, and occasionally death occurs. Some of these symptoms with varying 
grades of severity may recur a dozen or more times a day, or only at long and infrequent intervals, and may be so slight as to attract but little attention. There is a tendency to recurrence after weeks or months with lessened frequency towards the close of the period of dentition.

Diagnosis.-It is diagnosed from croup by the absence of febrile symptoms and cough, the unchanged voice or ery, and in severe eases the more complete although temporary occlusion. The differentiation will be difficult or impossible when eatarrhal laryngitis and spasin of the glottis are both present. In neurotic children any laryngeal inflammation may be complicated by stridor. From asthma it is diagnosed by the absence of expiratory spasm, cough, and emphysema.

Prognosis.-Fatalities from laryngospasm are less frequently observed in this country than in Europe. The milder forms are usually regarded as significant of a need for better nutrition. It should never be forgotten, however, that the severe attacks present conditions of grave peril. In poorly nourished, rhachitic infants the gravity of catarrhal disorders of the respiratory tract may be greatly increased by the addition of this neurosis.

Treatment.-The treatment should be directed to the improvement of the underlying condition and to the relief of the acute attack. If the symptoms be alarming, relaxation of the spasm may be induced by fanning or sprinkling the face with cold water. The epiglottis should be raised by dragging the tongue forward. Cautious inhalation of ammonia or camphor may be tried. Bromides, chloral, and belladonna are all serviceable. Bromoform, if exhibited, must be used guardedly. Immediate evacuation of the bowel by a copious enema, and the administration of a laxative, are always indicated. In extreme cases intubation may be necessary, or a hard eatheter may be introduced into the trachea for temporary relief. Oxygen may then be used. All lesions of the upper respiratory or genito-urinary tract should be corrected.

\section{THOMSEN'S DISEASE-MYOTONIA CONGENITA.}

Myotonia congenita is characterized by inertia of the muscles. It may be confined to one group, as of the leg, or all the extremities may be involved. It is congenital, distinctly hereditary and familial, recurring in several generations.

Although present from birth in some degree, it becomes more marked at puberty and continues throughout life. Its etiology is obscure. It is most marked upon first attempting to use the muscles, disappears during prolonged exercise, only to reappear after long periods of rest. The condition of the affected muscles is best described as inertia from the tardy initiative contractibility and the delay in relaxation. If the child is presented with a toy or coin, after hesitation the hand is extended with apparent difficulty to grasp the object, and the same difficulty appears in relinquishing his hold. There may be extreme difficulty in rising from the sitting posture or inability to walk after long 
standing, as though the muscles were locked in a tonic spasm. As before stated, the disability disappears after exercise.

The muscles involved are larger than the average, although not proportionately strong. Microscopical examination of the affected muscles during life has shown hypertrophy of muscular fibres, a distinct division of these fibres into angular fields, and proliferation of nuclei. The motor nerves and end-plates show no deviation fiom the normal. Response to mechanical or electrical stimulation is slow; a sharp tap over the muscle is tardily followed by an exaggerated wave of contraction which sweeps throughout its length. To both faradic and galvanic currents the affected muscles show increased excitability, while the conductivity of the nerves remains unchanged.

Diagnosis.-From tetanic contraction and all other spastic conditions it is diagnosed by its characteristic disappearance during exercise and reappearance after rest. It is to be distinguished from the physiologic myotonia neonatorum by the disappearance of the latter with normal development. By the same transient duration may be excluded also the tonic spasms of the new-born (paramyotonia) which are caused by the sudden change of temperature, and may last from a few minutes to several hours.

To pseudohypertrophy the only point of resemblance is the increased bulk of the affected limb.

No specific treatment is known. Active exercise improves the function of the muscles. By gradually acquired familiarity with his idiosyncrasy and self-training, the patient becomes able to avoid accidents and follow some occupations.

\section{HYSTERIA.}

From whatever point of view, the psychical aspect of hysteria is the most prominent. Of all the stigmata of this protean disorder, mental impressionability is clearly the most pronounced. If in addition to this there be vicious education and neurotic heredity, the etiology of hysterical phenomena is complete. The older idea, still somewhat prevalent, that hysteria is a disorder peculiar to women was a natural result of the exploded dogma that its cause lay in diseases of the uterus. That hysterical manifestations and stigmata were so long unrecognized in childhood may further be accounted for by the lack of application of definite methods of diagnosis to disorders of this period. From the present knowledge of hysteria, children are as prone to this disease as their elders. The non-recognition of this is probably due to the fact that childhood does not present as many varieties of stigmata in the same individual as frequently may be seen in older cases. Time, however, develops some of these obscure cases into the commonly recognized mature type, with wealth of phenomena sufficient to satisfy the most incredulous.

Since there is no anatomical lesion in hysteria its causation must be due to functional disturbances of the nervous system. 
The dramatic paroxysmal attacks which receive so much attention are of less importance than the interparoxysmal and underlying conditions that allow the explosions. The acute manifestations may be induced by any physical or mental shock or excitement, acting upon an unstable nervous organization, feebly presided over by an uneducated will. Children whose immediate or remote ancestry show hysteria, insanity, epilepsy, alcoholism, and possibly gout and tuberculosis, exhibit a predisposition to hysteria which may be augmented by the effects of recent sickness, school-strain, physical fatigue, or even imitation. If the life and education of such children be not such as to develop an unusual degree of self-control, the question of acute hysterical phenomena depends entirely upon the presence or absence of an exciting cause, in itself insignificant.

Fits of screaming or immoderate laughter may represent the lightest manifestations of a hysterical tendency. Between these and the major attacks every degree of hysteria may be seen in childhood.

The picture of the grand attack in children differs from that in adults principally in the demonstrations of the dramatic stage, which are restricted in accordance with the limited knowledge and observations of the patient; thus some of the heroic emotional attitudes may be wanting. The convulsions and delirium may represent every phase of its adult type. The motor symptoms, both paretic and spastic, are seen in all forms and degrees. Paraplegia occurs more frequently than in the adult, and a monoplegia or hemiplegia may be the only pronounced or initial symptom of the disorder. The sudden onset, sometimes the unexpected transference to other groups of muscles or abrupt disappearance, are in marked contrast to the plegias of organic origin. Tremors are not as frequent as in older life. The hysteric joints may closely simulate genuine arthritic or bone lesions, as tuberculosis of the hip and vertebræ, and have been mistakenly treated as such.

Laryngeal paresis with aphonia is a very common symptom in young children, especially following fright. Vesical spasm causing retention of urine is usually transient. Persistent singultus is frequently observed. From involvement of the intestinal tract there may follow diarrhœa, or meteorism to enormous abdominal distention. Occasionally vomiting occurs and proves obstinate to control from apparent perversity.

Torticollis is sometimes seen, and deformities such as spinal curvature from tonic contractures of the great muscles of the trunk, may persist for weeks. The tissues about the flexed joints may swell and the muscle contractures from long-continued malposition and disuse add to the deformities. The involved areas may show exquisite tenderness to the touch.

All the various disturbances of sensation, as anæsthesia, hyperæsthesia, paræsthesia, analgesia, and hypalgesia, present all the vagaries seen in the adnlt. Tender points along the spine, over the craninm and trunk are common. The cranial tenderness may or may not be associated with headache of the typical boring character (clavus). Hysterogenic areas may be found, but diminished sensation to touch and pain is less 
common. Hemianæsthesia is occasionally seen. Faucial and laryngeal hyperasthesia with resultant cough is a more frequent symptom.

Disturbances of the special senses are common and may be the only symptoms present, as deafness in one or both ears, perversion or loss of taste or smell, or there may be blindness (uni- or bilateral) for which the oculist can find no cause. As in adults the visual field may be restricted, laterally or concentrically, but this is a symptom difficult to bring out in the young child. No attempt is here made to go over the entire field of psychomotor-sensory disturbances. A few only are mentioned which are more characteristic of this disorder in childhood.

Diagnosis.-The possibility of the engraftment of hysterical symptoms upon any pathological condition must never be lost sight of in treating children of a neurotic tendency. Frequently the refinements of diagnosis are necessary to differentiate between the organic symptoms and those of hysteria. Previous aequaintance with the child's history, or with the action of remedial agents, frequently aid the physician in the elision of neurotic features.

From epileptic seizures, hysterical fits should be diagnosed by the emotional symptoms preceding: the absence of aura, tongue-biting, or other self-inflicted injuries, of spasmodic evacuation of bladder and rectum, and rarely of complete unconsciousness. The movements of hysteria are more purposeful, less jactitating in character, and wider in the amplitude of their range.

The differentiation is not always easy, as is evident by the term hystero-epilepsy,-a misnomer, as an epileptic attack needs no adjective. The possibility of alternation of the two kinds of convulsions in the same child must be remembered.

The relation between chorea and hysteroid manifestations is interesting in so much as both are imitative in character and develop in nervous children under similar conditions.

From true plegias, hysteria should be distinguished by the absence of all evidence of changes due to anatomical lesions in the central nervous system, excepting the moderate atrophy from disuse.

From all the simulated diseases of nervous, muscular, or visceral origin, the absence of evidence of structural changes and the presence of some of the stigmata of hysteria should clear up the diagnosis.

Prognosis.-Hysteria is never reported as a cause of death, although hysterical delirium may lead to delusions, melancholia, mania, and suicide.

Treatment.-The evolution from the hysterical diathesis is probably purely educational. Improvement in physical health and in environmental conditions, with developing inhibition, may do much for the relief of the hysterical. The study of the individual, with the application of the best known principles of hygiene, physical, mental, and moral, a change of control from that of an emotional parent to a person of perfect equipoise, of gentle nature, and firm discipline, may at this early period of life do much to overeome the morbid inheritance. 
CATALEPSY.

This condition, closely associated with hysteria, epilepsy, melancholia, and developing insanity, is extremely rare in infancy and seldom seen in childhood.

The state is characterized, as in the adult, by more or less loss of consciousness, moroseness, irritability, and other hysterical manifestations, but more particularly by the well-known lead-pipe spasticity of the limbs, which retain for a long time whatever position they are made to assume.

The etiology is obscure. It has been known to take the place of the chill in malaria, to follow fright, intense emotional disturbance, or high temperature in febrile disorders. It appears as a psychomotor neurosis, engrafted on or induced by other diseased conditions. In many cases it has an erotic complexion and has been manifest in children addicted to masturbation.

The treatment is primarily that of the underlying disorder. For the cataleptic attacks cautious inhalation of ammonia, mixed bromides in full doses, and cool sponging, are worthy of trial. Quinine is indicated in malaria. Circumeision or attention to genital irritation, thorough oversight of moral and mental hygiene, change of environment and associates, may all be instituted with a view to intercepting the morbid suggestions before the cataleptic spasms become habitual. The careful management of the child through pubescence may rescue him from the evil sequels of this malady.

\section{CHOREA.}

The chorea of Sydenham is generally regarded as a functional affection, unattended by any demonstrable lesion. It is characterized by a series of exaggerated normal or purposeless movements of voluntary muscles, without loss of consciousness, and associated usually with considerable emotional irritability. The movements may involve any or all of the voluntary muscles. They may appear in one member only or involve one side of the body,-hemichorea. They may range in severity from barely perceptible twitchings of a limited group to widely grotesque, aimless muscular movements of face, head, trunk, and extremities. In cases of average severity the temporary control of the movements by exercise of the child's will is always followed immediately by increase in the muscular incoherency.

It occurs most commonly between the ages of five and fifteen years and three times as frequently in girls as in boys. It may be seen in younger children, and congenital cases have been reported. By far the large proportion, probably one-half, develop during the spring months, so that at this time recurrences are apprehended by parents. Many cases show a marked neurotic heredity, and a direct history of chorea in mother or older sisters is obtained.

Chorea is so frequently associated with rheumatism that it has come 
to be regarded as one of the manifestations of that diathesis. Even if this association be limited to those cases showing acute rheumatic arthritis, a rather rare form in early childhood, the proportion is still too large to be considered a mere coincidence. While if the common symptoms of rheumatism be considered, as tonsillitis, endocarditis, myalgia, and "growing pains," this association becomes convincing. Furthermore, continued observation of cases of chorea shows, sooner or later, subsequent development of other rheumatic symptoms. The urinary findings in uncomplicated chorea correspond to those of rheumatism in the increased percentage of urates and uric acid. The mode of onset, the selflimited character of the attacks, the accompanying anæmia, the subsequent heart lesions and its tendency to recurrence, all stamp the chorea

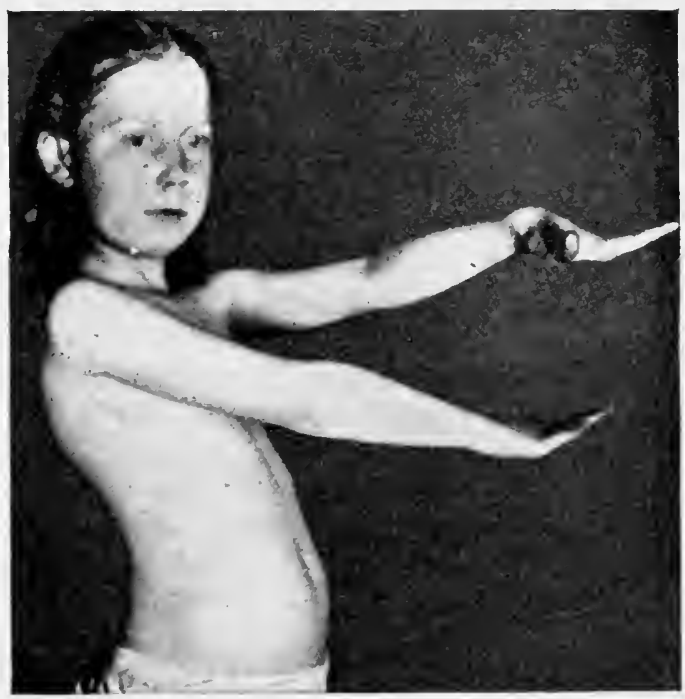

FIG. 150.-Chorea minor.

of childhood as a phase of rheumatism, with more than a suggestion of microbic etiology.

The fact that choreic movements occasionally follow certain definite lesions of the motor tract and obvious reflex irritation, has given rise to classification, such as Huntington's chorea, electric chorea, habit spasm, tic convulsif, etc., but these should not be confounded with the chorea minor of childhood. Huntington's chorea is an hereditary disease which rarely develops until after puberty.

Chorea minor is seen most frequently in poorly nourished children of bad hygienic surroundings, or in those who have been subject to excitement, worry, overstrain from study, or whose vitality has been reduced by acute sickness. Cold and emotional disturbances, particularly fright, are often given as exciting causes.

The attack may develop insidiously, the first symptom often being an 
unusual irritability. The child is peevish and fretful, weeps at the least reproof, or it may stumble in walking, drop objects, and show awkwardness in all accustomed motions. The child is restless and fidgety, especially when fatigued or embarrassed. Incoördinate movements may be first observed at the table in the uncertain attempts at feeding. This incoördination is usually more pronounced and earliest developed in the upper extremities. Gradually other groups of muscles share in the irregular movements until the child is unable to feed himself or perform any of the habitual duties of daily life. Speech is affected, words being indistinctly enunciated or explosively uttered. A symptom peculiar to chorea is the appearance of the tongue, which, upon request, is protruded with lightning rapidity from the widely opened mouth, while its dorsal surface undulates with wave-like movements. After going through unusual gyratory motions it may be jerked back as suddenly as it was protruded.

Some of the affected muscles show weakness amounting at times almost to a paresis. Loss of sleep, the constant movements, occasionally so violent as to throw the child from the bed, and inanition from interference with feeding, may account for the anæmia and general weakness which rapidly develop in severe cases. The movements usually disappear during sleep, which is secured only for short periods.

No constant change is seen in the deeper reflexes. The same is also true of the temperature in uncomplicated cases. The pulse shows great variation, suddenly accelerating without apparent cause, the heart sharing in the general muscular insanity. Atony of the heart muscle is seen in the frequent dilatation. Hæmic murmurs, both basic and apical, are rarely absent in advanced cases, and endocarditis may oceur.

Diagnosis.-Although probably only a secondary symptom of some condition as yet unknown, the so-called idiopathic chorea is unmistakable in diagnosis. The duration may be from a few weeks to many months, many clinical histories showing an average of eight to nine weeks. The tendency to recurrence is marked, under conditions favorable for its development, for several years.

Prognosis.-The prognosis is hopeful as far as life is concerned, although death from inanition or exhaustion may very rarely occur. A fatal termination from the cardiac inflammation must not be lost sight of. A not uncommon sequel is valvular lesion or dilatation from the muscular atony.

Treatment.- The treatment consists in protecting the child from all influences that will excite or irritate, avoiding all reference to his infirmity. He should be taken out of school and relieved of all tiresome duties and responsibilities. The question of keeping him constantly in bed depends upon the condition of the child and his environment. Close attention should be given to the digestive organs. Constipation must be relieved and elimination promoted. The heart must be daily watched for early indications of endocarditis. Rest is imperative and sleep must 
be secured by adequate means, best by warm baths and gentle massage. In severe cases sedatives may be necessary. For this, full doses of the mixed bromides are useful, to which may be added chloral hydrate. When the continued violent jactitations prevent sleep and threaten exhaustion, morphine, hypodermically, may be indicated or even chloroform by inhalation. If the stomach is irritable rectal medication may be employed. Sometimes it is wise to restrict the tired limbs in their erratic movements by well-padded splints. Non-exciting amusements to divert the child's mind should be provided.

The diet must be nutritious and non-bulky because of the difficulty in feeding. It may be necessary to give fluids from a feeder ending in a rubber tube, on account of the unexpected contractions of the masseters.

Disturbance of pulse-rate, rise of temperature, cardiac souffle or friction sounds indicative of inflammatory involvement of the heart, require appropriate treatment.

It is doubtful if any specific medication is available in this disorder. Arsenic holds the front rank among the scores of remedies that have been employed. It should be given well diluted, in the form of Fowler's or Pearson's solution, three times a day, by the increasing plan. Gastric irritation from the extravagant use of this drug defeats its therapeutic intention. In cases of absolute gastric intolerance Pearson's solution may be administered hypodermatically in five- to ten-minim doses (0.3-0.6 C.c.). For the anæmia, in the absence of fever, iron is indicated, Blaud's mass and Basham's mixture being valuable preparations. Codliver oil, either plain or combined with hypophosphites, should be given in moderate doses.

From the beneficial effects of salicylates in acute rheumatism these agents are worthy of a trial in early choreic attacks. Gratifying results, in shortening their duration, have been reported from the use of salicylate of sodium or strontium. This treatment is advisable in cases where the rheumatic stamp is especially marked.

The cacodylate of sodium is advocated at the present time by several who claim excellent results from its use.

\section{HABIT SPASM-TIC CONVULSIF; HABIT CHOREA; FACIAL TIC.}

These forms of local spasm are of special interest in childhood, for at that period the only opportunity is afforded to overcome a disorder which may prove to be not only an annoyance but a great inconvenience in later life. There is a great variety of these habit spasms or tics, many of which are originally due to local lesions in or adjacent to the affected muscles, such as grimacing as the result of nasal catarrh, blepharospasm from ocular defects or palpebral lesions. Ill-fitting garments or irritation about the neck may be the cause of shoulder-shrugging or necktwisting. And so throughout the muscles of the face, trunk, and extremities, movements of a purposive nature, primarily induced by some local discomfort, become a habit from frequent repetitions. Imitation, 
also, enters largely into the etiology of habit spasm. This is frequently seen in tricks of speech, meaningless vocal utterances, or gestures accompanying certain words or phrases.

The pathological significance, in the majority of these cases, is unimportant; but for the child's future welfare all these irregularities of speech should be corrected before the habits have become permanently fixed. This may be done by the exercise of thoughtful tact and patience on the part of the parents, after the removal of all reflex irritations. Training the muscles in regular rhythmic movements under the control of the will, as in calisthenies, is especially to be recommended.

\section{IMPERATIVE MOVEMENTS.}

Imperative movements are subjects of psychical interest since they are seen, in the most marked degree, in idiots. In minor forms they are very commonly observed, irrespective of impaired mentality, in children as well as in adults. Probably every individual who analyzes his habitual daily routine will recognize some movements which have no meaning or significance other than the result of an habitual impulse,- - such as the purposeless counting of objects or patterns which appear in series, the stepping on certain stones in the daily walk, etc. Between the two extremes may lie an intermediate class of individuals in whom imperative conceptions may be the only explanation for some outré demonstration or criminal act. The importance of securing absolute control of volition in early life is apparent in this connection.

SPASMUS NUTANS, HEAD-NODDING, NYSTAGMUS.

Spasmus nutans and nystagmus are repeated nodding, rotating, or oscillating movements of the head and eyes, frequently associated but occasionally seen separately. The movements may be horizontal, lateral, or rotary, or the whole body may oscillate or bow rhythmically as in salaam. The nystagmus may affect one or both eyes.

The age of most frequent occurrence in childhood is from the sixth to the eighteenth month, although both affections are seen at all ages. The oscillations of the eye may vary in frequency from fifteen to three hundred to the minute, and may be intensified by fixing the child's attention upon some bright object, or by holding the head still.

Occasionally one or both of these spasms, beginning in infancy, may continue throughout life. As a rule they last but a few weeks or months, disappearing gradually. Both are also seen as terminal symptoms in cerebral disease.

Their etiology has been a subject of much discussion. As the movements involve muscles of volition which are among the first to develop purposive function, it would appear that prior to the development of inhibition, early volitional movements may readily degenerate into habitual movements. A careful study of the environments of these purely functional cases usually brings ont some circumstances, as the habitual position of the child relative to the light or to the visual range of some 
bright or attractive object, as the origin of these purposive lateral or vertical movements of eyes and head. Meningitis, cerebral tumor, atrophy, sclerosis, and encephalitis are lesions of which these phenomena may be either early or terminal symptoms.

The prognosis, therefore, must be guarded, recalling the extremes of etiology. In a considerable proportion of cases, rickets and malnutrition have been observed. Ocular defects should be sought for. The nystagmus of albinism is well known. The movements may be interrupted in quiescent periods and cease entirely during sleep.

The treatment is that of the underlying cerebral affection, if such exist, or the improvement of nutrition in rhachitis and marasmus, the removal of all causes of reflex irritation, and change of the child's environment with reference to light and objects to which his attention has been especially directed.

\section{ATHETOSIS.}

First described as a disease, athetosis can hardly be considered more than a symptom. The term is applied to slow, rhythmic, incoördinate

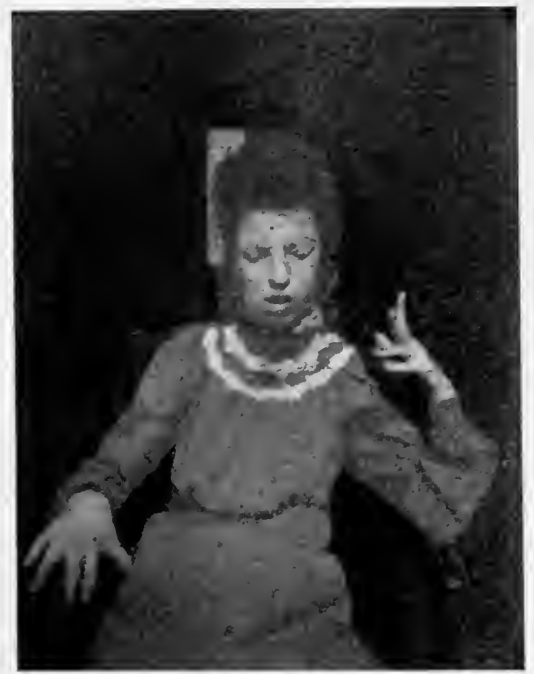

FIG. 150.-Hemiplegic athetosis. (Dr. G. W. Hall.)

movements of different members, especially the fingers and toes, although it may involve the limbs, trunk, and head. They may continue during sleep. These movements are described as gliding or peristaltic, and, when the trunk is involved, as squirming or writhing.

Athetoid movements are so commonly seen in very young infants that it is a question if they are of any pathologic import at this age. As in tetany the muscles most involved are the interossei and lumbricales, with this difference, that the contractions are slowly clonic, irregular, and grotesque. Although apparently non-pathologic in new-born infants 
(Fig. 5), cases are reported in which athetosis persisted for years, rendering the patient helpless. It may be unilateral or appear in the fingers of one side and toes of the other. It is a frequent symptom of posthemiplegia, appearing on the paralyzed side after the partial restoration of motion. Athetoid movements should always lead to an inquiry for the history of a previous palsy.

The muscles involved in the movements show hypertrophy. When confined to the fingers and toes, the larger muscles of the corresponding forearm and calf show slight rigidity.

Causative lesions have been found in some cases in the corpus striatum and optic thalamus.

Occasionally the athetoid movements may be almost choreic in their rapidity, or the two forms may be associated in the same child.

In athetosis due to an anatomical lesion there is little hope of cure, although exercise, occupation, and efforts of the will may modify the movements. No treatment by drugs has been of benefit.

\section{PAVOR NOCTURNUS-NIGHT TERRORS.}

Pavor nocturnus is a form of disturbed sleep usually occurring during the first hours of the night. The child suddenly sereams loudly and is found sitting up in bed, staring with dilated pupils, and begging to be protected from some imaginary object, as an animal or hobgoblin, rarely of known persons. He fails to recognize familiar faces for several minutes and is then quieted with difficulty and may finally sob himself to sleep. The nature of the attack may vary, sometimes assuming the form of a dream or nightmare from which the child awakes in terror at finding himself alone. He may relate his dream, take a drink of water, and go quickly to sleep again. The attacks may recur frequently, but rarely twice in the same night.

Among many varieties two types are presented. One, the high-strung child, overworked at school, with imagination stimulated by injudicious reading or story-telling, anæmic, and poorly nourished from insufficient or improper food, malhygiene, or previous sickness. His nervous system is in a state of unstable equilibrium in which imagination is overdeveloped. Children of this type most frequently " see things" at night, and occasionally have hallucinations in the day (pavor diurnus).

The other class may be unimaginative, apparently well nourished children, whose sleep is disturbed by interference with respiration from enlarged tonsils or adenoid growths, or from reflex irritation from an overfull stomach, undigested food, or intestinal parasites. These acting through the pneumogastric may influence respiration and cause partial asphyxiation, from which the child awakes in fright.

Prognosis.-Although the prognosis is good in a large majority of cases, as they usually outgrow the tendency in later childhood, the fact must not be overlooked that epilepsy occasionally follows night terrors, the pavor apparently assuming the place of the epileptic seizure. 
Treatment.-The treatment is indicated by the apparent exciting causes and predisposition. The neurotic child should be relieved from overwork, so common in our schools. If necessary the child should be removed from school, music- and dancing-lessons should be curtailed, company restricted, and late hours prohibited. The imagination must be trained by less sensational reading, and interest developed in outdoor occupations and amusements. Protection from errors of diet, as to quantity, quality, and time of feeding, are important. The relief of all conditions which cause reflex irritation should be instituted. Nor should the mental and moral hygiene of the ehild be overlooked. None but the sympathetic mother can appreciate the tender conseiences of these little ones to whom night brings the retrospect of the day's naughtiness. Going to bed should be relieved of all idea of isolation. A door ajar, a light in an adjoining room, serves to steady the shrinking consciousness of many a child from the terrors of the night. A good physic, a warm bath before retiring, a well-ventilated room, with good digestion of a plain supper, will usually secure sleep free from pavor, without the administration of bromide or chloral, which should be given only in extreme cases.

\section{SPEECH DEFECTS.}

Defects in speech are very common in childhood and may vary in degree from complete alalia to the merest lisping. If the child show total absence of speech at two years the parents usually consult the physician. A prognosis as to the permanency of alalia at this early age is sometimes difficult and should be made only after the exclusion of all possible conditions known to interfere with the normal development of speech. If the child has never spoken, the question of his intelligence should be first considered, since alalia is a common accompaniment of idiocy, and even minor defects of speech are held by some authorities to indicate slight mental impairment. Careful scrutiny and ordinary tests as to the degree of interest and attention displayed by the child, together with his physical condition and history of birth and development, will aid the physician in his decision. The question of hearing should be settled at once, as total deafness in infancy, either congenital or acquired, always results in mutism. Examination for defects in the organs of speech, or for the presence of adenoids, should be made. The environment of the child has much to do with his learning to talk. If associated with other children or instructed by attentive parents, speech will develop earlier than in children who are left to amuse themselves or are much in the care of a reticent nurse. Occasionally a child may not talk until the age of four years, and in rare cases children have reached the age of six before attaining speech. Usually the retarded development is compensated by the rapid acquirement of a vocabulary average for age.

Tongue-tie, commonly supposed to interfere with speech, probably does so only to the extent of lisping, a defect in which the short frenum changes the sibilant $s$ to $t h$, from inability to approximate the tip of the tongue to the roof of the mouth. Even section of the frenum, however, 
does not immediately correct this defect, as the habit must be overeome by persistent efforts at correct pronunciation.

A distinction between stammering and stuttering, terms formerly synonymous, is now made. Stammering is employed to designate habitual erroneous utterance of certain sounds, usually due primarily to some defect in the speech organs or of their innervation. In children it may be due, also, to habits resultant from careless and uncorrected articulation. Such habits of speech are seen in racial peculiarities of dialect. A good illustration is seen in the faulty enunciation of an acquired language, so that one may be said to stammer in the imperfect utterance of all languages save his own.

Stuttering may assume a variety of forms, the most common of which is hesitation with a more or less prolonged or repeated effort before the utterance of certain syllables usually beginning with explosive consonants. Occasionally the same hesitancy is seen in the linguals and even vowel sounds. The abortive effort to enunciate may appear distressing, the face is congested, the muscles, especially of the throat, chest, and vocal organs, are in tetanic spasm until suddenly the tension terminates in an explosive utterance, followed often by several words in rapid succession.

Of the many causes, probably the most common is defective coordination of the vocal and respiratory apparatus, and it is usually aggravated by excitement or fatigue. Children also stutter from imitation. The habit is most readily acquired before the forms of speech are fully established, and the child's ideas run ahead of his ability of expression. Faulty methods of breathing undoubtedly favor the formation of the stuttering habit.

The treatment of these defects requires first the removal of any known cause and the teaching of correct breathing. Excitement and undue haste should be repressed and the child required to repeat daily, for short periods, slowly and deliberately, word for word, sentences pronounced by the teacher. Singing and intonation prove easier methods of expression. Rhythmical motions of the limbs or body, as in marching or dancing, may assist the enunciation. Important in the correction of stuttering is deep inspiration before the beginning of a sentence. Infinite patience and perseverance will be necessary to overcome the confirmed habit, though many cases of stuttering, lisping, or stammering, due to hasty utterance, are outgrown in later childhood.

\section{ECHOLALIA AND COPROLALIA.}

Echolalia, an explosive repetition of the last word or syllable of a sentence, and coprolalia, a violent ejaculation of profane or obscene words, frequently accompanied by involuntary gesticulations, are seen occasionally in neurotic children as expressions of convulsive tic, hysteria, and some cerebral disorders. The requirements of treatment are improvement in hygiene and nutrition, which are invariably defective in these cases. 


\section{APHASIA.}

Loss of speech is known as aphasia and may be complete or partial, transient or persistent, visual or auditory. Many varieties, from an etiological classification, are recognized, the two best known being sensory and motor aphasia. Both of these forms, of which the motor is more common, occur as a result of cerebral lesion, tumor, abscess, or inflammation, which involves the cortical areas. Of these, the third frontal, first temporal, and inferior parietal convolutions of the left side, or their direct or associated tracts, are most often affected. In right-handed children the left side, in very young children both sides, are probably involved.

The prognosis of aphasia from cerebral lesions which do not destroy life is better in children under seren or eight years, before which the opposite hemisphere is more likely to assume the suspended functions of the left.

Temporary aphasias are not uncommon after scarlet fever, pneumonia, measles, whooping-cough, and typhoid fever, especially the last named. In this form, speech may be lost for weeks or even months, the function being gradually restored with the return of strength. Temporary aphasia, with or without amnesia, may occur as the immediate result of a sudden fright, fall, or blow upon the head from which there may be no loss of consciousness. In the absence of severe intracranial lesions, return of speech and memory may be expected.

Up to the sixth year, aphasia from deafness following acute infectious diseases, as scarlet fever or influenza, is occasionally seen. The fact that mutism may follow deafness acquired after several years of familiarity with spoken language emphasizes the importance of guarding the function of speech in all cases of loss or impairment of hearing. In early childhood the acquired vocabulary can only be preserved by frequent use to its fullest extent. Daily exercises must be begun as soon as health will permit. This should include every word and expression with which he is familiar, that none be lost from disuse. As absolute deafness is rare, even among congenital mutes, advantage is taken of the modicum of perception of sound-waves, through air or bone conduction, for aural instruction. In many cases the auditory apparatus is sensitive to vibrations of a certain pitch. This, being determined, is utilized for teaching articulate language. The results obtained by this method are highly satisfactory, but ean only be secured by specially trained teachers.

The heredity of deaf-mutism seems to be well established, though occasionally children born of congenitally deaf parents are free from the infirmity.

\section{MASTURBATION.}

Masturbation is in many instances primarily due to a number of lesions and disorders of the genitals. It is also provocative of irritation, congestion and eatarrh of the genital mucosa. Very young infants, 
more especially girls, are known to masturbate, generally by rocking or rolling with the thighs together, or rubbing the parts against the clothing, floor, or furniture. It is very evident that the habit originates in irritations resultant from uncleanliness, or in the genital disorders heretofore enumerated. In later childhood, boys especially learn the habit from older children. Its ill effects, aside from those of local disease, are seen in a premature development of erethism, which paves the way to erotic emotionalism of later years. Comparison of the visible phenomena of a sexual orgasm with an attack of petit mal suggests their clinical similarity, a conclusion which helps to explain the morbid effects upon the developing organism of a frequent occurrence of such cataclysmic intensity.

The real, causative relation of sexual perversion to the practice of masturbation has been much discussed. Whichever may cause the other, or whether each acting as factors in a vicious circle intensifies the other, the fact is generally acknowledged that masturbation is a vice fraught with peril to the future well-being of its victim, and that parents and nurses should be ever on the alert to prevent the inception of the habit formed by neglect of hygiene. All possible causes of local irritation, whether functional, structural, or accidental, should be relieved by appropriate means. Vigilant, intelligent surveillance, with tireless self-denial, may be necessary on the part of the mother or nurse to divert the little victim from his newly-found enjoyment. Mental oceupation, with healthy stimulation to rational entertainment, will surely wean the normal child from the habit of self-abuse. Good hygiene, fresh air, frequent bathing, clean clothing, with good digestion, normal fatigue, and sound sleep, are curative agencies. Sedative drugs-those which reduce reflex excitability-may be necessary in extreme cases for a short period. For these the best are the bromides, or the monobromide of camphor pill, in dosage suitable to age.

\section{REFLEXES.}

The instability of the nervous system in childhood, due largely to the lack of development of the higher or inhibitory centres, not only renders the child susceptible to a variety of disorders of purely reflex origin, but marks as peculiar the symptomatology of all diseases of childhood. In addition to this, the nervous centres are more quickly exhausted, and not only show inability for sustained function, but are readily influenced by innutrition from insufficient food, indigestion, etc.

The enormous demands for tissue growth interfere with function upon the slightest impairment of food supply, so that vicious circles are readily established involving trophic, motor, and secretory control. The tendency to vasomotor disturbances from the most trivial causes adds to the functional confusion in the disorders of childhood. Structural changes, too, in the immature tissues follow hard upon derangements of function, so that organic disease, especially of the nervous system, is frequently established in the first months of life. 
Infancy and childhood is the physiological borderland of neurasthenia, while reflex neuroses of infinite variety are characteristic of this period.

General convulsions of purely reflex origin are common and oceasionally fatal. In these the only discoverable cause may be local irritation of the intestinal tract from worms or undigested food, also from adenoids, foreign bodies in the ears, genital irritation, or burns.

Reflex spasm of the bladder may be due to genital irritation, cold, and fright. Cough, without pulmonary lesion, may be due to reflex irritation from chronic ear disease, impacted cerumen, or a foreign body in the external auditory meatus, adenoids, or from irritation in the digestive tract. To the same causes may be due laryngospasm and asthma of alarming and persistent type, which yields only upon removal of the distal cause.

Persistent hiceough and alarming attacks of dyspnœa, with gasping and cyanosis, may be caused by irritation of the diaphragm from an overloaded stomach. Relief is obtained in such cases by prompt emesis.

Recurrent obstinate vomiting is frequently of purely reflex origin and may be excited by many causes, as from intracranial pressure, fright, shock, or other sensory disturbances, and also from laryngeal and pharyngeal irritation, and is frequently relieved only by the treatment of the exciting cause.

Functional tachycardia is extremely common in childhood, especially from the sixth to the sixteenth year, and is easily induced by mental, emotional, and many physical conditions.

Headache is very commonly of reflex origin as in some ocular defects, such as ametropia, astigmatism, or insufficiency of the ocular muscles. Reflex headache may be induced through the pneumogastric nerve by hunger or gastric irritation.

Pathological processes in the nasopharynx, in the auditory canal and middle ear, also dental caries, especially in the upper jaw, may give rise to headache. Headaches are occasionally due to irritation of the genitals, and are often an accompaniment of early menstruation.

\section{REFLEX DISORDERS OF DENTITION.}

Innumerable reflex disorders have been attributed to dentition, among which are irritability, pyrexia, cough, asthma, laryngospasm, coryza, headache, earache, adenitis, anorexia, indigestion, diarrhœa, loss of weight, skin eruptions, convulsions, and even death. The pernicious tendency to attribute all the ills of later infancy to dentition has been vigorously combated by pediatrists for the obviously good reason that many infants are annually sacrificed by the neglect of some pathological conditions, the symptoms of which are erroneously ascribed to teething.

Some able teachers in their enthusiasm have gone so far as to assert that teething, being a physiological process, could produce nothing but teeth, hence was unworthy of nosological recognition. The same reason- 
ing applied to parturition and several other physiological processes will furnish a reductio ad absurdum.

\section{HEADACHE.}

Headache in children is a common accompaniment of the febrile state from whatever cause. It is also a prominent symptom of graver forms of intracranial disease, and for this reason its appearance in very young children should never be lightly regarded. Aside from the above and local circulatory conditions, as congestion or ischæmia of the cerebral vessels, the ordinary headaches of children may be due to a variety of causes, among which are toxæmia ; reflex irritations from eyes, ears, nasopharynx, teeth, digestive tract, or genito-urinary tract; general anæmia and malnutrition; neurotic tendency; migraine.

The first class is most often due to absorption of toxins from the alimentary tract from constipation, overingestion or deficient action of the emunctories, or the headache may be an indication of serious renal disease. Systemic poisoning may be due to impure air, tea, coffee, or lead from pigments, confectionery, and other sources; also from the toxines of infections diseases. Children of rheumatic or gouty heritage are especially subject to toxamic headaches.

The headaches of the anæmic and poorly nourished are known to disappear with improvement in nutrition. In underfed and overworked children who are ambitious in school, or in precocious children with capricious appetities, headaches are common and yield only to the evident requirements of better hygiene.

The tonic daily sponge-bath followed by brisk friction, good ventilation in sleeping apartments, more hours given to sleep, more exercise in the open air, four meals a day of increased supply of animal food and diminution in purely saccharine and farinaceous articles are indicated. A diet of eggs, milk, meat, soups and broths, with cocoa in place of tea and coffee, and limited application to lessons, music, art, or school curriculum, are recommended. Many cases need the judicious administration of iron and arsenic.

Neurotic children with a tendency to neurasthenia, hysteria, chorea, or epilepsy, are frequent sufferers from headaches from any of the foregoing exciting causes. In these children general indisposition may frequently assume the form of headache from imitation, especially if the mother or older members of the family are subject to this malady. Too much sympathy should not be expressed for this class of patients, and unobtrusive mental and moral hygiene is the best line of treatment, with but little obvious medication, as the habits of invalidism and drug-taking are easily established.

Quite a number of children are sufferers from migraine, attacks of which may be precipitated by any or all of the known causes of headache. In some eases the premonitory ocular symptoms, as fanciful and often colored geometrical figures, floating balls or muscæ volitantes, are suggestive of the aura of epilepsy. Yawning, pallor, nausea, or vomiting, 
hemicrania followed by a profound sleep, with relief of headache in twenty-four hours, is characteristic of migraine in a child. So, also, is periodicity of attacks after intervals of two or more weeks in children of otherwise good health. Preceding the attack the urine may be climinished in quantity and show high specific gravity with excess of solids. Juring and immediately following the attack large quantities of pale urine of low specific gravity are passed. A distinct heredity is traceable in nearly all cases of migraine, and the confirmed victims of this malady may show remarkable exemption from other disorders. Occasionally, however, attacks of migraine are replaced by those of epilepsy. In later life it is known to give way to chronic rheumatic and gouty manifestations.

In the treatment of migraine a careful examination of the eyes should always be made, as refractive and other ocular defects are very frequently associated with this class of headaches. Undoubtedly the number of the attacks may be lessened and their severity mitigated by correction of conditions known to favor headache. Correct habits of living, avoidance of fatigue or excitement, care of the diet, attention to the bowels, with the exhibition of saline aperients, may often anticipate and prevent an attack.

The list of anodynes for the relief of the hemicrania is a long one, prima facie evidence of their curative inefficiency. The wrecks of humanity everywhere in evidence as a result of drug habits for the relief of migraine are a standing admonition against the employment of purely analgesic medication for a recurrent, self-limited malady which never endangers life nor threatens the integrity of organic function. The coaltar products may not be administered to all children with impunity, and should never be used except to relieve severe suffering. Upon the appearance of symptoms of migraine the probability of undigested food in the stomach would suggest prompt emesis, secured by copious draughts of tepid water, salt solution, or ipecac and soda bicarbonate, to be followed by evacuation of the bowels with magnesium citrate or any promptly acting saline laxative. The child should be put to bed in a well-ventilated, darkened room. Dry heat to the feet to improve the circulation may be necessary. Food should not be urged. If called for, a little warm gruel or thin broth with a eracker may be given. Hot or cold applications, according to the sensation of the patient, may be made to the head. If the case be uncomplicated, the paroxysm will subside in twenty-four hours, usually after a night's rest.

\section{MENINGITIS.}

Varieties.-Cerebral meningitis; spinal meningitis; cerebrospinal meningitis; pachymeningitis of the dura; leptomeningitis of the pia; meningitis of the convexity as distinguished from basilar meningitis.

From our present knowledge of inflammation and infection it is difficult to conceive of a meningeal inflammation not due to some specific agent,-i.e., secondary to some infection. 
Metastatic inflammations of the brain (meningitides) have long been clinically associated with most of the acute febrile disorders, the exanthemata and visceral inflammations, so that cerebral symptoms and brain complications have from time immemorial clouded the prognosis in most of the acute and many of the chronic constitutional disorders.

Year by year as various pathogenic microbes are isolated in causative relationship to meningeal inflammation, the cases of so-called idiopathic meningitis are narrowed down until the term has come to express merely an absence of a determinate cause.

Inflammation of the meninges may be due to the diplococcus intracellularis of Weichselbaum, the tubercle bacillus, the pneumococeus, the streptococeus pyogenes, the typhoid bacillus, the bacillus coli communis, the bacillus pyocyaneus, and undoubtedly a number of other bacteria. Meningitis is known to follow or complicate measles, scarlet fever, pertussis, influenza, mumps, erysipelas, otitis media, arthritic and endocardial inflammations, catarrhal lesions of the nasal, pharyngeal, or faucial mucosa, also lesions and inflammations of the lower digestive tract as well as septicæmia, pyæmia, and necrotic or suppurative lesions in near or remote parts of the body. To these may be added trauma, insolation, shock, and mental excitement. Meningitis is the commonest of the grave affections of childhood, and although met with at all ages it may be considered peculiar to ehildhood and infancy. The first decade of life shows about seventy-five per cent., the first lustrum sixty per cent., and the first three years about fifty per cent. of all cases. A few cases are reported in the first weeks.

A number of reasons are apparent for this early prevalence of meningitis. The susceptibility of infants to meningeal inflammations is not surprising when we consider their peculiarities; the extensive mucous tract in the relatively large tympanum and mastoid antrum, affording cultural facilities for various pathogenic bacteria; the easy access to the meninges from these eavities through their thin walls, through the unclosed squamopetrosal suture, as well as along the sheaths of nerves and vessels through their several foramina; the proximity of the large venous sinuses to suppurating foci and bony necrosis, with resulting thrombosis; the freer anastomosis between the extra- and intracranial vessels; the relatively rich supply and great activity of the lymphaties; the vascularity of the meninges and adjacent structures; the lower resistance of only partially developed tissue; the activity of the cerebral circulation, with the enormous metabolism for both function and growth; the frequent occurrence, from trifling causes, of extreme cerebral congestion owing to the undeveloped vasomotor apparatus at this period; the effect upon the limited lung capacity of pulmonary lesions, in causing blood stasis in the cerebral veins and sinuses favoring thrombosis, transudations, and infection; the greater tendency to eatarrhal inflammations and adenoid conditions of the upper respiratory mucosa affording cultural beds in close proximity to the Eustachian tubes and the cribriform foramina; the prevalence in childhood of the many in- 
fectious diseases commonly associated with meningeal involvement, and the proverbial frequency of shight traumatisms from falls and jars due to the helplessness of infancy.

Symptoms.-The symptoms of acute meningitis are those of a general intoxication, to which are added indications of increased intracranial pressure. Several varieties, dependent upon the nature of the infection, the extent and location of the meningeal lesion, are recognized. The symptoms are sufficiently conmon to render unnecessary a separate description of each variety.

In the acute forms the onset is more or less abrupt, with headache, fever $\left(101^{\circ}-104^{\circ} \mathrm{F}\right.$., $38.5^{\circ}-40^{\circ} \mathrm{C}$.), prostration from anorexia, restlessness or even delirium, frequent vomiting (projectile type), photophobia and contracted pupils, or there may alternate dilatation and contractions (hippus). Rarely the paradoxical pupillary reaction is observed (dilating in the light and contracting in the shadow). There may be slight strabismus, more frequently upward, and lateral conjugate deviation, or nystagmus may be present. Twitching of the facial muscles are sometimes premonitory of a general convulsion. The conjunctivæ are congested and lids are swollen. There is general hyperæsthesia with local tenderness and pain, especially over the cervical and upper dorsal spine. The pulse may be at first accelerated, but later is slow and irregular. The bowels are usually constipated, and though constipation may persist the abdomen is retracted, showing the familiar "boat-shape" or "bread-tray" belly. The " tache cérébrale" may be elicited by stroking the skin lightly with the finger. The tongue may be furred, although more often its surface is clean. Rigidity of the neck, with head retraction, is common. More or less spasticity of the limbs is observed, with increased reflex excitability and occasional paralysis. If the sole be irritated by drawing a sharp object, as a pencil, along its surface, the great toe may show extreme dorsiflexion, while the remaining four are plantar-flexed (Babinski's phenomenon). This reflex has no significance in early infancy before medullation of the pyramidal tracts. Initial convulsions are not infrequent and terminal convulsions are common. The decubitus of the child is significant. To avoid the pain of the flexion of the rigid neck the patient lies upon his side with head retracted and thighs and legs flexed upon the body (gun-hammer position) (Fig. 152).

In young infants bulging fontanelles give evidence of increased intracranial pressure. The distention of the lateral ventricles with fluid gives rise to a tympanitic note on percussion over the frontal or parietal bones (Macewen's sign). The closed eyelids, corrugated brows, dread of light, and sharp cephalic cry, are all indicative of cerebral pain.

The stage of excitement or delirium is succeeded by apathy, stupor, or even coma. The pupils may show inequality or tardy reaction to light. Ophthalmoscopic examination of the fundus reveals tortuosity of the retinal vessels. There may be partial or total blindness, the hearing is usually affected, and complete deafness may follow. As the 
pressure increases, the pulse becomes slow and irregular, while pupillary and tactile reflexes are abolished. The eyes may be wide open and staring (Fig. 153), and show rheumy films on the sclerotic and cornea. The slow and irregular respiration assumes the Cheyne-Stokes type. The temperature shows no characteristic are and may be only slightly above normal. Urine and frees are passed involuntarily. Extreme opisthotonos may develop. Kernig's sign is present in fully eighty per cent. of the cases. This phenomenon is best obtained by placing the thigh at a right angle with the body, whereupon efforts to extend the leg will be met by resistance and tremors if forced beyond an angle of ninety degrees. Before pupillary paralysis occurs, Squire's sign may be elicited in the following manner: The child lying on his back, the head is grasped firmly by the physician and rotated slowly backward to extreme extension. During this act the pupils will be seen to dilate, reaching their maximum in extreme extension. If now the head be brought for-

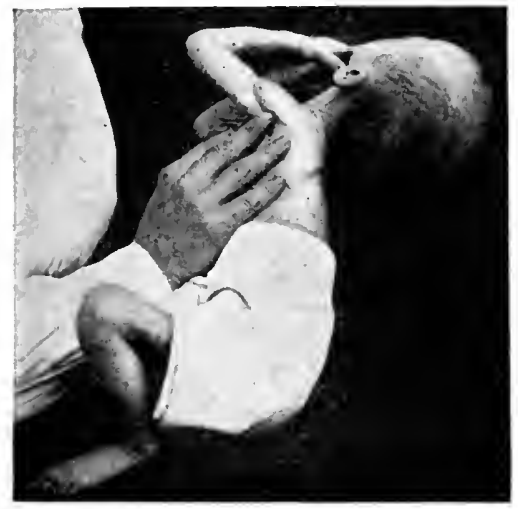

FIG. 152.-Meningitis. Gun-hammer position.

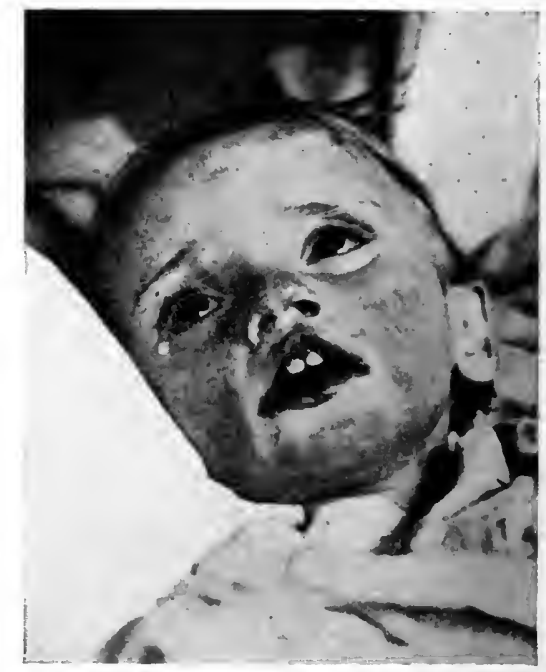

FIG. 153.-Meningitis, semicoma, s1x nours belore death.

ward, the pupils will contract, the extreme point being reached when the chin is pressed against the sternum. Some force may be necessary, and the procedure is painful.

The coma may continue from three to fifteen days, during which time there is increasing difficulty of deglutition, shallow respiration, weak, rapid pulse, and general failure of all the vital processes, with one or more convulsions, followed by death. Sometimes amelioration of all the symptoms and partial return to consciousness precedes by a day or two the fatal termination, thus engendering an elusive hope, against which the physician must be always on his guard.

Simple acute or leptomeningitis is an inflammation of the pia mater: which, as a rule, also involves the dura and the gray matter. Pus is rarely found, the inflammation being essentially serous, with accumu- 
lation of fluid in the ventricles and subarachnoid space. The brain substance may become distinctly cdematous. The meninges of the convexity are involved, those of the base usually eseaping. Occasionally post-mortem reveals no macroseopic changes whatever. The microseope shows engorgement of the blood-vessels and extravasation of leucocrtes in their vicinity. The pia may be agghutinated to the subjacent gray matter or fused in places with the dura. In the more chronic cases, besides leucocytes, the extravasation may contain fibrin, pus, and ser'um in varying quantities, which go to form a plastic exudate filling the interstices of the convexity or base. This results in the formation of semi-organized tissue with adhesions and sclerosis of adjacent meninges and brain substance.

The duration varies greatly with the nature of the infection and the form of the disease. A fulminating type of the epidemic variety may complete its course with fatal termination in from twelve to forty-eight hours, whereas the tubereulous meningitis, equally as fatal, may cover a period of from two to twelve weeks, showing remissions and ameliorations. A meningitis of unknown etiology may run an average fatal course in ten or twelve days.

Recoveries are preceded by a gradual return of intelligence, deepened respiration, subsidence of the fontanelles in infants, improved deglutition and a general amelioration of all the symptoms. Convalescence may be protracted over a period of weeks or months. Irritability and easily-induced headaches are not uncommon for a long time following recovery. Vision improves, though strabismus may persist. Deafness is not infrequent, resulting in the earlier years in mutism. Occasionally spastic paralysis of one limb, more often an upper, is permanent. Mental impairment of varying degree is not an uncommon legacy of cerebral meningitis.

Although meningitis may be caused by a number of micro-organisms, it is customary to consider the disease as belonging to one of three varieties,-namely, tuberculous, due to the development of tubercles of the pia mater at the base, hence called basilar meningitis; second, the epidemic form, due to the diplococeus intracellularis of Weichselbaum, which frequently involves the upper portion of the spinal as well as the cerebral pial membrane, hence the term cerebrospinal meningitis ; third, the so-called simple variety, sometimes miscalled idiopathic because of its unknown etiology. It is in reality secondary to any of the many before-mentioned infections, the tuberculous and epidemic varieties excepted.

Tuberculous meningitis is characterized by its insidious onset and longer duration. The child may suffer for days and even weeks from general malaise and recurrent headaches. Frequently the earliest indication of meningeal involvement may be night attacks, resembling paror, accompanied by a shrill scream. The mild prodromata may have attracted but little attention in the busy household and are only recalled upon the development of acute symptoms. Diagnosis may have been 
made of worms, gastro-intestinal indigestion, malarial fever from the recurrent pyrexia, or more often typhoid fever, which it simulates in the temperature, headache, and malaise.

The symptoms, beginning with temperature, headache, sopor, or coma are common to all forms of meningitis and do not require a separate enumeration. As might be expected in the tuberculous form, with its primary basic lesions, the symptoms show more extensive and persistent involvement of the cranial nerves, with the consequent ocular, facial, and auditory disturbances. The ophthalmoscope shows in a few cases (fifteen per cent.) the presence of tubercles in the chorioid. Since the inflammation in the pia and subjacent structures induced by the growth of tubercles is serous, rather than purulent, the transudation of fluid is sometimes enormous, filling the lateral ventricles and the entire subarachnoid space throughout the brain and spinal column. This accumulation may produce distention of the fontanelle and separation of the cranial bones in early infancy, so that the term acute hydrocephalus is frequently applied.

Cerebrospinal Form.-The meningitis due to the organism of Weichselbaum occurs in epidemics, though sporadic cases are not rare. The symptoms and intensity vary considerably, as in other infectious diseases, with different epidemics.

The onset is usually abrupt. Abortive and fulminating types are also recognized. In the former the symptoms suddenly subside on the third or fourth day of the attack and speedy recovery follows. In the latter, high temperature, convulsions, delirium, coma, and death, some or all, follow in quick succession, within a period of a day or two. During these epidemies, as well as in sporadic cases, the pneumococcus is often found as the apparent etiologic organism, and the frequent occurrence of meningitis as a fatal complication of pneumonia is a noteworthy fact of increasing interest. The simultaneous prevalence of the two diseases in epidemic form is suggestive of some closer relationship than is now known.

The name "spotted fever" was formerly applied to the epidemic cerebrospinal meningitis because of the frequent appearance of purpuric areas on the ear, tongue, palate, neck, and trunk, varying in size from a split pea to a half dollar (Fig. 154). These spots are preceded by a petechial or urticarial eruption appearing in the first or second day of the attack. This rash may be finely discrete or grossly confluent, resembling measles, for which the disease has been mistaken. Herpes labialis also is usually seen in an early stage.

The neck rigidity common to all types is extended to general opisthotonotic spasm in the cerebrospinal form, while spastic rigidities and paralyses are more extensive. Pain and hyperæsthesia, especially over the spine, are more pronounced. The characteristic lesions are those of a purulent meningitis which may involve the convexity, base, and spinal cord. Septic endocarditis and joint affections are frequent complications. 
While not considered strietly eontagious, instances are eited in which different members of a family developed the disease successively. During the prevalence of epidemies the disease occurs in distriets remote and unassociated, showing a preference, however, for those where evidences of squalor and malhygiene abound.

Diagnosis.-In differentiation, tubereulons meningitis shows a slow onset, is frequently accompanied by tubereulous history or lesions in other parts of the body. There is a preponderance of eerebral-nerve symptoms and absence of epidemic, traumatism, sunstroke, or conditions known to faror metastatic meningitis. 'The most valuable method of differential diagnosis, not only between the various forms of meningitis but from other diseases, is found by examination of the

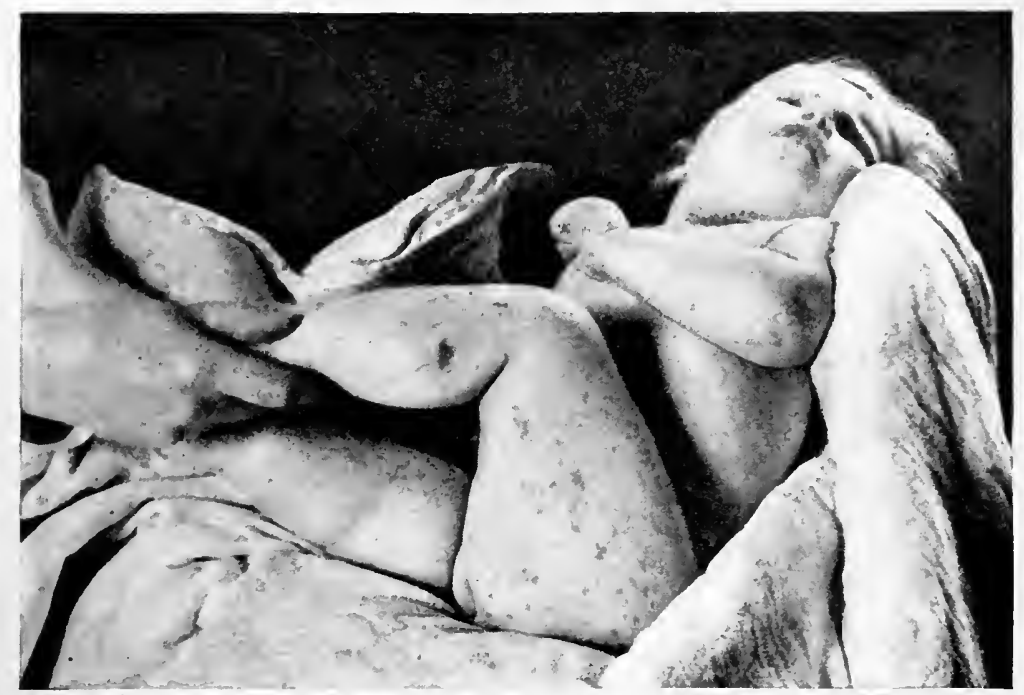

Fig. 154.-General purpuric eruption. Death on the twelfth day of continuous convulsions. (Dr. J. C. Cook.)

spinal fluid obtained by lumbar puneture. Increased pressure gives evidence of meningeal inflammation. A clear fluid during the first week excludes the suppurative or epidemic form. Injeetion of the fluid into the peritoneal cavity of the guinea-pig may corroborate the diagnosis by the development of tuberculosis in the animal. A quicker method of cultivation is obtained by injecting the suspeeted fluid into the mammary gland of the guinea-pig during the early period of lactation. Cultures of the tubercle baeillus, when present, may be obtained within a few days from the milk. The fluid of tubereulous meningitis shows less extensive leucocytosis than is seen in the purulent form, though lymphocytes are usually more numerous. The mononuclear cells predominate in tuberculous meningitis. The polymorphonuclear neutrophiles of the purulent form may largely disappear in a later stage. The different stages of the various forms and the findings in chronic disorders of the 
nervous system serve to render cytodiagnosis uncertain unless due regard be paid to all the attending conditions. It is claimed that more reliable information is obtained from macroscopic examination of the clot. In tuberculous meningitis the clot is of firmer consistency and of lighter color, while that of the purulent type is yellow, less firm, and smears more readily.

The sediment in centrifuged fluid may show, under the microscope, pus cells enclosing the organism of Weichselbaum, or the diplococcus pneumonia may appear as an extra-cellular form. The presence of the tubercle bacillus may be occasionally demonstrated, and when found is conclusive.

The tendency in infancy and childhood to so-called cerebral symptoms, not only at the onset of acute disorders but also during the progress of wasting diseases, not infrequently leads to a diagnosis of meningitis when no infiammation exists. It is extremely difficult and at times impossible to make the diagnosis from the symptoms present at one examination. The sequence of symptoms with the preceding history, and the exclusion of all disorders that might possibly give rise to the phenomena, will be oftentimes necessary for a diagnosis. Here lumbar puncture will be of value. It should be borne in mind, however, that absence of inflammatory products in the spinal fluid does not disprove the existence of cerebral meningitis. Neither does the want of pressure in the spinal canal, since its communication with the ventricles of the brain may be cut off by occlusion of the Sylvian aqueduct. Sopor, coma, cephalic cry, hyperæsthesia, spinal algesia, retracted abdomen, constipation, irregular or irresponsive pupils, photophobia, strabismus, neuroretinitis, deafness and dysphagia, retarded pulse, projectile vomiting. slow irregular respiration in the presence of elevated temperature, convulsions, exaggerated reflexes, or spasticity, cervical or spinal opisthotonos with Kernig's, Babinski's, and Squire's signs, are conclusive evidences of meningitis.

Pneumonia should show increased respiration with rapid sthenic pulse and the physical chest signs. From typhoid fever, with its cerebral symptoms and acute onset, sometimes seen in childhood, the diagnosis may be very difficult. The absence of opisthotonos, head retraction, leucocytosis, herpes, cerebral cry, projectile vomiting, and the rarity of spasticity with the presence of the usually distended abdomen, the initial epistaxis, the dorsal decubitus, the temperature curve, and the Widal reaction, will positively declare the typhoid character,

Scarlet fever shows the initial erythematous rash and accompanying angina, also pulse and respiration in keeping with the high temperature, and frequently there are other cases occurring in the same family or house.

The diagmosis from influenza is, at times, impossible. The prevalence of an epidemic must be taken into consideration, although this may be misleading, as meningitis may be caused by the Pfeiffer bacillus. In the absence of actual meningeal inflammation, the cerebral symp- 
toms of la grippe soon ameliorate, at a time when the symptoms of true meningitis are intensifying.

In uræmic convulsions or coma, the history of an antecedent exanthem, the presence of odema, the absence of high temperature and spasticity, with suppression of urine or the presence of abnormal constituents, as albumin and easts, should exelude meningitis.

The student should be notified and the older physician reminded of the clinical fact which is frequently responsible for mistaken interpretation of the cerebral symptoms in children,-viz., that changes in bloodpressure alone may produce temporarily nearly all of the symptoms of meningitis. Thus the stasis due to active congestion which ushers in many acute disorders of childhood, and on the other hand the cerebral ischæmia which accompanies an exhausting disease, such as cholera infantum, may induce a "cerebroid" condition or "meningism." The post-mortems of these cases show no evidence of true inflammation.

It is doubtful if full recovery ever follows tubereulous meningitis. Cerebrospinal meningitis shows a mortality varying with different epidemies of from forty to eighty per cent. In children under three years of age recoveries are extremely rare. Acute meningitis from other causes, as traumatism, insolation, and infections of unknown etiology, show a more hopeful prognosis as to life. The sequelæ of meningitis of all forms, as spasticity, plegias with contractures, hydrocephalus, ocular and visual defects, deafness, mutism, and various grades of mental impairment, attest the ravages of this most grave disease of early life.

Treatment.-A suspected meningitis calls for absolute rest in bed in a cool and darkened room,- the noiseless slippers, the quiet nurse, the ice-cap or Leiter's coil, ice-bag to spine if opisthotonos be severe, free purgation with ealomel and salines, sedatives, as warm baths, bromides, ergot, chloral, codeine or opium if necessary, and persistent attention to nutrition.

Pressure symptoms may be relieved by escape of cerebrospinal fluid through lumbar puncture. This may be repeated as frequently as the urgency of the symptoms requires. Whatever curative value may be claimed for this procedure, its immediate benefits are frequently obvious in the diminished severity of the symptoms.

Iodide of potassium or sodium as a sorbefacient should be given. Indications of heart failure should be met with alcohol, camphor, or digitalis. Strychnia should rarely be used in this disease.

In difficult deglutition, gavage may be employed. The maintenance of gastric digestion is so important that, if threatened, other routes must be employed for medication, as the hypodermic and rectal.

To the shaved head inunctions of unguentum iodoformi (ten per cent. in lanolin), unguentum hydrargyri, or unguentum Credé, applied daily, have enthusiastic supporters. The same is true of the applica-tions of belladonna ointment, tincture of iodine, vesicants and actual cautery along the spine and over the mastoid. It is doubtful if any 
procedure which increases the discomfort or interferes with the rest of the patient is of practical value.

Recent experimenters report favorably upon intraspinal injections of lysol and other antiseptic solutions after the reduction of pressure by lumbar puncture. Further observations are necessary to confirm the value of this procedure.

As the convalescence is tardy and the susceptibility to cerebral irritation marked in infants and children who survive acute meningitis, the management of these cases is of the greatest importance. To secure absolute freedom from exeitement and annoyances, an entire change of environment may be necessary. A purely vegetative condition in the open air is the ideal life.

For the residual paralyses and contractures daily gentle massage with oleaginous inunctions, passive movements, and later the application of electricity, may do much for the affected muscles.

The prophylaxis of meningitis, by careful attention to eatarrhal conditions of the entire upper respiratory tract, is of paramount importance, since it is well known that the route of infection frequently lies along the mucosa of the middle ear, nose, and accessory sinuses. The habitual use of cleansing, antiseptic and oil atomization, early attention to adenoid conditions, and prompt and thorough treatment of middleear inflammations, will undoubtedly lessen the frequency of meningitis.

SIMPLE BASIC MENINGITIS-INFANTILE BASILAR MENINGITIS OF NON-TUBERCULOUS ORIGIN; POSTERIOR BASIC MENINGITIS.

Accumulated reports have revived interest in a form of meningitis most frequently observed in infancy. Like the meningitis due to the tubercle bacillus, it attacks the posterior portion of the basal pia mater.

It was formerly described as cervical opisthotonos of infancy, for which a variable etiology was claimed. The preponderance of evidence points to the opinion that some of the cases reported under the above titles were sporadic cases of cerebrospinal meningitis. Other cases were undoubtedly of syphilitic origin and were cured by antisyphilitic treatment. Suppurative otitis media is frequently held responsible for simple basic meningitis and the opisthotonos and other symptoms have been known to subside upon thorough treatment of the middle ear disorder.

Symptoms.-The leading symptom, to which it owed its former name, is extreme retraction of the head with rigidity of the cervical and dorsal spine. All the ocular symptoms of meningitis, including blindness, may occur, excepting optic neuritis, which is rarely observed in these cases. Bulging of the fontanelles is a pronounced feature indicative of the hydrocephalus, which is a usual accompaniment. Vomiting, also, is common and persistent, while diarrhœa may replace the usual constipation of meningitis. The initial temperature is high. Muscular wasting is rapid and extreme. With the extreme opisthotonos there is general persistent rigidity with tonic spasm of the upper extremities. Paralysis is uncommon, while the pulse and respiration are not typical of meningitis. 
After the initial fever the temperature may remain normal throughout, with terminal hyperpyrexia in fatal cases. Irritability followed by hebetude is the rule, although coma is unusual.

The peculiar pathology is basic exudation with agglutination of the structures at the base of the skull, as pons, medulla, and cerebellum. Occlusion of the ventricular foramina and canal oceurs, giving rise to a mild degree of internal hydrocephalus.

In the following points it differs from tuberculous meningitis: The temperature, after the onset, is rarely febrile; the extreme and persistent cervical opisthotonos is the most prominent symptom; the eres are staring, the lids retracted, and photophobia is not a feature. Optic neuritis is absent. Constipation is rarely present and the pulse and respiration are usually not typical of meningitis. There are no evidences of infection by the tubercle bacillus in the spinal fiuid or at post-mortem examination. Recovery is possible.

The prognosis of non-tuberculous infantile basilar meningitis is more hopeful than in that of any other form at this age. As before stated, tuberculous meningitis is nearly always fatal. In epidemic cerebrospinal meningitis recoveries under three years are extremely rare; whereas the infantile basilar form, with its longer average duration, according to some observers, shows not over fifty per cent. mortality, although many recorded recoveries have chronic hydrocephalus and permanent mental impairment as sequelæ.

Lumbar puncture in these eases may aid the diagnosis, but its therapeutic value is limited to the relief of pressure in the spinal canal alone, since the communication through the ventricular foramina is almost always cut off by exudate.

The possibility of syphilis as a cause makes the free use of iodides and mercurials advisable in this class of cases. Furthermore, the undisputed sorbefacient action of these drugs would suggest their use on account of the characteristic exudate.

Early examination of the ears in infants with head retraction, and prompt puncture of the membrane, with thorough treatment of tympanic suppuration, may in some instances abort this form of meningeal attack.

\section{ENCEPHALITIS-CEREBRITIS.}

Acute non-suppurative encephalitis probably occurs in children both with and without meningitis. It may follow any of the acute infectious diseases, but most frequently that of the Pfeiffer bacillus. Occasionally at post-mortem there are found scattered throughout the brain small areas of inflammation which appear as softened, bright red spots. There is general hyperæmia, but the vessels in the area of inflammation are enormously distended, and punctate hemorrhages are seen in close proximity to their walls. Cell proliferation is in evidence, not only in the vessel walls but in the neuroglia of the nerve-tissue. Other reports show, instead of diffuse distribution, a large or small circumscribed area in one lobe, or a group of inflammatory foci confined to a single region of the 
brain. These two forms of non-suppurative lesions represent two types of inflammatory processes,-viz., hemorrhagic and non-hemorrhagic encephalitis. The length of the intervening time, however, between the development or occurrence of the lesion and the opportunity for postmortem examination, will ever prove an obstacle to a satisfactory demonstration of the precise pathology in the initial stage. Secondary lesions, however, such as porencephaly and sclerosis, especially where the areas involved correspond with the history of early focal symptoms, confirm the probability of a non-suppurative, non-hemorrhagic, cortical primary encephalitis.

The symptoms, as might be expected, correspond to the form and location of the inflammatory lesion,--focal symptoms indicating its circumscribed character. In the main, the symptoms of diffuse encephalitis, when not masked by those of the primary disease, resemble those of an acute non-tuberculous meningitis. From this it is, in some instances, indistinguishable. As a rule, however, the onset is less abrupt, beginning with headache, vertigo, and vomiting, with sopor but rarely coma, and occasionally convulsions, general or local. The pulse and respiration are not characteristic as in meningitis. Paralysis is of more frequent occurrence and may be transient.

Whether a primary cortical encephalitis, in which the lesions are analogous to the process in the gray matter of the anterior cornu in infantile spinal paralysis, may occur (in other words, the possibility of an acute polioencephalitis), is still a mooted question. However, acute idiopathic or primary polioencephalitis, superior and inferior, are recognized lesions, the areas involved being the anterior part of the floor of the fourth ventricle and the medulla respectively. The former presents ophthalmic symptoms, the latter labioglossopharyngeal symptoms. Although rarely found in children, it is mentioned because the general symptoms frequently resemble those seen in the encephalitis of influenza. The frequency of infantile cerebral palsy and idiocy after traumatisms and infections is explained by the peculiar susceptibility due to the state of immaturity, lack of eranial support, and great vascularity of the fetal and infant brain.

The treatment of encephalitis in general is the same as that of meningitis.

INSOLATION-SUNSTROKE; HEAT PROSTRATION; THERMIC FEVER.

Hyperpyrexia from prolonged exposure to heat is common in early life, although the proportion of children in the recorded cases of insolation for all ages is insignificant. Premature or even vigorous infants may show a temperature of $105^{\circ}$ to $107^{\circ} \mathrm{F}$. $\left(40.5^{\circ}-42^{\circ} \mathrm{C}\right.$.) from prolonged proximity to a hot stove or hot-water bottles. Undoubtedly heatstroke is frequently overlooked in infancy and young children, the prostration being attributed to intoxication from some slight disorder, such as summer complaint, etc. It is not possible, nor indeed necessary, at all times to exclude pre-existing disorders before making a diagnosis of heat- 
stroke. A sudden development of hyperexia, temperature $105^{\circ}$ to $108^{\circ}$ F. $\left(40.5^{\circ}-42.2^{\circ}\right.$ C. $)$, with history of exposure to high temperature and humidity, followed by great prostration, with coma or convulsions, is always suggestive of insolation, although it may prove to be an initial stage of almost any of the infectious diseases of childhood. The definite etiology of sunstroke is unknown, although a debilitated condition from any cause is recognized as predisposing. Prolonged intense heat is always the dominating factor in the exciting cause.

In heatstroke there is meningeal congestion with varying degree of general venous engorgement and superficial capillary stasis. At first the child may show a rapid sthenic pulse, hot and dry skin, flushed face, and contracted pupils, accompanied by headache and perhaps romiting, with or without diarrhoea. The temperature is high, $103^{\circ}$ to $107^{\circ} \mathrm{F}$. $\left(39.5^{\circ}-42^{\circ}\right.$ C.), with malaise, delirium, or prostration. Somnolence, coma, or convulsions may ensue, with dilated pupils, strabismus, rapid thready pulse, dyspnœa, and eyanosis, with increasing hyperpyrexia, followed by death in less than twenty-four hours.

Early energetic treatment may reduce the temperature, restore consciousness, and lead to convalescence in two or three days. A moderate degree of pyrexia may continue for several days-a form known as thermic fever-and the child may finally succumb to general intoxication or to failure of heart or respiration.

The blood at first shows high hæmoglobin (125 per cent.), and an increased number of erythrocytes $(5,300,000)$. This concentration of the blood has been attributed to excessive perspiration. Later the evidences of hæmolysis are unmistakable. Petechiæ frequently appear on the limbs and trunk and hemorrhages may occur. As erythrocytes are not decomposed by the degree of heat observed in these cases, the hæmolysis must be due to some toxin produced in the changed metabolism under the influence of extreme heat.

The post-mortem shows venous engorgement, with dark, subalkaline blood, subpial œdema, and increase of fluid in the ventricles.

A microbic hypothesis has been advanced from cellular changes similar to those of known bacterial origin. Other resemblances to microbic disease are cited, such as its geographic distribution, its occurrence in epidemic form, its appearance under certain thermic and atmospheric conditions, with tendency to relapse. However, the one condition essential for its occurrence is unusually extreme heat.

Among the sequelæ are pneumonia, nephritis, recurrent headaches, especially on slight exposure to heat, cerebral hemorrhage, encephalitis, and meningitis. Some of these, particularly the latter, may follow so closely as to raise the question as to their primary or secondary importance.

Diagnosis.-The diagnosis of a sthenic form of sunstroke from a fulminating meningitis may be very difficult. The history of exposure to heat, followed by hyperpyrexia and cerebral symptoms without paralysis, points to heatstroke. It is not improbable that extreme thermic con- 
ditions may modify the onset of any disorder of infancy so as to present symptoms of insolation.

Prognosis.-Mild cases recover with but little treatment save rest and cold applications to the head, although the tendency to headaches from subsequent exposure to heat or the sun's rays is peculiar to all forms. It is difficult to estimate the mortality in infancy and childhood, for the reason that probably many cases are not recognized. Reports of severe uncomplicated sunstroke show about fifty per cent. of fatalities.

Treatment.-The efficiency of the treatment depends largely upon its early initiation. It is one of the few disorders in which reduction of the hyperpyrexia is the prime object. The condition presented is that of excessive heat production from unusual chemical changes, with retarded radiation from capillary stasis and atmospheric conditions. Prompt reduction by cold applications is indicated. At the same time the circulation, especially where there is a tendency to collapse, must be maintained by appropriate stimulation. An ice-cap should be applied to the head, the child should be stripped, wrapped in a blanket, and placed in a bath of $60^{\circ} \mathrm{F}$. $\left(15.5^{\circ}\right.$ C.) to which cracked ice is rapidly added. Constant friction should be applied to the trunk and extremities. If comatose, cold water may be poured upon the forehead from a height, as the shock aids the friction in promoting cutaneous circulation. Coldness of the extremities calls for applications of heat or mustard poultices to the feet and legs. Aromatic spirits of ammonia should be given, and, in persistent cyanosis, nitroglycerin for the relief of vasomotor spasm. The tubbing and friction with ice should be kept up until the temperature shows signs of subsidence. If this be rapid the child should be removed from the tub before the temperature reaches $100^{\circ} \mathrm{F}$. $\left(38^{\circ}\right.$ C.), as it may become subnormal. Digitalis, by mouth or hypodermically, may be necessary to sustain the heart. Strychnia is contraindicated. Copious enteroclysis with cold, normal salt solution may be employed for heat reduction and to free the bowel from toxic material. Spiritus mindereri, with free administration of water, is useful for its diuretic and diaphoretic effect. Tea or coffee may be necessary, or even alcoholic stimulation. The temperature per rectum must be watched, and any elevation above $102^{\circ} \mathrm{F}$. $\left(39^{\circ}\right.$ C.) should call for a renewal of the hydrotherapy. In less severe cases tepid sponging may be sufficient, always with ice to head, or sprinkling the child, covered by a sheet, from a watering-pot held some distance above the bed. In coma the water may be made to impinge with force against the skin to stimulate the capillaries. The child will require careful watching for several days to guard against rise of temperature, collapse, and pneumonia.

The diet should be restricted to liquids until convalescence is estab. lished.

THROMBOSIS OF THE CRANIAL SINUSES.

Formation of a thrombus, with complete or partial occlusion of the intracranial sinuses, is by no means rare in infancy and childhood. 
The causes of thrombosis have been ascribed to increased density of the blood, as after exhausting diarrhœas; to roughening of the sinus walls; to emboli in the blood stream; to pressure upon the ressels by tumors and exudates, and to any condition which eauses retardation of the blood-current, as in mechanical obstruction from an incompetent heart.

It is evident that in the presence of any or all of the first three mentioned conditions, the occurrence of either of the last two, or purely mechanical conditions, would act as an exciting cause.

Thrombosis may be acute or subacute in its development. If parietal and slow in its formation, the sinus being only partly occluded, the resultant diminution in the blood-current would produce effects gradual in their development, with symptoms difficult of recognition and continuous for an indefinite period. Sudden and complete occlusion of a sinus produces immediate stasis in vessels and areas beyond the obstruction. This results in venous engorgement, œdema, and eapillary hemorrhages.

If infection be a cause or accompaniment of the process, emboli dislodged from the coagulum may be swept to distant parts of the body with resultant abscesses. The lungs from their anatomical neighborhood are especially liable to these metastatic abscesses.

Two general varieties are recognized,-viz., eachectic and infectious, the distinction being based upon their apparent etiology. Cachectic thrombosis most commonly occurs after exhausting disease, as enteritis or typhoid fever. Its most constant location is in the superior longitudinal sinus. The symptoms of occlusion of this vessel appear as venous distention and cedema of the scalp and bulging fontanelle. This is especially significant if, during the course of the primary disease, it has been depressed. Headache, somnolence, coma, and occasionally convulsions and paralysis-in fact, the general symptoms of acute meningitis -may attend the formation.

Septic thrombosis most frequently develops in the lateral or petrosal sinuses or in the tributary veins, the radicles of which drain the capillaries of the mastoid and tympanic circulation. It constitutes a dangerous and not infrequent complication of mastoid and middle-ear disease, and is especially apt to follow caries of the mastoid or petrous bones. Tenderness or œdema behind the ear, retraction of the head and stiffness of the neck, are among the early symptoms of petrosal or sigmoid thrombosis and should be watched for in all tympanic suppurations. In complete occlusion the clot may extend to and fill the internal jugular and be felt as a cord, while the external jugular may be full and tense from the extra work imposed upon it. Thrombosis in the cavernous sinus may be due to infections from the face, nose, or orbit, through the veins whick drain these areas. Stasis in the superficial veins of the face, epistaxis, exophthalmos, external strabismus, ptosis and œedema of the lids, occurring suddenly, are suggestive symptoms of cavernous thrombosis. Optic neuritis is occasionally seen as a later symptom. These symptoms are 
usually unilateral, but both sides may be affected. Occlusion of the straight sinus blocking the veins of Galen results often in hemorrhage into the lateral ventricles. If extensive, this will simulate internal hydrocephalus.

Diagnosis.-The diagnosis from abscess or meningitis is difficult, and the latter may precede or accompany thrombosis. Points in differentiation of the non-septic variety from acnte meningitis are the absence in the former of fever, characteristic slow pulse, irregular respiration, constipation, and retracted abdomen.

Prognosis.-The duration of a slowly developing thrombus is not easily deternined. The prognosis as to duration depends upon the character of the thrombus and its method of development. When due to the altered condition of the blood, it may be the terminal complication of some acute disease and explains many of the later cerebral symptoms frequently attributed to meningitis. Infective thrombosis adds, to the dangers of local congestion and anæmia, sepsis in the tissues of the brain and other organs. Thrombosis, as distinguished from "meningism," so frequent in the later stages of wasting diseases, should be suspected when there is distention of the veins of the face and head, epistaxis, definite paralysis, and, in infants, prominence of a previously depressed fontanelle. Parietal and slowly developing thrombi may persist for months or years before occlusion is followed by fatal termination.

Treatment.-The prognosis, if medical treatment only is relied upon, is fatal. Surgery promises much when the location of the thrombus renders it operable. This is especially true of lateral and petrosal thrombi in connection with mastoid and tympanic disease. In acute or chronic otitis sudden cessation of the discharge, with headache, rigor, coma, or convulsions, warrant immediate operation, not only for the release of mastoid or extradural pus, but as exploratory of the adjacent sinuses. Clots, if present, should be removed. The percentage of recoveries in such operations is steadily increasing.

Prophylactic.-However brilliant the achievement, the physician's duty is but half performed in the diagnosis and location of sinus thrombosis. He should endeavor to prevent the catastrophe in all conditions known to favor its development. In marasmic conditions, support of the heart's action by food and stimulants when nceded, as well as maintenance of the volume of blood by saline solutions injected into colon or under the skin, may prove prophylactic. During infections of the throat and ear especially does the responsibility of warding off this complication rest heavily upon the attending physician.

\section{TUMORS OF THE BRAIN.}

Tumors of the brain are not rare in early life and have been found at birth. Many cases diagnosed as hydrocephalus are undoubtedly due to tumors. So, also, meningitis, tubereulous or otherwise, may be the last expression of cerebral neoplasms.

Aside from tuberculosis and traumatism, the etiology of brain tumor 
is obscure. Syphilis, a frequent cause in adults, rarely shows gummata in infancy and early childhood, and may only be mentioned as a remote possibility. The frequent occurrence of blows on the head and falls in the histories of children with brain tumors is held lightly by some as common to the histories of all children, but must still be regarded as of etiological importance. The relation of the location of the tumor to the site of traumatism is frequently suggestive of at least an exciting causal connection. External neoplasms, as of the scalp, and cranial orifices have been known to cause brain tumors by inward extension of growth. Tuberculosis is probably responsible for more than half the number of intracranial tumors found in young children. The tubereles may develop in a large solitary mass or may appear as multiple lesions, varying in diameter from one to fifty millimetres. The most common sites are the cerebellum and basal meninges. They are always secondary to tuberculous lesions in other parts of the body.

In a diminishing order of frequency, brain tumors have been reported as gliomatous, sarcomatous, eystic, and carcinomatous. Gliomata, unlike tubereulosis and sarcomata, select the white matter, are consequently deep-seated, and rarely involve the meninges. Cysts of parasitic origin are rarely found in this country, although occasionally reported by foreign observers. More rarely the teratomata and mixed forms are found.

Symptoms.-The symptoms are general and local. The general symptoms are entirely independent of the nature of the growth; they are due to intracranial pressure and as such correspond to other cerebral lesions, as meningitis or hydrocephalus. The rate of growth is more important in the production of symptoms than the nature or size; as a small though rapidly developing tumor causes greater disturbance than a much larger neoplasm of slow increase. Cessation of symptoms followed by exacerbation is not uncommon in the history of tumors. These evidently mark alternating periods of growth and quiescence. In fact, a latent tumor, especially if in the centrum ovale, may exist for a long time without symptoms. Post-mortems occasionally reveal the presence of tumors entirely unsuspected during life.

Among the most frequently observed symptoms, in the order of their occurrence, are headache, vertigo, vomiting, optic neuritis, psychic disturbances, or general convulsions. The headache is persistent, usually severe, and may be very intense. It frequently shows a diurnal periodicity, occurring with greatest severity during the night or early morning hours. Closely associated with headache are vertigo and vomiting. The vomiting is of the projectile type and may occur independently of meals. Ordinary "sick headache" from dyspepsia may simulate these phenomena for a day, but subsides quickly and yields to appropriate treatment. The persistence of this group of symptoms is very suggestive of an intracranial growth. Optic neuritis accompanies brain tumor in about eighty per cent. of cases. A review of a large number of reports of choked disks shows ninety per cent. due to brain tumors. 
The most common psychic disturbances are irritability or excitability, moroseness or sonmolency. The latter symptom, if persistent, increasing, and associated with headache and obstinate vomiting, should put the practitioner on his guard.

General convulsions of an epileptic type are observed in at least half the cases, occasionally as precursory of all other evidences of a new growth, although, like the headache and vomiting, they may disappear in the terminal stage when condensation of tissue adjacent to a rapidly developing tumor may have been succeeded by a zone of softening and disintegration. In young infants there may be enlargement and asymmetry of the cranium.

Special or focal symptoms are those mainly due to the destruction or embarrassment of nervous tissue immediately involved in the neoplastic process, to local pressure, or stretching by displacement of nerve roots. Focal symptoms are absent in about one-fourth of the cases.

The bilateral structure of the brain explains the development of unilateral symptoms dependent upon the location of the morbid growth. If this be above the point of decussation, the focal symptoms will be manifested upon the side opposite the lesion. A central location or a degree of enlargement sufficient to involve both sides of the brain would occasion bilateral symptoms, so that the extent and direction of enlargement may be indicated by the successive disturbances of functions. Thus a unilateral disturbance becomes bilateral as the tumor encroaches on the other hemisphere or line of conduction. Since the internal capsule includes all the cortical fibres, both motor and sensory, a moderate-sized tumor in this area (or in the basal ganglia and lateral ventricles on account of their proximity to the internal capsule) necessarily produces extensive and complicated symptoms. If disturbance of sensation accompany motor symptoms, there is involvement of the posterior as well as the middle portion of the internal capsule. A tumor of the pons, where the nerve-fibres are crowded into a limited area, may affect large and varied extents of distribution.

The most easily recognized focal symptoms are disturbances of the motor function which accompany a tumor in the cortex.. Thus a growth in the Rolandic area may cause tremors, Jacksonian epilepsy, or a transitory hemiplegia of the opposite side. If the neoplasm primarily involve the cortex, convulsions appear early in the history. If subcortical within the white tissue, paralysis may develop without convulsions, the occurrence of which at a later period notes the inclusion of the gray matter in the morbid process. The same is true of headaches, which, as a primary symptom, point to early cortical and meningeal involvement. Developing later, they mark the progress of growth towards the periphery. Stretching of the dura mater is considered the most prolific cause of cephalalgia in intracranial affections.

Perversions of function, such as word-blindness and amnesic aphasia, show involvement of the third frontal convolution of the left side in older, right-handed children. This symptom is not found in infants and 
young children before the age of speech or prior to the restriction of speech function to one hemisphere,-i.e., about the eighth year.

Tumors of the crura cerebri may cause eye symptoms, such as disturbance of pupillary reflex, nystagmus, strabismus, also crossed paraly'sis, in which involvement of the third nerve oecurs on the side of the lesion associated with hemiplegia of the opposite side. Crossed paralysis is also caused by tumors of the pons, the eranial nerve disturbance appearing on the side of the lesion; sensory and motor disturbance of the extremities appear on the opposite side. Facial neuralgia, corneal ulceration, external strabismus, pupillary dilatation and ptosis from involvement of the third and fifth nerves, indicate upper pontine lesion. Deafness, facial paralysis, contracted pupils, and internal strabismus show implication of the sixth, seventh, and eighth nerves from tumor of the lower pons.

In all these tumors of the base of the skull, headache, optic neuritis, and vomiting are common, although convulsions are rare.

Labioglossolaryngeal paralysis is always suggestive of a tumor of the medulla and when associated with glycosuria, polyuria, optic neuritis, projectile vomiting, and headache, the diagnosis is confirmed. The last five mentioned symptoms serve to differentiate tumor from degenerative bulbar paralysis.

More than half the intracranial tumors of childhood are cerebellar, of which probably eighty per cent. are tubereulous. As equilibration is one of the principal functions of the lesser brain, so evidences of such disturbances are almost pathognomonic of disease of this organ. This symptom is known as cerebellar ataxia, the result of incoördination confined chiefly to the lower extremities. The patient walks with a staggering gait, likened to that of a drunken man, or is unable to even stand, but shows a tendency to fall forwards or backwards. 'These symptoms usually point to disease of the central lobe. Next in importance to the ataxia are vertigo and headache. The latter is usually oceipital in location, the best illustration of focalized headache in intracranial lesions.

A tumor located in one of the lateral cerebellar lobes will eause the patient to incline or fall towards the affected side when walking. Not infrequently a coarse intention tremor is present in the arm on the same side as the lesion. This symptom is produced by fibres leading from the cerebellum through the red nucleus of the opposite side to the motorcentres of the arm in the cortex of the brain. This irritation produces the tremor of the hand on the opposite side or, in other words, on the side of the lesion. In these cases if the child be instructed to turn the wrists it will be noticed that he cannot rotate the wrist of the affected side as rapidly as the other, and, after rotating the wrists for a few moments, if the patient stretches them above his head, that wrist will involuntarily continue the rotary motion for a short period.

Bound down by the firm, unyielding tentorium above on its dorsal surface, enlargement from tumor growth causes impingement of its ventral surface against the medulla, pons, corpora quadrigemina, and all the cranial nerves; so that, in addition to the ataxia, there may be 
present any of the symptoms of disturbance of these parts, including hemiplegia. This, however, is rare. Advanced cases may show retraction of the head. A peculiar symptom of cerebellar tumor is seen in the so-called forced attitudes, possibly due to pressure on the middle cerebellar peduncles. In this the patient inclines his head or body to one side. Tenderness may be elicited by pressure or percussion of the skull over the seat of growth.

Diagnosis.-The diagnosis of intracranial lesion depends upon the persistence of certain symptoms, mainly those indicative of increased pressure. Since a number of diseases, such as meningitis, hydrocephalus, abscess, and hemorrhage, may cause these symptoms, the differentiation of tumor is often difficult and sometimes impossible. Especially is this true when hemorrhagic meningitis or hydrocephalus occur as complieations of the new growths.

In hemorrhage there is a sudden onset of symptoms, apoplectiform in eharacter, coma, and paralysis. Optic neuritis, vomiting, vertigo, and mental changes are absent. Localized or Jacksonian epilepsy, the presence of choked disk, vertigo, vomiting, and persistent headache, are points upon which to base a diagnosis of tumor. The persistency and increasing severity of the symptoms in tumor are in marked contrast to the improvement from apoplectic seizures.

Slowly developing basilar meningitis may simulate tumor very closely. Large tubercular masses may constitute the new growth. The differentiation between cerebral meningitis and tumor should be made by the absence in the latter of fever, constipation, retracted abdomen, slow, irregular pulse, Cheyne-Stokes respiration, and pupillary changes. Examination of the fundus and cerebrospinal fluid should be made.

As abscess of the brain is always secondary, there may be a history of sepsis, occasionally rigors, pyrexia, leucocytosis, and greater localized tenderness over the scalp. The general symptoms of pressure are less severe because an abscess is a destructive process. The focal symptoms are usually less pronounced, as the parts involved are more often in the latent regions.

Hydrocephalus in early childhood almost invariably presents the characteristic cranial enlargement, changes in the visual axes, and more often apathy without the intense headaches and choked disks.

Prognosis.-The prognosis of cerebral tumor is exceedingly grave, although recoveries are reported in which all the symptoms of tumor were present. There is, however, always the possibility of mistaken diagnosis. Syphilitic gummata, rare in infancy, will yield to proper exhibition of iodides and mercurials. The growth may become quiescent and life may continue with more or less mental impairment, although the tendency of all intracranial neoplasms is towards a fatal termination, nnless within the range of operative relief. The duration from the development of symptoms may vary from ten weeks to ten years. The average from a large number of cases in children is about two years.

Death from general asthenia may oceur suddenly from intracranial 
hemorrhage, respiratory and cardiac paralysis or cardiac syncope; or it may be preceded by prolonged coma.

Treatment.-Medical treatment of cerebral tumor is not at all promising. The routine administration of full doses of the iodides is occasionally followed by a recovery. Palliative treatment is in order, as relief of headaches, nausea, and vomiting, by hypodermic injections of morphine where bromides are unavailing.

Surgery offers the only encouragement, and some prominent surgeons advise operation whenever brain tumor is diagnosed, except in syphilitic processes. The operation is usually performed in two stages. In the first stage, the skull lying over the region of the tumor is removed and antiseptic dressings are applied. After an interval of a week or so the removal of the growth is completed.

Unfortunately, the cerebellum, the most frequent site of tumors in childhood, is far less accessible than the cerebrum.

\section{ABSCESS OF THE BRAIN.}

Abscess of the brain is considered of rare occurrence in infancy, although possibly this rarity would be diminished with increased facilities for diagnosis and post-mortem examinations. They are known to occur in early infancy.

Brain abscesses are probably always secondary, with the exception of those which follow septic perforation of the skull. The recognized causes are middle-ear disease, traumatisms of the head, caries of the cranial bones, and metastasis from suppurative lesions in any part of the body.

Of all the causes, middle-ear disease is the most common. Retention of pus is not necessary for the extension of infection from the tympanum to the brain. Cases are reported of abscess formation after destruction of the tympanic membrane. In fact, the majority of abscesses are reported in connection with suppurative otitis of long standing. Those of the cerebellum most frequently follow mastoid disease, while tympanic suppuration alone leads more directly to cerebral abscess formation.

The white matter of the cerebrum is the favorite seat of abscesses, and they are rarely found in the structures of the base. They may be single or multiple. The single abscesses vary in dimensions from a few millimetres to several centimetres, or they may involve an entire lobe and even an entire hemisphere. The pus may perforate the cortex or break through the lateral ventricles and, destroying the septum lucidum, flood the entire ventricular area. Subdural abscesses may occur primarily or secondarily.

All the common pyogenic organisms have been found in the pus of cerebral abscesses. If of long standing, the purulent collection is frequently found encapsulated by a more or less dense membrane. Occasionally the limiting membrane is absent, the walls of the cavity consisting of irregular masses of disintegrating brain substance. 
An abscess may remain a long time in the white substance of the brain with the production of few or no symptoms.

Naturally the symptoms have much in common with those of brain tumor, although less marked, especially when we consider their greater extent and more rapid growth. This may be explained in part by their location in latent portions of the brain and by the difference in the process of formation, the tumor increasing by displacement and condensation, the abscess by destructive absorption of adjacent brain tissue.

The symptoms, more especially of chronic abscess formation, are usually recognized as initial, latent, and terminal.

The initial symptoms may be masked or confounded with those of the acute disorders to which they are secondary. When recognized, they may appear as chill, pyrexia, headache, vertigo, vomiting, and, possibly, convulsions followed by a transient hemiplegia. These symptoms may continue and the disease may run a more or less acute course resembling sepsis, with lencocytosis, rapid emaciation, and prostration, terminating fatally in ten to fourteen days.

On the other hand, the initial symptoms may subside, the temperature remain normal, and for weeks, occasionally for months or even years, no symptoms appear, with the possible exception of occasional headache, nausea, or vertigo, when, with a sudden onrush, symptoms of an acute meningitis or sudden coma may terminate the history. The post-mortem may reveal rupture of an encysted abscess through the cortex or into the ventricles.

As the structures at the base are rarely the seat of abscess, the symptoms due to involvement of the cranial nerves are not common, although optic neuritis, hemiopia, and facial paralysis are occasionally observed.

Localized headache and local pain or tenderness on percussion may be present when the abscess is near the cortex or extradural. This is especially true when the pus is located in the cerebellum, in which case staggering gait may be added to the general symptoms of pressure.

Diagnosis.-The diagnosis of brain abscess, especially in young children, is extremely difficult and is most frequently made at the autopsy. The frequent accompaniment of meningitis, both initial and terminal, makes differentiation impossible. The early age renders valueless most subjective as well as many objective symptoms, so that motor disturbances are about all the indications of value in diagnosis. The presence of leucocytosis, with the elimination of other causative conditions, may aid in diagnosis, but the well-known frequency of leucocytosis in infancy renders its presence less significant. The persistence or frequent recurrence of headache, vertigo, and vomiting, with possibly seizures of Jacksonian epilepsy and other focal symptoms of cerebral origin, negative findings from spinal puncture, with marked leucocytosis not explained by suppuration elsewhere, may be taken as presumptive evidence of intracranial abscess. In differentiation from brain tumors, their rarity in infancy should be remembered. (For other points see Brain Tumors.)

Treatment.-No medical treatment is of avail in the cure of cerebral 
abscess. Surgery furnishes an inereasing list of suceessful operations for eollections of pus within the eranium. For obvious reasons early operation is important. Reports show more than fifty per cent. of postoperative recoveries.

In the management of ehildren, prophylaxis must continue to be of paramount importanee. The easy access to the brain and its meninges for pyogenic bacteria from the eommon purulent affections of the respiratory and aural traets is diseussed in Chapter I, I'art I, and Chapter XIII, Part II. The value of early attention to these disorder's, as protective from the graver secondary inflammations, cannot be unduly emphasized.

HYDROCEPHALUS-HYDROPS CEREBRI; WATER ON THE BRAIN.

Hydroeephalus is an accumulation of serous fluid in the cranial eavity. If ventricular, it is known as internal hydrocephalus. If confined to the subdural area by the elosure of the foramen of Magendie, it is external hydrocephalus, a rare form. The exeessive aecumulation is usually both internal and external. Hydrocephalus is, strictly

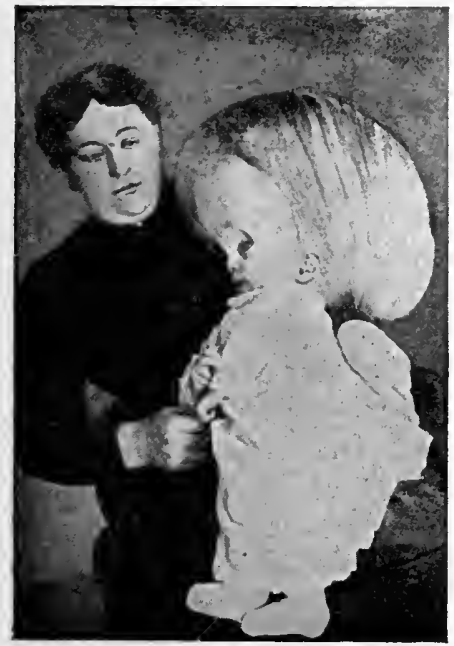

FIG 154.-A remarkable degree of hydrocephalus. (Copyrighted, 1888, by Langhill, Hanover, N. H.)

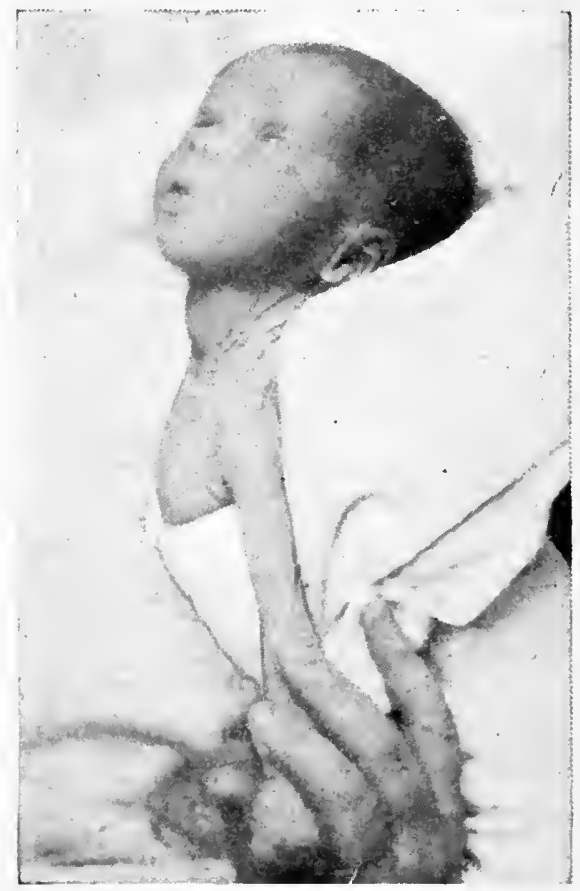

FIG. 155.-Congenital enlargement of thyroid gland.

speaking, a symptom and may only be considered a disease when by excessive pressure it interferes with funetions or causes atrophy of nerve or brain substance. The conditions which may cause hydrocephalus are numerous and varied.

The normal cerebrospinal fluid is the product of the secretion from 
the chorioid plexuses which are most abundant on the endyma of the lateral ventricles. This process is continuous. The fluid disappears normally by absorption through the lymphatic channels which accompany the nerve sheaths in their exit through the pia. In health the balance is thus maintained between secretion and drainage of the cerebrospinal fluid. An excessive accumulation of this fluid may be due to one or the other of three classes of causes or to the three acting simultaneously: first, there may be hypersecretion, as in serous inflammation of the meninges; second, there may be a freshet of blood supply from vasomotor paralysis of the basilar or other large arteries; third, there may be transudation of serum from mechanical stasis due to cardiac incompetency, pressure on venous trunks from neoplasms, hemorrhages or exudates or the occurrence of venous or sinus thrombosis. In all of these, if the cause be transient, the excess of fluid will ultimately be carried off by natural absorption.

It is easy to see how basilar meningitis, perhaps of mild type, may fill both causative rôles by causing excessive serous accumulation or by sealing up the channels of outlet, in which case the result is obviously a dropsy limited only by the resistance of the enveloping structure.

The common classification into external and internal hydrocephalus is of little importance, clinically, except as an explanation of the processes to which they are due. Thus, a mild serous meningitis, in the course of which closure of Magendie's foramen occurs, would shut off the communication of the subdural fluid with the ventricles, the accumulation thereby remaining external. On the other hand, an endymitis, a common accompaniment of meningitis, with occlusion of the foramen of Monroe on one or both sides, or of the Sylvian aqueduct, thus cutting off the excessive ventricular fluid from the fourth ventricle with its facilities for drainage, would result in ventricular or internal hydrops.

It is evident that the most frequent cause of hydrocephalus is meningitis, especially of the basilar form. It may be congenital or acquired. Of a large number of cases developing in the first half year of life, more than ten per cent. showed cranial enlargement at birth. It is more than probable that a majority of the remaining cases were due to causes operating in utero, and not infrequently of syphilitic origin. Infants under two years show the greatest susceptibility, inversely as to age, although acquired hydrocephalus is occasionally seen in older children and even in adults.

The disease is essentially chronic, although acute attacks are not uncommon and as sueh are closely allied to tuberculous meningitis, with which the term is frequently synonymous.

Symptoms. - The symptoms of hydrocephalus are similar to those of meningitis, so far as they relate to pressure as a cause. Usually the first evidence of hydrocephalus is the abnormally large head, which may measure at birth, or a few days after, forty to forty-six centimetres. When the accumulation of fluid occurs before birth, the large head may prove such an obstacle in parturition that destruction of the 
infant is necessary to effect delivery. An infant, apparently normal at birth, may show this enlargement in the early months, with or without precedent convulsions. The fontanelles bulge under the tense, shiny scalp; the sutures may be widely separated; the hair becomes scanty from atrophy of the follicles due to tension of the scalp. The pressure from within eauses congestion of the collateral eirculation, so that the superfieial veins are full and tortuous.

The head may assume a globular form with dome-like vertex, or there may be occipital and frontal bulging. Lateral asvmmetry is common. There is a marked fulness at the root of the nose and the skin of the eyelids is stretehed. The scleroties show above the irides because of the downward inclination of the visual axes from pressure upon the supraorbital plates.

Even in older infants the weak neck fails to sustain the enlarged head, which rolls helplessly from side to side or falls forward against the chest. The entire muscular system is weak and flabby, although oceasionally the infant shows considerable deposit of adipose. Even older children are unable to stand or sit alone because of the muscular atony. Occasionally plegias of -spastic type with subsequent contractures are seen. Appetite and digestion are astonishingly good in the majority of cases. The special senses are rarely affected. Hemiopia occasionally is seen, and rarely amblyopia. Converging strabismus is common, and nystagmus is occasionally present.

The infant suffers little or no pain, is usually apathetic, but exhibits more intelligence than would be thought possible from the evidence of enormous intracranial pressure. The face, frequently described as weazened, is probably proportionate to the undeveloped body. The vertical, longitudinal and lateral expansion of the cranium makes the face appear insignificant. The head as a whole presents an inverted pyramidal shape. Acquired hydrocephalus, after complete ossification, does not usually show the marked enlargement of the head, although the sutures may yield, even after bony union, to the great pressure from within.

Lesions.-Post-mortem examination reveals but little resemblance to normal encephalic structures. The convolutions of the convexity have disappeared. The membranes of the convexity may show little evidence of inflammatory changes. At the base they are often somewhat thickened and opaque. The ventricular ependyma is thickened, its blood-vessels distended, and its surface roughened. Differentiation between gray and white matter is impossible. The cortical substance may be extremely attenuated from the distention of the lateral ventricles. These appear like large bags containing fluid, from one to several pints in amount. This fluid is clear, colorless, slightly alkaline, and contains chlorides of potassium and sodium and alkaline phosphates. Occasionally globulin, albuminose, peptone, and, rarely, a trace of albumin, are found; also a copper-reducing agent formerly supposed to be sugar. The specific gravity ranges from 1.003 to 1.009 . The denser fluid shows turbidity 
from inflammatory products. In extreme cases the meninges and cerebral tissue are compressed into one apparent membrane less than a millimetre in thickness. A matter of constant surprise is the persistence of function, or even life, with such extensive destruction of cerebral substance.

The changes in the bones of the skull are not constant and appear in those of the vault rather than at the base. Thinning is sometimes plainly evident, the diploe having been quite obliterated in some parts. The structures of the cerebellum and pons frequently show pressure effects and retardation in development. Developmental defects, such as porencephaly, spina bifida, meningocele, cleft palate, hypospadias, etc., are associated with congenital hydrocephalus with sufficient frequency to attract more than passing attention. Brain tumors may be found which bear an undoubted relationship to the dropsy.

Prognosis.-Congenital hydrocephalies rarely outlive the second year. Occasionally a condition of helpless idiocy is prolonged for four or five years. They usually succumb to marasmus or, having feeble resistance, fall victims to some trifling intercurrent affection.

Acquired hydrocephalus is influenced in its duration and termination by the nature of the primary disease to which it is due. A considerable degree of cranial enlargement and mental impairment is not incompatible with prolongation of life to the adult period. Occasionally the rapid cranial expansion slackens while the increased body growth renders the diserepancy less marked. There is a gradual disappearance of pressure symptoms with apparent recovery in all the functions. The general enlargement of the head, however, remains as evidence of the early hydrocephalus. Complete recoveries from an extreme degree of cerebral hydrops are rare. The usual course, which may continue for years, is marked by periods of apparent improvement alternating with exacerbations of pressure symptoms.

Paralyses and spasticity usually mark the victim of this chronic type, and mental impairment of varying degree is the general rule, until intercurrent disease or acute convulsions terminate life.

Diagnosis.-Hydrocephalus is diagnosed by the abnormal increase in the size of the head. Its other symptoms are common to cerebral irritation and intracranial pressure from any cause. Since the head of a normal baby at birth averages thirteen and one-half inches $(34 \mathrm{Cm}$.), at six months seventeen inches $(43 \mathrm{Cm}$.), at one year eighteen inches (46 Cm.), and at two years twenty inches $(51 \mathrm{Cm}$.) in circumference, any marked excess over these figures would constitute an enlargement. The ordinary rapidity of increase should be determined by repeated measurements at regular intervals. This head enlargement, in conjunction with a history of the before-mentioned symptoms, should render the diagnosis plain.

Other causes of head enlargement, such as bony hypertrophy from rhachitis and syphilis, should show, in the history or on physical examination, other evidences of those dyscrasiæ. The rhachitic head lacks the 
globular character of hydrocephalus, is more angular on account of the parietal ridges, and presents bossæ with intervening depressions or plain areas. The intellectual precocity of the rhachitic is in marked contrast to the impaired mentality of the hydrocephalic. The syphilitic head gives evidence of cranial thickness from bony overgrowtl. In both forms of enlargement the pressure symptoms characteristic of hydrocephaly are wanting.

In regard to size, however, it must be remembered that premature ossification with resulting microcephaly may mask the commonest sign of hydrocephalus. In these cases of microcephalic hydropsia the positive diagnosis is only made post-morten.

Treatment.-Congenital hydrocephalus yields to no treatment. Since cases of the acquired form have been known to recover, it is probably wise to attempt the amelioration of pressure symptoms by all possible means. During an exacerbation of acute symptoms, withdrawal of fluid by repeated lumbar punctures in cases where the communication is uninterrupted is worthy of trial. If unsuccessful, the ventricles may be aspirated with due aseptic caution, care being taken to avoid the longitudinal sinus.

The fact that syphilis is responsible for a certain proportion of cases warrants the exhibition of iodides and mercurials.

Various surgical procedures for drainage are still attempted with encouraging results in but a small number of cases. It is believed by some surgeons that a method of drainage will ultimately be devised which will maintain intra- and extra-vascular equilibrium. It must be borne in mind, however, that the primary cause of fluid accumulation may also be responsible for many of the symptoms attributed to the pressure of the fluid.

INFANTILE CEREBRAL PALSIES-SPASTIC HEMIPLEgIA; DIPLEgIA; PARAPLEGIA.

For clinical convenience, the cerebral palsies are divided, according to the time of occurrence of the cerebral lesion, into three classes,- - prenatal, natal, and postnatal.

These disorders are very common during the first decade of life, as the records of any children's clinic will attest. The onset of the diseasc in more than eighty-five per cent. of the cases occurs before the end of the third year. Infantile cerebral palsies include all plegias of cerebral origin from lesions (not absolutely determinate, like encephalic tumor, abscess, or dropsy) which cause contractures, rigidity, choreiform, and athetoid movements or mental impairment.

Prenatal paralyses are due to some defects in cerebral development, as porencephaly (in which a greater or less portion of the brain is wanting) or "agnesis corticalis" (arrested or defective development of the cortical and pyramidal cells), or possibly to intracranial hemorrhages occurring during the latter period of gestation. The causes are variously attributed to neurotic family history, traumatism to mother 
or child, as by blows or falls, also to shock, fright, convulsions, or illness of the mother. The ehild at birth may show loss of power, spastic flexures, or rigidity of one or more of the extremities, with later evidences of mental impairment which may amount to idiocy. Fortunately many of these defective children die early of inherent weakness or from inability to nurse.

Natal Paralysis (birth palsies).- These are probably due, in the majority of instances, to meningeal hemorrhages, asphyxia neonatorum, prolonged and premature labors, and rarely to the use of forceps. The

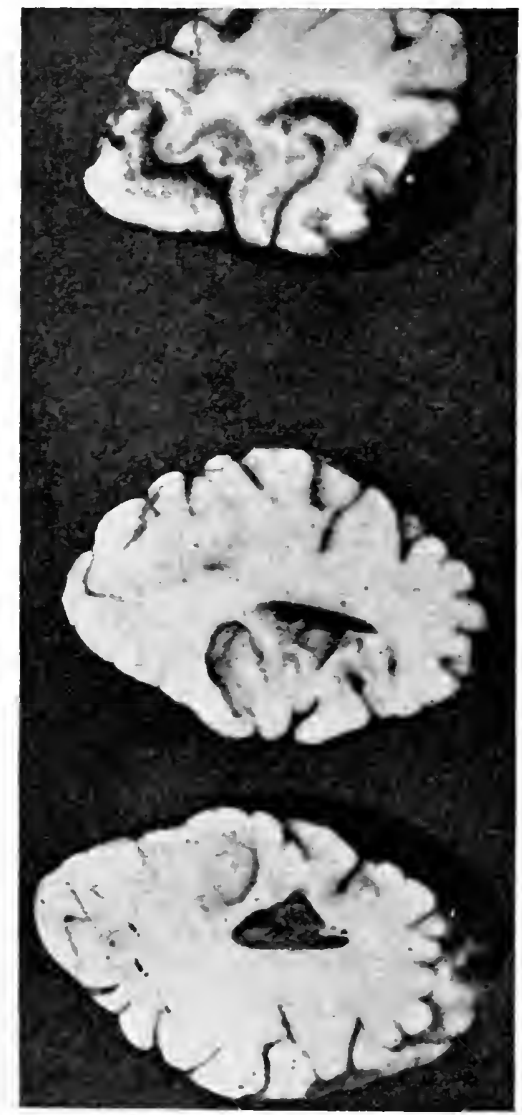

Fıg. 156.-Infant, 3 days old. Forceps delivery. Hemorrhage into the perieto-occipital and calcarine fissures, with softening of the surrounding cortex. (Dr. P. Bassoe.) early and skilful use of instruments would, no doubt, prevent this accident in many instances. The greater frequency of birth palsy in the first child of a family is suggestive of their etiology.

Among the lesions reported are meningoencephalitis (Fig. 156), followed by thickening and adhesion of the pia mater, with cellular proliferation in the walls of the blood-vessels, obliteration of the pyramidal cells of the cortex and degeneration in the pyramidal tracts. Sclerotic changes may occur with atrophy more or less extensive, occasionally involving large portions of one or both hemispleres. Cysts may develop and secondary degeneration in the lateral columns of the cord follow the extensive atrophy and sclerosis.

The immediate or primary symptoms usually indicate the extent of the hemorrhage. If this be widespread, convulsions occur. Paraplegia or diplegia develop early, and coma may follow, with danger of death. If the baby survive the attack, the secondary symptoms will depend largely upon the amount and distribution of the hemorrhage and the secondary lesions which develop.

In paralysis of antenatal origin the majority of palsies are para- or diplegic. In this class the mortality in severe cases is fortunately high, since the certainty of physical helplessness and mental deficiency makes early death a boon to be desired (Figs. 159-161).

Infants surviving the less extensive injuries may exhibit only slight 
rigidity or spastic involvement of the legs, or occasionally only one limb (monoplegia) may show this symptom and is often overlooked. It often happens that no symptoms are observed by the parent and no history of convulsions is given, the physician being consulted because of the child's physical and mental "backwardness." There may be a tendency to head retraction, to strabismus, or the legs may be weak and the neck limber, suggestive of rhachitis. Interrogation may bring out the fact of a prolonged, difficult, or premature labor, delayed forceps delivery, or asphyxiation. Examination may show slight spasticity and exaggerated knee-jerk. The child may learn to walk late, possibly in the third year, but the gait is unsteady, there is a tendency to crosslegged

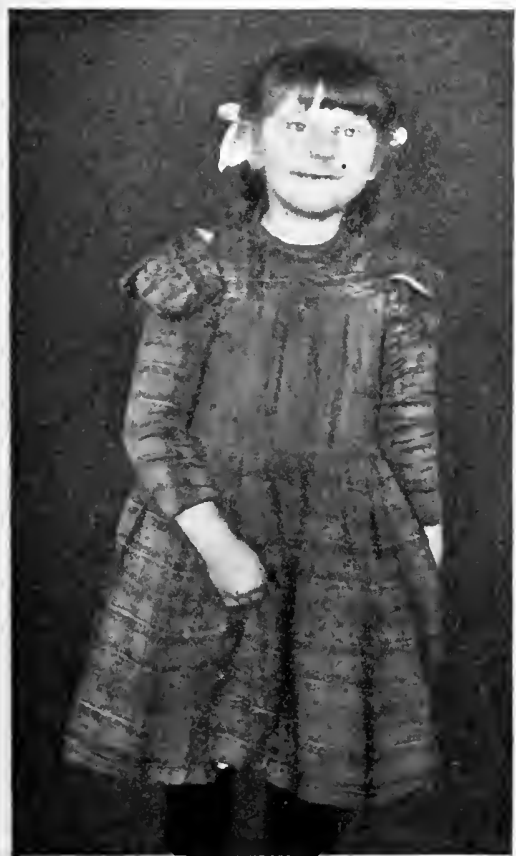

Fig. 157.-Birth palsy. Aged 4 years. Microcephalic idiot; strabismus, facial asymmetry, right hemiplegia.

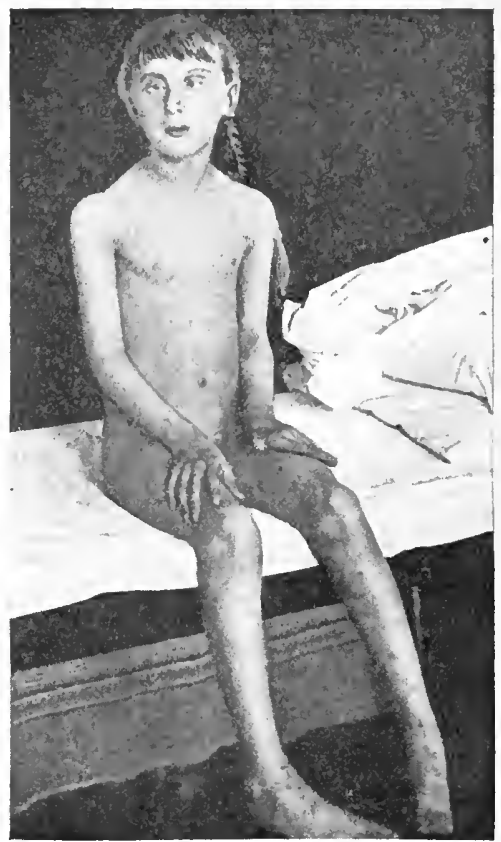

FIG. 158.-Cercbral palsy (natal). Aged 10 years. Microcephalous, strabismus, ptosis, facial paresis, slight contractures and spastieity, exaggerated reflexes, chorcic, athetoid, and associated movements; very slight mental impairment.

progression, and the feet turn under. The child may be microcephalic or show cranial or facial asymmetry with gothic palate and other degenerative stigmata (Fig. 157). Convulsions may have occurred and borne the responsibility for the maldevelopment of shortened limb and defective mind, which are really due to the birth injury and the progressive central changes incident thereto. Athetoid movements in one or more members, usually the hand, or mild localized chorea (Fig. 158), may lead the physician to suspect the true lesion. Epilepsy is very common, 
usually beginning as the Jacksonian type in the most affected limb, and later becoming general.

Postnatal Palsies (acute acquired cerebral paralysis).-Most of these cases occur before the fifth year and nearly half during the second year of life. The paresis characteristic of this form is of the hemiplegic variety. Although double hemiplegia and apparent monoplegia of an upper limb are oceasionally seen, paraplegia is rare.

Among the causes usually aseribed are the infectious fevers, pneumonia, pertussis, shock, traumatism, and convulsions. The tissues involved in the causative lesions may be the blood-vessels, the meninges, or the brain itself.

Undoubtedly the majority of attacks are the direct or remote result of meningeal hemorrhages which, because of faulty development of the

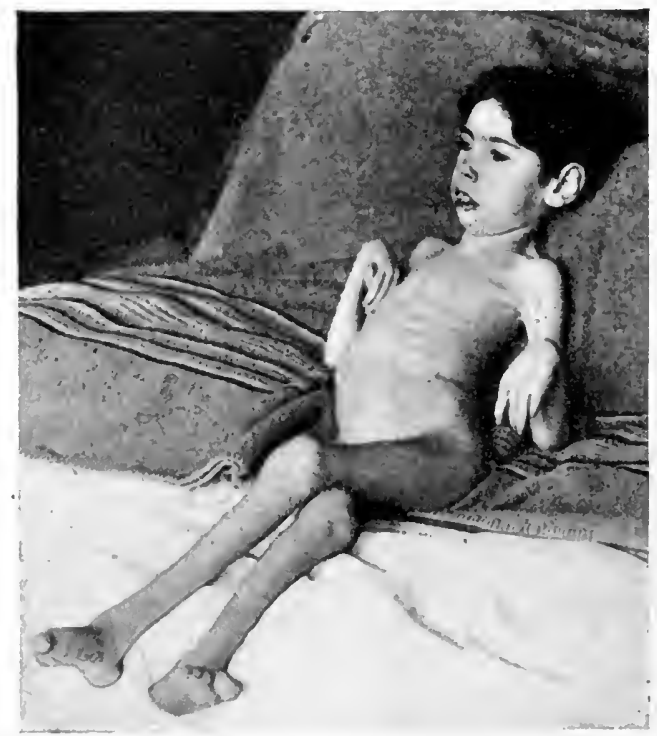

FIG. 159.-Aged 10 years. Prenatal form of cerebral palsy. Diplegic idiot, with spasticity.

vessel walls, are readily induced during any of the acute infections and when the blood-pressure is unduly raised from any eause, as in paroxysms of coughing, in pertussis, pneumonia, in eardiac disease, etc. More especially is this true of severe or prolonged convulsive seizures, although undoubtedly the etiologic relationship of convulsions and cerebral lesions may be reciprocal. In all forms of cerebral palsy embolism and sinus thrombosis may prove to be the exciting cause due to endocarditis, arteritis, or venous stasis, however induced. The postnatal palsies are called "acquired" or "acute" because due to causes not operative before birth (although this is questionable), and because the onset is acute. In this respect there is resemblance to acute spinal paralysis (acute poliomyelitis anterior) and this, with other clinical 
similarities, has led some eminent observers to regard acute polioencephalitis as a frequent etiologic lesion. However interesting the clinical analogy, recent post-mortem findings do not bear out this theory.

Pachymeningitis, or meningoencephalitis resulting from previous inflammations or from syphilis and occasionally tubercles, may be a primary lesion, but whatever may be the original cause, whether infective, mechanical, or both, the secondary changes in the brain substance and upper cord are of the greatest importance, for by them the vicious circle is perpetuated, with resultant permanent impairment of function, both mental and motor.

Among the terminal brain lesions there may be, as in the natal variety, cysts, atrophy, and sclerosis of the brain substance, more or less extensive, with descending degeneration into the spinal cord.

The onset of postnatal cerebral paralysis is sudden and is preceded by convulsions in more than half the cases. Febrile symptoms are frequently pronounced and there may be vomiting. The convulsions may be repeated at short intervals and coma often ensues. Speech may be

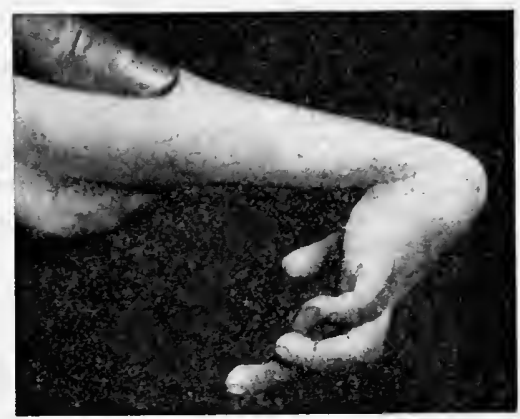

FIG. 160.-Spastic contractures in diplegia.

affected, especially with left cerebral lesions, and the mind is impaired. After the acute symptoms have subsided the paralysis is evident and may rarely involve the face, although strabismus is common. The commonest type is hemiplegia, at first usually quite complete, and sensation may be temporarily abolished, while the deep reflexes are exaggerated on the affected side. Later, sensation returns and motion is frequently restored to the affected limb, although rarely completely. Spasticity gradually asserts itself and, in time, contractures follow (Fig. 160), while the tendon jerk and ankle clonus remain a persistent feature. Occasionally slight evidence of the paralysis may remain, except postplegic athetoid or choreic movements. Spasticity of the limbs may always be detected upon careful examination. In half the cases eclamptic seizures recur, and confirmed epilepsy is the result, usually focal in character at the beginning. Convulsions may be wanting, the child awakening with hemiplegia after retiring in apparent health. This onset is very similar to that occasionally seen in acute spinal paralysis. The face, 
when involved, usually recovers early. Paralysis of the ocular muscles frequently persists, with resulting strabismus. Permanent aphasia, both motor and intellectual, is common,--the younger the child the more frequently do speech defects follow right cerebral lesions. Exaggerated deep reflexes may be found in the opposite as well as in the paretic limb. They are normal, lessened, or absent, in about five per cent. of the eases, although rigid contractures may prevent their elicitation. Athetoid, choreie, and associated movements are common, also rhythmic contractions, tremors, and nystagmus.

Rigidity and contractures are the characteristic features of all cerebral palsies. The arm is flexed and pronated with extreme flexion of wrist, hand, and fingers, with strong adduction to the side. The knee and thigh may be flexed more or less, and the foot shows talipes equinus or equinovarus. The adductors of the thigh are contracted so that cross-legged locomotion is the rule, while the rigid contractures limit

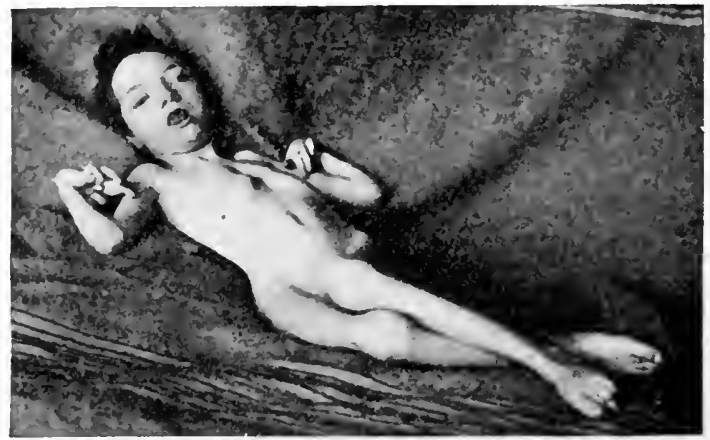

FIG. 161.-Aged 10 years. Prenatal form of cerebral palsy. Microcephalic, strabismus, diplegic, spasticity and contractures.

the movements (Fig. 161). If able to walk, the gait is spastic, jerky, and springy in character.

There is atrophy of the muscles from disuse and retarded growth, so that after a time the entire limb may be smaller and shorter than its unaffected mate.

Mind impairment and idiocy are in direct ratio to the extent of the cerebral lesion, the paraplegies and diplegies showing the greater deficiency. In hemiplegies mental defects are less common and severe. Taken altogether, half the cerebral palsies show mental impairment while other stigmata of degeneration are common,- as cranial asymmetry, high palate, abnormal ears, hairy skin, etc.

Prognosis.-It is not possible to predict the extent of damage at the beginning of the attack. Children suffering from diplegia and paraplegia usually die, before the end of the second year, of some intercurrent disease. The unfortunates who survive for a longer period lead a purely vegetative existence, being helpless and hopeless idiots (Figs. 159-161). In the cases of hemiplegia, the prognosis is not so grave, although an 
entire recovery eannot be expected. The face and leg regain power earlier and to a greater extent than does the arm. Speech may be delayed for weeks or months, but in young children is fully recovered. Epilepsy, which may appear a year or more after the paralysis, renclers the prospect of normal mental development unfavorable. All the possibilities should be carefully explained to the parents.

Diagnosis.- The diagnostic points are paralysis (paraplegia, diplegia, hemiplegia, and rarely monoplegia) more or less complete with rigidity or spasticity, with possibly unilateral ehoreic or athetoid movements. No early atrophy or change in electrieal reaction is present. The tendon reflexes with elonus are inereased in nearly all eases. Mental impairment occurs in fifty per eent. of cases and recurrent convulsions in the same proportion. Rarely a spinal palsy may develop in an old eerebral hemiplegic and furnish symptoms of both. Well-marked eases of infantile eerebral palsy are not diffienlt to diagnosticate, but those of slighter degree, affecting only one extremity, may suggest a spinal lesion. Infantile spinal palsy selects usually groups of muscles rarely involving an entire limb; the tendon reflexes are absent; the paralysis is flaccid; the wasting is rapid and marked; the reaction of degeneration is present, and there is no impairment of the mind. In a paralysis due to neuritis, there is no rigidity or imbeeility, and there is the changed eleetrical reaction. A paraplegia due to caries of the spine would show the angular deformity of the vertebræ and an absence of mental weakness or epilepsy.

Treatment.--Special edueation, if begun early, may do mueh for the mentally defective. This is especially true in the eases of hemiplegia, as there is the possibility of one hemisphere eseaping damage. Massage and electricity are of value in keeping up the nutrition of the museles and in arresting the deformities. Orthopxdic surgery may relieve, to a certain extent, the contractures and allow locomotion.

PROGRESSIVE BULBAR PARALYSIS-LABIOGLOSSOLARYNGEAL PARALYSIS.

Closely allied to the amyotrophie palsies is progressive bulbar paralysis. Although bulbar symptoms may be present in a great variety of pathological processes, as tabes, multiple sclerosis, lateral selerosis, polioencephalitis, hemorrhages, tumors, etc., reference is here made to a distinct form of bulbar lesion which, by giving rise to eertain common definite symptoms, renders the ante-mortem diagnosis possible.

The disease is rare at any period of life but is seen in ehildhood with sufficient frequency to warrant its mention. The etiology is obseure both as to predisposing and exciting causes.

The first symptom to attract attention is usually a speech defect, as indistinet enunciation of certain sounds; or. possibly difficulty in deglutition, which gives rise to eoughing and strangling while eating. The physician may not see the ease until after the development of a classical group of symptoms, known as labioglossolaryngeal or pharyngeal paralysis. These point strongly to the medulla as the site of lesion (Fig. 162), the primary character of which is determined by the exclusion of all other 
known processes. The child may appear normal in every respect, aside from the following group of symptoms.

Althongh usually somewhat emotional, laughing and erying at the same time, the face shows the absence of the usual orolabial participation in the expression (Fig. 163). The nether lip is pendulous, with the suggestion of tapir-mouth, from which the saliva drools and to which during mastication the hand is frequently applied to assist in the retention of food. The appearance of the tongue is characteristic, as it lies obviously atrophied in the floor of the month. It is usually furred, markedly fissured, and shows fibrillary tremors. The child may be unable to protrude the tongue beyond the teeth or approximate its tip to the roof of the mouth. The voice is weak and nasal in quality. The dental-labial consonants are imperfectly enunciated from paresis of tongue and lips. For the same reason the child cannot whistle or purse

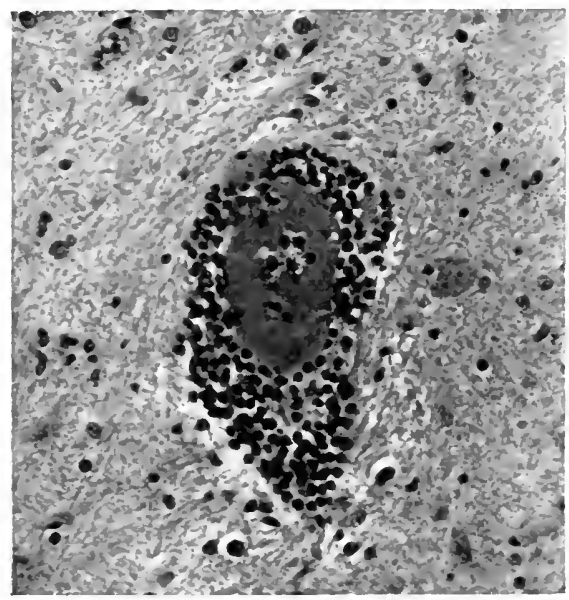

FIG. 162.-Round-celled infiltration around a blood-ressel in the medulla in ease of bulbar paralysis. Shown in Fig. 163. (Dr. P. Bassoe.)

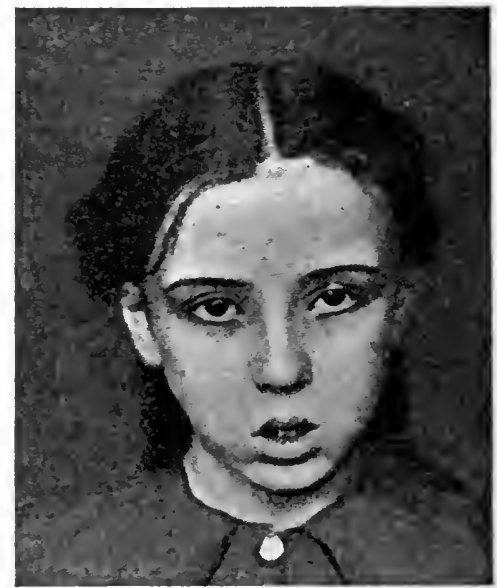

FIG. 163.- Progressive bulbar paralysis. Aged 11 years. Death 7 months after first appearance of symptoms.

the mouth. Fluids may regurgitate through the nose in swallowing, while choking and coughing may result from particles entering the unguarded larynx. Tactile sensation and the special senses are not involved, with the occasional exception of taste near the tip of the tongue. As an occasional accompaniment, paralysis of the upper part of the face, with lagophthalmos and ptosis, oceurs.

In the early part of the disease the muscles, with the exception of the tongue, show no atrophy or change in electrical reaction. Later on, however, wasting and the reaction of degeneration are found in all the muscles involved.

As the disease progresses, the heart action becomes rapid and irregular, respiration shallow and easily disturbed, and attacks of angina distress the child. The general weakness of the muscular system is due in 
part to the insufficient food supply from imperfect mastication and difficult deglutition. Bronchial and pneumonic complications are common from aspiration of particles of food and secretions. The child becomes irritable, morose, and peevish.

Prognosis.-Some intercurrent disease, as pneumonia, often terminates the history in anticipation of the progressive asthenia.

Diagnosis.-True bulbar paralysis is diagnosed from other diseases having bulbar symptoms by the history and the several characteristic symptoms of these diseases.

Myasthenia gravis, or pseudobulbar paralysis, is a term applied to a similar group of symptoms in which, however, no bulbar lesion exists. With care it may be differentiated from true bulbar paralysis by the fact that the pseudo-labioglossopharyngeal paresis always follows upon the use of the muscles involved, disappearing after an interval of rest. In the same way electrical response disappears after repeated faradization, to reappear after a period of discontinuance.

This temporary paresis of exhaustion is of interest in connection with convalescence from any severe illness in children. In them the weak nasal voice, dysarthria, and dysphagia are evident to a mild degree, but disappear with full return of strength.

Treatment.-Progressive bulbar paralysis, from the nature of its pathology, is not amenable to treatment. The pseudo form is best treated by absolute rest, accompanied by forced feeding of concentrated and easily digestible articles of diet. Gavage is employed, not only on account of the dysphagia but to secure rest for the muscles involved in mastication and deglutition. Electricity should not be employed.

\section{IDIOCY-IMBECILITY AND FEEBLE-MINDEDNESS.}

Idiocy, imbecility, and feeble-mindedness are too frequently among the penalties of eivilization. The variations in degree of mental development are endless, and numerous arbitrary classifications have been made.

The answer to the query of the anxious parent as to the prognosis regarding the mentally defective child depends so largely upon the cause and nature of the defect that the following simple classification is suggested:

First, as to cause: A, heredity; B, accident. To Class $\mathrm{A}$ belong the children of mentally defective progenitors who are neurotic,- such as epileptics, insane, hysterical, highly emotional, alcoholic, syphilitic, tuberculous, and blood-related.

Second, as to time of commencement: A, antenatal; B, at birth; C, postnatal.

Accidental causes are those which operate in such a way as to arrest the growth of the brain or to destroy its function by the production of pathological lesions. The first class follows the law of nature that perfect fruit cannot spring from degenerate seed. The second, that interference with the growth of an organ during its period of develop- 
ment may not only arrest the growth but will pervert its function. The growth of the brain is practically complete by the eighth year. The period of most rapid postnatal growth is the first two years, at which time this organ more than trebles its birth weight. The intrauterine period, however, shows the greatest activity, as in addition to its remarkable increase in weight, cell multiplication is completed before birth.

Among the accidents which arrest or pervert brain growth, the commonest are intracranial hemorrhage and meningitis. These by the pressure of effused blood or inflammatory exudate so interfere with the nutrition of the brain tissue that normal growth is prevented. Other influences undoubtedly operate to disturb the nutrition of the brain by impoverishing its blood supply or interfering with its circulation. Infections, disturbances of trophic innervation, extremes of temperature, physical and psychical shock, are mentioned among the possible causes of brain accident. Both heredity, as predisposing cause, and accidental lesion as determining cause of mental defect, may operate in the same individual. Congenital idiocy may be due to either cause, as undoubtedly the accidents and contingencies of gestation are responsible for idiocy in children of healthy parentage. Both meningitis and hemorrhage are known to oceur in utero, while examples of prenatal arrested or perverted brain growth are seen in congenital porencephaly, microcephaly, hydrocephaly, and asymmetry. Instances are numerous in which injuries to the mother from falls, blows, or shocks, also emotional disturbances, excessive coitus, hemorrhages, severe sickness, or general impairment of health, have preceded the birth of idiotic children.

It has been shown that over fifty per cent. of idiocy is congenital. Of these about ninety per cent. showed histories of hereditary predisposition. Among the same children birth accidents, premature delivery, and difficult labor occurred in more than twenty-one per cent. Competent observers have noted as a cause prolonged labor in about thirty per cent. of all idiotic children. The preponderance of male idiots is suggestive of the greater liability of the larger heads to parturition injuries.

The number of cases of acquired idiocy, resulting from injuries or brain lesions occurring after birth, is probably less than the congenitally defective, though the percentage of cases assigned to postnatal influences appears greater. Hereditary influences and morbid antenatal conditions may exist in earliest infaney without evidences of brain impairment. Such evidences appearing later as imbecility are likely to be ascribed to any accident or affection shown in the child's postnatal history. It is undoubtedly the ease, however, and amply demonstrated in the later years of childhood, that an acute process-as meningitis or intracranial hemorrhage-may leave its impress upon the brain, as seen in paresis and impaired mentality. The division of responsibility for mental impairment as between heredity and accident from antenatal, natal, and postnatal occurrences is obviously impossible. In many instances both causes-one as predisposing, the other as exciting-operate in the same individual. 
It is a mistake to assume that the brain in idiocy always presents unmistakable gross lesions. Occasionally the idiot's brain furnishes no macroscopic indication of functional impairment in contour or proportion. The cellular elements, however, may show wide-spread abnormality, with malarrangement or disintegration of the cell constituents indicating degenerative changes as a result of agenesis. Abiotrophy (a term applied to inherent weakness) of the nerve tissues is probably an inheritance from enfeebled ancestry, which yields to trifling intereurrent causes, especially during the periods of stress.

The question of the normality of the brain which yields so readily to the accidental disturbances of childhood has been much discussed and will probably never be satisfactorily settled. The same degree of gross disturbance is frequently observed in adult brains with but trifling or transient impairment of function. It is noticeable that the most disastrous results to mentality from such eauses oceur during infaney and earlier childhood, the period of rapid brain growth, and that after the eighth year (completion of brain growth) a certain degree of immunity from such extreme effects exists. How much these facts are due to the survival of the fittest is still a question.

Idiocy, imbecility, feeble-mindedness, and backwardness are terms used to express the extent of mental deficiency, the indications of which are varying degrees of departure from the average at a given age. The early symptoms are obscure, and frequently no hint of the congenital defect may appear before the completion of the first year. One test of mentality from the earliest to the latest development of that function probably best determines the degree of defieieney,- the test of attention. Its absence or impairment is held to correspond to the degree of mental defect. Usually physical signs and motor defects in infancy accompany imbecility, such as inability to support the head, sit alone, support the body, or walk at periods when these functions are ordinarily established. Mere muscular weakness, however, may be misleading, since malnutrition and rhachitis (both in infants and older children) are frequently responsible for these conditions. Marked abnormalities of the head, in size and contour, with other stigmata of degeneration, such as premature closure of fontanelles, persistence of lanugo, misshapen ears, high-arched or eleft palate, harelip, frontal or basilar encephalocele, spina bifida, genital abnormalities, and accessory fingers and toes, are occasionally corroborative signs of imbecility. Spastic plegic conditions are always suggestive of prenatal accident. The history of heredity, gestation, and parturition, as well as that of accidents and ailments since birth, may furnish a elue to the diagnosis. But the degree of attention and purposeful movements will always furnish the most important information concerning the mental development of the child. In this connection a fourth class of defectives must be remembered,-viz., children of tardy development, the so-called backward children, whose only fault is expressed in the term.

Four well-defined types of congenital idiocy among the many varieties 
may be mentioned on account of their uniformity in history and symptoms,-viz., eretinism, Mongolian idiocy, amaurotic family idiocy, and epileptic idiocy. (For description of the first, see Disorders of 'T'HYroid GLAND.)

The Mongolian or Calmuck type (Figs. 164 to 168) is named for its cranial and facial resemblanee to that race, especially in the inclination of the palpebral fissures and a peeuliar development of the epicanthic fold. They are usually good-natured, round-headed, undersized, but not disproportionate nor repulsive children. The prominent papillæ in infaney and the deeply fissured tongue in childhood are said to be found in no other class of imbeciles (Fig. 166).

Mongolism is much more frequently met with in Great Britain, especially in England, than on the Continent or in the United States. Exhaustion and age, especially of the mother, is claimed as an etiologic factor in the production of this type, the greater number being found among the youngest children of large families. Consanguinity, syphilis, and alcoholism occur in the ancestry of these children with sufficient frequency to attract attention. Antisyphilitic treatment has thus far produced no amelioration of the condition. To cretins they present a marked contrast in the clear complexion and smooth, white skin. The dark hair is fine, soft, and straight. There is no puffiness of the eyes nor puckering of brows. The forehead may be wrinkled transversely from action of the occipitofrontalis in elevating the eyelids, but not from myxœedematous redundancy of skin. The head is brachyeephalic, with flattened instead of overhanging occiput (Fig. 165). The premature ossification of the base of the skull, with the high arehing of the palate, may be responsible for the backward eneroachment of the vomer in the pharyngeal vault and the common tendency to adenoid growths in these cases. The features and extremities are cleaner cut and better formed. A peculiar incurvation of the little fingers has been observed, but this peculiarity is not eonstant nor is it confined to this elass of ehildren. The voice is coarse and guttural, in which respect it resembles that of cretinism. They are not so dull, apathetic, nor slow and clumsy in movements as the eretin. They are prone to congenital heart defects, and show feeble resistance to the diseases of childhood, and especially to pneumonia. The fact that they early succumb to disease may explain, in part, the infrequency of the recognition of this elass of defectives. The term imbecility is not applicable to all cases of Mongolism, as the degree of mental impairment shows a wide range of gradation, extending from mere backwardness to hopeless idiocy. The former condition is illustrated by Fig. 168 and the latter by Fig. 167.

Many older infants and children present evidences of the cause of their mental deficiency in physical defects, such as hydrocephaly or microeephaly, spastic plegias, contractures, and deformities. They are usually short-lived, though unfortunately many, even congenital idiots, continue a vegetative existence into adult life. The greatest interest attaches to the degree of mental defect and the possibility of improvement. 


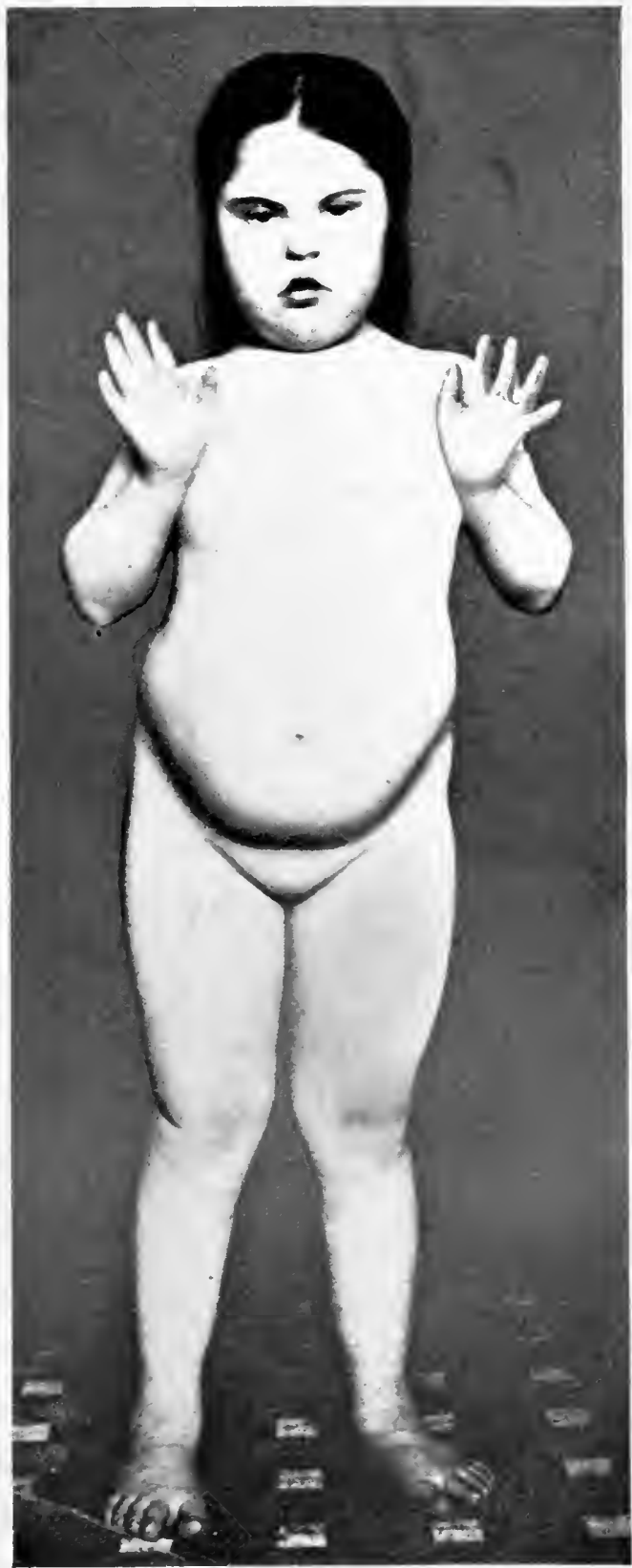

FIG. 161.-Mongolian imbecility. Aged 9 years. (Dr. J. D. Merrill.) 


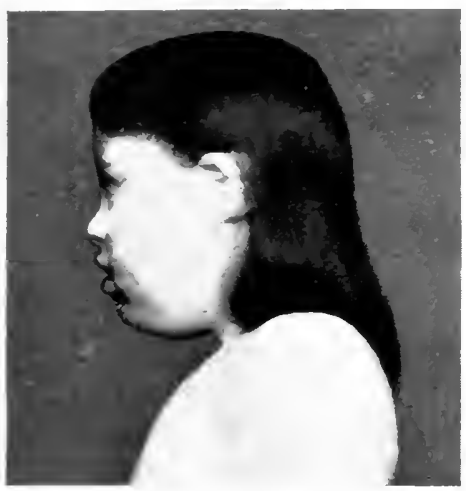

FI(G. 165.-Mongolian, showing flat oceiput.

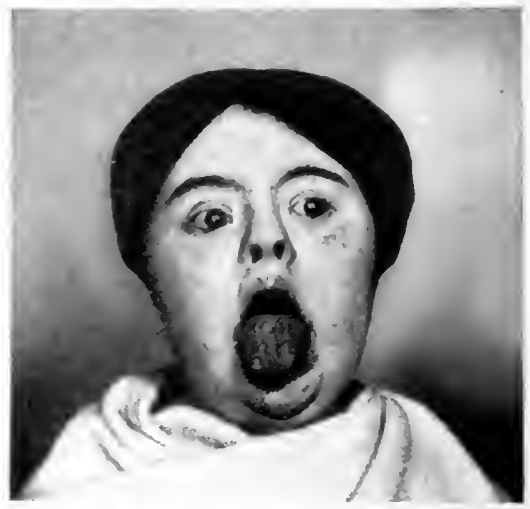

F1G. 16h.-Mongolian imbecility, showng large fissured tongue. (Dr. J. D. Merrill.)

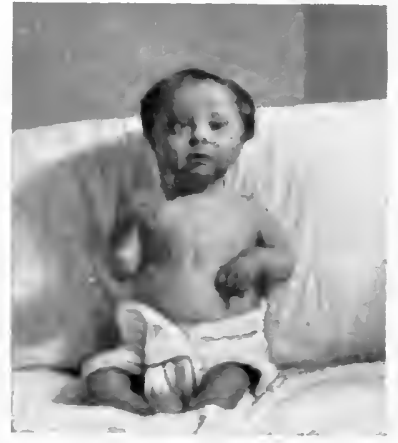

FIG. 167.-Mongolian imbecility. Age, 1 year. (Dr. G. H. Vaughan.)

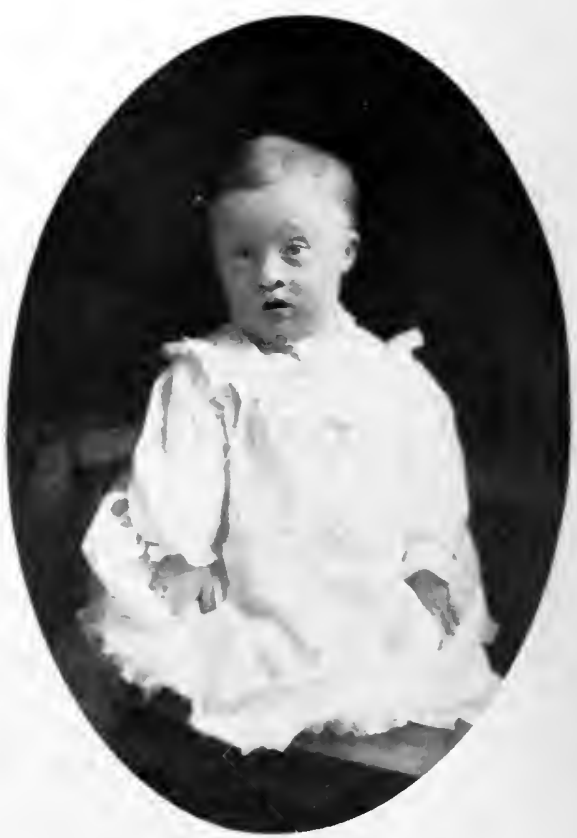

Fs, 168.-Slight degree of Mongolism. Age, 15 months. 
Sensorial or idiots, by deprivation due to congenital deaf-mutism, with blindness, are susceptible of a high degree of mental development by proper methods of education. So, too, much may be clone for children of the imbecile class in institutions especially adapted for this work.

The merely backward child, outclassed at school, should also receive the benefit of specialized educational training. This cannot be accomplished in the environments of the ordinary home, nor in schools whose curricula are graded to meet the requirements of the average intellect. It should be remembered that backwardness in school is frequently due to physical rather than mental defect-cye, ear, adenoids, ete--in which correction removes the handicap in the ordinary educational methods.

Early diagnosis of mental impairment is important, as special methods of training are successful in a direct ratio to its early adoption. The possibilities of prophylaxis is a question of paramount importance. With heredity, and with legislation restricting reproduction by neurotics and defectives, the physician has little to do. The march of civilization carries with it the steadily increasing discrepancy between the infant head and the maternal pelvis. The accoucheur may do much to shorten the duration of labor. The supervision of the pregnant woman may forestall or avert many of the accidents in utero. Supervision of the family may anticipate or mitigate many of the cerebral disorders of infancy.

\section{AMAUROTIC FAMILY IDIOCY.}

Amaurotic family idioey is a name given to a disease the symptoms of which appear in children who are apparently normal during the first few months of life (Fig. 169). It is a distinctly familial rather than

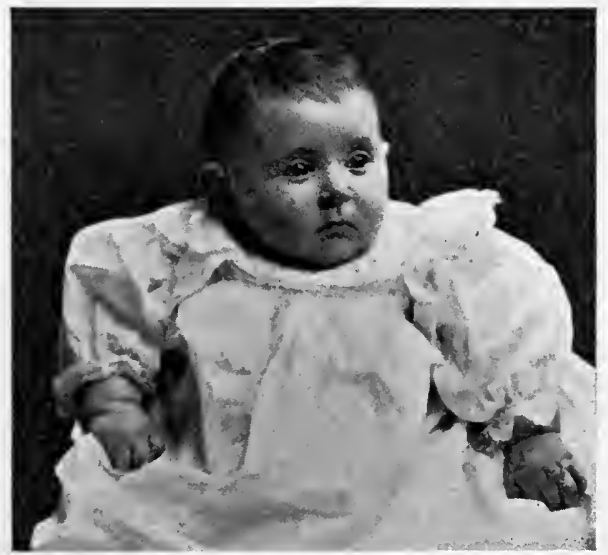

Fig. 169.-R. F., aged 11 months. Before development of symptoms of amaurotic family idiocy.

hereditary affection. Frequently two in one family, and in one instance three children in a family of five, have been reported.

Etiology.-The parents are, with rare exceptions, Jews and fre- 
quently of neurotic type. Amaurotic family idiocy, as at present understood, is probably due to defective vitality or to a degenerative tendency in the gray matter of the central nervous system. The cause is unknown. of the various theories advanced-as toxins in the mother's milk (Hirsch); abiotrophy (Gowers) ; deficiency of lecithin in the infant's food (author) -all lack confirmation from the limited number of observations.

Symptoms.-The symptoms, taken as a whole, form a unique picture. The onset is insidious, and the recognition of the disease in its early stages may be impossible. The first intimation of abnormality may be some backwardness in museular development,- -as inability to support the head, stand, or walk at the usual time. In older infants these functions, having been previously acquired, are lost. In explanation of this, some trifling indisposition is cited. The muscular atony, particularly if the

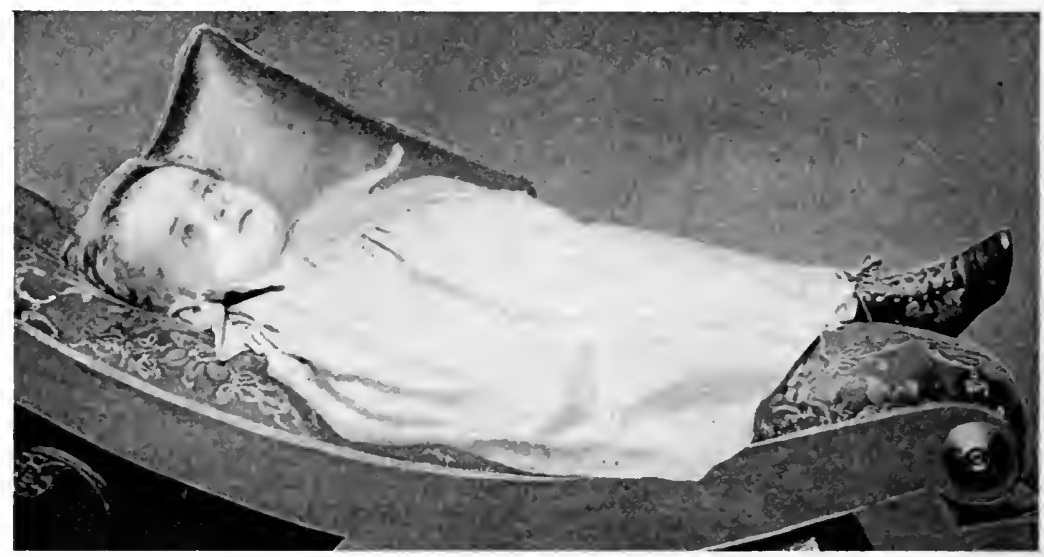

FIG. 170.-Amaurotic family idiocy. Same patient as Fig. 169, at 22 months.

child be bottle-fed, is frequently attributed to rhachitis, and the convulsive seizures may be erroneously diagnosed as tetany. Occasionally the physician may be the first to discover defective vision. Unless familiar with the disease, or particularly on his guard, he will fail in his diagnosis until unmistakable evidences of blindness lead to an ophthalmoscopic examination. The pathognomonic sign in found in the eyeground, which shows a dark reddish-brown or terra-cotta colored circular patch occupying the site of the macula lutea. This is surrounded by a larger whitish zone, about two or two and one-half times the diameter of the optic disk, through which the retinal vessels of this area may usually be seen (Fig. 171). Later, complete optic atrophy develops.

The picture of an advanced case is that of a well-nourished child, from one to two years of age, unable to walk, stand, sit, or even to support his head (Figs. 170 to 174). There may be a history of oft-recurring clonic spasms. The reflexes, both superficial and deep, are exaggerated, with spasticity and paralysis of the extremities. Hyperasthesia and 


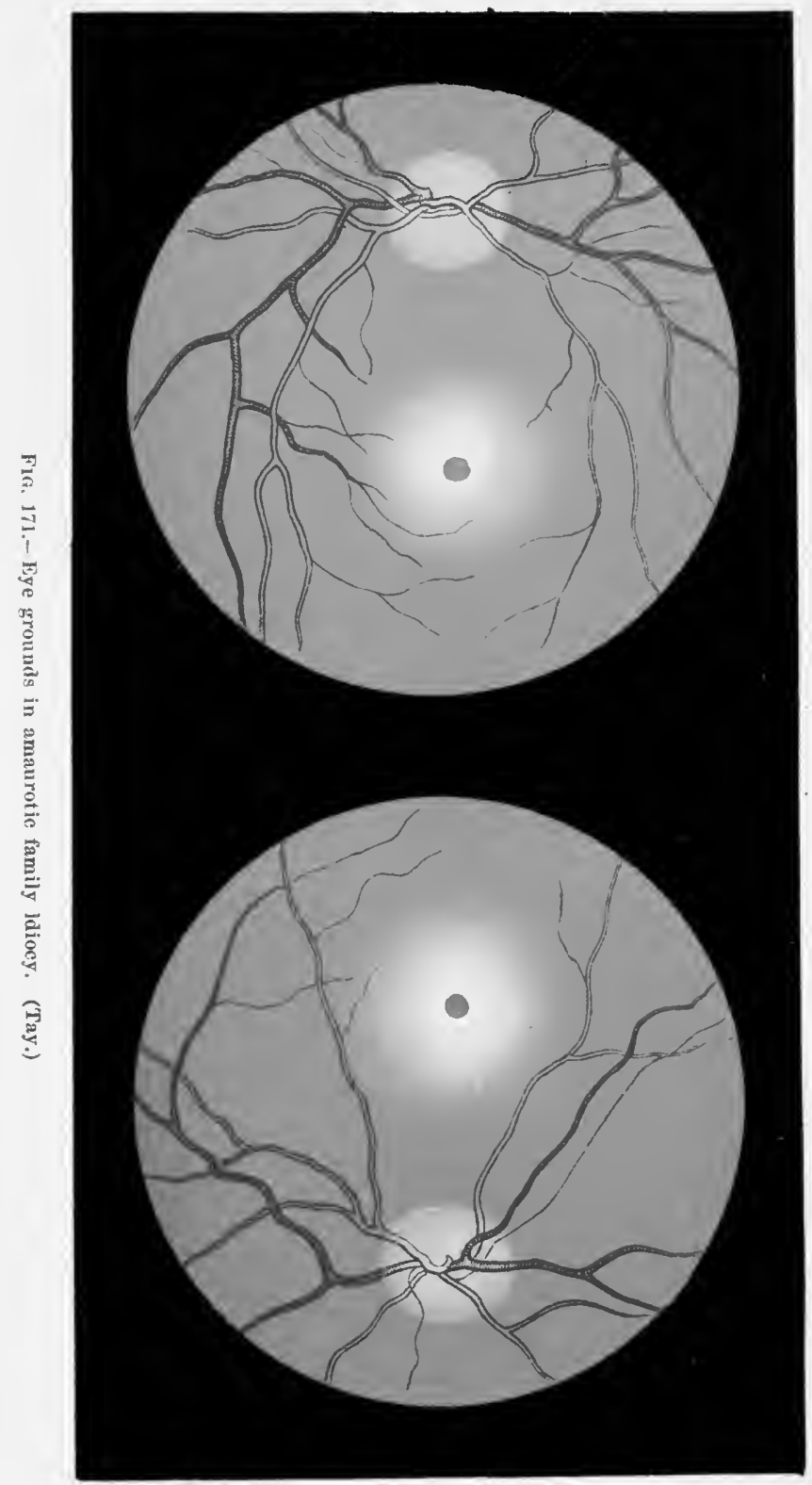



hyperacusis (Sachs), increased acoustic motor reaction (Oppenheim), may be so marked that slight disturbance by touch or sound will precipitate a general convulsion (Fig. 174). A symptom sometimes noted is an occasional outburst of laughter which, with the sightless, staring eyes and expressionless face, produces an uncanny effect. There may be constant nystagmus, conjugate deviation, or strabismus. Deglutition may be impaired or difficult, although the appetite and digestion remain remarkably

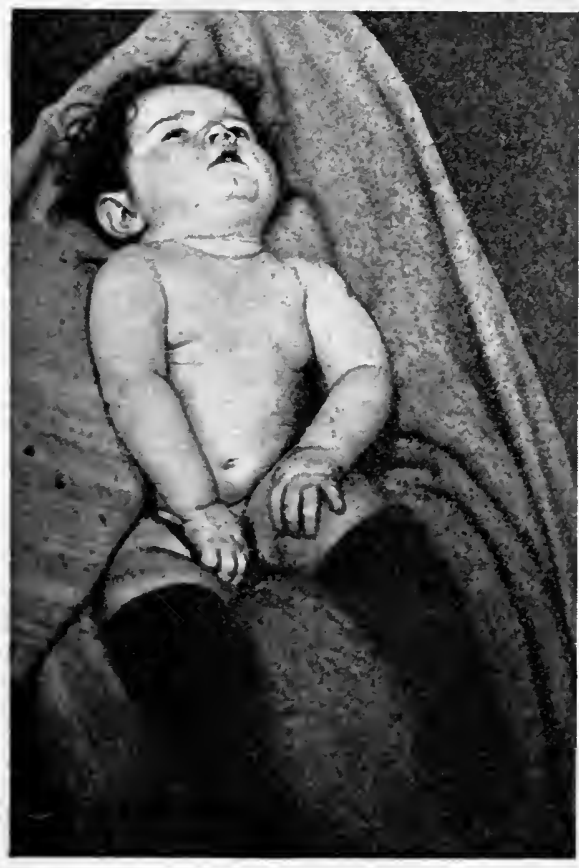

Fig. 172.-Ethel N., aged 1 year. Amaurotic family idiocy. (Dr. A. R. Martin.) good. In the later stages loss of adipose and general innutrition make their appearance. Temperature changes are not constant or significant. With the

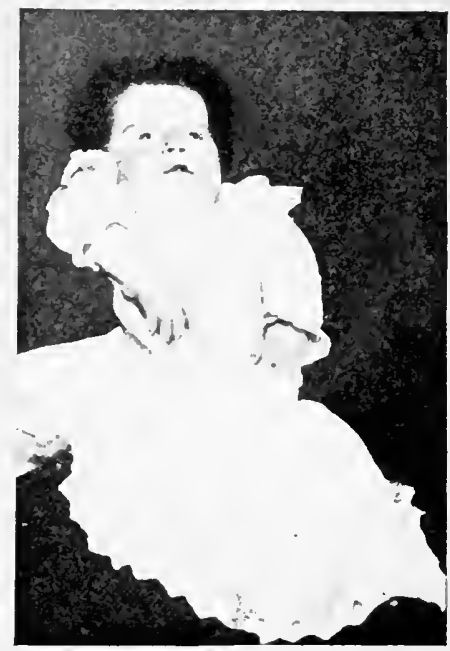

FIG. 173.-Amaurotic family idiory. Girl 16 months old.

developing blindness there is mental retrogression until complete idiocy obtains. In some eases there is almost continuous moaning and drooling of saliva (Fig. 170).

Prognosis.-The child rarely lives longer than two years after the development of symptoms. Death usually occurs from asthenia or some intercurrent disorder during convulsions.

Lesions.-Post-mortem records show wide-spread degeneration of the gray matter of the entire central nervous system, from which the ganglion cells have almost entirely disappeared by disintegration. There is also seen some deficiency in the development of the cerebral white fibres and a degeneration of the pyramidal tracts in the lateral as well as in the anterior columns of the cord (Sachs). The characteristic cloudy area of the eye fundus is due to opacity from the degenerated ganglionic layer of the retina. The liver-colored spot is that 
portion of the macula lutea in which there are no ganglion cells, the pigment of the chorioid and blood-vessels showing through.

Treatment.-No treatment is known to arrest the disease. As a prophylactic measure increase of lecithin in the infant's food is worthy of trial; hence, efforts to improve the mother's milk or a change to the

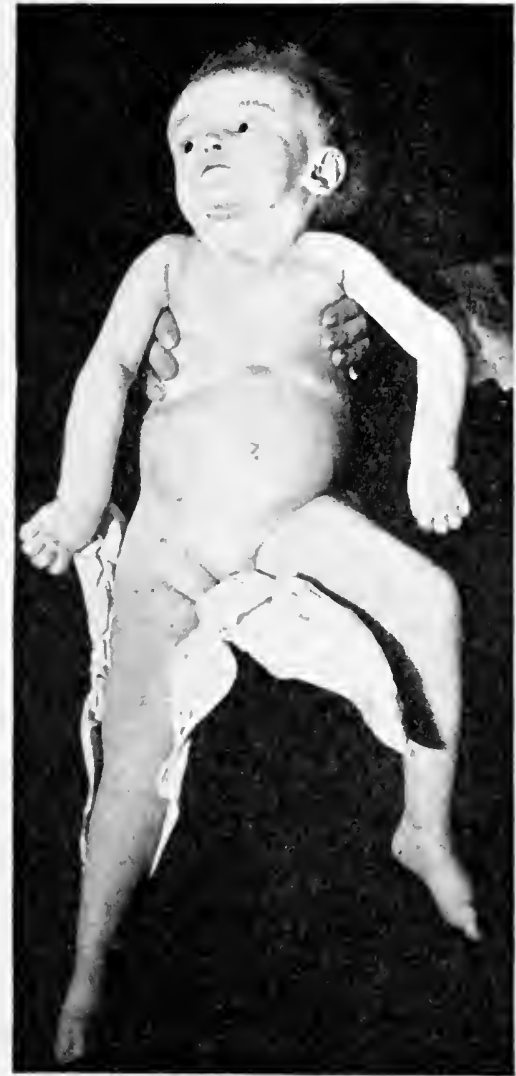

FiG. 174.-B. F., aged 22 months, one week before death. (Sister of R. F., Fig. 169), Convulsion of amaurotic family idiocy. wet-nurse is advisable in cases where the disease is suspected. Fats, rich in lecithin, may be obtained from egg yolk, which should enter into the food of the bottle-fed. Daily massage with fat inunctions should not be neglected.

\section{PARETIC DEMENTIA.}

Paretic dementia is rarely seen in children. When it does occur in early infancy it is usually mistaken for imbecility, which, symptomatically, it closely resembles. It is usually due to hereditary syphilis causing a diffuse meningoencephalitis with resultant lesions similar to those found in adult cases.

Occurring in an apparently normal child, after the age of five years, the precursory symptoms may begin with convulsions and elevation of temperature suggestive of meningitis. The attacks may be repeated at intervals of several weeks, after which the child's mind begins to show deterioration. Vertigo and epileptiform attacks are common, followed by paralytic disorders in the lower extremities which interfere with walking. Memory fails; the character changes; the child becomes apathetic and develops general tremors; the speech is "scanning," and control of the limbs and sphincters is lost.

The grandiose delusions of the adult type are not seen in the infantile form.

From two to four years may elapse between the initial symptoms and death. The child is meanwhile reduced to a state of mental and physical helplessness.

In view of its syphilitic etiology, mercurials and iodides are indicated, with some hope of benefit if taken in the early stage. Unfortunately, the diagnosis is rarely established until structural alterations 
have occurred in the brain cells. The average course in childhood is very rapid.

INSANITY.

Distinguished alienists claim that insanity is rare in infancy and childhood, but that all the known varieties have been observed at this period. Statisties of a large number of eases of insanity show that about one and one-half per cent. are recorded as congenitally insane, and that two and one-half per cent. acquired the discase during childhood. Such statistics, made up from institutional records, are obviously misleading since, from the character of the patients in public and charitable institutions, veritable and complete histories in a large number of cases are impossible. Such reports, moreover, do not include a large number of insane children outside of institutions and who rarely come under the eye of the alienist. It is highly probable that statistics of mental aberration gathered from the view-point of the family physician would show a large increase over this percentage of psychic disturbances in children.

In a work of this kind any effort at extensive classification of insanity is clearly out of place. For a study of this disease the reader is referred to the standard treatises on that subject. There is a growing belief that many psychopathic states of early childhood may be forerunners of the increasing insanity common to middle life. The strong hereditary tendency of insanity is accepted beyond question. Many of the exciting causes, - as traumatisms, extremes of heat and cold; cerebral diseases,- as epilepsy, acute infections, reflex irritations, fright, exhaustion from school work, environmental conditions, and habit,-are daily gaining recognition.

Such mental defects, both developmental and acquired, as idiocy and feeble-mindedness, although insane delusions may accompany the latter, are not included in the following, as they are discussed elsewhere.

The forms of recognized insanity most frequently seen in children are acute mania, melancholia, epilepsy, and insane hallucinations. These, with the exception of the last-named, occur in connection with the acute infectious diseases, - as scarlet fever, measles, acute rheumatism, pneumonia, and typhoid, especially typhoid. The delirium, not infrequent in hyperpyrexia, is usually transitory and subsides with the decline of temperature; but occasionally mania with delusions may continue for months after the termination of the disease.

A state of melancholia of more persistent duration is not rare, both in the terminal stage of fever and as an outgrowth of the convalescent stage, and has been considered as due to the exhaustive effect of the prolonged disease. There is reason to believe that many psychopathies are expressions of cerebral intoxication from pathogenic organisms peculiar to the parent disease. Psychopathies of this seemingly acute infectious variety, as a class, furnish the most favorable prognosis, as recovery is the rule under good hygienic conditions. A radical change of environ- 
ment may be necessary, with removal of objects or persons in any way associated with the febrile or convalescent period, during which the mania, melancholia, or hallucinations dereloped. A supporting dietary, with judicious employment of hydrotherapy and purposeful open-air occupation, may well exclude the routine use of sedatives or drugs. Unfortunately, in rare instances a marked hereditary tendency asserts itself in these cases with deplorable results.

The effects upon mentality from traumatism (particularly from blows on the head), intracranial disease, especially meningitis, meningoencephalitis, and hemorrhage, as productive of idiotic and imbecile states, have been presented in another chapter. The border line between imbecility and insanity is at times extremely vague, as is also the differentiation of the phobias of the insane and feeble-minded. Trauma as an exciting cause is not infrequently common to both of these mental conditions.

The hopelessness of cure in this class of unfortunates is as apparent as the gross pathological lesions induced by the disease. Kind but firm supervision, with moral education, occasionally may direct the eccentricities into harmless channels, as from destructive to philanthropic manias.

Mania resultant from exposure to extremes of temperature, as from insolation, or heat after prolonged refrigeration, though most violent in its manifestations, subsides, as a rule, under appropriate treatment after a few days or months of alternating outbreaks and remissions. The disease, however, may become periodic, especially if the vascular changes in the brain are permanent. A sequel to this form is sometimes seen in violent outbursts of temper, approaching maniacal excitement, from trivial causes.

The removal of a cause of reflex irritation-such as intestinal parasites, ingrowing toe-nail, or preputial constriction-is followed by the subsidence of maniacal symptoms with sufficient frequency to demonstrate the etiological relationship.

The most interesting phases of insanity, from the pediatric standpoint, are those forms due to emotional causes. These represent a great variety of psychopathic conditions, from the extreme homicidal or suicidal impulses to conditions recognized only as unimportant psychoses or emotional ecentricities. In most of these forms of mental unbalance, the predominating element is the inordinate egotism. This egotism, as an hereditary defect, plus the environment, as an exciting cause, act and react in a vicious circle to the establishment of many psychopathic conditions which continue throughout life. In this class are found the paranoias with their endless variety of insane delusions.

It is not difficult to see how the precordial apprehensian of a physically defective child may develop into a hypochondriasis or a pathophobia. Again, in the child without physical defect an abnormal self-consciousness may be the foundation upon which a foolish mother may help to erect a permanent mysophobia. In a similar manner may the recita- 
tion of stories of ghosts and hobgoblins, of fairy-tales and bizarre occurrences and erimes in real life, by overstimulation of the imagination, lead up to monophobia or even to panphobia. There is always a beginning of the unbalancing of the developing mind which may be largely due to environment. The early concept may, through mere circumstance, most trivial in character, become an insistent idea. Imperative acts, too frequently regarded as amusing or innocent peculiarities, may, by repetition, gain firm control,-each repetition weakening the will until the individual becomes the victim of morbid impulses or propensities. Undoubtedly many eases of pyromania, kleptomania, erotomania, dipsomania, morbid propensities to destroy property, kill or persecute animals, as well as suicidal and homicidal manias, owe their origin to lack of correction of the earliest manifestations of imperative conceptions. "Cranks" may owe to heredity their exaggerated egotism, and their special development to their environments.

The hopelessness of established paranoia lends additional emphasis to the importance of the recognition of its beginning in some of the trifling eccentricities of the developing period, at a time when judicious management might arrest the morbid tendency. Mental hygiene requires for the symmetrical development of mind, as does physical hygiene for that of body, a systematic regimen of purposeful function. Psychic toughening, like physical toughening, is accomplished only by the overcoming of obstacles,-by systematic training in the exercise of the will, judicious and unobtrusive direction of the mental activities into wholesome channels with simple, practical daily problems of whose solution the responsibility must clearly rest with'the child. This should replace the modern tendency to pamper the child's unreasoning whims and, as it were, to masticate and predigest his mental pabulum. Disillusioning of the infant mind may avert the phobias of later years.

Whether the underlying pathology of katatonia be due to vaseular hypoplasia or to stasis from vasomotor disturbances, it is quite generally conceded that dementia præcox, in which this symptom is most marked, is frequently the result of exhaustion. The development of symptoms of hebephrenia after a long sickness-as typhoid fever, exhaustive physical exertion, intense application to study accompanied by insufficient food, rapid physical growth, or masturbation-is of common clinical recognition.

The varied symptoms may include mania, melancholia, confusion of ideas and varied delusions with the characteristic stupor and persistent obstinacy. During the attacks the patients may refuse to eat or attend to any of the bodily functions, rendering eatheterization, enemata, and gavage necessary. All of these the patient most stubbornly resists. Of the motor symptoms, katatonia is the most marked and peculiar. This hypertonic spasm of limbs and trunk may be so extreme as to baffle all efforts at passive flexion. The bizarre attitudes of persistent rigidity, seen in some of these patients, are among the curiosities of clinical medicine. 
The gravity of dementia præcox with its low percentage of recoveries renders important the early recognition of its prodromata, the chief among which is apathy, despondency, and the easily induced fatigue in a mind previously ambitious and alert.

The stress of pubescence is too frequently forgotten in the parental pride at their rapidly developing progeny. Careful supervision of pubescent youth on the part of the family physician, with wise advice as to personal habits and the character and amount of work to be undertaken, may save the child from threatened, hopeless dementia.

The food should be nutritious but non-stimulating. Excess of proteids should be expressly avoided in the neurotic. Daily vigorous exercise in the open air, with positive exclusion of tobacco, alcohol, tea, and coffee, should be insisted upon. Studies and recitations--reading, music, and theatre-going-which strongly appeal to the æsthetic or emotional side of the nature should be interdicted.

TRANSVERSE MYELITIS.

Transverse myelitis is an inflammation of the spinal cord with resultant motor, sensory, and trophic disturbances in parts below the seat of the lesion. In form it may be acute, subacute, or chronic. In location it may be seen in the cervical, dorsal, or lumbar regions, but most frequently in the dorsal. Common causes in children are traumatisms, cold, acute infections, syphilis, or tuberculosis of the spine, hemorrhages, or any condition causing pressure upon the cord in any part of its extent. It has been found that infants and young children are peculiarly susceptible to hemorrage into the cord, especially into the gray matter of the anterior columns. This is explained by its vascularity, softer consistency, and the inferior support afforded to its vessels. Since the completeness of the motor-sensory trophic disturbance is dependent upon the amount of pressure and the extent of cord tissue involved, it follows that a limited hemorrhage into the anterior columns might produce only partial paraplegia, with unimpaired sensation and very little atrophy, the posterior horns being uninvolved.

From many observations upon still-born infants with hæmatomyelia, also from post-mortems upon very young infants, it is found that cord hemorrhages are not so rare as was formerly supposed. It is probable that transverse myelitis may have been frequently overlooked in young infants, the paralysis being attributed to other causes, or if incomplete, coming under observation subsequently, is supposed to be a complication of some later malady.

It is well known that the cord is remarkably tolerant of a compression which develops slowly, so that paraplegic symptoms are late and incomplete, with a tendency to recovery. This is well illustrated in Pott's. disease. The myelitis following infectious diseases may show this character of partial paraplegia, with tendency to restoration of motility, from a limited area of spinal involvement. This is of interest, as the acute infections appear to be the commonest cause of myelitis in child- 
hood. This disease has been considered extremely rare before the age of outdoor traumatisms and exposures, but recent reports of myelitis in the newly born presage a change of opinion.

The symptoms and course of transverse myelitis in childhood do not differ essentially from those of adult life, with the exception of the cases following the acute infectious diseases showing a less pronounced type.

The diagnosis is made from the rapid onset of the paraplegia, accompanied by anæsthesia and atrophy of all muscles supplied by segments below the spinal lesion, the involvement of bladder and rectum, and early tendency to the formation of bedsores. When cliplegia results from cervical lesion, the flaccidity and atrophy of the upper extremities is in marked contrast with the spasticity of the lower.

Prognosis.-Complete recovery is rare. In diplegic eases there is danger of early involvement of the cardiac and respiratory functions. Lumbar lesions, always attended by paresis of the bladder and bowel and necrotic bed-sores, are of grave import to the extent of these lesions. Those cases of myelitis in the dorsal segment of the cord due to syphilis, as well as those following acute infectious fevers, offer the most favorable prognosis as to their ultimate recovery, with the minimum impairment of the affected muscles.

The treatment is essentially rest in the strictest sense of the word. In the earliest stage a spinal ice-bag should be applied over the affected portion of the cord for a week or ten days, after which a rubefacient, as an attenuated mustard-plaster, may be substituted over the upper twothirds of the spinal column. The dorsal decubitus should not be persistently maintained, as extreme vigilance is necessary to prevent the formation of bed-sores. This will be rendered all the more difficult by the involuntary evacuation of the bowels and the dribbling of urine. A water-bed should be provided if possible. Too much eare cannot be given to the skin, especially over the buttocks. All parts exposed to pressure should be rubbed with diluted alcohol or solutions of tannic acid and dusted with powders. To the beginning sore, collodion dressings may be carefully applied and later there should be thorough cleaning with bichloride of mercury $(1: 5000)$ or peroxide of hydrogen.

The condition of the bladder requires careful watching, with aseptic eatheterization. Cystitis may call for vesical irrigation with a two per cent. solution of boric acid, and the use of potassium acetate or urotropin. Pads of borated absorbent cotton may be used for bowel dejections or dribbling urine.

The bowels should be flushed with normal salt solution. Calomel may be given in suitable dosage to secure free purgation, whether there be diarrhœa or constipation. The diet must be bland and nutritious.

In syphilitic cases potassium iodide should be administered, if the stomach be tolerant, or mercury by inunction may be used. To overcome the contractures, extension is indicated. This may be secured by lowering the foot of the mattress, the patient being retained by a strap 
attached to the head of the bed and fastened to a harness similar to that used in suspension for spinal deformities.

Oil inunction with gentle massage, after the subsidence of the acute symptoms, with later more vigorous massage of the affected muscles, to which faradism may be applied-although of little use to the spinewill delay the general atony and paresis. Continued rest, cool bathing, spinal douching, with sunlight and fresh air, will improve tone and promote recovery.

\section{ACUTE ANTERIOR POLIOMYELITIS-INFANTILE SPINAL PARALYSIS.}

Actue anterior poliomyelitis is the commonest cause of palsy in infancy and early childhood. The disease is so common to this age that it is more frequently known by the indefinite term of infantile paralysis, and also by the more expressive term of infantile spinal paralysis. Poliomyelitis anterior acuta, in distinction from a chronic form of rare occurrence, is, as its name implies, an acute inflammation in the anterior horns of the gray matter. Opportunities for post-mortem examination in the early stage of this disease are so infrequent that doubt still exists as to the exact character of the primary lesion. An infection it undoubtedly must be considered, both from its mode of onset and from its many analogies to other infectious diseases, although the specific etiologic microbe or toxin is not known. If it begin as an infective endarteritis of the vessels entering the anterior median fissure, it soon extends to the adjacent gray structures with resultant parenchymatous and interstitial degeneration. Atrophy and diminution of the multipolar ganglionic cells have been observed as a constant change in late post-mortems, and were formerly urged as the primary specific lesion of the disease.

The degenerative process may extend to the white matter of the affected half, the nerve-fibres from the atrophied cells disappear, and the entire segment show evidence of general sclerotic changes. Macroscopically, the affected side is seen to be smaller than the opposite half. Occasionally both horns are involved. The richness in blood supply of the anterior gray matter has been assigned as a reason for the frequency of its selection for the initial toxic lesion. Some fibres of the anterior nerve roots show degeneration which extends throughout their course to their distribution in the muscles which, ultimately, share in the changes.

The disease is confined almost exclusively to the period between the sixth month and the fifth year, eighty per cent. of all cases occurring in the first three years of life. Rare cases are reported in early infancy and it is less often seen after the sixth year, although no doubt it occurs more frequently in the adult than is generally supposed, being diagnosed as multiple neuritis. No predisposition as to heredity, sex, race, or physical condition has been observed. It occurs with the greatest frequency during the summer season, usually in children in apparently good health, yet it is known to follow or to complicate acute infectious diseases, as measles, scarlatina, and typhoid fever. A few limited epi- 
demies have been reported in communities where at the time no other infection was prevalent. Occasionally a more or less recent history of a fall or blow is given, and quite as frequently exposure to wetting or sudden change of temperature is reported as preceding the attack.

Clinically, four periods in this disease are usually recognized: first, stage of onset; second, stage of paralysis; third, stage of improvement; fourth, stage of atrophy and deformities. The onset is always sudden, with febrile symptoms ranging from slight indisposition, with but little elevation of temperature, to symptoms of profound intoxication with high temperature $\left(102^{\circ}-104^{\circ} \mathrm{F}\right.$., $39^{\circ}-40^{\circ} \mathrm{C}$.), vomiting, headache, occasionally convulsions, and rarely coma. There may be pain and tenderness over the trunk and particularly in the extremities, the picture simulating that of an acute exanthem before the appearance of a rash. This stage may last from three hours to as many days, during which the diagnosis is rarely made. A few reports of tardy development of paralysis have appeared, from one to two weeks elapsing between the beginning of the first and second stages. Upon subsidence of the acute symptoms it is discovered, too frequently by accident, that the child has lost the use of one or more limbs. Occasionally all of the extremities are involved, as well as some of the trunk muscles. The sphincters and respiratory muscles escape. Not infrequently the acute stage is wanting,--a healthy child, the night before, showing paralysis the following morning without other symptoms. This form of spinal paralysis has been known to occur in a child at play, his inability to walk developing without warning. The paralysis may be mono-, hemi-, para-, or diplegic in form. A review of a large number of cases shows the following percentage of primary involvement of different members:

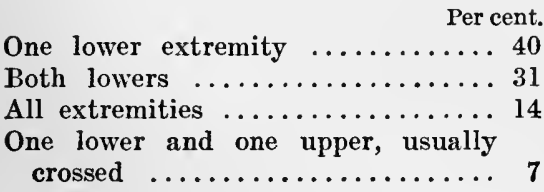

Per cent.

Both lower and one upper ....... 3

One upper $\ldots \ldots \ldots \ldots \ldots \ldots \ldots \ldots .3$

Other forms $\ldots \ldots \ldots \ldots \ldots \ldots, 2$

Rarely all the muscles of an extremity are involved. In a large majority of the cases it is the extensors that suffer and of these occasionally only a single group. This selection of groups is rather characteristic of poliomyelitis. Of the lower extremities the groups of muscles are most frequently affected in the following order: the peronei, the tibialis anticus, and quadriceps femoris, and of the upper, the deltoid, the supinatores, and triceps. Exceptionally the flexors are involved, as the gastrocnemius and soleus. Although a number of muscles may be involved in the beginning of the second stage, movement is recovered in the majority, as a rule, within a few weeks or months-a peculiarity of this disease-leaving one or more groups only of one or more members paralyzed, thus completing the second stage of the disease, which may have begun as a diplegia or hemiplegia, to terminate in a monoplegia or crossed variety. 
Pain or hyperesthesia over the affected muscles and their nerves are rarely seen in this stage, although sensation is not inpaired. Tendon reflexes of the muscles involved are lost. Faradic excitability gradually diminishes and is finally lost, while galvanic response increases in those muscles which ultimately show permanent impairment, in all of which the reaction of degeneration is well marked.

The resultant deformity is often seen in one lower extremity which is atrophied, shortened, and cold, as with relaxed ligaments it hangs a helpless appendage to the body. More frequently, however, some power is left, the deformity taking the form of talipes varus, valgus, equinus, or equinovarus, according to the different degrees of paralysis of the tibial or peroneal groups of muscles. The quadriceps rarely escapes, so that leg extension is lost, causing the familiar flail gait in walking. The rarer deformities of the upper extremities usually appear in subluxation of the shoulder with deltoid atrophy,-the arm swinging helpless at the side or the scapula may stand out wing-like from involvement of the serratus magnus. The forearm only may show atrophy with loss of supination and relaxed wrist. Contractures occasionally ensue from the action of opposed muscles, so that the hand is carried in extreme pronation with the fingers flexed.

The diagnosis is never made until the second stage, as it depends entirely upon the form of the paralysis. The nature of the spinal lesion is revealed by certain characteristies which can rarely be misinterpreted,such as the sudden development; unimpaired sensation; flaceidity of involved muscles with their loss of tendon reflex; atrophic changes; early spontaneous improvement in certain groups, and the reaction of degeneration in muscles permanently paralyzed. Differentiation must be made from multiple neuritis, ccrebral paralysis, transverse myelitis, Erb's palsy, and the pseudoparalyses of rhachitis, scorbutus, and acute rheumatism.

Prognosis.-Acute anterior poliomyelitis is rarely if ever fatal to life. The extent and permanency of the paralysis is the important question, the answer to which cannot be predicted from the extent of primary involvement, as extensive diplegia may terminate in a limited monoplegia or in complete recovery, while initial monoplegia may persist, with complete functional loss of the member. Early loss of faradic irritability and rapid wasting are of grave import for the muscles involved. Partial response and subsequent improvement in susceptibility to faradic stimulation are favorable prognosties of the ultimate return of function. The hopefulness of the case depends upon the duration and degree of the atrophy, and non-response to galvanism. Clinical experience proves the importance of reservation in prognosis and perseverance in the treatment of apparently hopeless cases. Complete recovery is rare, and in long-standing cases is not to be expected.

Treatment.- The first stage should be treated like any other acute febrile onset,- by prompt elimination, by induced catharsis, and by bromides. Even antipyrin should be given if the excitement warrant. If 
acute spinal lesions seem probable from epidemic prevalence, on indication of motor disturbance, an ice-bag should be applied to the spine, bromides pushed, and ergot administered every two hours. In the second stage the affected muscles should be masséed twice daily and the member supported to prevent dragging upon the relaxing ligaments. After the first month, regular application of faradic electricity may aid, not in restoring the degenerate nerves, for their ganglion cells are atrophied, but in maintaining the nutrition of the muscular fibres and lessening atrophy from long disuse.

The effects of heat in maintaining the circulation and promoting metabolism should not be forgotten. Treatment should be persisted in for months and even years, as evidences of its beneficial effects are abundant.

The orthopædic surgeon ean do much by means of operation and mechanical appliances for the resultant deformities.

Transplantation of tendons and, recently, transplantation of nerves, have been followed in some cases by recovered function.

TUMORS OF THE SPINAL CORD.

Tumors of the spinal cord are occasionally found in young children. They may be syphilitic, tuberculous, carcinomatous, sareomatous, gliomatous, hemorrhagic, or metastatic. As the etiology of many of these neoplasms is obscure, so must be the eause of their location in the spinal canal.

Presumably traumatism plays an important rôle in their origin, especially in systemic conditions favorable to their development, as tuberculous, syphilitic, and other dyscrasiz.

The location of the tumor, whatever its nature, produces focal symptoms usually unilateral, at first motor, sensory, and trophic, with late or early symptoms of compression myelitis similar to that in earies of the vertebræ.

The treatment depends upon the cause, which may sometimes be conjectured by associated conditions. In some rare instances surgery may hold out a fair promise of relief.

\section{SYRINGOMYELIA - MYELOSYRINGOSIS.}

This disease, which is characterized by eavity formation in the spinal cord, is rarely observed in children. The cervical portion is the usual seat, although the process may extend to all parts of the cord or the medulla, producing symptoms characteristic of the structure involved. Anterior horn lesions cause paralysis, lost reflexes, and atrophy in the muscles of the affected segment. There is often a unilateral, or, at least, an uneven distribution of two sides.

Destruction of the central gray matter gives rise to trophic changes and vasomotor disturbances, such as fissures or glossiness of the skin of the fingers, brittle nails, painless felons with phalangeal necrosis, boils, and dermal or subdermal atrophies. 
Invasion of the posterior columns is followed by analgesia and sensory disturbances which are pathognomonic. There is dissociation of thermo-anæsthesia from tactile anæsthesia, which is typical of syringomyelia, although it is occasionally seen in hysteria and anæsthetic leprosy.

The symptoms are focal and mark the location and progress of the destructive process in the cord.

The diagnosis from hydromyelia (a congenital dilatation of the central canal), from hemorrhages, tumors, syphilitic and tubercular growths, must be made from the gradual onset, the variety and distribution of its manifestations, and absence of specific constitutional disease; from hysteria, by the development of trophic changes and plegias with degenerative reaction in the muscles.

The disease progresses by stages and is incurable.

\section{HEREDITARY SPINAL ATAXIA-FRIEDREICH'S DISEASE.}

Hereditary spinal ataxia is a family affection in which there is attenuation of the spinal cord, most marked in the dorsal region and in the direct cerebellar tract. This is due either to inherited lack of development, to disappearance of nervefibres, or to sclerotic shrinking. Several generations or a number of children in the same family may be affected. Syphilis, neuroses, and alcoholism in parents are regarded as predisposing causes. The disease develops usually between the fifth and fifteenth years, more often in males, and may follow acute infections.

Symptoms.-Ataxia and weakness beginning in the legs, steadily increasing, and spreading until in four or five years the arms are involved, is characteristic of the onset. Loss of patellar reflex occurs early, with atrophy of muscles. Later disturbances of speech (slow and scanning), nystagmus, mental impairment, and contractures from paralysis of the muscles, follow. As a rule, no vesical or rectal disturbances occur. Characteristic plantar flexions of the foot, with extreme dorsi-plantar flexions of

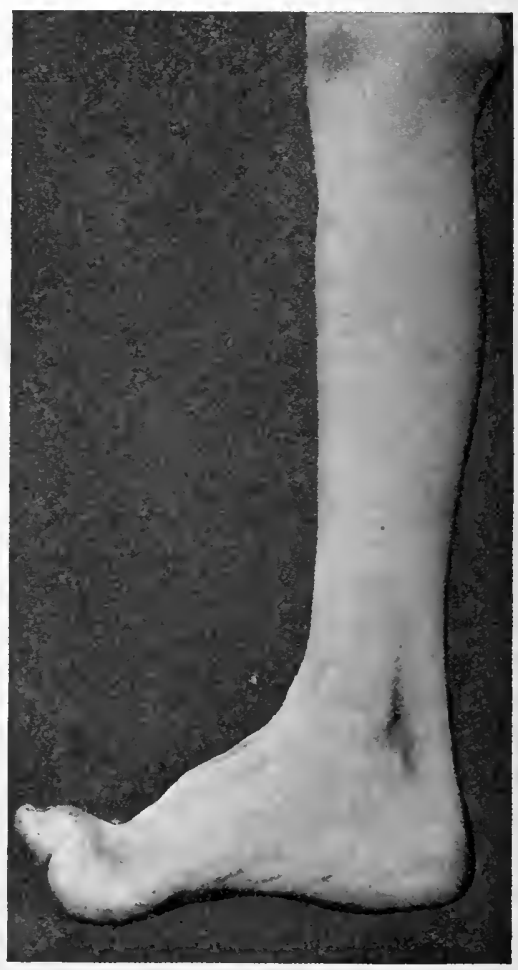

FIG. 175.-Cupped foot. the first two toes (eupped foot) (Fig. 175), and spinal scoliosis, are seen. Oscillation of the head and choreiform movements of the extremities 
may appear. Bulbar symptoms may develop with fibrillary twitchings of the tongue and motor impairment of the labioglossopharyngeal muscles.

In the cerebellar form of Friedreich's disease (Monne-Marie type) the patellar tendon reflexes may be exaggerated and talipes is absent. There is vertigo and general incoördination of movements which improve or disappear when the patient is recumbent. There are marked ocular symptoms. The pupils are unresponsive to light or accommodation, while diplopia, color-blindness, limitation of visual field, or amblyopia from optic atrophy, may be present.

Friedreich's disease is progressive and incurable, although it may remain stationary for months or years. The mental faculties are impaired; paraplegia becomes complete, with quite general muscular atrophy; speech is lost, and the child is helplessly bedridden.

The diagnosis is established by ataxia extending slowly from the legs to the upper extremities and tongue, talipes and spinal curvature, with loss of knee-jerk, retained cutaneous sensation, and developing paraplegia. No treatment is of any known benefit.

LANDRY'S PARALYSIS-ACUTE ASCENDING PARALYSIS.

Landry's paralysis is rare in childhood. The etiology is unknown. Although it has been commonly classed with the spinal affections, insufficient proof of a common spinal lesion exists. A micrococcus has been isolated which produced in a rabbit rapidly spreading palsy. An identical organism was subsequently recovered from the dura of the rabbit.

Landry's paralysis has been known to follow exposure to cold and acute infectious diseases. Febrile symptoms may precede the attack, which begins in the legs and extends upwards, involving snceessively every portion of the body, extremities, and head, in a flaccid paralysis, with loss of reflexes and anæsthesia following hyperæsthesia. Atrophy is not marked nor is there change in electrical reaction. The sphincters are not involved and bed-sores are uncommon. The complete involvement may occupy from two days to three weeks, and death may occur from failure of respiration, or the paralysis may continue for months. Occasionally improvement begins in reverse order to its invasion, and rarely recovery follows. There is no medicinal treatment other than to promote comfort, maintain nutrition, and correct faulty elimination.

\section{HEREDITARY SPASTIC PARALYSIS-CEREBROSPINAL PARALYSIS.}

Occasionally there are seen conditions to which the term hereditary spastic paraplegia is applied. With few exceptions a history of similar symptoms in one or more members of the family is obtained.

The characteristics of this disease are the presence of paraplegia, spasticity, contractures, inçreased deep reflexes, without rectal and bladder involvement, atrophy, or disturbance of speech. Some of these cases also present ocular and cerebral symptoms,--as amaurosis, nystag- 
mus, mental impairment, or idiocy. These are classed as cerebral or cerebrospinal spastic paraplegia.

This disease is distinct from Little's disease and other birth palsies due to dystocia, instrumental delivery, or convulsions after birth.

Present knowledge can only assert that there seems to be an inherent weakness in the nervous system that is unequal to more than a few years of normal function.

\section{LOCOMOTOR ATAXIA-TABES DORSALIS.}

Locomotor ataxia may occur in children born of syphilitic parents. A number of cases have been reported in children, between five and sixteen years of age, in which the symptoms and lesions were similar to those found in the adult. The patients all had histories of parental syphilis.

MULTIPLE SCLEROSIS-DISSEMINATED SCLEROSIS; INSULAR SCLEROSIS.

Multiple sclerosis is a disease the first symptoms of which appear between the ages of ten and twenty-five years, although a number of cases have been observed in infancy and some even at birth. It is characterized by a more or less definite set of symptoms,-as intention tremor, difficult enunciation, ocular symptoms and peculiar gait,-although many variations are seen.

Etiology.-Neurotic heredity is considered a predisposing factor. Acute infectious diseases, metallic poisons, exposure to cold, shock, fright, and trauma are reported as exciting causes. Whether or not irritating substances in the blood cause extravasation of toxic lymph into the surrounding nerve-tissue, resulting in degeneration of the myelin sheaths of the nerves, is not at present proven. Examinations of the blood have failed to detect corpuscular alteration or microorganisms.

Pathology.-As the name suggests, the lesions consist of areas or patches of sclerosis irregularly disseminated throughout the central nervous system, as well as the roots of spinal and cranial nerves. Although the process involves many nerve-sheaths, only a few nerve-fibres are totally destroyed. As a rule the white substance is involved to the greater extent, and for this reason involvement of the cord has shown greater motor than sensory disturbances.

Symptoms.-The gradual onset of this disease is first indicated by weakness of the upper or lower extremities, with trembling awkwardness of fingers on movement. An early symptom which continues throughout, is an "intention tremor," which occurs upon voluntary effort at fine co-ordination,--such as writing, tying a knot, passing a glass of water, or protruding the tongue. The speech is slow and the words are pronounced with eare, while the consonants $l, p, g$ and $r$ are indistinctly enunciated. There may be inequality of the pupils with imperfect reaction to light and accommodation. Horizontal or vertical nystagmus may appear if the eyes be directed sharply to the right, left, or up- 
wards. The visual field may be narrowed as in hysteria. This may be unilateral or bilateral. In a good pereentage of cases early changes in the retinal papillæ are observed which show a gray discoloration of the entire disk. The ophthalmoseope reveals this optic atrophy and aids in diagnosis. A peeuliar, vague, or stupid expression pervades the countenance. The mind seems weakened and the child is emotional. Spastic paralysis gradually develops in the extremities, the gait becomes stiff and awkward, and the deep reflexes exaggerated. There is no muscular atrophy, no reaction of degeneration, and in many cases no loss of eontrol of anal or vesical sphineters. Babinski's and Oppenheim's signs are present. Bulbar symptoms may supervene, and labioglossopharyngeal or laryngeal involvement, with interferenee in mastieation, deglutition, and even respiration, may eomplete the picture of functional demoralization. The age, the intention tremor, the nystagmus, exaggerated knee-jerk, and spastic gait with optic atrophy, make up a group of symptoms which eannot be mistaken for any other disease. Many years may elapse before the patient dies of some intereurrent disease. This disease is noted for its periods of remission, and even temporary improvement, but reeovery is hardly possible.

Treatment.-In view of the prognosis, nothing but palliative treatment is indicated. Above all, is moderate rest for the tired muscles and massage for the spastie limbs. Warm baths contribute to the ehild's comfort, but drugs are of no avail. These eases, however, should never be put to bed for any length of time, but should receive a moderate amount of exereise daily.

PROGRESSIVE MUSCULAR ATROPHY-HAND TYPE OF ARAN AND DUCHENNE;

LEG TYPE OF CHARCOT-MARIE-TOOTH (PERONEAL FORM); MUSCU-

LAR ATROPHY WITH PSEUDOHYPERTROPHY; JUVENILE FORM

(ERB'S TYPE) ; FACIO-SCAPULO-HUMERAL (LANDOUZY-

DEJERINE TYPE).

Until recently the term progressive muscular atrophy was employed to describe several diseases, all of which show progressive loss of power and ultimate atrophy of some muscles, and all probably hereditary or familial in character.

The first elass begins in the extremities, usually in the hand (AranDuchenne type) as a wasting of the thenar and hypothenar eminenees. The interossei are next involved, followed by atrophy of the forearm, flexors and extensors, resulting in "claw-hand" from resultant contractures. Occasionally the atrophic process gradually extends to the muscles of the arms, shoulder, back and trunk. Rarely the order of invasion may be reversed. One of the earliest symptoms is fibrillary twitehings of the museles involved. With a shight irritant, as a rap on the muscle, a tremor and wave of motion is set up that continues for some time. There is altered response to faradic and galvanic stimuli, advanced cases giving the reaction of degeneration. Sensation is not impaired, but the deep reflexes are diminished or lost. The principal 
spinal lesions are seen in atrophy of the ganglion cells of the anterior horns, and later of the motor nerve-roots. It shows distinct heredity and frequently begins before puberty.

The diagnosis, from atrophy due to other causes, is made by the characteristic course, beginning with the small muscles of the hands, the "individualization" of the atrophy,-i.e., selecting some muscles and avoiding others in close proximity; the slow progress; the fibrillary twitchings, and absence of pain or loss of control of the sphincters.

The prognosis for recovery is unfavorable, although the course may be very slow, lasting many years. Death usually results from some intercurrent disease.

The treatment is symptomatic. Massage and electrical treatment may arrest the atrophy.

In the second class the disease may begin in the lower extremities (peroneal form of Charcot-Marie-Tooth), in which the extensor muscles of the toes first show weakness, next the small muscles of the foot, after which the leg muscles are slowly involved in the atrophy. The result is seen in deformities of contracture, pes equino-varus, or double clubfoot.

Usually the first symptoms are seen in childhood, and there is a history of the same affection in several members of the family, or extending through three or four generations.

In this form also there are fibrillary twitchings, although these may not be so pronounced as in the hand type. Response to galvanic and faradic tests is light or entirely absent. The tendon reflexes are lost. Paræsthesia and pain may be present but there is no disturbance of the sphincters.

This type is probably confined in most cases to the muscles and nerves, not involving the ganglion cells in the anterior horns of the cord. Hypertrophy or pseudohypertrophy is rarely if ever seen, althongh occasionally individual fibres show overgrowth. The disease is incurable. The deformities are those of contracture, some of which have been mentioned.

A third class of progressive muscular atrophy is represented by the disease long known as pseudohypertrophic paralysis, in which there is marked wasting in some muscles or groups, with apparent or real hypertrophy; in others, however, atrophy in a later stage. All the affected muscles, whether primarily shrunken or enlarged, are weakened. The most marked form of pseudohypertrophy is seen in the enormous enlargement of the calves of the legs, coincident with atrophy of the thigh, back, shoulder, and arm muscles (Fig. 176). The muscles of the arms, neck, back, chest, and pelvis may show atrophy with pseudo (or real) hypertrophy of the deltoids, the supraspinati and infraspinati (Erb's juvenile type).

Again, the atrophy may show first in the face, extending to the shoulders and arms (the facioscapulohumeral type of Landouzy-Dejerine), during the early part of which certain muscles appear normal 
or slightly hypertrophied, as the flexors of the hand and forearm, the scapular muscles, and the lips. The prominence or drooping of the lower lip (bouche de tapir), with the paresis of the orbicularis palpebralis, constitute the facies myopathique of French authors (Fig. 177).

In these and other forms of mixed atrophic muscle groupings there are no fibrillary twitchings, and the electrical reactions are but slightly affected until late in the disease, after extreme atrophy. The mass of evidence goes to prove they are non-spinal in origin. They are myo-

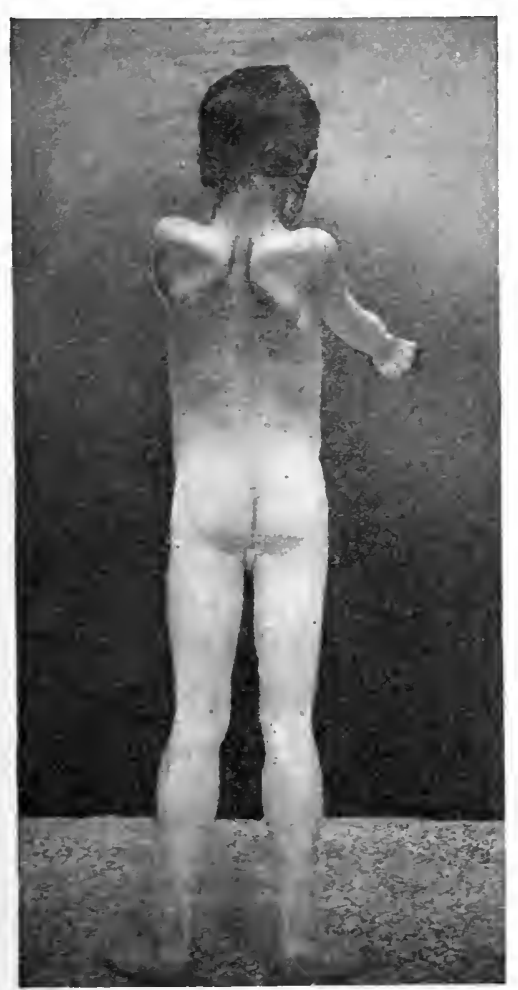

FIG. 176.-Pseudohypertrophic muscular paralysis, showing large calves, weak flanks, and atrophied shoulder muscles. (Dr. G. W. Hall.)

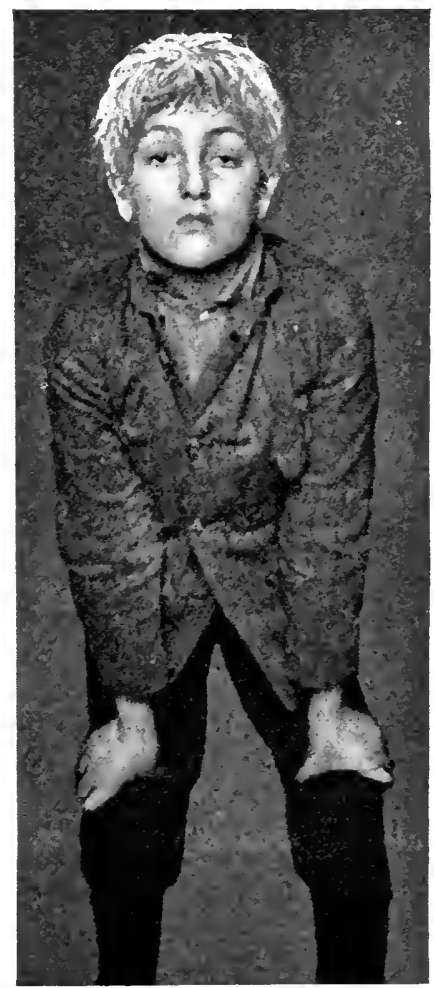

FIG. 177.-Progressive muscular dystrophy (Landouzy-Dejerine type). (Dr. G.W.Hall.)

pathic in distinction from the amyotrophic of spinal form. The variety of these myopathies has led to the use of the term muscular dystrophies as best expressive of the diseases in which atrophy, with or without associated hypertrophy, begins in the muscles themselves, the later nerveand spinal cord changes being regarded as secondary.

Hereditary etiology is marked in these muscular dystrophies. They begin in infancy or childhood (although an adult form is seen), usually with weakness of locomotion, fatigue after slight exertion, waddling gait, and inability to climb stairs, especially noticeable in the lower 
limb type. The characteristic phenomena are seen in the effort of the patient to rise from the prone position ("climbing the legs" as it is called), thus supplementing the weakness of the back, hip, and thigh muscles with arm strength (Figs. 178 to 185). Inspection of the erect pose shows lordosis and broad base, with large calves, in marked contrast with thigh, pelvis, trunk, and shoulder muscles, which show various degrees of atrophy (Fig. 176). So, too, in the Erb type, the enormous deltoids and spinati tower above the wasted arm, chest, and back muscles, while efforts to elevate the arm by making the hand climb up the back of the neck and head are dramatic evidences of loss of power.

No pain accompanies these muscular dystrophies. There is a steadily progressive atrophy until many muscles are involved, producing in the course of years complete helplessness. Occasionally the tongue and muscles of deglutition become involved, but death is usually due to intercurrent disorders, especially of the chest, owing to superficial breathing. The disease is incurable, although rest with massage and electricity to affected muscles retards its progress.

The orthopædie surgeon can do much to relieve the deformities as in the spinal forms of paralysis.

\section{MULTIPLE NEURITIS.}

Neuritis is a term applied to inflammation or acute degeneration of peripheral nerves. It may be caused by blows, prolonged pressure over a nerve trunk, cold, or by toxic agents circulating in the blood,-as lead, arsenic or alcohol. Arsenic from wall paper and artificial flowers, lead from foil-wrapped bonbons, water conveyed through lead pipes, and foods in soldered tins, are but a few of the many means by which these minerals may reach the circulation. Arsenic administered for a long time in moderate doses may produce multiple neuritis. The alcoholic form, from the reprehensible custom of giving beer and wine to small children, is not so rare in childhood as was formerly supposed.

Neuritis occurs most frequently in childhood during the course of, or as a sequel to, the acute infections,-as influenza, typhoid and searlet fevers, malaria and rheumatism, but especially diphtheria.

The pathology of polyneuritis does not differ from that seen in the adult. The process may be a perineuritis, an interstitial neuritis, or the inflammation may involve the parenchyma with degeneration of the nerve-fibre.

For some reason the circulating toxins, whether inorganic or bacterial, show earliest preference for the musculospiral nerve in the upper, and for the peroneal nerve in the lower extremities, so that the muscles of those distributions are usually the first affected, causing the familiar drop-wrist and foot. The most notable exception is seen in postdiphtheritic neuritis, which first appears in paresis of the palate and pharynx. Beginning in the extremities the motor and sensory disturbances may extend to any or many of the peripheral mixed nerves, though the post- 
Pseudohypertrophic muscular paralysis. Eight characteristic postures assumed in rising from the floor. (Dr. (t. W. Hall.)

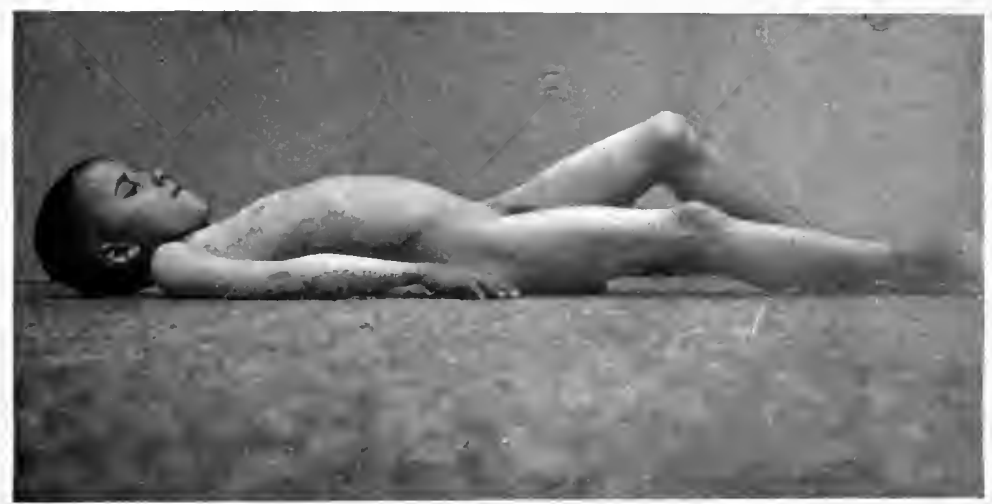

FIG. 178

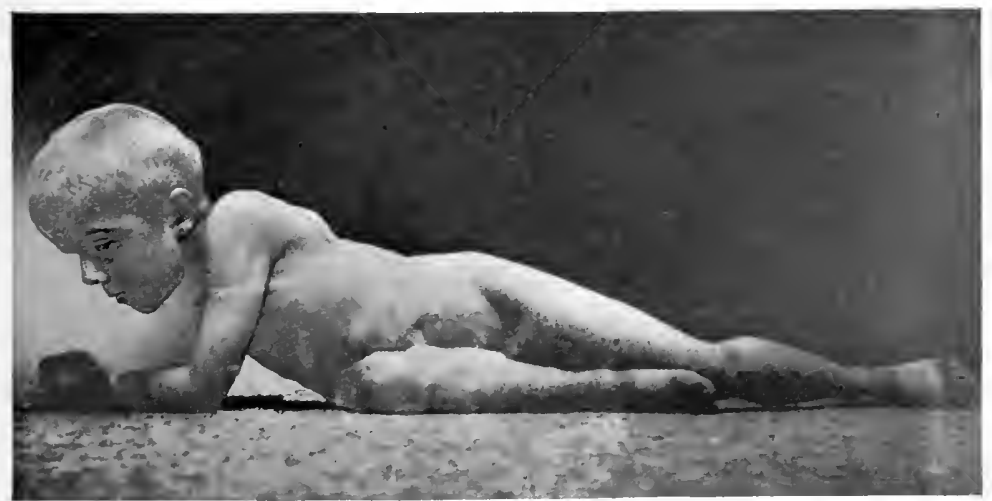

FIG. 179 


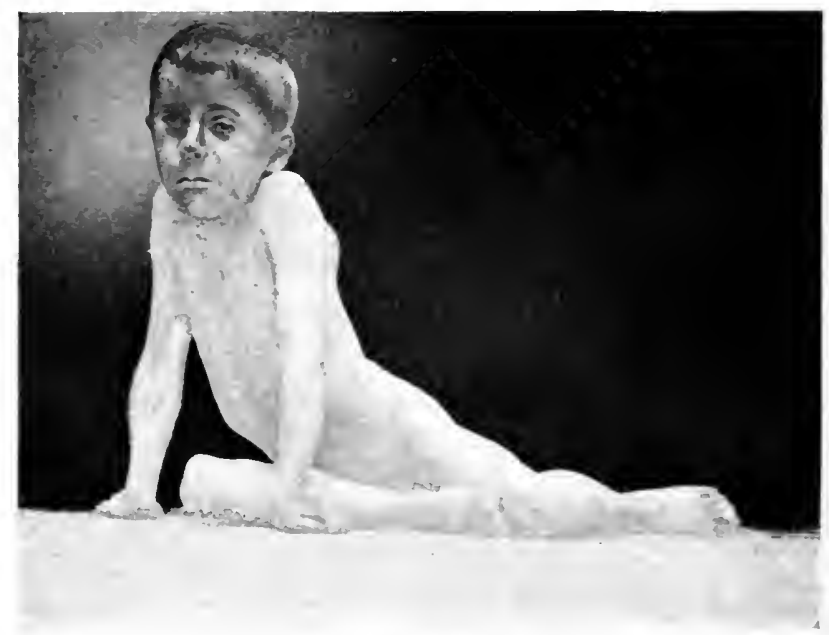

FIG. INU

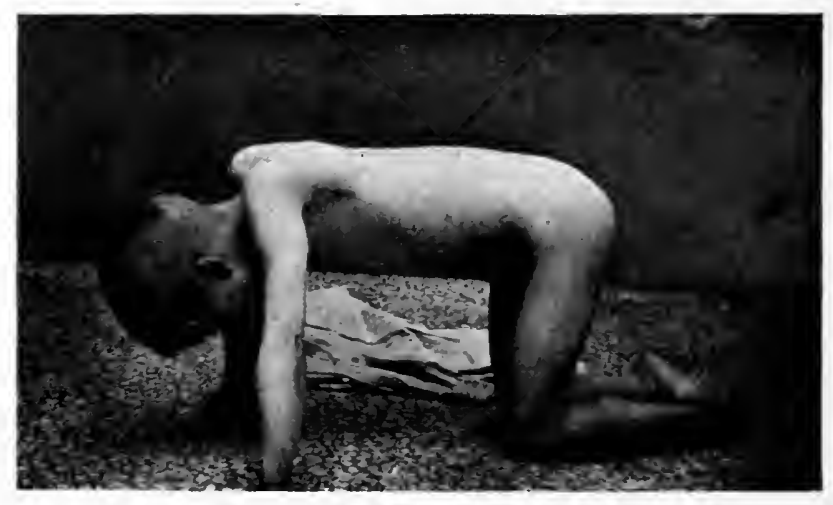

FIG. 181 


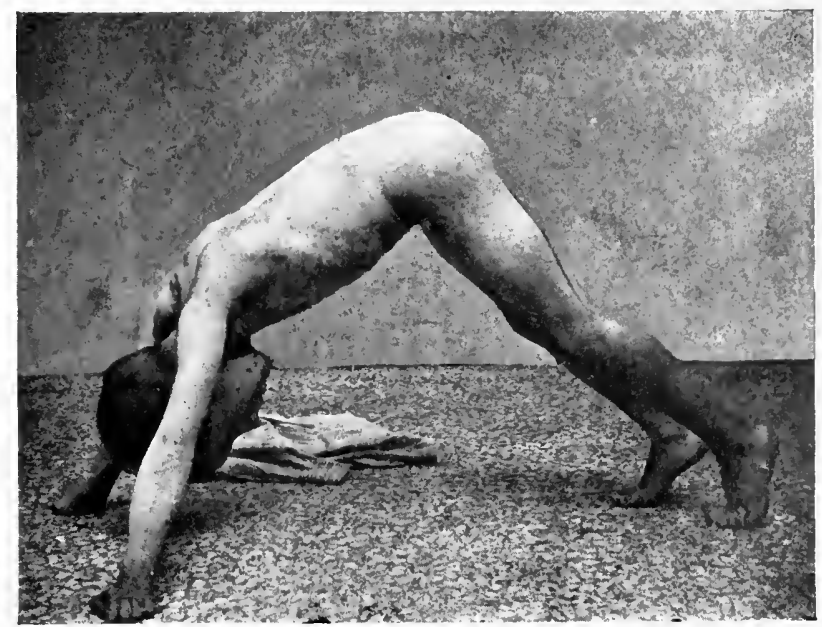

FIG, 18:

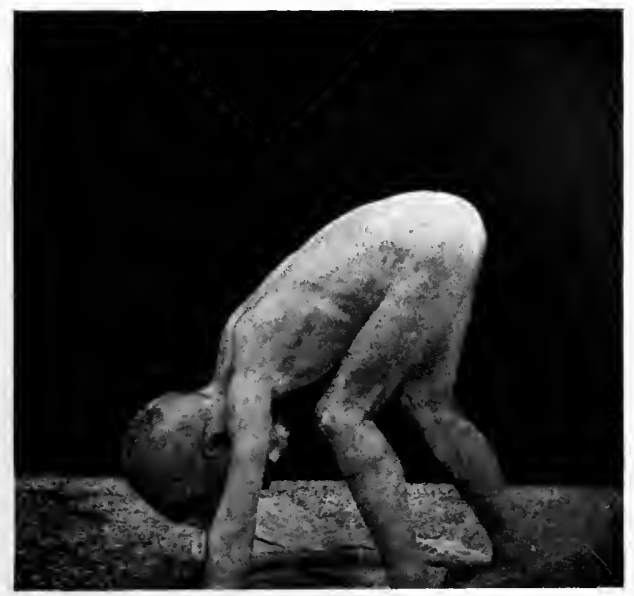

FIG. 183 


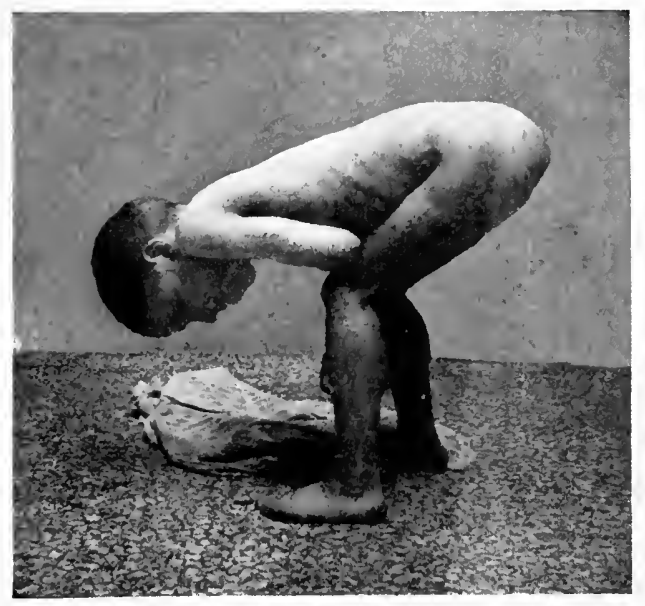

FIG. 184

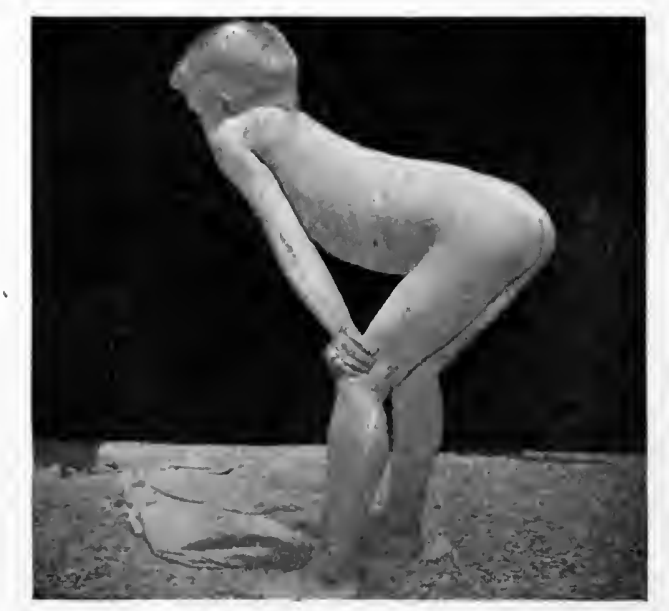

FIG. 185 
diphtheritic neuritis follows a somewhat exceptional course. (See DiPHTHERIA.)

Symptoms.-Characteristic of multiple neuritis is the association of motor, sensory, and trophic disturbances, symmetrically distributed, with resultant flaceid paralysis and diminution or absence of tendon reflexes and electric excitability. It may be confined to a few muscles in the extremities or involve all the limbs of the borly in complete motor and sensory paralysis. The head, eyes, and tongue usually escape. The sphincters ani and vesicæ are exempt. The onset may be acute, but is usually gradual. For several days it may be observed that the child does not use his hands accurately. IIe drops things and shows loss of power, stumbles in walking, does not sit erect, or evinces pain and tenderness on being handled, usually the first indication in young infants. Drop-wrist or foot may appear, accompanied by tenderness over the course of the nerve supplying the affected muscles. An acute onset may be accompanied by fever and rapid development of paralysis in a few days. The usual course is a gradual development of paralysis for three or four weeks, the pain and tenderness being most marked in the early stage, to be followed by anæsthesia of the affected areas. After a month, or in less time, improvement begins in restored sensation, and proceeds slowly, usually to complete recovery, although death may occur from cardiac or respiratory paralysis. Permanent flaceid paralysis in some member occasionally persists, with complete reaction of degeneration. Electrical tests are of prognostic value as to the outcome of the attack. Pneumonia in complication is to be dreaded.

Diagnosis.-From acute anterior poliomyelitis the diagnosis is at times difficult. The symmetrical character, the gradual onset, the persistence of tenderness or even pain over the affected nerve-tracts, and the existence of a cause, when determinable, will aid in clearing up doubtful cases. Obstetrical and other forms of traumatic neuritis show asymmetry and frequently the cause is evident.

Treatment.-Remove the cause, if possible, whether it be lead, arsenic, alcohol, or malaria. The child must be kept in bed. For the pain, dry heat may be sufficient, but as anæsthesia develops care must be taken not to burn or blister the skin, as obstinate lesions may be induced. Warm baths may quiet, or bromide and even chloral may be necessary to induce sleep. Codeine may be given in extreme cases, but the opiates should be withheld if possible. Gentle massage with fat inunctions comfort the patient and promote the nutrition of atrophied muscles. For obvious reasons arsenic should be withheld. Resultant deformities from contractures may require orthopædic appliances.

(Obstetric Paralysis, see Part II, Chapter I. 


\section{CHAPTER XII}

\section{DISEASES OF THE GLANDS, BLOOD, BONES AND JOINTS}

\section{LYMPHATISM}

THE term lymphatism carries with it a suggestion of the areas and tissues pathologically involved. It is preferred to the older terms, scrofula or struma, formerly employed to express not only the same condition but also conditions which have been demonstrated beyond question as tuberculous. Since some writers have found it necessary to differentiate between tubercular and nontubercular scrofulosis, it would seem that much that is vague and obsolete regarding both the diathesis and the infection might be eliminated from our literature by dropping the term scrofulosis. In its place lymphatism may be used, with proper adjectives, to express a wide range of varying degrees of disturbance, both structural and functional, from the slightest invasion of the narrow border which separates the pathologic from the physiologic, during the active metabolism of the developing period, to the most pronounced expressions of a diathesis, whether hereditary or acquired.

The commonest expression of lymphatism is seen in the sensitiveness to infection of the lymph nodes of the mucous and tegumentary areas which their channels drain. There is also a marked tendency to hypertrophy of lymphoid tissue, not only in the nodes but in the adjacent mucosa. Attacks of acute local catarrh establish a predisposition to its recurrence, so that the case soon develops into that of a catarrhal condition, with a history of repeated acute exacerbations. The adjacent lymph nodes in the earlier history show alternate engorgement and subsidence with each wave of infection. Later, these nodes show permanent enlargement with induration and hyperplasia of their structure. The lymphoid bodies in the mucosa hypertrophy with increase in their tissue elements, both connective and vascular. This is most frequently seen in the lymphoid ring of the oronasopharynx, the bronchial glands and those of the alimentary tract.

It has been claimed that the constitutio lymphatica is normal to infancy and early childhood. Without concurrence in this statement, it is true that it is during the developing period that lymphatism is commonly seen. Two clinical pictures representing types of this condition are familiar: First, the phlegmatic, torpid lymphatic type. These children are usually pale, fat, and flabby, and show general glandular enlargements which persist, especially those in the neck. The adenitis becomes chronic, with increasing frequency in acute exacerbations, each 
of which increases the nodular induration. The chronie eatarrhs of the adjacent mucosæ intensify this condition. These children are peculiarly suseeptible to pyogenie processes, while otorihwa, bronchorrhoea, and purulent discharges from all the areas, with tegumentary and phlegmonous suppurative softening and destruetion of tissues, leaving livid cieatrizations, complete the picture. Second, the neuro-sanguine lymphatic, of spare habit and precoeious mentality, in whieh the external lymph-nodes, although quiekly responding to loeal infeetions, do not show a tendeney to marked hyperplastie induration. The deeper nodes, however, as the bronehial and enteric, from repeated recurrenees of bronchitis and enteritis, show persistent hypertrophy with ever-threatening bronchopneumonia and enteritis of severe type, whieh keeps the physician on the alert for pulmonary and intestinal tubereulosis.

Growth is usually retarded, leaving the survivors stunted in childhood and undersized in maturity.

The oceurrence of sudden and unexplained death in the subjeets of lymphatism has led to a line of inquiry with the following anatomic findings: There is a tendeney to a persistenee or even hypertrophy of the thymus which, in some instanees, is so obvious as to eause substernal dulness on pereussion. Sometimes this enlargement is regarded as sufficient cause of death from mechanical pressure on the pneumogastric nerve, heart, or the arch of the aorta. Since in many of these cases the fatal syncope oceurred during extreme cervieal extension, eausing unusual pressure on substernal structures, the eause, not unnaturally, was attributed to the large thymus and sometimes to the hypertrophied thyroid. In this eonnection the so-called thymic asthma, presumably due to pressure of an exceptionally large gland upon the reeurrent laryngeal nerve, is a not infrequent aecompaniment of the status lymphaticus.

The before-mentioned enlargement of the bronchial-nodes which, at times, causes marked tumefaetions at the bifureation and roots of the larger bronchi, plays an important part in this tendency to substernal pressure, aggravated by the dorsal decubitus with head retraction.

Recent study of these eases has shown not only hyperplasia of the lymph-nodes, thymus, and spleen, but also hypoplasia of the heart and aorta, so that the conclusion is not unreasonable that the causes of fatal syncope are due to defects of the cardiovascular structures themselves. Whatever may be the relative etiologic value of these glandular and vascular conditions, the diagnosis of status lymphaticus has recently served as an explanation in the quest of cause for sudden death in infants of this type.

The importance of its recognition is apparent when the question of anæsthesia, operation, or any procedure likely to produce shock, is under consideration.

Although the largest proportion of cases of lymphatism is due to heredity, it occasionally appears as a familial type where neither parents have suffered from lymphatism, tuberculosis, or rheumatism. Again, 
lymphatism may develop in an infant previously free from dyscrasia, with a good family history, after an acute infectious disease,- - such as measles, scarlet fever, pertussis, or influenza.

It has long been believed that malhygiene is important, both as a predisposing and as an exciting cause. The crowded tenement-houses of cities furnish, by far, the greatest number of cases.

The treatment is essentially hygienic and nutritional. These children should have fresh air in abundance, preferably at the seashore, protection from sudden lowering of the body temperature, removal of adenoids, and treatment of local eatarrhs. Iodine and the iodides are almost always indicated, especially the iodide of iron for the anæmia which is usually present. The hydrocarbons, especially cod-liver oil, are as valuable to-day as during the past century. Where oil is not well tolerated by the stomach, much benefit may be derived from daily inunctions and thorough massage with cod-liver oil.or with a mixture of animal and vegetable fats,-as peanut, cocoanut, olive, beef suet, and wool fat.

Although lymphatism is amenable to treatment, and in uncomplicated cases the prognosis is favorable, the undeveloped condition of the heart and arteries, with the predisposition to fatality from otherwise insignificant causes, must not be forgotten. Many deaths from intercurrent disorders-as measles, scarlet fever, and diphtheria-are undoubtedly due to this condition. The marked predisposition to tubercular processes before that infection was so well understood, attached to scrofula a graver prognosis than its uncomplicated state deserves.

\section{SIMPLE ACUTE ADENITIS.}

The terms simple or idiopathic adenitis do not seem to harmonize with the present knowledge of infectious processes. Swelling, hypertrophy, and hyperplasia of the lymph nodes, with or without necrosis, is so frequently attributable to microbic invasion that it is difficult to conceive of such a thing as simple, idiopathic, or non-infectious adenitis. For the same reason many object to the term primary adenitis, which they elaim is merely a confession of the inability to locate the initial lesion or port of entry of the microbe or toxin which excites the adenitis. Possibly the only exception to microbic origin is seen in the not uncommon occurrence of enlargement of lymph-nodes following unusual or prolonged exercise of the muscles,-as, for instance, the enlarged inguinal glands at the beginning of skating or running, and the axillary enlargements of the young ball-player.

The term lymphadenitis is applied to all lymph nodes that are demonstrably enlarged. Although no age affords immunity, it is peculiarly an affection of the developing period. In clinical description it is convenient to speak of adenitis as acute and chronic, the former as an accompaniment of all the acute catarrhal lesions, including the acute infectious diseases. Chronic adenitis seems to be the common condition in childhood to which there are few exceptions. 
Palpable glands, especially in the neck, are the rule in children in institutions and in those who throng the dispensaries. Nor does private practice among the well-to-do class show marked exemption from this widely prevalent condition. It may be that the wide prevalence of catarrhal conditions, influenced largely by the climatic peculiarities of the lake region, may make these conclusions exceptional to those formed from observations in a more stable climate.

Although acute adenitis may develop in any lymphatic gland of the body, its most frequent occurrence is in the cervical lymph-nodes, both anterior and posterior to the sternomastoid muscles, beneath the angle of the jaw and under the chin (Fig. 186).

As a rule acute adenitis is rarely diagnosed as such, and is seldom brought to the physician for that condition alone. It is usually for

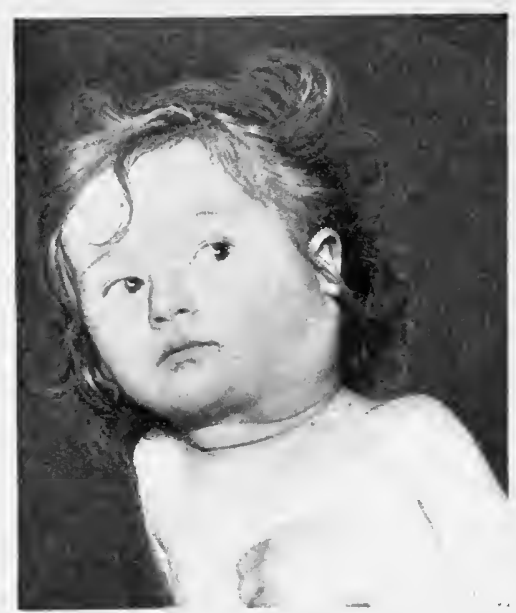

Fig. 186.-Acute cervical adenitis.

the mouth, throat, nasopharynx, or ear affections that the physician is called, the acute adenitis constituting, therapeutically as well as etiologically, a secondary matter. Rarely the child is brought to the physician for a lump in his neck which was not there at the time of last bathing, with no history of antecedent infection. Examination, however, seldom fails to reveal the remains of an acute aural, faucial, or nasopharyngeal disturbance. The nodes affected may be unilateral or bilateral, generally showing first on one side, and with different degrees of involvement. Rarely a single gland is affected, the enlargement usually showing in a group of nodules which may be separately outlined and which are freely movable. It occasionally occurs, however, that a large group swells simultaneously, as in a bunch, with much periglandular infiltration, forming a tumor in which the separate nodes are indistinguishable and over which the integument may be tense and shining. Palpation reveals tenderness which is occasionally marked, 
although unprovoked pain is rarely a feature. The feel in these acute cases is usually boggy but occasionally highly elastic. The skin is rarely adherent and the glands, unless there is much infiltration, are movable.

The course of the adenitis depends largely upon the nature of the infectious microbe, although in this connection the individual resistance eannot be overlooked. Infection from pyogenic organisms-e.g., staphylococcus and streptococeus-may lead to suppuration and breaking down of the glands and the adjacent cellular tissues with pus burrowing, in neglected cases. The necrotic process may be accompanied by hemorrhages. This occurrence, it is claimed, is most frequently due to infection by the diphtheria bacillus. Necrosed areas, when limited to the substance of the gland, may be enclosed by increased connective tissue growth with resorption of all but the calcareous material, which is occasionally found as a result of an old suppurative lesion. The abscess may point on the surface and discharge without the aid of surgical interference. Suppuration may be present, without discharge, the small amount of pus being absorbed. Suppuration, however, is not the rule in acute adenitis. The swelling of the nodes that follows the acute lesion in from two to four days subsides gradually in from one to three weeks. There is usually elevation of temperature, which subsides with the disappearance of the primary infection.

In some acute infectious diseases-as diphtheria and scarlet feverthe extensive glandular and periglandular involvement from the primary angina may be maintained for a considerable time by the sequelæ of nasal, faucial, pharyngeal, or aural extension.

Acute adenitis of the inguinal glands frequently accompanies vulvovaginitis in girls, and preputial or urethral lesions in boys. They may also be due to any suppurating lesions of the lower extremities. Abrasions and infected lesions of the upper extremities and pectoral regions affect the axillary nodes, a common occurrence in vaccination.

Mesenteric lymph-glands show acute enlargement from intestinal infection, as in ordinary enterocolitis, while those of the mediastinum are probably enlarged in all acute bronchial catarrhs and pneumonia. Although acute adenitis shows a tendency to rapid recovery in the majority of cases, the affected nodes remain permanently enlarged from slight increase in the fibrous tissue.

The immediate prognosis is good, except in neglected suppurative cases with extensive burrowing and systemic reinfection.

Treatment.-Aside from suppurative cases, acute lymphadenitis requires but little treatment beyond that directed to the primary affection. Local applications over the affected glands, except for relief of pain, are of doubtful utility. In this category may be placed ice-bags, hot fomentations, poultices, embrocations, etc. Since active phagocytosis requires hyperæmia, local depletion may interfere with the functional activity of the gland. The usual indications of pus, such as persistent 
or irregular fever, with or without chill, marked leucocytosis, and fluctuation in the tumor, eall for its prompt evacuation. In cloubtful cases, a judicious use of the hypodermic aspirator will determine the location of a small, deeply seated abscess. After free opening, the abscess must be thoroughly drained by a tent or wick. Care is necessary to prevent too early closure of the incision.

\section{CHRONIC ADENITIS.}

Chronic adenitis is a term used to express permanent enlargement of the lymph nodes, whether as a result of a congenital dyscrasiasuch as syphilis, tuberculosis, or lymphatism-or whether as a result of repeated attacks of acute adenitis.

The proneness to acute exacerbations in chronically enlarged lymph nodes is so well known to the physician that the presence of numerous permanently palpable lymphatic glands in the child affords an index of his susceptibility to infection from apparently trivial eauses. Aside from syphilis and tuberculosis, this is their main "significance. The indications are preeminently those of improved hygiene, to afford protection and to increase the resistance against infection. Restoratives, as iron and cod-liver oil, have proved of clinical value for the anæmia and malnutrition of these cases. The iodides are elaimed to promote reduction of the indurated glands, and iodide of iron holds a front rank in the therapy. Some elaim is made for the utility of persistent applications of mercurial ointment and compound iodine solutions over the affected nodes.

HODGKIN'S DISEASE-PSEUDOLEUKAMIA ; LYMPHATIC ANEMIA; ADENIA; LYMPHADENOMA.

The term Hodgkin's disease is preferable to any of the numerous names that have been proposed as substitutes, because it is not misleading in regard to the etiology or pathology of the particular condition.

This disease is rarely found in infancy, occasionally in ehildhood, and frequently in young adults.

The earliest and most noticeable manifestations appear in the enlargement of the glands in the anterior and posterior cervical regions (Fig. 187). Although bilateral, one side usually shows greater involvement. The adenitis often is of slow development, frequently covering a period of one to three years, with little or no recession. The enlarged nodes are at first freely movable, but later fuse and form adhesions to the overlying integument, presenting painless, doughy nodules, attaining at times an enormous size. These masses show no tendeney to caseate or suppurate. Glandular enlargements in the axillary and inguinal regions are noted in the majority of cases, and, in some, the bronchial and mesenteric nodes are found hypertrophied. The respiratory and alimentary mucous tracts do not often show the hypertrophic lymphoid involvement. 
Next to the local cervical enlargements the most noticeable sign is the anæmia. The general symptoms are those due to pressure of the glandular masses upon adjacent structures, in addition to those due to the steadily progressive impoverishment of the blood. Hence, there are usually present dysphagia, dyspnœa, spasmodic cough, cerebral congestion, hemorrháges, irregular heart action, muscular atony, and increasing physical weakness. Elevation of temperature is not a common symptom, and when present is probably due to some accompanying condition. The blood picture is not characteristic.

The etiology of Hodgkin's disease is not yet determined. The belief is prevalent that it is of infectious origin. Roux and Lannois claim

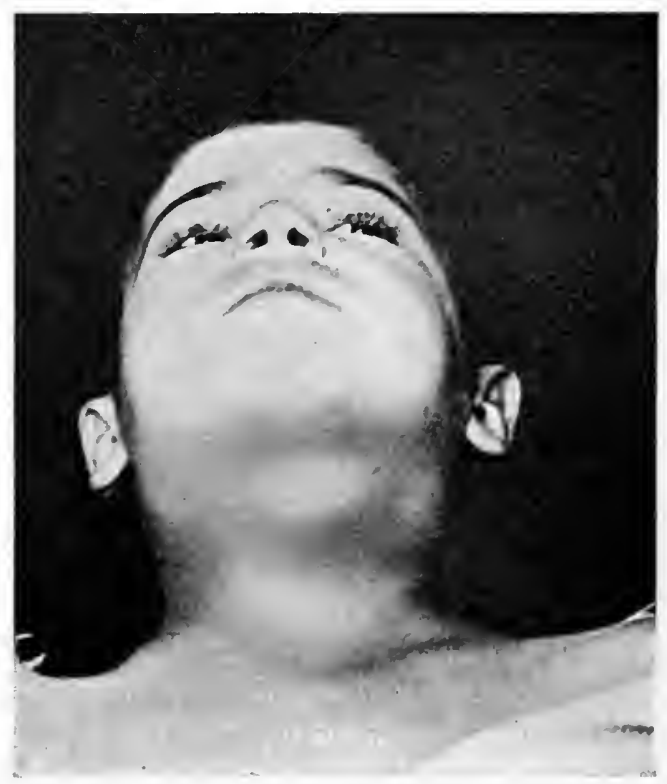

FIG. 187.-Hodgkin's disease. Girl, aged 11 years.

to have reproduced the disease in lower animals by the injection of a micrococcus from the blood and lymph-glands of a patient suffering from this disease.

There is a general increase in new lymphoid tissue (lymphadenitis) in nearly every organ of the body, excepting the brain and spinal cord. The spleen shows more or less enlargement in the majority of cases. Occasionally it becomes enormously enlarged but retains its normal shape (Fig. 188).

Microseopical examination shows great proliferation of lymphoid tissue, pushing beyond the gland eapsule, with increase in connective tissue, which results in the agglutination of the hypertrophied nodes and adjacent tissues into a dense mass.

The anæmia consists in more or less reduction in the number of red corpuscles with marked diminution of hæmoglobin, falling, in some cases, 
as low as twenty per cent. There is no increase in the neutrophiles, although a marked lymphocytosis is a regular accompaniment. The

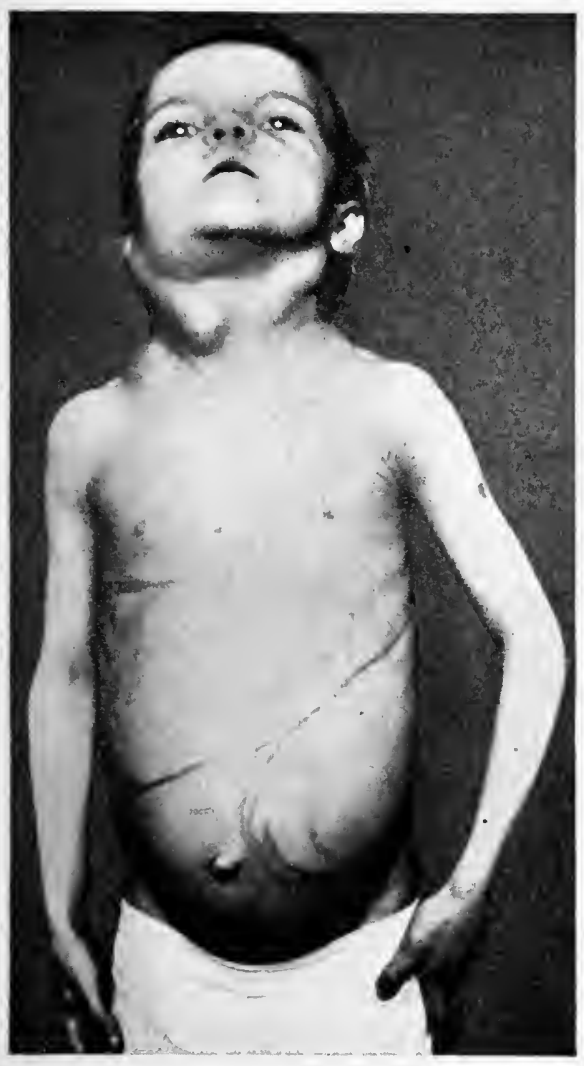

Frg. 188.-Hodgkin's disease. H. F., aged 7 years. Red cells, 3,715,000; white cells, 9,000; hæmoglobin, 55 per cent. Both spleen and liver enormously enlarged. diagnosis from leukxmia is based on the absence of the characteristic blood findings of that disease.

In differentiation f rom chronic adenitis, the history of some source of infection, painful swelling, and absence of profound anæmia, are of aid.

Tubercular adenitis usually gives a history of rise of temperature, with tendeney to caseous and suppurative softening of the hypertrophied glands, accompanied or followed by evidence of tuberculous invasion of other organs. The tuberculin test and inoculation of animals would establish the presence or absence of tuberculosis.

Cases of Hodgkin's disease have been reported cured by the persistent use of arsenic, both by mouth and by hypodermic injections of the affected glands. Early extirpation has resulted in cures in a few instances. From recent favorable reports the use of the X-ray is worthy of trial, but must be carefully employed in young children.

\section{DISORDERS OF THE SPLEEN.}

Disorders in which signs of splenic disturbances form part of the clinical findings are more frequent in childhood than in later life. That few of these are primarily of splenitic origin does not lessen the interest in the part played by this organ in a great number of infantile diseases. Acute splenitis, chronic hyperplasia, traumatisms, and septic abscesses, are met with in childhood, and rarely malignant neoplasms, primary splenomegaly, and hydatid cysts are reported by examining physicians.

Unlike adrenal decapsulation, splenectomy is not fatal to life. The functions of the spleen, whether digestive, antitoxic, or hæmatopoietic, find compensation in increased activity of other structures,-as the 
lymphoid, thyroid, and adrenals. It is not surprising, therefore, that death is rarcly attributable to disease of the spleen alone.

The spleen, in some instances, is freely movable and subject to displacement by violence or stretching of its pedicle from the weight of engorgement, appearing as a tumor in the lower abdomen.

Its peculiar structure and the relation of its histological elements may explain its characteristic susceptibility to enlargement, as is seen in congestion of the liver and any obstruction of portal circulation or from obstructed pulmonic circulation, as in extensive pneumonia or emphysema. Likewise this enlargement appears in cardiac incompetency, congenital or acquired. This effect upon the spleen is noticeable in malaria, typhoid fever, and congenital syphilis, and, as a rule, with the exception of the latter, the symptomatic diagnosis is not complete in the absence of demonstrable enlargement. Reports on congenital syphilis show splenic enlargement in from twenty-five to forty per cent. of all cases. Although common in malaria and typhoid fever, the fact

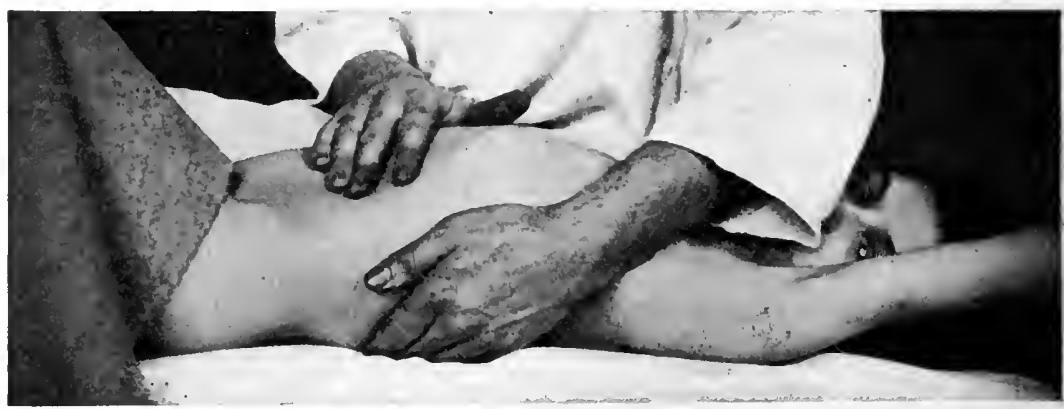

FIG. 189.-Palpating the spleen.

that the spleen may become palpable in almost all the acute infections deprives this sign of the pathognomonic importance formerly attributed to it.

Tuberculosis in children not infrequently shows splenic enlargement with occasional tubercular lesions in this organ. Splenic enlargement is quite common in rhachitis and not rarely accompanies extreme malnutrition from any cause. Usually this enlargement subsides with the disappearance of the primary infectious process. If long continued, however, the organ may undergo hyperplasia and remain chronically enlarged, or emboli may result in abscesses, as in infective endocarditis, pyæmia, etc. Amyloid degeneration follows long-continued suppuration or malnutrition.

The spleen may be ruptured by blows or falls, with extensive hemorrhage into the peritoneal cavity. Spontaneous rupture may occur from extreme distention, accompanying malaria and typhoid fever.

Sarcoma and even carcinoma of the spleen have been seen in childhood. Cysts, neoplasms, and abseesses can not be diagnosed as splenic, except by the location and outline of the tumor. In older children 
sensations of weight and dragging in the left hypochondriac region are described, following splenic enlargement from any cause. Acute pain is suggestive of perisplenitis. Rupture with intraperitoneal hemorrhage gives only the signs of profound exsanguination.

Aside from treatment of the primary conditions and surgery, no therapy of the spleen is of any marked benefit with, perhaps, the exception of local galvanism.

Much confusion still exists as regards both the etiology and clinical findings of a progressive enlargement of the spleen, known as splenomeg-

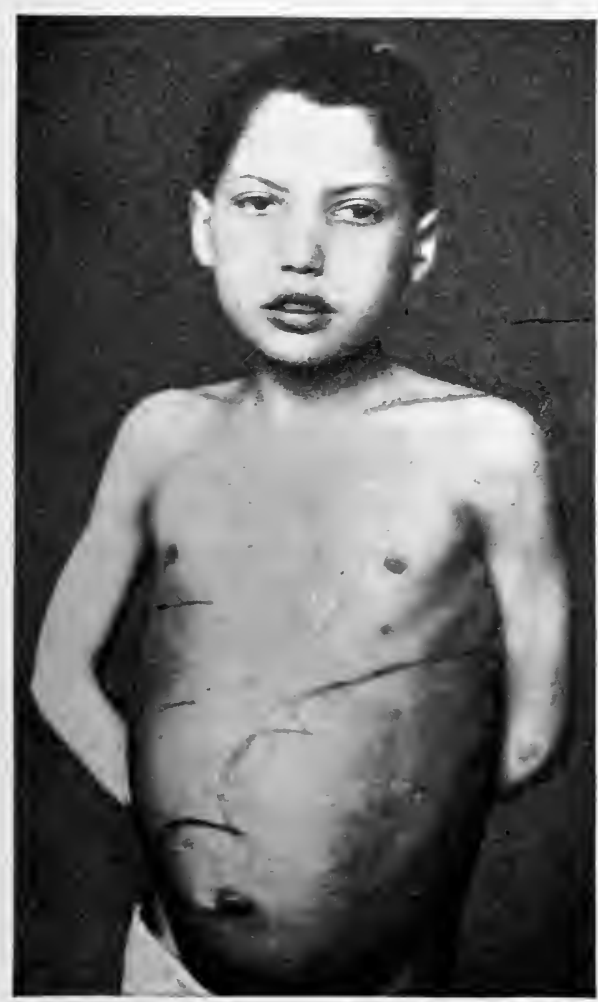

Frg. 190.-Herbert O., aged 12 years. Splenic anæmia. Red cells, 4.112,000; white cells, 2650; hæmoglobin, 50 per cent. ; color index, .6; polymorphonuclear, 84 per cent ; small mononuclear, 7 per cent. ; large mononuclear, 4 per cent. progress of this disorder save splenectomy, which shows about seventyfive per cent. of recoveries.

\section{DISORDERS OF THE ADRENALS.}

Hemorrhages.-Until the true physiological rôle of the suprarenal glands is established beyond question, the effects of their functional or structural disturbances must remain unsolved problems. Since death 
follows the removal of both glands in from three hours to three days, independent of surgical shock, analogy would suggest the same result from any sudden cessation of their function from any eause. This supposition is proven in cases of adrenal apoplexy, which is not infrequent in early infancy. Recent post-mortem reports of sudden deaths in infancy show an increasing number of hemorrhages into the suprarenal structures. In a number of instances the adrenals are the only organs involved. The free blood supply and the fragile structure of the tissue, aside from septic conditions of the blood, may explain the tendency to hemorrhage into these organs under all conditions which induce great intravisceral pressure. The manner of death, with its preceding symptoms, corresponds with remarkable fidelity to those accompanying abolition of these bodies. The symptoms of adrenal hemorrhage may develop suddenly and may be ushered in by acute abdominal pain, dyspncea, pallor, weak pulse, cold extremities, followed by coma or convulsions,all indications of collapse. Vomiting, and not infrequently diarrhœa, may be present. Death occurs within a few hours. Adrenal hemorrhage may occur in the course of pertussis, bronchopneumonia, retrocedent exanthems, and variola, or may follow convulsions or traumatismsas blows or extensive burns-and may be overlooked and unsuspected as a cause of death until revealed at the post-mortem.

Since no physical signs may indicate the extent of the involvement of one or both adrenals, as a forlorn hope efforts may be made to restore the equilibrium of the circulation by external heat and the use of adrenal extract. As in other hemorrhages, hypodermics of normal saline solution are indicated, and enteroclysis of milk of asafetida for its effects upon the abdominal sympathetic nerves may be given in proper quantity.

AdDison's Disease.-In children, as in adults, the adrenals are subject to degenerative changes, both cystic and interstitial, and also furnish the seat for neoplasms, benign and malignant. All of these, from our present knowledge, act as etiologic factors in the progressive neurasthenia known as Addison's disease. Although rare in early life, it does occur in infancy and has been reported as congenital, as in a case in which death occurred at eight weeks. In this the post-mortem showed eystic degeneration of both capsules.

This disorder, in the large majority of cases, is probably due to tubercular invasion of the suprarenal cortex, and is usually accompanied by other evidences of general tuberculosis. However, there are cases on record in which autopsies showed tuberculous changes in no organs other than the adrenals.

The disease, as in adults, is characterized by progressive muscular weakness and symptoms of secondary anæmia,- as rapid pulse, dyspnœa, headache, epigastric pain and tenderness. Pigmentation of the skin and mucous membranes is usually present. Diarrhœa is said to be more common than later in life.

Untreated, the disease is fatal in from one to three years, death 
resulting from inanition or some intercurrent disorder. Since hibernating animals bear the loss of their adrenals better than those in active life, a hint may be derived of value in treatment,-namely, to restrict muscular exercise to the lowest point compatible with life. If the disorder be due to restricted function through structural changes in the adrenal glands, the administration of the suprarenal extract is rational therapy. Transplantation of the gland from lower animals has been adopted, and the raw gland or dried extracts have been given with some success.

Symptomatic treatment consists in measures for the relief of general asthenia and irritability of the digestive tract by careful supervision of diet. Guaiacol, iodine, creosote, and carbolic acid are indicated in the double rôle of gastric sedatives and general antitoxies.

The thymus gland may be absent, atrophied, or hypertrophied. It may be the site of neoplasms, tubercular, syphilitic, sarcomatous, or carcinomatous, or of abscesses and cysts. In none of these conditions can more than a probable diagnosis be made. Post-mortems show atrophy of the thymus in infants dying of marasmus. On the other hand, thymectomy is not necessarily fatal. A vast amount of experimental work has thus far failed to determine the etiologic relation of disorders of the thymus gland to other conditions. The fact that the period of greatest thymic activity is coincident with that of most rapid growth suggests an intimate association with the process of development. It is more than probable that it supplements the action of the thyroid gland and with it exercises a very positive influence on nutrition. Cretins fed on thyroid extract increase rapidly in stature, but the bones become soft and bend easily. Under thymus extract this tendency to bone softening is said to disappear. Imbecile dwarfs not eretins have shown increased rate of growth under thyroid extract, with no sign of mental improvement until after the administration of thymus extract. In this connection it is interesting to note that a large percentage of autopsies of imbeciles and epileptics show absence or atrophy of the thymus gland. Although the future may promise brilliant results in thymic therapy our present knowledge warrants no more than its experimental use.

Much discussion has arisen as to the etiologic relationship of an enlarged thymus in cases of sudden death in infancy and childhood. The distance from the manubrium sterni to the vertebral column is only from two to three centimetres, and this narrow space must accommodate the trachea, œsophagus, great blood-vessels, nerves, and muscles. But little room is left for a normal-sized thymus. This organ is sometimes found enlarged to many times its average size, with the result of great pressure upon trachea, pneumogastric, and recurrent laryngeal nerves, as well as upon the heart and great vessels. Under these conditions a sudden increase of pressure-as from lying on the face or back with 
extreme extension, congestion from violent fits of coughing or vomiting, convulsions, and swallowing large pieces of hard material-would cause asphyxiation, dyspnœa, syncope, or sudden death. Intubation and tracheotomy afford but transient, if any, relief. Resection of a portion of the hypertrophied thymus has been performed with the amelioration of urgent symptoms.

Malignant growths of the thymus are rare. General tuberculous invasion not infrequently includes the thymus, while syphilitic gummata and abscesses from infective emboli have been found. Dermoid cysts have also been found in this gland. This is not surprising when its embryologic development from the second and third branchial clefts is considered.

\section{DISORDERS OF THE THYROID.}

As far as known, the function of the thyroid gland is the secretion of a colloid material which, entering the circulation, exerts a positive influence over metabolism. The structure of the thyroid, with its enormous blood supply, relatively eight times as abundant as that of the brain, is suggestive of the great activity of this organ, although the amount of the secretion is not even approximately known. The exact rôle of this secretion, in its relationship to metabolism, is not yet definitely understood, although some of the effects of interference with the function of the gland are known.

Of such conditions there are, 1, congenital absence of the thyroid; 2 , atrophy from overgrowth of fibrous tissue or obliteration of gland tissue by neoplasms, - as in syphilis, tuberculosis, carcinomata, etc.; 3 , destruction or removal; 4, interference with blood supply,-as in varicose and aneurismal vessels; 5 , thyroiditis; 6 , destruction of gland tissue following infectious diseases,-as typhoid, measles, etc.; 7, true hypertrophy of glandular parenchyma.

The conditions known as cretinism and myxœdema, with few exceptions, show absence or deficiency of thyroid function, while on the other hand hypersecretion of the thyroid, as seen in class seven, is commonly associated with exophthalmic goitre.

Ablation of the thyroid is not always followed by myxœdema, and late observations seem to show that in these cases the glandular function is carried on by structures known as accessory and parathyroid glands. Moreover, it has been shown that myxœdema may follow the removal of an accessory thyroid, the inference being that the main thyroid was functionless.

Every symptom of cretinism is suggestive of suboxidation, while the judicious administration of thyroid extract by mouth, or the transplantation of thyroid gland into any vascular area of the body of a cretin, is followed by certain well-defined symptoms,- - namely, increase in metabolism, elevation of temperature, increased heart action, muscular tone, tactile sensibility, mental activity, and improved nutrition of all tissues of the body. Under thyroid administration the cretin gradually changes 
toward the normal; the normal child develops hyperæsthesia, tachycardia and headache with general hyperexcitability; and the subject of exophthalmic goitre, with few exceptions, shows exaggeration of all his symptoms.

\section{CRETINISM.}

An infant, to all appearances normal at birth, with a negative history as to its gestation, parturition, and heredity, may attract attention before its sixth month by an apparent overdeposit of subcutaneous

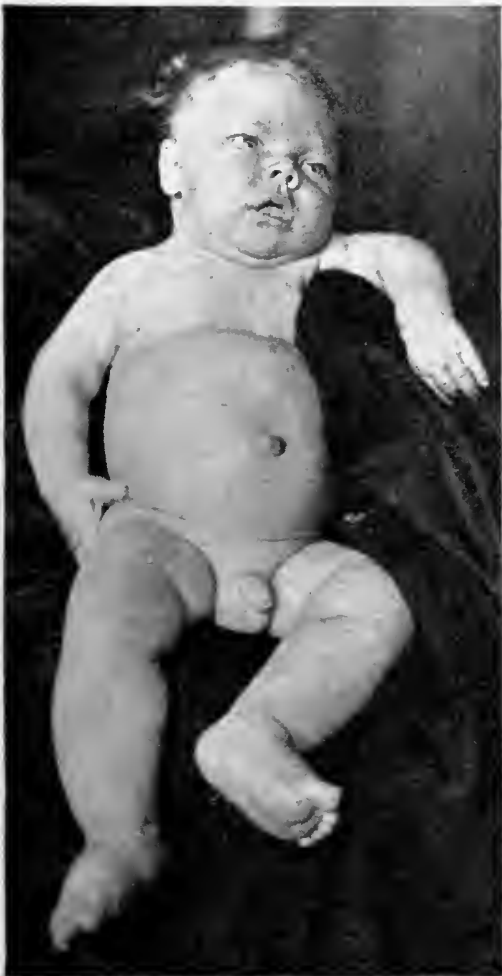

FIG. 191.-J. L., cretin, 21/2 years. adipose, with redundant integument, large protruding tongme, general muscular weakness, and hoarse, unnatural ery. These signs of maldevelopment mark the early stage of cretinism. If not arrested, these signs become more pronounced, involving primarily the tegmental, museular, osseous, and nervous systems. The overgrowth of skin becomes thickened, with large deposits of fat, particularly in the supraclavicular regions, which, with hanging jowls and nether face, almost obliterate the short, thick neck. The ears stand out, while the thickened alæ nasi, with upturned nostrils, intensify the effect of the flattened nasal bridge. With few exceptions the hair is harsh and dry, and the sparse eyebrows hardly separate the transverse wrinkles of the heavy forehead from the narrow slits of the swollen palpebral tissues. The whole face seems bloated, which, with the thick lips, large drooling tongue and expressionless eyes, complete the stamp of imbecility. The belly is protuberant, often with umbilical hernia. The extremities are short, with block-like hands and feet, and clumsy, thickened, widelyseparated digits.

Muscular development is retarded so that walking is late,--frequently not acquired until the fourth, fifth, or even the twelfth year, and is of a waddling and uncertain gait as though impeded by excess of fat. All muscular movements are slow and elumsy.

The fontanelle remains open long after the usual time. The growth of the long bones is retarded, the epiphyseal chondral condition being prolonged into adolescence, so that the trunk appears much out of pro- 
portion to the short extremities. The stature of a twelve-year-old cretin may not exceed that of an average child of three years.

The harsh, dry skin frequently shows a furfuraceous desquamation, the nails are brittle and striated, the teeth are tardy in eruption and are irregular in form and distribution, with a tendency to early decay. This is true of both temporary and permanent sets. In older children the voice becomes hoarse and inhuman.

The temperature is almost invariably from one to two degrees below the normal, and even during acute infections there may be an absence of the usual pyrexia.

The nervous system, both sensory and motor, seems sluggish, with general diminution or absence of the superficial reflexes. Cerebral development is retarded and shows all the stages from mental dulness to

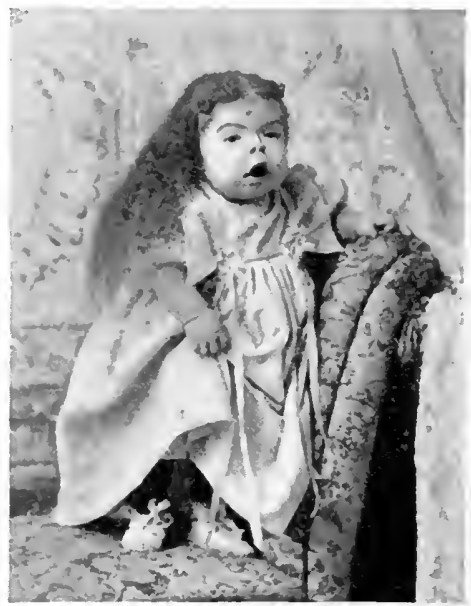

Fig. 192.-Cretin, 12 years of age.

absolute idiocy. The cretin is proverbially good-natured and shows little evidence of emotion or pain.

With the exception of the habitual constipation, the digestive system seems normally active. This is also true of the respiratory organs. The circulatory and urinary systems show no primary involvements, although secondary changes are not uncommon in advanced cretinism,-as albuminuria and degenerative renal lesions. The blood changes are those of a secondary anæmia, with nucleated red cells suggestive of fetal blood. The heart's action is weak.

Occasionally the signs of cretinism are first observed as a sequel to some acute disease. The degree may vary from the picture of profound idiocy, above presented, to very slight abnormalities in physical or mental development which are recognized as cretinoid.

Sporadic cretins are found the world over and no race is known to be exempt. In a few localities, notably shut-in valleys among high mountains, eretinism is so prevalent as to be endemic. From numerous de- 
scriptions no physical difference can be established between the sporadic and endemic types. An apparent difference as to the causation is seen in the more frequent association of cretinism and goitre in localities where both are endemic. It is on record that women who have given birth to cretins where the disorder was endemic, have borne normal children in localities free from that influence. Again, women who have borne cretinic children have been fed on thyroid in subsequent pregnancies which terminated in normal children.

Prognosis.-The prognosis without treatment is unfavorable as far as amelioration of cretinism is concerned, although the condition is rarely the immediate eause of death. In fact, during infancy the cretin shows a marked immunity from the prevalent contagious disorders of that period. It has been noticed that under thyroid treatment the disappearance of this immunity is coincident with that of the cretinoid condition. A fair percentage of cretins have reached middle life.

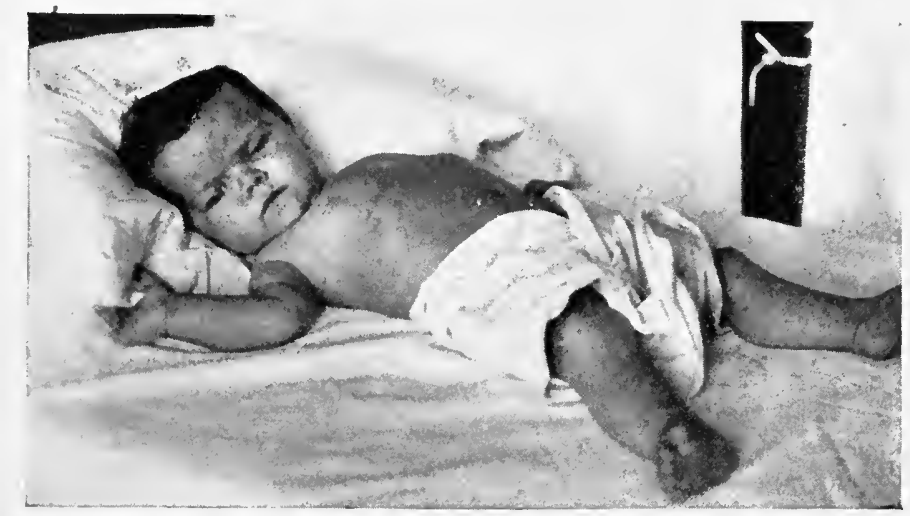

FIG. 193.-J. L., same as Fig. 191, after two months' treatment with thyroid extract.

Treatment.-The treatment of cretinism consists in the administration of animal thyroid, preferably in the form of the extract. Few eases have failed to show marked improvement of symptoms under its use judiciously carried out and many cases are reported where approximately complete recovery has followed thyroid administration. To this end the treatment should commence early, hence the importance of an early diagnosis. From one-half to one grain may be given once a day to an infant under two years, and continued in gradually increasing dosage, if tolerated, until there is a disappearance of cretinoid signs. The more advanced the cretinoid condition, the more prolonged will be the period of continuous medication. Improvement has been noted within the first month of treatment, but not infrequently the first stage of treatment will require a year or more.

No treatment should be undertaken without facilities for constant observation on the part of the physician, as much harm and occasional deaths have followed the reckless administration of this agent. 
An early and favorable result of treatment should be a slight rise in temperature, increase in pulse and respiration, quickened sensibility, increased elimination of urea, reduction in weight, and increase in height, all evidences of increased oxidation and improved metabolism. If the dose be excessive these symptoms will be intensified,--such as pyrexia, tachycardia, headache, rapid respiration, diarrhœa, glycosuria, albuminuria and tremors with a tendency to syncope; in other words, a push too far, a hyperthyroidism.

The physician must not forget the increased liability of his patient to intercurrent affections while under treatment and should be ready at any time to diminish or withhold the agent for a time. Additional protection against cold, or even removal to warmer climate during the winter months, is desirable.

Physical improvement is earlier and more marked than that of the mental condition. Growth in stature is oftentimes remarkable, and the bones, especially those of the legs, show a tendency to curvature. This must be guarded against by restriction of exercise. Cretins rarely reach the average mentality for age under the best of care, although physically up to the standard. Much disappointment will be avoided if the fact be recognized that cretinism is the result of a thyroid defect beyond the corrective power of the individual, and that this must be supplied by the administration of the animal thyroid throughout life. This need not be continuous, however, after the first period of treatment. The daily administration of the extract for a month in the year, or for a week during each month, has been found sufficient in some cases to prevent a recurrence of cretinoid signs. Each ease, however, should be governed by the individual susceptibility, and a small daily dose throughout life may be found necessary to maintain normal metabolism.

\section{EXOPHTHALMIC GOITRE-GRAVES'S DISEASE; BASEDOW'S DISEASE.}

That the condition known as exophthalmic goitre is due to increased functional activity of the thyroid gland is the belief most prevalent. The fact that all post-mortem reports on exophthalmus, with rarely an exception, show enlargement of the thyroid, even when not observable during life, and that a large percentage of operated cases have shown improvement after removal of a portion of the gland, are confirmatory of the above opinion.

Graves's disease, although rare in infancy and childhood, is suffciently frequent to warrant its mention. The symptoms vary somewhat from those seen in adult life,- the tachycardia may be extreme; the goitre is more constant than in adults; the exophthalmus and other ocular signs are seldom pronounced, and the tremors are rarely seen, choreic manifestations being more frequent. The youngest child whose case has been reported was two and one-half years old. It has been known to develop in childhood after acute infections,- as scarlet fever and influenza.

The symptom complex of this disorder is of shorter duration in 
children and appears often more suddenly than in adults. A case is reported in which symptoms developed and subsided in ten days. The approach of puberty marks the greatest frequeney of these symptoms. Probably this age furnishes the best examples of hyperemic goitres, which may be accompanied by tachycardia, thus simulating Graves's disease.

The goitre of puberty yields in a few months, with proper treatment, and may disappear spontaneously after the establishment of menstruation. The differentiation between Graves's disease and hyperæmic goitre with rapid heart action is not always easy. A number of examinations may be necessary to determine the persistency of the tachyeardia, in the absence of which the diagnosis of Graves's disease is improbable. Transient palpitation must therefore be excluded, as must also rapid pulse due to organie heart disease.

Heredity undoubtedly plays an important rôle in the etiology of Graves's disease. In fact, the neuropathic is given precedence over the glandular disturbance by many able observers who eite neurotic family histories-as epilepsy, chorea, hysteria, and alcoholism-in a majority of their patients. Some remarkable instances of this disease, as a family affection, are reported, where all five children of the same mother showed some of the cardinal symptoms of Graves's disease. Other reports give histories of exophthalmic goitre in four successive generations.

Treatment.-In severe cases, the child should be confined to bed, or at least kept in the horizontal position and restricted to a light, nutritious, and nonstimulating diet. Elimination must be promoted by laxatives, diuretics, and gentle massage, if well borne. Cardiae sedatives, especially tincture of strophanthus, beginning with minimum doses with gradual daily increase, carefully watched, may be needed. In extreme cases ice-bags over the pericardium, if well borne, are efficacious. For the goitre, aside from surgical interference, which has some advocates, galvanism has been found effective in reducing the size of the tumor with amelioration of all the symptoms. The galvanic eurrent of two or three milliamperes may be used two or three times a week for from one to three minutes. This treatment must be continued for weeks and even months. The daily application over the thyroid gland of iodine ointment or that of the iodide of mereury, with gentle massage, has proved beneficial in some cases. The internal administration of eligible preparations of iron, as syrup of the iodide, in small doses, are indicated for the anæmia. The value of suprarenal and thymus preparations is still sub judice. The administration of thyroid extract is contraindicated. The resemblances between the symptoms of exophthalmic goitre and fright are so striking as to suggest a line of treatment. This should include absolute freedom from anxiety, and measures to secure entire mental and physical repose.

The value of rodagen from the thyroidectomized goat is now on trial in this disease, and has found a number of enthusiastic advocates, as has 
also the serum from thyroidectomized animals, which is administered in tablet form.

\section{ANAMIA.}

Anæmia is a condition in which there is a deficiency of hæmoglobin or of one or more of the corpuscular elements of the blood. 'The present knowledge of anæmias does not permit a definite scientific classification. Those classifications most in vogue depend partly upon preceding or associated conditions, and partly upon the known peculiar changes in the blood itself. They have been called primary, idiopathic, or essential, in the absence of any known cause (pernicious anæmia, chlorosis, and leukæmia), and secondary or symptomatic anæmia when preceded or accompanied by conditions upon which the blood changes clearly or presumably depend. The growing belief is that all anæmias are secondary or symptomatic,-i.e., that the blood conditions are symptomatic of some preexisting or accompanying disturbance in the metabolic process upon which the integrity of the blood depends.

Among the known causes of anæmia in childhood are hemorrhages and toxines. Hemorrhages may result from traumatisms or occur in the course of disease. Intoxications may follow the ingestion of drugs, as chlorate of potash, mercury, ete.; any of the acute infectious fevers,as malaria, diphtheria, etc.; malignant neoplasms,-as sarcoma or careinoma; nutritional disorders, - as rickets or scorbutus; enteric disturbances,-as enteritis or intestinal parasites; and organic lesions,- as nephritis and disease of the central nervous system. In general, any condition, plysical or environmental, that interferes with normal nutrition, may be counted a factor in anæmia. That the infant or child is peculiarly susceptible or prone to blood deterioration is well known. Indeed, the entire period of development is a struggle for blood equilibrium, and anæmia in varying degree is the rule rather than the exception during this precarious period. An explanation for this is seen in the peculiarities of infant blood. The fact is that the enormous demands for daily tissue growth, work the blood-making organs to their full capacity. Moreover, the child must run the gamut of infectious diseases before immunity is secured.

It is seen that the chief characteristic of infant blood is the low degree of hæmoglobin and specific gravity. Moreover, the red cells have less stability, exhibit a greater variety of forms, present staining peculiarities (polychromatophilia), part with their hæmoglobin more readily, and on slight provocation show nucleated forms (normoblasts). That is, the tendency to reversion toward fetal blood conditions, of such grave pathologic significance in the adult, is characteristic throughout the period of childhood. Slight loss of blood, transient infection, and even temporary digestive disturbances, produce a marked effect upon the already low color index, so that the condition of hydræmia is common, and although children make blood rapidly, it is with great difficulty. While the excess of red marrow shows great activity in the blood-making processes, the child is unable to keep up with the enormous demands 
for growth at this time, even with the accessory work in the spleen and other adenoid tissues, and, possibly, the liver. In other words, the bloodmakers have no reserved store of material for emergencies, as seen in the yellow bone marrow of the adult. In this diffieulty of supplying the ever-inereasing demand for normal blood elements, interrupted as it is by the recurrent causes of anæmia, is seen the ever-present handicap of infancy.

In infantile anæmias the presence of a large number of white eells is less significant than when seen in the adult, as hyperlencocytosis is practically normal. The large proportion of lymphocytes is but one of the expressions of the intense glandular activity of this period, while splenic enlargement is a common aceompaniment of ehildhood anæmias.

Symptoms.--If the hydræmia be extreme, the deficieney of hæmoglobin shows in the pallor of the skin, but is particularly marked in the mucosa of the mouth and the conjunetiva. The selerotics are pearly, the ears have a waxy appearance, the musenlar system is atonic, and the child is listless and fatignes easily. He is often peevish and fretful, subjeet to vague pains in limbs and viseera. Headache is common. The pulse is weak, rapid, and oeeasionally irregular. A hæmie murmur may be heard over the heart (partieularly over the pulmonary area), although not so commonly in very young infants. A venous hum may be heard over the great vessels of the neek. Respirations are shallow, with dyspnœa on slight exertion, and oceasionally moist râles are heard. Vertigo with tinnitus aurium and syneope oceur in extreme cases. Digestive disorders, with eapricious appetite or disinclination for food, are common. Catarrhs of the nasopharyngeal mueosa are frequent, with tonsillar and adenoid engorgement and reeurrent epistaxis. So, also, vesical irritability or sphineter atony with ineontinence may be a result. Vulvovaginal eatarrhs are oceasionally seen in girls. Cold hands and feet attest the diminished oxidation, while amblyopia and symptoms of eyestrain, hallucinations, broken sleep, and bad dreams, with mental morbidity, are among the train of symptoms.

Too frequently anæmia is overlooked as the cause of innumerable affections, to many of which it may be justly attributed also as an effect.

Diagnosis.-The diagnosis should not wait for the full development of the foregoing too common picture of neglected anæmia. The lips may be bright red and the cheeks, especially under excitement, show heightened color, in spite of a very appreciable fall in hæmoglobin. Any signs of irritability, headache, capricious appetite, or tendency to "cold catching," should lead to a suspicion of anæmia, which may be confirmed by examination of the blood. Hæmanalysis should be kept up at intervals after all of the infectious fevers until the blood becomes again normal. The fact eannot be unduly emphasized that in the secondary anæmias lies the greatest danger from all the infections of childhood, and that a physician's duty is not completed with the termination of the acute attack. 
Prognosis.-The prognosis of the morbid results of a persistent anæmia in childhood is obvious. It furnishes a constant predisposition to a multitude of infections and the many disturbances of metabolism. The name of some intercurrent disease usually appears upon the death certificate.

Treatment.-The treatment of anæmia consists first in the removal or mitigation of the cause. The primary cause may have disappeared long since. It is then necessary to break up the vicious circle of secondary causes and their effects, as impaired muscular tonicity with its weakened cardio-vascular conditions; impoverished secretions with their train of digestive disturbances; neurasthenia with its exhausting insomnia; mucous catarrhs with their constant production of intoxications, and the general impairment of nutrition from all these distressing causes combined.

The anæmia itself must be treated by efforts to increase the number of erythrocytes, and particularly the percentage of hæmoglobin. If accomplished, this will, by the improved oxidation, greatly relieve the other morbid conditions. Of prime importance are nutritious foods, adapted to the condition of the digestive organs, plenty of air with high percentage of oxygen, with exercise to promote deep respiration but not to the degree of excessive fatigue, bathing with friction and massage, the maximum amount of sleep with perfect ventilation, and relief from school (for older children), or fatiguing, worrying tasks. Iron and arsenic in suitable forms are valuable adjuncts to a careful hygienic regimen.

\section{CHLOROSIS.}

Although not a disorder of childhood, chlorosis is of interest in the study of the developing period. Very few eases have been reported in boys.

The cause is not understood, all the various etiologic theories previously advanced having been proved untenable. The period of its occurrence and the occasions under which it is known to recur, point to ovulation or some disturbance of the menstrual function as etiologically significant. The nature of that disturbance and the predisposing conditions which have long been regarded as intimately related with the development of chlorosis are at present a mystery. Shock, fatigue, exposure to cold, mental emotions-as homesickness, grief, and many other conditions which have done duty in its etiologic category-can only be considered as exciting causes.

The blood findings are unique. There is lowered specific gravity, a somewhat diminished number of erythrocytes, disproportionately reduced hæmoglobin, with poikilocytosis and normoblasts in severe eases. The lencocytes show little change. The specific gravity of the plasma is higher than normal and the fluid shows increased tendency to clot.

The symptoms of the disease are due primarily to circulatory dis- 
turbances. The muscular structures of the heart and vessels show want of oxygen, and this is shared by all muscular tissues of the body. General muscular atony, with cardiac dilatation, apical and basal murmurs, venous hum, palpitation, dyspnœa, vertigo, syncope, indigestion, flatulence, morbid appetite, gastroptosis, constipation, pale nucosa, pearly scleroties, and in about sixty per cent. of cases a greenish-yellow hue of the skin, are some of the conditions seen in this disease.

There is a predisposition to venous thrombosis and to the development of gastric ulcer.

Diagnosis based upon the elinical picture and the blood findings is not difficult. Pulmonary tubereulosis shows greater emaciation, characteristic pulmonary symptoms, and bacilli in the sputum.

The duration of chlorosis may be from a few months to a year, with the possibility of recurrence of symptoms.

It is rarely fatal except from such complications as gastric ulcer or tubereulosis.

In the treatment of chlorosis iron has proved a specific in the restoration of hæmoglobin. The indications for oxygen call for a plentiful supply of fresh air. Constipation must be relieved,- - best by the free use of fruits, massage, and a regular habit in efforts at defecation. If these means are at first insufficient, cascara, nux vomica, or rhubarb may be used temporarily. Dietary errors-as excess of candy, cakes, or pickles-must be corrected. Mental influences have much to do in promoting assimilation, so that frequently a change of environment will hasten recovery.

\section{PERNICIOUS ANEMIA.}

The assumption that pernicious anæmia is rare in infancy is based upon the number of reported cases. This is an unfair conclusion when the infrequency of blood examination in the disorders of this age is considered. The readiness with which anæmia develops in infancy and early childhood is well known. In children, as in adults, digestive disturbances have naturally been aceredited with the symptoms of the progressive debility, and even the anæmia itself.

The list of causes, predisposing and exciting, which has been given for pernicious anæmia, would include almost every condition and infection that is known to lower vitality or cause general debility. The fact that intestinal parasites can produce all the clinical symptoms, including a picture of the blood findings, which invariably disappear upon the removal of the cause, increases the etiologic confusion of this disease. The belief in the infectious origin of pernicious anæmia is widely prevalent, although as yet no specific micro-organism or group has been discovered.

The chief characteristic is the extensive hæmolysis to which all the blood findings point. The volume of blood is said to be diminished, specific gravity is lessened, the erythrocytes are reduced in number (not infrequently below $1,000,000$, sometimes below 200,000 per C.c.), and 
the hæmoglobin is diminished, although its percentage is relatively high (high color index).

There is marked poikilocytosis with large numbers of nucleated red corpuscles, in which the megaloblasts far outnumber the normoblasts, also a prevalence of macrocytes but paucity of microcytes. The presence in the blood serum of débris and other evidences of cell destruction, together with staining anomalies (polychromatophilia), is characteristic. The rouleaux agglutination of the red cells is lost. In the early stage, the drawn drop of blood is a bright red, but later looks thin and pale (hydræmia). Iron from the disintegrating red corpuscles is found in all the viscera, particularly the liver, while cell nuclei and free hæmoglobin appear in the blood stream. The picture is one of blood destruction rather than that of disease of the blood-making organs. There is little or no increase, but frequently diminution in the number of white cells, of which a large proportion are lymphocytes. Myelocytes are rare or absent.

The symptoms are those of a general anæmia, with little or no emaciation. The rotundity of the figure persists throughout in many instances, although muscular atony and general flabbiness of the tissues are always present. The color of the skin is usually described as lemon yellow rather than waxy, pallid, or pigmented. Petechiæ, ecchymoses, and hemorrhages, especially epistaxis, are common. Disturbed vision, even blindness, may result from retinal hemorrhage. Stomatitis and glossitis are frequent accompaniments, and gastro-enteric disturbances are usual during the progress of the disease.

The urine is pale, of low specific gravity (1006), neutral or alkaline in reaction, and frequently contains albumin and a few hyaline casts, or it may be dark with bile pigments or contain uric acid and an excess of urates.

During the course of the disease there is occasional pyrexia with irregular fluctuations, toxic in character. The pulse is usually rapid, soft, compressible, and frequently irregular. The heart is enlarged, and systolic murmurs are heard both at the apex and base. Edema of dependent parts is a common symptom and occasionally there are accumulations of fluid in serous cavities. Fatty degeneration is common in the heart-muscle, blood-vessels, and many other organs, late in the disease.

Paræsthesia, ataxic symptoms, and muscular incoöordination with rapid muscle atrophy, may occur from hemorrhages or secondary lesions in the spinal cord.

The progressive increase in the languor and debility is usually interrupted by periods of apparent improvement of all the symptoms, so that a certain degree of periodicity of exacerbations is the rule in the downward progress of this disease.

The duration is essentially chronic and may continue with remissions from a few months to three or four years, although children rarely survive a long period. 
The symptoms of pernicious anæmia, although suggestive, are never conclusive. The diagnosis depends upon the careful, repeated examination of the blood, and the absence of any known cause.

\section{DIAGNOSTIC POINTS OF BLOOD IN PERNICIOUS ANAMIA.}

1. Low specific gravity.

2. Extreme reduction in red cells.

3. Erythroblasts numerous.

4. Megaloblasts many; normoblasts few.
5. Polychromatophilia.

6. Hamoglobin reduced, but

7. Color index liggh.

8. Leucocytes normal or diminished.

Prognosis.-Recovery from pernicious anæmia is claimed in a few cases, but this must be questioned.

Treatment.-Aside from the general treatment for anæmia the agent most highly regarded in pernicious anæmia is arsenic, which should be administered to the full degree of toleration. The possibility of a gastrointestinal infection as a cause for pernicious anxmia has led to a thorough antiseptic treatment of the digestive tract, with encouraging results. Lavage and enteroclysis are indicated. Antiseptic agents-as mercuric chloride, thymol, or betanaphthol-are administered cautiously, care being taken to conserve digestion.

Muscular exertion or any expenditure of energy must be reduced to the minimal point and systematic daily massage substituted. Inhalation of oxygen is theoretically indicated. In extreme cases this may be repeated four or five minutes every hour during the waking period. Serum therapy has its advocates and the antistreptococcus serum has been used with success. The eacodylate of sodium is also highly recommended by recent writers on the subject.

\section{LEUKÆMIA.}

Leukæmia is a term applied to a condition of the blood in which not only the numerical ratio between the red and white cells is changed but both show marked morphological changes. This ratio between leucocytes and erythrocytes varies from 1 to 100 up to 1 to 15 . Cases have been reported in which the leucocytes equalled one-half the number of erythrocytes. This disturbed ratio is the result of the enormons leucocytosis rather than a poverty of erythrocytes, although the red cells show a diminution, $-2,000,000$ frequently, and even as low as 800,000 per C.mm. having been recorded.

In the white cells the normal polymorphonuclear neutrophiles are replaced by an enormous overgrowth of lymphocytes and myelocytes. Nucleated red cells, also microcytes and macrocytes, are present. Poikilocytosis and karyokinesis are to be seen. The specific gravity and hæmoglobin correspond with the decrease in erythrocytes.

Leukæmia is properly classed among the rare diseases. The comparatively greater infrequency in infancy and childhood may possibly diminish upon the application of the same diagnostic methods that are used among adults. Much confusion in classification has resulted from 
the failure to appreciate the peculiarities of normal metabolism during the developing period, and that hæmatogenetic processes in infancy exhibit normal peculiarities that would be regarded pathological in adult life, chief among which is the ready reversion to fetal types. Lymphoeytosis is the blood condition of infancy; hyperleucocytosis is normal, and nucleated red cells appear without great pathological significance.

Etiology.-The etiology is unknown. Of many theories the two receiving the most attention to-day are the infectious, from bacteria or their toxins, and the neoplastic. No micro-organism constant in all cases of leukæmia has thus far been isolated from the blood or other tissue, although a striking analogy is seen between some of the acute cases and sepsis, especially in the sudden onset, rapid course, hypertrophy of lymph glands and spleen, great anæmia, and tendeney to hemorrhage.

The neoplastic theory is based upon the fact that normal lymphatic tissue shows a marked tendency to hyperplasia and is replaced by lymphadenoid tissue of atypical character. This abnormal tissue shows a tendency to invade neighboring structures, even the walls of bloodvessels, with destruction of their endothelium. These and other metastases in the chronic form of leukæmia, with the clinical picture of cachexia, are suggestive of malignant growths.

The disease may occur at any age, a few congenital cases being on record. Among the predisposing causes, heredity has been mentioned with some show of evidence. It has developed in the syphilitic, rhachitic, tubercular, and lymphatic, and after traumatisms, attacks of malaria, influenza, and gastro-enteritis, with a possibility of etiologic relationship.

Usually the disease develops insidiously. The duration may be from one to twenty-five weeks, but as there is no means of noting the exact inception, the probability is that the morbid process is of much longer duration and that frequently the first pronounced symptoms are really the terminal. The division, however, into acute and chronic is convenient and seems warrantable from the character and duration of the symptoms in different cases.

The first evidence of this disorder may be a hemorrhage, marked or slight, from the nose, mouth, stomach, or bowels, with a history of recent indisposition. There may be a rise of temperature $\left(101^{\circ}-103^{\circ}\right.$ F., $38.5^{\circ}-39.5^{\circ}$ C.) preceded by a chill or vomiting. Diarrhoea may be present, with anorexia and coated tongue. The child is pale and anæmic and there may be hemorrhagic spots in the mouth. Petechiæ or ecchymoses may appear over the trunk and limbs. There may be headache and disturbance of vision from retinal hemorrhages. The spleen is enlarged and sometimes tender, and the liver is somewhat larger than normal. There is no ascites. Tenderness on pressure may be found along the tibiæ. The glands in the neck axillæ, and groins are palpable. Hæmic murmurs are heard over the base of the heart and the great vessels of the neck. The lungs frequently are negative. There may be a slight amount of albumin in the urine and also some blood cells. Uric acid is increased in amount. 
The course is acute, with rapid emaciation, prostration, and intensification of all the symptoms, death intervening from pulnonary cedema or from hemorrhage. Many cases run a more chronic eourse and death results from asthenia. Throughont the disease, the blood count shows an increasing lymphocytosis, a sudden fall in the white corpuscles preceding, by a few days, a fatal termination. Accompanying this decrease there is a marked reduction in the size of the spleen, with partial subsidence of the lymph glands.

In the chronic type the fever is less marked or absent, and emaciation and loss of strength gradual. The child may walk abont with little discomfort, excepting for easily induced dyspnœa and fatigue. The spleen may become enormously large and hard and, curiously, show temporary variations in size and consistency. The glands, especially in the neck, become aggregated in masses as large as a hen's egg, without signs of suppuration. Hemorrhages may be frequent and alarming, - after which the blood shows enormons increase in lymphocytes. The sternum and long bones may show tenderness, and even tumefaction or nodules; the pulse is weak and rapid; the heart may be dilated; the skin is pallid and waxy. . In advanced stages, œedema due to hæmic, cardiovascular, and obstructive causes is rarely absent. Death from asthenia may be forestalled by hemorrhage or some intercurrent affection.

The present trend of opinion is that the disease is primarily myelogenetic in all cases.

Two widely distinct types of this disease-namely, myelocytic and lymphocytic-are recognized. In the former the splenic enlargement is an early and prominent symptom, and in the leucocytosis the myelocytes greatly predominate, frequently reaching sixty per cent. of the total whites. The polymorphonuclears and eosinophiles are much inereased in absolute numbers, although not relatively. The same is true of both large and small lymphocytes. No other known condition presents such a variety of associated cellular elements. It is this richness in varied cell forms that constitutes the blood picture of the disease, although the preponderance of myelocytes is pathognomonic of the myelocytic form.

It is in the second or lymphocytic type that the interest for the pediatric student mostly lies, for this is the form of leukæmia most frequently seen in infancy and childhood. It should be recalled in this connection that at this age the blood shows a normal tendency to lymphocytosis and there is great activity of the lymphatic glands. Sometimes there occur mixed forms in which the myelocytic blood changes are accompanied by lymphadenitis, or the lymphocytic form may show early and marked enlargement of the spleen.

Clinically, the lymphocytic type is characterized by extensive enlargement of the lymph nodes with only moderate splenic hypertrophy. The blood picture furnishes the differentiation in an overwhelming preponderance of lymphoeytes over all other forms,-in fact, the per- 
centage is rarely below eighty and not infrequently reaches ninety-nine. The myelocytes are absent and eosinophiles and neutrophiles are rarely seen. The nucleated red corpuscles are fewer than in the myelocytic type.

Pathologic ehanges oceur in all tissues and organs of the body. Those which are most characteristic and most constant involve the hæmatopoietic organs, the spleen, lymph-nodes and bone-marrow. The changes found post-mortem in the spleen are those of true hypertrophy, with increase of all its histologic elements. The capsule is thickened and has cicatrices from previous hemorrhages and infarcts. Sections of the lymph nodes, whether superficial or deep-seated, give evidence of marked hypertrophy. There is infiltration of all parts with lymphoeytes, which crowd the follicles and invade the ressel walls with resultant hemorrhages.

The changes in the bone-marrow, always present, are sometimes so extensive as to show macroscopically the appearance of pus. This replaces the normal red marrow of infancy and encroaches to such an extent that actual erosion of the surrounding shaft results. These changes are largely due to an overgrowth of lymph-nodes normally present in the medullary substance. Here, as elsewhere, the lymphocytes prevail, crowding, eroding, and infiltrating the vessel walls, with changes and hemorrhages similar to those found in other parts of the body.

Diagnosis.-The diagnosis of leukæmia rests entirely upon the blood findings during life and upon the changes in the bone marrow at autopsy. After any severe, prolonged disturbance of nutrition, as from gastroenteritis, rickets, or tuberculosis, a severe grade of anæmia with leucocytosis, nucleated red cells and even myelocytes, associated with enlargement of the spleen and lymph nodes, may result, owing to the ease with which the blood in early life reverts to the fetal type. It may be difficult or even impossible to differentiate this from an early stage of true leukæmia. The evident eause, improvement under treatment, and ultimate recovery, would finally locate the case among secondary anæmias. The tendeney to-day is to do away with the term "pseudo" as in "pseudoleukæmia of infancy, anæmia splenica pseudoleukæmia of von Jaksch," in anticipation of a better knowledge as to the causes of many forms of anæmia.

Prognosis.-At present, the prognosis of leukæmia is extremely grave.

Treatment.-Until the etiology is known, the treatment must be palliative and symptomatic. The administration of arsenic induces a return of the blood constituents to their normal proportion, yet children have died after the disappearance of the hyperleucocytosis during the administration of this drug. Iron and oxygen are indicated and their judicious use has seemed, in a few eases, to arrest, at least temporarily, the progress of the disease. The heart must be sustained by digitalis or strychnia, while albumin, of which there is an enormous drain, must be supplied in a form suitable for easy assimilation. 

The hemorrhages must be met with styptics-as ergot, calcium chloride, or adrenalin, internally or locally-as even a trifling loss of blood is of great importance in the existing anæmia. This is especially true in infancy.

\section{HAMOPHILIA.}

Hæmophilia is a disorder characterized by a tendency to uncontrollable hemorrhage from the vessels into the subcutaneous tissue, joint cavities, mucous surfaces, and the skin. The hemorrhages are due to capillary oozing, and follow wounds or abrasions, however slight, and may oceur spontaneously.

The etiology is unknown, except as to its heredity, being transmitted, with rare exceptions, through the mother, who may herself have shown no hæmophilic symptoms. It occur's eleven times as frequently in males as in females, yet the male rarely transmits the disorder, except through a daughter. It is seen at all ages,-rarely in advanced life. This latter fact is largely due to the high mortality of hæmophilia and partly to the alleged outgrowing of the diathesis.

- No blood or vascular condition, peculiar to this elass, has yet been demonstrated.

The site of hemorrhage is most frequently the nasal mucous membrane; next in order of frequency are the mouth, urethra and lungs. All male children of the same mother may not be bleeders, the first-born being the most likely to be exempt. The discovery of the diathesis, unless suspected from the heredity, is usually made from some traumatism, such as circumcision, cutting the frenum lingux, or, later, the extraction of a tooth, yet the bleeding may occur spontaneously from any surface.

Hemorrhages into and around the joints may occasion painful swelling, with local heat and tenderness. The joints may be attacked successively, the larger - as the hip, knee, ankle, shoulder, and elbow-being the more frequently the seat of disease. The affected joints are first immobilized by the pain, and later, after more or less complete reabsorption, motion is limited by pseudoankylosis, due to adhesions from fibrous bands. Still later, true ankylosis may follow from the formation of exostoses about the joint. The articular hemorrhages recur, after months or years, into the same or other joints, pain and sometimes rise of temperature preceding. It is claimed that in many cases spontaneous hemorrhages are preceded by prodromes-as exhilaration of spirits, or a sense of plethora-and that the bleeders experience relief after a moderate loss of blood. Any considerable hemorrhage, as in other children, is followed by the anæmia of exsanguination. Death has resulted from trifling lesions, and the diathesis positively contraindicates any surgical operation. The coagulation of the blood is much retarded.

Diagnosis.-The diagnosis is not difficult. The heredity, when known, the obstinate bleeding from slight lesions, the extravasations from bruises, and the joint hemorrhages, all unmistakably stamp the bleeder. 
Scurvy, rheumatic and hemorrhagic purpura, rheumatism, and tubercular disease of the joints, have many symptoms in common; but a careful study of the history as to heredity and previous hemorrhages, as well as diet, will clear up the diagnosis.

No specific treatment is known. For the local hemorrhages, pressure, ice, styptic applications of sulphate of iron, and suprarenal extract, have all been used with varying success. Ligatures are unavailing, as the oozing is capillary. Calcium chloride has been given internally for a long period to increase the coagulability of the blood. For the same purpose gelatin, in from two to five per cent. solution, by hypodermic injection, clysters, or by month, has been tried. It has seemed to be effective in some cases, but the increasing number of reports of tetanus, in spite of antiseptic precautions, have discouraged the hypodermic use of this agent. Stypticin has been highly recommended by some writers, but clinical evidence is still too limited to warrant its use in young children.

After the hemorrhages have been checked, tonic and reconstructive treatment should be carried ont to overcome anæmia.

\section{PURPURA.}

From our present knowledge purpura should not be classed as a blood disease. In fact, it is not entitled to the rank of a disease but

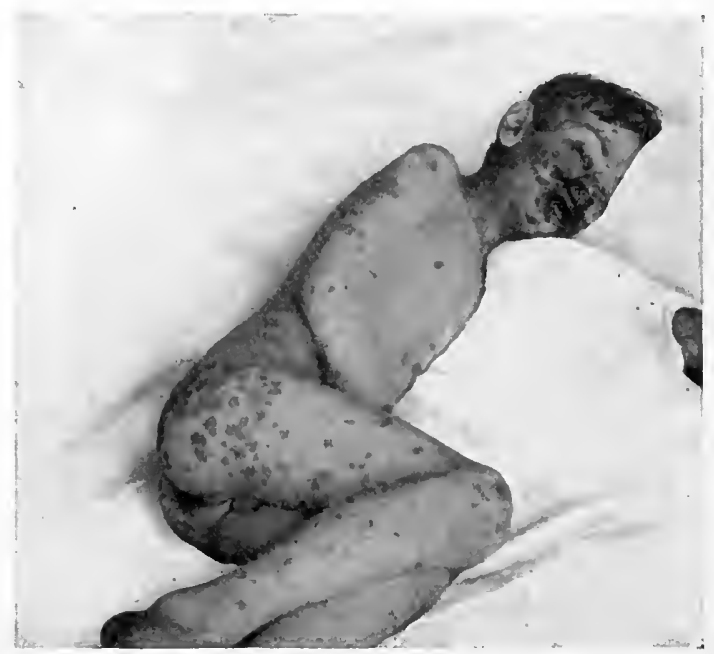

FIG. 197.-Post-diphtheritic eruption. Antitoxin was not used. (Dr. J. C. Cook.)

appears as a symptom, the underlying cause of which is still unknown. The term is applied to all conditions in which there are extravasations of blood into the skin and mucous membranes. These appear as small, discrete, pinhead red spots (petechiæ) which do not disappear on pressure. It may involve larger areas of the cutis vera (ecchymoses), or may 
form collections of blood in the deeper tissues (hæmatomata), which appear as fiuctuating tumors. No etiologic classification is possible so long as the cause is not known, hence classifications in vogue are based upon either associate conditions or variations in symptoms and severity.

It may occur as an accompaniment or sequel of any of the acute infectious fevers, - as variola, measles, diphtheria (Fig. 197), influenza, gastro-enteritis, sepsis, scarlatina, or rheumatism (Schönlein's disease (Fig. 198), peliosis rheumatica), during the course of which its appearance has been regarded as adding gravity to the prognosis. Purpura of the integument occasionally precedes or accompanies hemorrhages, more or less extensive, from the mucosa of the nose, mouth, or digestive and urinary tracts, as in morbus maculosus Werlhofii.

Occasionally the extravasation may occur in the structure of the walls of the bowels beneath the mucosa, giving rise to acute pain, local tumefaction, and spasm of adjacent portions, diminishing the lumen of the intestine. Vomiting may be stercoraceous from reversed peristalsis, as in Henoch's purpura. In this variety there is hæmaturia and often effusion of blood in and around the joints, in which respect it resembles one phase of hæmophilia. Frequently, aside from the skin eruptions, the mucosa of the mouth is principally involved with congested and

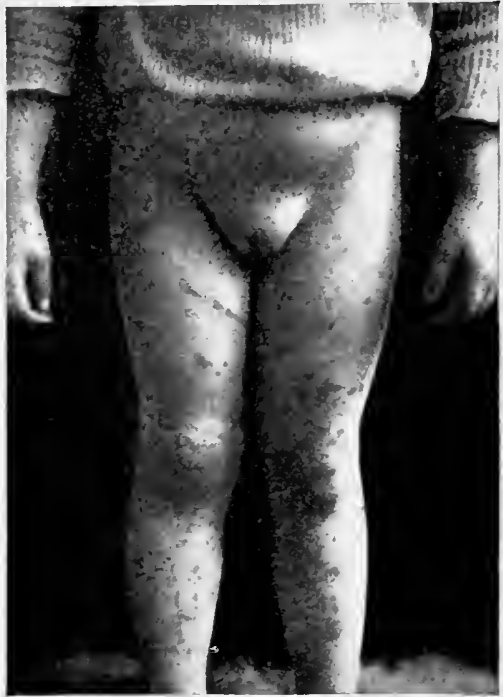

FIG. 198.-Peliosis rheumatica. (Dr. J. C. West.)

bleeding gums, in which form it is very suggestive of scorbutus. When uncomplicated with hemorrhages from any mucous surface or with constitutional signs, and seen only in the integument of forearms, legs, or trunk, as bright red or purplish petechiæ, it is known as purpura simplex. Occasionally the eruption assumes the form of wheals, red or purplish in color, and is attended with pruritus. It is then known as purpura urticans. A number of drugs and chemical agents produce purpuric extravasations,-as quinine, salicylates, potassium iodine, chloral, mercury, and phosphorus. Decomposed meat sometimes causes this eruption. Rarely cases have been reported in which collapse follows within a few hours an apparently trivial eruption of petechiæ. Considerable quantities of blood are sometimes lost from the gastric, intestinal, or nasal mucosæ. This bleeding may be extremely intractable. Purpura fulminans is the term well applied to such an attack.

Etiology.-Various micro-organisms have been described as present in cases of purpura. Some, it is stated, will produce similar lesions when 
inoculated into lower animals. Although quite generally accepted as of bacterial origin, no constant organism has been isolated.

Pathology.-The only lesions peculiar to purpura are the petechiæ and ecchymoses. The blood changes are variable, and may depend on other causes. Changes in vessel walls and adjacent tissues vary in different cases, some showing a tendency to necrotic processes. Some observers have found the proportion of blood constituents normal, until altered by the effects of repeated hemorrhages.

The duration may vary from one to many weeks, with a tendency to recurrence, the eruption appearing in crops.

Diagnosis.-From scurvy the diagnosis is sometimes difficult, especially in purpuric extravasations beneath the periosteum, which, from their location, give rise to pain. The history of the feeding and the effects of vegetable acids will clear the diagnosis. The hemorrhages occurring in leukæmia and pernicious anæmia may strongly resemble those of purpura. Examination of the blood would show the characteristic findings of these diseases. Insect-bites may always be excluded by the central puncture and the excoriations due to pruritus. Henoch's purpura has been mistaken for intestinal obstruction from the acute pain, stercoraceous vomiting, and bloody stools. A careful examination of the skin and mucous membrane, and review of the history for eruptions or arthritic symptoms, may prevent useless laparotomy. Old lesions of erythema nodosum may simulate purpuric ecchymoses, but location and tenderness on pressure reveal the nature of the disease.

Prognosis.-The prognosis should be guarded, as it varies with the character of the attack. This may vary from a simple eruption, with no other symptoms, to a fulminating seizure, with fatal hemorrhages, within twelve hours. Cases are reported in which purpuric attacks have been followed, more or less remotely, by chronic nephritis.

Treatment.-Since the danger is from extensive hemorrhage, the treatment is directed to its control. Keeping the child warm and quiet in bed will lessen this tendency. The difficulty of diagnosis from scorbutus has led to the routine administration of vegetable acids, sometimes with apparent benefit. If severe intestinal symptoms are present, food should be restricted to a bland diet, or withheld entirely until the dangerous hemorrhages have ceased. Ice may be given. Subgallate of bismuth, tannic acid, tannigen, ealcium ehloride, ergot, and suprarenal extract, especially the last, have been of undoubted benefit. In grave cases, maximum doses are indicated. In one instance the administration of twenty-drop doses every hour of adrenalin solution $(1: 1000)$ to an apparently moribund child of five years was followed by recovery. To control the pain of abdominal crises tincture of opium in starch enema, or morphine hyperdermically, may be necessary. Concentrated proteids, as meat juice, predigested foods, and milk, are indicated for the apepsia due to the extreme anæmia. A hydræmic condition indicates iron to increase the hæmoglobin, and calcium chloride for its effect on the coagulability of the blood. 


\section{DISEASES OF THE BONES AND JOINTS.}

Like the soft tissues, bones are subject to inflammatory hyperplastic and necrotic changes with resultant pus formation, overgrowth, or earies, as the ease may be.

The disease may begin as a supra- or sub-periostitis; in the epiphysis as a chondritis or osteochondritis; in the epiphyseal line as an epiphysitis; in the head of the bone as an osteitis; in the substance of the shaft as an osteomyelitis, or in the artieulation as a synovitis. In any case the inflammation may extend by contiguity of structure, by infection through the lymphaties, or by eutting off the eireulation, eausing death of parts.

The infecting agent may be any one of the pyogenie organisms attacking a part anatomieally favorable, as one in whieh eireulation and resistance have been disturbed by trauma, passive eongestion, or lowered nutrition.

Sinee by far the most frequent eauses of bone and joint lesions in childhood are tuberculosis and syphilis, only sueh disorders will be discussed here, space allowing mention only of the commonest forms. It should be borne in mind that in whatever of the above-named tissues the infeetion first oceurs, it may end in the involvement of any or all, so that abseess formation, joint involvement, bony neerosis with sequestration, rarefieation, fistula formation, or extensive pus burrowing in soft tissues, may be the result.

The most frequent sites of these diseases are in the long bones (their proximal epiphyses and adjacent articulations), and in the segments of the vertebral eolumn.

Although the treatment of these diseases and of their resultant deformities should be relegated to the orthopædic surgeon, their early diagnosis usually falls within the province of the family physieian, henee a few will be taken up briefly under the classes of tubercular and syphilitie lesions.

\section{TUBERCULOUS DISEASE OF THE BONES AND JOINTS.}

\section{SPINAL CARIES (POTT'S DISEASE); SPONDYLITIS.}

Spinal caries usually begins in the anterior portion of the body of a vertebra, at its epiphyseal line or in the intervertebral eartilage and involves, if allowed to proeeed, two or more eontiguous vertebræ. No portion of the eolumn is exempt, but the most common site is the middorsal region. A large number of cases, reduced to percentages, gives the following as the relative frequeney of location: cervical, 10; upper dorsal, 50; lower dorsal, 20; lumbar, 18; sacral, 2.

Pott's disease, although it may occur in adults, is essentially peculiar to ehildhood and is rare before the third year. The bodies of the affeeted vertebræ soften by caseous degeneration, rarefication, or neerosis with 
suppuration, which may be slight or extensive. Adjacent structures are occasionally involved by inflammation or pressure, giving rise to neuralgia of nerve distributions or to compression myelitis. The vertebral bodies collapse under the superincumbent pressure, resulting in angular deformity, kyphosis (gibbous), which is characteristic of the disease (Figs. 199 and 200).

Pus may burrow through adjacent tissues, and in cervical caries collect in front (retropharyngeal abseess, Fig. 130), or find exit at the

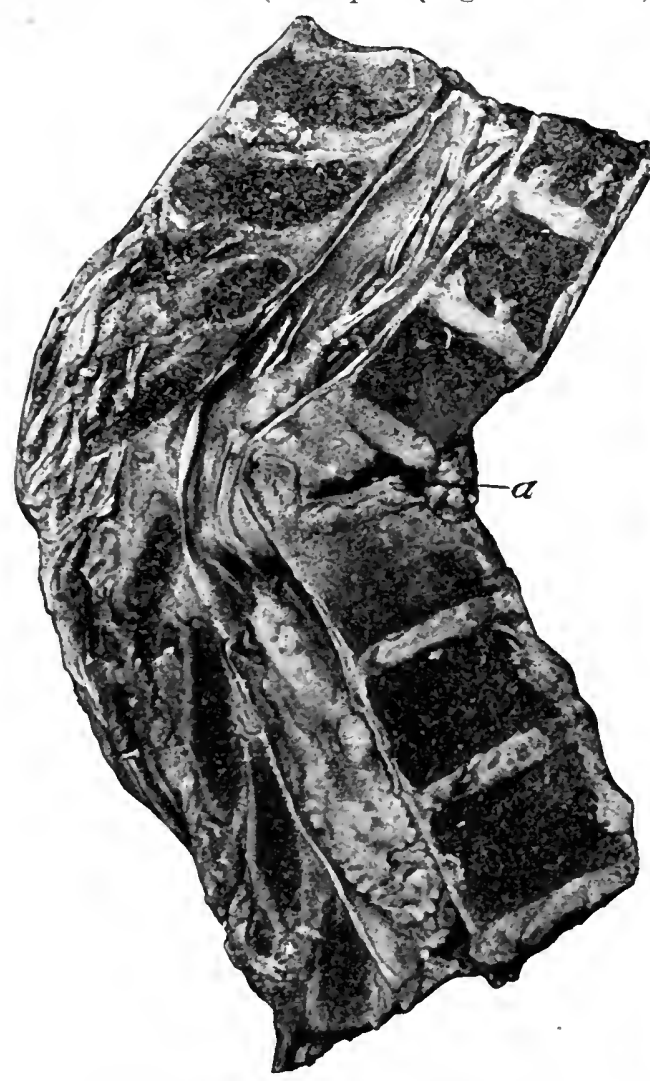

Fig. 199.-Spinal caries. (Dr. John Ridlon.) side of the neck. In upper clorsal lesions pus may find its way into the posterior

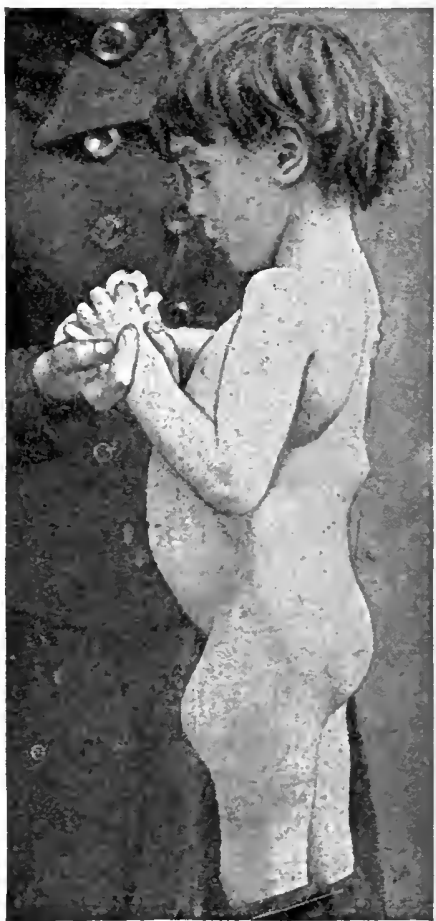

FIG. 200.-Spinal caries, with psoas ab. scess pointing below Poupart's ligament. (Dr. John Ridlon.)

mediastinum or under the deep fascia of the neck or back. Lower dorsal necrosis frequently causes psoas abscess, which points either above or below Poupart's ligament (Figs. 200 to 202), or a collection of pus may appear in the gluteal or sacroiliac region.

Symptoms.-Lassitude, disinclination to play, sometimes slight fever, fixation of the spinal column upon stooping, rigidity of back when the child is raised by the feet from the dorsal decubitus, tenderness on pressure over certain spinus processes, boring pain in back, starting 
pains in sleep, and neuralgic pains in chest, abdomen or genitals, are among the early symptoms.

The attitude and movements of the child are characteristic. He rests his hands or elbows upon his knees in sitting (Fig. 20:3), and walks with a careful, steady gait. In stooping to pick up an ohject he holds the spine rigid or squats to reach it. These symptoms, and the presence of gibbous or of pointing alsscess, render the diagnosis certain. In cervical and upper dorsal lesions some paralysis of the extremities occurs in about half of the cases. Psoas alnsceus induces

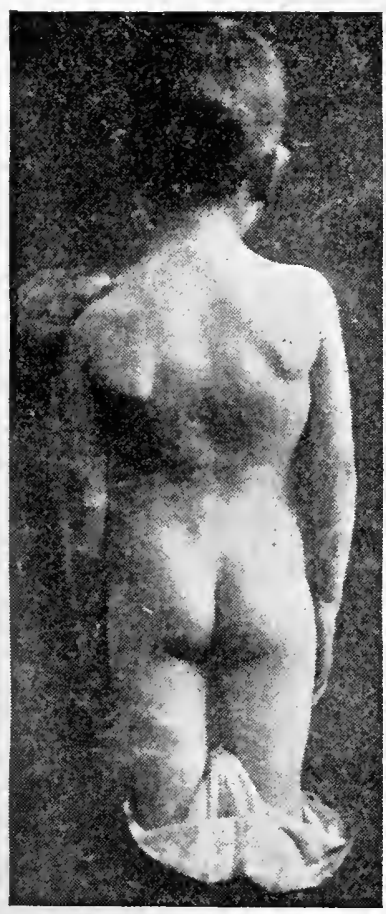

Fig. 201.-Caries of upper dorsal vertebræ, abscess pointing below scapula. (Dr. John Ridlon.)

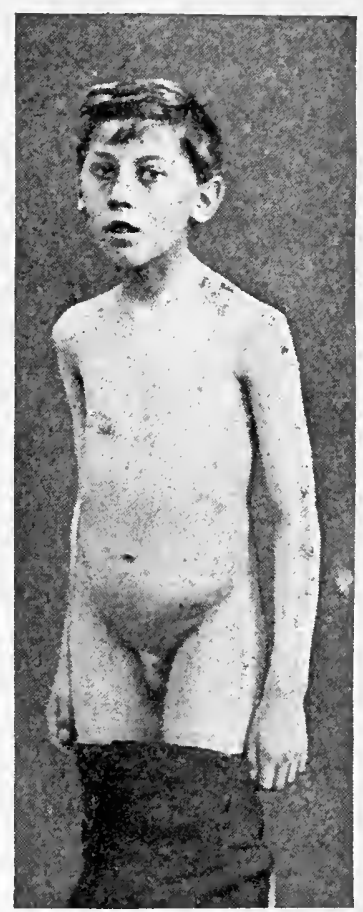

Fig. 202.-Spinal caries with psoas abscess pointing above Poupart's ligament. (Dr. John Ridlon.)

flexion of the thigh upon the affected side with resistance to rotation upon forced extension.

Diagnosis.-From rhachitic spine, Pott's gibbous is differentiated by not disappearing upon suspending the child by the arms and by the tonic rigidity of the back muscles. Rhachitis is, moreover, a disease of an earlier age. Lateral and rotary spinal deformities appear later in life than caries. Abscesses from perinephritis and perityphilitis lack the other symptoms of Pott's disease and run a more acute course. Anxstheties and the X-ray may aid diagnosis in doubtful eases.

Prognosis.-The prognosis is good as to life if treated early, althongh the danger of general tuberculous infection is imminent. Usually some 


\section{TUBERCULOUS DISEASE OF BONES AND JOINTS}

deformity results even with early treatment. The course of spinal caries is chronic, eovering sometimes two or three years.

Treatment.-Aside from the constitutional treatment for tuberculosis (q.v.), the spinal column must be immobilized and the pressure removed from the bodies of the diseased vertebra. A number of ingenious methods are now in vogue applicable to lesions of different portions of the vertebral columm which fulfil the indications and still allow the child

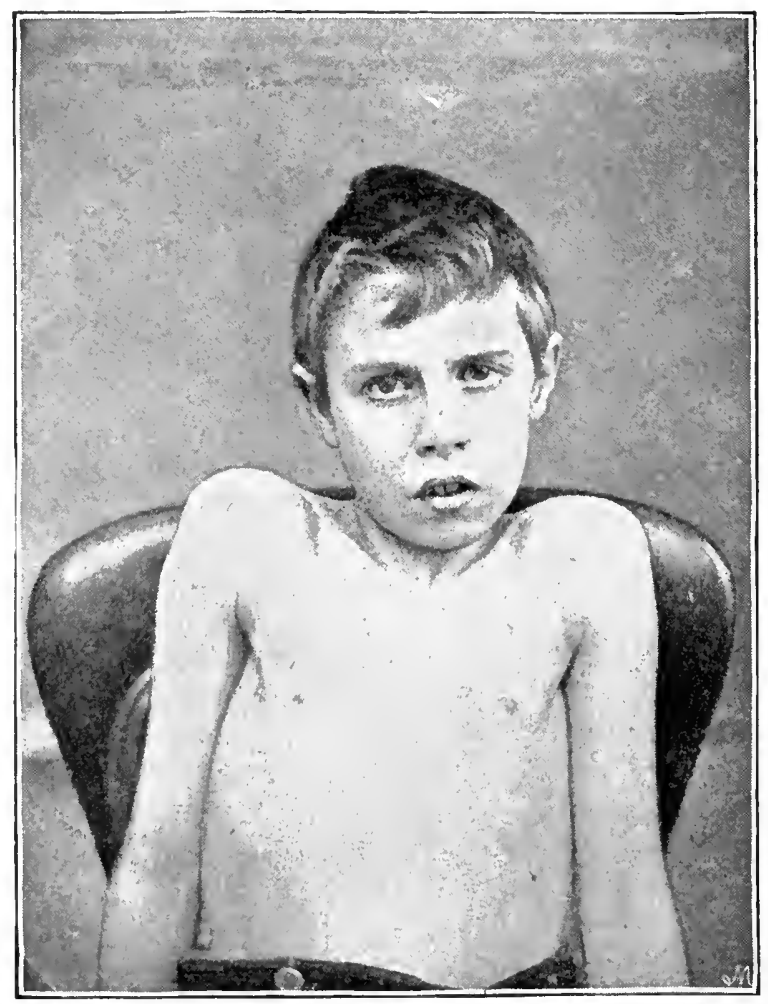

FIG. 203.-Characteristic sitting posture of spinal caries. (Dr. John Ridlon.)

freedom of exercise and locomotion. The modern orthopædic surgeon has robbed spondylitis of much of its former terrors.

HIP DISEASE-MORBUS COXARIUS; COXITIS.

Hip disease is confined almost exclusively to childhood, and begins usually as an epiphysitis of the head of the femur, or as an osteitis of the femoral neck. Like all tuberculosis of bone the location of the lesion is probably determined by trauma. It frequently follows acute diseases,- such as measles, scarlet fever, pertussis, ete. Contiguous tissues suffer in this femoral osteochondritis, so that synovitis and acetabular disease soon follow, or occasionally precede, the epiphysitis of the femur. 
Advanced cases show extensive destruction of the femoral head and neck as well as of the acetabular structures and pelvic bones which meet at this point. Partial or complete luxation of the diminished head of the femur from the changed shallow socket is a later feature of the disease, while suppuration may lead to destruction of the capsule, and burrowing pus to abscess formation of greater or less extent. Fistulæ form through which spiculæ of necrosed bone are discharged with the pus. The process is chronic, occupying months; occasionally acute and rapid.

Symptoms.-Pain is a frequent symptom in the early part of the disease and indicates involvement of the articular surfaces. The various sources of nerve-supply to this joint lead to peculiar distribution of the pains which may appear in the knee, inner side, back or front of the thigh, any part of the leg or foot, in the buttocks, or over the joint itself. Tenderness may be absent, but pressure of the femoral head against the acetabulum almost always causes pain. Starting pains at night are not uncommon, as during sleep the muscles which immobilized the joint relax and allow apposition of sensitive parts.

Usually the first symptom to attract attention is limping or stumbling, for which there is no apparent reason. The child fatigues easily and prefers to sit or to rest the affected leg, although marked lameness with pain does not develop until later, when it is usually attributed to some disorder of the knee joint because of the pain in that region. There may be swelling, in acute attacks early, from effusion into the synovial sac. In chronic cases this oceurs later from suppuration and caseation in the joint cavity. The swelling may be seen in front, just outside of the femoral vessels, or posteriorly filling out the depression behind the great trochanter. The inguinal glands may be enlarged and occasionally suppurate. Wasting of the limb begins early and proceeds rapidly from atrophy of both museles and bone, although the hip may appear full and rounded from hyperplasia and collections of inflammatory débris in and around the joint.

Three features of altered contour are most always present: 1, the inguinal groove is flattened and almost obliterated when the limb is abducted with outward rotation, or deepened with adduction and inward rotation; 2, there is flattening of the buttock on the affected side with obliteration of the smaller gluteal fold; 3 , the prominence of the great trochanter. The apparent lengthening of the affected limb is due to the downward and forward tilting of the pelvis, while the limb shows a characteristic slight degree of flexion, abduction, and outward rotation. Placing the child upon the table and attempting passive movements shows the rigidity due to spasm of the great muscles about the joint which limits extreme extension, flexion, abduction or adduction. In later stages fixidity may be due to matting together of the tissues about the joint by inflammatory exudate, and rarely by bony ankylosis. Crepitus is sometimes detected upon rotation, suggesting erosion of the head or acetabulum. Rigidity may be so marked as to require chloroform to determine its true nature. Extension of the affected thigh by 
force tilts the pelvis forward, causing the lumbar spine to leave the table in a high-arched curve.

In the later stage the limb is sharply flexed, adducted, and rotated inward where it is rigidly fixed (Fig. 204), the trochanter lying close to the side of the ilium above Nélaton's line, which position shows shortening of the limb. Collections of pus and sinuses may appear at various points sometimes at long distances from the hip.

The course of morbus coxarins is essentially chronic, and with few exceptions covers months and even years in its different stages.

Diagnosis.-While advanced cases may hardly be mistaken, the early stage or absence of history makes the diagnosis often extremely difficult. Among the disorders which simulate hip-joint disease may be mentioned rheumatic arthritis, strain of the joint, ostitis or periostitis of the great trochanter or upper end of the femur, coxa vara, sacroiliac disease, abscesses (psoas, iliac or gluteal, glandular, perityphilitic, or parasigmoidal), syphilitic synovitis, injuries of the knee, hip dislocation, separation of the epiphysis, fracture of the neck. poliomyelitis and hysteria.

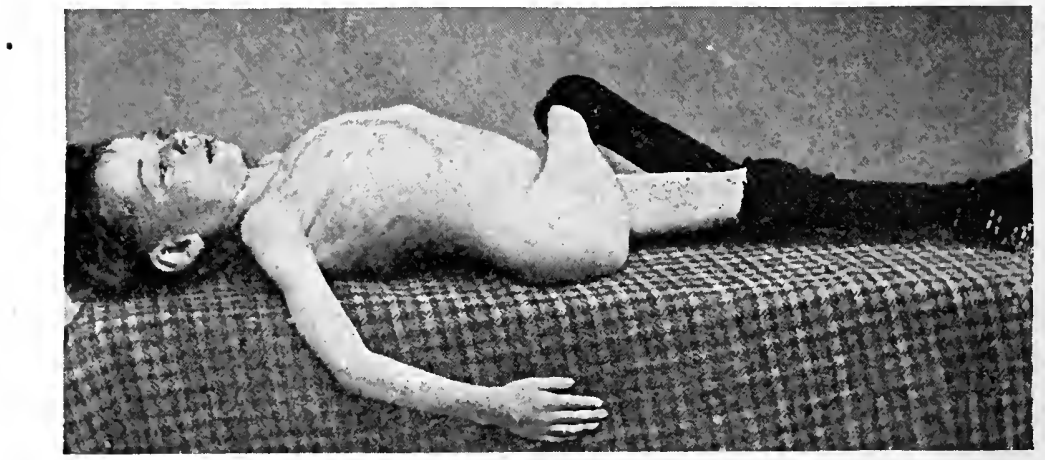

FIG. 204.-Hip disease. (Dr. John Ridlon.)

The diagnosis must be made from the history and by exclusion of other conditions which may interfere with the free, smooth, painless mobility of the joint.

Prognosis.-As a tuberculous, suppurative, wasting disease, the prognosis is always doubtful, since many die from extension of tubercular infection to other parts. While life is spared in the majority of cases, permanent deformities, such as ankylosis with rigid flexion and atrophy of the limb, are the invariable result with a tendency to recurrence of the disease upon the slightest injury to the hip joint. Early treatment, however, at the hands of the expert orthopredist gives to the prognosis a very hopeful tone. Under proper care and treatment from the beginning, resultant deformity is averted in a great majority of cases and the mortality lessened correspondingly.

Treatment.-Two methods of treatment have advocates for their respective merits,-viz., immobilization of the joint with continuous ex- 
tension and early excision of the diseased head of the femur. In this country radical surgery is not popular save as a last resort, after treatment by mechanical appliance has failed to arrest suppuration and bony necrosis.

The disease is essentially surgical and should be referred to the orthopædic specialist. The general treatment should follow that outlined for tuberculosis (q.v.).

KNEE-JOINT DISEASE-WHITE SWELLING.

As before stated tuberculosis may attack any joint, the hip being affected most frequently if spondylitis be omitted. Next in order of susceptibility is the knee joint, in which the disease may rarely begin and

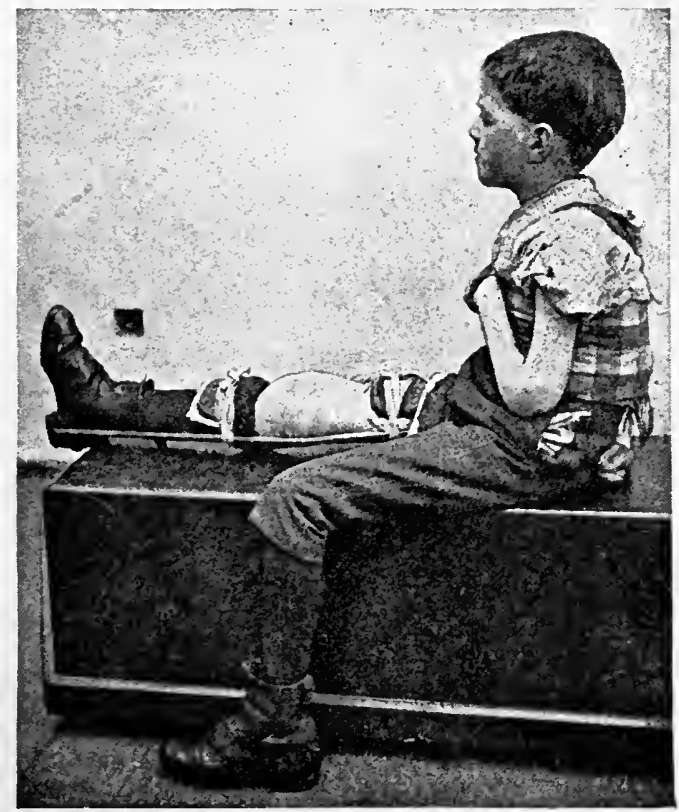

FIG. 205.-Tuberculous affection of knee and elbow joints. (Dr. John Ridlon.)

end as a synovitis or may extend to the adjacent cartilaginous structures, ligaments, and epiphyses or even to the bone of the diaphysis. Inflammatory foci in the bone may be the initial lesion. The synovial membrane is thickened or replaced by velvety or gelatinous granulations, or fungiform growths, and the cartilages are eroded away or present worm-eaten depressions filled with granulation and caseous tissue. The ligaments are thickened and give to the joint the appearance of bony enlargement when no real bony overgrowth is present. The synovial sac is rarely much distended with fluid, as is the case in simple acute synovitis.

Tonic rigidity of the muscles in their efforts to immobilize the joint 
causes gradually increasing flexion with outward rotation, finally resulting in luxation, the femur overriding the tibia, which is flexed to a right angle where it becomes ankylosed. Ostitis of adjacent parts, osteochondritis, and osteomyelitis may occur, while pus burrowing up the femur and down the tibia forms fistulous tracts.

Symptoms.-White swelling occurs most frequently in children between the third and eleventh years, and is usually attributed to an injury.

The child limps with slightly bent knee but usually there is little pain in the beginning. Later there may be pain (starting pains at night) and tenderness on pressure over certain points. Examination shows enlargement of the joint with atrophy of the leg and thigh. Pressure gives a doughy feel unless the rare effusion yields fluctuation in the synovial sac. Months may elapse before the knee is very troublesome, and exacerbations are not uncommon with intervals of quiescence, usually regarded as cures from some local therapeutic measures. The disease, if neglected, usually proceeds to total disablement with the characteristic triple deformity, with abscesses and discharging fistulæ.

Diagnosis.-Tuberculous knee may be mistaken for arthritis (simple, traumatic, rheumatic, gonorrhœal or syphilitic), or for osteosareoma of the lower end of the femur.

Treatment.-Immobilization, fixation, and extension are the indications, which may be fully met by orthopædic appliances (Fig. 205). The treatment should begin early; hence the importance of early diagnosis. General treatment for tuberculosis must never be omitted. Neglected cases require resection of the joint or excision of the knee,- surgical procedures of no mean magnitude.

\section{DACTYLITIS-CHRONIC OSTEOMYELITIS; SPINA VENTOSA; SPINA PEDARTHROCACE.}

The phalanges of the fingers and metacarpal bones, and less frequently of the toes and metatarsals, are frequently the seat of tuberculous osteomyelitis or periostitis. It usually develops between the first and third year, but may be met with later. The process is one of rarefication of the shaft, with bony deposition under the periosteum, until the enlarged bone is but a shell containing caseous material, pus, fungoid granulations and necrotic débris.

To the tubercle bacilli other pyogenic microbes may be added, the skin may become involved, and a discharging sinus develop. Occasionally resolution occurs, but more frequently the destructive process goes slowly on until all bone is destroyed, when the process terminates with cicatricial contraction and deformity. Frequently the disease extends to adjacent bones, especially in the metatarsal and metacarpal forms, and chronic indolent sinuses form which discharge inflammatory débris for years, with remissions and recurrences (Fig. 206).

Symptoms.-In a tuberculous child there is first observed a painless swelling of one of the proximal phalanges, most frequently of the hand. 
The enlargement is smooth, fusiform, hard, and gradually increases from month to month without inconvenience, occasionally remaining stationary, or appearing even to retrograde. The skin, which at first is freely movable, later becomes attached, reddens, and breaks down, disclosing a fistula which discharges scantily for months (Fig. 207).

Prognosis.-The outeome depends upon

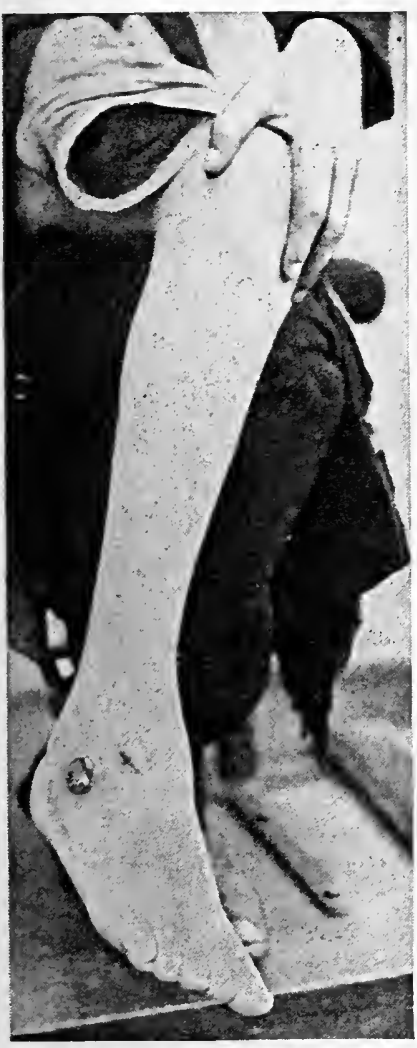

FIG. 206.-Chronic tuberculous sinuses of ankle. (Dr. John Ridlon.) the presence or absence of general tubercular infection or the extension of the disease to adjacent tissue.

Diagnosis.-The only disorder that resembles this disease is syphilitic dactylitis, from which it ean be distinguished only by confirmatory indications of syphilis. Mereurialization promptly relieves syphilitic dactylitis. Enchondroma is harder, runs a more chronic course, and does not suppurate.

Treatment.-General treatment for tuberculosis should be instituted. The affected

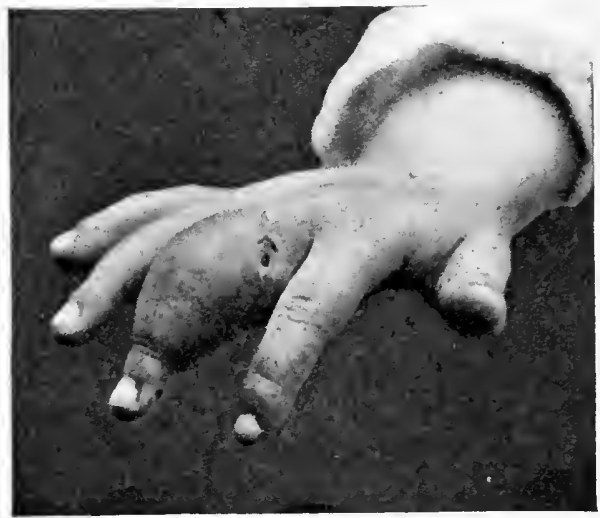

FIG. 207.-Tuberculous dactylitis. (Dr. S. W. Kelley.)

part should be put at rest by a proper splint or plaster, with slight, firm compression. If fistulæ form, the diseased bone should be thoroughly scraped with as little damage as possible to the soft parts, the cavity filled with aristol, boric acid crystals or iodized gauze, and dressed antiseptically.

\section{CHRONIC POLYARTHRITIS, WITH SPLENIC AND GLANDULAR ENLARGEMENT.}

Cases of chronic and recurrent polyarthritis, with enlargement of the lymph-nodes and spleen, first described by Still in 1896, are occasionally seen and have been reported in children as young as three years. It is usually symmetrical, beginning with the larger joints. There is an 
irregular pyrexia. The joint swelling is considerable and there is no grating on motion. Bony changes are not usually marked. There may be thickening of the capsule and occasional adhesions. There is enlargement of the lymph-glands throughout the body, as well as of the spleen. The general appearance is suggestive of intoxication, although no specific organism has been found. The blood findings are not characteristic, but are simply those of a secondary anæmia. From recent reports there is reason to believe that these cases may prove to be peculiar forms of tuberculosis.

Several eases have been recorded in which pericardial adhesions were found. As yet no treatment can be recommended, save that directed to amelioration of the symptoms.

\section{SYPHILITIC DISEASES OF THE BONES AND JOINTS.}

\section{ACUTE EPIPHYSITIS.}

In hereditary syphilis the bones and joints frequently furnish the first lesions of the disease. In very young infants this may appear in the form of enlargements about the ends of the long bones, particularly of the ulna, radius, humerus, metacarpals, and phalanges, and oceasionally of the metatarsi and toes.

These enlargements are due to an epiphysitis or periostitis near the joint in which the epiphyseal line is involved and may result in osteomyelitis of the adjacent end of the shaft, or in a synovitis of the articulation. Frequently the process is confined for a long period to the epiphyseal junction, which undergoes softening by the formation of gelatinous and granulation material, with retardation of ossification and ultimate detachment of the epiphysis. Pus may form in this area, in the epiphysis, in the joint, or in the end of the bone, and burrowing appear on the surface through fistulous openings.

Symptoms.-The enlargements may be first discovered about the lower end of the ulna, radius, humerus, or tibia. Rarely the hard swelling may extend to the middle of the shaft, as of the femur. Again, the infant may ery when handled or avoid the use of some limb which appears to be paralyzed.

Diagnosis.-In the presence of a syphilitic history or of other manifestations of the disease the diagnosis is plain. The pseudoparalysis is due to pain upon motion. Examination will sometimes reveal a detatched epiphysis and manipulation may elicit crepitus. The disease may be mistaken for scorbutus which, however, shows other symptoms of that disease, also a history of dietetic errors. The same is true of rickets, which the enlargements often simulate even to the occasional beading of the ribs, presence of eraniotabes, and pain on handling. In fact, differentiation is at times difficult until further developments or until the therapeutic test of treatment is made.

Birth-palsies, fractures, and dislocations must be eliminated by careful examination. 
The prognosis is fairly good if the case is seen before extensive suppuration or osteomyelitic processes have developed, to which the infant quickly succumbs. Destructive processes of the nasal and palate bones have been mentioned under syphilis.

An acute syphilitic arthritis in infants is occasionally observed in which the process begins in the synovial sae. It may be multiple and show considerable local distention and pain. This arthritis may be serous or purulent. In the latter case the capsule soon rields, with resultant formation of diffuse abscesses which open spontaneonsly.

The treatment is antisyphilitic, to which the acute epiphysitis and periostitis yield promptly in children with sufficient vitality to secure response. Specific medication should be supplemented by the best of nourishment and general hygiene. Sinuses, pus eavities and bony necrosis must be treated surgically. Many surgeons favor early incision down to the bone, to be followed, if necessary, by free opening into the bone by trephine or gouge for the release of pus.

CIIRONIC OSTEOPERIOSTITIS.

In late hereditary syphilis, bone lesions develop much like those of the tertiary stage of the acquired disease. The favorite seat of these lesions is the periosteum and its vicinity. The processes are very chronic, covering years of time, and rarely develop before the fifth year and frequently after the tenth year. Whether it begins upon or beneath the periosteum, that membrane becomes thickened, sometimes enormously, and deposits new bone beneath its surface, resulting in changes in the contour of the underlying structure. This form affects principally the diaphysis of the long bones, most frequently the tibia, which becomes curved anteriorly, or anterior-laterally, in a characteristic deformity known as "sword leg." Other bones, as the ulna, radius, and humerus, may be affected, and the circumseribed bossæe seen upon the cranium in late syphilis are due to subperiosteal deposits. These thickenings occasionally appear near the ends of the long bones as osseous tumors or nodes which are liable to necrotic softening, with fistula formation and discharge of pus and bony detritus. The process of local bony thickening may go on for years with increasing deformity, some tenderness, and little pain. There may be acute night pains.

Periosteal gummata may break down and lead to single or multiple discharging lesions, which persist until the bone sequestrum at their base is entirely evacuated, after which they heal, leaving permanent characteristic sears.

Allied to ehronic periostitis is dactylitis (spina ventosa), which is occasionally due to syphilis. It can rarely be diagnosed from the tuberculous lesion except by the presence of other symptoms and specific history. The course is essentially chronic and painless, with ultimate involvement of the skin and necrosis of the rarefied bony shell.

Diagnosis.-Rickets and tubereulosis are to be excluded, although the child may suffer from the three diseases concurrently. Rhachitic de- 
formities of the legs show bending rather than irregular osseous hyperplasia, and are rarely complicated with discharging nlcers and sinuses. Further, the nodular terminal enlargements are symmetrical and affect all the long bones, whereas in syphilis the ulna may show thickening from which the radius is free, and vice versa.

Syphilis at this stage rarely fails to give other evidences-as keratitis, Hutchinson's teeth, etc.-while the persistent boring pains at night are almost pathognomonic.

Treatment.-Osteoperiostitis is the most obstinate form of hereditary syphilis and rarely yields to mercury alone. Full doses of iodides long continued may be necessary to arrest its progress. Both specific and tonic (mixed treatment) are indicated, with special attention to hygiene. Necrotic, fistulous, and suppurating lesions call for surgical treatment, and bony sequestra may require the chisel.

Opiates may be necessary for the temporary relief of the night pains, which yield permanently, however, only to full doses of the iodides. Special care of the stomach is necessary, as medication must necessarily be long continued.

\section{ACUTE OSTEOMYELITIS.}

Acute osteomyelitis of infancy, unfortunately, is not a very rare disease. It has been described under the terms acute arthritis of infants, acute purulent synovitis of infants, and acute epiphysitis, - unfortunate terms in their failure to suggest the site of the original lesion, which is in the marrow of the shaft, usually, though not always, in close proximity to the epiphysis. It may occur at any age in infancy and childhood with a marked predisposition for the early suckling period. Its etiology includes a variety of the pus organisms, the staphylococcus evidently predominating. Infection may occur through the cord of the unhealed umbilicus, or any abrasions of skin or mucous membranes in older children.

The onset is sudden, with symptoms of an acute infection, vomiting, pyrexia, localized swelling, and pain in the affected part. The commonest sites are the femur, tibia, humerus, radius, and ulna.

The course is rapid, with extensive burrowing of pus if not early released. The epiphysis may be early involved and is loosened from the shaft by the extensive suppuration, which quickly invades the synovial eavity. This is seen especially in those joints where the epiphyseal line lies within the capsule, as in the hip and shoulder. Multiple lesions may appear in different parts of the body. The clinical picture is that of acute pyæmia with high temperature, local œdema, and extensive suppuration.

The early mortality of neglected osteomyelitis makes a prompt diagnosis imperative. It is distinguished from scorbutus by the pyrexia and absence of hemorrhages; from rheumatic arthritis by the more rapid onset, more pronounced constitutional symptoms, more marked leucocytosis, early evidences of suppuration, and the fact that rheumatism is comparatively rare in young infants. From tuberculous processes it is 
differentiated by the fulminating character of the invasion. The possibility of gonorrhœal infection should be kept in mind, as infants are especially susceptible to infection by the gonococcus. Examination of the vaginal, urethral, and ocular mucous membranes may aid in diagnosis. Death may follow in a few days if not speedily relieved by thorough surgical measures.

\section{ARTHRITIS DEFORMANS.}

As the name implies, arthritis deformans is a chronic progressive disorder affecting many of the smaller articulations and most of the larger ones, resulting in ankylosis and deformity. The joints most frequently affected are the metacarpo-phalangeal (the thumb usually excepted), knees, hips, ankles, elbows and wrists.

The deformity, when far advanced, particularly of the phalangeal articulations, resembles subluxations, with additional enlargements around the head of the bones. This deformity is exaggerated by extreme wasting of adjacent muscles. There is a tendency to ankylosis after gradually increasing limitations of motion, so that the victim, with unimpaired mental and vital functions, becomes quite helpless. The limbs become gradually rigid in positions of moderate flexion.

The etiology is still obscure, but, whether of neuropathic or of infectious origin, it is probably a complex condition in which the varying results are brought about by different causes-as inflammatory, trophic, and mechanical. Moreover, under the title of arthritis deformans, undoubtedly different observers have described a variety of disorders varying in their etiology. For this reason the descriptions of the onset vary from an acute synovitis or from a periarticular inflammation to a gradual, almost imperceptible, beginning of mere stiffness.

Although most frequently seen in young adults, it occasionally begins in childhood, after the fifth year, notably among poorly nourished victims of malhygiene, whose family histories show gout, rheumatism, or allied disorders. In these patients freedom from cardiac involvement renders doubtful the diagnosis of rheumatism, and, from the absence of urates in joints, that of gout; moreover, the treatment suitable for either of these affections is not beneficial. The disease, though not fatal to life, is refractory and influences general nutrition in childhood through enforced confinement. Amelioration from the pain during acute attacks may be secured by heat and anodyne embrocations, with massage of adjacent muscles. Later, electricity and passive motion aid in retarding complete contractures and ankylosis. Hot-sand baths are always grateful and result in transient benefit.

Arsenic, iron, and cod-liver oil are recommended for the general nutrition. Claimants are not wanting for beneficial results in the arrest of the progress of the disease by means of these agents.

In so far as arthritis deformans selects the impoverished, the prophylactic indications are plainly in the maintenance of nutrition and avoidance of unfavorable conditions. 


\section{CHAPTER XIII}

\section{DISEASES OF THE EYE}

AFFECTIONS OF THE LIDS

THE following conditions are common among children, and some are peculiar to the early years. No special instruments are required for their diagnosis or treatment, and such cases must often be cared for by the family physician.

BLEPHARITIS is the commonest affection of the lids. It is seen in two forms,- the simple and ulcerative. Both forms are apt to be very chronic and the ulcerative may follow the simple form.

Symptoms.-In the simple form the margins of the lids are slightly reddened and swollen, and small whitish scales are seen amongst the lashes. The latter may be pulled out easily, but they are soon replaced.

In the ulcerative form the edges of the lids are redder and more swollen, and the lashes are glued together with yellowish-brown crusts. When these crusts are removed small ulcers are seen about the roots of the lashes. The hair follicles are infected, the roots of the cilia are destroyed, and the cilia fall out, not to be replaced again. The lashes which remain are apt to be misdirected from the distortion of the lid margin due to scar contraction (trichiasis). In both forms of blepharitis we have itching, soreness, tearing, and photophobia, in proportion to the severity of the inflammation.

Etiology.-In infancy the commonest cause is malnutrition and poor hygiene. The disease may follow the exanthems, especially measles and conjunctivitis of any form. In children of school age the same causes operate, but eye-strain is a very common and potent factor.

Treatment should be first directed to securing good nutrition and perfect cleanliness. The crusts should be gently removed once or twice a day by the application of warm water softened by the addition of powdered borax, one teaspoonful to the quart. When the lids are quite clean and free from scales and crusts, they should be dried and an ointment applied. One made from yellow oxide of mercury (only that from reliable ehemists should be used), five grains to the ounce of vaseline $(0.3-32 \mathrm{Gm}$.$) , is the best. In the nlcerative form it is usually$ necessary to use, occasionally at least, a stronger antiseptic. A one per cent. solution of nitrate of silver, carefully applied to the ulcers only, is a favorite. Argyrol in twenty-five per cent. solution is better and may be used freely. It should be mubbed in well with a cotton swab. In patients who are using the eves for reading, etc., the eyes should be examined for errors of refraction and the correcting glasses worn constantly. 
Hordeolum, or StYe, is a cireumseribed inflammation of the lid margin usually due to an infection of a hair follicle.

The subjective symptoms are those of blepharitis,-pain, soreness, lachrymation, and sensitiveness to light. A red swelling, frequently accompanied by considerable odema of the entire lid, finally points at the root of a cilium.

Etiology.-Styes occur at all ages, often in crops, and are frequently associated with derangement of digestion, constipation, and, in girls at puberty, with menstrual disorders. The congestion of the lids incident to eye-strain undoubtedly acts as a predisposing cause.

Treatment.-A stye can often be aborted by pulling out the affected eyelash and making frequent applications of hot or very cold solution of boric acid. When suppuration shows itself the pus should be evacuated by a small horizontal incision. A crop of styes suggests improvement in hygiene and the correction of faulty nutrition by regulation of diet and the administration of tonics and alteratives. Errors of refraction should be corrected.

Chalazion is an inflammatory tumor of a Meibomian gland due to infection, and is to be differentiated from a stye by its location. As the glands involved are located between the tarsus and the conjunctiva, the chalazion first shows itself on the inside of the lid, but later as a rounded tumor beneath the skin. Small tumors, involving the ducts of the glands only, sometimes appear at the lid margin, but should not be confounded with stye by a careful observer.

Symptoms.-These little tumors are not painful, except when they suppurate, and are annoying chiefly because of the disfigurement they produce when of large size, and a certain amount of conjunctival irritation.

Treatment consists in opening by incision through the conjunctiva and thorough eurettage, preferably with a small serrated curette. Applications are usually a waste of time, although a chalazion is sometimes seen to disappear, or become very small, without treatment. Crops of chalazia may be due to chronic constipation and eye-strain and call for examination of the child for errors of refraction with appropriate treatment.

Trichiasis is an inturning of the lashes so that they rub against the cornea. It is usually due to cicatricial deformity of the lid margin.

Distichiasis is a double row of lashes, the inner row being so displaced as to rub against the cornea. The condition is usually congenital and is rare.

ENTROPION is a rolling in of the tarsal portion of the lid so that the lashes rub against the cornea. The commonest cause is cicatricial contraction of the conjunctiva from old trachoma, burns, etc. It may be spasmodic.

Symptoms.-These three conditions cause mechanical irritation and inflammation of the cornea with pain, lachrymation, photophobia, ulceration and opacities. 
Treatment.-The cilia may be removed by epilation or electrolysis, or an operation may be done to restore the position of the lid margin.

ECTROPION consists of an eversion of the lid, leaving the eyeball more or less exposed, causing irritation, inflammation, and in some cases ulceration of the cornea with pain, lachrymation and photophobia.

Etiology.-It may occur as an acute affection, in children, accompanying conjunctivitis and inflammation of the cornea, and is almost always present in facial paralysis. It is usually due, however, to scar contraction, the result of burns and other injuries of the skin of the lids and neighboring parts of the face.

Treatment depends upon the variety and cause of the affection. Some cases disappear quickly when the cause is removed, but the cicatricial form yields only to operation.

PTosis, as seen in children, is usually congenital and is due to an imperfect development of the levator muscle. It may also be due to mechanical causes,-as tumors, accumulation of fat, hypertrophy of connective tissue, and to syphilis and rheumatism.

Treatment.-The congenital variety can be relieved by operation only. Cases due to syphilis and rheumatism usually yield to appropriate medication.

INJURIES OF THE EYELIDS are quite common in children and include contusions, wounds, insect-bites and burns.

Ecchymosis is usually due to a blow over the eye or at the root of the nose. It may follow a fracture at the base of the skull and has occurred after a violent paroxysm of whooping-cough from the breaking of a small vessel.

Treatment consists in the application of hot compresses and gentle massage with a bland ointment.

INSECT-BITES commonly cause great swelling, which ean usually be controlled by iced compresses and a soothing ointment,--borated vaseline, cold cream, camphor-ice, etc.

BuRns of the lids are of serious importance because of the great deformity which frequently follows.

Treatment.-After thorough but gentle cleansing they should be well covered with sterile vaseline and a moist boric dressing. If there is much discharge it is well to renew the dressing twice a day. As soon as the surfaces granulate 'Thiersch's grafts should be applied.

BlePHAROSPASM is an annoying condition. It may vary from a slight intermittent contraction of a few fibres of the orbicularis to a strong tonic spasm which makes it difficult to force the eye open for examination. The simple twitching of the lids seen in patients suffering from eye-strain and chronic conjunctivitis is usually relieved by the removal of the cause. A more serious form, accompanied by contractions of the facial muscles, is very common in nervous school children-" habit spasm" or " habit chorea." It is usually initiated by eye-strain and follicular conjunctivitis, and is relieved by appropriate treatment if resorted to early; but if treatment be delayed until the vicious habit is 
firmly fixed it is an exceedingly stubborn affection. Tonic spasm is a persistent cramp of the orbicularis muscle, and may be cansed by the irritation of a foreign body, by phlyctenular conjunctivitis, or keratitis.

Treatment consists in removal of all sources of irritation, attention to the general health, and the exhibition of gelsemium or conium in refractory cases.

Conjunctivitis.- Inflammations of the conjunctiva are very common in childhood and their complications and sequelæ sometimes cause permanent impairment or loss of sight. Various clinical and etiological classifications will be found in text books on ophthalmology, but the very simplest will serve best the purposes of this chapter.

Acute Catarrhal Conjunctivitis is eharacterized by a rather sudden onset and a mucoid or mucopurulent discharge.

Symptoms.-The conjunctiva of the lids and formix is very red and swollen and in some cases there is injection and redema of the bulbar conjunctiva, with small hemorrhages and æedema of the lids. The more severe the inflammation the more pus and fibrinous exudate is found in the discharge, and the greater the aceumulation gluing the lids together during sleep. The patient will complain, if at all, of itching, smarting, or burning of the lids, and usually of the sensation of foreign bodies in the eye. There is slight photophobia, and some blurring of vision from the discharge covering the cornea. Attempts to use the eyes aggravate the symptoms. When the disease occurs in debilitated patients and is neglected, infiltration and nlceration of the cornea may occur and the opaque scar resulting from the healing of the ulcer may impair the sight. As a rule, however, the disease tends to recovery in a week or two, if the eyes are kept clean and not irritated.

Etiology.-The conjunctival sac always contains micro-organisms from the air, which may become pathogenic and increase in numbers with irritation and increased secretion from the conjunctiva. Conjunctivitis may occur at any time of the year from exposure to wind, dust, smoke, etc., but is more common in the spring and fall. It may follow direct infection from soiled fingers, towels, or handkerchiefs of those suffering from the disease, and it is best to regard any discharge from an inflamed eye as contagious. Catarrhal conjunctivitis is a common accompaniment of measles, scarlatina, smallpox, impetigo contagiosa, or eczema. It is almost always associated with severe coryza, hay-fever and influenza, and may be a direct extension from the inflammation in the nose.

Treatment.-Much can be accomplished by local applications to shorten the duration of this disease, to relieve the patient's discomfort, and to prevent its becoming chronic. During the first day or two in severe cases great relief may be obtained from the use of iced compresses, applied from half an hour to an hour three times a day. These are best prepared by cooling, on a block of clean ice, pledgets of cotton saturated with boric acid solution and transferring a fresh one to the eye every three or four minutes. The lids should be gently opened and the eye irrigated from three to six times daily with a warm solution of 
boric acid, after which a drop or two of a twenty-five per cent. solution of argyrol should be instilled. A bland ointment, thirty grains of boric acid and one ounce of vaseline $(2-32 \mathrm{Gm}$.), applied to the edges of the lids at bedtime, will prevent their sticking together and may help to prevent blepharitis, a frequent complication in poorly nourished children. If the disease tends to become chronic the treatment for chronic conjunctivitis should be employed.

Chronic Conjunctivitis may follow any of the acute forms of the disease, or it may come on gradually as a result of eye-strain or constant exposure to irritation.

Symptoms.-The conjunctiva is red but not much swollen, and there is little change in the amount or character of the secretion, which may even be diminished. The patient complains of itching, burning, and dryness of the lids and the eyes tire easily, especially when used in the evening.

Treatment.--Errors of refraction should be corrected and the lenses worn constantly. The habits of eye-work and the environment must be looked after, and locally the prolonged and faithful use of astringent solutions insisted upon until all symptoms are relieved. Zinc acetate, one-fifth to one per cent.; silver nitrate, one-tenth to one-fifth per cent.; alum, one-fifth to one-half per cent., and the yellow oxide of mercury ointment, one to two per cent, may be tried in succession. The treatment must be changed every two or three weeks.

Follicular Conjunctivitis is a chronic inflammation in which the conjunctiva, especially of the lower lid and fornix, is studded with round, pinkish elevations consisting of little masses of lymphoid tissue resembling the granules of trachoma, except that they disappear and leave no scars.

Etiology.-The cause of this disease is unknown, but it is peculiar to children and young people. Poor hygiene, indoor life, and bad nutrition seem to be predisposing causes.

Symptoms.-In mild cases the patients frequently do not complain and the discovery of the condition is accidental, but usually the symptoms are those of ordinary, chronic conjunctivitis.

The treatment is also that of chronic conjunctivitis. If the granulations are large and do not disappear under the usual treatment they may be expressed with forceps constructed for the purpose.

TRAснома is a contagious form of inflammation of the conjunctiva: It is usually chronic and of long duration, and is characterized by hypertrophy of the conjunctiva, the formation of "granules," with subsequent cicatricial changes in the lids and vascularization and ulceration of the cornea.

Symptoms.-Trachoma may come on insidiously and exist for months without the knowledge of the patient, or it may be ushered in by an acute inflammation with purulent discharge, making the diagnosis difficult. As a rule, however, it manifests itself by photophobia, lachrymation, itching, pain, sensation of mote in the eye, and disturbance of 
vision. There is swelling of the lids, drooping of the upper lid, and a variable amount of mucopurulent discharge. The conjunctiva of the lids and fornices is red, hypertrophied, thrown into folds and studded with granulations. The ocular conjunctiva is usually injected, and as the disease progresses the cornea becomes infiltrated, vascular, roughened, and finally opaque. The disappearance of the granules is accompanied by the displacement of the mucous membrane by glistening white scar-tissue which contracts, obliterating the folds of the cul-de-sac and producing entropion. The constant irritation of the cornea from the inverted lashes keeps up the inflammation and ulceration, prolonging the patient's suffering. Unless this course can be checked by treatment, the end is blindness from cicatrization of the cornea.

Etiology.-Trachoma is not so common among children as in adult life, but many cases oceur among the children of the poor. It is most common among the Jews, Irish, and Italians, but very rare among negroes. The contagion is transmitted by contact and by towels, handkerchiefs, etc., through the secretion. It spreads rapidly in schools, asylums, and in tenements.

Treatment.-Acute cases are to be managed on the principles laid down for the treatment of acute conjunctivitis. Chronic cases are best treated surgically, by the expression of the granulations, except when they are small and there is considerable thickening of the conjunctiva. In these later cases if there be much discharge a two per cent. solution of nitrate of silver, carefully applied to the everted lids in such a way as not to come in contact with the cornea, the excess being neutralized with salt salution, seems to be the best remedy. If there be little or no discharge a 1:1000 solution of bichloride of mereury or boroglyceride should be applied every day or two by the physician, the patient meanwhile using some efficient cleansing measures several times a day. 'The patient with trachoma should be put in the best possible general condition and should be isolated from his fellows, or guarded in such a way that he cannot spread the disease. Individual towels, basins, soap, etc., should be the rule, and each patient should have his own bottle of drops, pipette, cotton, and whatever else is used about the eye in all cases of conjunctivitis.

PuRulent Conjunctivitis may occur at all ages and as a result of infection by any of the pus-producing microbes. The most virulent cases of this disease occur in babies born of women with recent gonorrhœa, although the gonococcus is found in less than fifty per cent. of the cases. The eyes are usually infected during the passage of the head through the birth canal, but infection may occur in utero when the membranes are ruptured prematurely. It may also occur after birth by indirect contamination.

Symptoms.-First stage: After a period of incubation, never longer than five days unless from secondary infection, the conjunctiva becomes red, the lids swell, and a slight serous or mucous discharge appears. The eye is tender. This is followed by greater swelling of the lids, chemosis 
of the conjunctiva, and slight constitutional disturbance. Second stage: The swelling of the lids and conjunctiva may diminish, the eye become less tender, while a more or less profuse purulent discharge appears. Third stage: After two to four weeks the discharge ceases and the eye may return to the normal, but as a rule the thickening of the conjunctiva and so-called papillary swelling continue for some time. The chief danger in this disease is from ulceration and sloughing of the cornea. The chemosis of the conjunctiva strangulates the vessels at the margin of the cornea, shutting off its nutrition and reducing its vitality. When infiltration and ulceration begin, the tendency is to spread and perforate. If perforation occur the eye may heal, but be blind from adherent leucoma; or general infection and panophthalmitis may result and destroy the eye entirely. In some virulent cases in very delicate and poorly nourished babies the cornea seems to melt away.

Treatment.-In all cases where an infection of the birth canal is suspected, efforts should be directed to cleansing it thoroughly before the membranes have ruptured or as early in labor as possible. As soon as the head is born, if there be a delay in the delivery of the shoulders, the baby's face should be washed with boric solution and immediately afterwards the eyes filled with a twenty-five per cent. solution of argyrol, or a ten per cent. solution of protargol. A two per cent. solution of nitrate of silver, according to the original method of Credé, is less used than formerly. If, in spite of these precautions, the disease develop, a vigorous campaign shonld be commenced at once, and the first requisite is a trained nurse. The eyes should be gently irrigated during the first stage every three hours night and day with warm boric solution, using an ounce or two for each eye each time, the lids being held open as well as possible withont touching the conjunctiva or cornea. Aftereach irrigation a drop of twenty-five per cent. solution of argyrol should be instilled into the eye and the edges of the lids anointed with borated vaseline to prevent agglutination and to allow eonstant drainage. As: soon as pus begins to flow the eyes should be irrigated every hour and the argyrol may be used every two hours and more freely. If the cornea become hazy a drop of one-half per cent. solution of atropia. sulphate should be instilled three times a day, after a hot fomentation applied by saturating pledgets of cotton in boric solution at a temperature of $120^{\circ} \mathrm{F}$. $\left(48.9^{\circ} \mathrm{C}\right.$.), changing the compresses every minute for fifteen minutes. As the discharge of pus begins to diminish it will not be necessary to disturb the baby so often, and when it has ceased. altogether the case should be managed as one of chronic conjunctivitis. The treatment of these cases has been very much simplified by the discovery of the organic salts of silver, of which argyrol unquestionably holds first place. Protargol is as effective but more irritating, and the nitrate of silver, which for a century was facile princeps, but which in unskilled hands did so much harm, need no longer be considered. Iced compresses have been much used in the first stage of this disease, 
but cold has uridoubtedly a depressing effect upon the nutrition of the cornea. If used at all it should be very early, and only in the case of vigorous babies for short periods of time.

Croupous Conjunctivitis is an inflammation in which an exudate forms upon but does not infiltrate the conjunctiva. Micro-organisms identical with those found in diphtheritic membrane may be present, but there are no constitutional symptoms and the cornea is not involved.

The symptoms are those of catarrhal conjunctivitis. The membrane forms on the palpebral conjunctiva, and when it is pulled off a raw surface is exposed upon which the membrane re-forms.

Etiology.-This form of conjunctivitis results from burns with lime, acids, molten metals, and nitrate of silver. It may also be due to infection.

Treatment is that of acute catarrhal conjunctivitis. Irritating applications must be aroided.

Diphtheritic Conjunctivitis.-The Klebs-Loeffler bacillus may cause a variety of forms of conjunctivitis. The streptococeus also may cause a membranous form which eannot be differentiated clinically from socalled true diphtheritic infection. Diphtheritic conjunctivitis is an acute contagious inflammation due to the Klebs-Loeffler bacillus and characterized by exudation and infiltration, with a tendency to necrosis of the involved tissues and profound constitutional depression. The disease affects children,- -is rare in this country, but common in North Germany.

Symptoms.-The lids are swollen, red and tender. The conjunctiva is covered by a yellowish-gray exudate which also infiltrates its substance. The exudate disappears at the end of a week and is followed by suppuration; the cornea usually ulcerates, and the prognosis for sight is always grave.

Treatment.-If the Klebs-Loeffler bacillus is found, antitoxin should be used at once, and in any case the general strength and nutrition should be maintained. Locally the treatment should be similar to that described for purulent ophthalmia.

Phlyctenular Keratoconjunctivitis is characterized by the development of phlyctænules or pimples on the bulbar conjunctiva and cornea, which break down at their apices and form ulcers.

Symptoms.-The phlyctænules are small elevations, the size of milletseed, surrounded by circumscribed areas of redness. They often occur in crops and may heal without ulcerating. When they are situated on the cornea the ulcer is usually superficial and heals without much scarring, but may spread into the substance of the cornea and even perforate. There is usually great photophobia and blepharospasm when the cornea is involved, and always considerable lachrymation. As a result of the tearing there is frequently blepharitis, and eczema of the lids and face. Children with this disease avoid the light, keep the head down, the eyes closed, and seek the dark corners. Nasal catarrh and adenoids are usually present and may be etiological factors. 
Etiology.-The disease may affect adults, but is eommonest in poorly nourished children of the lymphatic type. It always seems to depend upon some constitutional error even though it occasionally occurs in the children of the well-to-do who are apparently in good health.

Treatment.-Calomel dusted into the eye daily is the remedy par excellence. After the acute symptoms have subsided the ointment of yellow oxide of mercury helps to promote the absorption of infiltrates and fresh scars of the cornea. The eyes should be irrigated three or four times a day with warm boric solution. If there be pain and photophobia, atropine one-half per cent. solution should be instilled after the use of hot fomentations for fifteen minutes, three or four times a day. Bandages should not be applied. If fissures occur at the outer canthus they should be touched with two per cent. solution of nitrate of silver. Appropriate general treatment and regulation of diet are necessary. Sweets, pastry, tea and coffee should be interdicted. Syrup of the iodide of iron and cod-liver oil are often helpful. Fresh air and sunshine are very necessary. If blepharospasm be not relieved by the atropine, holocaine in one per cent. solution may be tried in addition. Frequently a cold douche to the eyes and face is an excellnt measure.

Injuries of the Conjunctiva comprise contusions, wounds, and burns.

EсcHy mosis of the conjunctiva may occur from blows and from the rupture of a small vessel during a severe paroxysm of whooping-cough (Fig. 213). It is unimportant and will disappear in a few days. Absorption may be hastened by hot applications and massage.

Burns of the Conjunctiva and cornea are very painful, and serious complications are apt to follow their healing. If union between the lids and globe occur the condition is called symblepharon.

Treatment.-The eye should be thoroughly flushed with boric or salt solution as soon as possible, and if the burn be due to lime, acid, or other caustic, it should be neutralized by appropriate means. It is well to remember that sugar forms an insoluble compound with lime, and syrup of some kind is always at hand. Diluted vinegar will neutralize and dissolve lime. The conjunctival sac should then be filled with sterile vaseline and iced compresses applied, as already described, and continued for twenty-four hours if there be pain. If the cornea be involved, atropine should be used. Irrigation should be kept up every three or four hours, the vaseline used each time, and once a day the agglutinated surfaces gently separated with a sterile probe. A sharp wooden toothpick is the best instrument with which to pick grains of powder from the conjunctiva and cornea, and a fine stream of boric solution facilitates the operation.

Wounds of the Conjunctiva, not involving the deeper structures of the eye or orbit, heal kindly if carefully drawn together by fine sutures and kept clean.

Interstitial Keratitis is a chronic inflammation of the cornea characterized by cellular infiltration of its middle and posterior layers. It 
never leads to ulceration, but is accompanied by more or less inflammation of the iris and ciliary body. It is of frequent occurrence in childhood, usually beginning between the fifth and fifteenth years. It is rarely seen in infancy, though congenital cases have been reported, and one case was seen at sixty years.

Symptoms.-The infiltration may begin at the centre or at the periphery of the cornea, but in either case it gradually spreads until the entire area is opaque and vision is sometimes reduced to perception of light. At this period deep-seated, newly-formed vessels make their appearance, usually in circumscribed sectors of the cornea, giving rise to a yellowish-red discoloration known as the salmon-patch. This period of infiltration and vascularization may last two months and is accompanied by pain, photophobia, lachrymation, and poor sight. Both eyes are usually affected. After the infiltration is complete the inflam. mation begins to subside, the cornea clears up, the vessels disappear, and vision improves. Several months are required for this process, and as the centre or pupillary area of the cornea is the last to clear, the vision is very poor for a long time, and in cases which do not receive proper treatment early, the eyes may be rendered practically blind by iridocyclitis, chorioiditis, and permanent opacities of the cornea.

Etiology.-More than fifty per cent. of the cases are due to inherited syphilis,-practically all of those occurring in children. The disease may be due to trauma, to acquired syphilis, and to tuberculosis.

Treatment.-Atropine should be used in sufficient dosage to relieve the pain and keep the pupil dilated. Its effect is increased by the addition of cocaine and the use of hot fomentations. Smoke-tinted glasses should be worn in a bright light. When the cornea begins to clear absorption may be hastened by massage with yellow oxide of mercury ointment, one per cent. The constitutional treatment must be suited to the condition of the patient. Good nutrition must be maintained. Calomel in small doses, iodonucleoid, corrosive sublimate, syrup of the iodide of iron, and nutrient tonies are appropriate remedies.

IRITIS.-Inflammation of the iris may occur in an acute form in the early months of infancy from hereditary syphilis, and the more chronic gummatous variety is occasionally seen in the early years of childhood. Tubercular and traumatic iritis may also occur in childhood.

Symptoms.-The disease is recognized by pericorneal injection, discoloration of the iris, sluggish or fixed pupil, and adhesions between the pupillary margin of the iris and the lens capsule. The adhesions may not be apparent until a drop of atropine solution is instilled. In the gummatous and tubercular varieties there is in addition the presence of nodules or circumscribed swellings in the iris. Pain is not always present, but usually is severe, neuralgic in character, and worse at night. There is always photophobia and lachrymation.

Treatment.-Hot fomentations should be used every three hours while the pain is severe, and sufficient atropine to keep the pupil well dilated. The eyes must be protected from the light. If these measures 
do not relieve the pain, leeching of the temples is of great benefit. Appriate constitutional treatment must be employed.

Cataract.-Children are sometimes born with completely developed eataract, often associated with other defects or diseases of the retina, optic nerve, or chorioid. Cataracts of various forms may also develop during infancy and childhood. Anterior polar cataract is due to perforation of a corneal ulcer and inflammatory changes in the anterior portion of the lens and capsule.

Symptoms.-Diagnosis is readily made from the gray pupil and evident inability to see.

Treatment.-Congenital cataract should be operated upon by the method of discission during the second year of life, if possible. In central and pyramidal cataract, if there be sufficient clear lens available, an iridectomy may serve better than removal of the lens.

INJURIES OF THE Eve, with perforation of the globe, are very common in children. Such injuries are always serious, often resulting in the loss of the injured eye by infection, and the sound one by sympathetic inflammation.

Symptoms of perforation are the presence of a wound, reduced vision, possibly blood in the anterior chamber, and loss of the normal tension.

Treatment.-Atropine should be used as soon as the eye has been cleansed, and dilatation of the pupil secured and maintained if possible. Iced compresses do much good in the first day or two, while asepsis must be observed if the eye is to be saved. If an eye become sightless after such an injury, especially if it is shrunken or tender, it is a source of danger to the fellow-eye and should be removed.

Refraction of the Eye in Childhood.-Myopia almost never occurs in infancy, but is an acquired defect manifesting itself during school life. If not properly managed it may continue to increase and even result in blindness. Hyperopia, so-called far-sightedness, is the usual condition in infancy and childhood, and astigmatism of measurable degree is found in perhaps ninety per cent. of all eyes. The great frequency of errors of refraction in school children is responsible for many of the inflammatory conditions, and at least fifty per cent. of headaches are due to eye-strain. Many a backward child is so because of the difficulty he experiences in eye-work, and the constant strain upon the nervous system is no donbt the cause of much general nervousness, irritability, and poor health. In all such cases the eyes should be examined under the influence of a mydriatic, as no accurate measurements for glasses can otherwise be made. If glasses are prescribed early, when they are really needed, the eyes of the children often develop more completely and become so much stronger that the lenses may after a time be discarded.

PARALYSIS of one or more of the extra-ocular muscles may occur after diphtheria, meningitis, and other diseases. If complete, the deviation of eye is easily seen, and if the patient be old enough diplopia will be com- 
plained of. It will also be noticed that when the fixing eye is covered the patient cannot turn the other eye in the direction of the paralyzed muscle. Prognosis and treatment depend upon the cause. Paralysis of accommodation, with or without paralysis of one or more of the extraocular muscles, is not infrequent after diphtheria. It is manifested by inability to see near things. Recovery is usually complete, but rest and strychnia are indicated. Congenital absence of one or more of the eye muscles has been noted.

Strabisuus, or Squint, is a faulty co-ordination of the movement of the two eyes. The excursions of both eyes are normal in all directions, but there is a deviation of the visual line of one cye, the same faulty relationship of the axes being maintained in every direction in which the eyes are turned. This fact distinguishes the condition from paralysis and gives rise to the term concomitant. Convergent, concomitant strabismus is the commonest form. It may be occasional or constant, monocular or alternating. There is no diplopia except in the very beginning, the image in the squinting eye being quickly suppressed. There is usually diminished acuteness of vision in the squinting eye, but this may be a cause or a consequence of the squint.

Etiology.-Congenitally defective vision in one eye lessens the normal desire for binocular vision; errors of refraction disturb the relation between accommodation and convergence, and make co-ordination more difficult; and acquired defects interfere with the vision of one eye. Strabismus may be precipitated by any exhausting illness and may follow a true paralysis of one muscle in which contraction of the antagonist occurs before the paralyzed muscle fully regains its power. Squint usually develops between the second and fourth years of life, when the child is beginning to use the eyes more for near seeing.

Treatment consists in the improvement of the vision of the defective eye by the use of the blinder over the better eye some hours every day; the accurate correction of errors of refraction under atropine, and perhaps the prolonged use of the mydriatic; stereoscopic and other exercises to develop binocular vision, and finally operation, if necessary. All cases should be brought under treatment as early as possible to secure favorable results.

Nystagmus is a more or less rhythmic involuntary oseillation of the eyeballs, vertical, lateral, or rotary, sometimes due in children to imperfect sight in both eyes. The involuntary movements do not interfere with the voluntary movements of the eye, but accompany them. Nystagmus and squint are frequently associated. The oscillations are increased by fatigue or excitement. If the sight can be improved by glasses, the distressing symptoms are often much relieved and some cases have been benefited by operations for the associated squint.

Exорнтнацмоs is seen at all ages. It occurs in infancy as a result of hemorrhages into the orbit usually associated with scorbutus. Prominence of the eyeball with thyroid enlargement, with or without tachycardia, is occasionally seen in young children. 


\section{DISEASES OF THE EAR}

\section{IMPORTANCE OF OTITIS MEDIA}

The results of two converging lines of observation have in recent years emphasized the importance of disorders of the ear in infancy and childhood. First, elinically, it is becoming more apparent that otitis media is a common complication of catarrhal and adenoid disorders of the nasopharyngeal tract, as well as a frequent sequel to the more acute infections, as diphtheria, measles, searlet fever, and influenza. Second, accumulating data from careful post-mortem findings show an astonishing percentage of suppurative, ulcerative, and necrotic processes of the middle ear and adjacent structures. No age of childhood is exempt. Infants are born with pus-engorged tympanic cavities, so that there is evidence that the pyogenic infection developed in ntero.

The seriousness of tympanic suppuration becomes apparent when the anatomical relationship of this cavity in infancy is recalled (page 21). Not only the embryonal structure, but the functional rôle of the aural mechanism, brings the consideration of its disorders into three distinct fields. The external ear, including its meatus, canal, and outer drum surface, as a portion of the integument is susceptible to skin disorders, modified by its relations to other structures. Eczema, impetigo, furunculosis, erysipelas, congenital deformities, traumatisms, foreign bodies in canal, and impaction of cerumen are among the commonest outer ear diseases, affecting the function of hearing only as they interfere mechanically with the conduction of sound; or, secondarily, by extension of inflammatory processes to the adjacent deep aural structures.

Foreign bodies in the external meatus should be referred immediately to the physician, as awkward attempts at removal by the unskilled are frequently productive of mischief. In the majority of cases forcible syringing with a warm, bland aseptic liquid should precede instrumental attempts, which are rendered thereby usually unnecessary.

Discharge from the ear is sometimes due to furuncles of the meatus which, in common with eczema and impetigo, are discussed under SkIN LESIONS.

The middle ear, including the tympanic cavity, ossicles, with mastoid antrum, and Eustachian tube, are, histologically, part of the upper air passages, and its normal function is largely dependent on its free connection with the same. Occlusion of the Eustachian tube, even temporarily, interferes with hearing, while its permanent closure invariably leads not only to deafness but to a train of pathologic conditions from interference with ventilation of the tympanum. Equable air pressure, secured through a patulous Eustachian tube, is not only necessary to tension and vibration of the drum membrane but is essential to the normal circulation of the blood and lymph channels of the tympanic mucosa. Diminished intra-aural pressure means engorgement 
of both blood and lymph vessels, with increased eatarrhal seeretions and diminished lymph drainage.

Without frequent renewal of tympanic air, the replacement of the absorbed oxygen by the inferior bulk of earbonic acid gas results in rarefication.

To this morbid train only pyogenic infection is necessary to light up one of the commonest disorders of infancy,--viz., suppurative otitis media. Staphylo-, strepto-, and pnenmococei, the influenza, diphtheria, tubercle and colon bacilli, and even the gonococeus, find their way to this tract in about the order of frequency named. The history of the subsequent infection and the involvement of adjacent tracts, as in the development of cerebral or cerebellar abscess, lepto- or pachymeningitis, thrombosis or phlebitis of the sinuses, bone necrosis, and subperiosteal aceumulations of pus, depends partly on the nature of the infection, whether simple or mixed, and partly upon the facility for extension from the tympanum furnished by the patulous squamo-petrosal and the squamo-mastoid sutures, the many communicating veins and the sheaths of the nerves which pass throngh the petrosal foramina.

To the list of exciting causes of middle ear inflammation may be added traumatism from external violence, as puncture or incision of drum membrane, rupture from concussion or blows on head or ear, seabathing, and long exposure to cold drafts. Vomited matter and even worms have found their way to the ear through the Eustachian tube.

The diagnosis of acute middle ear inflammation is not always readily made. Where suppuration is abundant pressure symptoms, such as excruciating otalgia, an uncomfortable feeling of fulness on the affected side, impaired hearing, ringing or roaring sounds in the ear, moderate or severe headache, persistent cough without other explanation, and various obstinate nervous symptoms, point to the seat of trouble. There are the following symptoms: a sudden rise of temperature from two to five degrees, with or without history of a chill or convulsion, sometimes vomiting, usually anorexia, and furred tongue. If an infant, there may be crying and sleeplessness. The ery is sharp and piercing, with oceasional rolling, and (in older infants) beating of the head with the hands. Examination reveals tenderness on pressure over the tragus and usually over the styloid and mastoid processes, and the drum membrane presents a convexity which sometimes appears reddened. Without interference these symptoms will continue from three to five days, or until relief is afforded by spontaneous rupture of the membrane and free discharge of pus. After subsidence of the acute symptoms, the ear may discharge pus continuously or intermittently for days or even weeks. One or both ears may be involved. Double otitis is most frequently seen complicating or following the infectious diseases characterized by anginas. Scarlet fever furnishes the greatest number of double lesions, usually as sequelæ, and they are especially obstinate and destructive after this exanthem. Otitis, complicating an acute disorder-as pneumonia, enteritis, typhoid fever-is frequently marked at its onset by symptoms of 
the prevailing disorder. Occasionally, meningitis is suspected, until a purulent discharge from the auditory meatus reveals the cause of the supposed cerebroid symptoms. Many cases which occur alone, or as complications or sequelæ to other disorders, continue discharging at intervals after recovery from the acute attack. So that the running ear marks every fresh exposure to cold during months and even years of childhood, thus constituting a chronic or recurrent form of suppurative otitis media.

Although a common disorder most prevalent among children of malhygienic environment, the prognosis is always uncertain. The longcontinued pressure of suppurative processes in close relation to important structures is a prolific cause of the grave cerebral disorders of infancy and early childhood. The permanent impairment of hearing from destruction of the drum by necrosis, or ankylosis of the ossicles or other structural changes in the auditory apparatus, is not nearly so common as one would be led to suppose.

The prophylaxis of otitis media should begin with care of the nose and throat, as in the large majority of cases the tympanum is probably infected through the Eustachian tube. During all the infectious diseases of childhood the ear should be frequently examined as to the condition of the drum membrane. If this is found bulging it is, even in the absence of other symptoms, an indication of pressure from within, probably from pus. This pressure is sometimes due to hemorrhage into the tympanum, occasionally seen in cerebrospinal meningitis, scorbutus, leukæmia, Hodgkin's disease, pernicious anæmia, hæmophilia, and purpura.

Treatment.-The presence of pus calls for its evacuation, best accomplished by a semicircular incision of the membrane, parallel with and near to the lower anterior border. This location avoids the ossicles and secures better drainage. A bulging confined to the upper posterior quadrant is indicative of attic suppuration, and may best be drained by puncture of Schrapnell's membrane. Discharge, if tardy on account of viscidity, may be promoted by irrigation of the external meatus with hot boric solutions. A pledget of absorbent cotton should be left in the meatus to act as a wick. The same treatment is applicable to spontaneous perforation of the drum membrane which is occasionally the first evidence of otitis. Intense otalgia, without drum convexity, may or may not indicate beginning suppurative otitis. The pain may be relieved by hot applications, dry or moist. The former are made by means of the bag of hot water or salt, the Japanese hot-box, or an electric heater applied over the auricle. The second method consists of filling the external meatus with hot sterile water, being especially careful to dry out with warm absorbent cotton. This process may be repeated frequently.

The macerating effect of poultices and extensive fomentations is considered sufficient reason for condemnation. At the onset of acute otitis, general and local depletion is indicated, as some of the symptoms, espeeially pain, may be due largely to accompanying congestion. Hence, 
free purgation, heat to the extremities, and occasionally rubefacients and even leeches behind the auricle, are in order. Symptoms have disappeared and apparent abortion of the inflammatory process has followed this treatment. Persistent or frequently recurrent discharge from the tympanum, covering a period of several weeks, is considered by many good authorities as evidence of mastoid involvement. Persistent cases should always be referred to the aural surgeon.

Neglected suppurative otitis media, in the majority of eases, sooner or later develops mastoiditis. When the intimate relation of the mastoid antrum to the tympanum is recalled, both cavities and the connecting aditus having a common mucous lining, its frequency as a sequel is not surprising. On the contrary, the wonder is that any continued middle ear suppuration fails to invade this easy route of extension. That many such lesions of the mastoid antrum, and even cells, when they exist, go undiagnosed with ultimate recovery, is undoubtedly true. Still the condition must remain a perpetual menace to life through necrosis of the intervening bony tissue and invasion of adjacent structures. Not infrequently acute mastoiditis follows hard upon acute suppuration of the tympanum with or without marked middle-ear symptoms. There is then a sudden rise of temperature, throbbing pain, remittent tinnitus, in infants convulsions, somnolence or coma, tenderness over the postauricular region, occasionally boggy tumefaction and redness over the mastoid, with outstanding auricle, coated tongue, and constipation, with leucocytosis.

On the other hand the symptoms of suppuration may be obscure and resemble atypical typhoid, influenza, or malaria, in which the absence of plasmodia and presence of leucocytosis point to pus formation. Inspection of the ear may show bulging of the membrane. Paracentesis yields but a little viscid pus, followed by an improvement of the symptoms or even apparent recovery. Days or even weeks later, a sudden attack of vertigo or coma may call attention to the forgotten aural discharge. An operation upon the mastoid may show the antrum and cells filled with purulent material and granular detritus from necrosis of both soft and hard tissues with sequestra. The destruction of the thin bony walls may have laid bare the lateral sinus or dura mater, exposing subdural collections of pus. The pus may find exit through the mastosquamosal suture, not infrequently patulous in later childhood, and appear under the periosteum, back of the ear, as a superficial abscess. It may erode through the thin bony wall into the external meatus, filling that channel with its tumefaction. An incision in either position will relieve the local pain, but is misleading in its effects since it delays the more urgent radical operation.

From the foregoing it is not difficult to see how complications and sequelæ from neglected purulent otitis and mastoiditis should arise, such as phlebitis, thrombosis of adjacent veins and sinuses, cerebral abscess, meningitis, internal ear involvement, and facial paralysis from pressure on the seventh nerve. 
EAR TUMORS.

Of the tympanic and mastoid neoplasms, tubercles are undoubtedly the most common, although rarely of primary occurrence. It may occasion symptoms of subacute suppurative disease of these eavities and is usually associated with tuberculous meningitis. That brain abscesses so seldom follow this invasion may be explained by the rapid fatal termination of the basilar meningitis.

The subsequent history of these cases makes the prognosis extremely grave, yet recoveries have been reported after extensive destruction of the mastoid bone from tubercular processes.

Cholesteatoma is occasionally found in the antrum as a benign though most persistent neoplasm, reappearing after repeated operations for removal. Sarcoma of this location is not extremely rare even in early infancy, against the malignancy of which all operations are futile.

\section{INTERNAL EAR.}

Otitis interna is rare in infancy and childhood and is seldom a primary disorder. Its commonest form, labyrinthitis, is generally due to pneumococcic infection, cerebrospinal meningitis, mumps, and adenoids of the pharyngeal wall. Infection from the middle ear occasionally invades the vestibule, although the infrequency of the infection by this route is a matter of surprise. The want of articulations and brittleness in the petrous bones of children render them less liable to fractures and hemorrhages with resulting injury to the auditory nerves. Although rare, the possibility of labyrinthitis should be kept in mind in prolonged obstinate vomiting, with or without occipital headache, not explained by other eauses. Chronic nephritis, diabetes, and congenital syphilis are occasionally responsible for internal disease and, as in later life, cause symptoms of vertigo, nausea, sudden and usually permanent deafness and, in older children, tinnitus and staggering gait. Pressure upon the auditory nerve from hemorrhages, serous exudates, tumors, sequestræ, or from atrophy, may produce symptoms of labyrinthine disease.

In double labyrinthine disease the suddenly suspended hearing is seldom restored. In patients under five years of age this deafness usually results in mutism. The importance of preserving the memory of language already aequired cannot be overemphasized. 


\title{
CHAPTER XIV
}

\section{THE SPECIFIC INFECTIOUS DISEASES}

\author{
EXANTHEMATA
}

\section{SCARLET FEVER-SCARLATINA}

SCARLET fever is an acute, contagious, self-limiting disease. It presents four fairly constant and well-defined symptoms,-viz., sore throat, high temperature, characteristic rash, and desquamation. It may oecur sporadically, but its most familiar appearance is in the form of recurring epidemics after intervals of comparative exemption in the community. In large cities the disease is, to a certain extent, endemic. The severity of the disease does not appear to depend upon the extent of the epidemic, although, as in many other diseases mitigation of symptoms occurs in the decadence. Mild symptoms in a given ease are no assurance that the next victim in order of transmission will not develop a severe type of the disease. The reverse is also true. In scarlatina there is a noticeable lack of the universal susceptibility which children show in the other specific contagious diseases. Probably little more than fifty per cent. of all who are exposed contract the disease in recognizable form.

Etiology.-On account of the gravity and wide prevalence of scarlet fever a great amount of research and much discussion have been devoted to the etiology, thus far with disappointing results. Although no organism or toxin out of the many which have been subjected to rigid scrutiny has fulfilled all the requirements of a specific agent, the attention of bacteriologists constantly recurs to the streptococcus, both on account of its constant presence and because of its behavior in the graver forms of this disease. While normally present with other flora of the mouth in health, in the angina of searlet fever this organism more than any other shows evidence of great activity and rapid multiplication. Its presence in the blood is occasionally demonstrated even in mild forms, but it is seen most frequently in fatal cases, and always in large numbers after death from this disease. In fact, many have claimed that whatever be the specific cause of the infection, in all probability the fatal termination is due to streptococexmia.

Symbiotic activity of the streptococcus with some unknown, perhaps ultra-microscopic, organism appears to many a reasonable hypothesis for the phenomena. Among the later claimants for etiologic recognition in scarlatina are the diplococcus of Class and the protozoön of Mallory. In regard to the former, several bacteriologists have been unable to confirm the findings of Class, while Mallory's organism is too recently announced to have allowed time for demonstration. 
No age is exempt from scarlet fever, although its occurrence in typical form in adult life is sufficiently rare to attract attention. Its infrequency in early infancy is a matter of common observation. Cases are reported, however, of scarlatina in new-born infants whose mothers were suffering from the disease. There are also records in which healthy infants have been born of mothers who were passing through an attack of scarlet fever. The susceptibility to searlatina increases steadily from the end of the first to the fifth year, after which it progressively diminishes. During this period all children are not equally susceptible, as the histories of epidemics show a selection of individuals exposed to the contagion even in the same family. This presupposes some unknown receptivity. That this apparent immunity to the scarlatinal infection varies in the same individual is also well known. Children who escape from one exposure may yield to a later, under conditions which suggest even diminisleed virulency of infection. Instances are not wanting in which life immunity seemed possessed by the individual who passes unseathed through many epidemics.

Season has apparently some influence upon the occurrence of scarlet fever, the early winter months showing not only the greatest number but the highest mortality. Several explanations have been offered, among which three are somewhat generally accepted: first, the aggregation of susceptibles in schools which reopen in September; second, the confinement to the house in the winter; third, the unpacking of winter clothing which has been stored in dark closets and drawers during the summer, with the consequent release of bacteria the vitality of which, under favorable conditions of darkness and dryness, has been proven to be very tenacious. There are many instances which go to show a remarkable vitality, frequently covering a period of several years, of the infecting agent of scarlet fever when protected from the action of sunlight and fresh air.

The common source of infection is the scarlet fever patient, from whose personal emanations (nasal and oral secretions, sputum, urine, frees, sweat, dermal exfoliation, and possibly breath) the poison may extend to the susceptible child. Most frequently this occurs by direct contact, but the poison may be conveyed by clothing, books, letters, toys, domestic pets, flies, and through food and drink, even to great distances. A common carrier, as has been demonstrated in numerous epidemies, is milk, which forms a favorable culture medium for the scarlet-fever poison, and may introdnce it in active, virulent form into many homes.

The desquamative stage of the disease was formerly regarded as the one most favorable for dissemination, which oceurred through the particles of exfoliated epithelium, in which form the poison was readily transmissible through any medium, and might be air-borne. Indubitable instances, however, have shown that transmission by direct eontact with a patient may occur at any stage of the disease, even including the period of incubation. In this connection attention should be called to 
a source of infection from the prevailing sore throat so commonly seen during epidemies of scarlet fever. This is justly considered a masked form of scarlatinal infection.

The mode of entrance to the body of scarlet fever contagion is not positively known. The infection from milk would suggest the probable absorption from the digestive tract, while many circumstances go to show that the mucosa of the upper respiratory tract offers ready access to the invading germ. As in other infections the tonsils and absorbent tissue of the adenoid ring probably afford a gateway for the scarlatinal organism or its toxins. This is emphasized by the anginal disturbance which is a common feature of this disease. Inoculation experiments lave shown that the abraded skin may absorb the poison, and the familiar puerperal intoxication from scarlatinal infection shows the susceptibility of the blood to this agent by whatever route introduced. The period of incubation varies widely-in exceptional cases from one day to three weeks-but in the United States the very large majority develop characteristic symptoms in less than a week after exposure.

Symptoms.-No picture of scarlatina can be presented to the student that may not be misleading, so wide are the variations from the type in this disease. A typical attack, and this may represent a third of the cases as met in general practice, develops abruptly, usually after a few hours of malaise, with vomiting-which may be repeated, but rarely occurs after the first day - chill or chilliness, high temperature $\left(103^{\circ}-104^{\circ} \mathrm{F}\right.$., $39.5^{\circ}-40^{\circ}$ C.), full and rapid pulse $(120$ to 160$)$, headache, possibly delirium, or even convulsions, in young infants. Examination shows a grayish-yellow coating of the tongue through which the swollen, fungiform papillæ appear as bright red dots. The throat is hyperemic, the tonsils are often enlarged, and the glands under the angle of the jaw are swollen and tender. By the second day the rash appears, usually in the clavicular region or along the side of the neck, behind the ear, whence it spreads around the neck and downwards over the trunk, involving successively the upper and lower extremities. In twenty-four hours from its first appearance the exanthem usually covers the entire body, with the exception of portions of the face,-as the prolabia, nose and chin. The pallor of these latter present a vivid contrast to the surrounding redness. The rash is characteristic and has been variously described as punctate and uniformly hyperæmic. Strictly speaking, it is composed of fine, bright red points, in diameter less than the head of a small pin. These are distributed evenly, are slightly elevated and show hyperæmic areola which merge into those of adjacent puncta. As the exanthem develops it presents the appearance, at a short distance, of bright, uniform redness, which fades under the pressure of the finger but quickly resumes its color as the capillaries refill. Close inspection, especially with a low magnifier, will show the points of deeper scarlet appearing through the hyperæmic surface, which by this time has swollen to their level. Coincident with the development of the exanthem the temperature rises to $104^{\circ}$ or $105^{\circ} \mathrm{F} .\left(40^{\circ}-40.5^{\circ}\right.$ C. $)$ with increase in pulse and respiration. 
The faucial inflammation increases in intensity and the nasal discharge, which has been slight in the beginning, increases perceptibly and may, with extreme throat involvement, become mucopurulent. The throat may be so swollen and painful as to make deglutition difficult. The tongue sheds its thick coating about the third day and presents the characteristic bright red "raspberry" tongue.

The urine in the first days of the attack shows the ordinary concentration of the febrile state. It may contain traces of albumin, which is transient, although some observers claim albumin, renal epithelium, and red blood cells are common in the initial stage. Diarrhœa may accompany the initial vomiting and prove troublesome during the entire course. The eruption usually lasts from four to six days, reaching its brightest intensity on the third day. It recedes in the order of its appearance, becoming gradually less distinct, the skin assuming a yellowish stain, which is last seen on the dorsum of the hands. As a rule the temperature, which shows a morning and evening fluctuation of a degree or more, follows the rash by lysis and reaches normal a day or two after the disappearance of the rash. Occasionally, without evident complication, the temperature fluctuates between $100^{\circ}-102^{\circ} \mathrm{F} .\left(38^{\circ}-39^{\circ}\right.$ C.) throughout the second week, or it may run a subnormal course for a few days. Even before the onset of symptoms the blood shows a marked leucocytosis, which increases with the appearance of the rash and may reach as high as 20,000 per C.c. or more in moderate cases. The increase is seen principally in the polynuclear cells. The eosinophiles remain normal or may show slight increase. Their total disappearance always renders the prognosis grave. Erythrocytes and hæmoglobin show slight diminution, while in protracted cases the anæmia is pronounced. During the height of the eruption there is considerable itching of the skin, especially noticeable about the hands and feet, which appear swollen. The face may also have a swollen appearance, while the eyes, although rarely deeply injected, are usually brilliant.

A day or two after the subsidence of the rash, desquamation begins, being usually most marked in areas of greatest eruption. The exfoliation of the trunk occupies six to ten days and occurs in fine furfuraceous scales. That of the extremities continues longer, the thickened skin from the palmar surfaces of the fingers and toes coming away in large patches or casts. This is peculiarly characteristic of scarlet fever and may require from four to six weeks for its completion. In uncomplicated cases, with the decline of the temperature the angina disappears, the appetite returns, and the child makes a rapid convalescence.

Instead of the case just described, all of the symptoms may be intensified and the stage of hyperpyrexia prolonged, marking a more severe type of the disease, indicative of profound sepsis.

Variations from this type, as before mentioned, are frequent, some of which have given rise to the terms scarlatina sine eruptione, sine febre, sine angina, also scarlatina hemorrhagica and scarlatina maligna. The rash may be delayed for several days or it may appear in circum- 
scribed patches as a local erythema. It may appear as extremely fine papules, like "goose flesh," blotchy, resembling measles, or in the form of numerous small vesicles.

The rash may recede on the day of eruption, to reappear or not a few days later. The hemorrhagic form is marked by a deep purple color of the eruption, which may be interspersed with petechiæ. Ecchymoses from a pea to a hand-breadth in size may appear.

The throat lesions vary greatly, as to their character and extent, from simple hyperæmia to extensive tonsillar and pharyngeal inflammation and even gangrene and sloughing. Pseudomembranous angina is common. In this there is coagulation necrosis involving the tonsils, fauces, buccal surfaces, and even the entire pharyngeal wall, with a plugging of the posterior nares. Clinically the pseudomembrane can not be distinguished from that of diphtheria, from which it differs bacteriologically. Occasionally the membrane appears early in the attack, but it is usually of later development and is significant in proportion to the area involved.

In scarlet fever there is a tendency to adenitis which, in severe cases, may result in glandular suppuration. Those of the neck show most extensive suppuration, while the axillary, inguinal, and mesenteric lymphnodes show swelling, and there may be considerable splenic enlargement.

Complications. - The middle ear is a common seat of infection through the Eustachian tube. This is often followed by a purulent discharge from the meatus and occasionally by bony necrosis of the mastoid and tympanic walls. The otitis is usually bilateral and constitutes the most frequent sequel of scarlet fever. It may occur during the height of the attack but more often develops in the second week. Acquired deafmutism, aceording to statisties, owes its origin in a large proportion of cases to scarlatinal otitis. From the middle ear, as well as from the accessory nasal sinuses, meningitis, cerebral abscess, and sinus thrombosis may develop.

Scarlatinal arthritis is by no means rare, and may constitute a true suppurative lesion of the joints, or there may be only infiltration and swelling of the periarticular tissues accompanied by pain and fever. The latter form may appear coincidently with the eruption or as a sequel to the disease.

Scarlatinal nephritis is one of the common complications of scarlet fever. Indeed, by the nephritis alone an atypical attack of scarlatina is occasionally diagnosed. It may occur during the height of the attack as an acute diffuse nephritis, although it is rarely attended at this stage by much œdema. The renal complication generally develops ten to thirty days after the subsidence of the rash and during apparent convalescence. The first indication may be seen in diminution or sudden suppression of the urine, often with a history of exposure to cold. The swelling of the eyes and puffiness of the face and feet point to the nature of the complication. This is confirmed by the urinary findings. The heart occasionally suffers in searlatina from endo-, myo-, or pericarditis, 
and a retrocedent rash may be the first intimation of cardiac involvement. Most frequently cardiac involvement is seen in conjunction with the post-scarlatinal nephritis before mentioned.

Bronchopneumonia may complicate scarlet fever, especially if there be profound sepsis, in which case it is an early complication and contributes to a fatal termination. Later pleuropneumonia may occur with empyema, or œdema of the lungs may accompany nephritis.

In addition to the above-mentioned complications and pyæmic processes, resultant from general and local infection, scarlet fever may be accompanied by any of the acute infectious diseases, in which event the diagnosis must be made from the preponderance of symptoms, the differential findings, and the history of exposure. The concomitant or successive occurrence of the characteristic rash of different exanthems presents many puzzling anomalies to the diagnostician. The importance of diagnosis in these cases is self-evident, not only in relation to the prognosis, but for its prophylactic value concerning other children who may have been exposed.

Diagnosis.-The diagnosis of a typical case of scarlet fever presents few difficulties. In the atypical cases there is usually present some one of the cardinal symptoms, such as the raspberry tongue, and later the desquamation and McCollom's white line at the junction of the nails and the flesh. Efflorescence from a variety of causes may simulate that of scarlet fever. Medicinal rashes from the administration of quinine, belladonna, antitoxins, and antipyrin, are to be distinguished by the history of the medication and absence of other confirmatory signs of scarlet fever. A local erythema, indistinguishable from that of scarlatina, may be due to rubefacients,-as kerosene oil, turpentine, "capsicine,", etc.

In all anginas, cultures should be examined for Klebs-Loeffler bacilli. For a comparative diagnosis from measles, varicella, variola, and rötheln, see table, page 560 .

Prognosis.-The prognosis in scarlet fever should always be guarded, since even in mild cases complications, such as suppurative otitis, endocarditis, and nephritis, may arise. As in other disorders, personal idiosyncrasy has much to do with the course and complications of scarlet fever. High temperature, above $105^{\circ} \mathrm{F} .\left(40.5^{\circ}\right.$ C. $)$, at the onset, with persistent vomiting, portends a severe attack, while extensive throat involvement, with or without Klebs-Loeffler bacilli, must always be regarded with apprehension. Sudden retrocession of the rash is a danger signal and should lead to a careful examination for cardiac or pulmonary inflammations. The appearance of petechiæ, suggestive of the hemorrhagic type, is always of grave import. A sudden increase in leucocytes to 25,000 or 30,000 C.c. indicates extensive suppuration.

In the malignant form death may occur in the second or third day from the overwhelming intoxication. In this form no rash may have developed or the eruption may be hemorrhagic. The attack may begin with convulsions, or early coma may supervene, from which the child 
never recovers. The temperature is high $\left(105^{\circ}-107^{\circ} \mathrm{F} ., 40.5^{\circ}-41.5^{\circ} \mathrm{C}\right.$. $)$, or it may not rise above $100^{\circ} \mathrm{F}$. ( $38^{\circ}$ C.), with weak, irregular pulse, pale, eyanotic skin, and stupor from which the child cannot be aroused.

The nephritis of scarlatina usually terminates favorably. This is especially true of the renal complication which develops as a sequel and which runs a course of an acute parenchymatous inflammation. The nephritis occurring at the height of the attack is likely to prove more serious by the addition of uramic to the scarlatinal intoxication. Arthritis in the purulent form is a dangerous complication from the possibility of septic endocarditis. Epidemics differ widely in their mortality. From the reports of numerous epidemics, as well as from several large hospitals and institutions for children, the average mortality of scarlet fever may be fairly stated as from ten to twelve per cent. for children of all ages, under five years about twenty per cent., while in young infants this disease shows a much higher fatality.

While scarlet fever rarely occurs in the same individual more than once, cases are recorded of a second and even a third attack, usually after an interval of years. As in typhoid fever, true relapse may occur from reinfection, in which event the symptoms and complications are likely to be more severe than in the primary attack. In case of true relapse the temperature, which had fallen to about normal, suddenly rises, and although desquamation may have been well under way, an efflorescence spreads over the body. The tongue again becomes coated and the angina reappears with increased intensity. In contradistinction to the above, cases of pseudorelapse are not uncommon. These amount to little more than a recrudescence of the eruption before the beginning of desquamation. All the symptoms of the early stage, including fever, angina, and anorexia, may return and persist for a week or more.

Treatment.-No specific treatment is recognized. Sera have proved disappointing, a though recently Escherich has endorsed the Moser serum which he elaims has reduced the mortality by half. It should be remembered that the disease is self-limiting, running a fairly definite course with a tendency to recovery in the absence of complications. A recognition of the complications will enable the physician to meet the impending danger and intercept some of its most serious consequences. The high temperature, unless unduly prolonged, calls for no special treatment. The use of antipyretic drugs should be discouraged, not only as causing disturbances of the digestive tract but as tending to weaken the heart. The proper application of hydrotherapy conduces to the comfort of the patient and reduces the temperature, develops or maintains the eruption, and promotes elimination. The method of bathing should depend upon the conditions in the individual case. If the skin be hot in proportion to the temperature shown in the rectum, the graduated full bath, beginning at $98^{\circ}$ and reducing to $75^{\circ}\left(37^{\circ}-24^{\circ} \mathrm{C}\right.$.), for five minutes, may prove beneficial. The pack at a temperature of $75^{\circ} \mathrm{F}$. $\left(24^{\circ}\right.$ C. $)$ may be repeated several times a day if for any reason the 
cold bath be impracticable. Tepid sponging may be employed at a temperature comfortable to the patient. Frequent inunctions of the entire surface of the body with boric acid, two per cent. in vaseline, or of one per cent. carbolic acid ointment, tends to allay the pruritus, promote sleep by relief of irritation from the desiccating effect of the high temperature, and limit the spread of contagion during the stage of desquamation.

The early vomiting will rarely require treatment, as it is usually limited to the first day. Of special importance, but too frequently neglected, is the treatment of the angina. It is believed that the intensity of the systemic infection may be positively limited by early and persistent disinfection of the throat and nasopharynx. Bland antiseptic alkaline solutions should be used in gargles, also in sprays and douches, in both the throat and nose. A flexible rubber tube attached to the nozzle of a fountain syringe will answer the purpose. On aceount of its action on the already threatened kidneys, potassium chlorate, so frequently used in throat affections, is contraindicated.

Symptoms of otitis media must be constantly looked for and incision of the drum membrane should be made at the first appearance of pressure. Early operation for drainage in mastoiditis may avert the fatal consequences of deeper infection. Extensive cervical adenitis is best treated by the ice collar. Incision of the enlarged glands is not recommended in the absence of unmistakable evidence of pus. The possibility of renal insufficiency, both as an early and late complication, calls for the free administration of water. Repeated high copious enteroclysis of hot saline solution, $100^{\circ}-110^{\circ} \mathrm{F}$. $\left(38^{\circ}-43^{\circ}\right.$ C.), undoubtedly promotes elimination from the kidney. Upon the first occurrence of urinary suppression saline diureties, as potassium acetate and citrate, may be given with or without digitalis. A weak and irregular pulse ealls for digitalis or caffeine to counteract eardiac insufficiency. This, if accompanied by a retrocedent rash, should be met by nitroglycerin, given hypodermically, every hour or two.

The practice of administering urotropin throughout the attack, as a prophylactic against nephritis, has been claimed to lessen the frequency of that complication. Highly septic cases, with signs of prostration, call for the use of alcohol unless specially contraindicated by the condition of the kidneys. In this case camphor or strychnia may be substituted, although the latter drug is not as efficient in scarlatina as in some other conditions.

The proof or the strong probability of the presence of diphtheritic infection demands the immediate injection of antitoxin, 2000 to 5000 units.

The arthritis rarely requires specific treatment further than application of anodyne embrocations and cotton wool to the painful joints. Evidence of cellular or synovial suppuration should receive prompt surgical attention.

The early vomiting and anorexia will prevent dietetic errors unless 
food is unwisely forced upon the unwilling patient. Indigestion but adds another element of intoxication. Upon the subsidence of the hyperpyrexia, bland liquid nourishment may be cantiously administered. Except in rare cases the best representative of this type of food is milk. Next in order come animal broths and cereal gruels, with fresh fruit juices; later, blanc-mange, light porridges and puddings, ice-cream, custard, eggs cooked soft, a little jelly from fruits or meats, and toast, may be added. It should be remembered that according to present teaching a concentrated nitrogenous diet increases the eliminative work of the kidneys and is contraindicated in view of the possible later renal complication. For the same reason, increased metabolism incident to exercise should be guarded against by keeping the child quiet thronghont the danger period of convalescence. A tendency to acidosis from diminished ingestion of food and increased metabolism shonld be met by the use of alkaline salts, either by mouth or by high enteroclysis of saline or alkaline solutions.

At the onset of the attack the child should be put to bed and kept there, no matter how mild the symptoms, since it is well known that grave complications may develop in apparently light attacks. Teaching and practice vary widely as to the length of time quarantine should be maintained. The protection of others requires sequestration while desquamation is in progress and until the nasal and pharyngeal mucous membranes are normal, although that process may take seven or eight weeks.

\section{MEASLES-RUBEOLA MORBILLI.}

Measles is a highly contagious acute disease distinguished by a characteristic eruption on the skin and mucous membranes. No age is exempt, except through immunity gained by a previous attack. Many instances of recurrence have been observed. The suckling period shows a lessened susceptibility to the infection, yet cases are reported as early as the second week of life, and the possibility of congenital measles from infection in utero is admitted. The disease occurs regardless of race or climate, in epidemics, the severity of which seems to increase with the length of the intervening_period.

The infectious agent in measles is unknown. That it is present during the entire course of the disease is evident, and that it may be air-borne there is little reason to doubt. "Artificial measles" has been induced by inoculation with blood serum taken from patients during the eruption.

The vitality of the infecting organism and the danger of intermediary infection is much less than in scarlatina, while the susceptibility is more universal.

The period of incubation in measles is from seven to fourteen days (usually averaging about ten days), although variations occur in both directions.

The constant lesion of measles is a mild inflammation of the skin and mucous membranes, with perivascular, periglandular, and perifol- 
licular infiltration of round cells in the corium and rete. This is accompanied by an acute catarrhal condition of the upper respiratory and conjunctival mucosa, with swelling of the cervical and bronchial glands. There is hyperæmia of the oral and intestinal mucous membrane, with tumefaction of Peyer's patches and occasionally acute degenerative changes in the kidneys. The conjunctivitis, rhinitis, laryngitis, and bronchitis preceding and accompanying the eruption of measles are therefore simply expressions of the disease and not complications. Variations in the severity and extent of the mucous lesions depend upon the character of the micro-organisms present, among which the the staphylo-, strepto-, and pneumococcus, alone or associated, all of which find in the catarrhal mucosa favorable conditions for development. Examinations of the blood show normal or diminished lencocyte count, the latter amounting frequently to only fifty per cent. during the exanthem. The eosinophiles are diminished or absent during the pyrexia.

symptoms. - The onset of measles is usually gradual, the prodromal period occupying three or four days. The child is listless, drowsy, or irritable, refuses food, and shows some fever, coryza, and dry cough. The temperature may be high the first night $\left(102^{\circ}\right.$ to $104^{\circ} \mathrm{F} .\left(39^{\circ}-40^{\circ}\right.$ C.), in which case it usually falls two or three degrees in twenty-four hours, only to rise again a day later. The acceleration of pulse and respiration are proportionate with the elevation of temperature, which shows morning lemission. The palpebral conjunctive look moist and some congestion at the inner canthi is present. The tongue is coated, breath feverish, the palate is hyperæmic and shows dark red papules bearing on their crests minute vesicles. The arrangement of these papules is very suggestive of the exanthem as it appears later upon the skin. In a majority of cases, Koplik's_sign may be seen on the buccal mucosa. It consists of minute bluish white specks with a large irregular areola of rose-colored mucosa, separated at first by the normal pink tint. Later, as the hyperæmia extends, these specks show on a background of uniform rose color. (See Plate.) Only a few may appear, or rarely the entire buccal and labial mucosa may be thickly sprinkled with them. By wetting the finger these specks can be felt as minute elevations which may be removed with delicate forceps. Usually good daylight is necessary to bring out this sign plainly.

With increasing malaise and fever, the exanthem makes its appearance about the fourth day of onset,-first on the temporal region and around the angles of the nose whence it rapidly extends over the face, scalp, neck, trunk, and extremities, reaching its maximum in from thirty-six to forty-eight hours. Although usually quite regular in this order of development, the rash may occasionally appear first upon the back or other portions of the trunk.

The exanthem of measles is rose-red, irregularly maculo-papular, primarily discrete, and somewhat crescentric, both in form and in their arrangement into clusters. In well-marked cases the efflorescence becomes confluent or blotchy over large areas, and the parts are distinctly 
Fig. 1.

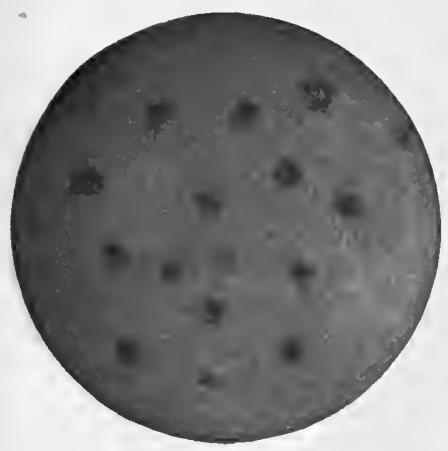

Frg. 3.

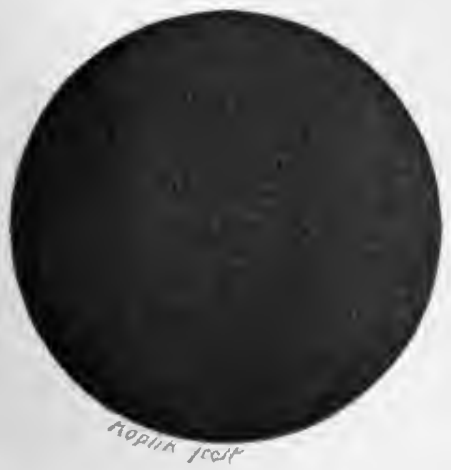

FIg. 2.

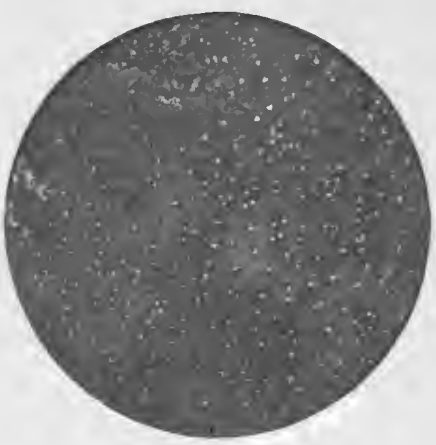

FIG. 4.

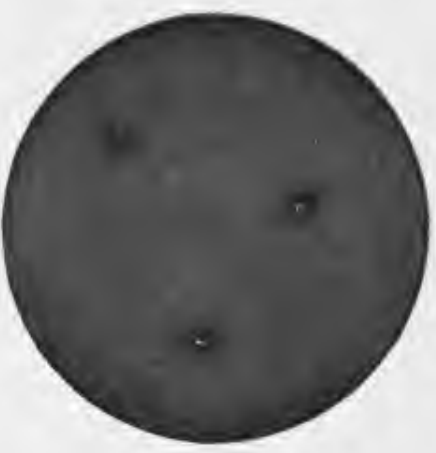

Fig. 208-The Pathognomonic Sign of Measles (Koplik's Spots).

F1G. 1.-The discrete measles spots on the buccal or labial mucous membrane, showing the isolated rose-red spot, with the minute bluish-white centre, on the normally colored mucous membrane.

Fig. 2.-Shows the partially diffuse eruption on the mucous membrane of the cheeks and lips patches of pale pink interspersed among rose-red patches, the latter showing numerous pale bluishwhite spots.

FIG. 3.-The appearance of the buccal or labial mucous membrane when the measles spots completely coalesce and give a diffuse redness, with the myriads of bluish-white specks. The exanthema on the skin is at this time generally fully developed.

Fig. 4.-Aphthous stomatitis apt to be mistaken for measles spots. Mucous membrane normal in line. Minute yellow points are surrounded by a red area. Always discrete.-Med. News, June 3, 1899. 

swollen. This is particularly true of the face which, with the conjunetivitis, photophobia, and coryza, presents the typical physiognomy of measles.

At the height of the eruption the temperature begins to decline, reaching normal in about three days, although usually the fall is abrupt. The efflorescence fades from above downwards; the swelling subsides, so that in about four days the skin shows only brownish stains, gradually disappearing with a fine branny desquamation which frequently escapes notice. Desquamation is nearly complete in about two weeks from the first appearance of the exanthem.

The photophobia, lachrymation, coryza, angina, laryngitis, and bronchitis reach their height with that of the pyrexia, and gradually sulsside with the disappearance of the rash and subsequent desquamation, while ocular and bronchial irritability may persist for some time.

ATYPICAL MEASLES-COMPLICATIONS AND SEQUELE.

Measies may run its course with no ermption on the face, or the exanthem may appear irregularly on different portions of the body, or be entirely wanting. The rash may develop tardily, requiring sometimes from five to twenty days, and oceasionally it is neither preceded by prodromata nor accompanied by fever. The full efflorescence may suddenly disappear under the influence of some visceral inflammation, or any condition which diminishes the volume of blood in the superficial capillaries. The cutaneous congestion may be so intense as to cause minute extravasation of blood into the eruption. This is known as hemorrhagic or "black measles." Sometimes the papules show minute yellow vesicles on their apices, morbilli miliaria. The eruption may vary widely from the maculo-papular type to that of a mild erythema which may be eonfined to the face or appear upon portions of the trunk. 'The crescentric arrangement is occasionally replaced by a discrete punctate papnlar eruption on the forehead and parts of the body.

Relapses occur after an interval of a week, in which the exanthem is repeated, and measles may recur after several weeks, and repeat the process even to the third attack.

The complications are usually outgrowths of disorders of the mucosa incident to the disease, nor is it strange that resident bacteria should become pathogenic under these catarrhal conditions, nor that the affected membranes should afford favorable soil for accidental infections. Thus the nose, pharynx, and larynx are the common seat of lesions which produce cough, aphonia, and obstruction to respiration, so that in the infant, nursing may be difficult or impossible. Pseudomembranes may form on these parts from diplococcic invasion, and Klebs-Loeffler diphtheria is especially to be dreaded. Extension to the middle ear, with mastoid suppuration, is not rare, while every form of stomatitis and angina may be encountered. The swollen lymph-nodes to which the channels of these areas are tributary attest the intensity of the local infection. Thrombosis and gangrene of the skin and subcutaneous 
tissues about the mouth, face, genitals, and extremities are not rare in severe measles.

The commonest serious complications are capillary bronchitis and atelectasis, especially in infants; also bronchopneumonia as an extension of the catarrhal bronchitis peculiar to the disease. Occasionally fibrinous pneumonia may develop, with accompanying pleuritis, while tuberculosis, either from processes latent or acquired, in the form of miliary lesions, is a too common sequel. The intestinal tract may suffer from any of the catarrhal and structural lesions peculiar to that area. Rarely the kidneys suffer from extensive degenerative changes, and but few instances of nephritis following measles have been observed. The eyes may be seriously affected with blepharitis, conjunctivitis, and keratitis, in chronic form, and the photophobia causing blepharospasm may lead to persistent tic. The heart shows no marked tendency to lesions further than the slight ventricular dilation incident to all acute infectious fevers. Occasionally, however, especially with extensive bronchopneumonia, endo-, peri-, and myocarditis develop. The nervous symptoms are not usually marked. Occasionally in infants, the initial fever is ushered in with convulsions. Stupor and coma are seen in severe hemorrhagic cases, and rare instances of post-febrile polyneuritis with paraplegia have been reported. Pertussis as a complication or sequel is much to be dreaded, especially in the winter and in young children, as the accompanying bronchitis or bronchopneumonia help to form a vicious circle from which complete recovery is rare.

Diagnosis.-The diagnosis of atypical measles from a number of diseases and conditions-such as scarlatina, rubella, varioloid, influenza, acute eczema, syphilitic roseola, and the rashes due to drugs or antitoxin-mav at times be difficult. Koplik's spots should always be sought for in good daylight, as their presence or absence will clear up many otherwise doubtful cases. The presence of cough, hoarseness, coryza, fever, and Koplik's sign will establish the diagnosis before or during the exanthem, whatever may be the character of the latter. (See Plate.)

The leucopenia and the paucity or entire absence of the eosinophiles in measles, will help to differentiate from scarlatina, in which disease leucocytosis is marked and eosinophilia is usually present. Increase in white blood corpuscles is also the rule in syphilitic roseola. In other doubtful cases the history of onset and the absence of the typical buccal and throat signs of measles should exclude that disease. It should never be forgotten that measles and other exanthemata may coexist with a blending and modification of their characteristic signs. and symptoms.

Prognosis.-The prognosis depends so largely upon the complication, environment, and the patient's age that no tabulation of statistics can be of much value. In infants under two years the mortality of measles is very high, especially in institutions, where it exceeds fifty per cent. In private practice, with fair nursing and surroundings, four per cent. of deaths in older children would be a high estimate. The 
indirect mortality and morbidity, however, emphasize measles as the dread disease of early childhood. That this fact is rarely reeognized by the laity should increase the alertness of physicians who appreciate its significance.

Among the grave indications in measles may be mentioned high febrile onset, intense, rapidly developing rash of dark hue, especially of hemorrhagic type, retarded eruption, recession of the rash, which points to heart failure, or to severe visceral complication. A continued high fever after the second day of efflorescence is always suggestive of accidental infection whieh, if the ratio of respiration to pulse be inereased, is probably pneumonia. Chronic bronchitis, bronchiectasis, adenoids, and the ever-threatening tubereulosis as sequela, give to measles an importance not exceeded by any other acute disease of childhood.

Treatment.-As a self-limiting disease of unknown etiology measles has no specific curative treatment. Proper management will do mueh to mitigate its severity and forestall complications. The child should be put to bed, with light covering, in a well-ventilated room with an even temperature of about $68^{\circ} \mathrm{F} .\left(20^{\circ} \mathrm{C}.\right)$. After the first cleaning out with a mild laxative (castor oil) the bowels should not be teased by cathartics. When necessary, bland enemeta may be administered. The eyes must be protected from bright light, cleansed frequently with boric acid solution, and the lids anointed with vaseline if necessary to prevent agglutination. The nose, mouth, and throat should be sprayed freely and often with Seiler's solution to limit extension of infection to larynx, bronchi, and intestinal tract. Tepid or warm sponge baths two to four times daily will promote comfort and lessen fever, as will also inunctions of carbolized vaseline or borated lard (Formulas 33, 34).

The child should be kept on fluid diet and encouraged to drink water freely, which need not necessarily be warm. The feet must be kept warm and the head cool, the latter with ice-cap if necessary. "The eruption, if delayed, may be promoted by hot baths and hot drinks. A sudden recession of the efflorescence also requires hot applications to the surface and extremities, and the internal administration of hot stimulants. If the cough be troublesome, sodium bromide in syrup of lactucarium (Formulas $20,21,22$ ), may be given or, if necessary, small doses of codeine or paregoric. The same remedies may be extended for restlessness. The child must be watched carefully for threatened complications, which should receive early and appropriate treatment.

Strict quarantine should be maintained and the child kept in bed until desquamation is well advanced. Sechusion should be kept up for three weeks from the onset of symptoms, in the most favorable cases, and a thorough bath, and fresh clothing, should be given before the child is allowed to come in contact with others. Subsequent care is necessary for several weeks to guard against_bronchial and eye troubles. After removal, the sick-room must be thoroughly cleaned and allowed to air for a week before further occupancy. 
Delicate and cachectic children should be protected from exposure to measles at whaterer pains and expense.

\section{RUBELLA-RÖTHELN (GERMAN MEASLES).}

Rubella is a distinct, contagious, eruptive disease, though for a long time after its recognition by competent observers it was refused a place in the nosology.

Its close resemblance to rubeola first suggested the diminutive, rubella, as an appropriate name and as such it is generally accepted by the profession in this country. On the continent, especially in Germany and Russia, the terms röthcln and rubeola are used synonymously, to the confusion of younger students.

The etiology of rubella is unknown. It is about as contagious as rubeola and like that disease it rarely appears except in epidemies. The period of incubation is from one to three weeks, stage of invasion one day, and stage of eruption from one to three days.

Symptoms.-General malaise and slight fever may precede the eruption by a day, the temperature rarely exceeding $102^{\circ} \mathrm{F} .\left(39^{\circ} \mathrm{C}\right.$.). The tongue is slightly coated and the soft palate and uvula may show a few rose spots about the size of a pinhead. The post-cervical lymph-nodes show discrete enlargement in most cases, although the anterior cervical and submaxillary glands are rarely affected. Mild catarrhal symptoms may be present but are not constant.

The rash appears on the second day, occasionally without prodromata. It consists of light red or pink maculo-papules in size from a pinhead to a split pea, which are sliglitly elevated and may be felt with the finger. They appear first on the face and spread rapidly over the body and limbs, disappearing from the first situation by the time the feet are reached. The eruption is usually discrete, and sometimes punctate or hard and shot-like to the touch. At other times it is more macular and tends to coalescence in large areas. The temperature falls at the height of the exanthem, which rarely remains more than forty-eight hours. Close scrutiny will usually detect slight furfuraceous desquamation on trunk and limbs.

Complications are rare, although the exanthem may occur coincidently with other acute disorders. There are no characteristic sequelæ.

Prognosis is good.

Treatment.-Mild laxatives and light diet are all that is necessary in the majority of cases. The child should be isolated from the rest of the family, as in measles.

It is in the diagnosis that rubella assumes any particular importance. It is so frequently confounded with rubeola and scarlatina that it has received much attention which it otherwise would not merit. From rubeola it is distinguished by its long period of incubation, short stage of invasion, low temperature, lighter shade of eruption, which is rarely crescentric, and the general mild character and brevity of the disease. The absence of Koplik's spots, also of pronounced catarrhal symptoms, 
should complete the diagnosis. One fairly constant feature of rubella is an enlargement of the lymph-nodes behind the sternocleidomastoid muscle. From scarlatina it should readily be differentiated by the absence of high temperature, severe angina, raspberry-tongue, confluent rash, and extreme malaise characteristic of that disease.

In their atypical forms these exanthemata may be so difficult to distinguish that every doubtful case should receive the close attention due to the gravest possibility, and sporadic rubella must always be regarded with suspicion.

\section{VARIOLA-SMALLPOX.}

Variola was formerly the most dreaded of the acute contagious diseases. Since the prevalence of vaceination the immunity to this infection is so general, and its supervision by health officers so complete, that the general practitioner is rarely called to treat it.

The limits of this volume will allow mention only of some points of importance in diagnosis from the common exanthems.

Variola in children differs in no essential from the disease as it occurs in adults, except for its higher mortality. It is especially fatal in young infants. The nature of the infection is not known but is probably due to bacteria ultramicroscopic in character. Its vitality is well recognized, as the disease is propagated throngh nearly every medium of communication, and instances are known in which years have elapsed between infector and infectee, the virus having been retained in clothing or books with its virulency preserved by the exclusion of light and moisture. The susceptibility to smallpox infection is almost universal, save in those immune by a previous attack or by vaccination. This susceptibility varies so widely in degree that the severity of an attack depends more upon the personal equation than upon the virulency of the infection, so that the effects of a contagion can never be premised from the degree of severity exhibited in the parent case.

The period of incubation lasts from one to three weeks, with an average of thirteen days. The prodromata cover three or four days and always present symptoms of severe intoxication, such as chill, high temperature, rapid pulse, malaise, headache, backache, epigastric pain, anorexia, vomiting and delirium or convulsions.

Young infants frequently snecumb to the intense toxæmia at this stage. A rash, somewhat like that of scarlatina, is frequently seen at this time, usually on the abdomen and inner side of the thighs and arms, and may extend to the chest and face. It is transient, however, and gives way to the characteristic exanthem which makes its appearance quite regularly on the fourth day. The eruption begins on the forehead, appearing soon after on the dorsum of the hands and wrists, and spreads rapidly over the body and limbs until no portion of the integument is exempt.

An enanthem involving all the visible mucosæ precedes or accompanies the exanthem.

With the appearance of this eruption the temperature falls from 
three to five degres and occasionally reaches normal. In discrete variola the skin first shows small red macules which quickly become hard papules, and these may be felt like small shot beneath the skin. The following day each papule bears a tiny vesicle on its summit which enlarges rapidly to the size of a pinhead or split pea and is filled with clear serum. These lesions are surrounded by a narrow areola of hyperemic skin and are crossed by trabeculæ which, as the vesicle becomes more distended, limits the epidermal elevation, causing a central depression or umbilication characteristic of the disease. Gradually the vesicles, which were at first translucent, become opaque, then yellowish, as their serum changes to pus, so that by the eighth day of the attack the eruption is distinctly pustular and the secondary fever develops.

Good illumination will show the same sequence of changes in the enanthem, somewhat modified by the different character of the tissues. The vesicles and pustules of variola are also peculiar in that when punctured they do not collapse as in varicella, with escape of all the contents, because of the histological difference in their structure, for, owing to the involvement of the rete they are multi-cellular.

In confluent smallpox the papules are more numerous and the vesicles coalesce, which, with the odema and infiltration, causes in the pustular stage such extreme bloating as to render the patient unrecognizable. The mucosæ also share in this distortion. The odor of confluent smallpox in the pustular stage is never to be forgotten.

Diagnosis.-The diagnosis of a typical case presents no difficulties. In the form modified by vaccination, however, and known as varioloid, recognition is sometimes quite difficult, as all the symptoms are modified and the eruption may be present only here and there as isolated lesions. Occasionally one only may be found upon the entire body. In doubtful cases the mucosx should be carefully inspected by a good light, especially that of the mouth, prepuce, and vulva, as on one of the areas a tell-tale lesion may surely be found if the case be varioloid. No other disease presents the typical character and sequence of dermal lesions and temperature. In every suspicious case vaccination should be promptly performed upon both the patient and members of the household, since the modifying influence of even late vaccination is well recognized. After this the case should be reported to the health authorities, as no general practitioner can afford to remain in charge of a smallpox patient.

For the course of the disease and treatment, see standard works on practice.

\section{VACCINIA-COW-POX.}

Vaccinia is an infectious fever induced by inoculation with cow-pox virus obtained from calves, artificially infected with the disease. The vaccine lymph containing the virus is now obtained under strict aseptic precautions and kept hermetically sealed until required for use.

The arm at the insertion of the deltoid is usually selected as a most eligible spot for the inoculation, and should be prepared with all the 
care essential to aseptic surgery. The part being clean, a small area (onefifth of an inch, $5.0 \mathrm{Mm}$.) of the epidermis should be removed by teasing with a rather dull needle or pointed ivory vaccine quill until the serum oozes through the abraded surface. No blood should How to wash away or attenuate the virus and delay absorption.

If dry virus or points be used, a drop of sterile water will be necessary to moisten the quill. Liquid virus in sealed glass tubes is of the proper consistency. This should be gently applied to the abrasion and rubbed in with point or sterile blade and allowed to dry, after which an aseptic dry gauze dressing should be applied and retained by adhesive strips for a week. If successfully vaccinated the child will develop symptoms of vaccinia at the end of five or six days.

Slight fever, malaise, anorexia, and other evidences of mild intoxication, usher in the disease. Some children are quite ill and are put to bed, but usually the symptoms subside in two or three days with no further disturbance than the discomfort from the local lesion. This usually shows activity by the fifth or sixth day, when with a little redness one or more papules develop, quickly changing to vesicles, which increase in size and coalesce, becoming umbilicated and opaque. By the end of the second week it has dried into a firm, dark crust. This scab should never be disturbed, but should be allowed to fall off, whereupon a red scar appears which gradually fades in color and remains permanent. Sometimes there is considerable infiltration around the lesion, with brawny induration and redness. The axillary glands are swollen and the child may be quite ill.

If accidental infection of the wound occur, there may be deep and extensive ulceration, rarely sloughing, or erysipelas. A variety of rashes and transient dermal lesions are occasionally encountered, all of which should receive treatment according to their indication.

The child should not be vaccinated if sick, very delicate, or under three months of age, unless in the presence of smallpox. The best time to vaccinate is in the late spring or early fall, thus avoiding the extremes of temperature. The vaccination should be repeated every few months until it "takes," after which revaccination should be performed every three to five years to test immunity.

VARIOLOID-MODIFIED SMALLPOX.

That vaccination grants immunity from variola has been proven to the satisfaction of the scientific world. In many this immunity is absolute, as seen in nurses and physicians who pass unscathed through epidemics, although brought into daily contact with the disease in all its stages. A relative immunity, however, is quite common, especially among children, so that exposure to infection induces a modified form of smallpox (varioloid).

Symptoms.-The onset may be as severe as in variola vera, but the eruption is irregular and atypical and rapidly dries up. Careful examination will usually disclose one or more somewhat typical vesicles, 
most frequently on the mucosa or pseudomucous membrane about the mouth, eyes, or genitals.

The treatment is symptomatic so far as the patient is concerned, yet the strictest isolation should be enforced, with every precaution on the part of physician and attendants, since the contagion is just as dangerous from the mildest varioloid as from the most pronounced case of variola.

\section{VARICELLA-CHICKEN-POX.}

Varicella is the mildest of the exanthemata. What clinical importance it has is due to its occasional confusion with diseases of a more serious character, as variola and varioloid.

The incubation period lasts for from one to three weeks, with an average of about fifteen days. It is essentially a disease of childhood, being rarely seen after puberty, and is most common between the second and tenth year.

Varicella occurs sporadically and in epidemics, is highly contagious, and probably air-borne, while its specific infectious agent is unknown. It has been reproduced by inoculation with serum taken from the vesicle at the height of eruption, without modification of the disease, save in a reduction of the incubation period to eight days.

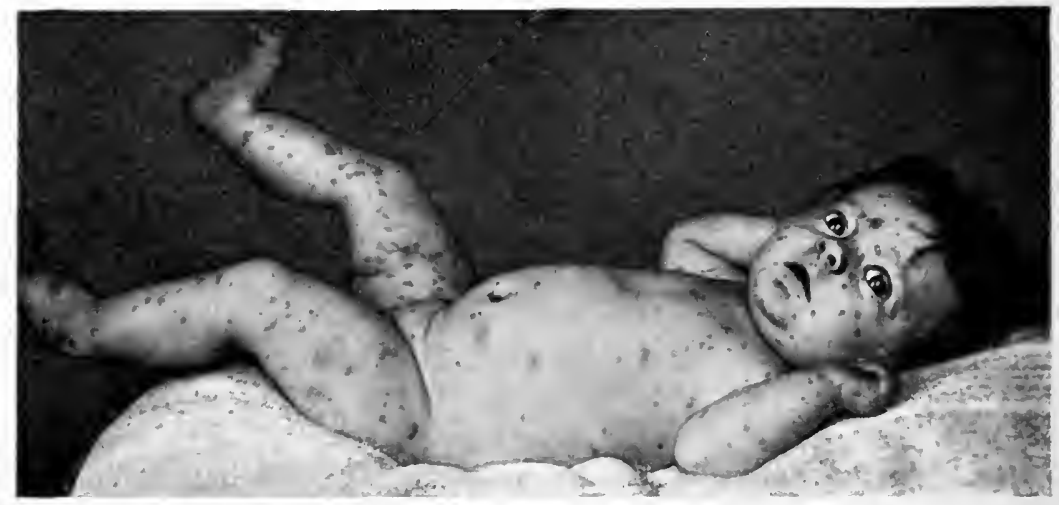

FIG. 208.-Chicken-pox. Third day of eruntion. Baby, 4 months.

Immunity is conferred by a previous attack of the disease, and to a certain extent by adult age, yet exceptions to both are noted.

The prodromata are mild and not characteristic. There may or may not be a little fever and malaise for a day or two. The exanthem begins on the back or chest and extends irregularly over the scalp, trunk, and limbs with but little involvement of the face. Simultaneously with the skin the mucosie of the mouth, pharynx, prepuce, vulva, and occasionally of the eyes and nose, show the eruption.

The characteristic lesion consists of rose-red macules, round or oval, without definite arrangement or distribution, changing quickly to soft 
papules which fade under pressure, and within twenty-four hours become distinct vesicles, in size from a pinhead to that of a large split pea. The vesicles are diserete, unicellular, translucent, and filled with clear alkaline serum. They rarely become pustular, rarely umbilicate, and when pricked the epidermis flattens, turns dark, dries and falls off in two or three days, leaving oceasionally a sear.

A peculiarity of this exanthem is its appearance in successive irregular erops, three or more, so that in a fully developed case all stages of the eruption are seen side by side, as macule, papule, vesicle, and scab (Fig. 208).

When the exanthem is developed the slight fever subsides, only to rise again witli each successive crop of macules, if they be abundant; otherwise the temperature is about normal.

The child is rarely very sick, but may show slight angina and coryza for a day or two. The disease usually lasts a week, and in uncomplicated cases is never fatal.

Complications.-The pruritus induces scratching, so that the lesions may become infected with resultant suppuration and pitting. Gangrenous areas may develop (varicella gangrenosa), especially in poorly nourished and tuberculous children. Otitis, pneumonia, arthritis, conjunctivitis, and vulvitis are occasional complications. Nephritis has been reported as a sequel of severe varicella by a few observers, although it is regarded as very rare.

Diagnosis.-During epidemies of smallpox the difference between varicella and that disease becomes a matter of great importance. The earlier theory of a relationship between the two exanthems has long since been disproved. Quite recently mild epidemics in the middle western United States have led to much acrimonious diseussion as to their true character, many local practitioners maintaining that the health authorities wrongly diagnosed as mild variola atypical cases of varicella. As between typical cases, the brevity or absence of prodromata; the early eruption of vesicles occurring in crops, without pustulation, umbilication, or cicatrization; the short duration; the absence of immunity from vaccination, should make clear the diagnosis of varicella from variola. Herpes zoster follows the course of some nerves and is never widely distributed.

The prognosis is invariably good, with proper care.

Treatment.-The treatment is entirely symptomatic. The child should be kept indoors and protected from changes of temperature. Diet, care of the bowels, and the protection of other children against the infection, is about all that the ordinary case requires. The lesions must not be scratched. Itching may require ointment of boric acid (1:20) or bismuth subgallate dusted on the spot of irritation. For mouth and throat lesions, a teaspoonful of potassium chlorate solution (1:30) may be gargled and swallowed every few hours. The urine should be watched for the rare possibility of renal complications. 


\begin{tabular}{|c|c|c|c|c|c|c|c|}
\hline 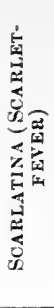 & 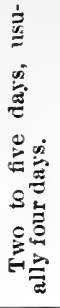 & 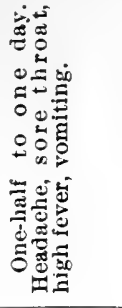 & 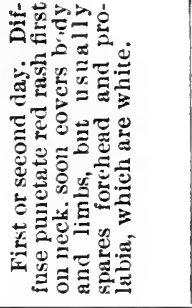 & 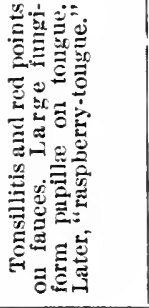 & 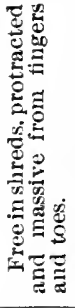 & 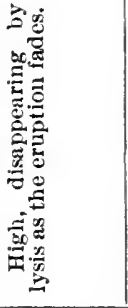 & 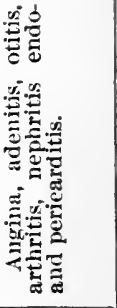 \\
\hline 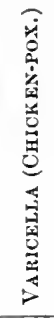 & 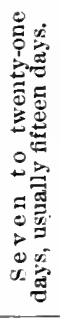 & 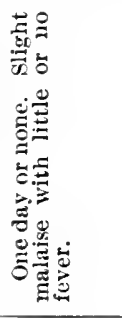 & 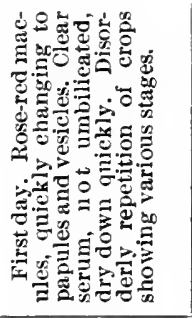 & 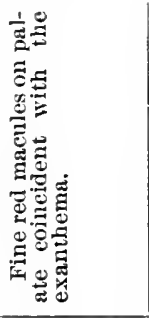 & 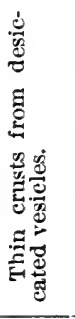 & 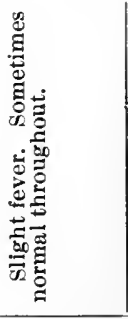 & 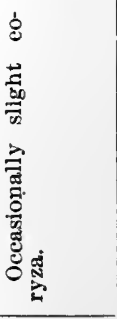 \\
\hline 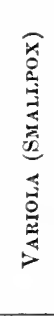 & 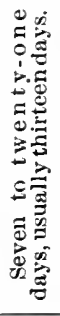 & 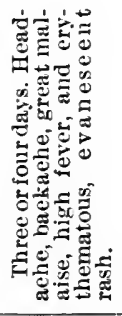 & 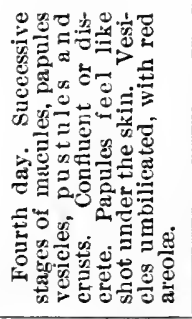 & 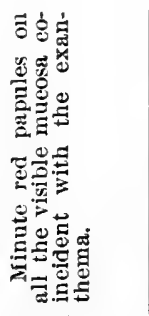 & 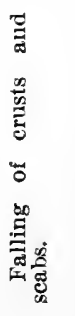 & 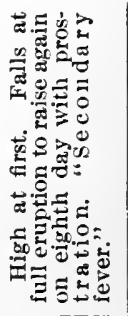 & 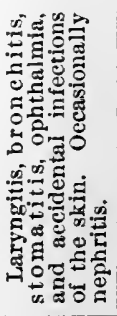 \\
\hline 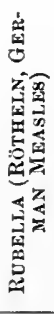 & 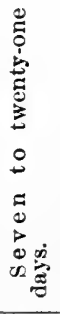 & 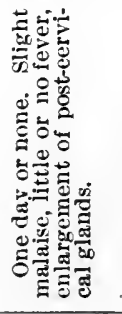 & 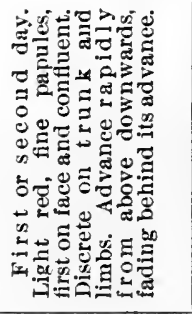 & 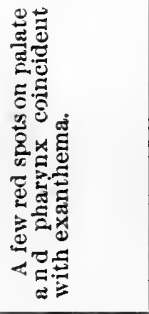 & 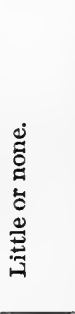 & 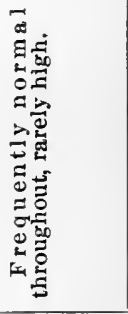 & 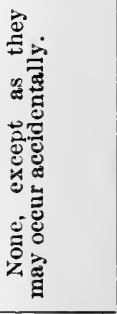 \\
\hline 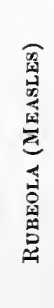 & 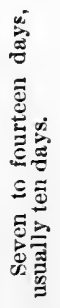 & 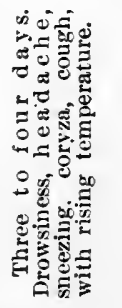 & 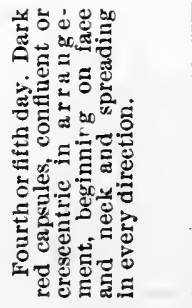 & 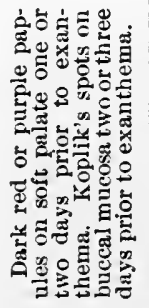 & 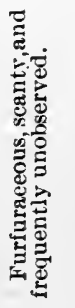 & 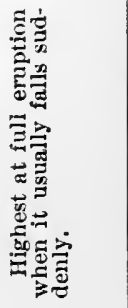 & 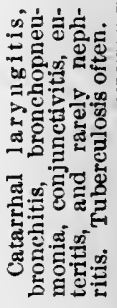 \\
\hline & 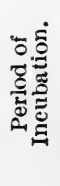 & 范 & 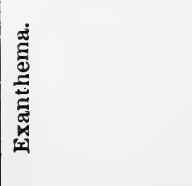 & 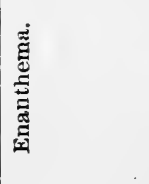 & 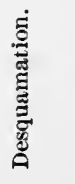 & 怤 & 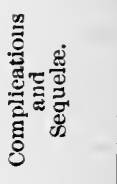 \\
\hline
\end{tabular}




\section{CHAPTER XV}

\section{THE SPECIFIC INFECTIOUS DISEASES (Continued)}

\section{PERTUSSIS-WHOOPING-COUGH ; TUSSIS CONVULSIVA}

Pertussis is a contagious disease characterized by paroxysmal eough, frequently accompanied by inspiratory whoop, and followed by ejection of tough, glairy mucus, and frequently by romiting.

Although no age is exempt, it is essentially a clisease of childhood, occurring most frequently in the first four years.

Its etiology is unknown, yet it is probably of microbic origin and a number of micro-organisms are claimants for this rôle. Pertussis is usually encountered in epidemics, although sporadic cases are seen. Immunity usually follows an attack.

The only anatomic lesion of uncomplicated pertussis is seen in an acute catarrhal condition of the nasolaryngeal and tracheal mucosa. The laryngoscope shows congestion of the posterior pharyngeal and interarytenoidal surfaces. Immediately prior to a paroxysm of coughing a tenacious plug of mucus is seen in the trachea, and as the paroxysm terminates with the extrusion of this mass, its presence must be regarded as the exciting cause.

The period of incubation is indefinite, owing to the insidious onset, but it is probably from nine to fourteen days.

History and Symptoms.-A child in apparently good health is observed to cough occasionally without distress or annoyance. Physical examination shows no lung lesion and there is no expectoration. Later there may be evidence of slight nasolaryngeal catarrh. The attacks of coughing become more frequent and severe during the course of two or three weeks, which is known as the catarrhal stage. There is usually little or no rise in temperature and the true nature of the disease may be only suspected. A blood examination, even at this time, will show hypereucocytosis of the mononuclear type.

The paroxysm becoming more severe, especially at night, the spasmodic stage is reached and the clinical diagnosis confirmed. The typical paroxysm consists in a series of expulsive efforts of violent conghing during which the lung seems to be entirely emptied of air and the chest walls markedly collapsed. The child's face becomes red and then purple and blue with the violence of the attack, and swollen with the extreme venous stasis. The eyes are bulging and bloodshot, and the respiration is finally suspended in complete apnæa. After a few seconds, during which asphyxiation seems threatening, a tremendous inspiration occurs, 
accompanied by a prolonged stridulous whoop, caused by the inrush of air over the vocal cords. The eyes are suffused and streaming, the nose discharges mucus, and the child elings to the nearest object for support, while his entire body is convulsed with the violent suffocative cough. A third or fourth repetition may occur before relief is obtained in the expulsion of a mass of glairy, frothy mucus from the throat, frequently accompanied by ejection of the stomach contents. In severe cases the child shows signs of complete exhaustion, is livid, bathed with perspiration, and seems dazed. After a few moments of languor he resumes his play as though nothing had happened.

Inspection of the child during this stage will reveal loss of flesh and signs of innutrition, although the face may seem swollen. Extravasations

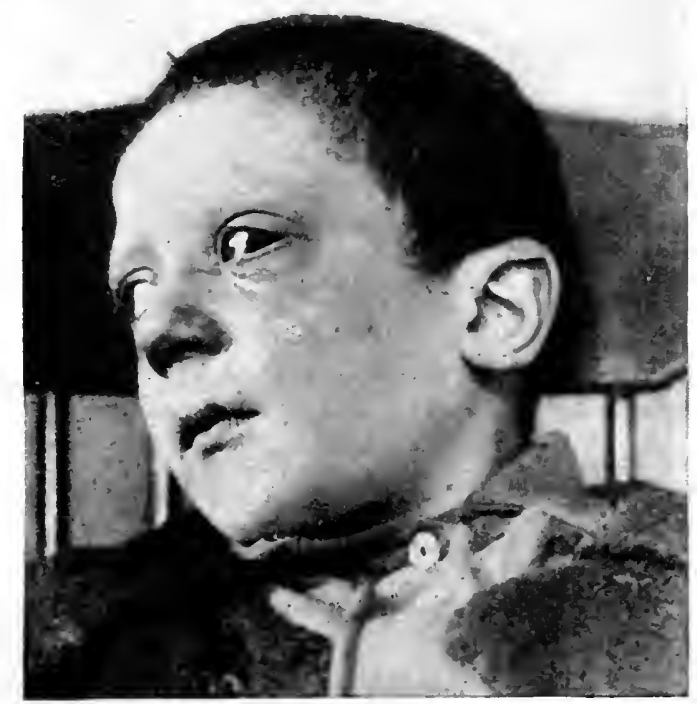

FIG. 209.-Conjunctival ecchymosis and swollen face in pertussis.

of blood may occur beneath the sclerotic conjunctiva, in the subcutaneous cellular tissue under the eyes, and in other portions of the integument (Fig. 209). Hemorrhages may occur from the nose and ears and oceasionally from the throat and stomach. Pulmonary emphysema is rarely absent and may become extensive. The emphysema may become interlobular from rupture of the vesicles, and very rarely general from escape. of air into the subcutaneous areolar tissue,

After two weeks, more or less, the stage of decline supervenes and all the symptoms ameliorate. A typical uncomplicated case of pertussis may occupy from eight to sixteen weeks.

Prognosis.-Before the third year pertussis is a grave disease and exceeds in fatality measles or scarlatina. The malnutrition is often 
extreme from the frequent vomiting of food. In the infant fatal convulsions may be induced.

Older children rarely succumb to pertussis, but the complications and sequelæ are more serious and far-reaching than in any other disease of childhood. The most common complications are bronchitis and bronchopneumonia which, in young infants, prove fatal in more than twentyfive per cent. of cases.

Complications.-As in other infectious diseases nephritis is common, the urine showing albumin, blood and hyaline casts. The right heart is frequently dilated, pulmonary emphysema and atelectasis prevail, while permanent bronchiectasis and adenopathy are established as pathological bases for subsequent disorders. Few children pass unscathed through a severe attack of whooping-cough.

Any disorder may complicate pertussis. Among the graver are bronchopneumonia, measles, diphtheria, meningitis, and influenza. Convulsions are not rare in infants, probably from intracranial circulatory disturbance, and meningeal hemorrhages may occur with resultant paralysis, usually hemiplegia.

Among the sequelce, besides the before-mentioned pulmonic conditions, tuberculosis claims many victims. Myocarditis and otitis media may occur, and, in rhachitic children, permanent deformity of the chest is the rule. The nervous system suffers in a variety of ways, many of which are explainable only upon the theory of profound intoxication. Loss of vision and, in fact, of all the special senses have been reported, also cases of Landry's paralysis, multiple sclerosis, spastic paralysis, and polyneuritides, although such sequelæ are infrequent.

Diagnosis.-The disease is recognized by the convulsive cough, with or without whoop, ending in expectoration-a rare occurrence in infants under any other disorder-and may be confirmed by leucocytosis and the presence of a sublingual ulcer. In doubtful cases the negative chest findings favor the diagnosis of pertussis, yet it may co-exist with bronchitis. The cough that accompanies bronchial adenopathy and adenoid vegetations of the nasopharynx may simulate the spasmodic cough of pertussis, but it rarely develops to an extreme degree, and is unaccompanied by vomiting or expectoration, while a careful examination of the young patient's chest and pharynx will reveal the true nature of the cause.

Treatment.-No specific treatment for whooping-cough is known, although a multitude of remedies have been exploited. Unanimity of opinion centres more especially about the hygiene. Fresh air in abundance is recommended by all. In winter or inclement weather the child should be changed from room to room to secure good ventilation and freedom from the effects of concentrated infection. The bringing together under one hospital roof a large number of children suffering from whooping-cough is irrational, and serves but one purpose,-viz., isolation for the protection of the community. Schools should be protected by the prompt exclusion of suspected cases, as the disease is contagious 
in every stage. Isolation should be continued two weeks after the cessation of all symptoms.

The difficulties of nutrition constitute an important feature in the treatment of whooping-cough. Feeding upon bland, concentrated food (milk, beef juice, broths, etc.), immediately after a paroxysm_will secure the greatest amount of absorption before the next emesis.

Cold drinks and draughts of air should be avoided as likely to induce coughing, and for the same reason all excitement, exertion, and discomfort should be prevented. Drugs which secure rest and obtund reflex action may be employed in severe eases. Belladonna and bromides are still used with evidence of some benefit (Formula 23). Coaltar derivatives which depress the heart should be avoided. Digitalis may be needed for cardiac support, and alcohol in some form may be useful.

Codeine may be necessary to secure sleep, and bromoform still finds many advocates where paroxysms are very severe and the danger of convulsions is imminent. The latter drug must be used cautiously. Two or three drops to an infant, and three or four drops to a four-year-old child, may be given in water or on a lump of sugar. The dose may be repeated two or three times in twenty-four hours.

Inhalation of the vapor of tar, creosote, carbolic acid, or turpentine, finds favor with many, and the vapo-cresoline lamp seems to lessen the severity of night paroxysms in some cases. Older children who can take quinine without gastric disturbance are occasionally benefited by large doses-five to ten grains-three or four times daily.

The alkalinity of the body fluids should be maintained. Sodium bicarbonate and alkaline waters are indicated, and milk may be given in seltzer-water.

\section{INFLUENZA-LA GRIPPE; CATARRHAI, FTVERP.}

Influenza is an acute infectious disease characterized by eatarrhal inflammation of the respiratory and gastro-intestinal mucosa, profound nervous disturbances, and extreme debility. It occurs in both epidemic and sporadic forms, is self-limited, and confers no immunity to subsequent attacks. Although no age is exempt, its occurrence in young children is apparently less frequent than in adults. Cases have been reported in the newly born. The disease is caused by a specific organism, Pfeiffer's bacillus, which has been found in the mucous secretions and occasionally in the blood.

The period of incubation is very brief, frequently only a few hours, and no distinct prodromata are recognized. The post-mortem findings are inadequate to explain the severity of the symptoms, and consist principally of hyperæmia and inflammation of the mucous membrane, more particularly of the upper respiratory tract, in addition to complicating lesions which are not constant. The heart may show dilatation with changes in the myocardium, and rarely acute endocarditis. The spleen is usually enlarged and occasionally the kidneys may present the changes 
of acute nephritis. The blood changes are peculiarly insignificant for an infection of so severe a type.

Symptoms.-Among the many symptoms of this disease three groups stand out somewhat prominently, which has led to the use of such terms as abdominal, pulmonary, and nervous forms of grippe. In children the catarrhal symptoms usually predominate, the attack resembling that of measles in its coryza, cough, and mild angina. The onset is ustially sudden, with high temperature (which may follow a chill), also severe headache, backache, and vague muscular pains. Vomiting may be the first symptom, accompanied by abdominal cramps, with either constipation or diarrhœa. Great restlessness and even delirinm may be present, or convulsions in infants; or there may be apathy, sommolence, or coma.

The temperature usually shows marked daily remissions of wide range, frequently reaching normal or below in the morning. Angina is rarely absent and may be severe, so that swallowing is difficult; the tongue is coated, the conjunctival vessels injected, and the cough may be frequent and harassing, though examination of the chest may yield only a few moist râles and the pulse-respiration ratio show no disturbance. Sometimes the bronchial catarrh extends to the capillary tubes, or occasionally a fibrinous pneumonia from the diplococcus of Fraenkel develops with accompanying pleuritis. With convulsions there may be stupor, head retraction, cervical rigidity, and symptoms of meningitis with bradycardia and sighing respiration.

In infants the diarrhœa and vomiting may simulate acute gastroenteritis with frequent green or watery stools and rapid emaciation. In fact, the degree of prostration in la grippe is almost always remarkable for the brief period of duration. In from two to five days the acute symptoms usually subside, leaving the child sometimes with subnormal temperature, weak and irregular or very slow pulse. Convalescence is often tedious and may be marked by recurrence of symptoms upon the slightest exposure to cold. Other cases are so mild as to constitute merely an indisposition.

Complications.-No other acute disorder presents the variety of complications seen in influenza. It is owing to this fact that a typical picture of simple grippe is rather the exception. Among the most common complications are pneumonia, pleurisy, empyema, otitis media, mastoid disease, pulmonary atelectasis, emphysema, myocarditis, endocarditis, meningitis (cerebral and cerebrospinal), follicular tonsillitis, herpetic stomatitis, cervical adenitis, and a number of urticarial and erythematous skin eruptions, with occasionally acute or chronic nephritis. The most frequent sequelæ are anæmia, hypertrophied lymph-nodes, adenoids, enlarged tonsils, and tuberculosis.

Diagnosis.-A mild, simple influenza resembles acute eatarrh (common cold), and in the absence of an epidemic it is usually so diagnosed. It differs, however, in its greater communicability and in the severity of its complications. The severer uncomplicated forms may be diagnosed from diseases which they resemble-as pneumonia-by careful examina- 
tion for physical signs, by the sequence and duration of symptoms, and by the absence of leucocytosis, which invariably accompanies fibrinous pneumonia. Malarial fever, which it may so closely resemble, shows the peculiar hæmatozoön and yields to quinine. Typhoid fever is more persistent in its pyrexia, with rose spots, or Widal reaction in confirmation. Measles shows Koplik's spots and an early characteristic rash. Searlet fever may be suspected in the presence of an accidental erythematous eruption, but should be accompanied by early leucocytosis and later by desquamation. Pertussis usually shows increase in lymphoeytes, and the characteristic cough is progressive with only slight tendency to pyrexia. In gastro-enteritis, grippe may be suspected if high temperature and catarrbal symptoms of the respiratory tract persist. From meningitis differentiation may be made by the disappearance of cerebral symptoms upon subsidence of the temperature.

During the prevalence of epidemic influenza that disease is usually credited with many disturbances to which it bears no relation. In doubtful sporadic cases a bacteriologic examination of the eatarrhal secretions may be necessary.

Prognosis.-Few ehildren die of uncomplieated grippe, especially in its epidemic form. The many possible complications afford so wide a range of morbidity as to leave no basis upon which to compute its - mortality. Occasionally the child is overwhelmed with influenzal toxæmia and dies within a few days after the initial symptoms, but such occurrence is rare and death is usually due to some complication. Influenza is to be dreaded, especially for the predilection of its convalescent patients for all other acute infectious disorders, also for neurasthenia, weak heart, pulmonary disorders, and tuberculosis.

Treatment.-There is no specific treatment for la grippe, and much harm has resulted during recent epidemies by the wholesale use of favorite remedies. The obvious need for stimulation in many forms of influenza emphasizes the probability of harm from the free use of the depressing coal-tar derivatives so much in vogue. It is possible that such therapy must share the responsibility for much of the postgrippal cardiac asthenia.

The child should be kept in bed, however mild the attack, and isolated from the other members of the household. The same hygiene should obtain as for other infectious and contagious diseases.

Hydrotherapy, in all forms that the reactionary powers of the child will permit, is indicated for hyperpyrexia and restlessness. The icebag to the head is invaluable. Bromides are useful to allay coughs which, if severe, may call also for heroine or even paregoric or codeine in small doses. The bowels must be kept free with gentle salines, preceded by small doses of ealomel, ipecac, and soda (Formulas 23-25). Gastroenteric disturbances, with vomiting and diarrhea, may be met with bismuth subgallate and high enteroclysis of normal salt solution containing sodium bicarbonate, two and one-half drachms to the quart (10 $\mathrm{Gm}$. to 1 litre). 
The feeding should be carefully supervised, severe cases requiring concentrated liquid diet as in other asthenic fevers. Stimulation must not be forgotten, and the heart may require digitalis and full closes of whiskey or brandy. Strychnia is invaluable during convalescence and may be needed earlier if the pulse show weakness or irregularity.

\section{EPIDEMIC PAROTITIS-MUMPS.}

Mumps is a highly contagious disease of unknown etiology. It is rarely seen except in childhood between the third and tenth years; still, no age is exempt. It occur's most frequently as an epidemic in schools and institutions, and one attack usually confers immunity. The disease is an inflammation of the parotid glands with cellular infiltration of the intra- and peri-acinous connective tissue, which is followed by complete resolution. The body of the gland is much enlarged, and there is swelling and occlusion of Steno's duct. The affection is most often bilateral, one gland preeeding the other in the inflammation by a few days. Oceasionally, however, only one side is involved. The incubation period is from two to three weeks, with an average of seventeen days.

Symptoms.-At the onset there are chill, vomiting, fever, anorexia and malaise, any or all, with swelling and tenderness over the parotids

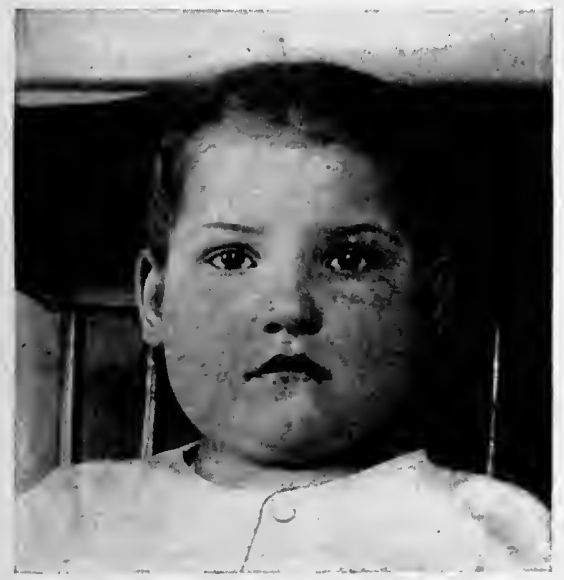

Fig. 210.-Mumps. and behind the angle of the jaw. There may be drooling in infants, but as a rule the salivary secretion is diminished and the mouth is dry. Swallowing and attempts at wide separation of the jaws cause pain. The child may feel quite ill for two or three days and be obliged to stay in bed. Usually by the end of a week, all symptoms have disappeared, save some swelling of the glands and a peeuliar sensitiveness to acids, which may persist for months or years.

Complications and Sequelce.-A complication in boys rarely seen before adolescence is orchitis, which develops after the acute symptoms have subsided and may prolong the case to a week or more. The testicles may remain somewhat enlarged for several weeks and some atrophy follows. Hydrocele is one of the rare accompaniments. In girls the glands of Bartholini, the ovaries, and the breasts, may show swelling and tenderness, which subside in a few days withont permanent lesions. The internal ear is occasionally involved, and deafness is not a rare sequel from affection of the labyrinth or of the auditory nerve. The parotid gland rarely suppurates in this disease. The submaxillary 
lymph-nodes frequently share in the attack and the disease is occasionally confined to these glands. Mumps may be associated with any of the infectious diseases of childhood.

Diagnosis from acute adenitis is made from the nature of the onset, location of the tumor, and history of exposure. The swelling in mumps develops quickly and is found mostly above a line drawn parallel with the lower border of the jaw. The centre of the tumescence is marked also by the ear lobe, which is pushed outward by the swelling (Fig. 210).

The prognosis in parotitis is good.

Treatment.-Mild laxatives and protection of the glands by a flannel passed under the chin and secured on top of the head are all that are required. The child should be isolated for three weeks to prevent the spread of the infection.

\section{DIPHTHERIA.}

Klebs-Loeffler diphtheria is a highly infectious and communicable disease, caused by the diphtheria bacillus, first discovered by Klebs in 1883. The disease manifests itself by local processes caused by the growth of the micro-organism, by constitutional disturbances_due to absorption of their toxins, and by complications and sequelæ which are characteristic.

Etiology and Mode of Infection.-No age is exempt, yet diphtheria occurs with the greatest frequency from the second to the sixth year, and attacks both the weak and strong. A catarrhal condition of the throat predisposes to the infection, also adenoids of the pharyngeal vault, in the sulci of which the Klebs-Loeffler bacilli find an ideal cultural condition. One attack does not grant immunity except for a limited period, but, on the contrary, rather predisposes to subsequent infection from the resultant disordered condition of the affected mucosa. The infectious agent is always the Klebs-Loeffler bacillus, from other diphtheritic lesions. Domestic animals - such as poultry, cats, dogs, rabbits, or cows-are all known to suffer from the disease. The bacilli gain entrance through some abrasion or fissure in the mucous membrane or skin. The period of incubation is not known, as the organisms may remain indefinitely upon the mucosa until some catarrhal process or other solution of continuity furnishes favorable conditions for their pathogenic activity. From a few hours to several weeks may intervene between exposure to infection and the development of symptoms.

No doubt much depends upon the virulence of the invading organism as well as upon the resistance of the child, as patients infected from the same source differ widely in their reaction to the poison. So, also, different epidemies show marked differences in their severity and fatality.

The bacillus is found in the secretions from the affected surfaces, as the nasal discharge, sputum, etc., but not in the urine or faces. The organisms are very tenacious of life and may retain their virulence for weeks in dried secretion or shreds of membrane. They may be conveyed long distances on clothing, toys, books, or transferred directly 
by contact with the patient, or by using spoon, napkin, or dishes from the sick-room. Often the bacilli are found in the mouths of healthy persons who have been about a patient, and doctors or nurses quite frequently convey the infection without themselves feeling its influence. In the same way pupils and teachers coming from homes of patients spread the epidemic through schools and communities.

Pathology. - The characteristic local lesion is a psendomembraneous formation on the mucous membrane or denuded skin. The most common lesions are found in the throat, nasopharynx, nares, and larynx, though it may extend to the trachea, bronchi, Eustachian tube, middle ear, accessory nasal sinuses, buecal surfaces, esophagus, or stomach. The membrane may be found upon the palpebral conjunctiva, lips, vutra, or about the corners of the mouth, behind the ear, and at the umbilicus. Diphtheritic pseudomembrane is made up of degenerated epithelium, débris, pus cells, cocei, blood cells, round cells, and diphtheria bacilli enmeshed in a stratum of fibrinous exudate. It varies greatly in its components as to thickness, color, and consistency, from a mucous, catarrhal coating, which may be wiped off, to a dense exudate which adheres closely to the underiying membrane with which it is structurally incorporated. The latter form is most commonly associated with squamous epithelium. From the columnar variety it is more readily detachable (Fig. 145). Other organisms, many of which are pathogenic, are invariably associated with this local process, foremost among which are the strepto-, staphylo-, and pneumococcus, and the colon bacillus, whose toxic products by symbiotic action intensify the systemic disturbance. In fact, the severity of the disease depends so largely upon the activity of these associated bacterial toxins that "mixed infection" greatly increases the gravity of the prognosis.

Aside from the local lesions of the infected mucosa, changes occur in other tissues and organs, not from the bacilli themselves but from their absorbed toxins. There is adenitis and sometimes breaking down of the cervical, bronchial, and mesenteric lymph-nodes; clondy swelling and degeneration occur in the kidneys and frequently severe acute inflammation; in the liver there is cell necrosis and hemorrhages beneath the capsuTe; the heart muscle is softened and shows areas of fatty changes; the spleen is congested and may be degenerated, and the lungs may show diphtheritic bronchitis, bronchopneumonia or, with the strepto- and pneumococeus, develop a true fibrinous pneumonia. The blood shows some loss of hrmoglobin and slight decrease in the erythrocytes; early leucocytosis is practically constant and corresponds in a general way with the severity of the symptoms, although not necessarily with the extent of the primary lesion. Rapid increase in toxæmia at times overwhelms phagocytic activity and leucopenia results. The nerve tissues are especially vulnerable and rarely escape degenerative changes. Even in mild attacks the nerve-fibres show degeneration which may be so extensive as totally to destroy their function.

Symptoms.-The prodromata are rarely recognized. If on the alert 
for symptoms after a known exposure, a slight chill may be noted with some malaise and the fancial mucosa may show hyperæmia. Occasionally general indisposition with fever, headache, romiting, anorexia, or cough, with coated tongue, constipation, or diarrhea, may exist for several days.

With such symptoms any one of a variety of diagnoses may be made, and correctly, too; for in many instances the diphtherial infection is but accidentally engrafted upon some other disorder which increases the child's vulnerability. On the other hand, the onset may be abrupt, in the midst of perfect health, with chill, fever, or vomiting. The initial temperature is usually not high, but may reach $104^{\circ} \mathrm{F} .\left(40^{\circ} \mathrm{C}\right.$.) the first night and in infants convulsions may rarely occur. The pulse is usually rapid. Unless a thorough examination be made the throat lesion may escape detection. In some cases angina, with a feeling of rawness and painful deglutition, is the first indication. Inspection shows faucial hyperzmia with swelling of the tonsils, one or both of which may show a whitish speck which resembles lacunar tonsillitis. In fact, the clinical differentiation is often impossible and the two may be coincident, or more frequently diphtheritic infection complicates a pre-existing benign angina, so that negative findings, both clinical and cultural, need embarrass no practitioner if later the case develop true diphtheria. Usually in a few hours the whitish speck declares its true character by extending rapidly over the surface, and appears upon the opposite tonsil or upon the adjacent face of the uvula and connecting palatal arch. The exudate may be seen upon the wall of the pharynx and edges of the epiglottis, and by the second, third, or fourth day the nasal voice and discharge from the nostrils indicate invasion of that area through the posterior nares. The breath is fetid, the throat is swollen, the tongue coated, and the cervical and submaxillary lymph nodes are enlarged. In severe infection tumefaction extends from the angle of the jaw almost to the clavicle, owing to infiltration of the periglandular cellular tissue, and abscess formation seems imminent, yet as a rule resolution occurs without suppuration. In mixed infection with the streptococcus, suppuration and necrosis may occur with occasionally extensive slonghing of tissues. The voice is thick, the face gray, and the pulse weak and rapid. The membrane, at first white and thin, becomes gray and thick with well defined, thick, rounded edges, and looks as though it might be lifted entire. Later it is brownish-green, pultaceous and necrotic in appearance. The temperature is rarely high, considering the gravity of the infection, and may not exceed $102^{\circ} \mathrm{F}$. $\left(39^{\circ} \mathrm{C}\right)$. Frequently a fairly severe case may run its course with temperature below $101^{\circ} \mathrm{F} .\left(38.5^{\circ}\right.$ C.). However, the temperature is erratic and may be high at the onset. This is especially true in infants and young children.

Albumin usually appears in the urine by the second or third day and in some cases it may increase rapidly. Casts are found, both granular and hyaline; also blood in small quantities. Occasionally symptoms develop showing that the larynx has been invaded. (See Membranous LARYNGITIS.) 
The nervous symptoms are quite variable. In severe toxiemia, especially in mixed infection, the sensorium is overwhelmed. The child lies in a stupor or lethargy with pallid, swollen face. The head is retracted to relieve the pressure upon the larynx from infiltration of the cervical and pharyngeal tissues; a thin, mucopurulent secretion, sometimes bloody, exudes from the nose, excoriating the lips, which are black and crusted; while the dry, black tongue is fissured and foul from desiccated epithelium and secretions. The noisy oral respiration and high-pitched, querulous voiee, the fetid odor, and profound prostration, present a picture never to be forgotten. Other cases, although severe, may show no mental disturbance save irritability, and the mind is often clear till near the end.

Diphtheria presents many grades of severity, but for convenience of description five varieties may be mentioned,-first, severe extending diphtheria, described above; second, mild tonsillar diphtheria; third, nasal diphtheria; fourth, laryngeal diphtheria, and fifth, eatarrhal diphtheria, or diphtheria sine membrana.

The second variety may show only a limited exudate on one or both tonsils. Epidemics occur in which this form predominates. The diphtheritic membrane shows no tendency to extend beyond the inner surface of the tonsils, and the constitutional symptoms are not marked, older children being kept in the house with difficulty. Without careful routine examination the local lesion might have been overlooked. At other times there is some soreness and tenderness upon swallowing that first attracts attention. The cervical glands are but slightly involved. Infants at the breast sometimes refuse to take the nipple, thus leading to discovery of the angina.

The third, or nasal, variety may complicate the anginal, or it may begin de novo in the nasal eavity and remain confined to that area. This form is most frequently seen in infants and simulates chronic rhinitis or syphilitic snuffles. The constitutional symptoms may be mild and attributed to a simple nasal catarrh. A sanious or ichorous diseharge from the nostrils should always suggest its presence, although frequently no membrane may be seen. The infection may extend to adjacent areas or to the lungs, or appear in other members of the household as a severe faucial diphtheria. In this form the child may harbor bacilli in the accessory nasal sinuses for months and prove a very magazine of diphtheritic infection.

The fourth, or laryngeal, form is also seen most frequently in infants, although it may complicate the other forms. Frequently the first intimation is the sudden development of croup, and the false membrane may be confined to the larynx. Occasionally its true nature is revealed by extension of the exudate upward or its development in other members of the family. Every case of croup should be held suspicious until the cessation of all symptoms.

The fifth variety cannot be distinguished clinically from other forms of catarrhal or amygdalar tonsillitis. No membrane appears, the throat 
may be quite sensitive, and adjacent glauds may show moderate enlargement. The prevalence of epidemic diphtheria, or its occurrence in other members of the family, should suggest its true character.

Diagnosis.-Not all membranous lesions of the fauces and upper respiratory tract are Klebs-Loeffler diphtheria. Occasionally acute lesions without visible membrane show that organism to be the etiologic agent. A wise conservatism would regard all acute nasal, pharyngeal, faucial and laryngeal inflammations as suspicious until negatived by repeated cultural and clinical tests. This is especially true if diphtheria be known to exist in the community. A case showing well-marked diphtheritic membrane presents few diagnostic difficulties. In doubtful eases little harm follows an error in favor of diphtheria. The consequences of error in the other direction are incalculable, from which the physician may not escape responsibility. Smears and cultures should be made in every doubtful case and repeated until the non-existence of Klebs-Loeffler bacillus is established. Every form of diphtheria, even the mildest, may furnish infection of the most virulent type. A number of extensive epidemics have been traced to a single mild, unsuspected case.

The contention is still on regarding the status of non-infectious forms and pseudodiphtheritic bacilli. For all practical purposes they may be treated as Klebs-Loeffler diphtheria, since a number of grave mistakes have resulted from overrefinement in differentiation. All forms of diphtheritic membrane upon wounds or abrasions of external parts should be regarded as true diphtheria - as indeed they usually are-and they have been known to induce infection of a severe type in others. (For Conjunctival Diphtheria, see chapter on the EYE.)

Prognosis.-Death in diphtheria may be due to toxæmia in the second or third day of the attack, or after a severe mixed infection in the second week, or from asphyxiation due to laryngeal stenosis, or at any time during the disease, whether mild or severe, from heart failure or from cardiac thrombosis. Three causes operate to render the stability of the heart extremely precarious under the action of diphtheritic toxamia,- - viz., the myocardial changes resulting in asthenia of the heart muscle, the changes in the blood and in the vascular intima, with the danger of thrombosis, and the degeneration of nerve tissue (toxic neuritis), with paralysis of the pneumogastric or cardiac nerves. The fatal syncope may occur without warning either during the attack or after convalescence as a result of some trifling exertion or excitement. In the latter case it is attributed to the postdiphtheritic paralysis. In some instances the fatal syncope is preceded by vomiting, abdominal pain, and weak, irregular pulse, gallop rhythm, anxions facies, apathy, and cyanosis. In the general postdiphtheritic paralysis death may oceur through respiratory failure from paralysis of the diaphragm,

The prognosis of diphtheria depends so largely upon the age of the patient, the virulence of the infection, the location of the lesion and the complications, also the promptness and method of treatment, that no tabulation of any value can be made. Infants succumb quickly and statistics, 
including many thousand eases, give a mortality of over fifty per cent. After the fifth year ten per cent. would be a high estimate. All clata prior to the advent of antitoxin are rendered worthless as to their prognostic value by the remarkable decrease in mortality under that treatment. The disease, though still grave, has lost much of its terror during the past decade for the above reason.

Complications and sequele include bronchopneumonia, pleuritis, otitis media, gastro-enteritis, suppuration of the cervical glands, retropharyngeal abscess, postnasal adenoids, myocarditis, and cardiac paralysis, either during the disease or as a sequel, also acute nephritis and rarely pericarditis and endocarditis. Cerebral complications may cause convulsions, aphasia, or hemiplegia. If peripheral, monoplegia, anæsthesia, or gangrene of a part may result.

Sequelæ most characteristic are the postdiphtheritic neuritides, both peripheral and spinal, the latter involving the multipolar ganglion cells of the anterior columns, and the former representing many forms of multiple neuritis. The most eommon form of postdiphtheritic neuritis is seen in the paresis of the levator palati which allows regurgitation of fluid through the nose upon attempting to swallow. This may occur during the attack, if prolonged, but usually appears as a sequel and has led to a diagnosis of diphtheria in many previously unsuspected cases. In the same manner paresis of the epiglottis and the arytenoidei may allow entrance of food and cocei into the trachea and cause aspiration pneumonia. After severe cases there is always profound anæmia with extreme myasthenia, and even a mild attack eauses muscular weakness to a remarkable degree.

Treatment.-The treatment of diphtheria is special, local, and prophylactic. The past decade has developed the antitoxin treatment. so that to-day it is justly regarded as a specific. Several firms now produce a diphtheritic antitoxin which is of guaranteed potency and is both safe and reliable. As the efficiency of antitoxin depends upon its early administration it should be injected upon the first indication of diphtheria. Mindful of the possible serious complications and sequelæ of even a mild diphtheria, the physician will not defer unnecessarily for even an hour the use of this agent. In suspicious cases the antitoxin should take precedence of the bacteriologic diagnosis, for it should be borne in mind that antitoxin will not repair the damage to tissues and organs already sustained, but will only combat the toxins and thus prevent further injury. The deduction is obvious. Stop the process before extensive degenerative changes occur. With a surgically clean hypodermic needle (leading manufacturers now furnish a sterile injecting apparatus with each package of antitoxin so that the pocket syringe is practically obsolete for this purpose) the fluid should be injected slowly under the skin between the scapulæ, upon the abdomen, or upon the outer aspect of the thigh, the part having first been rendered aseptic as for an operation. The site of the puncture after withdrawal of the needle should be covered with a dry, aseptic dressing. For a child 
under two years 3000 units, at least, should be injected. Older children should receive proportionately larger doses-from 4000 to 6000 unitsand in severe or advanced cases 8000 units should be used. If signs of improvement do not follow in eight hours, another dose should be administered and this repeated every eight hours until signs of improvement are positive, when smaller doses may be used. In very severe cases the antitoxin should be given oftener and in larger doses. The limited space will not allow a further discussion of this subject. Statistics are ample and conclusive concerning the value of antitoxin in diphtheria if administered early, and frequently repeated in large doses, with strict aseptic precautions.

Local treatment should not be neglected. Gargles, sprays, swabbings, and irrigation may be employed (if they do not excite or fatigue the child) to keep the affected surfaces and their adjacent areas as clean as possible, for it is to be remembered that associated organisms, against which the antitoxin is powerless, are in full operation, with pathologic results hardly inferior to those of the Klebs-Loeffler bacilli. Hydrogen peroxide and water (1:5); Seiler's solution (Formula 11); solution of boric acid (five per cent.) ; potassium permanganate solution $(1: 5000)$, are all available for this purpose. The nose should be irrigated as well as the throat, for which normal salt solution answers quite well, as the purpose is largely to clean out the fossa and flush the nasopharynx. The ice-bag to the neck is the only external application indicated. Hot poultices are contraindicated.

The tendency to cardiac myasthenia calls for the early use of strychnia in full doses. The toleration for this drug in diphtheria is out of all proportion to the amounts usually given. A four-year-old child may need one-fortieth grain $(0.0016 \mathrm{Gm}$. $)$ hypodermically every three hours for a number of days or weeks to sustain the pulse. Whiskey may be given to combat the toxæmia. A child of two years will easily take onehalf to one and one-half ounces (15-45 C.c.) daily, in divided doses properly diluted.

The possibility of cardiac syncope contraindicates measures which tax the child's endurance or arouses excitement, so that a tactful, experienced nurse is indispensable.

An irregular pulse not controlled by strychnia may require digitalis in addition, if well borne by the stomach, or digitaline hypodermically. Aromatic spirits of ammonia may serve a purpose in extreme cardiac weakness, but most reliable in the fluttering pulse of threatened syncope is morphine, hypodermically, in doses sufficient to maintain a continuous narcotic effect.

Upon the appearance of diphtheria the members of the household, and all who have come in contact with the patient or any probable source of infection, should receive immunizing doses of antitoxin, -300 units for a baby; 500 units for a child of five years, and 500 to 1000 units for older children.

When diphtheria is known to exist in a community or school it is 
desirable to give immunizing injeetions to all the children of that community. Although the period of immunity is not definitely known, if it continue for only six weeks, an epidemie may be averted from want of susceptible material for propagation of the infection.

It is the duty of health boards to attend to this matter which, if thoroughly done, diphtheria, like variola, would be eliminated from the perils of ehildhood. Physieians and nurses who pass in and out should, upon entranee to the siek-room, wear a gown of wash material to protect the clothing, a simple eap also covering the hair, both to be left hanging by the door. Absolute eleaniness in the care of the hands and nails by use of soap, brush, and antiseptic solutions, must be observed.

The effects of antitoxin are usually seen within ten to twenty-four hours, in a general amelioration of all the symptoms. The extension of the pseudomembrane is arrested and its edges loosen a little and finally large masses come away. At times the exudate seems to melt away under the action of the antitoxin. In laryngeal diphtheria the greatest benefit is seen, cases that were formerly regarded as hopeless reeovering without even the use of the tube.

Two effeets of antitoxin should be mentioned here so that the inexperienced be not taken unawares. The first is seen after its administration in laryngeal diphtheria. If intubation be deemed advisable (it rarely is), the action of antitoxin in loosening the membrane should be remembered, sinee the tube is likely to double down the loose edges of the membrane and push it ahead, with danger of oeclusion of its lumen. The other is an eruption of several varieties, some of which develop within a few hours, others not until one or two weeks after the injection. The eruption is benign and requires no treatment.

The eare of the patient requires the application of the best-known hygiene,- a large sunny room with free aceess of air (sunlight and air are the great foes to the baeilli diphtheria). All carpets, rugs, upholstery, and tapestry should be removed and the ehild placed under strict quarantine. The food should be liquid, concentrated for older ehildren, and, if necessary, partially predigested. The bowels should be kept in order by appropriate laxatives. All secretions should be received on old cloths, which must be burned. Feeding utensils should not leave the sick-room, and a plentiful supply of carbolic acid (five per eent. solution) should receive everything that comes in contact with the patient. A nursing baby should be taken from the nipple and fed on the pumped breast milk.

Convalescence should be earefully guarded because of the danger of postdiphtheritic neuritis with syncope. Elixir of iron, quinine, and strychnine is indieated as a restorative tonic at this time. The child should be considered infectious until three successive cultures, taken at twenty-four-hour intervals, show negative results. The nasal cavity is the last place to harbor the bacilli and should receive thorough antiseptic irrigation three or four times daily. After recovery a most thorough antiseptic cleaning of patient and room is necessary. 


\section{DIPHTHEROID-PSEUDODIPHTHERIA.}

Pseudomembranes may develop in which the Klebs-Loeffler bacillus plays no part. They are a frequent accompaniment of acute infectious diseases with angina, especially scarlatina, and may develop upon any inflamed mucous membrane.

The cause of this membrane formation may be the streptococcus, staphylococcus, pneumococcus, gonococcus, or the bacterium coli. Since these membranous formations may not be distinguished clinically from those due to the bacillus diphtheriæ, they have been termed diphtheroid. Aside from the bacteria above mentioned, an organism has been isolated in pure culture which resembles morphologically and shows similar staining properties to the Klebs-Loeffler bacillus, and may be differentiated only by its effects shown in animal inoculation. In a general way this organism is very aptly designated "diphtheroid" bacillus (pseudodiphtheritic bacillus).

Diphtheroid may simulate true diphtheria in every respect save in the intensity of its toxæmia and in the gravity of its sequelæ. Of the latter it has few worthy of mention.

The prognosis is good as regards diphtheroid per se, but as a complication of other acute infections it may increase the gravity. It is chiefly of importance in complicating the diagnosis of diphtheria, since at times the bacteriologic differentiation requires the most refined laboratory technique.

Treatment of diphtheroid is symptomatic, with proper hygiene and sanitary care of the affected mucosa. As stated under treatment of diphtheria, every doubtful or even suspicious case should receive antitoxin.

\section{INTUBATION OF THE LARYNX.}

The old controversy in regard to the relative efficacy of tracheotomy and intubation in diphtheritic laryngeal stenosis has been settled by wide experience in favor of the latter in a large majority of cases. The facts supportive of this conclusion need no further elucidation. The hesitancy to intube, on the part of the practitioner, is largely a matter of unfamiliarity with its technique. Many physicians who readily undertake a laparotomy and other capital operations shrink from the introduction of a laryngeal tube. How many lives have been lost through this hesitancy it is useless to conjecture. Thanks to the efficiency of early antitoxin the need for intubation is rapidly lessening.

The operation is so simple and so important that a technical familiarity should belong to the equipment of every practitioner. This familiarity may be secured by a very little practice upon the child cadaver. With his steady nerve, an O'Dwyer intubation set, and two intelligent assistants (not the parents), he is ready to proceed. The proper tube for size rather than for age of ehild having been selected and threaded with ample loop of stout ligature silk, the obturator is screwed to the introducer and tested to see if the detacher works 
properly. The child, firmly wrapped in a blanket, arms included, is held by a nurse sitting so that the ehild's right ear is opposite the nurse's left jaw. The tongue is depressed, the gag inserted behind the left molars, and opened widely where it is steadied by the left hand of the second assistant, who stands behind the nurse fixing the ehild's head with both hands. Only very slight extension of the child's neck is advisable, as it deranges the relations of the field of operation. The physician, standing or sitting, holds the introducer (tube attached) lightly in his right hand, thumb resting upon the slide, and index-finger in the ring or in front of the trigger below. The thread is passed back between two fingers. The left forefinger is introduced into the right angle of the child's mouth, its tip earried back so as to engage the epiglottis, which is pressed forwards and a little to the child's right, and there held against the dorsum of the tongue. The tube is then advanced in the median line following the left finger as a guide to its tip. The flat palate of the child makes it necessary to hold the handle of the introducer at first parallel with the child's sternum; when the tip of the tube reaches the epiglottis the handle is raised sharply, describing a quadrant; the tip of the tube having now passed the tip of the finger is made to hug the posterior surface of the epiglottis, and with slight further elevation of the handle and gentle depression of the tube it enters the chink half its length, where it is under eontrol of the tip of the left index-finger. The button is quickly pushed and the tube sent home with the tip of the left finger. The introdueer removed, the thread loosely held, the operator listens for the peculiar whistling cough (always to follow) which announces the successful seating of the tube in the larynx. Failure to steady the epiglottis, or to elevate the introducer handle at the right instant, sends the tube into the esophagus, whence it may be recovered with the thread whose sudden tightening shows its loeation in the gullet. The trachea will never swallow the tube. The disposition of the thread may depend upon cireumstances. Many European operators leave it attached seeurely to the left ear or to the left eheek by a pieee of adhesive plaster. Americans usually eut and withdraw it cautiously a few minutes after the tube is settled, steadying the tubehead with the finger. If the thread be left it should be passed back of the bicuspids to prevent its being bitten in two. If the tube be coughed up it must be replaced. If the loosened membrane be pushed ahead of the tube it will probably be coughed out at once; if not, and the breathing stop, it must be removed. If the membrane be still impacted, tracheotomy must be done quickly. With this in view the arrangements for that operation should be made before the intubation. Fortunately, tracheotomy is very rarely necessary. Gentleness in tube introduction is necessary to avert the making of a false passage. If the tube point be kept exactly in the median line there is but little danger of its engagement and arrest in the ventricle of the larynx.

The length of time a tube should be worn is from one to five days. The use of antitoxin has shortened the period. After the first day or 
two, with signs of improvement, the tube may be withdrawn tentatively. If marked dyspnœa result it must be returned. Prolonged wearing of the tube may lead to ulceration by pressure at its lower end, hence the need for early removal. Extubation is somewhat more difficult than introduction. The same preparation and routine must be followed; the finger serving as a guide to the head of the be into which the beak of the extractor is quickly inserted; the mandibles separated by firmly depressing the lever, and the tube lifted straight upward, then outward by reversing the movements of introduction. If a tube be coughed up repeatedly a size larger should be tried.

In all manipulations one thing must be kept in mind,- - not to shut off the child's air for longer than ten seconds. There should be deliberation in preparation and celerity in execution. If difficulties are encountered, repeated trials should take the place of a long-continued effort during which the child may suffocate.

Feeding with the tube $i n$ situ, to avoid the slight danger of aspiration of liquids, may require semisolid food-as custard, junket, mush, etc.or infants may be fed through the œsophageal tube passed through the nose or mouth. Casselberry's method of feeding with the head lowered is practised by many physicians.

\section{TYPHOID FEVER-ENTERIC FEVER.}

Typhoid fever is an acute infectious disease caused by the bacillus typhosus (Eberth's bacillus), which gains entrance through food or drink.

The source of the infection is always the excreta (fæces or urine) of some typhoid fever patient and may have been conveyed some distance in water polluted with human dejecta. Soiled clothing and rags used about a patient may furnish a velicle, and want of cleanliness in the household of a typhoid patient is a common cause of its extension to other members. Flies carry the infection, and probably dust containing dried excreta may be wind-borne from long distances. Many isolated cases can be explained in no other way. The common means of germ dissemination, however, is throngh polluted water, whether used for drinking, dilution of milk, or for rinsing fruit, vegetables, milk-cans, or ice. Statistics abound showing a remarkable decrease in typhoid fever following improvement in the water supply of cities and communities. In some instances this reduction in morbidity reaches as high as 90 per cent.

Of the predisposing causes it must suffice, from lack of space, to mention but three,- - season, age, and condition.

Season.-Statisties show that more than half of the year's typhoid fever is reported in the three fall months, hence "autumnal fever."

Age.- It is customary for text-books and treatises to represent typhoid fever as infrequent at the extremes of life and to quote statistics showing that the period from fifteen to thirty years includes more than half of all reported cases. Although many clinicians and the profession 
at large have frequently diagnosed typhoid fever in infants, some pathologists have refused to admit its possibility, claiming that the disease is not common in early childhood and that it is rarely, if ever, seen before the third year. In support of this attitude they cite reports of autopsies by the thousands, covering a long period of years made in hospitals for children and foundling asylums, in which the characteristic lesion (intestinal ulceration) was not found. Until recently no other means of positive identification of this disease in its atypical forms was recognized. During the past decade the widely increasing employment of the diazo reaction, Widal reaction, and of blood examination, lias placed the diagnosis of typhoid fever beyond the need of post-mortem confirmation, and reports are rapidly multiplying of unquestionable typhoid in young children and infants. No valid reason las ever been advanced why infants should be exempt from typhoid fever other than the partial immunity of nurslings to all infections which come through unsterilized food and drink, because of their freedom from exposure. By the above-mentioned means of greater precision, typhoid fever is now diagnosed in young children in whom the disease was formerly only surmised from the absence of other known cause for the clinical phenomena. A systematic routine examination of infants showing fever and malaise during the prevalence of typhoid fever will bring to light many unsuspected cases of the disease. It is too early to attempt any systematic tabulation of this newer class of typhoid patients, as the necessary observations are yet far from general. Two facts, however, are established from the reports along this line of work: first, typhoid fever in infants rarely furnishes the clinical picture as seen in adults; second, the intestinal lesions formerly regarded as pathognomonic of this disease (enteric fever) are usually wanting or greatly modified.

Condition.-The increasing frequency of positive Widal reaction in infants suffering from marasmus and summer dyspepsia suggests an increased susceptibility to infection by Eberth's bacillus, especially when other members of the household show immunity. Lowered resistance from previous disease, or from a catarrhal condition of the digestive tract, is probably a predisposing cause of typhoid fever.

PECULIARITIES OF THE INFANTILE FORM OF TYPHOID FEVER.

Only some of the principal peculiarities of typhoid in infants as compared with the well-known adult type will be briefly-mentioned.

Lesions.-As before stated, extensive ulceration of the intestine is not common in this class. Fetal typhoid, of which there are several recorded instances, shows no bowel lesion whatever, although Eberth's bacillus may be found in the blood, bile, and various viscera and tissues.

Fatal postnatal typhoid may show only swelling or perhaps superficial necrosis of portions of the agminate and solitary glands of the intestine; or when shallow ulcers occasionally are found they may be indistinguishable from similar lesions of enterocolitis.

Onset.-The onset of infantile typhoid is often abrupt, frequently 
with vomiting, high fever, rapid pulse, and occasionally convulsions. Initial epistaxis is rare, although it may occur later during the pyrexia or convalescence. Pharyngitis is not uncommon, and erythematous or urticarial rashes may accompany the onset or complicate the elinical picture at any stage of the disease. Splenic enlargement, although earlier in evidence, is not so constant nor usually so marked as in the adult form, nor is hepatic enlargement always demonstrable. Persistent splenic enlargement is usually noted in relapse. The rose spots occasionally appear during the first week, and herpes labialis is not uncommon. Contrary to what might be expected, bronchitis is not a regular accompariment of infantile typhoid. This form of the disease is less severe and its course is usually shorter by a week, yet relapses are probably more frequent.

Blood examination shows earlier positive Widal reaction, early and rapid reduction of hæmoglobin, earlier leucopenia, but with a quicker return towards the normal leucocyte count. More rapid increase is seen after the second week in the mononuclear elements, especially in the lymphocytes, and always quicker leucocytic response to complications which increase their number.

Abdominal Symptoms.-Tympanitis is less frequent or extreme and iliac gurgling and tenderness are usually absent, while extremes of constipation and diarrhœa are not the rule. The stools are rarely the characteristic "pea-soup" movements of the adult, but.may contain curds, mucus, or undigested food, as in ordinary enterocolitis.

The period of anorexia is not so prolonged and is less pronounced,children in the hospital ward frequently crying for food during the pyrexia. Intestinal hemorrhages and perforation are less frequent and occur oftenest during a relapse.

Nervous Symptoms.-Headache is quite common, also restlessness, which at night is sometimes almost a querulous delirium. Apathy, stupor, and coma are not so frequent, but when seen may form part of a symptom complex simulating cerebral meningitis. There may be exaggerated knee-jerk, ankle-clonus, Kernig's sign, and even transient partial hemiplegia. True meningitis, which but rarely complicates adult typhoid, is believed to occur more commonly as a complication in children.

Heart.-Cardiac inflammations are rarely met with, but a systolic bruit, with some dilatation of the left ventricle, is common, as during other infectious fevers in children, and subsides with return to convalescence. Otitis, as a complication and suppurative parotitis in the third week, are rather peculiar to children; so also is aphasia, which is frequently observed during convalescence and from which children usually recover in a few weeks. Fine desquamation is not uncommon after a severe attack. Furunculosis occasionally complicates convalescence and multiple gangrene has been reported. Post-typhoid neuritis is probably less frequent in children than in adults.

Diagnosis.-It is evident that the clinical diagnosis of typhoid fever may be attended with great difficulty in infancy and childhood, a fact 
which undoubtedly accounts for the long prevailing belief in its rarity at this period.

While the positive recognition of typhoid depends upon the agglutination test or the demonstration of Eberth's bacillus in the excreta, blood, or rose spots, the difficulties and uncertainty of cultural methods, and the necessary delay before a positive Widal reaction may be expected, makes the early diagnosis depend upon the history, symptoms, and blood count. The well-known tendency in early life to leucocytosis upon the slightest pretext adds special significance to leucopenia, so that febrile disturbance attended by a reduction in white corpuscles is, in itself, suggestive of typhoid fever. By exclusion of other possible causes for the leucopenia, a tentative diagnosis of typhoid may be made in the absence of typical symptoms of that disease. Among those causes may be mentioned tuberculosis, measles, malaria, and influenza, as well as secondary anæmias, or any condition of profound disturbance of the eirculation: like shock, prolonged exposure to cold, quick hot baths, or the action of certain drugs, - as atropine, sulphonal, tannic acid, or ergot. The diagnosis of typhoid is extremely difficult when the symptoms resemble those of tuberculous meningitis, and many apparent recoveries from that disease were probably cases of meningeal typhoid, a form by no means rare in infancy and childhood. Rapid, regular pulse and respiration, normal pupils and retina, with negative lumbar puncture, would point rather to typhoid fever, regardless of flat abdomen, impalpable spleen, and the signs and phenomena of Kernig, Babinski, and Oppenheim. Further symptomatic developments, including the Widal reaction, may be necessary to change doubt into certainty.

Malaria should show the plasmodium and yield to quinine.

Influenza shows no early decrease in hæmoglobin so characteristic of typhoid, otherwise it may baffle differentiation for several days. The same may be said of acute general miliary tuberculosis when compared with atypical typhoid in infants until diazo reaction, rose spots, or Widal's agglutination determine the nature of the disease.

Prognosis.-Uncomplicated typhoid, if carefully managed, is rarely fatal in young patients, and fortunately the graver complications of the adult type are of rare occurrence. In the absence of definite data two per cent. is probably a high estimate of the mortality in children before the fifth year.

Treatment.-Careful nursing and feeding will meet all the requirements of a large majority of typhoid fever cases, as it is a self-limiting disease with a quite definite course and a tendency to recovery. Pure air, bland liquid diet, and a free use of water, are of great importance. Hydrotherapy is the sheet-anchor in typhoid. That it eliminates toxins and promotes leucocytosis may be seen in the reduction of pyrexia, increase of bacilli in the excreta, increase in the white blood corpuscles, and increased comfort of the patient.

Baths may be made to depend somewhat closely upon the range of temperature and evidence of toxæmia. The method of bathing, the 
temperature of the water, ete., must be governed by the effects, and the idiosyncrasis of the child. No bath should eause discomfort, excitement, or fatigue. Reaction in young children is not good after cold tubbing. If tubbing be practised the child should be lowered in a blanket hammock to prevent shock. Sponge bathing or the fan bath usually answers better for ehildren. A gauze sheet is moistened with tepid water and alcohol $(4: 1)$, from which evaporation is promoted by a current of air. The ice-cap is invaluable both for high temperature and cerebral excitement. The hair should be cut short in the beginning of the disease. The child's mouth must be kept clean by gentle applications of boric acid solution on a soft swab of gauze. The decubitus should be frequently changed by turning the child in his erib.

The use of drugs should be restricted to absolute indications. The early use of calomel in two or three full purgative doses or in small doses every two or three hours for a few days, is of unquestioned benefit. Bromides may be necessary to relieve headache or excitement and promote sleep, aided by bathing.

Constipation is best relieved by moderate saline enemata. Records of temperature, pulse, and respiration should be made every four to six hours. Special care is necessary to avoid traumatizing the rectum in the frequent use of thermometer and tube. Complications should be anticipated, as far as possible, by constant watchfulness on the part of the physician and nurse, and receive early attention. Intestinal hemorrhage demands application of an ice-bag or Leiter coil to the abdomen, absolute quiet, withdrawal of food, and the hypodermic use of morphine. In perforation the surgeon must be summoned without delay. In prolonged cases or relapse, the heart failure should be anticipated by strychnine and alcohol in some eligible form, and convalescence should not be forced by early return to solid food or attempts at exereise. Solid food should not be allowed for a week or more after the temperature has become normal. In suitable weather the child should be allowed to lie in the open air, properly guarded against annoyances or excitement.

Elixir of iron, quinine, and strychnine, as a tonic, may be valuable after the pyrexia. For food, milk, properly modified and peptonized if necessary, meets the requirements of most cases. Broths, raw meat juice, peptonoids, egg-water, koumiss, and matzoon afford a choice for sensitive stomachs.

Even the eare of the patient is hardly more important than a thorough disinfection of the stools, urine, bedding, and all articles used in the sick-room. (Appendix.)

\section{MALARIA-INTERMITTENT FEVER; PALUDISM.}

Malaria is an infectious fever due to the presence in the blood of a parasite, the plasmodium malarice. The disease in its typical form is characterized by periodical paroxysms of fever preceded by a chill and followed by sweating. 
The hæmatozoön gains entrance through the bite of a mosquito (genus anopheles) which has been previously infected, the life cycle of the parasite determining the periodicity of the exacerbations.

No age is exempt from malaria. Congenital cases have been reported of infants born of malarial mothers. Infants are especially susceptible from their great vulnerability to mosquito bites.

The predisposing cause is sojourn in wet marshy regions, or near bodies of stagnant water during the warm season, where mosquitoes abound. The disease, though infectious, is not communicable in the ordinary meaning. One attack does not confer immunity, yet a degree of toleration seems to follow long residence among the mosquitoes.

The etiology and general pathology in the infant do not differ materially from that of the adult, the blood in addition to the parasitic phases of the erythrocytes showing pigmented lencocytes and leucopenia with relative lymphocytosis.

It is in the symptomatology that infants show variations from the adult type of the disease, and these only will be considered.

The anæmia is marked in children and the blood shows an early low color index. The differentiation between quotidian, tertian, and quartan forms of the disease is not usually well marked, nor is the regular sequence of phenomena (chill, fever, sweating) common. Any of the usual manifestations peculiar to these stages may be absent, or they may all be wanting, and in their stead, symptoms of visceral disorder, nervous manifestations, or circulatory disturbances, may appear. Periodical headache, vomiting, somnolency, one or all, may take the place of febrile paroxysms, or the chill may be replaced by delirium or in infants by convulsions. Recurrent diarrhœa, periodical malaise with frontal headache, lassitude, anæmia, pallor, cyanosis, sleepiness, cold extremities, cough, polyuria, wry-neck, abdominal or epigastric pains, and unexplainable sweats or fever should, in children, raise the question of malaria. Hepatic tenderness is not always demonstrable, though splenic enlargement is rarely absent, and may be enormous. The spleen may occasionally be felt extending below the umbilicus.

Malarial anæmia is an early sign in children, as are other evidences of cachexia.

From an insidious onset the fever may become almost continuous, with but slight intermissions which follow no regular type, or it may resemble typhoid, meningitis, or tuberculosis. Again, the onset may be sudden, with vomiting, high temperature, and cough, with the physical signs of bronchopneumonia. Pulmonary symptoms are common, as the infant lung shares readily the congestion of other viscera so peculiar to malarial toxæmia. So true is this that frequently an attack is construed as abortive pneumonia. Malaria is not incompatible with other disorders of childhood, any one of which it may simulate or complicate.

Diagnosis.-Formerly the diagnosis of malaria in infancy and early childhood was attended with so many difficulties that the infection was regarded as infrequent at this period. An enlarged spleen and the 
therapeutic test of quinine were the only means of assurance. While the former is common to many of the diseases of childhood, it is still a valuable diagnostic point when considered with manifestations of an intermittent or periodic character. The blood, however, furnishes means for a positive diagnosis. Lencopenia with pigmentation of the white corpuseles is alone sufficient for a probable diagnosis, which the accompanying periodic symptoms may render quite positive. It is for the characteristic hæmatozoön of the red corpuscle, however, that search should be made, as its presence excludes all doubt. If the plasmodia be few they may at first escape detection by an unskilled observer, so that the blood should be taken just before or at the height of the febrile paroxysm, if such there be, and with the assurance that no quinine has. been administered during the previous seven hours.

Prognosis.-Children seldom die from malaria, save in its rare pernicious form. The debility and anæmia, however, of persistent infection render them especially liable to intercurrent disorders which they poorly resist. The prognosis is always good when the disease is recognized and proper treatment instituted.

Treatment.-Quinine is a specific in malaria, and though other agents are useful they hardly need mention, as the efficiency of the former is beyond question. Children bear quinine well and it should be given in full doses, preferably just before the paroxysm. If the type of the disease be obseure the remedy may be given three times daily, the larger portion best taken at bedtime, to avoid the symptoms of cinchonism to which some children are predisposed. The objectionable bitter taste may be obviated, if necessary, by the use of fresh eapsules, or wafers when they ean be swallowed. Syrup or elixir of yerba santa disguises. the bitter taste if mixed immediately before taking. So, also, chocolate, with which the mouth may be smeared (chocolate cream) just before administering the drug. Quinine tannate in tablets, made up with chocolate, are eaten readily as confections and answer where a small dose is sufficient. Quinine bisulphate is most efficient because of its ready solubility. The addition of dilute sulphuric or hydrochloric acid promotes the solution and absorption of all the alkaloidal salts. A tasteless preparation, recently introduced, is euquinine, which is highly recommended by those who have used it.

In case of gastric intolerance, rectal medication may be employed by clysters of the solution with dilute acid, or by suppositories, though these are less reliable. An appreciable amount of the bisulphate may be absorbed by the skin if rubbed up thoroughly with oleic acid, lard, or lanolin (quinine bisulphate one part; oleic acid one part; lard six parts). A moderate dose of the quinine salts is one grain (0.06 Gm.) for each year of the child's age. This should be repeated two to four times. daily, or double this dose administered just before or at the height of the exacerbation. In chronic eases arsenic (Fowler's solution, two to. eight drops) is a valuable adjunct, and may well be combined with iron for the anæmia, as in the elixir of iron, quinine, and arsenic, given in. 
teaspoonful doses to a child of five years. Chronic malaria is very refractory and may continue in the system indefinitely, the spleen remaining enlarged in many cases. Such children require a course of the above treatment, with moderate doses of calomel every few weeks.

Prophylaxis consists in the avoidance of malarial localities during the mosquito season, or, if that be impossible, protection by netting at doors and windows and over the bed, and avoidance of the night air, at which time the anopheles is most active. Lpper rooms are preferable for sleeping apartments, as these pests fly near the ground. Every known case of malaria should be protected from the mosquito in order to curtail the supply of infection.

\section{HEREDITARY SYPHILIS.}

Syphilis is a communicable disease probably due to a micro-organism of unknown nature. No age is exempt. Infancy is subject to two forms of the disease, inherited and acquired, the former being much the more common.

The only practical difference between acquired syphilis in infants and in adults is the more acute symptoms, rapid course, and greater fatality in the former.

Notwithstanding the prevalence of syphilis and the amount of study and observation it has received, some questions in regard to its transmission from parent to child are still sub judice: first, whether an apparently healthy mother can bear a syphilitic child, second, whether a syphilitic mother can bear an apparently healthy child; third, whether a syphilitic father can beget an apparently healthy child; fourth, whether an apparently healthy child can be produced by parents both of whom are syphilitic fifth, whether postconceptional infection of the mother may include the child in utero; sixth, whether an apparently healthy mother may nurse her syphilitic child with impunity; seventh, whether an apparently healthy child may nurse its syphilitic mother with impunity.

The answers to the first five questions are, by the consensus of opinion, in the affirmative.

The sixth and seventh are yet considered doubtful, notwithstanding Profeta's law and Colles's law to the contrary. The question is raised by many as to whether hereditary syphilis is contagious, as but few cases of undoubted infection from congenital syphilis are known. The wellknown fact that syphilitic transmissibility not only is intermittent, showing long periods of quiescence or latency, but that it tends to diminish with time, explains, no doubt, many apparent contradictions as to its transmission. The more recent the infection in the parent the more certain is its appearance in the offspring, the earlier and more pronounced are its symptoms and the greater its fatality. In line with the higher degree of virulence of recently acquired syphilis is the tendency to early miscarriage; then later miscarriage; then premature births; then viable but tainted babies; then apparently healthy babies 
(a not rare experience even in untreated cases). An apparent contradiction is seen in the absence of syphilitic lesions in some of the products of these early miscarriages.

The possibility of a primary infection of the child in the birth passage of a syphilitic mother should not be forgotten, with subsequent development of secondary symptoms, the primary lesion having been overlooked or misinterpreted. The diagnosis of congenital syphilis is so dependent upon the symptom complex of known lesions that it may best be approached by a consideration of its pathology. This divides readily into three parts, -

(1) The mechanical structures, including the skin with its appendages, and the skeletal structures.

(2) The mucous membranes.

(3) The organs and viscera.

The skin shows swelling and thickening of the rete with intra- and perivascular infiltration of round cells, one result of which is a rapid shedding of epidermal cells and a transudation of bloody serum which raises the epidermal layer in the form of blebs. These bullæ appear most frequently on the palms and soles, and about the buttocks, genitals, and extremities. They may be sanguino-purulent and change readily to deep ulcers. Nonspecific pemphigus is more serous in character and is rarely seen before the third year.

A common skin lesion is roseolous maculæ, with well-defined margins, about the genitals and over the face and body. They are bright red at first, then change to a brownish terra cotta and are followed by desquamation, especially upon the soles and palms, leaving the surface glazed and shiny. Boils with purple areolæ and deep indolent ulcers, which cause neither pain nor itching, are common.

The hair is dry and scanty, with falling of eyebrows and lashes, with seborrhœe of the brows and patches of alopecia of the scalp. Oceasionally the hair is dark, fine, abundant, and bushy, which, in contrast to the pallid skin, has been called the "syphilitic wig." The nails are dry, brittle, and stunted. They may be contracted laterally, giving them the appearance of claws. Pustular onychix develop in the matrix or, later, dry verrucous neoplasms, from the size of a pea to that of a filbert, overhang their lateral margins.

The deciduous teeth show late eruption and early decay. The permanent set is also delayed and shows irregularities. The central upper incisors especially are small, widely separated, converging, peg-shaped, or notched, or concave on their free edges. Transverse striations or erosions of the enamel occur, which may be seen also on the canine teeth or the first molars. The latter, also, show loss of enamel on the cusps, which are merely tubercles of yellow dentin.

The skeletal structures, bones, cartilages, and articulations show characteristic lesions in both early and late inherited syphilis. The most common of these are osteochondritis and epiphysitis of the long bones at their distal ends, with separation of the epiphyseal cartilages and 
enlargement of the terminal tuberosities. The cartilages may be softened, the adjacent articulations become invaded with pyogenic microbic infection and resultant purulent arthritis of a low grade. Later the periosteum of the shaft shows thickening from subperiosteal deposition of bone, or from the development of gummatous nodules beneath it. The skull bones may be thinned by pressure, especially the occipital (craniotabes), or may be thickened, showing irregular enlargements or bossie, especially over the parietal and frontal eminences, or gummatous nodules under the periosteum or beneath the dura mater. The nucous membrane shows early catarihal lesions, especially of the uasal tract, resulting in the familiar coryza or " suuffles," with later destructive uleeration of the nasal eartilages and bones by necrosis, also by deep uleeration of the pharyngeal and faucial submucous struetures. Laryngitis is common and is sometimes followed by perichondritis of the laryngeal cartilages.

Mucous patches form in the month and later deep ulcers perforate the soft and hard palate. The pseudomucous membranes rarely escape. Papules, vesicles, and mucons patehes form about the lips and angles of the mouth, at the corners of the palpcbral fissures, and about the anus and genitals. Crusts may form over these lesions, which erack and bleed, or result in obstinate fissures which extend into the adjacent skin, leaving, when healed, linear cicatrices. In later stages, condylomata form about the anus and genitals, and grow luxuriantly in their own fetid secretions.

Of the viscera, the liver shows the most constant changes in the newborn and even in the fœtus. The hepatitis may be interstitial or gummatous, although the former is more frequent in early infancy. Increase of connective tissue is followed by atrophy of the liver cells, with intercellular exudate and obliteration of the smaller portal and hepatic vessels. In the later stage gummatous tumors form, with zones of new connective tissue, causing local or general hepatic eirrhosis, and rarely ascites.

The spleen rarely, if ever, escapes enlargement, and in older children shows gummata and interstitial changes (syphilitic splenitis).

The pancreas may be enlarged and show diffuse sclerosis, or gummatous formations which accompany similar degeneration of the liver, spleen, and kidneys. The latter organs may in the later stages of the disease show ehronic interstitial nephritis, with interstitial changes in the adrenals. The testicles may be affected with chronic orchitis and subsequent atrophy. Occasionally the thyroid and thymus are the seat of interstitial and gummatous changes similar to those seen in the other solid viscera.

The circulatory system frequently shows changes, such as endarteritis, interstitial myocarditis, with occasional thrombus formation and embolism.

The nervous system is seldom affected in very young infants, excepting the hydrocephalus of the new-born, although rarely an acute meningitis may have syphilis for its underlying cause. Occasionally chronic 
basilar meningitis occurs, though rarely in young infants; pachymeningitis from gummata may be encountered later.

The respiratory tract, even in the fœtus, is frequently the seat of characteristic lesions, the most common of which is interstitial or white pneumonia. This is a peribronchial interstitial fibrinous process, with fatty degeceration of the alveolar epithelium. It may be circumscribed or involve an entire lobe. In older children there may be gummata which, breaking down, form pulmonary eavities accompanied by bronchiectatic and emphysematous dilatation and atelectatic areas. The larynx and rhinopharyngeal structures rarely escape.

The ear is frequently involved, not only in a low grade of otitis media with little or no suppuration or discharge, but bilateral otitis interna and atrophy of the auditory nerves, followed by deafness, is not uncommon.

In the eye interstitial keratitis is a frequent result of syphilis in older children and is occasionally seen in infants; yet iritis is rare, as are affections of the chorioid and of the optic nerve.

Symptoms. - The most noticeable symptoms are those due to lesions of the skin and mucous membrane. The infant may be born weazened, cachectic, and covered with bulla from which the epidermis slips, leaving large denuded areas of angry, parboiled appearance, or the blebs may be found only on the palms and soles, with roseolous patches about the anus and genitals. The color of the skin may be earthy or cyanotic, and the infant may soon succumb to the low state of vitality or to the interstitial pneumonia. A large percentage of these infants are born prematurely.

Frequently, however, at birth no symptoms of syphilis are seen. To all appearances the babe is well nourished. About the third week, in the majority of cases, symptoms of coryza ("snuffles") develop, may persist, and may interfere with nursing from obstruction to the respiration. The nasal discharge increases, may become bloody, mucopurulent, or fetid, and causes excoriations upon the lip, so that the labial and facial lesions are at first attributed to this eause. Later, .crusts form about the mouth, or rhagades radiate outwards from the pseudomucous membrane of the lips. Mucous patches may form in the mouth, about the anus, or upon the skin where it is thin and moist. These patches are slightly raised, whitish areas, from one-eighth to onehalf inch (3-12 Mm.) in breadth, and may be moist. Ulcers, or bluish, indolent boils and pustules, may appear. Blebs are seen on the soles and palms, or the skin in these areas is dry, shiny and tense. Onychitis may develop, and swellings may be observed about the elbows, wrists, knees, or ankles, which are tender. The child cries when handled and the cry becomes hoarse from the laryngitis. Some rise in temperature will be found, and the child begins to have a cachectic appearance, loses weight, is fretful, and the skin has a characteristic dirty pale-brown hue. The eyebrows show furfuraceous scales or crusts and fall out, as do the eyelashes, and hairs from the sealp.

Dactylitis swells the proximal phalanges of the fingers (one or more), 
which, however, rarely or tardily proceed to suppuration and bony necrosis. Pseudoparalysis is not uncommon, and is due to the pain induced by motion from the epiphyseal separation and subacute osteochondritis, and most frequently involves the arm, one or both. The spleen is always enlarged and dyspepsia is nearly always a marked feature. Rarely are all the above-described symptoms present in a given ease, and the babe may be under treatment for simple eatarrh and indigestion. Occasionally hemorrhages occur, not only from the nasal mucosa, but subcutaneously, and from the bullous eruption, the fissures, and orifices, including the umbilicus.

The glandular system shows but little involvement, save occasional enlargement of the lymph-nodes in the vicinity of extensive suppurative lesions.

Syphilis hereditaria tarda is a term applied to the manifestations of that disease which develop after the third year. These may have been preceded by symptoms of congenital syphilis in the early months of life which, subsiding, reappear after an interval of from three to twenty years, very frequently at or before puberty. Occasionally, however, the history of precedent symptoms is wanting and the first signs appear during childhood. If these be cases of true hereditary transmission, the virus must have lain dormant in the child's system for several years, or have been held in abeyance by some chemico-vital force not understood. The final yielding of the tissues to the virus corresponds in point of time to the recognized periods of stress, in so many instances, as to suggest lowered vital resistance as an exciting cause. This form of late hereditary syphilis is questioned by many who claim that the earlier symptoms may have been overlooked on account of their mildness or, in the absence of which, it is argued that late manifestations represent an acquired syphilis whose initial and perhaps secondary lesions have been overlooked or misinterpreted. The diagnosis of a late from an acquired form of the disease is therefore at times extremely difficult if not impossible. The lesions correspond to those of the tertiary stage of acquired syphilis. It is here that the specific keratitis with its corneal opacities is usually seen, and the occasional iritis which by its plastic adhesion distorts the pupil. The characteristic bone deformities from plastic periostitis and gummatous involvement are seen most frequently in the cuboidal head with its prominent bossæ and the sword-shaped tibia from the deposition of new bone along the shin.

The nose is exaggerated retrousse from the caving in of the bridge (saddle nose), and the palate may show perforation. Tender spots and nodules from low grade of periostitis or gummata may be found over various long bones and under the scalp. Old scars or indolent sinuses leading to neerosed bone are found in the vicinity of the epiphyses and upon the forearms, fingers, and legs. The lymph nodes may be enlarged, especially the cervical, submaxillary, epitrochlear, axillary, and inguinal. The oral mucosa and the skin about the mouth and anus show the cicatrices of old rhagadia, while the teeth show characteristic deformities. 
Deafness is not rare, or an indolent, destructive otitis media may develop, with occasionally mastoiditis.

Probably the most constant manifestation of late syphilis is seen in the skin lesions, which consist of subcutaneous gummata which are at first hard, elastic, grayish in color, with reddened borders. Breaking down they leave deep ulcers, having rounded indurated borders and a depressed base. They usually appear upon the face and thighs and may be covered by crusts. When healed, these uleers leave smooth, white sears, in contradistinction to the purple cicatrix from the shallow, irregular, soft tuberculous uleer. Enlargement of the liver and spleen are almost constant in late syphilis. There are anæmia and muddy pallor. The child is undersized, develops late or not at all, shows absence or paucity of pubic and axillary hair, small genitals, flat breasts, and a general condition recognized as "infantilism." These children furnish recruits to fill the ranks of the epileptic, imbecile, degenerate, and demented.

Diagnosis.-The diagnosis of early hereditary syphilis is usually not difficult. The "snuffles," pemphigus, pseudoparalysis, osteochondritis, mucous patches about anus and genitals, with enlarged spleen, and the cachectic appearance of the infant, point unmistakably to inherited infection. The first three symptoms are never found in the early acquired disease. The difficulty lies in differentiation between late syphilis and the acquired. The history of chancre-whether upon the lip from kissing, eye or nose from birth infection, or upon any mucoid or epidermal erosion from contact with cloths or utensils used by a syphilitic parent or nurse-settles all doubt.

The special dental deformities, such as Hutchinson's teeth, with early keratitis and deafness, with the claw-like finger nails, are considered peculiar to the inherited form.

" Hutchinson's triad"' has for many years been regarded as of diagnostic importance in hereditary syphilis. Although each may oceur in nonsyphilitic or even in healthy children, yet, taken together, they should go a long way towards establishing a diagnosis. The triad consists of, first, eye affections,-as interstitial keratitis and a peculiar form of chorioiditis alveolaris, atrophic foci, and pigmentary deposit in the chorioidea; second, affection of the internal ear or auditory nerves, with deafness or deaf-mutism; third, affection of the teeth, particularly the upper middle incisors, which are small, peg-shaped, grayish-white, with notched edges and loss of enamel.

Prognosis.-Hereditary syphilis shows a high fatality never approached in the acquired disease, as in this form the new being has had to cope with the infection from the beginning of existence. Its farreaching effects are seen in the majority of those who survive the period of infancy. The mortality from intereurrent affections due to lowered resistance may never be estimated. Early treatment will cause the disappearance of all symptoms in a fair proportion of cases. The abatement of syphilitic symptoms, however, does not constitute a cure, as 
they are liable to return after an interval of years. Noreover, the accidents of this disease, recognized as "parasyphilitic" symptoms, such as anæmia, cachexia, and rhachitis, with retarded growth and atrophic conditions, furnish a constant menace to life and health. The prognosis is rendered still more unfavorable if the infant, already badly nourished and eachectic, is deprived of natural food. Bottle-fed babies furmisl a large proportion of the fatal cases.

Treatment.-Prophylaxis is all-important. A syphilitic woman or the wife of a tainted husband should receive steady mercurial treatment during the entire period of gestation. At the beginning of labor the vagina should be thoronghly disinfected. This latter precaution should always be observed in any case of suspicious mucous lesion about the genitals of the parturient woman.

Children should be jealously protected from infection from the secretions of syphilitic persons, whether parents, nurse, friend, or stranger. Social rank or distinction is no guarantee of freedom from infection. Were the foolish and criminal practice of kissing and promiscuous fondling of babies abolished, much syphilis in the innocent might be prevented.

So important is nutrition that the syphilitic infant should not be taken from the breast which furnishes suitable milk. If the mother give no history of syphilis she should be cautioned to take particular care to keep her nipples sound and clean; also to cleanse the baby's mouth before nursing; or a wet-nurse with syphilitic history may take the child. In cases of doubtful etiology and, in fact, in all cases of infected infants, great care should be exercised to prevent the secretion from moist lesions from coming in contact with non-infected persons. To this end, as well as for therapeutic purposes, such lesions should be dusted with calomel and bismuth, equal parts, three or four times daily; and all spoons, cups, cloths, etc., used about the child should be promptly sterilized by boiling.

The specific remedy in hereditary syphilis, as in the acquired form, is mercury, of which there are various methods of exhibition,-as by fumigation, baths, inunction, hypodermic, and internal administration. Mercurial ointment five to fifteen grains $(0.3-1.0 \mathrm{Gm}$.), with an equal quantity of lanolin, may be rubbed into the skin of a young infant, each day, varying the site of application to avoid undue irritation. If objectionable for any reason, the protiodide of mercury may be given in dissolved tablets containing one-twelfth to one-fourth grain $(0.005-0.016$ Gm.) three or four times daily. In obstinate cases calomel in the same dosage may prove more efficient, but may not be sustained as long on account of its purgative properties. To correct diarrhœa, tannic acid preparations may be used with the mercury. The anæmia calls for iron, so that the "mixed treatment" should be employed either conjointly or alternately, for which the syrup of the iodide of iron in doses of from three to fifteen minims $(0.2-1.0$ C.c.) may be given three times a day, according to age. 
The following is much used and may be given four times in twentyfour hours in one powder: calomel, one-sixth grain $(0.01 \mathrm{Gm}$.) ; saccharated carbonate of iron, three grains $(0.18 \mathrm{Gm}$.). Calomel is useful for moist lesions, especially for condylomata about the anus and genitals. A good method in extensive growths is the following: Wash the parts thoroughly with salt solution, and after drying shightly, dust calomel freely over the surface. The reaction is obvious and very effective. Foul and obstinate ulcers after cleansing should be touched with the solid nitrate of silver every second day.

Severe rhinitis is best treated by irrigation with a nasal syringe daily with corrosive sublimate solution $(1: 4000)$, followed by the application of iodoform ointment with a camel's hair pencil.

The presence of bone lesions, gummatous tumors, hepatic and other visceral lesions, common to the tertiary stage, calls for potassium iodide, fifteen grains to one drachm $(1.0-4.0 \mathrm{Gm}$.) daily in broken doses well diluted. This also shonld be alternated or accompanied by tonies and preparations of iron.

Specific treatment must be continued for a year at least, or until all symptoms have disappeared, after which it should be resumed in courses of a few weeks, once or twice daily. Good nutrition and supporting and tonic treatment, should not be neglected.

\section{TUBERCULOSIS.}

No other disease has received the amount of study given to tuberculosis. While formerly it was thought to be somewhat rare in infancy, it is now known that deaths in children's hospitals and foundling institutions are caused by this disease in thirty-three per cent. of all cases, and that of the remaining fatal cases over twelve per cent. show tubercles in latent form.

The tubercle bacillus gains entrance to the tissues by many routes. It may penetrate the mucous membrane or pass through the placenta of the tuberculous mother to her child in utero. It is found in the secretions, excretions, and morbid discharges when they are derived from parts involved in active tuberculous processes, as urine from a tuberculous bladder or kidney, fxees from ulcerated bowels, or discharges from tuberculous skin lesions. The organism is occasionally found in the blood of tuberculous patients, and in the milk of a tuberculous mother, but most frequently in the secretions of the respiratory tract. The most common method of dissemination is through the sputum, which, dried and pulverized, is taken with food, drink, and inspired air. The infective germs are ommipresent, and that all do not succumb to the infection bespeaks individual resistance. This resistance may be overcome by lowered nutrition of the whole or a part, or by a special virulence of the bacillus. That the first is most frequently the case is evident from the long list of diseases now recognized as predisposing eauses to tubercular infection.

The most prolific predisposing cause is seen in the lymphatism of 
infancy and childhood, and accords with the period of widest prevalence of the disease,-during the first three years of life. Although direct hereditary transmission is rare, children undoubtedly inherit a diathesis which strongly predisposes them to this form of infection. In this way hereditary syphilis is a predisposing factor.

Many instances of tuberculosis in early infancy, formerly regarded as evidences of heredity, are now known to be due to postnatal infection, even though developing and terminating fatally before the sixth week of life.

Regarding the most common mode of infection in early life, especially as to the relative frequency of microbic entrance through the respiratory or digestive tract, widely varying opinions prevail. Recently renewed interest in the controversy has developed, the extremes of opinion being represented by Koch and Behring.

Aside from the question of the identity of human and bovine tuber-

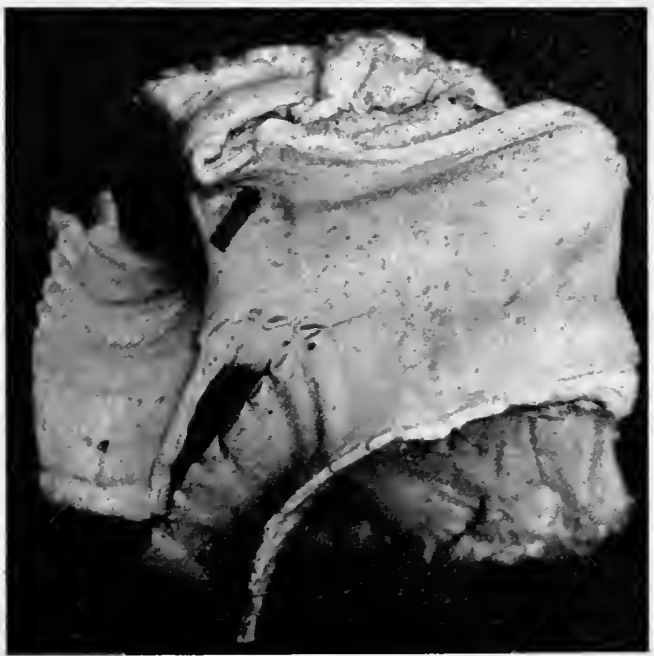

FIg. 211.-Rupture of tuberculous peribronchial gland into trachea. (Rush Medical Museum.)

culosis, it is well known that milk affords an excellent culture medium for many bacteria, including the bacillus of Koch. It is believed that, when introduced by the ingestion of such milk, the cervical lymph-nodes and probably the intestinal and mesenteric, yield readily to their invasion.

As to the pathology it must suffice to state that the form most common to early infancy is the lymphatic; that tuberculous meningitis is peculiar to later infancy; that childhood is especially marked by tuberculosis of the bones and articulations, and that prolonged latency is less common in infants than was formerly supposed, because of the susceptibility of young tissue to tubercular processes. This same reason may explain the rarity of the chronic pulmonary form.

The lymph channels furnish ready conveyance of the bacilli after 
their passage through mucous membrane or skin. Like other foreign bodies in the lymph current, they usually lodge in some neighboring gland with resultant adenitis. Glands in which the bacilli are arrested, may show hyperplasia and undergo degenerative changes, as hyaline or calcareous, with ultimate extinction of the germ. The glands may become surcharged with tubercular bacilli and other pathogenic organisms, leucocytes, and connective tissue overgrowth. This reduces their blood supply and favors caseous degeneration, necrosis of the conservative enveloping zone, and escape of the liquefied mass into adjacent tissues. Throngh the Tymph channels and blood the bacilli are distributed to remote parts, the location of the new tubercular process depending upon the lowered resistance, as from injuries.

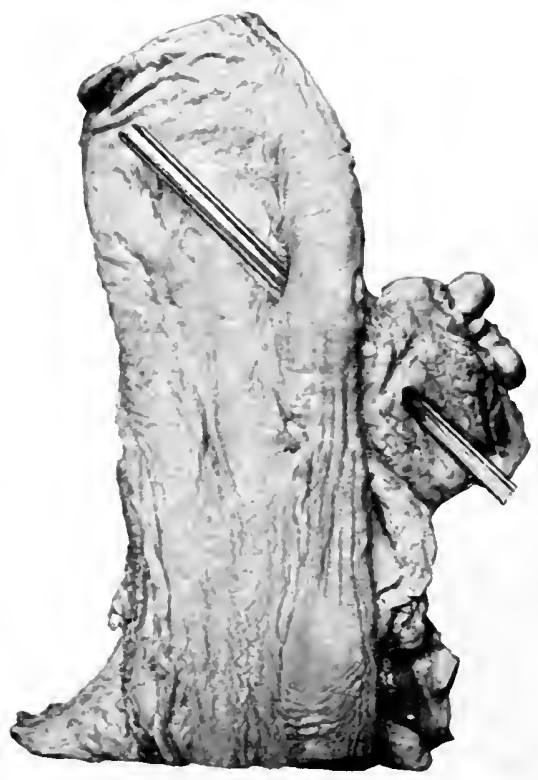

FIG. 212.-Rupture of peribronchial lymph-gland into œsophagus. (Rush Medical Museum.)

If the general systemic resistance be low, or if the bacilli enter the blood stream in great numbers, a generalized tuberculosis of acute type is lighted. The lymph-nodes most susceptible to tubercular invasion in children, are those which have been subject to frequent attacks of inflammation from eatarrhal processes of their areas of drainage. For obvious reasons these are the bronchial glands, especially those situated at the pulmonary hilum. By enlargement and coalescence these glands may form mediastinal tumors of sufficient size to cause pressure symptoms. By caseous softening of these glands and rupture into adjacent structures, as the oesophagis, bronchi, or trachea (Figs. 211, 212), the lung becomes quickly infected, resulting in acute pulmonary phthisis.

Pulmonary tuberculosis runs a much more rapid course in infancy 
than in adult life. In the majority of cases it is the upper lobes which are first invaded, but the tendency is to rapid generalization not only in all the lobes but throughout the system. In deaths from tuberculosis of any form more than seventy per cent. show lung changes. Pulmonary tuberculosis, although presenting in infants and children under seven years a great variety of atypical manifestations, after that age conforms more nearly to the adult forms. Roughly speaking, the disease may be divided into three general types,-

First, miliary form, in which miliary tubereles are scattered throughout the lung, upon the alveolar septa, the walls of the tubes, the interstitial tissues, and under the pleura. Other organs may show these miliary tubereles. This form may develop quite suddenly during convalescence from some acute infectious fever, or after recurrent attacks of bronchitis.

Among the symptoms of this form there is fever which may develop insidiously or suddenly, and may be high as in pneumonia or low as in subacute bronchitis. The temperature is erratic and marked by exacerbations and remissions, but rarely remains normal for an entire day. Cough is present and may be spasmodic, like pertussis, or croupy. Prostration and malaise may be marked. The physical signs are not distinctive, and more nearly resemble those of subacute bronchopneumonia. As the infant does not expectorate, secretions for examination must be obtained by passing a tube_into the cesophagus, as the swallowed sputum clings to its walls. The microscope may confirm suspicion as to the true nature of the disease.

Not infrequently during an attack of miliary tuberculosis, the development of meningitis is the first intimation of its tuberculous character. This form of tuberculosis is fatal, younger infants dying of the pulmonary disorder and older ones of the meningitis, if they survive so long.

The second type seen in infants may be called the marasmic type. It may begin as a digestive disturbance, for which it is usually treated. There may be exacerbations and intervals of improvement. In these cases there are often local tubercular lesions of the bones, as a dactylitis. (Fig. 207), enlarged cervical glands, or the spleen may be enlarged, but through it all there is wasting. There may be a history of tubereulosis in the family to guide the diagnosis, and the infant may have been weakly from birth. The slight cough may at first attract but little attention. In older infants and young chldren some positive bone or joint lesion may precede the more acute attack, such as cervical or dorsal spondylitis, or hip-joint disease.

There is great prostration and emaciation, with capricious appetite and frequently marked anorexia.

The pulmonary symptoms develop sometimes quite suddenly, with high temperature, rapid respiration, pain in the chest suggestive of pleurisy, and restricted cough. The physical signs point to acute fibrinous pneumonia, and the child quickly succumbs. It may rarely follow a protracted course with pleurisy and empyema. The special 
feature of this type is more or less steady wasting, which most frequently ends abruptly in acute pneumonia.

The third type is seen most frequently in children past the age of five years. They are delicate, thin-skinned, and have prominent winglike scapulæ between which the skin shows a growth of fine hair. The chest may be long and flat, while the triangle of which the clavicle forms the hypothenuse is large and sunken. The chest and head may give evidence of early rhachitis, or the child may have a syphilitic history.

No serious disease may have affected the child, but a succession of transient spring and winter catarrhs is reported, or the exanthemata may have left slight but persistent attacks of bronchitis. The tonsils are usually enlarged and adenoid vegetations of the nasopharynx are common. Enlargements of the cervical lymph nodes, which have occurred at various times, show a tendency to become permanent and may be very pronounced. Previous ulceration of a gland may have left an angry cicatrix upon healing. Otitis media, with discharge of pus from one or both ears, may have impaired the hearing.

The child, which has been regarded as delicate for years, may be dull, backward, listless and a mouth-breather, or extremely bright and precocious and of a highly nervous temperament. The growth in height may be rapid, but the child does not put on flesh, and the weight remains the same for long periods. Evidence of intrathoracic pressure from mediastinal tumors may develop. There may be tachycardia, asthma, or dyspnœa after exertion, with fulness and throbbing in the vessels of the neck when the head is retracted. The pulse is always rapid, and while apparently in ordinary health, the thermometer may show febrile exacerbations, especially at night. The sleep is not restful, and there is occasional sweating in the latter part of the night. The child is languid and shows dark circles under the eyes. Respiration will be found rapid, especially upon slight exertion, and every draught induces coughing, which is attributed to tickling in the throat. The pharyngeal wall looks glazed and dark red, with the follicles enläged.

Several years may elapse before some acute "cold," more persistent than its predecessors, may be pronounced by the physician bronchopneumonia; an attack of measles or whooping-cough occurs, with delayed convalescence, after which there is a constant cough with some daily temperature. Careful examination of the ehest may now reveal signs of an unresolved pneumonia or of a chronic interstitial pneumonia. In some instances careful and repeated examinations may locate vomice, although in children this is at times extremely difficult, as cavities, while not infrequent, are usually filled with secretions and débris. The common occurrence of bronchiectasis with atelectatic and emphysematous areas renders the plysical signs ambiguous. Occasionally, however, a child of eight years will furnish a typical picture of adult phthisis pulmonalis. 'The finger tips show signs of clubbing. Respiration, pulse, temperature, emaciation, languor, anorexia, sweats, cough, 
and hectic flush, may combine to form a picture of tubereulosis pulmonalis of the chronic type (Fig. 213).

The blood findings are inconclusive in tubercular disease. In acute cases the erythrocytes and hæmoglobin are but little affected, and a leucocytosis means some accidental pyogenic infection. In prolonged cases anxmia finally asserts itself in the diminution of hæmoglobin and some loss of the red cells. In later stages the anzmia may be marked. Hæmoptysis is unusual in children and extremely rare in infancy.

Prognosis. - The prognosis is more favorable in this third type than in the first and second. The process may cover a period of years during

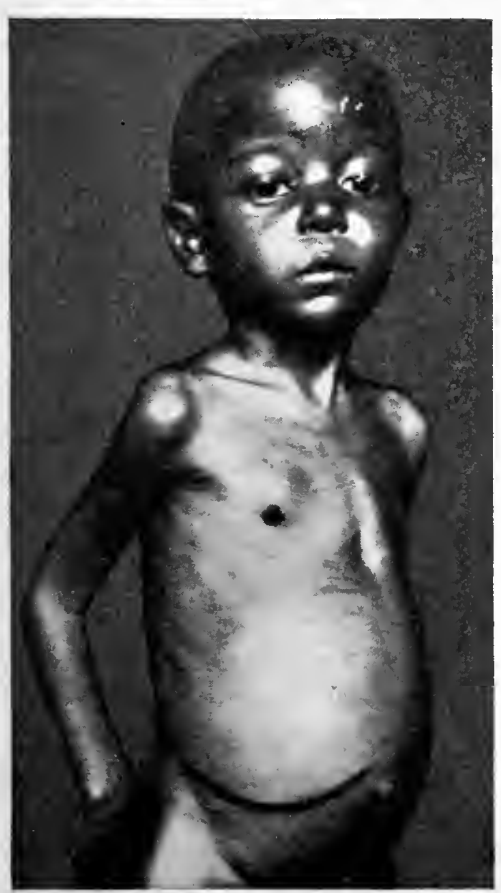

Fig. 213.-Boy, aged 3 years. Pulmonary and mesenteric tuberculosis, with large liver. (Dr. J. C. West.) which the nature of the disease is hardly more than suspected. Much depends upon early recognition, prompt, judicious treatment, and the degree of resistance in the individual case. The personal equation depends quite largely upon the family history. If this be good the prognosis is hopeful up to the stage of cachexia.

Diagnosis.-The diagnosis is made from the consensus of symptoms and history and by exclusion of other definite causes for the wasting. It is elaimed that the blood of the tuberculous shows agglntinating properties with properly prepared cultures of the bacilli. XThe tuberculin test, while still employed by some reputable physicians, should be regarded as of doubtful propriety. A blow of the hammer may demonstrate the true nature of dynamite. X Sputum examinations should never be neglected. In young children and infants the tube may be passed into the œsophagus, or the pharynx may be wiped with a swab.

Brain tuberculosis probably occurs through the blood current which carries the bacilli to the capillaries of either the white or gray matter. Characteristic solitary or multiple tubercles develop, and the latter, coalescing, may form tumors varying in size from a pea to a walnut, which give rise to pressure symptoms, or if superficial may cause meningitis. (See Diseases of the Nervous System.)

Subcutaneous abscesses are frequently the result of subjacent bone necrosis, with sequestrum formation and fistulous openings, which discharge sanious pus and bone débris. The principal articulation involved in tubercular processes is that of the femoral head, while both 
bony necrosis and absorption of interarticular cartilages is best illustrated by spondylitis.

GLANDULAR TUBERCULOSIS.

Formerly regarded as one of the manifestations of scrofula (a term now obsolete), tuberculous adenitis was considered a menace to life from its frequent clinical relation to tabes mesenterica, osteomyelitis, and pulmonary phthisis, all of which are now known to be merely different phases of tubercular infection in which adenitis is often the primary lesion.

Tuberculous adenitis exceeds in frequency all other glandular affections combined. Probably in half of all autopsies upon children some tuberculous lymph-nodes may be found, most frequently in the bronchial, mesenteric, or retroperitoneal areas which, on account of their location, are rarely observed ante-mortem. Of the accessible glands, the cervical outnumber in frequency of involvement all the others, after which in order come the axillary and the inguinal. While no age is exempt, this affection is common to the first decade of life.

That other bacteria are associated with the tubercle bacillus is well established, and undoubtedly they act both as predisposing and determining causes in the adenitis. In this way such lesions as eczema of the scalp and face, sore lips, carious teeth, various forms of stomatitis, affections of the tonsils, nasopharyngeal catarrh, adenoids, and otitis, are largely responsible for the non-resistance of the cervical lymph-nodes to invasion of the bacilli and for their pathogenic activity in the arresting glands. It is now known that the tonsil not only furnishes a ready portal of entry but is the occasional seat of tuberculous processes, a fact of the greatest etiologic importance.

Symptoms.-Glands which may be palpated are the seat of adenitis. Examination of children who crowd the dispensaries and out-patient clinies show less than five per cent. free from palpable glands. The symptoms are often those of malnutrition, maldevelopment, and evidences of unhygienic life and surroundings.

If the adenitis be purely tuberculous there may be no other specific symptoms until softening from caseous degeneration in a later stage. Whether this caseation and softening would ever oceur without superadded infection or lowered nutrition it is impossible to say, but it is probable that some benign form of degeneration of the gland would terminate the pathogenic career of the bacilli. In a moderate degree of infection with Koch's bacilli, therefore, the adenitis tends to run a chronic course, with few or no symptoms, towards ultimate recovery.

Glands quiescent after old and repeated involvements, may flare up suddenly in acute exacerbation with constitutional symptoms of intoxication and rapid extension of adenitis to adjacent glands, which, coalescing, form matted tumors on the sides of the neck.

With pyrexia, coated tongue, malaise, anorexia, and headache, the enlarged glands may soften, perforate the skin, and discharge pus. The abscess, if tuberculous, is chronic, continuing to discharge until 
all the gland has broken down, and usually until neighboring deeper glands have gone through a similar process, healing finally with red, unsightly cicatrices.

Diagnosis.-The presence of chronic adenitis of the neck, which may be attributed to no local lesion, is presumptive evidence of tuberculosis. This is especially true if there be a history of family tuberculosis or exposure to infection. Simple adenitis tends to undergo resolution, with subsidence of the gland. Pyogenic adenitis tends to early suppuration, with prompt healing. Syphilitic adenitis is more general and symmetrical in its distribution, gives a history or shows other signs of that disease, and yields to mercury.

Hodgkin's disease is rarely found in early childhood, and usually shows more extensive glandular and splenic involvement and earlier anæmia with a lower temperature than is seen in tubereulosis of that extent. There are eminent observers, however, who consider the two diseases identical.

Lymphosarcoma may at first simulate tuberculosis of the glands, but its malignant nature is not long concealed.

\section{ABDOMINAL TUBERCULOSIS.}

Post-mortems upon children dying of tuberculosis show lesions of the abdominal organs in more than seventy per cent. of cases. In a large majority of these there is ulceration of the bowels and caseous degeneration of the mesenteric glands. In a few there is mesenteric tuberculosis without intestinal lesions, but ulceration rarely exists without mesenteric involvement. Nor is this strange, since the intestinal mucosa with its lymphoid structures bears a relation to the mesenteric and abdominal glands similar to that which exists between the upper respiratory mucosa and the cervical and bronchial lymph nodes.

Recent research seems to lead to the conclusion that the portal for primary infection is more frequently through the intestinal tract than previous opinions have been willing to allow, and that the thoracic duct furnishes a ready avenue for the distribution of bacilli with resultant general miliary forms of the disease. The modern conservative attitude is a natural reaction from the older practice of regarding every case of fatal wasting, with diarrhœa, as "consumption of the bowels," pure and primary, in which no other tuberculous lesion need be expected. It is the fact, however, regardless of the controversy concerning the relative frequency of the location of the primary lesion, that infants do occasionally come to post-mortem with tuberculous lesions of the bowels and mesenteric glands to the exclusion of all other organs and structures.

While common to all ages, infants in the first year are less frequently found suffering from intestinal tuberculosis, and those at the breast rarely, unless nursed by a tuberculous mother. At the post-mortem the lung lesions which hasten the fatal termination are usually found. The ileum and cæcum are the most frequent sites for ulcers which, if recent, present a "punched-out" appearance. Old ulcerations run crosswise 
of the bowel and show thickened, irregular margins; and the intestinal walls, especially of the crecum, may be considerably thickened. The appendix is occasionally the seat of tuberculous ulceration, and healed lesions may, by contracting cicatrices, produce stenosis of the bowel with obstruction.

The mesenteric glands show different stages of caseous degeneration; the mesentery and adjacent structures may be agglutinated by plastic exudation; tubercles are found in the capsule of the liver, and perihepatitis may lead to hepatic eirrhosis with ascites (Fig. 213).

Symptoms.-There is diarrhœa, fever, abdominal pain, and wasting. The abdomen may be distended with flatus or

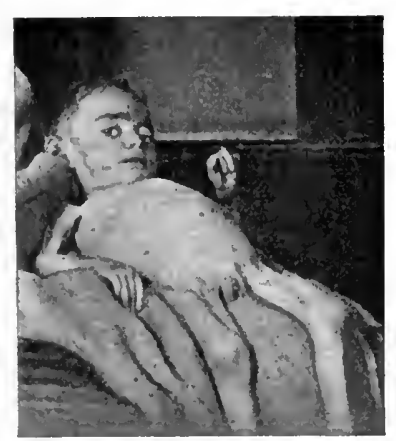

FIG. 214.-Mesenteric and pulmonary tuberculosis. fluid and show stasis of its superficial veins, or it may be flat and retracted. In longcontinued cases the enlarged and matted giands may occasionally be felt through the abdominal wall by skilful palpation when the distention is not extreme.

There is the usual evening rise in temperature of tuberculosis, with general wasting arid malaise. The symptoms are those of chronic enterocolitis with marasmus, while the dejecta are not characteristic (Fig. 214).

Diagnosis.-Intestinal and mesenteric tubereulosis should not be pronounced upon in the absence of corroborative tuberculous manifestations. Careful examination of the lungs, and lymph-nodes in other parts should be frequently made and a review of the child's history and. environment should enter into the estimate. The chronic obstinacy of the enteritis, the night fever, the history of infection, and above all the demonstration of tuberculous lesions elsewhere, especially in the lungs, may be necessary to a diagnosis. Quite frequently the diagnosis is reversed by the autopsy, the case proving to have been chronic ileocolitis with terminal acute bronchopneumonia of nontubercular type.

PERITONEAL TUBERCULOSIS.

It is doubtful if chronic general peritonitis oceurs in childhood in the absence of tubercle. The disease is not rare. It may be primary, yet most frequently it is a local expression of the general infection. A number of varieties are usually described dependent upon the location of the lesions and the behavior of the tissues in the process of tuberculization. For ordinary clinical purposes two forms will suffice, the wet and the dry, or the ascitic and the plastic.

The first is characterized by large fluid accumulations in the abdomen, with little or only occasional pain, some tenderness on pressure, alternating diarrhœa and constipation, little if any fever, moderate malaise, and loss of flesh. The most noticeable feature is the large belly, for which the child is brought to the clinic (Figs. 215 and 216). 
Diagnosis of fluid is made by the usual signs. Hepatic eirrhosis as a cause must be excluded. This is not always easy, as perihepatitis occasionally accompanies this form, and the stools may be at times crumbly and light-colored. In the absence of tubercular manifestations elsewhere, some of the ascitic fluid centrifugalized should be examined for bacilli, or, better, injected into a rabbit or guinea-pig as a test.

The dry or plastic form shows little tendency to fluid accumulation. The abdomen is flat, or distended with gas. Careful palpation may outline nodules and masses of cnlarged glands, matted omentum and viscera, which are agglutinated by the profuse plastic exuclate. The finger in the rectum may feel tubercular masses and bands of adhesion in the lower bowel, that cause obstruction. Fecal masses must

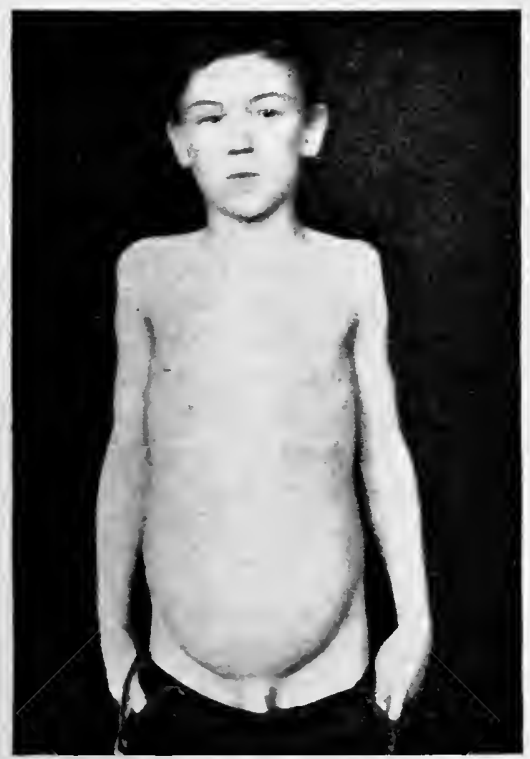

FIG. 215.-Boy, aged 12 years. Tuberculous peritonitis, ascitic form. Recovery.

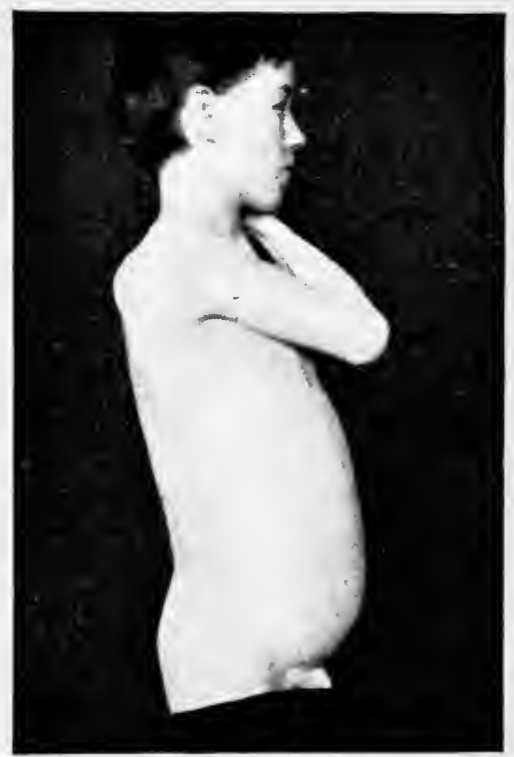

FIG. 216.-Side view of Fig. 215.

be excluded, as thorough evacuation of the bowel sometimes changes the abdominal topography. Fever, tenderness on pressure, lancinating or colicky pains, 'wasting, malaise, and diarrhœa, are usually more pronounced than in the wet form. The diagnosis is made by the presence of nodules and chronicity, and corroborated by other signs of tuberculosis or history of exposure.

An intermediate form is encountered in which the fluid is walled off by adhesions, giving atypical signs on percussion and palpation, which change of posture does not affect. Rectal exploration or examination under anæsthesia, after thorough cleaning out of the bowels, may be necessary, and if fluid be located, aspiration with animal inoculation may be practised. 
The prognosis is fairly good in the ascitic form and not necessarily fatal in the plastic. It depends, of course, upon the evidence of general tubercular infection, recuperative power of the individual, and, in no small degree, upon the treatment. The disease is essentially chronic, although it is occasionally met with in a subacute form. The presence of albumin in the urine increases the gravity of the prognosis, as suggestive of amyloid degeneration.

The local treatment of tuberculous peritonitis has occasioned much discussion. The fact that a majority of laparotomies in the ascitic form of this disease have been survived has led some surgeons to advocate the operation, although there is no evidence to show that the transient exposure of the peritoneum hastened reparative changes or absorption. Evacuation of the fluid by aspiration, and absolute rest in bed, with other appropriate treatment, furnishes as large a percentage of recoveries as the more heroic methods. Spontaneous recovery is not rare in cases where the tuberculous process is restricted to the peritoneum.

In all abdominal tuberculosis the digestive function must be promoted by all means, and the pain and diarrhœa controlled by opium if necessary. Application to the abdomen of unguentum Credé, unguentum iodoformi with ten per cent. lanolin, or the four per cent. yellow oxide of mercury, rubbed up with unguentum belladonnæ, may be applied and covered with impervious protective tissue. Concentrated proteid foods are essential. The bowels should be evacuated when necessary by saline enemata rather than by purgative drugs. The general treatment for tuberculosis must not be neglected.

\section{GENERAL TREATMENT FOR TUBERCULOSIS.}

Since no specific treatment for general tuberculosis is known, the importance of prophylaxis is obvious. Our knowledge of the nature of the infection and its methods of propagation furnish us at once the key to its prevention. It is not necessary to eat or inhale tuberculous sputa, either moist or dried, to become infected. The vapor from the lungs of a tuberculous patient when laughing, coughing, or sneezing, though free from palpable sputum, may carry bacilli whose levity permits of prolonged suspension in the air. Hence, personal proximity is always dangerous to a susceptible ehild. The infant should be immediately removed from a tuberculous mother, nor should children be allowed in the same house with a known or suspected case.

The danger of tuberculous infection is but one of many reasons why kissing and coddling of infants should be forbidden. Wet nurses and attendants should be subjected to a careful examination by the physician for indications or history of tuberculous lesions. Delicate children, and those with family tendency towards tuberculosis, should always be put upon the suspected list and supervised accordingly. Nothing should be omitted to develop respiratory vigor and promote healthy metabolism. The individual resistance must be constantly ap- 
pealed to and strengthened by all known means, such as cold baths, massage, exercise, etc., while avoiding exposure to possibilities of infection. Since most diseases of infancy and childhood predispose to tuberculosis, all should be treated with eare, even though known to be self-limited. In fact, all influences, oceupations, or customs, whether domieiliary, educational, or social, which interfere with the fullest physical development, should be corrected.

All lesions of the respiratory tract which restrict free breathing or favor infection, such as rhinitis, tonsillitis, adenoid growths, otitis, or bronchitis, should receive prompt treatment; and all enlargements of lymph nodes must be regarded with suspicion. It seems hardly necessary to state that the sputum of a tuberculous person should be promptly destroyed, and all articles in his vicinity frequently boiled or disinfected.

The treatment of a tubereulous child must depend upon the individual case and nature of the lesions. A few general principles only may be given. Fresh, dry air and sunlight are the great desiderata both in the prophylaxis and treatment. In this way change from a damp and variable climate to one which is dry and warm, with the maximum of sunshine, may be necessary, so that the child may practically live out of doors. Feeding is all-important, while guarding jealously the stomach and digestive tract from disorder. Concentrated assimilable nutrients must be selected,-as milk, cream, proteids, and cereals rich in phosphates. Stomachics and appetizing bitters and tonics, such as calisaya, nux vomica, and cinchona preparations, are useful, and feeble digestion may require hydrochloric acid, pepsin, pancreatin, or the partial predigestion of food temporarily.

Frequent or forced feeding may be advisable, and many cases require the judicious use of alcoholic stimulants. Egg-nog, or warm milk and raw egg at bedtime, are usually indicated.

Fatiguing exercise must be avoided; massage and sleeping or resting in the open air may take its place. Enlarged glands which tend to chronicity should be removed, mucous lesions and carious teeth promptly treated, and the body carefully examined for early signs of bony or articular involvement which, if found, should receive attention.

A few drugs, while not specifie, have won a reputation for retarding the extension of tuberculous processes and promoting healthy tissue growth. Cod-liver oil and the hypophosphites have decided value when judiciously administered. Creosote, or, better for children, guaiacol (the carbonate), is well borne and should be given, five to twenty grains (0.33$1.3 \mathrm{Gm}$.) daily in broken doses every four to eight hours. Arsenic is of value in the form of Fowler's solution, well diluted, after food, one to ten minims (0.06-0.6 C.c.), care being taken not to disturb the stomach.

In weak and rapid pulse, digitalis should be given in small doses and may be continuéd for weeks, with good results upon nutrition and elimination. If not well borne by the stomach, strophanthus or eaffeine may be substituted. Pulmonary and other tuberculous lesions should receive appropriate treatment, which is discussed elsewhere. 


\section{CHAPTER XVI}

\section{DISEASES OF THE SKIN}

\section{PREVALENCE IN CHILDHOOD}

THE importance of the skin as an organ through its multiple functions of protection, respiration, absorption, elimination, secretion, excretion, seusation, and heat regulation, cannot be unduly emphasized. Although much is yet to be learned, enough is known of the interdependence between these functions and those of general metabolism to lend importance to any integumentary disturbance, whether structural or functional.

With a better understanding of the complex processes of metabolism, it seems less strange that skin changes have been long regarded as indicative of constitutional disorder, than that modern pathologists should try to minimize this relationship by ignoring disturbances of metabolism in their search for local causes. Without attempting to lessen the importance of local causes for local lesions, many of which are obvious, attention is called to the unanimity of opinion among those most familiar with the disorders of infancy, that careful search rarely fails to find adequate constitutional cause for the occurrences and persistence of many skin lesions in which extraneous influences merely act as excitants.

Did the importance of disturbances of metabolism as a factor in skin disease need emphasis, it might be secured from the fact that the developing period, with its tremendous activity and double burden of metabolism, furnishes the largest proportion and greatest variety of skin disorders.

This prevalence has been variously accounted for on the ground that the infant skin is delicate and peculiarly susceptible to local irritation; that his helplessness increases the liability to trauma, and that immunity is not yet secured to certain infections which occur but once.

The first two reasons are but half truths, for the prompt repair of skin traumatisms in early life is proverbial, while the limitations to locomotion in infancy more than offset the helplessness in the infrequency of exposure to heat, cold, sun, wind, trauma, infection, and other extraneous causes to which disorders of the skin are due.

Although few, if any, skin lesions are confined exclusively to childhood, the pathology of the developing period is such as to give to certain skin diseases peculiarities characteristic of this age. Among these may be mentioned the skin lesions of congenital syphilis in the early months of life, ichthyosis (either congenital or as an early childhood affection), impetigo contagiosa, ringworm, scabies, and pediculosis common in the school age. The erythemas and the greater frequency of rashes from 
obscure infections, and urticaria from indigestion, with eczema in its protean forms, find their most favorable field in the integument of children in the first five years of life.

\section{ERYTHEMA SIMPLEX (REDNESS OF SKIN).}

From anatomical and physiological reasons hyperæmia is readily induced in the delicate skin of infancy and childhood. The varieties of erythema are almost as numerous as the causes which lead to the condition. Anything which induces unusual determination of blood to the superficial capillaries, may cause an erythema, while paresis of the arterioles or obstruction to the efferent circulation may be responsible for its persistence. The skin may be reddened from the local action of irritants, - as mustard, acrid secretions from plants, local traumatism, heat, reaction from cold, or retained secretions in the folds of the integument. Erythema is the most common accompaniment of fever, autointoxication, and derangements of the circulation, either from nervous or mechanical causes. The internal administration of certain drugsas belladonna, quinine, chloral, and diphtheria antitoxin-may give rise to general or local erythema. The vicinity of superficial wounds or ulcers may show extensive erythema and infiltration which is frequently mistaken for erysipelas.

The prognosis and treatment of symptomatic erythema are those of the determining conditions.

The erythema from local irritants-one of the best examples of which is seen in the intertrigo of neglected infants from long contact with soiled diapers-needs treatment, lest the process develop a true eezema, a common sequel. Cleanliness alone will often suffice, but obstinate cases, especially where digestive disturbances or acrid urinary and fecal discharges tend to keep up the irritation, require topical application. Diapers not thoroughly rinsed after being washed with strong soap or alkaline solutions, may cause scalding of the buttocks, although frequently changed and wet only with bland urine.

In addition to the correction of indigestion and acrid discharges, the reddened area should be dusted with a bland powder (Formula 28 or 29). Obstinate cases may require the protection of a soothing ointment like oxide of zine and vaseline or bismuth and castor oil.

\section{SEBORRHGA.}

Seborrhœa is due to an abnormal activity of the sebaceous glands, the discharged products of which collect upon the cutaneous surface in the form of an oily exudate (seborrhoea oleosa), or of dry friable crusts or scales (seborrhoea sicca). The disorder usually occurs in infancy as seborrhoea capitis. It appears on the vertex, especially over the anterior fontanelle, in thin, dry, dirty-yellowish scales ("milk crust"), which may adhere quite firmly to the scalp. It may cover the entire head and even involve the eyebrows. Gentle removal shows the scalp pale or slightly hyperæmic, but devoid of inflammation. Though patches of 
seborrhœa may appear upon the head of an apparently healthy infant, the abnormal activity of the sebaceous glands is usually associated with conditions of disordered nutrition, and may be seen in obstinate form on the scalp of the poorly nourished bottle-fed baby. In older children it appears in the form of dandruff, which collects in little heaped-up masses around the orifices of the sebaceous ducts and, if persistent, causes itching and loss of hair.

The prognosis of seborrhœa capitis is good, as it usually disappears after the nursing period, but it may recur with the various disturbances of the general nutrition. Misguided efforts at the removal of these scales by anxious mothers cause persistency of the seborrhœa and frequently result in traumatism and infection. If the crusting be thick or extensive, decomposition of the deeper layers may lead to true eczema capitis,-hence the need for early treatment in every case.

Aside from attention to general nutrition and hygiene the treatment is local and consists in the gentle removal of the scales and crusts. This may be accomplished only after prolonged maceration with oil. Warm olive or almond oil should be freely applied over the affected area twice daily, and the head covered with a cap of muslin or, preferably, rubber tissue.

Applications for several days may be necessary before the macerated crusts will yield to the gentle application of warm water and castile soap, and the process may require several repetitions. Since removal of the crusts does not diminish the seborrhœa, the head should be gently shampooed once a week with superfatty soap, with the application every two to four days of an ointment of sulphur and vaseline $(1: 50)$, or salicylic acid and vaseline $(1: 100)$. The use of the fine comb and strong alkaline soap should be avoided.

Seborrhœa in other parts of the body-such as the umbilicus, prepuce, and vulva-is sometimes troublesome, the excessive secretion undergoing decomposition with subsequent inflammation of the parts. The treatment is cleanliness, and the application of weak solutions of alum and tannin.

\section{ECZEMA.}

No definition of eczema may be given which will embrace all forms, as no one characteristic lesion is common to all. In the majority of eases there is an inflammation of the superficial layers of the skin accompanied by congestion, infiltration, exudation, transudation, and pruritus, with resultant papules, vesicles, pustules, and the formation of crusts, scabs, and ulcers. Several or all of these processes may appear concurrently or consecutively over a given area of the skin.

The disease is very common, representing in frequency one-third of all skin disorders. Of many thousands of tabulated cases of eczema, one-fourth were found in children under five years of age.

As to the cause of eczema the dermatologists are still divided, some holding that it is a specific parasitic disease; others regard it as a polymorphic inflammation of the skin due to some undefined condition of 
constitutional debility. Many speak of an eczematous dyscrasia of which the various skin lesions are but a few of the manifestations. Again, others question the entity of such a discase as eczema, claiming that its symptom complex is made up of many heterogeneous skin disorders caused by a variety of unrelated conditions.

The pediatric clinician will be slow to accept any theory which fails to give etiologic prominence to dyscrasia, autointoxication, and other constitutional conditions.

Among the exciting causes may be mentioned extremes of heat and cold, sudden changes of temperature, the drying effects of wind and sun, maceration from prolonged moist contact, excessive perspiration, accumulation of dirt and secretions, neglected seborrhor, the too strenuous efforts at cleanliness, strong soaps, rancid cosmetics, rough clothing, especially coarse woollens, animal parasites,-especially the pediculus capitis and any mechanical or chemical local irritant. It is elaimed that a careful study of any ease of eezema in childhood will bring to light some error in diet or disturbance of digestion.

Excess of fats, proteids, or carbohydrates, especially oatmeal and potatoes, is known to promote eczematous outbreaks, while a gouty history is very commonly associated with this disease.

Whatever be the primary exciting cause, the local lesions, especially if moist, soon become infected with pyogenic and other micro-organisms which add variety and chronicity to the morbid processes, with resultant destruction or hyperplasia of various tissue elements. That the pruritus and discomfort react upon nutrition is not only theoretically probable but clinically obvious, so that a vicious circle increases the obstinacy of the disease.

Common features are itching and burning. Excoriation from scratching is a prolific eause of its continuance. A number of adjectives are used to describe its protean forms, but elinically the disease may best be described as acute, subacute, and chronic.

The eczemas of childhood are usually of an acute inflammatory type with recurrences which may lead to chronicity, although self-limitation of the disease is the rule. The affection as seen in sucklings shows a tendency to recovery before the end of first dentition and early eczema rarely persists beyond the fifth year.

The favorite seat of infantile eczema is the scalp and face, where it appears in recurrent attacks in the form of eczema rubrum, so ealled from its red, raw appearance. This form, beginning as a circumseribed area of coalescing papules or vesicles, spreads by gradual radiation to adjacent surfaces. Later it shows areas denuded of epidermis, from which thin serum oozes and dries upon the surface like varnish, eausing intolerable pruritus. Adjacent vesicles may break down and become infected with pyogenic eocei and form crusts and seabs, beneath which the pus is confined, constituting the ulcerative variety.

A pre-existing seborrhœa eapitis affords beneath its thickened crusts good facilities for the development of papular, vesicular, and pustular 
forms. Enlargement of the lymph-nodes in the vicinity of persistent eczematous lesions is not uncommon.

While infiltration of the skin is a feature of the subacute and chronic forms, the large areas of leathery integument seen in adults is not common in childhood.

A more chronic type varies from groups of discrete or coalescent flat papules, to circumscribed, scaly, hyperæmic areas which may simulate nearly every known form of dry dermal lesions.

Diagnosis.-The recognition of eczema in children is usually not difficult. It is the cause which is frequently obscure. Its location upon the face and scalp is characteristic in infancy. If lesions occur at the nucha or on the occipital scalp, pediculi or their ova will usually be found. Papular lesions upon the buttocks and around the anus may resemble syphilides and specific mucous patches. However, syphilitic lesions do not itch, but show copper-colored areas and corroborative lesions in other parts, especially upon the palms and soles, with splenic enlargement, cachexia, and history of " snuffles."

Scabies with its multiform lesions rarely involves the scalp. It is first seen in areas of thin skin where its cuniculi may be demonstrated with a moderate magnifier, gives a history of infection, and yields promptly to treatment.

Prognosis.-The obstinacy of eczema is to be expected from the multiplicity and nature of its causes. Its early subjugation is dependent upon the recognition and removal of the cause. This means careful diagnosis, and faithful co-operation on the part of the mother or nurse, hence no general prognosis is possible. Unfortunately, the routine methods of treatment by favorite formulæ with indifferent adaptation to the requirements of the special case, has made of eczema an unjustifiable bugbear. The utterance of a well-known clinician - that "the practitioner is lucky who happens to be treating an eczema when it happens to get well" - -is the outgrowth of the general misconception of the requirements of diagnosis and treatment, and the lay tendency to hawk the case from clinic to clinic in search of a quick specific cure.

Treatment.-As before stated, careful scrutiny of eczema in a child will usually reveal some underlying cause or predisposition. It is true that the disease may have become chronic through neglect, although the primary cause has long since disappeared.

Obviously, then, gastro-intestinal disorders, if present, should receive careful attention according to requirements. So, too, any catarrhal process or organic disturbance should be carefully treated. It should be borne in mind that perversion of metabolism and morbid products of disassimilation are frequently unaccompanied by gross evidences of dyspepsia. The child may be apparently well nourished according to the standard of growth and weight, and the earliest evidences of autointoxication may be this very predisposition to inflammatory lesions of the skin.

It is common to attribute an eczematous intertrigo to the irritating 
discharges of bowels and kidneys as an exciting cause. It is less common to regard the condition of bowels and kidneys eliminating this acrid material as expressive of the predisposing cause. Renal insufficiency, as in the gouty diathesis, meaus integumentary insufficiency as an eliminating organ.

Eczema of the acute inflammatory or highly congestive type, common in infancy, needs eliminatives, such as small doses of ealomel, with moderately full doses of bicarbonate of soda. This treatment should be alternated with alkaline diuretics-acetate or citrate of potassiumwith a free supply of water.

In eczema, the skin, like any other diseased organ, should be given rest from excessive elimination by the above-described measures, and by reduction of the quantity of food ingested, especially the proteids and carbohydrates. In bottle-fed babies the casein should be diminislied. Older children should be given less meat, and oatmeal and potatoes may be profitably reduced or withheld for a time.

Hyperæmia and the perverted function of the skin may also be reduced in older children by putting them to bed. This also seeures relief from the irritation of clothing and affords a better opportunity for thorough topical treatment.

In the main, the purpose of local treatment is twofold,-(1) relief of irritation, (2) protection from infection. Incidentally it may be necessary to free the parts from desiecated, inflammatory débris, for which purpose olive oil, plain or carbolized (one per cent.) may be used, or a bran poultice, sterilized by thorough cooking, may be employed. The parts once cleansed, bland applications like oxide of zinc, either in the form of ointment with vaseline $(1: 8)$, or as a lotion with lime-water (1:5), may be made on aseptic lint or gauze.

Three sources of irritation must be constantly guarded against,air, water, and finger nails. The nails must not only be cut short, but the child's hands should be muffled or even confined by the outer garment, or a bandage, if necessary. This is a detail of special importance, as an unguarded moment may undo the work of days of therapy. The face and head should be protected by a mask of firm muslin in which holes are cut for the eyes, nose, mouth, and ears. This mask will serve also to retain the dressings over the affected surfaces, which should be changed as often as they become dry.

For the zinc ointment Lassar's paste may be substituted, thickly applied on muslin or linen as affording greater relief from the intolerable pruritus. It may be necessary to administer hypnotics temporarily to secure the needed rest,-as bromides, sulphonal, or trional. Chloral hydrate and opium are contraindieated.

Exuding surfaces are sometimes best protected by a varnish of gelatin and oxide of zine (Formula 32).

Impetiginous ulcers must be cleansed from pus and products of decomposition by irrigation with boric acid solution or peroxide of hydrogen. The application of nitrate of silver may prove valuable, as 
indolent lesions with chronic infiltration of tissues require gentle stimulation.

Applications of tar, Peruvian balsam, unguentum hydrargyri ammoniati, and sulphur are favorites with many, but the particular remedy is of less importance than that it should fulfil the indications by being mildly stimulating, astringent, antiseptic, and nonirritating.

The same principles of treatment apply to eczema in other portions of the body. The ingenuity of the attendant is often taxed to provide means of retention and prevent traumatisms and excoriations from scratching. Necessary cleansing ablutions may be made with nonirritating, superfatty, or tar soaps, or bran water.

MILIARIA.

Miliaria is an affection of the skin due to the obstruction of the ducts of the sudoriparous glands, from congestion of the cutaneous vessels and from exudation around the duct. It is closely associated with hyperæmia of the skin.

The lesions may be inflammatory or noninflammatory. To the former belongs the papular eruption known as prickly heat, lichen tropicus, strophulus, or red gum. In infancy and childhood this form may appear on any part of the body. It is invariably associated with exposure to high temperature or too heavy clothing. It frequently develops in infants during the first few days of life, and aside from heat is associated with rough clothing or irritating applications to the skin.

The commonest lesions are small, discrete, dark red papules upon an erythematous skin. These occasion great discomfort and insomnia from an intense prickling or burning. Some of the papules may quickly become vesicular or even pustular, while the scratching frequently produces traumatic lesions which may become infected.

The noninflammatory variety, miliaria crystallina (sudamina), appears as a profuse, discrete eruption of vesicles which glisten from the transparency of their contents. They resemble minute drops thickly studding a normal skin. Efforts to wipe these off reveal the fact that they are minute transparent vesicles upon a non-inflamed base. They do not rupture but disappear by absorption, leaving rarely a slight scaly desquamation. Occasionally the fluid contents becomes slightly opaque (miliaria alba), in which case the desquamation is more noticeable.

Both forms may accompany profuse perspiration from any cause, and are not uncommon in debilitated children, after the crises of acute fevers, and during convalescence from typhoid. These papules or vesicles last from one to four or five days, but, with continuation of the cause, successive erops appear.

The diagnosis from papular eczema is made by the sudden development and transient character of the rash, which is discrete and not attended by infiltration or oozing. From the persistent, flattened nonirritable syphilides, miliaria should be easily distinguished. Sudaminal 
vesicles differ from those of varicella in the smaller size, greater profusion, and absence of areolæ and constitutional symptoms.

A miliary rubra, complicated by an acute cold, may resemble a mild attack of measles. The progress and distribution of the eruption, and the presence of Koplik's spots, would decide the diagnosis. Rötheln occur in epidemics and usually give a history of exposure. Children should not be compelled to wear heavy woollens in hot weather, and when light flannels irritate, muslin or linen may be interposed. Frequent cool bathing, and free dusting of the affected surface with some drying powder (Formula 28 or 29), will relieve the irritation. Profuse sweating may be modified by applications of weak solutions of alum or of cupric sulphate $(1: 300)$.

URTICARIA-NETTLE RASH; HIVES.

Urticaria in infancy and childhood is so commonly associated with disorders of the digestive tract that it has come to be regarded as a symptom of indigestion. Even when apparently induced by external influences - such as sudden change in temperature, removal of clothing in a cold room, or scratching, induced by bites of insects-the unusual appearance of wheals and raised blotches calls attention to the state of the child's digestion. There is usually found a furred tongue, bad breath, some elevation of temperature, flatus, and later foul stools, with a frequent history of palpable errors in diet.

An undoubted predisposition to skin symptoms of indigestion exists in certain children, usually those of neurotic or gouty parentage. Every boy of the older days, when the rod ruled in school and "lap jacket" was a common pastime on the playground, recalls the diathesis for wheals and welts from slight irritation of the skin in some children and its total absence in others.

The list of dietary articles reported to have caused urticaria is a long one. The most familiar are fish, oysters, lobsters, crabs, strawberries, buckwheat-cakes, pastry, mushrooms, pork, cucumbers, and even eggs and milk in susceptible individuals. The ingestion of certain drugs - such as quinine, chloral, hyoscyamus, copaiba, and valerian, also the use of antitoxin-are known to give rise to urticarial wheals. Urticaria is also regarded as one of the symptoms of worms.

In infancy and childhood, although urticaria may consist only of an outbreak of evanescent wheals which disappear in from a few minutes to a few hours, it not infrequently produces a more permanent type of lesion,-as papules, vesicles, and even small bullæ. Pustulation oceasionally follows, and scratching and infection may result in ulceration.

A curious relationship is occasionally observed between urticaria and respiratory disturbances, as attacks of cough and dyspnoea, asthmatic in character, occasionally accompanying or alternating with the lesions of the skin. Wheals are also seen upon the nasal, oral, and faucial mucosa, and swelling of the epiglottis may sometimes endanger life from obstructed respiration. The respiratory and gastric disturbances are sug- 
gestive of an urticarial enanthema from which no mucous tract may be exempt. Vomiting, hæmatemesis, diarrhœa, and hæmaturia, in addition to the above-mentioned symptoms, have all been reported in corroboration of this theory.

As wheals are the common sign of urticaria, so pruritus, tantalizing and insatiable, is the common symptom. Seratching not only fails to give relief but may induce the outbreak of wheals upon the susceptible skin (urticaria factitia).

Prognosis.-The disorder is not dangerous to life save in the respiratory obstruction above mentioned. In prolonged and frequent recurrent attacks (chronic form) the loss of sleep and systemic disturbance may affect the general health. In children the attack is usually acute and generally yields to treatment very promptly.

Treatment.-Removal of some of the causes may be effected by emptying the stomach and bowels and promoting elimination from the blood 'of imperfectly oxidized products of digestion. Castor oil, ealomel, or saline cathartics are indicated and prompt emesis may be advisable if unusual food has been recently ingested. Sodium or potassium bicarbonate, in full and repeated doses, are generally useful. Avoidance of anusual articles of food, especially those known to cause an eruption in susceptible children, is but a dictate of common sense.

For the pruritus, alkaline lotions are useful,-such as sodium or potassium bicarbonate, sodium biborate, and dilute aqua ammonia. Dilute alcohol, spirits of Cologne, Florida water, domestic vinegar, dilute acetic or nitric acid, or a solution of menthol in water $(1: 200)$, have all been found effective. Carbolic acid in glycerin and water (one or two per cent. strength) or a few drops of chloroform or ether in dilute alcohol, are also used with benefit. The skin must not be rubbed. The medicaments must be applied by daubing with a pledget of cotton or, better, by atomization.

Vesicular, pustular, and ulcerative lesions should be treated like similar lesions of eczema or impetigo, either of which disorders may be complicated by urticaria.

\section{IMPETIGO CONTAGIOSA.}

Impetigo contagiosa is a disease of the skin characterized by discrete, vesiculo-pustular lesions which quickly form crusts. As the name implies, it is contagious. Although most frequently seen in children it may affect adult members of the family. While undoubtedly contagious, no specific organism has been isolated which fulfils all the etiologic requirements. Strepto- and staphylococci have been found, conjointly and separately, in both ruptured and unruptured vesicles.

The favorite seat of the lesion is the lower face, whence it may extend by autoinoculation by scratching to the more accessible parts of the head, trunk, and limbs. Hence, it is rarely found upon the back. A form of stomatitis has been described in connection with this affection too frequently for mere coincidence. 
Lesions of the conjunctiva and vulvar mueosa also have been reported as co-existent with impetigo and were probably of common origin.

The early lesion appears as a small, flat, flaceid vesicle, the centre of which is depressed as the periphery extends and becomes pustular. Undisturbed, it may attain the size of a split pea or even a dime, occasionally showing a transient areola. The contents exude, forming a yellowish crust which stands out sharply upon the surrounding healthy skin and falls off at the end of a week or two, leaving only a slightly reddened area which soon assumes a normal tint. Where a number of lesions are closely situated the crusts coalesce and form irregular patches, especially over the chin and around the angles of the mouth. The pruritus, although not intense, is sufficient to cause scratching, whereby the characteristic lesions are distorted, the crusts darkened with blood, and occasionally deep ulcers induced. Meanwhile, fresh lesions are established by autoinoculation, so that the patient often presents a variety of lesions in all the different stages of development. Enlargement of the lymph nodes which drain the areas involved is common, as in other purulent infections of the skin. The frequency of the disease in the dispensary class of patients may be accounted for partly by the crowded condition of their homes, which favors contagion, and partly from lack of cleanliness, which promotes extension of the lesions.

Impetigo contagiosa may complicate any other disease, hence it is not infrequently associated with eczema, pediculosis, scabies, and occasionally with syphilis.

The diagnosis is made from the history, other members of the family or associates showing similar lesions. There is rarely the intense itching of eczema, the extension is by inoculation, and not by contiguity as in the latter disease, and the erusts, even when picked off, leave an entire, healthy skin instead of the moist, inflamed surface of eczema. The early vesicles of varicella are full and tense and are usually accompanied by some fever and malaise, and dry down quickly into thin flat scabs.

Treatment.-The characteristic lesions being self-limiting, ordinary cleanliness and abstinence from scratching should bring the disorder to a termination in a week or ten days. The customary treatment, in addition to bathing and change of clothing, consists in antiseptic, soothing applieations, such as boric acid and lanolin $(1: 10)$, after removal of the crusts with eastile coap and hot water. Extensive lesions are well treated by daily applications of citrine ointment or one composed of hydrargyrum ammoniatum and unguentum zinci oxidi $(1: 40)$.

\section{HERPES.}

Herpes is a name applied to an eruption of vesicles surrounded by a narrow area of inflammation, usually occurring in clusters. From the location the disorder is called herpes labialis, herpes facialis, herpes frontalis, herpes zoster, zona, or shingles. Discrete or grouped herpetic. vesicles may occur on any portion of the skin or mucous membrane and 
frequently show irregular linear distribution along the course of a nerve trunk.

Zoster is a term used to distinguish herpetic lesions which follow the course of a large nerve, and are presumably due to a peripheral or spinal neuritis. The true etiology, however, is still in doubt. It is an interesting fact that it rarely oceurs a second time in the same individual. It is usually preceded and accompanied by stinging and burning pains over the affected area, also by some fever and malaise. In childhood, however, the neuralgia is infrequent and rarely severe after the eruption has appeared. The appearance of zoster is that of an irregular succession of groups of vesicles, which upon the trunk are unilateral and extend from the spinal region along the course of a rib. The vesicles, at first clear and more or less discrete, tend to coalesce while their contents become at first milky and later purulent. If undisturbed they soon form scabs which, falling off, leave the skin slightly reddened without permanent cicatrices. The process is usually complete in from four to seven days.

Herpes facialis, the favorite site of which is upon the lips or about the angles of the mouth, is a common accompaniment of acute febrile conditions, especially those in which the pulmonary tract is involved. It is rarely absent in cerebrospinal meningitis and may accompany the high temperature of malaria and pyæmia. Exposure to a raw wind, or even wetting the feet, may give rise to the ordinary "cold sore."

The lesions of herpes simplex are attended by only a slight degree of pain. They change quickly from vesicles to pustules, forming scabs which, from their location, are subject to maceration by saliva. They may crack deeply and bleed, producing in some instances obstinate sores. Usually, however, the crusts fall off and the skin returns to normal in a week.

The treatment of all forms of herpes consists in allaying irritation and preventing rupture of the vesicles. For zoster, thick compresses wet with alcoholic solution of camphor and menthol (two per cent. of each), bound tightly abont the chest, fulfil the indications. For pain or restlessness Dover's powder or codeine may be necessary. "Cold sores" on the face may be treated at their inception by the frequent application of spirits of camphor. Deep fissuration of the crusts may be obviated by unguentum aquæ rosæ or unguentum zinci oxidi.

\section{TINEA TRICHOPHYTINA-RINGWORM.}

Ringworm is a parasitic disease due to the trichophyton fungus and other varieties of fungi which attack the skin, hair, and nails. According to its location it is known as (1) tinia corporis or circinata ; (2) tinea eapitis or tonsurans, and (3) tinea unguium or onychomycosis.

The micro-organism may be transferred from one individual to another by personal contact, so that barber's-itch in the father may be responsible for tinea circinata and tonsurans in mother or child. A number of domestic animals are known to be subject to infection by this 
fungus, so that these sources must be reckoned with in the seareh for origin in a given case. Epidemies of this disease oecur in schools and institutions where many children are brought into close contact.

The first is not uncommon among school ebildren and the last mentioned, which is of rarer occurrence, may be seen throughout advanced life. Tinea capitis is essentially a children's disease and rarely, if ever, attacks the scalp after puberty.

Tinea circinata, or ringworm of the body, usually begins as a slightly raised circular spot presenting a red furfuraeeous surface upon the faee, neck, dorsum of hands and other nonhairy portions of the body. From one-eighth of an inch it may slowly extend its periphery to one or two inches. During this process the eentral portion resumes the appearance of normal skin while the periphery presents a ring of reddened papules and vesicles undergoing fine, scaly desquamation. The peripheries of two or more rings may approach and intersect each other so that the interrupted margins form serpentine curves like a figure eight, trefoil, etc.

Usually after a few weeks, portions of the raised margin subside and gradually the affected skin regains its normal condition, while the development of new lesions proceeds in other localities. A chronic form is occasionally encountered in which the lesions, after nearly complete disappearance, tend to recur in the winter, the process being repeated with change of season for a number of years.

In the rare affection of the nails, tinea unguium, the fungus inserts itself between the horny layers and penetrates the nail bed, so that growth is irregularly arrested with resulting distortion and deformity. Areas of crumbling hypertrophy alternate with healthy nail tissue. This form may be primary, but is usually secondary to lesions elsewhere on the body.

Ringworm of the scalp involves not only the epidermis, but also the hair follicles, the sheath, and the capillary cylinders themselves. The involved areas, like the disease in non-hairy portions, are circular and increase gradually by extension at the periphery, but show different features because of the penetration of the fungus through the underlying hair follicles to the deeper layer of the skin.

Attention is first ealled to this disease by a circumseribed bald spot which upon close examination shows an elevation covered with fine, whitish, powdery scales. These, when removed, leave the surface of the scalp slightly red or bluish-gray in color, according to the complexion of the patient. The surface bristles with irregular stubs of broken-off hairs, while the hairs around the periphery are dry and lustreless. The bald patch gradually extends in all directions and others may appear in close proximity which, coalescing, produce serpentine tracts.

In both this form and tinea corporis there may be more or less itching, occasionally scratching, and the development of a secondary eczema.

The disease is very obstinate to treatment, tends to chronicity, but 
rarely extends beyond puberty. When cured, the hairs resume their normal growth, although occasionally a bald spot is left.

The diagnosis, aside from the characteristies above mentioned, is made by the mieroscopic demonstration of the fungus upon the hair root plucked from the affected area.

Children suffering from tinea should be kept from contact with others. Health- and school-boards should forbid their attendance at schools and social gatherings. A close-fitting cap should be worn constantly to prevent dissemination of the infection. A large number of parasiticides have been employed in the treatment of this disease. Their efficacy depends more upon the method of employment than upon the character of the medicament. Green soap alone will destroy the fungus, and as the scales must be removed to secure access to the follicles, vigorous shampooing with sapo viridis should precede all other treatment. The hair immediately surrounding should be closely cut. After drying from the shampoo, one of the following medicaments should be thoroughly rubbed into the affected area: an ointment of the oleate of mereury (five to ten per cent.); equal parts of sulphur ointment and lard; boroglyceride (fifty per cent.); bichloride of mercury (1:500), or tincture of iodine. With the exception of the last-named, these applications should be repeated two or three times a day, as the spores mature in from six to eight hours. Trichophytosis capitis is the most refractory of the parasitic skin diseases, and occasionally yields only after several months of conscientious treatment.

A few applications of any of the above-mentioned agents is usually sufficient to effect a cure in tinea circinata. The rare affection of the nails is extremely obstinate. The treatment requires removal of as much of the horny layers as possible with the knife, after softening with potash solution. This is followed by the application of the ointment of oleate of mercury (ten to twenty per cent.) or bichloride of mercury solution $(1: 500)$.

FAVUS-TINEA FAVOSA; CRUSTED RINGWORM; HONEYCOMBED RINGWORM.

Favus is a parasitic disease caused by the fungus achorion Schönleinii. Like trichophytosis, this disease is highly contagious and may be contracted from infected persons or domestic animals, either by personal contact or by dissemination through the air. While no age or station is exempt, it is more frequent in the neglected children of the poor, and is quite common among the immigrants from eastern and southern Europe. Its favorite location is upon the scalp, but it is occasionally found upon other parts of the body. As in ringworm, the hair follicles and even the hairs themselves are invaded by the fungus, causing loss of lustre and final atrophy of the hair bulb with permanent. alopecia.

Its appearance upon the scalp is in circumscribed yellowish crusts showing cup-like depressions (scutula). These areas extend and the scutula thicken until, in neglected cases, the entire scalp is covered with 
massive yellowish crusts which present the characteristic cup-like depressions and emit a peculiar musty odor. The crusts, when removed, leave a depressed, slightly reddened, or pale and atrophied surface devoit of hair.

Unlike trichophytosis there is no tendency to spontaneous recovery, neglected cases continuing throughout life.

Poorly-fed children show a predisposition both to the development of the disease and its persistency under treatment. The disease may be complicated by eczema capitis, rendering microscopic examination of the plucked hairs necessary for a diagnosis.

Treatment.-The destruction of the fungus necessitates the removal of the crusts and the plucking of the hairs from the follicles. The first may be accomplished by the application of warm oil for a few days, after which they may be removed by a blunt curette or spatula. The tedious process of epilation must be conscientiously performed, although several sittings may be necessary. The process should include the entire affected area and a liberal margin, as the diseased follicles extend beyond the visible boundary. Vigorous shampooing with green soap and a brush may be practised daily. The application of parasiticides is similar to that recommended in tinea capitis.

\section{SCABIES-ITCH.}

This disease in infants differs from that seen in the adult in so far as the greater delicacy of the skin encourages its wider distribution, and the uncontrollable scratching adds traumatic lesions to those made by the itch mite.

The female acarus, burrowing in the tenderest portion of the skin to deposit her eggs, causes minute papular vesicles and pustules, first upon the wrists, between the fingers, and in the flexures of the body and limbs. The face is never affected except in young infants. In neglected cases the skin over all parts of the body, even the soles and palms, may be the seat of lesions. The cuniculi may be obscured by the profuse eruption of vesicles, or pustules may form beneath the denser portions of the skin, and scratching change the character of the primary lesions.

The diagnosis is usually not difficult. Itching lesions on the wrists and hands of a child are suggestive of scabies, and inquiry will usually reveal the disease in other members of the household.

Linear excoriations upon portions of the body accessible to the child's hands are usually in evidence, while examination with a lens will show the burrows like dark lines from one to six millimetres in length beneath the epithelium.

It should be remembered that scabies may complicate eczema, impetigo, urticaria, and other skin affections of totally different nature, and that the primary lesions may become infected with different varieties of pus germs.

Treatment.-The cure of scabies, though seemingly simple, requires attention to details, which may include the treatment of other members 
of the household. Bedding and clothing used by the child must be disinfected by fumigation or heat (steaming, baking, or boiling).

After a thorough scrubbing with green soap and hot water, a parasiticide should be applied to the affected skin and the child put into a clean bed.

For older children nothing is better than the official sulphur ointment. For younger children this should be modified by adding an equal quantity of Peruvian balsam and six parts of vaseline, while the delicate skin of the young infant may be treated with balsam of Peru one part, to two of glycerin. These applications should be repeated for three or four successive nights, after which a thorough cleansing bath and clean clothes will complete the cure.

\section{PEDICULOSIS.}

The pediculus capitis is not an infrequent guest on the heads of school children and oceasionally of younger children in neglected families. Sores on the posterior portion of the scalp or enlargement of the postcervical lymph nodes should lead to a careful examination for lice. Nits (ova) clinging to the hairs are sometimes the only evidence of the parasite. The pediculus pubis, which occasionally infests the eyebrows and the finer hair of the nucha, is so small as to escape detection without the aid of a glass. This louse may be seen as a minute dark red speck lying quietly close to the skin, from which it may be lifted with the point of a needle, whereupon it shows remarkable activity.

The itching due to louse bites may induce scratching, which causes excoriations of the scalp. These, becoming infected, may occasion ulcers and crusts, or this parasite may add to the torture of eczema capitis. Lousy heads are so common among applicants for admission to hospitals and dispensaries that a routine treatment is adopted. It is rarely necessary to cut the hair, but it should be thoroughly shampooed with soap containing sulphur, tar, or resinol. After rinsing and drying, unguentum hydrargyri may be lightly applied to the roots of the hair with the tip of the finger. The treatment may be repeated twice, with intervals of two or three days. Equally effective is washing the head with vinegar or spirits of camphor after a thorough shampoo with green soap.

The pubic louse retires after one or two applications of a one per cent. solution of carbolic acid.

\section{FURUNCULOSIS.}

Boils may occur in children of all ages as well as in adults. A peculiar form is seen in infancy in which the lesions are multiple. These may occur on any part of the body, but are most frequently situated on the face, neck, and scalp. They may vary in size from a grain of wheat to a walnut; are dull red or purple, soft and indolent, occurring in crops; are less painful than the sporadic furuncle, rarely contain a core, and when incised discharge a dark, bloody purulent matter. Furunculosis is most frequently seen in poorly nourished infants and 
those recovering from a prolonged illness. The lesions are often indolent and may occur as a sequel to other acute disorders of the skin. They may result in abscesses and occasionally in gangrenous processes.

The treatment should be hygienic, including properly balanced food, with the administration of cod-liver oil and compound syrup of hypophosphites. The skin should be kept clean and frequently moistened with solutions of boric acid. Incipient boils may occasionally be aborted by tincture of iodine, strong spirits of camphor, or one per cent. solution of carbolic acid. As soon as pointing occurs the contents should be evacuated by an incision, the eavity cleansed with bichloricle of mercury $(1: 2000)$, and a firm compress, wet with boric acid, applied to prevent refilling. The use of calcium sulphate and alkalies in furunculosis has long been advocated.

\section{PSORIASIS.}

Psoriasis in childhood presents some peculiarities, among which are its milder character, its usually discrete form, and greater tractability to treatment. It is often hereditary, being present in two or more generations. Although rare before the sixth, it has been seen during the first year of life.

Psoriasis should be differentiated from eczema by the greater profusion of scales, absence of infiltration of the skin, less pruritus, and its symmetrical location upon the flexor surfaces. Seborrhœa differs from psoriasis of the scalp by the presence of crusts that are greasy and friable to touch. Removal of the crusts of seborrhœa leaves a pallid surface rather than the easily bleeding one of psoriasis.

In syphilis some lesions may be found upon the palms and soles; psoriasis never attacks the hands and feet. Syphilitic scales are of a dirty color and do not extend to the margin of the inflamed patch, while psoriasis shows abundant pearly scales that crowd over upon the healthy skin. The coppery hue of syphilitic lesions, the presence of mucous patches, and the ready yielding to specific treatment, will help to exclude psoriasis in doubtful cases.

Ichthyosis is usually a disease of early infancy, is unattended by evidences of inflammation, and shows a rough, dry skin; while psoriasis is rarely seen before the sixth year, and presents healthy skin between its patches of silvery scales.

Treatment.-Arsenic has proved the most valuable internal remedy and should be continued for some months. Thyroid extract has been administered with apparent success in some cases. Locally, ichthyol ointment (five to ten per cent.) may be used after removal of the scales by vigorous shampooing with green soap. Chrysarobin in vaseline or collodion (two to five per cent.) every third or fourth day, is probably the most efficient remedy. In the employment of this drug the danger of irritation of the eyes and adjoining normal skin must be kept in mind. The daily use of hot water and soap is a necessary adjunct to any treatment of psoriasis. The obstinacy of the disease and its well-known tendency 
to remissions and recurrences are prominent among the surprising and perplexing features of dermal therapy.

ICHTHYOSIS.

Ichthyosis is generally regarded as a congenital deformity rather than a disease. The paucity of normal secretions leaves the skin dry, with apparent hypertrophy of the horny layer. It is usually congenital and probably always hereditary. Even cases which develop in later childhood show a family tendency. Occasionally a generation is exempt from the disease, which reappears in their progeny. Further than this family tendency, the cause is unknown.

Different degrees of this dermal defect are described which has resulted in no little confusion as to the pathology and prognosis of ichthyosis. Ignoring the refinements of clinical differentiation, it is safe to assume that ichthyosis developing at any period of childhood is congenital, and that any persistent, dry, parchment-like, noninflammatory condition of the skin which spares the flexor surfaces, is ichthyosis. Milder degrees may show only a roughening of the skin (xeroderma), principally on the arms and thighs. In severe types the epidermal layer of any portion of the body is cracked into irregular, polygonal shapes, or scutula, whose loosened, upturned edges suggest fish-scales,-hence the name. This scaly skin presents a dirty-gray and sometimes pigmented appearance, with intervening fissures of red skin or raw surfaces denuded of epithelium.

In young infants the general appearance suggests that the fœtus in utero was hidebound and its subsequent growth burst the inelastic epidermis by underlying muscle contractions. When occurring in the newly born, other congenital defects-as malformations of the ears, nose, mouth, palpebral fissures and fingers-are often associated. In severe cases the infants rarely survive more than a few hours or days. The disease as it occurs in the second or third year of life (ichthyosis vulgaris) shows variations in severity which correspond with the general health and changes of season (always worse in the winter), also with complicating dermal lesions, - as eczema or dermatitis.

The course is essentially chronic and incurable, though the condition may be ameliorated by treatment and attention to hygiene. Ichthyosis has been known to disappear after an attack of one of the exanthemata, to reappear at a later period.

The diagnosis of a well-marked case of ichthyosis is unmistakable. In questionable cases the fact that this disease spares the flexor surfaces and presents no subjective symptoms may be of differential value.

Treatment.-In young infants a continuous warm bath of five or six days' duration has proved beneficial in some hands. In general the treatment requires warm baths and thorough scrubbing with green soap two or three times a week to loosen the epithelium. This should be followed by the application of glycerole of starch. In addition, in severe cases, 
the scaly surfaces may be anointed with a small quantity of pure glyeerin, the hygroseopic property of which absorbs moisture from the air and prevents desiceation. Daily inunctions with cod-liver oil, eacao-butter, lanolin, or the mixed fats may be used. Stimulation of the sudoriparous glands by Turkish or vapor baths is highly recommended, and the administration of jaborandi has been advocated, although in infants such measures should be applied with extreme caution. From the fact that the thyroid gland has been found defective in some ichthyotic children, thyroid treatment seems rational and worthy of trial. The internal use of cod-liver oil and arsenic has seemed beneficial in many cases. It shonld be remembered that ichthyosis usually improves in the summer months and is aggravated by cold, from which fact residence in a semi-tropical climate is the easiest mode of treatment for these children.

Moderate degrees of ichthyosis, while not dangerous to life, may so interfere with the normal function of the skin as to render the patient extremely susceptible to metabolic perversions and infectious disorders, constituting a general feebleness of resistance.

SCLERODERMA-DERMATOSCLEROSIS; CUTIS TENSA CHRONICA.

While usually a disease of adult life, scleroderma is occasionally met with in children. This disease should not be confounded with sclerema neonatorum. The etiology is obscure, although it has been known to develop after prolonged exposure of a portion of the body to cold.

The disease develops slowly, the lesions appearing somewhat symmetrically, in which there are local swelling and induration, with either waxy pallor or dirty-gray mottled redness. The affected areas have a hard, tallow- or corpse-like feel, but seldom pit under pressure. Later, atrophy occurs, after which the skin is tightly drawn (skin-bound), and is adherent to the subjacent muscles or bony prominences.

The sclerosis may occur in strips or bands which constrict the underlying tissues and may limit motion. If on the face the expression is wooden (sclerodermic mask). If on the hands, the fingers may be partly flexed, rigid, and the hands atrophied and elaw-like.

Both local and general temperature may be subnormal. There is connective-tissue hypertrophy and lymph stasis, with enlargement of the lymph spaces.

The disease is rarely fatal, although chronic and refractory to treatment. Spontaneous improvement and even recovery occasionally occur.

Treatment.-Internal medication is of little avail. Good nutrition must be secured. Local treatment-as oily inunction with vigorous massage, hot baths, and salt rubbings-gives the best results and is sometimes followed by marked improvement, especially if employed prior to extreme atrophy. When the hands and fingers are the seat of the disease, burying them for an hour at a time in a box of hot sand improves their mobility. Galvanism also stimulates local circulation. 
XERODERMA PIGMENTOSUM-MELANOSIS LENTICULARIS PROGRESSIVA; KAPOSI'S DISEASE; ANGIOMA PIGMENTOSUAI ET ATROPHICUM.

Xeroderma pigmentosum is a rare disease, beginning in infancy occasionally as early as the third month. The cause of the disease is unknown, but it presents a distinct familial type.

It usually appears first on the face, hands, or other exposed surfaces in pigmented spots like ordinary freckles. The intervening spaces soon show depressions which resemble the cicatrices of smallpox. Small areas of hyperæmia, telangiectasis, and soft warty growths develop later until all portions of the skin not protected by clothing present these multiform lesions. Later, atrophy and ulceration of the new growths occur, with cicatricial deformities of the mouth, nose, and eyes (ectropion). Masses, resembling keloid and lupus-like ulcers, appear on different parts of the surface in increasing numbers as the disease progresses. The blood shows no constant changes.

The course of xeroderma pigmentosum is chronic, and may extend to twenty years, with an invariably fatal termination. The neoplasms in a large proportion of the cases sooner or later become malignant.

No therapy is as yet known to be beneficial. As this disease affects the portions of the body exposed to light, treatment by exclusion of certain rays has been suggested. In a few cases exposure to light passed through red and green glass has been tried with practically negative results.

\section{VERRUCA-WARTS.}

Warts, although occurring at any age, are very common in childhood and may be congenital. Many varieties are described in terms suggested by difference in form,--sessile, acuminate, digitate, filiform, etc. They consist of papillary excrescences which arise from a connective tissue base, are supplied with a vascular loop, and are covered with a more or less hypertrophied epidermis.

The greatest interest centres around the etiology, which is little understood, although there is a revival of the older belief in their contagious and autoinfectious character. That they are sometimes of trophoneurotic origin is suggested by their sudden development and as sudden disappearance under sympathetic influences.

Warts are never painful unless injured, and are of little importance except as a curiosity, since the warts of childhood rarely persist beyond that period. Their unsightliness and occasional inconvenience stimulate efforts at removal. This may be accomplished by the firm application of a compress saturated with salicylic acid solution, or by painting for three or four successive nights with salicylic acid and flexible collodion $(1: 10)$. After this the horny hypertrophy may be rasped down. Filiform and pedunculated warts may be clipped off with scissors and the base touched with tincture of iodine or solid nitrate of silver. Warty children often show other evidences of malnutrition, in which case the hygiene should receive attention. Iron should be exhibited for anæmia, 
while arsenic in moderate doses seems to have a specific effect in some cases. It is claimed that the persistent administration of magnesium sulphate in small doses will arrest the development of verruca.

\section{GEDEMATA.}

Many varieties of œdema occur during infancy and childhood. Various causes operate to produce this condition, such as obstruction to the lymphatic or venous circulation, also dilatation of the capillaries, or atony of the arterioles. Thus the odema of cardiac insufficiency, with or without valvular lesions; renal insufficiency, with or without albuminuria and casts; enlargement of liver, spleen, mediastinal, cervical, axillary, inguinal, and mesenteric lymph-nodes, are familiar pictures. So also is the anasarca of the extremities common to extreme marasmus and anæmia. Edema may be due to toxins, whether locally applied, as the sting of insects, or cireulating in the blood, as in uræmia.

It is safe to assume that all odemata are secondary. Since in some instances the primary cause is indeterminate such terms as idiopathic, neurotic, essential, and angioneurotic have been employed. Some children develop swelling of the face, hands, feet, or other areas, in a few hours, which may as quickly subside, and for which no known disturbance of heart, kidneys, or blood may be held responsible. This tendency in some instances amounts to a diathesis and appears to be hereditary. Occasionally it occurs from reflex irritation of the genitals, mouth, or gastro-enteric tract, and at times seems closely allied to urticaria. The term gigantic urticaria is still employed by some writers for angioneurotic œdema.

It is rarely dangerous, save when the epiglottis, larynx, or Jungs are involved, and usually subsides as quickly as it appears, but shows a tendeney to recur. Unlike the wheals of urticaria, areas of neurotic œdema do not itch, and no discomfort usually attends their appearance, except a feeling of tension and stiffness due to the swelling.

The treatment should be addressed to any known local irritation. Eliminations should be promoted by saline laxatives and alkaline diuretics, and nutrition maintained by bland, easily digested food. 


\section{CHAP'TER XVII}

\section{GENERAL DISEASES}

\section{DIABETES MELIJTUS}

Most authorities agree in the statement that diabetes mellitus is rarely found in the extremes of life, but give no comparative figures.

The fact that analysis of urine is now recognized by the majority of the profession as an essential procedure in the examination of adults may help to explain the recent increase in the total number of diabetic patients reported. If this be true it may not be unreasonable to urge that the well-known neglect to examine the urine of little patients may partially account for the seeming rarity of this disorder in young children.

Since vital statisties furnish the only information on this subject, the following deductions from Stern's comments on the official records of New York City, also from figures obtained through the courtesy of Assistant Commissioner Reilly, of the Chicago Health Department, are presented:

NEW YORK FOR TEN YEARS.

\begin{tabular}{|c|c|c|}
\hline Age. & $\begin{array}{l}\text { Number of deaths } \\
\text { from diabetes. }\end{array}$ & Percentage. \\
\hline All ages ..... & .... 1867. & 100.00 \\
\hline Under 10 years & $\ldots \quad 24$ & 1.24 \\
\hline Under 1 year. & $\ldots$ & 0.21 \\
\hline
\end{tabular}

CHICAGO FOR FOUR YEARS.

\begin{tabular}{|c|c|c|}
\hline All ages .... & 418 & 100.00 \\
\hline Under 10 years & 15 & 3.5 \\
\hline Under 1 year & 3 & 0.7 \\
\hline
\end{tabular}

In Chicago, during this period, the deaths from diabetes are 0.44 per cent. of deaths from all canses. Deaths under ten years of age from diabetes were 0.04 per cent. of deaths from all causes.

That heredity plays a rôle in the predisposition to diabetes mellitus there seems to be little doubt, since its history, or that of allied conditions-such as gout, tuberculosis, and other diathetic disorders-in the immediate ancestry, occurs too frequently to be passed by as a mere coincidence. Different observers have noted the presence of heredity in from ten to thirty per cent. of their cases. It is claimed that diabetes may be congenital. It has been found not only in the infant of three months, but in the saccharin-hydramnion surrounding the dead fœtus of a diabetic mother.

Diabetes associated with congenital syphilis has yielded to antisyphilitic treatment, and glycosuria in cretins has cleared up under thyroid treatment. 
Some are inclined to attribute to the infectious diseases of thildhood a causal relation to diabetes mellitus, although it is not improbable that the closer attention indneed by the acute disorder has oceasionally led to the diseovery of a pre-existing glycosuria. It is well known that attacks of some of the acute infections are frequently aceompanied by a disappearance of sugar from the urine of diabetics. The same phenomenon has been observed during an attack of jaundice in a child.

In some instanees diabetes has been known to follow tranmatismsespecially blows on the head-psyehic shocks, fatigue, or exposure to debilitating influences. Any one of these exciting eauses may act to produce transient glyeosuria, and the patient, reeovering from the disturbance, may subsequently, even after a period of years, develop a serious diabetes.

It has been found by injections of sterilized sugar solution into the cireulation, that the glyeogen storage eapacity of the tissues is relatively high in infants. From this it might be inferred that transient glyeosuria, at least as far as it is dependent on overingestion of carbohydrates, would be of less frequent oceurrence in infants than in adults.

Since the obese type of diabetes is practically unknown in early ehildhood, an advanced case presents a picture of extreme emaciation, muscular weakness, dry skin and hair, brittle nails, extreme irritability, and sensitiveness to cold. The special symptoms-polyphagia, polydipsia, and polyuria-are always present.

Furunculosis and other skin lesions appear less frequently in childhood than in adult life. The rarity of a complicating albuminuria has been attributed to the integrity of the kidneys and the great suppleness of the vascular system in early life.

Any of the nervous and ocular symptoms frequently assoeiated with adult diabetes-such as symmetrical neuralgia, neuritis, motor, sensory, trophic, or psychie disturbanees, also amblyopia, cataract, iritis, or retinitis-may be present in children.

Children who exhibit symptoms of trophie disturbanees, or obseure neuroses, and a family history of diabetes, should be given full diet of mixed carbohydrates and its effeet watched for the production of glyeosuria.

The disease in childhood is essentially acute. Cases that survive more than a few months are rare.

Treatment.-So long as the etiology, and even the pathology, is involved in the obscurity which obtains at present, no routine treatment applicable to even the majority of cases may be formulated. Of the manydrugs that have found advocates-such as bromides, antipyrin, sodium salicylate, etc.-few, if any, have been approved by more than a very limited number of elinicians. With perhaps the exception of opium, which seems to retard the progress of the disease, and alkalies to counteract the acidosis and impending coma, the benefits of drug therapy are admittedly restricted to rare, exeeptional eases. Against the high rate of mortality from this disorder in childhood, the limited utility of opium 
affords but little encouragement. The prolongation of a life, with the establishment of the opium habit at its threshold, is not sufficient compensation.

The severe form is the one most frequently seen in early childhood, and the rapid course of the disease is rarely influenced by therapy. The death certificate follows hard upon the diagnosis. These facts enhance the value of prophylaxis.

It is now believed that diabetes, if not an hereditary disease, at least develops along the lines of a somewhat positive diathesis. To the extent that the function of the family physician is supervisory over his patients may he hope to avert such disorders by controlling their development through attention to hygiene. The young, whose immediate or remote ancestry shows diabetes, gout, tubereulosis, neuroses, or syphilis, should be sedulously guarded. Dietary errors-such as the ingestion of food beyond the child's capacity for absorption and assimilation, or the preponderance of saccharine substances, as sweetmeats, confections, and pastries-must be carefully avoided.

That the elimination in these little patients is of the utmost importance receives additional significance from many observations which emphasize autoinfection and reinfection as etiologic factors. It is of interest in this connection to mention that injection of frees as well as the urine of diabetic patients in lower animals will reproduce glycosuria. A thorough care of the digestive tract, including the teeth, is allimportant. So, too, is the care of the skin and respiratory organs that elimination by the former and oxygenation through the latter may attain the highest possible perfection. Adenoids should receive attention, as well as other evidences of lymphadenitis.

Especially should these children be protected from mental strain, shocks, frights, trauma, and exposure to inclement weather, since cases are reported in which the development of glycosuria was preceded by such disturbances.

In a child diabetes may be anticipated by the appearance of preglycosuric signs, such as incontinence of urine, muscular debility, irritability with progressive emaciation (in spite of voracious appetite), even though a single test of the urine fail to reveal sugar. The importance of an early diagnosis is evident, for it is admitted that success in treatment bears an inverse ratio to the previous continnance of the disease.

At the present time the regulation of diet seems to be the most important therapentic measure, and by far the greater number of important improvements have been attributed to this mode of treatment.

Fat is absolutely essential to the diet, and may be taken up to the limit of gastric toleration.

Recent investigations have shown that a certain amount of carbohydrates is necessary for the reduction of acetonuria and that a single member of this group is better borne than mixed carbohydrates. It is also claimed that a single form of albumin is more tolerable than a variety of proteid foods, and, further, that an excessive meat diet in- 
creases the acidosis. Hence Van Noorden has reeommended a mixture consisting of oatmeal gruel, egg albumen, and butter freed of fatty acids by washing in cold water. Such a mixture should not be made the exclusive diet for more than three or four days, on account of clisgust at the monotony.

Alkalies, as bicarbonate and citrate of sodinm, to combat the acillosis, should be administered in quantities sufficient to render the urine neutral.

The utmost care of the diet and hygiene is even more important in children than in adults, since a higher ratio of metabolism is essential to growth in addition to repair. But the clild will not bear radical dietary changes well. Hence, although so important, the reduction of carbohydrates should be gradual. 'The same may be said of the augmentation of fats. Finally, too much stress cannot be laid upon the importance of protecting the child form a sudden lowering of the temperature.

\section{DIABETES INSIPIDUS.}

Diabetes insipidus is still classed as a disease. As at present understood, the term represents a persistent polyuria of unknown etiology. As such it is an extremely rare disorder. No age is exempt, and infancy and childhood furnish their full proportion of cases. There is reason to believe there is a hereditary element, as cases have been traced through four generations, and sometimes several members of the same generation have been affected. The quantity of urine passed may be enormous,in some instances reaching ten times the normal quantity. It is of very low specific gravity, from 1001 to 1006, usually of acid reaction, and, with the possible exception of inosite, contains no abnormal constituent. The total solids excreted, as a rule, are slightly above the average for the weight of the patient and amount of food ingested. No constant anatomic lesion has been found, excepting some enlargement of the kidneys, dilatation of ureters, and hypertrophy of the bladder.

The onset is sometimes sudden, following shock, fright, traumatism, or the drinking of unusually large quantities of fluid. More frequently the development is gradual, attention being first attracted by the frequency of micturition at night. Strangely enough, among older children nocturnal incontinence is not of frequent occurrence, the bladder showing a remarkable degree of tolerance. Polydipsia is always present, and while a fairly constant relation exists between the amount of urine and the quantity of fluid ingested, the former is always in excesss of the latter. The general health may not appear to suffer for many weeks, yet there is usually considerable irritability. Later there is loss of flesh, with muscular atony, disinclination to exertion, and tendency to somnolency. The appetite is imperative, and the digestion is disturbed only as the patient yields to the bulimia. Constipation is the rule, due largely to the diversion of fluids to the urinary tract. The skin is dry, perspiration not being perceptible. The temperature is rarely elevated; usually subnormal.

The quantity of urine in healthy subjects is normally increased by 
the quantity of fluids ingested. There are many known causes of polyuria,- such as hysteria, fright, any nerve shock or mental emotion, exposure to cold, reflex irritation (as from presence of worms in the alimentary tract), and absorption of effusions. It is also seen in the early days of convalescence from acute infections, and it is well known that irritation of the floor of the fourth ventricle produces polyuria. The contracted kidney of interstitial nephritis must be excluded by a careful examination of the urine and consideration of the cardio-vascular changes characteristic of that disease.

Prognosis.-It should be borne in mind that in children saccharine diabetes has developed from the insipid variety. Diabetes insipidus is not incompatible with a fair degree of longevity, yet as a rule there is a general failure in health. A neurasthenic condition develops and the patient succumbs to some intercurrent disease.

Treatment.-The uselessness of drugs in this disorder has been demonstrated. The treatment is entirely hygienic. The child must be protected from cold, shock, and fatigue. The diet should be nutritious, consisting of a fair degree of proteids, with a restriction of the carbohydrates. Fluids should not be too rigidly restricted, as the unsatisfied thirst induces gastric derangement and wears out the nervous system. Free diaphoresis and eatharsis have seemed beneficial. The administration of asafœida-either in pill form by mouth or as an emulsion by rectum, to quiet the nervous system and stimulate the sympathetic ganglia-is worthy of trial.

\section{RHEUMATISM.}

A consideration of the numerous theories as to the etiology of rheumatism, however interesting or valuable, is precluded by the limited scope of this work. Whatever may be nltimately demonstrated-and the present trend of opinion seems to be strongly towards a microbic causationfor the present, at least, the most practical conception of this disorder is that of a diathesis.

It may seem a little old-fashioned not to follow the brilliant bacteriologists in their researches to establish the identity of a specific microorganism, but, admitting it to have been found, until some method of protection against its invasion shall be demonstrated, safety must be sought along the line of demonstrable clinical facts. To appreciate rhenmatism in infaney and childhood, the student may well forget the clinical picture of adult rheumatism. In fact, this picture so long obscured the view that, until quite recently, rheumatism was denied admission to the diseases of infancy and early childhood. The heredity of the rhenmatic diathesis is established beyond all question. This is so evident that double heredity predicts with almost certainty the appearance of rheumatic manifestations in the ehildren. Another well-established elinical fact is the influence upon the system of dampness and cold as an exciting cause.

It is endemic in localities marked by sharp variations in temperature and humidity, high and low altitudes showing remarkable exemption. 
Its epidemic eharacter depends upon variations of season, attacks occurring with notable frequency in spring and fall. It is prineipally seen in the temperate zone, near large bodies of water, and in low-lying districts.

Malhygiene as to food, clothing, sunlight, and pure air intensifies the diathesis.

Neither sex nor age shows immunity that is not explained by protection from exposure to malhygiene. Rapidly aceumulating reports of rheumatism in early infancy not only prove its existence, but emphasize the modern conception of its multimanifestations. It is fair to assume that some of these manifestations are daily overlooked or misinterpreted by practitioners to whom adult rheumatic arthritis is a familiar disease.

Multiple arthritis of severe type has been reported in an in iant only a few days old, although this form is rarely seen at this early age. Frequently the joint affection is so slight as to escape notice, careful examination being necessary to reveal the affected part, which may be neither red nor swollen, and show only slight pain on manipulation. It may be accompanied by a trifling rise in temperature, easily attributable to other causes.

Differential Diagnosis.-The evidence of the pain on handling may be attributed to rhachitis, and must be differentiated from the subperiosteal pain of scorbutus. The child may limp a little on his way to school, or rest from play on account of slight tenderness in knee or ankle, or stumble and fall from imperfect control of the limb. Upon examination, a slight elevation of temperature may be found, with history of preeeding malaise or irritability. The child may complain of discomfort in limbs, frequently after retiring, perhaps awakening in the night from pain. This is usually aseribed by the mother to "growing pains" or muscle cramps.

The myalgias of childhood are so common as frequently to pass unobserved, or at least, if moderately persistent, to secure only the service of hot applications. The young infant must usually be satisfied with the diagnosis of colic. Severe muscular and arthritic pains are, perhaps, the least frequent rheumatic expressions in child rheumatism.

Occasionally forms are seen in which multiform erythemas, purpuric eruptions; torticollis, or subcutaneous nodules are the only manifestations.

More common are chorea and tonsillitis, but the distinguishing features of paramount importance are the cardiopathies. Whatever the other rheumatic symptoms and lesions may be, the heart rarely eseapes involvement. The too prevalent belief that an endocardial murmur or a friction rub is a necessary expression of cardiac inflammation is an expensive error. That myocardial involvement may precede the endocarditis or pericarditis, or exist in the absence of either or both, is a fact gaining daily in recognition. The insufficiency, so frequently ascribed to the dilated ventricle of the developing period, is now more commonly regarded as of rheumatic origin.

The fact that the cardiac lesion is the one common, constant expression 
of child rheumatism, in view of the extent and gravity of the results, emphasizes the importance of careful examination in every case presenting any of these associated manifestations of a rheumatic diathesis.

Chorea, muscular or arthritic pain and heart lesion, have long been recognized as the tripod which supports the diagnosis of rheumatism in early life. These are not always present at the same time. So, too, of the other expressions, but one or more may appear, although their frequent association with a cardiae lesion is well established.

The fibrous nodules, infrequently reported in this country, are common in England. They consist of firm, discrete, subcutaneous, nodular masses, appearing over the wrists, elbows, patella, point of the shoulder, scalp, and back, freely movable and usually painless, varying in size from a wheat grain to a filbert. They may be few or numerous and may disappear in a few days or persist for long periods. European observers regard their appearance of grave import, suggestive of probable fibrous involvement of the peri- or endocardium. Inflammation of other serous structures, meningeal, pleural, or peritoneal, have long been regarded, whether correctly or not, as rheumatic, but the proof of the claim is difficult.

The duration of an attack of rheumatism may not be stated, so variable is its course and intensity. From six days to six months have been reported as periods during which the patient was not free from acute symptoms. Probably attacks of moderate severity as to fever and joint involvement, would average a period of three weeks. During this time pyrexia is fairly constant, rarely exceeding $103^{\circ} \mathrm{F}$. (39.5 $5^{\circ}$ C.). Anorexia, present at the beginning of an attack, is not persistent, the child frequently begging for forbidden food. Acid sweat of a peculiar odor is a common feature; respiration is accelerated in proportion to the temperature, but slow compared with the pulse. This is usually rapid and irregular, arhythmic or compressible, according to the nature and degree of cardiac involvement.

The arthritis involves the large joints-ankle, knee, wrist, and elbow -successively shifting (frequently in a few hours), with a moderate degree of heat, pain, and swelling, but with exquisite pain at the slightest touch or motion.

Different joints may become involved successively, either unilaterally or bilaterally. Rarely the arthritis is confined to one articulation. Occasionally in the neighborhood of the affected areas eruptions may appear, as erythema papulosum, marginatum, and nodosum. In some cases the back and chest may be covered with sudamina. Hemorrhagic urticaria is sometimes seen; also small petechiæ. In fact, the hemorrhagic tendency is quite marked in severe forms of this disease, and epistaxis is not uncommon, with evidences of profound blood changes. The hæmoglobin and red cells are diminished, while the white cells and fibrin are increased.

Diagnosis.-Mild or isolated manifestations of rheumatism may be overlooked. At times differentiation must be made from the tender, pain- 
ful limbs of scorbutus, in which the subnormal temperature, with other symptoms of the disease, should be a guide. The polyarthritis, described by Still, is characterized by splenie and glandular enlargement not common to rheumatism. The joint involvements in pywmia and epiphysitis, with fever and swelling, may for a time simulate inflammatory rheumatism, but the reeurrent ehills, early suppuration, and subserfuent history in the latter, should elear up all doubt. Bone tuberculosis may involve the joint and make the diagnosis difficult at first. Tuberenlons hip disease, with its early knee pain, should present but little diffieulty, after eareful examinations for signs of this lesion. The same may be said of gonorrhœal joint infection, thongh cases are reported of multiple purulent arthritis in infants who are victims of the gonococeus.

In children with a rheumatic heredity, epiphysitis of shoulder, elbow, knee, or ankle, makes differentiation extremely diffieult for a time. Early suppuration elears the diagnosis.

Prognosis.-The prognosis depends upon the gravity, extent, and nature of the heart involvement. As before mentioned, rheumatism is the most prolifie eause of eardiopathies whieh, with its predisposition to reeurrence, may not only eause death from syneope during the height of an attack, but handieaps the individual in his struggles against other aeute diseases.

Treatment.-Aside from the amelioration of pain, the treatment should be entirely prophylaetic against the one grave eomplieation. Hence the necessity for an early recognition of the diathetic stigmata. Upon the first appearanee of any of these, however seemingly trivial, the ehild should be put to bed. This procedure, although apparently heroic, is rational, in view of the conservation of heart aetion thereby obtained. This objeet should be secured by all synergistic measures. If there be painful arthritis, the parts should be swathed in cotton or wool that has been saturated with an embroeation eonsisting of oleum gaultheriæ, spiritus ehloroformi, or linimentum saponis, and eovered with protectives. The intoxication, however mild, should be combated by all means of approved efficacy. Elimination should be aided by eatharsis, diuresis, and diaphoresis.

Calomel in one-half to one-grain $(0.03-0.065 \mathrm{Gm}$.) doses, with one to ten grains $(0.065-0.65 \mathrm{Gm}$.) of sodium bicarbonate, should be given four times the first day and followed by salines, as magnesium eitrate or sodium sulphate, every two to four hours, suffieient to maintain free liquid evacuations. Water should be freely administered, preferably the lithia water, with hot baths or packs.

The consensus of opinion favors the use of sodium and ammonium salicylates, salicylic aeid, salacin, salol, salophen, salopirine, oil of wintergreen, and aspirin. An effort should be made to nentralize the acidosis by the free use of alkalies, such as sodium and potassium biearbonate, citrate and acetate, or fresh fruit juices. Initial doses of sodium salieylate, one grain $(0.065 \mathrm{Gm}$.) for each year of age, every three hours in syrup of gaultheria, or half the quantity in a drachm of five per cent. 
emulsion of oil of wintergreen, may be used. On account of gastric intolerance for these drugs, their use should not be prolonged beyond a few days, except in greatly diminished doses. If necessary, aspirin may be substitued in similar doses, as greater freedom from gastric and toxic symptoms is claimed for this agent. Prolonged heroic exhibition of salicylates combined with alkalies may aggravate or even induce rapid hæmolysis, and promote purpura, hemorrhagic symptoms, epistaxis, etc. If pain or restlessness be marked, relief must be secured by the judicious use of opiates, such as Dover's powder, one to five grains (0.065-0.32 Gm.), or codeine, cautiously administered. The prophylactic value of cardiac sedation fully justifies the exhibition of opium in these cases.

The abatement of the acute symptoms, if such there be, should not be the signal for allowing the little patient his freedom. On the contrary, he must be kept in bed to prevent relapse and damage to the heart, which is in all probability affected, thongh no positive evidence of valvular lesion be apparent. It is better to err on the side of too long detention in bed than in too early exposure to heart strain. The pronounced anæmia of rheumatism requires the early use of iron and tonies. Basham's mixture, in from five to forty minim (0.3-2.56) C.c.) doses, may be given four times a day, while moderate doses of quinine in chocolate or syrup of yerba santa is an eligible tonic. Cream and codliver oil are valuable during convalescence.

If, in spite of these measures, the heart's action become rapid, irregular, and weak, the ice-bag should be applied over the precordia and retained, if tolerated, until cardiac symptoms subside. At least one thickness of flannel should be interposed between skin and coil, which should be shifted from time to time to prevent chilling. Warmth in the extremities should be preserved by means of hot-water bottles. During an attack, milk is the ideal diet. Convalescence would warrant meat broths and soups, with custards, succulent regetables, plain puddings with cream, stewed fruits, unfermented grape juice, and lemonade. The diet, as a rule, in the rheumatic diathesis should contain a liberal amount of proteids, carbohydrates being limited. The proneness of these children for sweets should be remembered and guarded against.

The hygiene of the rheumatic diathesis would require flannel of seasonable thickness worn continuously. The child should be gradually habituated to cold bathing as a defensive measure. After unavoidable exposure and during changes of season, the child should be put upon salicylate salts, or the natural oil of wintergreen in emulsion, in moderate doses for a period of several days. Care of the throat and upper respiratory passages is important, including the treatment or removal of hypertrophied fancial and pharyngeal tonsils. The emunctories must be kept active, and alkaline waters and fruit juices should form an important part of the dietary. 


\section{Appendix}

\section{के \\ SICK-ROOM HYGIENE}

THE sick-room should be so situated as to secure free entrance of sunlight and the best of ventilation, also freedom from noise and disturbance. For these reasons an upper room is preferable. It should be plainly furnished, with washable hangings. A metal bedstead is desirable, which should be so placed as not to face windows, and to allow approach on either side. 'The floor should be bare except for small, removable rugs.

The importance of ventilation need not here be emphasized further than to suggest windows that may be opened at bottom and top. Light screens should be used to prevent a too strong, direct draught. 'The wideopen window, even with wire screen, may be inproved upon in most large cities by an additional netting of gauze or cheesecloth, which acts as a dust filter.

Where possible, great benefit may be secured by earrying the patient into another room for a portion of the day, while the sick-room is widely opened to air and sunlight. In very hot weather the temperature may be notably reduced by pails or tubs of broken ice to which salt is added, and over which an electric fan may play, thus securing more complete change of air. Stale air may be removed by a vigorous swinging of the door. Doors which are liable to slam should be protected by a towel fastened to both knobs, to serve as a bumper.

The bed should have a smooth, level mattress, preferably of hair (the pillow should also be of hair), and provided with a rubber sheet, linen or cotton sheets, and light blankets. A light, sick-room table, the top of which projects over the bed, is a great convenience for older children during convalescence. When not in use for the patient it may be lifted to one side and used for medicines and appliances, all of which should be kept out of the patient's sight.

Facilities for heating water should be close at hand, if possible in another room, unless an electric heater is available. In houses lighted by electricity, appliances-such as foot-warmers, hot pads, and waterheaters-are easily attached and are a great convenience. Gas- and oilburners and kerosene lamps consume much oxygen and render the air of the room impure.

The urinal may be a necessity, but the ordinary bed-pan is a nuisance, against which the majority of children protest. Unless especially contraindicated by a critical condition of the heart, a medical case, if old enough may be placed upon a commode, with increased comfort to the 
child and more thorough evacuation of the bowels. The vessel receiving the discharges should contain a deodorant solution-as bichloride of mercury, 1:1000; potassium permanganate, 1:1000; chloride of zine, $1: 50$; or a weak solution of formalin-and should be removed from the room immediately after use. Even older children should be diapered if there be any possibility of involuntary evacuations.

Air-cushions or hair-pads are useful to protect the bony prominences from undue pressure, and in prolonged sickness a water-bed may be necessary. A bent-wood or wicker device is useful for taking the weight of the bedelothes off the patient's feet. By these precautions, and frequent bathing of the parts subject to pressure with diluted alcohol, bedsores may usually be prevented.

Medicine-cups, "feeders," and bent-glass drinking-tubes are indispensable in the sick-room. Cleansing of the patient's month, both before and after feeding, will increase his comfort and lessen the danger of further infection. For this purpose a mixture of dilute alcohol and glycerin, or an antiseptic alkaline solution, as Seiler's, may be used.

The use of a bed-gown which opens the full length in front is a great convenience for both nurse and physician.

The nurse should be provided with noiseless slippers, and dress of wash material.

\section{CONTAGIOUS DISEASES.}

In the management of contagious diseases strict quarantine should be maintained. A sheet suspended over the doorway should be kept dampened with a solution of bichloride of mercury $(1: 2000)$, which, kept in a pail for that purpose, may be applied with a whisk-broom. $\mathbf{A}$ hook for the doctor's gown and cap may be fastened to the jamb between the door and the sheet. A washbowl, soap, nail-brush, antiseptic solution, and alcohol, should be placed near the door for the use of the attendant and physician.

Clothes soiled with mucus or other discharges should be thrown into a slop-jar containing bichloride of mercury solution $(1: 1000)$. Diapers, towels, bedlinen, and all clothing used in the sick-room should be soaked in an antiseptic solution before being sent to the general laundry. Granite-ware is good material for sick-room utensils, as it is light, unbreakable, nonabsorbent, inexpensive, and easily sterilized.

Raising quarantine should include a thorough disinfecting bath following one of soap and warm water, paying special attention to the nails and hair, as these harbor infection. The child should be freshly clad in an adjoining room. The mouth, throat, and nose should be sprayed with Seiler's solution, which operation should be repeated daily for some time after convalescence.

The room-including all bedding, clothes, and furniture-should be earefully fumigated after the patient's removal. This is best done by evaporating formalin from wet sheets suspended across the room, after all the cracks around doors and windows are carefully sealed. At least a pound (500 C.c.) of forty per cent. formaldehyde should be used to 
every thousand eubic feet of space, and the door locked for twenty-fon hours. If sulphur is used three pounds (1.5 kilos) should be employed in an ordinary bed-room. The sulphur may be burned in an iron kettle placed in a tub which is partly filled with water. Half a pint of alcohol should be poured over the sulphur to secure ignition. One objection to the use of sulphur is its effect npon metals and eolored fabries. Following smallpox and scarlet fever, mattress and pillows should invariably be burned.

After fumigation, the windows shonld be opened wide and the room and furniture thoroughly serubbed with soap and water. It should be aired continuously for several days.

For cheap and effieient disinfecting solutions sec Formulary.

\section{THERAPEUTIC SUGGESTIONS.}

While functional disturbanees and pathological conditions are easily induced in infants and children, it should be remembered that they are as readily responsive to remedial agents, whether food, hygienic measures, or drugs.

As in early life spoiled organs are rare, so, also, drug habits and idiosyncrasies are seldom encountered. Indeed, the response to drugs is keener and more satisfactory than in adults. However, but few drugs are necessary in the proper care of children. If polypharmacy be reprehensible in the therapy of adults, it is little less than eriminal in the treatment of children.

One thing is evident and daily demonstrable,-viz., the more thoronghly the practitioner's knowledge of the physiology of the developing period the more simple and efficient is his drug therapy.

The oft-repeated untruth, that disorders in children are relatively difficult of correction, is but a confession of the utterer's unfitness for the undertaking.

The cause of much error in the infant's treatment is the too common habit of regarding him as a miniature edition of the adult. Such an erroneous conclusion bears fruit in misguided efforts to apply therapeutic knowledge, obtained from observations of drug action in adults, to the correction of entirely different conditions in the infant. An intelligent manipulation of conditions which influence metabolismsuch as temperature, humidity, light, and air, with a better understanding of food principles, digestion, absorption, and eliminationwill reduce the multitude of drugs to a very limited, safe, and efficient few. It is apparent that the quantity of a drug necessary to produce a certain effect in an infant can never be determined by any mathematical ealculation based upon the effect of the same drug in an adult. The dose of any indicated medicament must always be enough to produce the desired effect, and as this varies widely in different cases the initial dose in any case is largely experimental; hence common prudence suggests small doses repeated at short intervals, accompanied by a careful watch of the results. For this reason simplicity in prescribing is of the 
utmost importance and the routine employment of synergists, adjuvants, and corrigents should be discouraged as at least confusing, if not detrimental. Infant absorption and excretion are notably rapid,-another reason for short intervals between the doses of agents to be absorbed. This is especially true of alkaloids and soluble crystallizable substances. Free dilution favors rapid absorption, nor should it be forgotten that a catarrhal condition of the digestive tract, or the presence of food, may conspicuously retard absorption. It is known that some alkaloids are so changed by long contact with digestive secretions as to interfere with their specific action.

Excepting in extreme emergencies no remedies should be exhibited that interfere with digestion. The double demand for nutrition in childhood lends special emphasis to this caution. Its disregard too frequently makes the effects of treatment worse than that of the disease. The employment of syrupy vehicles for drugs, for children whose digestive tracts are particularly sensitive to the fermentative changes of saccharine material, is a common illustration of this point. Flavored tablets, reduced to powder and washed down with water, may well replace the objectionable syrups, and rectal and hypodermic medication, if tactfully employed, have many advantages over administration by mouth. Oils and fats, so frequently obnoxious to palate and stomach, may be introduced with a certain degree of efficiency by inunctions with thorough massage. Quinine, mercury, iodine, and potassium iodide, as well as silver and iodoform, may be introduced in this way by incorporation with a vehicle rich in oleic acid. For this purpose lanolin possesses the highest value and vaseline probably the lowest.

Rectal suppositories of cacao-butter furnish valuable means for the administration of medicinal extracts and alkaloids, as well as for nutrients and evacuants.

\section{MASSAGE.}

The value of massage is too frequently overlooked. Metabolism in infancy demands the excessive muscular activity so common to growing, healthy mammals. Enforced quiescence of the sicksroom may interfere seriously with the distribution of pabulum and the elimination of waste products. Timely, systematic massage will do much to maintain these important functions, as wcll as to prevent hypostasis from long-continued decubitus.

\section{LUMBAR PUNCTURE.}

Lumbar puncture, as a means both of diagnosis and treatment, is so important a procedure that a few words concerning its technique may not be superfluous.

The site of the puncture is preferably the interval between the third and fourth lumbar vertebre which lies practically in a straight line connecting the iliac crests (Fig. 217). The skin over this area should be cleansed as for a surgical operation. Sharp antiflexion of the child's 
spinal column, by separating the processes, facilitates the puncture. The smallest trocar, or a large hypodermic needle, previously sterilized, should be introduced in the median line at right angles to the surface (in older children incline slightly upwards), to the deptls of one and one-half to two and one-half centimetres (three-fifths to one inch).

Aspiration is contraindicated, hence the syringe need not be attached. The escaping fluid may be collected in a sterile test-tube or beaker for examination. The force of outflow should be noted, as inclicative of the degree of pressure. The flow may be prevented by ocelusion of the needle, in which case it should be reintroduced after cleansing.

As a rule anæsthesia is not necessary, although some physicians prefer the local use of ethyl chloride. The child should be held firmly in the flexed position on his side to facilitate puncture and prevent accident.

The quantity of fluid withdrawn should depend upon the amount of pressure as indicated by the force of the stream or the subsidence of the

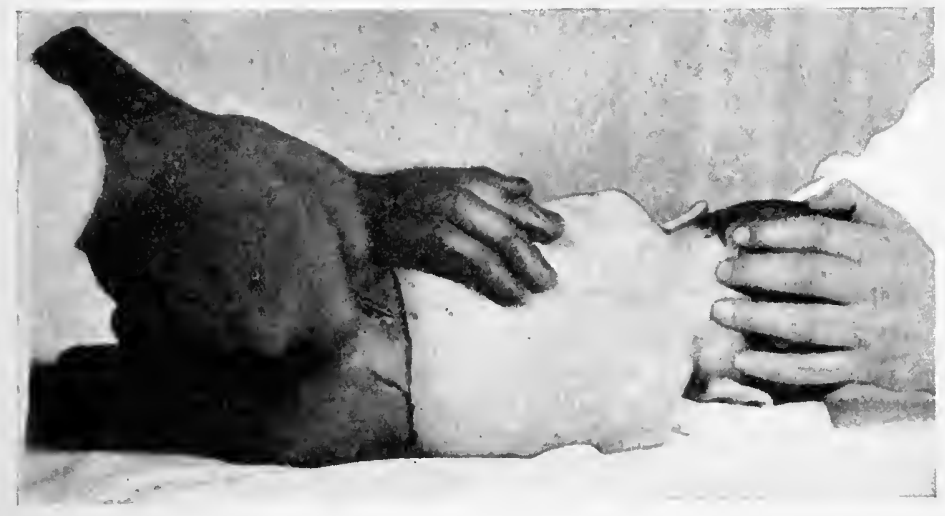

FIG. 217.-Lumbar puncture.

fontanelle, if that be open. A quantity of from ten to thirty cubic centimetres ( $21 / 2$ to 8 drachms) is certainly within the limits of safety. Much larger amounts are frequently withdrawn without apparent bad effect. For purposes of examination the first few drops, which usually contain blood from the superficial capillaries, should be rejected.

Upon withdrawal of the needle the wound should be sealed by collodion dressing.

\section{HYDROTHERAPY.}

HOT PACK.

The child should be enveloped in a small blanket or Turkish towel wrung out of water as hot as can be borne, and the whole covered with a rubber sheet. Ice or cold cloths should be applied to the head, and, if necessary, a hot-water bottle to the feet. The pack may be renewed in thirty or forty minutes if necessary. 
COLD PACK.

The trunk only should be enveloped in a sheet or towel wrung out of water at a temperature of $80^{\circ}$ to $90^{\circ} \mathrm{F}$. $\left(27^{\circ}-32^{\circ} \mathrm{C}\right.$. $)$, and covered with a light flannel blanket. Cold should be applied to the head and heat to the feet and limbs. This pack may be renewed in from thirty minutes to an hour, according to effect upon the child's temperature and circulation. The ice-eap to the head alone is frequently sufficient to reduce temperature.

SPONGE BATH.

The child, stripped and laid on a blanket, should be sponged with water to which twenty-five per cent. of alcohol or vinegar has been added. For warm sponging, water at a temperature of $100^{\circ}$ to $105^{\circ}$ F. $\left(38^{\circ}-40.5^{\circ}\right.$ C. $)$ may be used. For cool sponging it may be reduced to $90^{\circ}$ or even $60^{\circ} \mathrm{F}$. $\left(32^{\circ}-15.5^{\circ} \mathrm{C}\right.$.) according to comfort. A light blanket should cover the child, so that only a small portion of the body be exposed at one time, or the entire bath may be given under the blanket. In all cases, cold to the head and heat to the feet should be used.

To secure the effect of cold without the pronouneed shock of direct contact, the child may be covered with a sheet wet with water at a temperature of $100^{\circ} \mathrm{F}$. $\left(38^{\circ} \mathrm{C}\right.$.) over which pieces of ice are rubbed. The friction also stimulates circulation and promotes reaction. The cool air bath may be applied by means of a fan, electric or otherwise, which promotes rapid evaporation from the surface of moistened gauze, two thicknesses of which envelop the child's body and limbs. Moisture is maintained by sprinkling, from time to time, with warm water and alcohol.

\section{TUB BATH.}

In tubbing, the child should be suspended in a blanket, hammock fashion, and lowered into the water at $100^{\circ} \mathrm{F}$. $\left(38^{\circ} \mathrm{C}\right.$.) or more to prevent shock. By the addition of cold water or ice outside the blanket the temperature may be reduced as much and as rapidly as desirable, although rarely advisable to go below $75^{\circ} \mathrm{F}$. $\left(24^{\circ}\right.$ C. $)$. Meanwhile, friction should be applied to body and limbs by the busy hands of the attendants. The wisdom of using the cold bath in young and nervous children is questionable. Reaction should be carefully watehed and the time should rarely exceed five minutes. Upon removal from the tub the child should be quickly rolled in a dry blanket, without rubbing.

\section{HOT MUSTARD BATH.}

A mustard bath is made by the addition of a tablespoonful of mustard to the gallon of water. The temperature may be about $105^{\circ} \mathbf{F}$. $\left(40.5^{\circ}\right.$ C. $)$ and should never exceed $110^{\circ}$ F. $\left(43^{\circ}\right.$ C. $)$. This may be administered as a general bath in the tub or only as a foot bath in a deep bowl or pail. 
VAPOR BATH.

The hot vapor bath for young children and infants slould always be administered in bed, the covering of which is raised and supported above the ehild's body on a framework of half-hoops or a "cradle." The clothes, however, should be securely fastened about the child's neck. Into this air-space may be introdnced steam from a teakettle containing boiling water, or from a vessel of water in which red-hot bricks or irons are gently dropped. Tuley's apparatus for hot air bath consists of an ordinary lamp (placed on the floor) over which is a funnel supported on four legs. From the top a tin tube with elbows conveys the heat and vapor of combustion beneath the bedelothes. The free perspiration induced by the hot vapor may occasion great depression, so that the pulse must be carefully watched.

A tepid bath is given at a temperature of $95^{\circ}$ to $100^{\circ} \mathrm{F}$. $\left(35^{\circ}-38^{\circ} \mathrm{C}\right.$. $)$.

\section{BRAN BATH.}

A bran bath is given with tepid water into which a stout gauze or coarse muslin bag, containing a quart of wheat bran, is repeatedly dipped and squeezed until the water is milky.

\section{SHOWER BATH.}

The cold shower bath as a tonic and invigorator shonld be given in the morning, before breakfast, and should not be prolonged beyond one minute. The ehild should stand in warm water covering the feet, while water of a temperature of $60^{\circ}$ to $75^{\circ} \mathrm{F} .\left(15.5^{\circ}-21^{\circ} \mathrm{C}\right.$. $)$ is sprayed, or squeezed from a large sponge over shoulders and trunk. Brisk toweling with friction should immediately follow to secure reactionary glow to the skin. Goose-flesh or blueness contraindicates cold affusions. The same precautions apply to the dip or plunge baths.

\section{INTERNAL USE OF WATER.}

Water, plain or medicated, is used in irrigations of nose, throat, ear, stomach, bladder, vagina, rectum, and colon. Bland solutions of salines and alkalies, which slightly exceed the specific gravity of water, are less irritating to mucous surfaces than plain water.

\section{NASAL IRRIGATION.}

Nasal irrigation is best accomplished in young infants while the child is lying on his side, with the arms confined by a large towel or sheet. The syringe should have a blunt, soft rubber tip that will occlude the nostril without abrading the mucous membrane. While the head is steadied by gentle pressure of the hand, the fluid is slowly forced into the upper nostril that gravity may promote its outflow from the opposite side of the nose (Fig. 218). The infant's erying favors the thorough irrigation. It is better to force a plug backward into the pharynx than 
forward by pressure from behind, as in the latter ease fluids and secretions may be foreed into the Eustachian tube to the detriment of the middle ear. Older ehildren may receive nasal irrigation while sitting or standing. The head being inclined forward favors free circulation through the posterior nares and exit by the opposite nostril. For this purpose the syringe, nasal douche, or irrigator may be used.

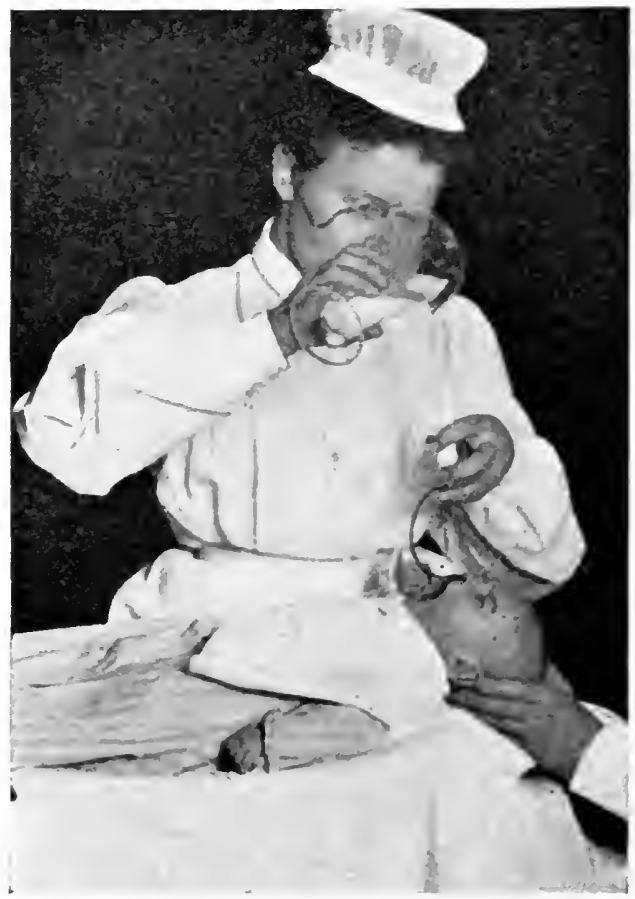

Fig. 218.-Niasal feeding.

L.AVIGE.

Gastric irrigation, or lavage, is best performed in infants by means of a No. 10 or No. 12 double-eyed flexible catheter. This is eonnected by a short glass tube with a piece of rubber tubing two feet long, terminating in a funnel. During the process the child's hands and.arms should be pinioned by a sheet while it is held in the arms of an assistant. The catheter, first wet, is passed quickly through the fauces for a distance of six inches $(15 \mathrm{Cm}$.) into the stomach. After allowing the escape of any contained gas, the irrigating fluid should be cautiously poured into the fumnel, which should be held, at first not more than three or four inches (7.5-10 Cm.) above the ehild's head. When the stomach is filled, or before, if vomiting oecur, the funnel should be lowered to empty the stomach, the tube acting as a siphon. After this it may be filled as before, and the process repeated until the fluid runs elear. If 
the tube become oceluded by solid particles, it may have to be withdrawn, which, like the introduction, should be done quickly, to avoid irritation of the fauces.

\section{GAVAGE.}

Feeding by the stomach tube is sometimes necessary when a child shows disinclination or inability to swallow. If vomiting be excited by irritation of the throat, or if for any reason its introduction be difficult, the tube may be passed through the nose into the resophagus, as a child fed in this manner will frequently retain the food (Fig. 218).

\section{IRRIGATION OF THE VAGINA.}

In vaginal irrigations, the small glass eatheter with multiple openings, forms the best tip, as it is easily sterilized, and the possibility of extension of the gonorrhœal infection must never be lost sight of.

\section{ENEMA.}

Enemata may be given through any sterile tube of proper calibre, care being taken to introduce the tip, especially if it be inflexible, in a direction parallel to the anal outlet, in order to avoid wounding the mucous membrane (Fig. 219). The best position for this purpose is with the infant lying across the nurse's lap face downwards.

For evacuation of the rectal contents from one to three ounces (3090 C.e.) is usually sufficient. For this purpose soapy water is appropriate. If pure glycerin be used half an ounce (15 C.c.) will suffice and may be introduced by a hard rubber syringe.

Nutrient enemata, to be retained, are best administered after a colonic flushing with free evacuation. To this end the quantity of food should rarely exceed four to six drachms (15-23 C.c.). It may be necessary to follow its introduction with firm pressure upon the anus for a few minutes to secure retention. Predigested foods, such as peptonized milk, or raw meat juice, salted egg-water and whey, may be used in this way.

\section{COLONIC FLUSHING.}

Colonic flushing requires the use of a long flexible tube, as a No. 10 or No. 14 rubber eatheter, attached by a glass connection to the hose of a fountain syringe. The best position for infants is across the nurse's lap, which should be protected by a rubber sheet (Fig. 219). After the point of the catheter, well lubricated, is introduced, the fluid should be turned on, as the stream will facilitate passage of the flexible tube over the rectal rugx and folds of the sigmoid. The height of the fountain above the body should rarely be more than twelve to eighteen inches $(30-46 \mathrm{Cm}$.), since if introduced too rapidly active peristalsis will be excited. The eatheter should be gently introduced its full length. If it double on itself, it must be reintroduced. Thorough flushing may be facilitated by elevating the buttocks and by gentle massage of the abdomen in reverse 
course of the descending colon. From one to four pints (1/2-2 litres), according to the age of the child, may be used in this way. Ordinarily normal salt solution is most suitable for colonic flushing, although various

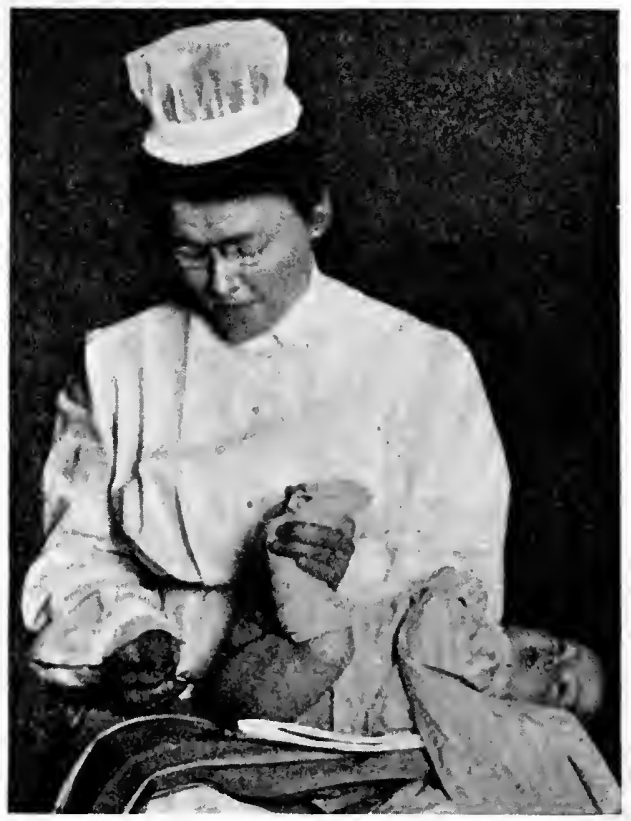

FIG. 219.-Colonic flushing.

medicated solutions may be employed according to the indications of the special case.

\section{DIETARY.}

BARLEY-WATER OR GRUEL.

Pour a pint of cold water over a tablespoonful of washed pearl barley; boil for two hours, adding boiling water as needed to maintain the pint; add a pinch of salt; strain and keep on ice. In the preparation of infant's food, glass, porcelain, or granite vessels only should be used.

For gruels of oatmeal, cracked wheat, and other cereals, except rice, the same method may be used.

RICE-WATER.

Macerate one ounce of well-washed rice in a quart of water for three hours at a gentle heat; boil slowly for one hour, adding boiling water to make up the quart as evaporation requires. Strain and keep on ice.

These gruels may be slightly sweetened and flavored with lemon peel or extract, if desired.

Jellies are merely concentrated gruels. When the finely ground flour 
of barley, oatmeal, or rice are used, thirty minutes boiling will suffice. Cereal fluids are partially dextrinized by the addition of a teaspoonful of thick extract of malt, when cooled enough to taste.

EGG-W.ITER.

Stir the white of one egg in six ounces of cool water ; strain through cheesecloth, adding a pinch of salt. For older children, sugar and slices of lemon, or nutmeg may be added for taste.

\section{CLAIII-BROTII.}

Wash six large clams in shells; put in kettle with eight ounces of cold water; boil one minute: pour off and give warm. A teaspoonful of pulverized cracker crumbs may be added, with a little butter and salt to taste.

CHICKEN-BROTH.

A small chicken, or half of a large fowl (with skin and fat removed), is chopped, bones and all, and placed in a stewpan with a quart of cold water and a teaspoonful of salt. Cover closely and allow to simmer for two hours. After boiling for five minutes, remove from fire and let it stand covered for half an hour. Skim off the fat and strain through a sieve or cloth.

For chicken jelly, allow more water to evaporate, strain into a mold, and place on ice.

\section{BEEF-BROTH.}

Mince a pound of lean beef; put it with its juice in an earthen vessel containing a pint of tepid water. Add a little salt and let it stand for one hour; strain through muslin until all juice is removed; place this liquid on the fire and stir briskly while slowly heating to the boiling point, after which remove at once; cover and place on ice.

\section{MUTTON-BROTH.}

To a pound of lean mutton add three pints of water and boil gently for an hour, adding a little salt. Strain into a bowl, and when cold, skim off the fat. Serve warm.

\section{OYSTER-BROTH.}

Cut into small pieces a pint of oysters ; add half a pint of cold water and allow to simmer gently for ten minutes. Skim, strain, and add salt and pepper.

\section{SCRAPED OR PULPED RAW MEAT.}

With a dull knife scrape the pulp of lean meat from the connective tissue, salt to taste, and give raw. A tablespoonful may be given to a year-old child.

The beef pulp may be slightly broiled and given warm, if preferred. 
RAW MEAT JUICE.

A steak from a leg of mutton or round of beef, three-quarters of an inch thick, should be quickly seared in hot pan or on broiler; remove and extract the juice with a lemon-squeezer or meat-press; add a little salt, and serve without heating. This may be given in quantities up to a tablespoonful, diluted with water or other liquid food.

Another method: To four parts of minced lean meat add one part of cold water; cover and allow to stand for one hour, stirring occasionally; after this squeeze through a meat-press and strain; add salt, and feed as above. Meat juice should always be freshly prepared.

WHEY.

Into a pint of fresh milk, slightly warmed, stir a teaspoonful or two of Fairchild's essence of pepsin, or its equivalent in liquid rennet, or one dissolved junket tablet. Let it stand until coagulation occurs (about twenty minutes), then cut up the curds with a knife and strain through a double thickness of sterilized gauze or cheesecloth, without pressure. (A pint of milk should furnish from eight to twelve ounces of whey.) If the whey is to be mixed with milk or cream, it should be first heated to $150^{\circ} \mathrm{F} .\left(65.5^{\circ} \mathrm{C}\right.$.) in order to kill the rennet enzyme. If heated above $155^{\circ} \mathrm{F}$. $\left(68^{\circ} \mathrm{C}\right.$.) the lactalbumin is liable to coagulation.

\section{JUNKET-SWEET CURD FOR OLDER CHILDREN.}

In the above process the curd may be sweetened and flavored and used for food, or the milk, treated with rennin, may be poured into custard cups. Sweetening and flavoring may be added to the milk before the rennin.

\section{EGG JUNKET.}

An egg beaten into a froth and sweetened with a teaspoonful of sugar may previously be added to the milk in the above, thus increasing the food value.

\section{LIME-WATER.}

Into a pitcher of water put a piece of unslaked lime the size of a walnut; stir thoroughly; allow to settle; decant into a bottle and stopper.

\section{CREAM OF TARTAR LEMONADE.}

Juice of one lemon, three or four teaspoonfuls of granulated sugar, five grains of cream of tartar, and eight ounces of water. Shake thoroughly and strain. 


\section{FORMULARY}

\section{DISINFECTING SOLUTIONS}

No. 1. $5 \%$ Solution of Carbolic Acid.

No. 2. $1: 1000$ Solution of Bichloride of Merenry.

No. 3. 1 : 1000 Solution of Potassium Permanganate.

No. 4. $2 \%$ Solution Chloride of Zinc.

No. 5. Saturated Solution of Fresh Lime.

(One pound of unslaked Lime to four gallons of water.)

No. 6. Dry Chloride of Lime.

No. 7. 11/2 \% Solution of Sulphate of Copper.

(One pound to eight gallons of water.)

No. $8.6 \%$ Solution of Sulphate of Iron.

(One pound to two gallons of water.)

For disinfecting Hands, etc.-After scrubbing with soap and water, use No. 1 diluted with an equal quantity of water, No. 2, or No. 3, remembering that the last leaves a transient stain on the skin and a more permanent one on fabrics.

For disinfecting White Clothing.-Use No. 1, preferably hot, No. 2, or No. 4.

For disinfecting Instruments and Dishes.--Use No. 1, hot.

For disinfecting Discharges.-Any of the above.

For Cesspools, Drains, Water-closets.-Nos. 3, 4, 5, 6, 7, or 8.

It should be remembered that hot soapsuds is a very efficient cleansing agent. Continuous boiling for an hour, baking in a hot oven, or steaming in an Arnold sterilizer, is usually sufficient to insure sterility.

No. 9 .

For Atomization.

To the ounce (30 C.c.) of albolene or lavolene add either one drop (.06 C.c.) of pure carbolic acid, one-third of a grain $(.022 \mathrm{Gm}$.) of thymol, one or two grains (.06-.13 Gm.) of menthol, or one or two minims (.06-.12 C.c.) of eucalyptol.

No. 10.

For Evaporation.

To the pint (500 C.c.) of boiling water add either one drachm ( 3.75 C.c.) of benzoin tincture, half drachm (2 C.c.) of eucalyptol, or the same quantity of terebene or creosote. 
No. 11.

Moutil-Wash and Spray.

Sciler's Solution.

\begin{tabular}{|c|c|c|}
\hline Sodium biearbonat & $3^{\mathrm{ss}}$ & \\
\hline Sodium biborate & $3 \mathrm{ss}$ & \\
\hline Sodium benzoate & gr. 11 & \\
\hline Sodium salieylate & gr. 11 & \\
\hline Eucalyptol & gr. ss & \\
\hline Thymol & gress & \\
\hline Menthol & gr. $\frac{1}{3}$ & \\
\hline Oil gaultheria & gtt. $\frac{1}{3}$ & \\
\hline Glycerin & $\overline{5}$ ss & \\
\hline Alcohol & $5 i$ & \\
\hline Water, to make & $\mathrm{Oi}$ & \\
\hline
\end{tabular}

No. 12.

Moutil-IWash and Spray.

Dobell's Solution.

$\begin{array}{llr}\text { Sodium biborate } & 3^{\mathrm{i}} & 4 \\ \text { Sodium bicarbonate } & 3^{\mathrm{i}} & 4 \\ \text { Carbolic acid } & \eta_{\mathrm{x} \times \mathrm{xiii}} & 25 \\ \text { Glycerin } & \overline{5}^{\mathrm{i}} & 15 \\ \text { Water, to make } & \tilde{\tilde{z}}^{\text {viii }} & 250\end{array}$

No. 13.

\section{ASTRINGENTS.}

1. Tannic Acid.

2. Alum.

3. Zine Sulphate.

4. Zine Sulphocarbolate.

5. Silver Nitrate.

6. Protargol.

7. Adrenalin.

No. 14.

Glycerite of TANNiN.

Tamnic acid 1 part, glycerin 4 parts.

No. 15.

GLyCERITE OF IODINE.

Iodine 5, potassium iodide 10 , glycerin to 100 .

No. 16. A GARGLE TO PREPARE THE THROAT FOR TONSILLOTOMY.

Boric aeid

Potassium bromide āā gr. $\mathbf{x x} \quad 1 / 3$

Water $\quad \underset{\mathrm{J}}{\mathrm{i}} \quad 30$

No. 17. ANODYNE SPRAYS USED IN TUBERCULAR LARYNGITIS.

1. Menthol, per cent. 1

2. Adrenalin $1: 1000$

3. Cocaine, per cent. 1 to 2 
No. 18.

Asperin (Acetyl Salicylic Acid).

Dose: Gr. i. (.065 Gm.) for each year of age for the first five years.

No. 19.

Antipyrin 5\% Solution.

No. 20.

No. 21.

No. 22.

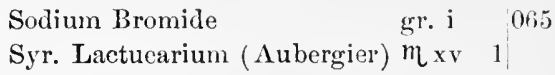

$\begin{array}{lll}\text { Sodium Bromide } & \text { gr. ii } & 18 \\ \text { Syr. Prunus Virginia } & 3 \mathrm{ss} & 2 \\ \text { Syr. Lactucarium (Aubergier) } & 3 \mathrm{ss} & 2\end{array}$

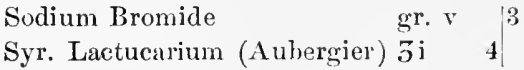

No. 23.

For Pertussis.

Tr. Belladonna

Sodium Bromide

Syr. Lactucarium

miii 2

gr. iii 2

ad. $3 \mathrm{i} \quad 4$

For a child of one year, every 4 to 6 hours, if necessary.

No. 24.

No. 25.

\section{INFANT CORRECTIVES.}

\begin{tabular}{lll|l} 
Calomel & gr. $\frac{1}{20}$ & 0032 \\
Ipecac Powder & gr. $\frac{1}{50}$ & 0013 \\
Sodium Bicarbonate & gr. $\frac{1}{2}$ & 032 \\
Bismuth Subnitrate & gr. 1 & 065 \\
Oil of Anise & $\eta_{\frac{1}{20}}$ & 003
\end{tabular}

$\begin{array}{lll}\text { Calomel gr. } \frac{1}{10} & 0065\end{array}$

$\begin{array}{llll}\text { Ipecac Powder } & \text { gr. } \frac{1}{20} & 0032\end{array}$

Sodium Bicarbonate gr. $1 \quad 065$

No. 26 .

\begin{tabular}{lll|l} 
Calomel & gr. $\frac{1}{5}$ & 013 \\
Ipecac Powder & gr. $\frac{1}{10}$ & 006 \\
Sodium Bicarbonate & gr. 1 & 065
\end{tabular}

No. 27. For Relief of Astima.

Paper saturated with a solution of Potassium Nitrate, and dried, may be burned with the powdered leaves of Stramonium and the fumes inhaled.

No. 28.

Anderson's Dusting Powder.

Powdered Starch

Zinc Oxide

Powdered Camphor

$\begin{array}{lr}3 \text { vi } & 23 \\ 3 \mathbf{i s s} & 6 \\ 3 \text { ss } & 2\end{array}$

No. 29.

Bland Dusting Powder.

$\begin{array}{lll}\text { Zinc Oxide } & 3 \text { ii } & 8\end{array}$

Powdered Lyeopodium Seeds 3 vi 23 
No. 30 .

Lassir's Páste.

Salicylic Acid
Zinc Oxide
Powdered Starch
Petrolatum

$\begin{array}{lr}\text { gr. } x & 65 \\ 3^{\text {ii }} & 8 \\ 3^{\text {ii }} & 8 \\ \bar{z}^{\text {ss }} & 15\end{array} \mid$

No. 31.

No. 32.

$$
\text { Lassar's Paste Modified. }
$$

Zinc Oxide
Talcum
Salicylic Acid
Vaseline

$\begin{array}{lr}3^{\text {ii }} & 8 \\ 3^{\text {iv }} & 16 \\ \text { gr. x } & 65 \\ \text { 亏ुss } & 15\end{array}$

VARNISH FOR ECZEMA.

Zinc Oxide
Gelatin
Glycerin
Water, to

$$
\begin{array}{lr}
3^{\text {iv }} & 15 \\
3^{\text {viss }} & 25 \\
\bar{j}^{\mathrm{i}} & 30 \\
\text { Oii } & 1000
\end{array}
$$

No. 33 .

Carbolized Vaseline 2 to $10 \%$.

No. 34.

$$
\text { Borated LARD } 10 \% \text {. }
$$

No. 35.

$$
\text { Mixed Fats (Russell's Emulsion). }
$$

Equal parts of Beef Fat, Cocoanut, Peanut, and Olive Oils, with two drops of Clove Oil to each ounce of emulsion.

No. 36 .

\section{RUBEFACIENTS.}

1. Camphorated Oil.

2. Turpentine and Oil or Lard, $1: 4$.

3. Mustard, mixed to a paste with cold water or white of egg. Mustard and flour, from $1: 6$ parts, and water to make a paste.

4. Capsicum 10 parts, Oil of Mustard 1 part, Croton Oil 1 part, and Vaseline 20 parts.

No. 3T.

$$
\text { Mulk of Asafetida. }
$$

Tincture of Asafetida and water $(1: 20)$, used as an enema.

No. 38.

\section{Simola Mixture Modified.}

$\begin{array}{lll}\text { Sodium Iodide } & \text { gr. iss } \\ \text { Sodium Phosphate } & \text { gr. iii } & 1 \\ \text { Sodium Chloride } & \text { gr. x } & 2 \\ \text { Water, to } & \mathfrak{Z}^{\text {jiv }} & 120\end{array} \mid$




\section{N D EX}

A

Abdomen, at birth, 34

Abdominal bands, 136; tuberculosis, 599

"Abiotrophy," 457, 460

Abscess, brain, 441; etiology, 441; surgery in, 443 ; psoas, 512; pulmonary, 355; diagnosis, 356 ; retro-cesophageal, 235 ; retro-pharyngeal, 55, 230, 512; tuberculous, 597

Accessory thyroid gland, 34

Achondroplasia, 164, 186

Acid albumin, 73; hydrochloric, 66, 73 to 76 ; lactic, 66,92 ; phosphocarnic, 92; sulphuric, in milk testing, 102

Acrania, 150

Acute yellow atrophy, 286

Addison's disease, 490

Adenia, 485

Adenitis, 480; acute simple, 482; chronic, 485; gastric, 241; in Hodgkin's disease, 485; primary, 482 ; treatment of, 484 ; tuberculous, 598

Adenoid vegetations, 224; examination for, 228; facies, 226 ; habit, 228 ; in tuberculosis, 229 ; treatment of, 229

Adipositas, 199

Adrenalin, 507, 510

Adrenals, at birth, 38; blood supply, 38; disorders of, 489; apoplexy, 490 ; hemorrhages, 489 ; symptoms, 490

Adriance, 93, 113

"Agenesis corticalis," 447

Ahlfeld, 96

Air hunger, 319

Albinism, 156

Albumen, 128
Albuminoses, 73

Albuminuria, at birtl, 67 ; cyclic, 368 ; extra-renal, 369 ; frequency of, in childhood, 369; functional, 365; in diphtheria, 570; in summer diarrhoa, 250; intermittent, 368; physiological, postural, 368

Alimentary tract, at birth, 35 ; development of, 35,55

Alkalinity in infant food, 115

Amaurotic family idiocy, 459; etiology, theories of, 460 ; eye-ground in, 460 ; symptoms, 460

Amblyopia, congenital, 156

Amniotic bands, 154

Amputation, intra-uterine, 154

Amyloid degeneration, 287; of kidney, 378

Amylopsin, 74

Anæmia, blood in, causes of, 498 ; diagnosis, 499; hæmanalysis in, 499 ; in Hodgkin's disease, 486; in malaria, 583; pernicious, 501, 502; psendolenkæmic, 506; splenic, 489; susceptibility in infancy, 498; symptoms of, 499 ; treatment of, 500

Anal atresia, 159

Analgesia in syringomyelia, 472

Anastomosis of nerves, 175; of tendons, 175

Anatomy of the new-born, 17

Anchylostomata, 269; anæmia, 269

Anderson's dusting powder, 647

Anencephalus, 21, 150

Angina, Vincent's, 210, 220

Animal amyloid, 93; animal gum, 93

Ankyloblepharon, 156

Anophthalmos, 156

Antitoxin, 573; effects of, 575; immunizing dose, 574

Antrum of Highmore, 48; mastoid, at birth, 20 
Anuria, 366; enteroclysis in, 367; of new-born, 163, 172

Anus, fissure of, 281; prolapse of, 280

Aortic insufficiency, 299; lesions, 299; stenosis, 299

Aphasia, 417; amnesie, 438

Aphonia, hysterical, 406

Aphthæ, 207 ; Bednar's, 208

Apoplexy of adrenals, 490

Appendicitis, 274; leucocytosis in, 276 ; recurrence of, 278 ; tuberculosis, 278

Aran and Duchenne type, 475

Arnold's sterilizer, 117

Arterial tension in infancy, 61

Arteries, growth of, $5 \pm$; umbilical, 32

Artluritis, acute, 521; deformans, 523; in rheumatism, 629; syphilitic, 521

Articulation, vocal, 72

Artificial feeding, 110, 114; composition of food, 110; difficulties in, 125; egg in, 12s; essentials for, 110 ; rules for, 125

Asafetida, milk of, 648

Ascaris lumbricoides, 269; treatment of, 271

Ascites, 285

Asperin, 647

Asphyxia neonatorum, 168; treatment of, 169

Aspiration in hydrocephalus, 152; in pneumonia, 170

Astlıma, 335, eosinophilia in, 336; gout in, 337; rhachiticum, 402; treatment of, 337 ; urticaria in, 337

Astigmatism, 534

Astringents, 646

Ataxia, cerebellar, 439, 473; hereditary spinal, 472

Atelectasis, 145; acquired, 356; congenital, 171; diagnosis of, 357 ; symptoms of, 357 ; treatment of, 171,358

Atelomyelia, 153

Athetosis, 68, 413

Athrepsia, 182

Atomization, 645

Atomizer, 134

Atresia ani, 159; of auditory canal,
157 ; of mouth, 158; of œsophagus, 159; recti, 159; urethral, 163; vaginal, vulval, 163

Atrophy, infantile, 182

Attention, power as test of mentality, 457

Auditory canal, atresia of, 157

A uricles, supernumerary, 157

Automobility, 72

\section{B}

Babcock, 93, 113; method of milk analysis, 101

Babinski's sign, 423, 475

Baby bag, 65; foods, 125, 126, 130

Bacillus, chromogenic, 250 ; coli communis, 92; Eberth's, 578; Hüppe's, 92; Klebs-Loeffler, in croup, 322 ; in diphtheria, 568

Backward children, 457 to 459, 534

Bacteria of frees in infancy, 76; intestines, 67 ; varieties of, 67

Bacterium coli commune, 67, 77; lactis aërogenes, 67, 77, 93; putrefactive, in milk, 93

Balanitis, 384

Baner's rule, 118

Banti's disease, 489

Barber's itch, 614

Barley-water, 642; analysis of, 130

Basedow's disease, 496

Baths, 82 ; bran, 82, 639 ; contraindications, 82 ; duration of, frequency of, 82; in childhood, 140; mustard, 638; salt, 82; shower, 639 , sponge, 638 ; temperature of, time of, 82 ; tub, 638; vapor, 639

Bednar's aphthæ, 208

Bed-sores in transverse myelitis, 467; prevention of, 634

Behring, 593

Bile acids, 67 ; bactericidal power of, 67 ; in infancy, 73 ; of new-born, 66

Birth-marks, 163

Birth-palsies, 448

Bladder, at birth, 39; capacity, 39, 40, 59 ; exstrophy, 162; growth of, 58 ; peritoneal covering of, 40,58 ; location of, $39,40,58$ 
Bleeders, 507

Blepharitis, simple, 524; treatment, 524 ; ulcerative, 524

Blepharospasm, 526

Blood, at birth, amount and characteristics of, 62 ; eirculation of, 31 , 61 ; diseases of, 498 to 510 . In anæmia, 498; appendicitis, 276 ; asthma, 336; chlorosis, 500; cholera infantum, 528; diphtheria, 569; Hodgkin's disease, 486; influenza, 565; leukæmia, 503; malaria, 583; measles, 550 ; meningitis, 427; pernicious anæmia, 501, 503; pertussis, 561: pneumonia, 342 ; rhachitis, 190 ; rheumatism, 630; searlet fever, 54t; tuberculosis, 597; typhoid fever, 5So. Peculiarities of, in infancy, 498. Supply of, adrenals, 38; brain, 63 ; liver, 63 ; lower extremities, 63; skin, 68; thyroid, 33,492

Blood-ressels, changes in, 54

Blue baby, 170

Bone-marrow, 18; in leukæmia, 506

Bones, composition of, at birth, 18; diseases of, 511; ethmoid, frontal, 22 ; inferior maxillary, 32 ; long bones at birth, 25; occipital, 20 ; parietal, 22 ; rhachitic, 192 ; sphenoid, 20; supernumerary, 20; temporal, 20; tubereulous, 508, 511; Wormian, 20

Bothriocephalus, 269; anæmia, 269

Bottle feeding, technique of, 124

Bouche de tapir, 477

Bowditch, 141

Bowlegs of infancy, 135; due to bulky diapers, 136

Brain, abscess of, 441; blood supply, 63; cellular multiplication, 59; coverings and vessels, 41 ; development, 41; growth, 59; time of most rapid, 456; causes of arrest, 456. Impairment of, causes, post-natal, 456; peculiarities, size, weight, 41 ; ratio to body weight, 59 ; tubereulosis, 597 . Tumors, 436 ; symptoms, 437; diagnosis, 440; treatment, 441
Branchial clefts, 22, 24: fistulæ, $15 \mathrm{~s}$

"Bread-tray belly," +23

Breast milk, changes in, during lactation, 94; conditions influencing secretion, 97; fats, rôle of, 91; means for regulating, 99 ; mineral constituents, 93 ; proteids of, 90 ; sugar of, 91; variations in, 97,106

Broadbent's sign, 309

Bromoform, $56 t$

Bronchial glands, 34

Bronchiectasis, 333; diagnosis and symptoms, 334

Bronchioles, 52

Bronchi, relation of, 52

Bronchitis, 326 ; absence of expectoration in, 32S; an accompaniment of infections, 327; acute, 326 ; bacteria in, 327; eapillary, 329, $34 \bar{\tau}$; chronic, 331; croupous, 333 ; diagnosis of, 329; etiology, 327; fibrous, 333; prognosis of, 329 ; symptoms, 328 ; treatment, 330

Bronchopneumonia, 329, 347; after measles, 552; bacteria in, 349 ; complications in, 350; diagnosis, 351; etiology, 34S; leeches in, 352 ; sequelæ, 351 ; symptoms, 349 ; treatment, 352

Broths, beef. chicken, clam, mutton, and oyster, 643

Budin, 129

Buhl's disease, 180

Bulbar paralysis, 439, 453; pseudo, 455 ; symptoms in Friedreich's disease, 473 ; in multiple sclerosis, 475

Bunge, 91

Buttermilk, 115

C

Cachexia, splenic, 489

Cæcum, in early life, 36

Calcium, 127; casein, 75, 92; paraeasein, 75; chloride, 508; phosphate in breast milk, 91 ; salts in milk, 129

Caleuli, salivary, 204. Vesical, 378; urine in, 379 ; treatment of, $379 ; \mathrm{X}$-ray in diagnosis, 379 
Calmuck type of imbecility, 458

Cancrum oris, 212

Canker sore mouth, 207

Capacity for attention, 143

Capillary bronchitis, 329

Caput obstipum, 157; succedaneum, 18,149

Carbohydrates, 93 ; of milk, 90, 91

Cardiac dulness, area of, 53, 300, 301 ; von Starck's type, 53

Caries, cervical, 512

Carpopedal spasm, 403

Casein, 75, 92; calcium, 74, 75, 92; hydrochloride, 75, 92; in cow's milk, 126, 128, 129; lactate, 75, 92

Casts in early infancy, 67

Catalepsy, 408

Cataract, 534; congenital, 156

Catarrh, acute nasal, 311; alveolar, 329 ; chronic intestinal, 265; gastric, 241 ; suffocative, 329

Centrifuge, Babcoek's, 102; Leffmann and Beam's, 103

Cephalhæmatoma, 149

Cephalic ery, 423

Cereal gruels, 129, 256, 642

Cerebellar form of Friedreich's disease, 473

Cerebral eroup, 402

Cerebritis, 431

Certified milk, 124

Chadwick, 143

Chalazion, 525

Chapin, 111, 113, 129; dipper, 121; method of milk modification, 121

Charcot-Leyden erystals, 333; in asthma, 336

Charcot-Marie-Tooth type, 475, 476

Cheadle's essentials, 110

Chemosis, 530

Cheyne-Stokes respiration, 424

Chicago milk commission, 116

Chicken-pox, 558; diagnosis, 559

Childhood, classification of, 42 ; diet in, 139 ; heart in, 141 ; physiology and hygiene of, 138

Child labor, 144

Chittenden, 113, 131

Chlorosis, 500; blood in, 500; symptoms, 500 ; treatment, 501
Cholæmia, 178

Cholera infantum, 257; blood in, 258; mortality, 257; pathology, 257; symptoms, 257 ; treatment, 258

Cholesteatoma, 540

Choluria in enteritis, 250

Chondritis, 511

Chondrodystrophy fotalis, 164

Chorea, 408; and rheumatism, 40S; electric, 409; habit, 411; Huntington's, 409; minor, 409 ; treatment, 410

Christopher, 141

Chronic adenitis, 485

Chrostek's sign, 401

Chyle, 74

Chyme, 73, 74

Cirenlation of blood, changes at birth, 61; obstruction of, during infancy, 63

Cirrhosis, liver, 2S5; etiology, 285; lung, 353

Class, 541

Clavicle at birth, 25

Claw-hand, 475

Cleft palate, 158

Cleido-cranial dysostosis, 165

Clitoris, adherence of prepuce, 359

Clothing, evils of, 65 ; infant's, 80,81 ; material, 65; of the new-born, 65; requirements of, 65

Clubbed fingers, 292

Club-foot, 155

Coagulability of milk, 128

Cold in the head, 311

Cold pack, 638

Colica mucosa, 265

Colic, due to uric acid crystals, 90, 244 ; intestinal, 244; renal, 244; symptoms, 245 ; treatment, 245

Colomba, 156; iridis, 156

Colon, characteristies of infant, 57 ; congenital dilatation of, 160

Colostrum, 70, 108; eharacteristics of, 94 ; rôle of, 86

Compensation in heart disease, 299

Condensed milk, 131

Congenital disease of heart, 289 ; malformations, 149

Conjunctiva, burns of, 532 ; injuries of, 532 ; wounds of, 532 
Conjunctivitis, 527; acute eatarrhal, 527 ; etiology, 527 ; treatment, 527. Chronie, 528; eroupons, diphtheritie, 531; follieular, 528; gonorrhœal, 529; kerato-phlyctenular, 531 ; purulent, 529 ; treatment, 530 Connor's table for milk modification, 123

Constipation, 262; in ehildhood, 140; in infancy, 137 ; treatment, 264

Constitutio lymphatica, 480

"Consumption of the bowels," 599

Contagious diseases, 634, care of, 634 Contractures, in myelitis, 467 ; in progressive muscular atrophy, 476 ; in spinal paralysis, 470

Convolutions of brain, at birth, 41

Convulsions, 394, 401; diagnosis in, 395; etiology, 394; in hydrocephalus, 152; prognosis, 396; in rhachitis, 198; treatment, 396

Coördination, 72 ; development of, 71 Coprolalia, 416

Cord, in Friedreich's disease, 472; hemorrhage in, 466 ; malformations of, 153 ; pressure symptoms, 466 ; spinal, tumors of, 154,471

Coryza, 311

Couveuse, 146

Cow-pox, 556

Cow's milk, how it differs from human milk, 126 ; intolerance of, 126

Coxitis, 514

Cranial sinuses, thrombosis of, 434

Craniotabes, rhachitis, 191

Cream, centrifugalized, 116, 124 ; gravity, 116, 118; percentage of fat in, 119; separated, 118

Cream of tartar lemonade, 644

Creamometer, Holt's, 100; Chevalier's, 100

Credé, 146

Creeping pen, 83

Cretinism, 493; acquired, 494; endemie, 495; sporadie, 494 ; symptoms, 493 ; treatment, 495

Cricoid cartilage, 52

Cromby, 253

Croup, 322 ; diagnosis, 322 ; membranous, 322 ; symptoms, 322 ; treatment, 323 ; true, 322
Cry, in infaney, 72; of new-born, 168

Cryptorchidism, 392

Cupped foot, 472

Curds, 75; effeet of sodium citrate on, 130 ; curds in stools, 129, 130

Curschmann's spirals, 333 ; in asthma, 336

Cutis tensa elnonica, 621

Cyanosis, 292; infantum, 170

Cyclic albuminuria, 368; romiting, 238

Cystic tumors of cord, 154

Cystitis, 381 ; in myelitis, 467; symptoms, treatment, 382

Cysts, dermoid, 156, 204; of kidney, 371 ; of mouth, 204

Czerniak, 224

\section{$\mathrm{D}$}

Dactylitis, syphilitie, 58s; tubereulous, 518 ; diagnosis, 519

Dairy, hygienic management of, 116 Dane, 134

Deaf-mutism, 417

Deafness from mumps, 567; in hereditary syphilis, 590

Decalcified milk, 129

Decaseinized milk, 128

Defects of bones, congenital, 164; of umbilicus, 160

Deformities, 144

Degeneration, acute fatty, 180

Dementia præcox, 465, 466

Dentition, 205; early, 205; otalgia, 205 ; reflex disorder's, 419 ; relation to disease, 205; retarded, 205; treatment of painful, 206

Dermatoselerosis, 621

Dermoid cysts, 156, 204; in mouth, 204

Development, overstimulation of, 83

Dextrinized gruels, 130

Diabetes insipidus, 627; melitus, 624; heredity in, 624 ; prophylaxis, 626 ; treatment, 625

Diapers, 66, 83; constrictions from, 136

Diaphragm at birth, 34

Diaphysis, 25

Diarrhœa, summer, 247; tubular, 265

Diastasis of recti muscles, 160 ; treatment of, 161

Diazo reaction, 579 
Diet, in later infancy, 137 ; in childhood, 139

Dietary, 642

Digestion, development, 132 ; evolution of, 75; in infancy, 73, 75; personal equation in, 93

Digestive system, diseases of, 201. Digestive tract, development of, 111; length of, in infants, 111; in calves, 111; malformations of, 158

Digitalis, 302

Dilatation, acute, of left ventricle, 303 ; of colon, 160; of heart, 299; of stomach, 160

Dilated ventricle, 143

Diphtheria, 568; albuminuria, 570 ; angina, 570; bacteriology, 568; blood, 569; complications, 573; convalescence, 575 ; diagnosis, 572 ; etiology, 56s; of the trachea, 326 ; nervous tissue, 569; paralysis, 572; pathology, 569; prognosis, 572; sequelæ, 573; sine membrana, 571; symptoms, 569; treatment, 573 ; types, 571

Diplegia, 447; in transverse myelitis, 467

Diploe, 46

Diplomyelia, 153

Diplopia, 534

Dipper, Chapin's, 121

Dipsomania, 465

Diseases, of blood, 495; bones and joints, 511; digestive system, 201; ear, 536; eye, 524; general, 624; genito-urinary tract. 366; glands, 480; glands, blood, bones and joints, 480 ; heart and pericardium, 289; infectious and hemorrhagie of new-born, 176 ; infectious specific, 541 ; intestine, 244 ; lips, 201; liver and pancreas, 283; mouth, 204; nervous system, 394; of new-born, 166; nutrition, 182; rectum and anus, 27S: respiratory tract, 311; skin, 604; stomach, 237: throat, pharynx, œsophagus, 215; tongue, 201

Disinfecting solutions, 645
Disinfection, 634

Dislocation of hip, congenitai, 155

Disorders, of digestive system, 201; of nutrition, 182

Disseminated sclerosis, 474

Distichiasis, 525

Diverticulum, Meckel's, 159

Dobell's solution, 646

Drop foot, 479 ; wrist, 479

Drugs, administration of, 635

Ductus arteriosus, 30 ; venosus, 31

Duodenum, at birth, 35; secretions of, 66

Dura mater, at birth, 41

Dusting powders, 647

Dyspepsia, acute, 246

Dysentery, anıbic, 261

\section{$\mathrm{E}$}

Ear, at birth, 21 ; diseases, 536 ; internal, 540; malformations of, 157; strain, 143

Eberth's bacillus, 578

Ecchymosis, 50S, 526, 532

Echinococcus, 287

Echolalia, 416

Eclampsia infantum, 394

Ectopia vesicæ, 162

Ectropion, 526

Eczema, 606 ; diagnosis of, 608; treatment, 608

Education, 141

Egg, albumin, 115, 12s; proteids, 128; water, 643 ; yolk, fat in, 129

Egotism, 464

Elaboration of brain cells, 60

Elongatio frenuli, 204

Emboli in leart disease, 296, 301

Emotions in infancy, 72

Emphysema, pulmonary, 358; subeutaneous, 359

Empyema, 363 ; treatment of, 365

Emulsion of fats, 648

Encephalitis, 431

Encephalocele, 150

Endocarditis, acute, 295; diagnosis, 297 ; lesions, 295; symptoms, 295; treatment, 297. Chronic, 298; diagnosis, 300 ; lesions, 295 ; prognosis, 301 ; symptoms, 299 ; treat- 
ment, 302. Infeetious, 296; in tonsillitis, 216; malignant, 296; prenatal, 290 ; rheumatism, eauses Enema, 641 of, 298; ulcerative, 296

Enteralgia, 244; in pneumonia, 244

Enteric fever, 578

Enteritis, acute, 247; classification, etiology, 248; bacteria, diet, 251; pseudomembranous, 252

Enteroelysis, 641; in anuria, 367

Enterocolitis, 252; diet in, 256; follicular, membranous, 253 ; prophylaxis, 253; pseudomeningitis in, 253 ; reinfection, 254; treatment, 253 ; nleerative, 253

Entropion, 525

Enuresis, 390; treatment, 391

Enzymes, of milk, 93; of saliva, 74

Eosinophilia, 269

Epicanthus, 156

Epiglottis, direct examination of, 28

Epilepsy, 463; and migraine, 420; diagnosis, 399; focal, 39S, 438; in birth-palsies, 449; Jacksonian, 398, 438; masked, 398; prognosis, 399 ; psychic, 398 ; treatment, 400

Epinephritis, 382

Epiphyses, 25

Fpiphysitis, acute, 520, 522

Epispadias, 163

Epistaxis, 316 ; treatment, 317

Erb's paralysis, 174; sign, 401; type, 475

Erotomania, 465

Eruptions from antitoxin, 575

Erysipelas, 179

Erythema simplex, 605

E'scherich, 76, 92, 547

Ethmoidal cells, 47

Ethmoid bone, 22

Eustachian tube, 24; at birth, 21, 22; growth, 47

Eustachian valve, 30

Examination of children, 166; of mouth, 168; rectal, 168

Exanthemata, 541; differential diagnosis, table, 560

Exencephalus, 150

Exereise, 83
Exomphalos, congenital, 160

Exophthalmos, 535

Exstroplyy of bladder, 162

External auditory meatus, 46 ; table of length, 46

Extremities, deformities of, $15 \pm$

Extubation, 578

Eye, at birtl, 23; diseases of, 524 ; injuries of, 534; malformations of, 155; paralysis of muscles of, 534 ; perforation of, 534; refraction of, 534

Eye-grounds in amaurotic idiocy, 460; eye-strain, 143

\section{$\mathrm{F}$}

Face, at birth, 23; growth of, 47

Facial defects, 158

Facies myopathique, 477

Facio-seapulo-humeral atrophy, 475

Fæces, at birth, 67 ; bacteria, 76 ; characteristics of, 73; color in infancy, 73 ; composition of, 73,76 ; frequency of, 73 ; incontinence of, 261 ; in infancy, 67,73 ; odor, 73

Farrington, 104

Fat absorption, 66; determination of, 100 ; methods of Babeock, Chevalier, De Laval, Feser, Holt, Leffmann and Beam, Marchand, Soxhlet, 100 ; relations of, to specifie gravity, 103

Fatigue, 144; period, 142

Fatty diarrhœa, 97 ; liver, 286

Favus, 616

Feeble-mindedness, 455

Feeding, 85, 89; artificial, 114; American methods of artificial, 115; advantages of, 115; failures in, 115; danger in, 116; percentage, 114; points to be observed, 132 ; sodium eitrate in, 129 ; whole milk in, 129. Bottle, 124. In pertussis, 564; premature infants, 148; nasal, 641 ; rectal, 641 ; substitute, 86 , 106 ; supplemental, 106; tube for premature infants, 148; tubes, 124 Feet, 134; care of, 135

Ferments, 67, 74; amylolytic, lipolytic, milk curdling, proteolytic, 67,74 
Feser's lactoseope, 101

Fetal circulation, 31

Fever, 72

Fibrillary twitehings, $473,475,476$

Fibrosis, pulmonary, 353

Fissures, Rolando, 41, 59; Sylvius, 41, 59

Fistulæ, branchial, 158; facial, 159

Flail gait, 470

Food, artificial, antiscorbutic quality, 111; forms of, 110; origin, 110 ; quantity, 110; sterility, 111. Essentials, antiscorbutic quality, 111 ; constituents of, 110 ; form of, 110 ; quantity of, 110 ; sterility of, 111. Eskay's, 131. In second year, 136. Liebig's, 131. Natural, 85. Nestlé's, 131. Dextrinized, 131. Milk, 131. Proprietary, 131; modification of, 132; temporary use of, 132 . Table of, 131. Variety not desired, 112

Foot and mouth disease, 208. Drop foot, 479

Fontanelle, elosure of, 46 ; in meningitis, 423

Fontanelles, 19

Foramen cæeum, 22, 47; ovale, 30

Forced attitudes, 440

Foreign bodies in the nose, 316; in pharynx and trachea, 325

Formulæ for home modification of milk, 119

Formulary, 645

Fraenkel's diplococeus, 338

Fragilitas ossium, 200

Freeman, 117

Freeman's pasteurizer, 116

Friedreich's disease, 472; cerebellar form, 473 ; sign, 309

Frontal bone, 22; sinuses, 47, 48

Fumigation, 634

Functional disease of heart, 293; diagnosis, treatment, 294

Furunculosis, 618

G

Galactagogue, 97

Gangrene of lungs, 355

Gargle, 646
Gastric gland, secretion of, at birth, 66 ; ulcer, 243

Gastritis, acute, 241; chronic, 259; feeding in, 260 ; treatment of, 260

Gastro-enteric tract, diseases of, 237

Gastro-intestinal infection, endogenous and exogenous, 251

Gastroptosis, 259

Gavage, 641

Gelatin, 180, 508

Genito-urinary organs, diseases of, 366 ; development of, 38 to 41

Gibbous kyphosis, 512

Gilbert, 141, 142

Glands, bronchial, 34 ; buccal, 55,66 ; cervical, 483; diseases of, 480 ; gastric, 66; inguinal, 484; labial, 55, 66; lachrymal, 68; Meibomian, 525 ; mesenteric, 484 ; of new-born, 66; palpable, 483; parotid, 66; post-pharyngeal, 55; salivary, 66; sebaceous, 68 ; sweat, 68

Glossitis, acute, 202 ; desquamative, 202 Glottis, œdema, 216, 323; treatment, 324 ; spasm of, $189,318,320,322$

Glycerite of iodine, 646 ; of tannin, 646 Glycosuria in infancy, 73

Goat's milk, 127

Goitre, exophthalmic, 496; simple hyperæmic, 497

Gonorrhœal conjunctivitis, '529; stomatitis, 213; vulvo-vaginitis, 386

Gout in asthma, 337

Gowers, 457, 460

Grand mal, 397

Graves's disease, 496; heredity, 497; treatment, 497

Green stools, 67, 73, 250

Grocery milk, 116

Growing pains, 629

Growth in infancy, rate of, 142; of arteries, 54 ; of brain, 59 ; relative, of head, chest, and pelvis, 44 ; retarded, 44 ; table of, 45

Gruels, barley, 130; cereal, 115, 130; dextrinized, 130

Gummata, periosteal, 521

Gums, lancing, 206

Gunhammer position, 423

Gurler's table, 120 
$\mathrm{H}$

Habit chorea, spasm, 526

Hæmatemesis, spurious, 244

Hæmatoma of sterno-mastoid, 157;

Hæmatomyelia, 466

Hæmaturia, 197, 296, 367, 509

Hæmic murmur, 504

Hæmoglobin, at birthi, 62; in Hodokin's disease, 486; in later infancy, 63

Hæmoglobinuria, $36 \tau$; epidemic, 180

Hæmolysis in peruicious anæmia, 501

Hæmophilia, heredity of, 507 ; joints in, 508

Hähner, 96

Hallucinations, 463

Harelip, 158

Harrington, 113

Hart, 92, 113

Headache, 419, 420, 580, 593; occipital, 439

Head-nodding, 412

Hearing, at birth, 69; development. of, 71

Heart, apex, location of, 54 ; at birth, weight, structure, position, 29; ehanges after birth, 30; chronic valvular disease, 298; consciousness, 293; defects in development, 32,33 ; development of, 32,52 ; diseases of, 289; embryonic, 32 ; functional disease, 293; in childhood, 141; in diphtheria, 572; in influenza, 564; malformations, 290; position, 53; rhytlim, 61; symptoms, 291; treatment, 292; valvular defects, 299

Heat prostration, 432

Hebephrenia, 465

Hemianæsthesia, 407

Hemiplegia, in endocarditis, 296; spastic, 447

Hemorrhages, adrenalin in, 180; calcium chloride in, 180; gelatin in, 180 ; in scurvy, 197 ; intracranial, 456 ; of the new-born, 180 ; subaponeurotic, 149 ; sub-dural, 41 ; sub-pial, 41 ; umbilical, 178 ; vaginal, 181

Hemorrhoids, 282
Henoch's purpura, 509

Hepatitis, suppurative, 284

Hereditary spastic paralysis, 473; spinal ataxia, 47.2; cerebellar form, 473

Heredity, 82; in imbecility, 455

Hernia cerebri, 150; aspiration in, 151 ; causes of, 151

Hernia, diaphragmatic, 162; inguinal, treatment ot, 161 ; of brain, 20 . 150 ; of umbilicus, congenital, 160 ; of umbiliens in eretinism, 493

Herpes, 613 ; treatment of, 614

Hip disease, 514, 515, 516

Hippus, 423

Hips, congenital dislocation of, 155

Hirseh, 460

Hives, 611

Hodgkin's discase, 485: etiology, 486

Holt, 113; creamometer, 100; home modification of milk, 118

Hordeolum, 525

Hot pack, 637

Hüppe, 92

Hydatids of the liver, 287

Hydrencephalocele, 150

Hydrocele, 392; congenital, infantile, 392 ; encysted, in girls, 393 ; treatment of, 393

Hydrocephalus, 426; acute, 443, 446; acquired, 446; congenital, 151; 446; diagnosis of, 446; lesions, 445; lumbar puncture in, 152; spontaneous evacuation, 152; symptoms, 444

Hydrochloric acid, 66, 73, 75; in infant stomach, $74,75,76$

Hydrochloride of casein, 92

Hydromyelia, 472

Hydronephrosis, 383

Hydrops cerebri, 443

Hydrotherapy, 637; in typlioid, 581

Hygiene, importance of, 82 ; of childhood, 13S; of first year, 78,85 ; of infancy, 77 ; of lactation, 96 ; of later infancy, 133 ; of the premature infant, 145: of the schoolroom, 143; of the sick-room, 633

Hymen, imperforate, 163

Hyperacusis, 461 
Hyperopia, 534

Hypertrophy, of the heart, 299; tonsils, 219 ; deafness, 220 ; treatment, 220

Hypochondriasis, 464

Hypodermoelysis, 256

Hypospadias, 163

Hypostasis, pulmonary, 355

Hysteria, 405; aphonia in, 406; diagnosis of, 407 ; heredity, 406 ; torticollis in, 406; treatment of, 407

\section{I}

Ichthyosis, 620

Ieterus neonatorun, 176 ; grave, 177 Idiocy, 455; amaurotic family, 459; lesions in amaurotic family, 461. Birth accidents as causes, 456; congenital, 456; etiology, 456; Mongolian, 458; prophylaxis, 459; types, 457

Idiots, brain pathology in, 457

Imbecility, 455; associated defects, 457 ; training in, 459

Imperative acts, 46.5; conceptions, 465 ; movements, 412

Imperial granum, 131

Impetigo contagiosa, 612

Inanition fever, 171

Incompetency, valvular, 299

Ineontinence, of fæees, 261; of urine, 390

Inenbator, 146

Indigestion, acute, 246 ; intestinal, 265 ; vomiting in, 237

Infancy, periods of, 42

Infantilism, 590

Infant, wants of, 78

Infections diseases, 541

Inferior maxilla, 23, 47.

Influenza, 564; blood in, complications, diagnosis, symptoms, sequelæ, types of, 565 ; treatment, 566

Inguinal canal, development of, 59

Inhalations, in asthma, 337; in laryn. gitis, 320 ; in pertussis, 564

Insanity, 463

Insolation, 432 ; blood in, 433; diagnosis, sequelæ, 433 ; treatment, 434

Inspection, value of examination, 166
Inspiration pneumonia, 170

Insular sclerosis, 474

Intention tremor, 474

Intermittent fever, 582

Intestiual occlusion, 159; parasites, 268

Intestines, at birth, 35,56 ; length of, 36 ; pecularities of, 35 ; aberrant, 56 ; bacteria of, 67 ; development of, 56. Small, growth of, 57; measurements, 56

Intubation, 576; feeding after, 578

Intussusception, 272 ; treatment of, 274 Iritis, 533

Iron, in breast milk, 91, 92; infant's liver, 92

Irrigation, colonie, 641; nasal, 639; stomach, 640 ; vaginal, 641

Iteh, 617

\section{J}

Jacksonian epilepsy, 398, 438

Jacobi, 129

Jacnbowiseh, 66

Janndice, of new-born, 176; pseudo, 177

Joints, diseases of, 511; tuberculous, 511

Jugulars, pulsation of, 301

Junket, 75, 644; egg, 644

$\mathrm{K}$

Kaposi's disease, 622

Katatonia, 465

Kennientt, 93

Kephir milk, 128

Keratitis, interstitial, 532

Kernig's sign, 424, 580

Kidneys, amyloid degeneration, 378; at birth, 38; congenital anomalies, 369 ; eystic degeneration, 369; diseases of, 366; displacement of, 370 ; growth of, 58 ; lobulation, 58 ; malformations, 369; movable, 370 ; peculiarities of, 38; position of, 38,58

Kindergarten, 140

Kirke, 73

Klebs-Loeffler bacillus, 322, 568

Kleptomania, 465 
Knee-joint diseases, 517

Koch, 593

König, 127

Koplik's sign, 550

Koumiss, 128

Krohn's diagram, 142

Kyphosis, 512

\section{L}

Labyrinthitis, 540

Lactalbumin, 92

Lactate of casein, 92

Lactates, 93

Lactation, 85; automatic adjustment of, 96 ; coitus, effects of, 98 ; conception, effects of, 98; defective, 97; diet in, 97; disturbances, causes of, 97; failures in, 97 ; hygiene of, 96 ; menstruation, effect of, 98; mental condition, -effects of, 97, 98; perversion, effect on child, 98

Lactic acid, 66, 92

Lactoglobulin, 92

Lactoseope, 101 ; Feser's, 101

Lactose, 92, 93

Ladd's table, 119

La grippe, 564

Landouzy-Dejerine type, 475

Landry's paralysis, 473

Lanugo, 17, 68

Laryngismus stridulus, 318, 402; relation to rhachitis, 403

Laryngitis, acute, 318; bacteria, 322 ; eatarrhal, 318; ehronic, 320; pseudo-membranous, 322 ; symptoms, 319 ; syphilitic, 321 ; treatment, 320 ; tuberculosis, 321

Laryngospasm, 318, 402

Larynx, at birth, 27 ; direct inspection of, 28; foreign bodies in, 325; position of, at birth, 28 ; tumors of, 324

Lassar's paste, 648

Laure, 96

Lavage, 640

Lecithin, 127; in amanrotic family idiocy, 460

Leeches, 293, 352; in pneumonia, 347 , 352
Leeds, 113, 131

Leffmamn, 131; and Bcam, 113; Leffmann and Beam method, 102

Length, at birth, 17 ; growth in, 44

Leptomeningitis, $42 t$

Lesage, 250

Leucoeytosis at birtli, 62

Leueopenia, 552; in malaria, 584; in typhoid, 580

Leukæmia, 503; blood in, 503: diagnosis, 506; etiology, 504; lymphocytic, 505; symptoms, 504; treatment, $506 ;$ types, 505

Lichen tropicus, 610

Lids, affections of, 524; burns, 526; injuries, 526

Lime, 91

Lime water, 115, 117, 124, 644

Lingua geographica, 202

Lips, diseases of. 201

Liquor calcis, 115, 117, 124, 644

Little's disease, 474

Liver, abscess of, 284 ; acute infectious, 284; acute yellow atrophy, 286; amyloid degeneration of, 287; blood supply of, 63; boundaries of, 88; congestion, 283; cirrhosis, 285 ; development of, 36,37 ; diseases of, 283; enlarged in icterus, 178; enlargement of, 37 ; fatty, 286 ; growth of, 57 ; hydatids, 287 ; iron in infant's, 92 ; location at birth, 37; tumors, 287; weight of, at birth, 37

Loeomotor ataxia, 474

Long bones, centres of ossification, 26; development of, 25: medullary canal, 26 ; periosteum of, 25

Lumbar puncture, 428, 636; in hydrocephalus, 152

Lumbricoides in larynx, 325

Lung, abseess, 355: alveoli, 29, 52; anatomical peculiarities, 327 . At birth, 28 ; position of, 29 ; structure of, 29 ; weight of, 29 . Bloodvessels, 52 ; cirrhosis of, 353 ; collapse of, 356 : development of, 51 : gangrene, 355; physiological congestion of, 327

Lussehka's tonsil, 224, 225 
Lymphadenitis, 482; in Hodgkin's disease, 486

Lymphadenoma, 485; of tongue, 202; splenic, 489

Lymphæmia, 489

Lymphangioma of tongue, 202

Lymphatic anæmia, 485

Lymphatisn, 319, 480; and tubereulosis, 5.93 ; treatment, 482 ; types of, 480

Lymphocytosis, 487 ; at birth, 62 ; in pertussis, 561

Lymphoid corpuseles, 66; ring, 228; tissue of stomach, 55

\section{M}

Macewen's sign, 423

Macrocheilia, 201

Macroglossia, 201

Macrostoma, 158

Macula lutea in amaurotic family idiocy, 460

Malaria, 582; blood, 583; diagnosis, etiology, 583; leucopenia, 584; prophylaxis, 585; symptoms, 583; treatment, 584

Malformations, congenital, 149; of digestive tract, 158; of ear, 157; of extremities, 154; of eye, 155; of heart, 290 ; of spinal cord, 153

Mallory, 541

Malted milk, 131

Mammary glands, at birth, 41; evolution of, 85

Mania, 463

Maransis, 184; treatment, 184

Marasmus, 182; diagnosis, 181; œdema in, 183; psendomeningitis, 183

Marchand's tube, 101

Massage, 83, 636

Mastication, 136, 176

Mastitis neonatorum, 176

Mastoid cells, 20 ; process, 46

Mastoiditis, 539; complieations, 539 ; sequels, 539

Masturbation, 417

Materna, 121

Matzoon, 128

Maxillary, inferior, at birth, 23

MeCollom's white line, 516
Measles, 549; artificial, 549; atypical, 551; black, 551; blood in, 552; eharacter of eruption, 551 ; complications, 551 ; conjunetivitis, 550 ; diagnosis, 552. German, 554; diagnosis, 554; symptoms, 554 . Hemorrhagie, 551; mucous membranes, 550 ; prognosis, 552 ; quarantine, 553; sequelæ, 552; symptoms, 550 ; treatment, 553

Meat juice, raw, 644; proteids, 115 ; raw, 643

Meatns, external auditory, 20, 21

Meckel's diverticulum, 159

Meconium, 67

Medullary substance, 60

Meigs, 113

Melæna neonatorum, 181

Melancholia, 413

Membrana tympani, 21

Meningitis, 421; basilar, 425; bacteria in, 42.2 ; blood in, 427 . Cerebrospinal, 426 ; abortive, 426 ; and pneumonia, 426; fulminans, 425. Diagnosis, 427; etiology, 422; examination of ears in, 431 ; in endocarditis, 297 ; infantile, nontubereulous, basilar, 430 ; lumbar puncture, 431, 427. Posterior basic, 430 ; prognosis, 431 ; symptoms, prophylaxis, 430 ; results of, 456 ; secondary to infections, 421 . Simple basic, 430 ; susceptibility in infancy, 422; syphilis in, 431; symptoms of, 423 ; treatment, 429 ; tubereulous, 425

Meningocele, 150 ; spinalis, 154

Meningomyelocele, 154

Mental dulness, 143

Meyer, 224

Microcephalus, 152

Microphthalmus, 156

Micturition at birth, 68; frequency of, 68 ; in infancy, 68

Migraine, 420 ; treatment, urine, 421

Miliaria, 610

Milk, acidity of, 94 ; alkali in, 117; analysis, 100, 107; microseope in analysis, 104; bacteria, in, 116; boiled, 117; breast, 90 ; carbo- 
hydrates, 91 ; certified, 124 ; coagulability of, 129; colostrum, 194; comparative analysis of goat, ewe, ass, and mare, 127; comparative analysis of bovine and human, 113; condensed, 131; constituents of, 90 ; eow's, curds of, 75; "erusts," 605; curdling ferments, 67 ; deealcified, 129 ; deeaseinized, 128; deeomposition of, 116 ; dilution, 129; enzymes of hunian, 93 ; fat free, 124; fats, 91 ; home modification, 116, 11s; rules for h. m., 118; utensils for h. m., 124; care of utensils, 124. Human, effeets of dry diet upon, 96; mental eonditions influeneing, 97 ; produetion of, 95 ; quantity at different periods, 96 ; laboratories, 114, 115; lime salts, 129; nuelein in, 92,126 ; of mammals, 112; paranuelein, 126 ; peptonized, 127 ; phenolphthalein test, 94; phosphorus, 92, 127; predigestion of, 127 ; production, 85 ; proteids of, 90 ; raw, 117 ; reaction, 94 ; salts, 91; secretion, agents influeneing quantity, 97 ; excess of fats in secretion, 97 ; regulation of secretion, 99 ; specific gravity, 90, 94; sugar, 91 ; fermentation of sugar in, 77; supply, 116; synthesis, 110 ; table of mineral constituents, 93; total solids, determination of, 104; Rules of Farrington and Woll, 104

Milkine, 131

Minnesota dairy report, 131

Mitral insufficiency, lesions, stenosis, 299

Mixed fats, 648; infection in diphtheria, 569

Moceasins, 135

Modification of milk, 118; Chapin's method, 121; Connor's table, 123; Gurler's table, 120; Ladd's tables for, 119

Mongolism (Mongolian idiocy), 458; degrees in, 458; obesity, skin in, tongue in, 458
Monne-Marie's disease, 473

Monophobia, 465

Monoplegia, 449

Morbilli, 5ł9; miliaria, 551

Morbus ecruleus, 170 ; coxarius, 514; maeulosus Werlhofii, 509

Morphine, in diphtheria, 574

Mortality of infants, eauses of, 108

Moser's serum, 547

Notor oculi nerve in infaney, 71

Moutl breathing, 226; care of, 133; of embryo, 22; washes, 646

Movements, imperative, 412

Mueveolitis, 265

Mucous disease, 265; dilatation of stomach and colon, 266; etiology, 266 ; treatment, 267

Muguet, 209

Multiple neuritis, 478; etiology, 478; symptoms, 479

Multiple selerosis, 474

Mumps, 567

Murmur, 301 ; apical, 216; hæmic, 504 ; systolie, 502

Museles, voluntary, development of, 71

Muscular atrophy with pseudohypertrophy, 476; dystrophies, 477; heredity, 477 ; pseudohypertrophy, 475

Mutism due to labyrinthitis, 540

Myelitis, eystitis in, 467; diplegia, symptoms, 467; transverse, 466;

Myelocytes, 505

Myelosyringosis, 471

Myocarditis, 303; lesions, symptoms, 304 ; treatment, 305

Myopia, 534

Myosthenia gravis, 455

Myotonia, 68; congenita, 404

Mysophobia, 464

Myxoneurosis coli, 265

Næri, 163

Nails, at birth, 17

Nasal diphtheria, 571; feeding, 641; irrigation, 639; irrigator, 134 ; septum, 47

Nasopalatine canal, 23

Nasopharynx, 24, 48; care of, 133 
Natural feeding, 85

Neek, at birth, 24; hydrocele, 158

Needs of the infant, 70

Nephritis, acute, 372; chronic, 376; diagnosis, 374; frequeney, 376 ; in pertussis, 563; cedema in, 373; pulse in, 373 ; treatment, 374

Nerve degeneration in diphtheria, 569 Nerves, anastomosis of, 175; peripheral sheaths of, 60

Nervous system, at birth, 68; diseases of, 394; growth in, 59 ; in amanrotic family idioey, 461 ; medullation, 60 ; tracts of, 71

Nettle-raslı, 611

Neuralgia enterica, 244

Neuritis, multiple, 478; obstetric, 479; post-diphtheritic, 475; treatment of post-diphtheritic, 479

Neutrophiles in Hodgkin's disease, 487 New-born, anatomy of, 17; anuria, 172 ; care of, 69 ; cord of, 69 ; diseases of, 166 ; eyes of, 69 ; infectious and hemorrhagic diseases of, 116 ; infant, needs of, 70

Night-terrors, 414, 415

Noma of face, 212

Normoblasts at birth, 62

Nose, at birth, 23

Nose-bleed, 316

Notch of Rivinus, 21, 46

Nourishment, 85

Nucleon, 92

Nursery, 79

Nursing, bottle, 124 ; infant's adaptation for, 85 ; instinet not a sufficient guide, 86 ; mother's adaptation for, 86

Nutrient enemata, 255

Nutrition, disorders of, 182

Nystagmus, 412, 535

\section{0}

Obstacles to application of hygiene, 77

Obstetrical paralysis, 174; diagnosis, 174

Oceiput, flat in Mrongolism, 4S5

Occlusion, intestinal, 159; common site of, 159; of bile-duct, congenital, 177
Edema, 623; in nephritis, 373; of glottis, 216, 323

Esophagitis, 233

Esophagus, at birtl, 35; bifurcation, 159 ; constrictions, 35 ; diseases of, 233 ; fistulæ of, 159, 233; foreign bodies in, 233; neurosis of, 234; ocelusion of, 158; spasm of, 234; stricture, 233

Oligæmia sicea, 258

Oliguria, 366

Omphalitis, 179

Ophthalmia. See Conjunetivitis

Opisthotonos, of infaney, cervical, 430

Oppenheim, 461

Optic atrophy in multiple sclerosis, 475

Ossification, at birth, 18; of long bones, 25

Osteitis, 511

Osteochondritis, 511

Osteogenesis imperfecta, 164

Osteomalacia, 199; lime salts, paucity of, 199

Osteomyelitis, 511; acute, 522; chronic, 518

Osteoperiostitis, 521

Osteopsathyrosis, 200

Otitis interna, 540; etiology, 540; relation to diabetes, syphilis, and ehronic nephritis, 540

Otitis media, 536 . bacteria, 537; diagnosis, 537; etiology, importance of, 536 ; prophylaxis, 538 ; sequel of scarlatina, 537; of pneumonia, 537; simulating meningitis, 538; treatment, 538

Outing, 83

Ova, number at birth, 40

Ovaries, at birth, development, 40

Overwork, 144

Oxyuris vermicularis, 269; treatment, 270

\section{$P$}

Packs, cold, 638; hot, 637

Palate bones, 23; cleft, 158; high arched, 226

Palsy, infantile cerebral, 447, 452; 
contractures, 451; diagnosis, 453; etiology, 450; history, 451; lesions of cord in, 448; orthopædic surgery in, 453; postnatal, 450; symptoms, 449

Paludism, 582

Pancreas at birth, 37

Pancreatic secretion, 73, 74; ferments of, 67

Panereatitis, syphilitie, 28s; tubereulous, 288

Panphobia, 465

Paracasein, 75, 76, 92

Paralysis, cerebrospinal, 473; bulbar, 439; crossed, 439; Erb's, 174; forms of, 469; hereditary spastic, 473; labio-glosso-laryngeal, 439, 453; Landry's, 473; natal, 448; obstetrie, 174; peripheral, 174; post-diphtheritic, 572; progressive bulbar, 453; psendohypertrophic, 476 ; spinal, 468

Paranephritis, 382

Paranoia, 465

Parapeptone, 73

Paraplegia, 447; following infectious diseases, 466

Parathyroid, 34, 492

Parasites, intestinal, 268; in anæmia, 501

Paretic dementia, 462; in hereditary syphilis, 462

Parietal bone, 22

Parotid gland, secretion of at birth, 66

Parotitis, epidemic, 567

Pasteurization, 117

Pathophobia, 464

Patulous ventricular septum, 32

Pavor diurnus, 414; nocturnus, 414

Pedatrophy, 182

Pediculosis, 618

Peliosis rheumatica, 509

Pemphigus neonatorum, 178; nonsyphilitie, peri-umbilical, syphilitic, 178

Pepsin, 73, 75

Peptogenic milk powder, 131

Peptonization of milk, 127

Percentage feeding, 114

Peribronchitis, 347, 353
Pericarditis, acute, 305; adhesions in, 306 ; aspiration in, 309 ; diagnosis in, 307; treatment, 307. Chronic, 309; sudden death in, 310. Effusion in, 305; exudate in, miliary tubercles in, symptoms, 306

Pericardium, adherent, 309; at birth, 19

Periostitis, 518

Perlèche, 201

Perles de Laennec, 336

Pernicious anæmia, 501, 502; blood in, 501; diagnosis, 503; leart, 502; symptoms, 502; treatment, 503; urine in, 502

Perspiration, 72

Pertussis, 561, and measles, 552; blood in, 561; complications, 563; diagnosis, 563; feeding in, 564; hemorrhages in, 562; inhalations in, 564 ; sequels, 563 ; treatment, 563

Petit mal, 397

Petrosal bone, 20

Petrosquamous suture, 21, 46

Pfeifer's bacillus, 564

Phalanges, tuberculous, 518

Pharyngitis, acute, 222; chronic, 224; rheumatic, 223 ; syphilitic, 224

Pharynx, at birth, 24; diseases of, 215

Phimosis, 388; effects of, 389

Phlyctænulæ, 531

Phospho-carnic acid, 92

Phosphorus in breast milk, 92

Phthisis, fibroid, 353

Physiology, of childhood, 138; of first year, 71

Pityriasis linguæ, 202

Placques pterygoidiennes, 208

Plasmodia, 582

Pleurisy, 359

Pleuritis, 359 ; aspiration, 362 ; diagnosis, 363 ; operation for effusion, 365 ; pathologic anatomy, 360 ; prognosis, 363 ; rheumatic, 360 ; symptoms, 361 ; traumatic, 360 ; treatment, 364

Pleuropneumonia, 360 ; pneumococcus in, 360

Pneumococeus, 338

Pneumonia, 33s; abdominal, 343; abortive, 342 ; aspiration, 170 ; 
atypical, 343 ; bacteria, 338 ; blood in, 342 ; capillary, 347 ; catarrhal, 347 ; central, 342 ; cerebral, 343 ; complications, 343 ; cough in, 340 ; erisis, 340 ; croupous, 338 ; diagnosis, 354; fibrous, 338; hypostatic, 184, 355; inspiration, 170 ; interstitial, 353; lobar, 338; lobular, 347 ; massive, 343 ; of short duration, 342; pathologic anatomy, 338, 353; Pfeiffer's bacillus in, 343 ; prognosis of, 344 ; prolonged, 343; pseudocrisis, 340; pulse, $3 \pm 1$; recurrent, $3 \pm 2$; simulating appendicitis, 377 ; symptoms, 339, 353; treatment, 345 , 354 ; urine in, 342

Pneumonitis, 338

Polioencephalitis, acute, 432 ; inferior, superior, 432

Poliomyelitis, acute anterior, 468; deformities in, 470 ; diagnosis, 470 ; etiology, 468; muscles involved, 469; pathology, 468; prognosis, 470 ; stages, 469 ; treatment, 470

Polyarthritis, chronic, 519

Polypi, nasal, 316 ; rectal, 281

Pomum Adami, 52

Porencephaly, 432

Porter, 141

- Posthitis, 384

Potassium salts in breast milk, 91

Pott's disease, 511

Poynton, 129

Precocity, 84

Predigestion of milk, 127 ; pernicious effects of, 127

Premature infant, feeding of, 148

Prematurity, 145

Prepuce, adherent, 40, 388; at birth, 40

"Prickly heat," 610

Proctitis, 278; prophylaxis, 280

Progressive muscular atrophy, 475

Prolapse of rectum, 280

Propeptones, 73

Proprietary foods, 131

Prostate gland, at birth, 40

Protection, 78

Proteids, in artificial feeding, proportion to fats, 115; in eggs, 128; in whey, 92, 128; of breast milk, 93; of milk, 90,91 ; reduction of excessive, 98 ; soluble, 128; split, 119, 121

Pseudo-ankylosis, 507

Pseudodiphtheria, 576; bacilli, 572, 576

Pseudoleukæmia, 485; of infancy, 506 ; splenic, $₫ 89$

Pseudomembrane in measles, 551; in scarlatina, 545 ; of trachea, 326

Pseudomeningitis in atrophy, 183

Pseudoparalysis, in rhachitis, 191; syphilitic, 520, 589

Psoas abscess, 512

Psoriasis, 619

Psychopathies, 463; prophylaxis, 465; treatment, 465

Ptosis, 526; congenital, 156

Pubescence, 142, 466

Pulmonary circulation at birth, 61; hypostasis, 189, 355; tuberculosis, 594

Pulse, 72 ; in second year, 136; rate affected by position, 61 ; rate at birth, in later infancy, 61; "water hammer," 301

Pulse-respiration rate, 327 ; ratio, 136 .

Puncture, exploratory, 309

Pupil, paradoxical, 423

Purpura, 508; diagnosis, 510; from drugs, 509 ; fulminans, 509; Henoch's, simplex, 509; treatment, 510 ; urticans, 509

Pyelitis, 380; etiology, 380

Pyelonephritis, 380

Pyloric stenosis, congenital, 159, 240 .

Pyonephrosis, 380

Pyrexia, in infancy, 72

Pyromania, 465

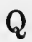

Quinine, in pertussis, 564

Quinsy, 216; apical murmur in, 216.

$\mathrm{R}$

Ranula, 204

Raspberry tongue, 544

Reaction of human milk, 94 
Rectum, at birth, 36; growth of, 57; malformations of, 159 ; peculiarities in childhood, 36; prolapse, 36 , 280 ; ulceration, 278

Reflexes, 418; at birth, 68, 69

Reilly, Health Commissioner, 624

Relative proportions of new-born, 18

Rennet, 73, 75, 92

Rennin, 92, 128

Respiration, 63, 72; causes of impairment of, 63 ; development of, 63 ; in second year, 138; in young infants, 63 ; rate of, 72 ; ratio to pulse, 64,327 ; types of, 64,72

Respiratory tract, diseases of, 311

"Rests," 39

Retardation in development, 292; in growth, 44

Retention of urine, 366

Retro-œsophageal abscess, 235

Retropharyngeal abscesses, 55, 230; lympharic, syphilitic, tubereulous, 230

Rhachitis, 91, 152, 185; acute, 186; atelactasis, 185; and adenitis, 190; and laryngismus stridulus, 189, 403 ; and tetany, 189 ; blood findings in, 190; bones in, 187, 192; craniotabes, 191; deformities in, 188; dentition in, 188; diagnosis of, 192; diastasis in, 160 ; diet, 193; etiology, 185; epiphyses, 188, 191; fetal, 186 ; Harrison's groove, 188; late, 186; pathology, 186; prognosis, 192 ; pseudoparalysis in, 191 ; rosary, 191 ; spinal curvatures, 189 ; splenic enlargement in, 190, 488; tendency to catarrh in, 189, 327; time of occurrence, 186; treatment, 193

Rheumatism, 628; blood in, 630 ; causes of endocarditis, 298; chorea in, 408, 630; diagnosis, 629, 630; exciting cause of, 628; heredity in, 628; treatment, 631

Rhinitis, 311; contagiousness, 311; symptoms, 311; treatment, 313 . Atrophic, 312; chronic, 312; treatment, 314. Effects of, 312; membranous, 315 ; syphilitic, 316
Ribs, at birth, 27

Rice-water, $6 \pm 2$

Richmond, 104, 113

Rickets, 132, 185

Riga's disease, 203

Ringworm, 614

Rivinus, noteh of, 21, 46

Roberts, 141

Rodagen, 497

Rosary, rhachitic, 191

Rotch, 93, 99, 113, 114

Rötheln, 554

Round-worms, 269

Roux and Lannois, 486

Rubefacients, 648

Rubella, 554

Rubeola, 549

Russell, 93, 113

\section{S}

Sachs, 461

Saddle nose, 312, 589

Saliva, 72, 74, 136; at birth, 66

Salivary glands, at birth, 66

Salivation in glossitis, 202

Salkowski, 127

Salts, effects of deficiency, 92 ; human milk, table of, 93 ; of breast milk, 91, 92; of milk, calcium phosphate, 91 ; iron, 91 ; potassium carbonate, chloride, sulphate, 91 ; sodium chloride, 91

Sarcoma of ear, 540

Säuglingsalter, 42

Scabies, 617

Scanning speech, 472; in paretic dementia, 462

Scapula, at birtl, 25

Scarlatina hæmorrbagica, 544; maligna, 544, 546

Scarlet fever, 541; blood in, 544 ; complications, 545; deaf mutism, 545 ; diagnosis, 546; etiology, 541; in infancy, 542; nephritis, 545; otitis, 545; prognosis, 546; sine angina, eruptione, febre, 544; sources of infection, 542 ; susceptibility, 542; symptoms, 543; throat lesions, 545; treatment, 547 ; types, 544 


\section{Schäfer, 94}

Schœnlein's disease, 509

Sclerema neonatorum, 173; temperature in, 173

Scleroderma, 621

Scorbutus, 132, 195; age of occurrence, 197; associated with rickets, 197; diagnosis, 198; exophthalmus in, 535; increased frequency, 196 ; prognosis, 199; symptoms, 197 ; treatment, 198; urine, 197

Scrofula, 480

Scurry, infantile, 195; complicating rickets, 193

Seborrhœa, 605

Seiler's solution, $6 \pm 6$

Sensation, 72

Senses, development of, 71 ; special, at birth, 69

Sensorial idiots, 459

Septic thrombosis, 435

Septum of nose, 47

Serum therapy, 498, 547, 573

Sexual perversion, 418

Shiga's bacillus, 252

"Shingles," 613

Shoe, orthopædic, 134

Sick-room, hygiene of, 633

Siegfried, 92, 126

Sight, at birth, 69; development of, 71

Signs, Babinski's, 423, 474; Broadbent's, 309; Chvostek's, 401; Erb's, 401; Friedreich's, 309; Kernig's, 424; Koplick's, 550; Macewen's, 423; Oppenheim's, 475; Squire's, 424; Troussean's, 401

Simola mixture, modified, 648

Skin, blood supply of, 68 ; care of, 68 ; diseases of, 604; constitutional causes of diseases, 604; glandular activity of, 68; of new-born, 17

Skull, 18; at birth, 20; fractures, 20

Sleep in infancy, 137

Slyke, von, 113

Smallpox, 555; modified, 557

Smith, E. E., 131

Sodium bicarbonate, 115, 117; chloride, 91 ; citrate, 129

Soor, 209
"Soother," 228

Sore mouth, canker, 207; putrid, 210

Southworth, 74

Soxhlet, 117

Spasm, habit, 411

Spasms, 394

Spasmus nutans, 412

Spasticity, 451

Specific gravity of human milk, 94 ; of milk, determination of, 105

Speech, defects of, 415 ; development of, 72

Spencer, 141

Spermatic cord, at birth, 40 ; composition, 40

Spina bifida, 25, 153

Spinal caries, 511; diagnosis, 513; symptoms, 512; treatment, 514

Spinal cord, at birth, 41 ; cystic tumors, 154; growth of, 60 ; malformations, 153 ; ratio to body weight, 60 ; weight at birth, 60

Spinal curvatures, 144

Spinal fluid in meningitis, 427

Spina ventosa, 518, 521; pedarthrocace, 518

Spleen, at birth, 37 ; disorders of, 487 ; enlarged, $178,300,488,580,583$; etiology, 488; functions, 487; in malaria, 583; in syphilis, 587; in typhoid, 580; palpability, 37; pecularities, 58; rupture, 488; supernumerary, 37 ; tumors, 488

Splenectomy, 487

Splenic anæmia, 489

Splenomegalia, 489

Spondylitis, 511

Sponge bath, 638

Spotted ferer, 426

Sprays, 646

Squamopetrosal suture, 21, 46

Squint, 535

Squire's sign, 424

Stammering, 416

Standing, 72

Starch in feeding, 130

Starr, 113

Starting pains, 512

Starvation, 132

Status epilepticus, 369; lymphaticus, 481 
Steapsin, 67

Stenosis of pylorus, 159, 240

Stephenson, 141

Sterilization, 117

Stern, Heinrich, 624

Sterno-mastoid hæmatoma, 157

Sternum, at birth, 27

Stigmata of degeneration, 157, 452

Still's disease, 519

Stomach, absorption from, 73;

birth, 35; function of, at birth, 66 ; eapacity of, 35; capacity of, in infancy, 55; derelopment of, 55 , 73 ; digestion in, 73 , 75 ; dilatation, 401 ; functions of, 73 ; lymphoid tıssue, 35,55 ; position of, 55

Stomatitis, 206; aphthosa, 207; catarrhalis, 206; follicular, 207; gangrenosa, 212; gonorrhœal, 213; herpetica, 207; membranosa, 213; mycetogenic, 209; myeosa, 209; parasitic, 209 ; ulcerosa, 210 ; vesicular, 207

Stools, green, 67 ; in infancy, 67,73 , 250

Strabismus, 535

Stridor, congenital laryngeal, 318

Strophulus, 610

Struma, 480

Strychnia in diphtheria, 574

Stuttering, 416

Stye, 525

Stypticin, 508

Subdural hemorrhages, at birth, 41

Substitute feeding, 106

Sucking pads, 23, 55, 86

Suckling, 86; asepsis, 87; control of, 88; duration of, 87, 89; effects of irregular, 87; frequency of, 87 ; hasty, 89 ; influence of mother during, 88; rules for, 87, 88, 89; too frequent, effects on child, 88,98

Sudamina, 610

Sudden death, 481 ; in enlarged thymus, 491

Sugar of milk, 91, 93

Sulphur, 92

Sunlight, 83

Sunstroke, 432
Suprarenals, at birth, 38

Sutures, 19, 21, 46

Sword leg, 521

Symblepharon, 532

Synovitis, 511; acute purulent, 522; tubereulous, 517

Syphilis, 285, 472., 585; acquired, 585; arthritis in, 521; hereditary, 5S5; deafness in hereditary, 590; dementia, 462; diagnosis, 586. 590; infantilism, 590 ; late, 589 ; lesions, pathology, pemphigus, 586 ; prophylaxis, 591; sunflles, 58s; spleen, 4S8; symptoms, 5SS; teeth in, 205, 586, 590; treatment, 591 ; transmission, mode of, 555

Syphilitic diseases of bones and joints, 520 ; pseudoparalysis, 520,589

Syringomyelia, 153,471 ; symptoms, 472

\section{$\mathrm{T}$}

Tabes dorsalis, $47 t$

Table, for home modification of milk, 119; Connor's, 123; Gurler's, 120 ; Ladd's, 119; of per cent. of fat and cream, 119

Tache cérébrale, 423

Tachycardia, 293, 419, 497

Tænia elliptica, 269; mediocanellata, 269 ; solium, 269

Talipes, 155, 473; in spinal paralysis, 470

Tapeworm, beef, 269; pork, 269; treatment, 272

Tapping in hernia cerebri, 151

Tarnier, 146

Taste, at birth, 69; development, 71

Tears, 72

Technique of bottle feeding, 124

Teeth, care of, 206; effects of malnutrition on, 205 ; eruption of, 50 ; grooved, 205; permanent development of, 50 ; syphilitic, 205, 586, 590 ; table of eruption, 51 ; temporary, development of, 49 ; characteristics of, 49

Temperature, at birth, 64 ; effects of lowering, 81 ; elevation of, 72 ; importance of even maintenance 
in new-born, 64; in sclerema, 173; normal, variations in, 64 ; subnormal variations in, 64; subnormal, 72

Testicles, at birtl, 40 ; development and descent of, 40 ; undesceuded, 392

Tetanilla, 401

Tetanus neonatorum, .179 ; nasal feeding in, 179

Tetany, 401

Therapeutic suggestions, 635

Thermic fever, 432

Thermo-anæsthesia, 472

Thermometer, bath, 79

Thierselı's grafts, 526

Thomsen's disease, 404

Thorax, at birth, 27; cartilage in, 27; changes in, 51 ; diameters, 51

Thread-worms, 269

Thrombosis of eranial sinuses, 434; etiology, 435; prophylaxis, 436 ; symptoms, 435

Thrush, 209

Thumb sucking, effect on jaw, 228; prevention of, 81

Thymus, cause of sudden death, 481, 491; changes in, 54 ; disorders of, 491 ; enlarged, 294, 491; secretion of, 491 ; gland, at birth, 33

Thyroid, 33

Thyroid, accessory, 492; blood supply, 33,492 ; development of, 54 ; disorders of, 492; extract, effect of, 492, 495; extract in cretinism, 495; transplantation, 492

Tic convulsif, 411 ; facial, 411

Tinea favosa, 616 ; treatment of, 616 ; trichophytina, 614

Tongue, at birth, 23; cysts, 201 ; diseases of, 201; geographic, 203; hypertrophy, 201; infant, 55 ; inflammation, 202; -tie, 204, 415; ulcer, 203

Tonsillitis, acute, 215; and chorea, 409 ; ehronic, 219; chronic, witb adenoids of nasopharynx, 219 ; infectious nature, 217; lacunar, 217 ; phlegmonous, 216; endocarditis, 216; pseudomembranous, 219 ; relation to other infections,
215; rheumatic, 218; suppurative, 216 ; ulceromembranous, 220

Tonsil, Luschka's, 48

Tonsils, 55

Torticollis, in hysteria, 406; in rheuTrachea, bifurcation of, 52 ; location matism, 629

Touch, at birth, 69

of, 28; pseudomembrane, 326;

size of, at birtl, 28

Tracheitis, 326 ; diphtberitic, 326

Trachoma, 528

Tracy, 134

Transplantation, of nerves, of tendons, 471

Trauma, as cause of insanity, 464

Trichiasis, 524

Tricophyton fungus, 614

Tricuspid valve lesions, 299, 301

"Trident hand," 165

Tronsseau's sign, 401

Truss, woollen, 161

Trypsin, 67; action of, 74

Tubbing, 638

Tuberculosis, 285, 592; abdominal, 599; symptoms, 597. Abscessies in, 597; and Addison's disease, 490 ; and influenza, 564 ; blood findings in, 597; diagnosis, 597; frequency, 592; general treatment, 602; glandular, 593, 598; diagnosis of glandular, 599; symptoms of glandular, 598. Heredity in, 593; marasmic, 595; miliary, 595; mode of infection, 593; of larynx, 321 ; of pancreas, 288; of the brain, 597; pathology, 593; peritoneal, 600 ; C. animal inocnlation in, 601; diagnosis of, 601 . Pulmonary, 594; spleen in, 488; symptoms and signs, 596 ; treatment, 602; tuberculin in, 597; tumors of cerebellum, 439

Tuberculous, adenitis, 598; portals of infection, 592, 593, 598; ulcers, 599

Tumors, of brain, 436; cerebellum, 438 ; crura cerebri, 439 ; ear, 540 ; larynx, 324; liver, 287; spinal cord, 471 
Tussis convulsiva, 561

Tympanic, eavity, 21; membrane, 21

Typhoid fever, 578; and meningitis, 580 ; blood, diagnosis, 580; etiology, 578; fetal, 579; infantile, peculiarities of, 579 ; intestinal lesion, 579 ; modes of infection, 578 ; prognosis, 581 ; susceptibility, 579 ; symptoms, 580 ; treatment, 581

Tyrotoxicon, 251

\section{$\mathrm{U}$}

Ulceration of rectum, 278

Ulcerative stomatitis, endemic, 210; Vincent's spirillum, 210, 221

Ulcer, of intestine in tuberculosis, 599 ; in typloid, 579 ; of stomach, 243 ; treatment, 244; syphilitic, 590; in tuberculous adenitis, 598

Umbilical cord, 34; separation of, 68

Umbilicus, defects of, 160; tumors of, 159

Uncinaria Americana, 269

Undescended testicle, 392

Ureters, anomalies of, 369 ; double, 369

Urethra, at birth, 40; imperforate, 163

Urethritis, gonorrhoeal, 385; simple, 384 ; specific, 385 ; treatment, 385

Urie acid, 90, 378; at birth, 67

Uricacidosis, 372

Urine, at birth, 67 ; characteristics of, 67,73 ; collection of, 168 ; composition of, 67; incontinence of, 390 ; in infancy, 73 ; inorganic salts in, 73 ; quantity of, 67,73 ; retention of, 366; specific gravity, 73

Urticaria, 611 ; factitia, 612 ; in asthma, 337 ; treatment, 612

Uterus, at birth, 41; growth of, 59; location and size, 41

Uvula, elongation of, 222

Uvulitis, 222

\section{V}

Vaceination, 557

Vaccinia, 556

Vagina, atresia of, 163
Vaginal diseharge, 68, 386

Vaginalitis, 393

Valvular disease, 295

Vanderslice, 129

Van Noorden, 627

Van Slyke, 74, 92, 113

Vapor bath, 639

Variola, 555; diagnosis, 556; exanthem, 555; rash, 555

Varioloid, 557

Ventilation, 633

Vernix caseosa, 17, 69

Verruca, 622

Vertebræ, diseases of, 511

Vertebral column, at birth, 24; curvatures, 51; development, 51

Vicious attitudes, 144

Vierodt, 141

Vincent's angina, 210, 220

Volvulus, 274

Vomiting, 237; cyclie, 238; in ear disease, 540; obstructive, 237; of indigestion, 237; projectile, 423; recurrent, 238; reflex, 235; stercoraceous, 237; toxæmia, 238

Von Jaksch, 506

Vulvo-vaginitis, complications, 387; simple, 386 ; specific, 386 ; treatment, 388

W

Wadswortl, 348

Walking, 72, 134

"Warts," 622

Wasting, 182

Water, infant's need of, 89, 92

"Water-hammer" pulse, 301

Water on brain, 443

Weaning, indications for, 106; substitute food in, 107

Weight, at birth, 17 ; charts, 43 ; inerease in ealves, 111 ; in infants, 111 ; loss of, in new-born, 86

Werlhof's disease, 509

Wescott's chart, 122

Wet-nurse, 108; selection, 108

Whey, 128, 644; and eream mixtures, 119 ; proteids, 92, 115, 128

White swelling, 517

Whole milk, 129 
Whooping-cough, 561

Widal's reaction, 579

Winckel's disease, 180

Wittmaack, 92

Woll's rule, 104

Worms, 268

Wright, 129

Wrist-drop, 479

Wroblewski, 126 $\mathrm{x}$

Xeroderma pigmentosum, 622

$\mathrm{X}$-ray, in diagnosis of calculi, 379 ; in examination of children, 168 ; in the treatment of Hodgkin's disease, 487

Z

Zoster, 614 


Date Due

University of California

SOUTHERN REGIONAL LIBRARY FACILITY

405 Hilgard Avenue, Los Angeles, CA 90024-1388 Return this material to the library
from which it was borrowed. rom which it was borrowed.

III

$09 / 30 / 99$ 

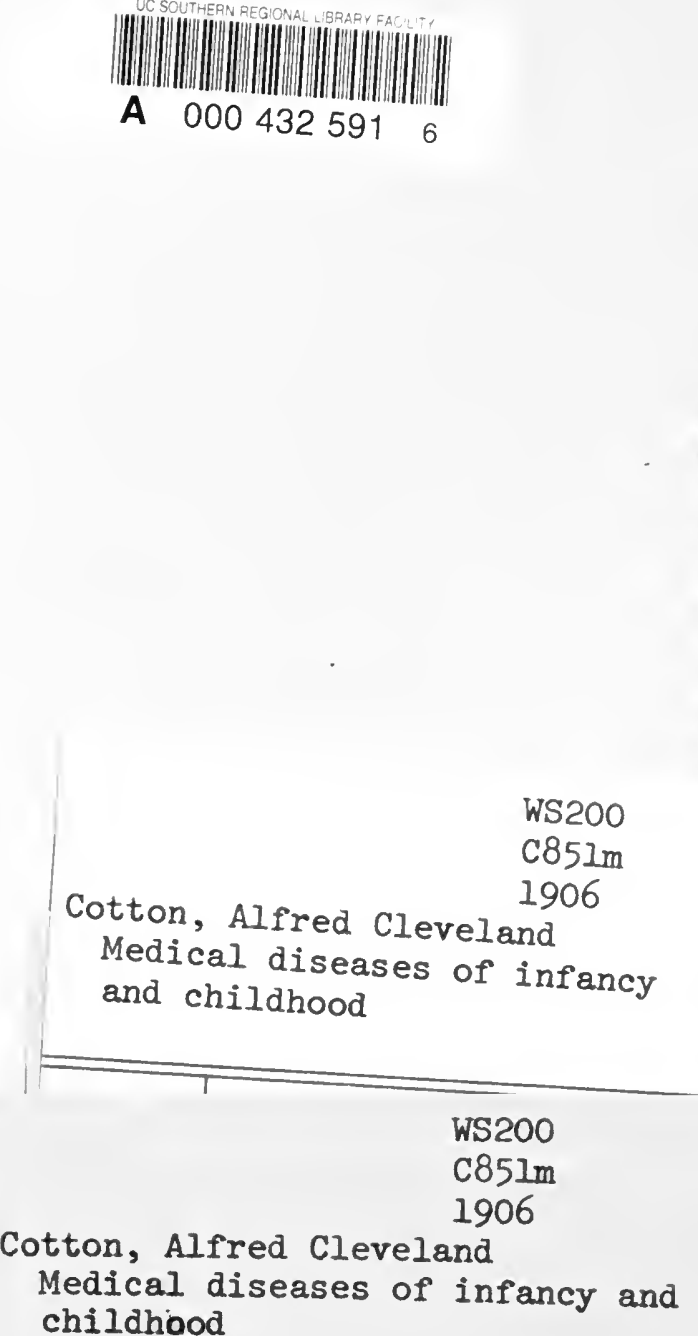

MEDICAL SCIENCES LIBRARY UNIVERSITY OF CALIFORNIA, IRVINE IRVINE, CALIFORNIA 92664 
